

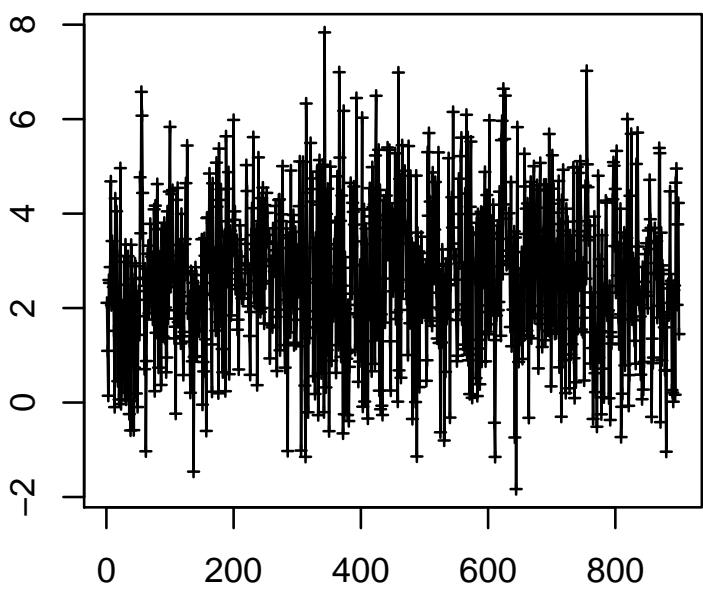

Time Point $(0.25 \mathrm{~Hz})$

Cell 7

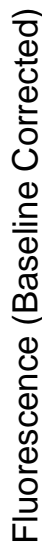

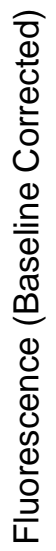

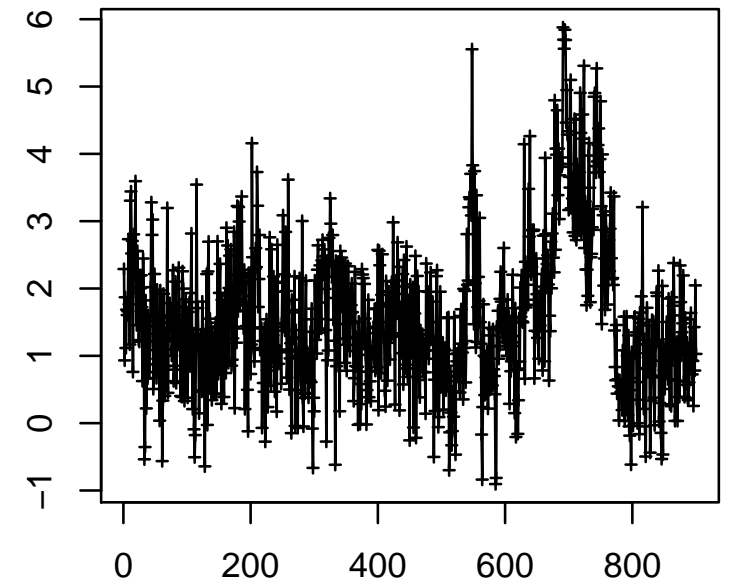

Time Point $(0.25 \mathrm{~Hz})$

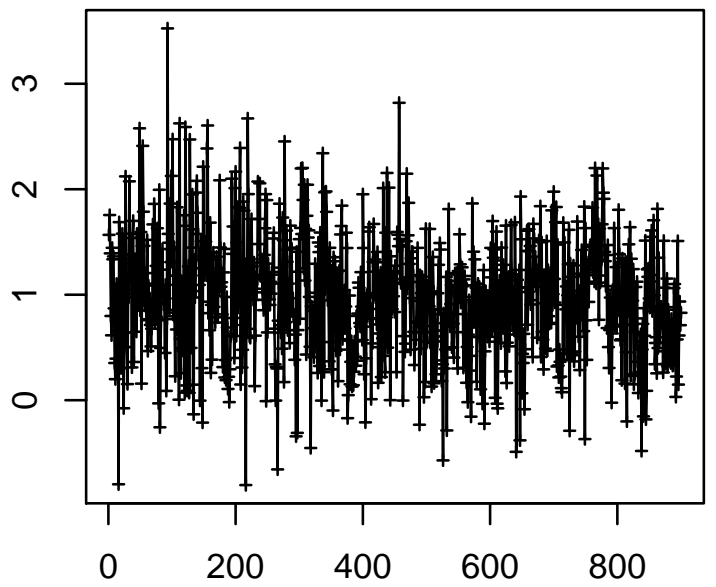

Time Point $(0.25 \mathrm{~Hz})$

Cell 8

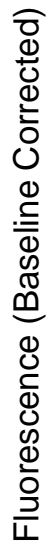

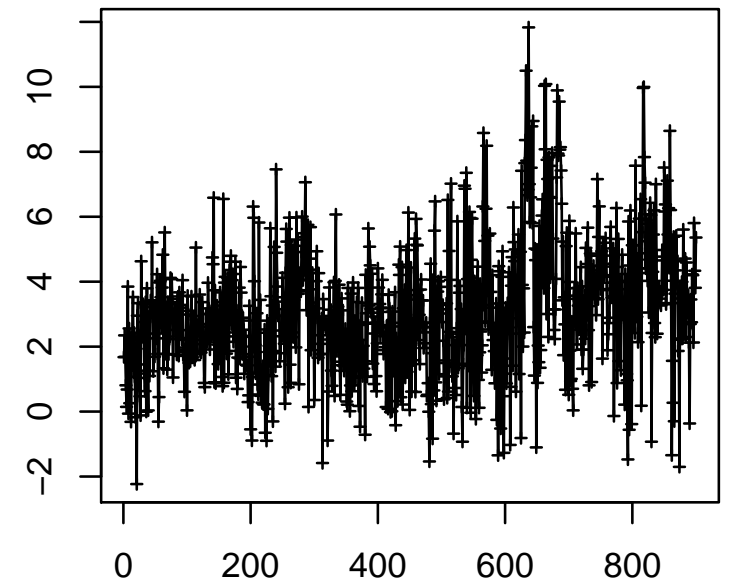

Time Point $(0.25 \mathrm{~Hz})$ 
Cell 9

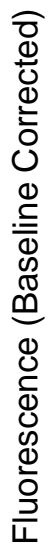

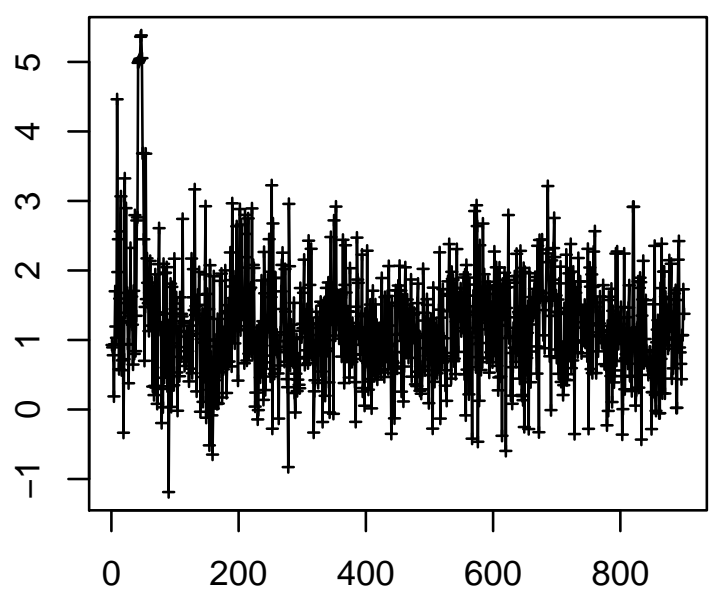

Time Point $(0.25 \mathrm{~Hz})$

\section{Cell 11}

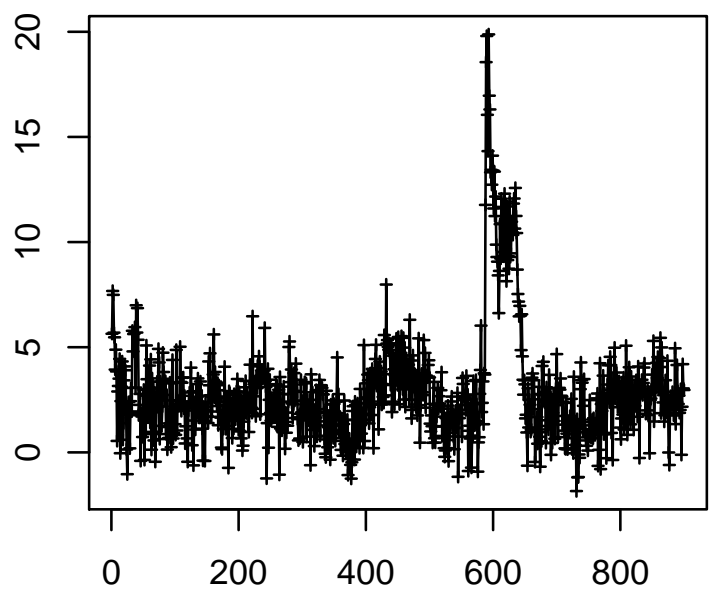

Time Point $(0.25 \mathrm{~Hz})$
Cell 10

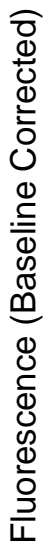

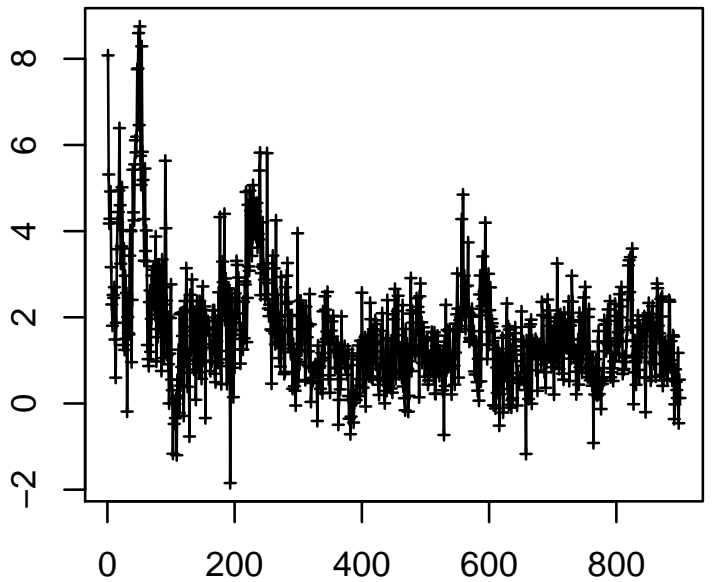

Time Point $(0.25 \mathrm{~Hz})$

Cell 12

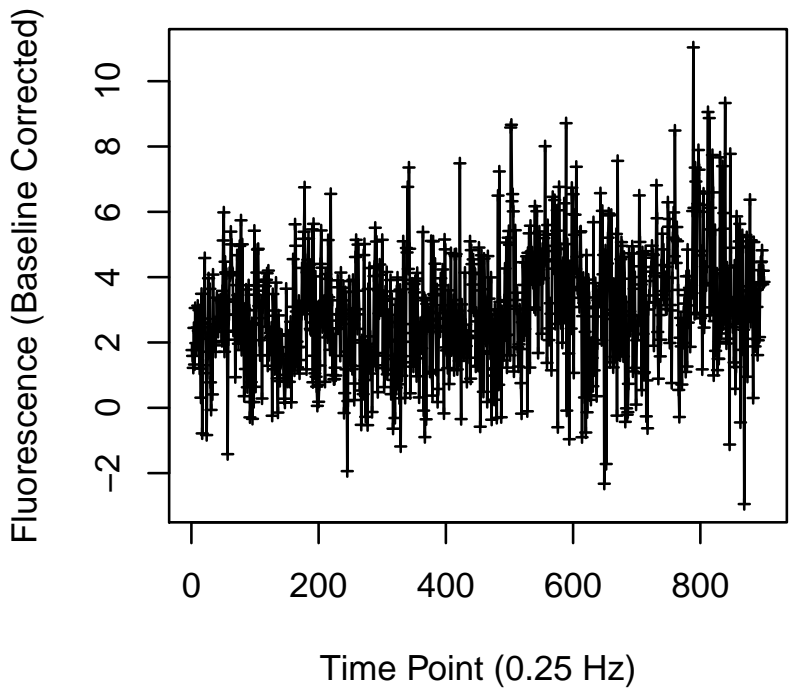




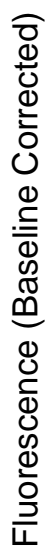

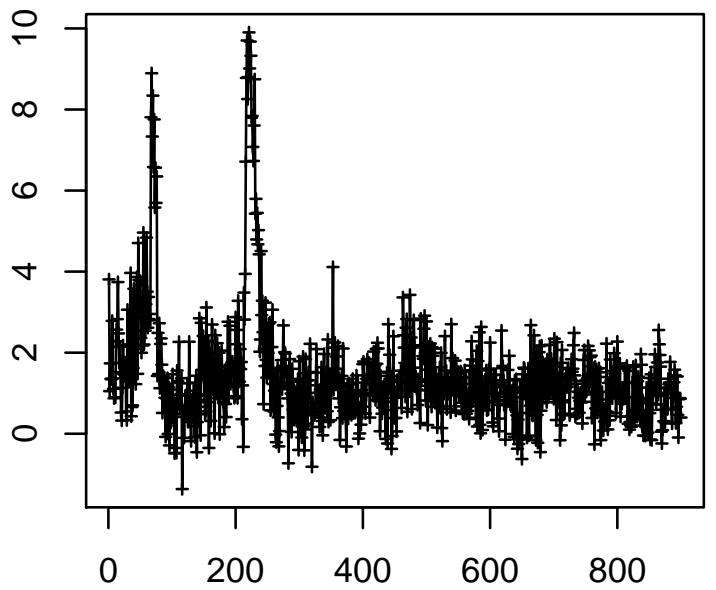

Time Point $(0.25 \mathrm{~Hz})$

Cell 15

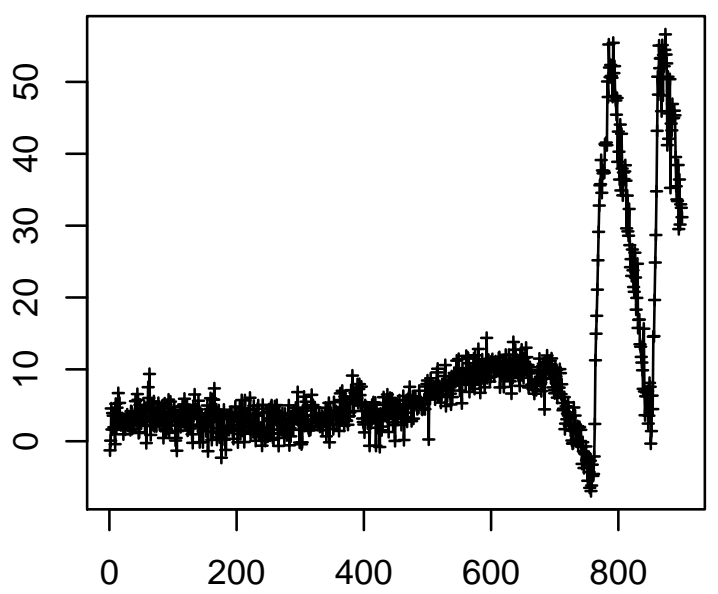

Time Point $(0.25 \mathrm{~Hz})$

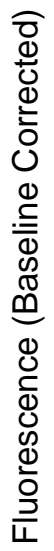

Cell 16

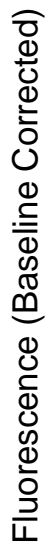

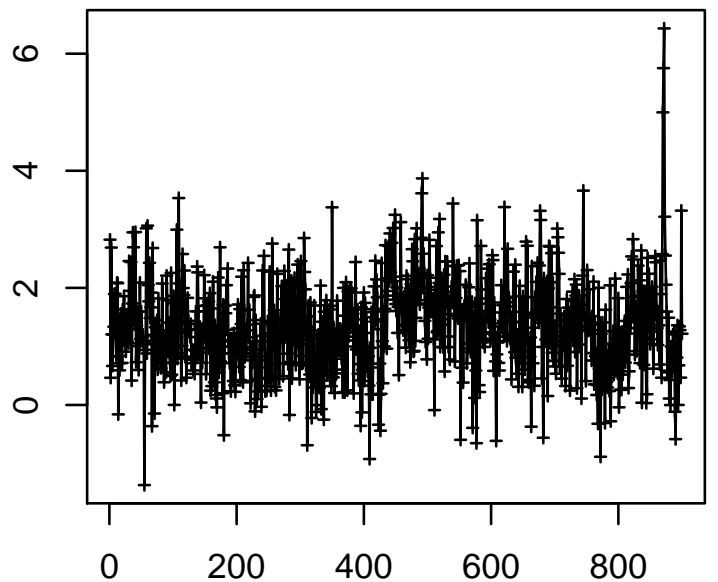

Time Point $(0.25 \mathrm{~Hz})$ 
Cell 17

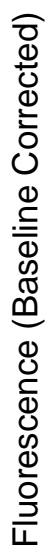

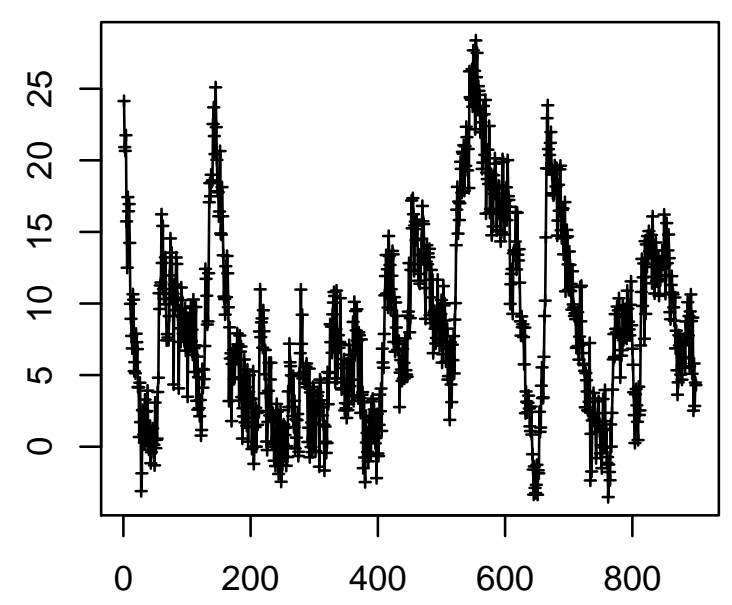

Time Point $(0.25 \mathrm{~Hz})$

Cell 19

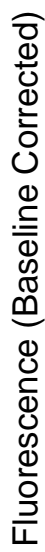

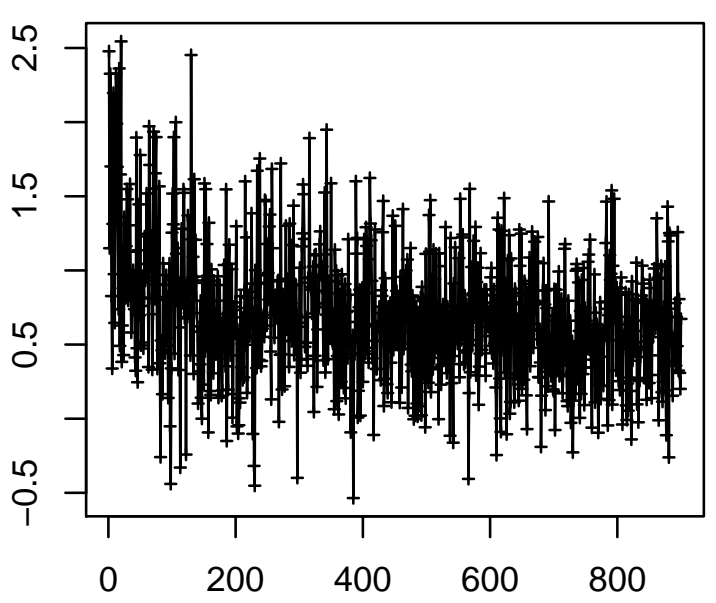

Time Point $(0.25 \mathrm{~Hz})$
Cell 18

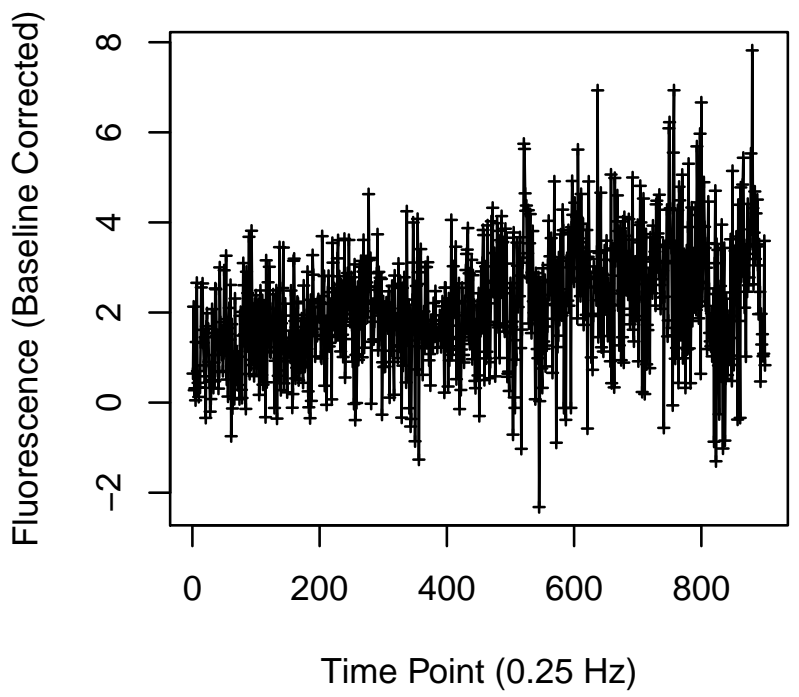

Cell 20

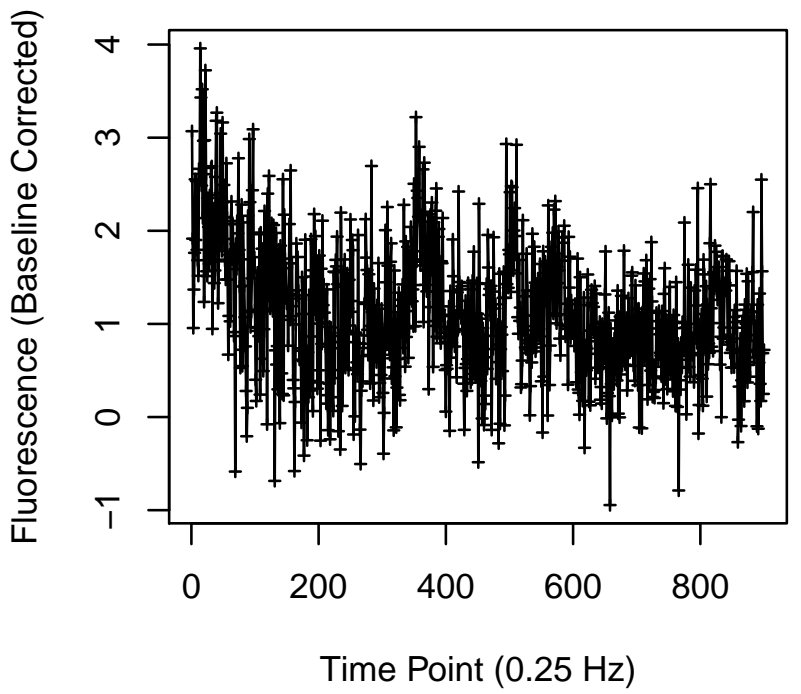


Cell 21

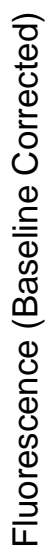

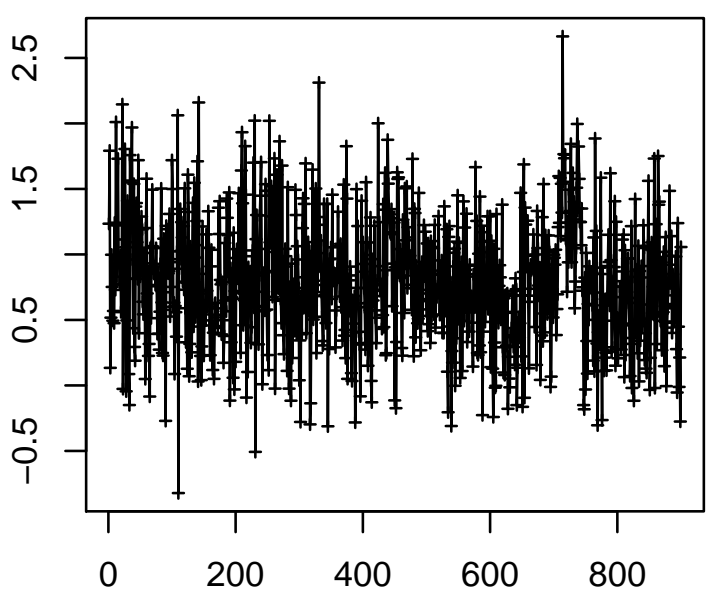

Time Point $(0.25 \mathrm{~Hz})$

Cell 23

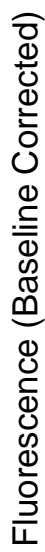

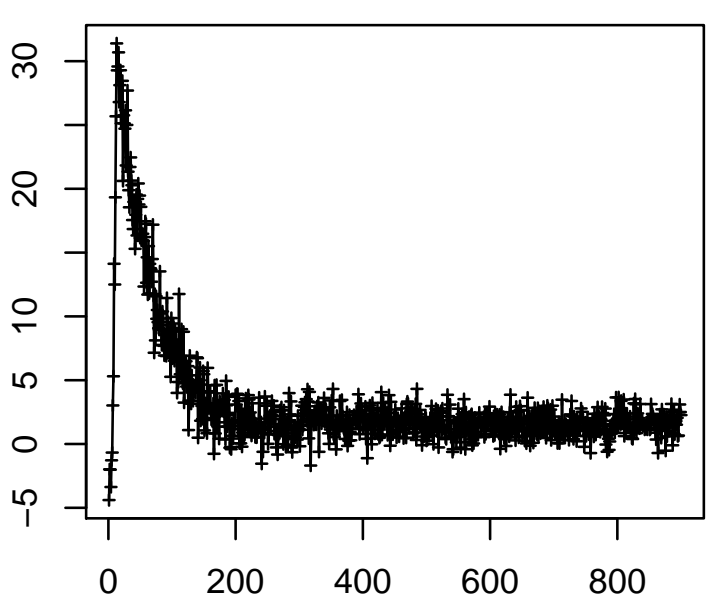

Time Point $(0.25 \mathrm{~Hz})$
Cell 22

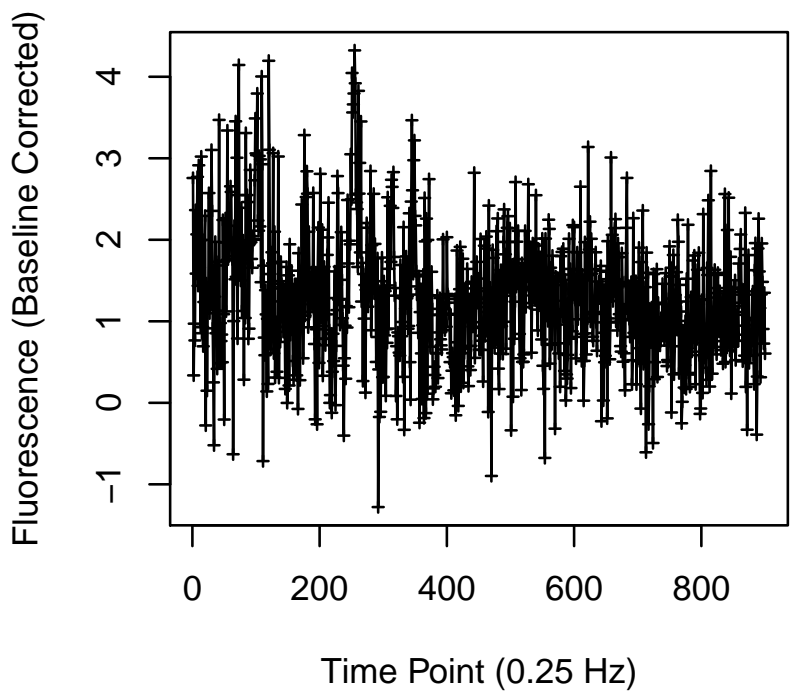

Cell 24

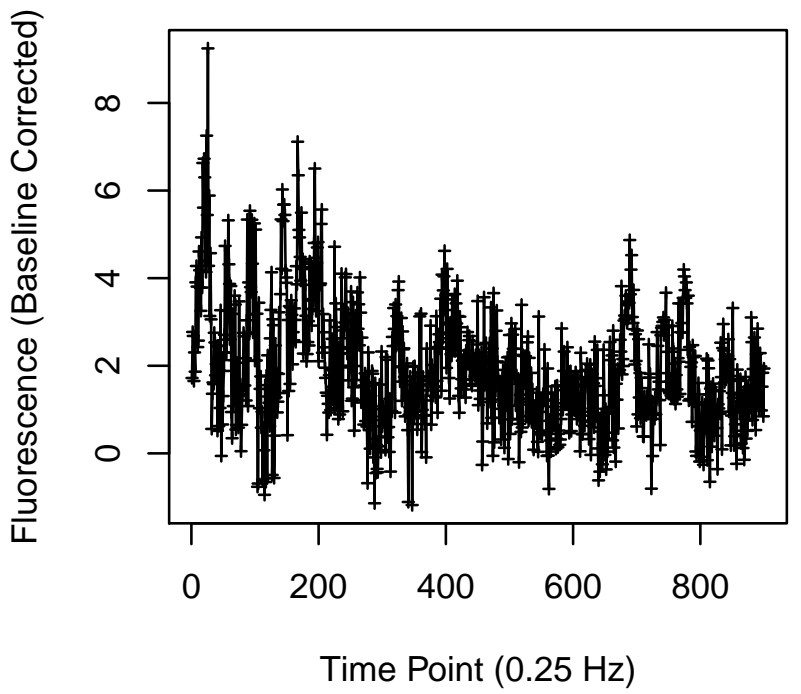




\section{Cell 25}
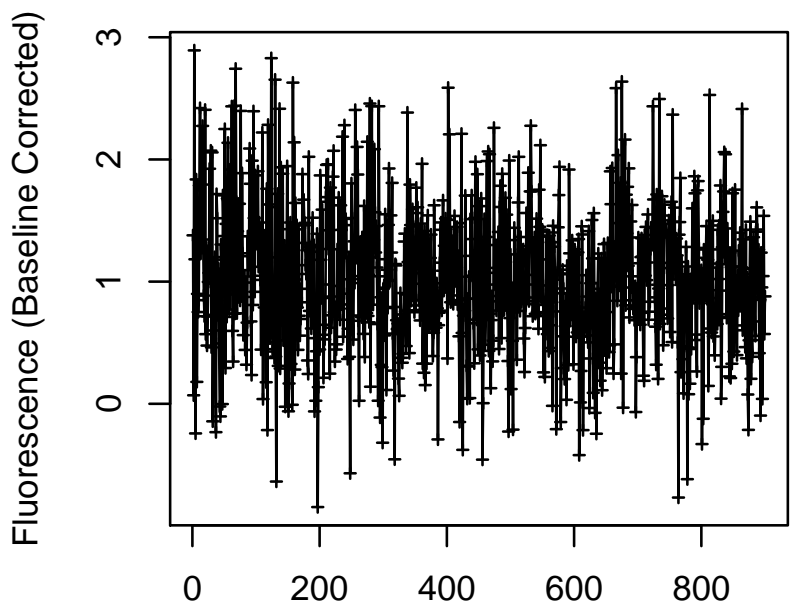

Time Point $(0.25 \mathrm{~Hz})$

Cell 27

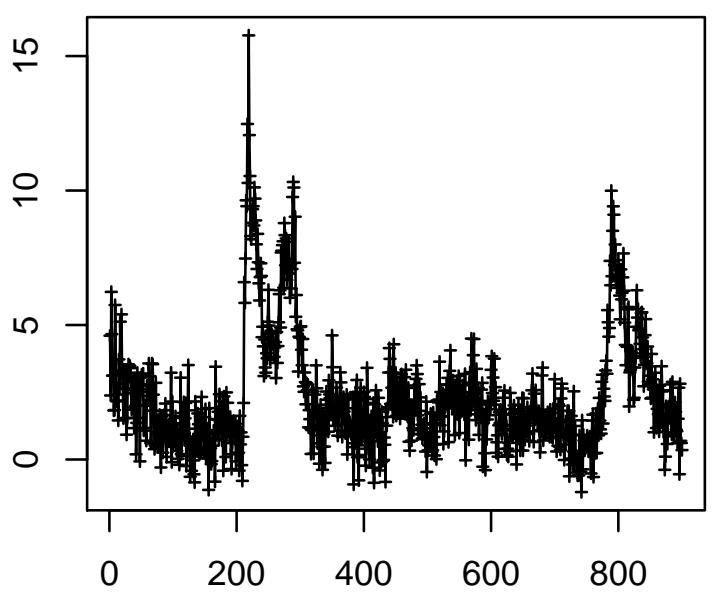

Time Point $(0.25 \mathrm{~Hz})$
Cell 26

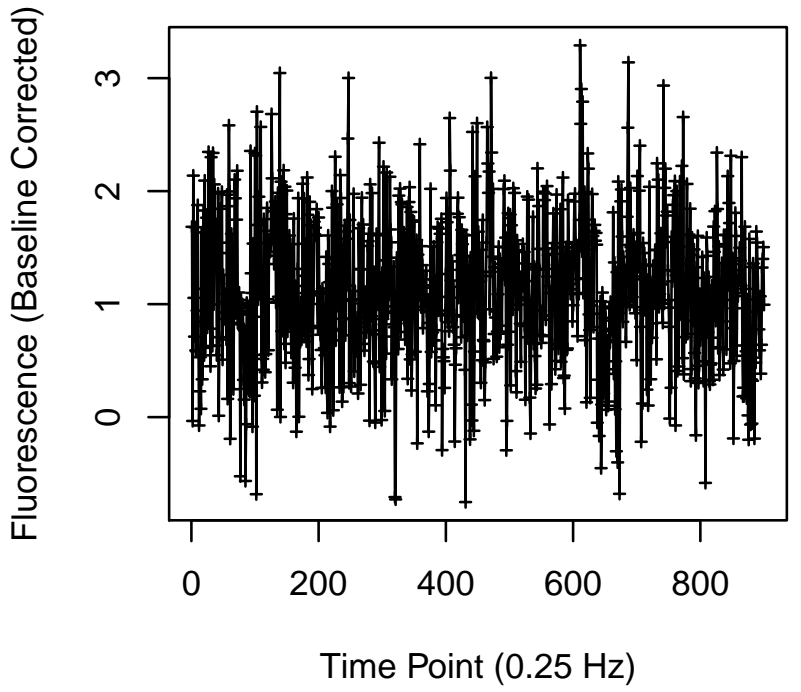

Cell 28

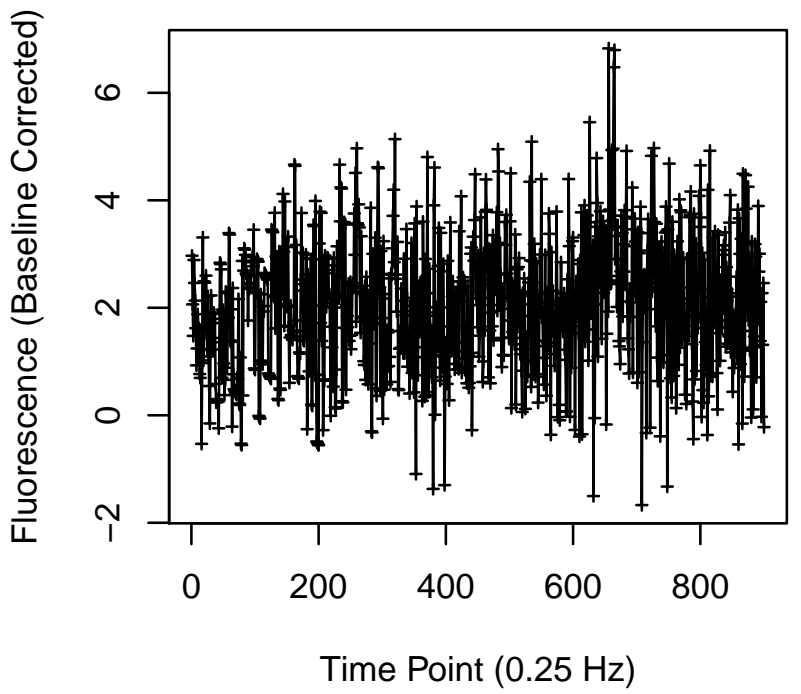


Cell 29

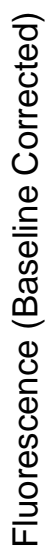

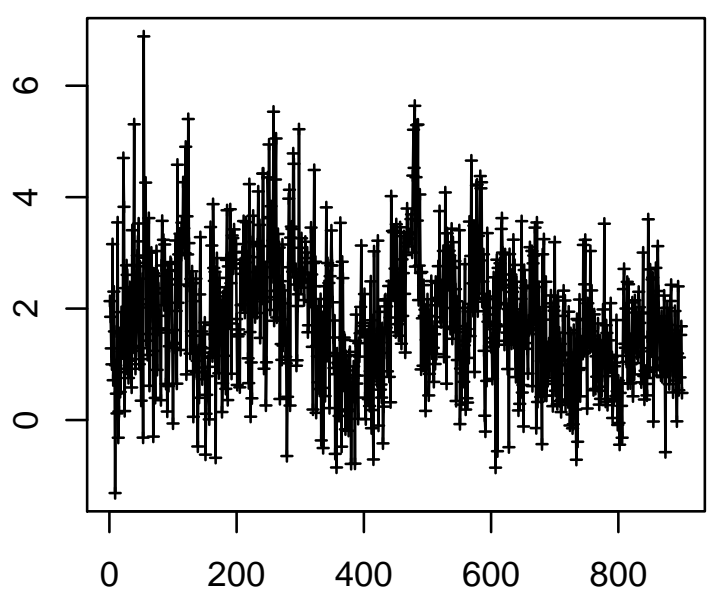

Time Point $(0.25 \mathrm{~Hz})$

Cell 31

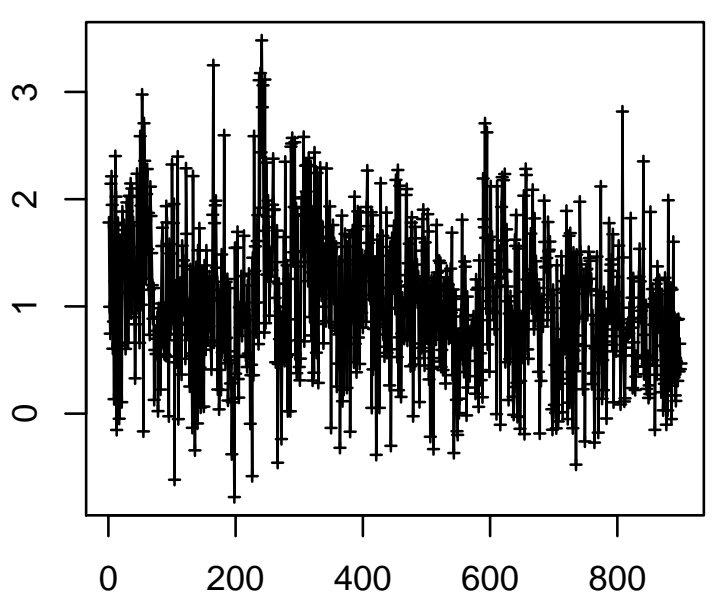

Time Point $(0.25 \mathrm{~Hz})$
Cell 30

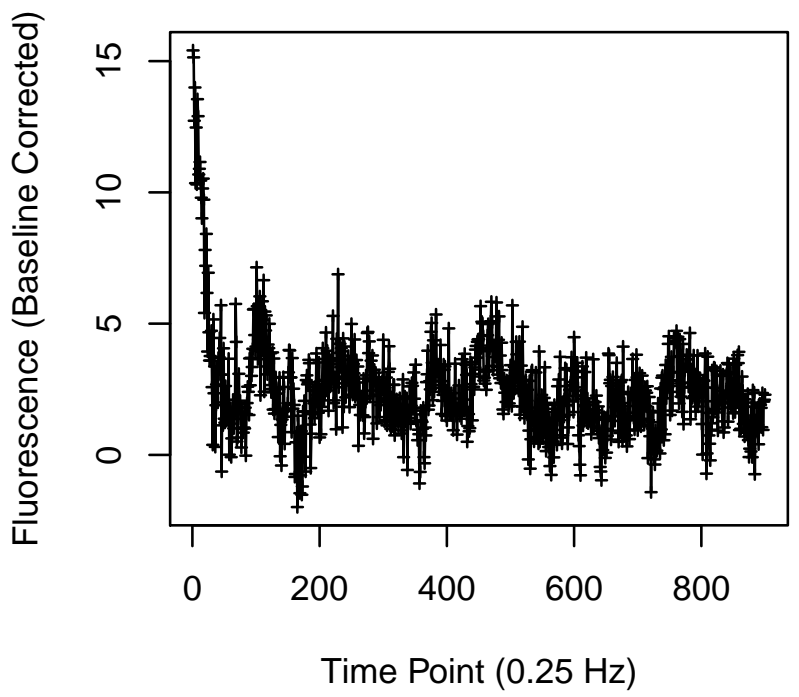

Cell 32

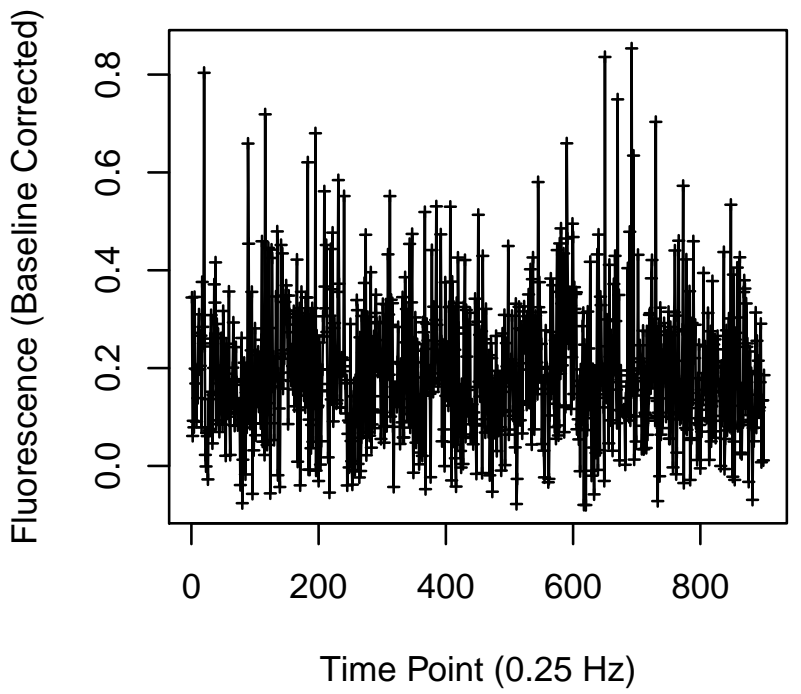


Cell 33

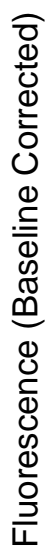

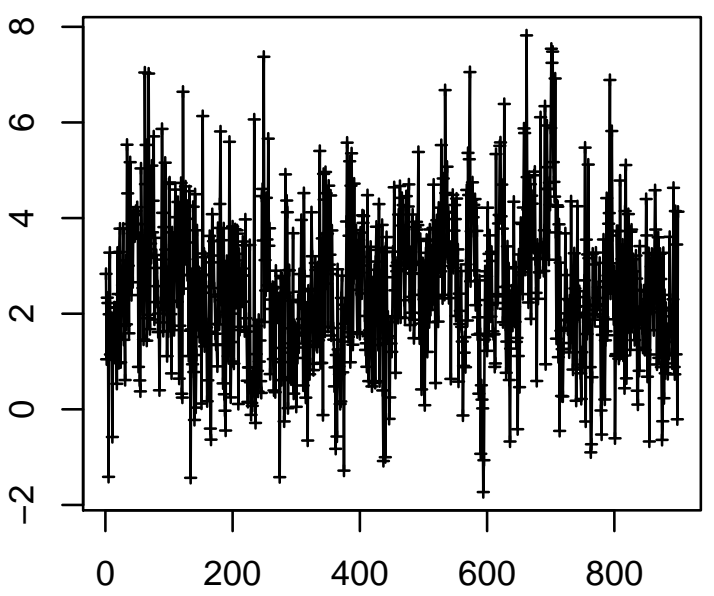

Time Point $(0.25 \mathrm{~Hz})$

Cell 35

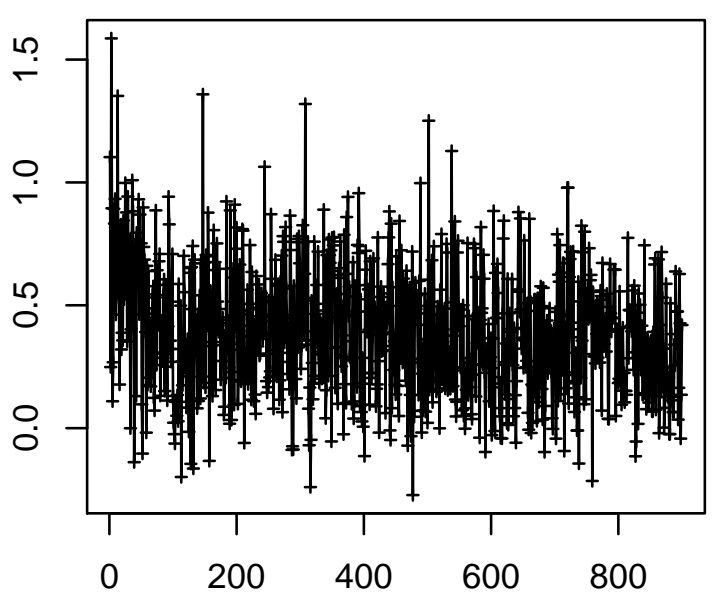

Time Point $(0.25 \mathrm{~Hz})$
Cell 34

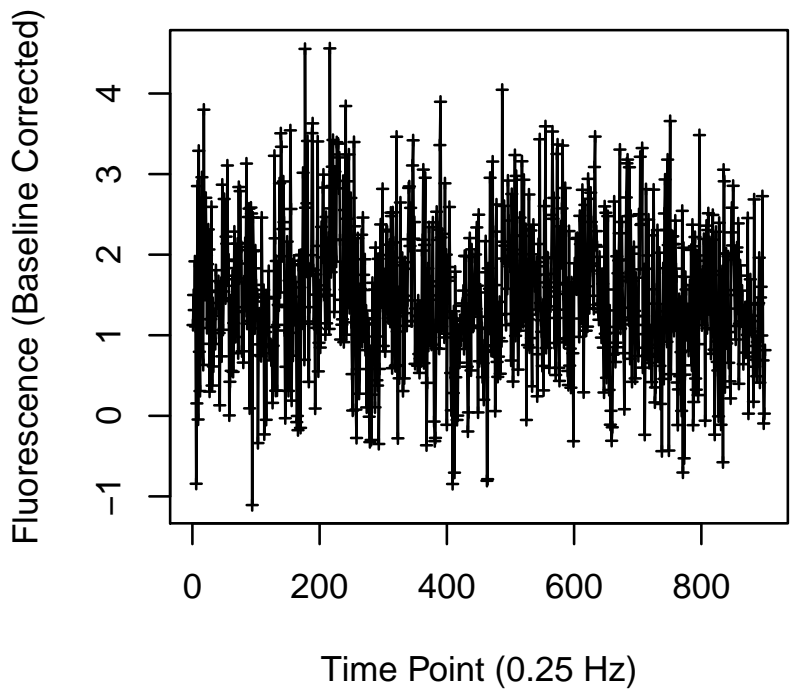

Cell 36

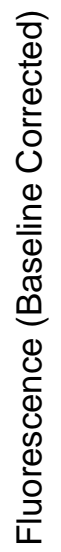

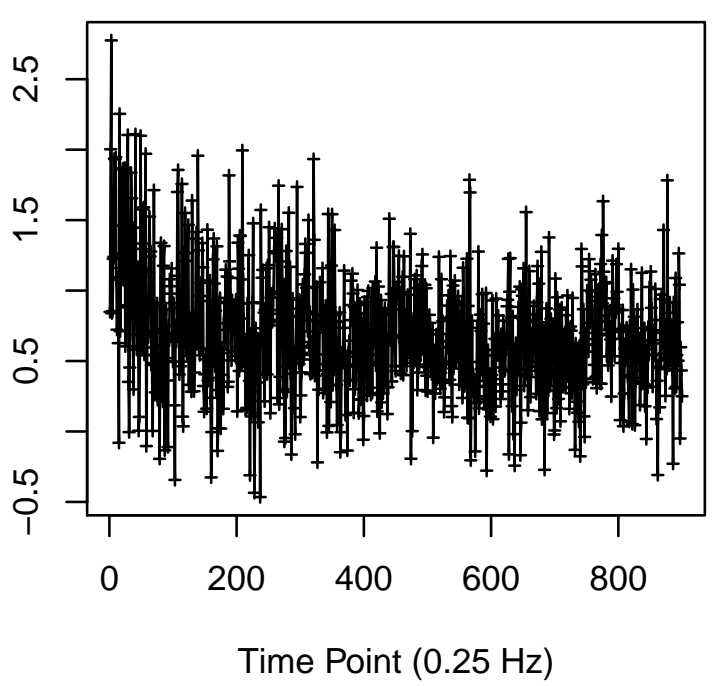




\section{Cell 37}

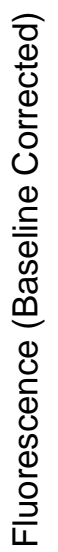

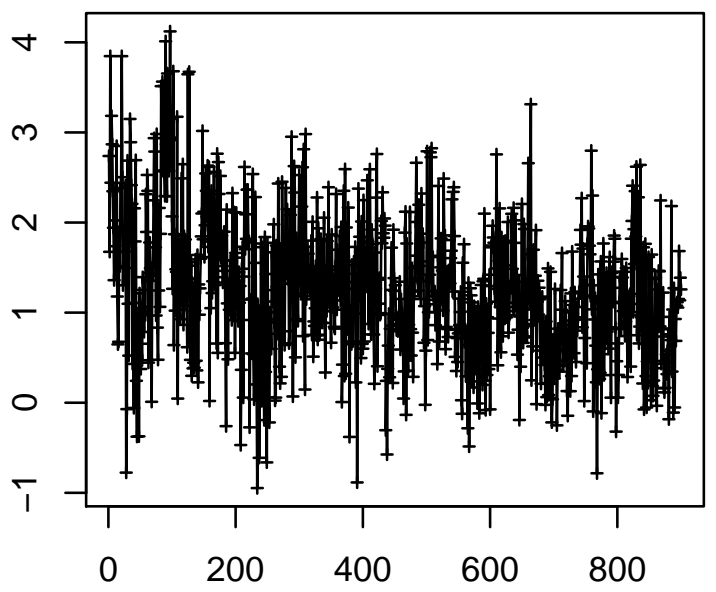

Time Point $(0.25 \mathrm{~Hz})$

\section{Cell 39}

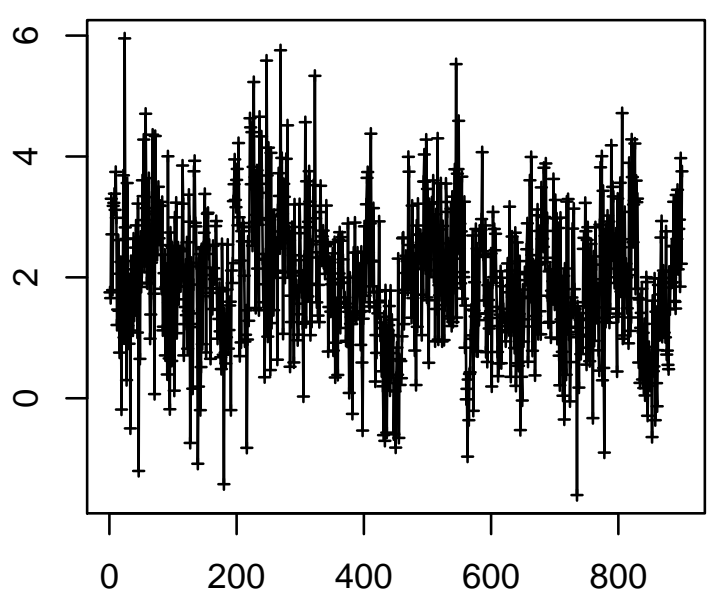

Time Point $(0.25 \mathrm{~Hz})$
Cell 38

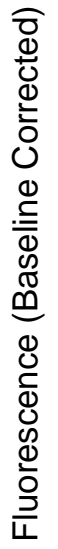

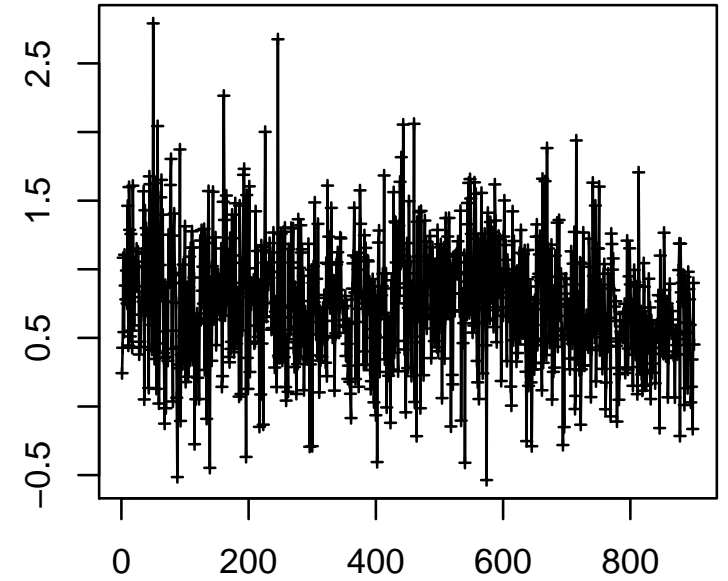

Time Point $(0.25 \mathrm{~Hz})$

Cell 40

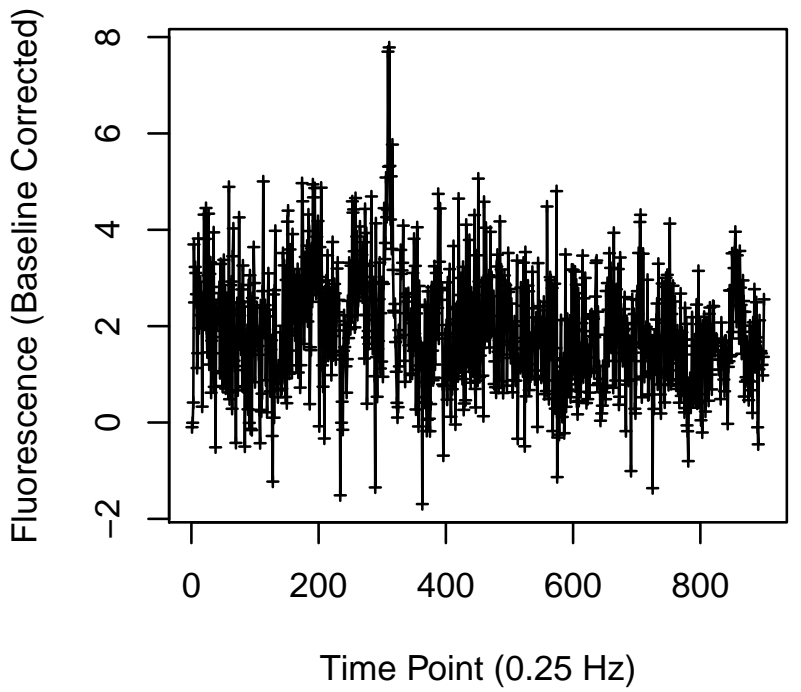




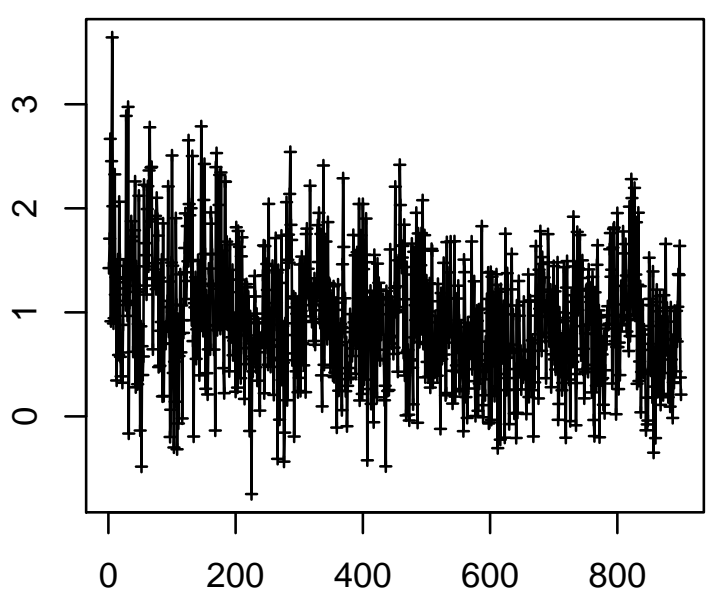

Time Point $(0.25 \mathrm{~Hz})$

Cell 43

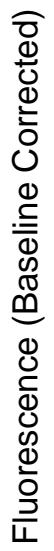

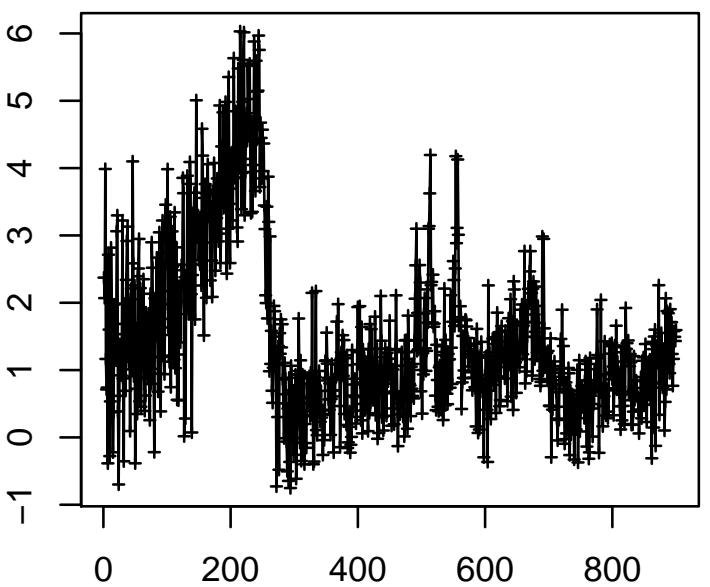

Time Point $(0.25 \mathrm{~Hz})$

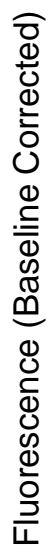

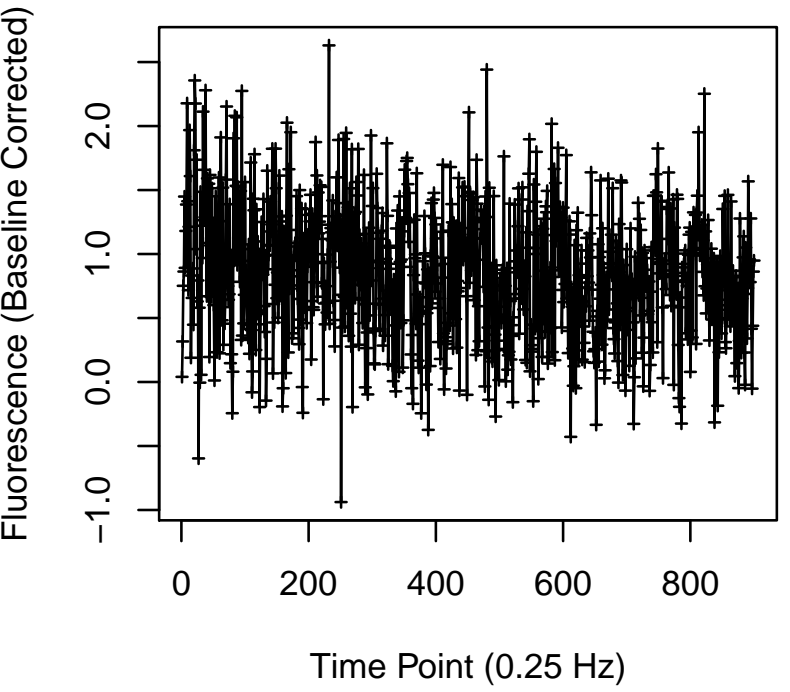

Cell 44

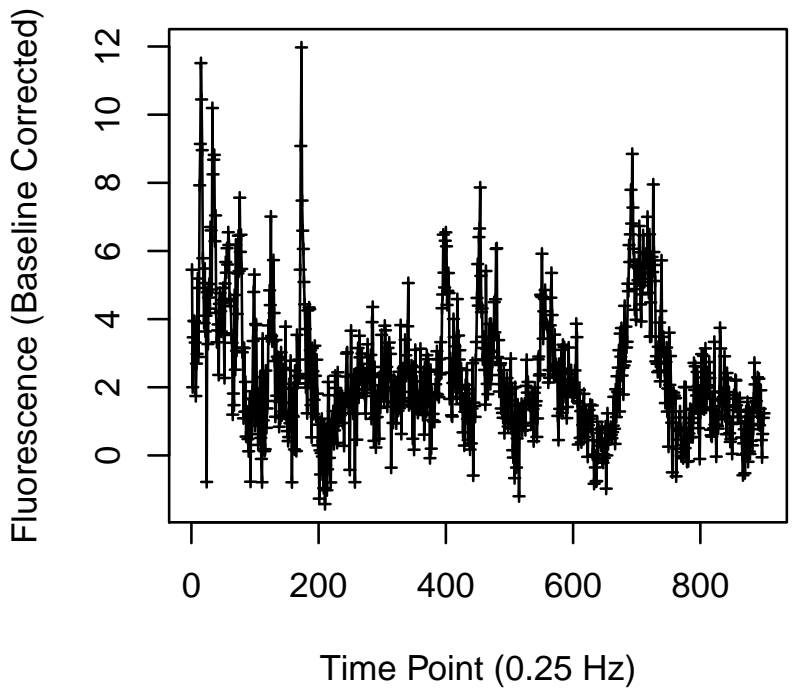


Cell 45

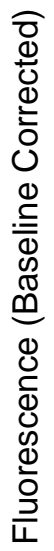

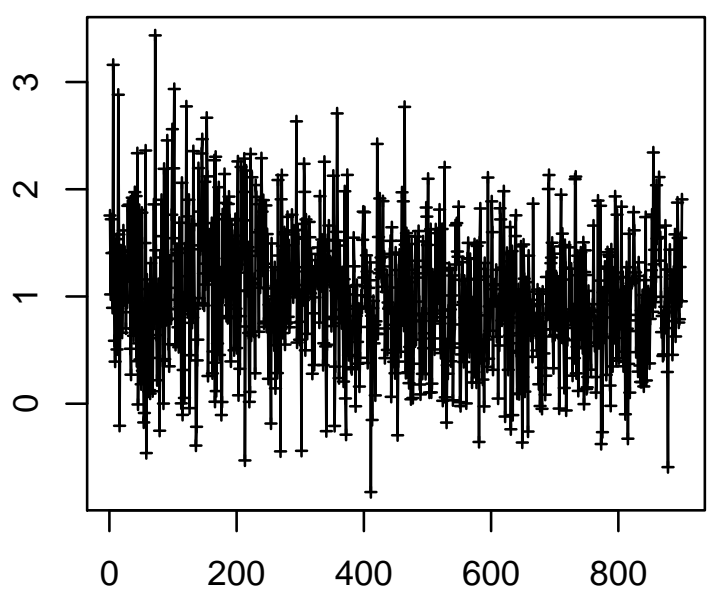

Time Point $(0.25 \mathrm{~Hz})$

Cell 47

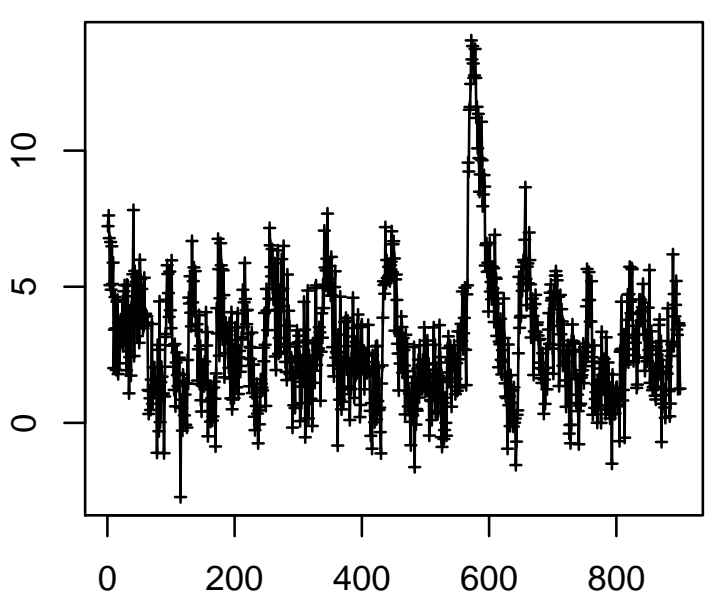

Time Point $(0.25 \mathrm{~Hz})$
Cell 46

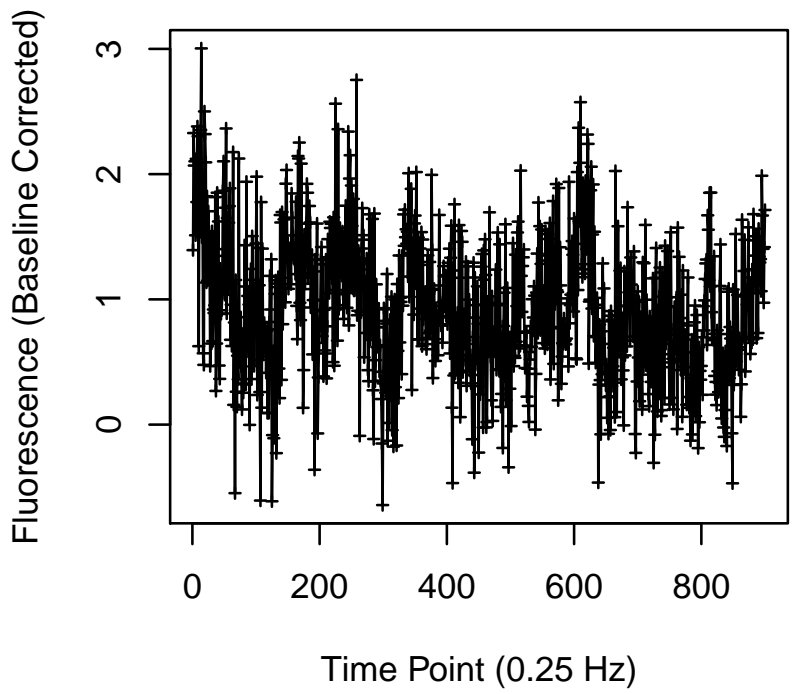

Cell 48

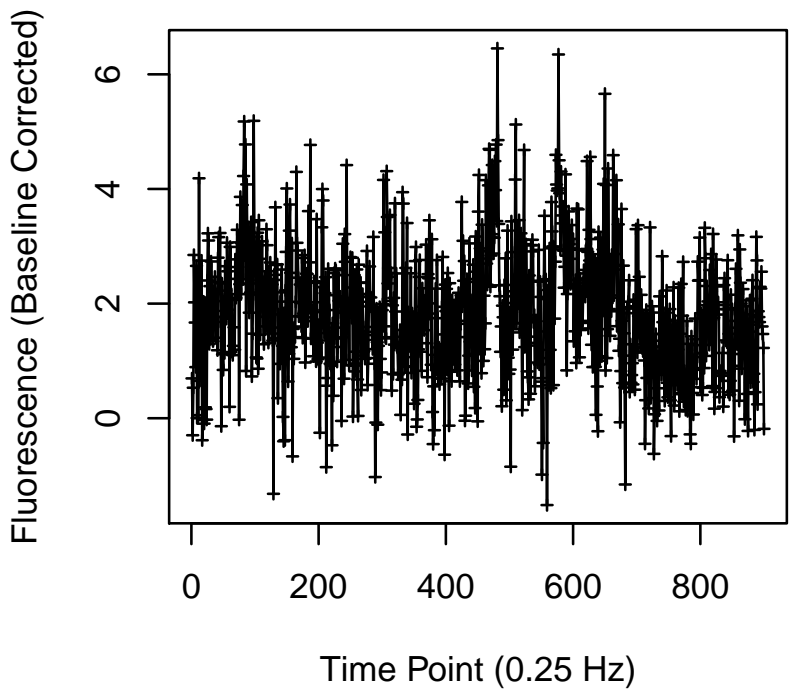




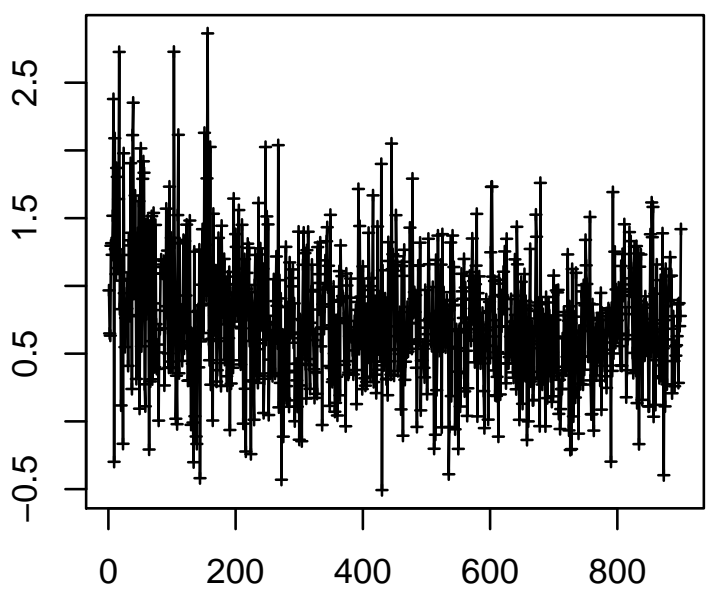

Time Point $(0.25 \mathrm{~Hz})$

Cell 59

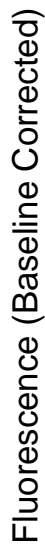

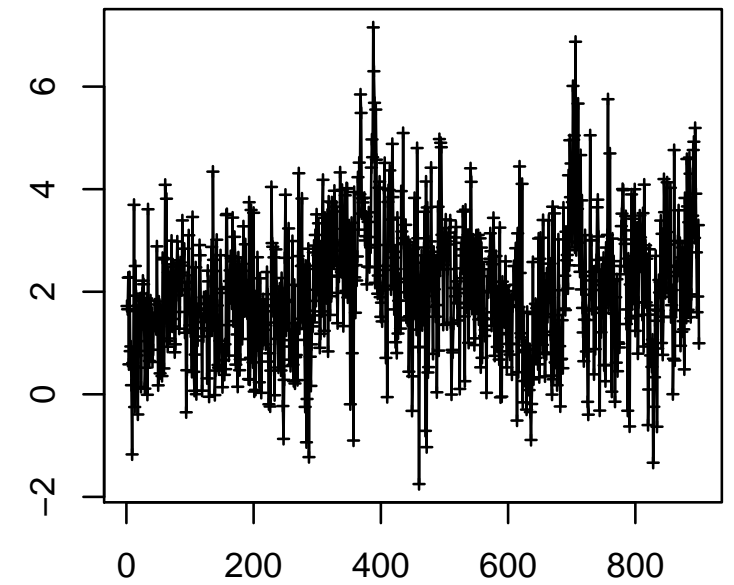

Time Point $(0.25 \mathrm{~Hz})$

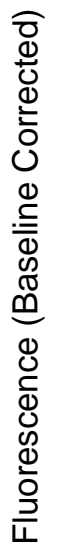

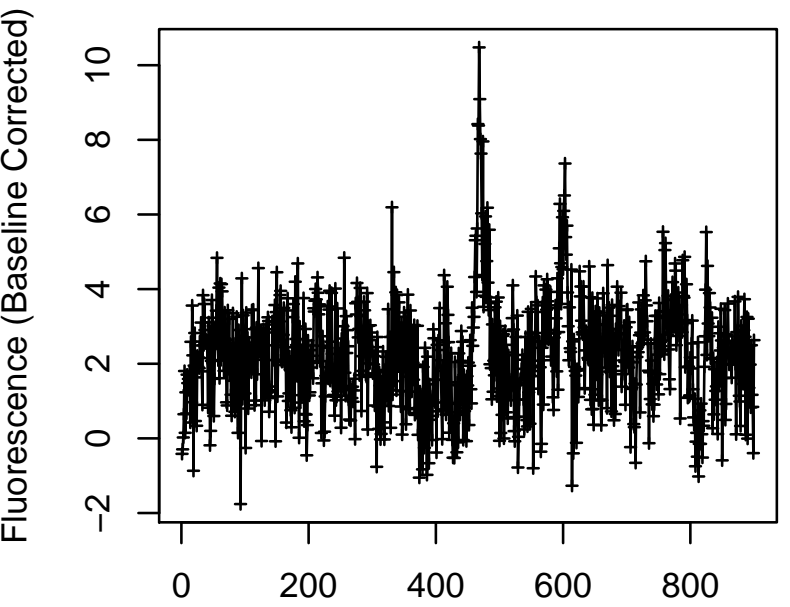

Time Point $(0.25 \mathrm{~Hz})$

Cell 60

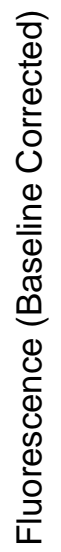

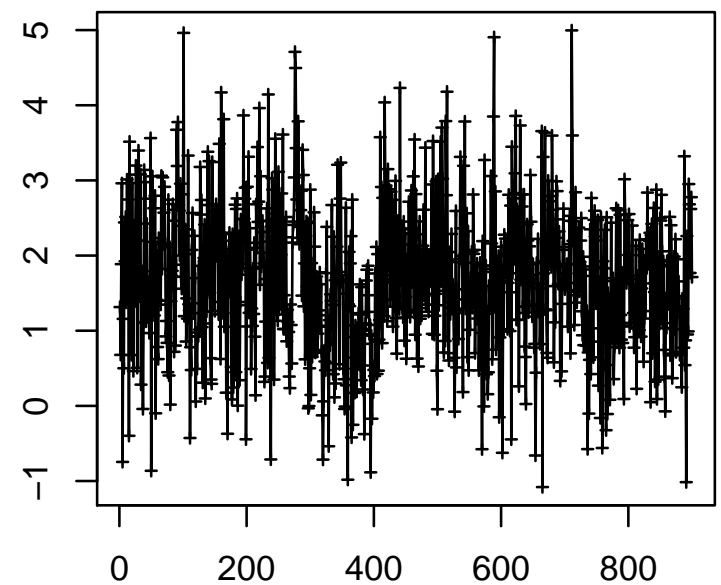

Time Point $(0.25 \mathrm{~Hz})$ 
Cell 65

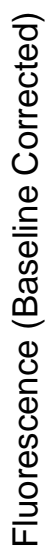

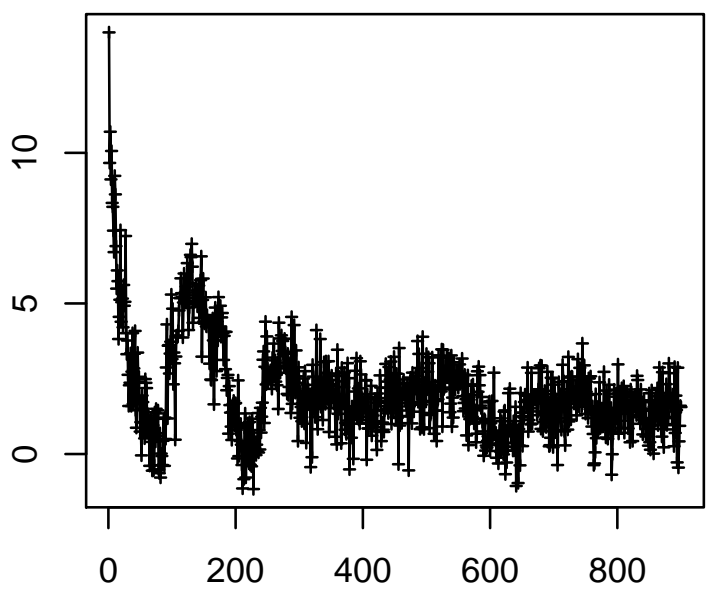

Time Point $(0.25 \mathrm{~Hz})$

Cell 67

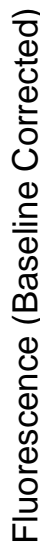

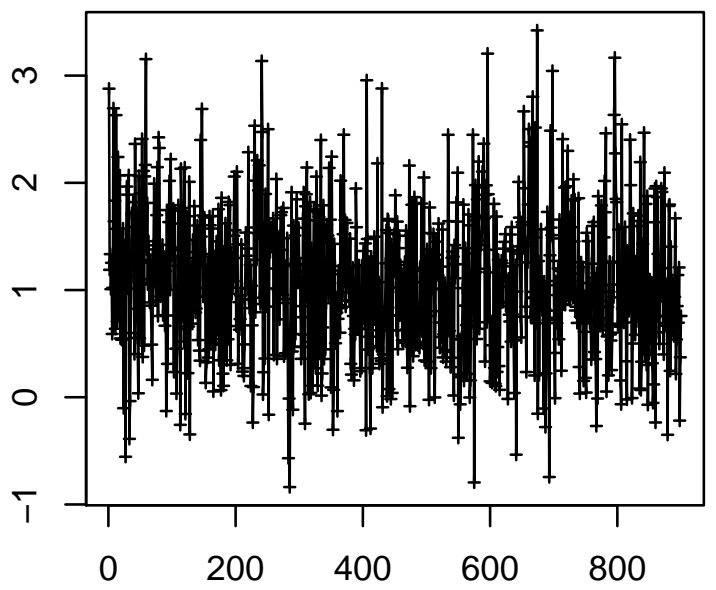

Time Point $(0.25 \mathrm{~Hz})$
Cell 66

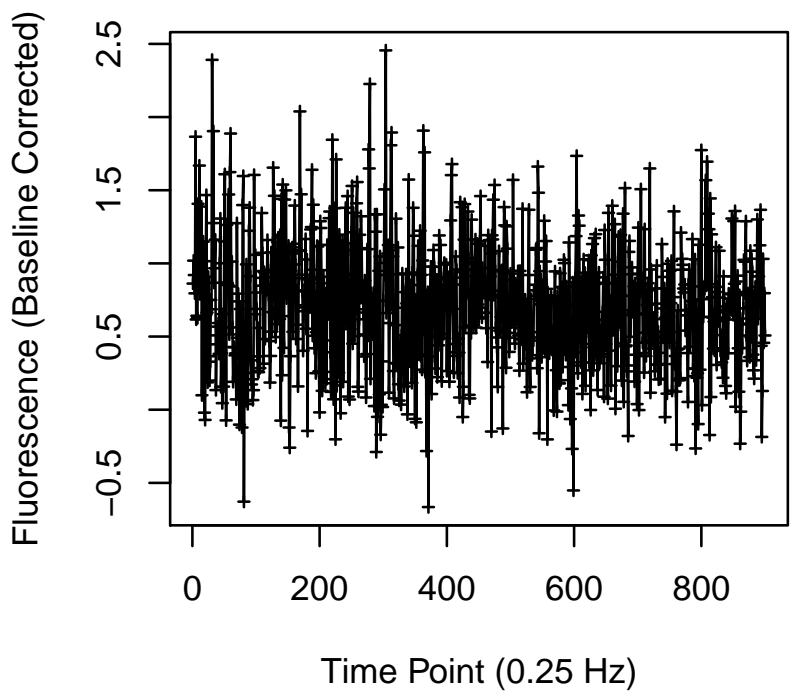

Cell 68

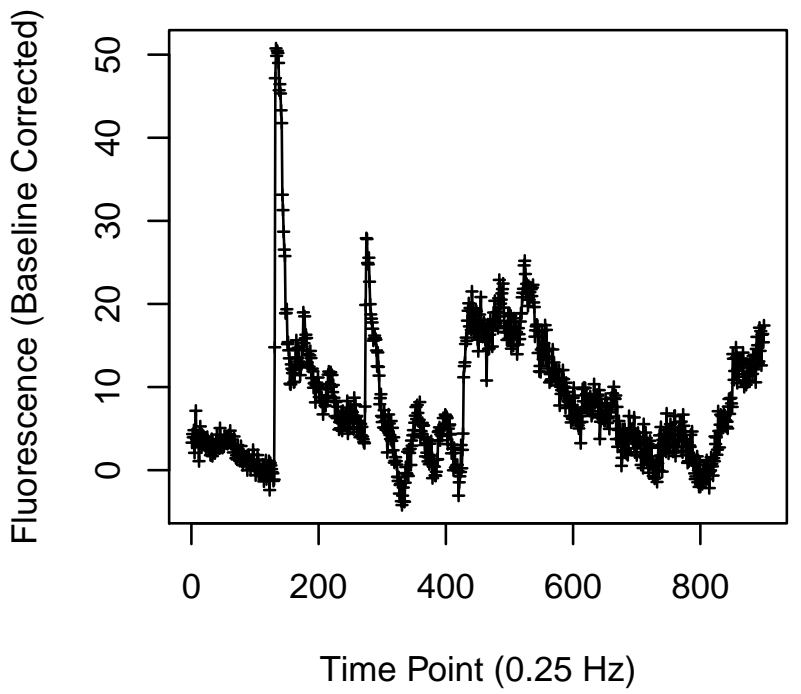


Cell 73

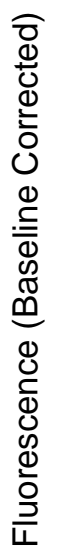

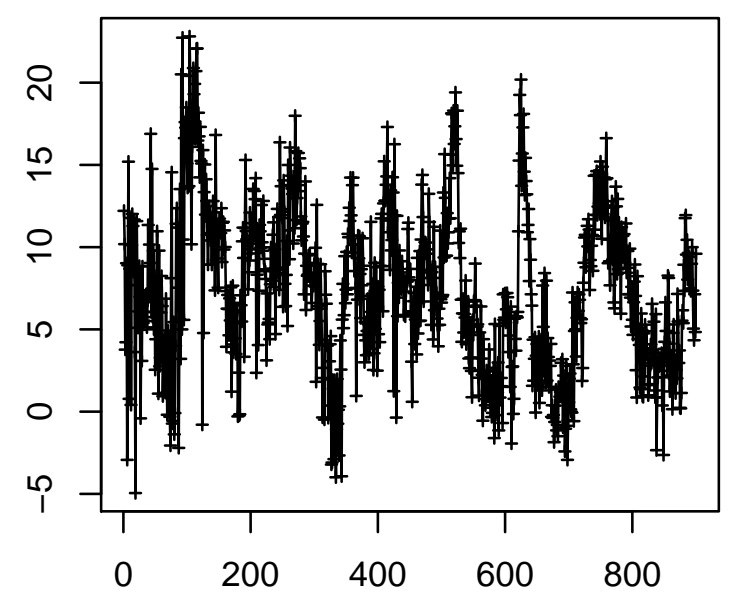

Time Point $(0.25 \mathrm{~Hz})$

Cell 75

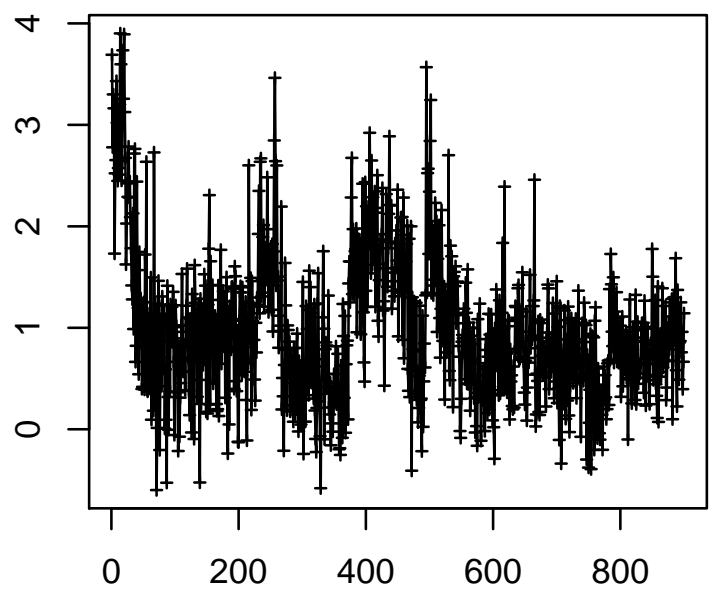

Time Point $(0.25 \mathrm{~Hz})$
Cell 74

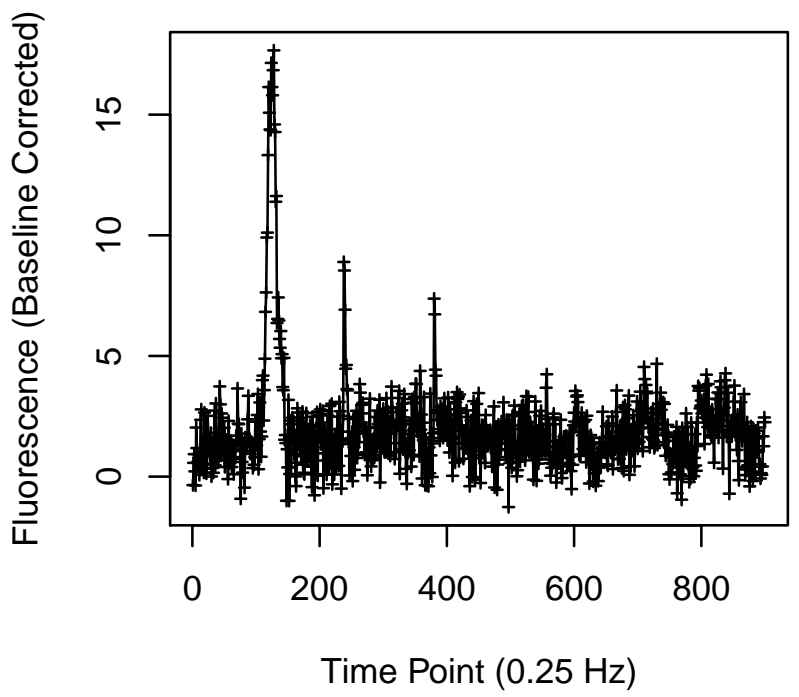

Cell 76

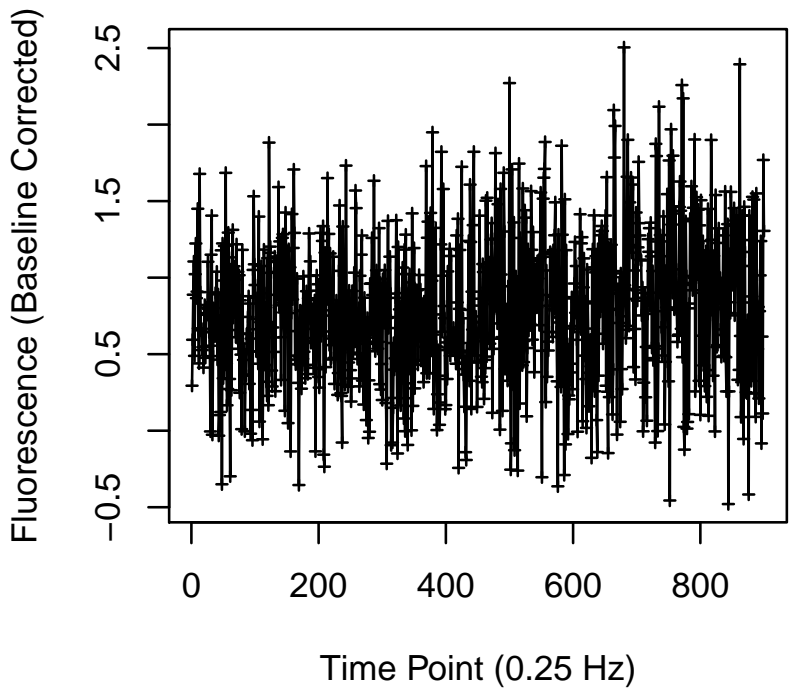




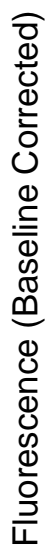

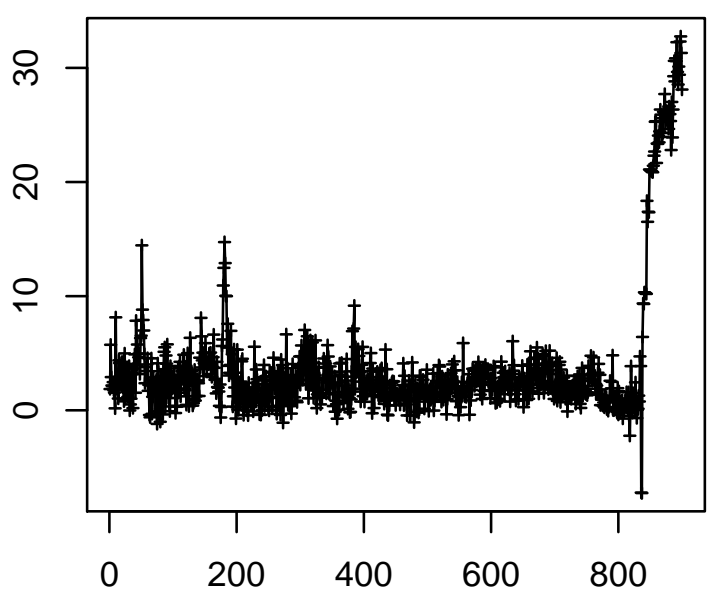

Time Point $(0.25 \mathrm{~Hz})$

Cell 79

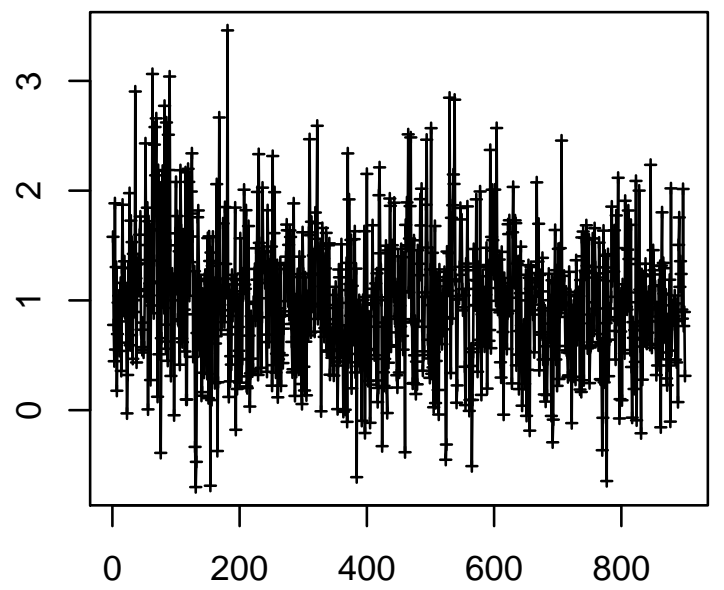

Time Point $(0.25 \mathrm{~Hz})$

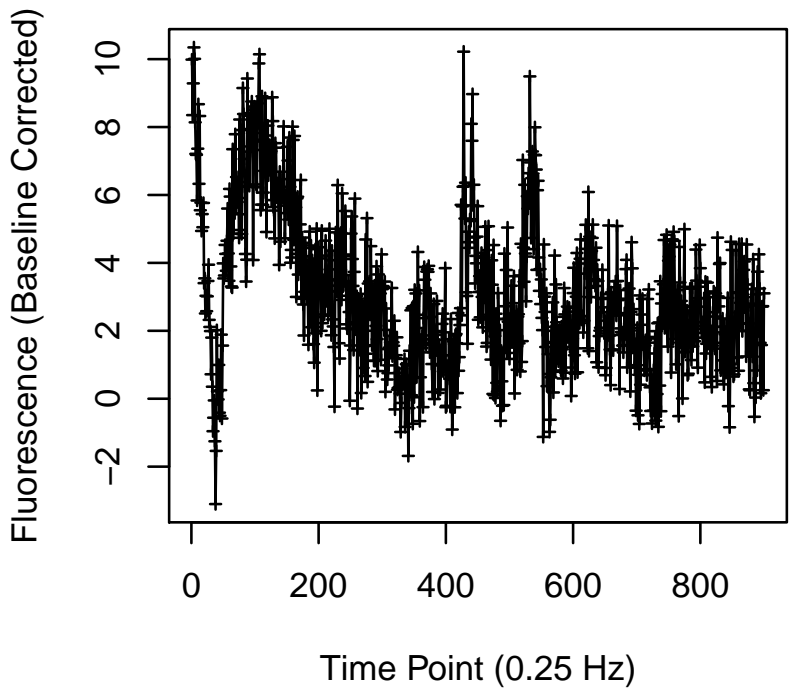

Cell 80

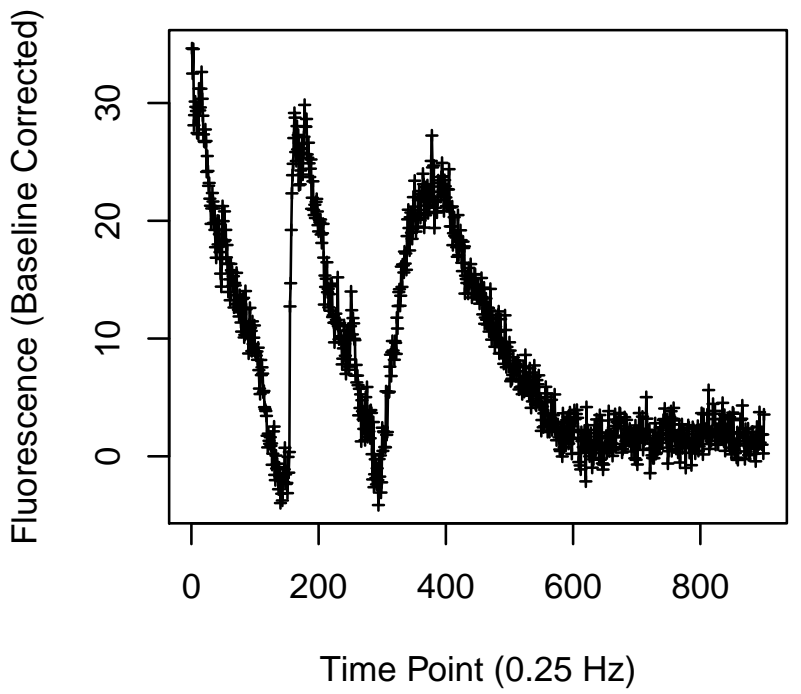


Cell 81

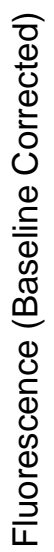

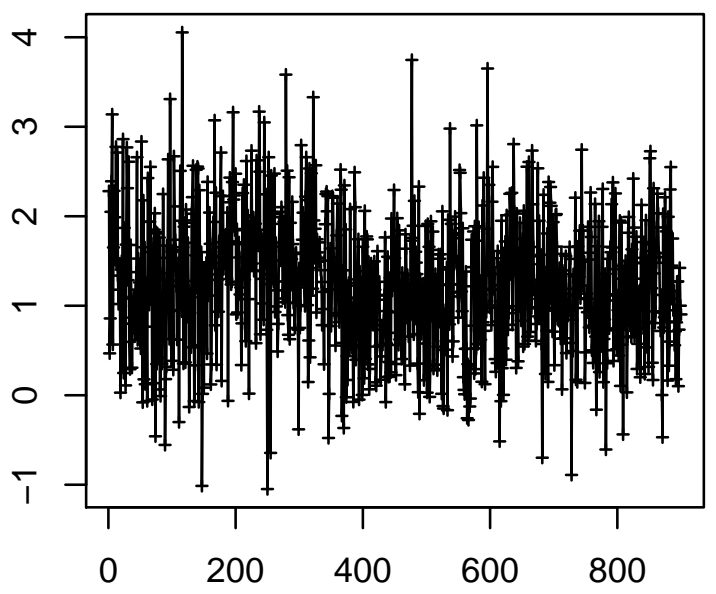

Time Point $(0.25 \mathrm{~Hz})$

Cell 83

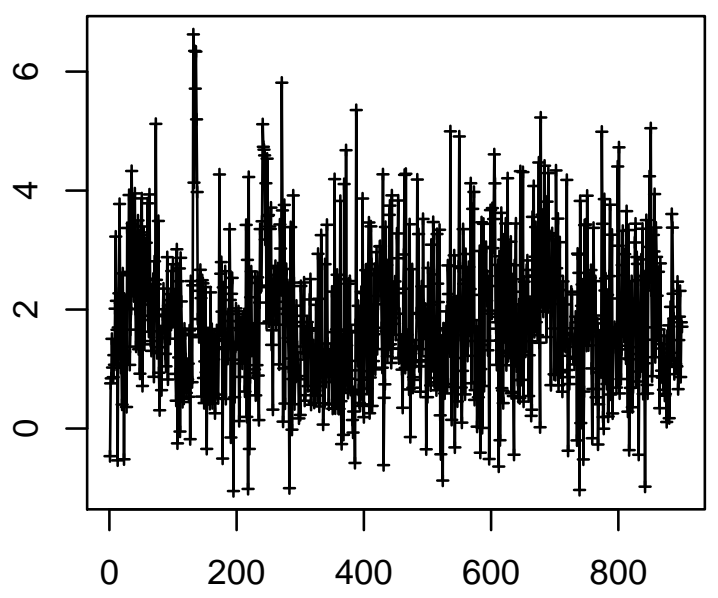

Time Point $(0.25 \mathrm{~Hz})$
Cell 82

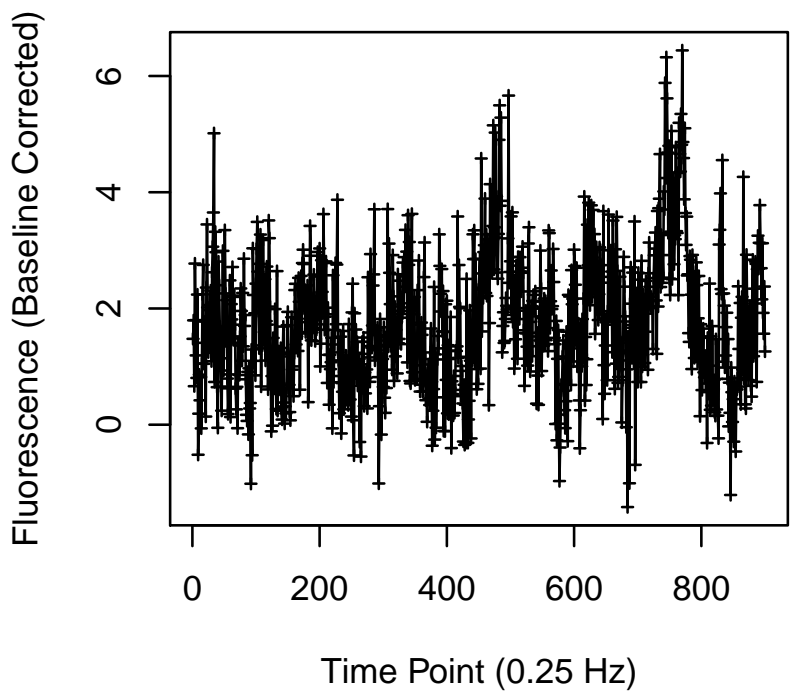

Cell 84

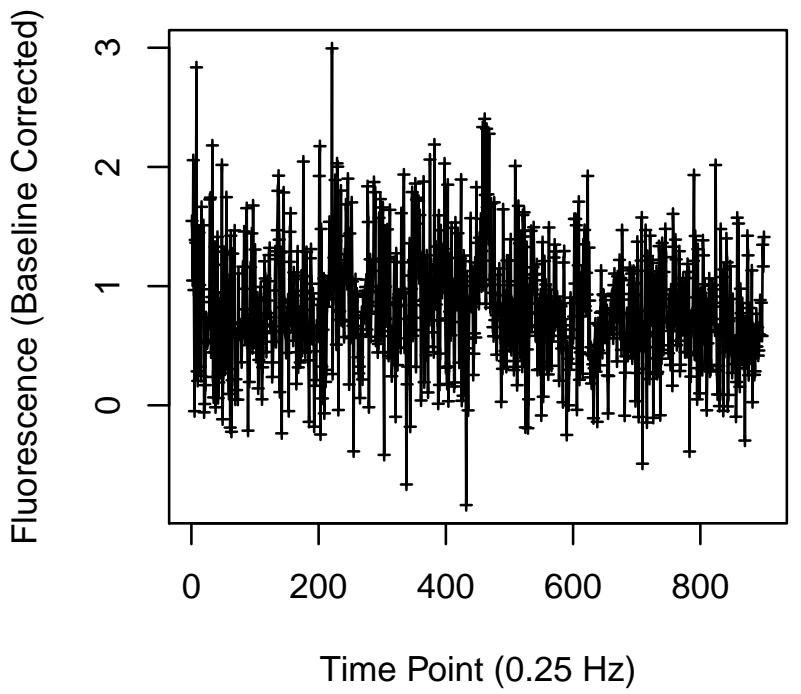


Cell 85

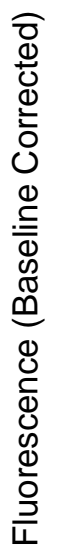

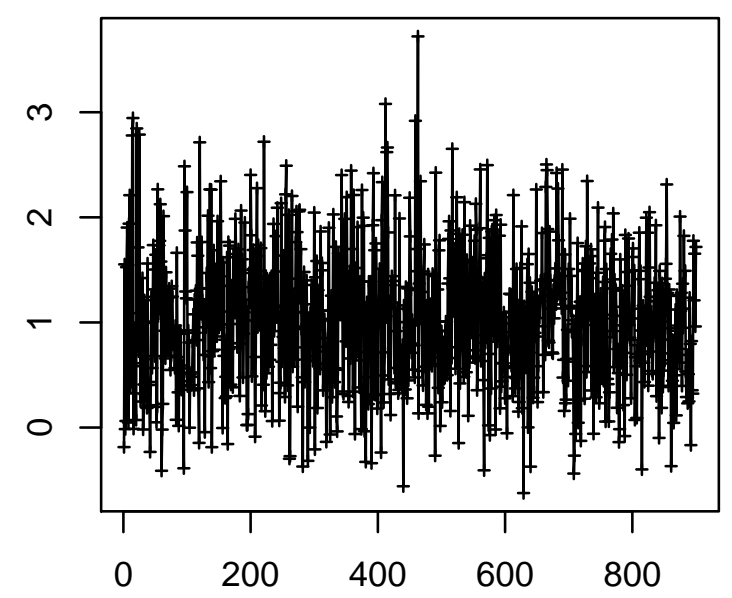

Time Point $(0.25 \mathrm{~Hz})$

Cell 87

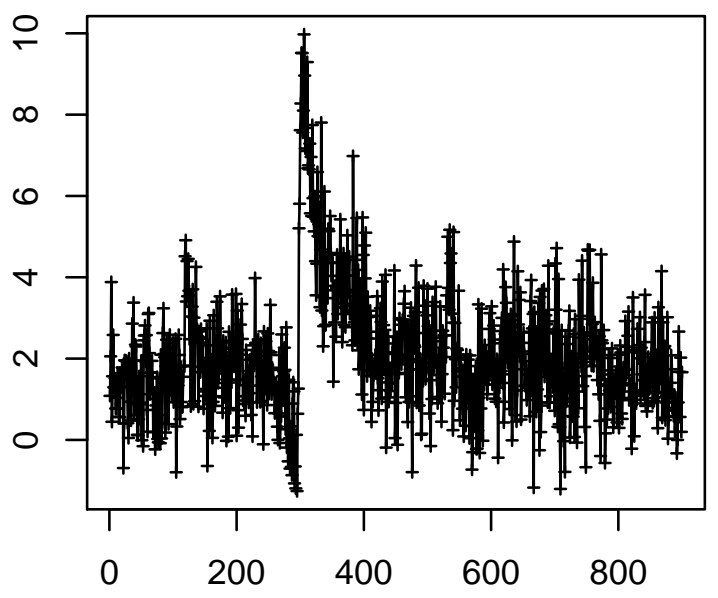

Time Point $(0.25 \mathrm{~Hz})$
Cell 86

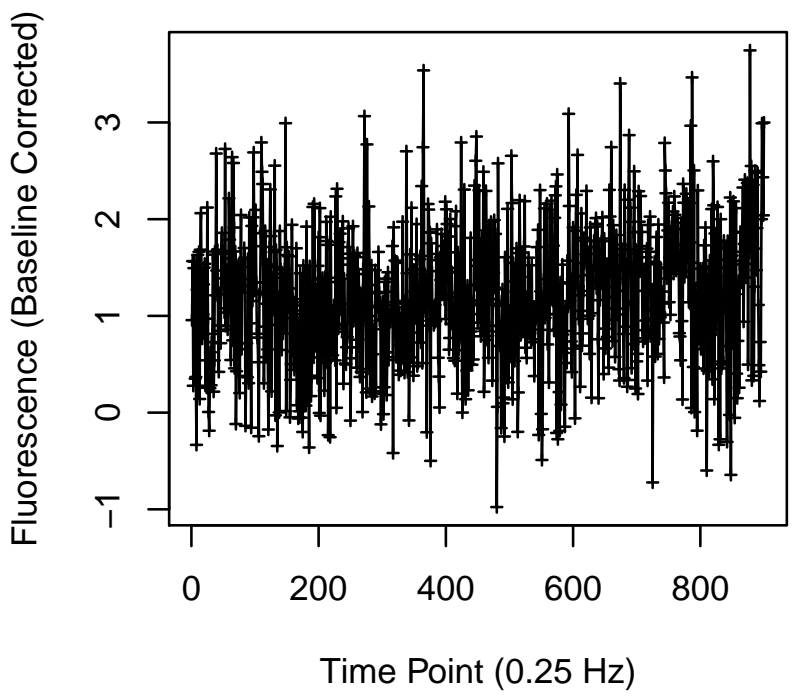

Cell 88

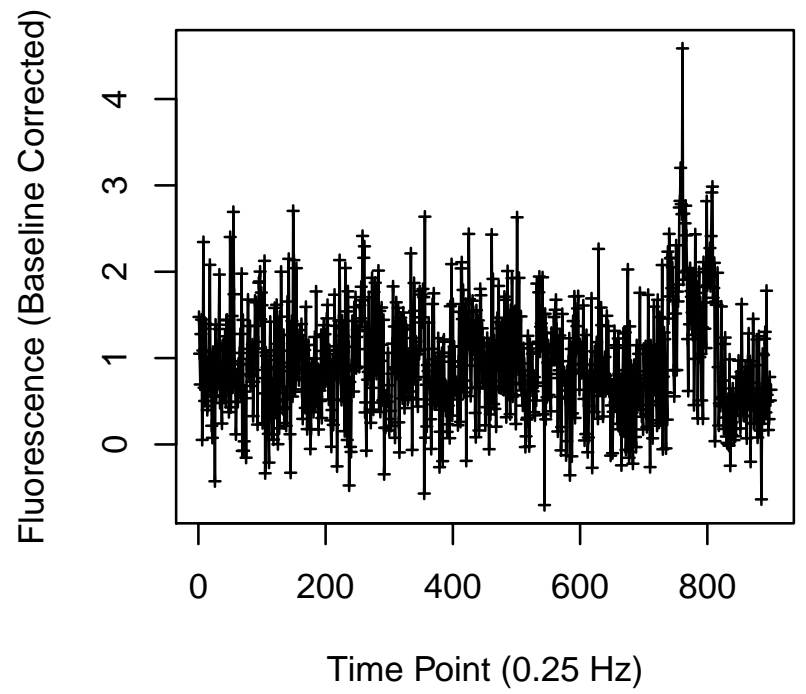


Cell 89

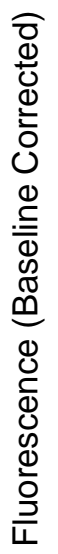

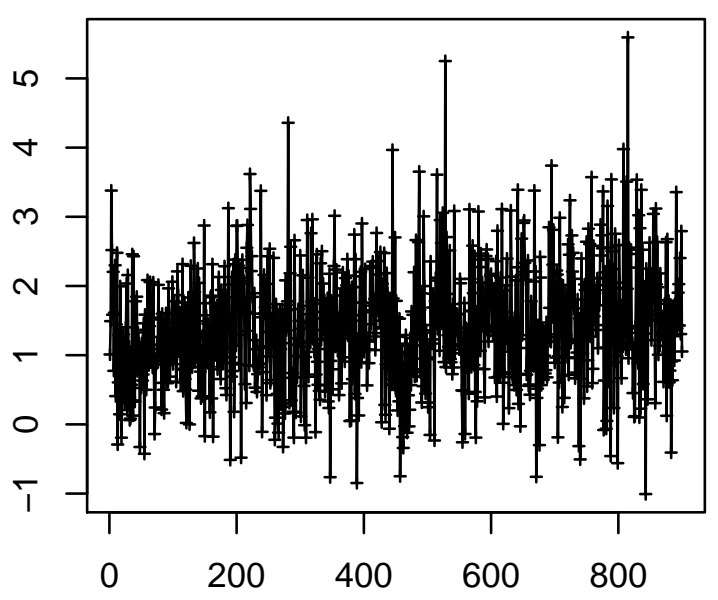

Time Point $(0.25 \mathrm{~Hz})$

\section{Cell 91}

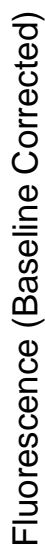

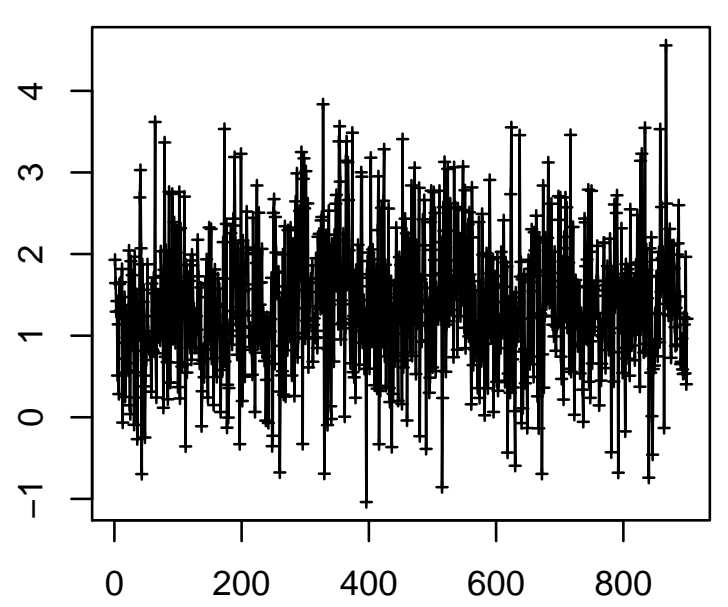

Time Point $(0.25 \mathrm{~Hz})$
Cell 90

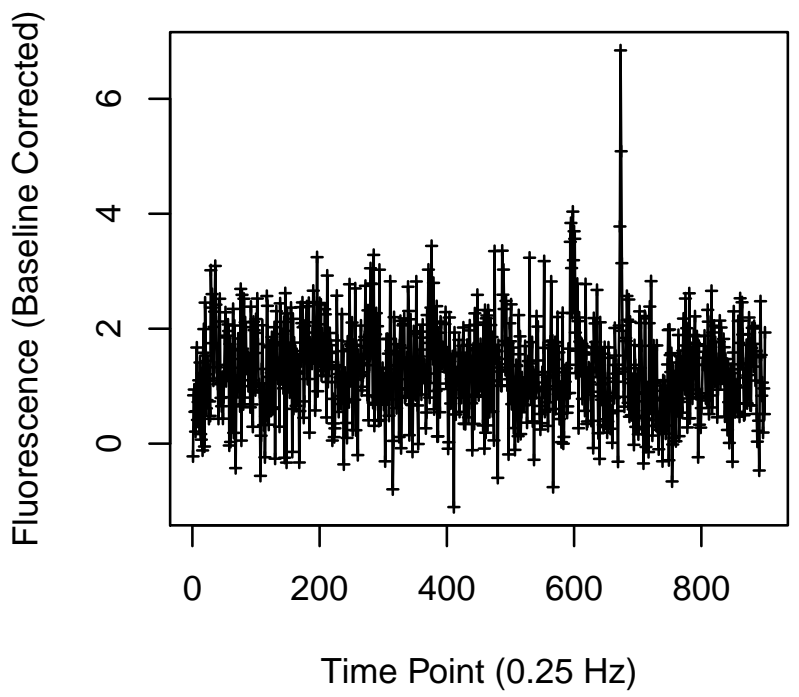

Cell 92

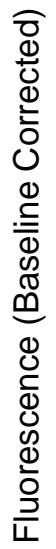

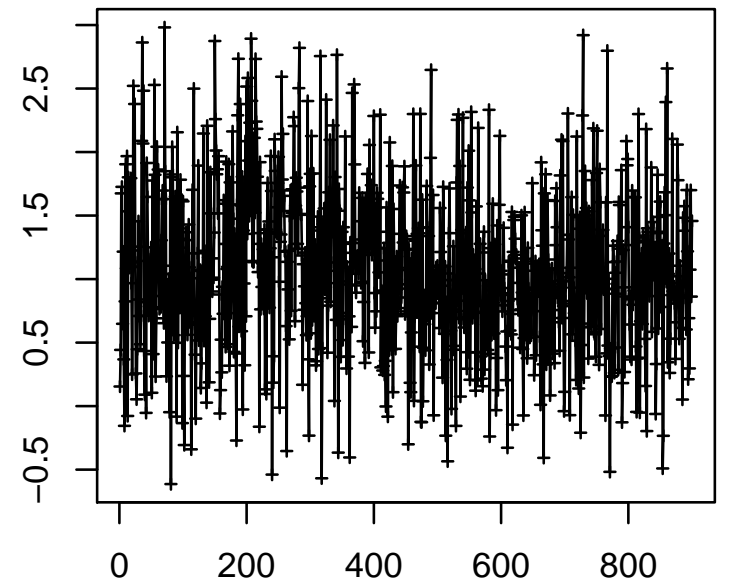

Time Point $(0.25 \mathrm{~Hz})$ 
Cell 93

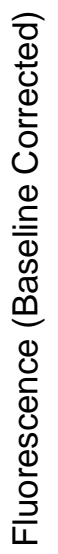

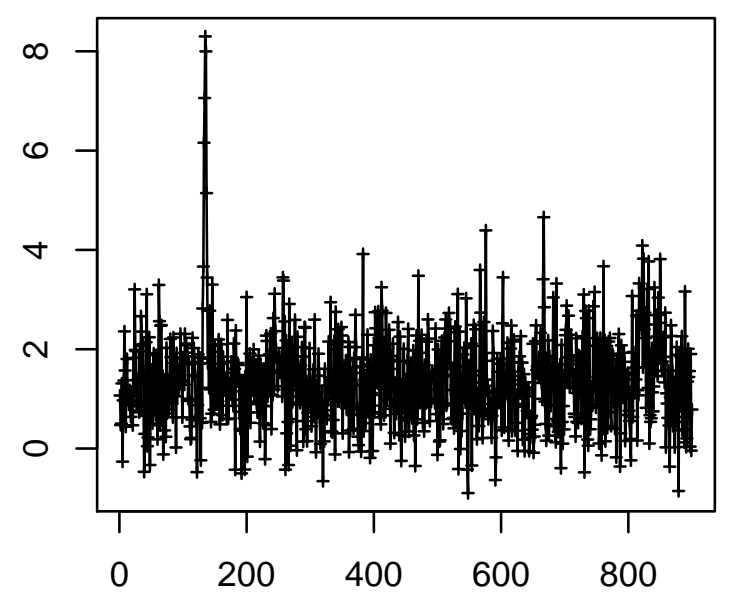

Time Point $(0.25 \mathrm{~Hz})$

Cell 95

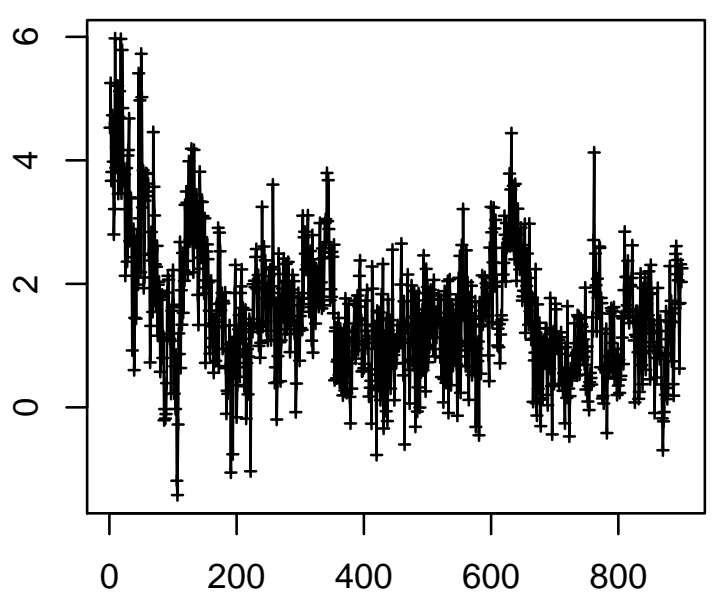

Time Point $(0.25 \mathrm{~Hz})$
Cell 94

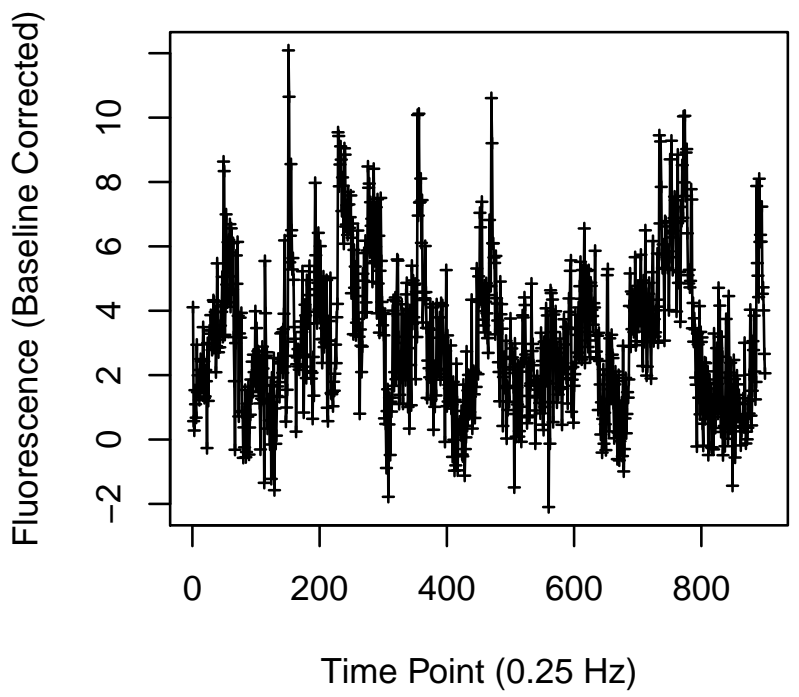

Cell 96

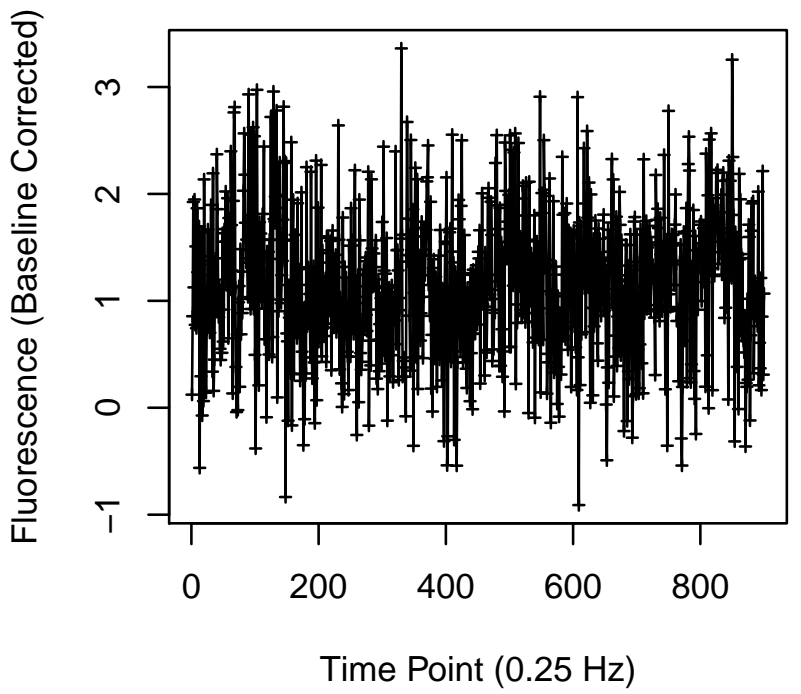


Cell 97

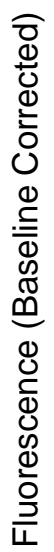

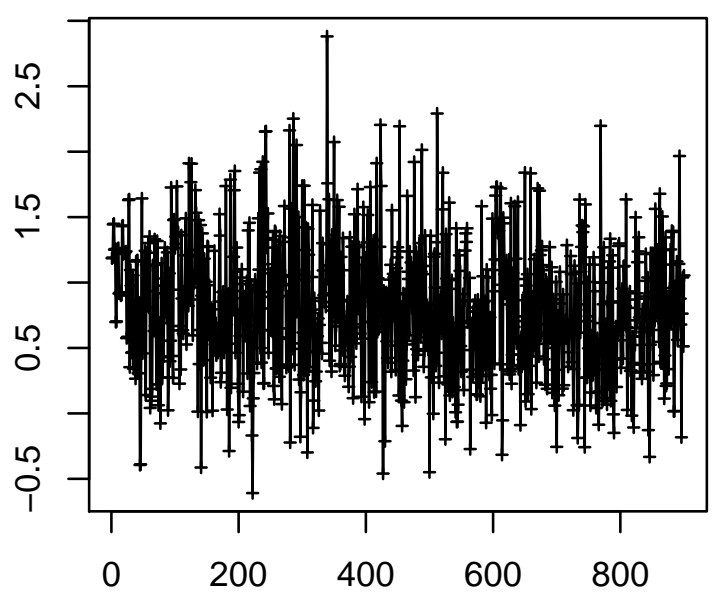

Time Point $(0.25 \mathrm{~Hz})$

Cell 99

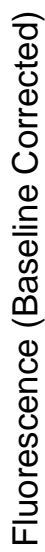

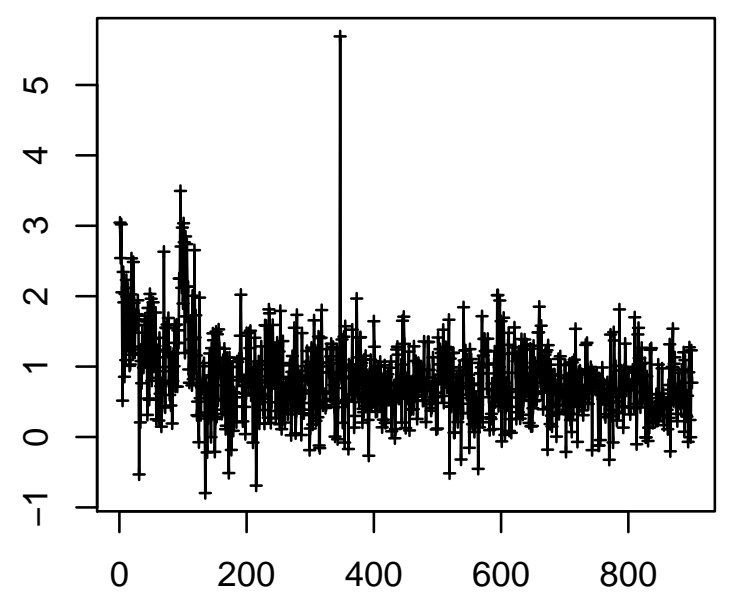

Time Point $(0.25 \mathrm{~Hz})$

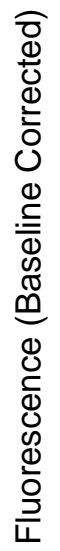

Time Point $(0.25 \mathrm{~Hz})$

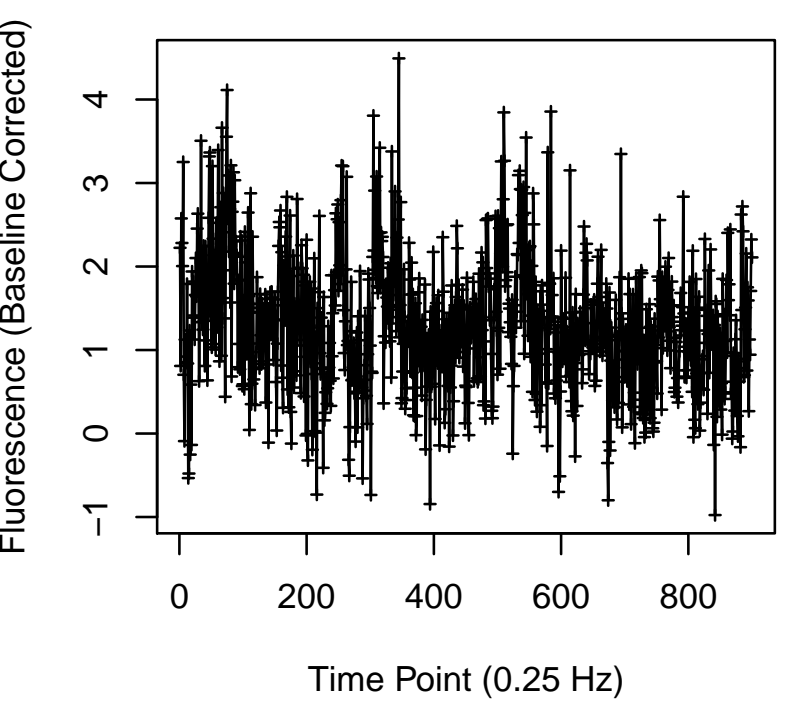

Cell 98

Cell 100

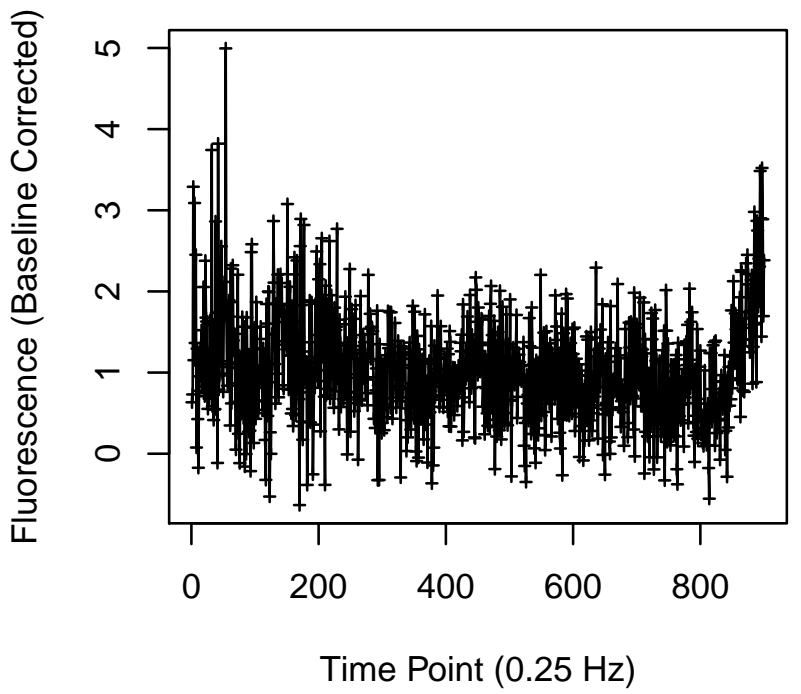




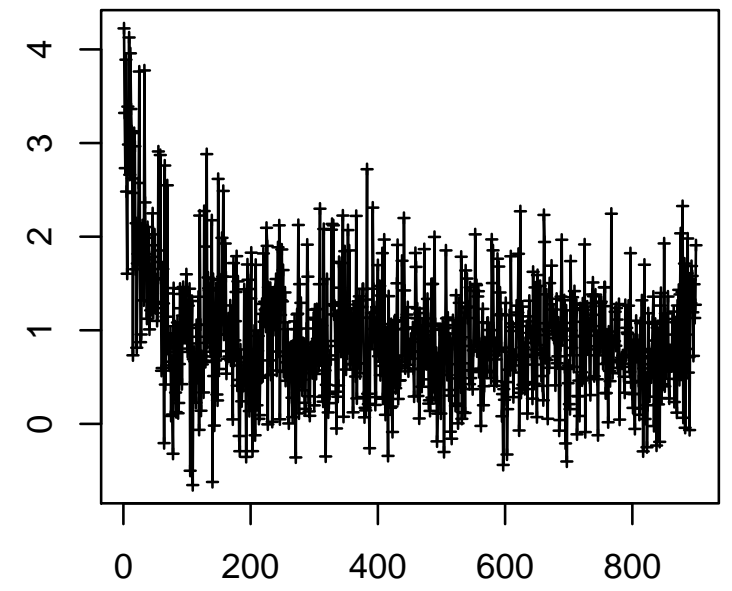

Time Point $(0.25 \mathrm{~Hz})$

\section{Cell 103}

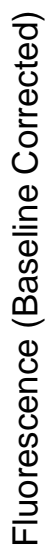

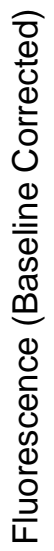

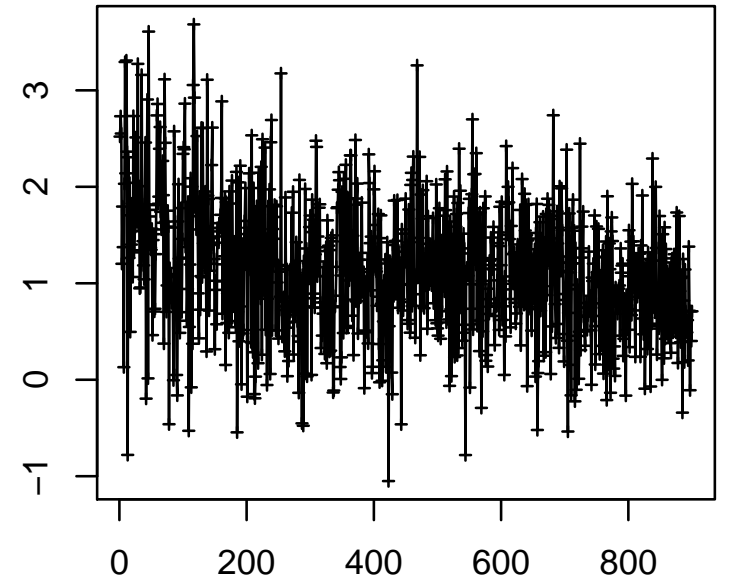

Time Point $(0.25 \mathrm{~Hz})$

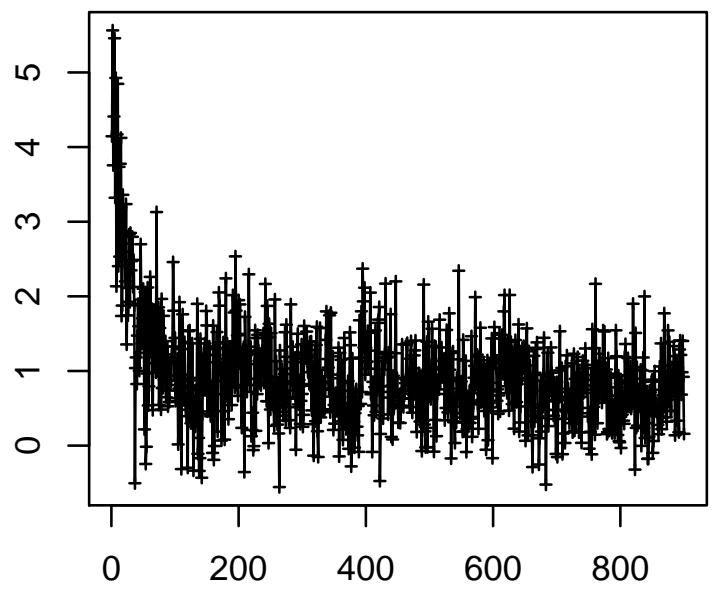

Time Point $(0.25 \mathrm{~Hz})$

\section{Cell 104}

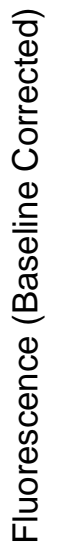

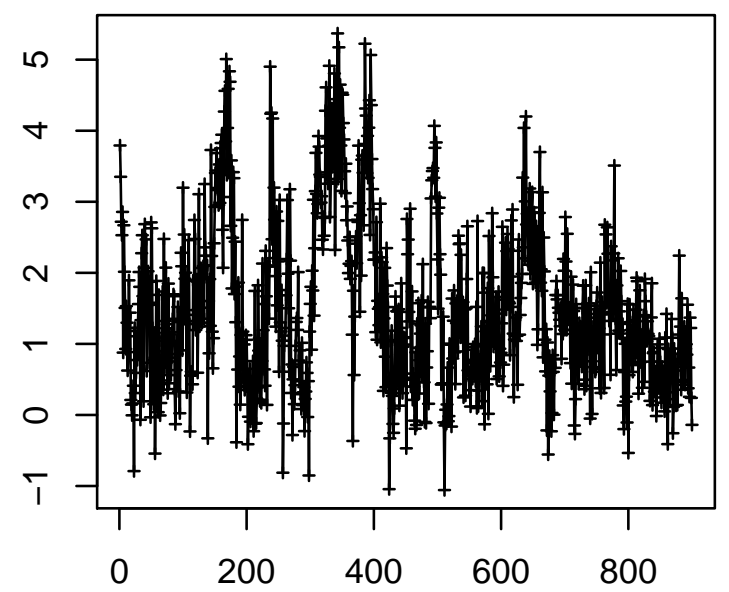

Time Point $(0.25 \mathrm{~Hz})$ 
Cell 105

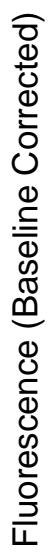

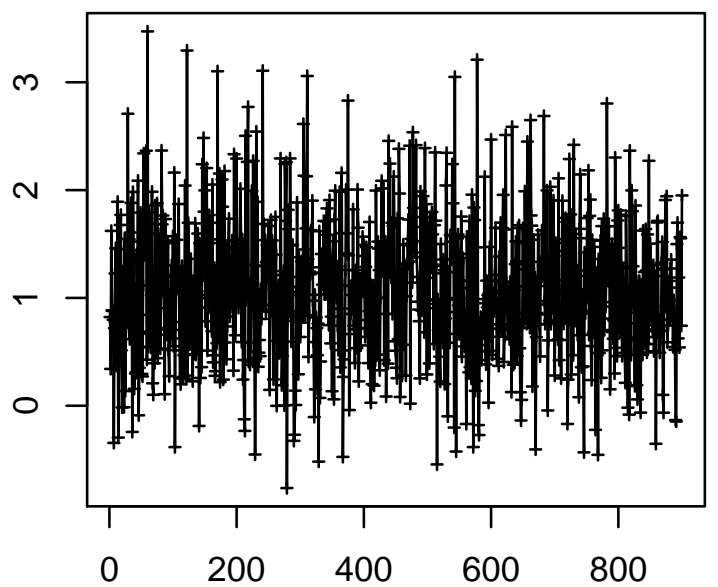

Time Point $(0.25 \mathrm{~Hz})$

Cell 107

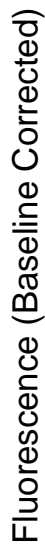

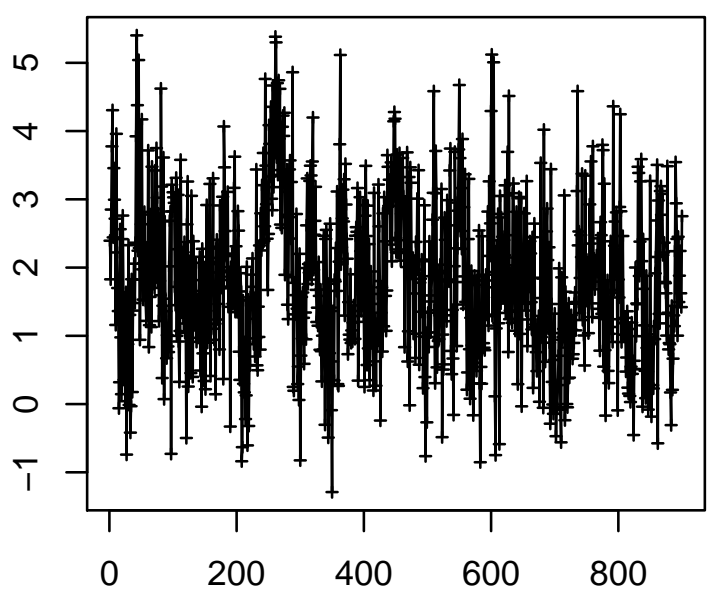

Time Point $(0.25 \mathrm{~Hz})$
Cell 106

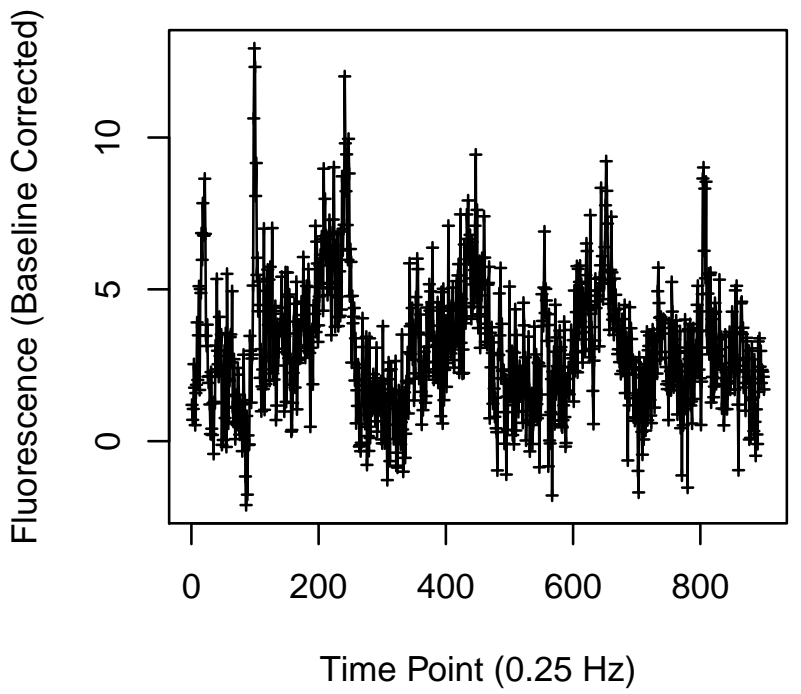

Cell 108

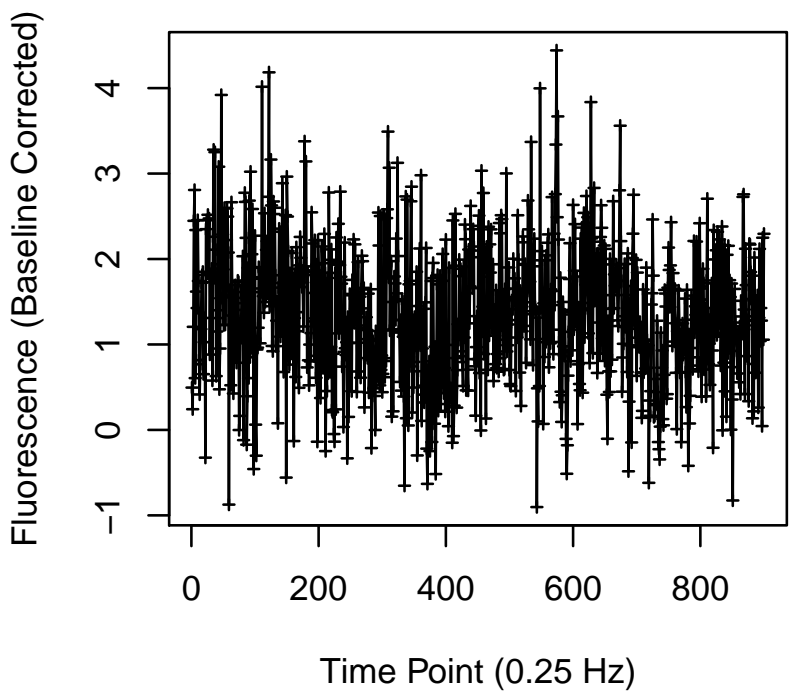


Cell 109

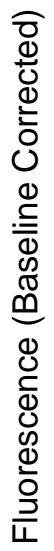

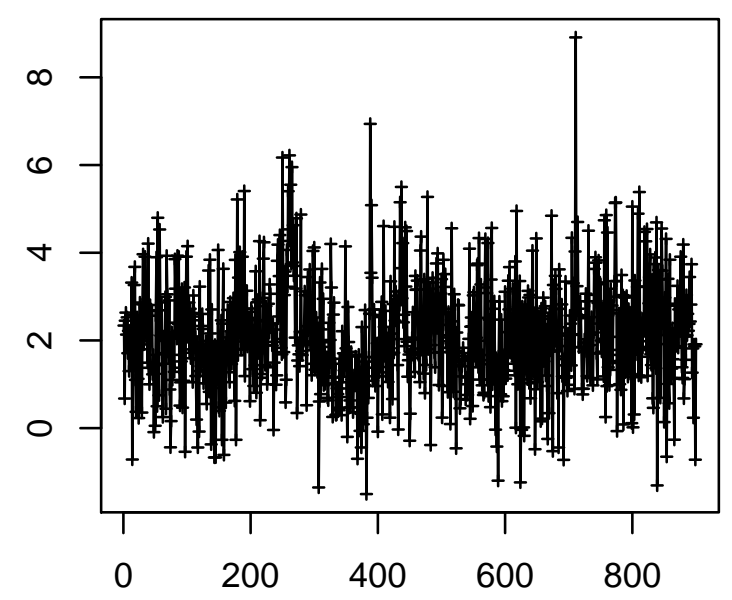

Time Point $(0.25 \mathrm{~Hz})$

Cell 111

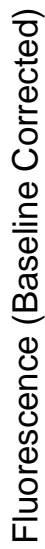

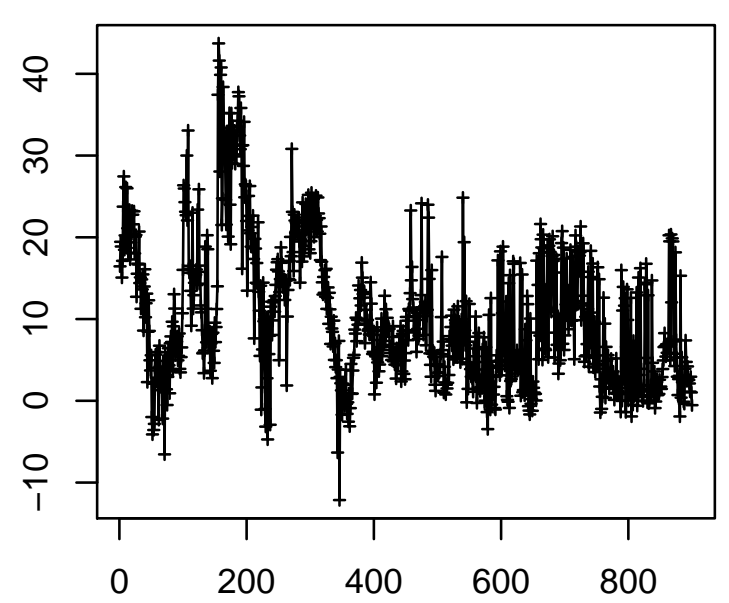

Time Point $(0.25 \mathrm{~Hz})$
Cell 110

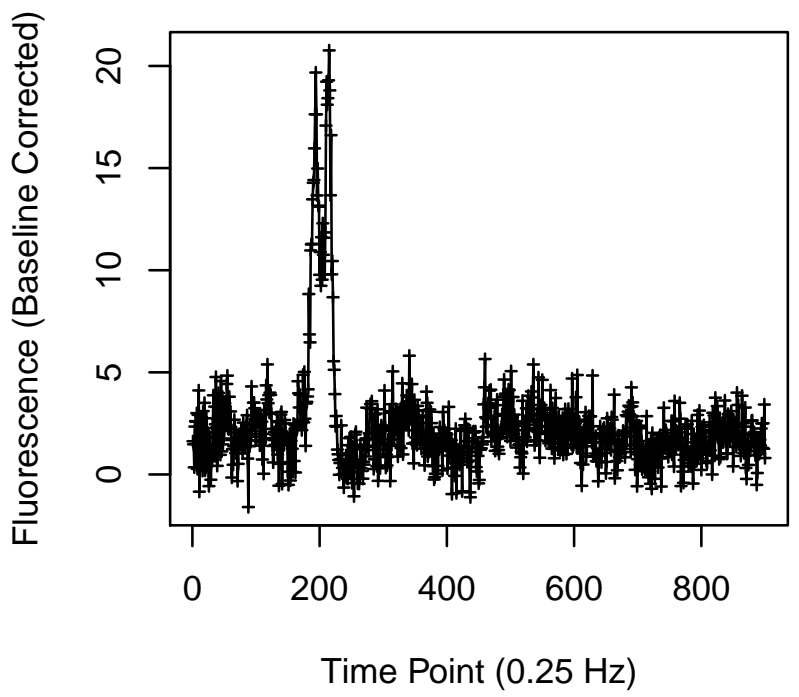

Cell 112

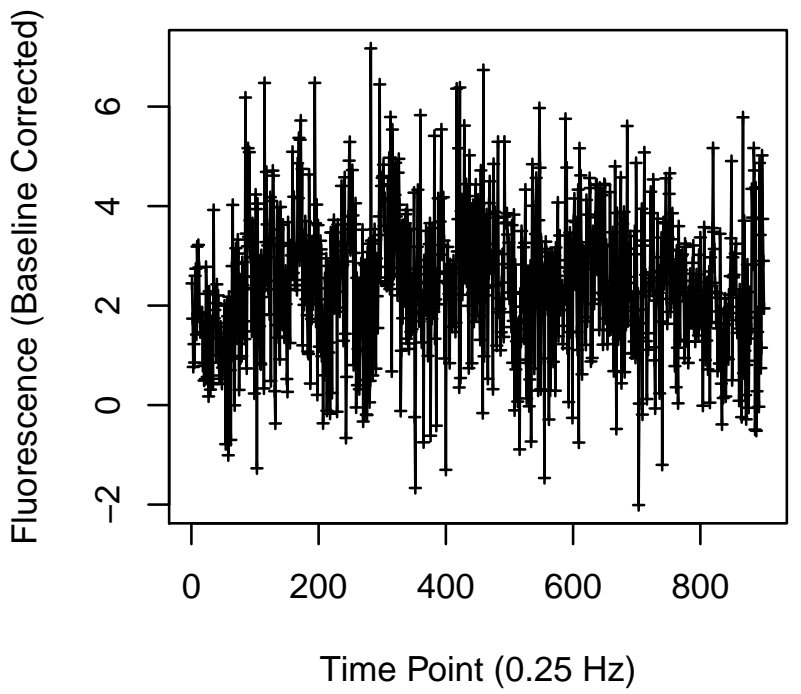




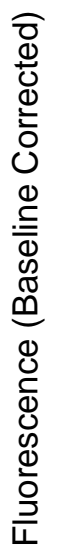

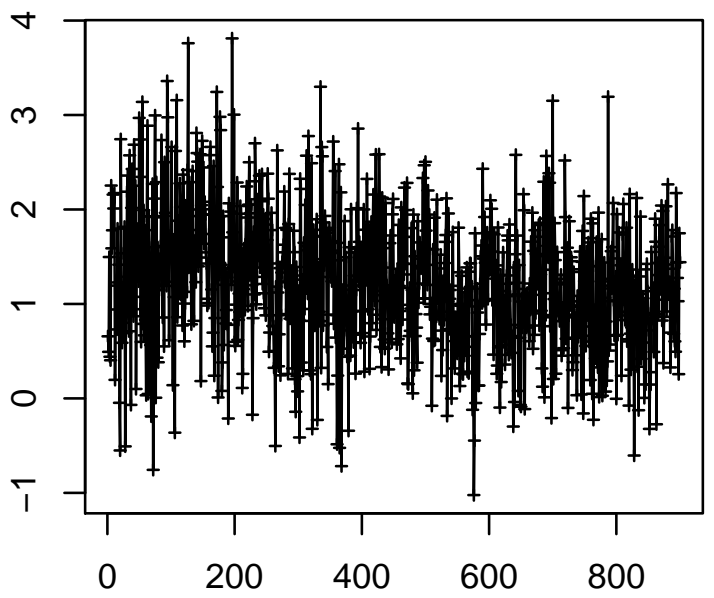

Time Point $(0.25 \mathrm{~Hz})$

Cell 115

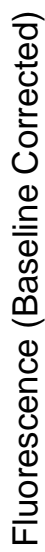

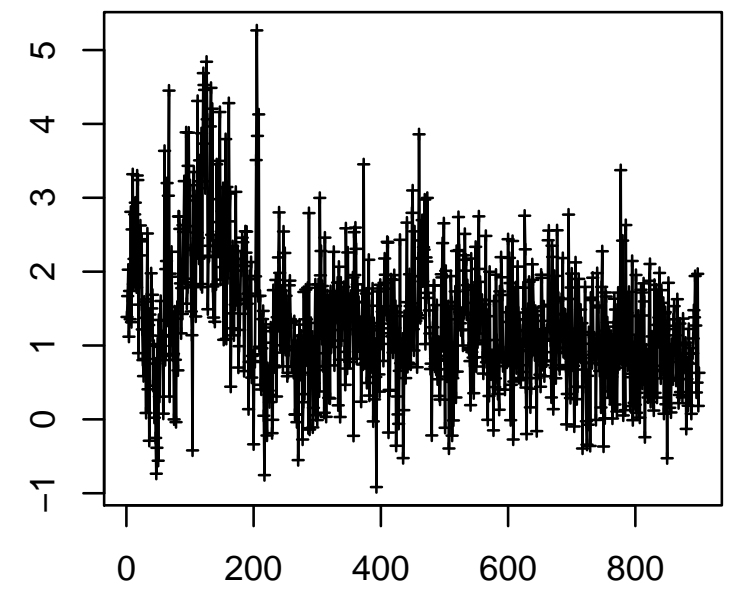

Time Point $(0.25 \mathrm{~Hz})$

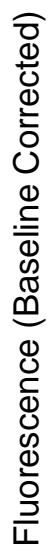

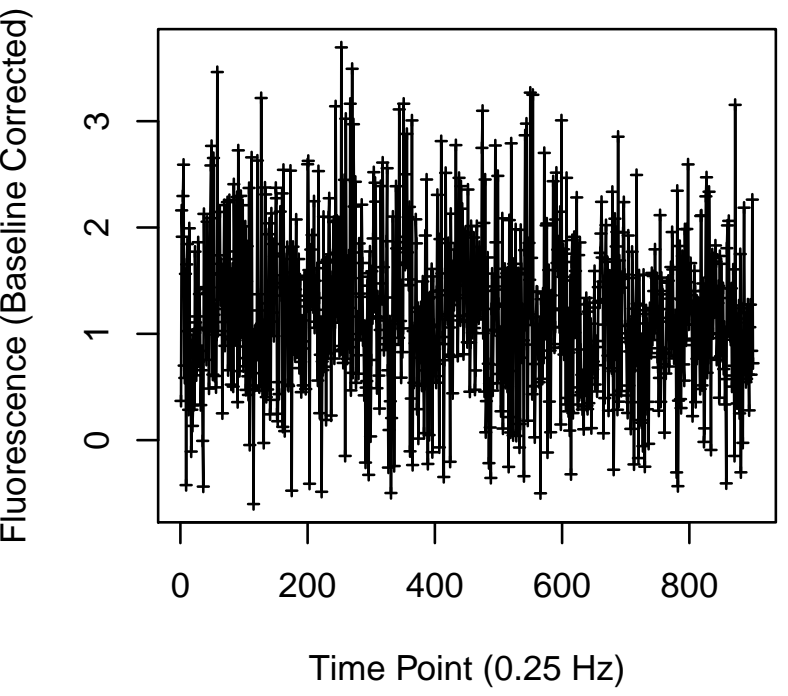

Cell 116

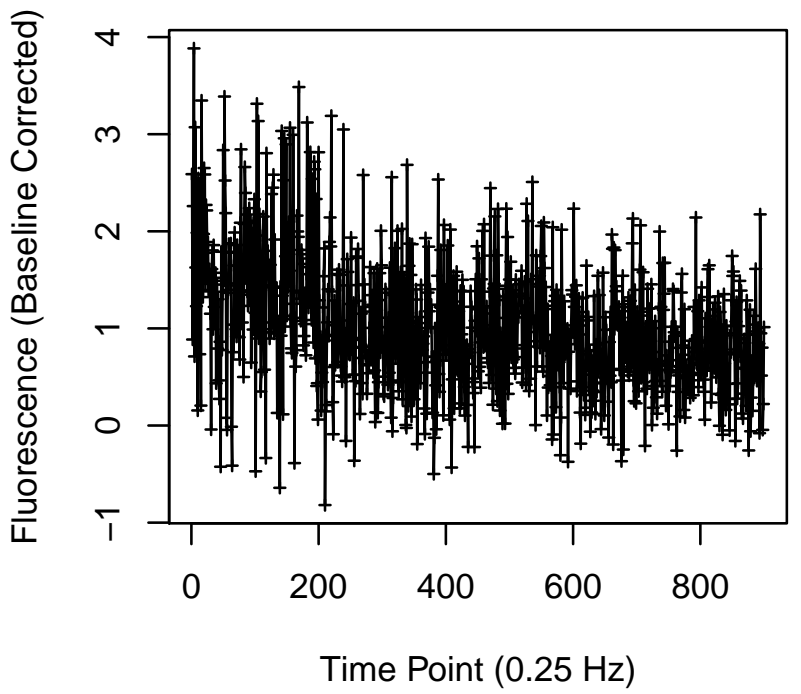


Cell 121

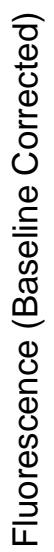

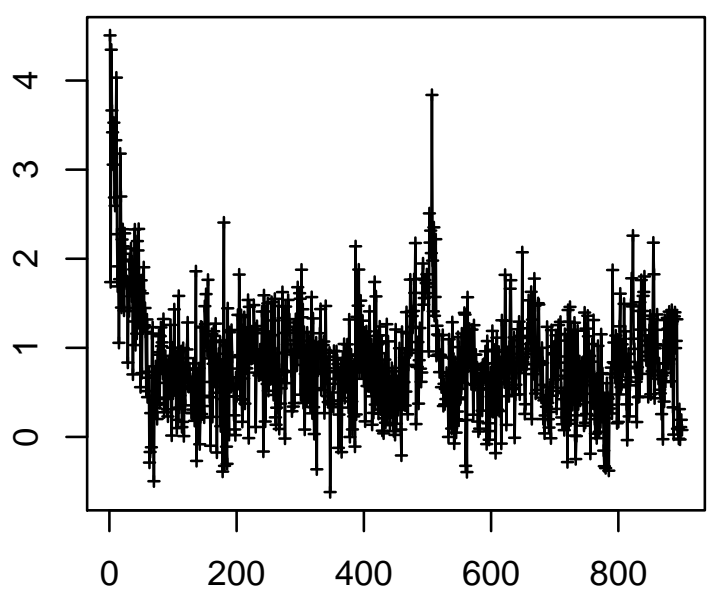

Time Point $(0.25 \mathrm{~Hz})$

\section{Cell 123}

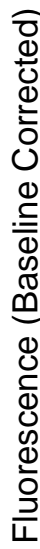

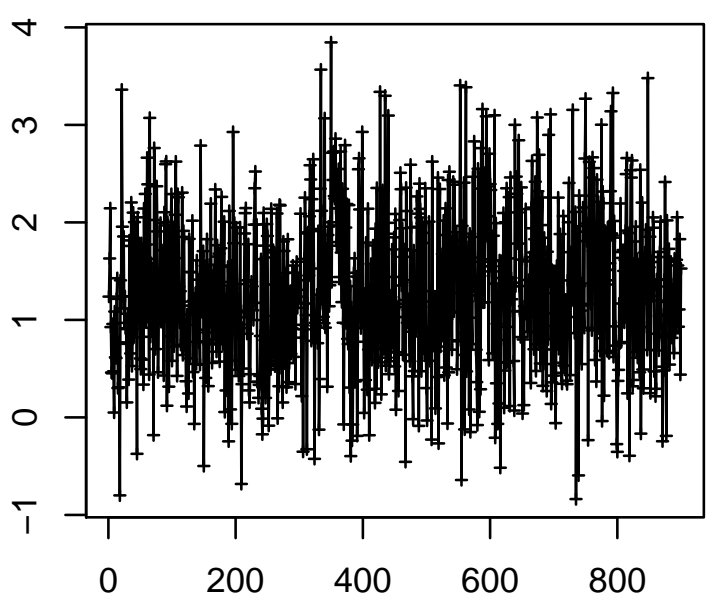

Time Point $(0.25 \mathrm{~Hz})$

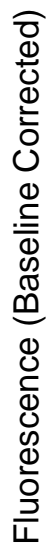

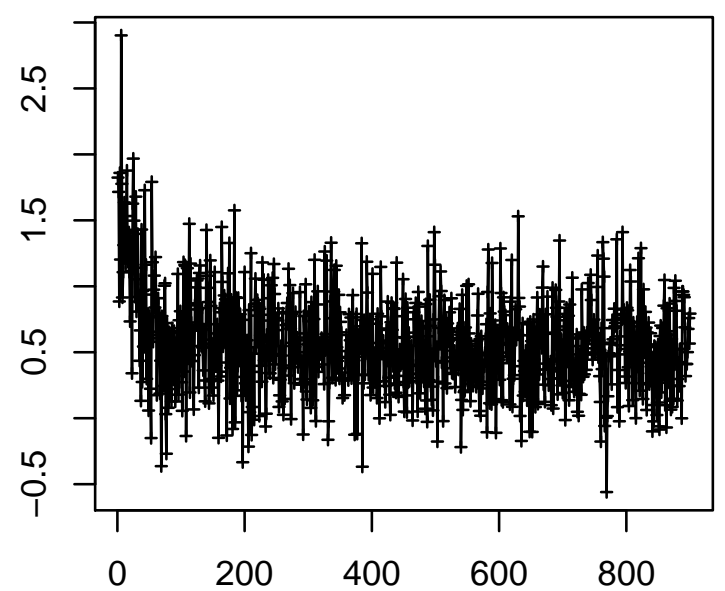

Time Point $(0.25 \mathrm{~Hz})$

Cell 124

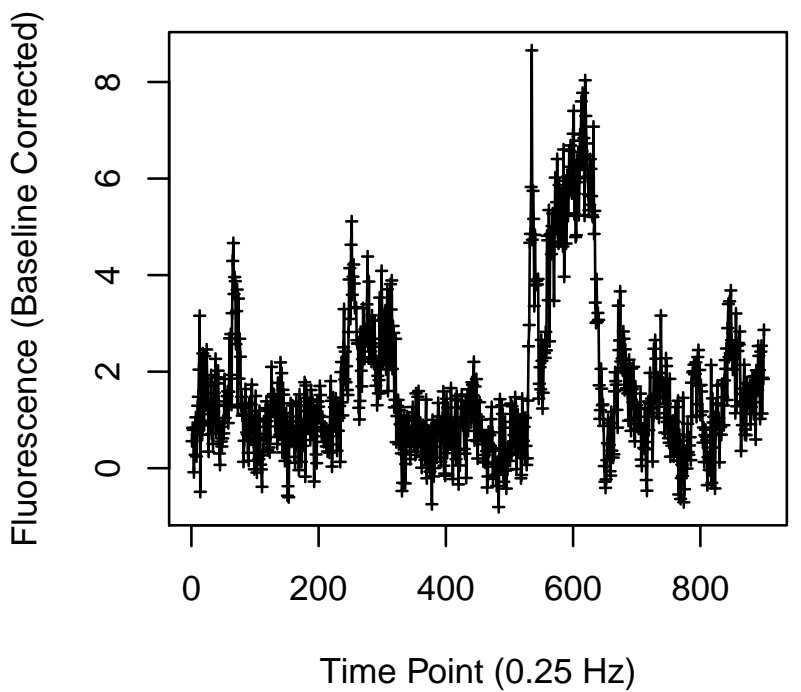




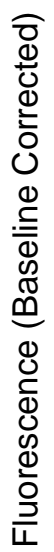

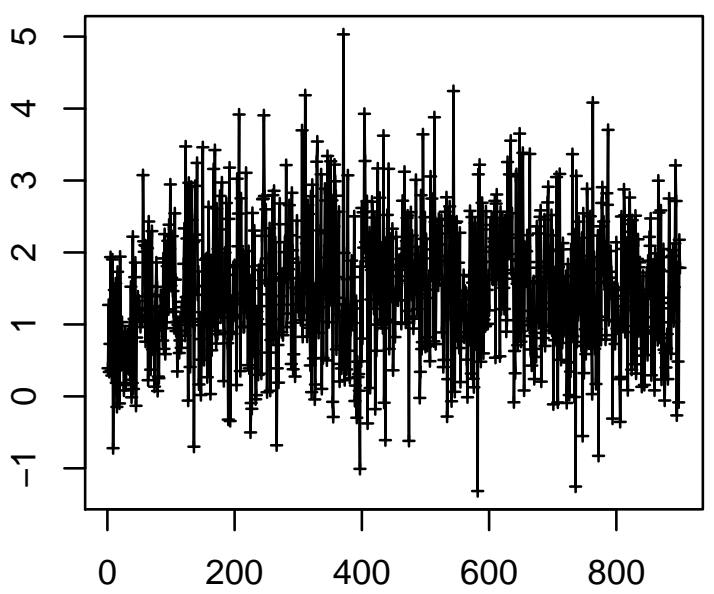

Time Point $(0.25 \mathrm{~Hz})$

\section{Cell 127}

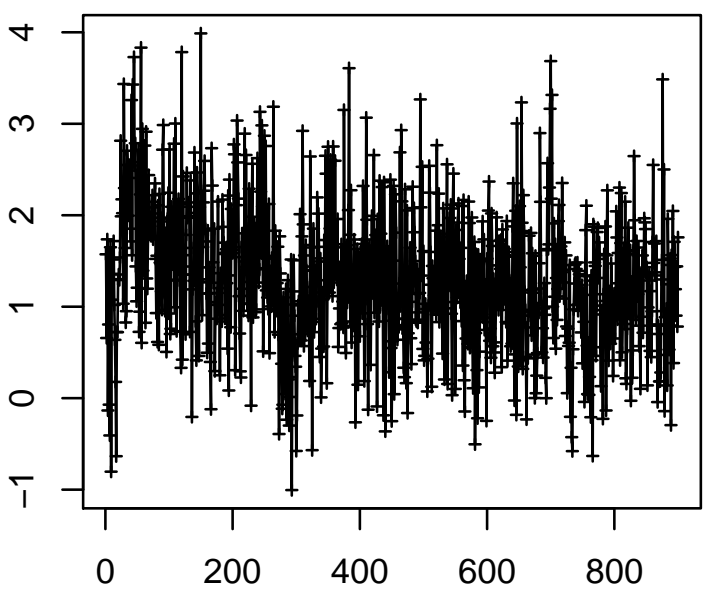

Time Point $(0.25 \mathrm{~Hz})$

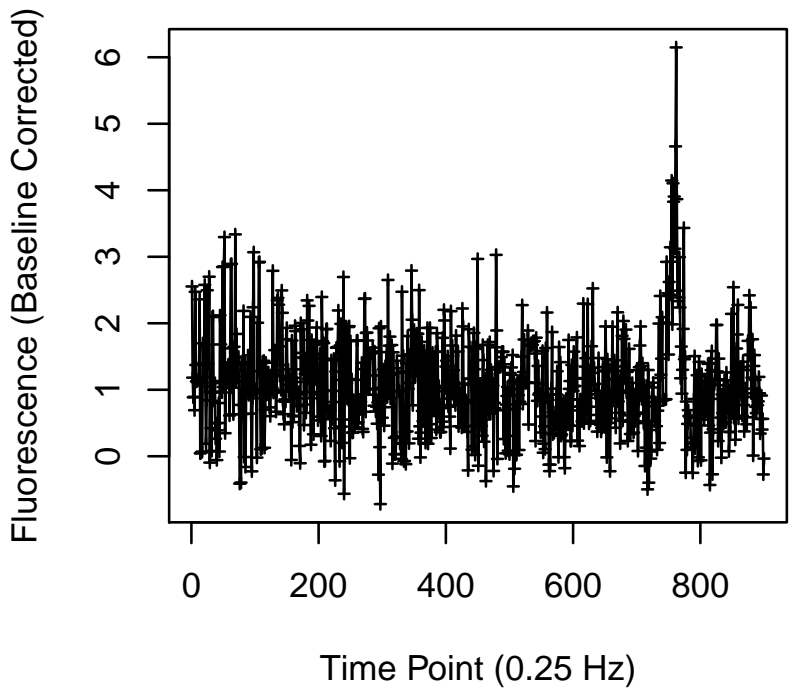

Cell 128

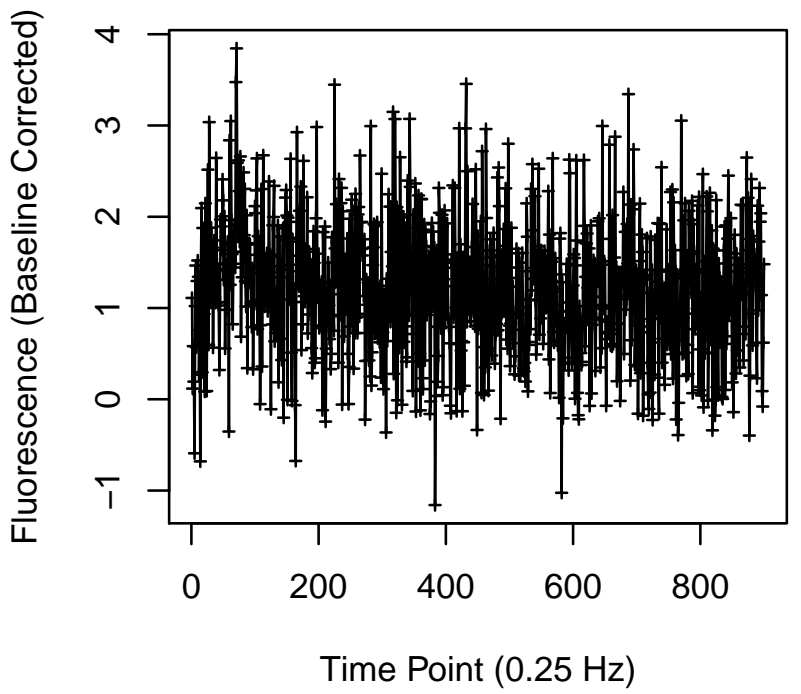


Cell 129

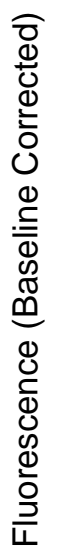

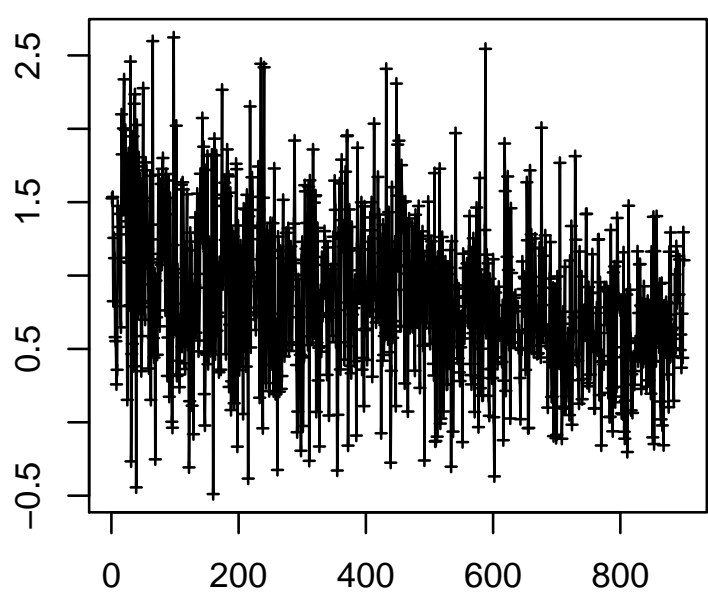

Time Point $(0.25 \mathrm{~Hz})$

Cell 131

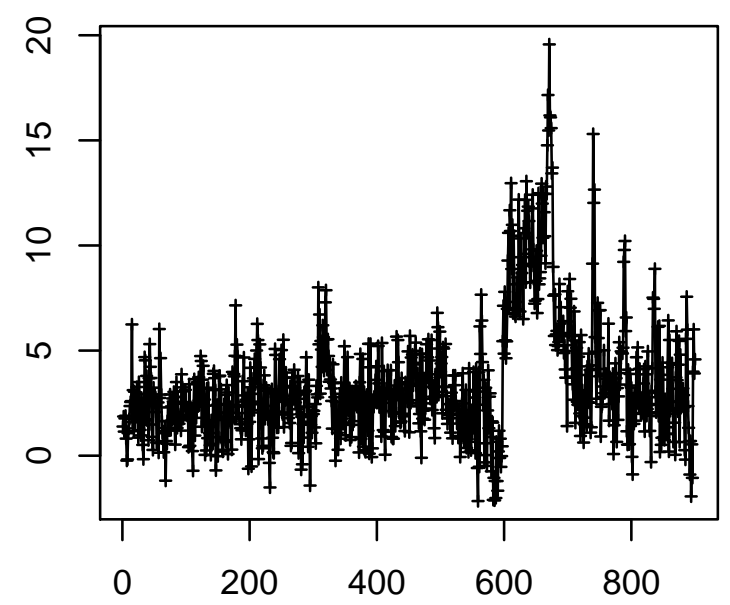

Time Point $(0.25 \mathrm{~Hz})$
Cell 130

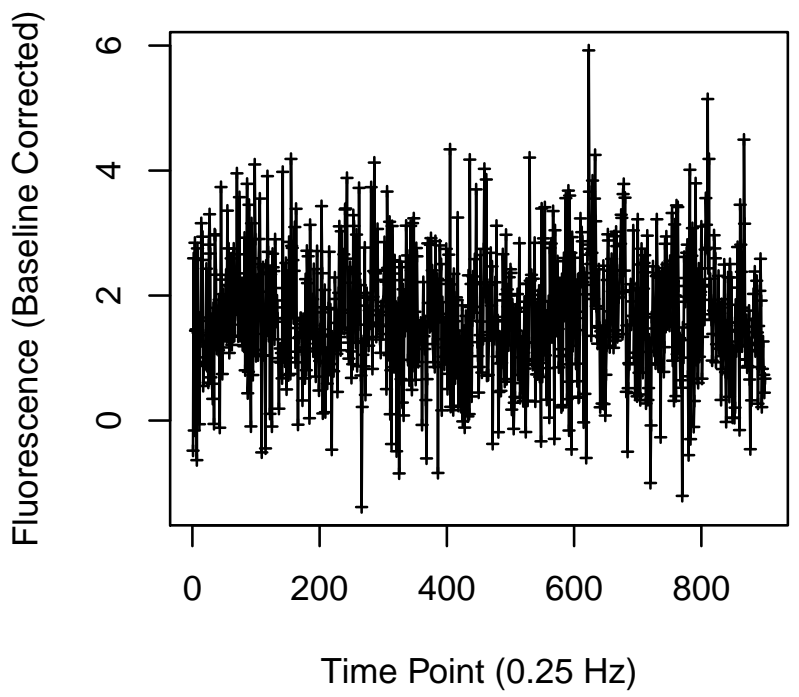

Cell 132

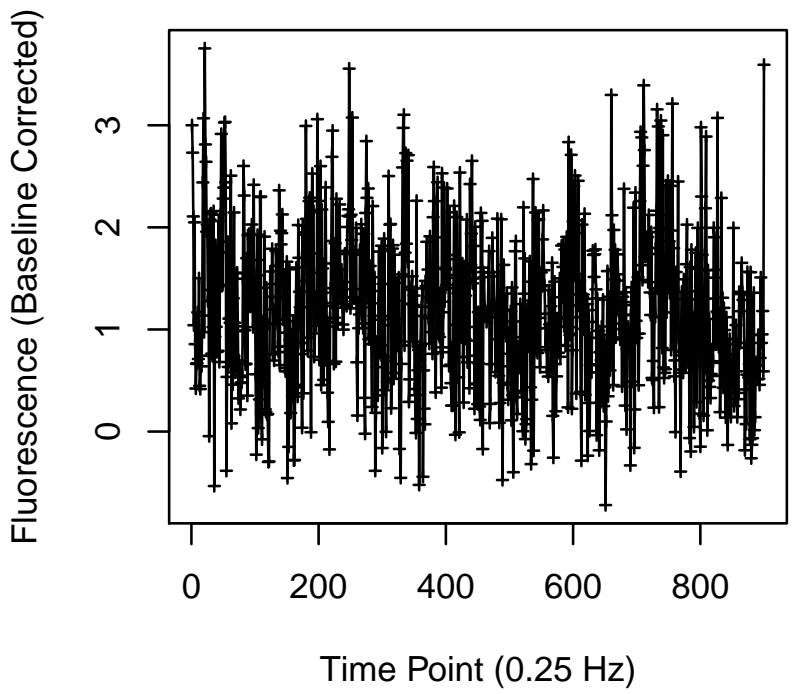


Cell 133

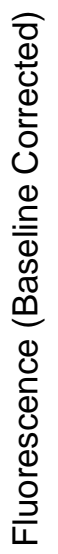

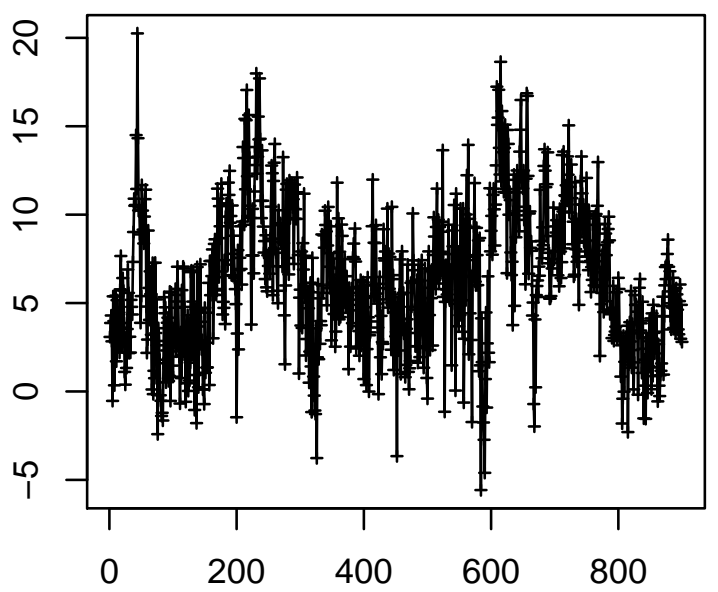

Time Point $(0.25 \mathrm{~Hz})$

Cell 135

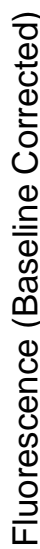

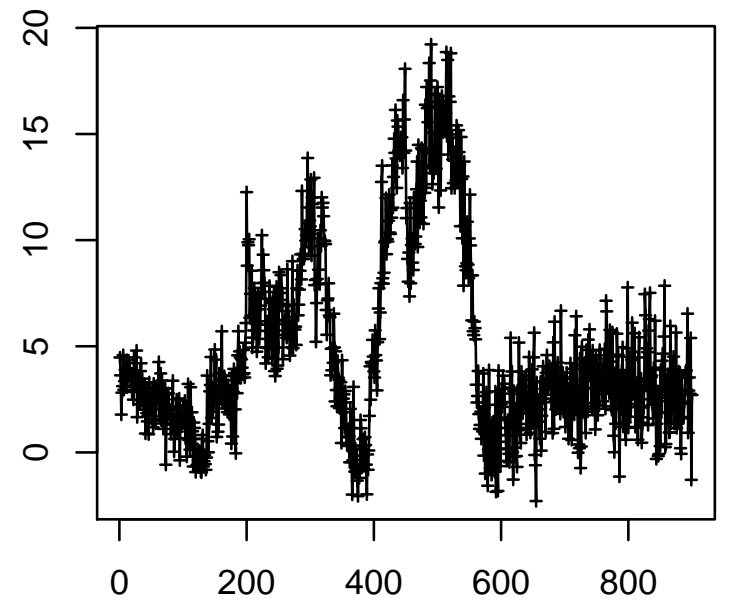

Time Point $(0.25 \mathrm{~Hz})$

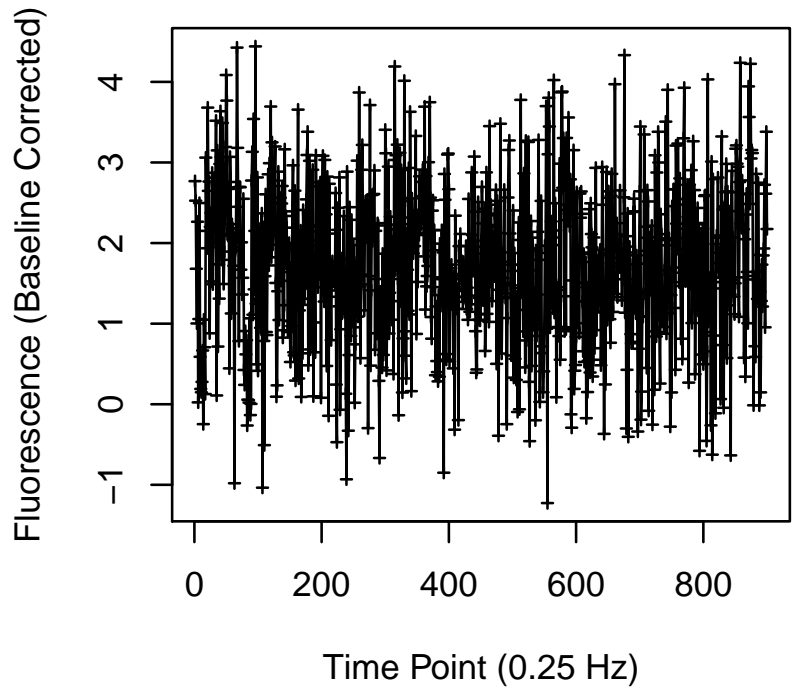

Cell 136

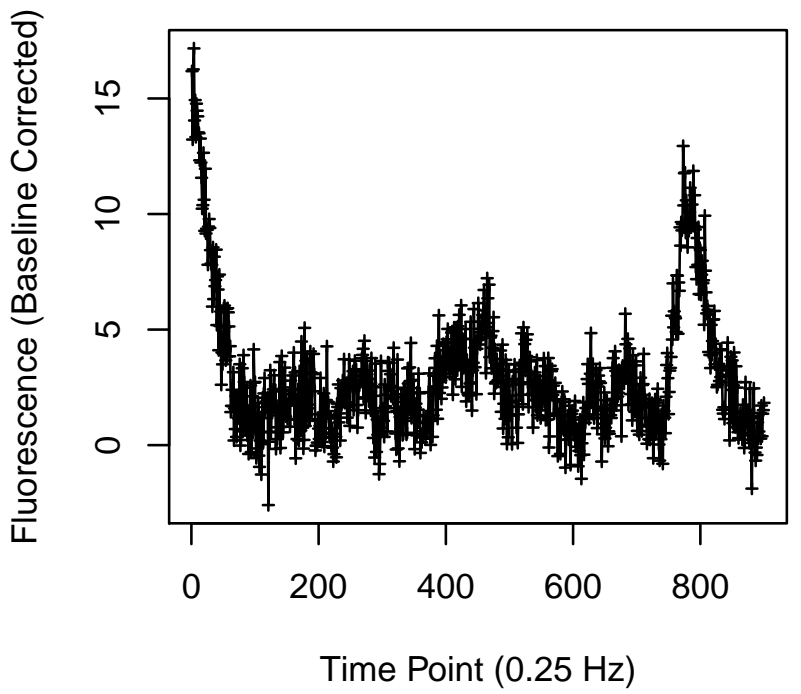


Cell 141

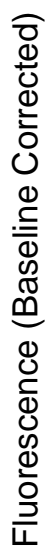

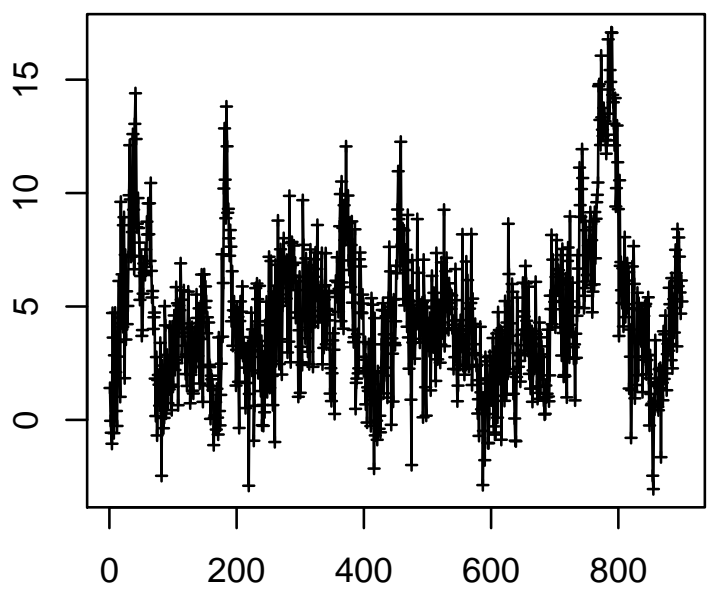

Time Point $(0.25 \mathrm{~Hz})$

Cell 143

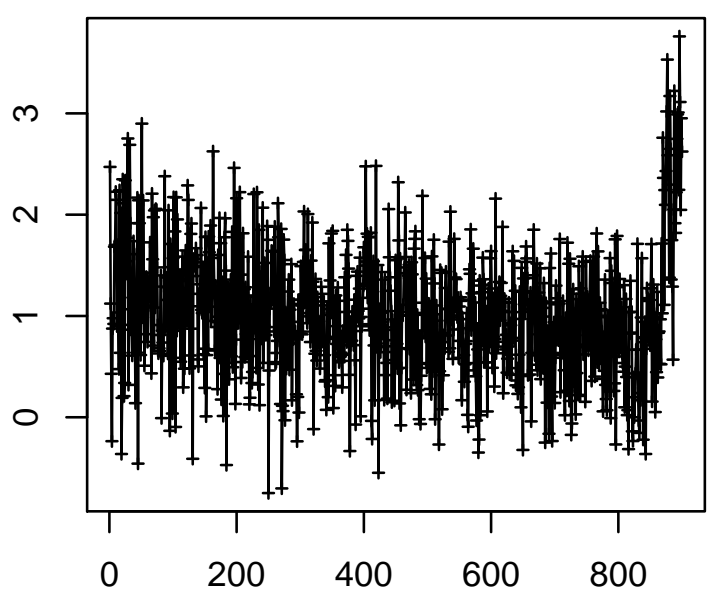

Time Point $(0.25 \mathrm{~Hz})$
Cell 142

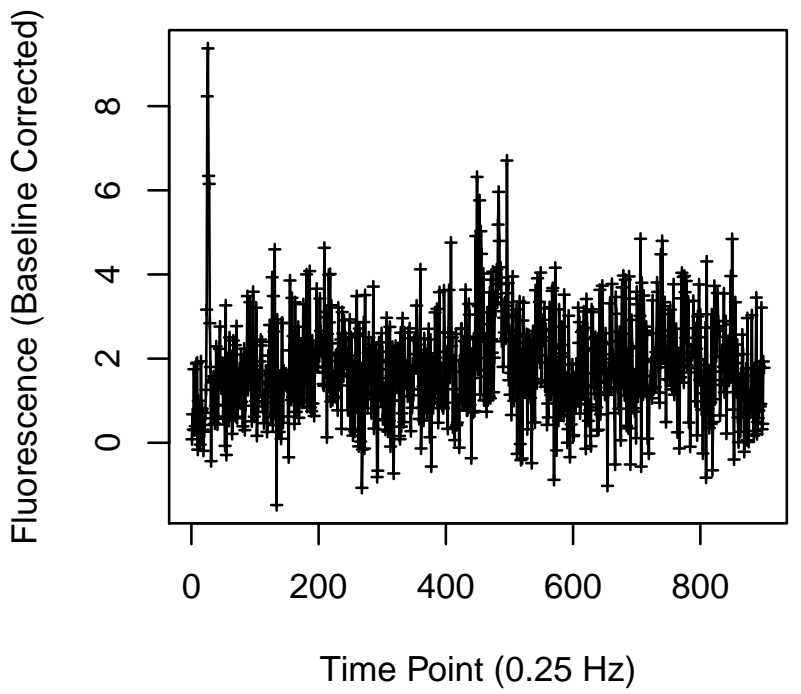

Cell 144

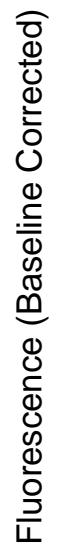

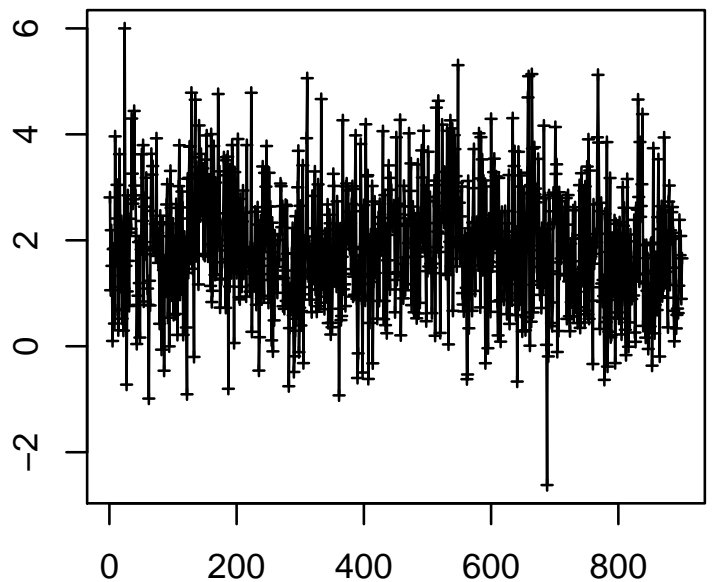

Time Point $(0.25 \mathrm{~Hz})$ 
Cell 145

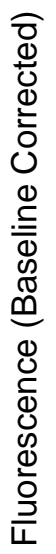

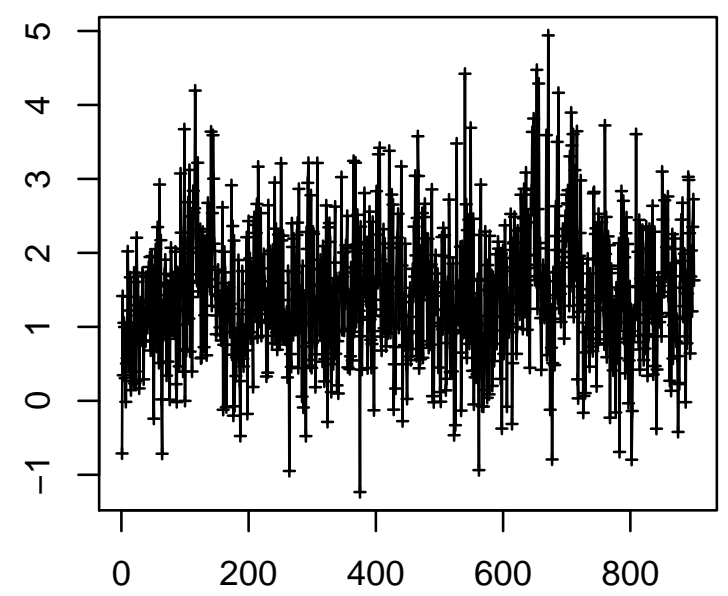

Time Point $(0.25 \mathrm{~Hz})$

Cell 147

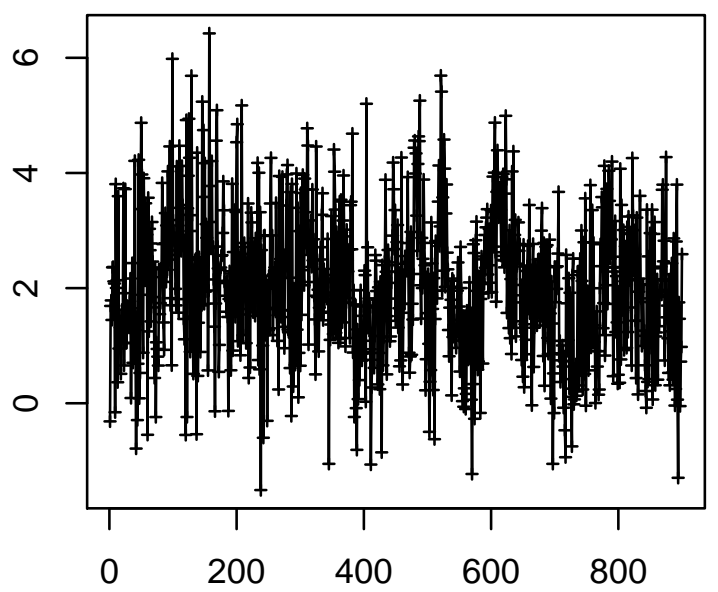

Time Point $(0.25 \mathrm{~Hz})$
Cell 146

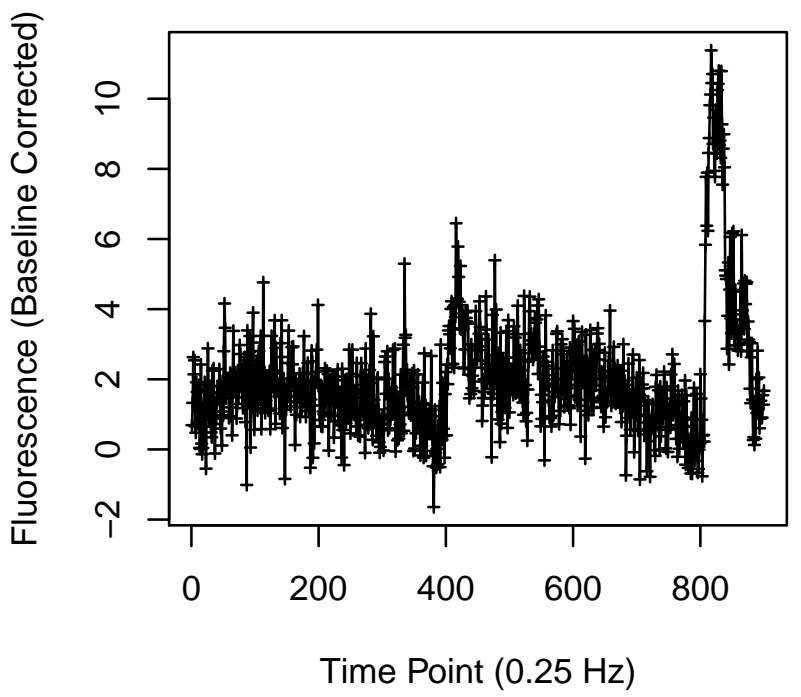

Cell 148

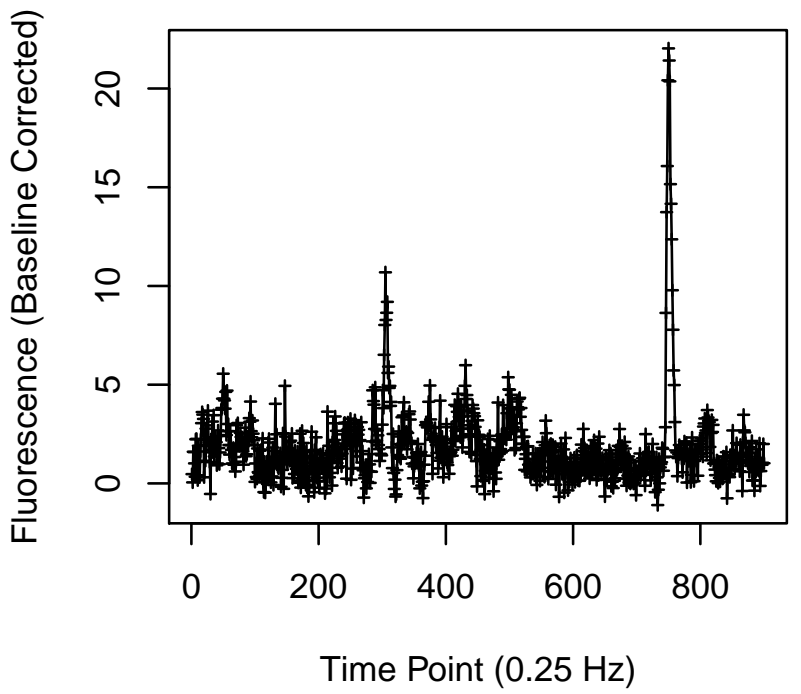




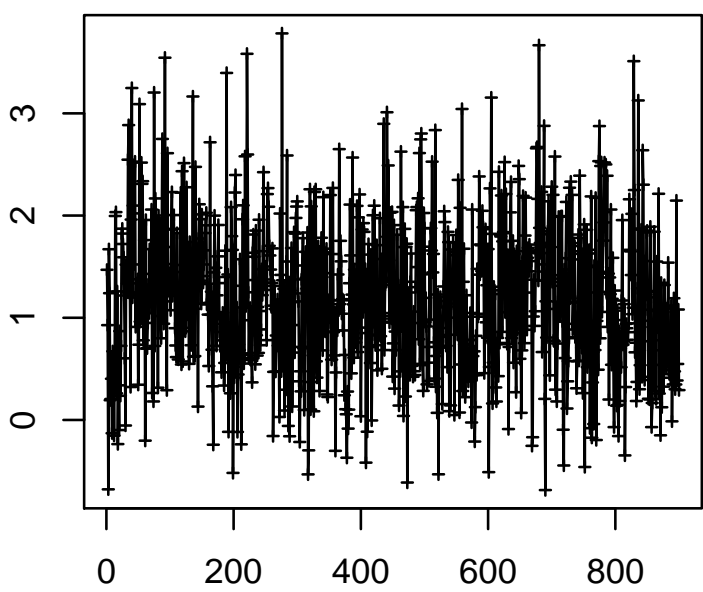

Time Point $(0.25 \mathrm{~Hz})$

\section{Cell 155}

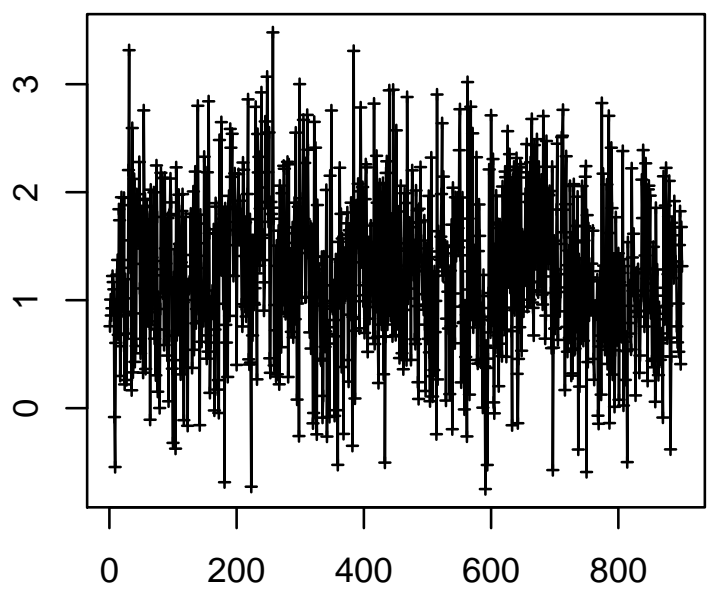

Time Point $(0.25 \mathrm{~Hz})$

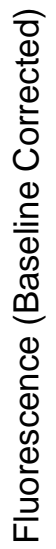

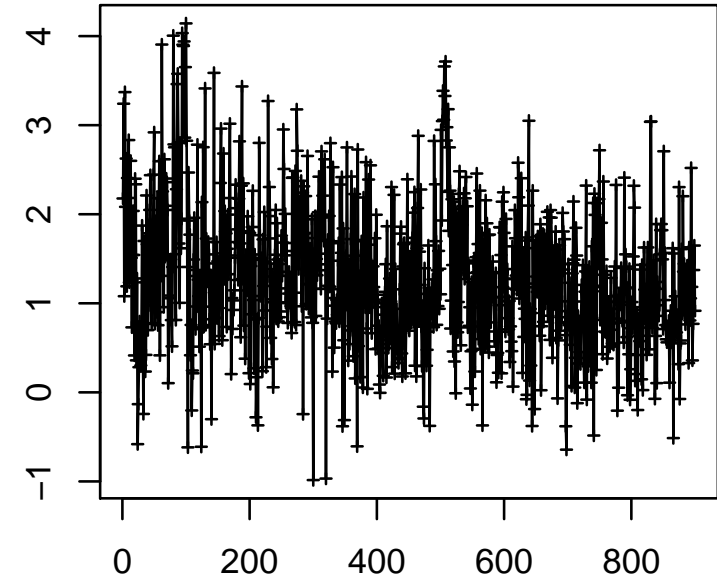

Time Point $(0.25 \mathrm{~Hz})$

Cell 156

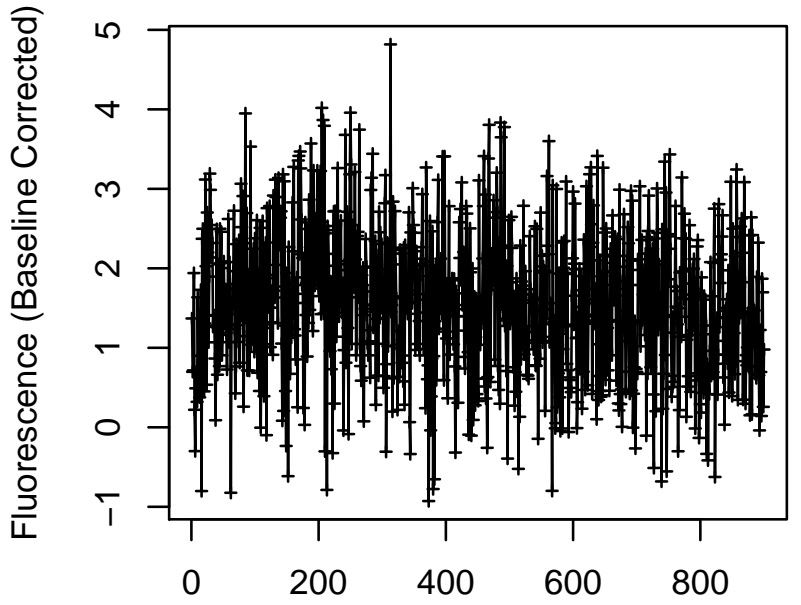

Time Point $(0.25 \mathrm{~Hz})$ 
Cell 157

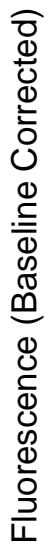

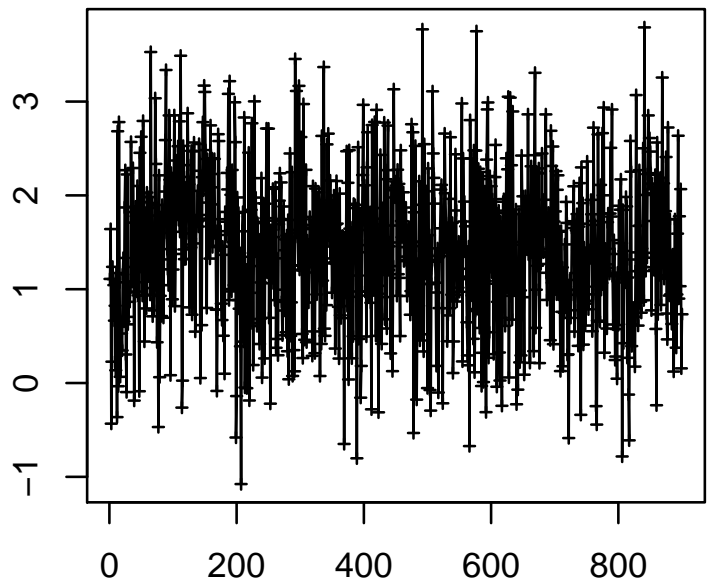

Time Point $(0.25 \mathrm{~Hz})$

\section{Cell 159}

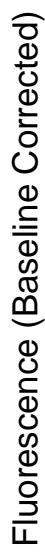

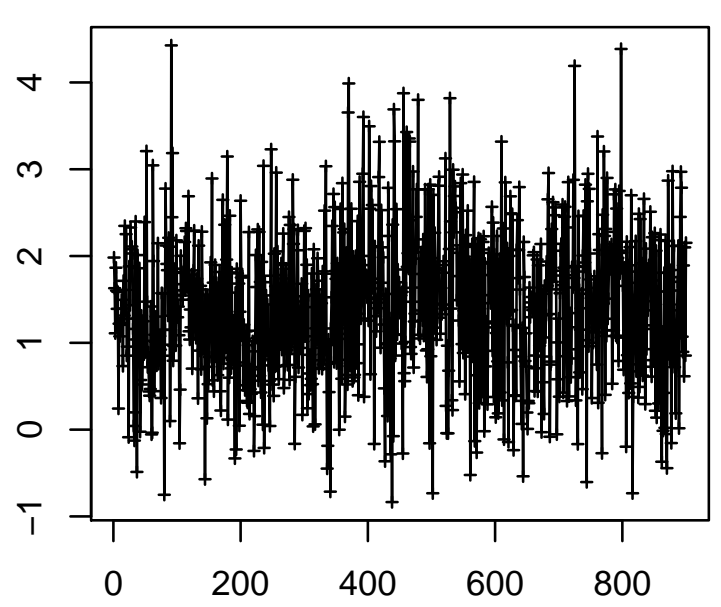

Time Point $(0.25 \mathrm{~Hz})$

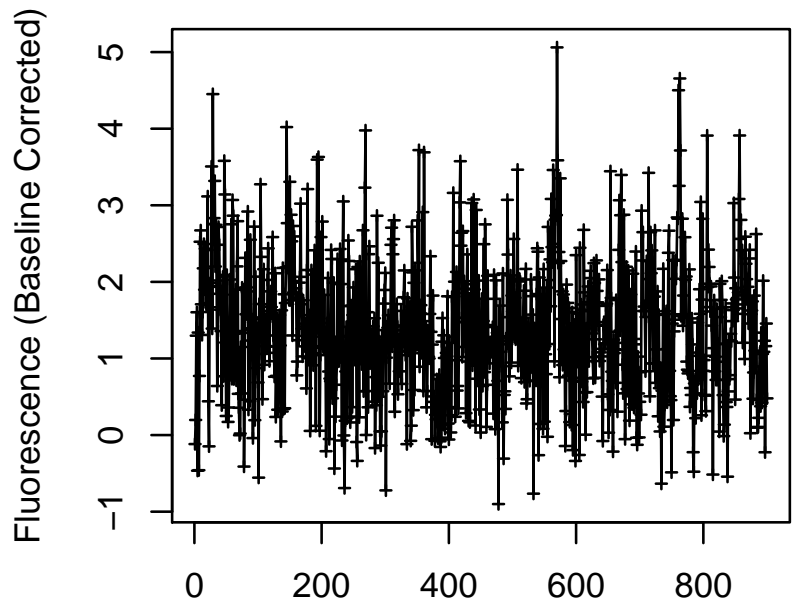

Time Point $(0.25 \mathrm{~Hz})$

\section{Cell 160}

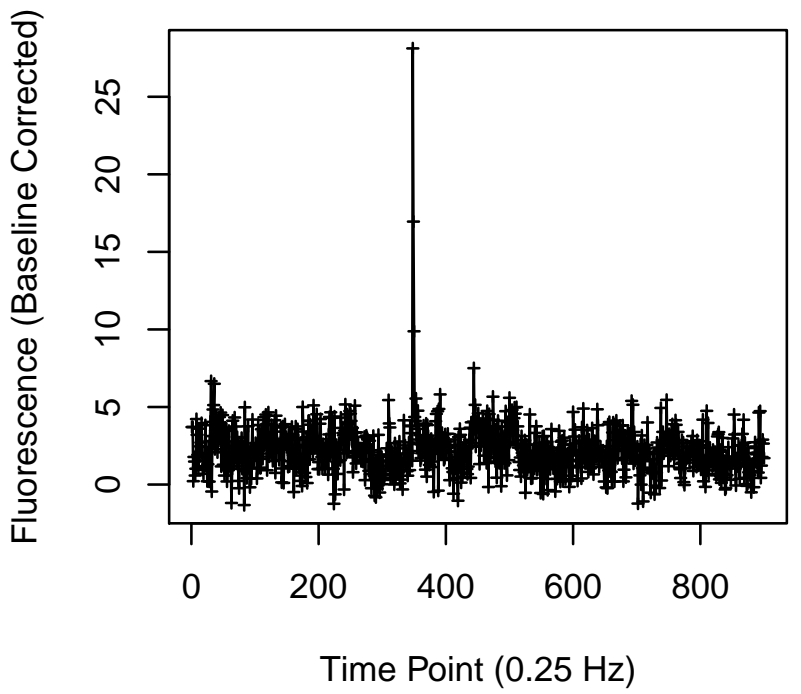


Cell 161

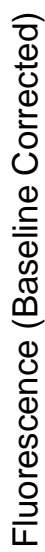

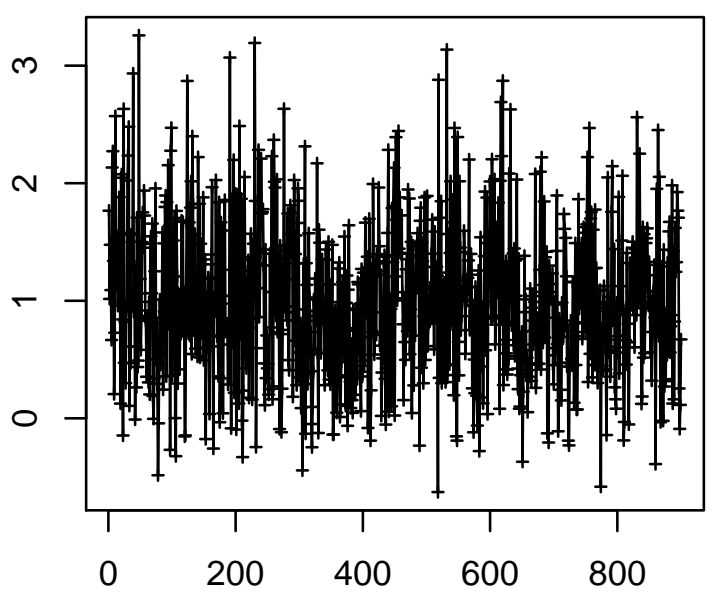

Time Point $(0.25 \mathrm{~Hz})$

\section{Cell 163}

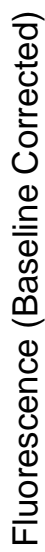

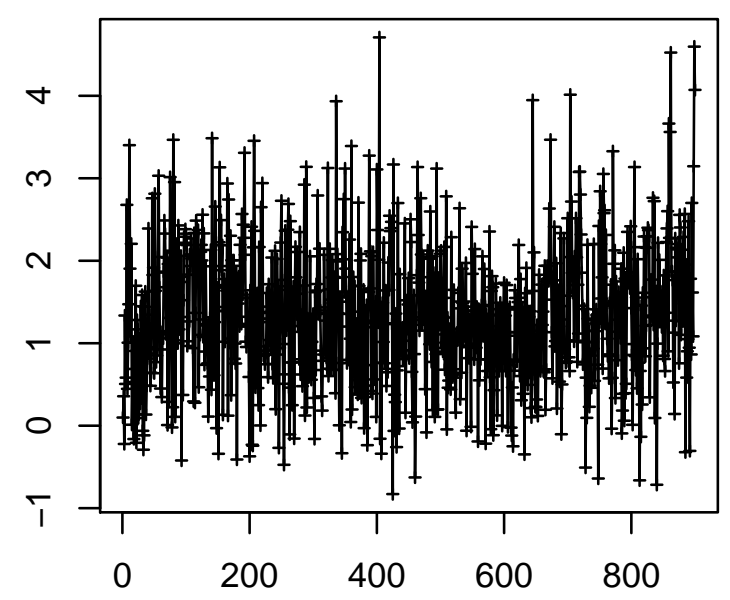

Time Point $(0.25 \mathrm{~Hz})$
Cell 162

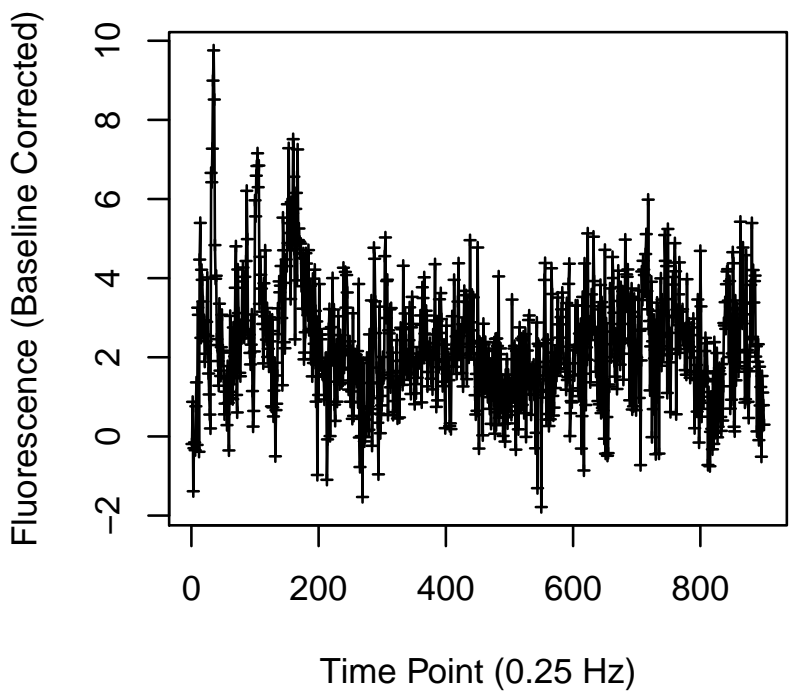

Cell 164

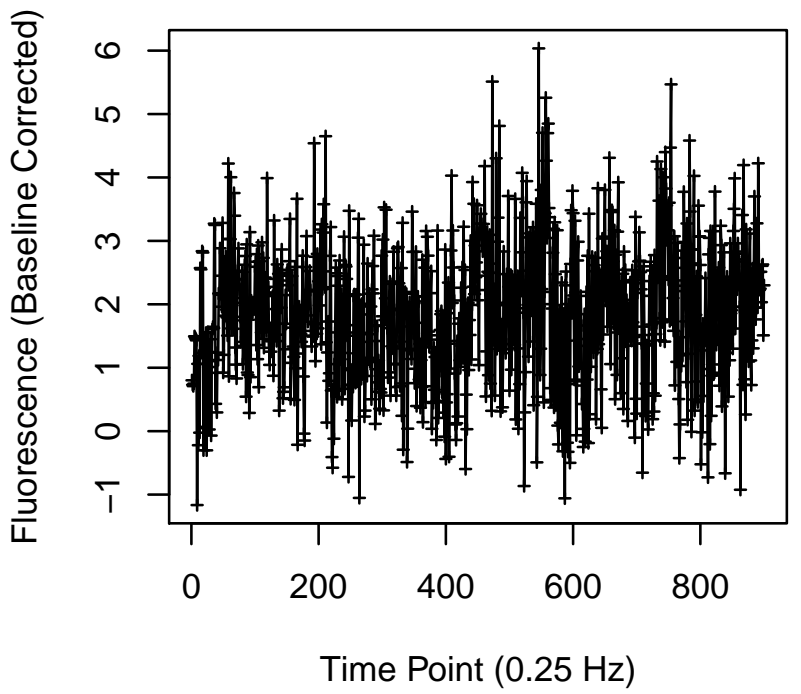


Cell 173

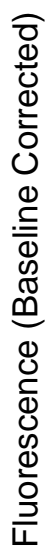

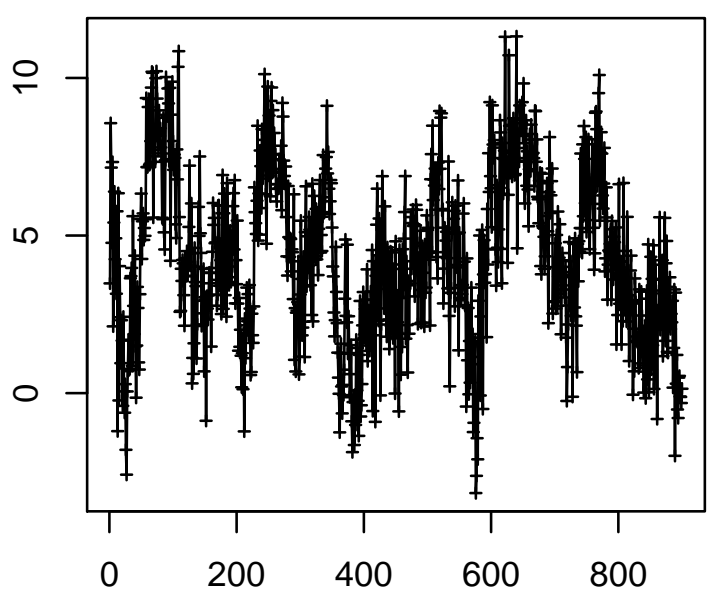

Time Point $(0.25 \mathrm{~Hz})$

Cell 175

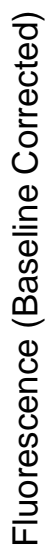

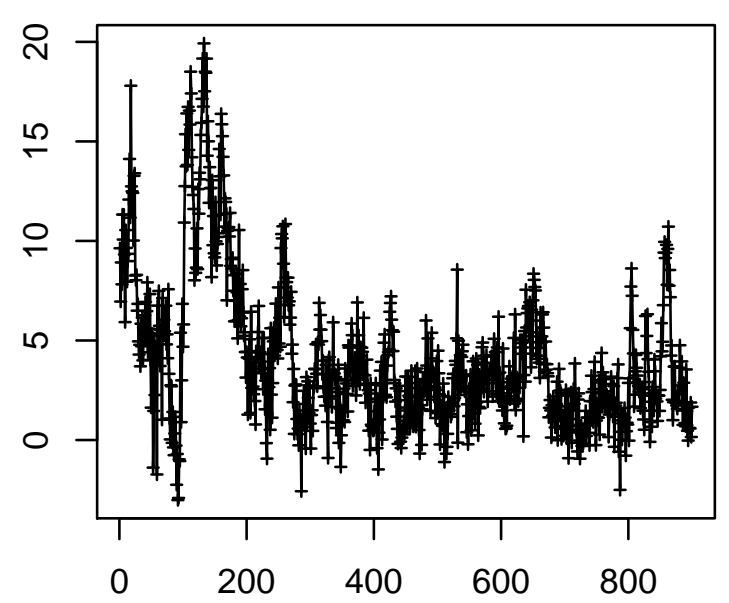

Time Point $(0.25 \mathrm{~Hz})$

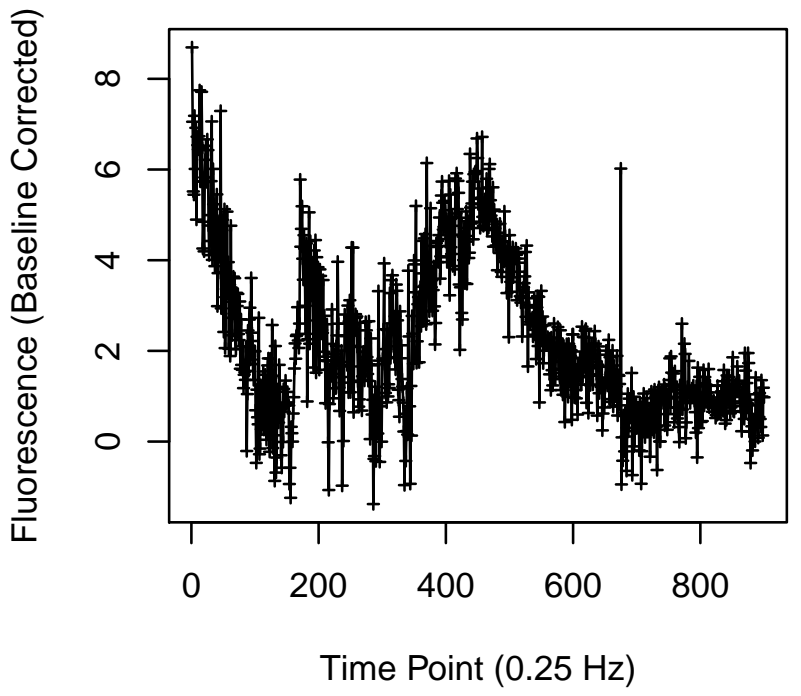

Cell 176

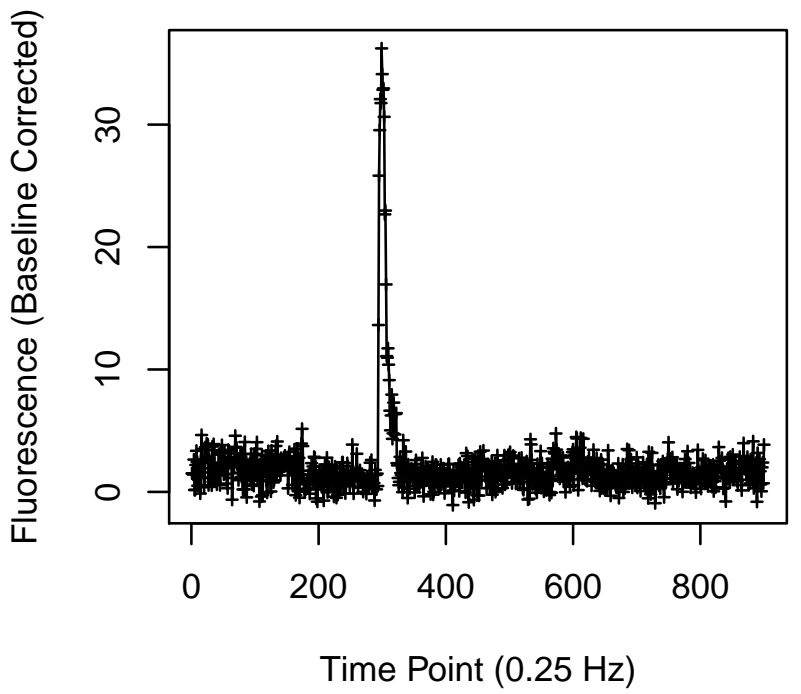




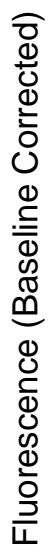

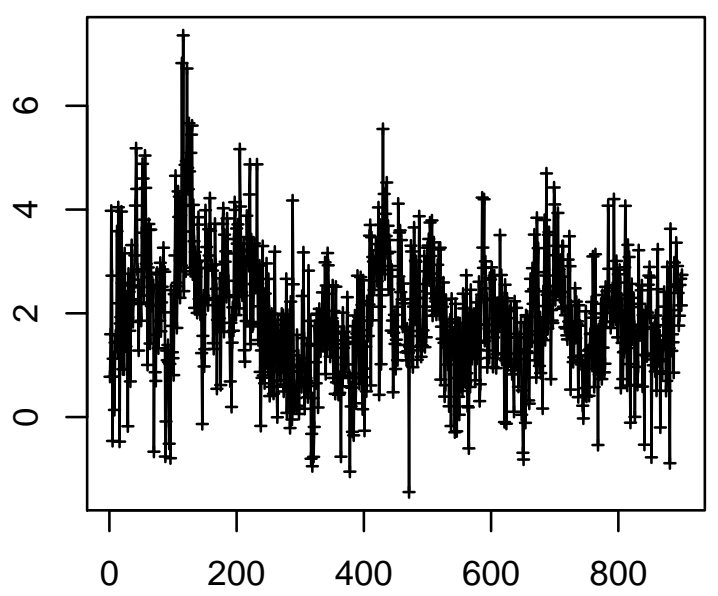

Time Point $(0.25 \mathrm{~Hz})$

\section{Cell 179}

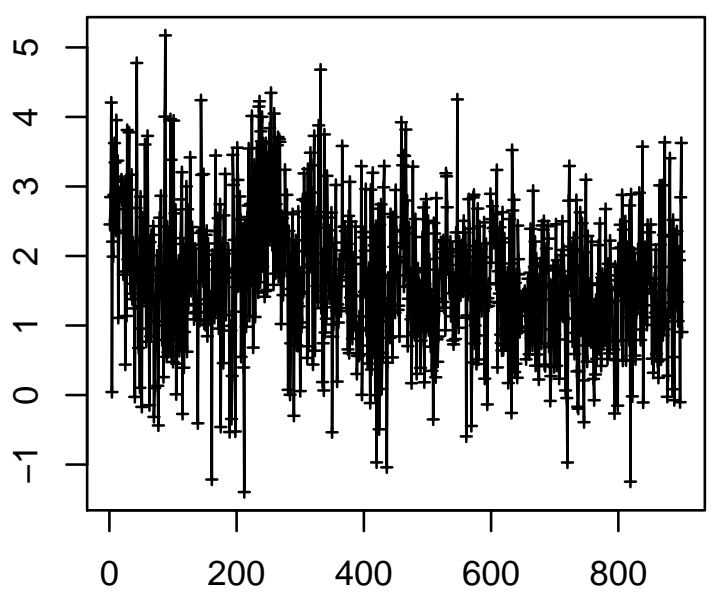

Time Point $(0.25 \mathrm{~Hz})$

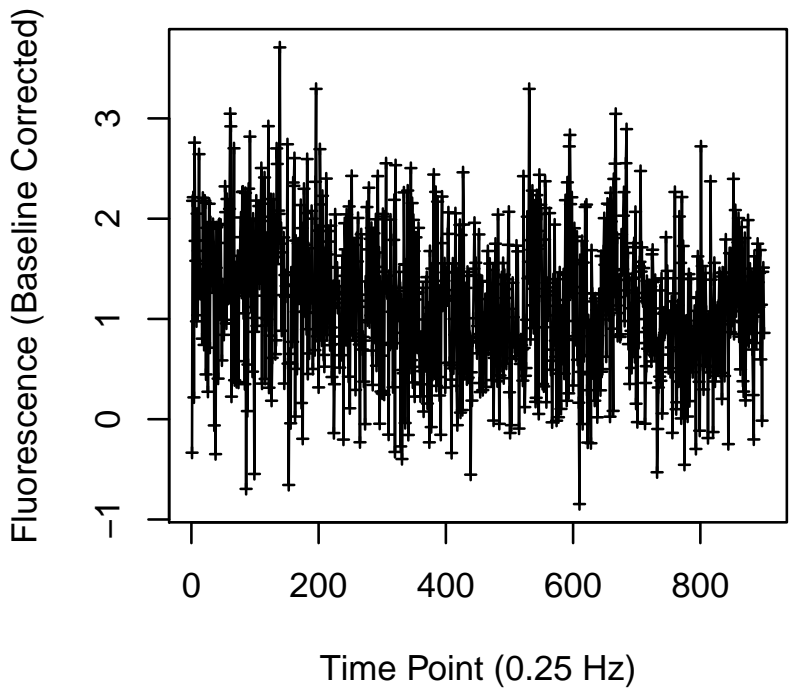

Cell 180

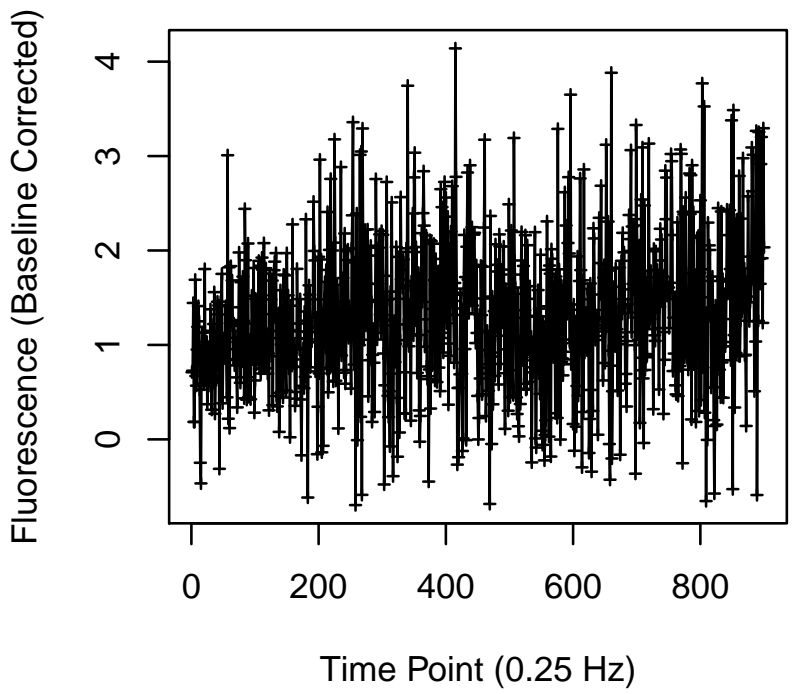


Cell 181

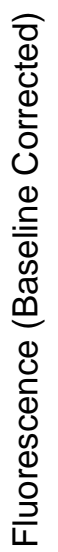

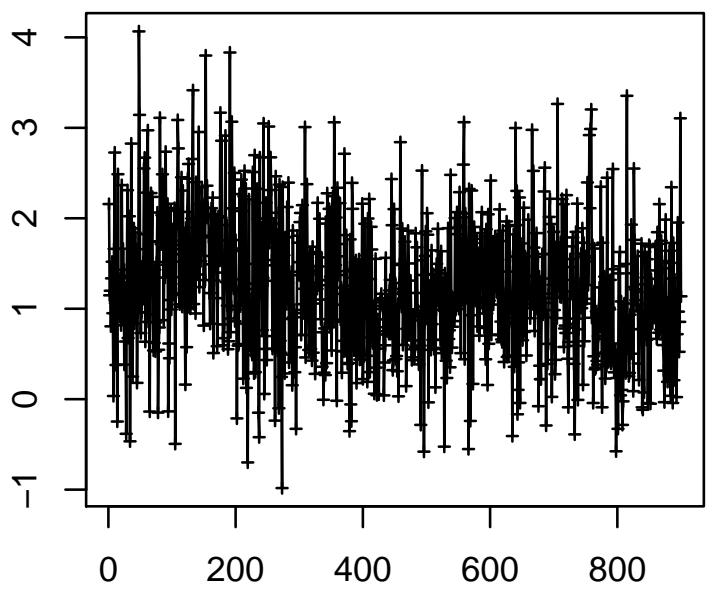

Time Point $(0.25 \mathrm{~Hz})$

Cell 183

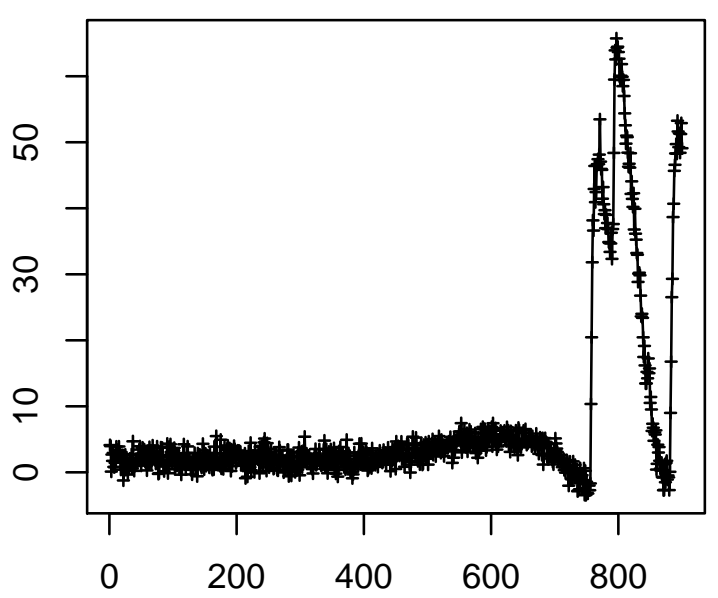

Time Point $(0.25 \mathrm{~Hz})$
Cell 182

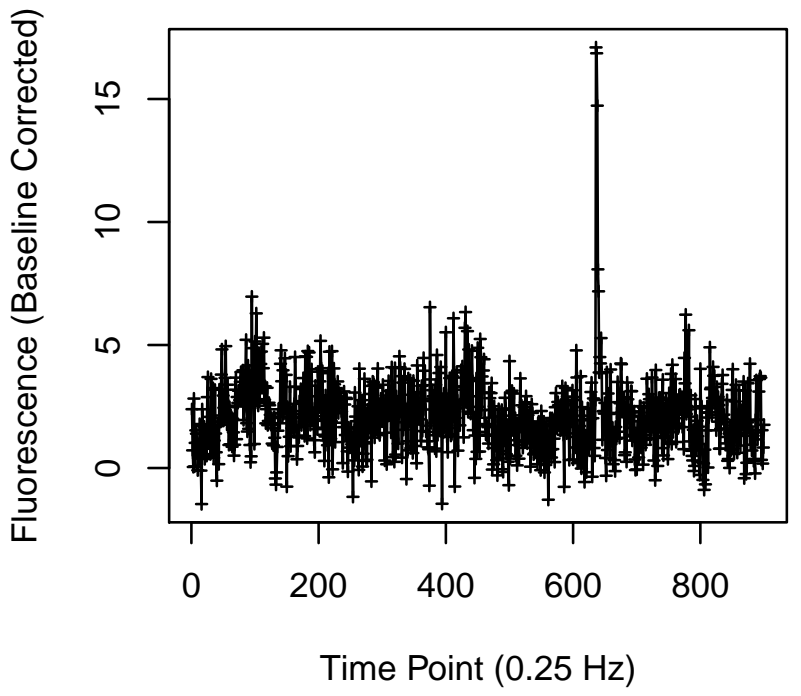

Cell 184

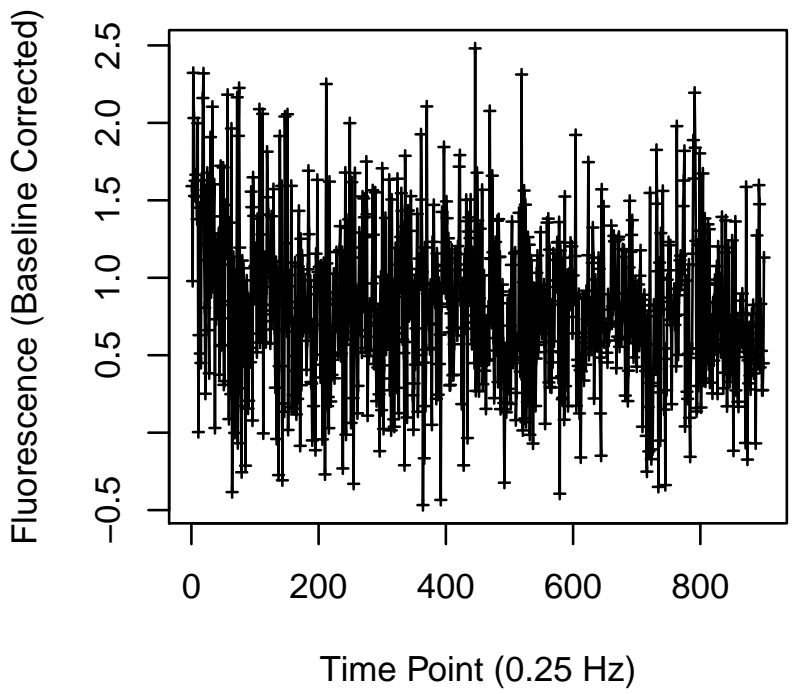




\section{Cell 185}

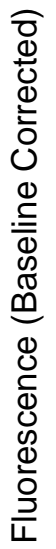

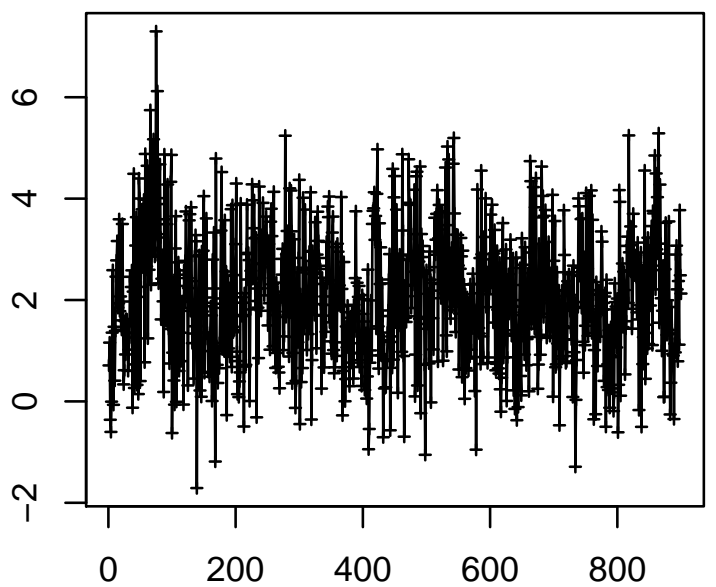

Time Point $(0.25 \mathrm{~Hz})$

\section{Cell 187}

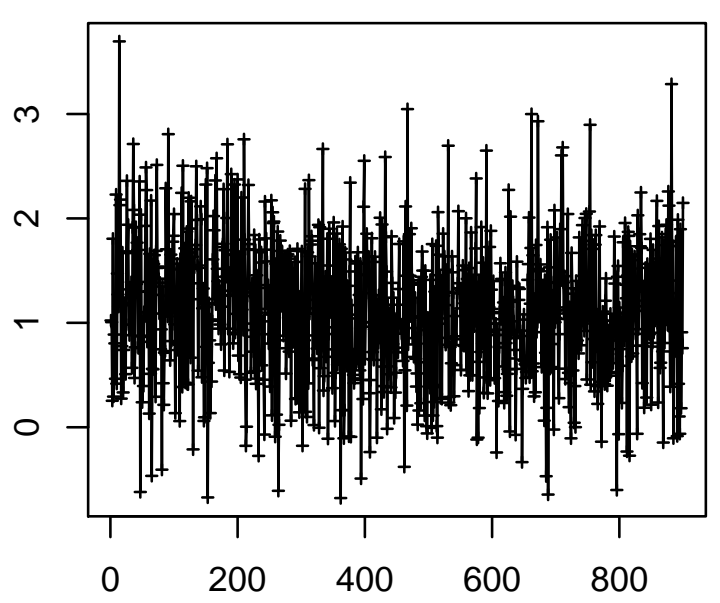

Time Point $(0.25 \mathrm{~Hz})$
Cell 186

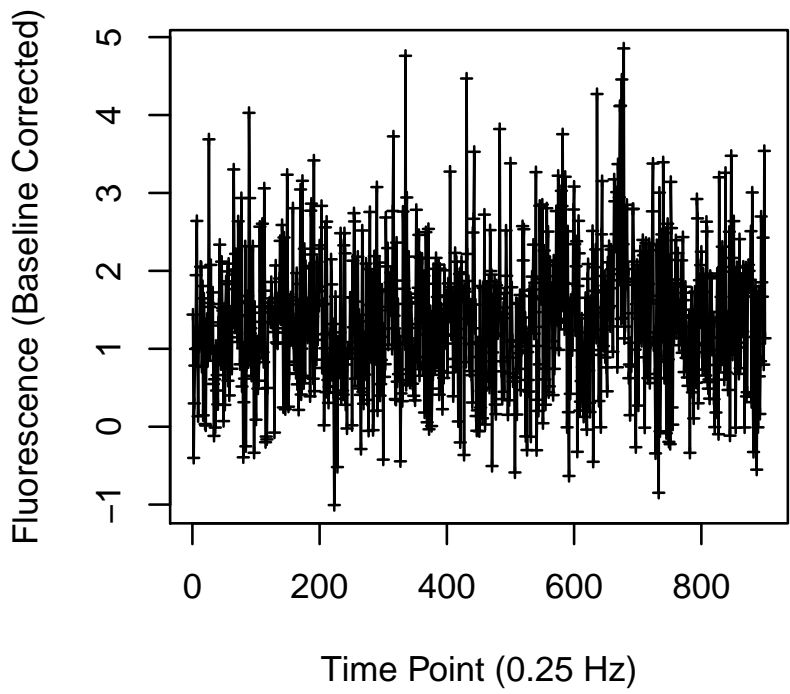

Cell 188

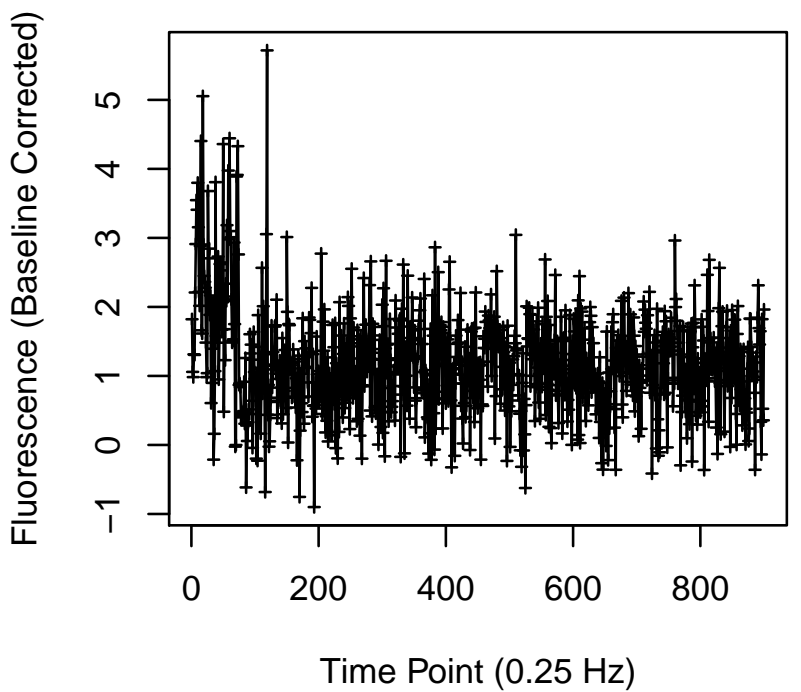




\section{Cell 189}

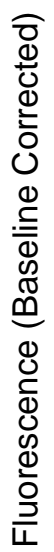

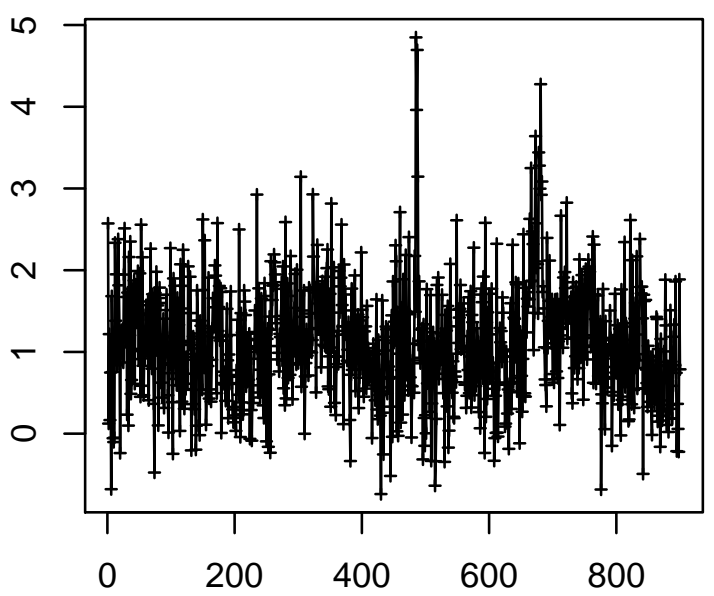

Time Point $(0.25 \mathrm{~Hz})$

\section{Cell 191}

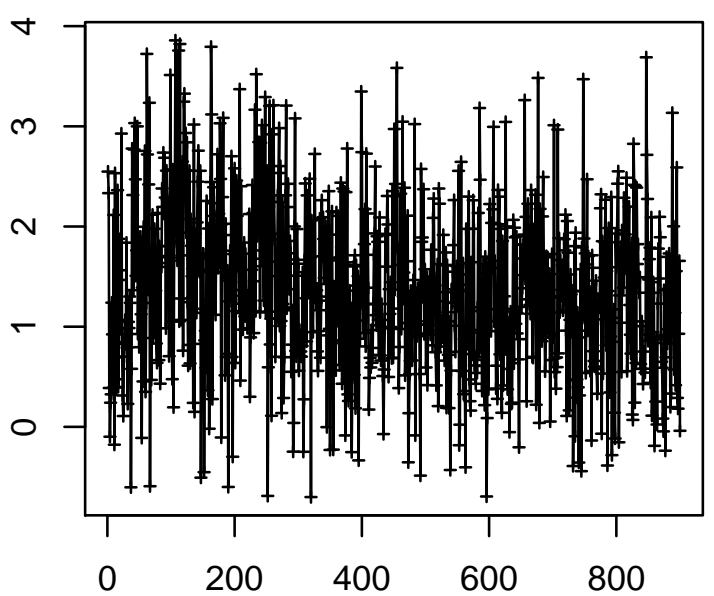

Time Point $(0.25 \mathrm{~Hz})$
Cell 190

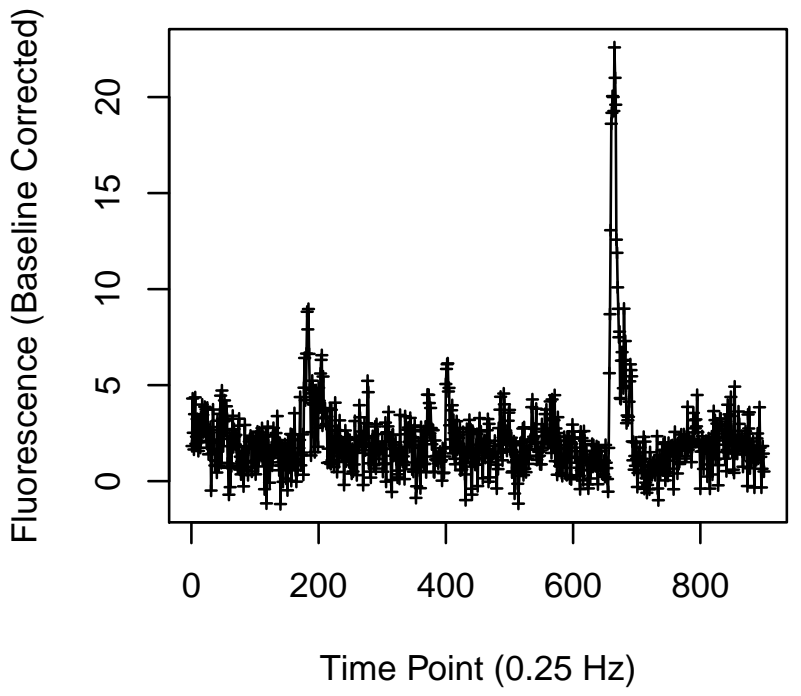

Cell 192

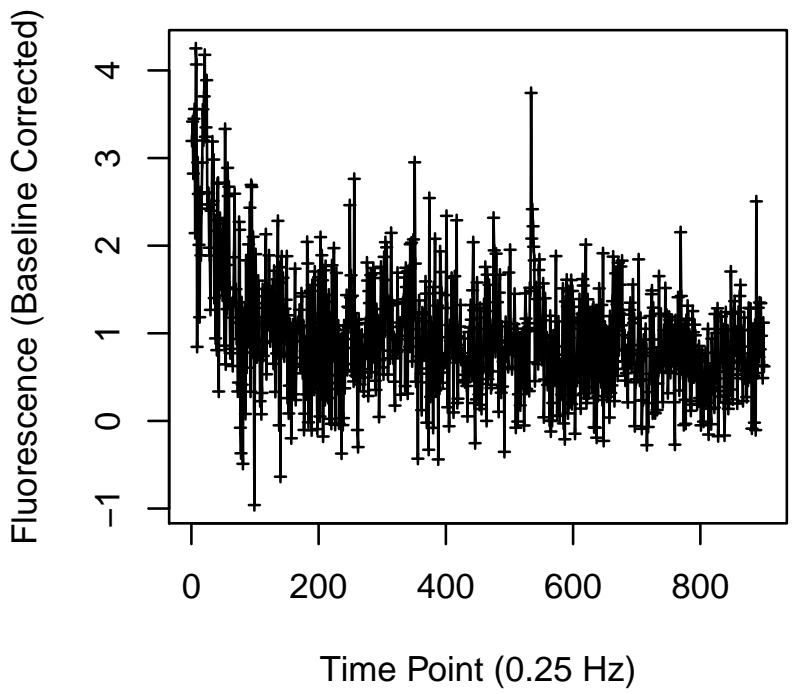




\section{Cell 193}

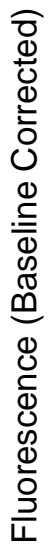

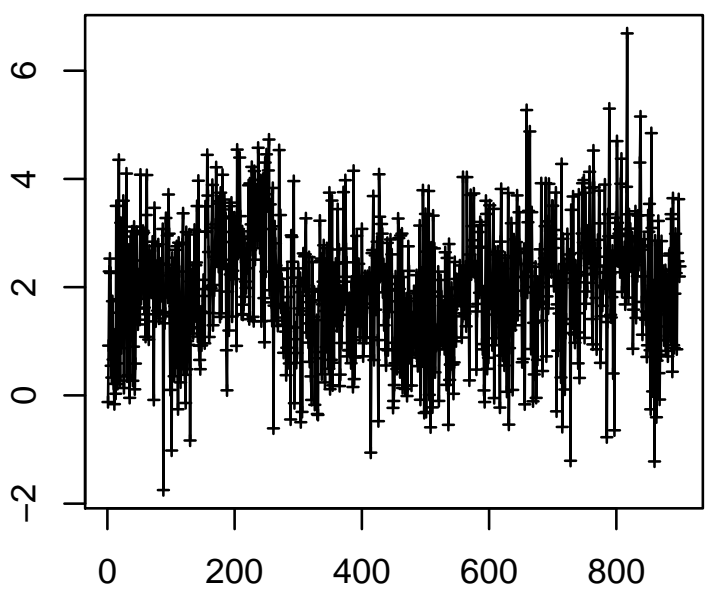

Time Point $(0.25 \mathrm{~Hz})$

\section{Cell 195}

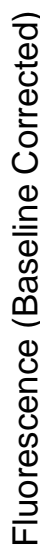

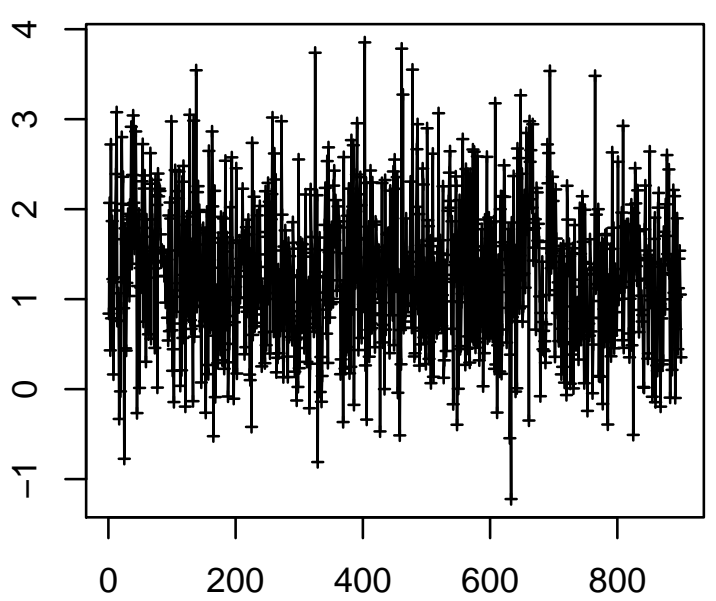

Time Point $(0.25 \mathrm{~Hz})$

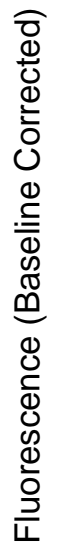

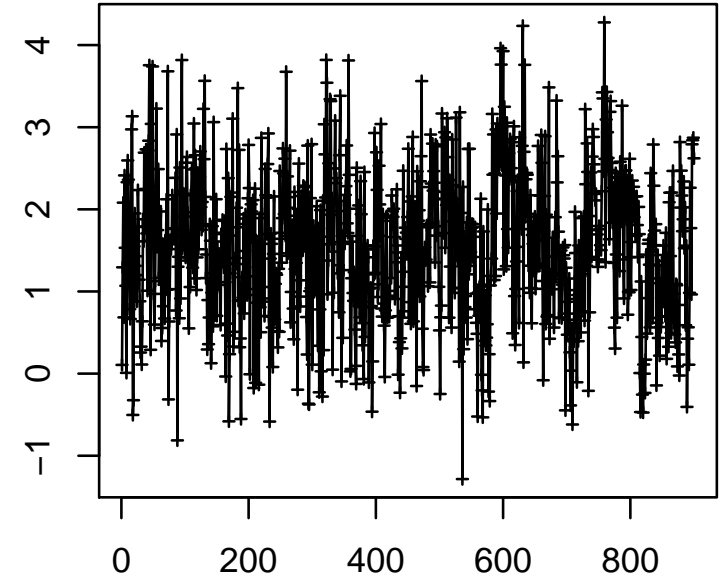

Time Point $(0.25 \mathrm{~Hz})$

Cell 196

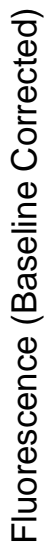

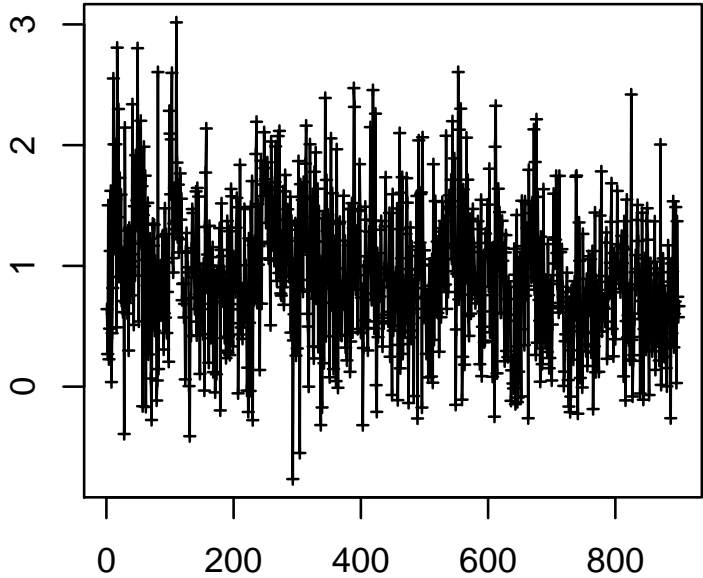

Time Point $(0.25 \mathrm{~Hz})$ 


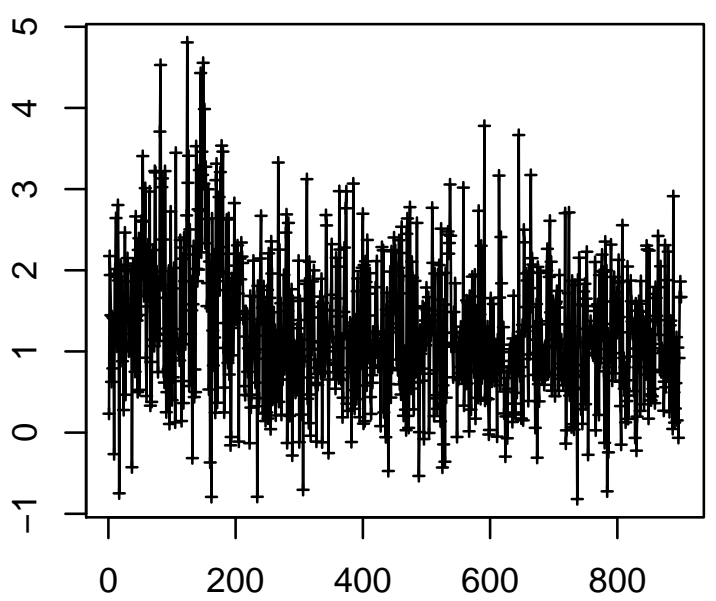

Time Point $(0.25 \mathrm{~Hz})$

\section{Cell 199}

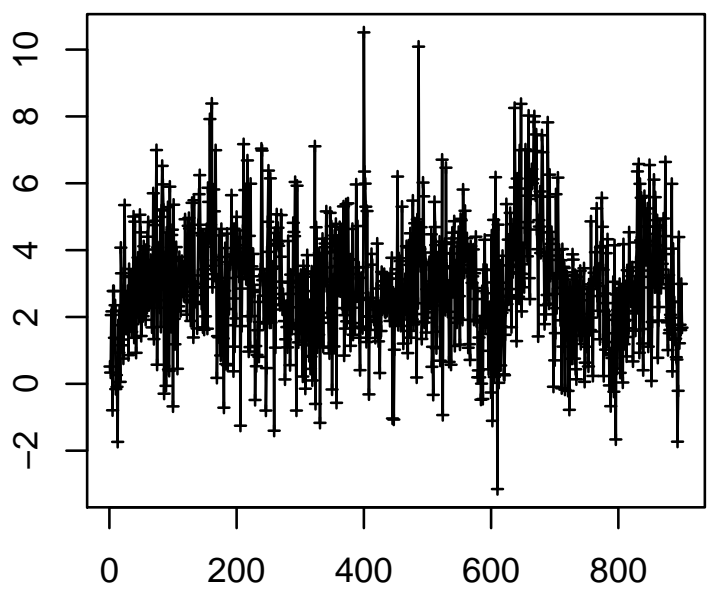

Time Point $(0.25 \mathrm{~Hz})$

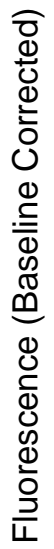

Cell 200

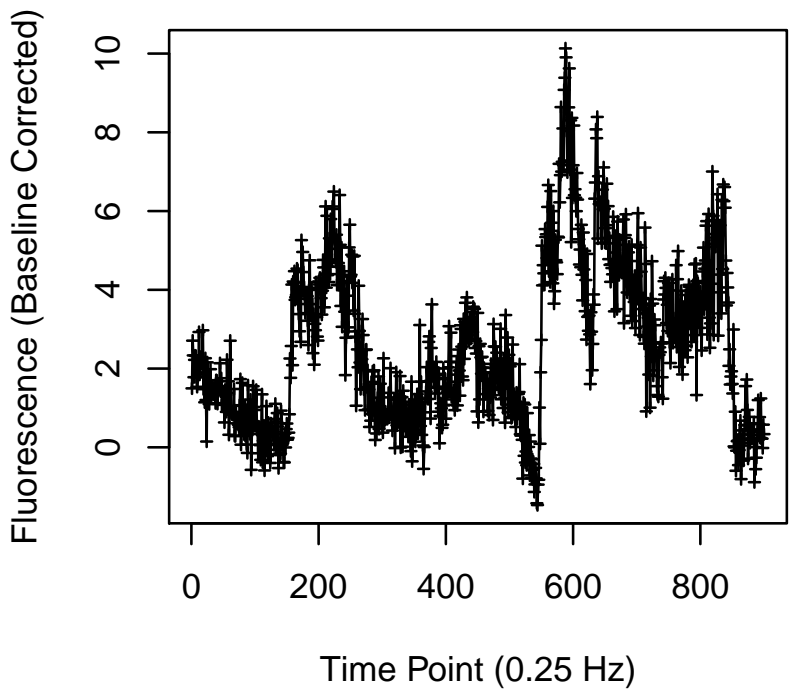


Cell 201

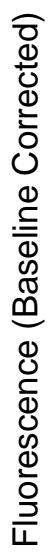

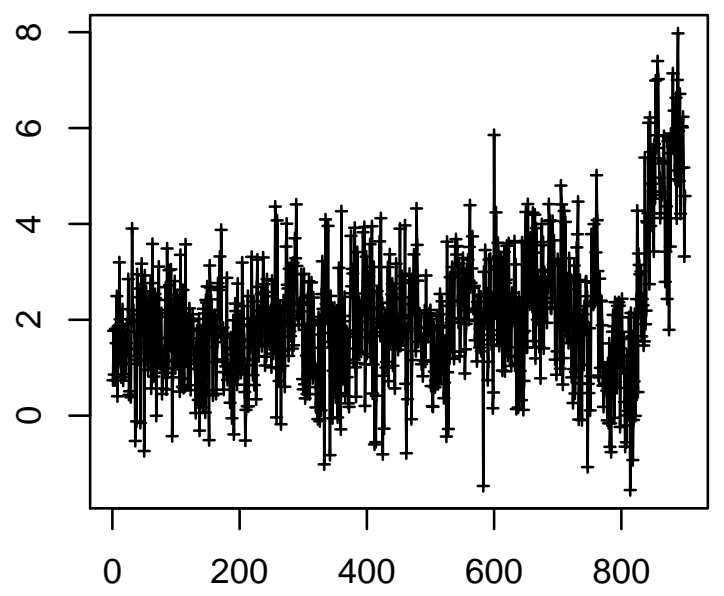

Time Point $(0.25 \mathrm{~Hz})$

Cell 203

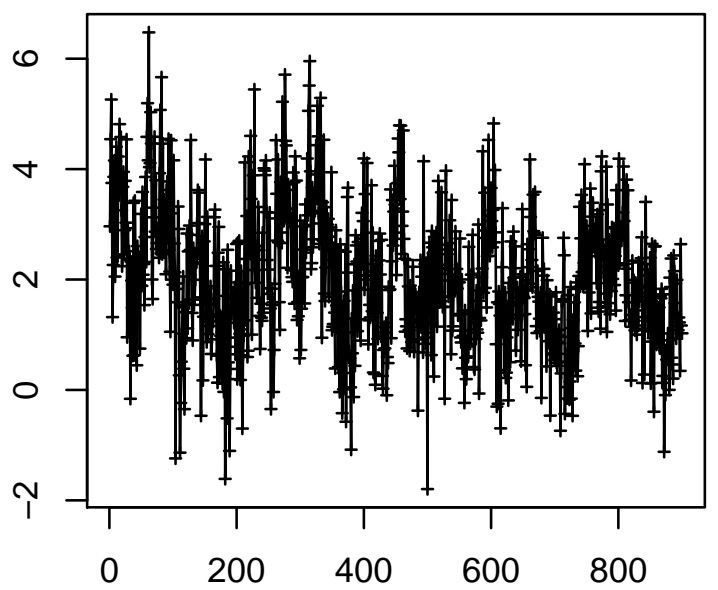

Time Point $(0.25 \mathrm{~Hz})$
Cell 202

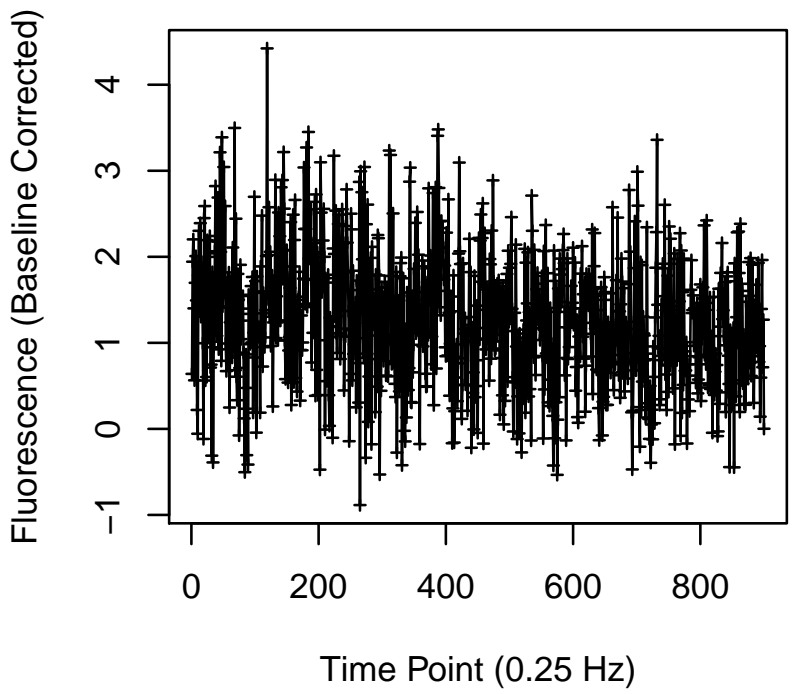

Cell 204

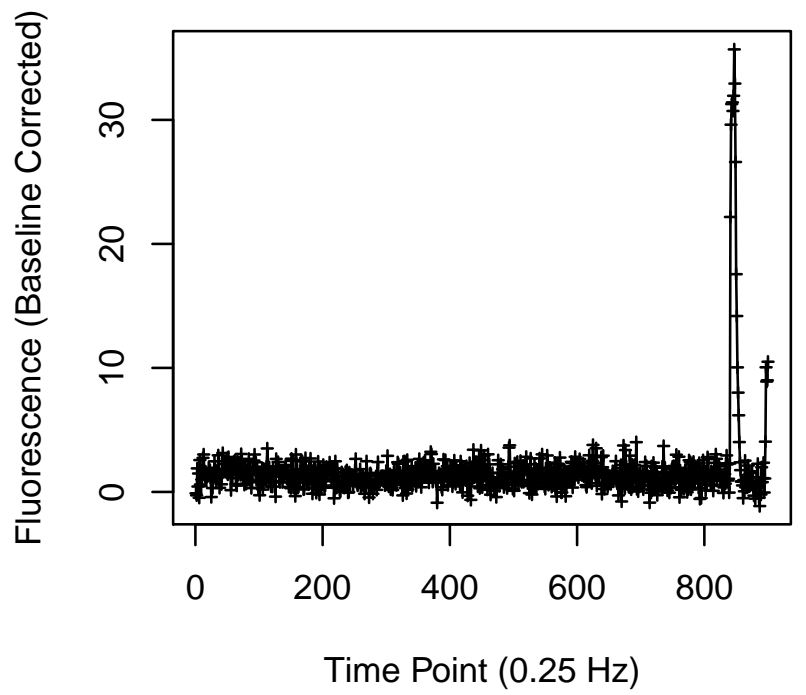




\section{Cell 205}

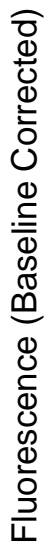

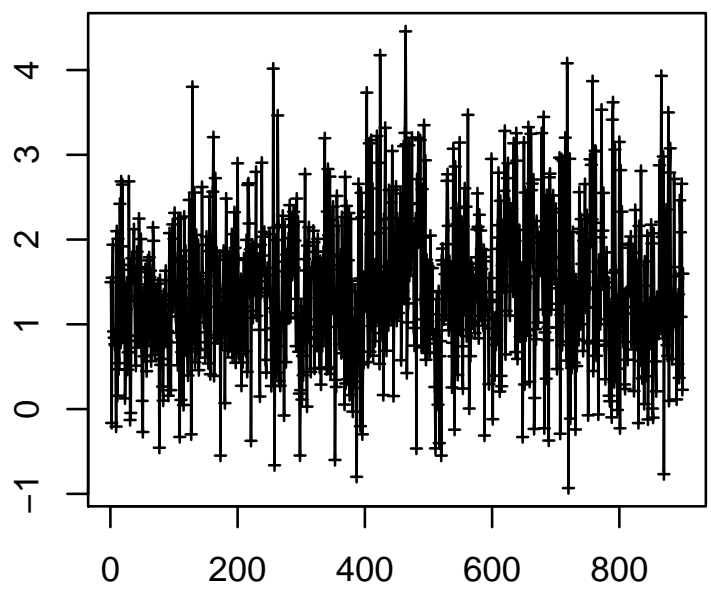

Time Point $(0.25 \mathrm{~Hz})$

\section{Cell 207}

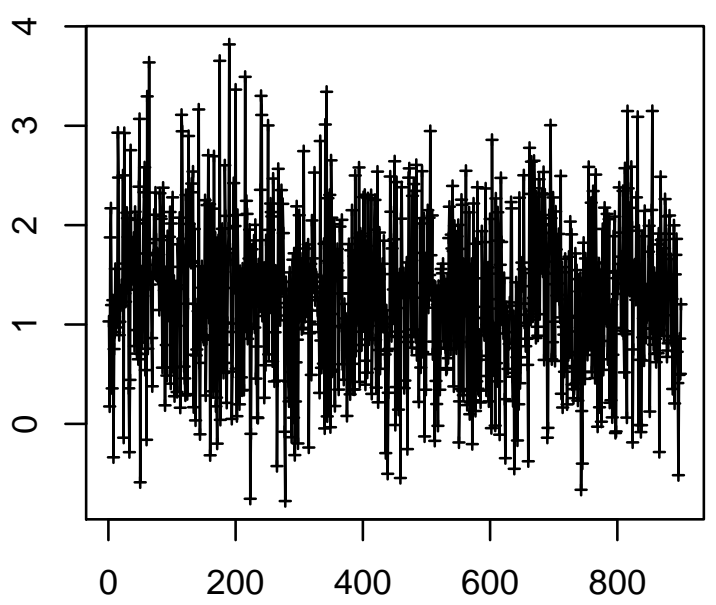

Time Point $(0.25 \mathrm{~Hz})$
Cell 206

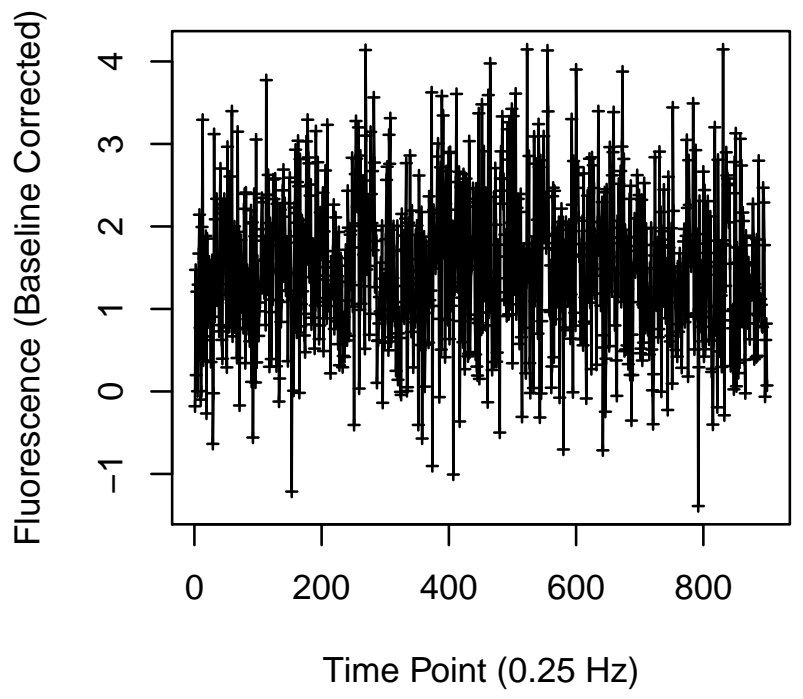

Cell 208

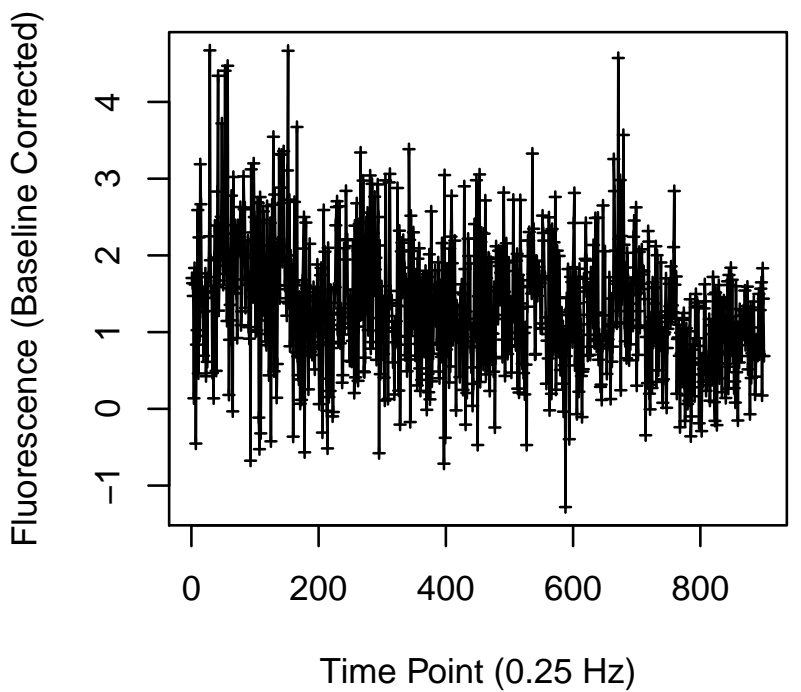


Cell 209

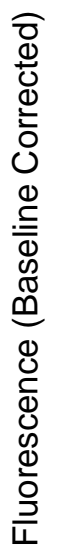

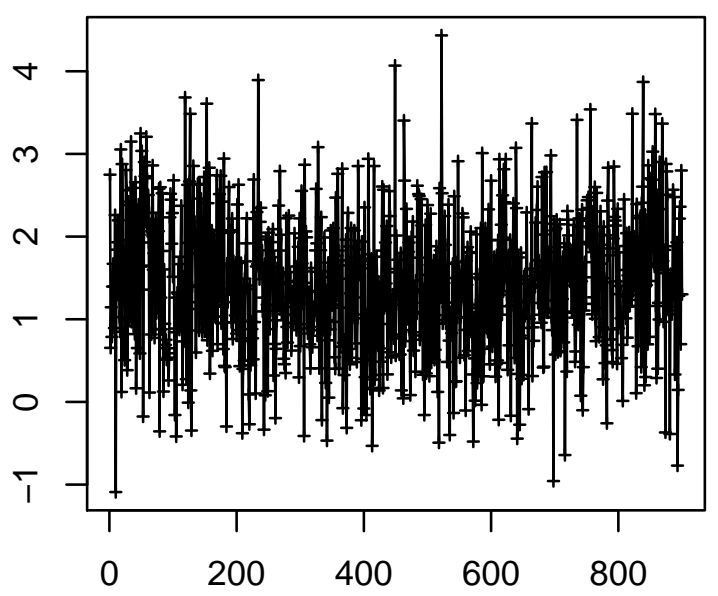

Time Point $(0.25 \mathrm{~Hz})$

Cell 211

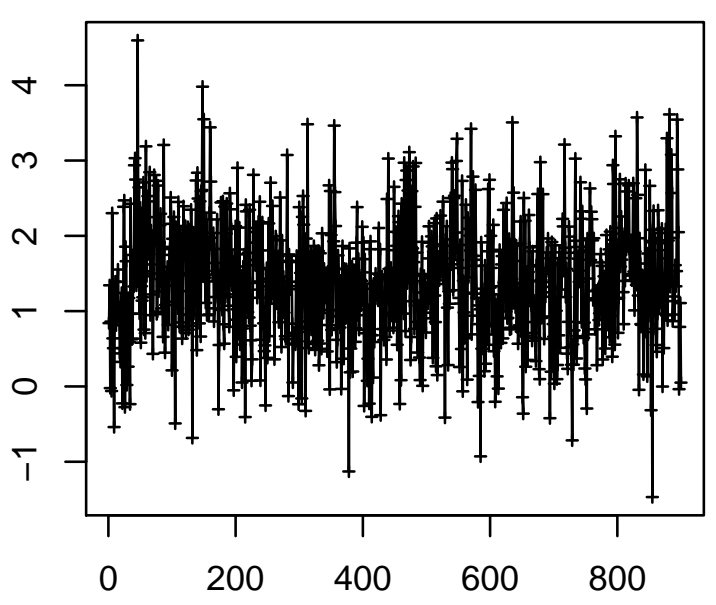

Time Point $(0.25 \mathrm{~Hz})$
Cell 210

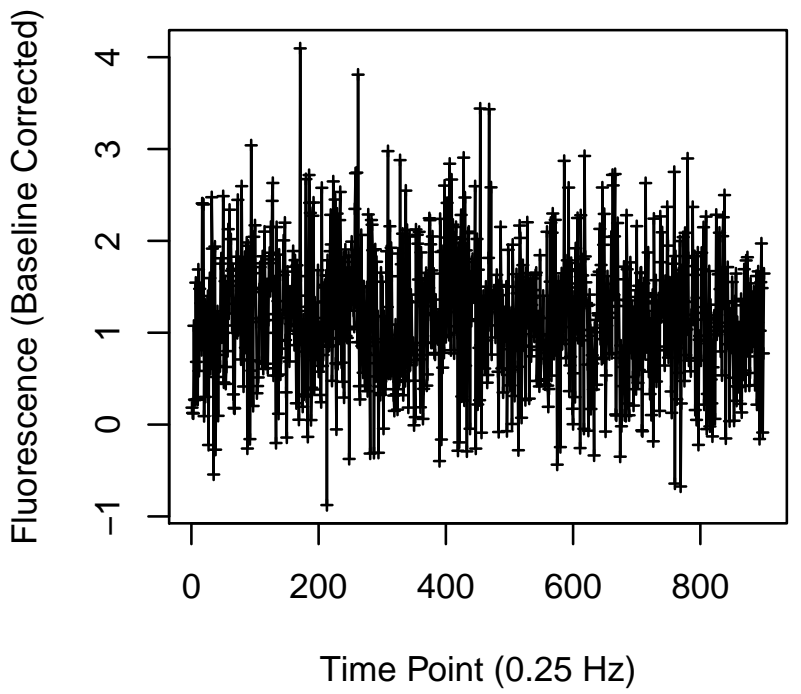

Cell 212

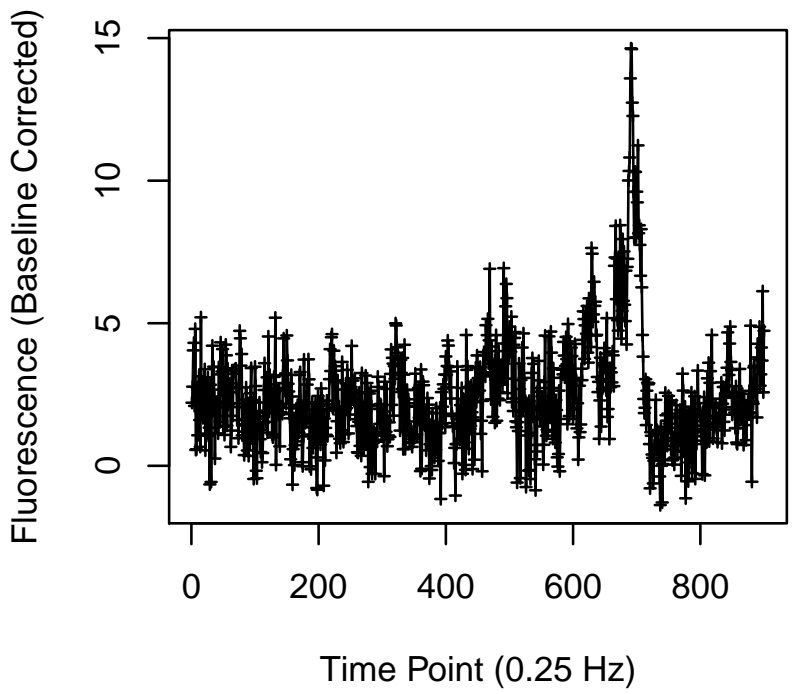




\section{Cell 213}
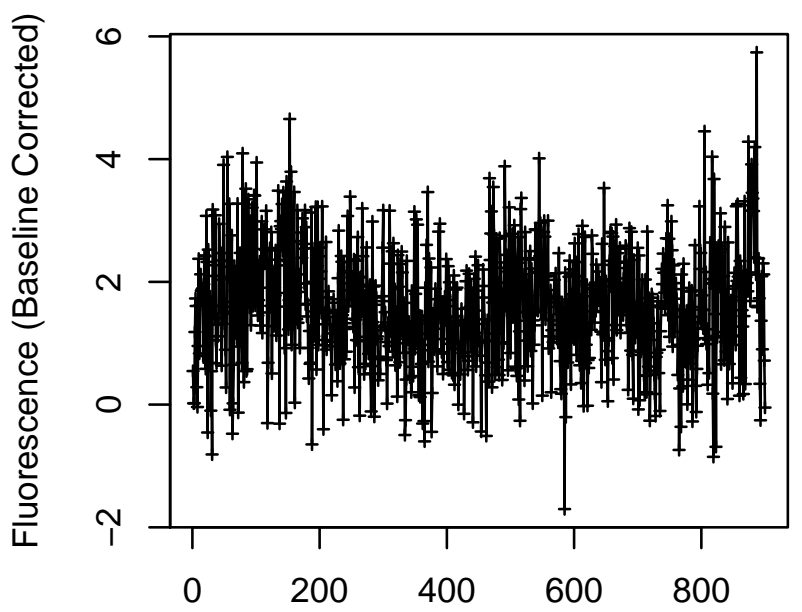

Time Point $(0.25 \mathrm{~Hz})$

Cell 215

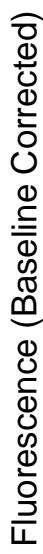

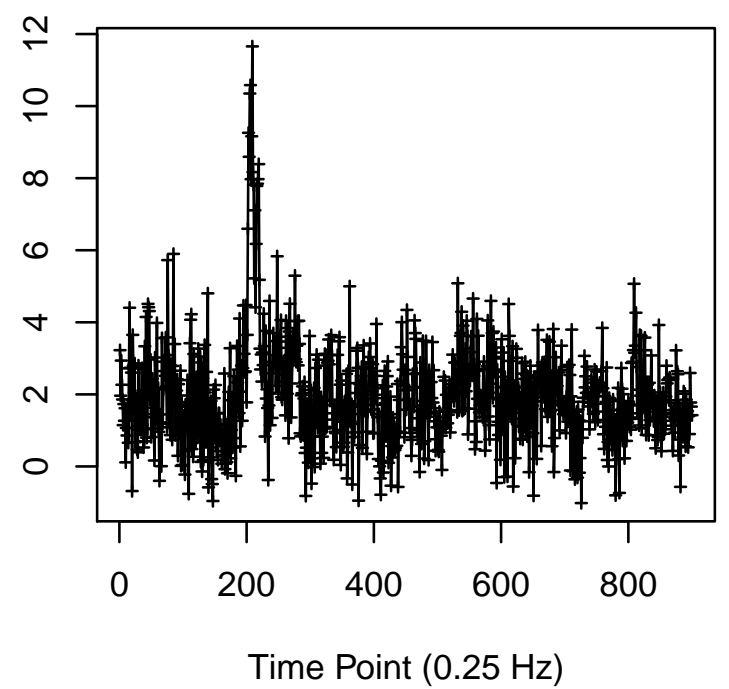

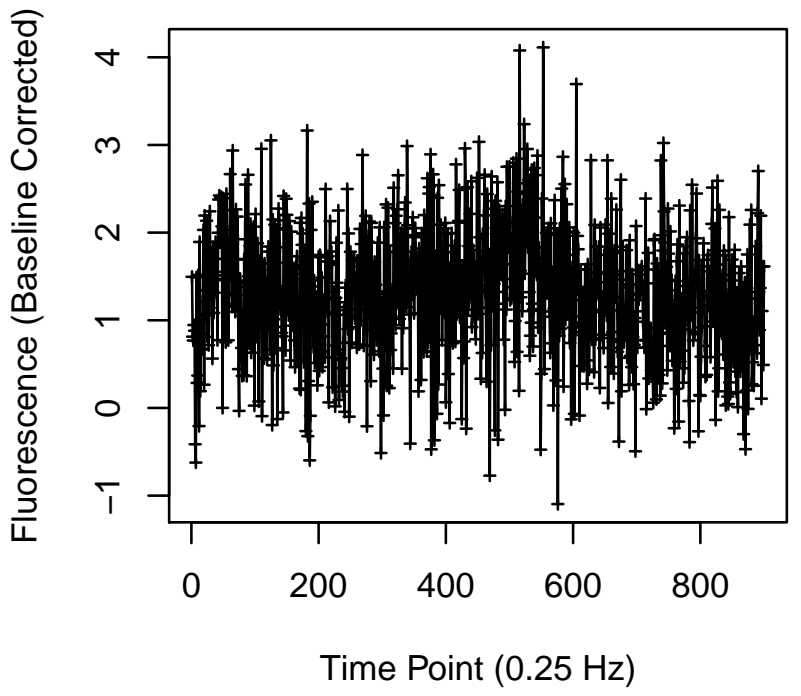

Cell 216

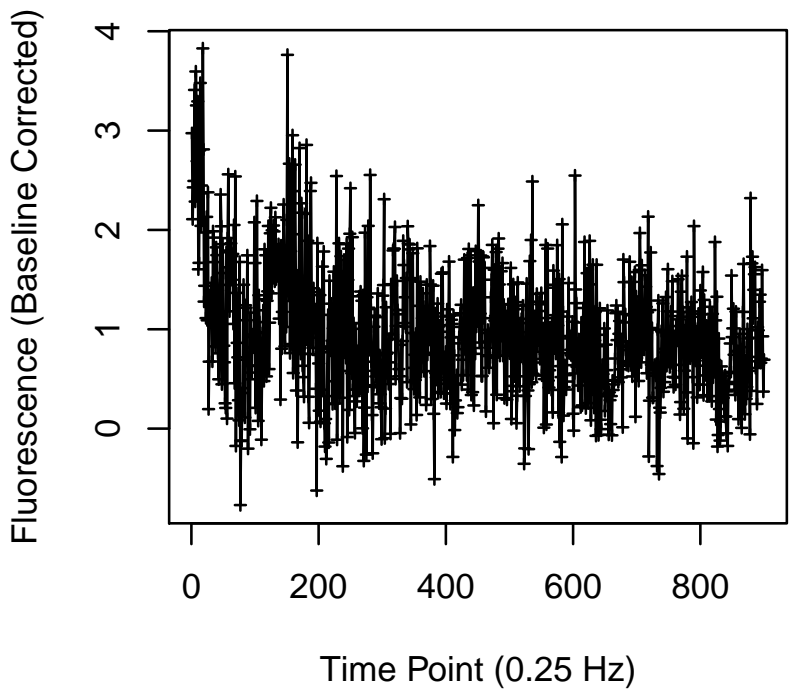




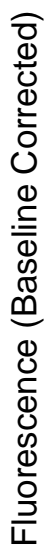

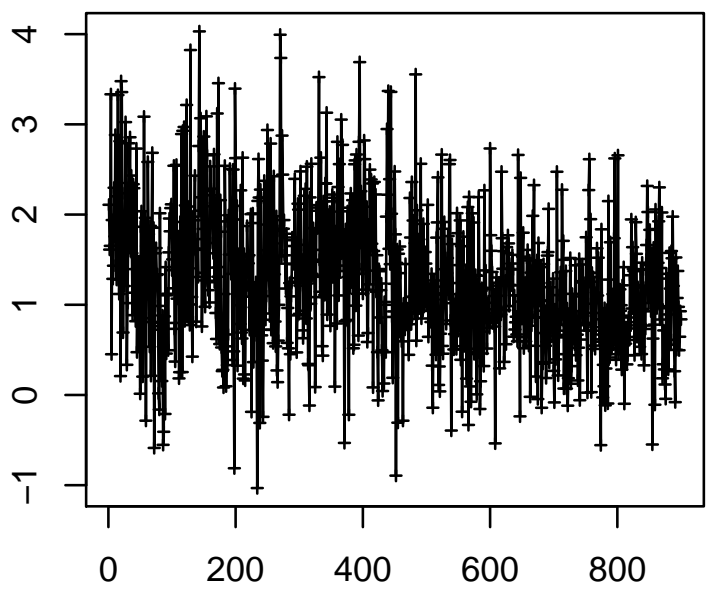

Time Point $(0.25 \mathrm{~Hz})$

\section{Cell 219}

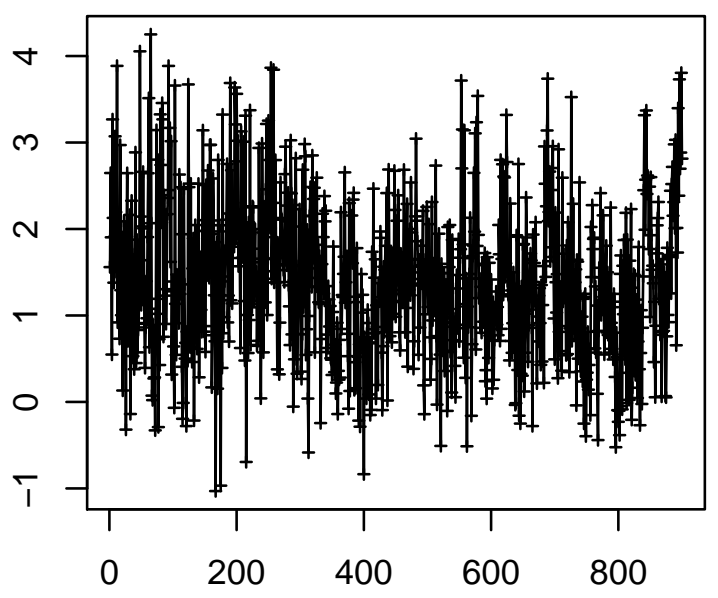

Time Point $(0.25 \mathrm{~Hz})$

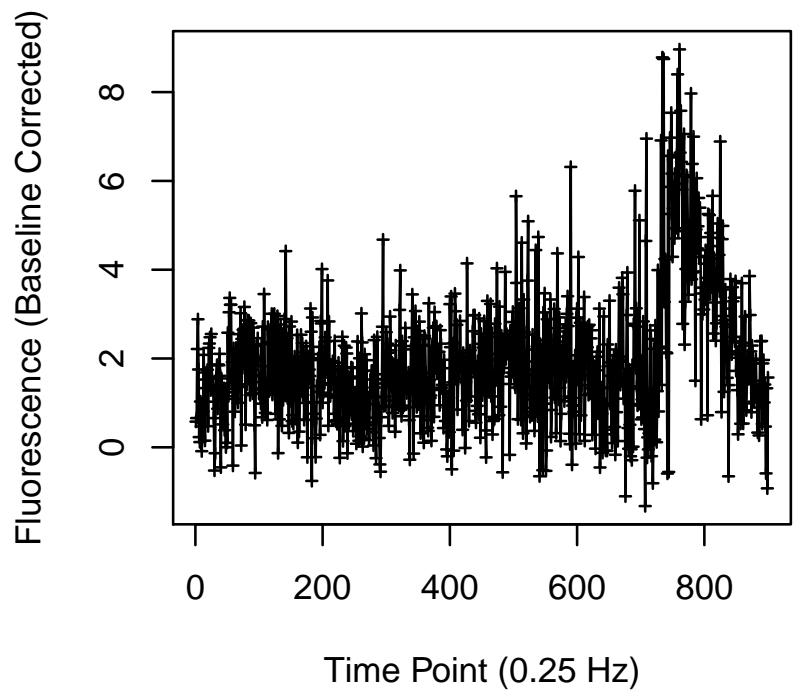

Cell 220

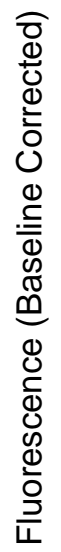

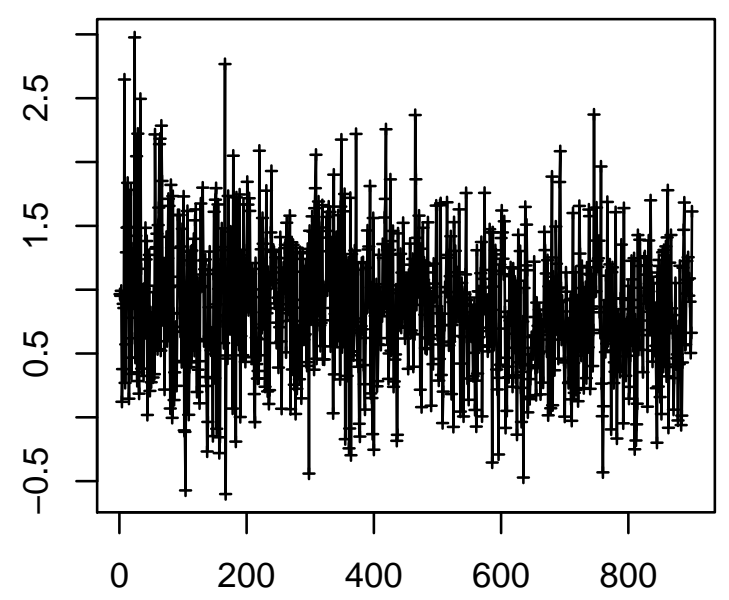

Time Point $(0.25 \mathrm{~Hz})$ 
Cell 221

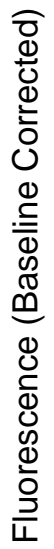

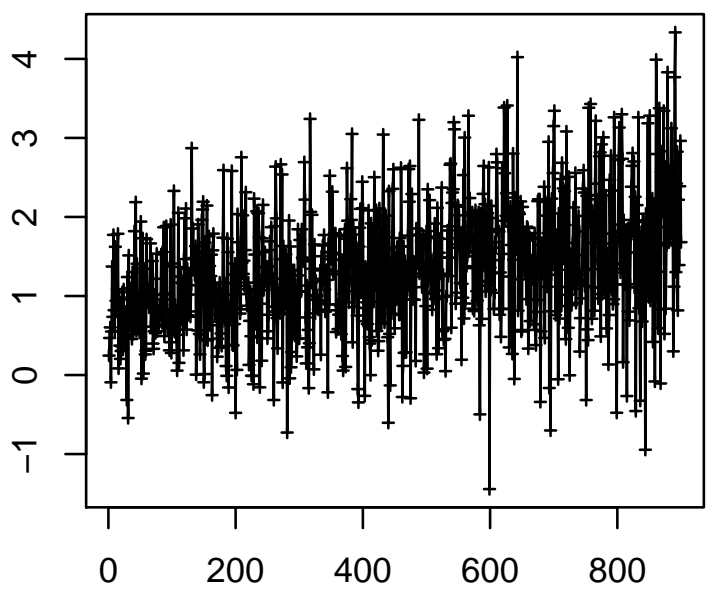

Time Point $(0.25 \mathrm{~Hz})$

Cell 223

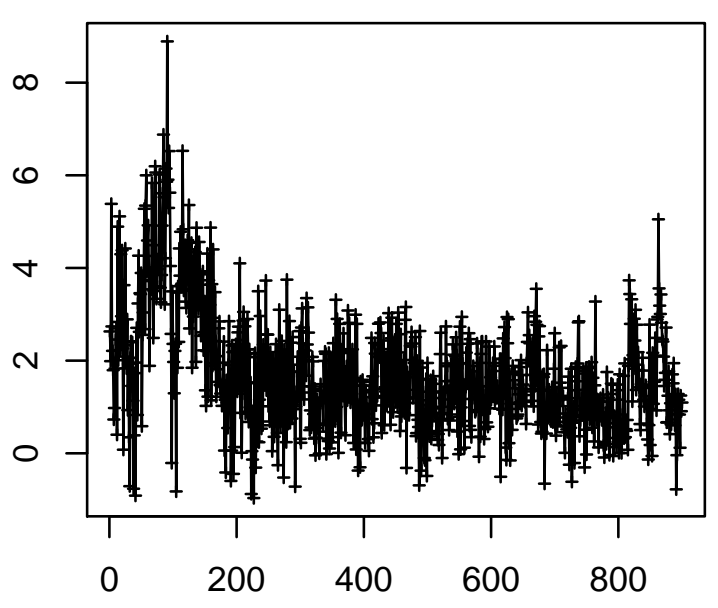

Time Point $(0.25 \mathrm{~Hz})$
Cell 222

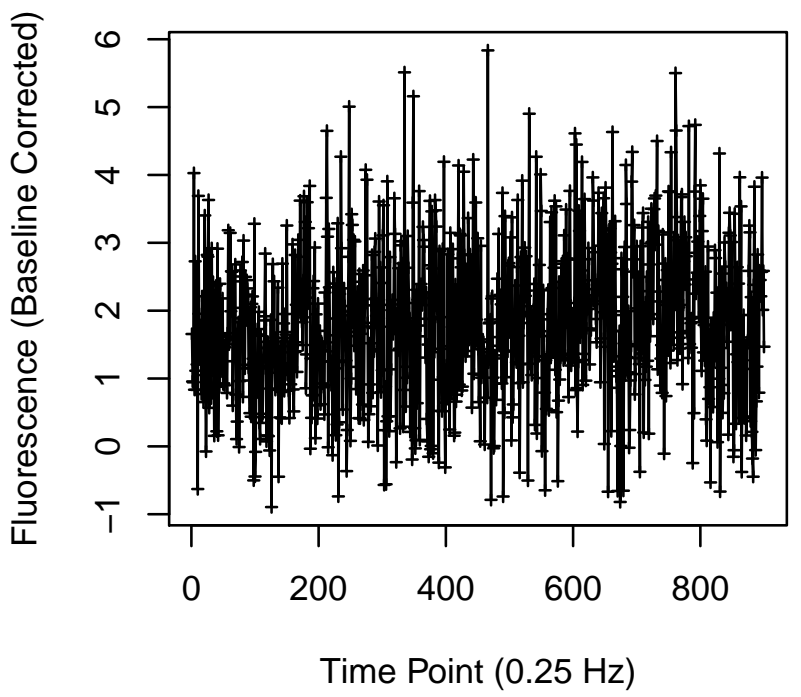

Cell 224

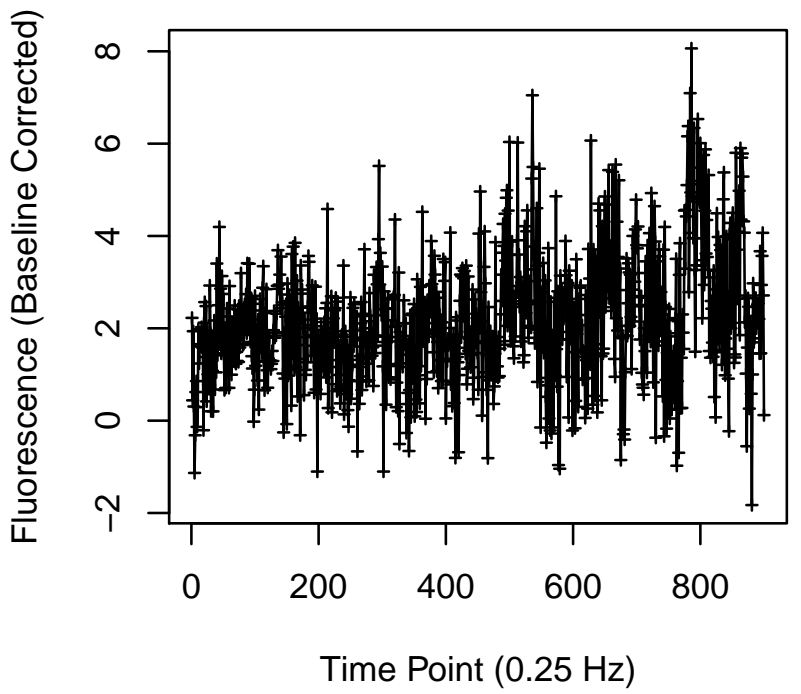


Cell 225

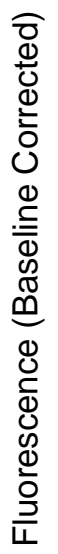

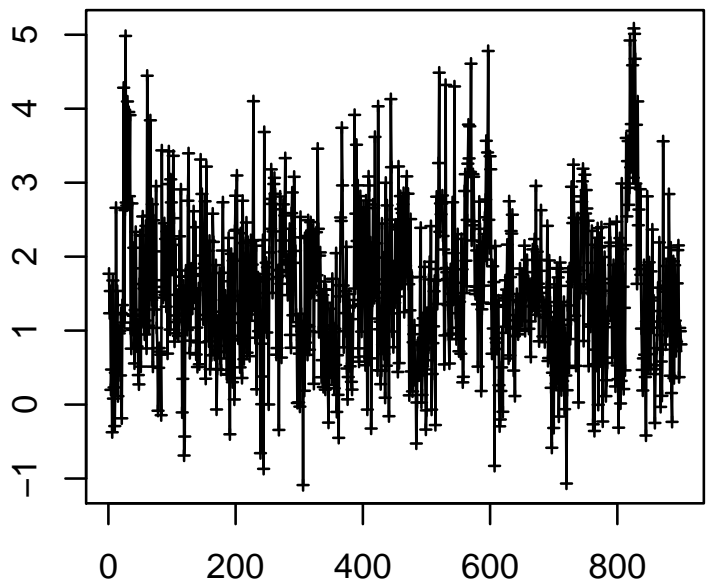

Time Point $(0.25 \mathrm{~Hz})$

Cell 227

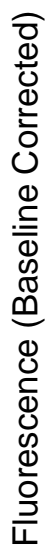

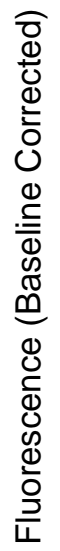

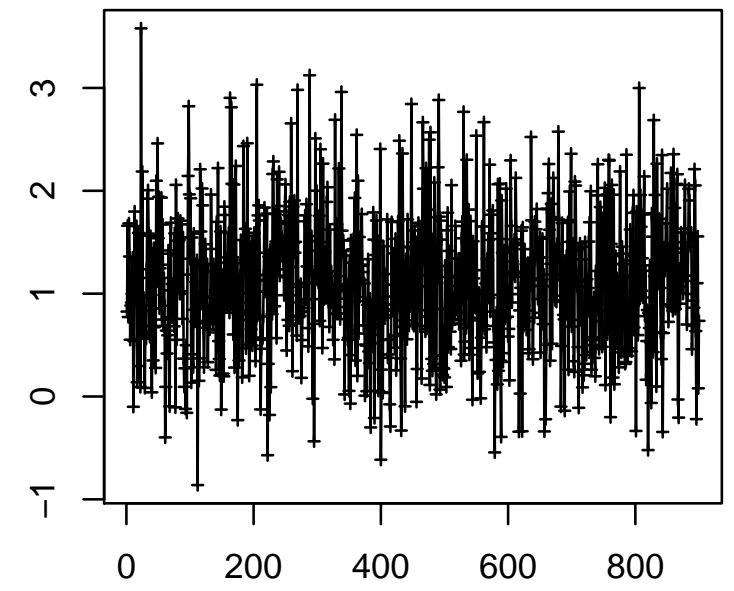

Time Point $(0.25 \mathrm{~Hz})$
Cell 226

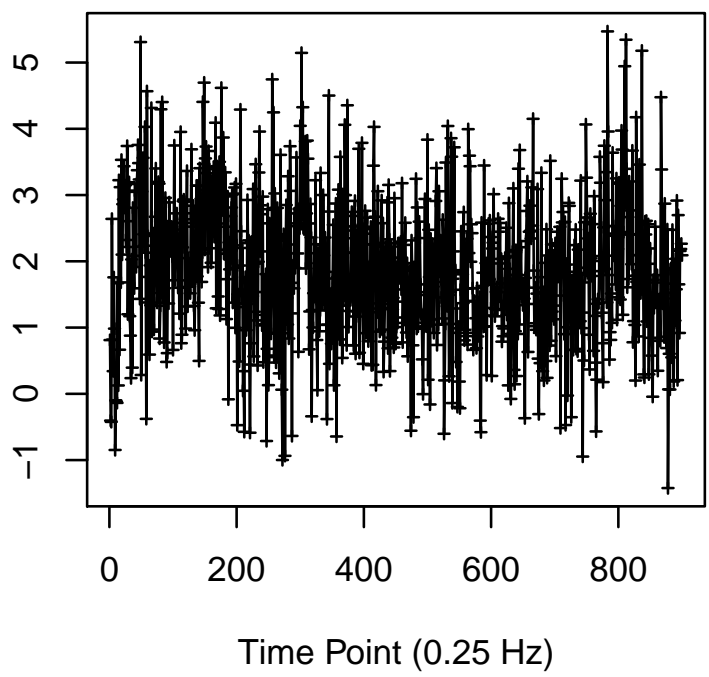

Cell 228

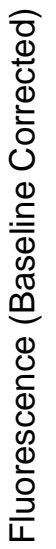

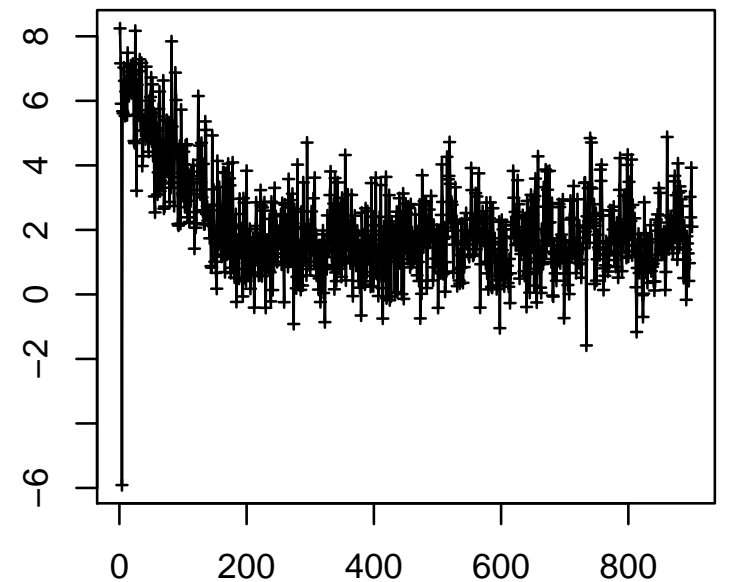

Time Point $(0.25 \mathrm{~Hz})$ 
Cell 229

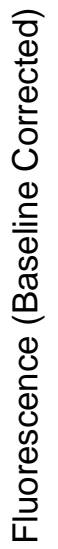

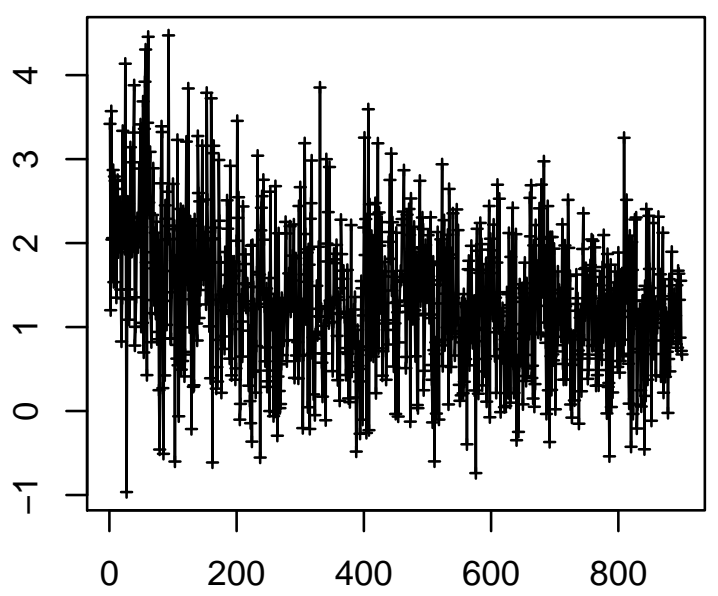

Time Point $(0.25 \mathrm{~Hz})$

Cell 231

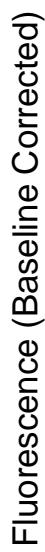

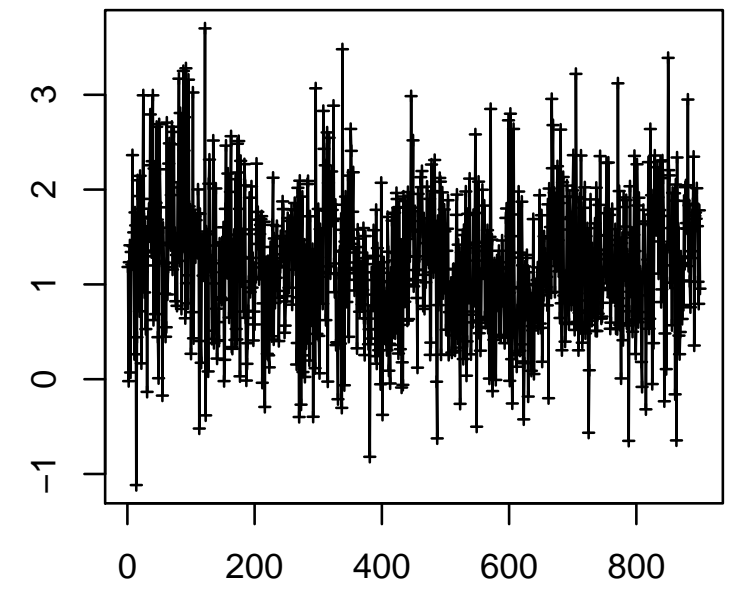

Time Point $(0.25 \mathrm{~Hz})$

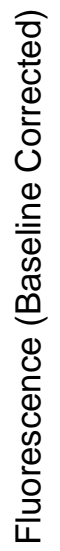

Cell 230

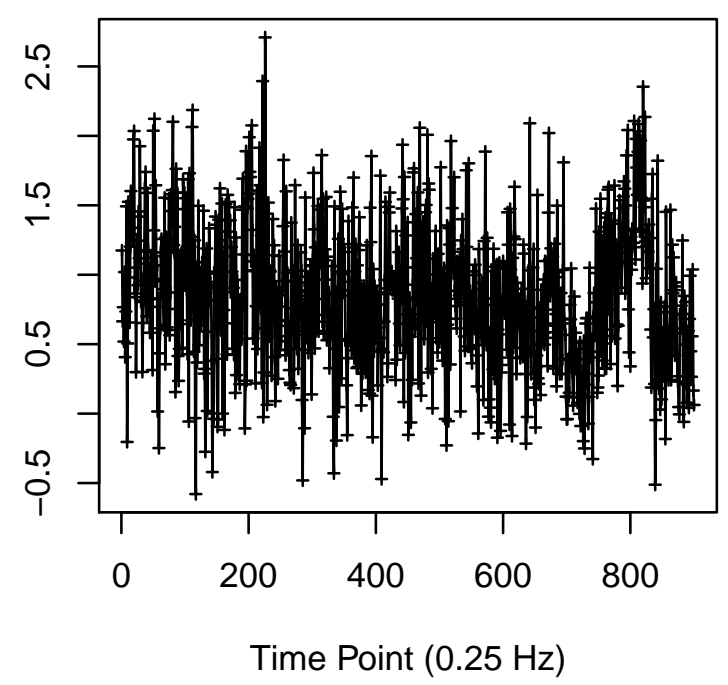

Cell 232

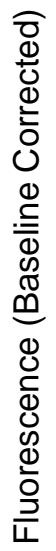

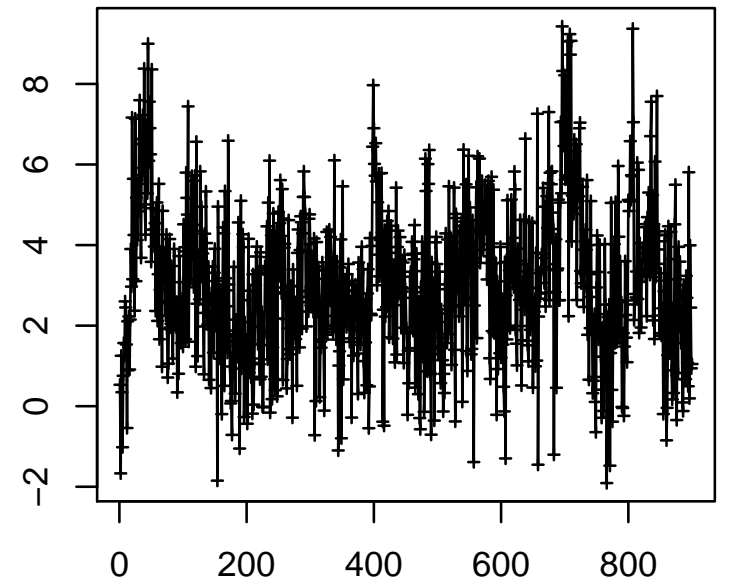

Time Point $(0.25 \mathrm{~Hz})$ 
Cell 233

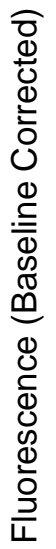

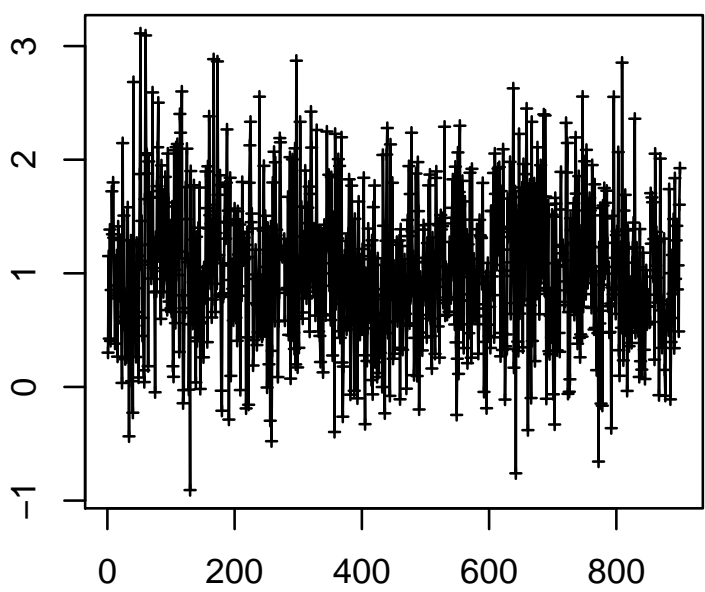

Time Point $(0.25 \mathrm{~Hz})$

Cell 235

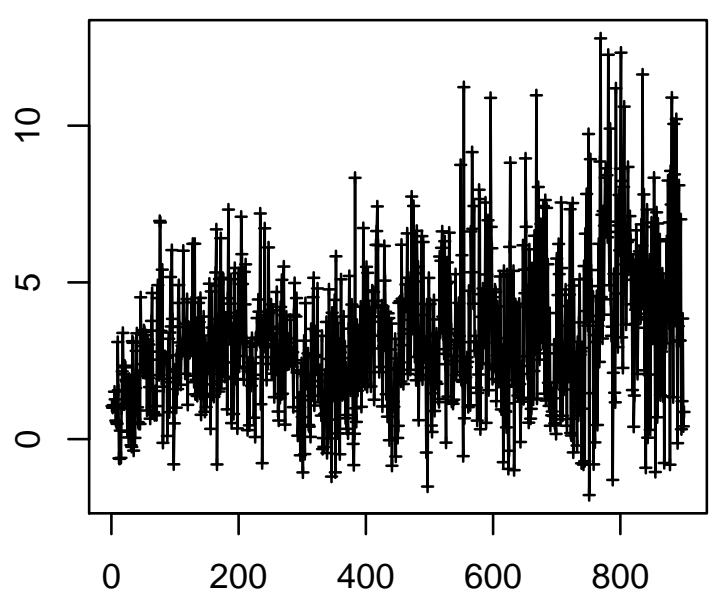

Time Point $(0.25 \mathrm{~Hz})$
Cell 234

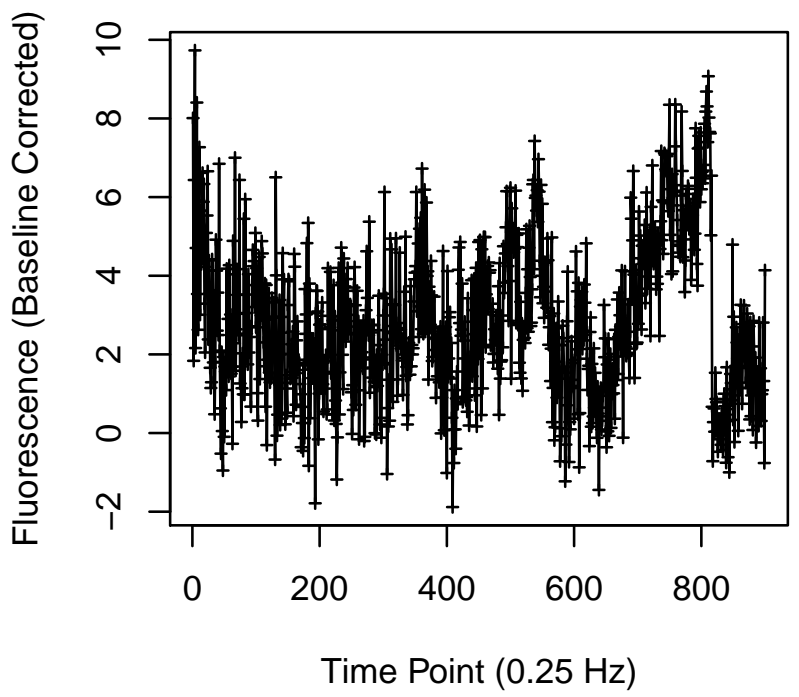

Cell 236

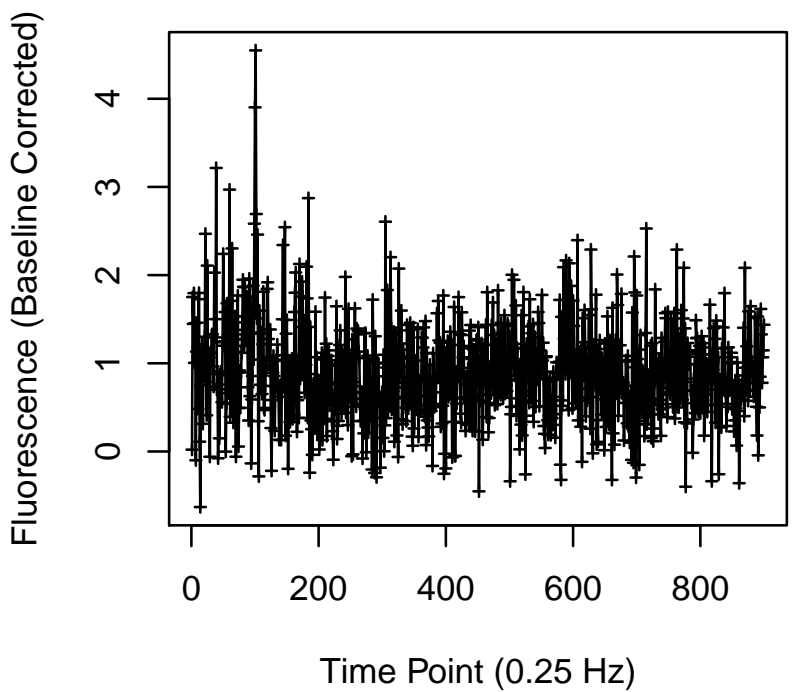




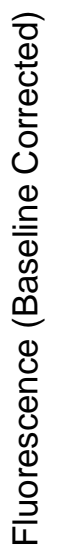

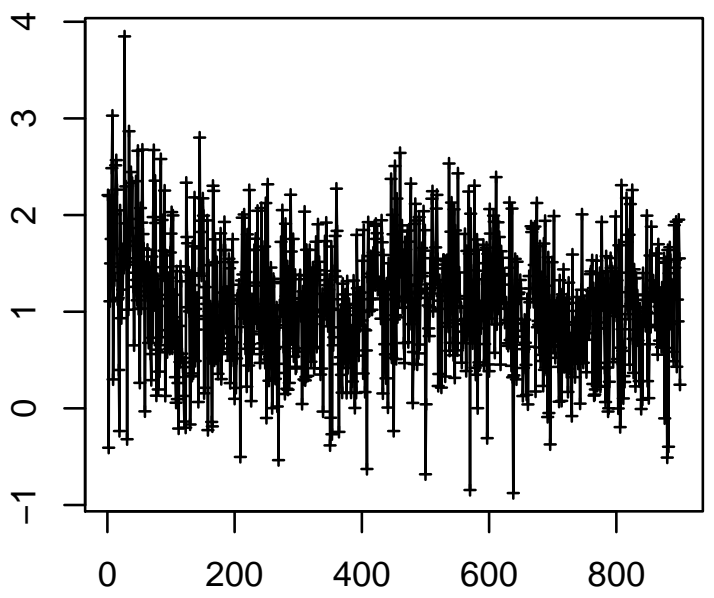

Time Point $(0.25 \mathrm{~Hz})$

Cell 239

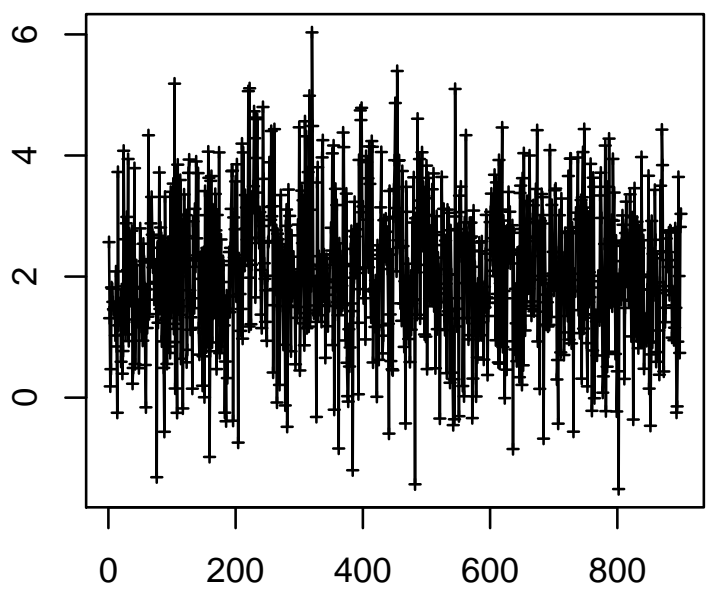

Time Point $(0.25 \mathrm{~Hz})$

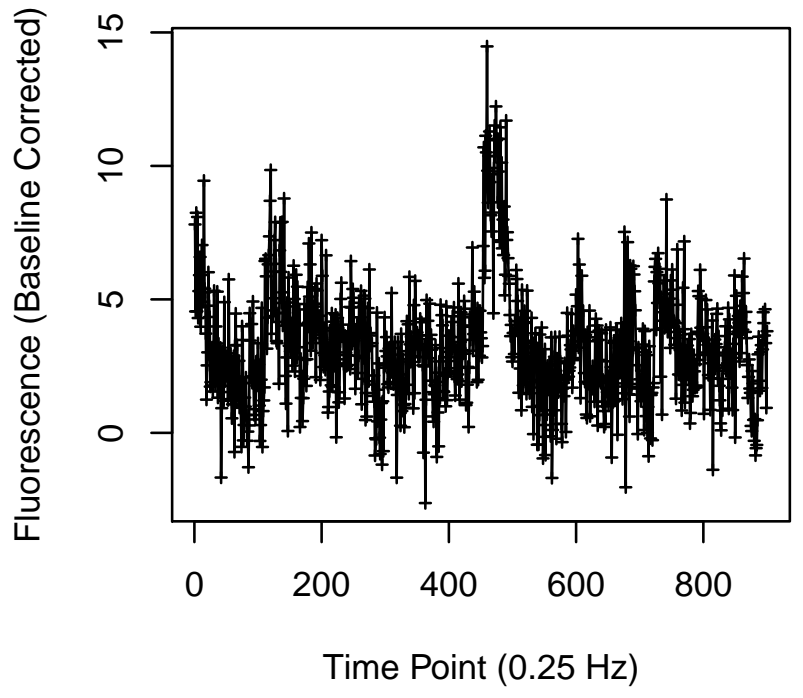

Cell 240

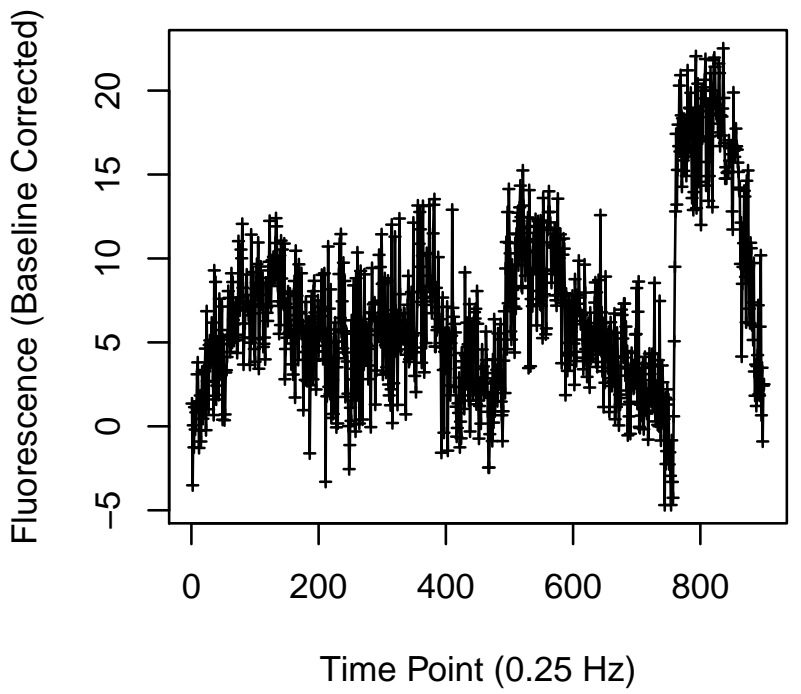




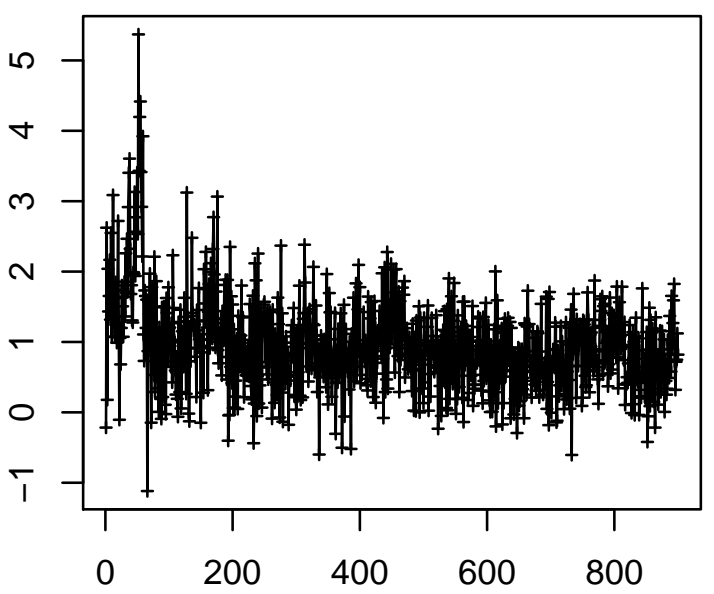

Time Point $(0.25 \mathrm{~Hz})$

\section{Cell 251}

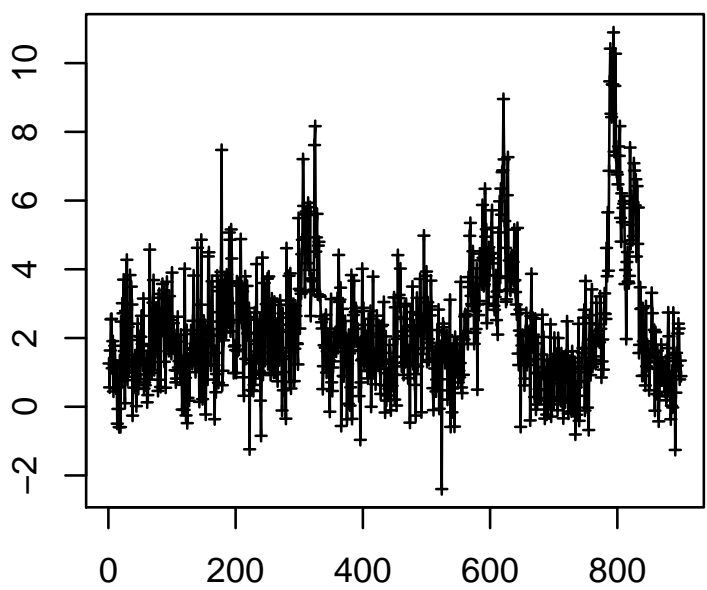

Time Point $(0.25 \mathrm{~Hz})$

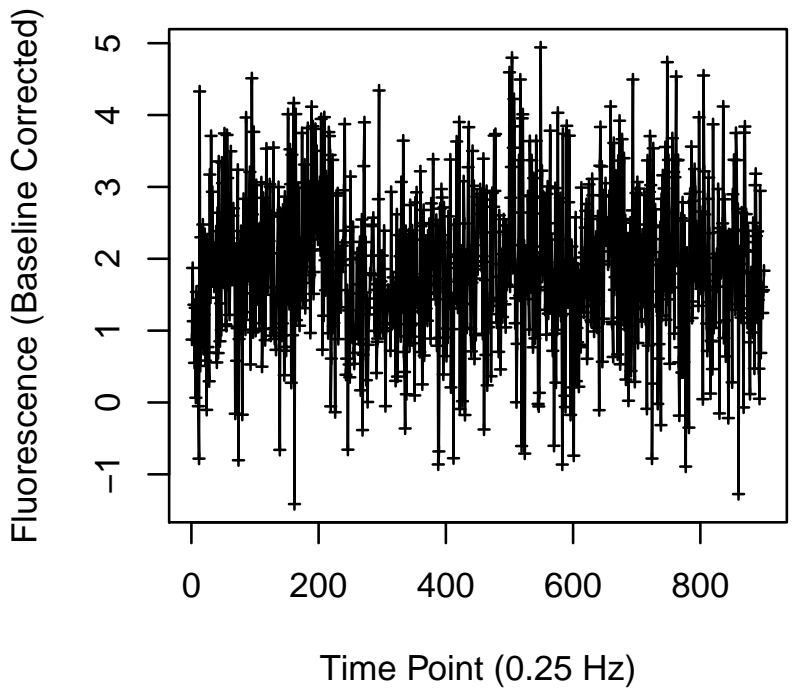

Cell 252

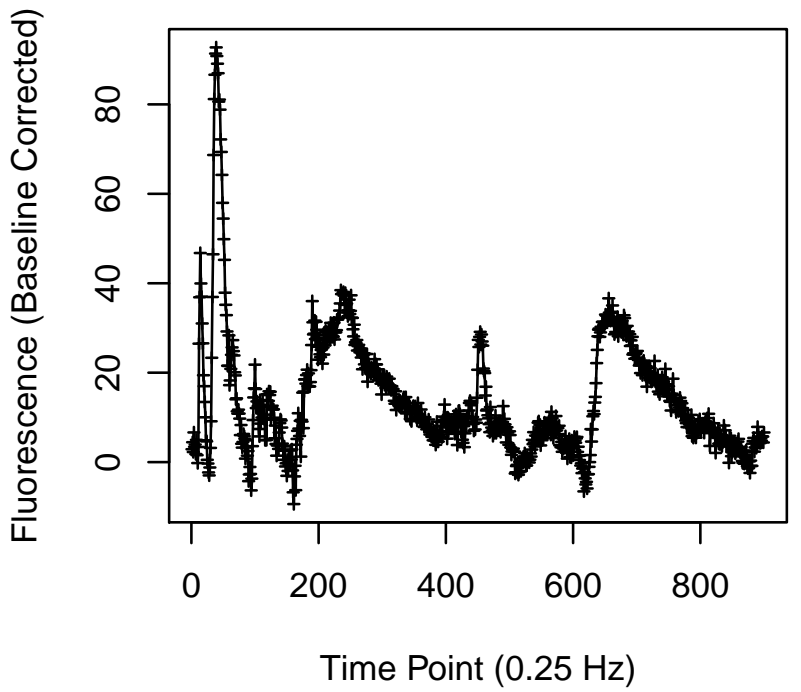




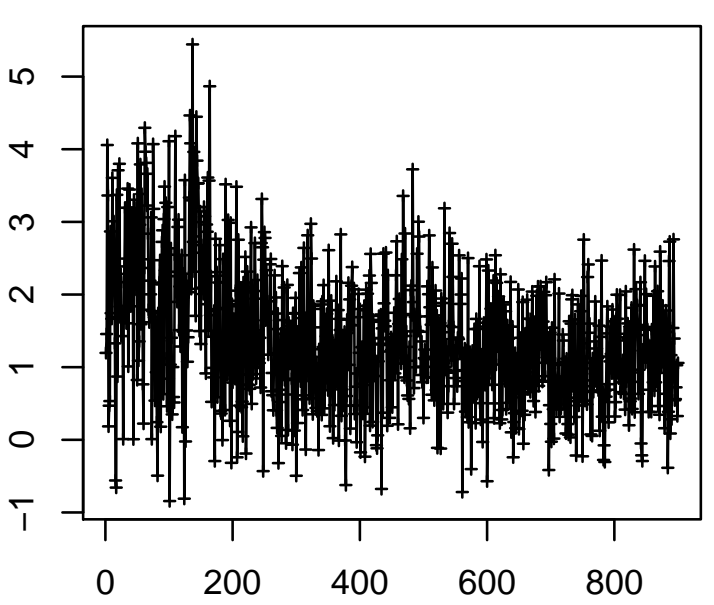

Time Point $(0.25 \mathrm{~Hz})$

\section{Cell 259}

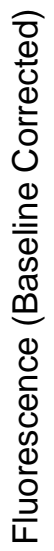

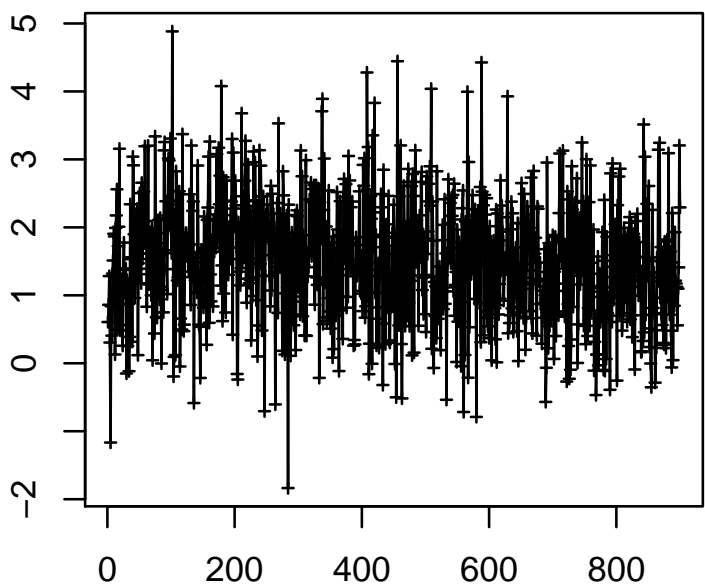

Time Point $(0.25 \mathrm{~Hz})$

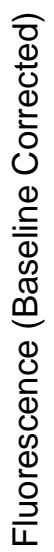

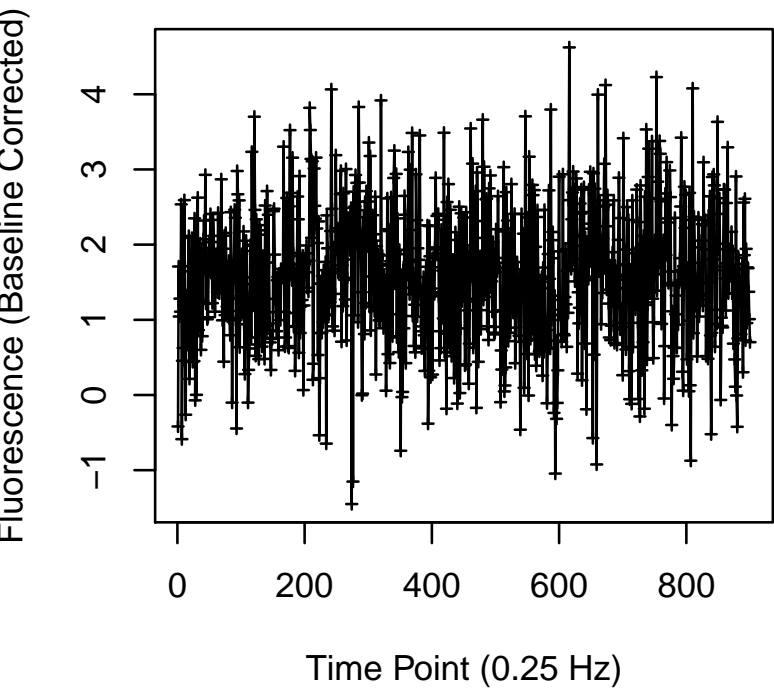

Cell 260

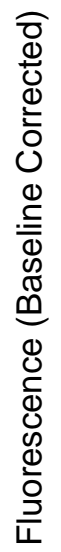

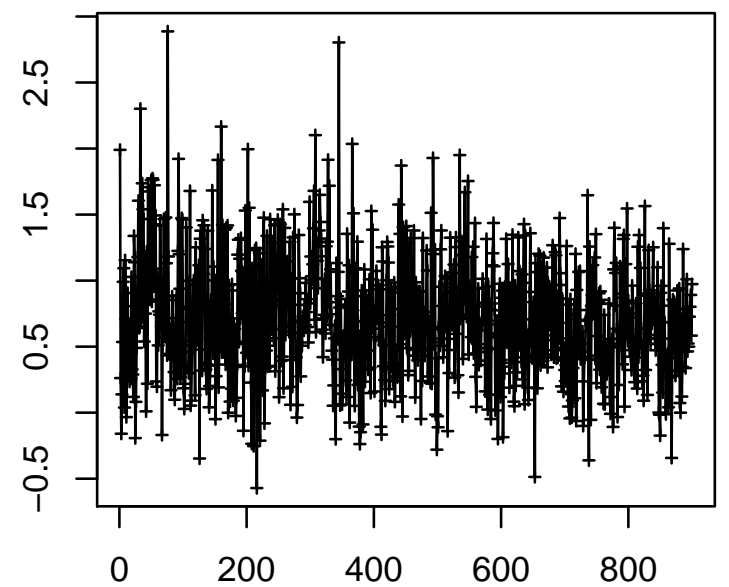

Time Point $(0.25 \mathrm{~Hz})$ 


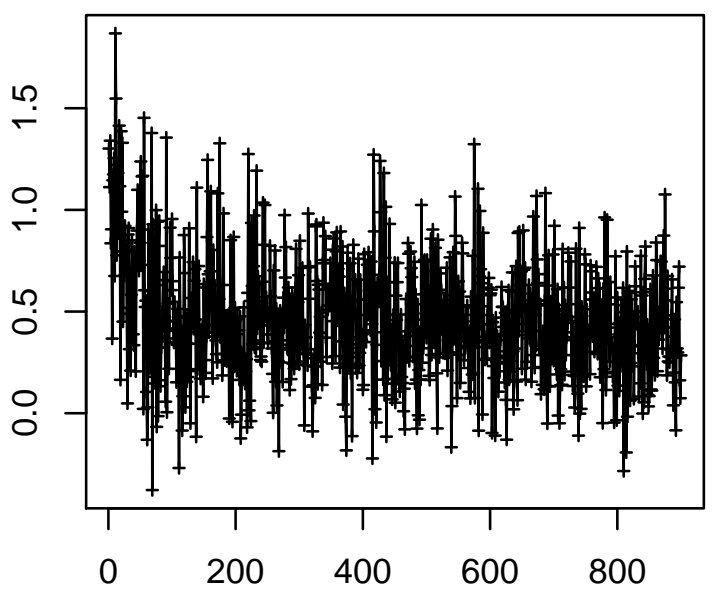

Time Point $(0.25 \mathrm{~Hz})$

\section{Cell 263}

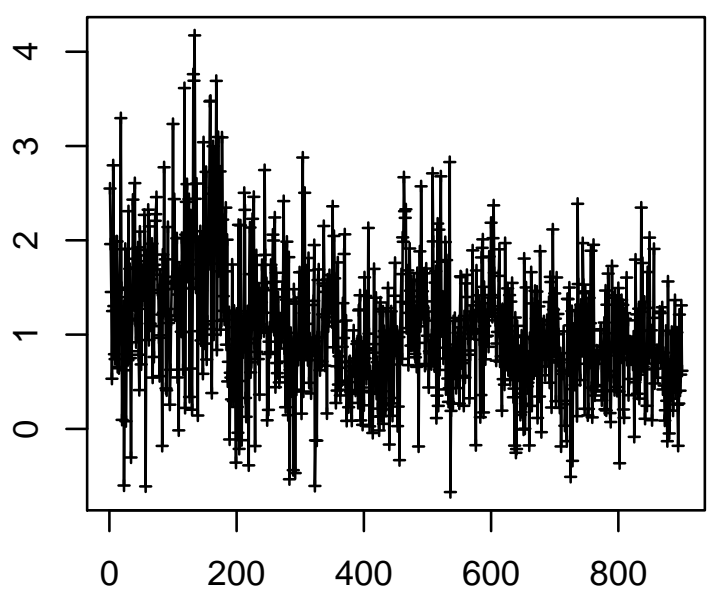

Time Point $(0.25 \mathrm{~Hz})$

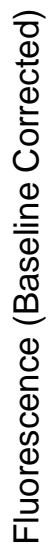

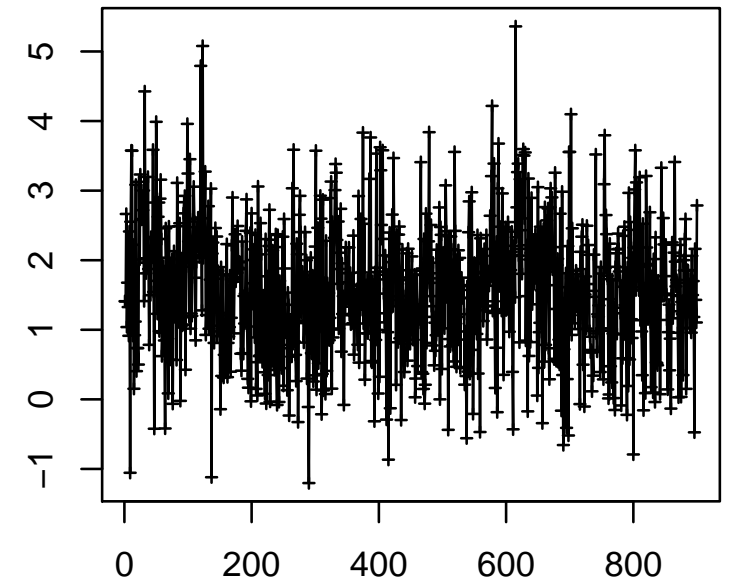

Time Point $(0.25 \mathrm{~Hz})$

Cell 264

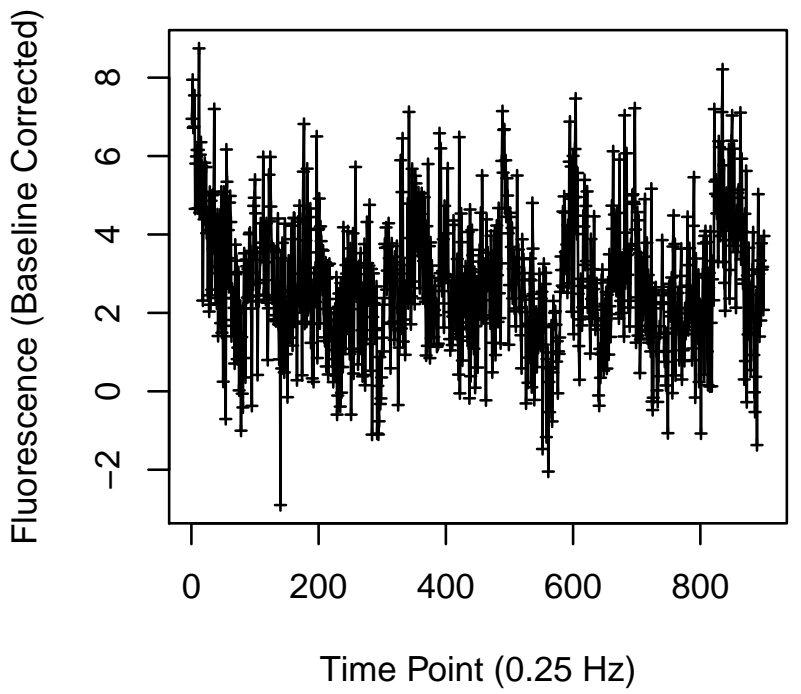




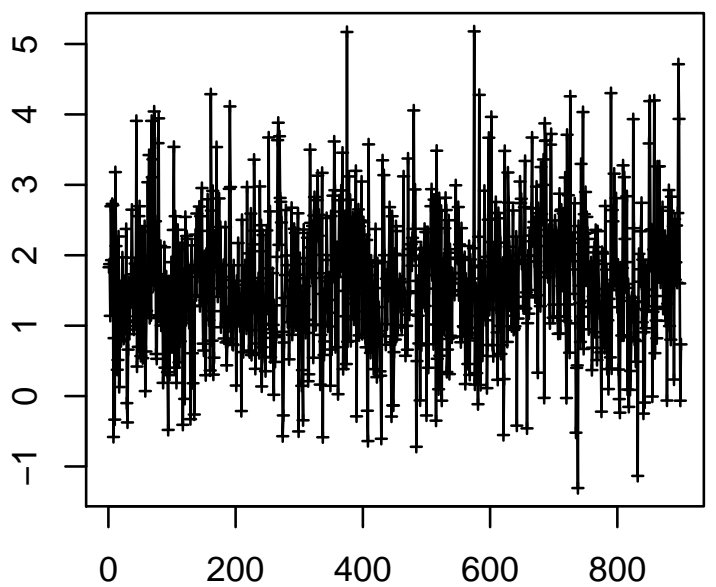

Time Point $(0.25 \mathrm{~Hz})$

\section{Cell 267}

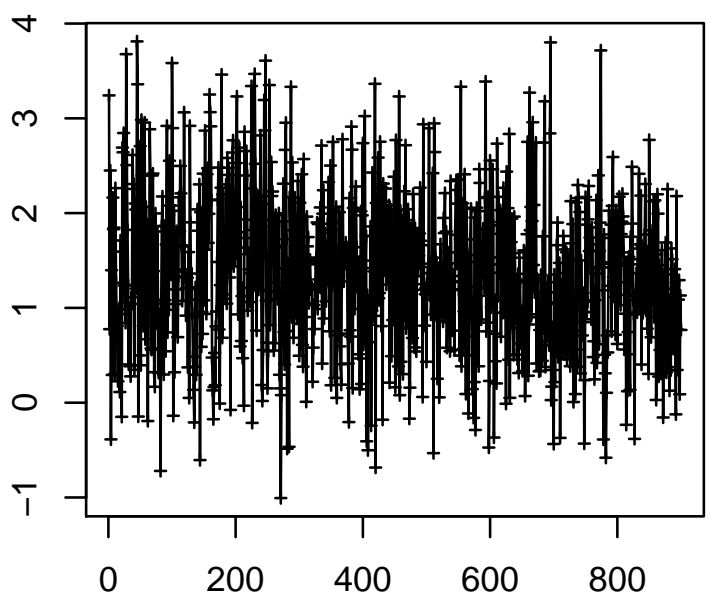

Time Point $(0.25 \mathrm{~Hz})$

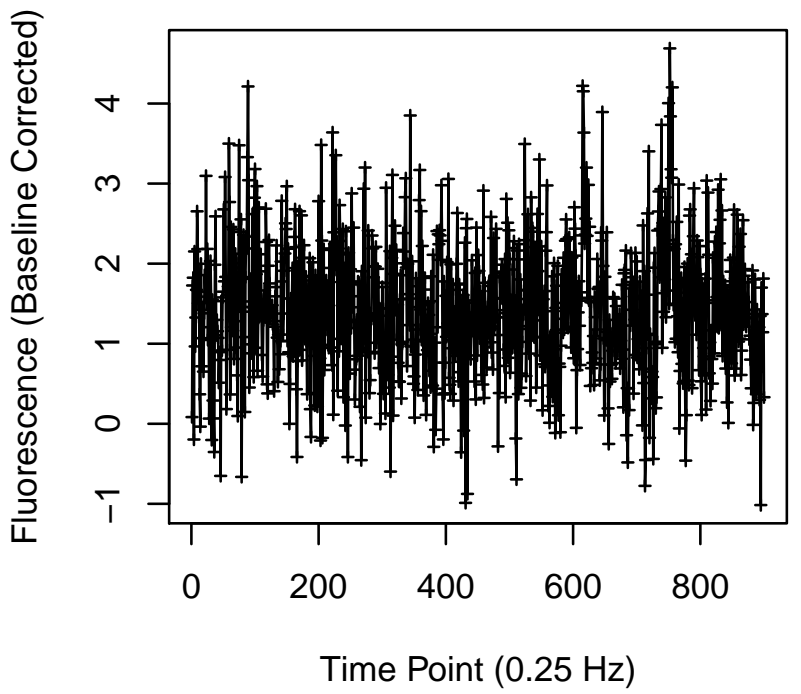

Cell 268

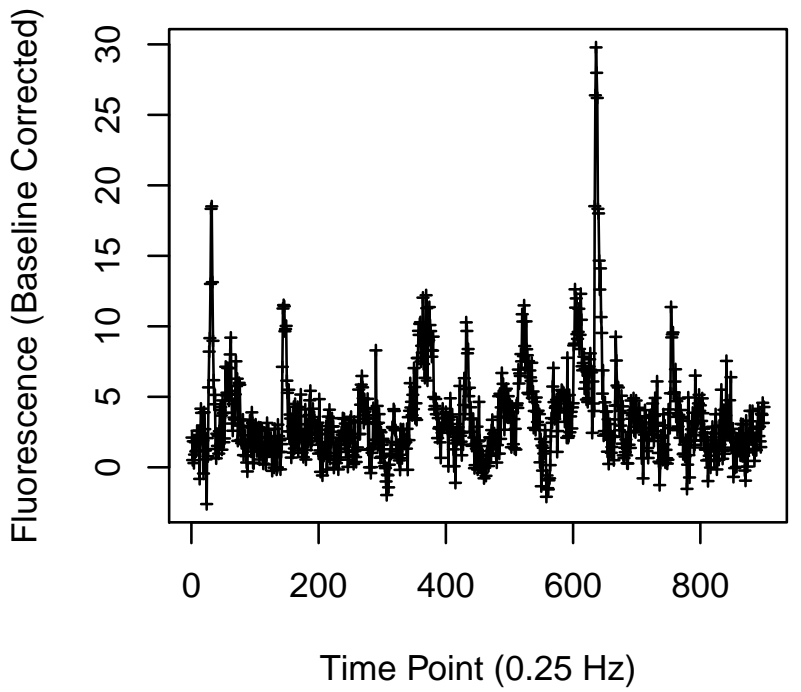




\section{Cell 269}

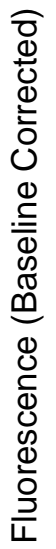

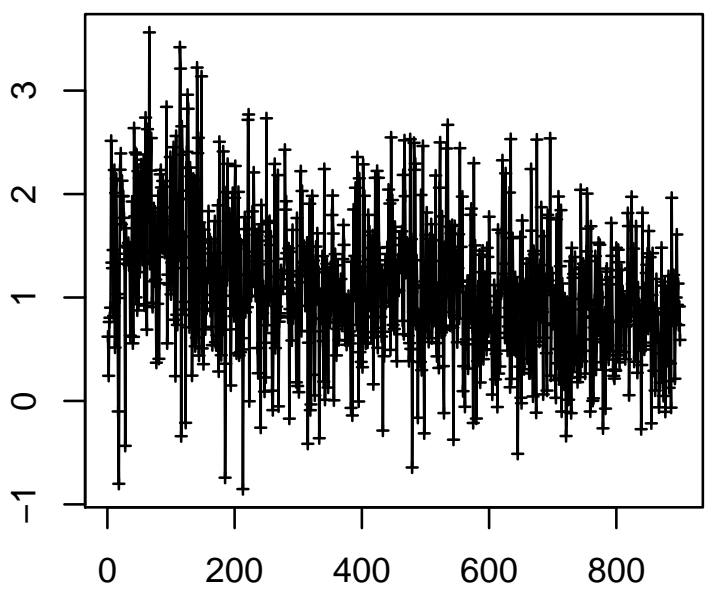

Time Point $(0.25 \mathrm{~Hz})$

\section{Cell 271}

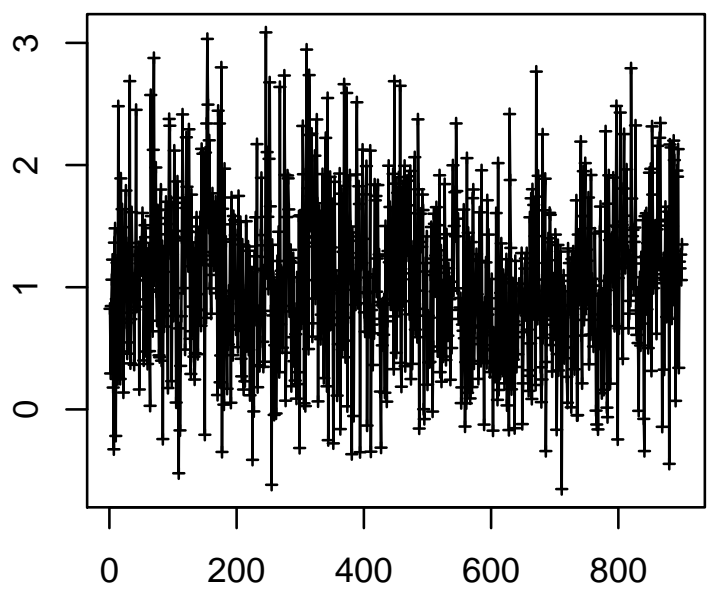

Time Point $(0.25 \mathrm{~Hz})$
Cell 270

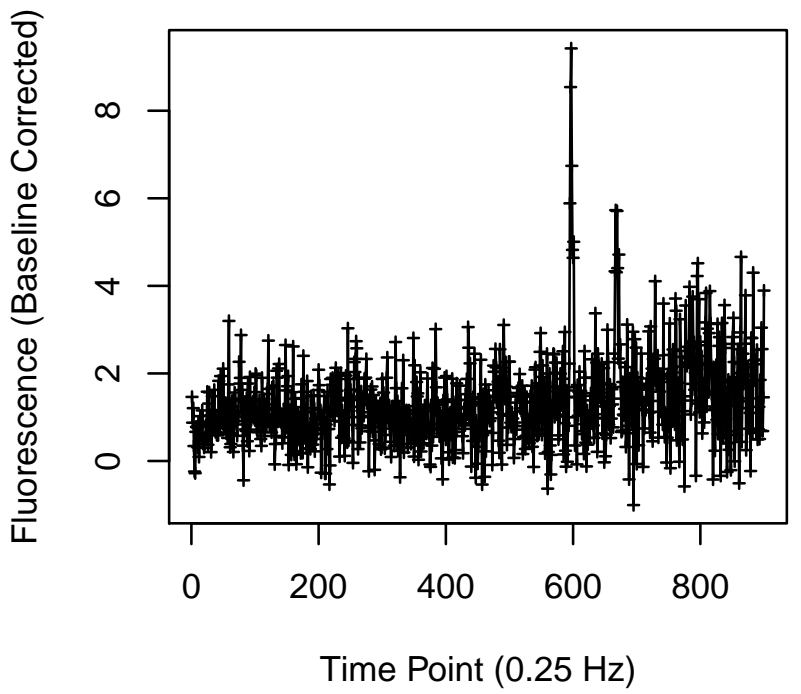

Cell 272

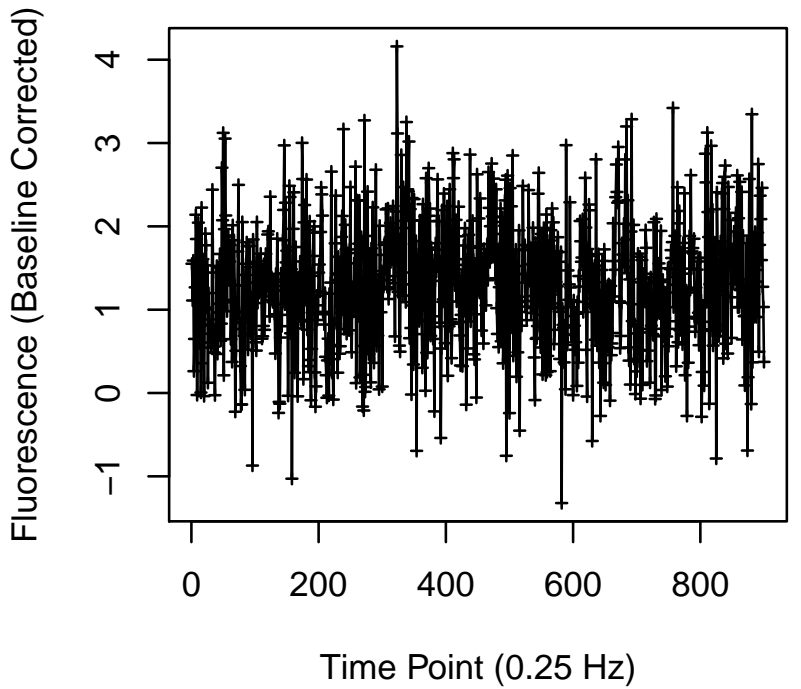




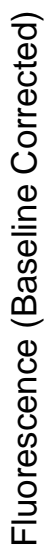

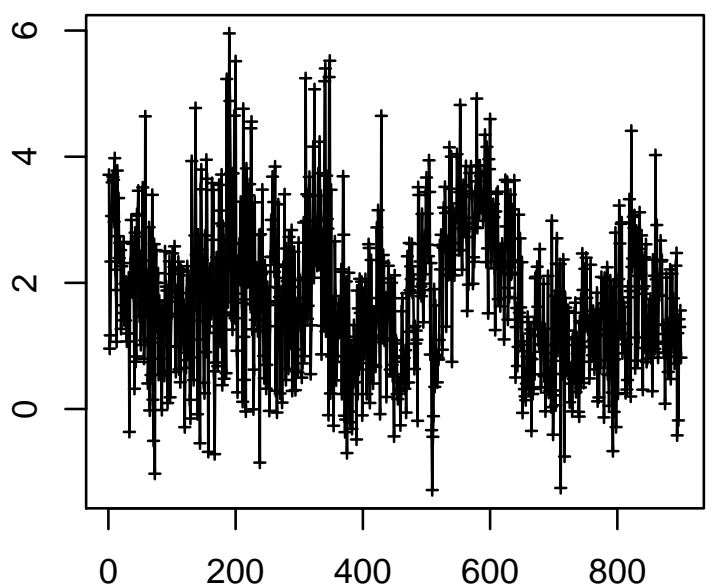

Time Point $(0.25 \mathrm{~Hz})$

Cell 275

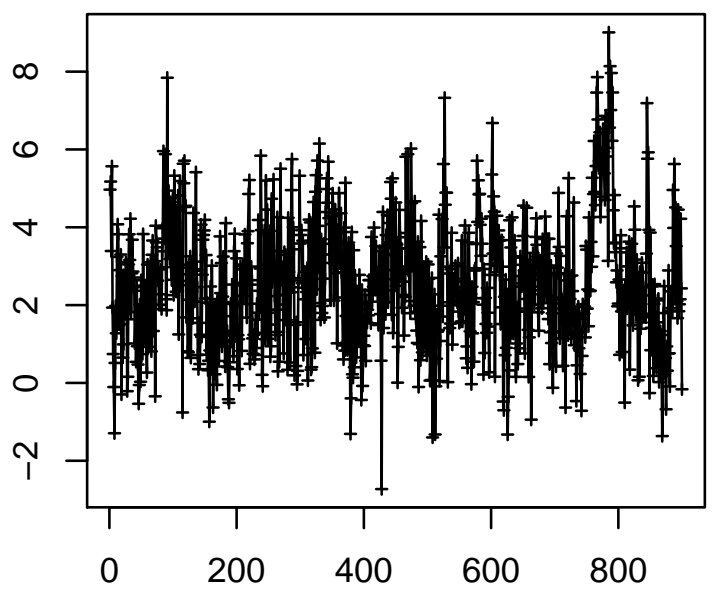

Time Point $(0.25 \mathrm{~Hz})$

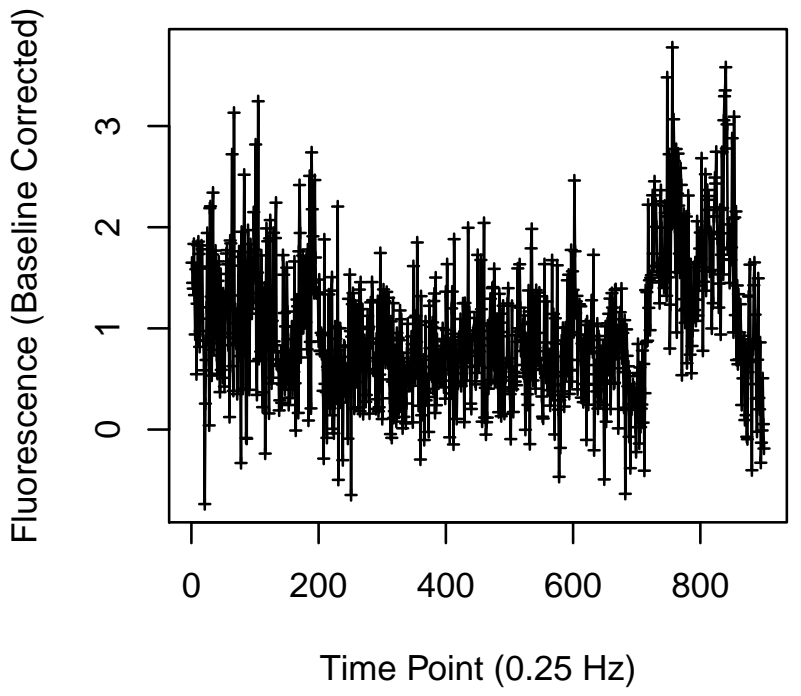

Cell 276

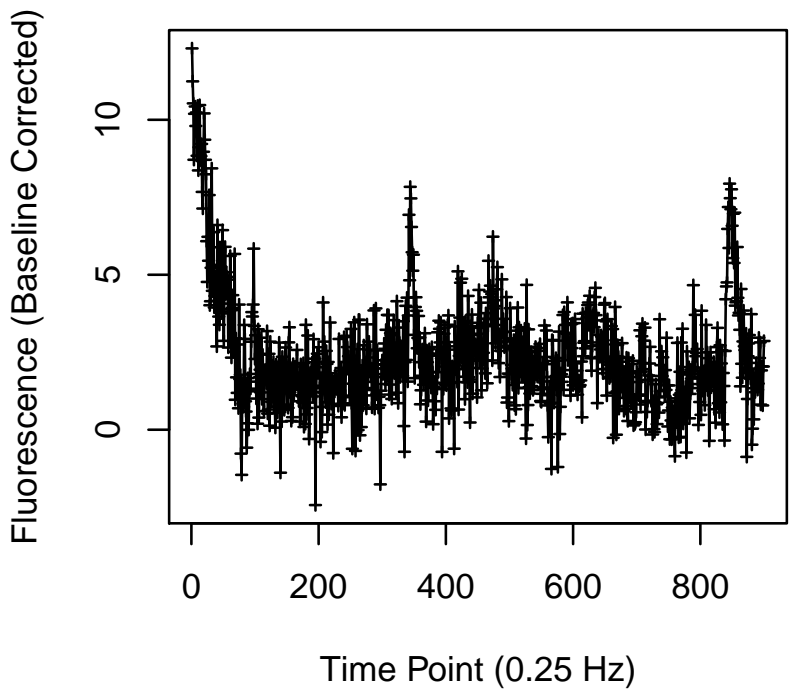




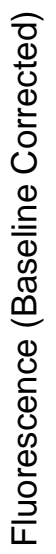

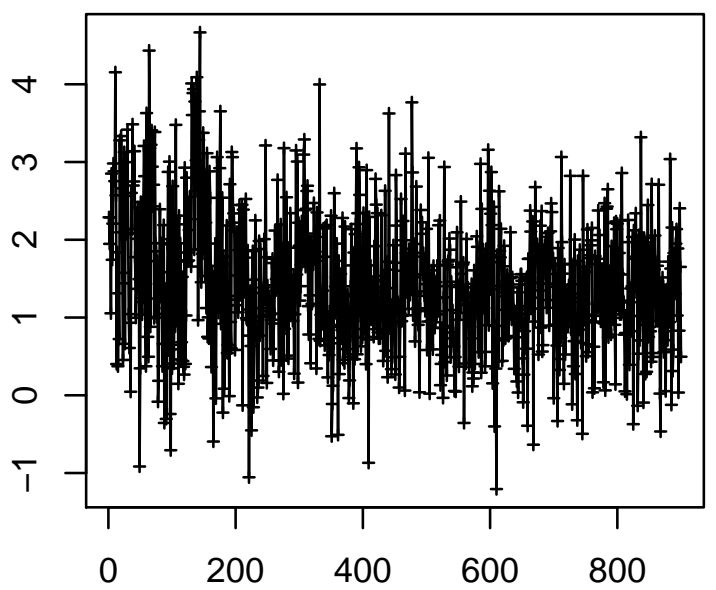

Time Point $(0.25 \mathrm{~Hz})$

\section{Cell 283}

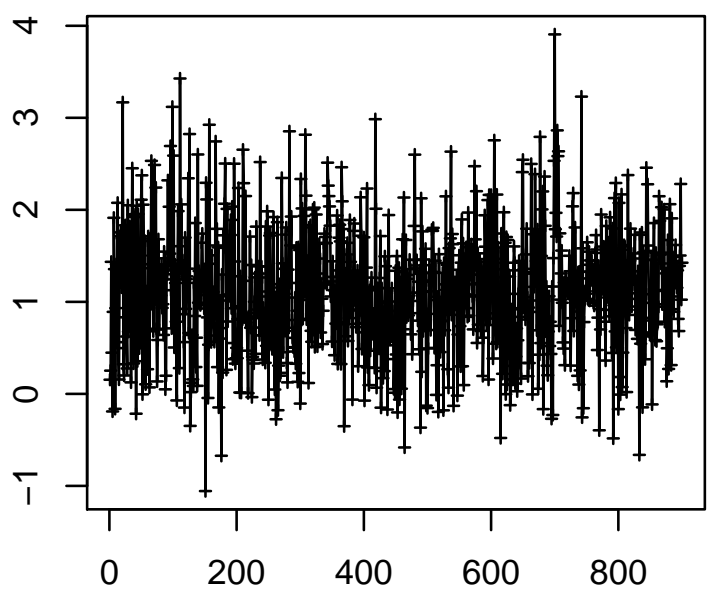

Time Point $(0.25 \mathrm{~Hz})$

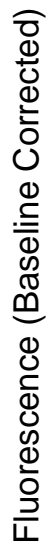

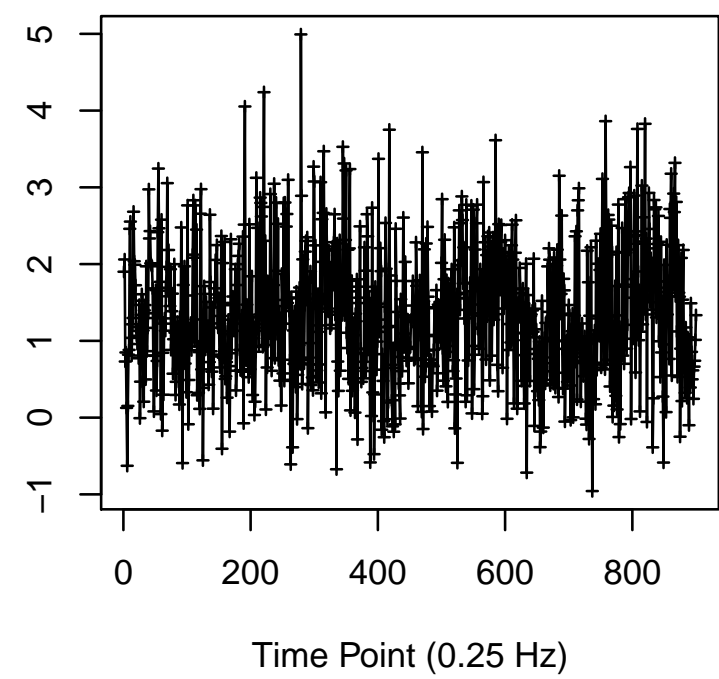

Cell 284

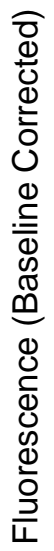

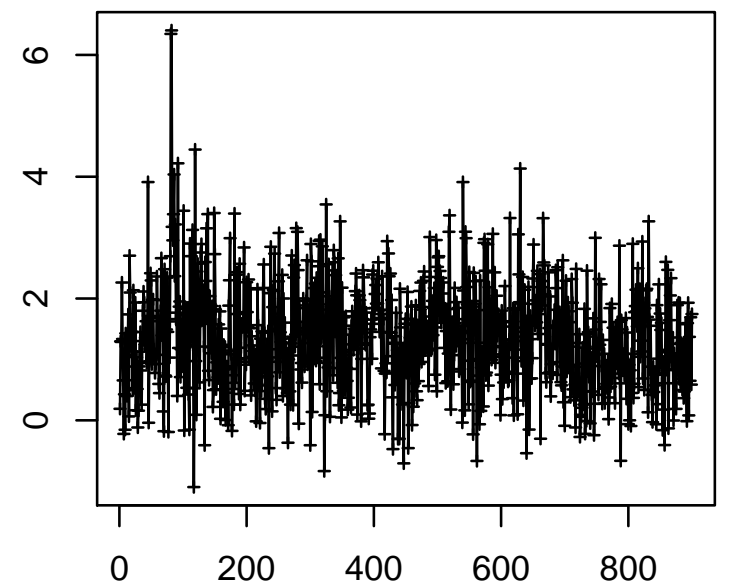

Time Point $(0.25 \mathrm{~Hz})$ 
Cell 285

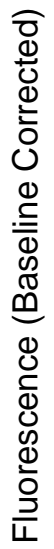

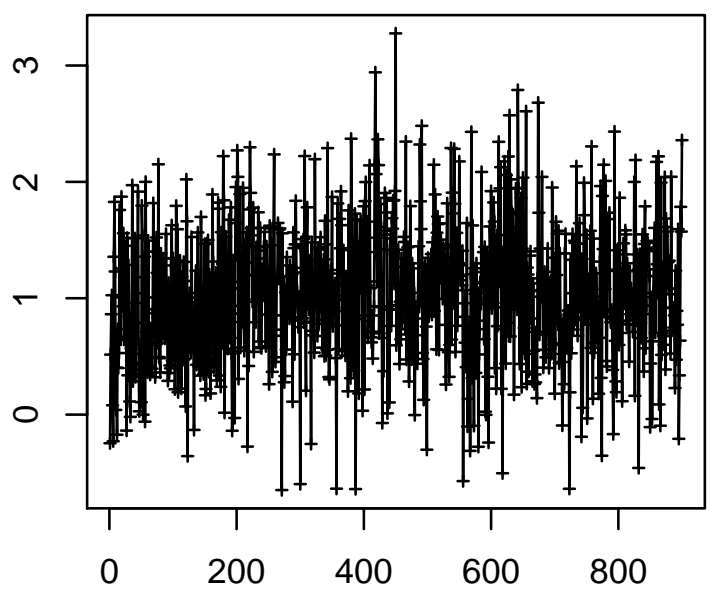

Time Point $(0.25 \mathrm{~Hz})$

\section{Cell 287}

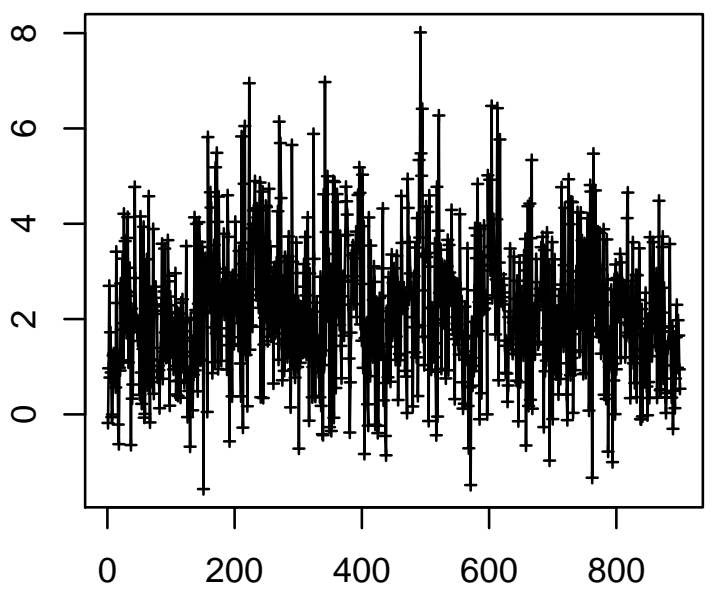

Time Point $(0.25 \mathrm{~Hz})$
Cell 286

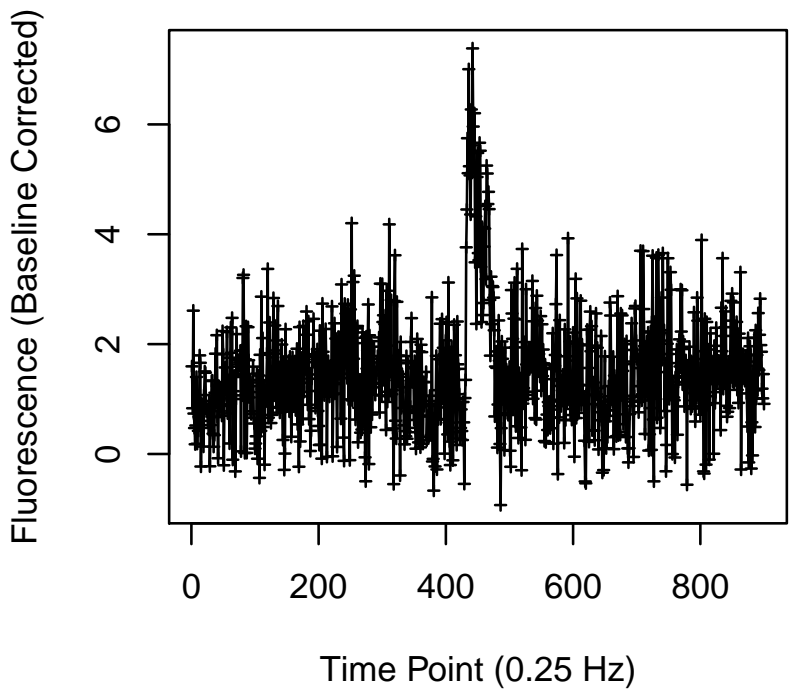

Cell 288

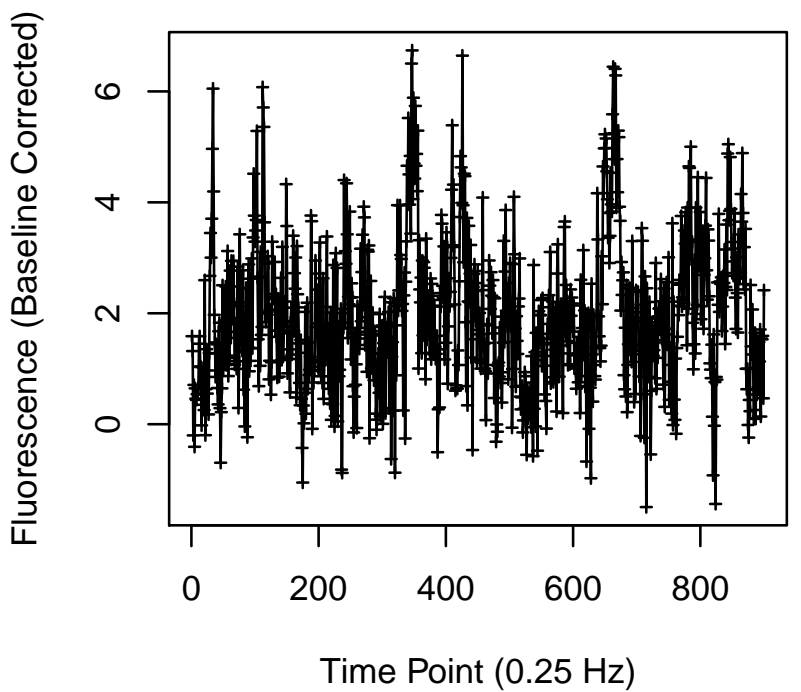


Cell 305

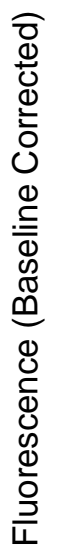

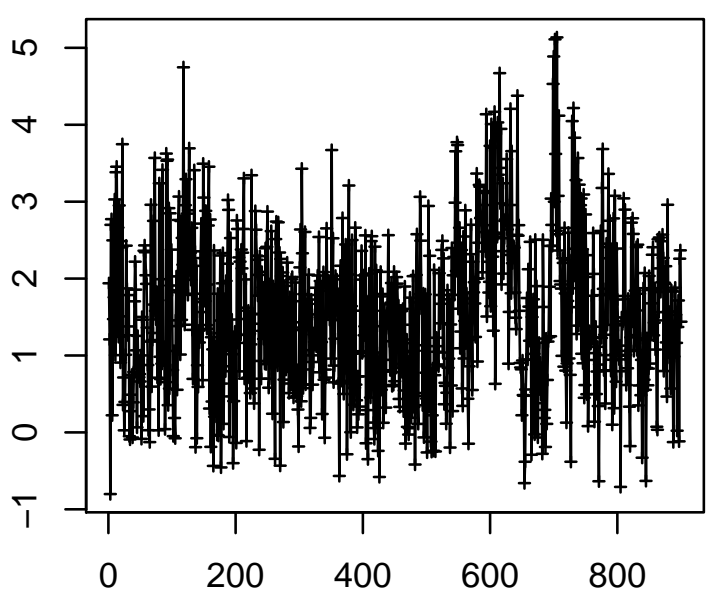

Time Point $(0.25 \mathrm{~Hz})$

Cell 307

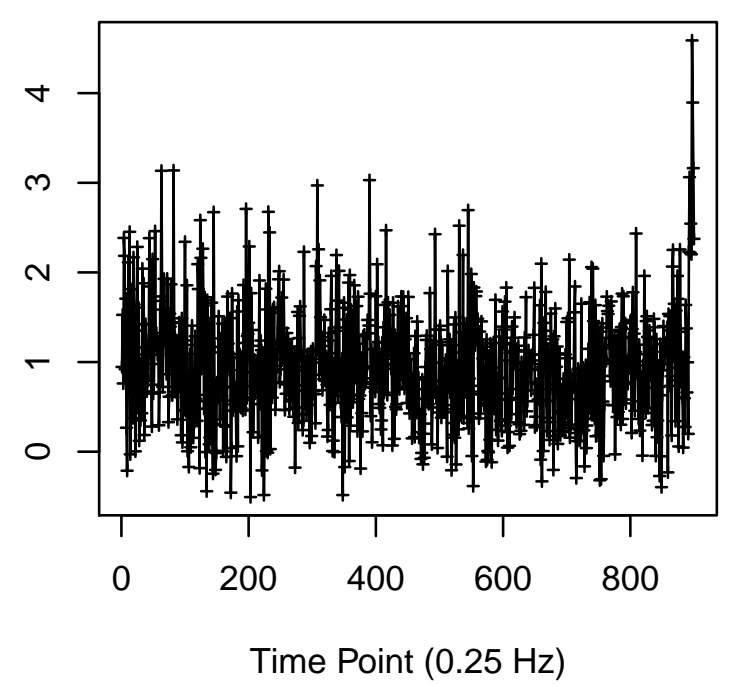

Cell 306

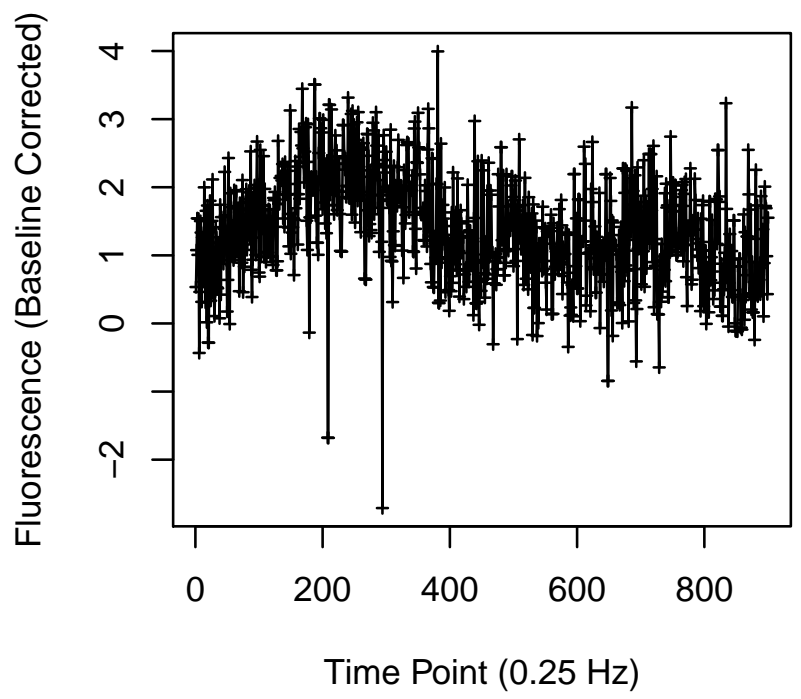

Cell 308

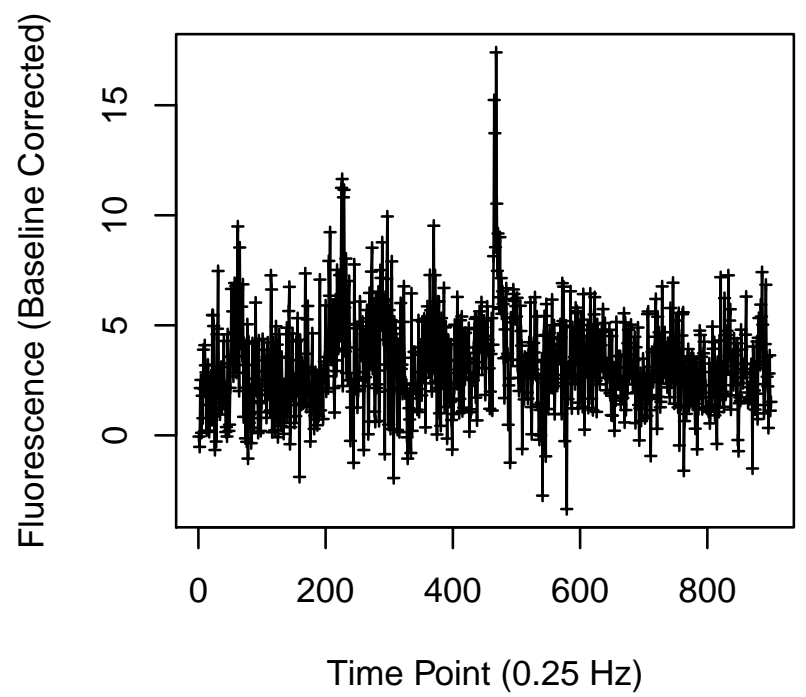


Cell 309

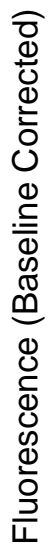

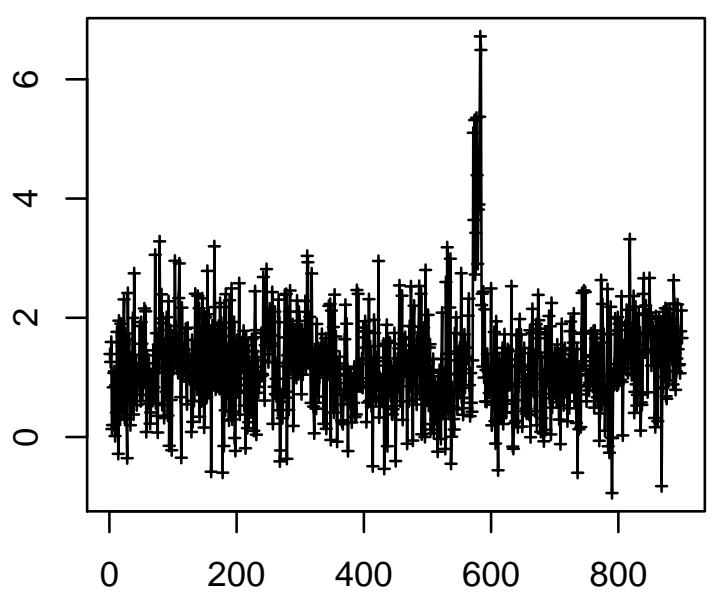

Time Point $(0.25 \mathrm{~Hz})$

Cell 311

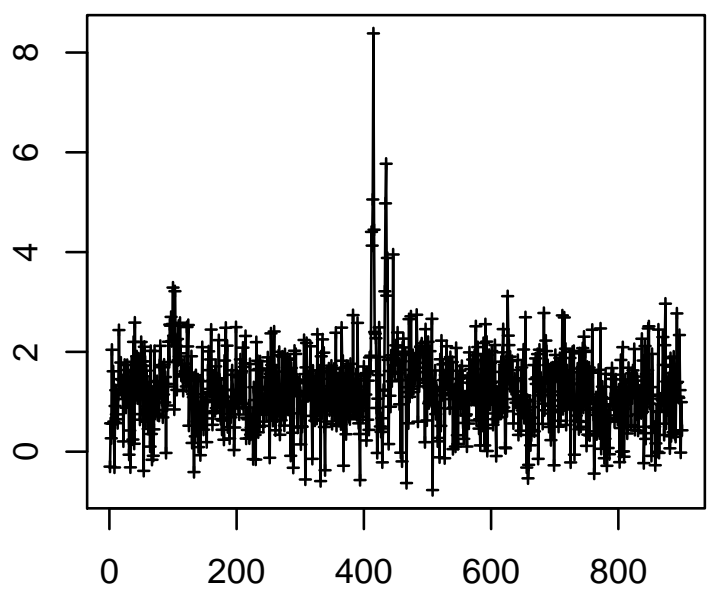

Time Point $(0.25 \mathrm{~Hz})$
Cell 310

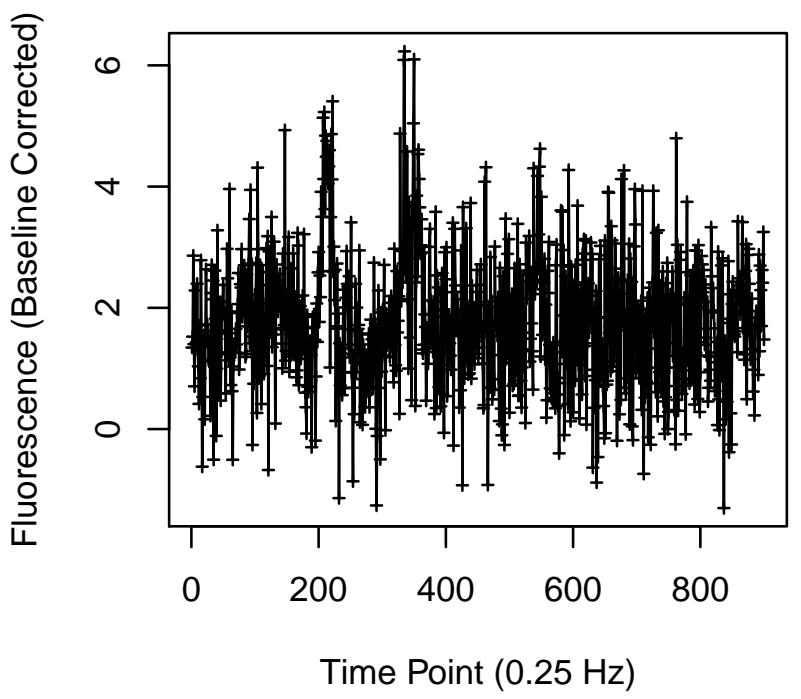

Cell 312

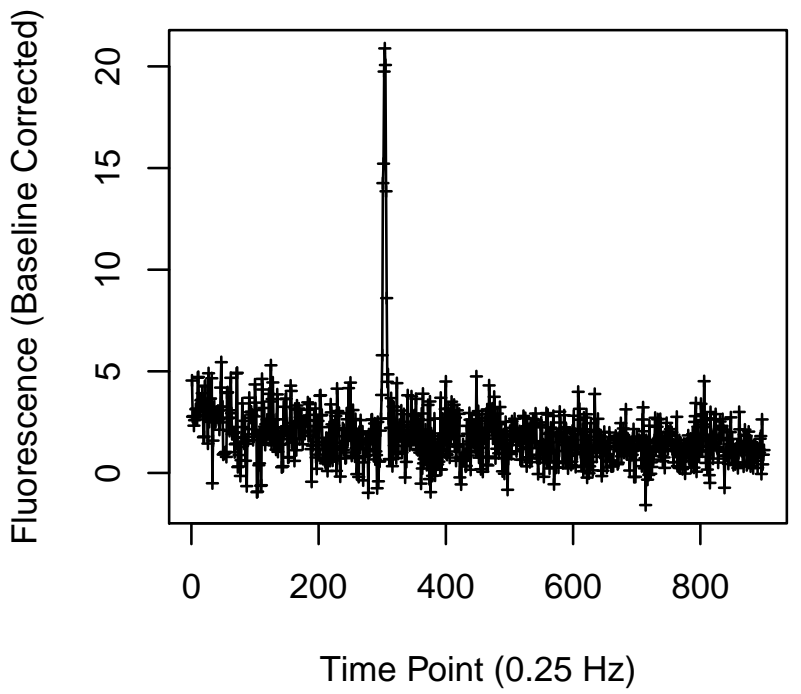


Cell 313

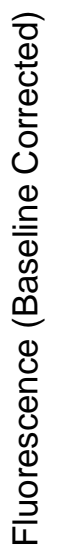

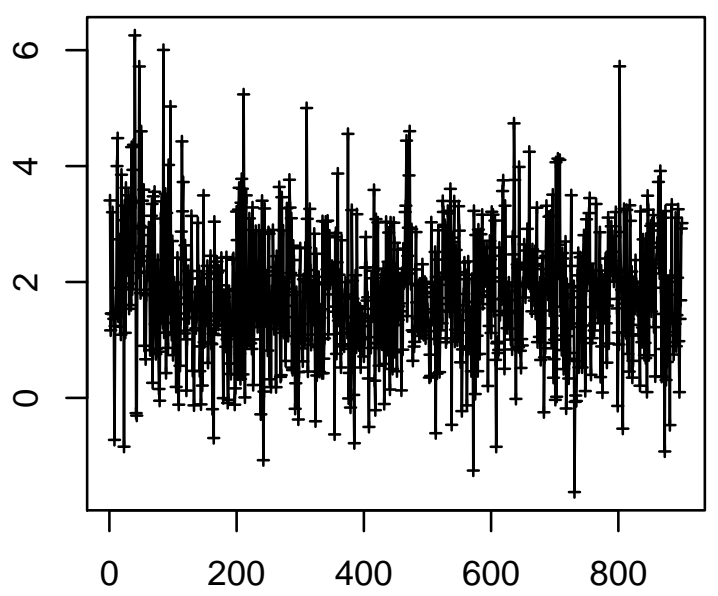

Time Point $(0.25 \mathrm{~Hz})$

Cell 315

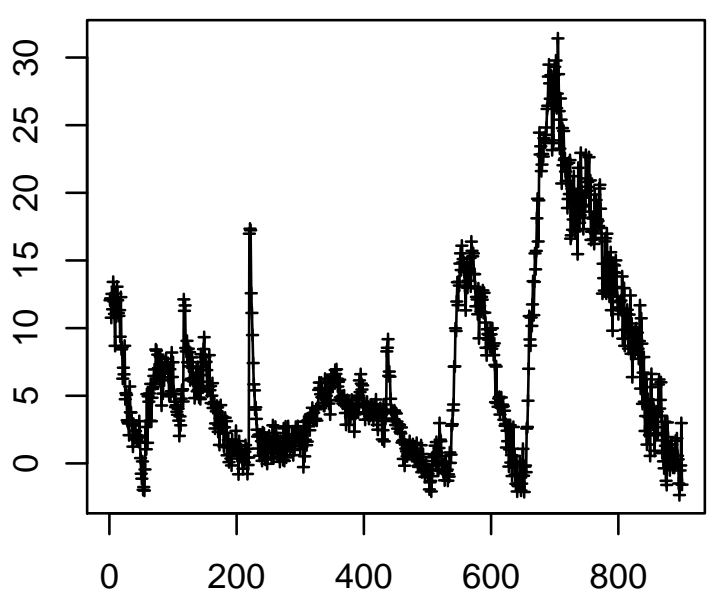

Time Point $(0.25 \mathrm{~Hz})$
Cell 314

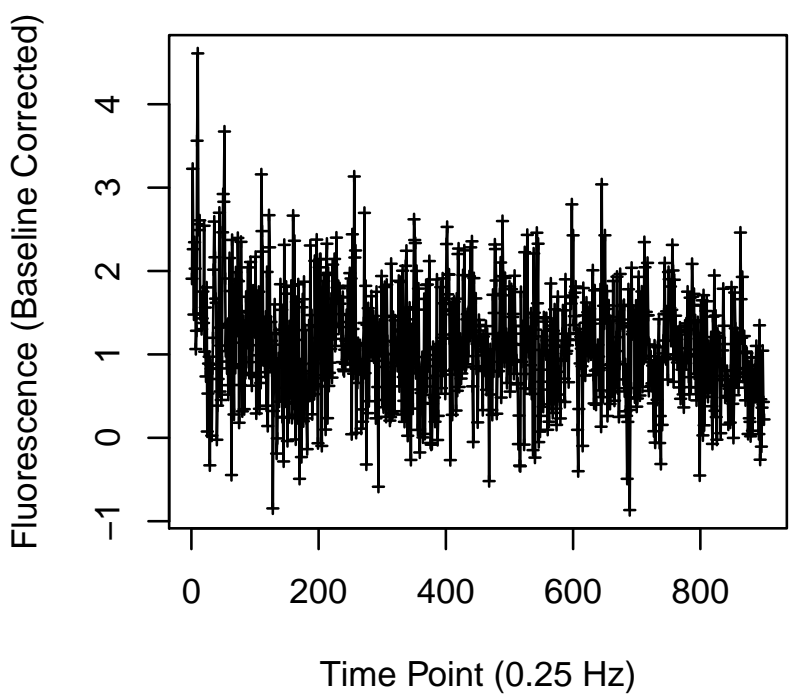

Cell 316

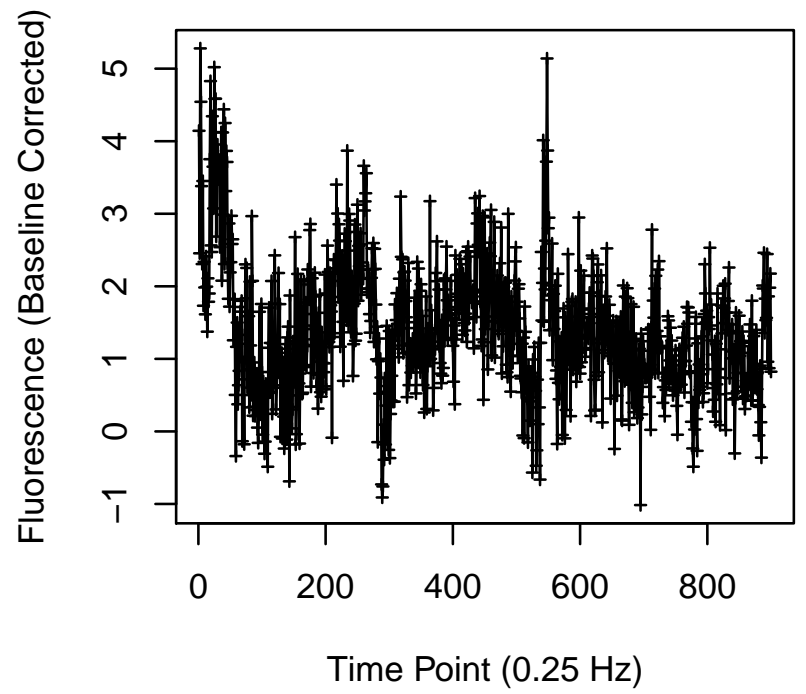


Cell 321

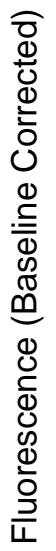

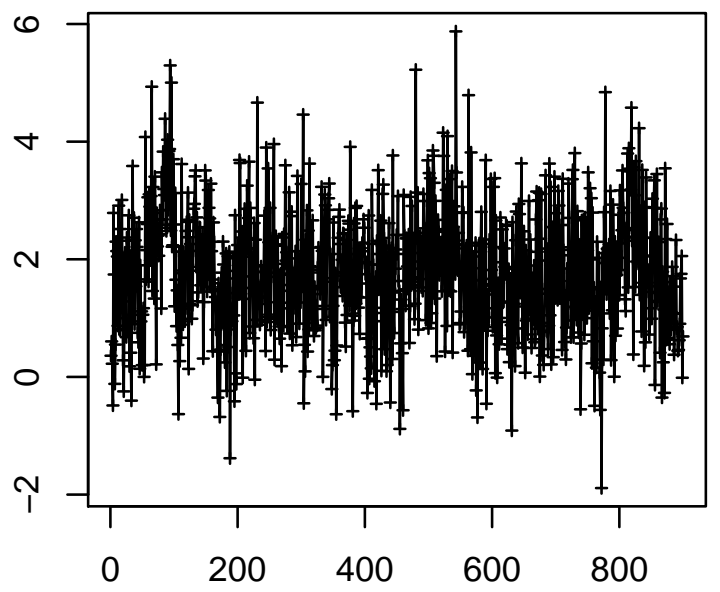

Time Point $(0.25 \mathrm{~Hz})$

Cell 323

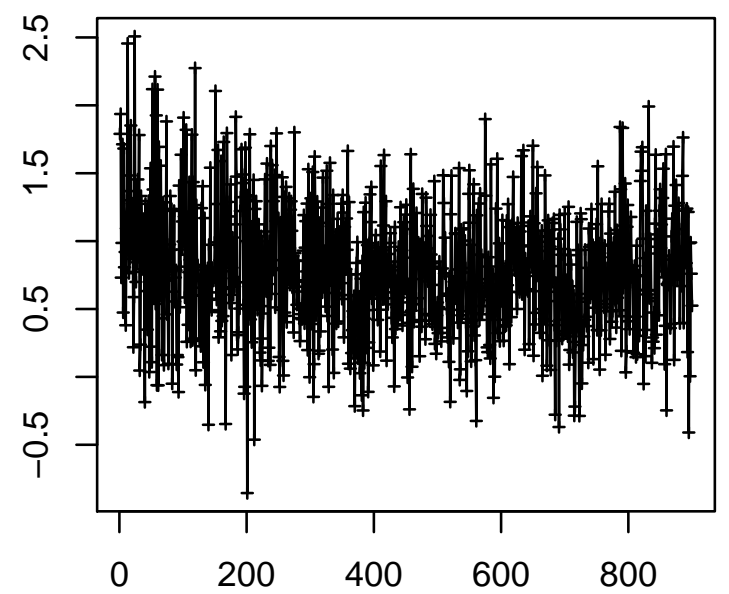

Time Point $(0.25 \mathrm{~Hz})$
Cell 322

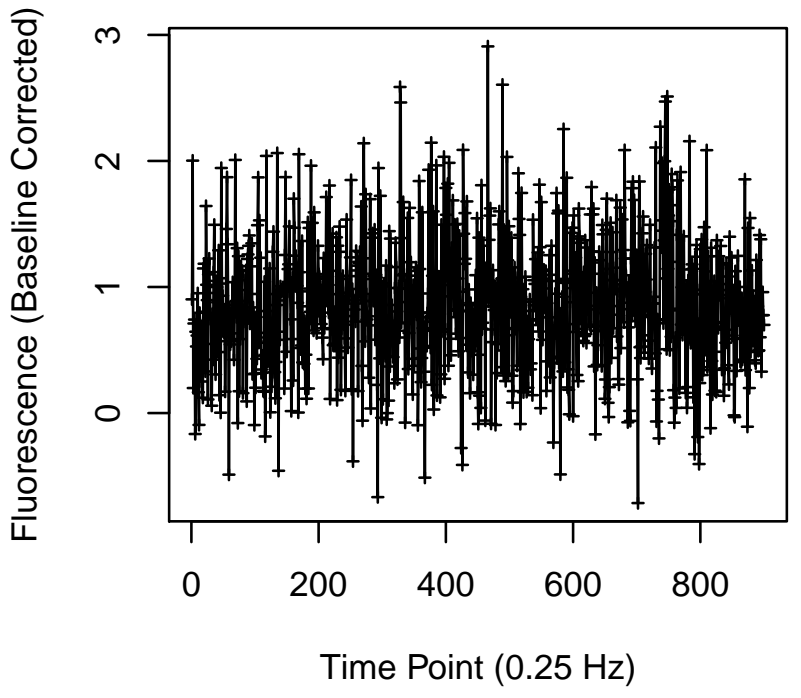

Cell 324

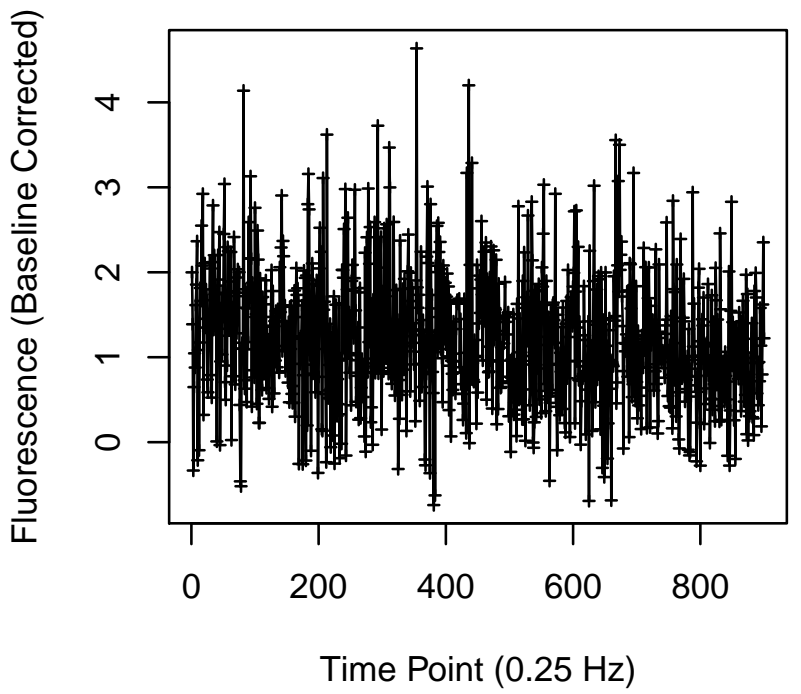


Cell 325

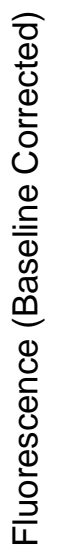

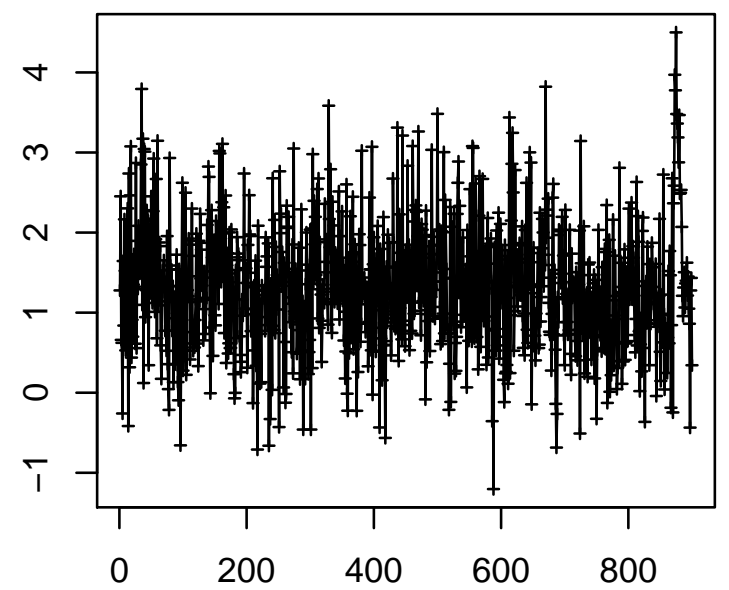

Time Point $(0.25 \mathrm{~Hz})$

Cell 327

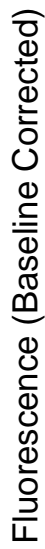

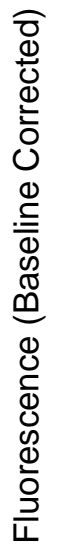

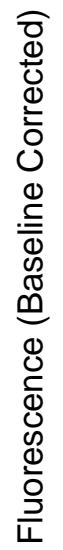

$\begin{array}{lllll}0 & 200 & 400 & 600 & 800\end{array}$

Time Point $(0.25 \mathrm{~Hz})$
Cell 328

Cell 326
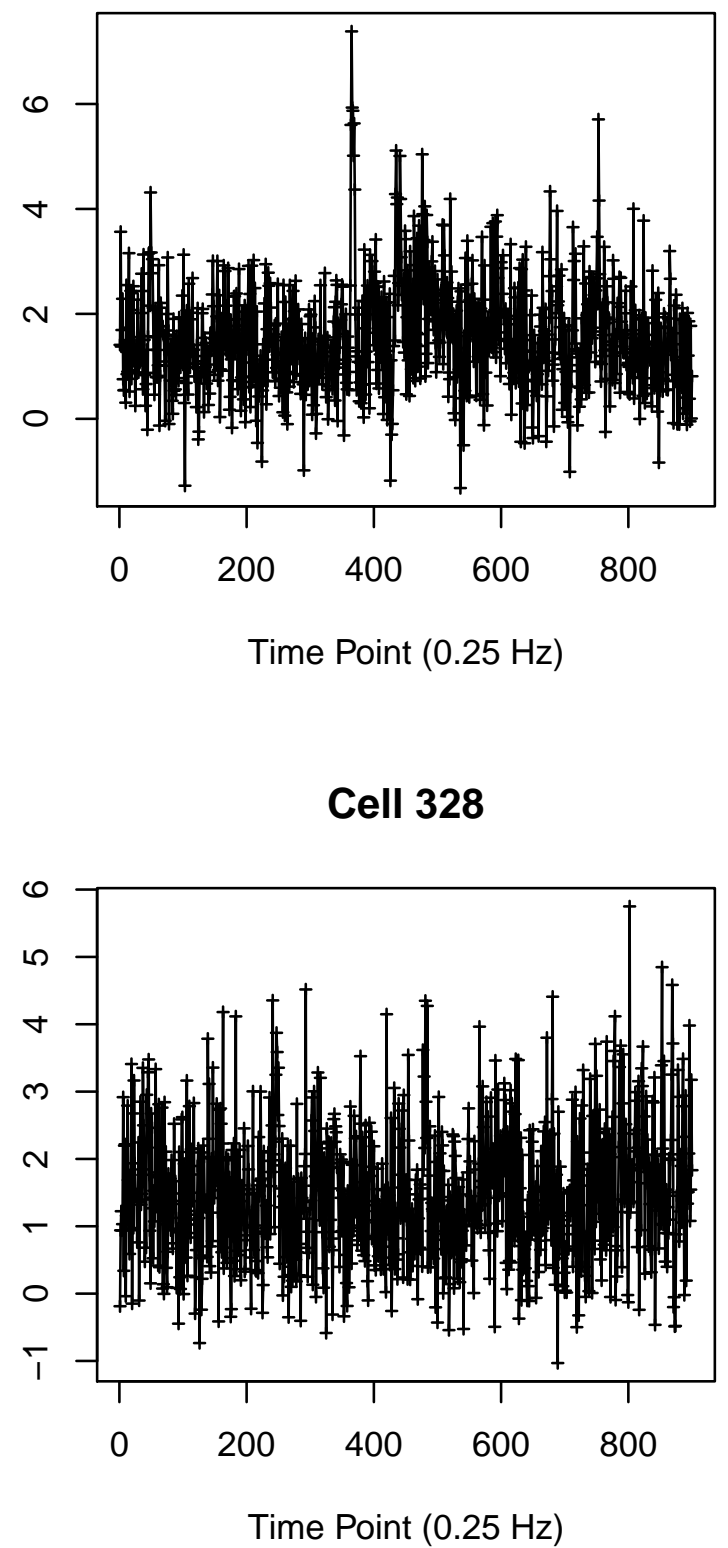


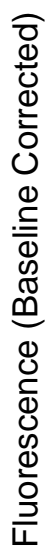

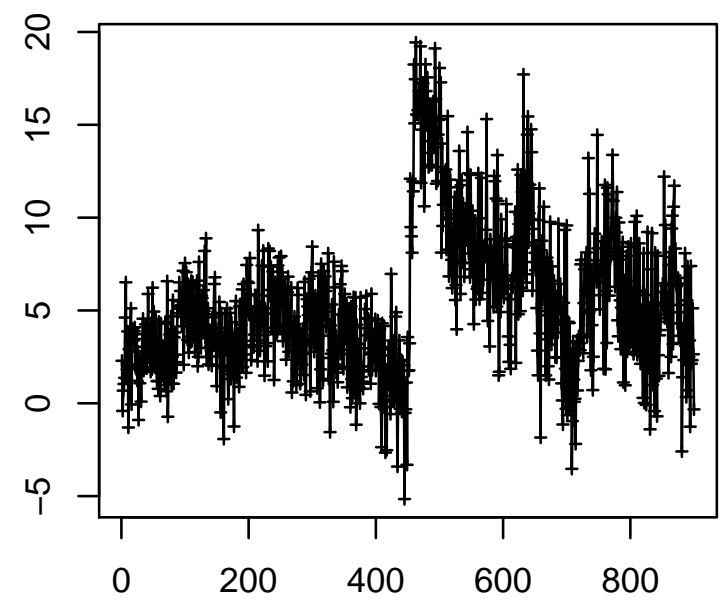

Time Point $(0.25 \mathrm{~Hz})$

Cell 335

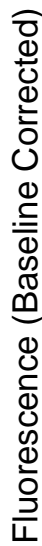

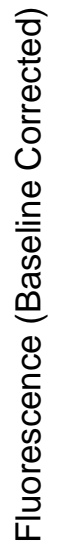

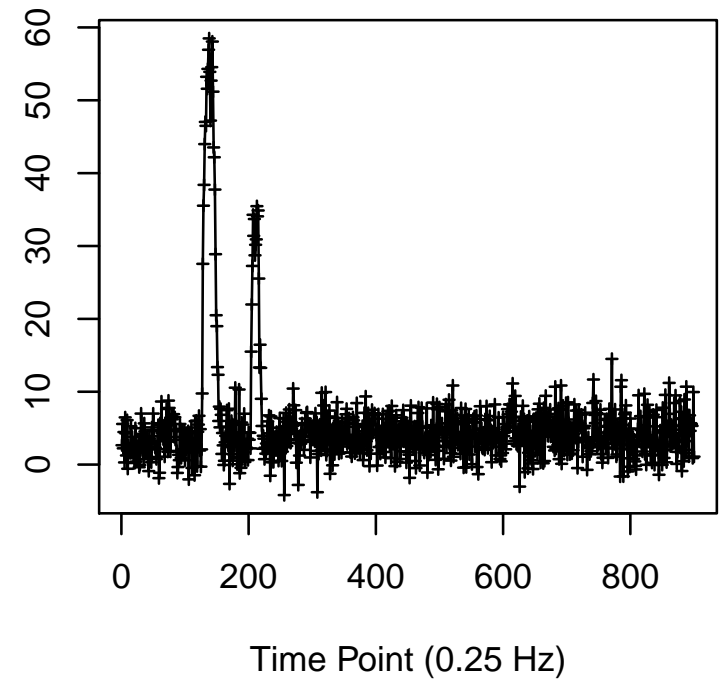

Cell 336

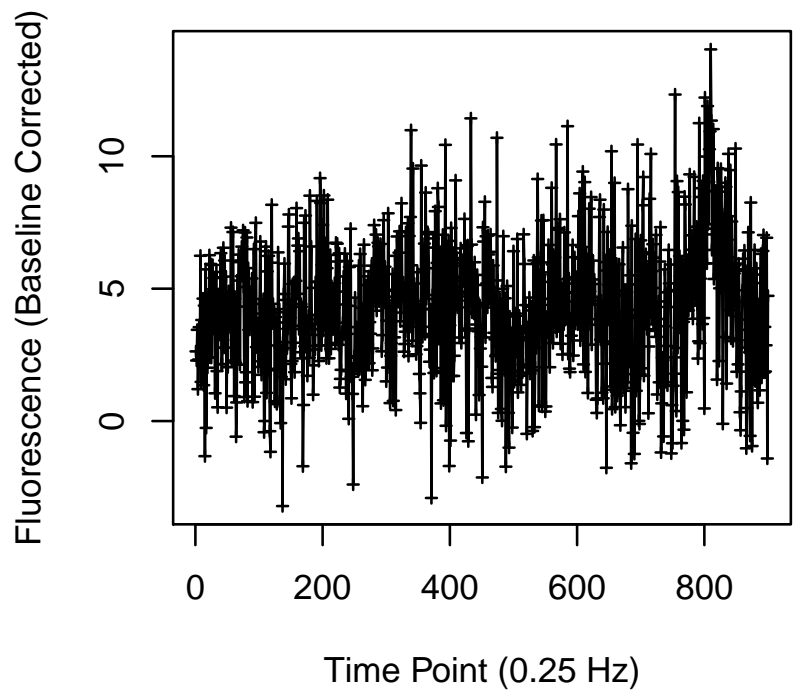


Cell 341

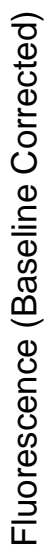

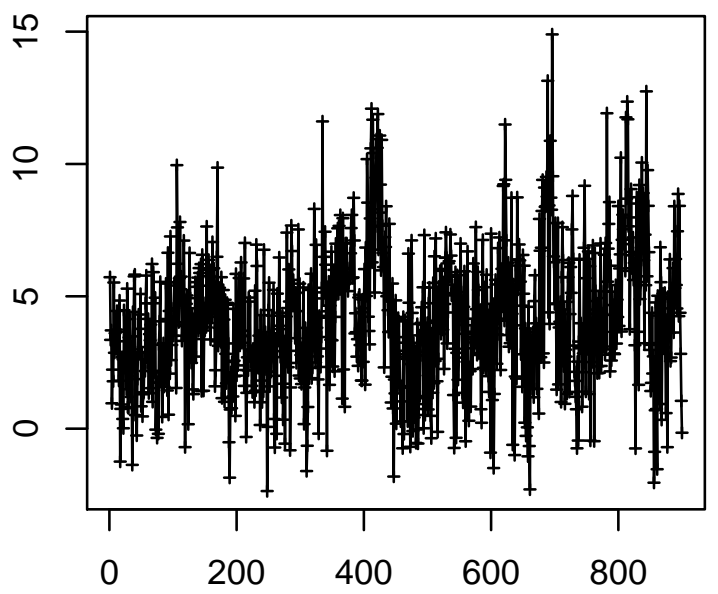

Time Point $(0.25 \mathrm{~Hz})$

Cell 343

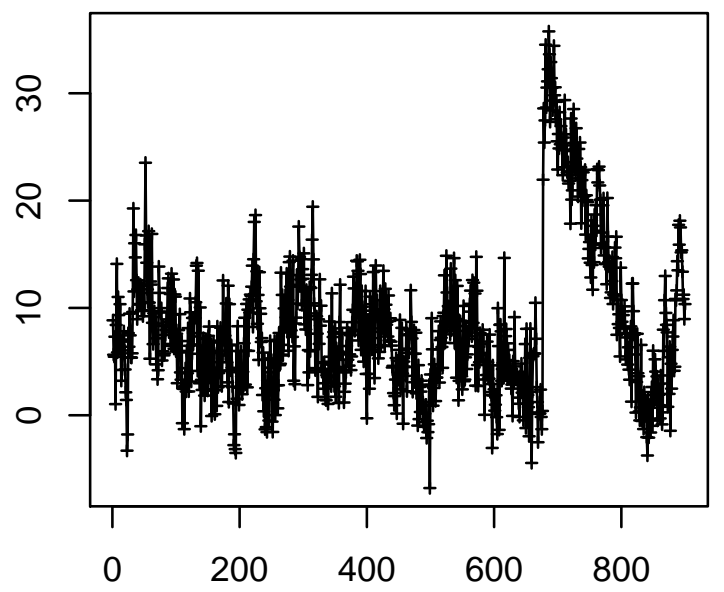

Time Point $(0.25 \mathrm{~Hz})$
Cell 342

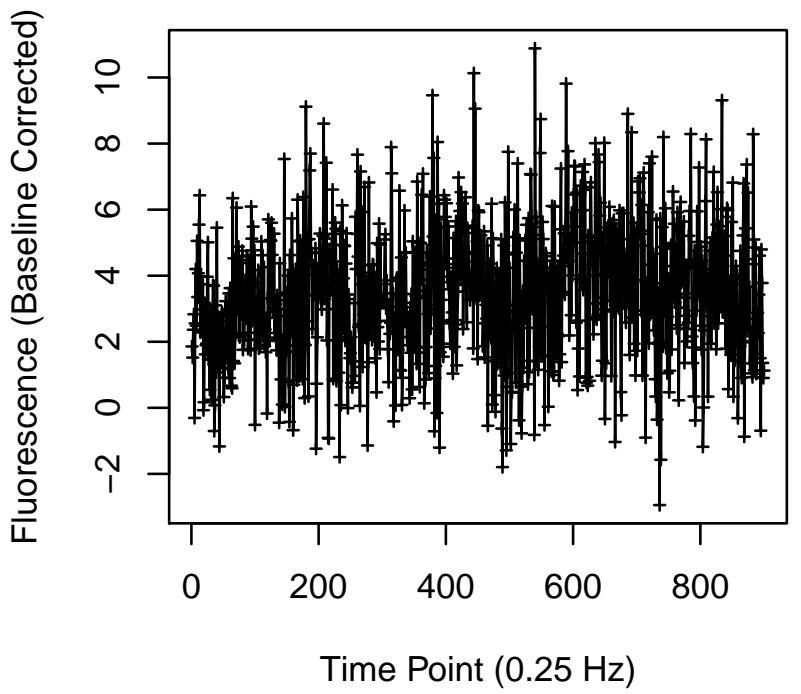

Cell 344

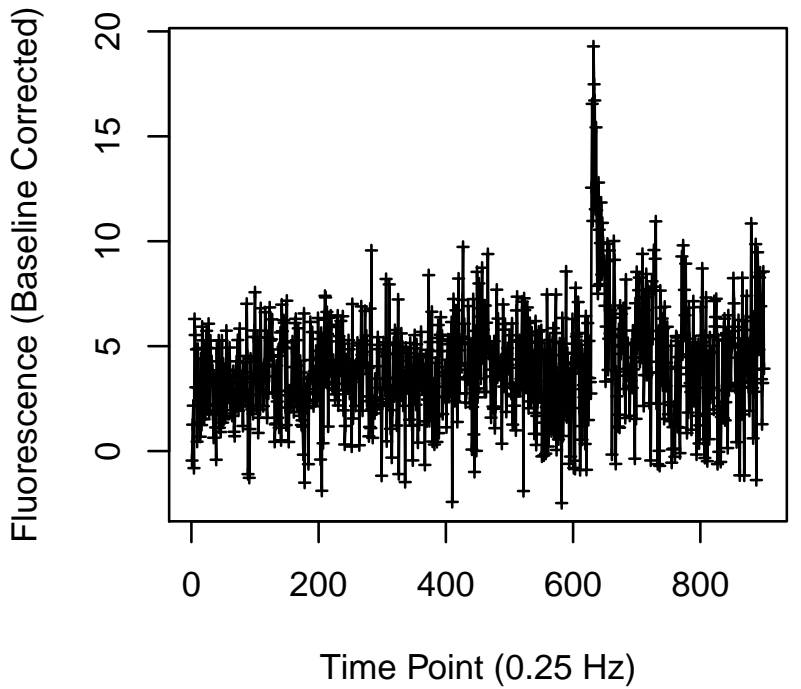




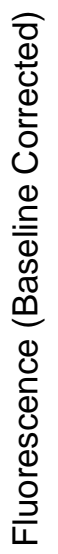

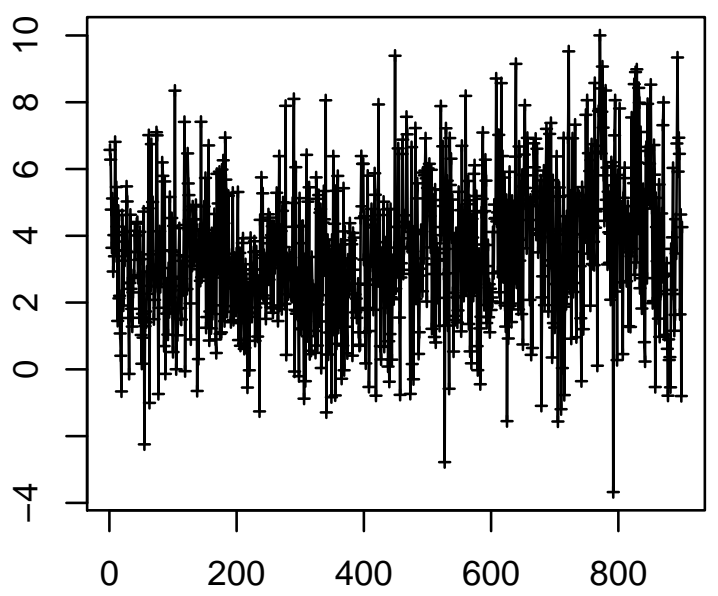

Time Point $(0.25 \mathrm{~Hz})$

Cell 359

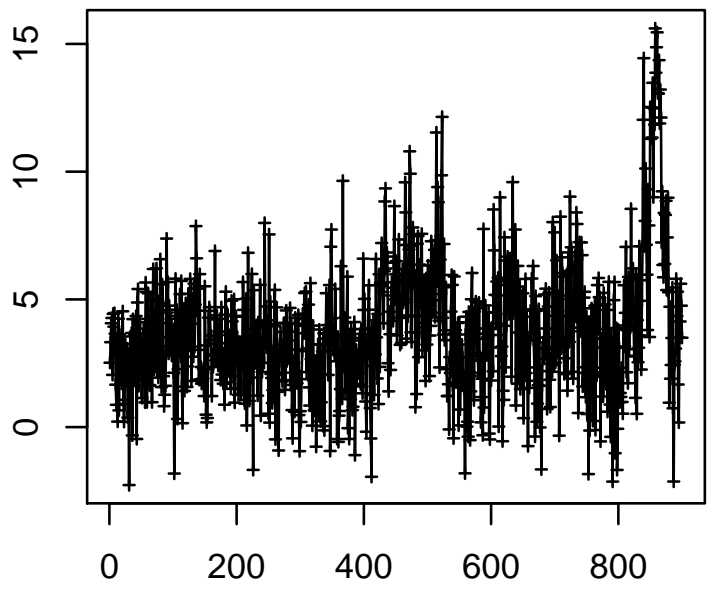

Time Point $(0.25 \mathrm{~Hz})$

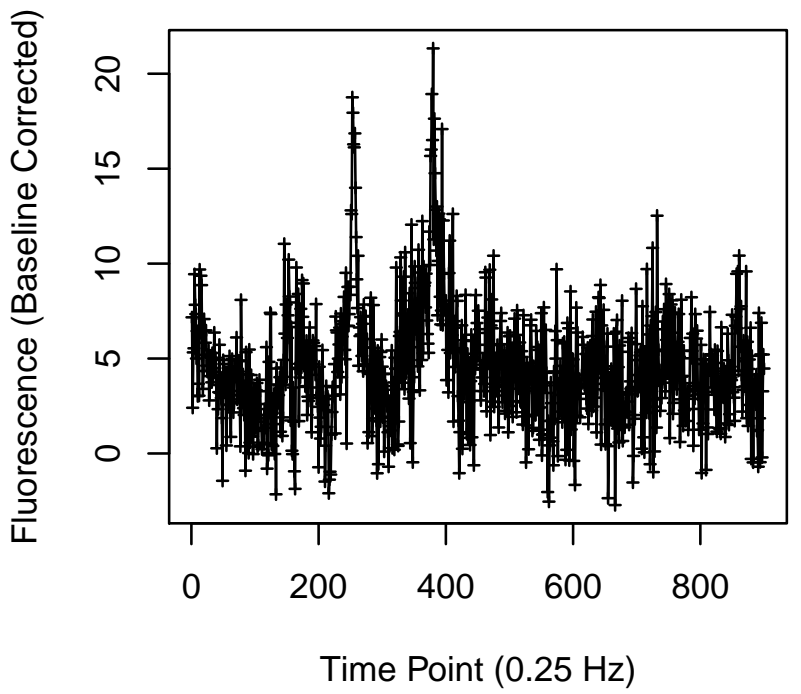

Cell 360

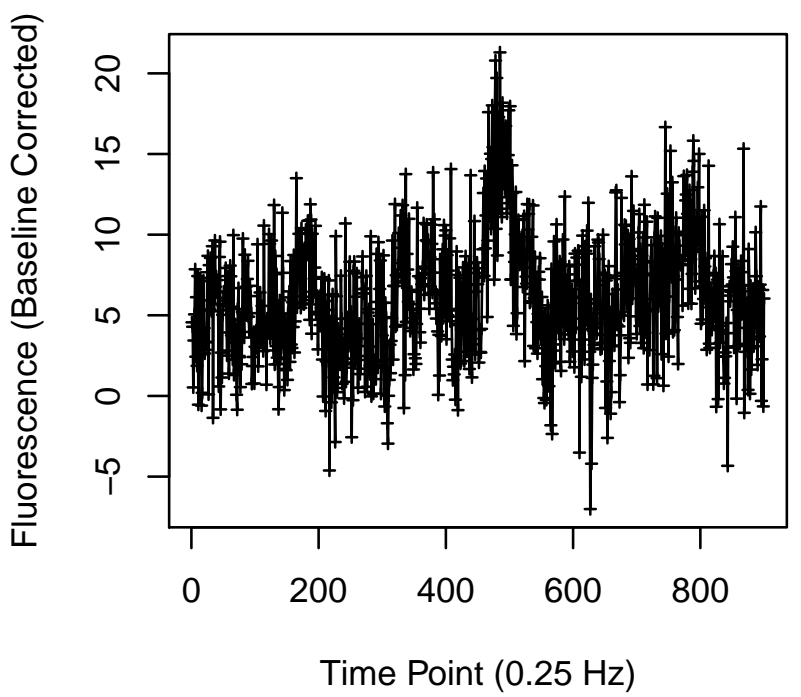




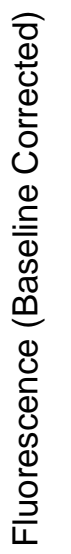

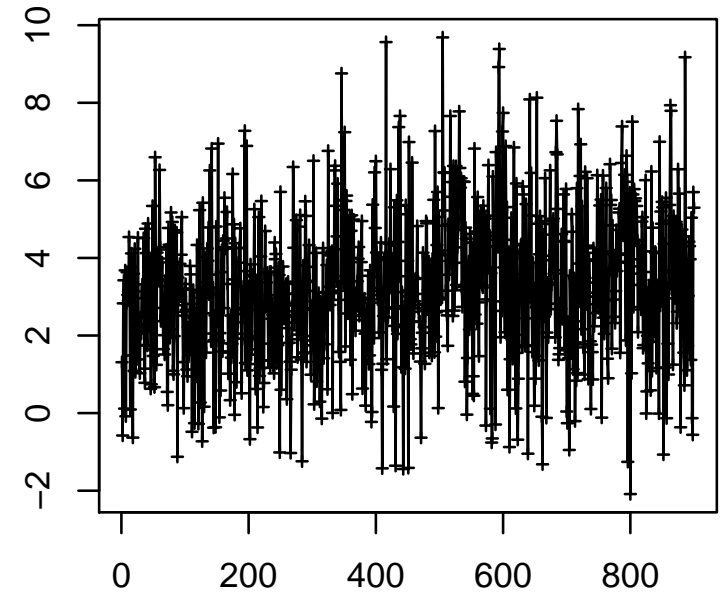

Time Point $(0.25 \mathrm{~Hz})$

Cell 367

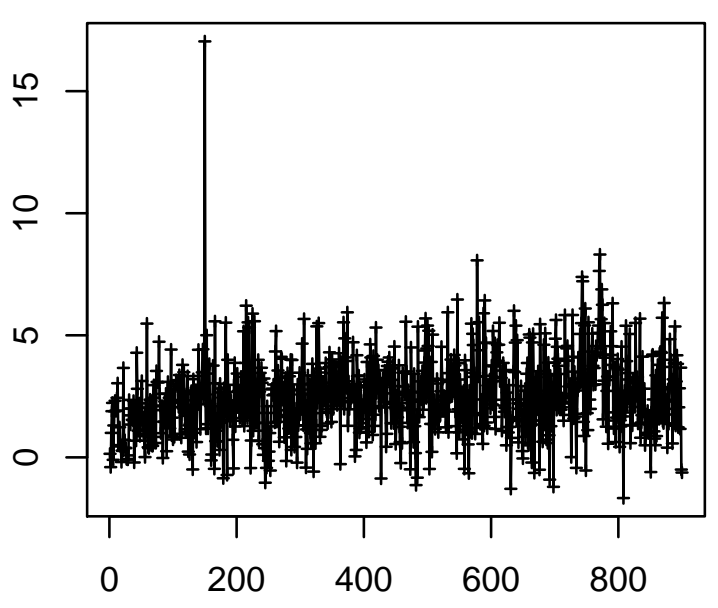

Time Point $(0.25 \mathrm{~Hz})$

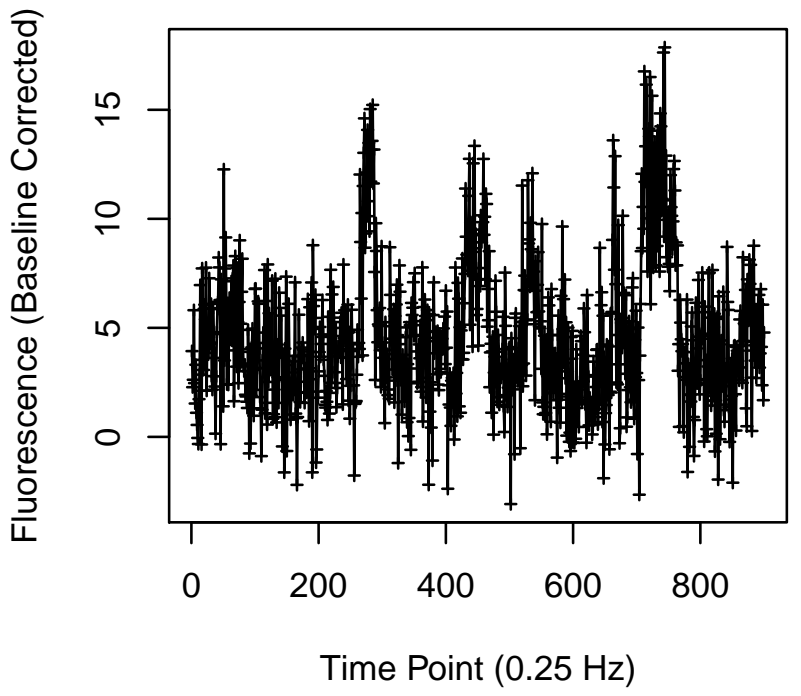

Cell 368

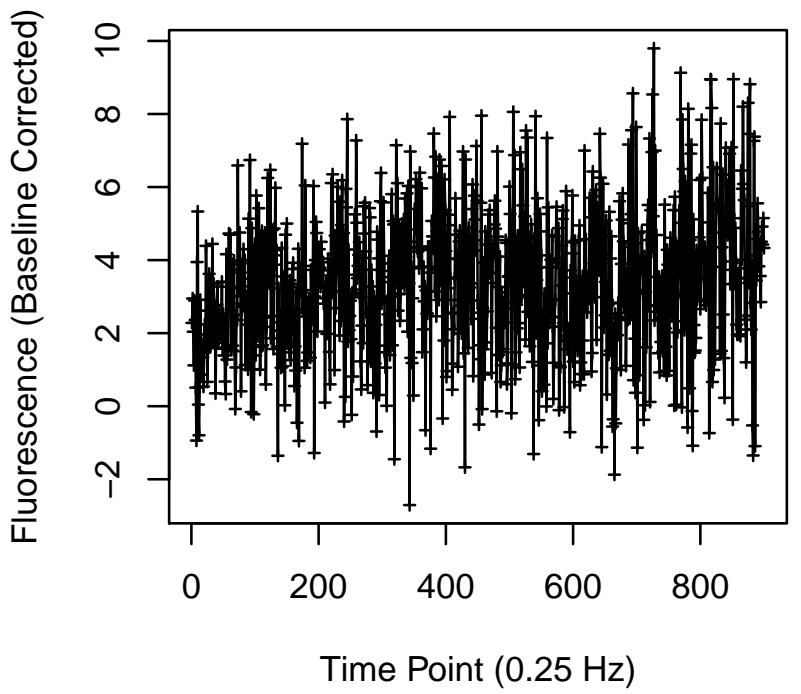


Cell 369

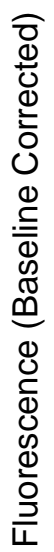

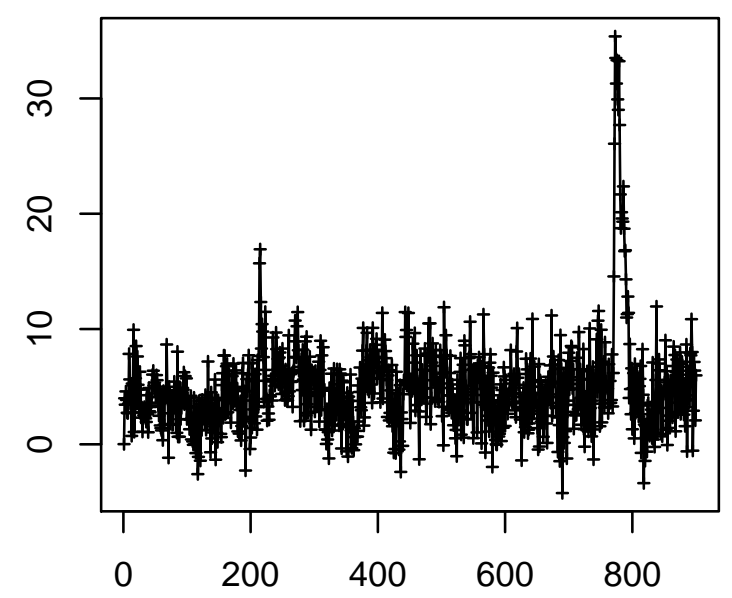

Time Point $(0.25 \mathrm{~Hz})$

Cell 371

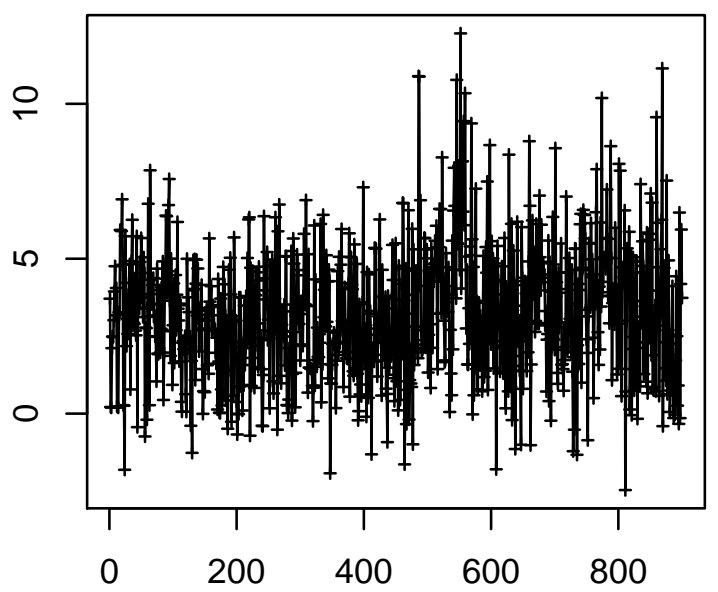

Time Point $(0.25 \mathrm{~Hz})$
Cell 370

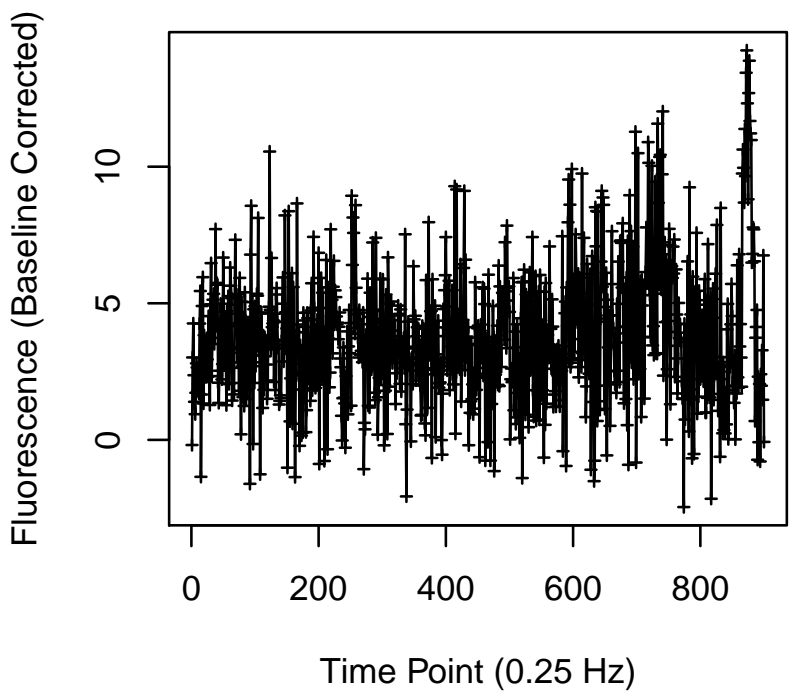

Cell 372

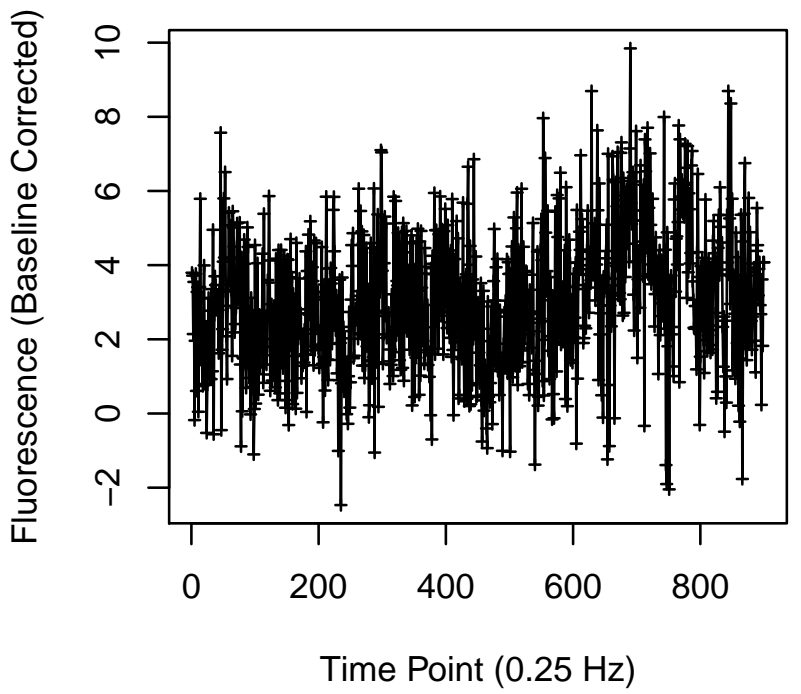


Cell 377

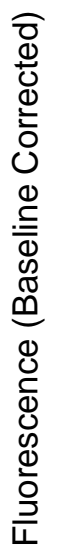

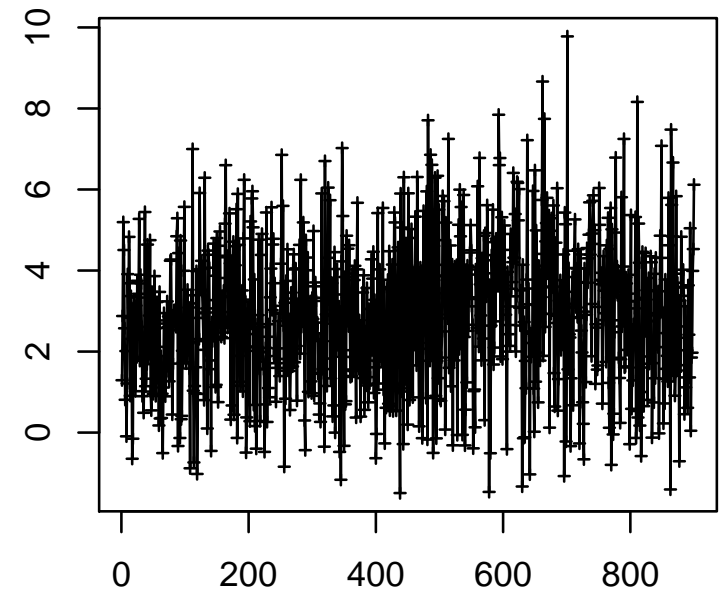

Time Point $(0.25 \mathrm{~Hz})$

\section{Cell 379}

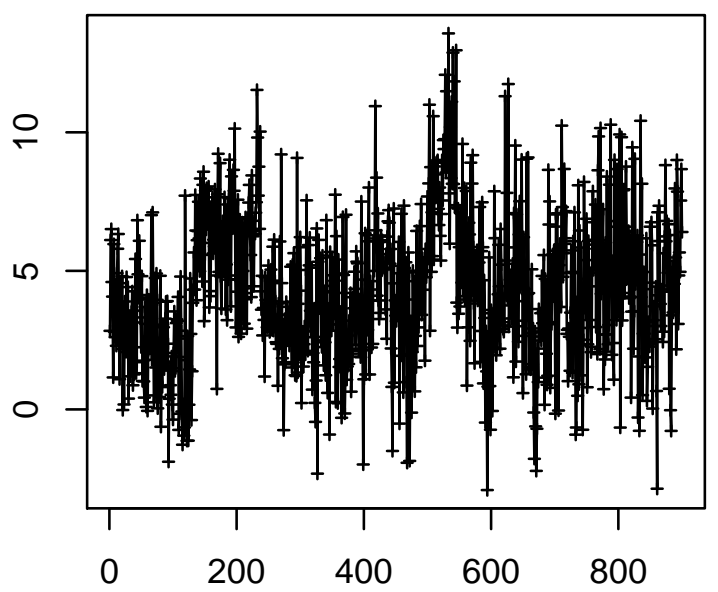

Time Point $(0.25 \mathrm{~Hz})$
Cell 378

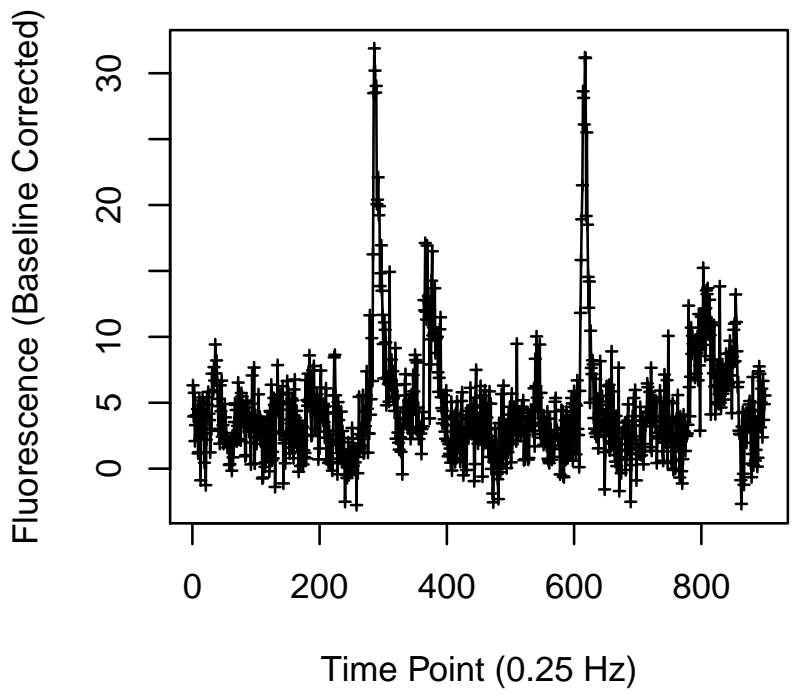

Cell 380

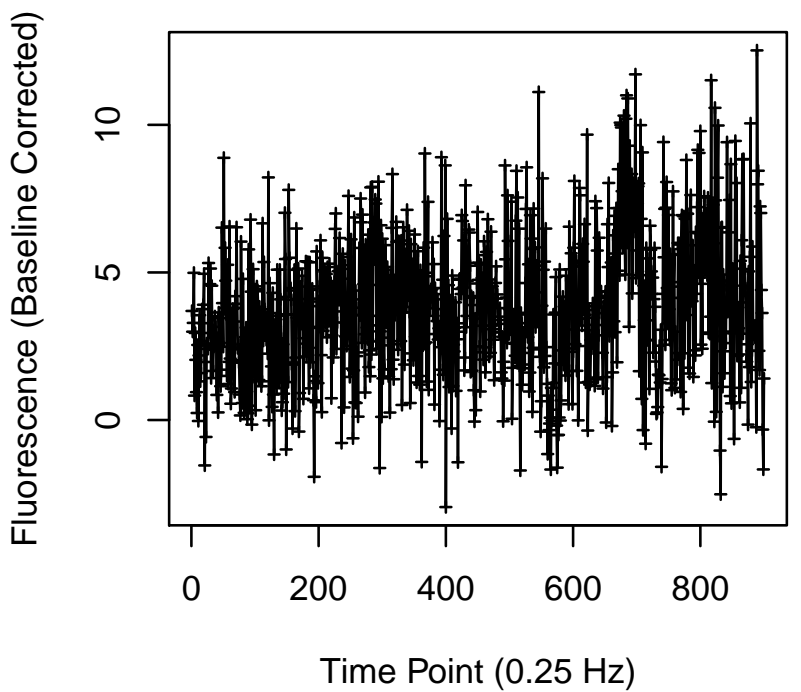


Cell 393

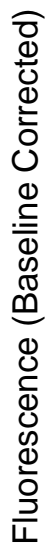

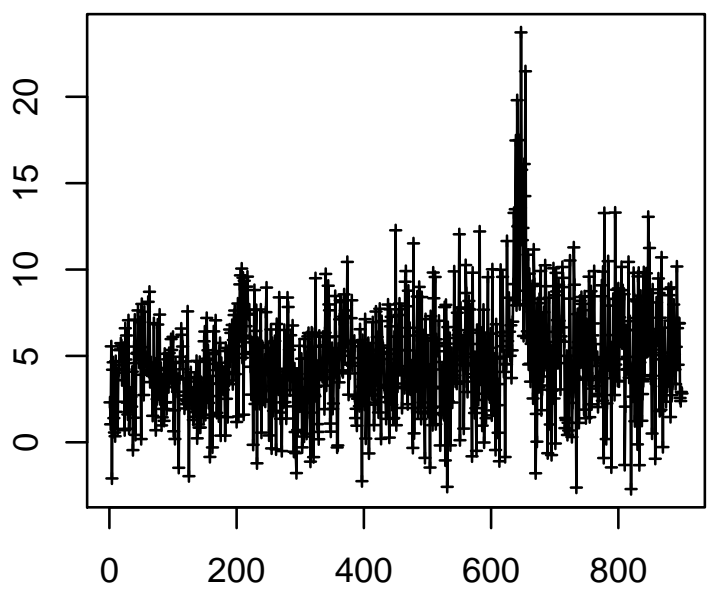

Time Point $(0.25 \mathrm{~Hz})$

\section{Cell 395}

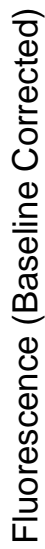

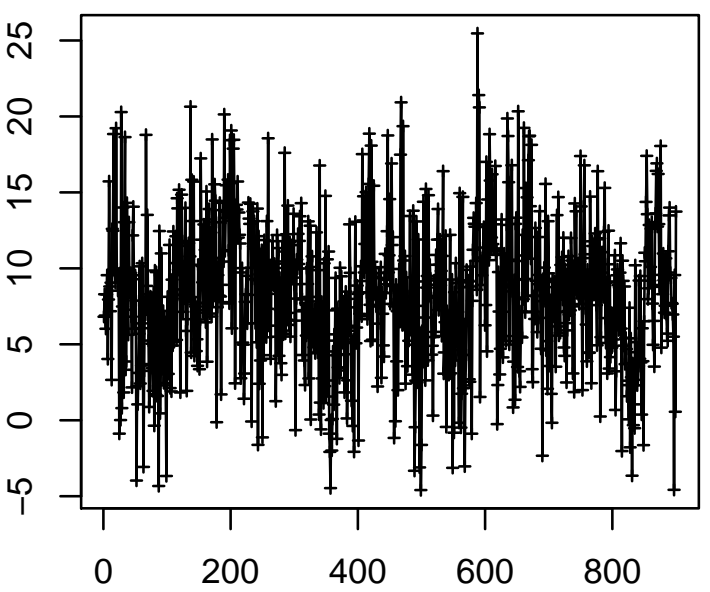

Time Point $(0.25 \mathrm{~Hz})$

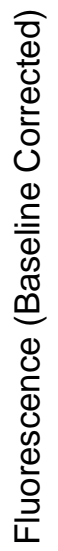

Cell 394

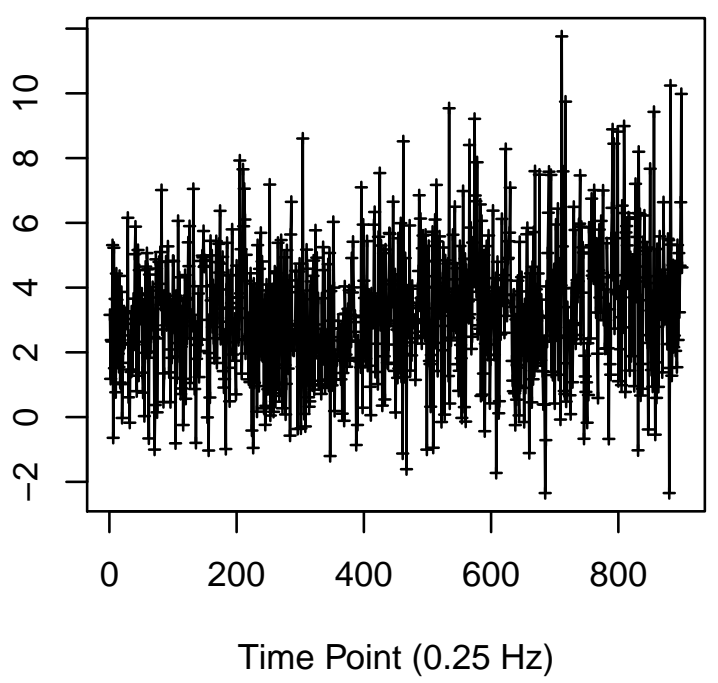

Cell 396

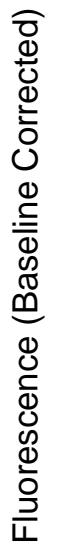

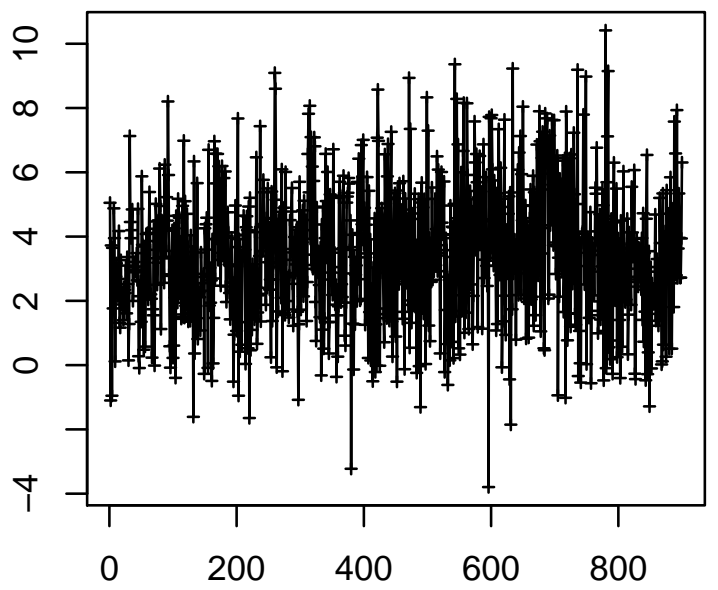

Time Point $(0.25 \mathrm{~Hz})$ 
Cell 413

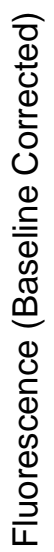

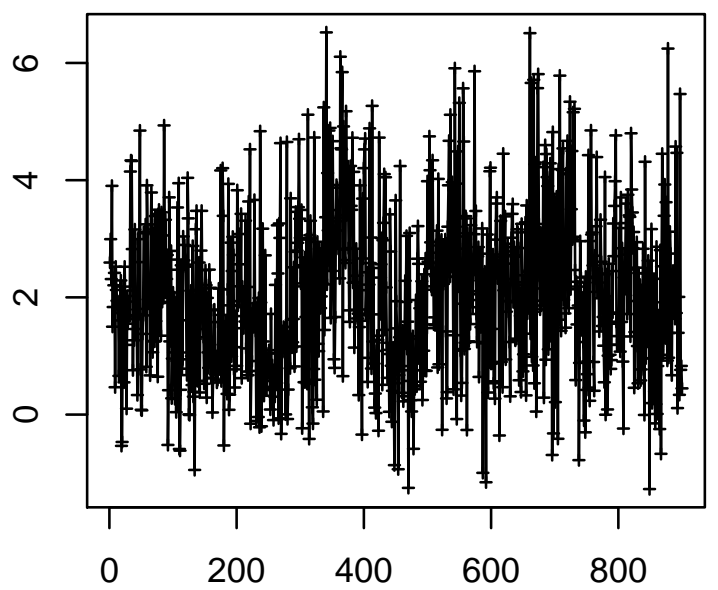

Time Point $(0.25 \mathrm{~Hz})$

\section{Cell 415}

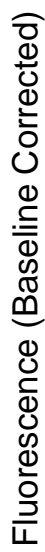

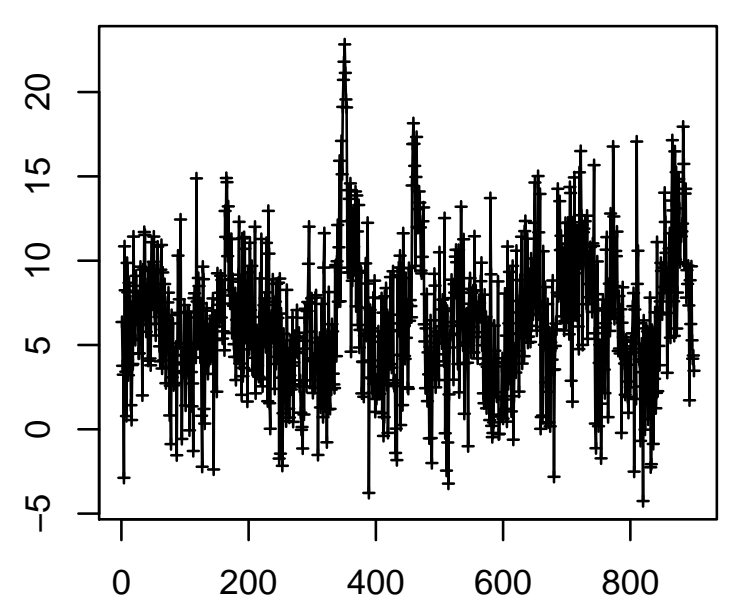

Time Point $(0.25 \mathrm{~Hz})$
Cell 414

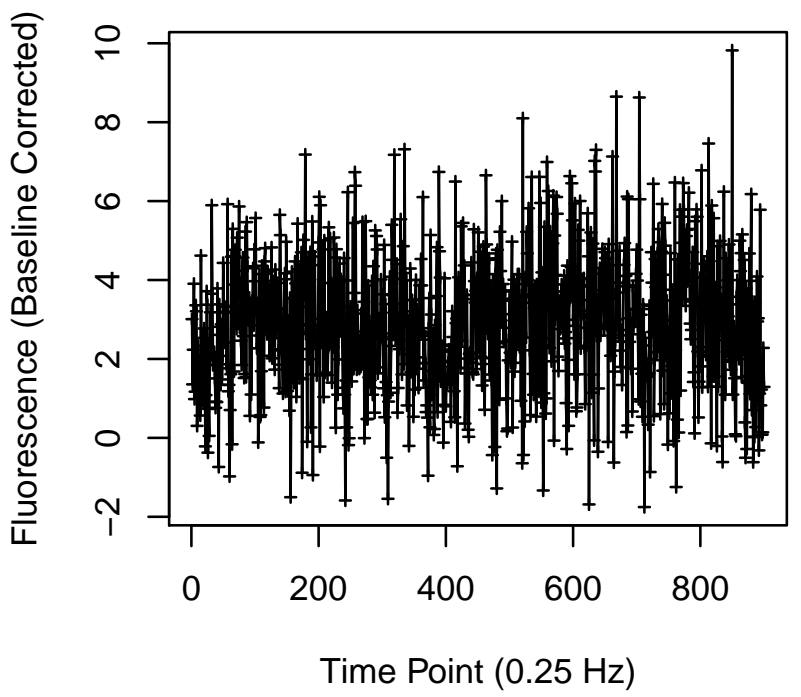

Cell 416

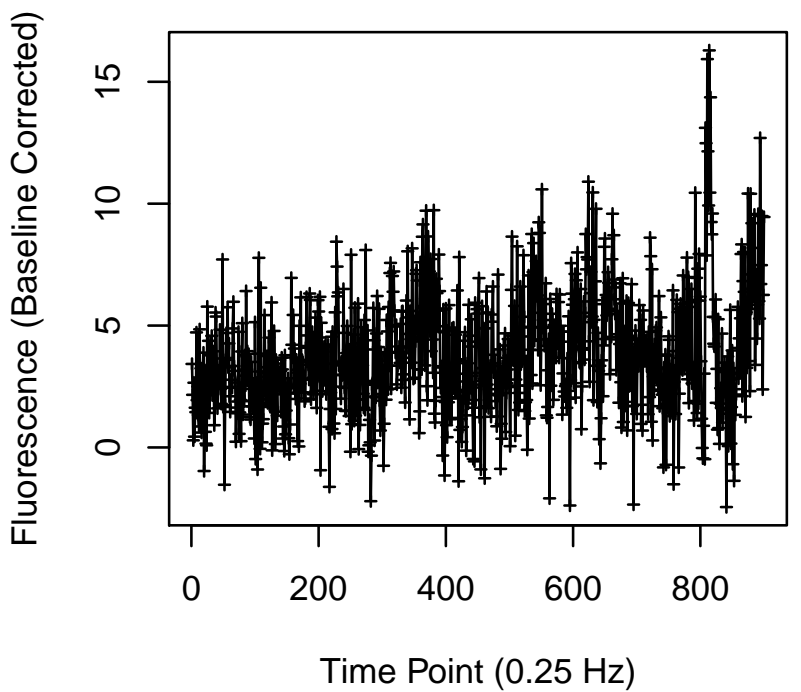


Cell 421

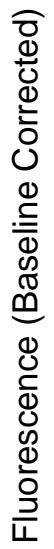

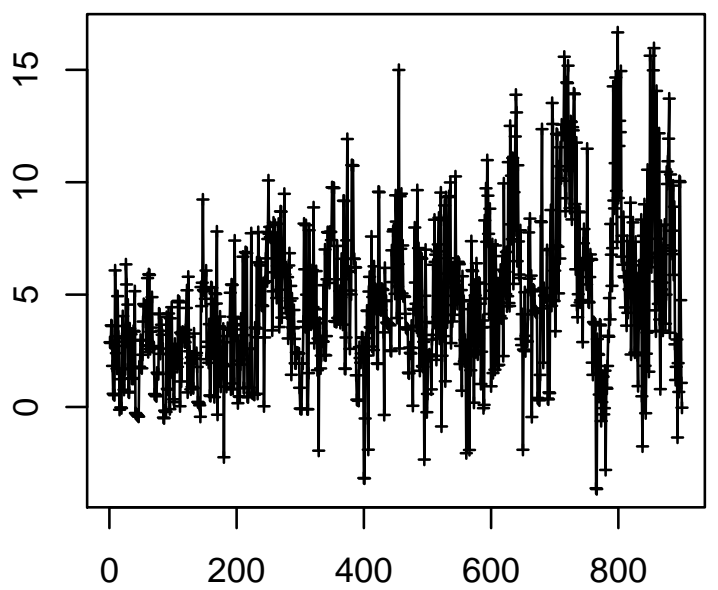

Time Point $(0.25 \mathrm{~Hz})$

Cell 423

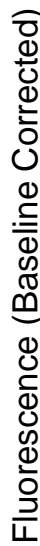

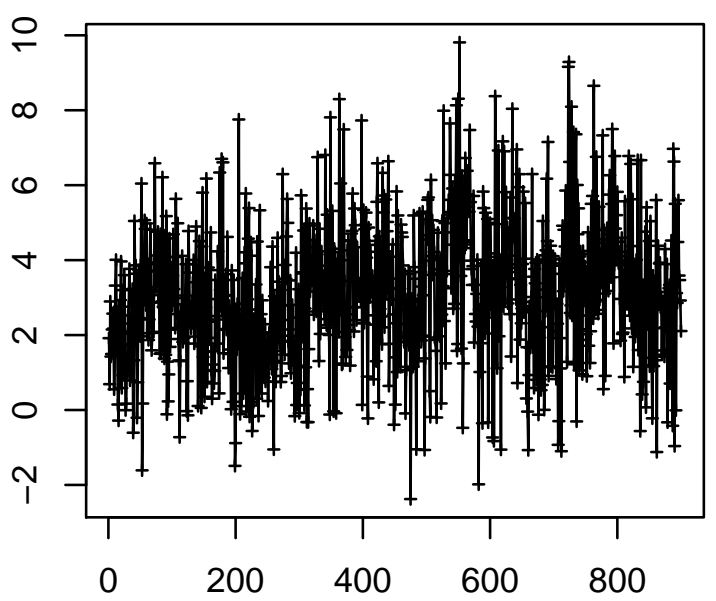

Time Point $(0.25 \mathrm{~Hz})$

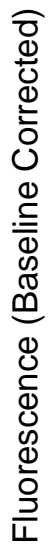

Cell 424

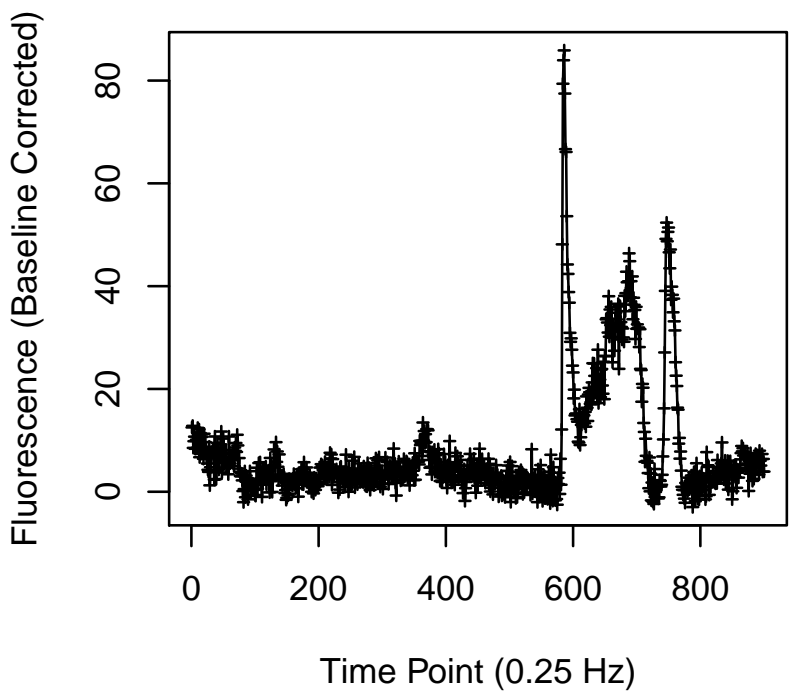


Cell 429

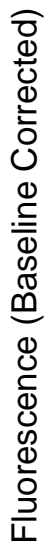

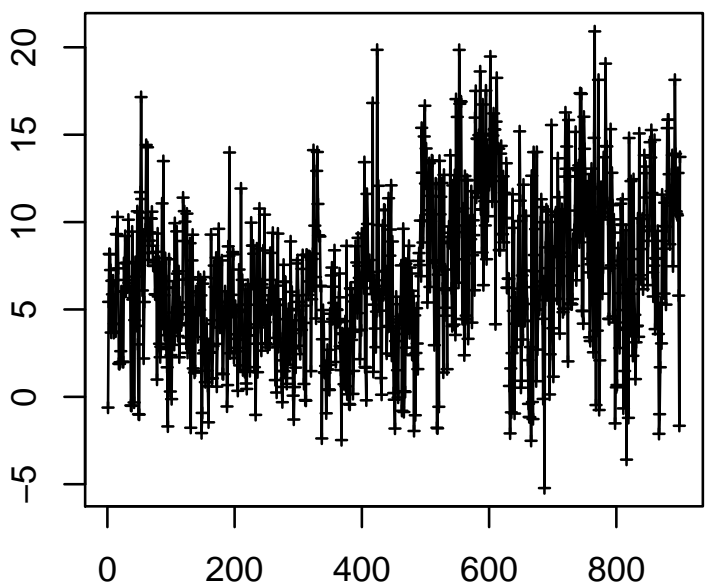

Time Point $(0.25 \mathrm{~Hz})$

Cell 431

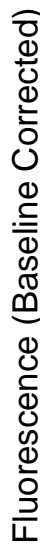

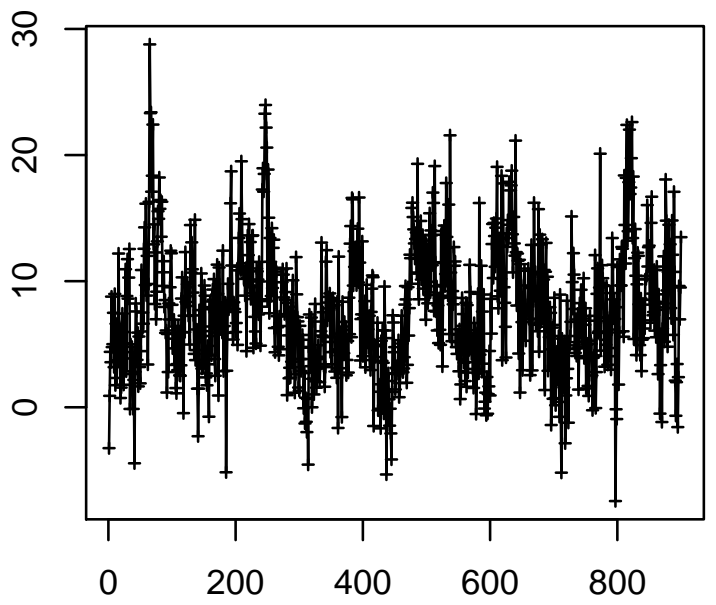

Time Point $(0.25 \mathrm{~Hz})$

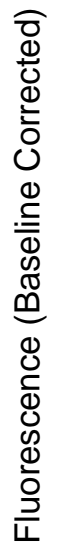

Cell 432

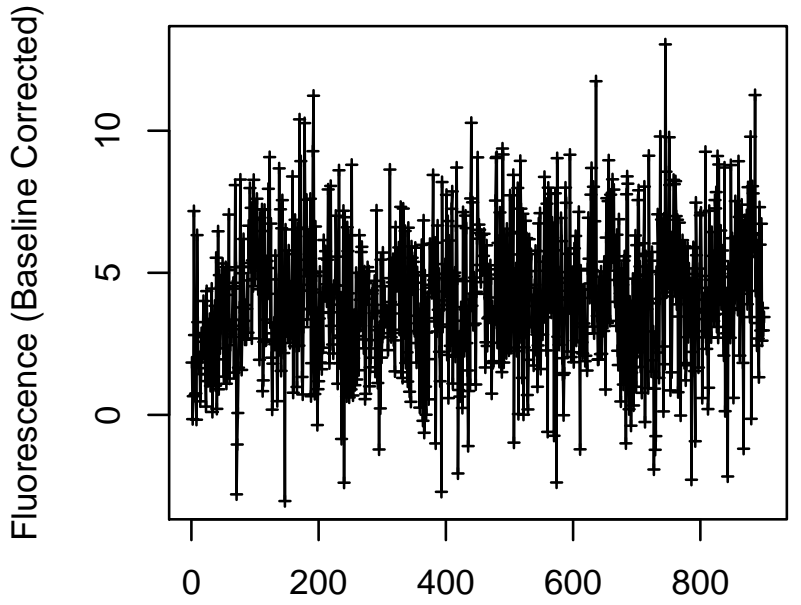

Time Point $(0.25 \mathrm{~Hz})$ 


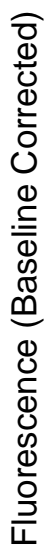

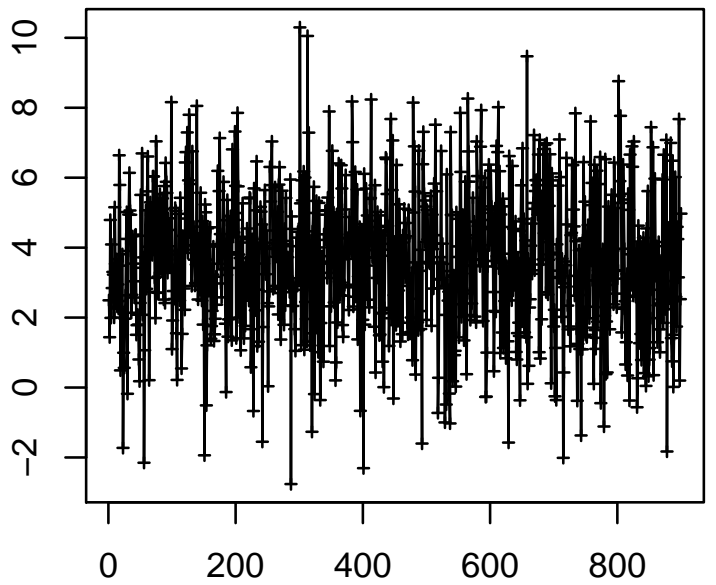

Time Point $(0.25 \mathrm{~Hz})$

\section{Cell 435}

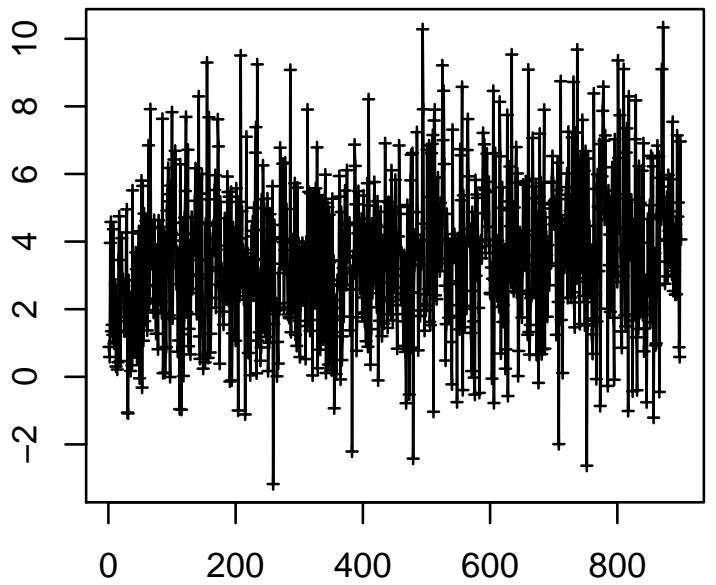

Time Point $(0.25 \mathrm{~Hz})$

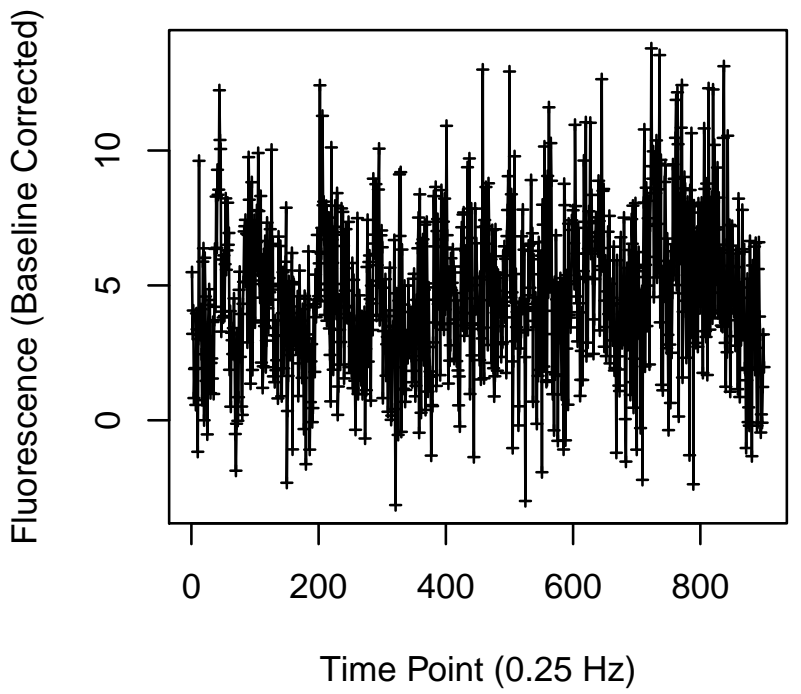

Cell 436

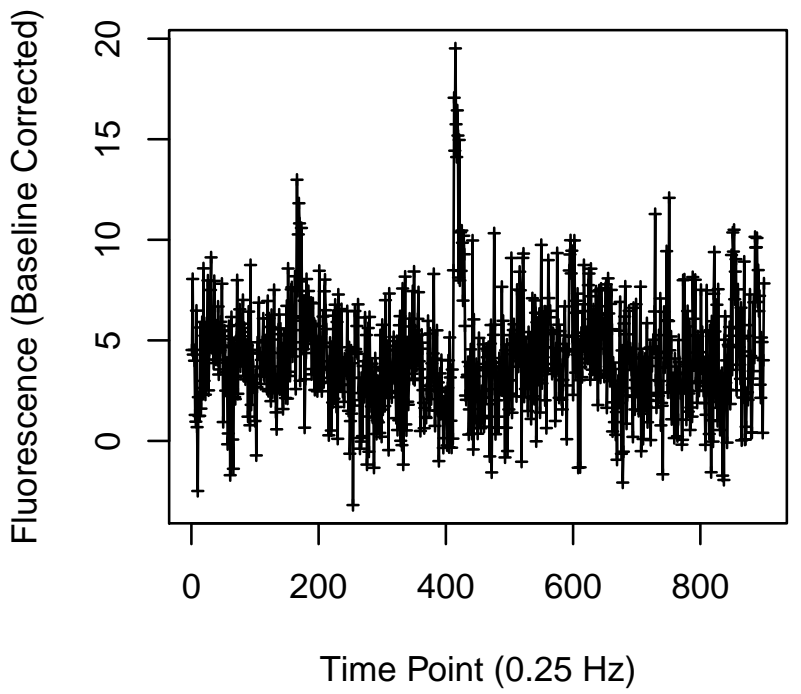


Cell 441

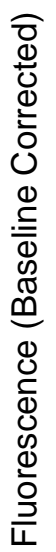

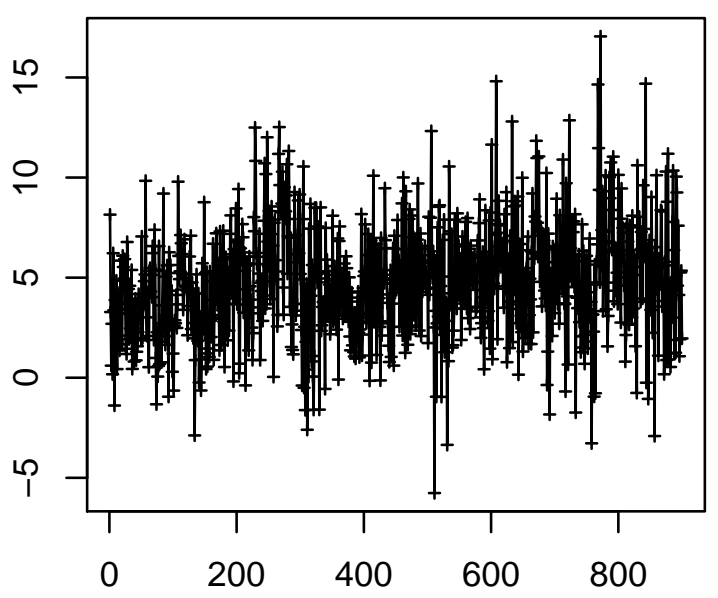

Time Point $(0.25 \mathrm{~Hz})$

Cell 443

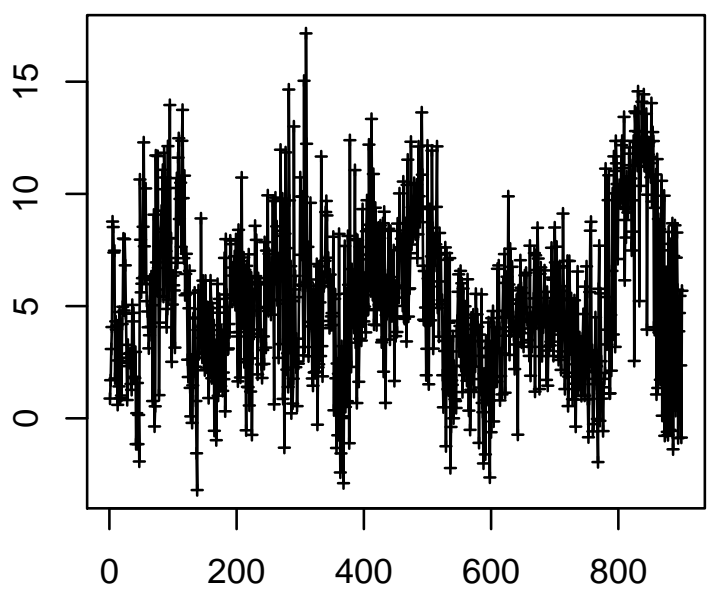

Time Point $(0.25 \mathrm{~Hz})$
Cell 442

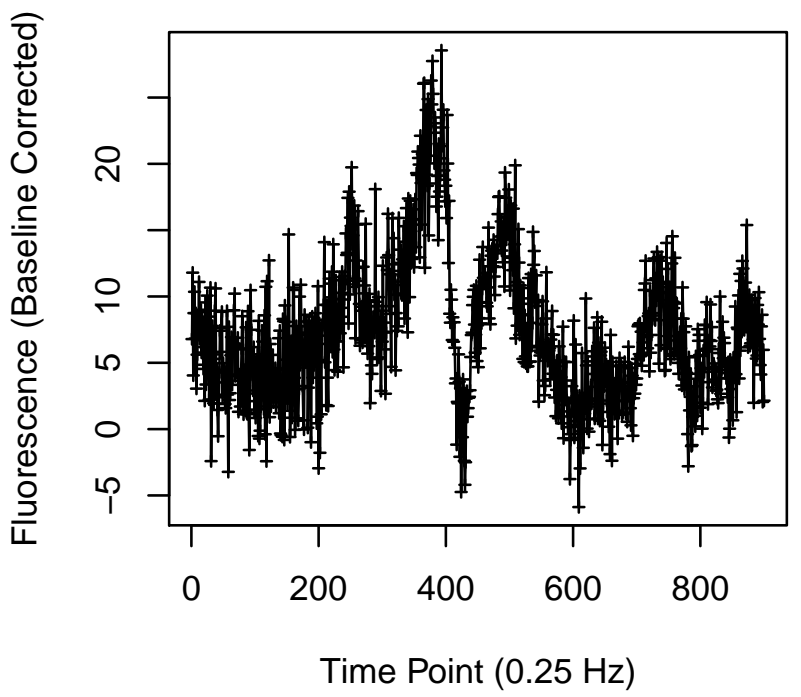

Cell 444

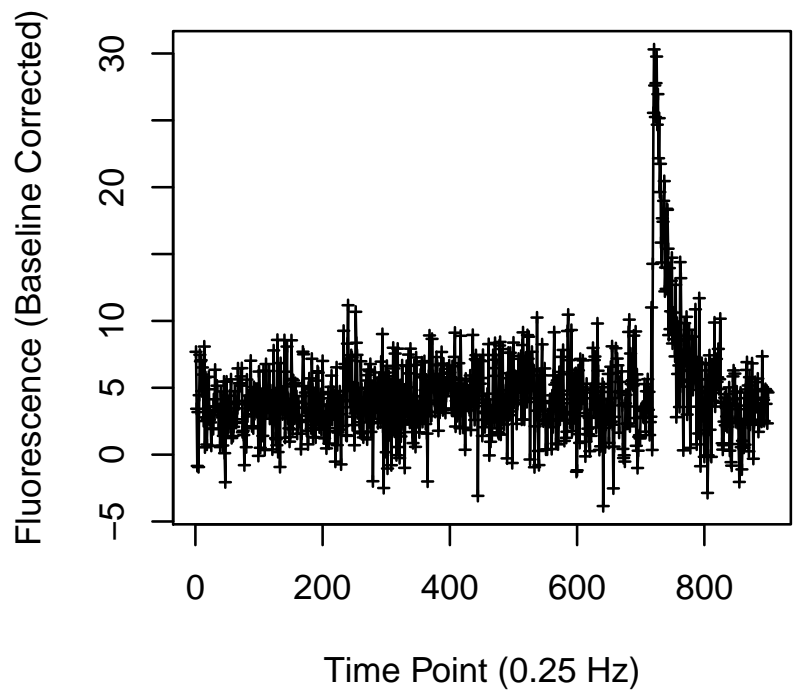


Cell 449

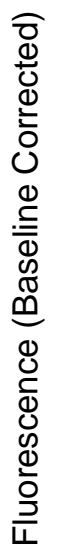

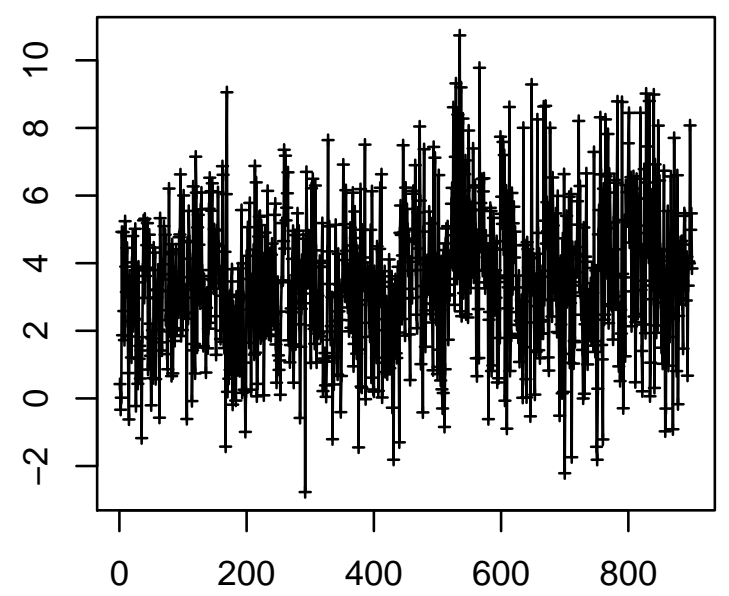

Time Point $(0.25 \mathrm{~Hz})$

Cell 451

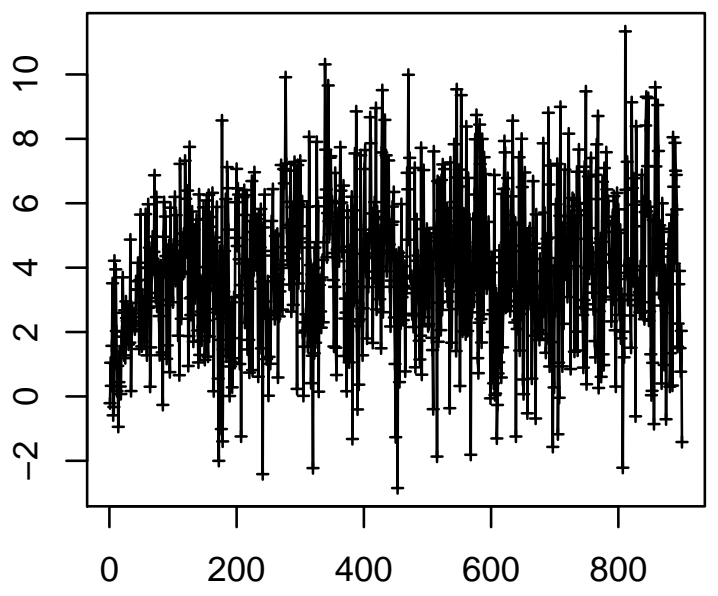

Time Point $(0.25 \mathrm{~Hz})$
Cell 450

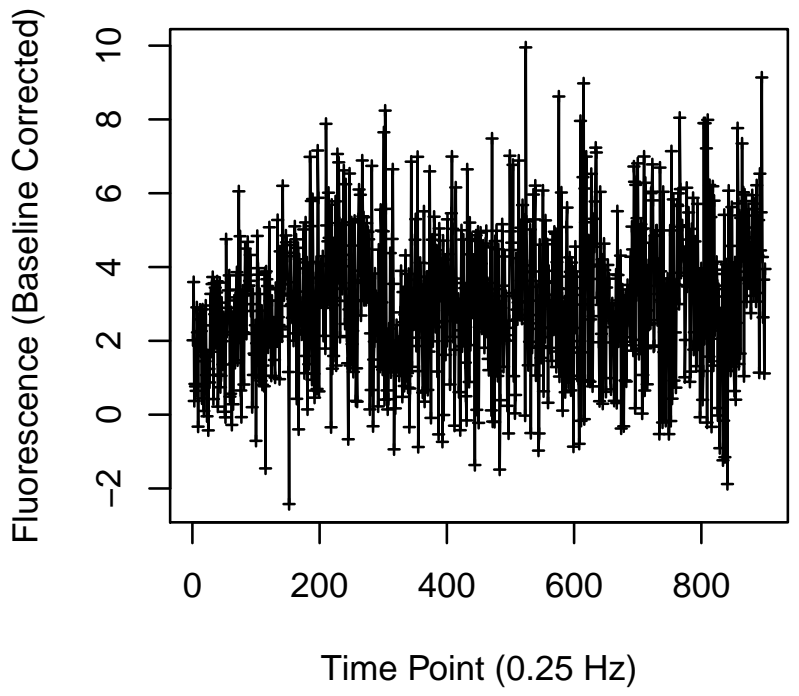

Cell 452

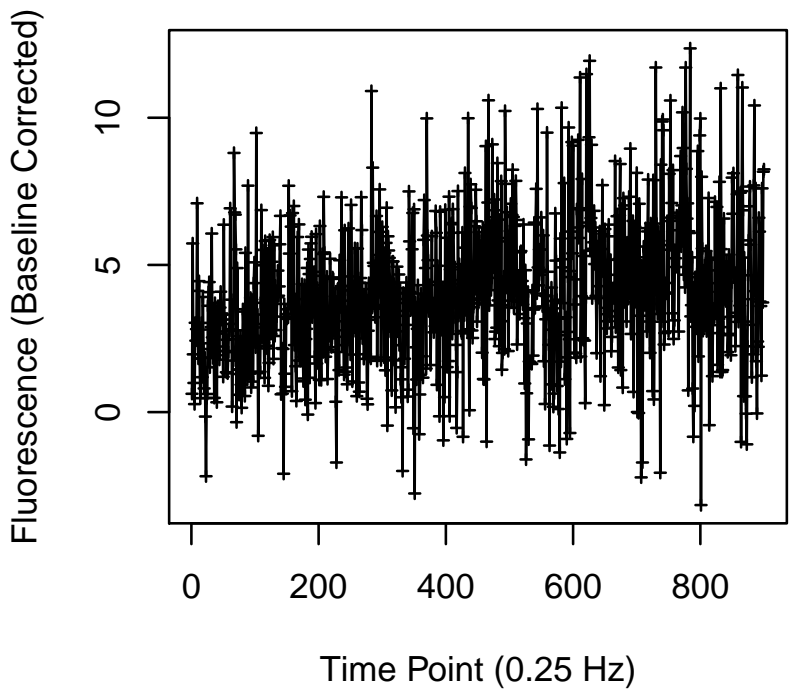




\section{Cell 457}

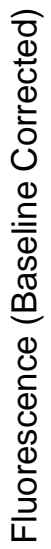

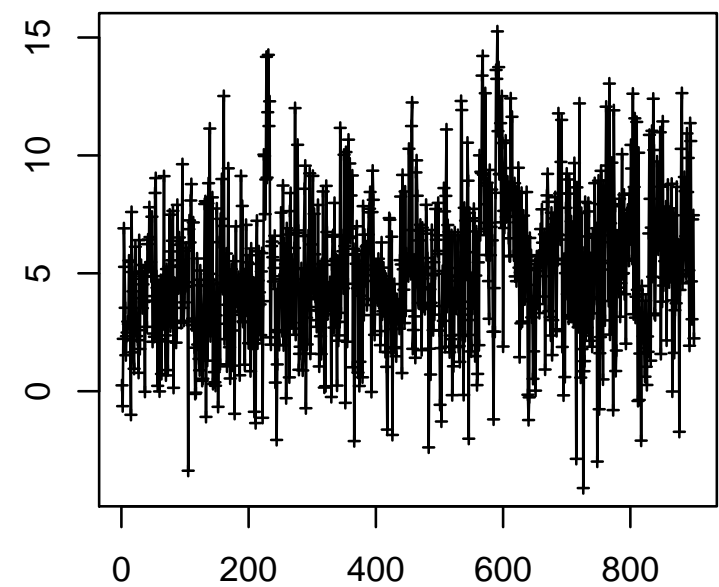

Time Point $(0.25 \mathrm{~Hz})$

Cell 459

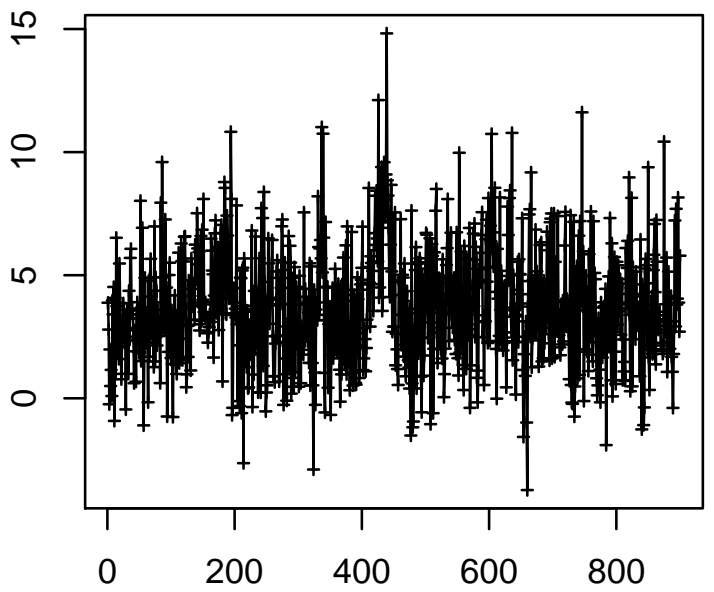

Time Point $(0.25 \mathrm{~Hz})$
Cell 458

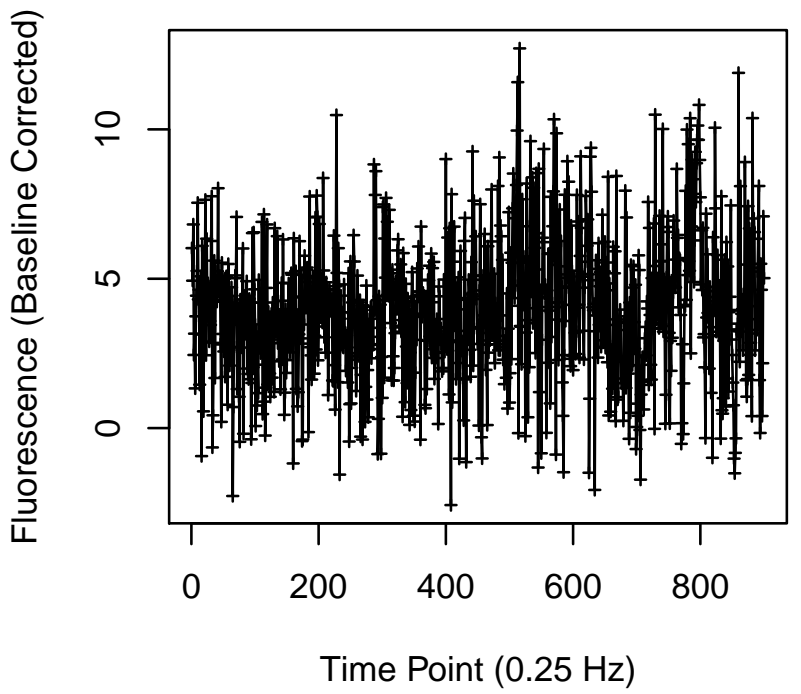

Cell 460

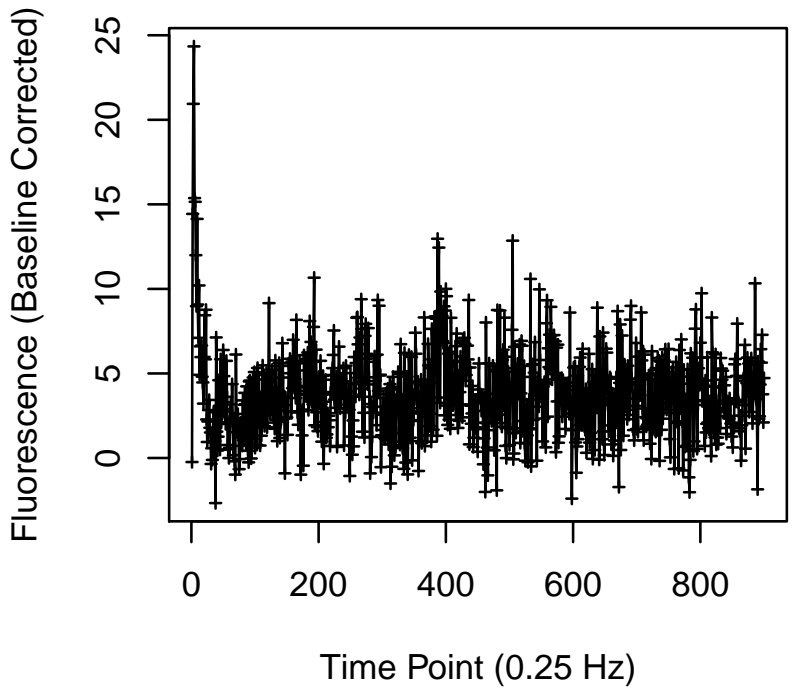




\section{Cell 465}

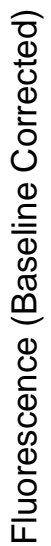

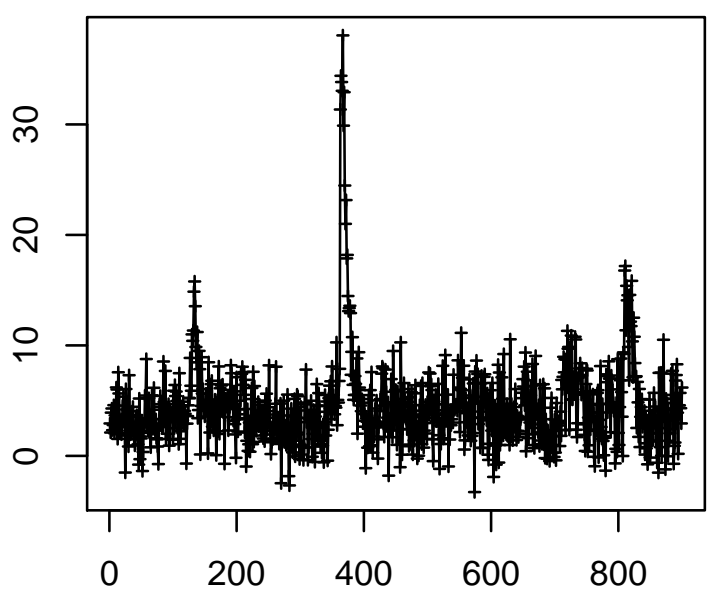

Time Point $(0.25 \mathrm{~Hz})$

Cell 467

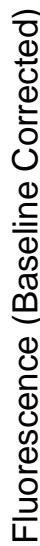

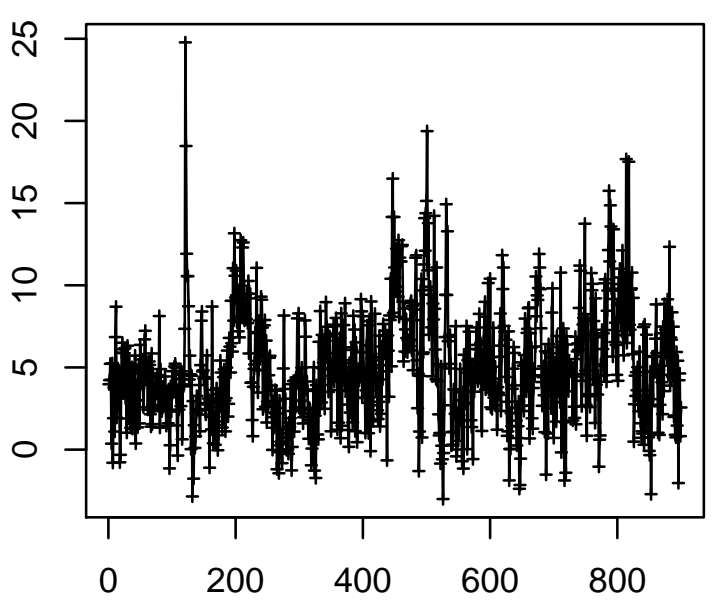

Time Point $(0.25 \mathrm{~Hz})$

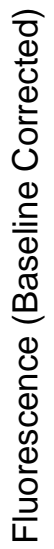

Cell 468

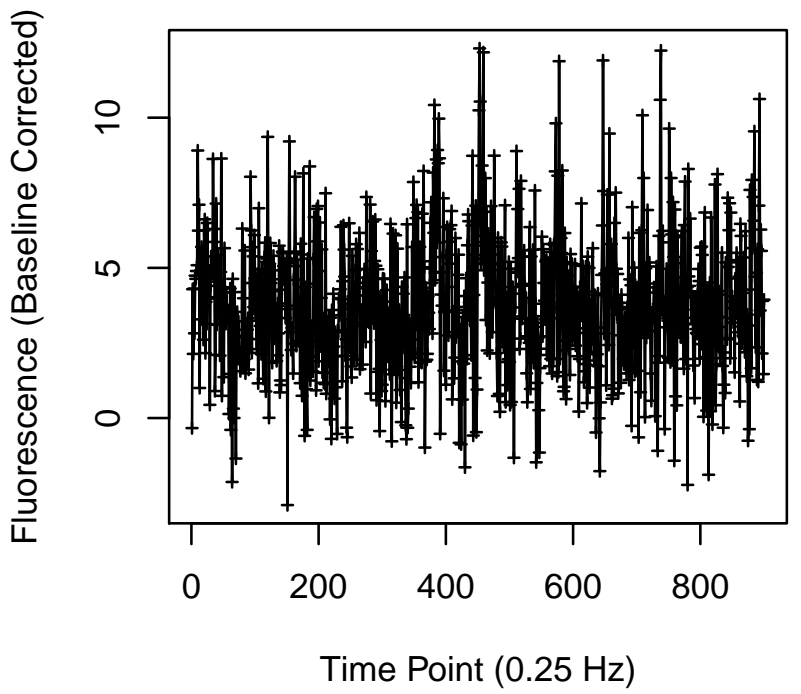


Cell 469

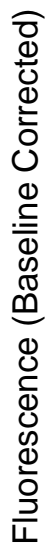

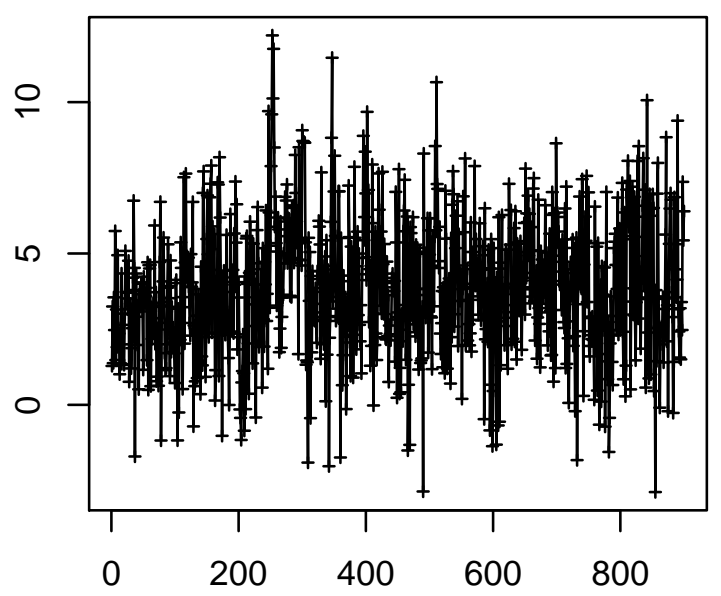

Time Point $(0.25 \mathrm{~Hz})$

Cell 471

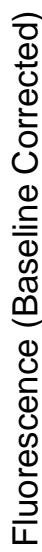

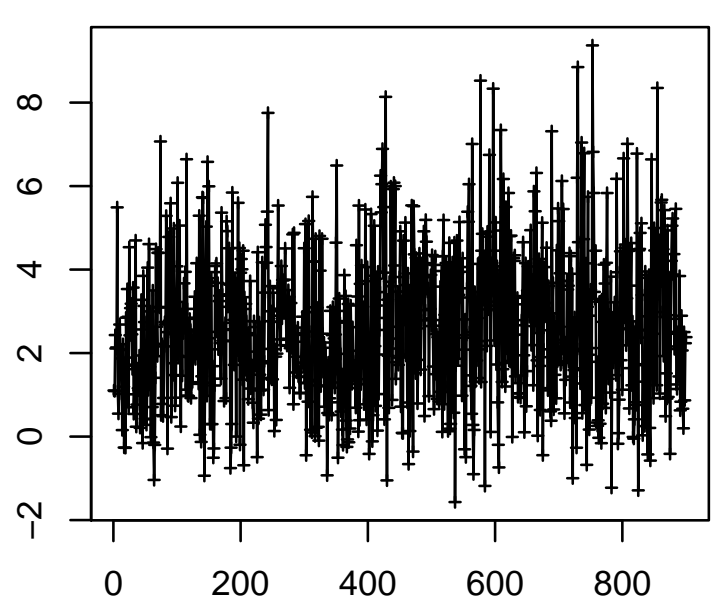

Time Point $(0.25 \mathrm{~Hz})$

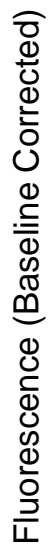

Cell 472

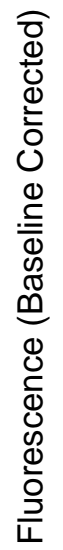

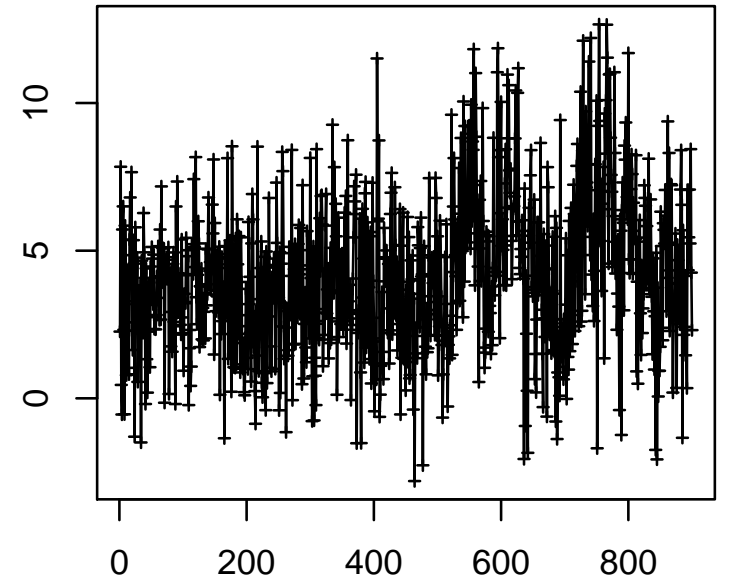

Time Point $(0.25 \mathrm{~Hz})$ 
Cell 481

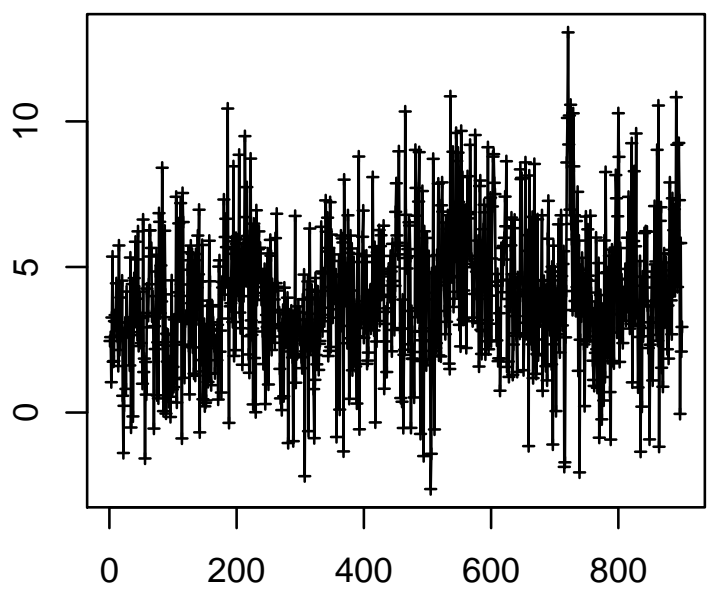

Time Point $(0.25 \mathrm{~Hz})$

\section{Cell 483}

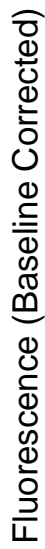

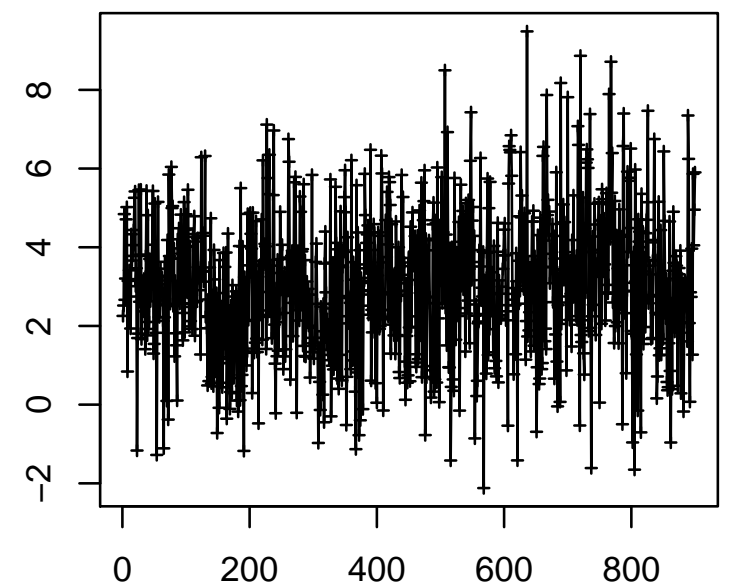

Time Point $(0.25 \mathrm{~Hz})$

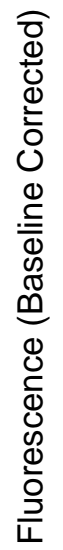

Cell 482

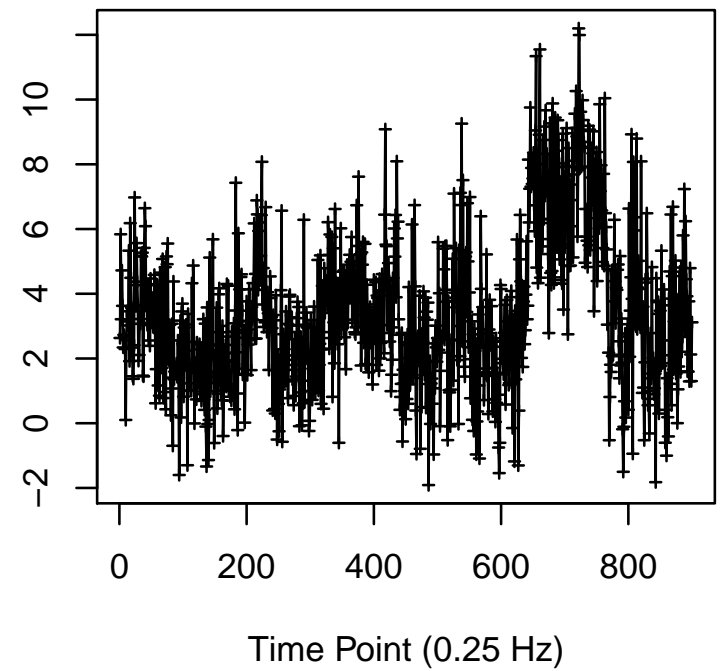

Cell 484

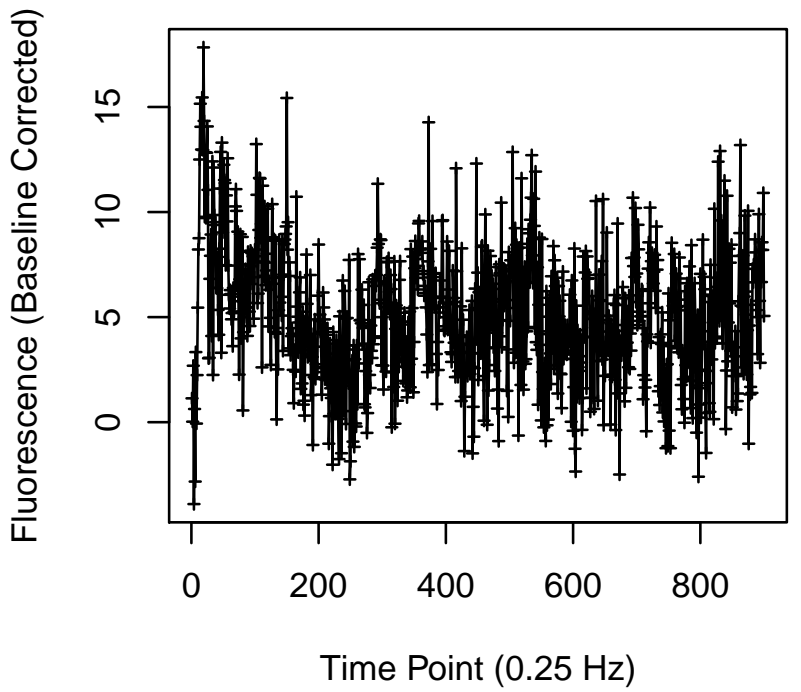




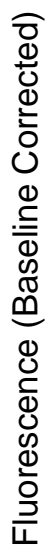

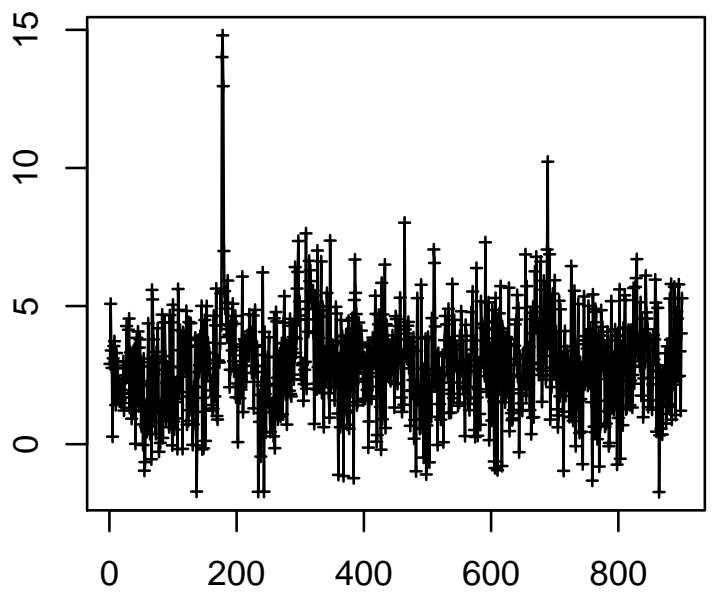

Time Point $(0.25 \mathrm{~Hz})$

\section{Cell 495}

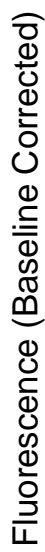

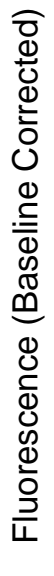

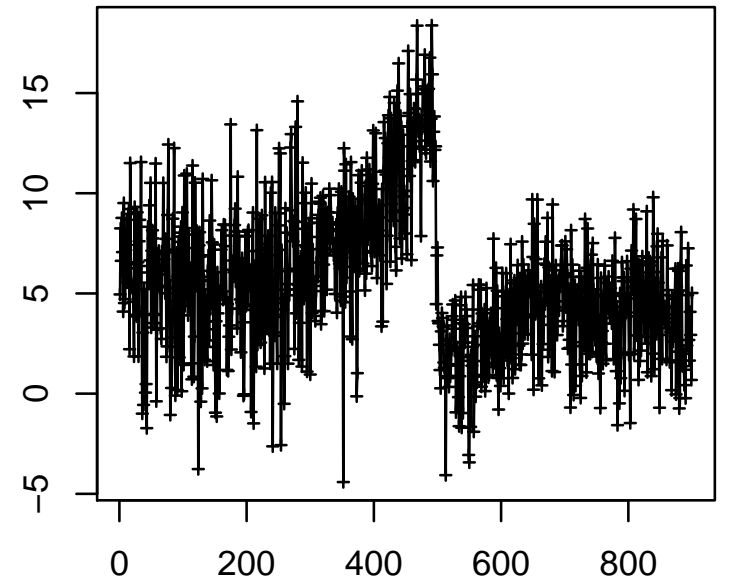

Time Point $(0.25 \mathrm{~Hz})$

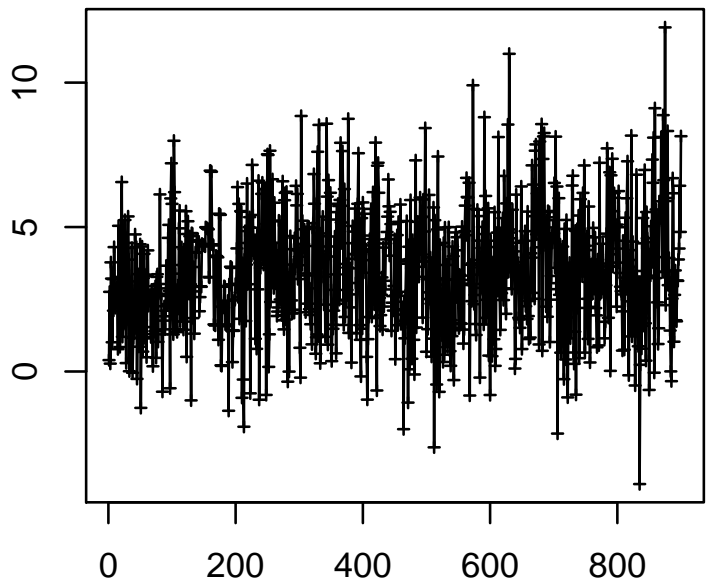

Time Point $(0.25 \mathrm{~Hz})$

\section{Cell 496}

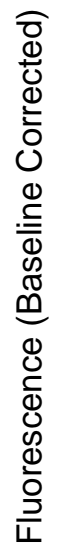

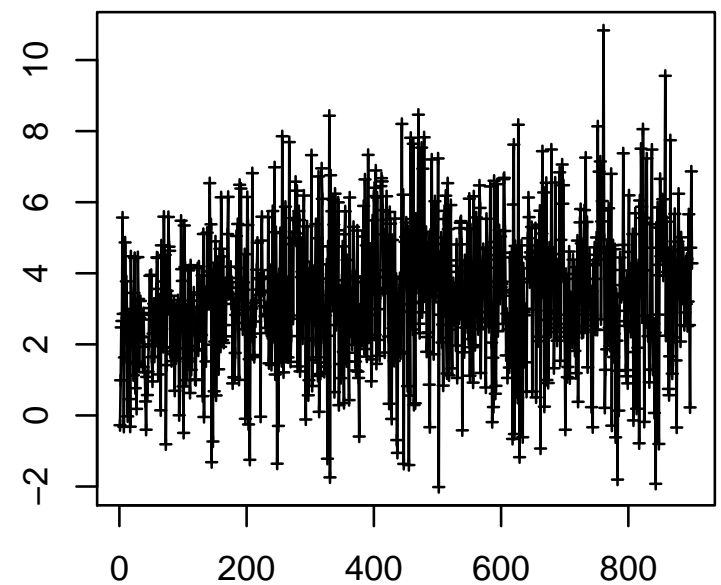

Time Point $(0.25 \mathrm{~Hz})$ 
Cell 505

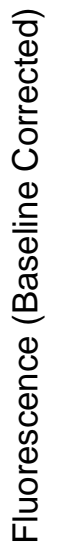

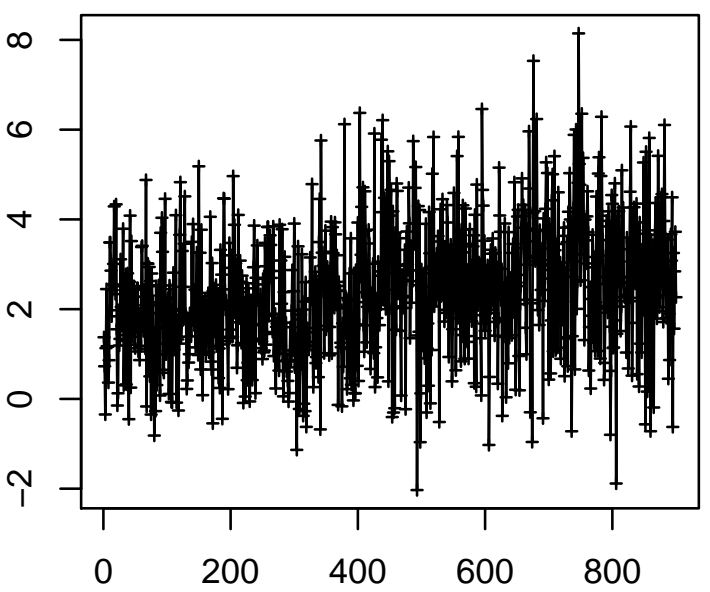

Time Point $(0.25 \mathrm{~Hz})$

Cell 507

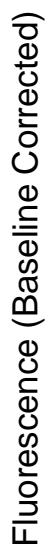

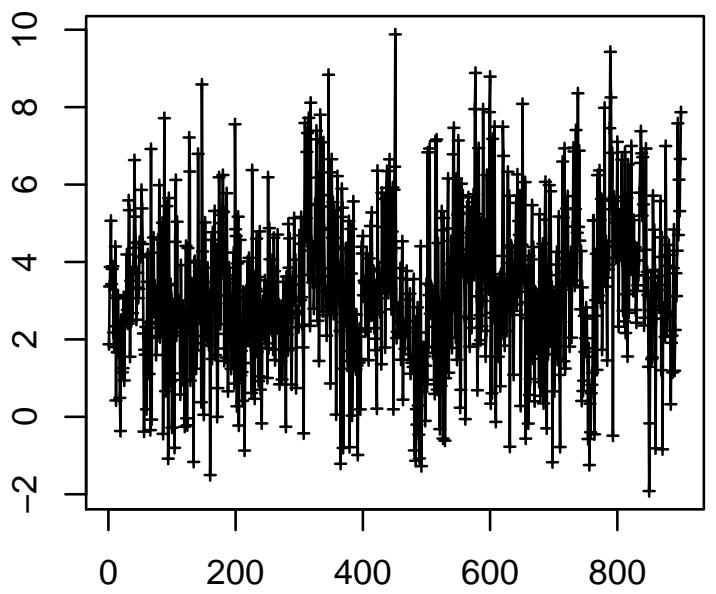

Time Point $(0.25 \mathrm{~Hz})$

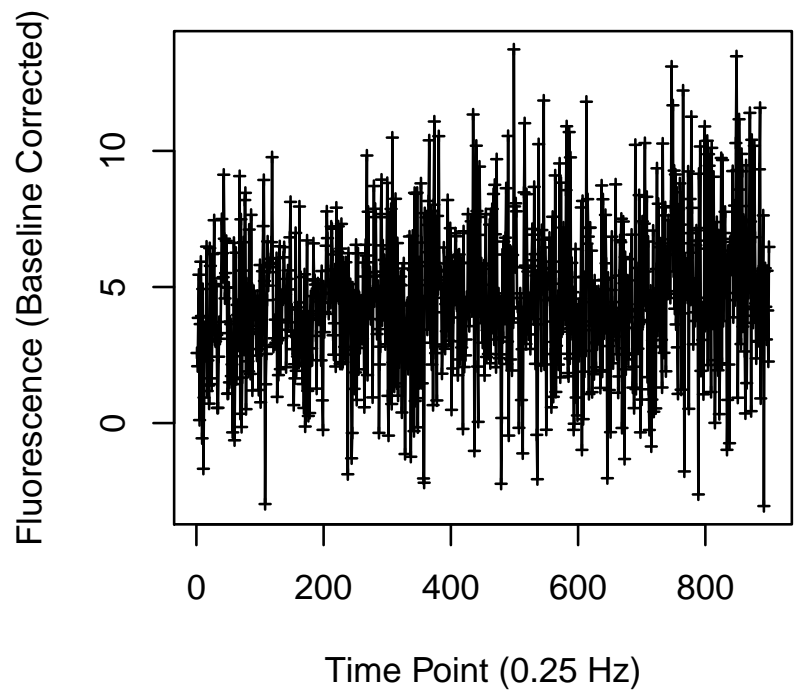

Cell 508

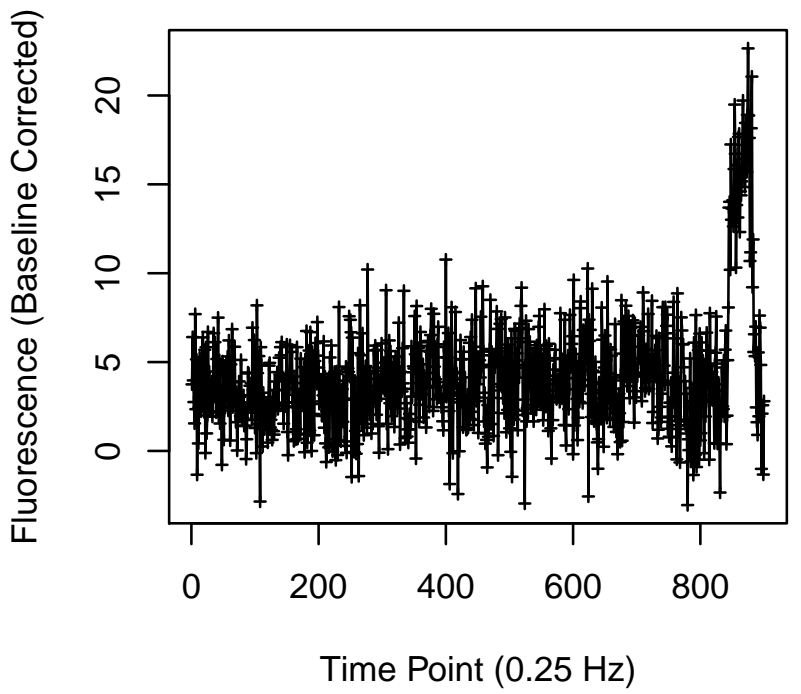


Cell 517

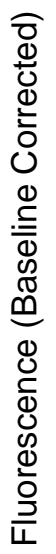

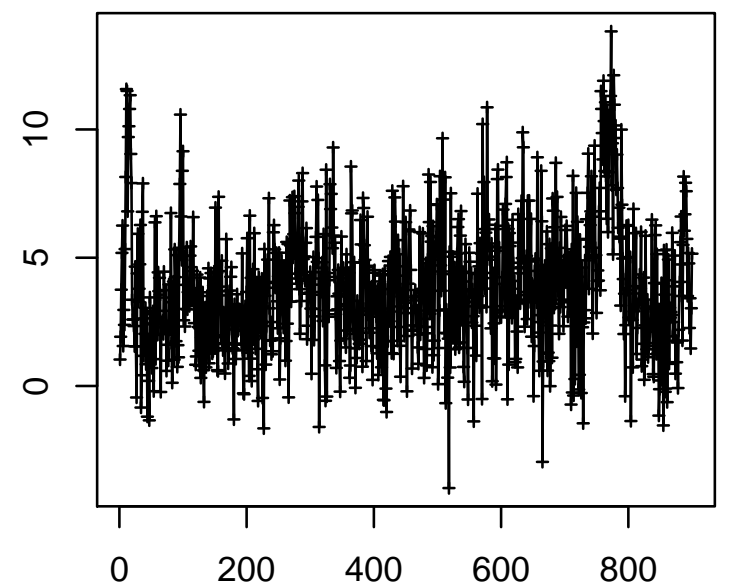

Time Point $(0.25 \mathrm{~Hz})$

Cell 519

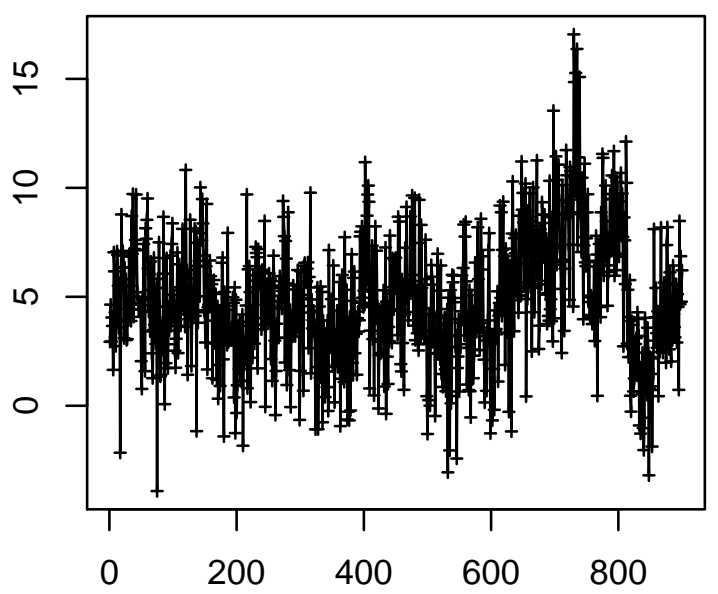

Time Point $(0.25 \mathrm{~Hz})$
Cell 518

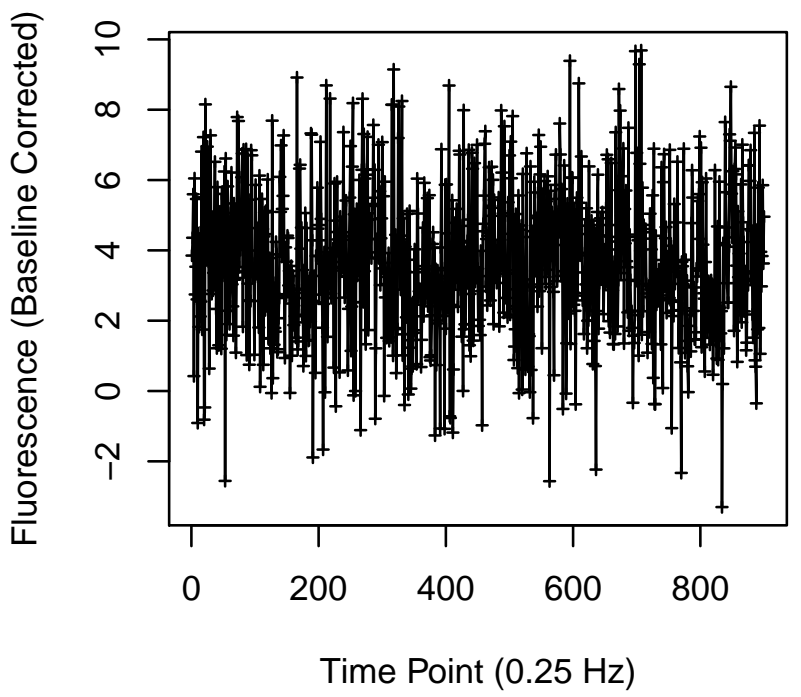

Cell 520

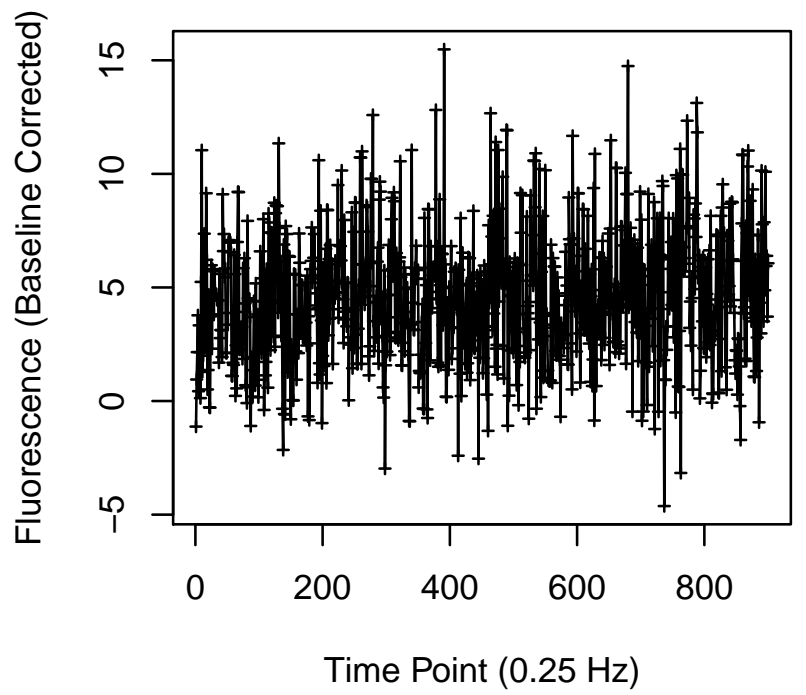


Cell 521

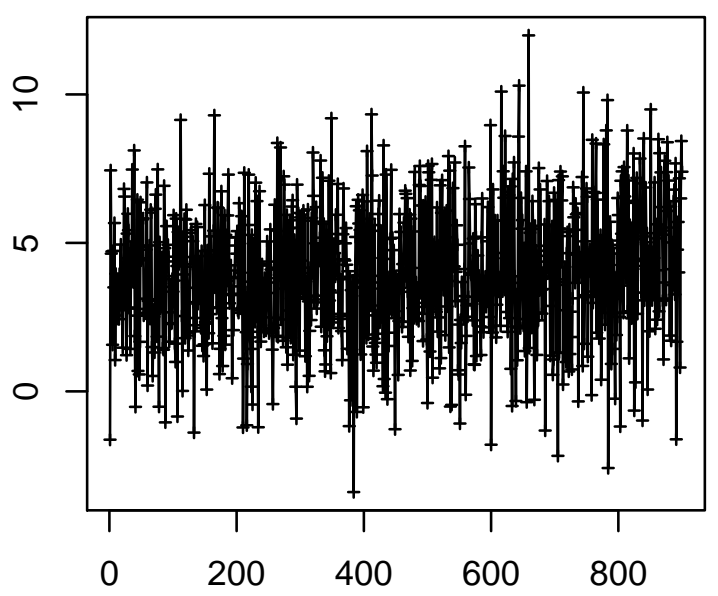

Time Point $(0.25 \mathrm{~Hz})$

\section{Cell 523}

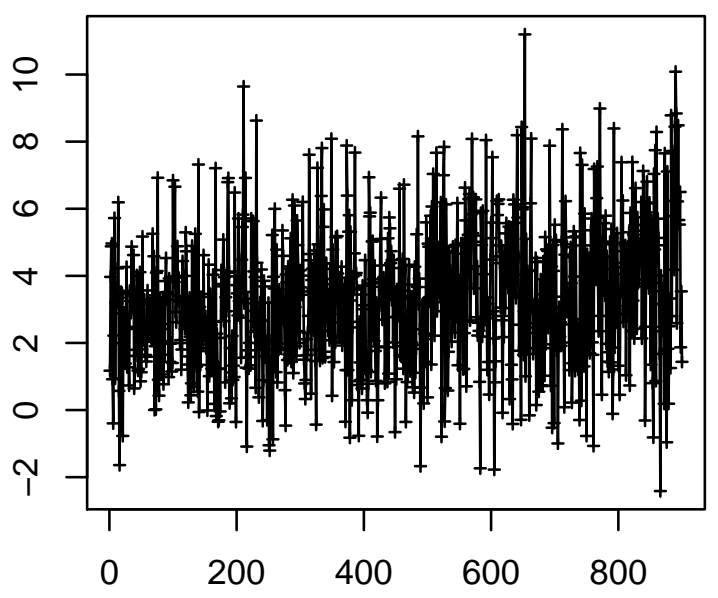

Time Point $(0.25 \mathrm{~Hz})$

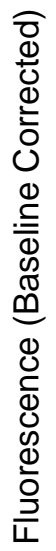

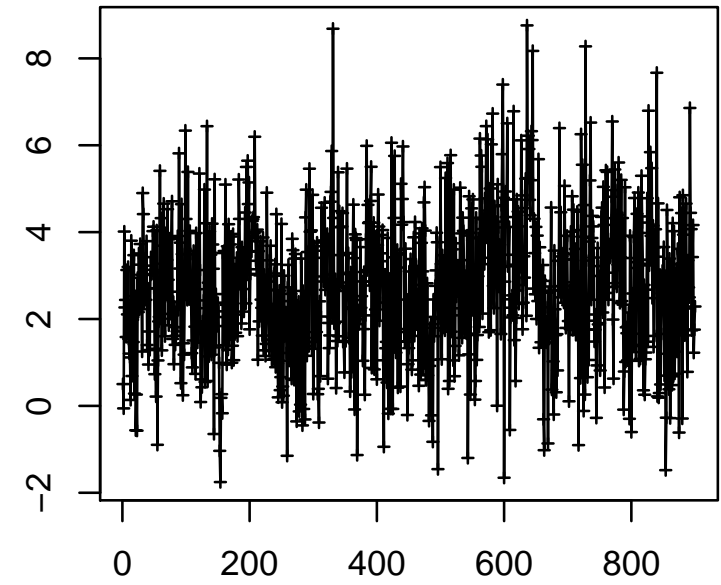

Time Point $(0.25 \mathrm{~Hz})$

Cell 524

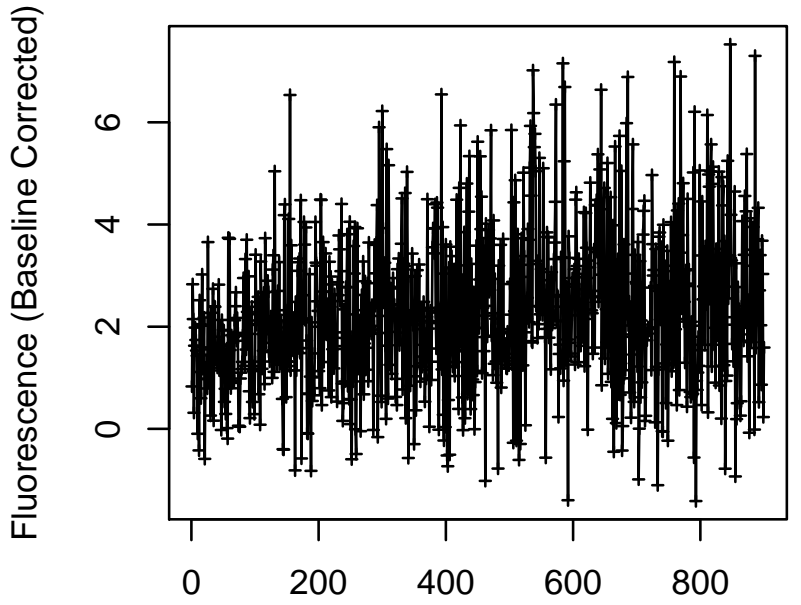

Time Point $(0.25 \mathrm{~Hz})$ 


\section{Cell 529}

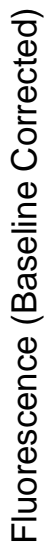

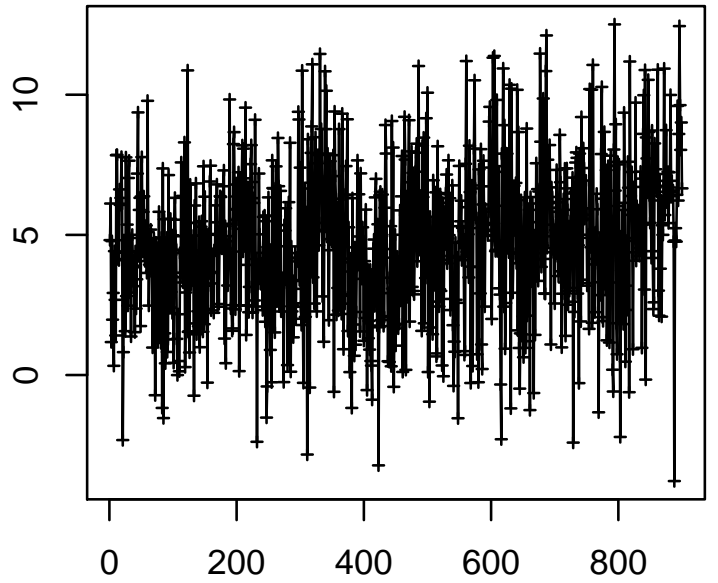

Time Point $(0.25 \mathrm{~Hz})$

Cell 531

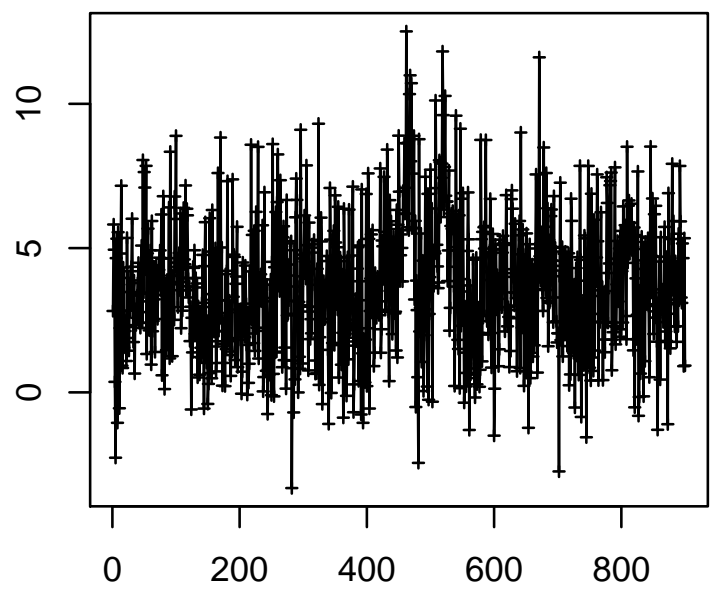

Time Point $(0.25 \mathrm{~Hz})$
Cell 530

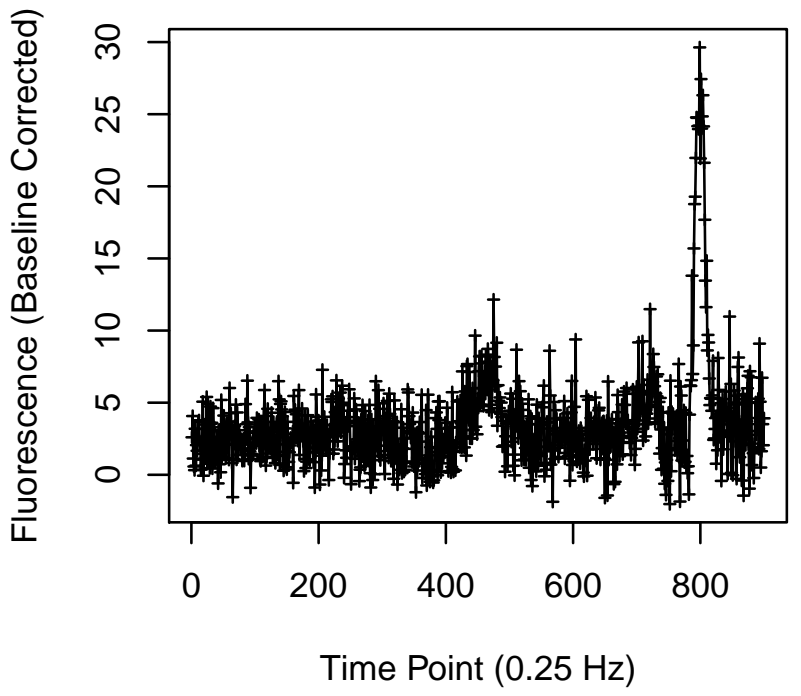

Cell 532

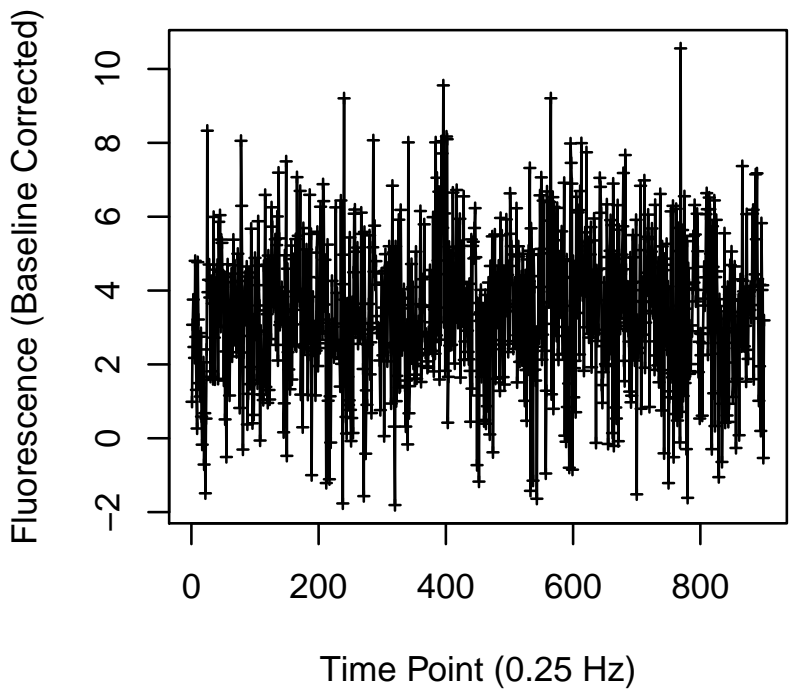


Cell 533

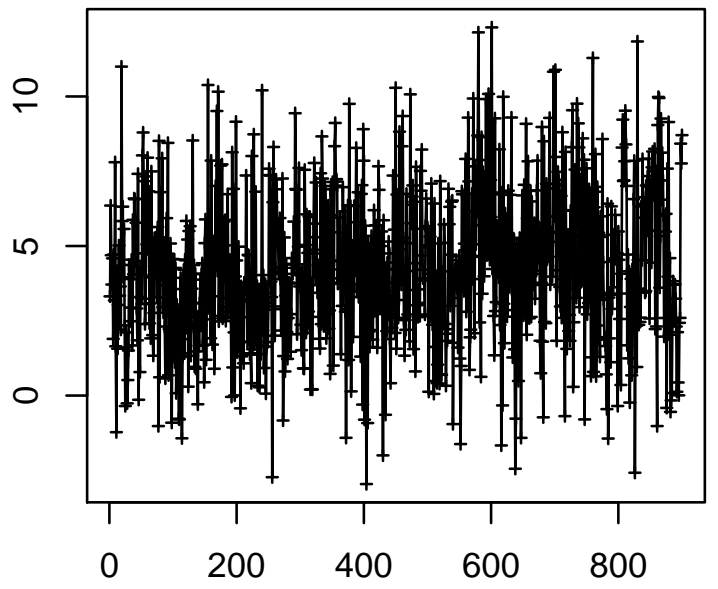

Time Point $(0.25 \mathrm{~Hz})$

\section{Cell 535}

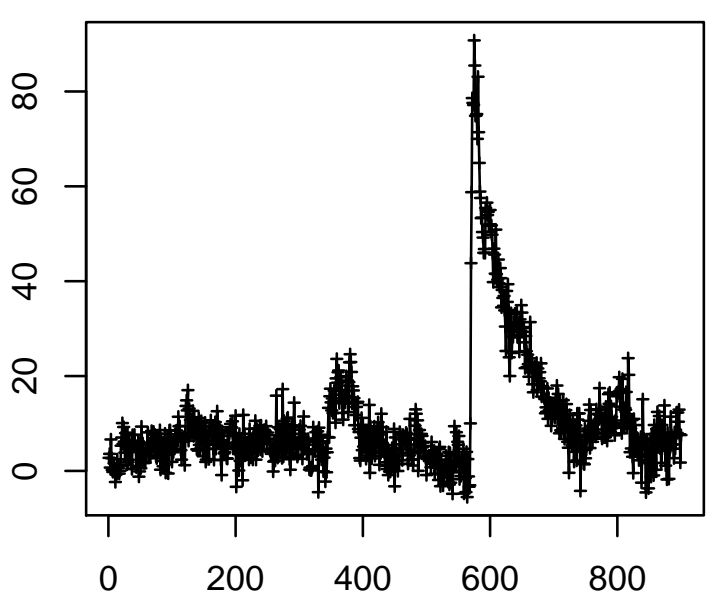

Time Point $(0.25 \mathrm{~Hz})$
Cell 534

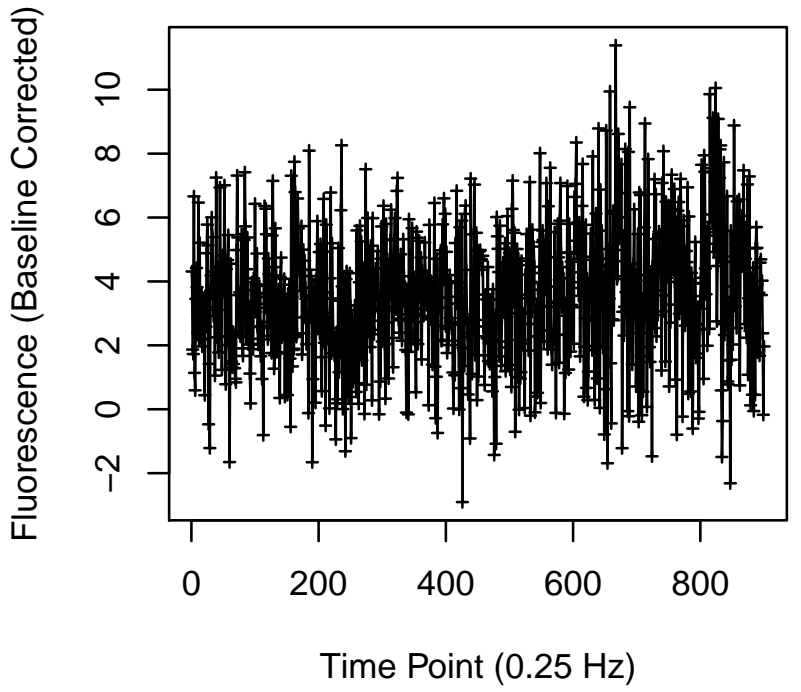

Cell 536

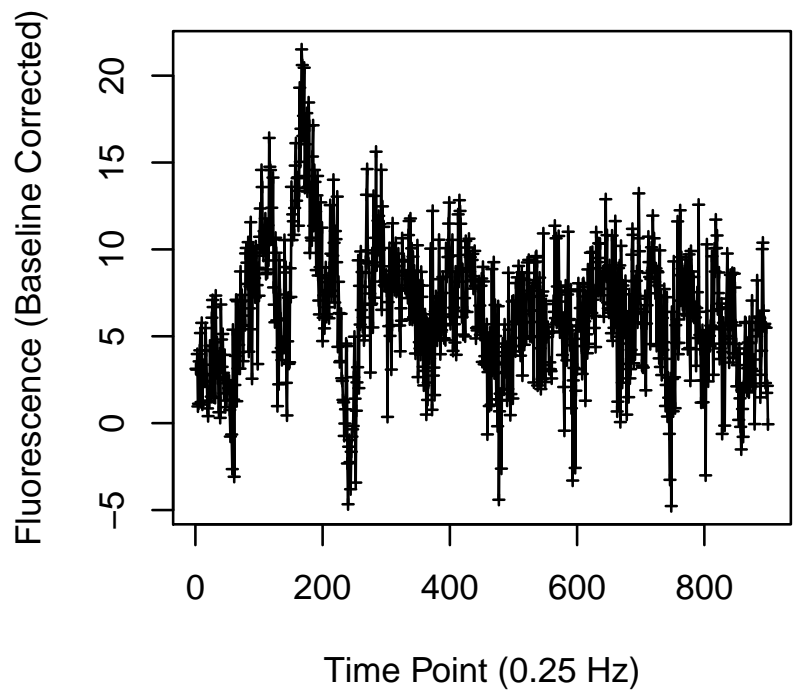


Cell 537

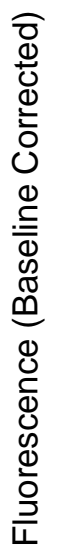

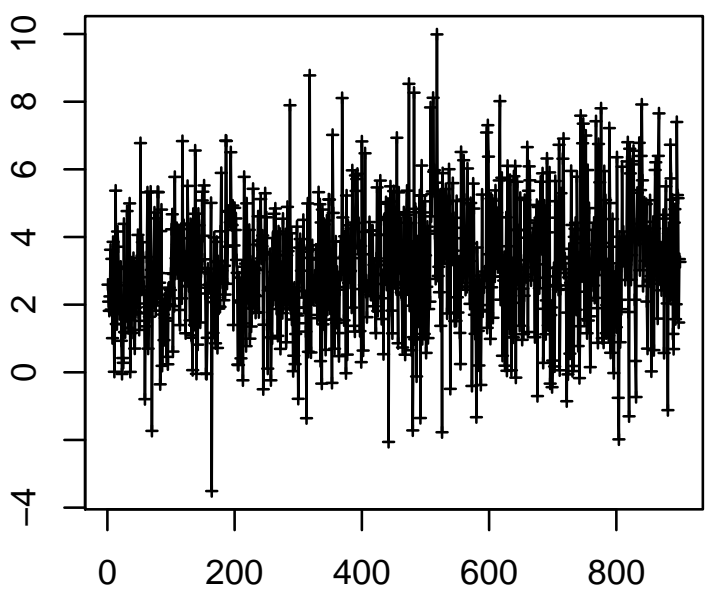

Time Point $(0.25 \mathrm{~Hz})$

\section{Cell 539}

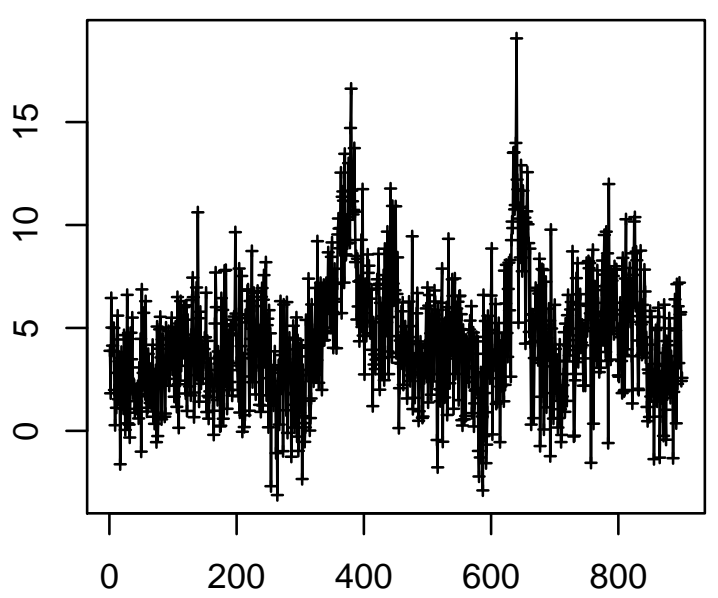

Time Point $(0.25 \mathrm{~Hz})$
Cell 538

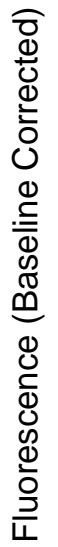

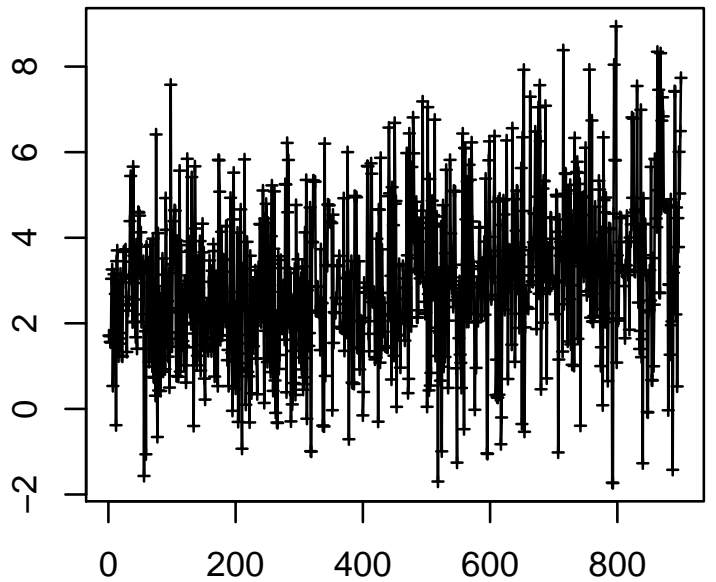

Time Point $(0.25 \mathrm{~Hz})$

Cell 540

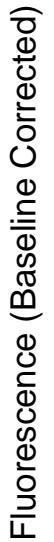

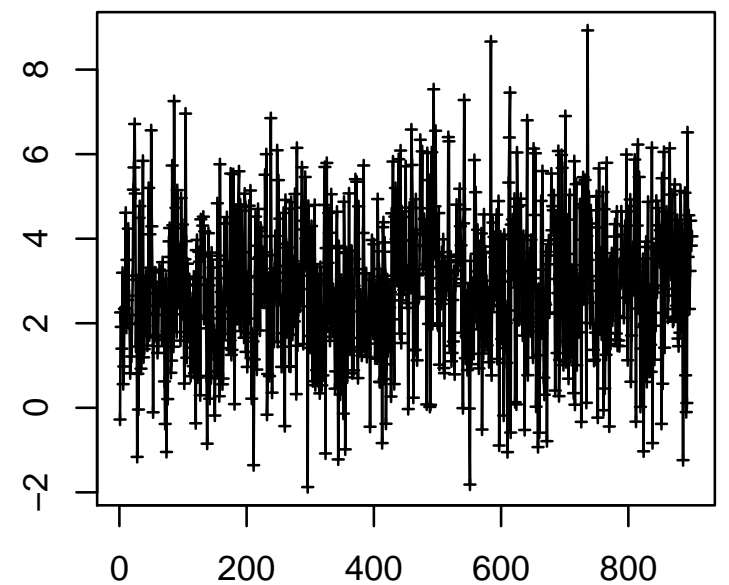

Time Point $(0.25 \mathrm{~Hz})$ 
Cell 541

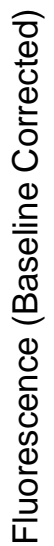

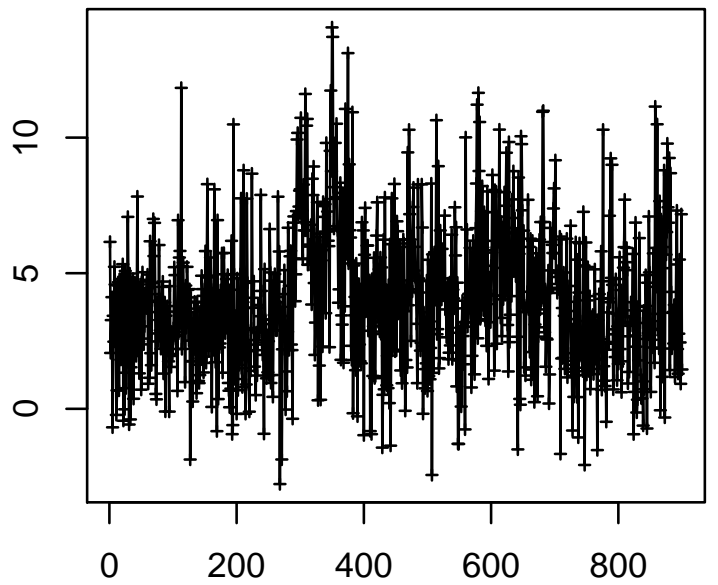

Time Point $(0.25 \mathrm{~Hz})$

\section{Cell 543}

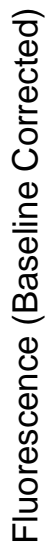

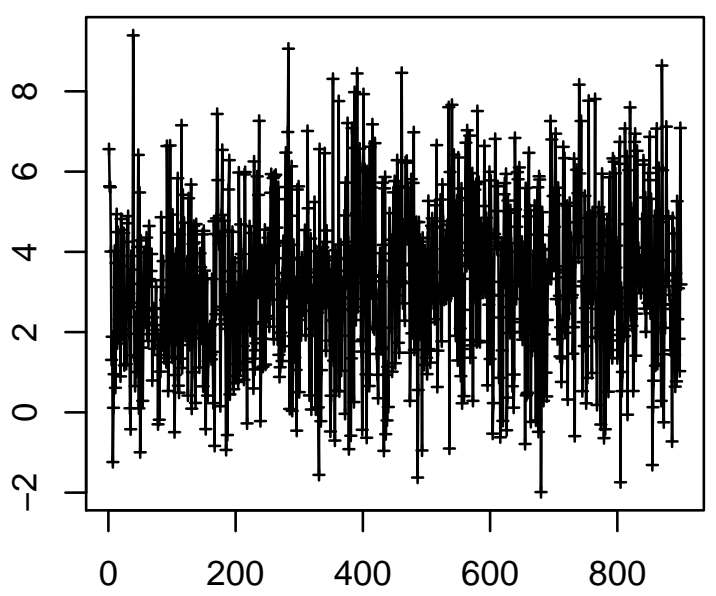

Time Point $(0.25 \mathrm{~Hz})$

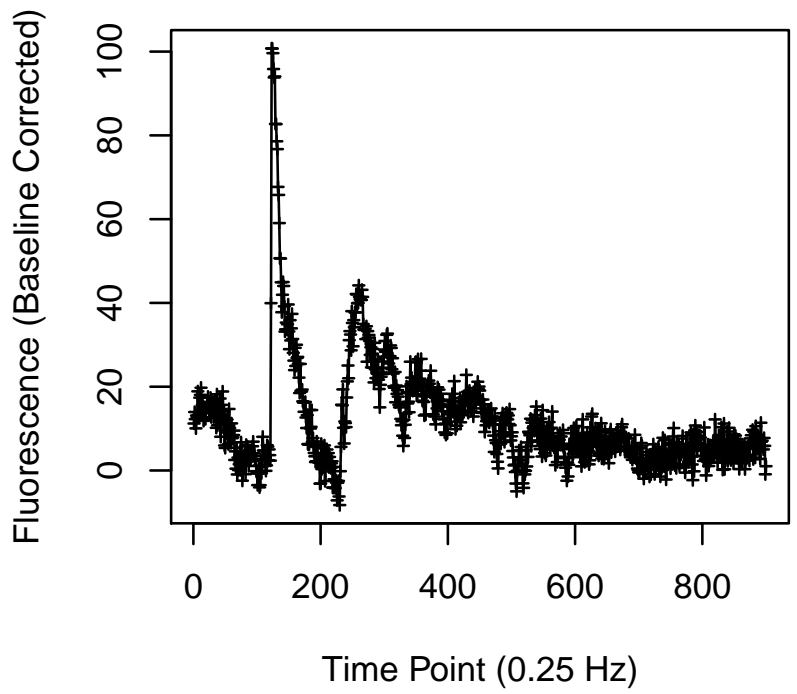

Cell 544

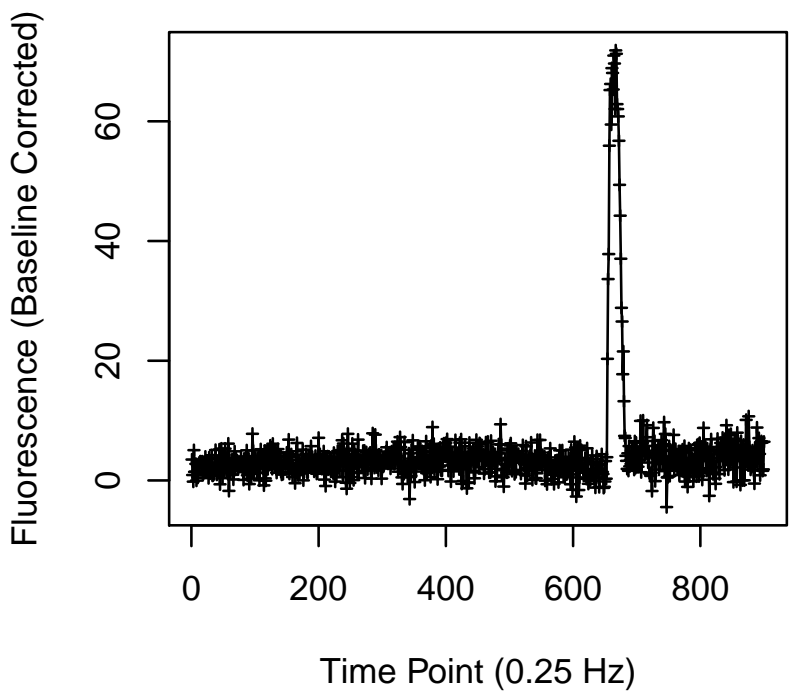




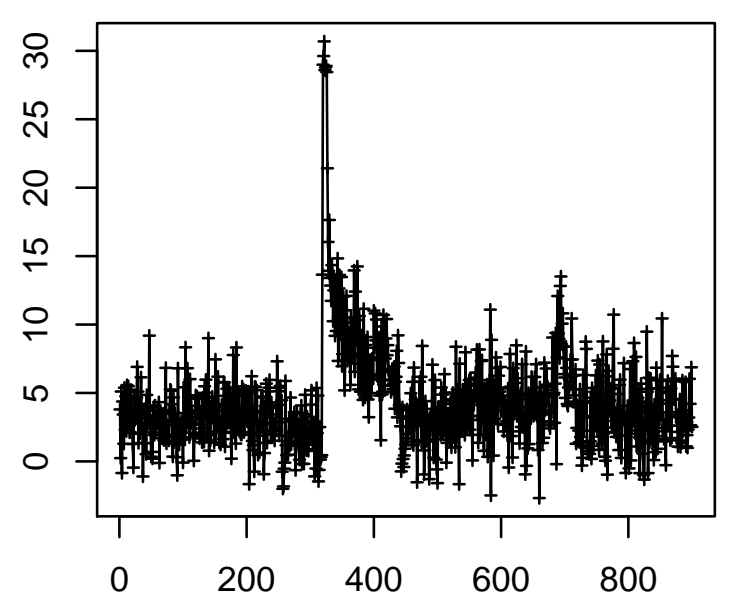

Time Point $(0.25 \mathrm{~Hz})$

\section{Cell 547}

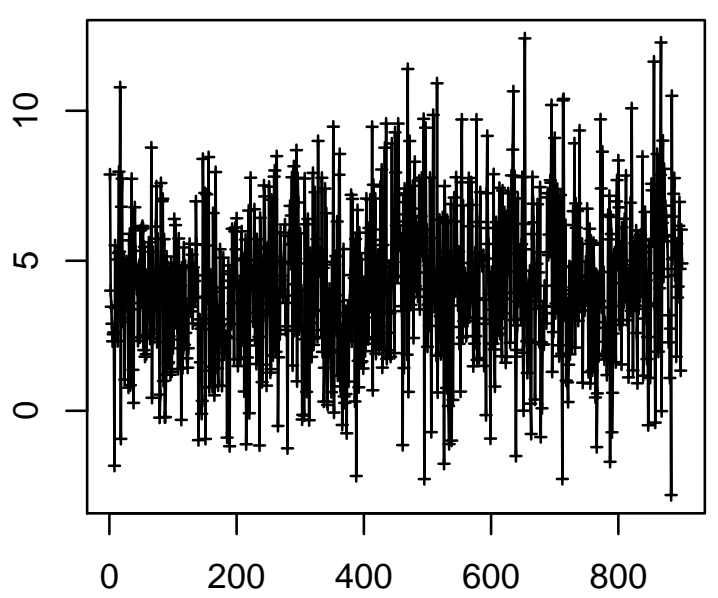

Time Point $(0.25 \mathrm{~Hz})$

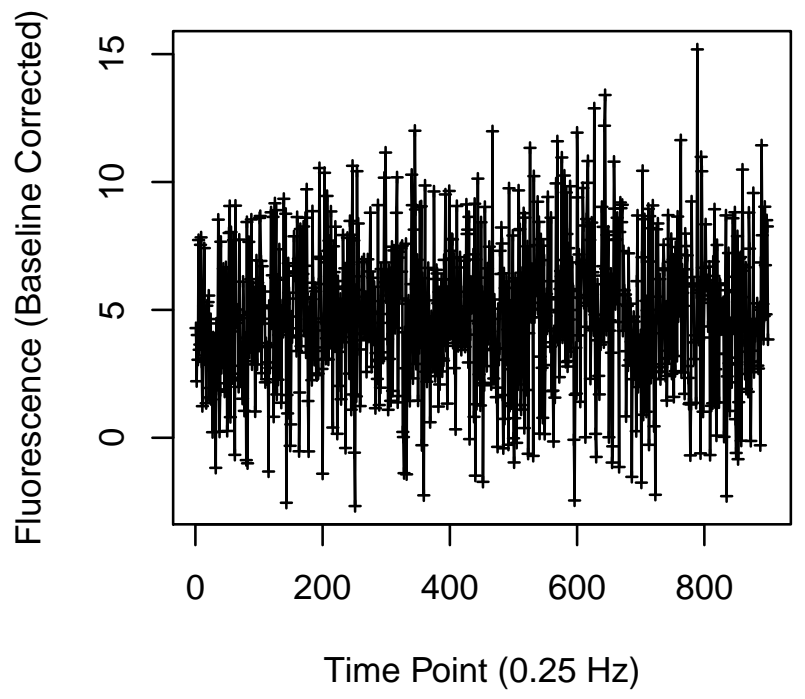

Cell 548

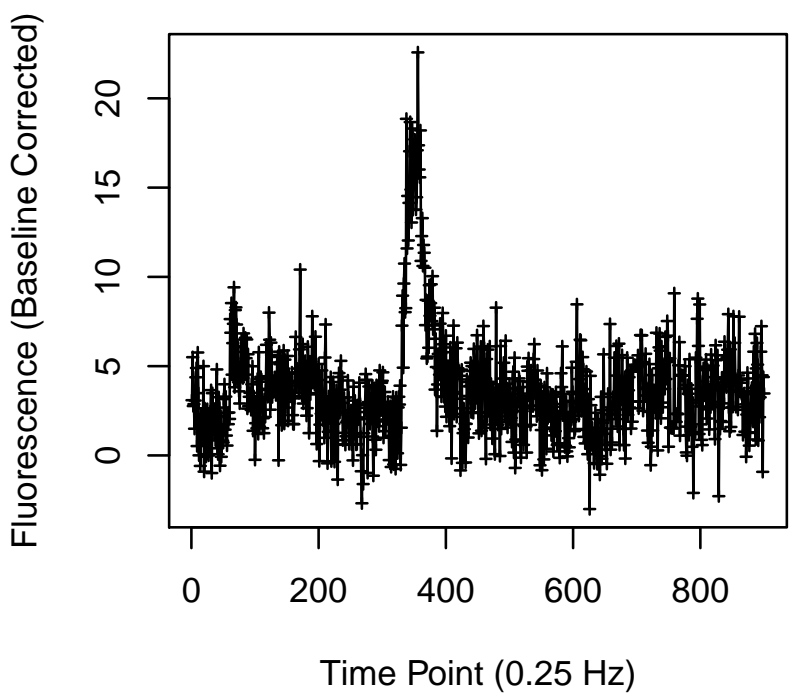




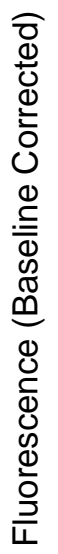

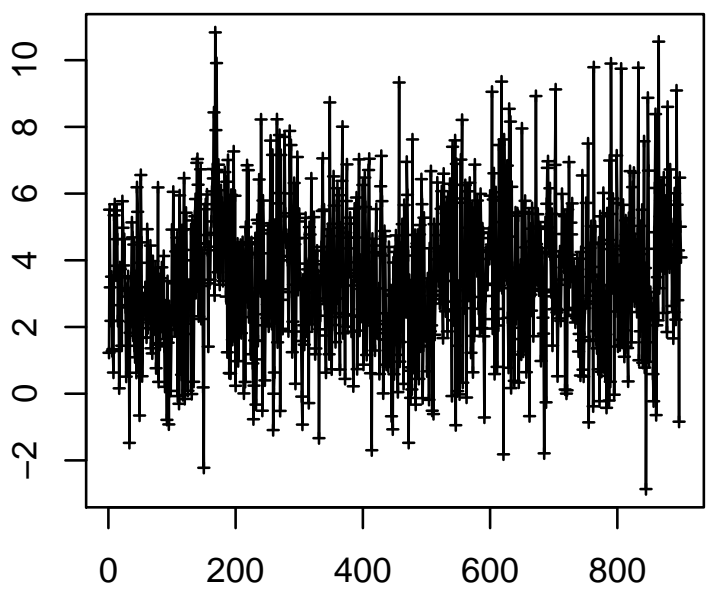

Time Point $(0.25 \mathrm{~Hz})$

Cell 559

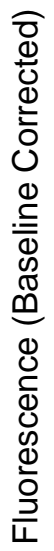

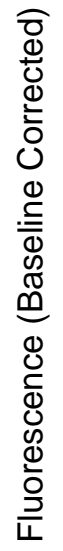

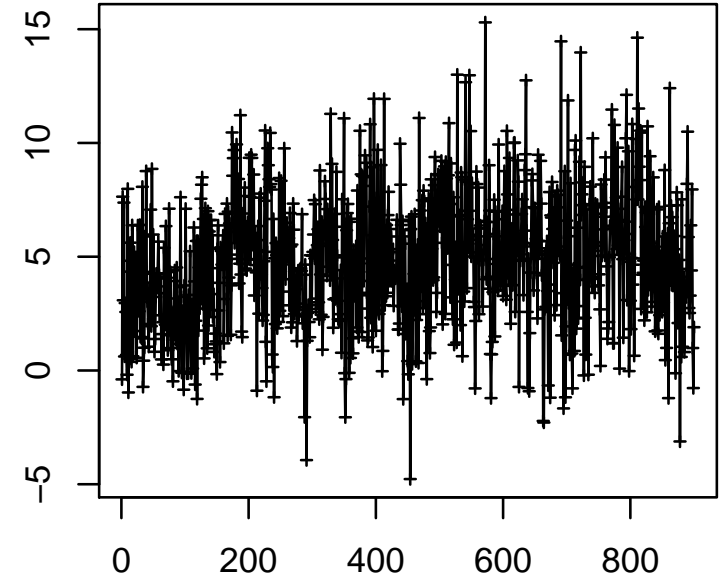

Time Point $(0.25 \mathrm{~Hz})$

Cell 560

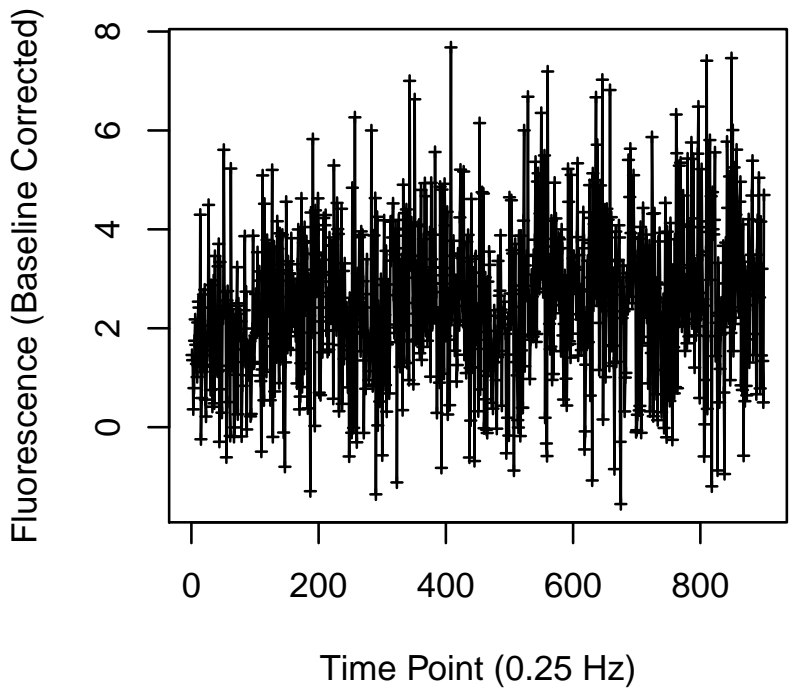


Cell 561

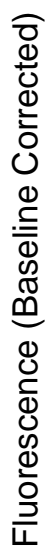

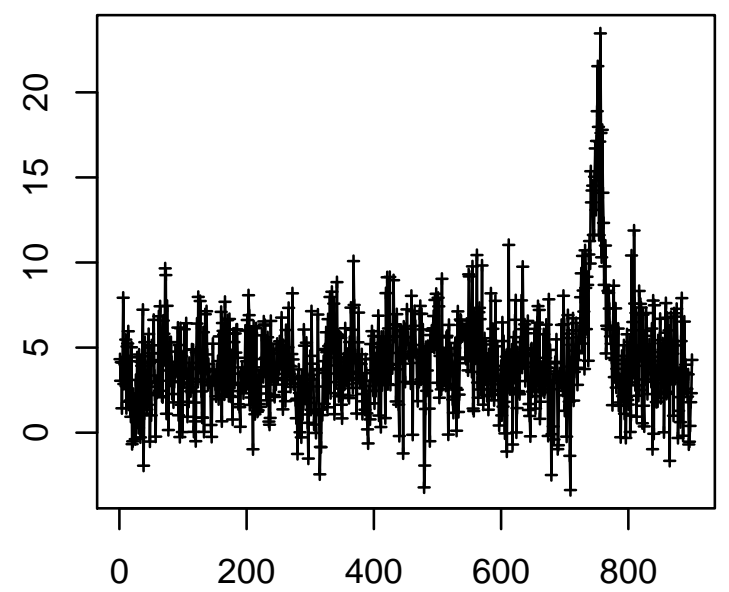

Time Point $(0.25 \mathrm{~Hz})$

Cell 563

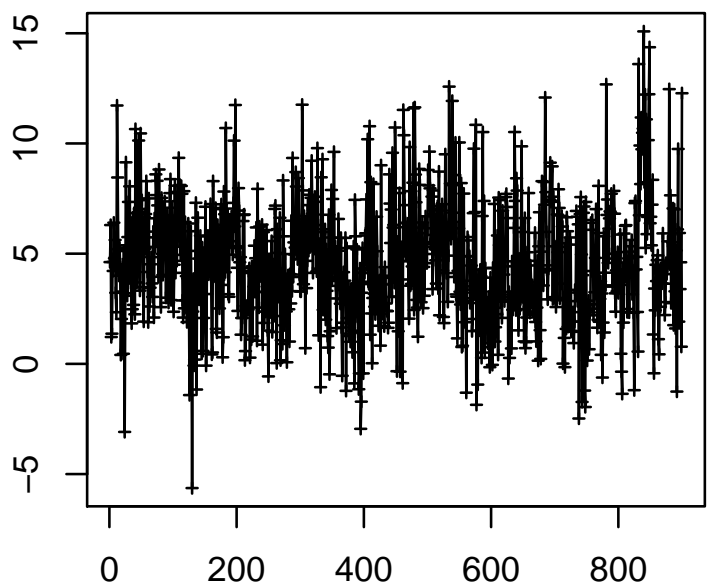

Time Point $(0.25 \mathrm{~Hz})$
Cell 562

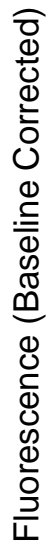

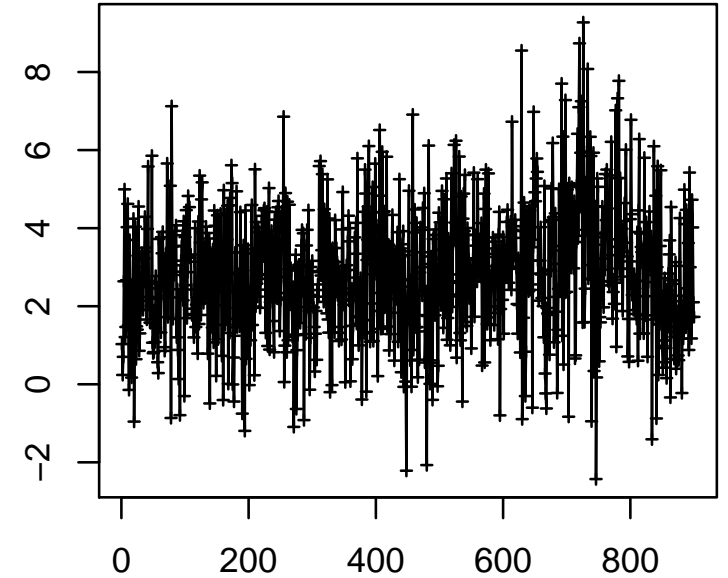

Time Point $(0.25 \mathrm{~Hz})$

Cell 564

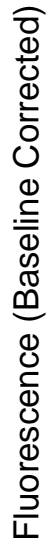

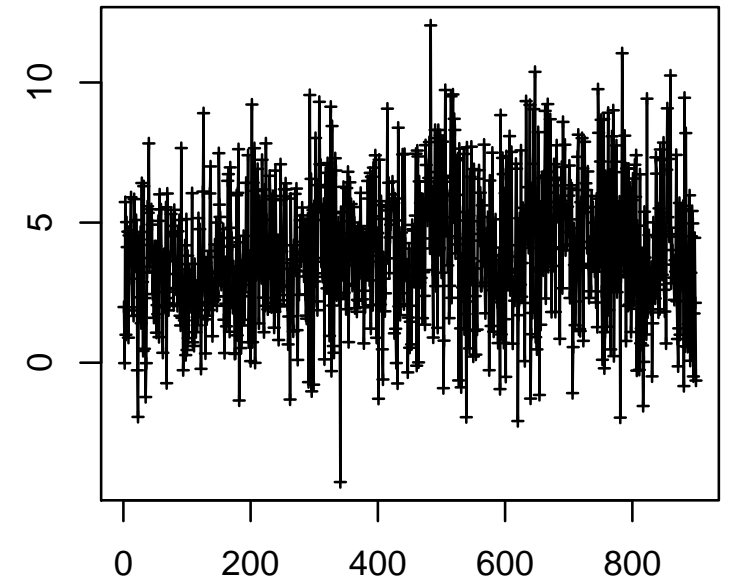

Time Point $(0.25 \mathrm{~Hz})$ 


\section{Cell 565}
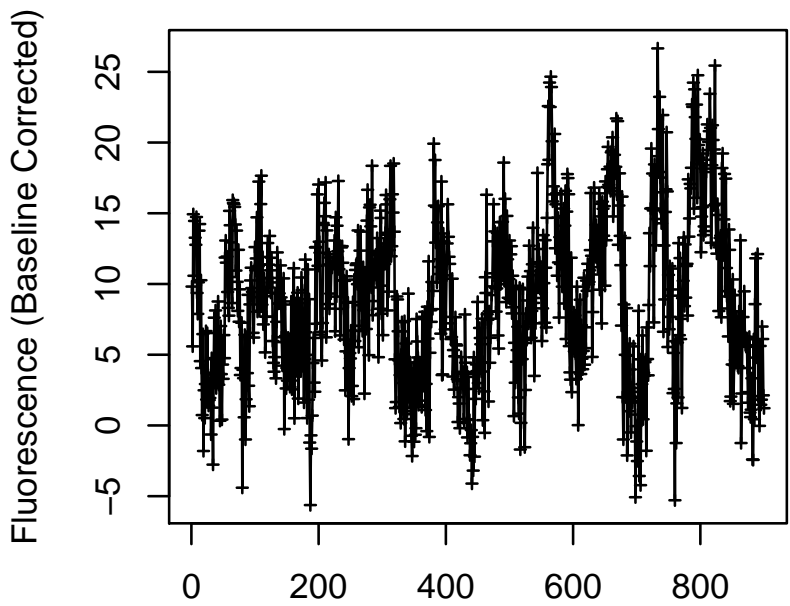

Time Point $(0.25 \mathrm{~Hz})$

\section{Cell 567}

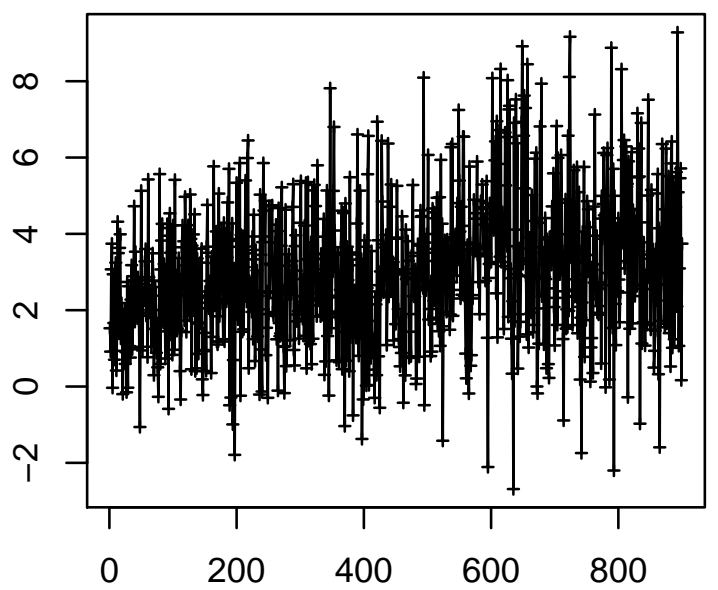

Time Point $(0.25 \mathrm{~Hz})$
Cell 566

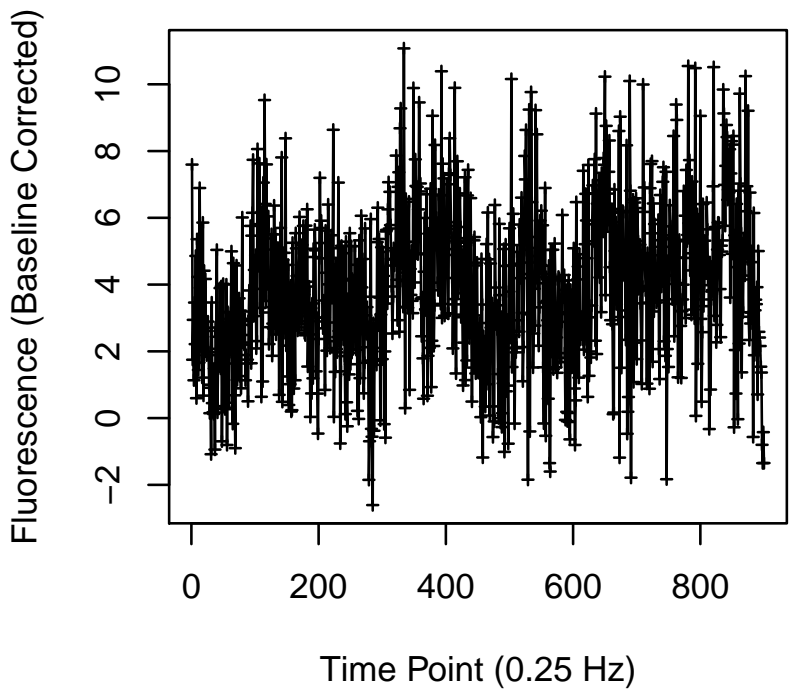

Cell 568

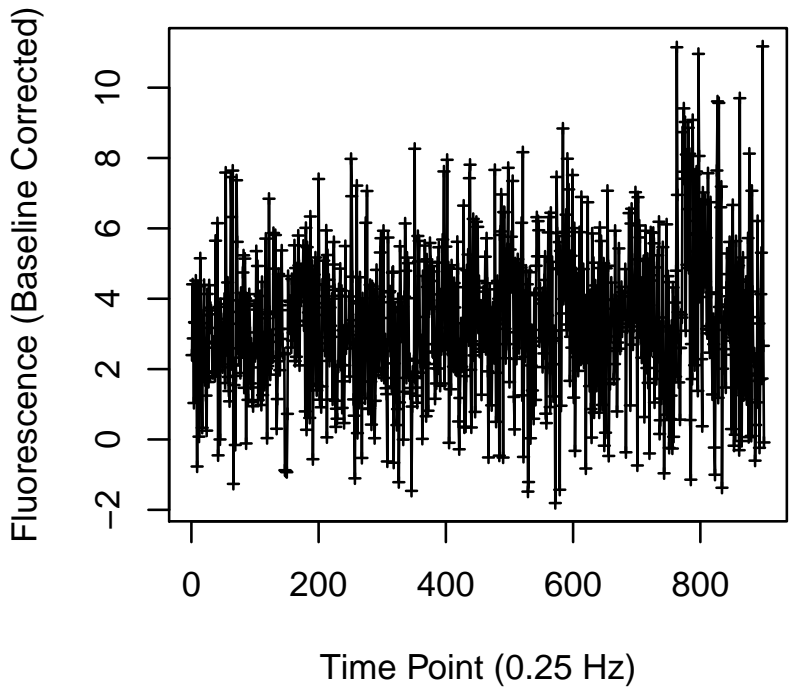


Cell 573

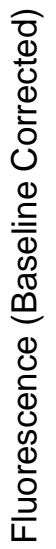

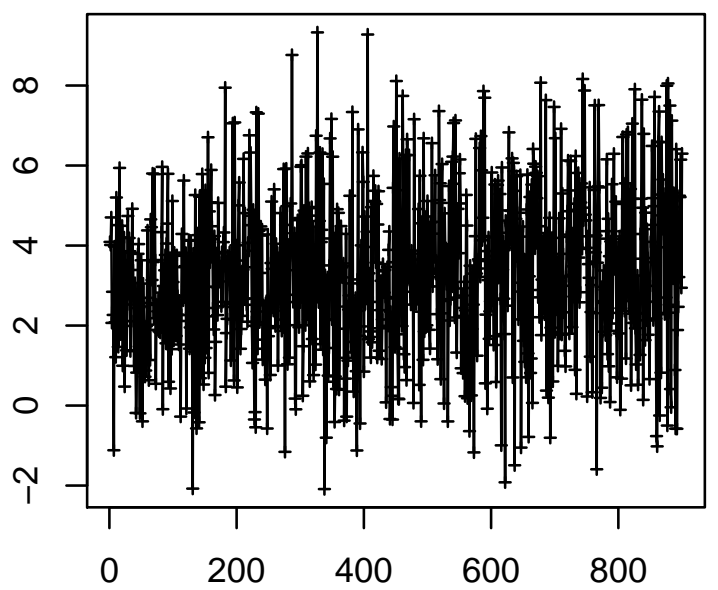

Time Point $(0.25 \mathrm{~Hz})$

Cell 575

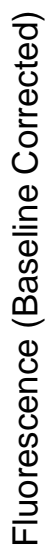

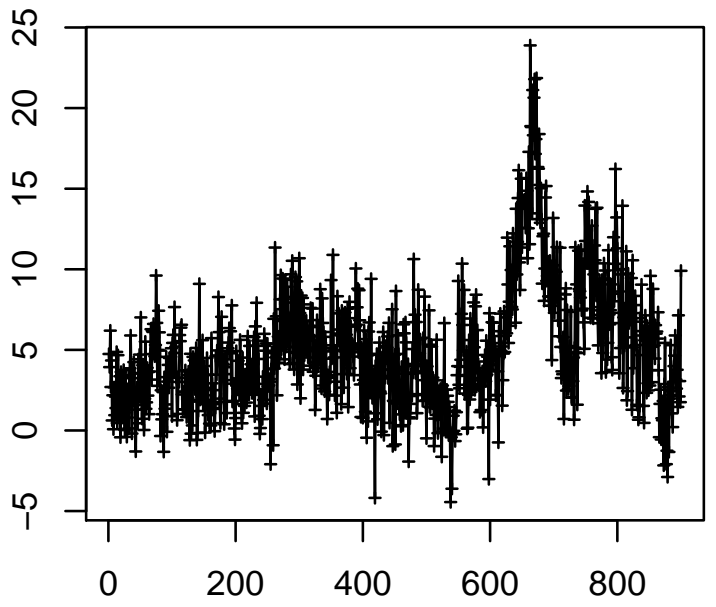

Time Point $(0.25 \mathrm{~Hz})$
Cell 574

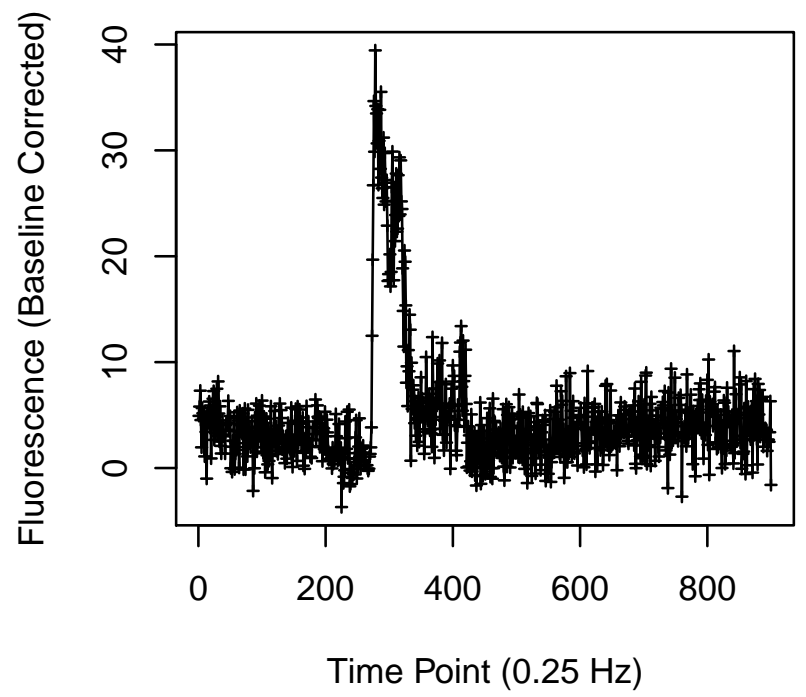

Cell 576

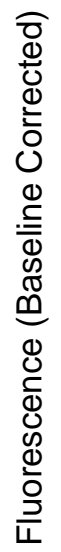

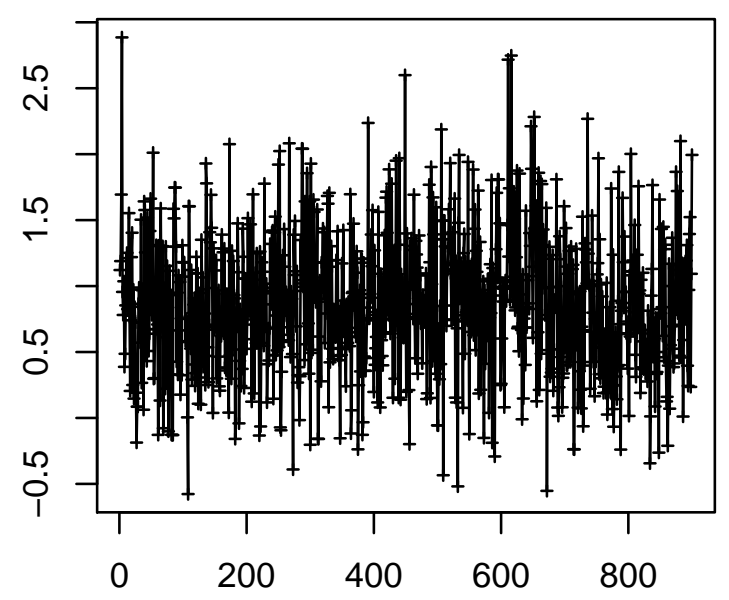

Time Point $(0.25 \mathrm{~Hz})$ 
Cell 585

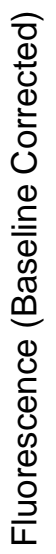

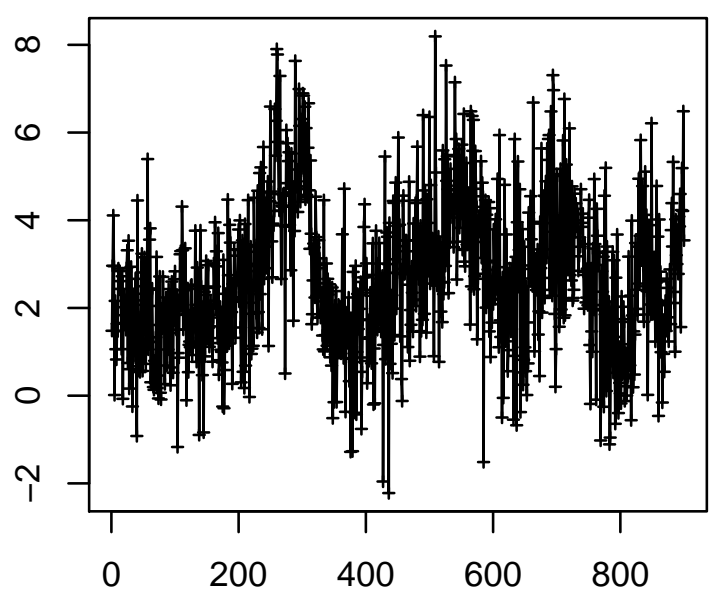

Time Point $(0.25 \mathrm{~Hz})$

Cell 587

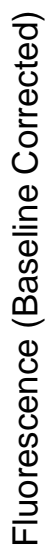

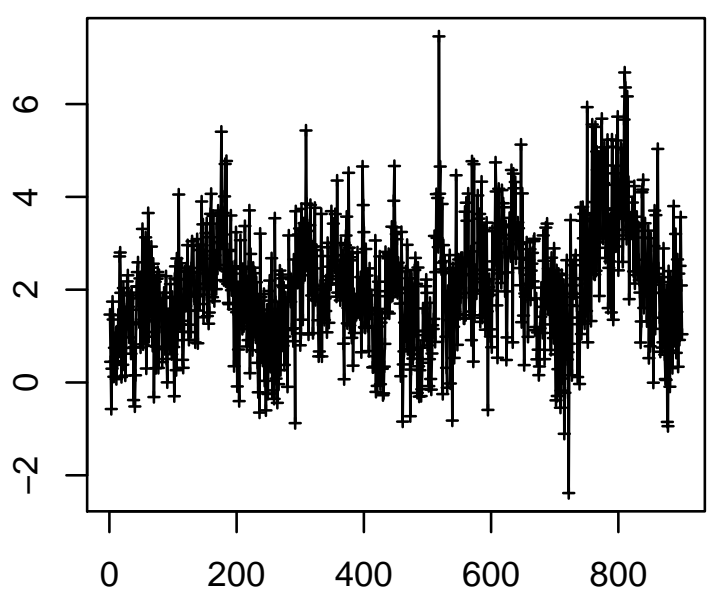

Time Point $(0.25 \mathrm{~Hz})$
Cell 586

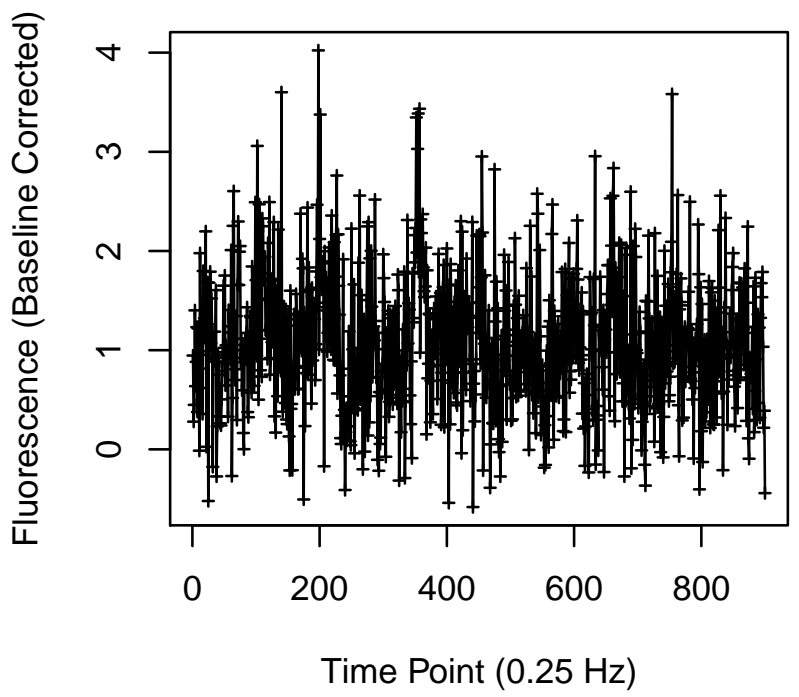

Cell 588

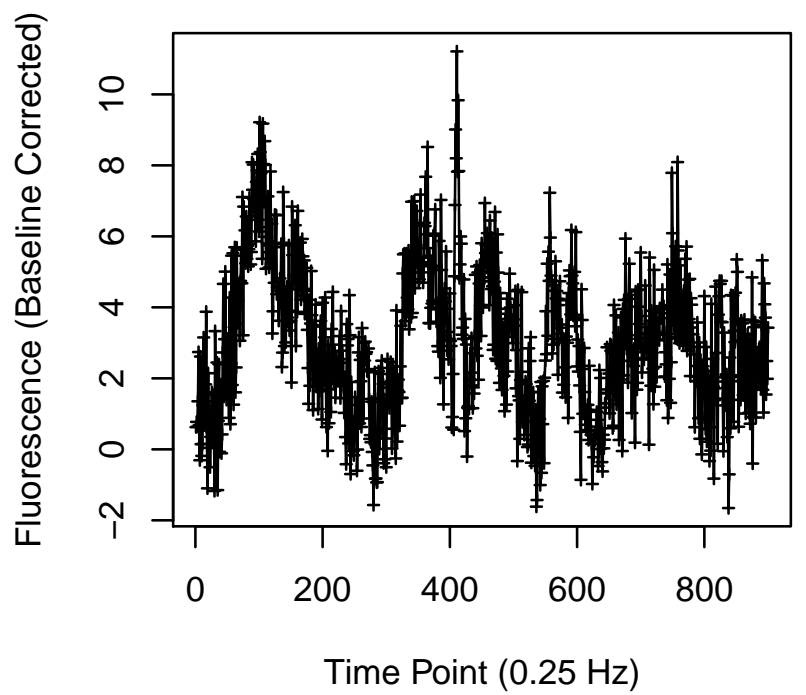


Cell 597

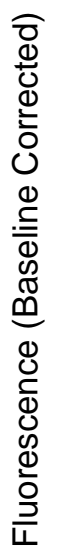

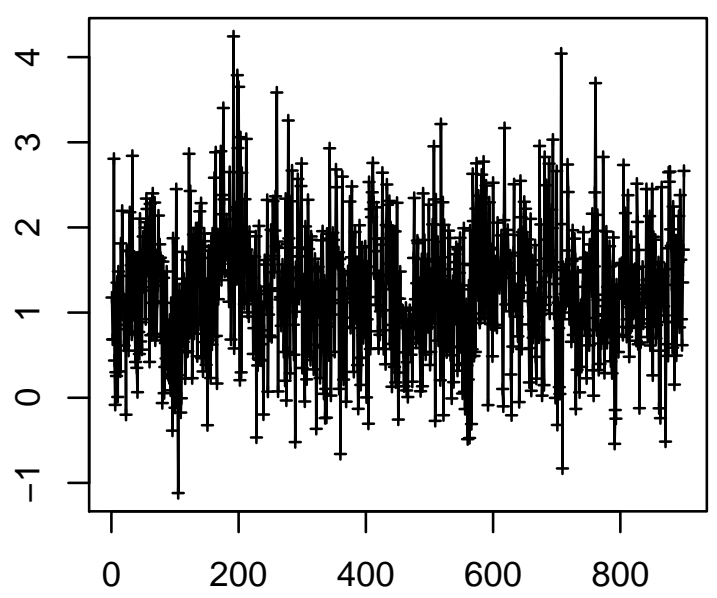

Time Point $(0.25 \mathrm{~Hz})$

\section{Cell 599}

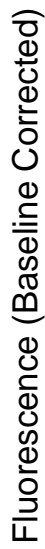

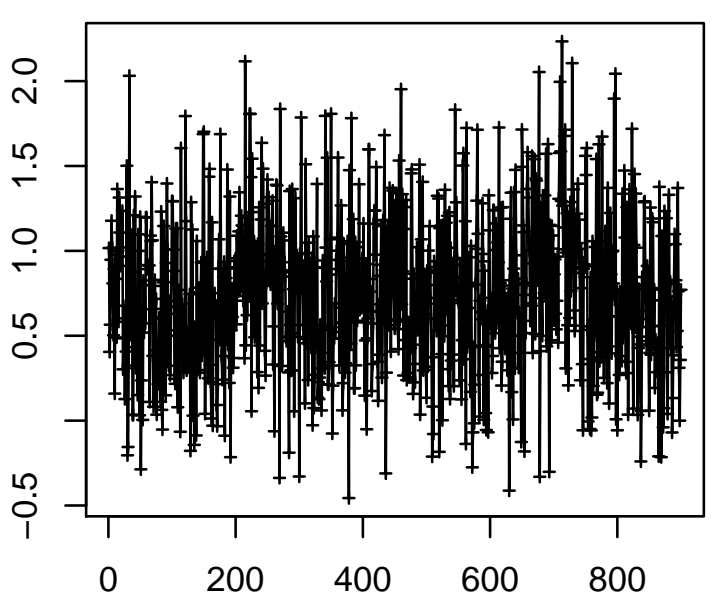

Time Point $(0.25 \mathrm{~Hz})$

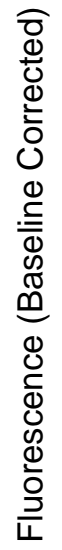
Cell 598

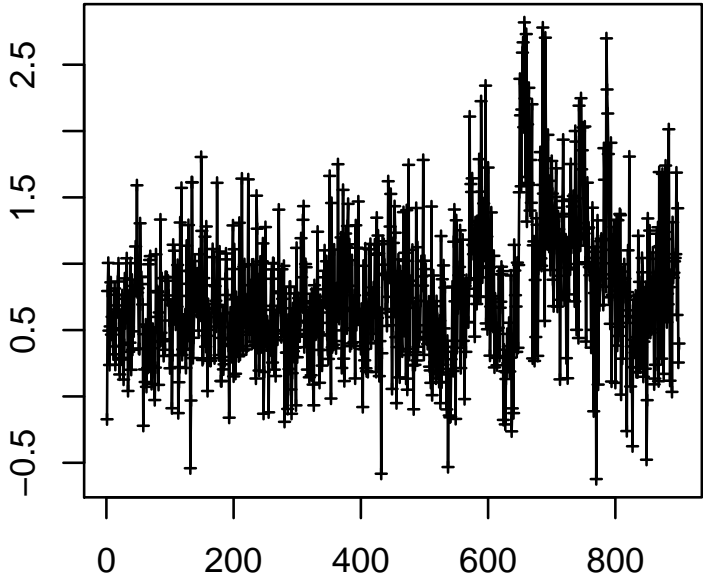

Time Point $(0.25 \mathrm{~Hz})$

\section{Cell 600}

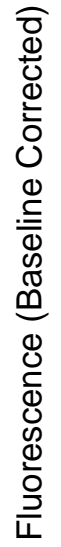

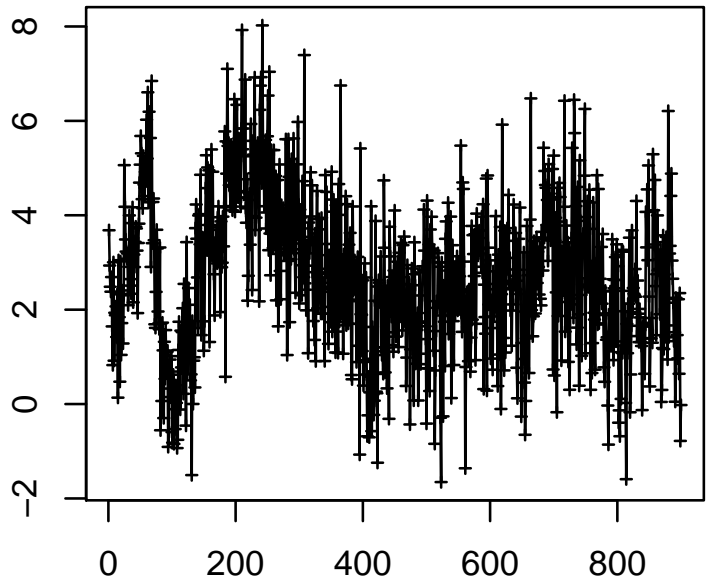

Time Point $(0.25 \mathrm{~Hz})$ 
Cell 601

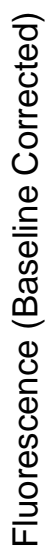

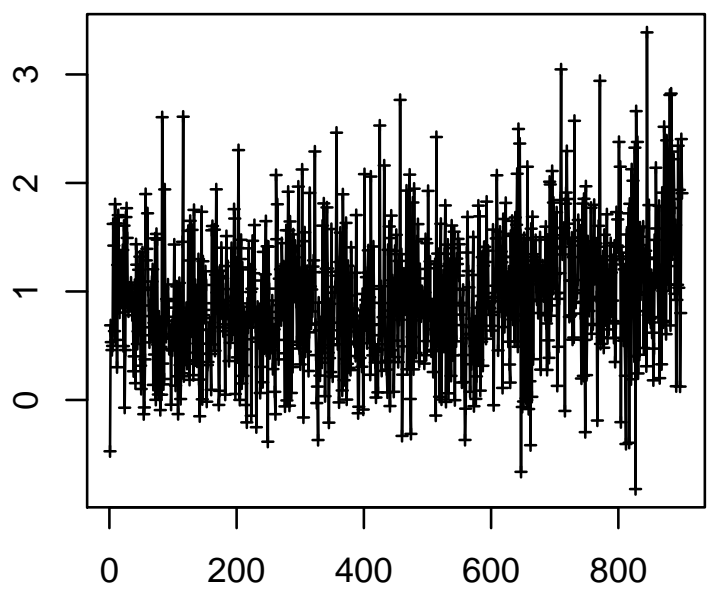

Time Point $(0.25 \mathrm{~Hz})$

Cell 603

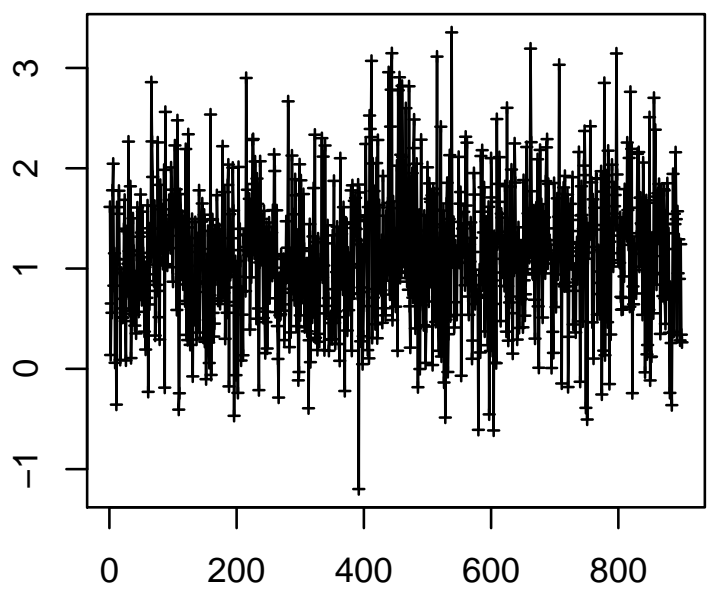

Time Point $(0.25 \mathrm{~Hz})$
Cell 602

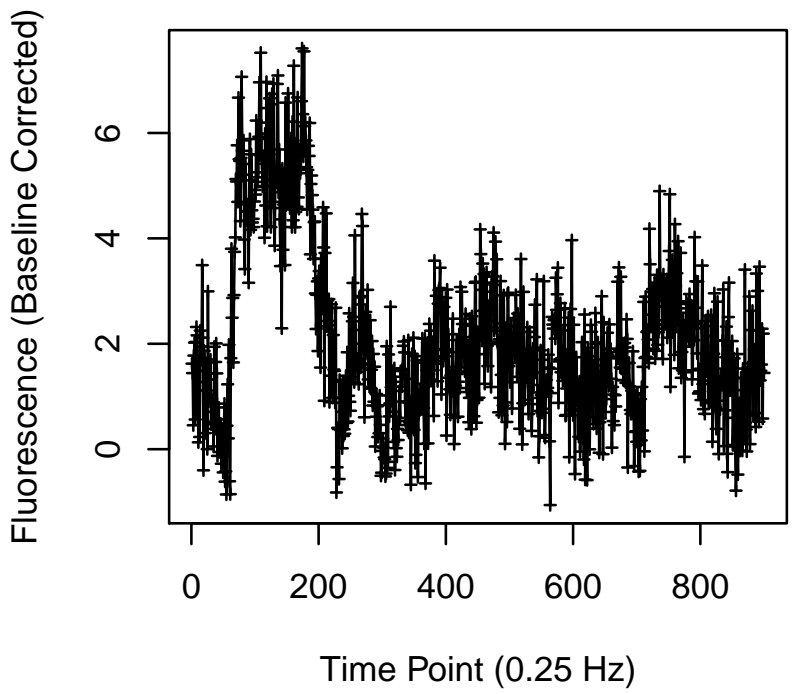

Cell 604

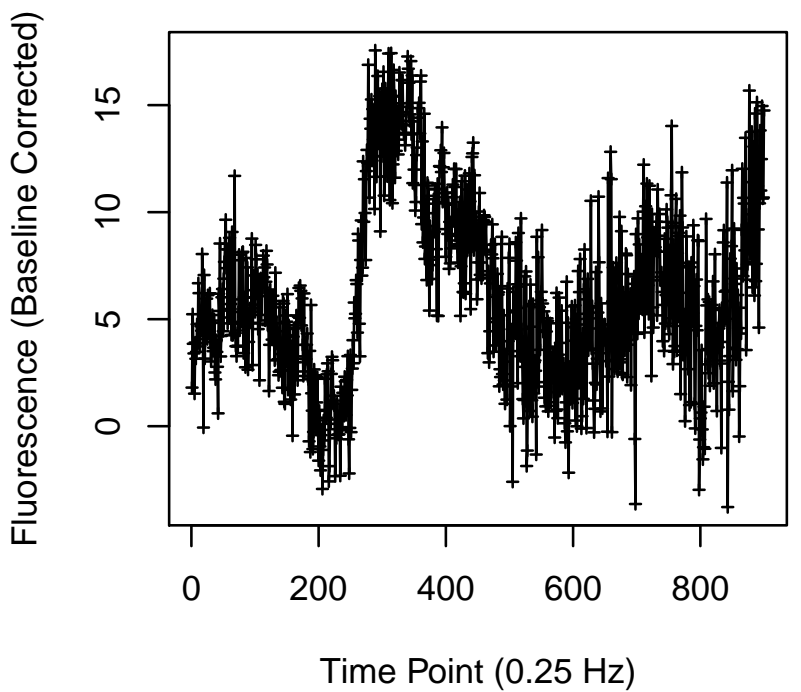




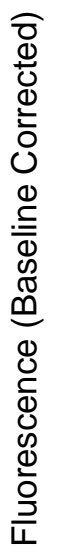

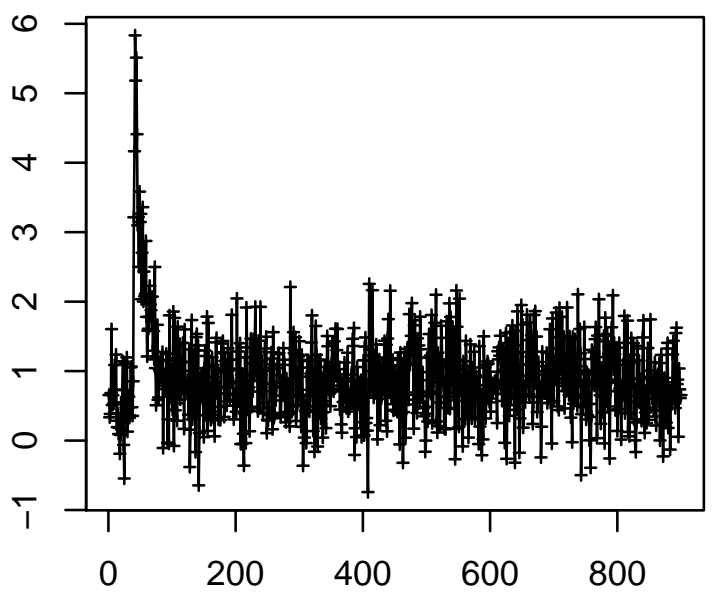

Time Point $(0.25 \mathrm{~Hz})$

Cell 611

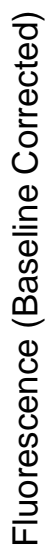

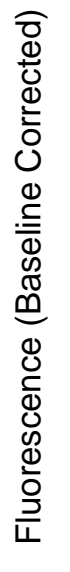

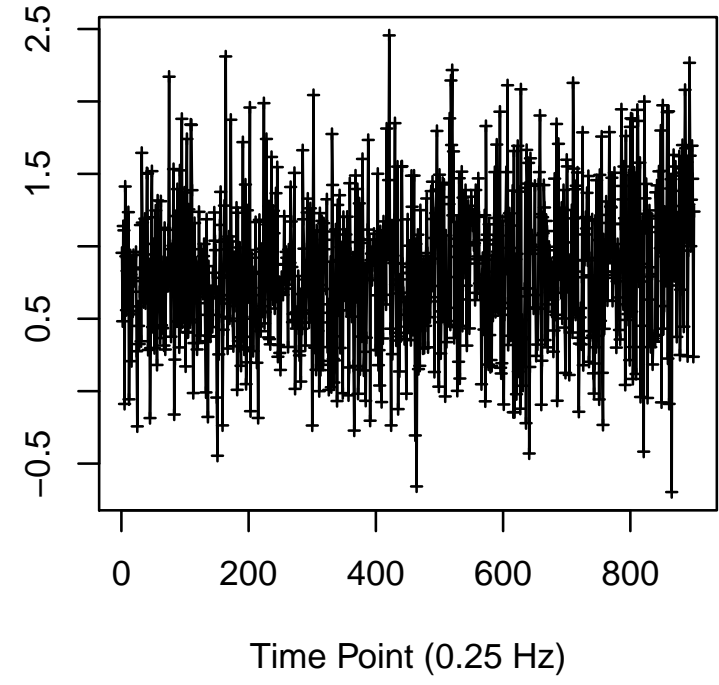

Cell 612

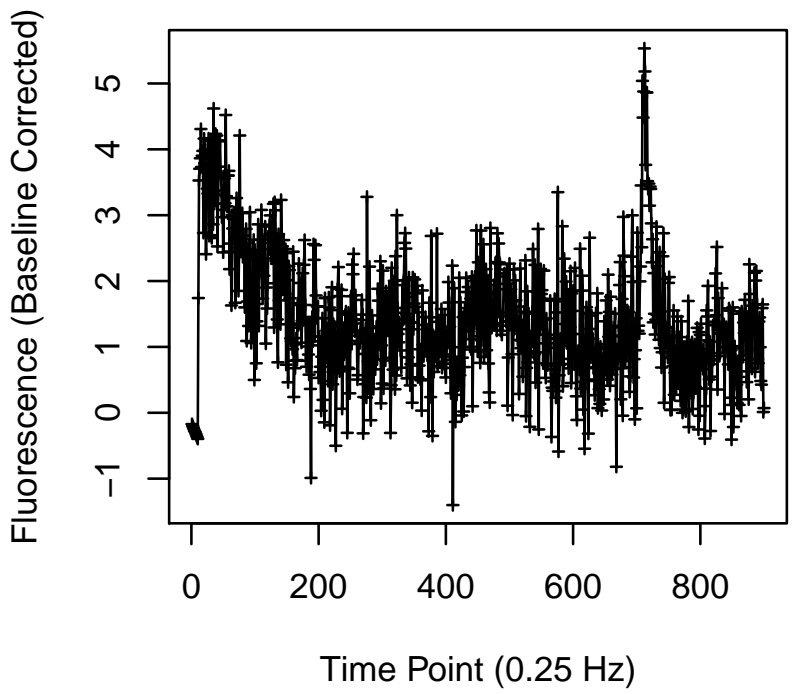


Cell 613

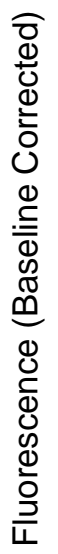

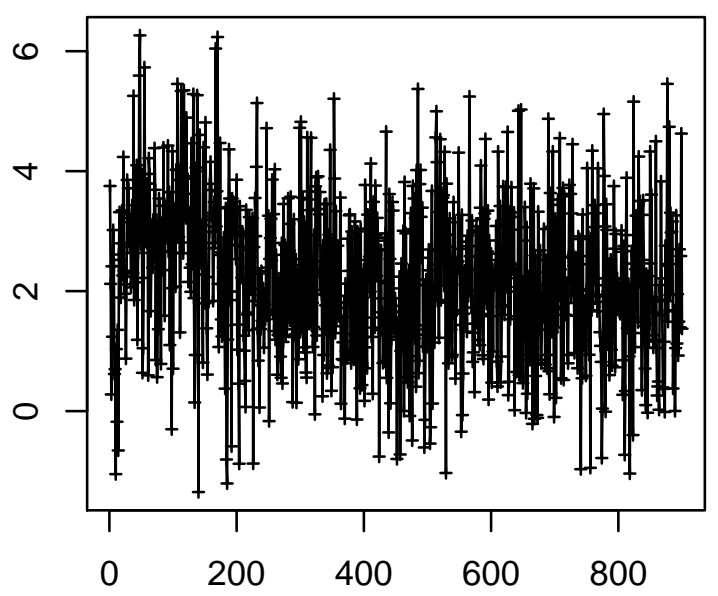

Time Point $(0.25 \mathrm{~Hz})$

\section{Cell 615}

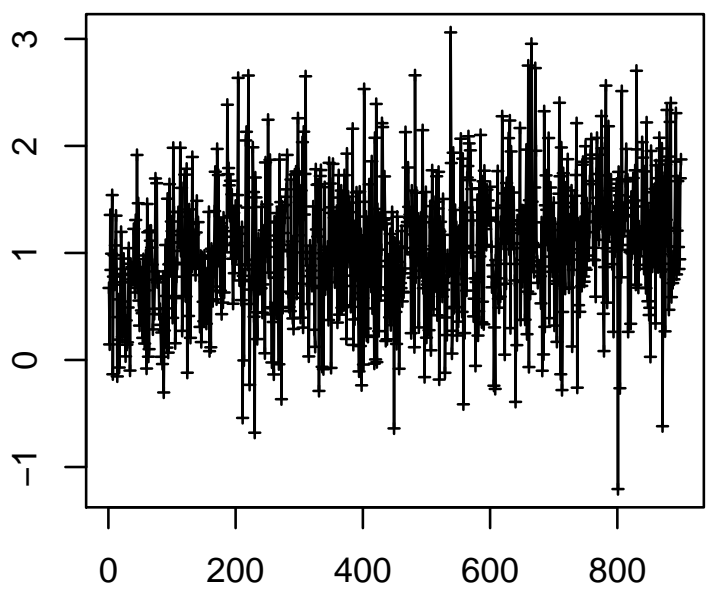

Time Point $(0.25 \mathrm{~Hz})$
Cell 614

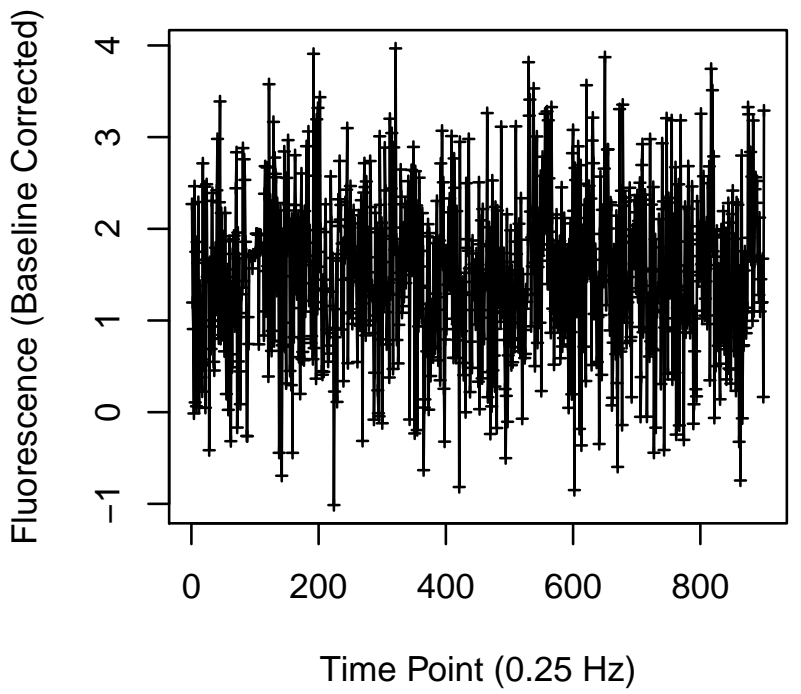

Cell 616

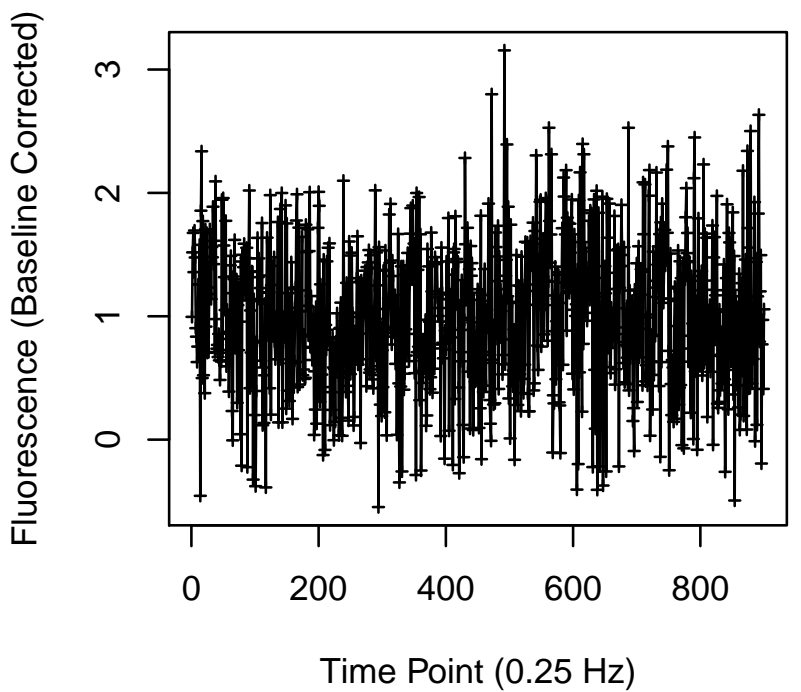




\section{Cell 617}

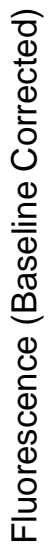

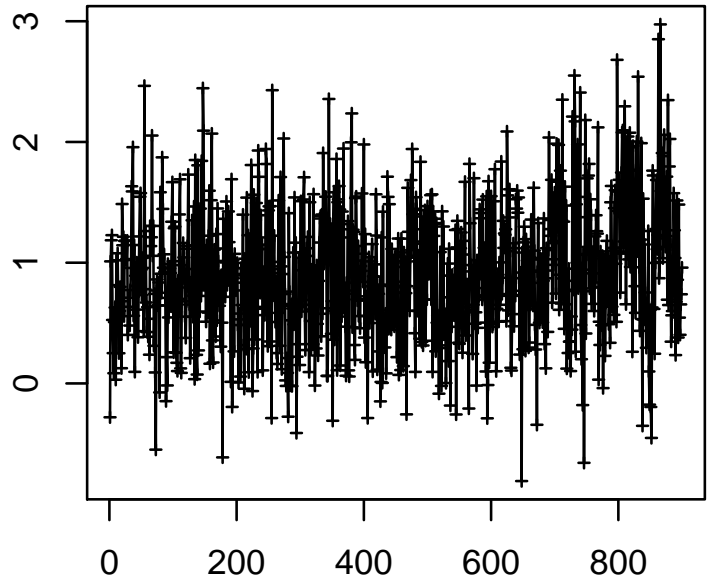

Time Point $(0.25 \mathrm{~Hz})$

\section{Cell 619}

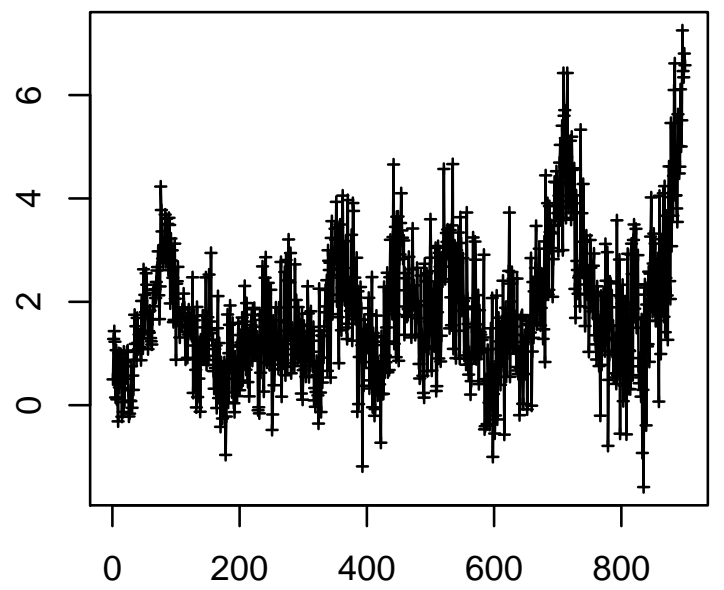

Time Point $(0.25 \mathrm{~Hz})$
Cell 618

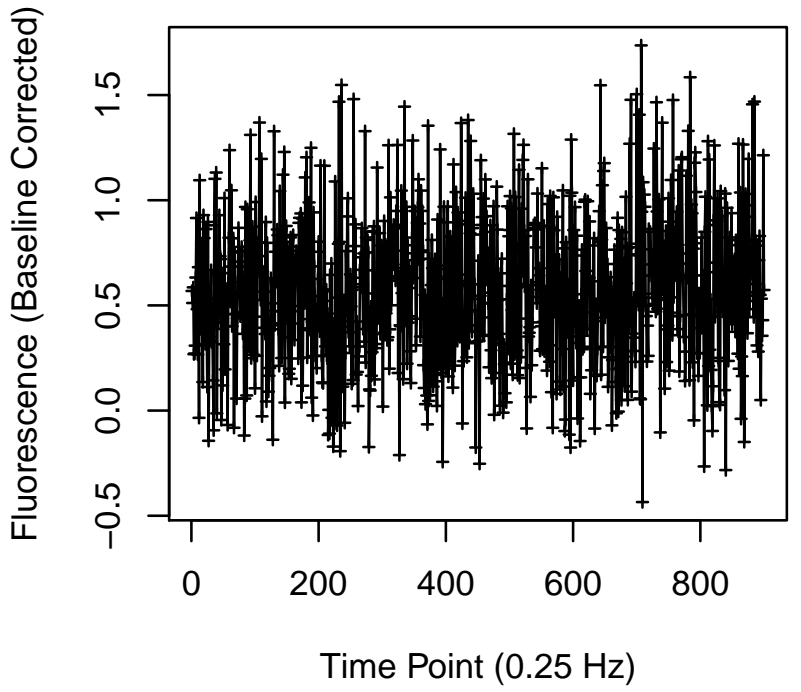

Cell 620

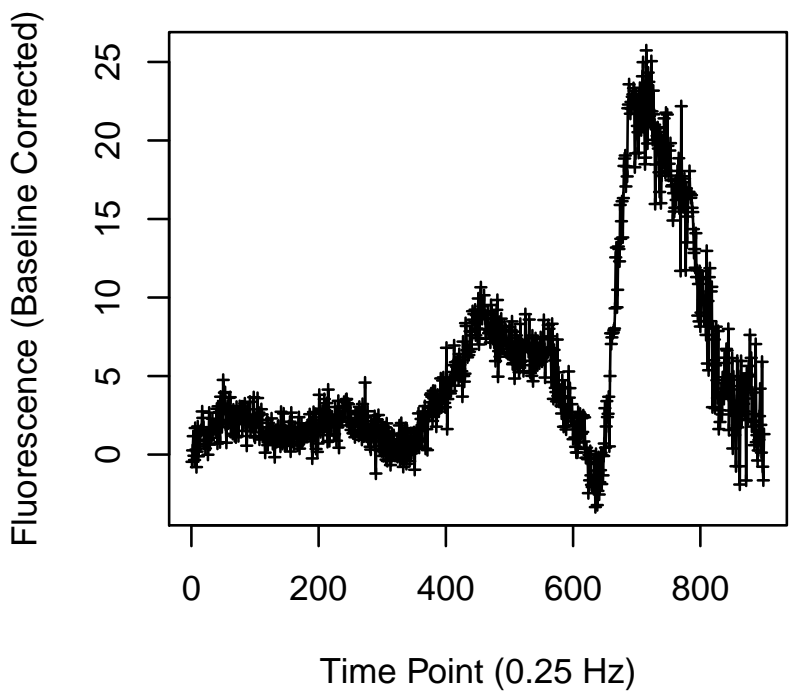


Cell 625

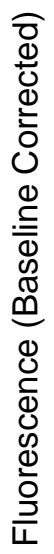

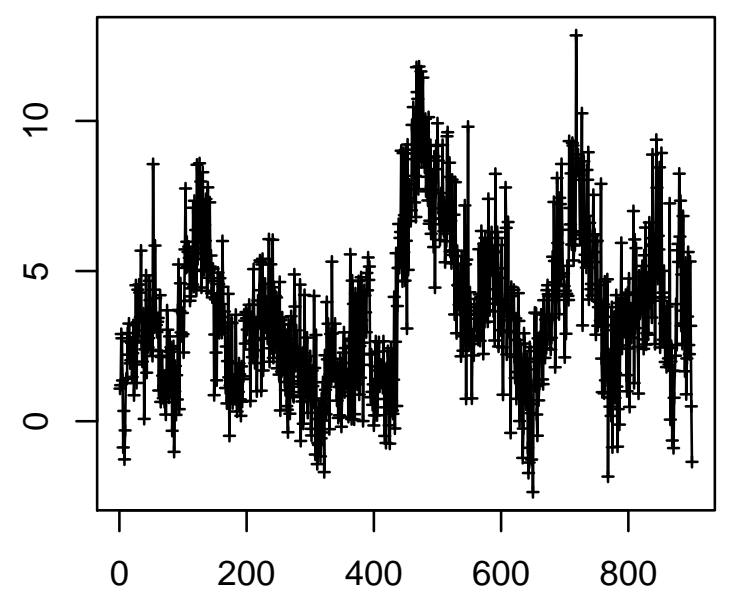

Time Point $(0.25 \mathrm{~Hz})$

Cell 627

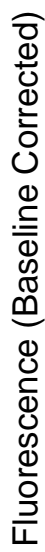

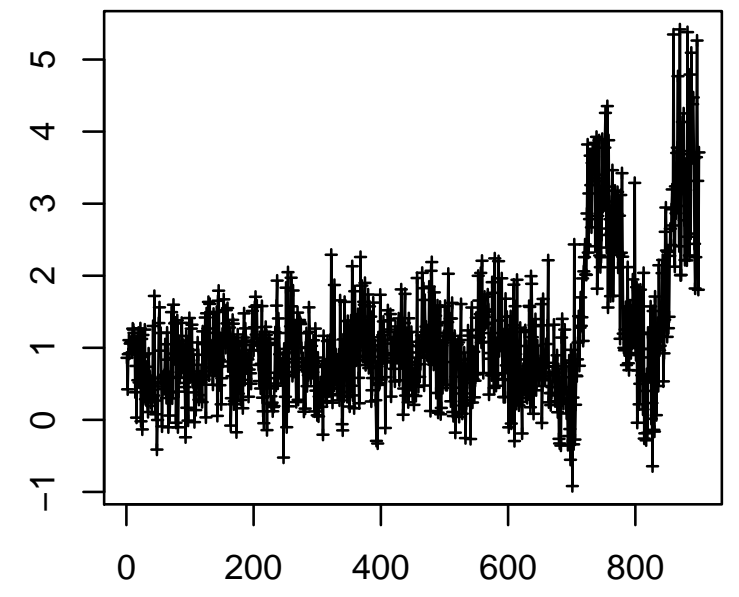

Time Point $(0.25 \mathrm{~Hz})$

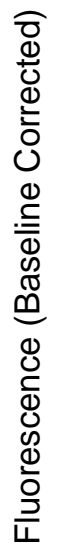

Cell 626

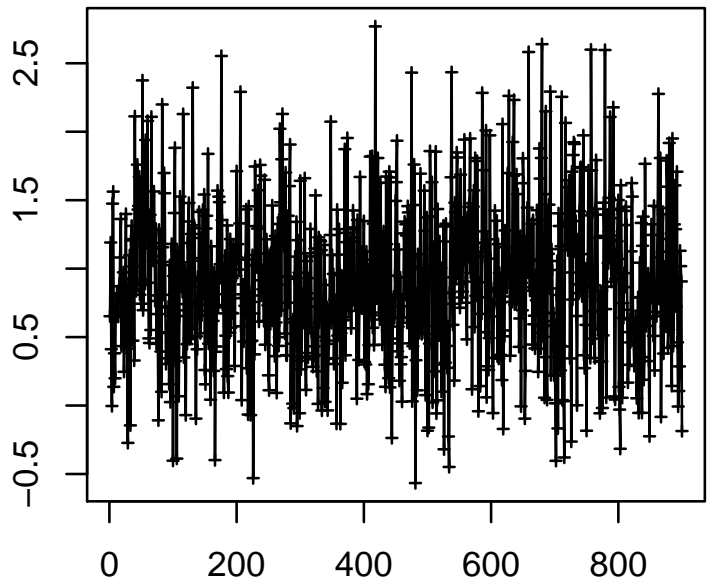

Time Point $(0.25 \mathrm{~Hz})$

Cell 628

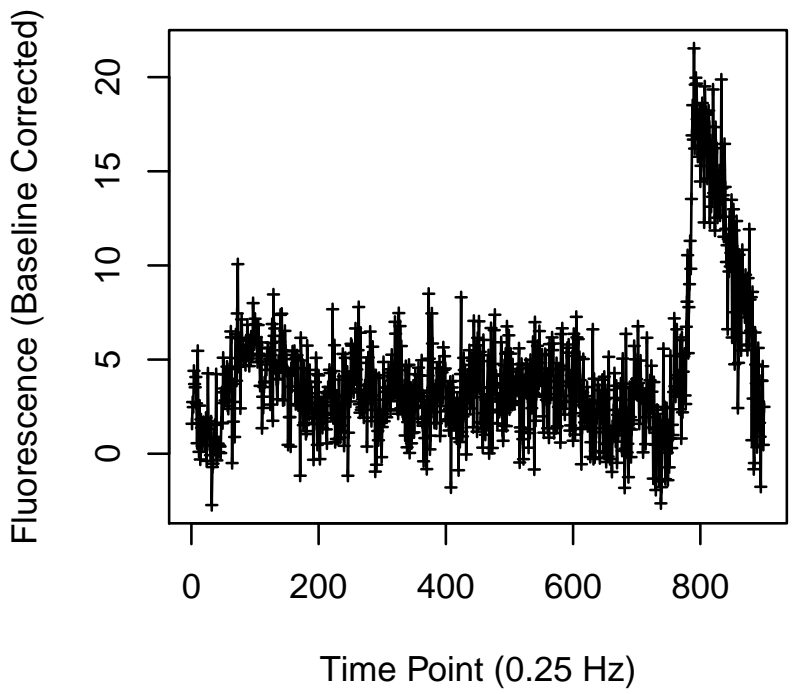




\section{Cell 629}

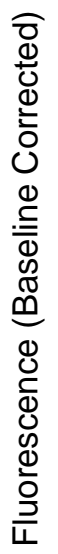

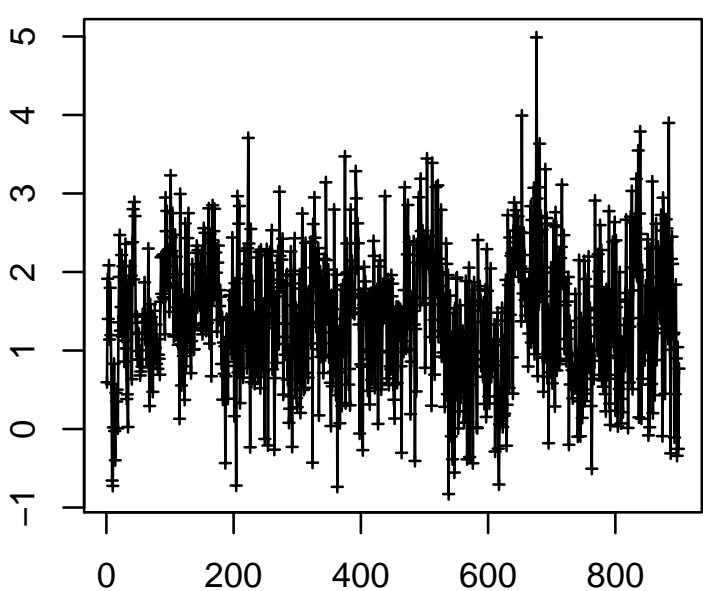

Time Point $(0.25 \mathrm{~Hz})$

\section{Cell 631}

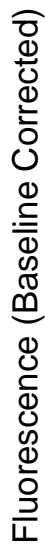

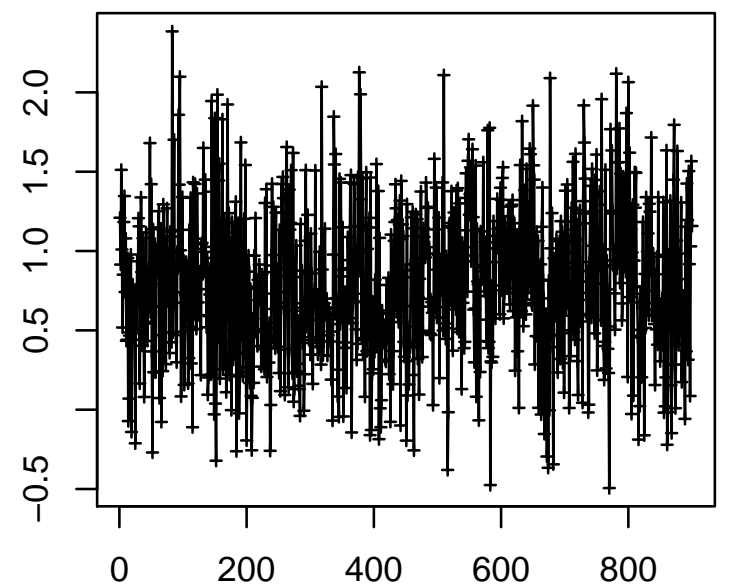

Time Point $(0.25 \mathrm{~Hz})$

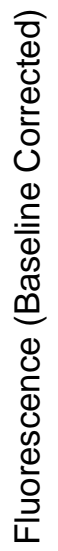

Cell 630

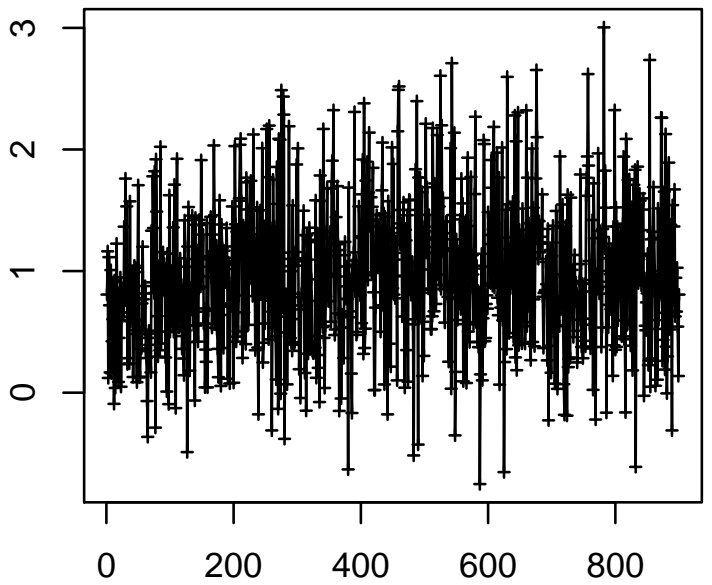

Time Point $(0.25 \mathrm{~Hz})$

Cell 632

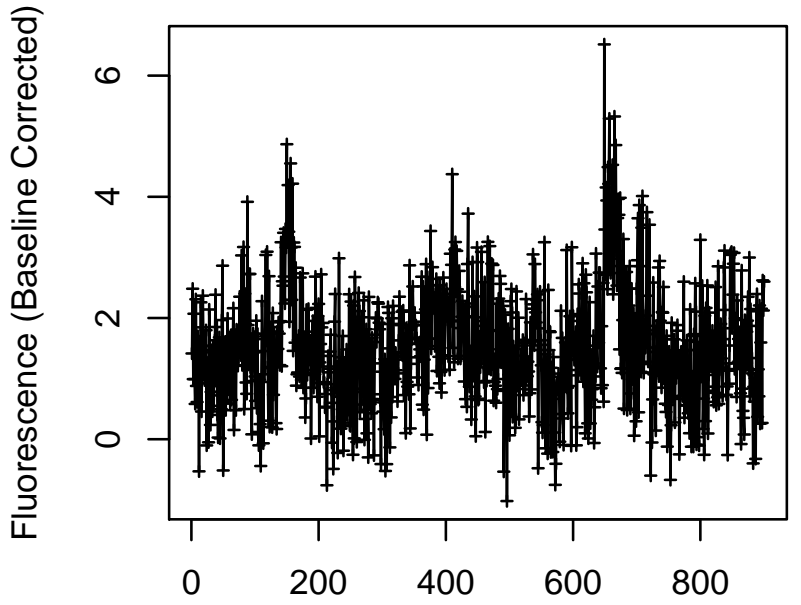

Time Point $(0.25 \mathrm{~Hz})$ 


\section{Cell 645}

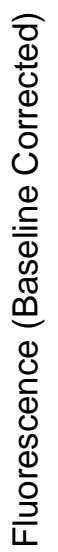

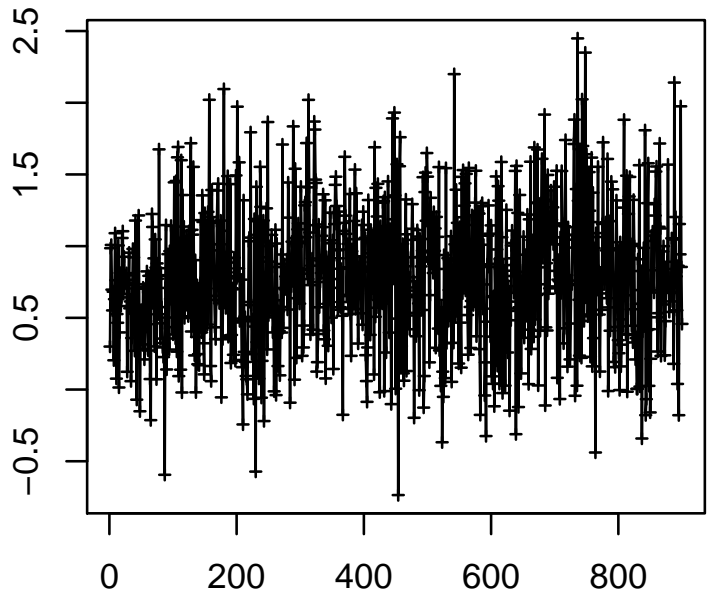

Time Point $(0.25 \mathrm{~Hz})$

\section{Cell 647}

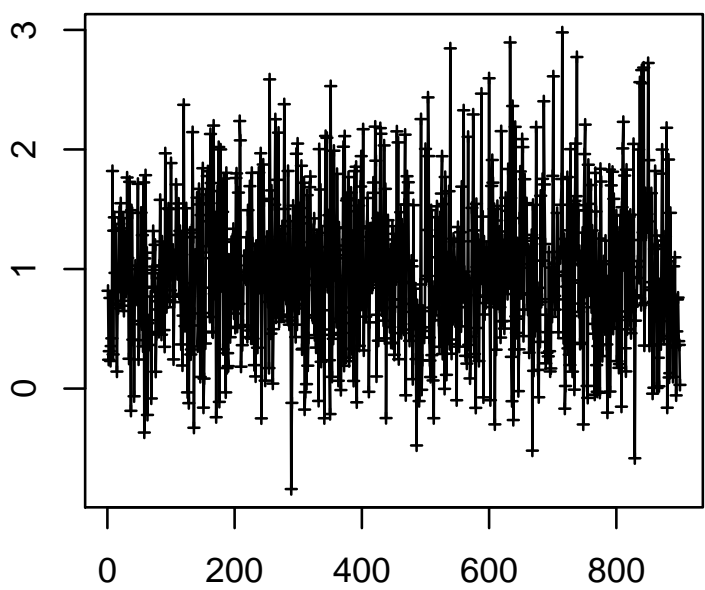

Time Point $(0.25 \mathrm{~Hz})$
Cell 646

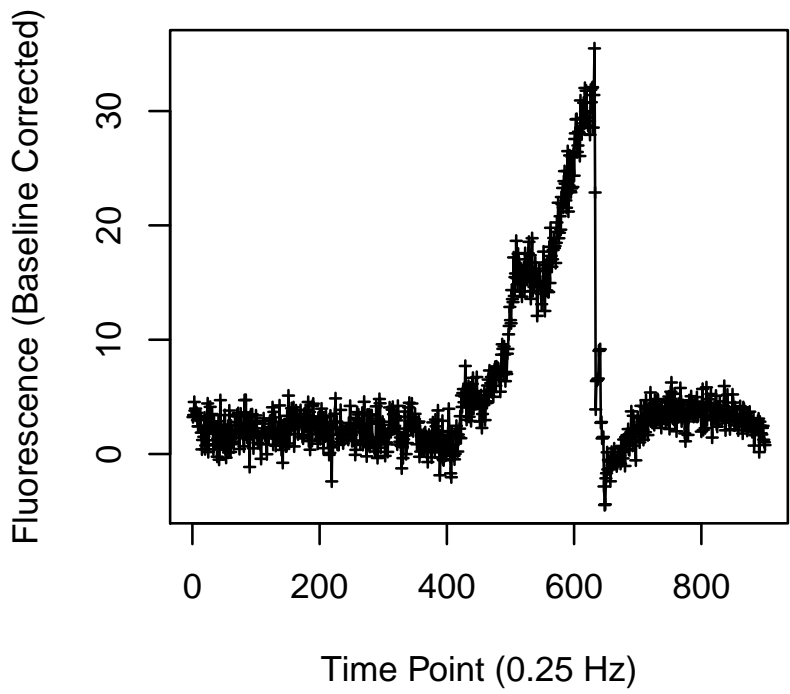

Cell 648

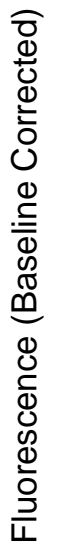

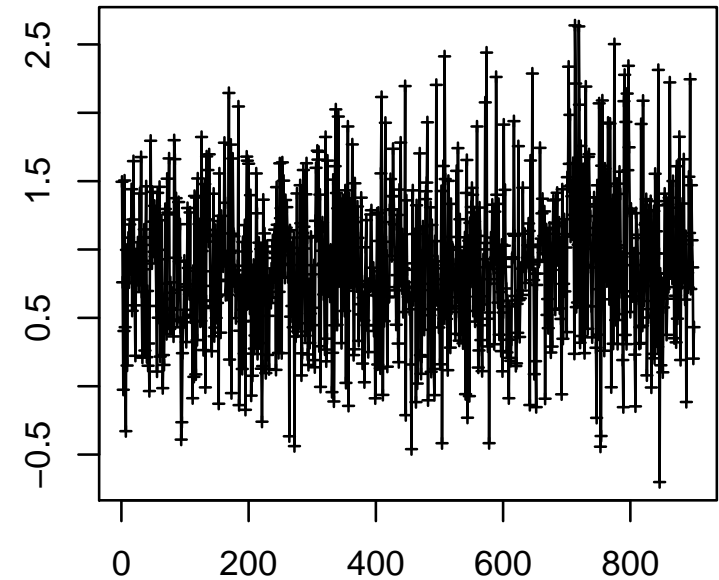

Time Point $(0.25 \mathrm{~Hz})$ 
Cell 657

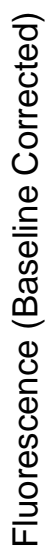

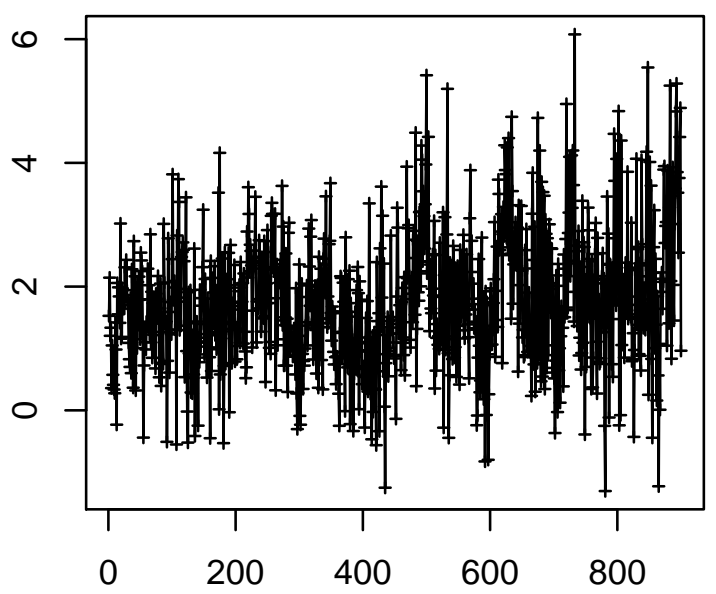

Time Point $(0.25 \mathrm{~Hz})$

\section{Cell 659}

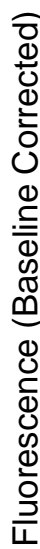

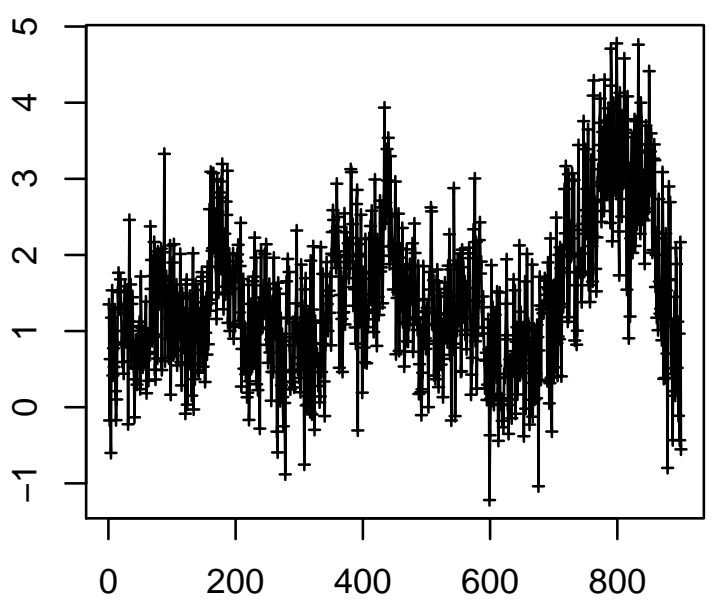

Time Point $(0.25 \mathrm{~Hz})$

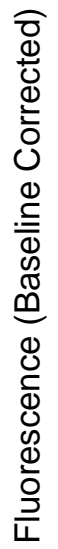

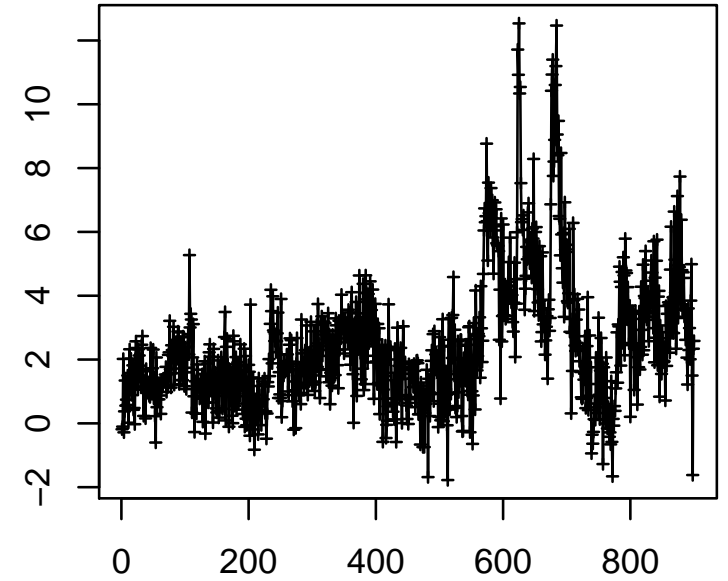

Time Point $(0.25 \mathrm{~Hz})$

\section{Cell 660}

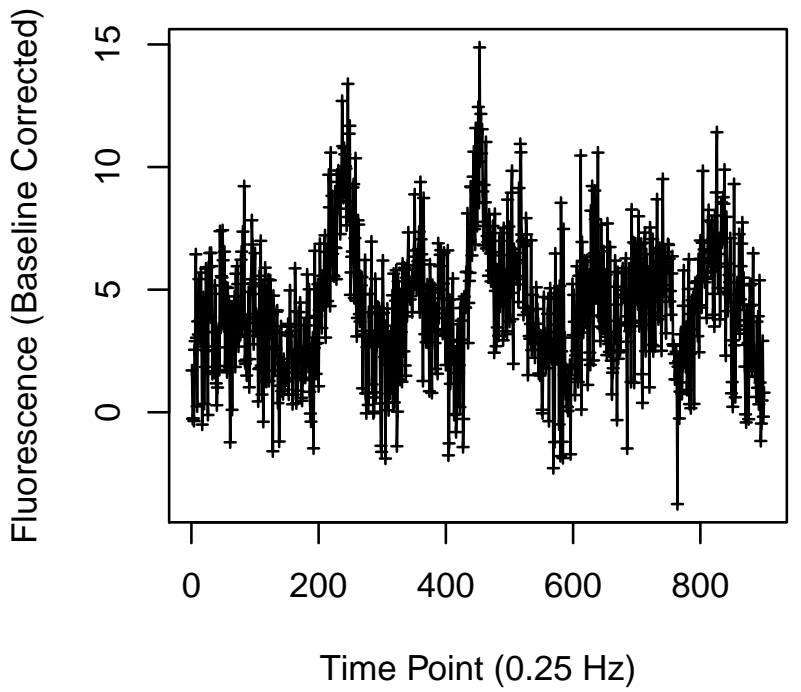




\section{Cell 669}

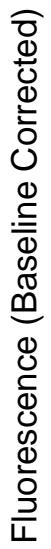

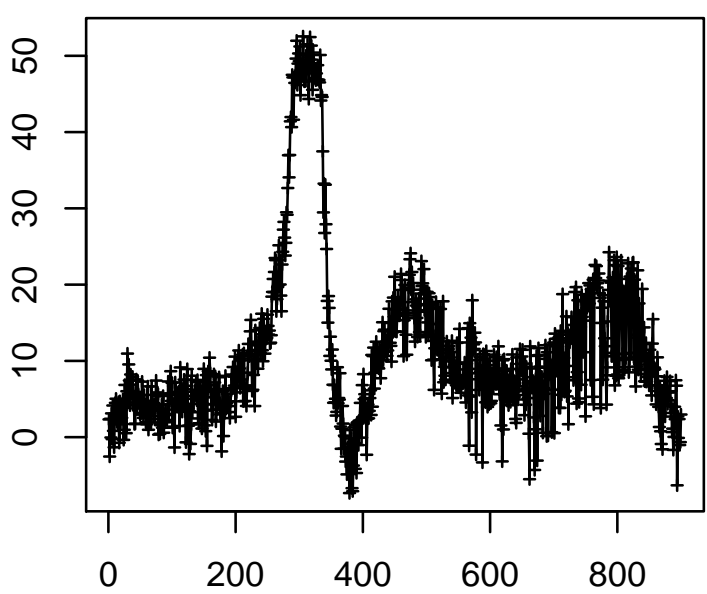

Time Point $(0.25 \mathrm{~Hz})$

Cell 671

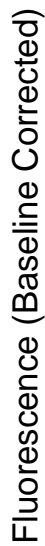

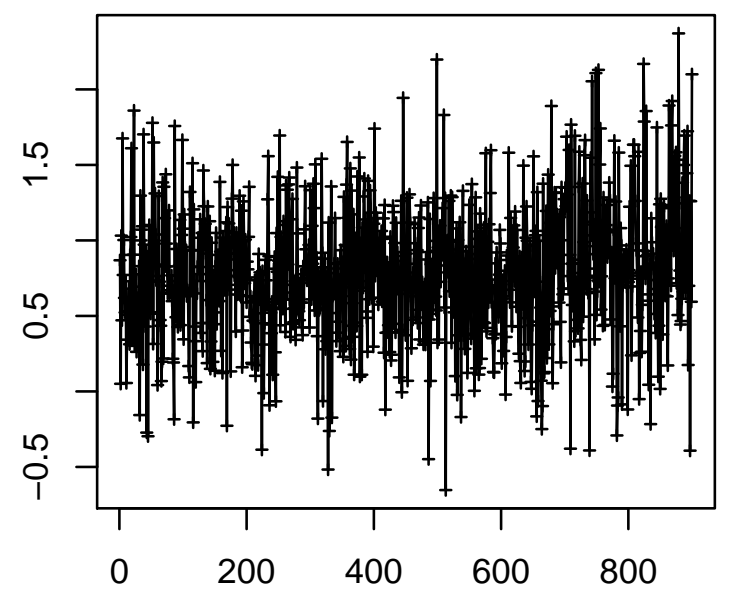

Time Point $(0.25 \mathrm{~Hz})$

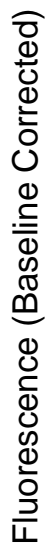

Cell 672

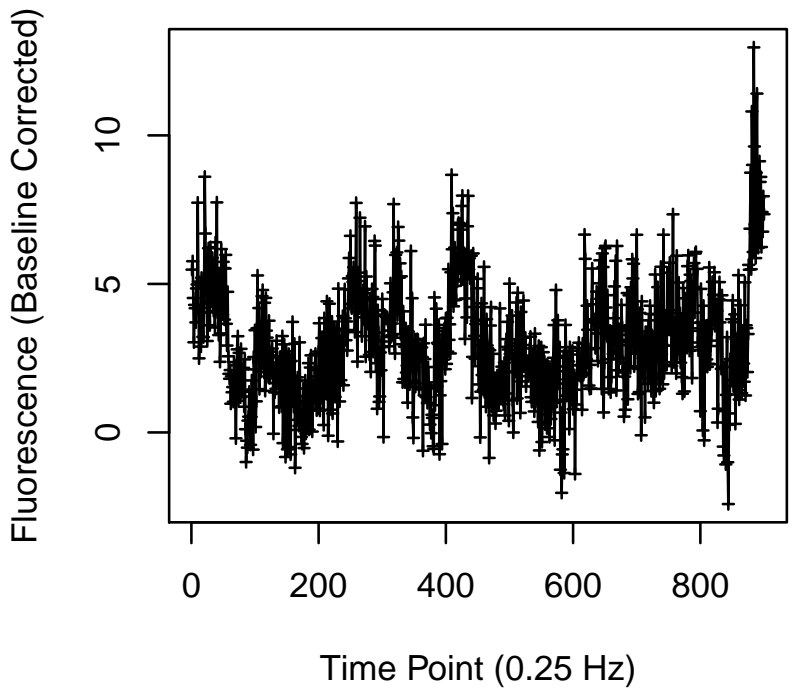




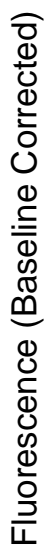

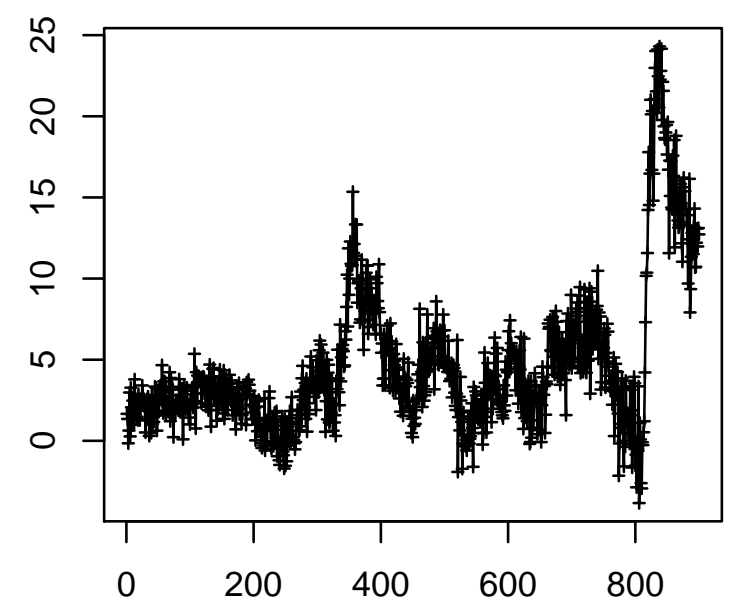

Time Point $(0.25 \mathrm{~Hz})$

Cell 675

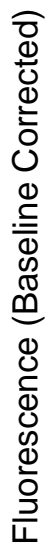

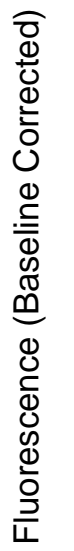

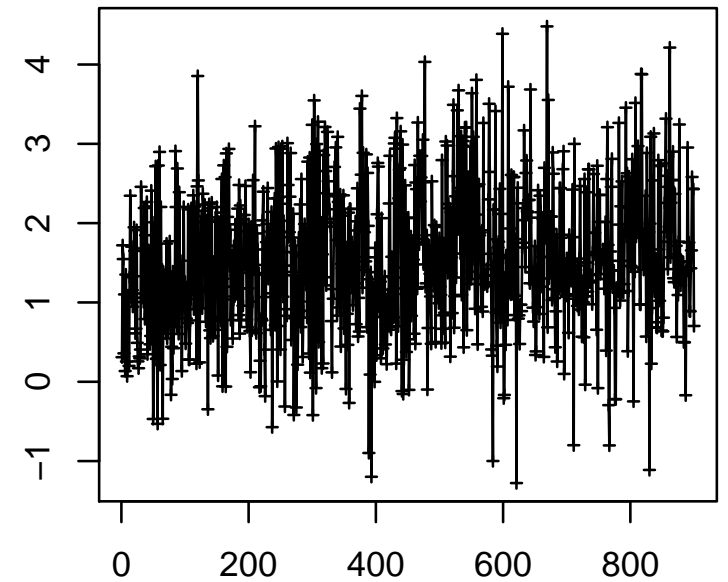

Time Point $(0.25 \mathrm{~Hz})$

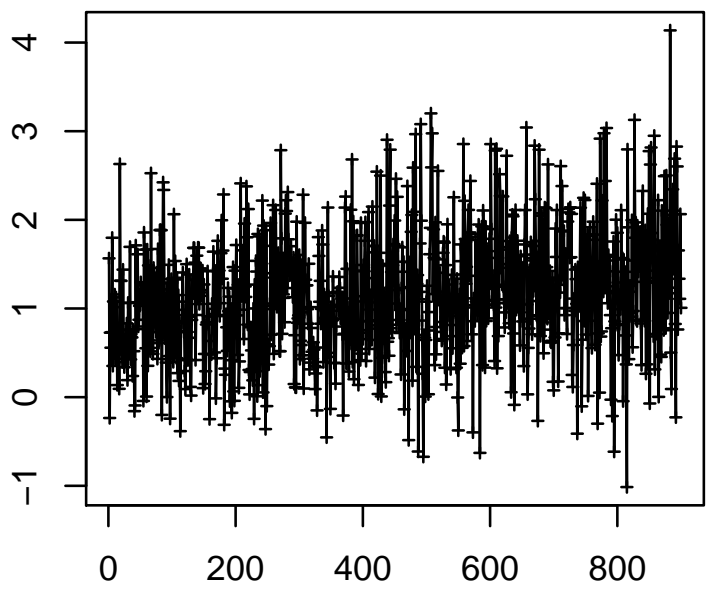

Time Point $(0.25 \mathrm{~Hz})$

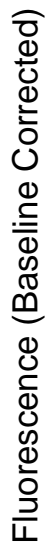

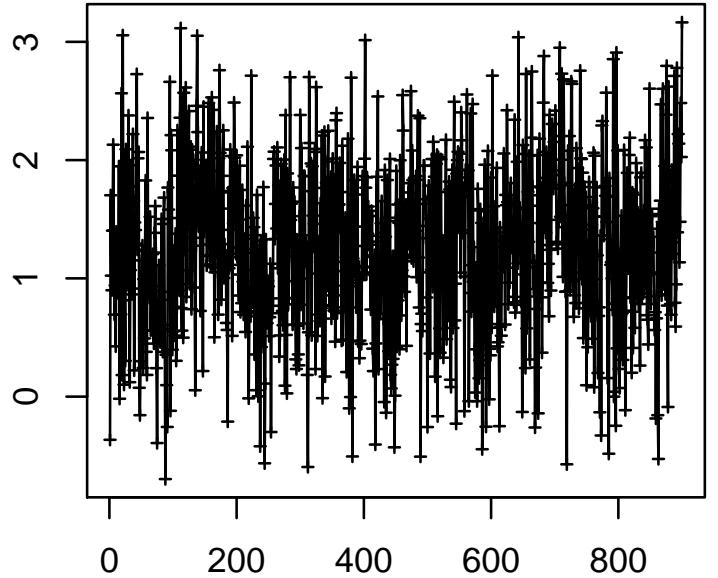

Time Point $(0.25 \mathrm{~Hz})$ 
Cell 677

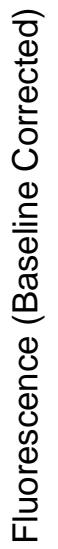

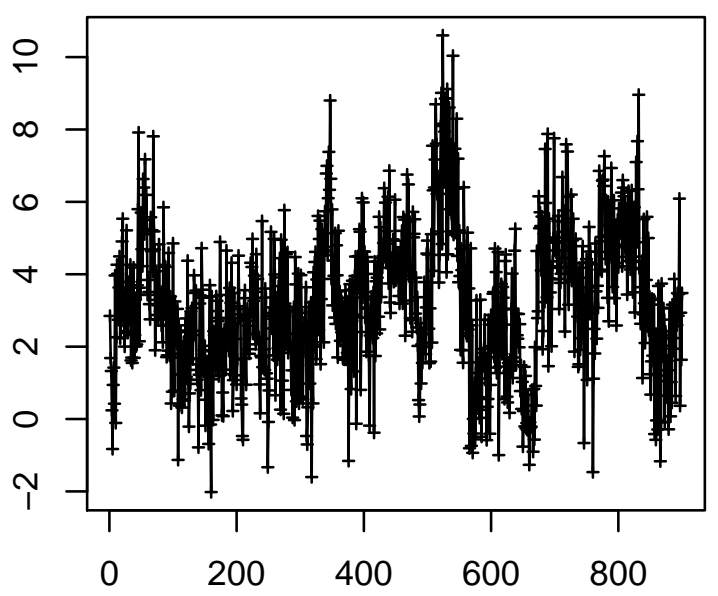

Time Point $(0.25 \mathrm{~Hz})$

\section{Cell 679}

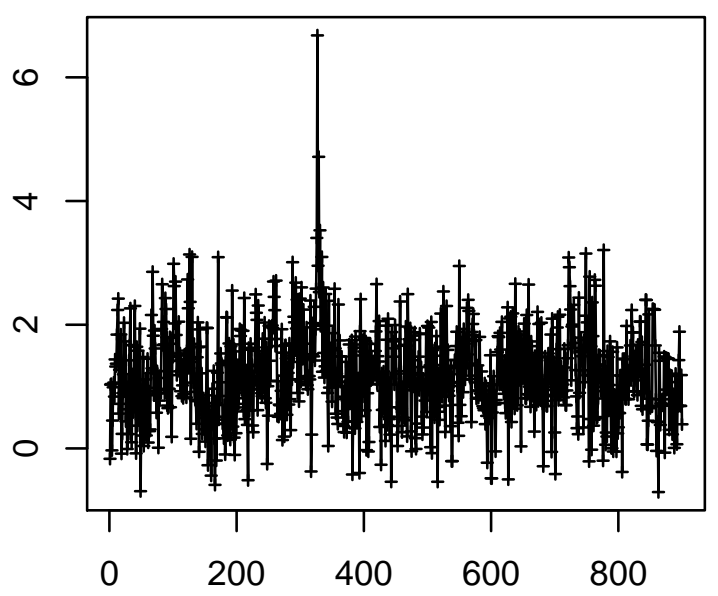

Time Point $(0.25 \mathrm{~Hz})$
Cell 678

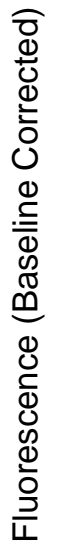

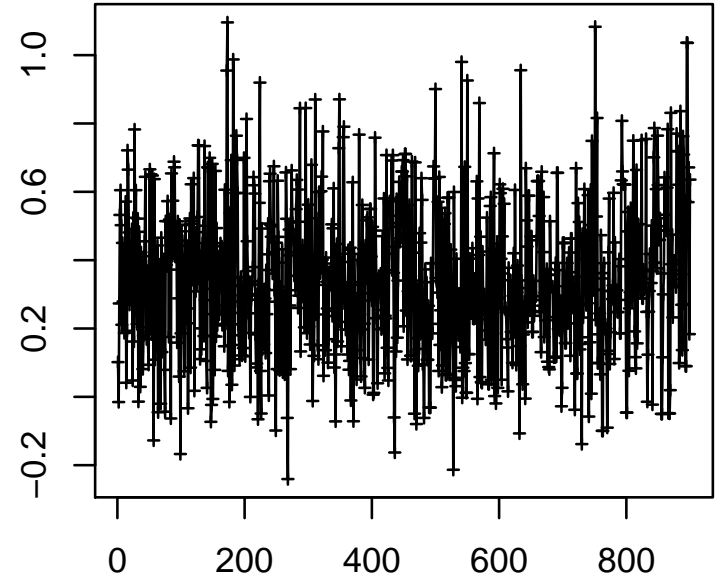

Time Point $(0.25 \mathrm{~Hz})$

\section{Cell 680}

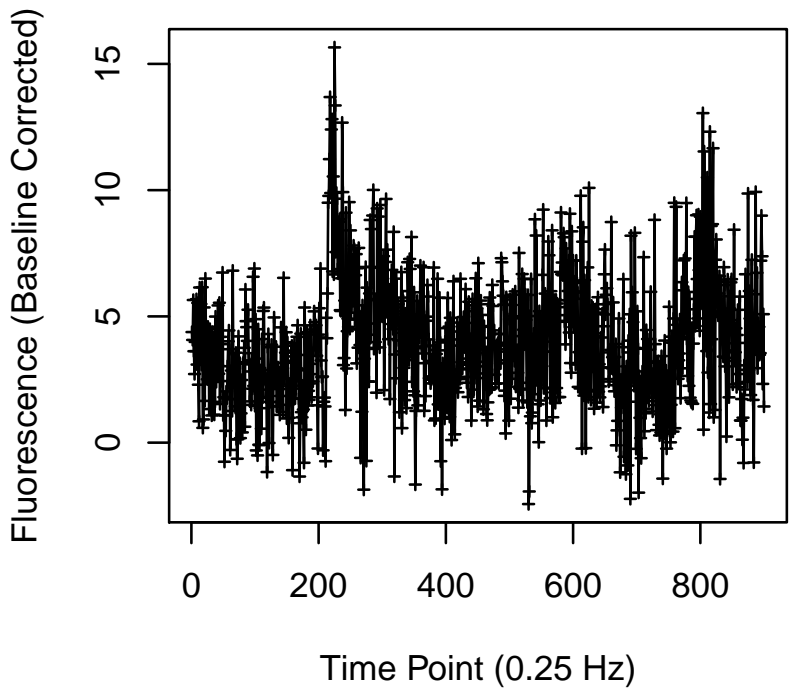


Cell 681

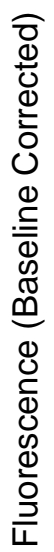

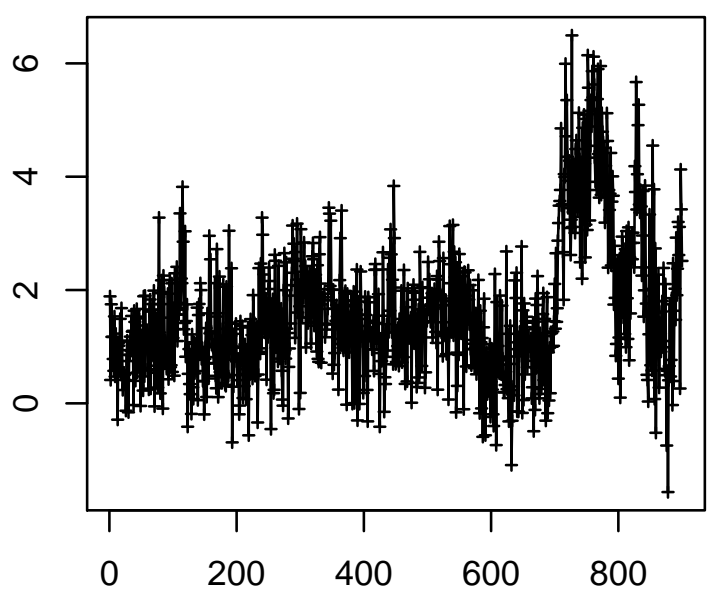

Time Point $(0.25 \mathrm{~Hz})$

Cell 683

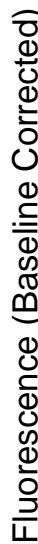

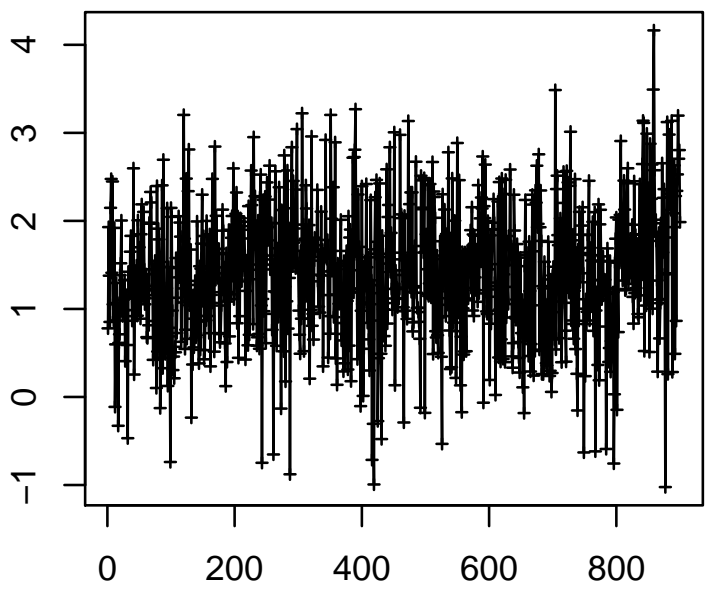

Time Point $(0.25 \mathrm{~Hz})$
Cell 682

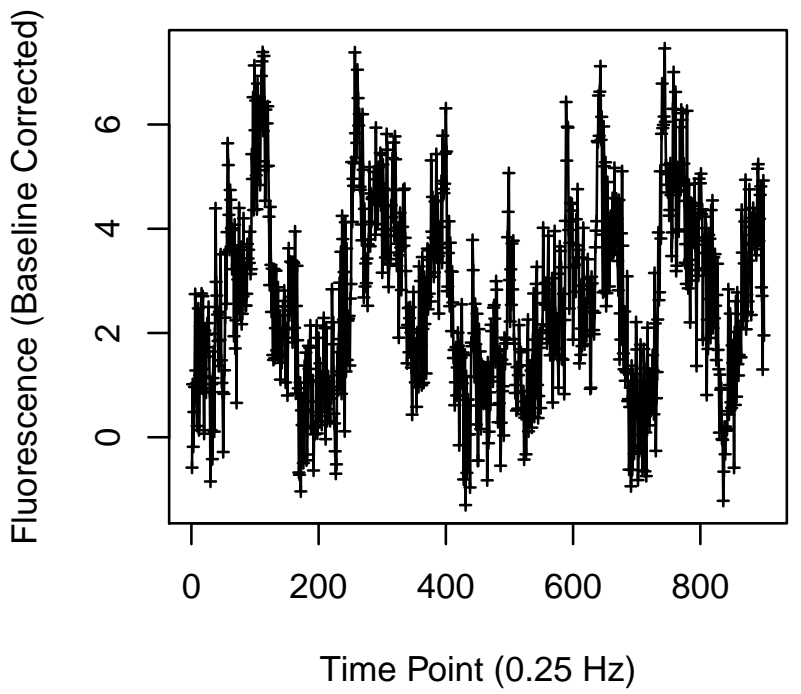

Cell 684

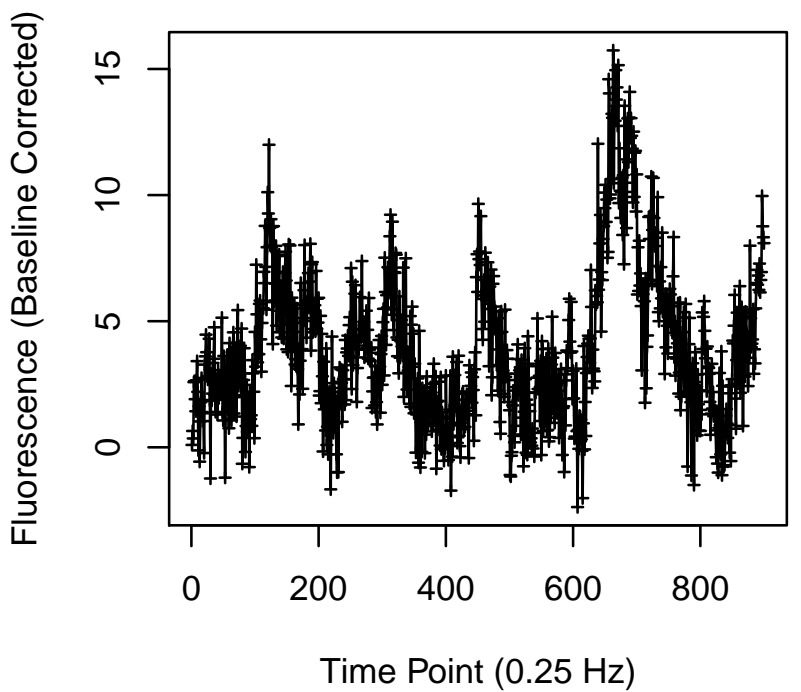


Cell 685

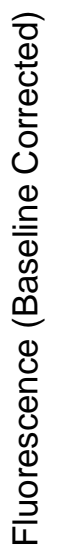

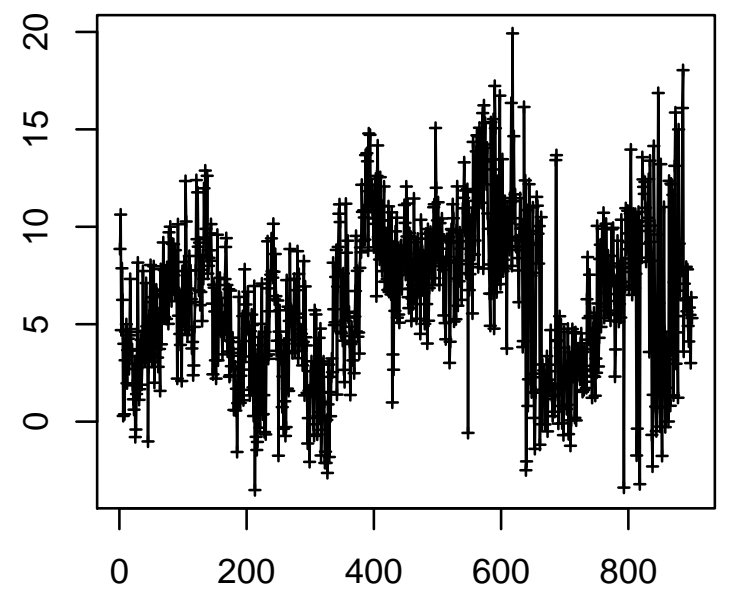

Time Point $(0.25 \mathrm{~Hz})$

Cell 687

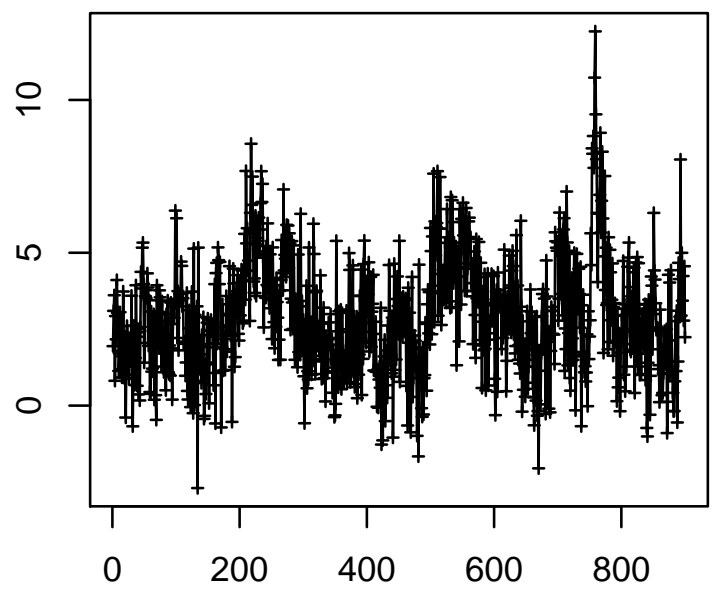

Time Point $(0.25 \mathrm{~Hz})$
Cell 686

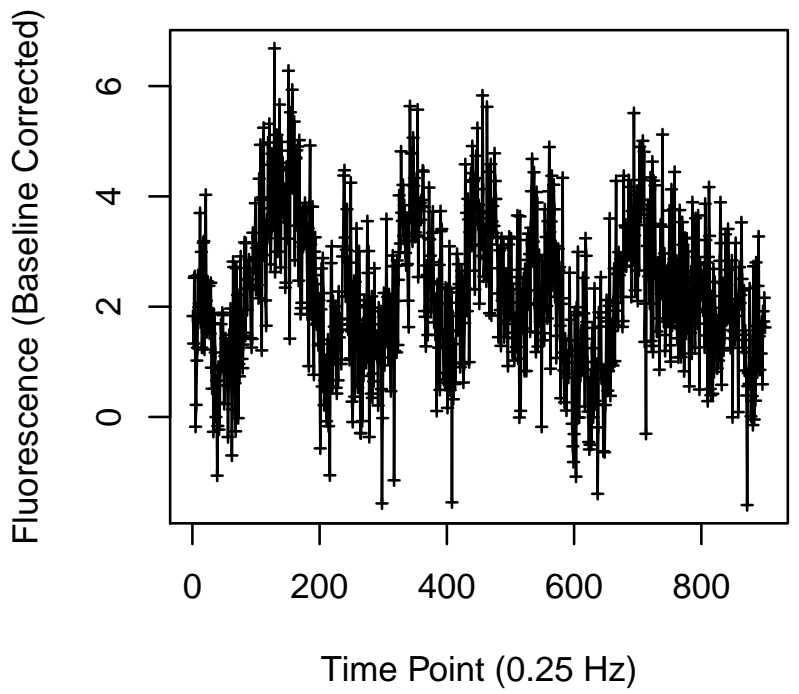

Cell 688

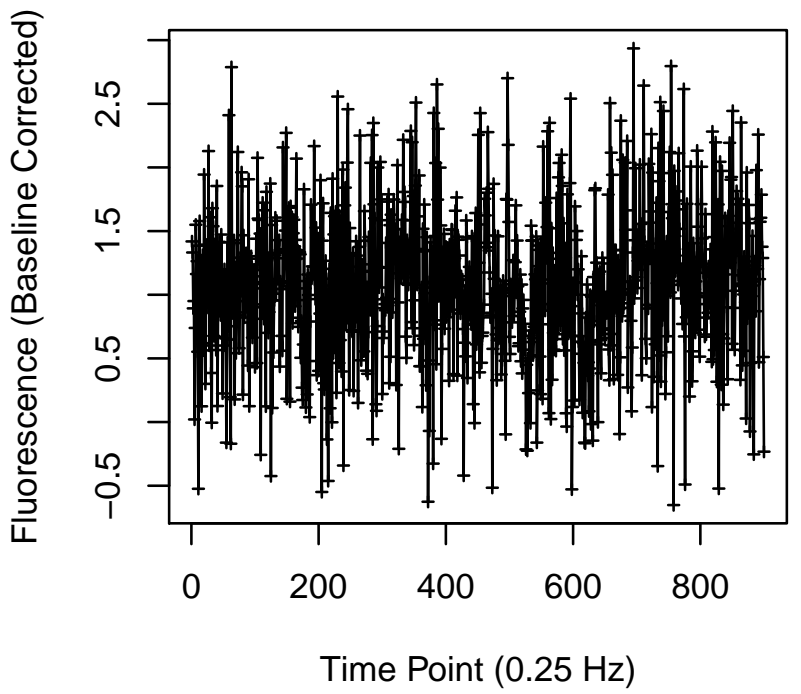


Cell 689

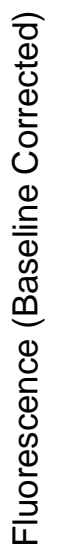

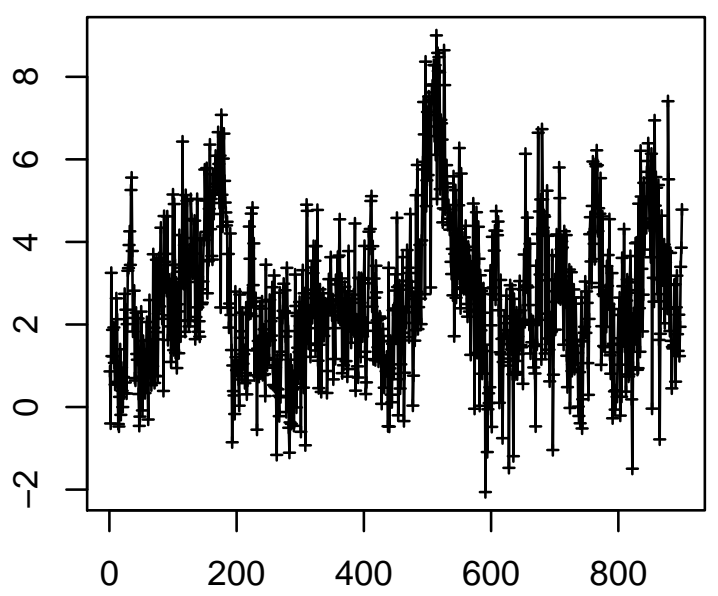

Time Point $(0.25 \mathrm{~Hz})$

Cell 691

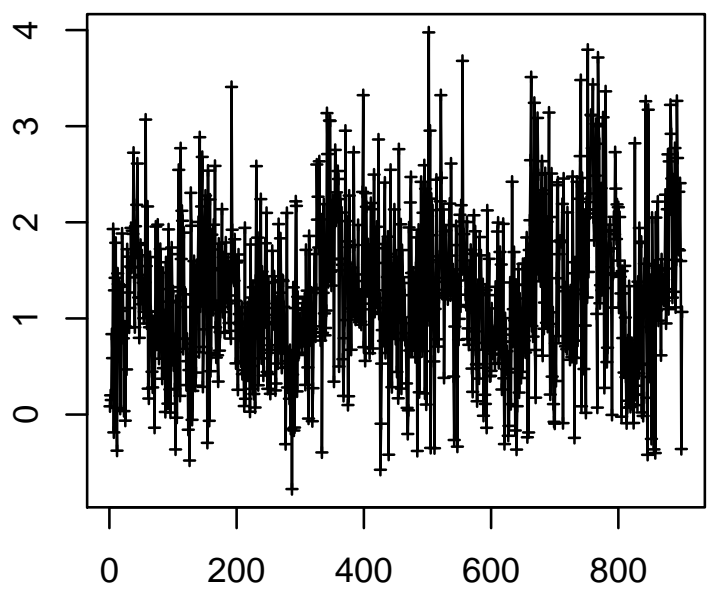

Time Point $(0.25 \mathrm{~Hz})$
Cell 690

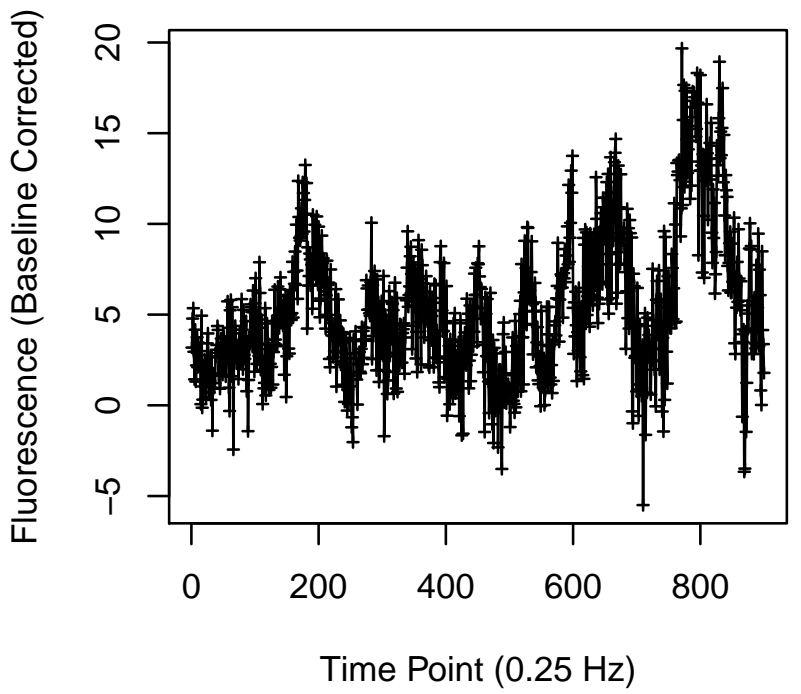

Cell 692

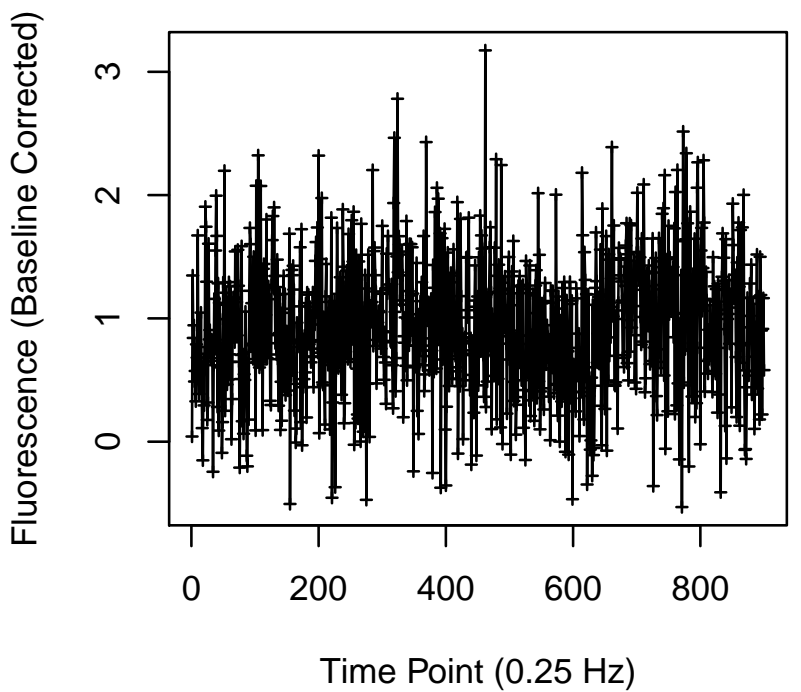


Cell 693

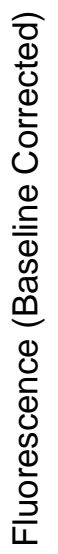

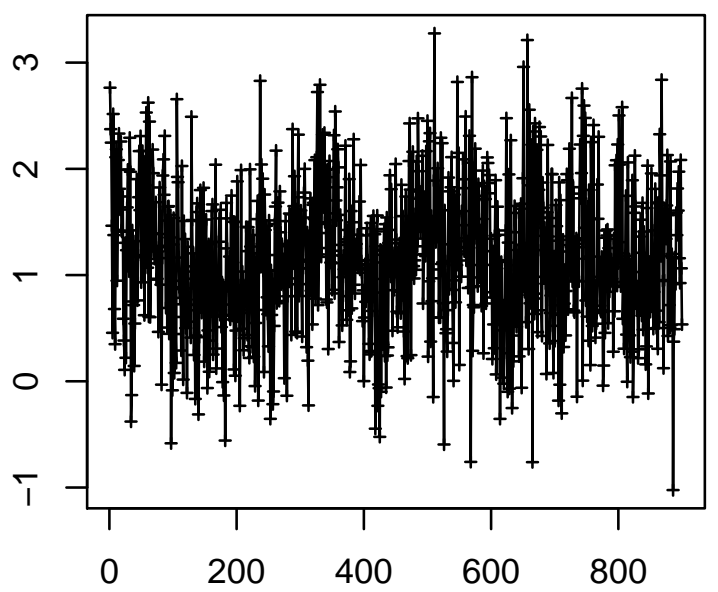

Time Point $(0.25 \mathrm{~Hz})$

\section{Cell 695}

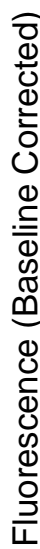

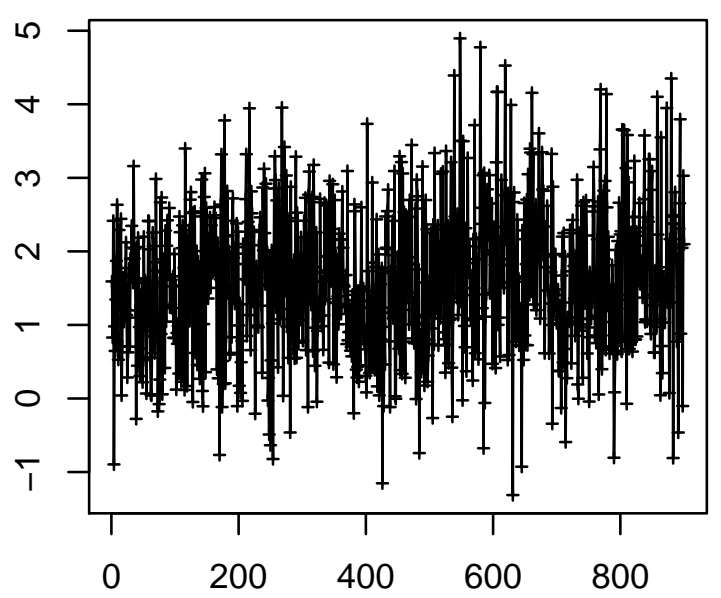

Time Point $(0.25 \mathrm{~Hz})$

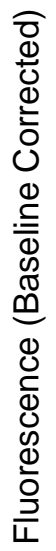

Cell 696

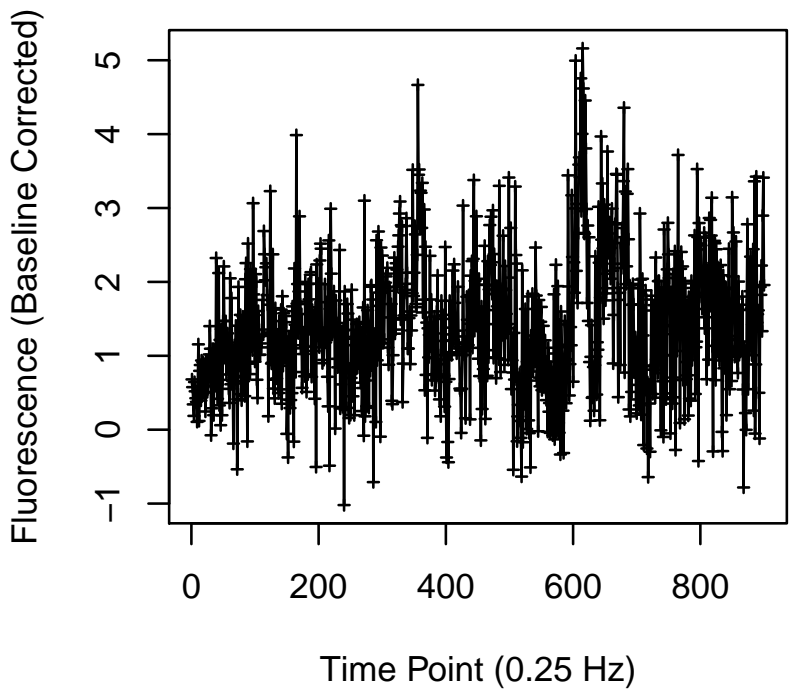


Cell 697

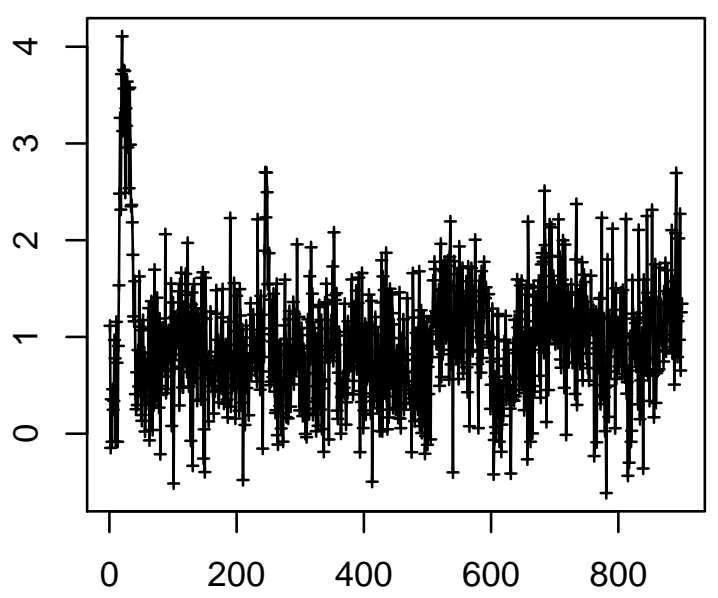

Time Point $(0.25 \mathrm{~Hz})$

\section{Cell 699}

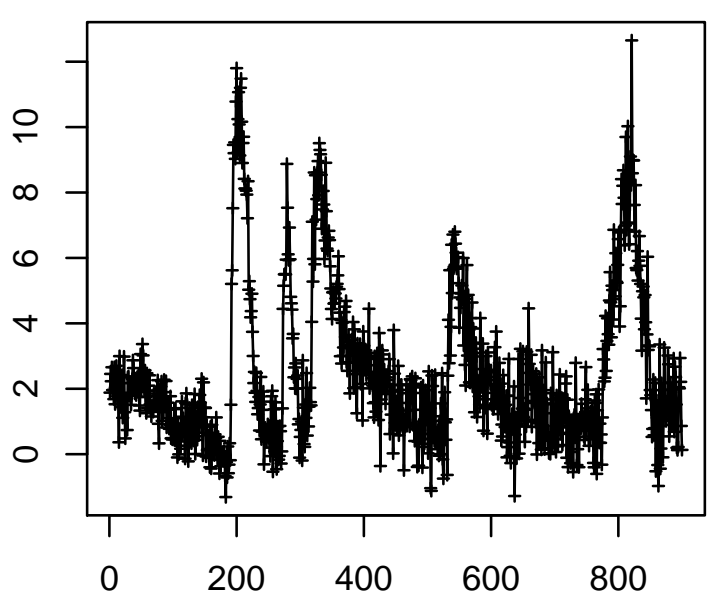

Time Point $(0.25 \mathrm{~Hz})$
Cell 698

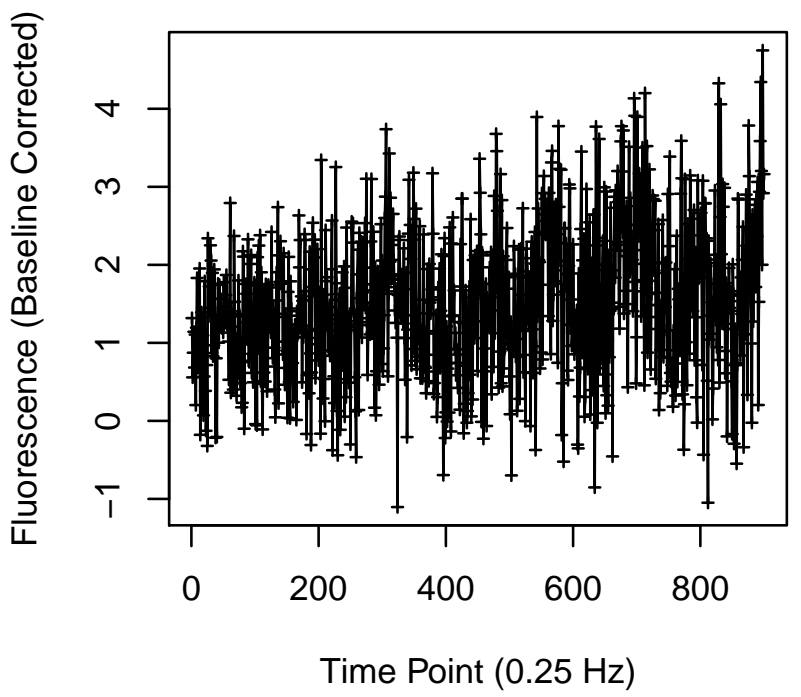

Cell 700

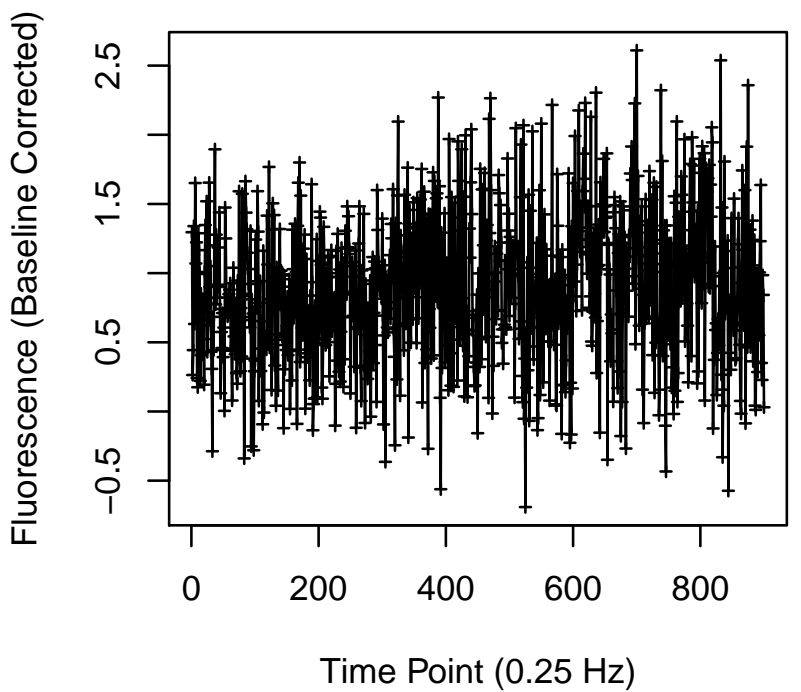


Cell 701

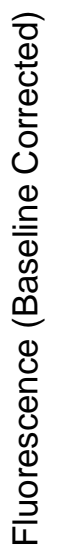

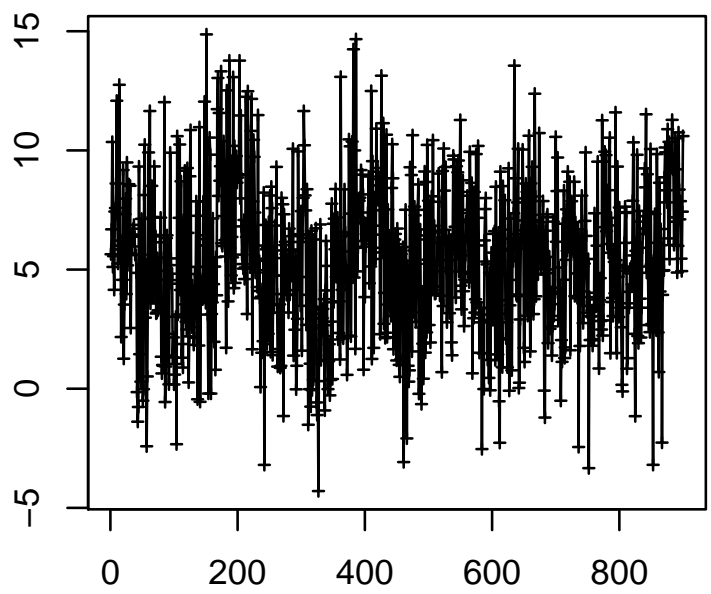

Time Point $(0.25 \mathrm{~Hz})$

Cell 703

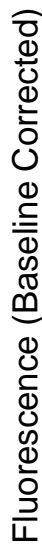

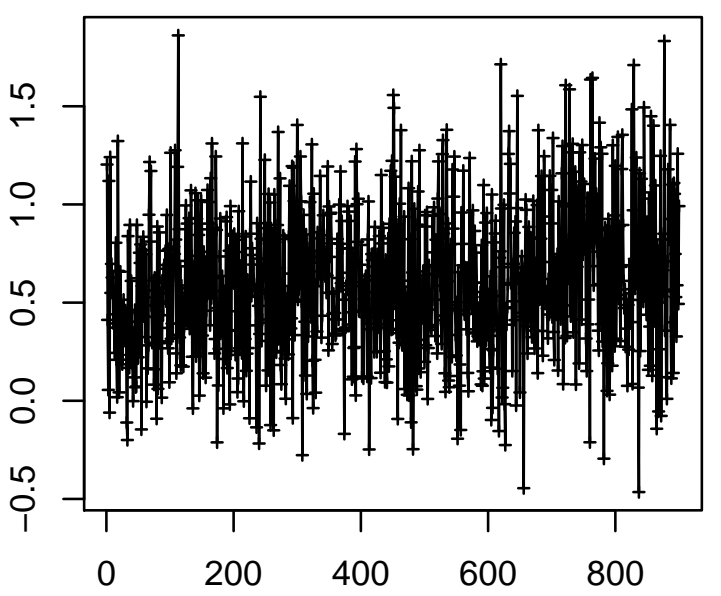

Time Point $(0.25 \mathrm{~Hz})$
Cell 702

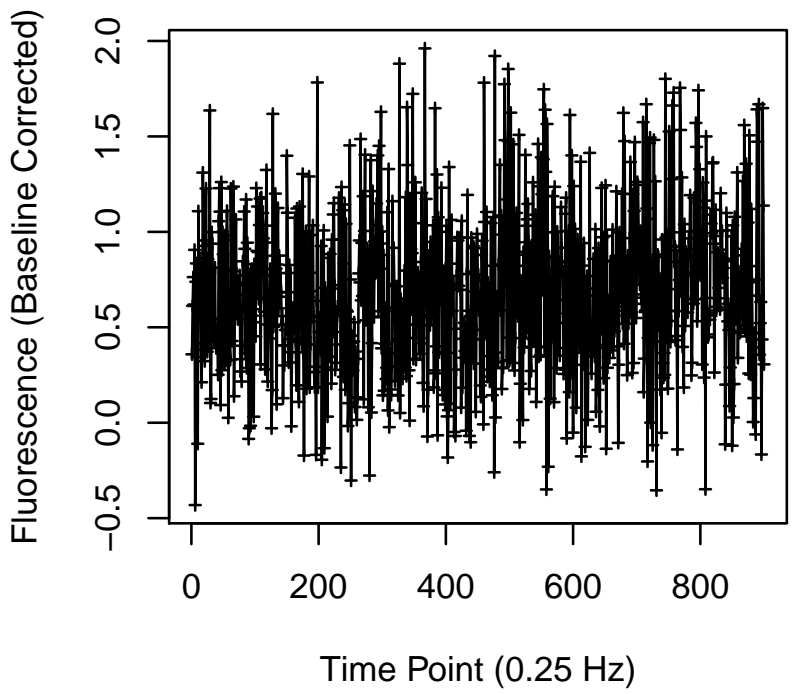

Cell 704

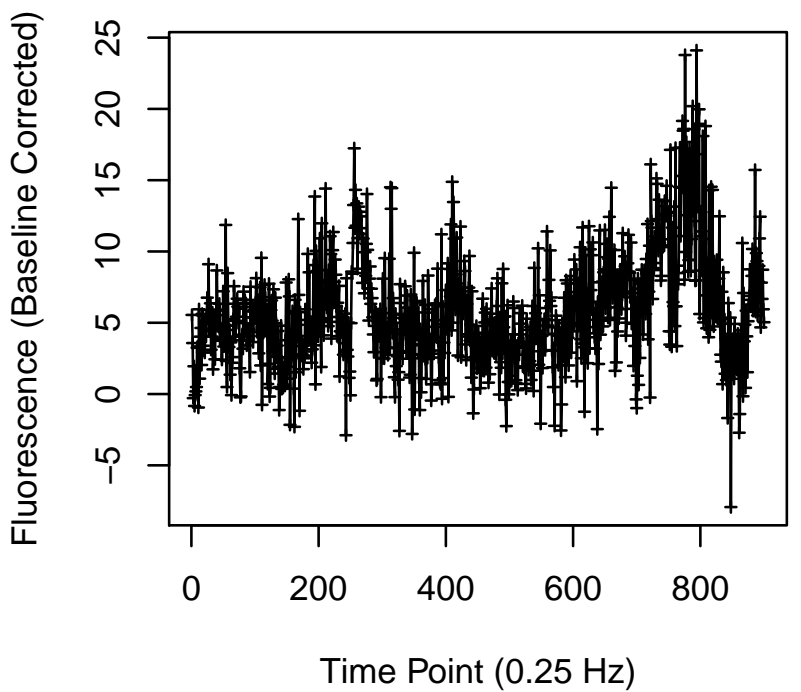


Cell 705

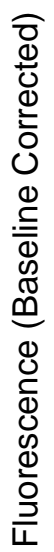

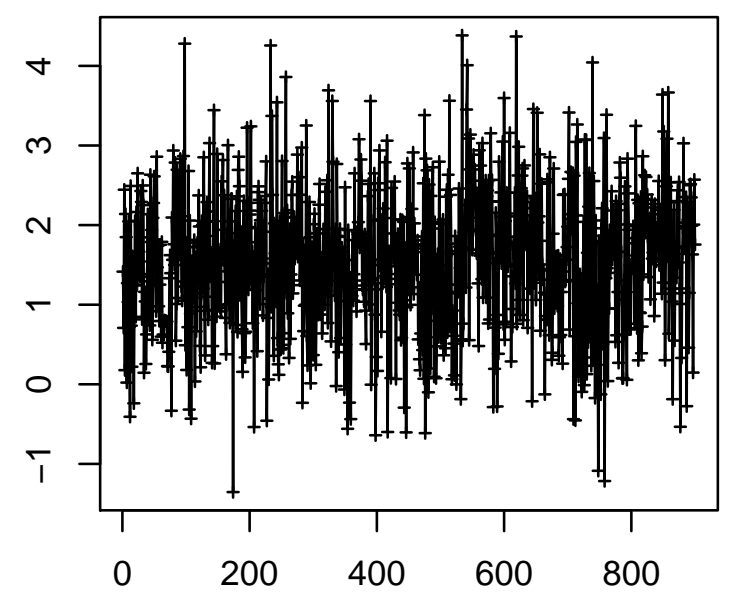

Time Point $(0.25 \mathrm{~Hz})$

Cell 707

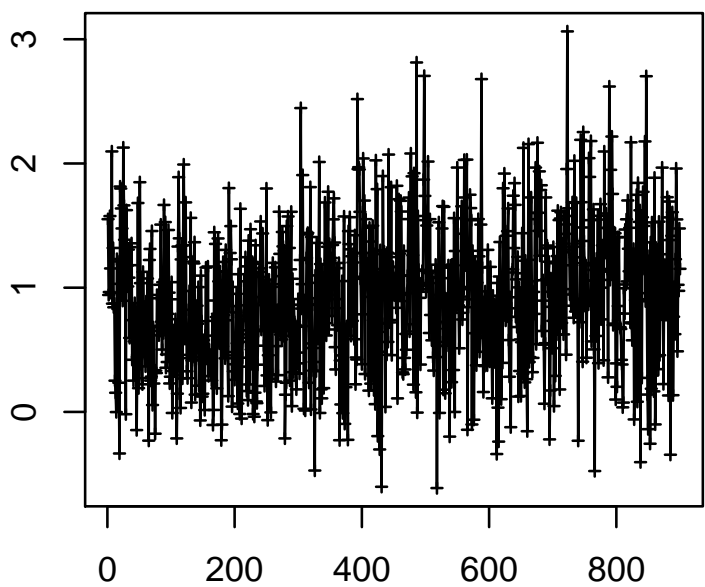

Time Point $(0.25 \mathrm{~Hz})$
Cell 706

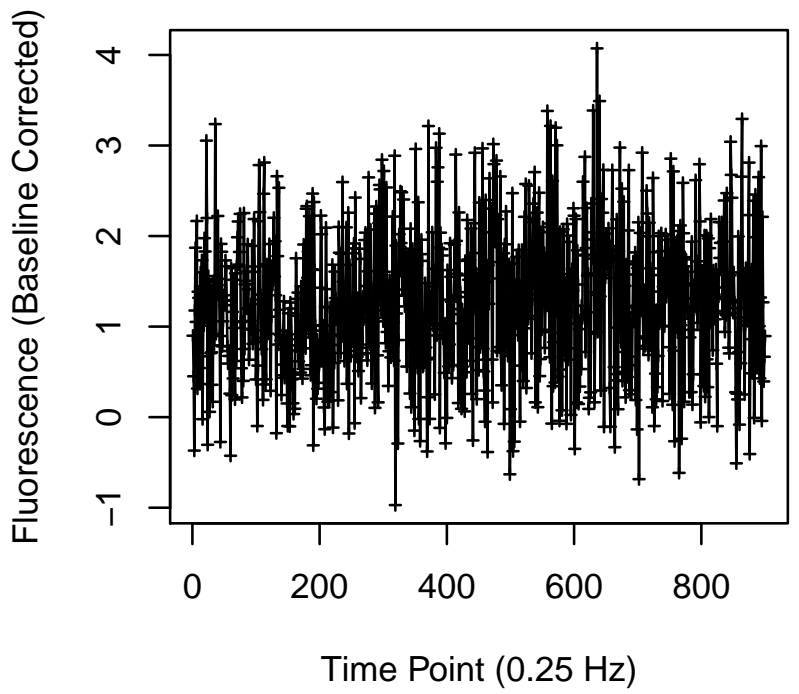

Cell 708

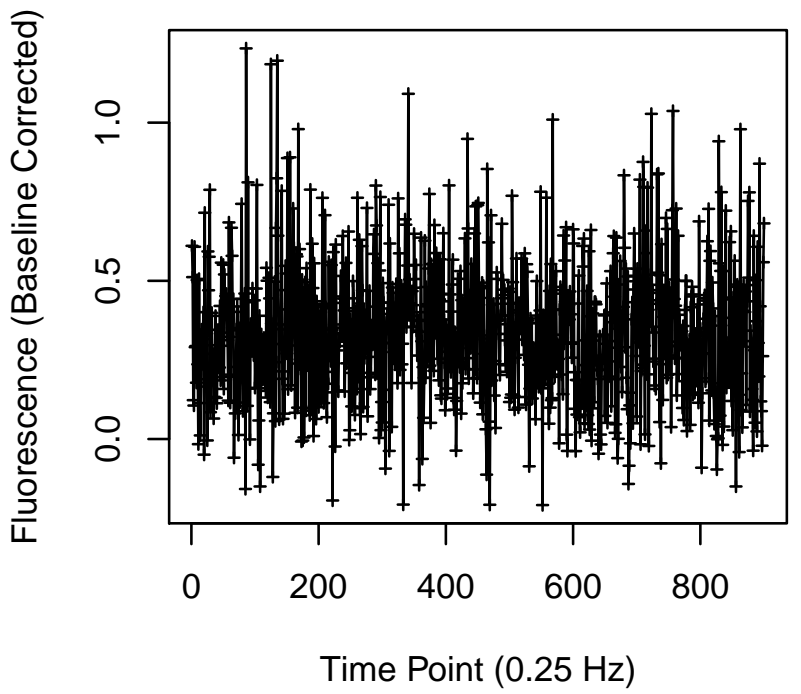


Cell 709

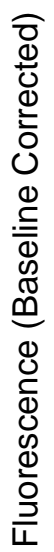

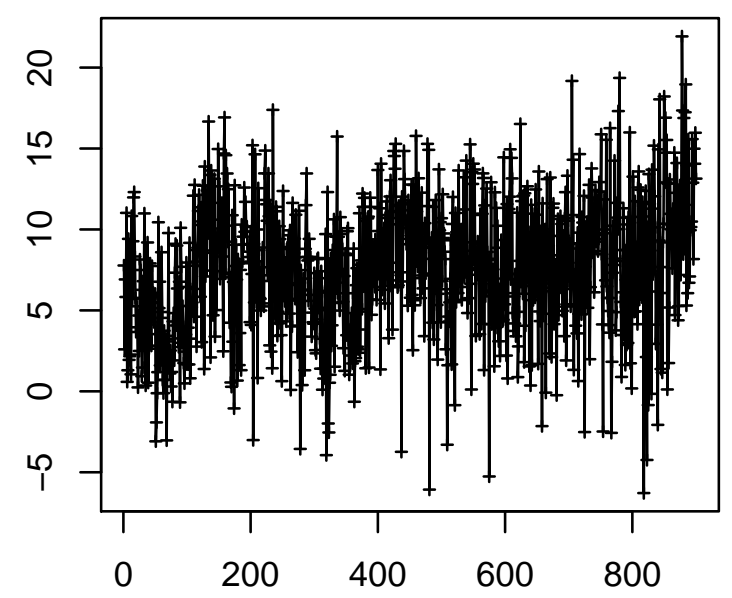

Time Point $(0.25 \mathrm{~Hz})$

Cell 711

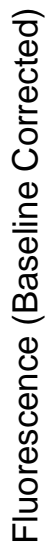

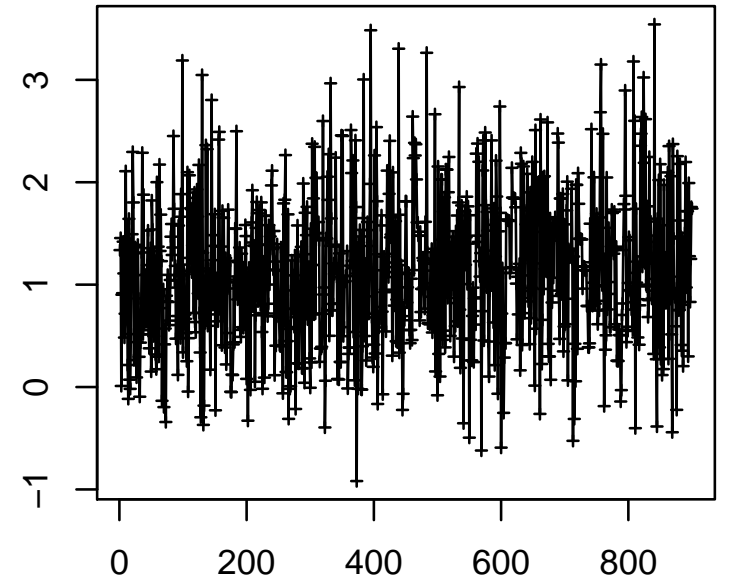

Time Point $(0.25 \mathrm{~Hz})$

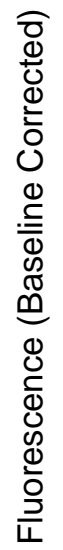

Cell 710

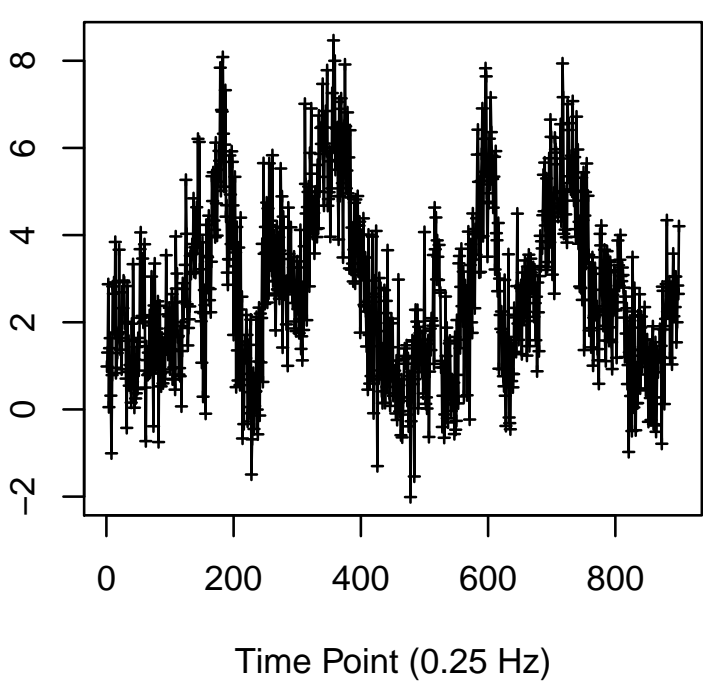

Cell 712

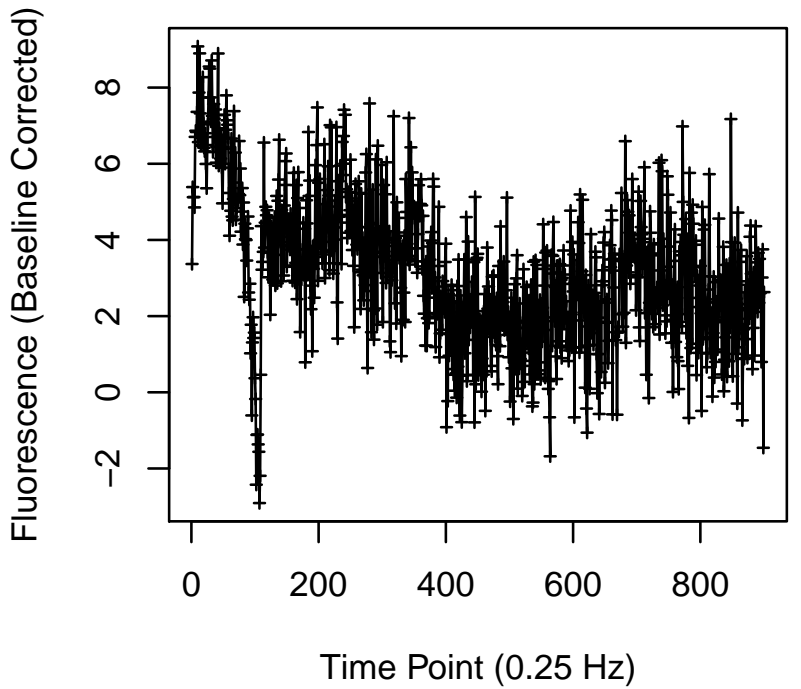


Cell 713

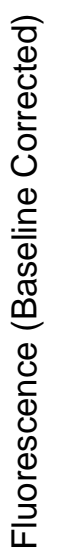

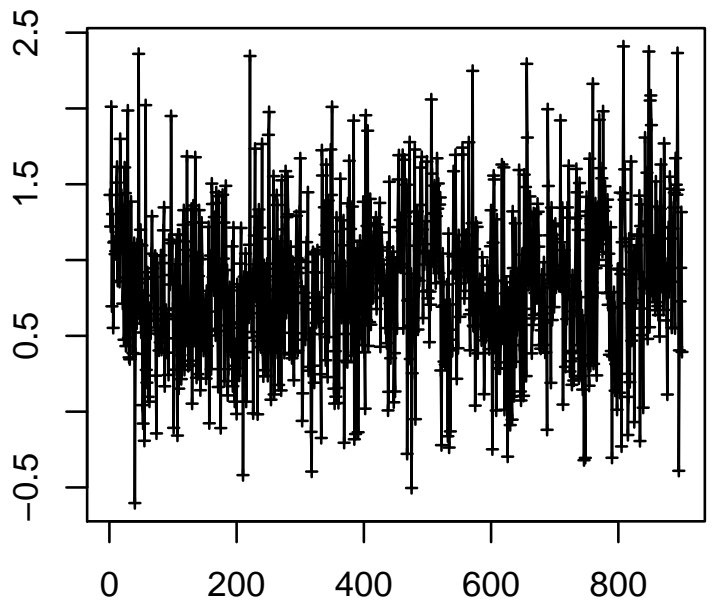

Time Point $(0.25 \mathrm{~Hz})$

Cell 715

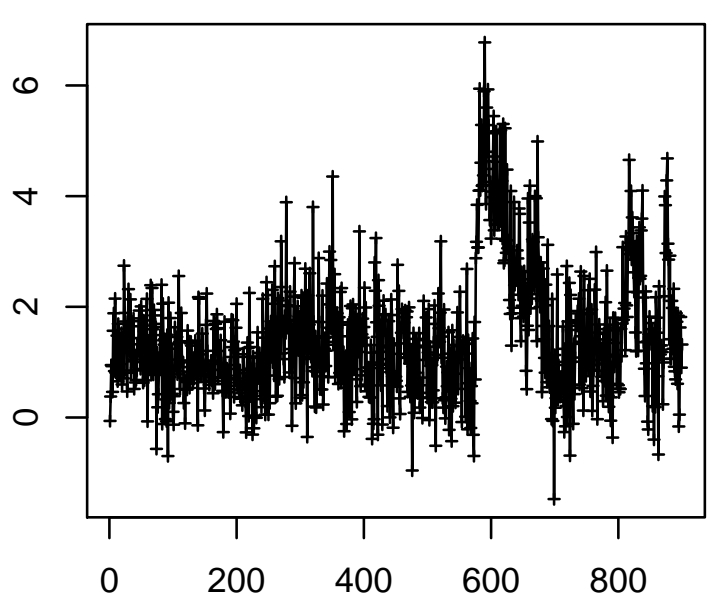

Time Point $(0.25 \mathrm{~Hz})$
Cell 714

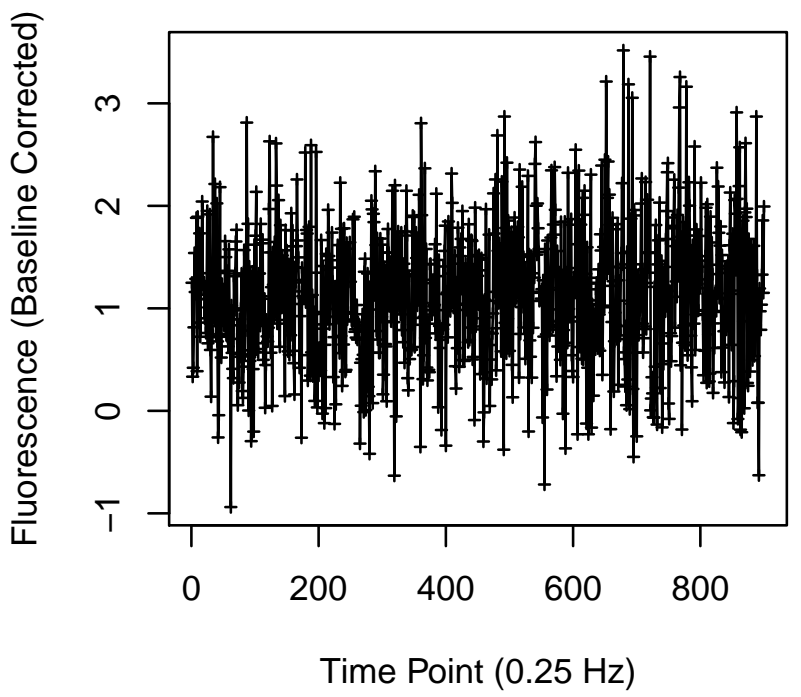

Cell 716

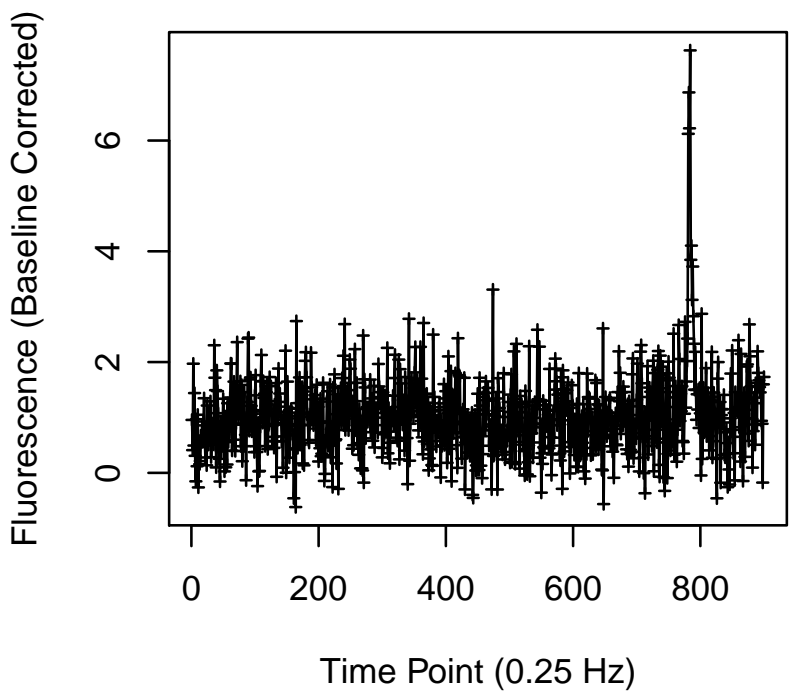


Cell 729

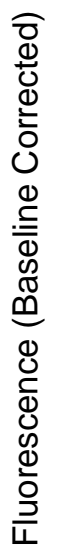

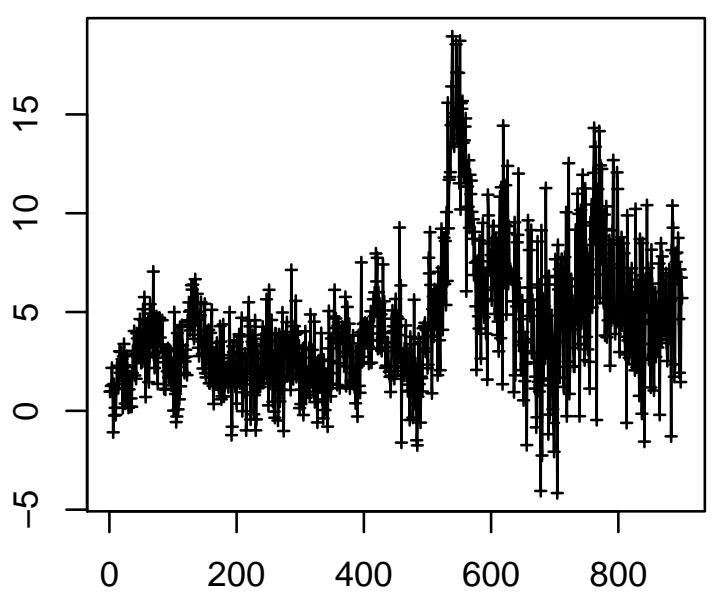

Time Point $(0.25 \mathrm{~Hz})$

Cell 731

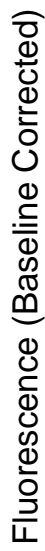

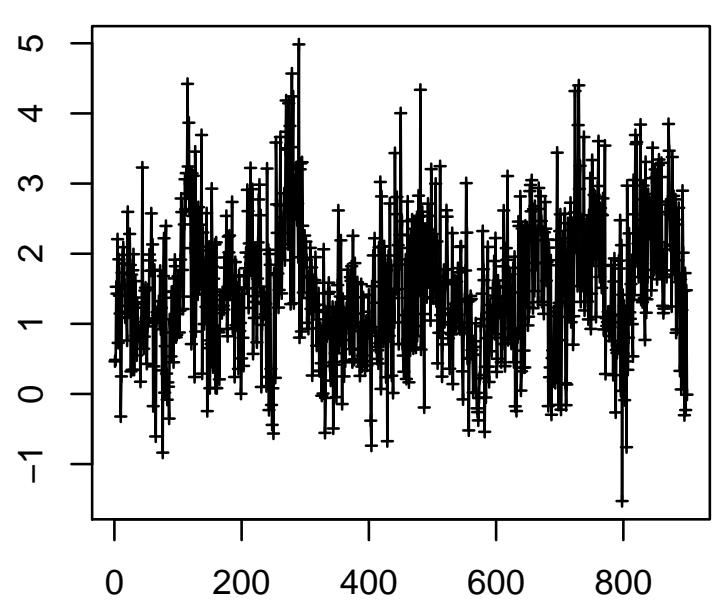

Time Point $(0.25 \mathrm{~Hz})$

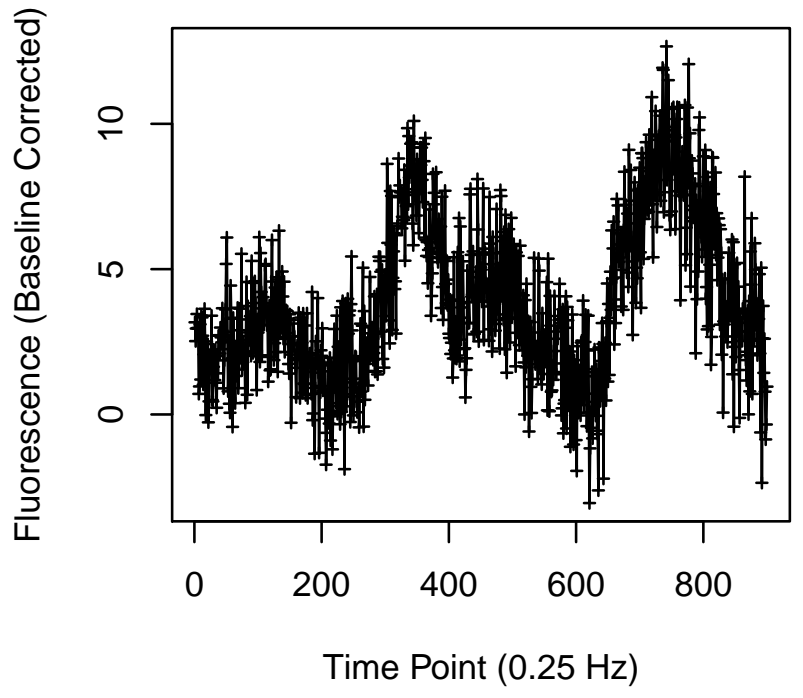

Cell 732

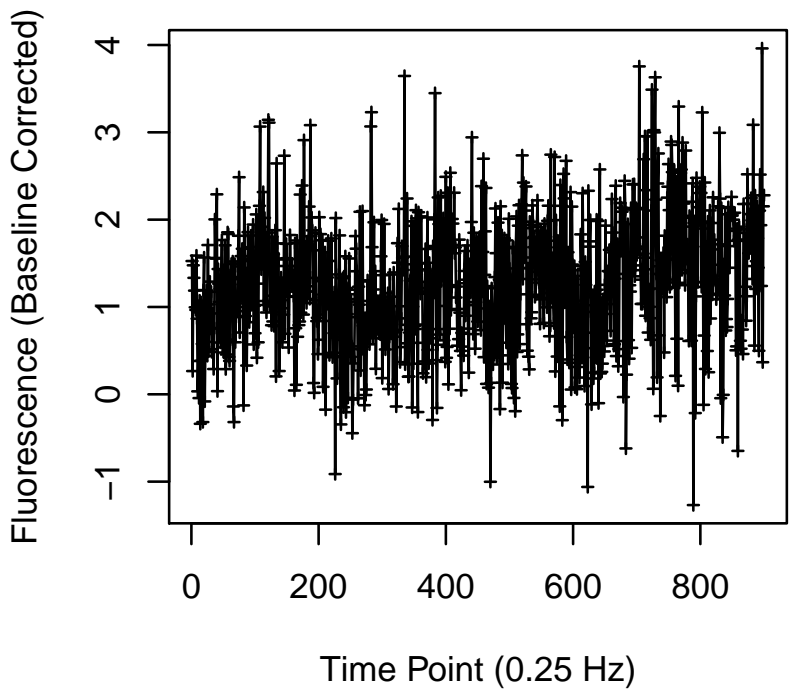




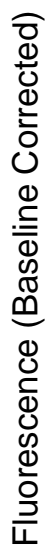

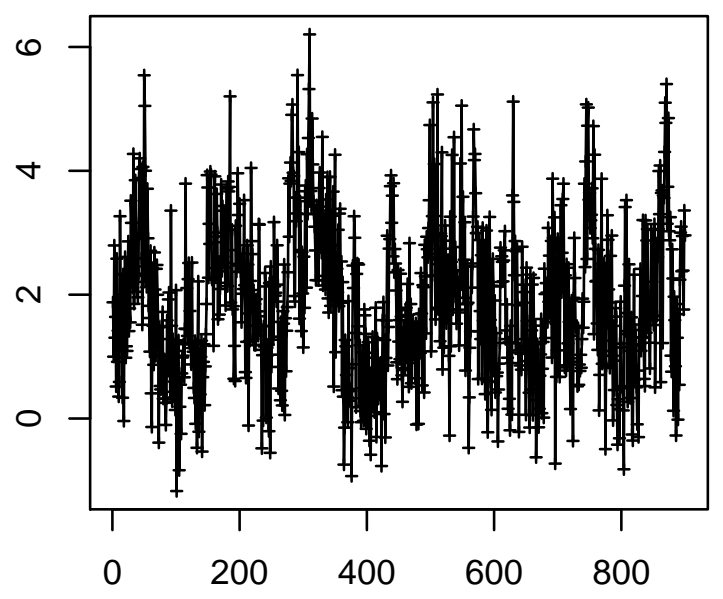

Time Point $(0.25 \mathrm{~Hz})$

Cell 743

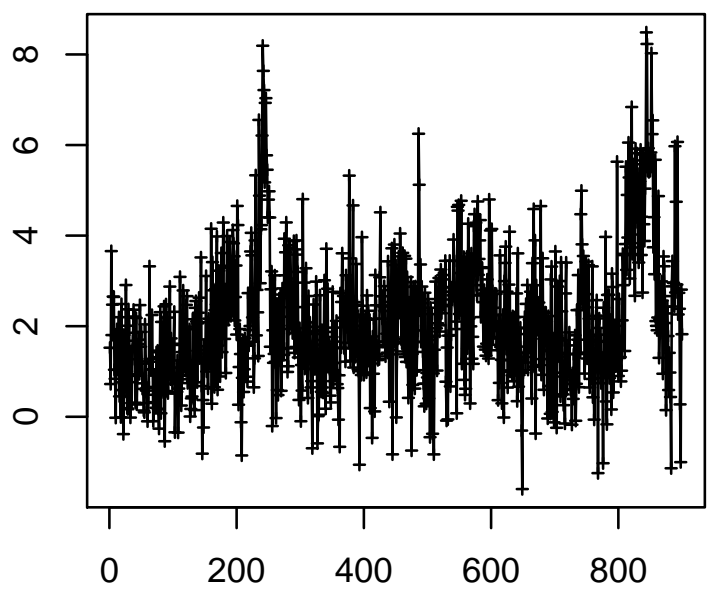

Time Point $(0.25 \mathrm{~Hz})$

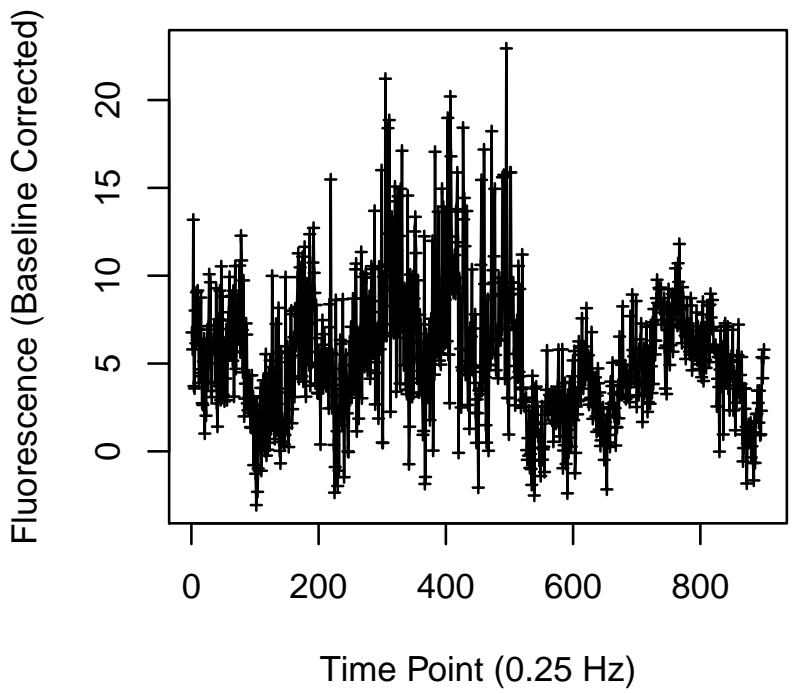

Cell 744

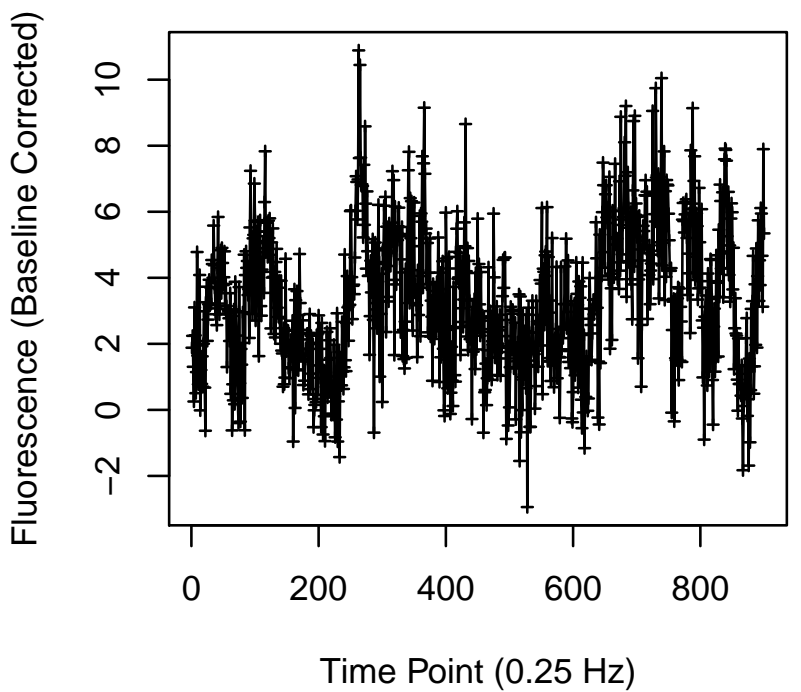




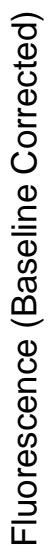

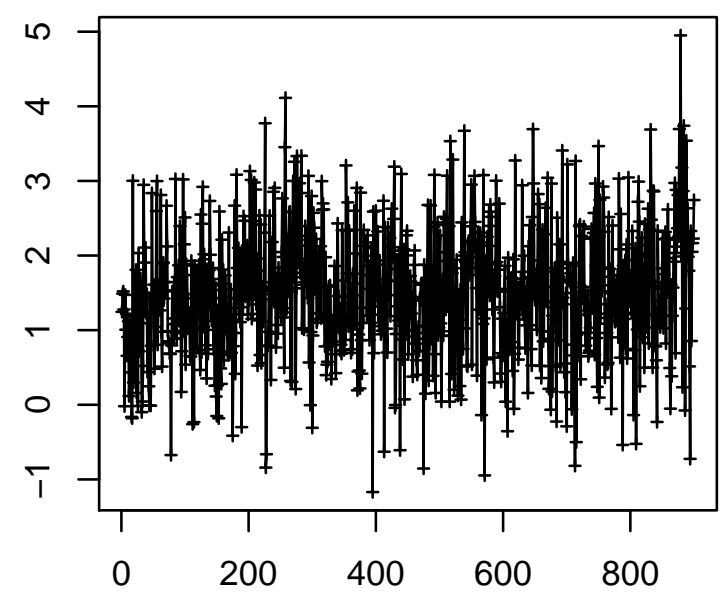

Time Point $(0.25 \mathrm{~Hz})$

Cell 747

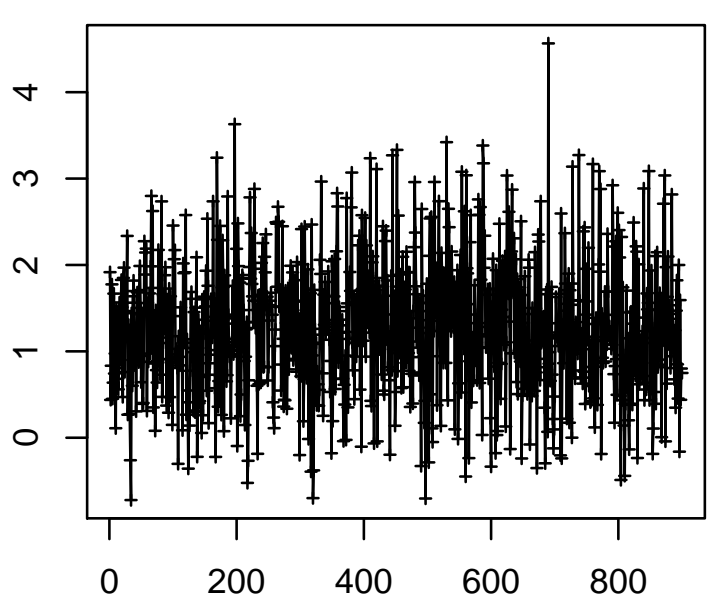

Time Point $(0.25 \mathrm{~Hz})$

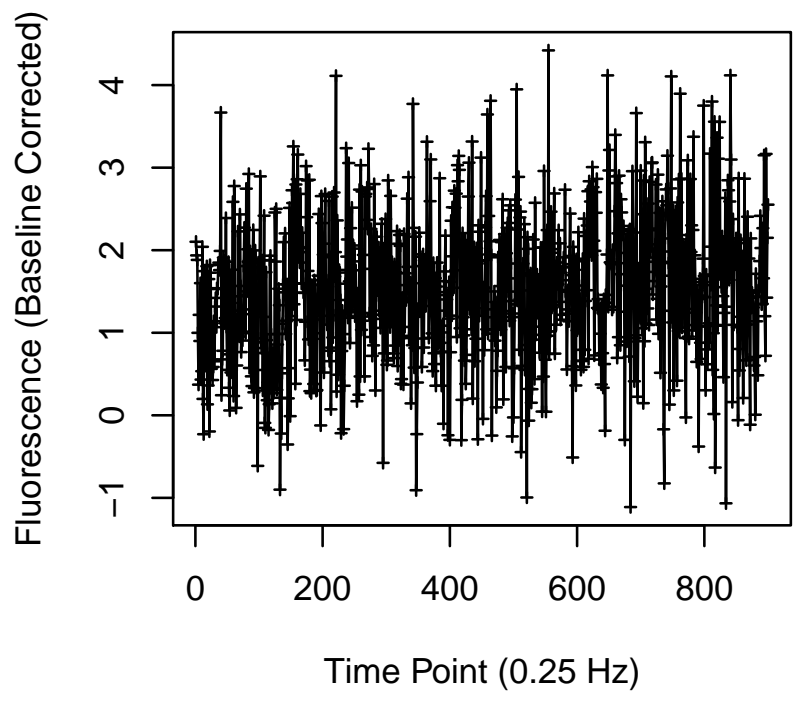

Cell 748

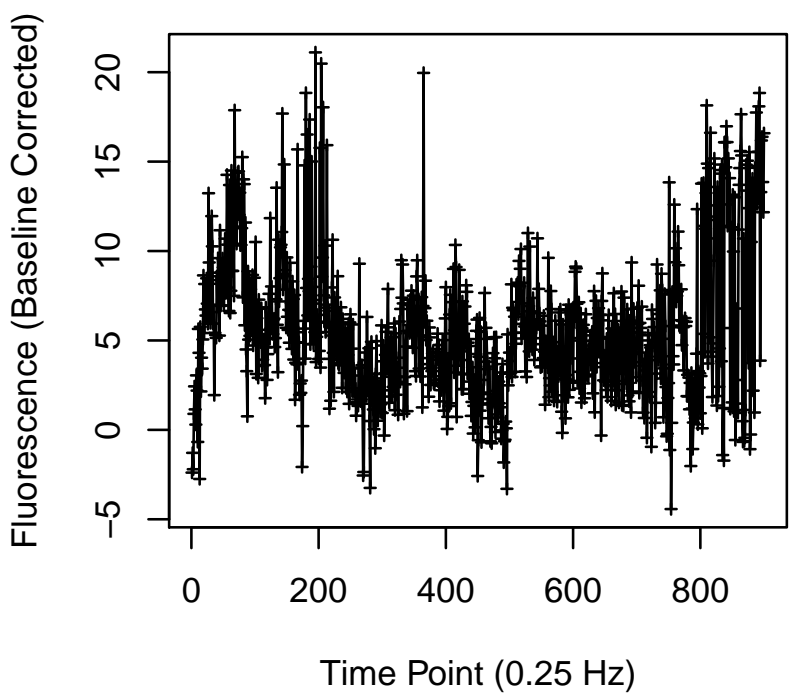


Cell 749

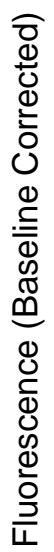

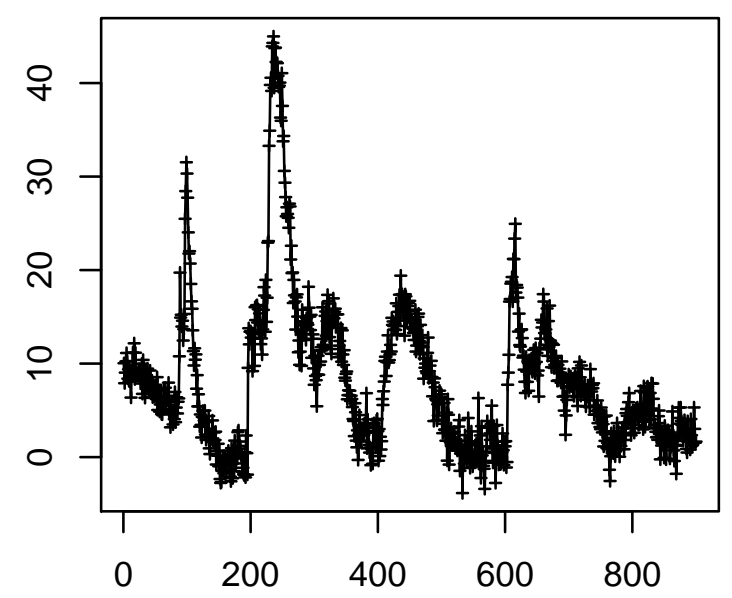

Time Point $(0.25 \mathrm{~Hz})$

Cell 751

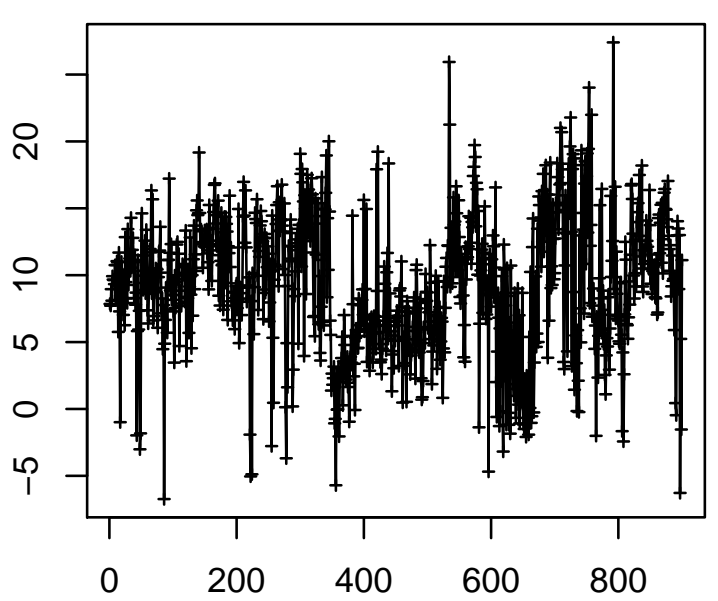

Time Point $(0.25 \mathrm{~Hz})$
Cell 750

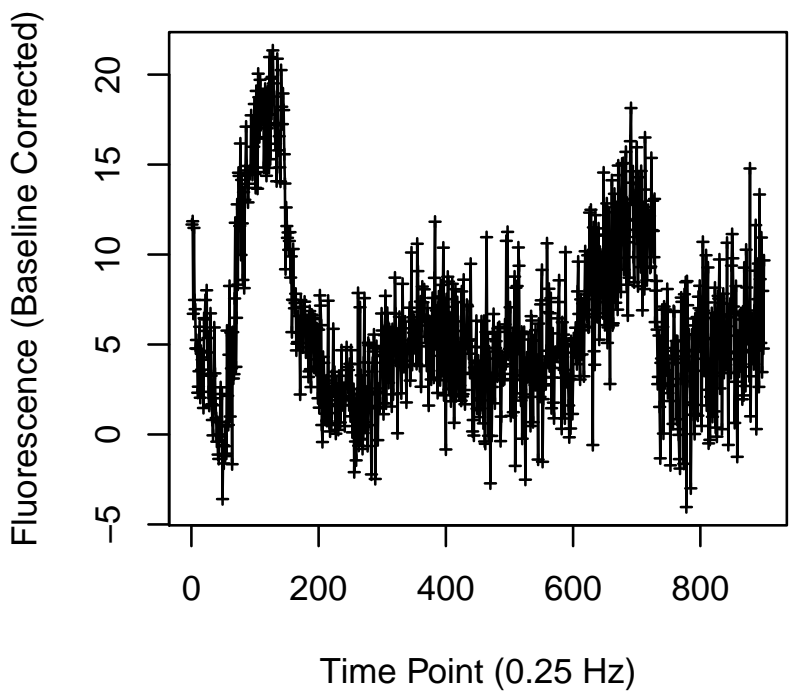

Cell 752

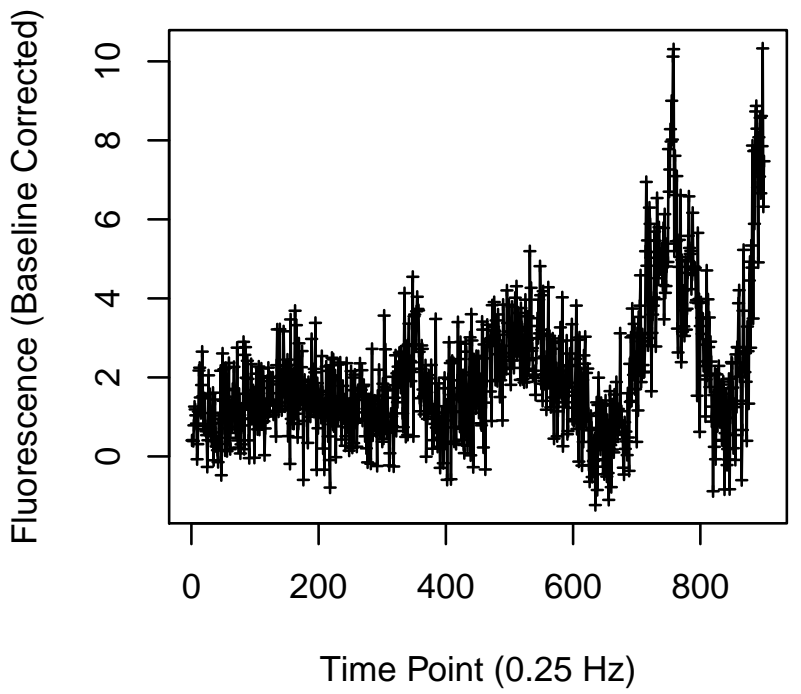


Cell 753

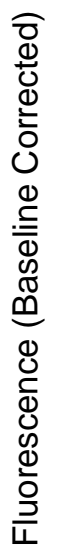

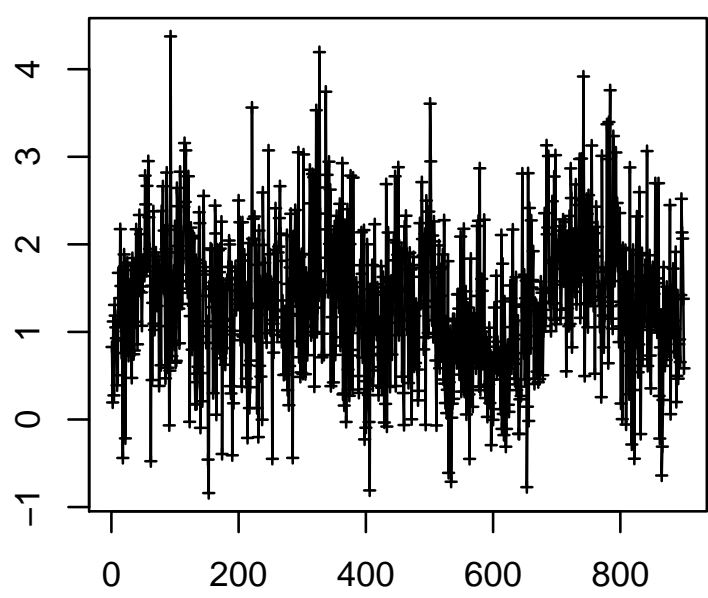

Time Point $(0.25 \mathrm{~Hz})$

Cell 755

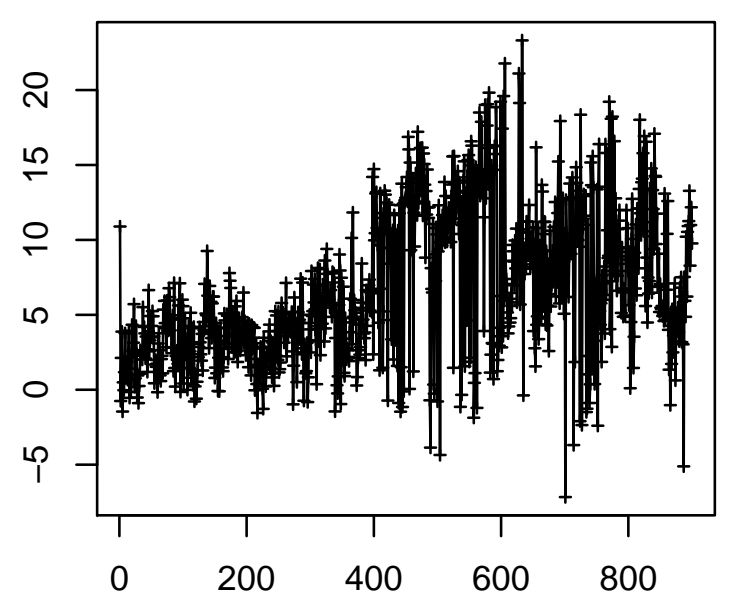

Time Point $(0.25 \mathrm{~Hz})$
Cell 754

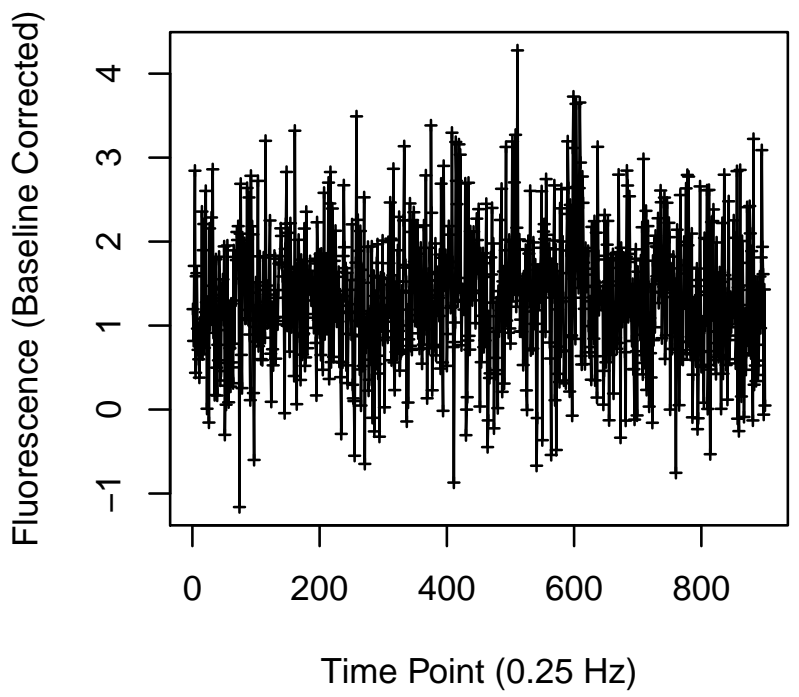

Cell 756

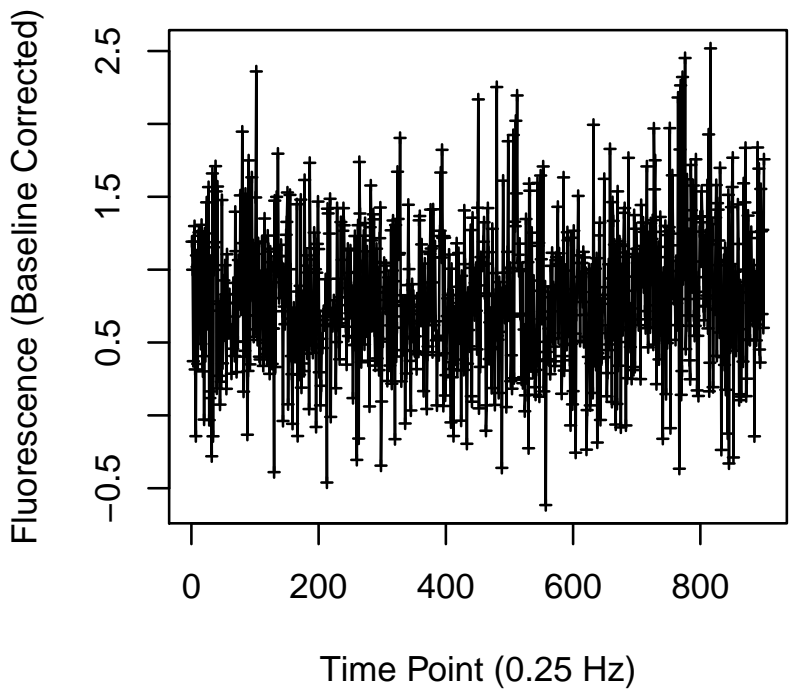


Cell 757

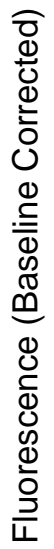

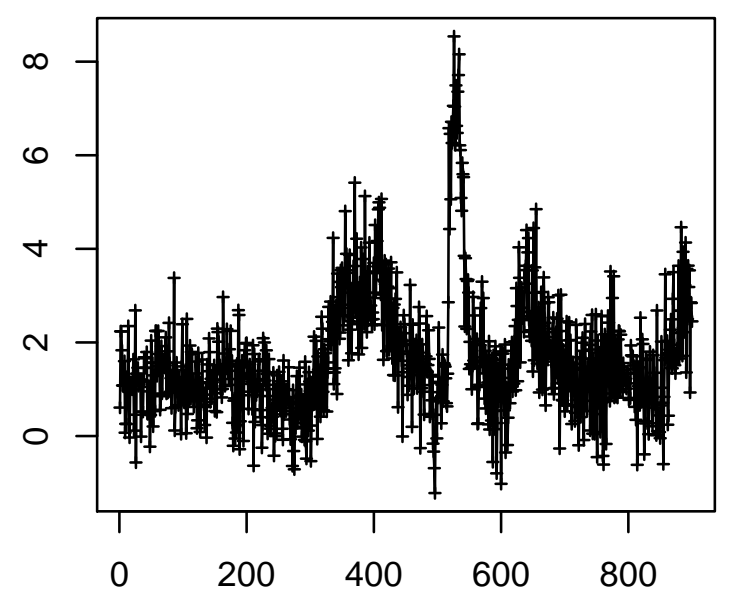

Time Point $(0.25 \mathrm{~Hz})$

Cell 759

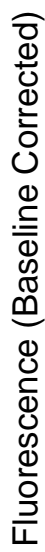

Cell 758

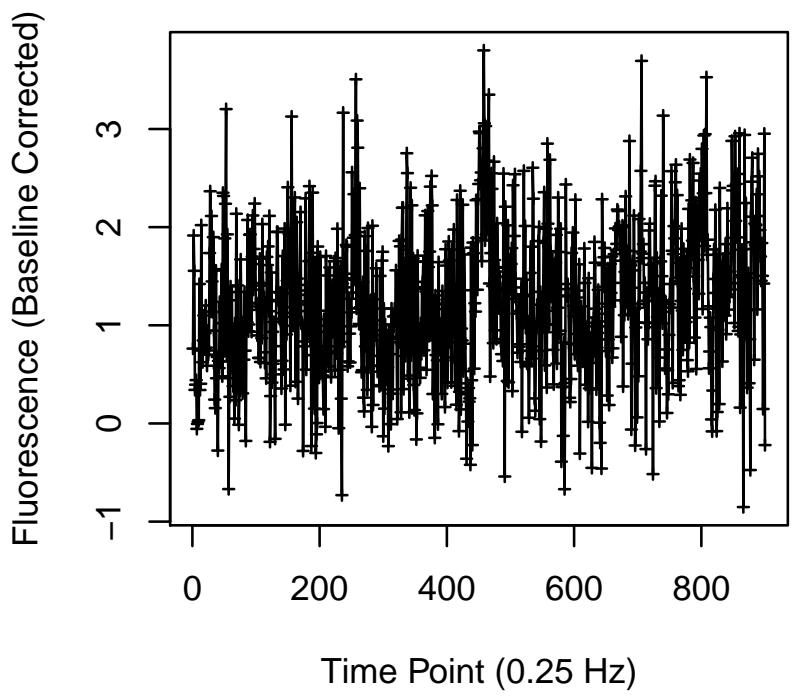

Cell 760

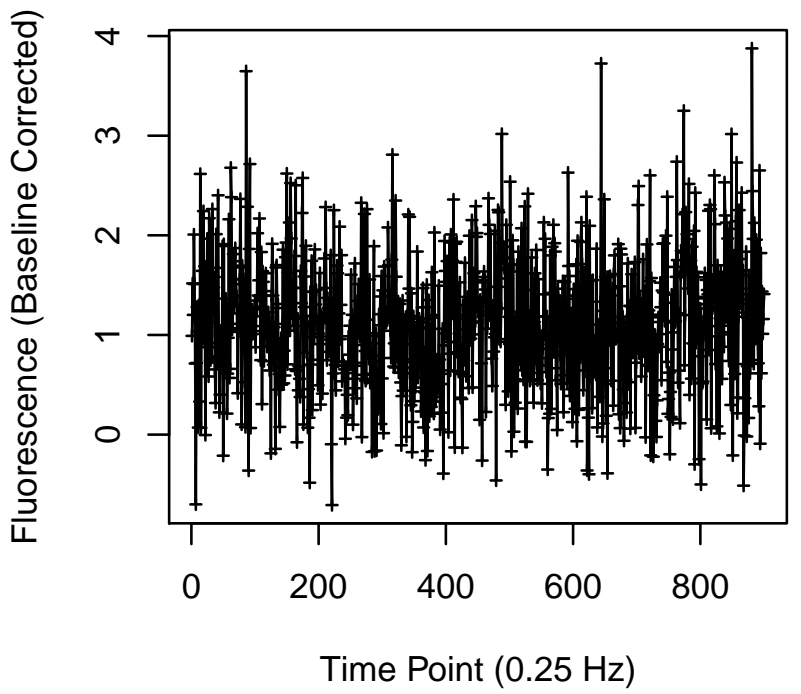


Cell 769

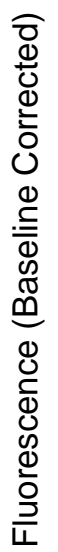

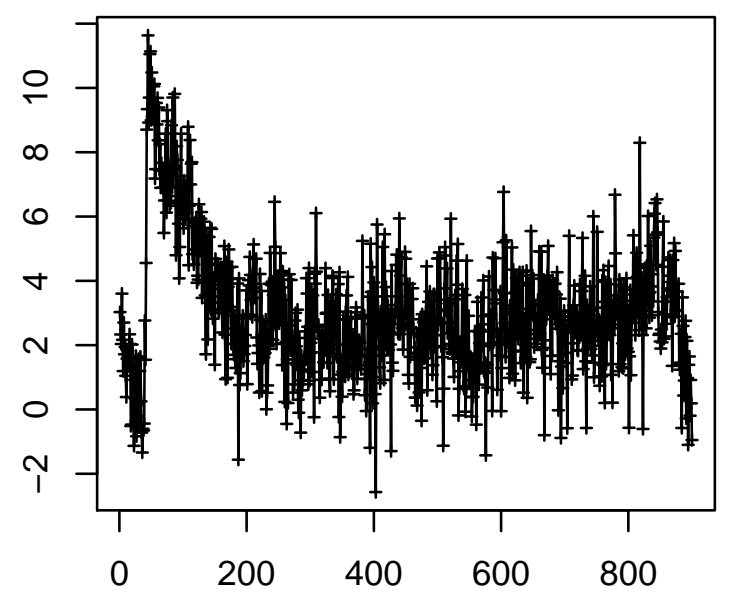

Time Point $(0.25 \mathrm{~Hz})$

Cell 771

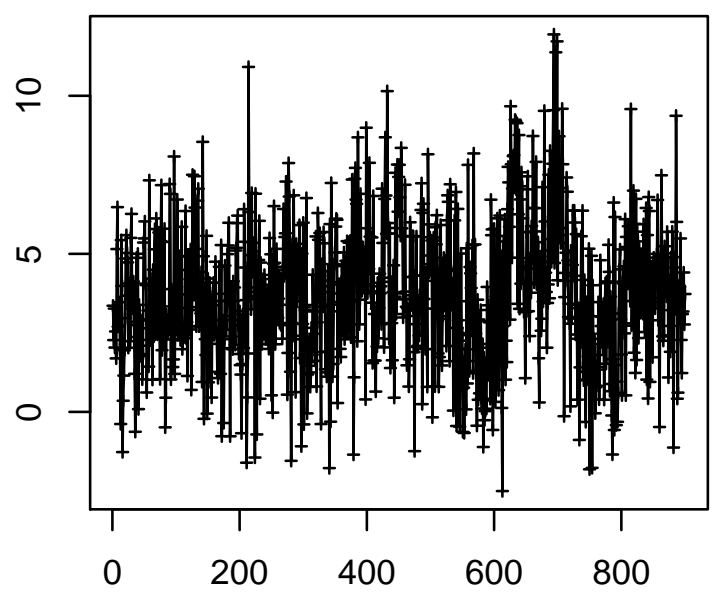

Time Point $(0.25 \mathrm{~Hz})$
Cell 770

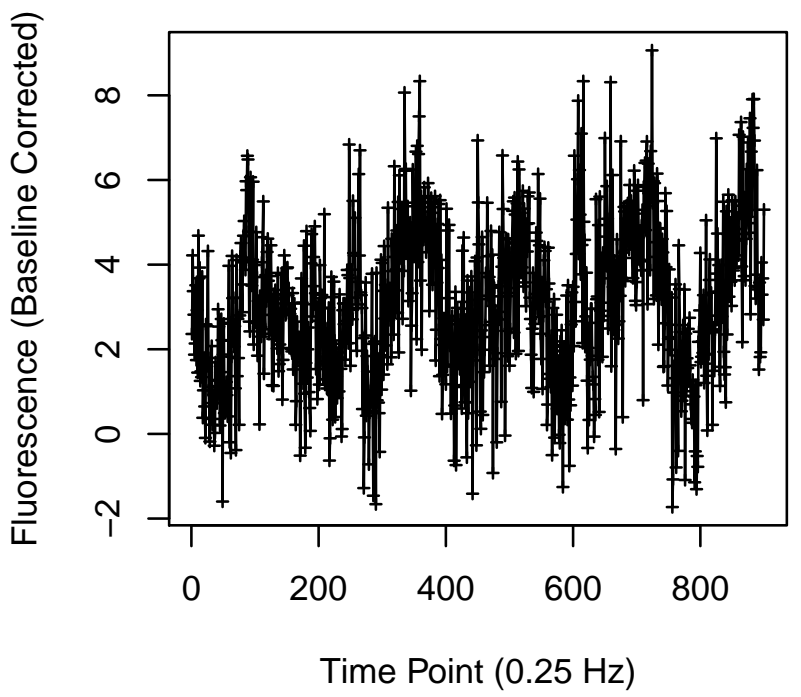

Cell 772

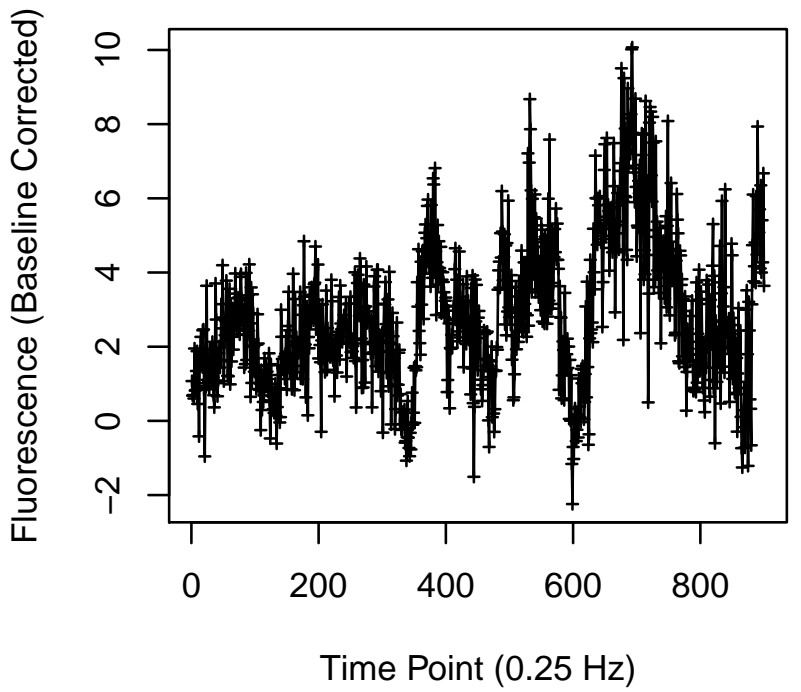




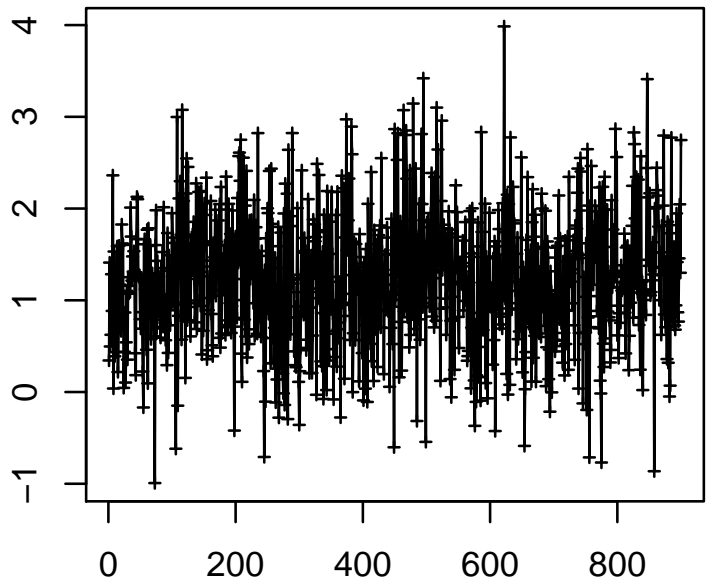

Time Point $(0.25 \mathrm{~Hz})$

\section{Cell 783}

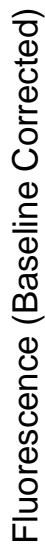

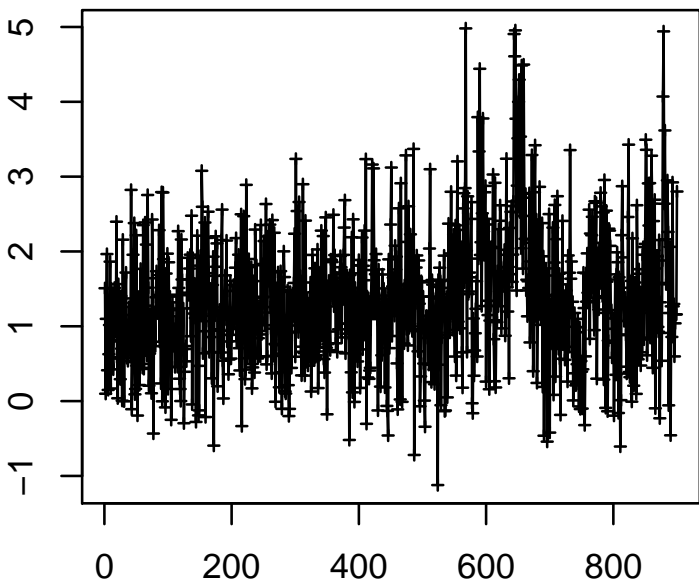

Time Point $(0.25 \mathrm{~Hz})$

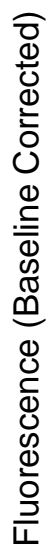

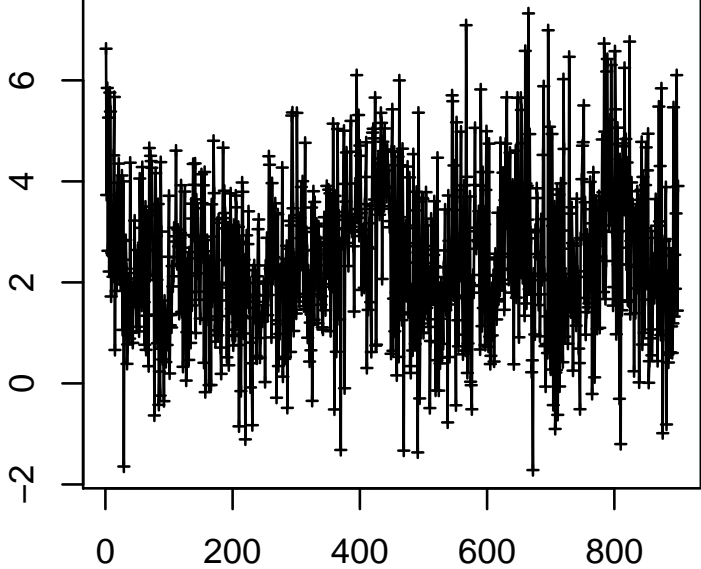

Time Point $(0.25 \mathrm{~Hz})$

Cell 784

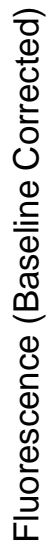

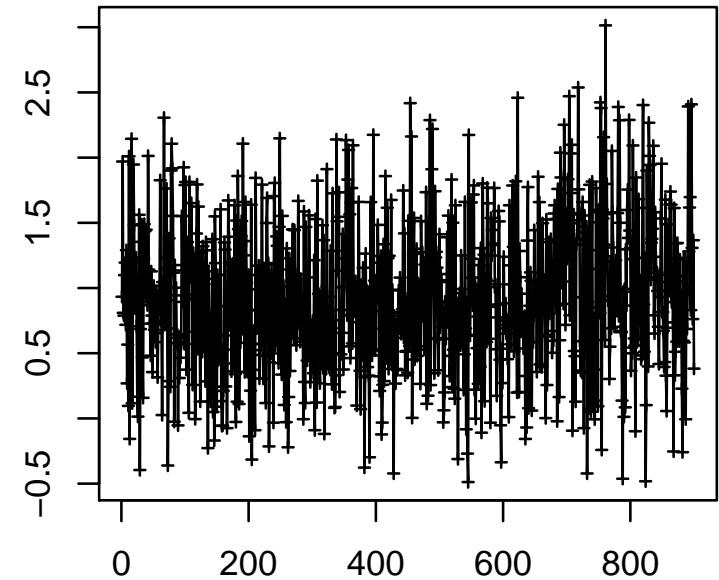

Time Point $(0.25 \mathrm{~Hz})$ 
Cell 793

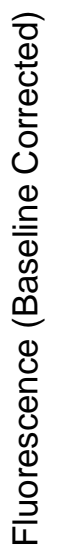

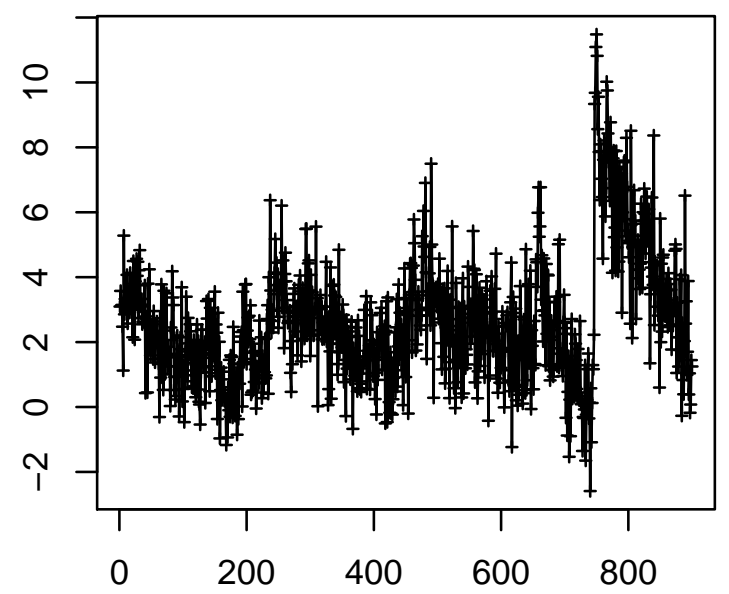

Time Point $(0.25 \mathrm{~Hz})$

\section{Cell 795}

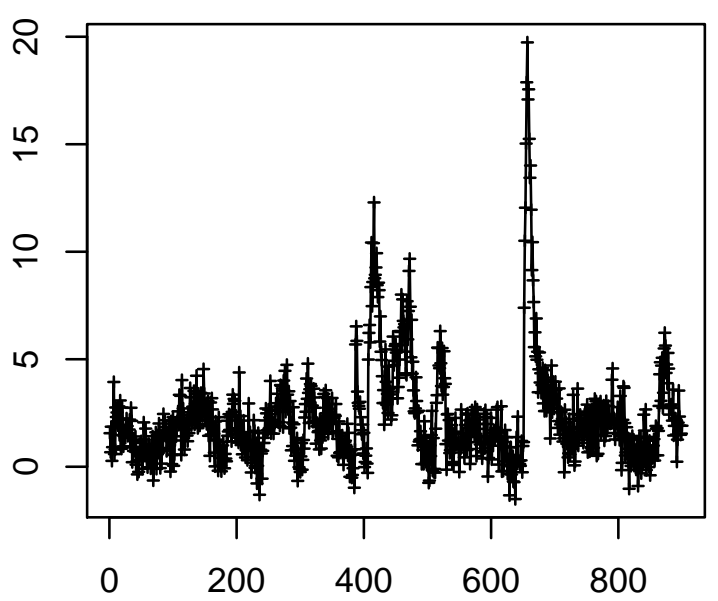

Time Point $(0.25 \mathrm{~Hz})$
Cell 794

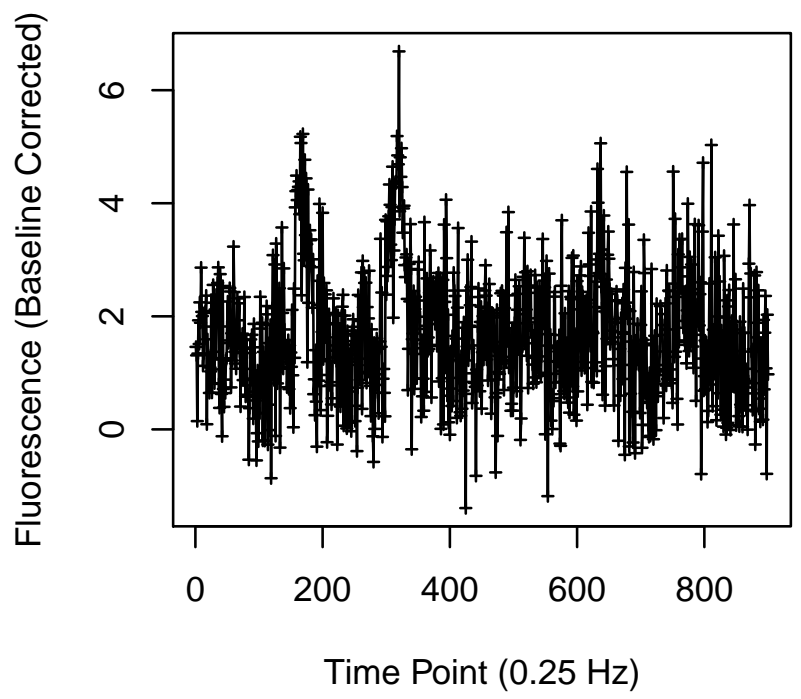

Cell 796

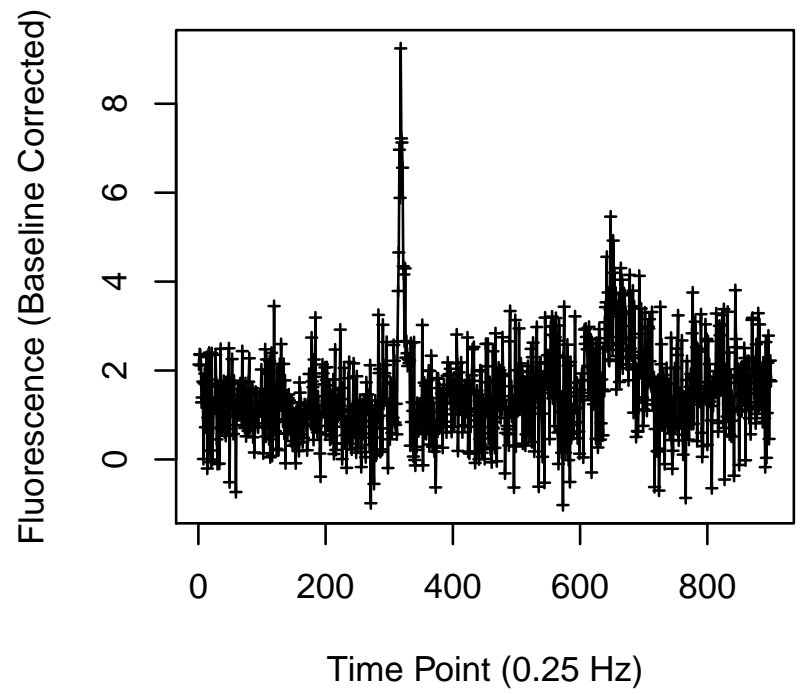


Cell 797

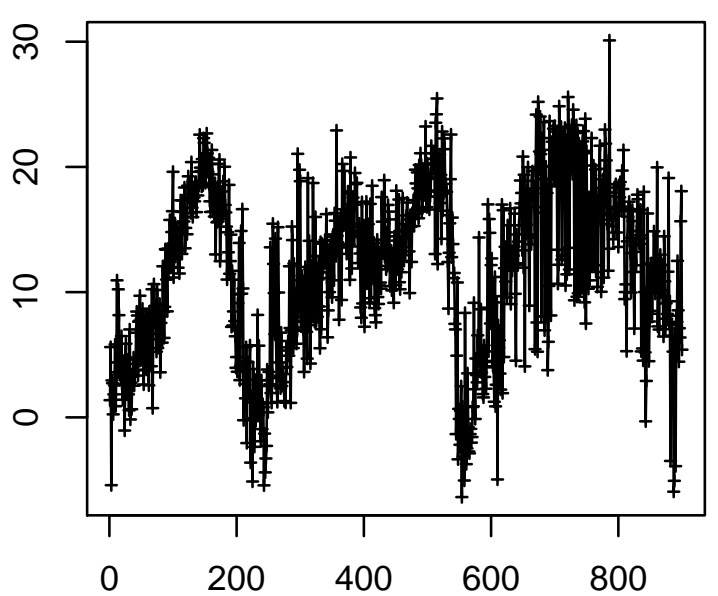

Time Point $(0.25 \mathrm{~Hz})$

Cell 799

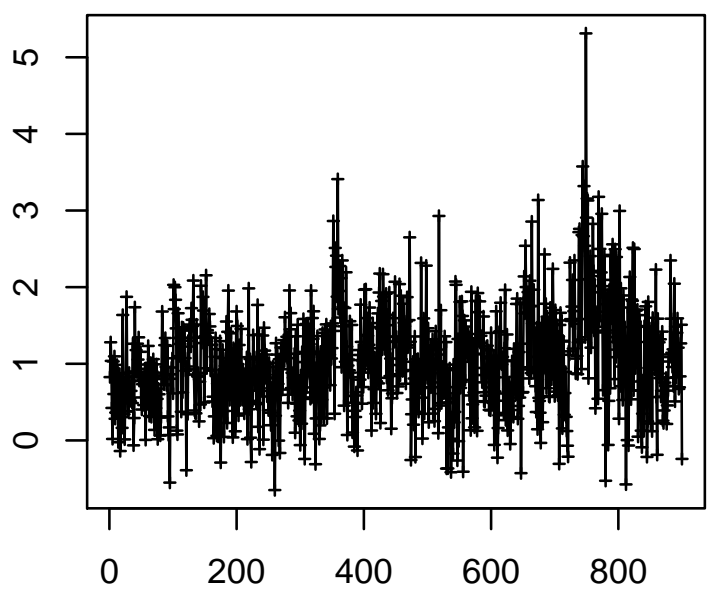

Time Point $(0.25 \mathrm{~Hz})$
Cell 798

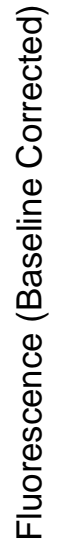

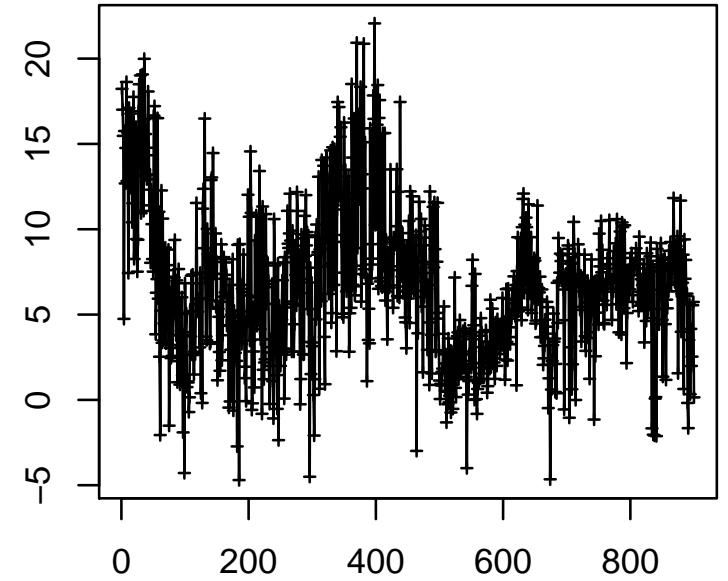

Time Point $(0.25 \mathrm{~Hz})$

\section{Cell 800}

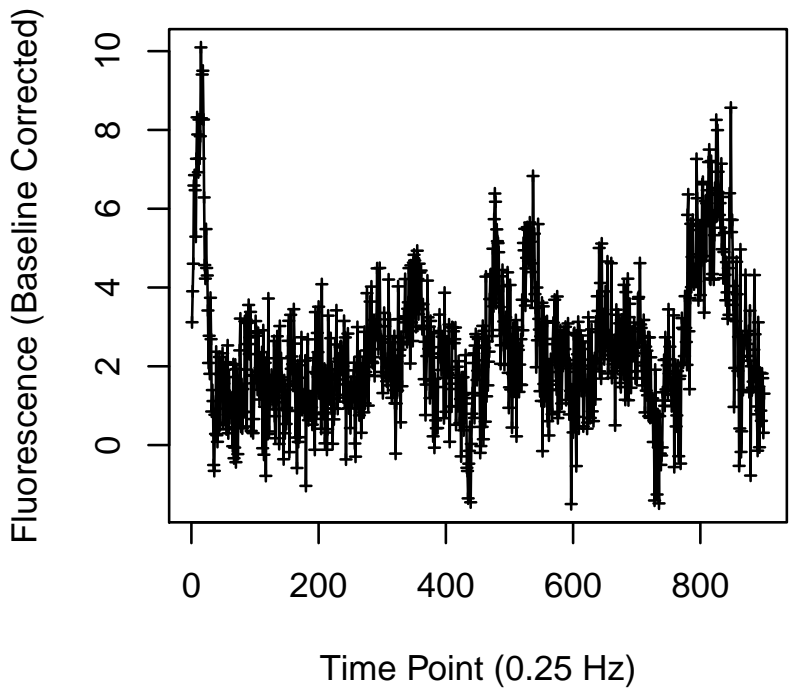




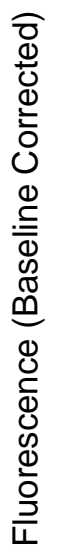

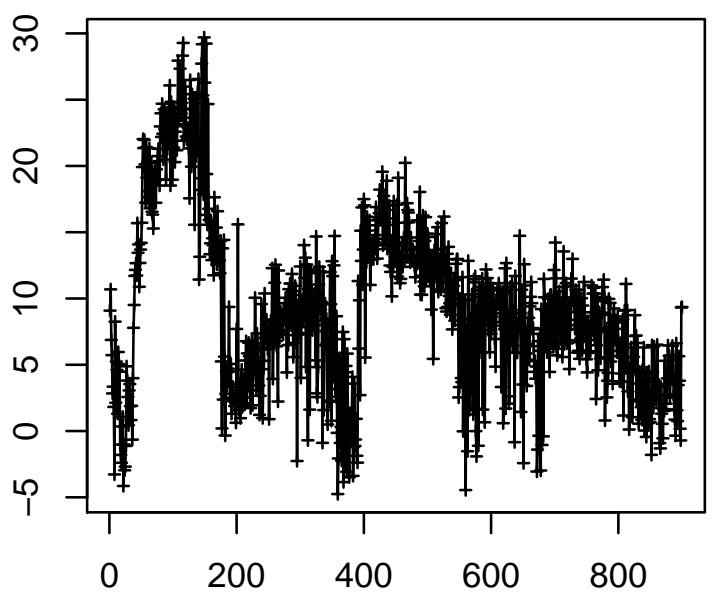

Time Point $(0.25 \mathrm{~Hz})$

\section{Cell 803}

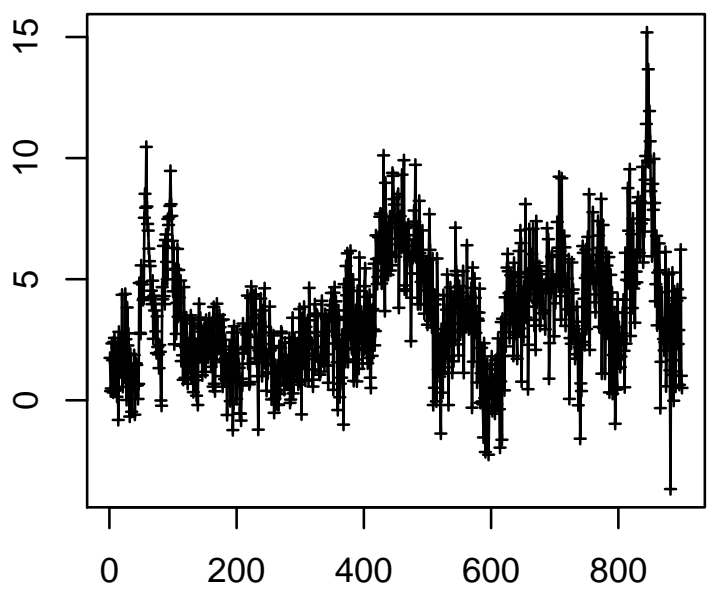

Time Point $(0.25 \mathrm{~Hz})$

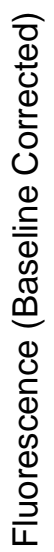

Cell 804

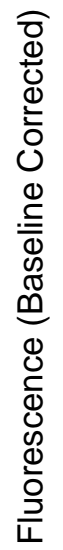

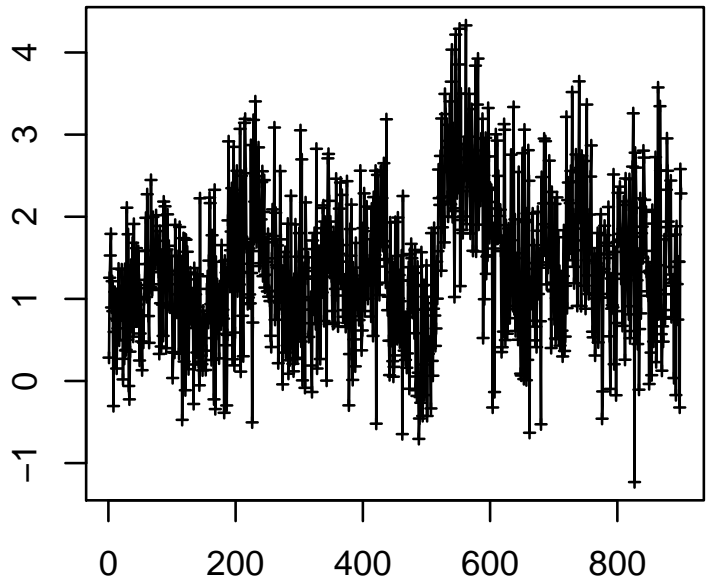

Time Point $(0.25 \mathrm{~Hz})$ 
Cell 809

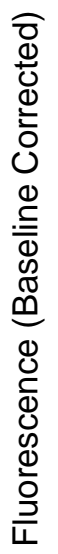

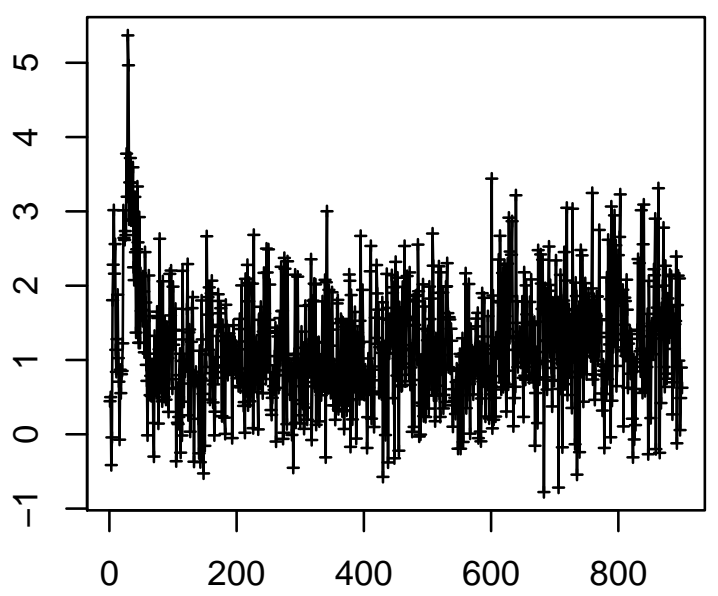

Time Point $(0.25 \mathrm{~Hz})$

Cell 811

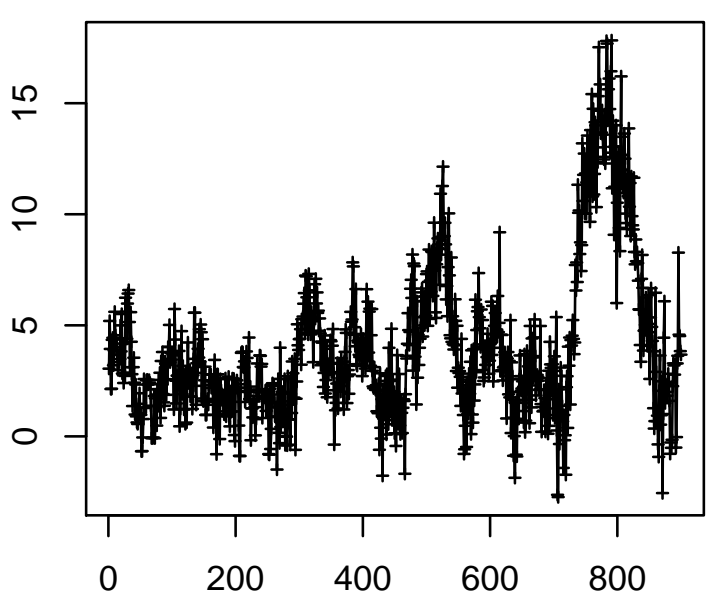

Time Point $(0.25 \mathrm{~Hz})$
Cell 810

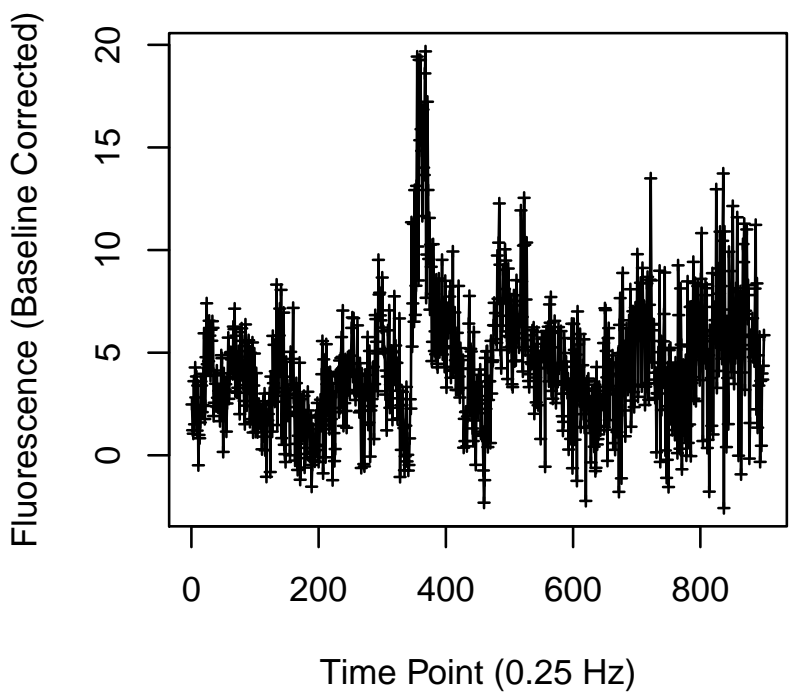

Cell 812

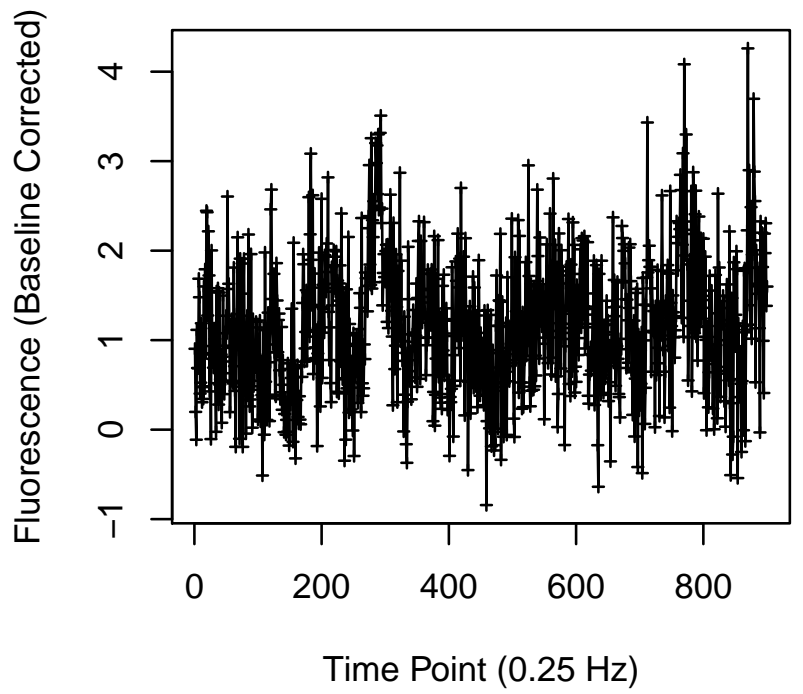


Cell 813

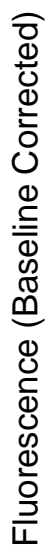

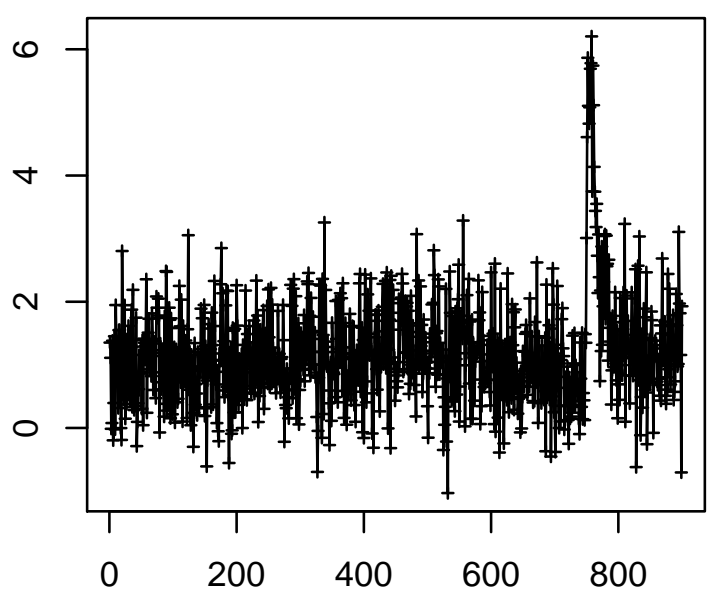

Time Point $(0.25 \mathrm{~Hz})$

Cell 815

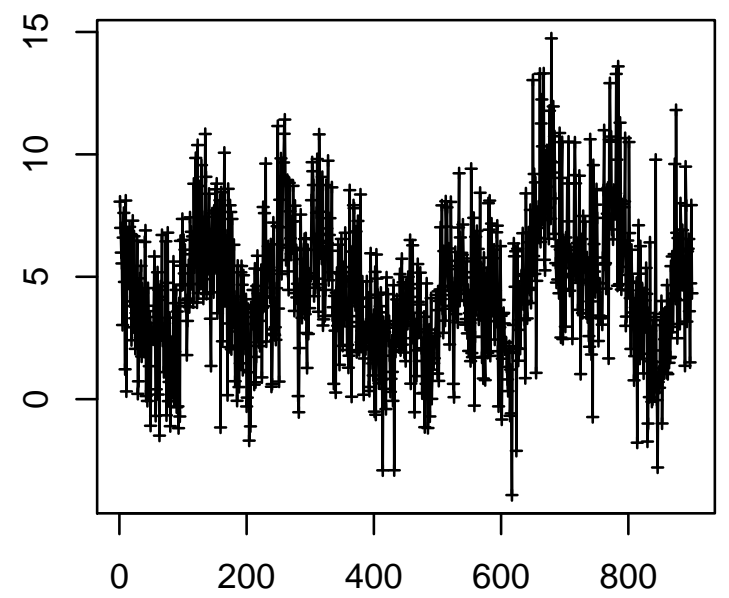

Time Point $(0.25 \mathrm{~Hz})$
Cell 814

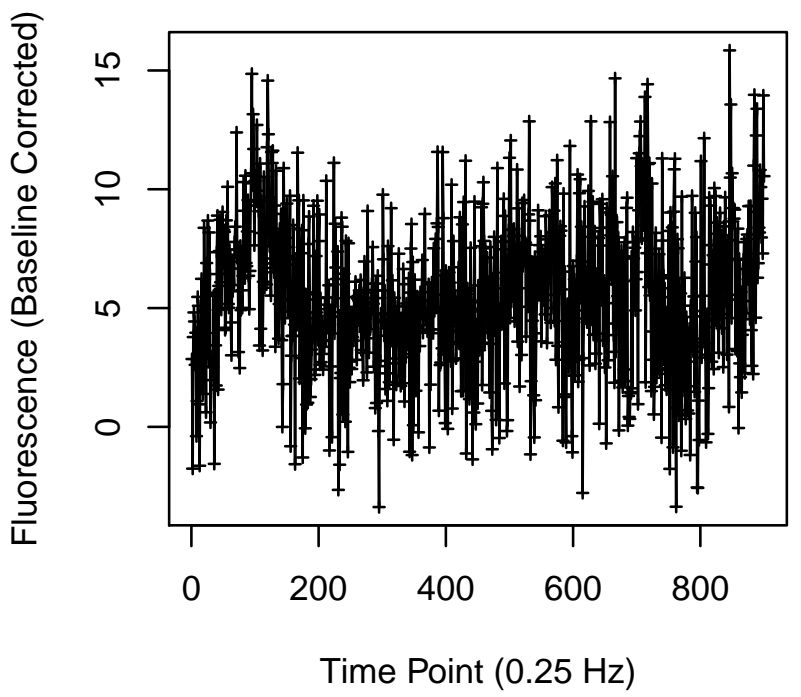

Cell 816

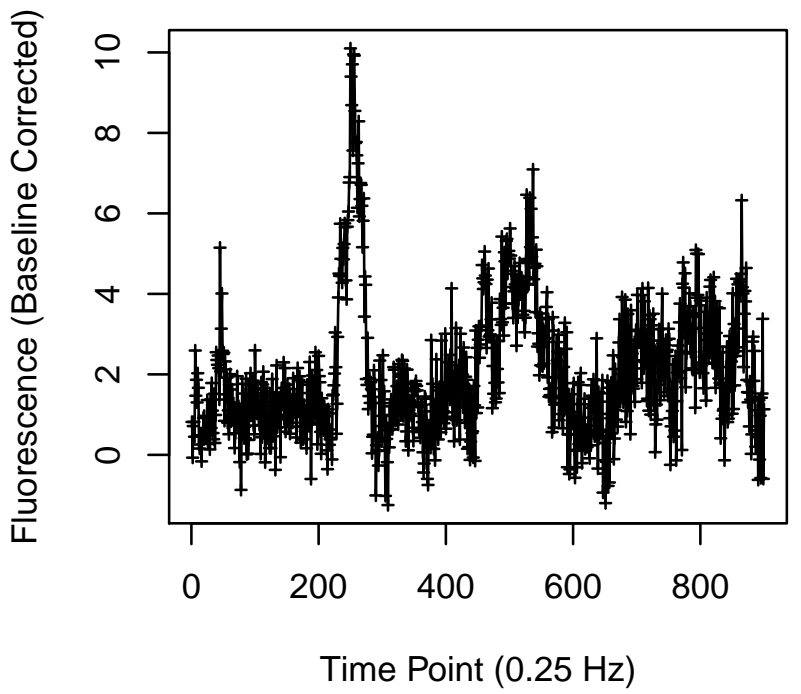


Cell 841

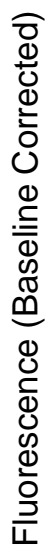

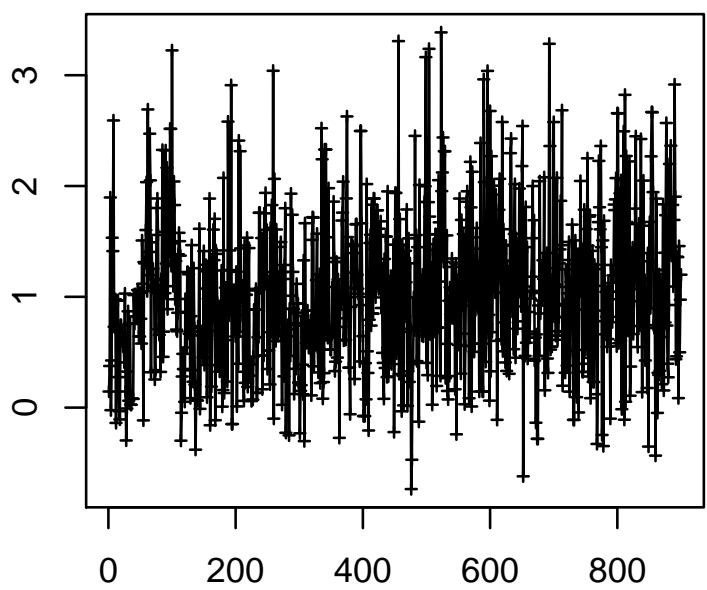

Time Point $(0.25 \mathrm{~Hz})$

Cell 843

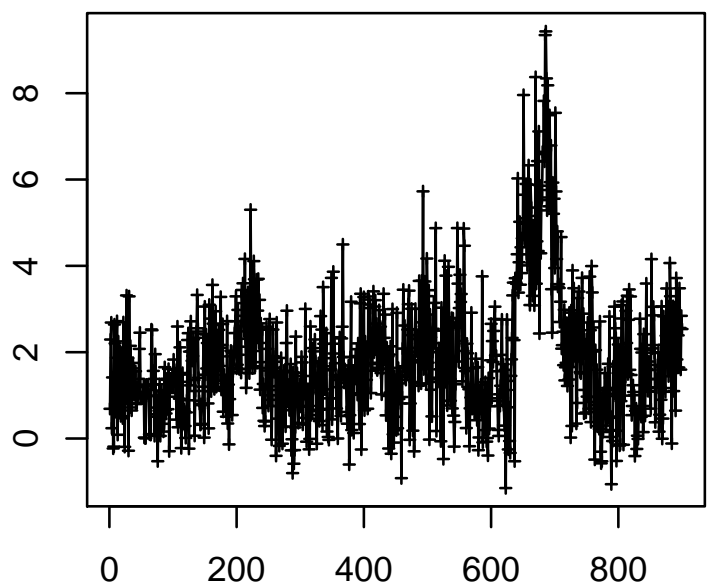

Time Point $(0.25 \mathrm{~Hz})$
Cell 842

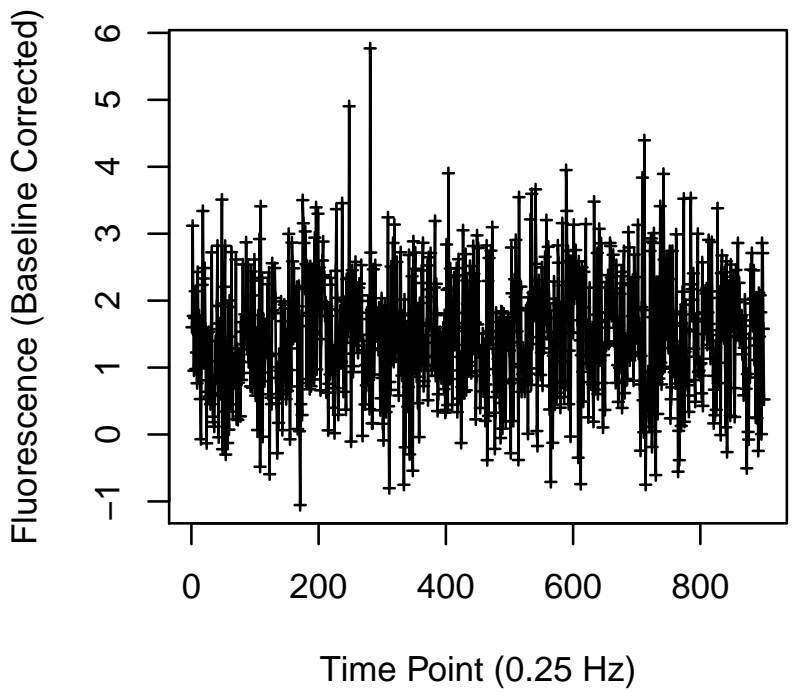

Cell 844

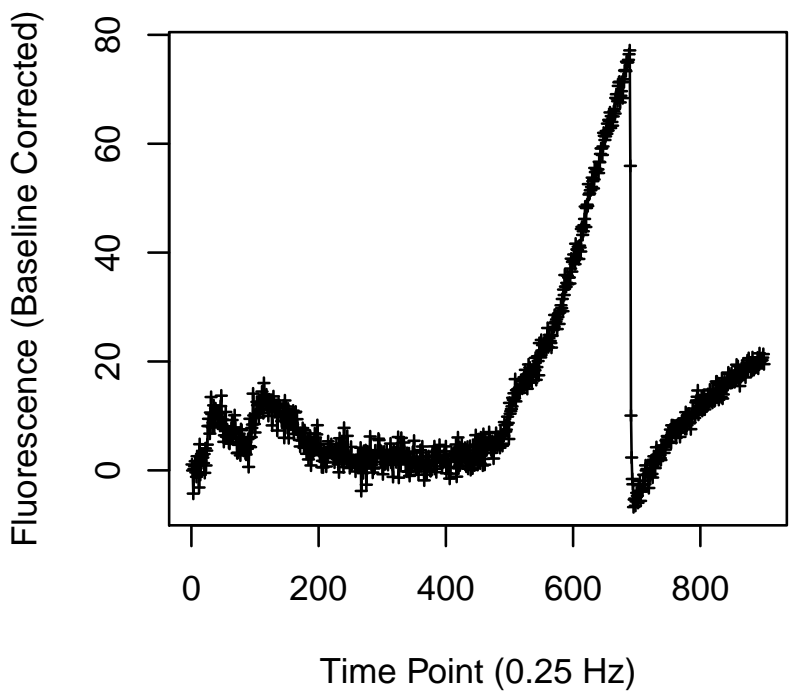




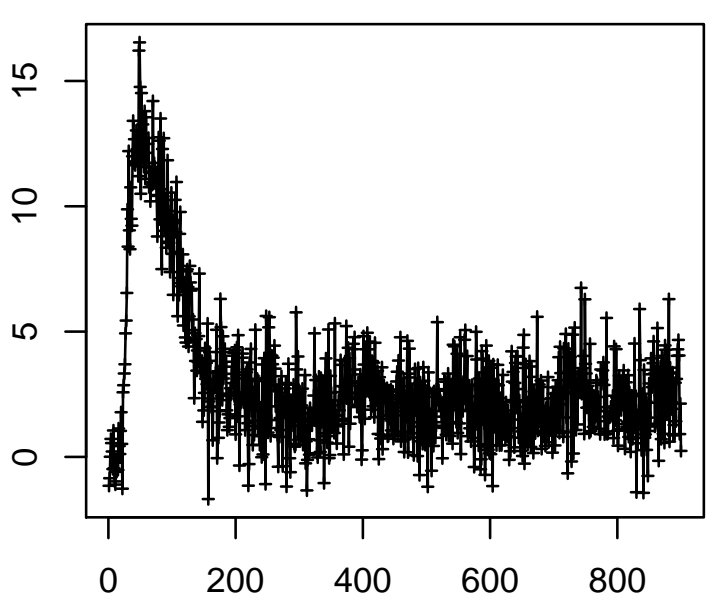

Time Point $(0.25 \mathrm{~Hz})$

Cell 847

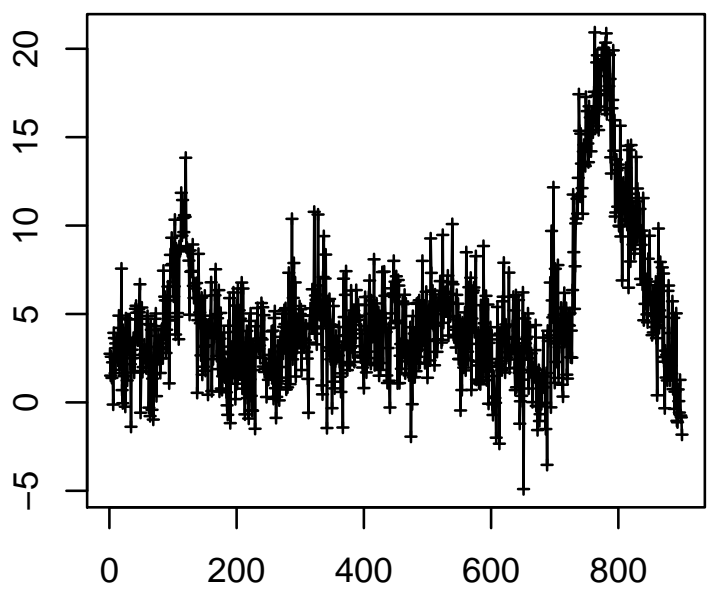

Time Point $(0.25 \mathrm{~Hz})$

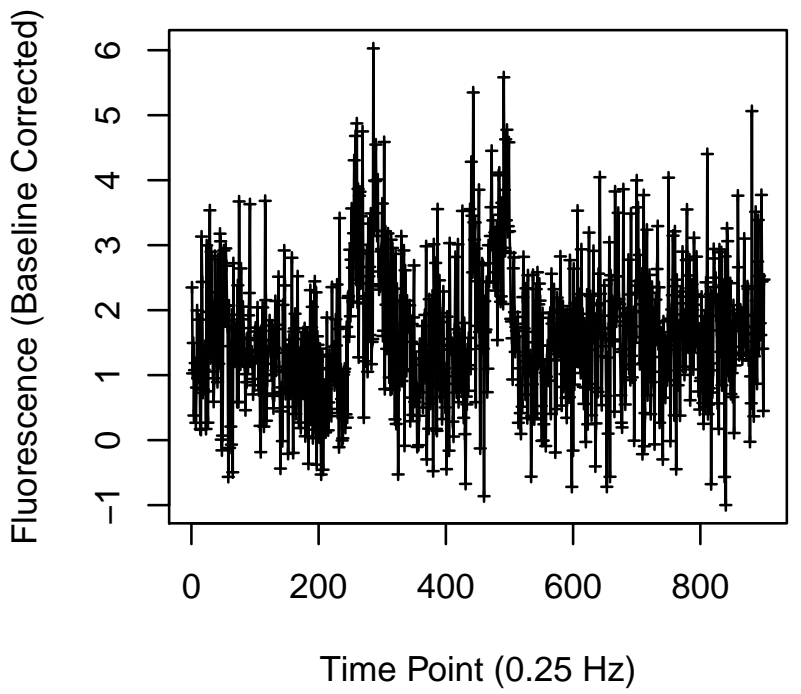

Cell 848

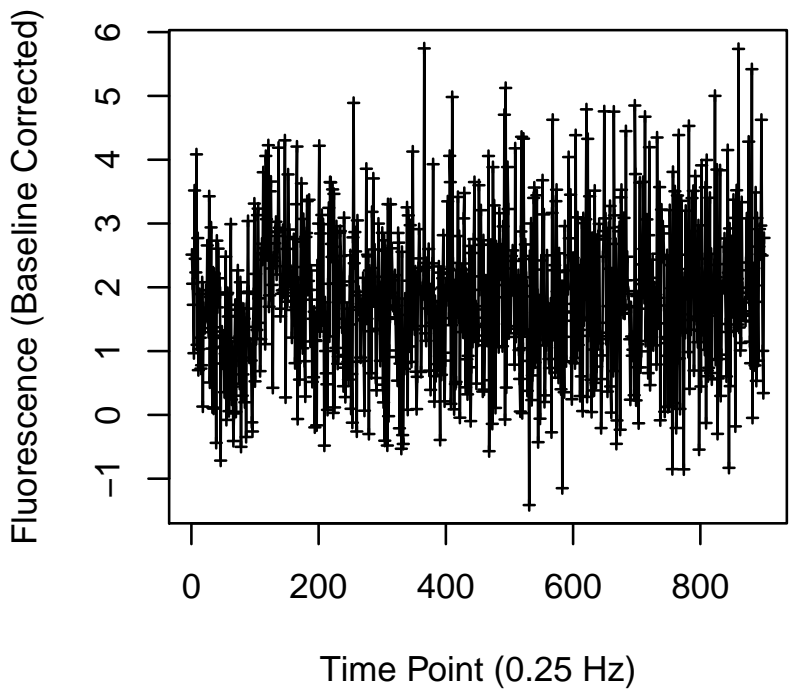




\section{Cell 849}

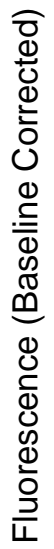

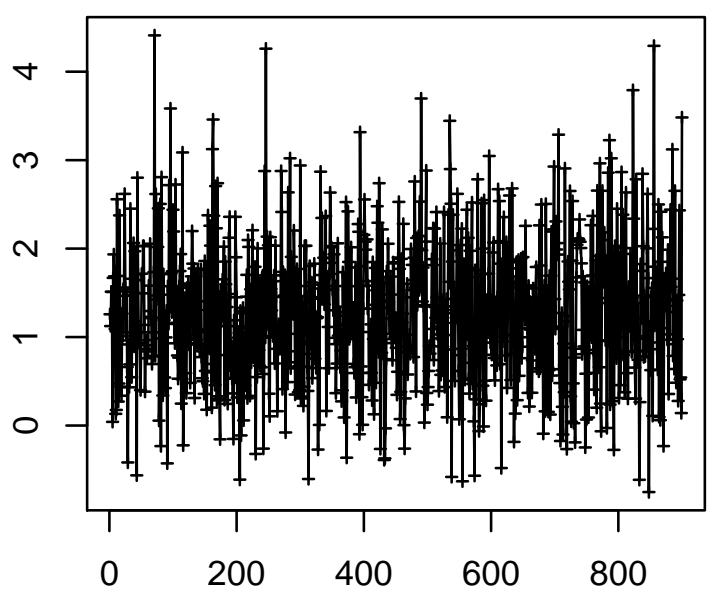

Time Point $(0.25 \mathrm{~Hz})$

\section{Cell 851}

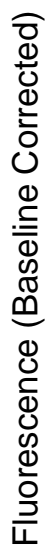

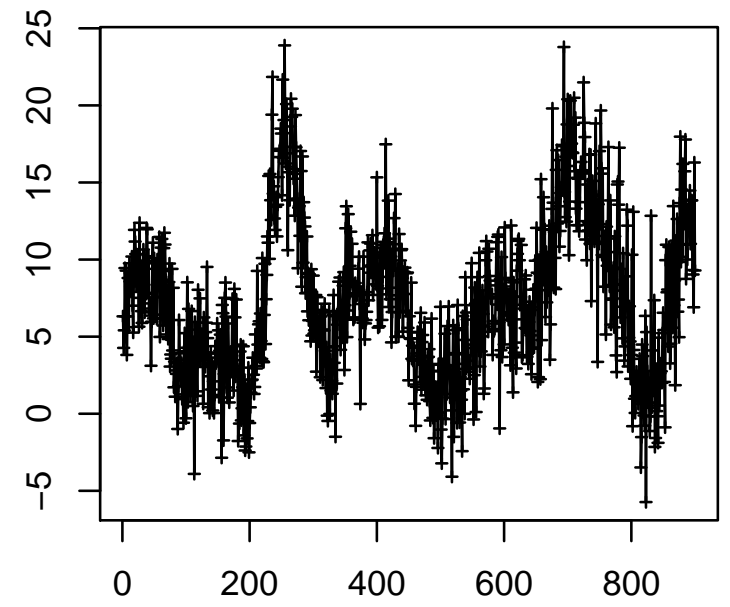

Time Point $(0.25 \mathrm{~Hz})$

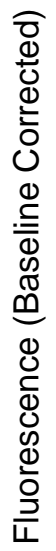

Cell 852

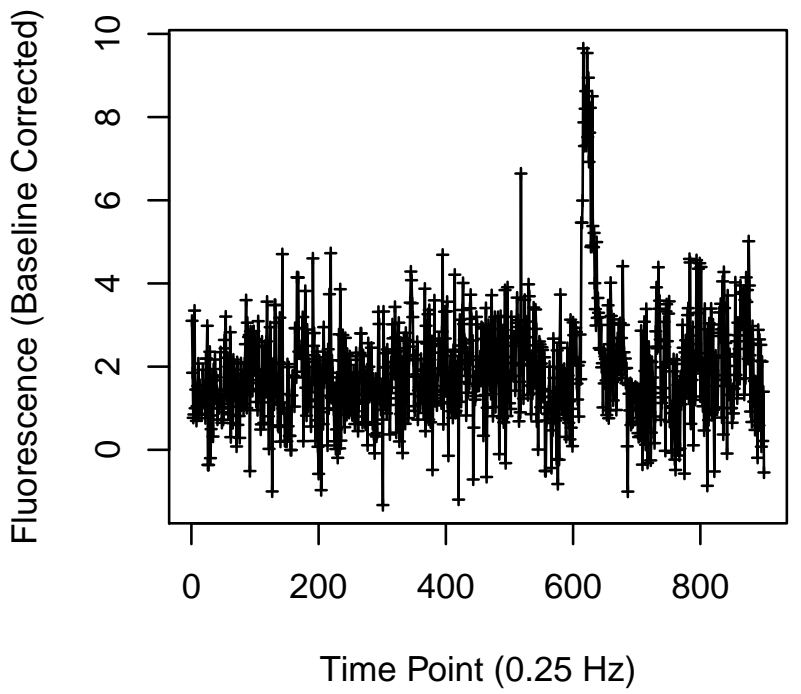


Cell 857

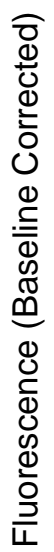

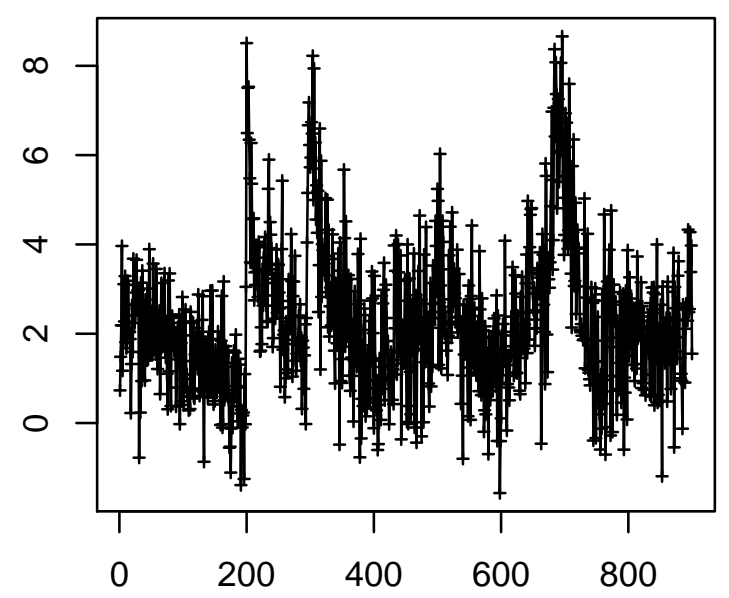

Time Point $(0.25 \mathrm{~Hz})$

\section{Cell 859}

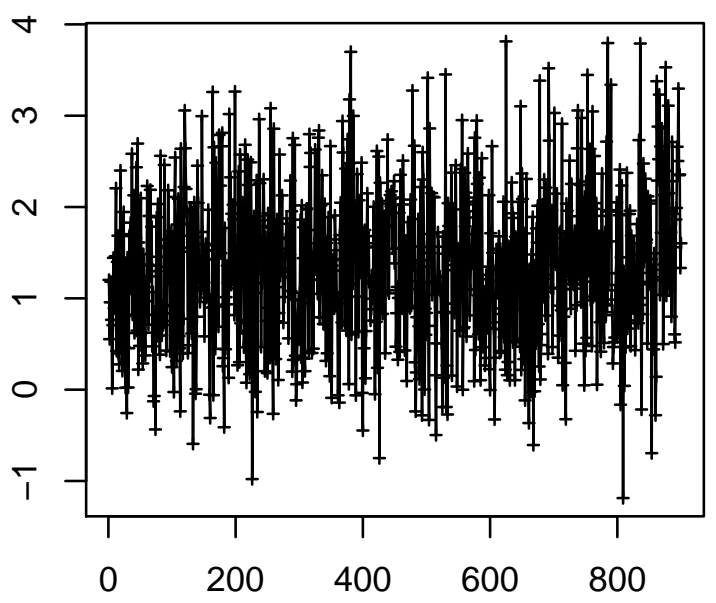

Time Point $(0.25 \mathrm{~Hz})$
Cell 858

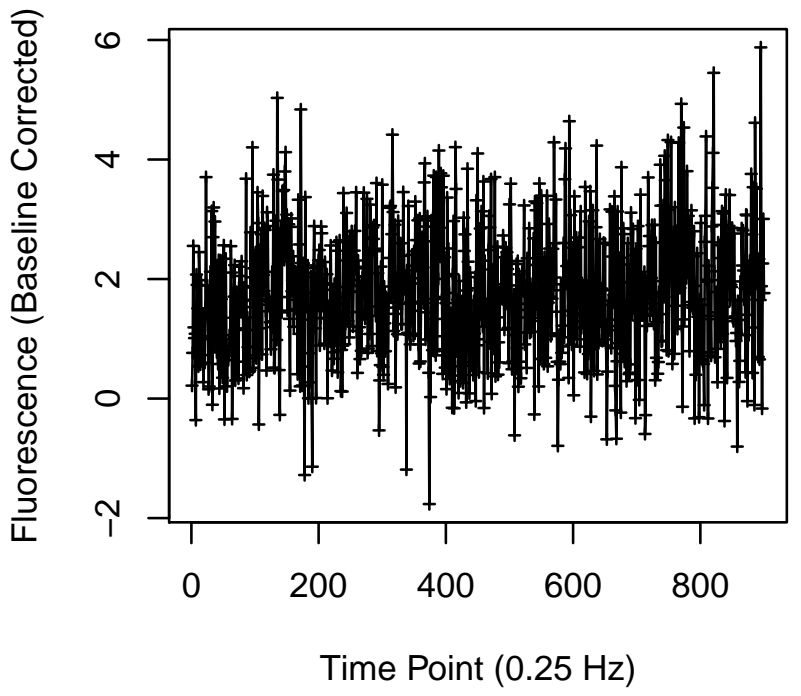

Cell 860

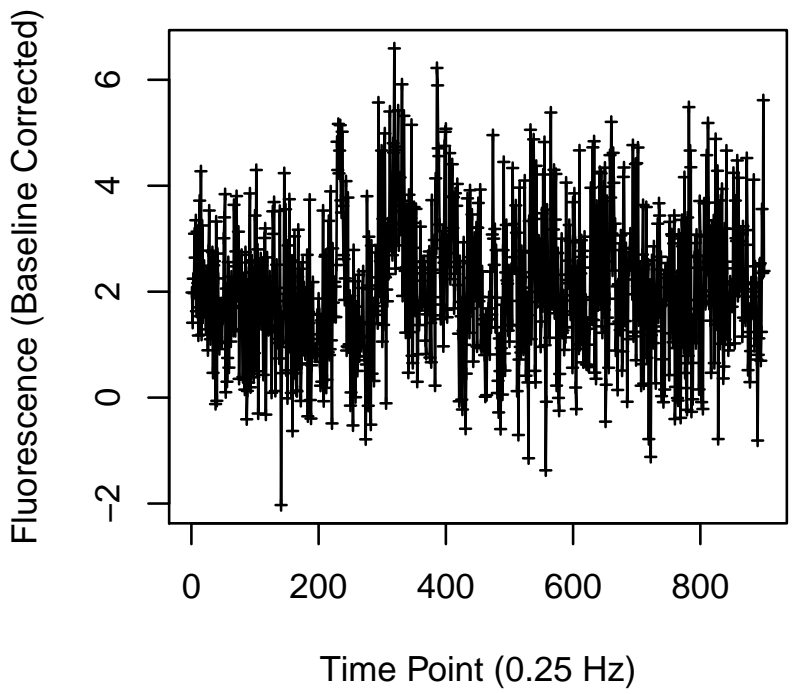


Cell 877

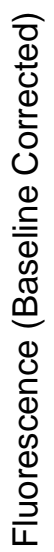

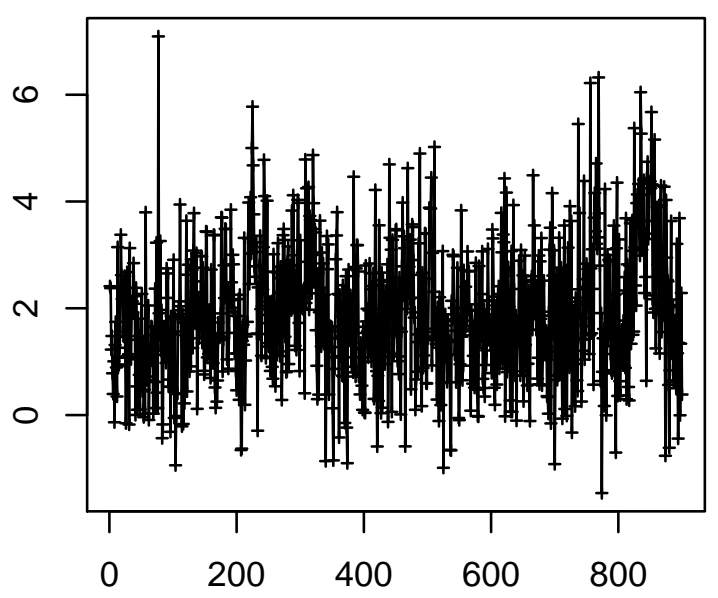

Time Point $(0.25 \mathrm{~Hz})$

\section{Cell 879}

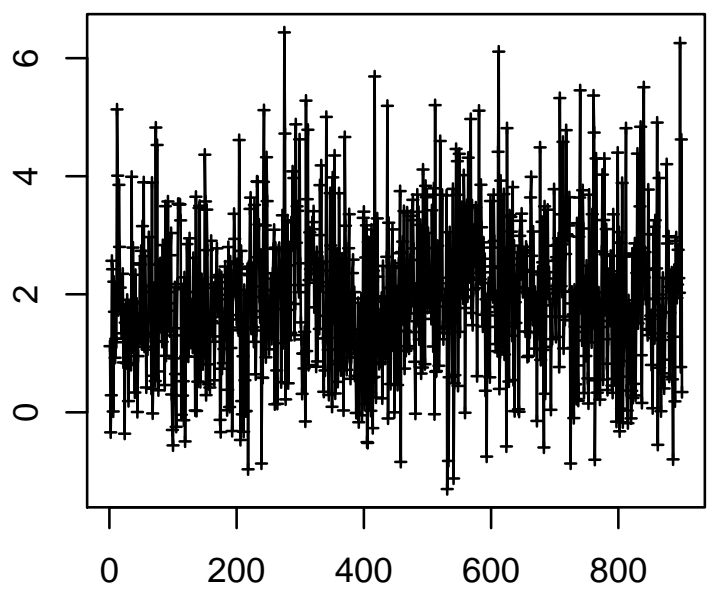

Time Point $(0.25 \mathrm{~Hz})$
Cell 878

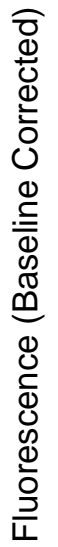

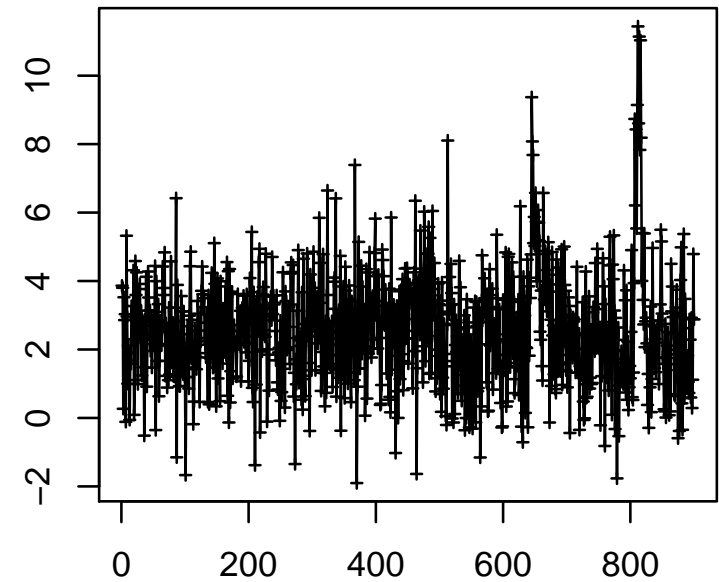

Time Point $(0.25 \mathrm{~Hz})$

\section{Cell 880}

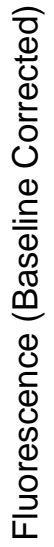

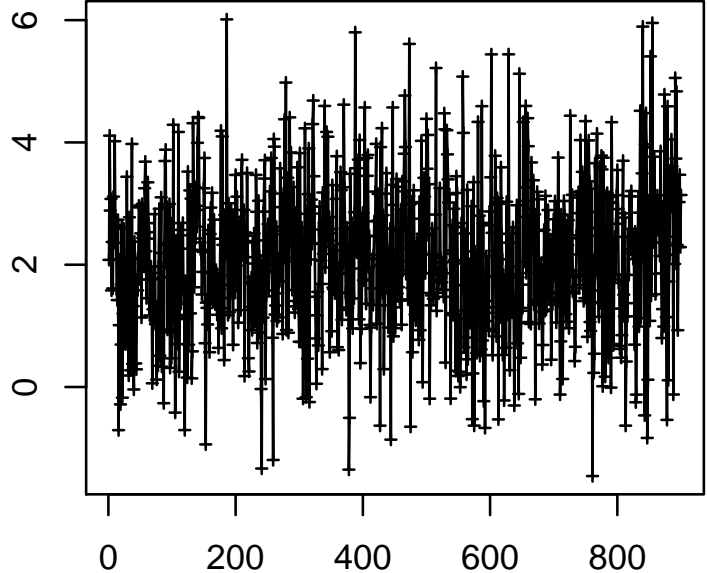

Time Point $(0.25 \mathrm{~Hz})$ 
Cell 881

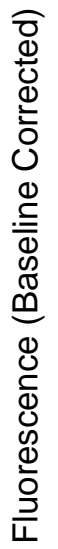

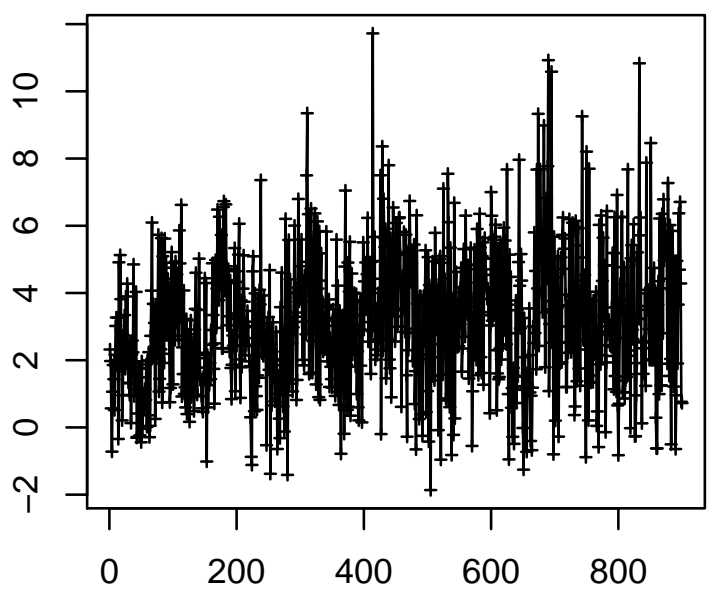

Time Point $(0.25 \mathrm{~Hz})$

\section{Cell 883}

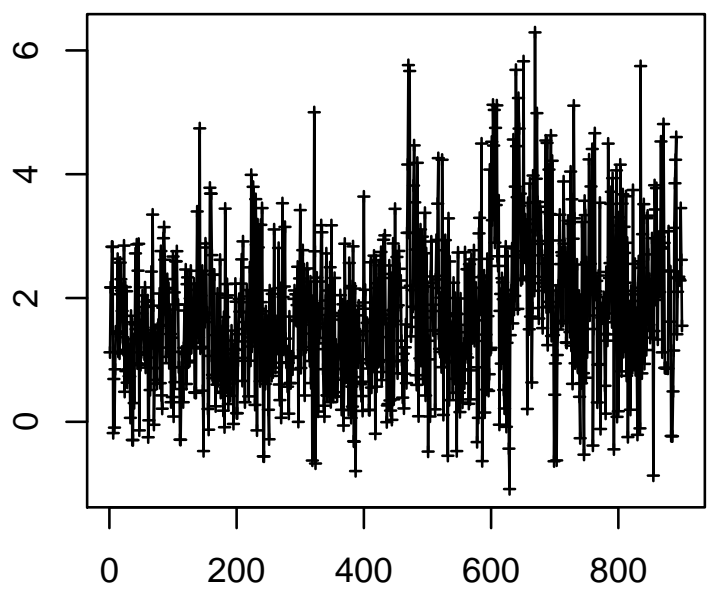

Time Point $(0.25 \mathrm{~Hz})$
Cell 882

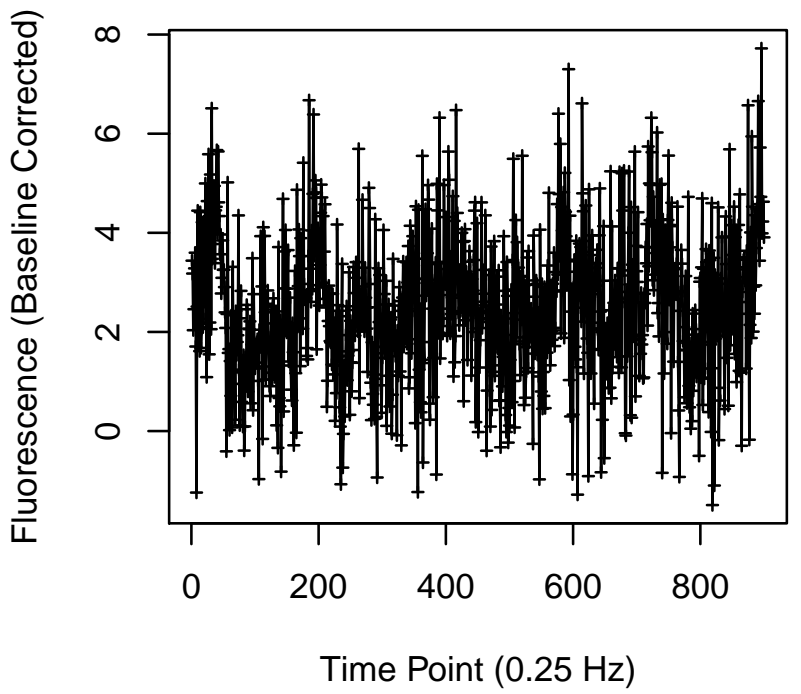

Cell 884

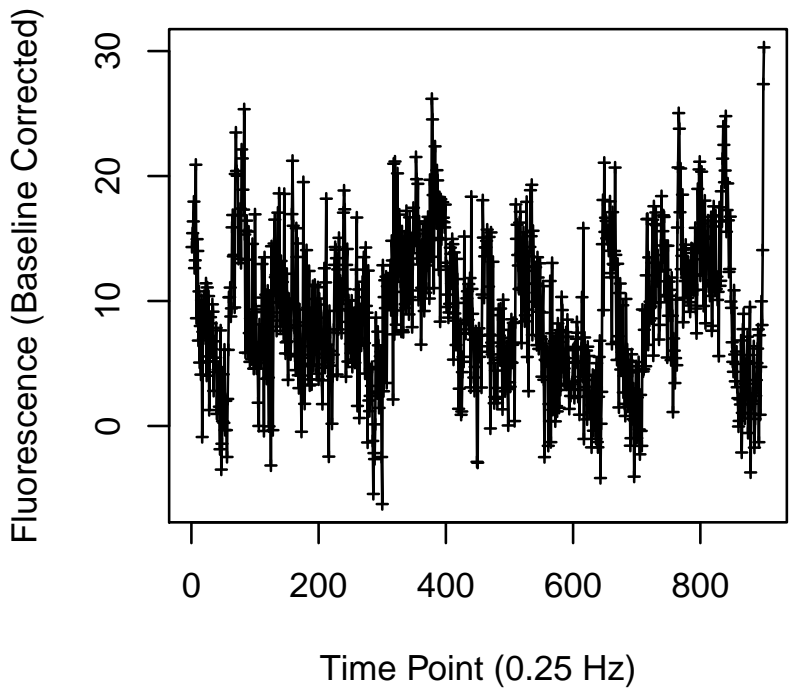


Cell 889

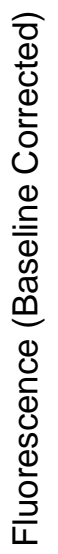

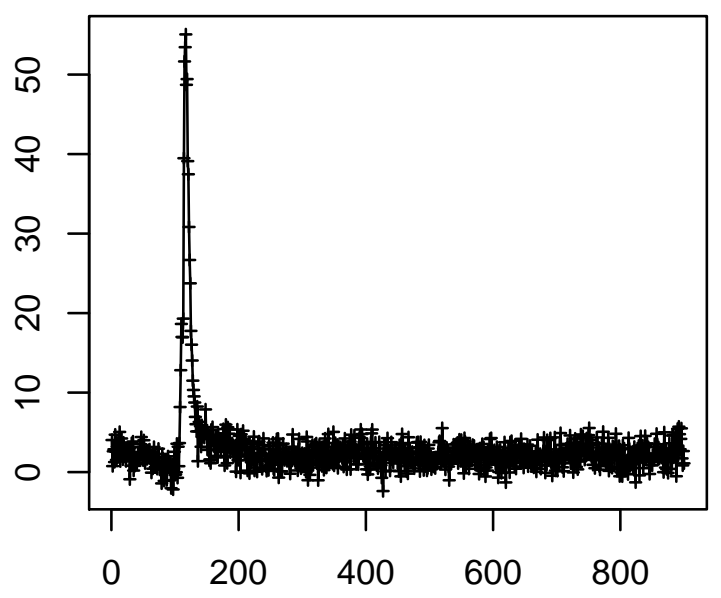

Time Point $(0.25 \mathrm{~Hz})$

Cell 891

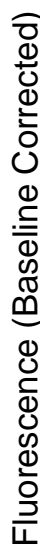

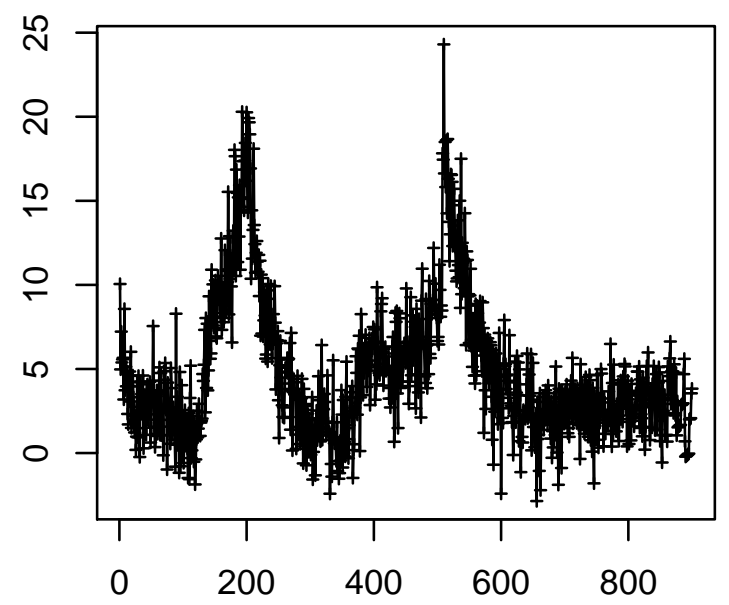

Time Point $(0.25 \mathrm{~Hz})$
Cell 890

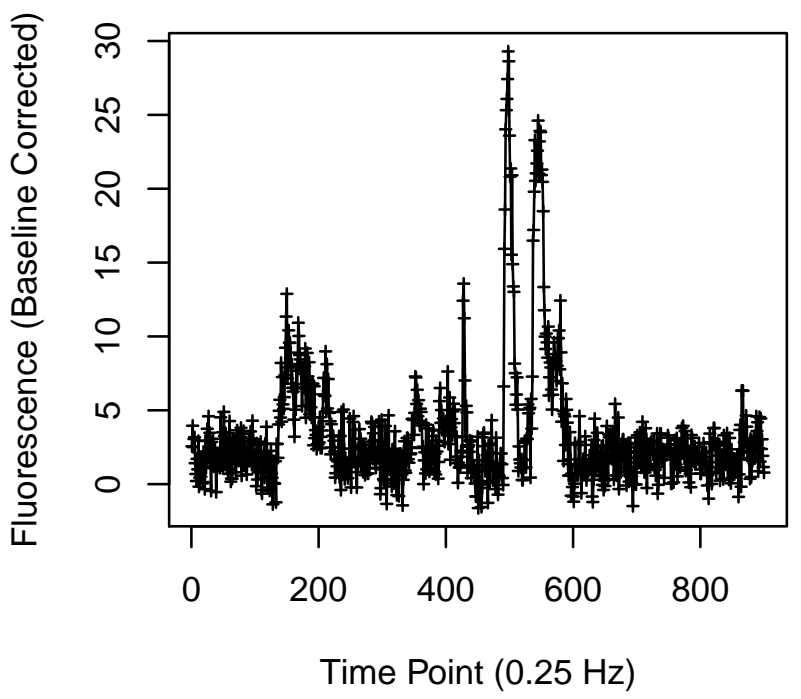

Cell 892

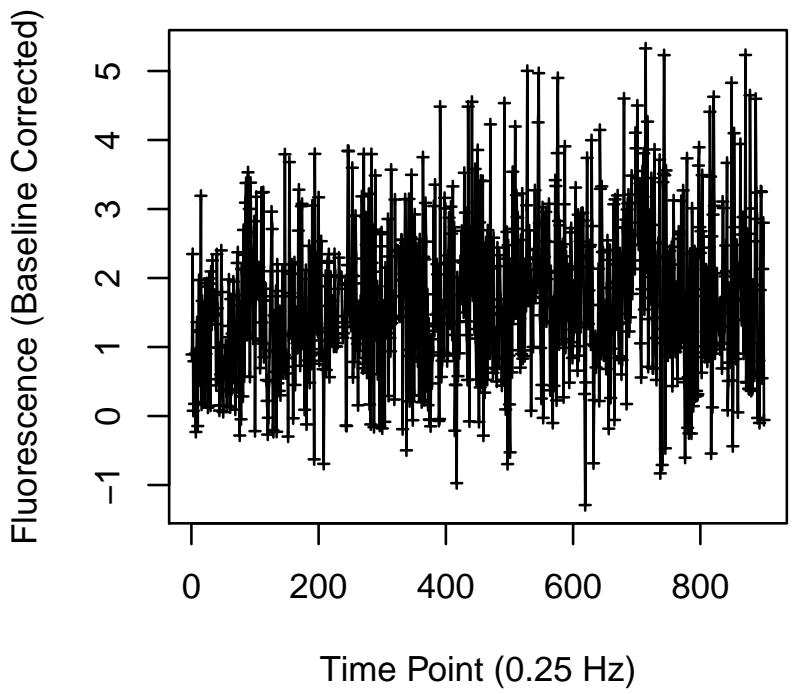


Cell 893

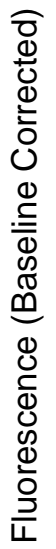

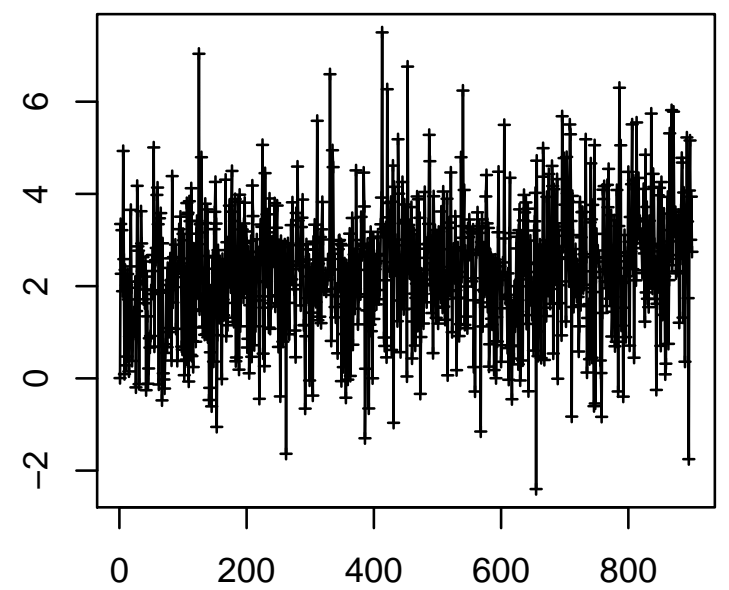

Time Point $(0.25 \mathrm{~Hz})$

\section{Cell 895}

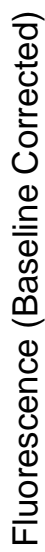

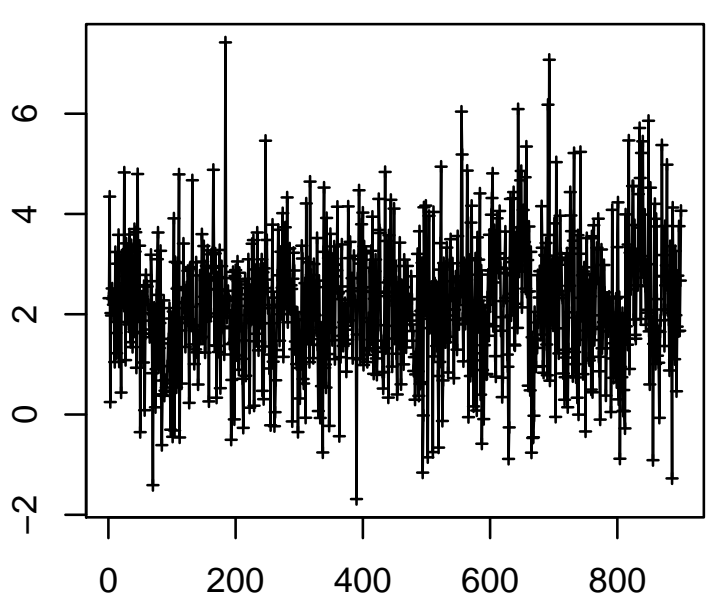

Time Point $(0.25 \mathrm{~Hz})$
Cell 894

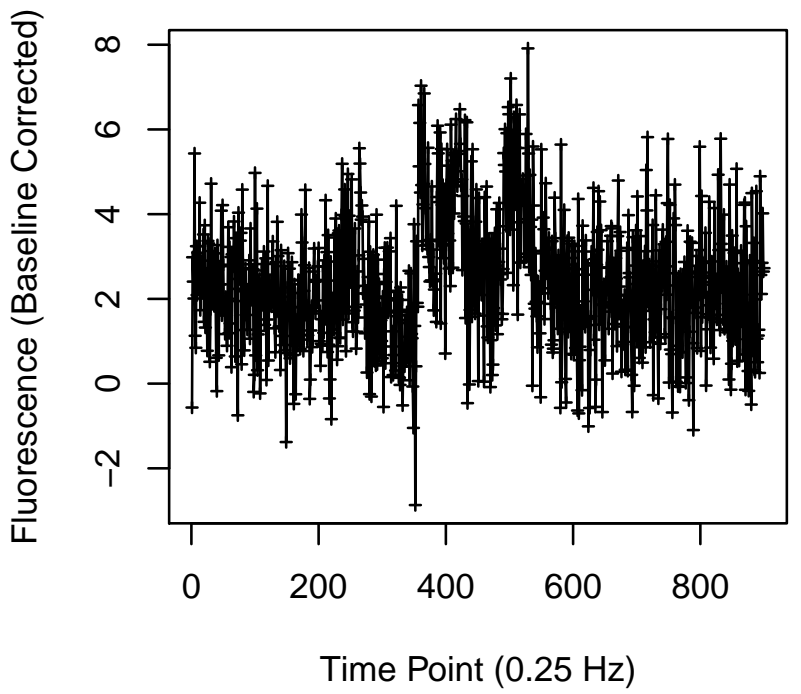

Cell 896

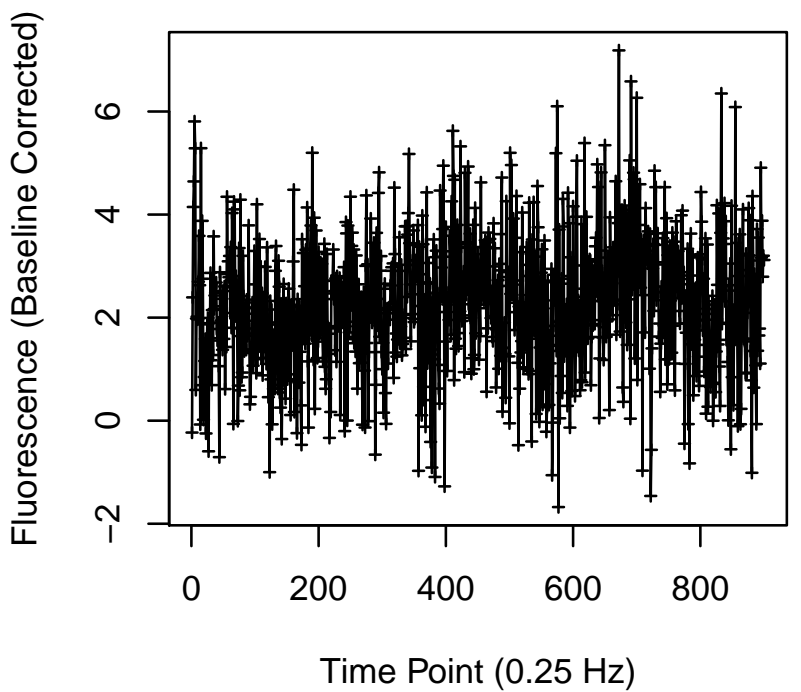


Cell 897

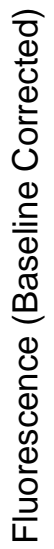

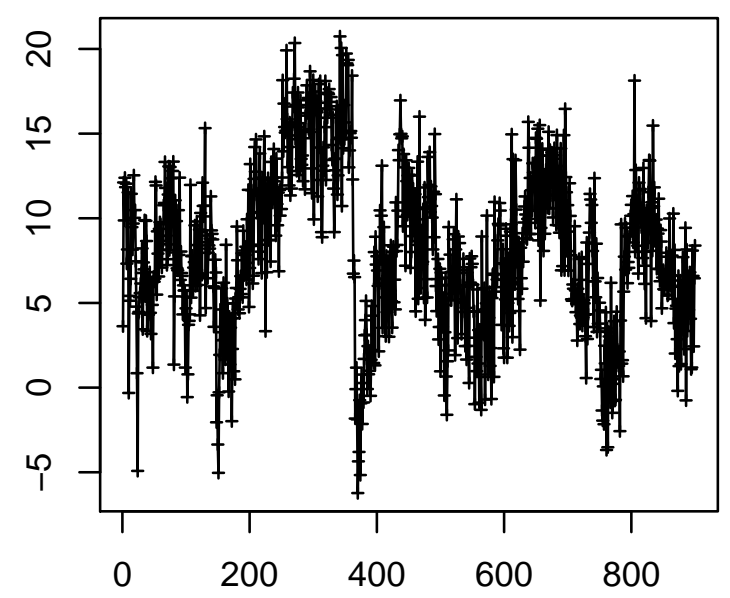

Time Point $(0.25 \mathrm{~Hz})$

\section{Cell 899}

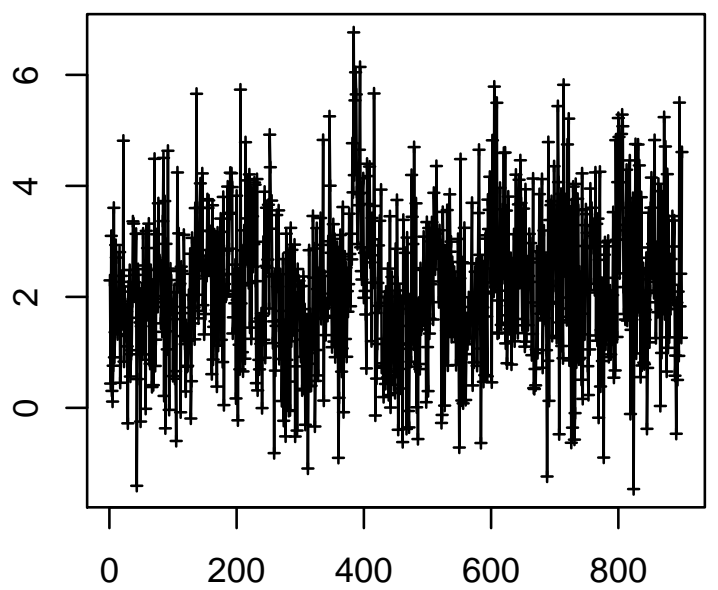

Time Point $(0.25 \mathrm{~Hz})$
Cell 898

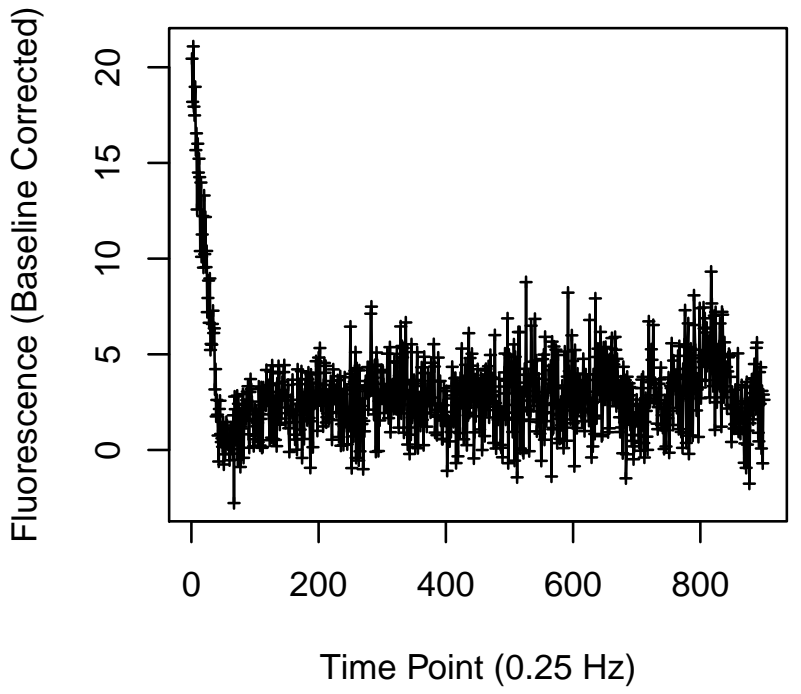

Cell 900

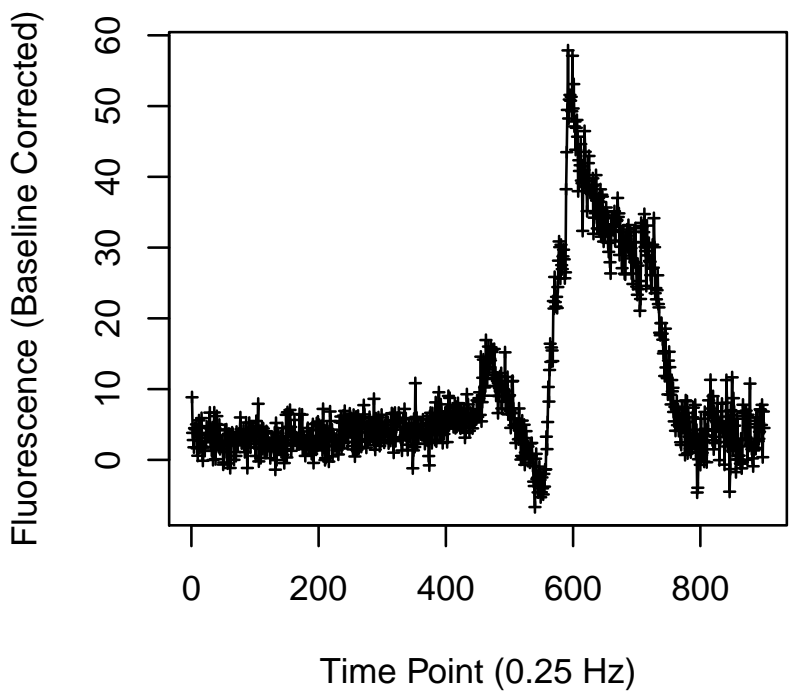


Cell 901

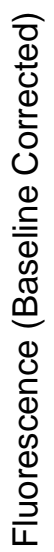

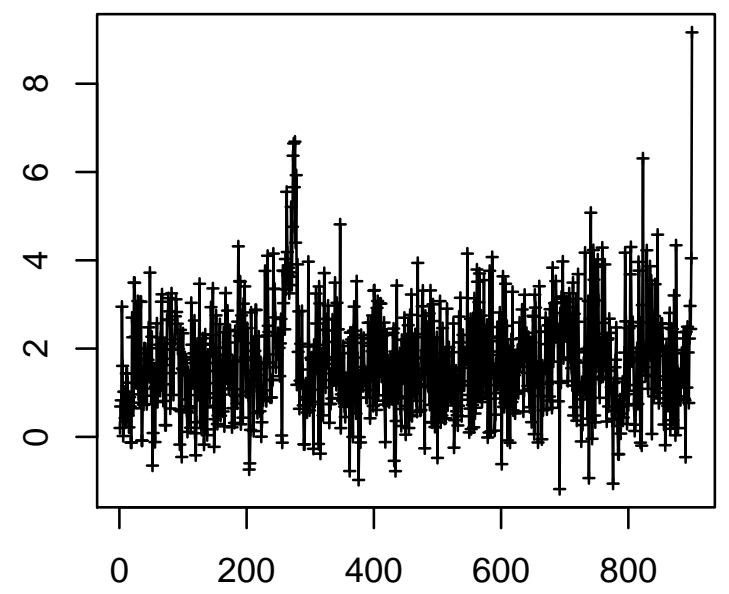

Time Point $(0.25 \mathrm{~Hz})$

Cell 903

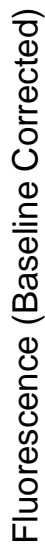

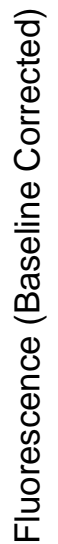

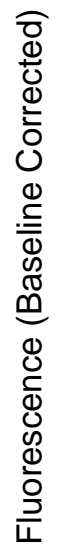

$\begin{array}{lllll}0 & 200 & 400 & 600 & 800\end{array}$

Time Point $(0.25 \mathrm{~Hz})$
Cell 904

Cell 902

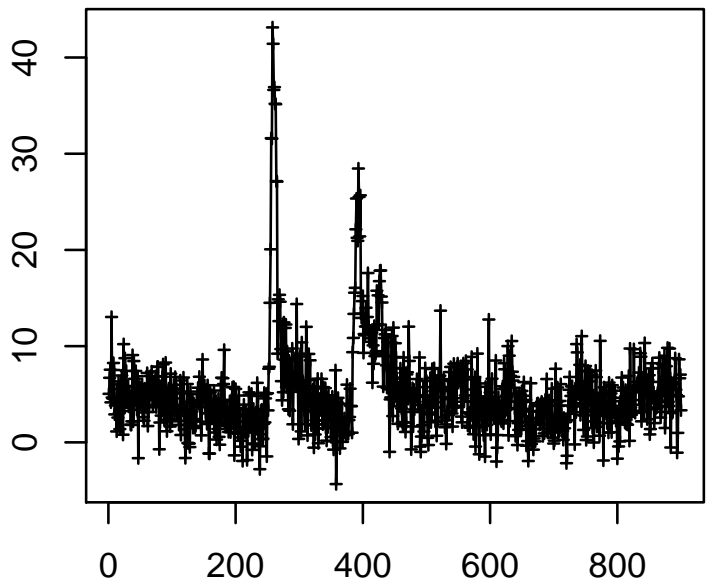

Time Point $(0.25 \mathrm{~Hz})$

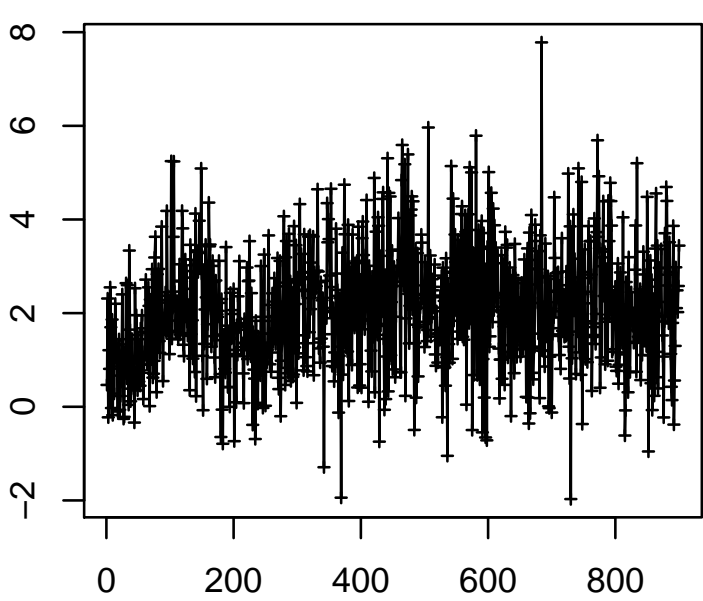

Time Point $(0.25 \mathrm{~Hz})$ 
Cell 921

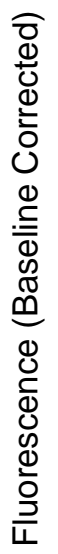

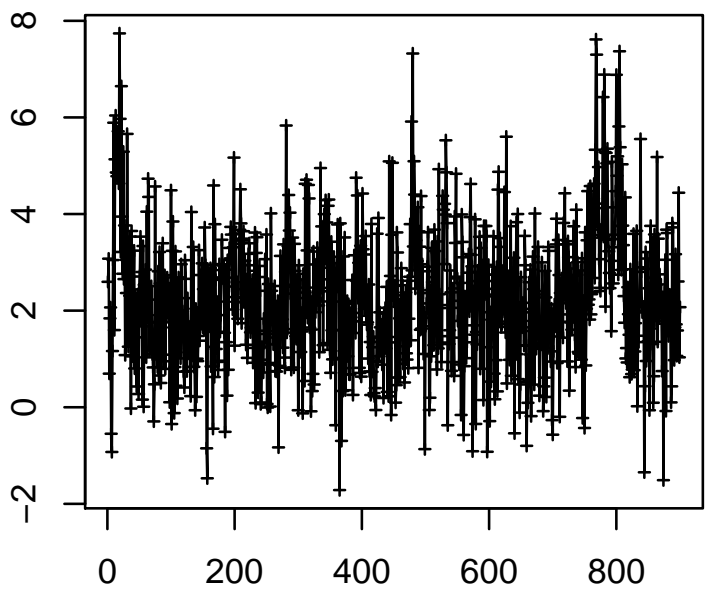

Time Point $(0.25 \mathrm{~Hz})$

Cell 923

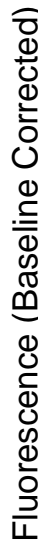

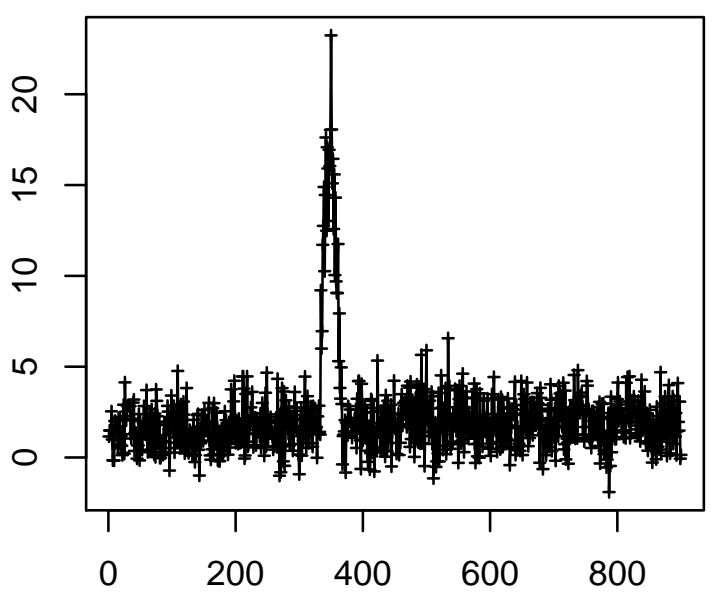

Time Point $(0.25 \mathrm{~Hz})$
Cell 922

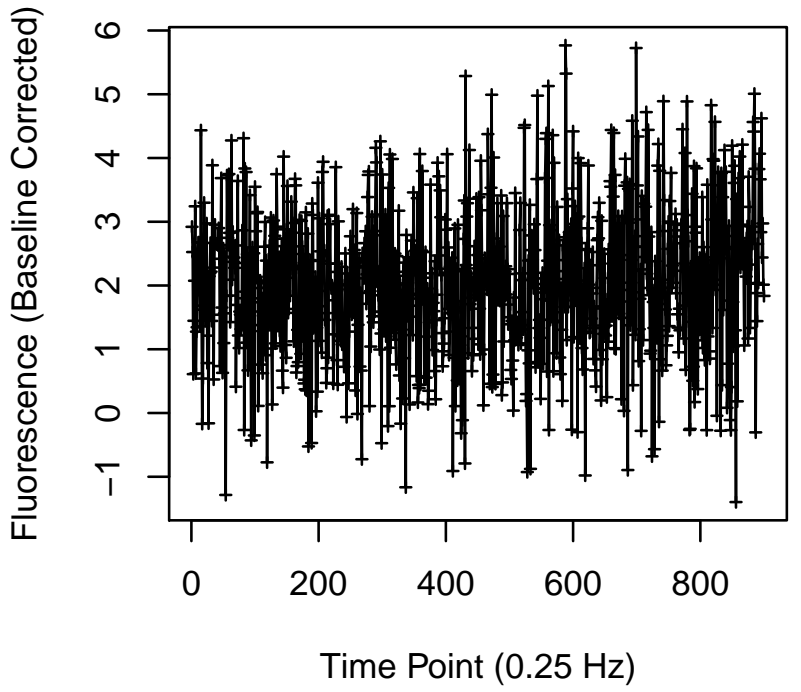

Cell 924

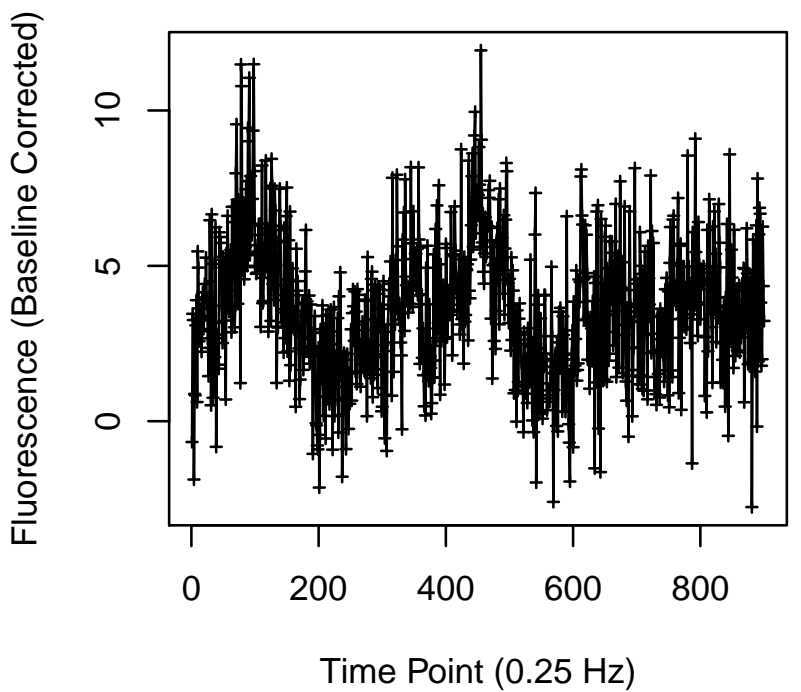


Cell 925

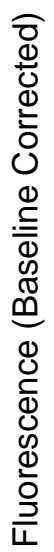

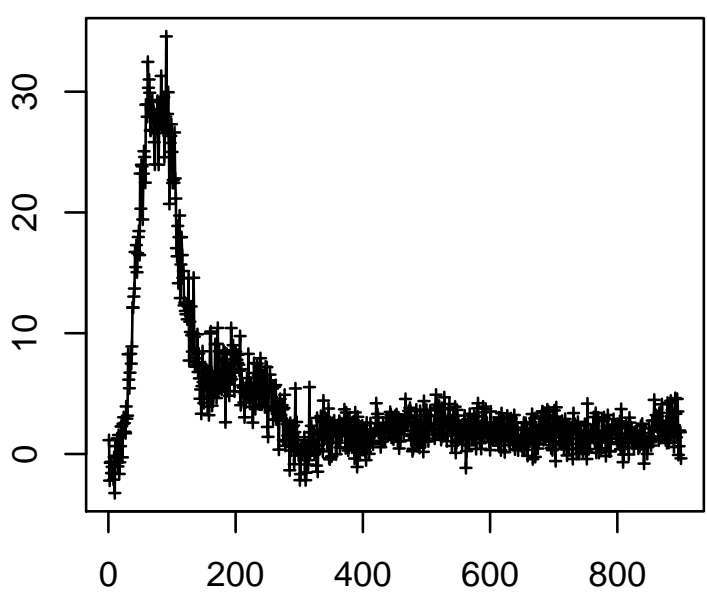

Time Point $(0.25 \mathrm{~Hz})$

Cell 927

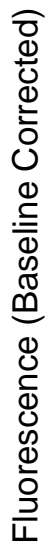

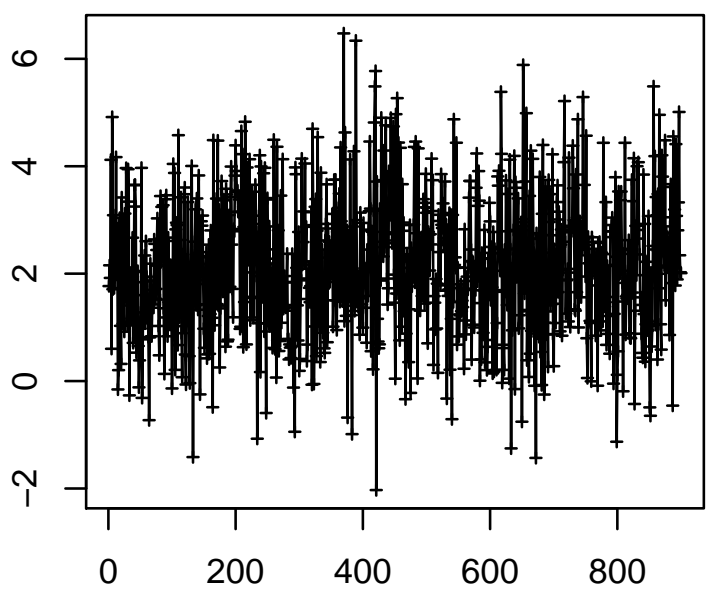

Time Point $(0.25 \mathrm{~Hz})$
Cell 926

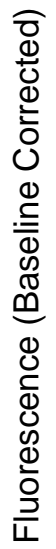

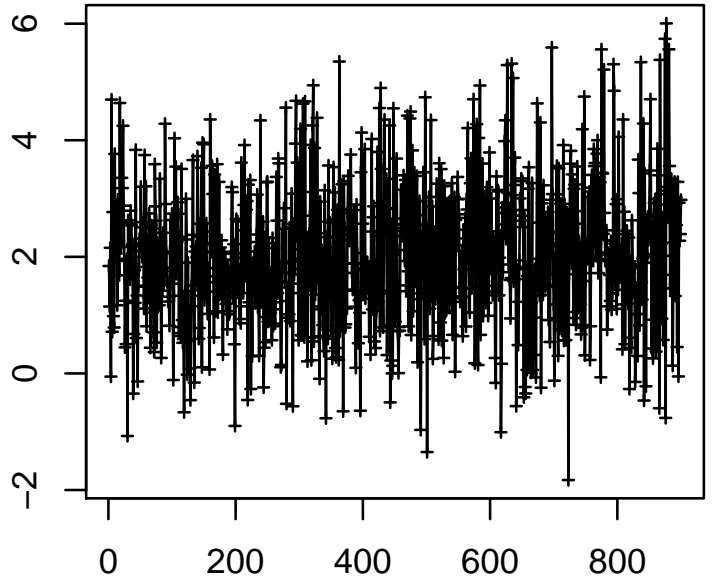

Time Point $(0.25 \mathrm{~Hz})$

\section{Cell 928}

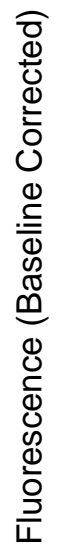

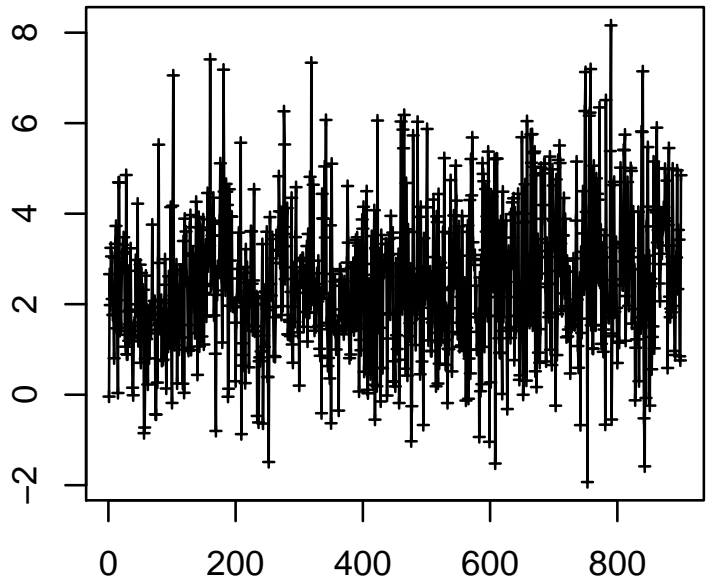

Time Point $(0.25 \mathrm{~Hz})$ 
Cell 929

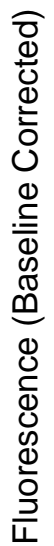

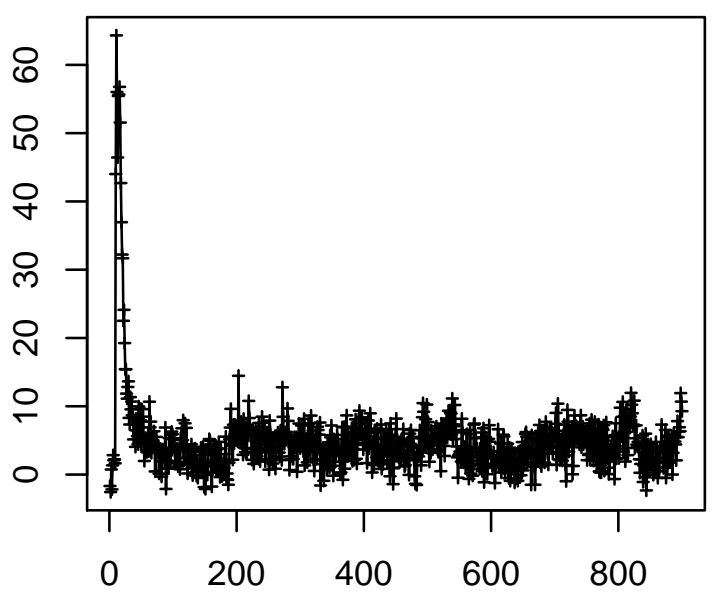

Time Point $(0.25 \mathrm{~Hz})$

Cell 931

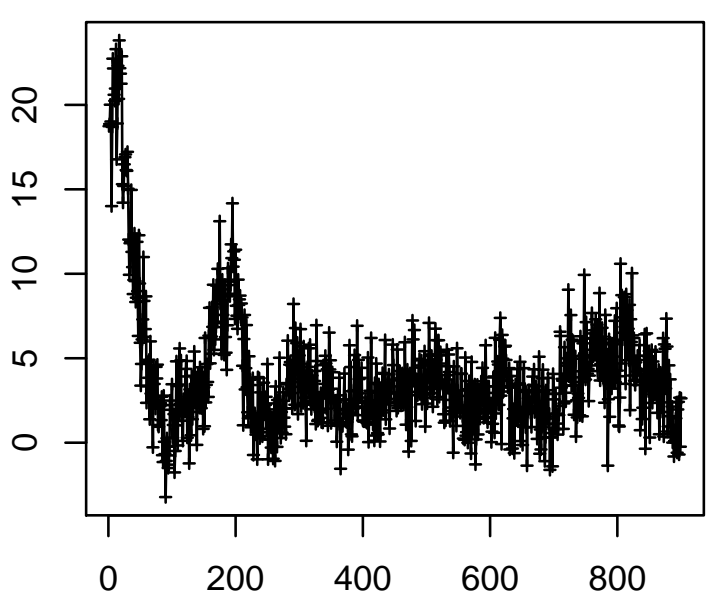

Time Point $(0.25 \mathrm{~Hz})$
Cell 930

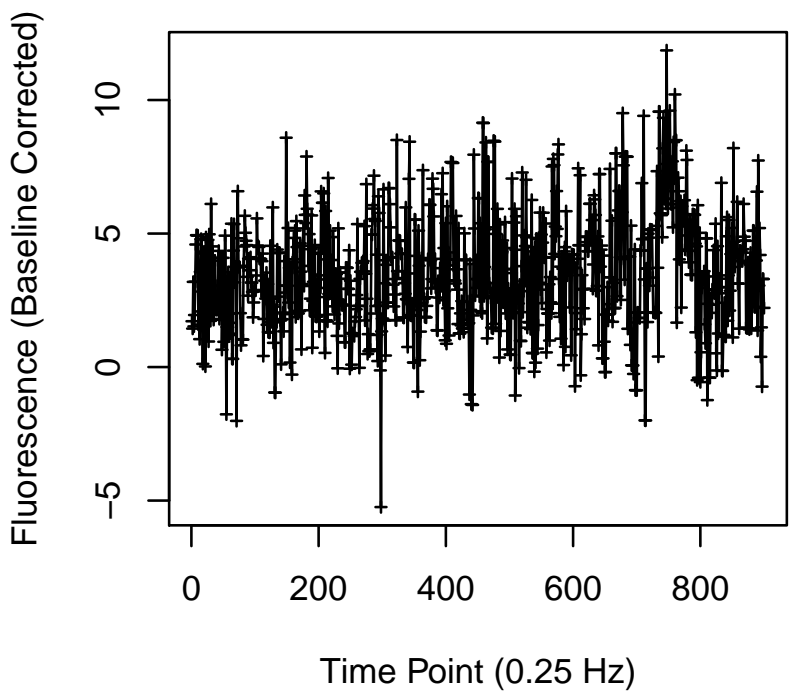

Cell 932

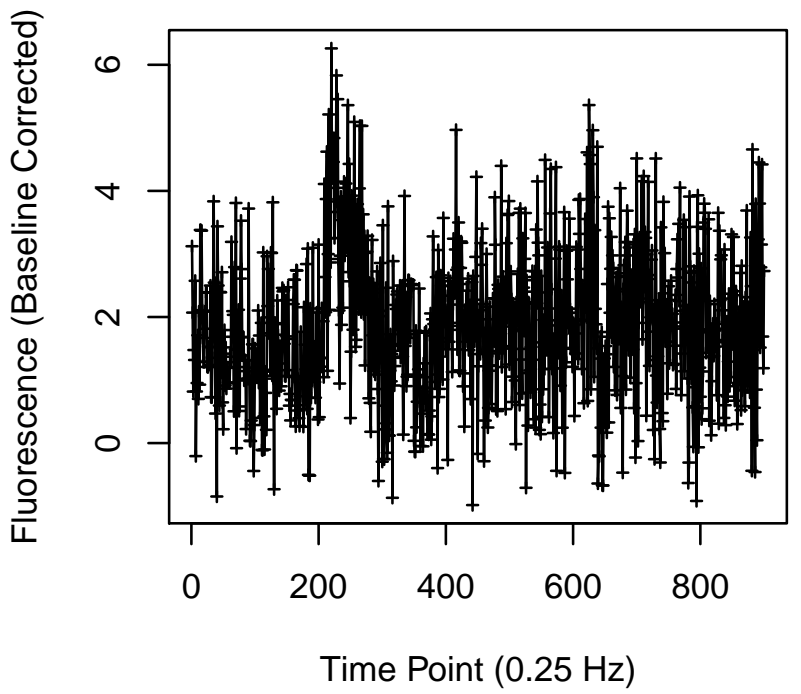


Cell 933

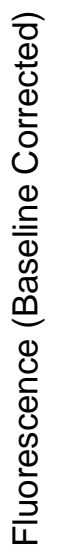

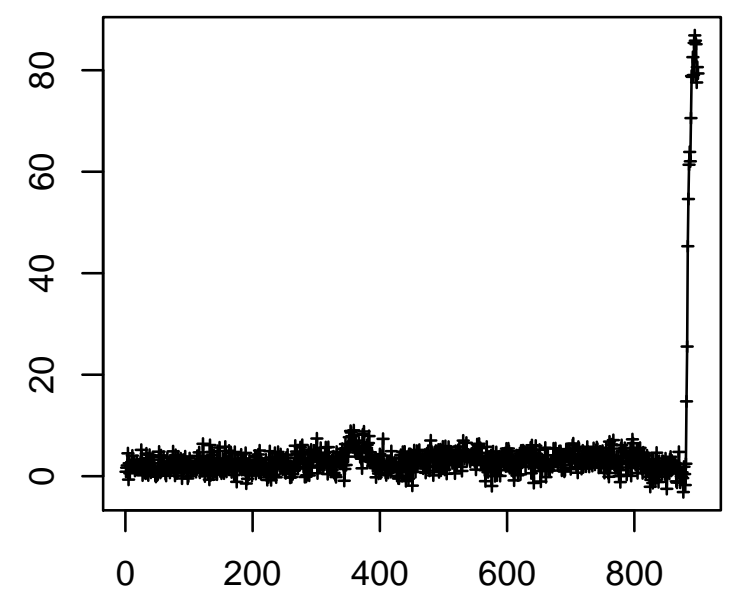

Time Point $(0.25 \mathrm{~Hz})$

Cell 935

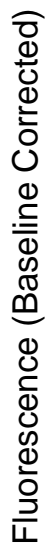

Time Point $(0.25 \mathrm{~Hz})$

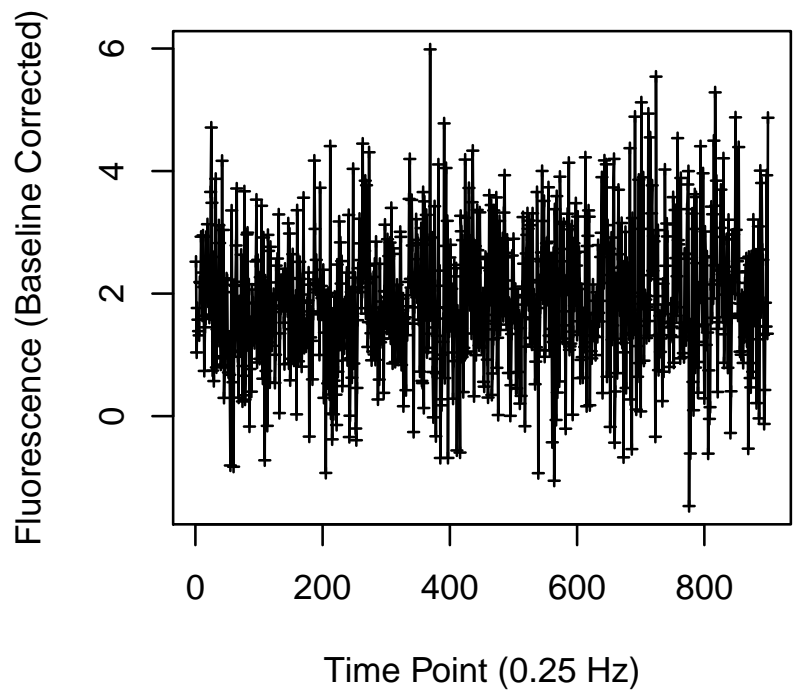

Cell 936

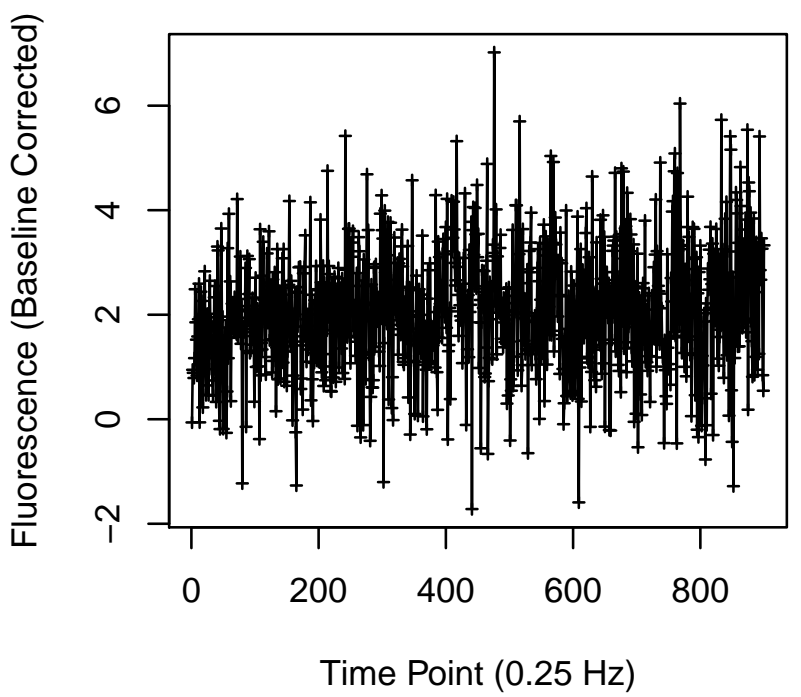




\section{Cell 949}

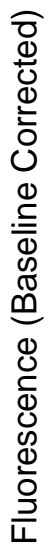

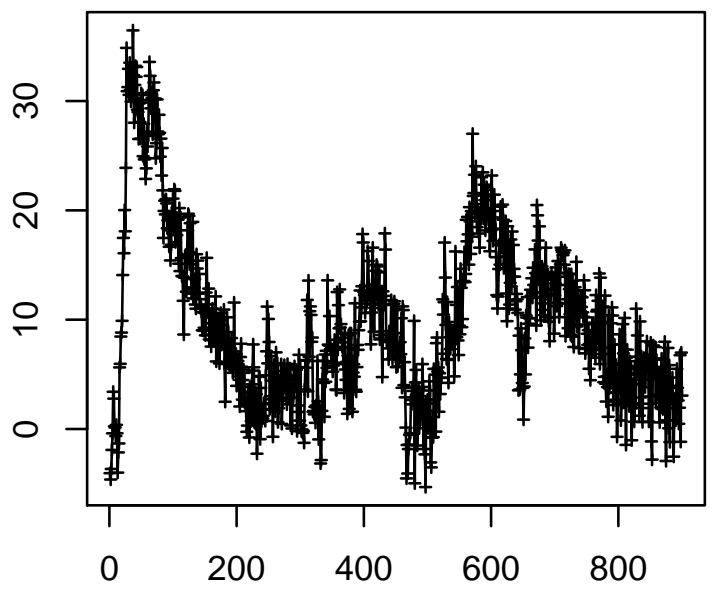

Time Point $(0.25 \mathrm{~Hz})$

\section{Cell 951}

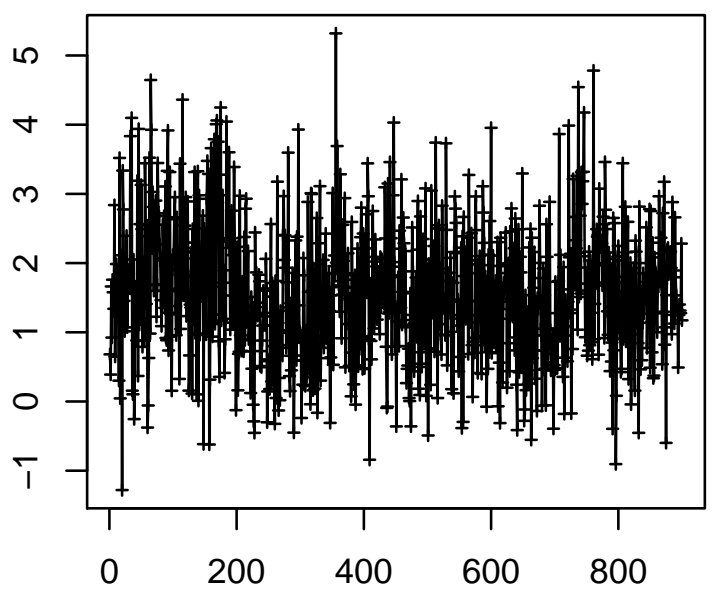

Time Point $(0.25 \mathrm{~Hz})$
Cell 950

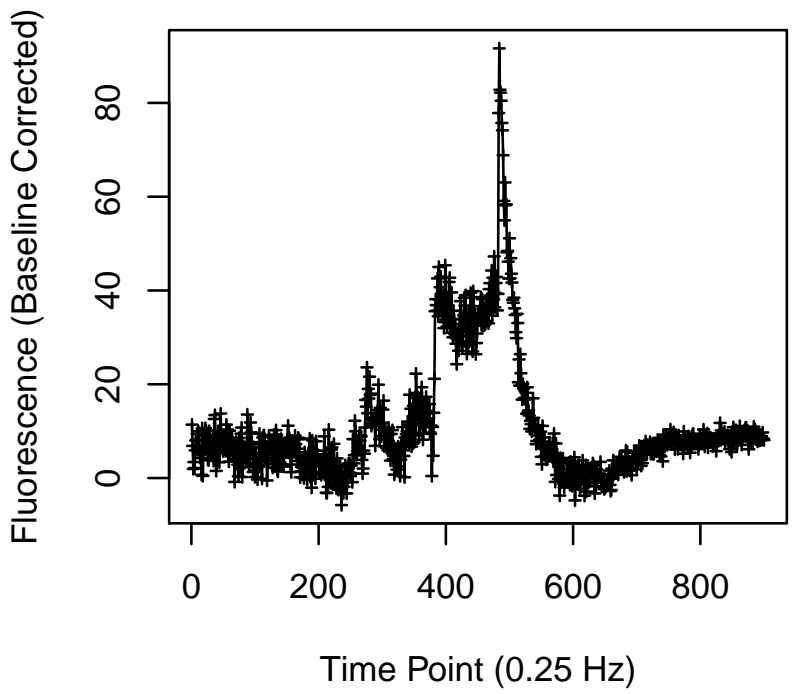

Cell 952

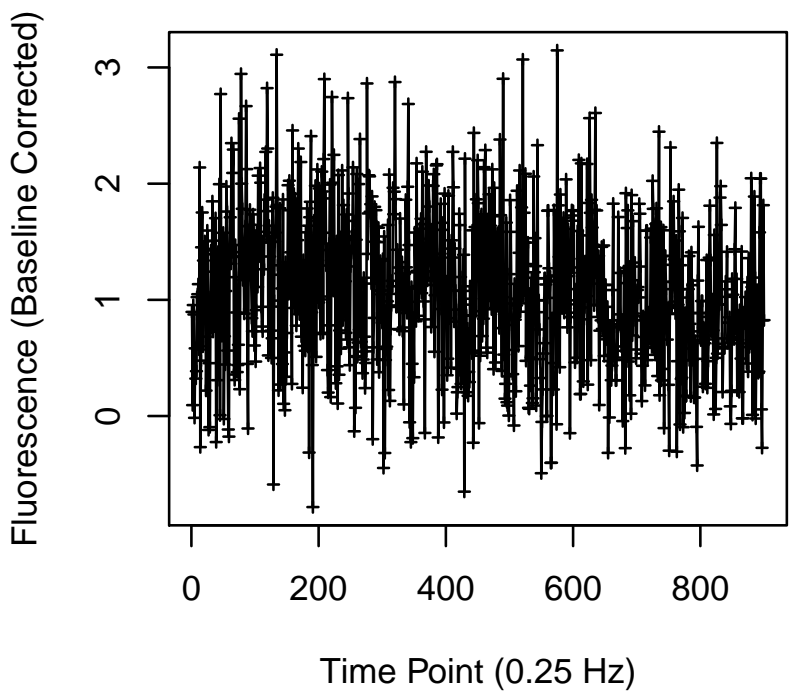


Cell 961

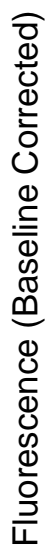

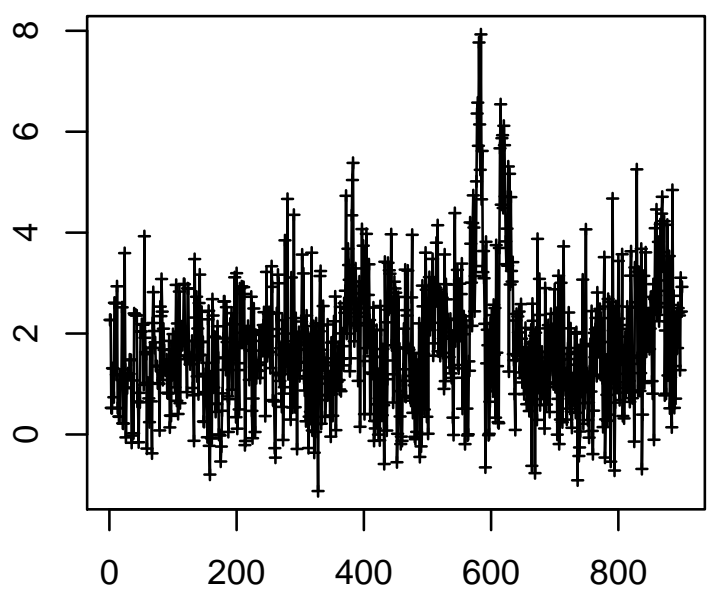

Time Point $(0.25 \mathrm{~Hz})$

\section{Cell 963}

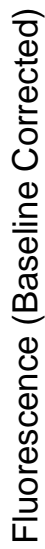

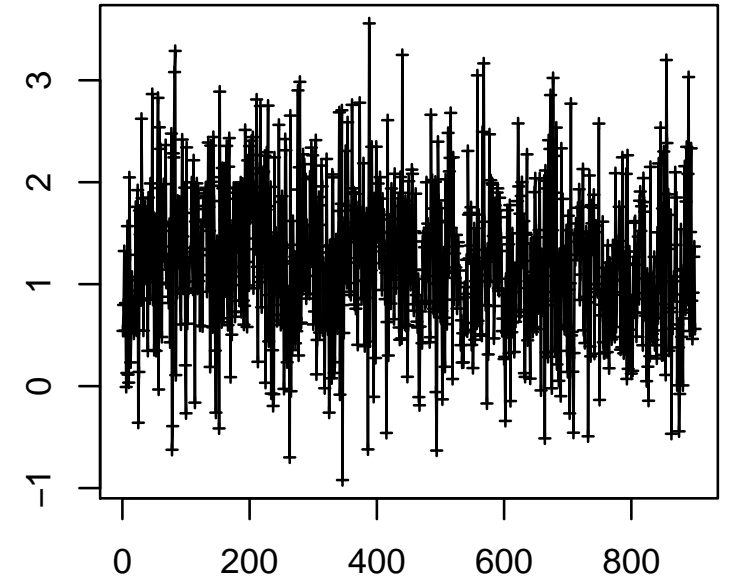

Time Point $(0.25 \mathrm{~Hz})$

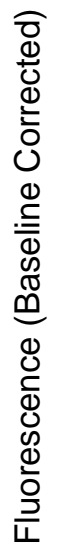

Cell 962

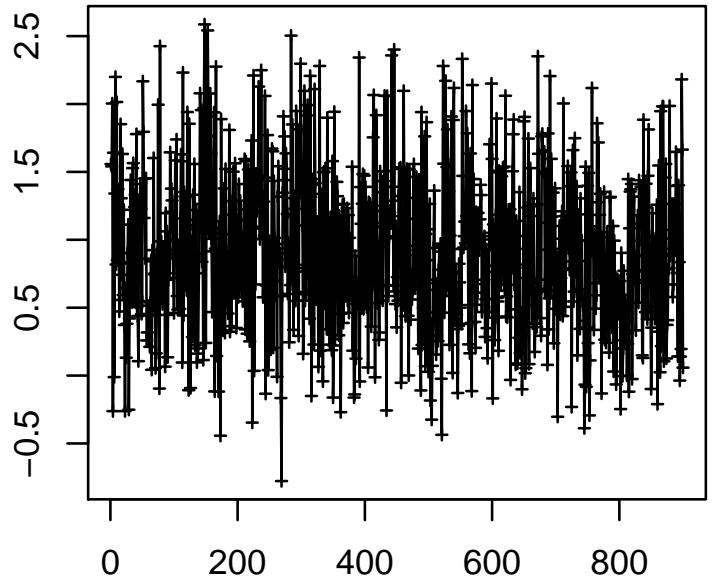

Time Point $(0.25 \mathrm{~Hz})$

Cell 964

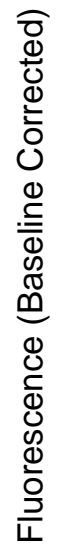

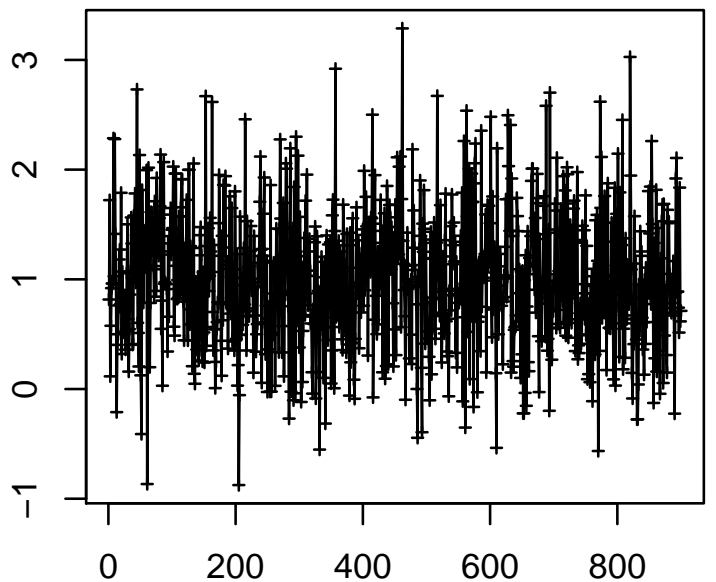

Time Point $(0.25 \mathrm{~Hz})$ 


\section{Cell 965}

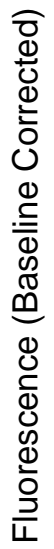

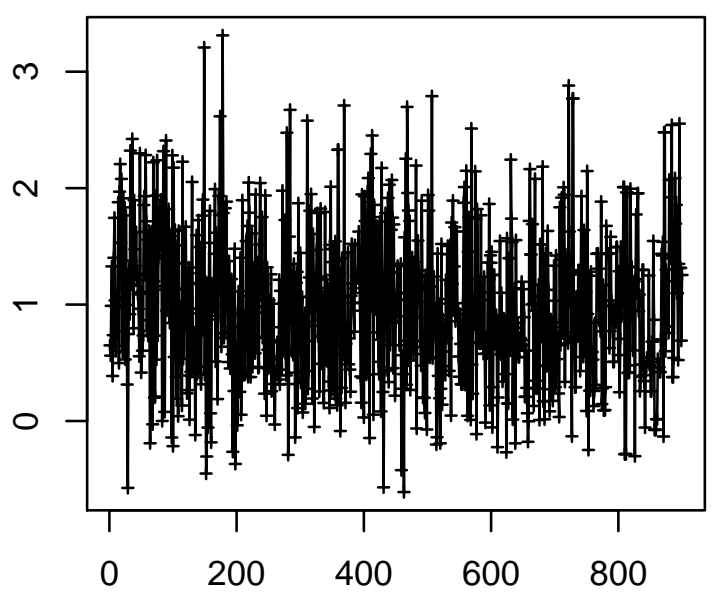

Time Point $(0.25 \mathrm{~Hz})$

\section{Cell 967}

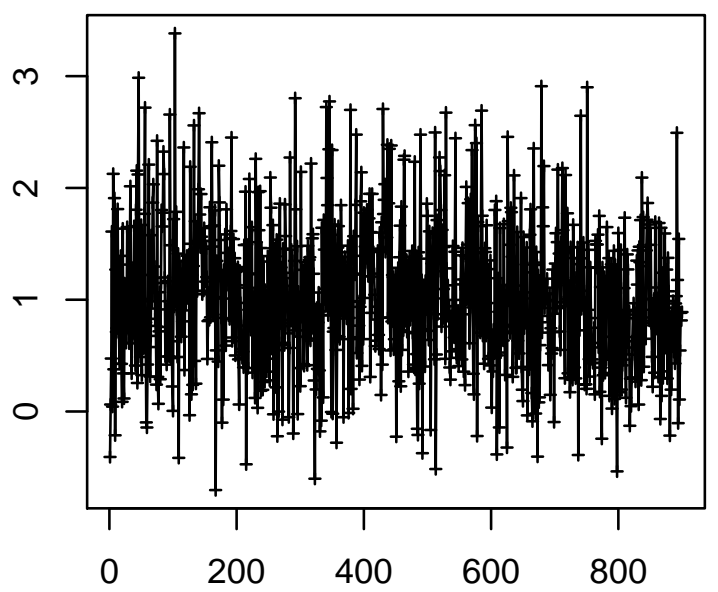

Time Point $(0.25 \mathrm{~Hz})$
Cell 966

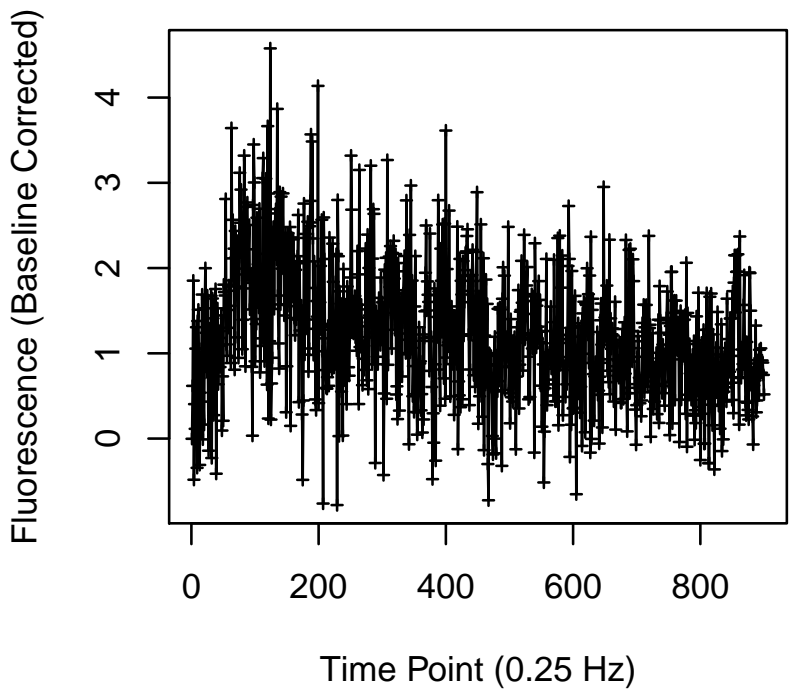

Cell 968

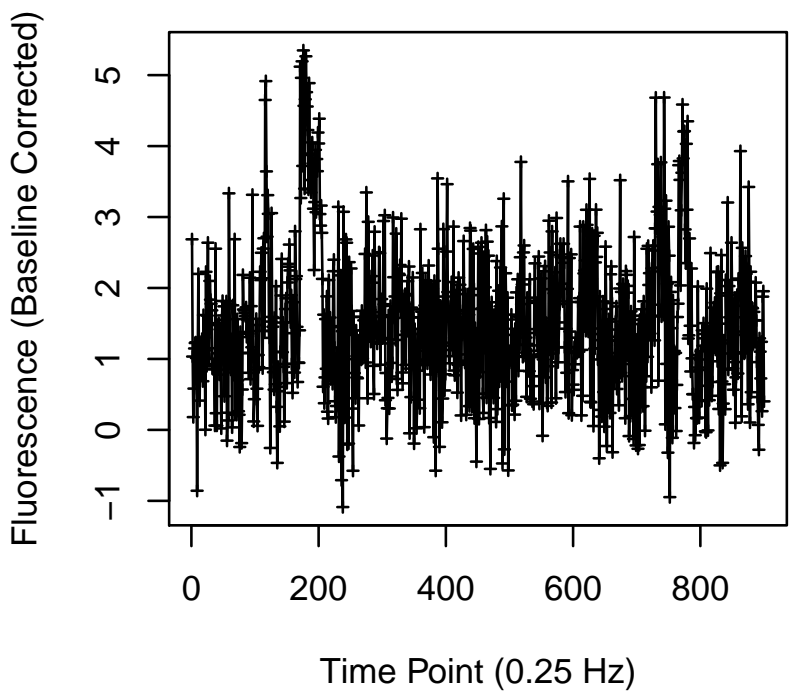




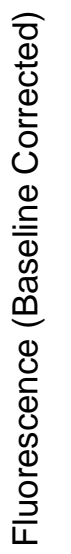

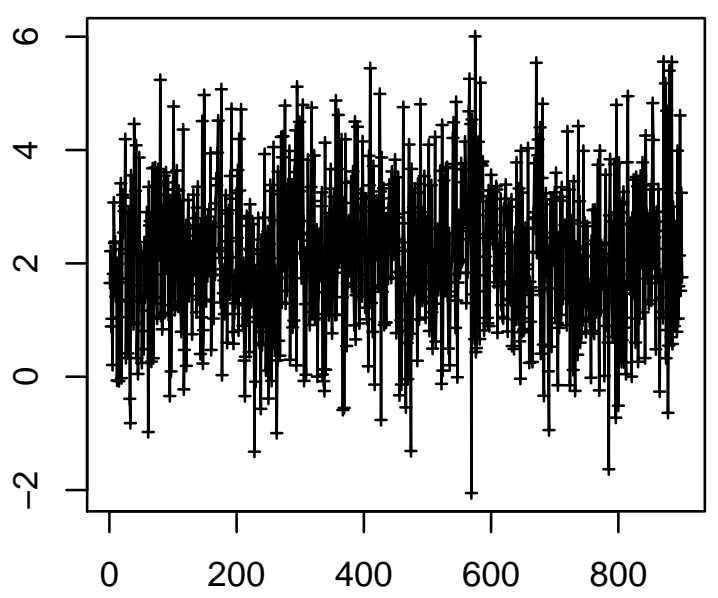

Time Point $(0.25 \mathrm{~Hz})$

Cell 979

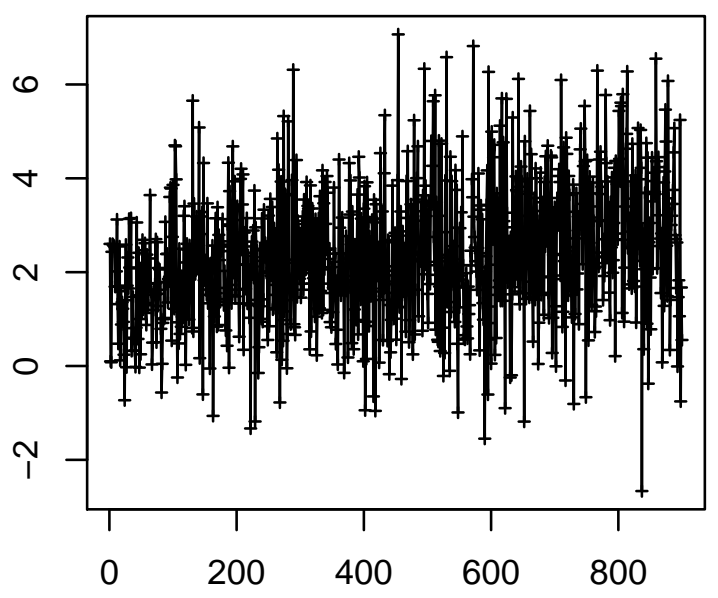

Time Point $(0.25 \mathrm{~Hz})$

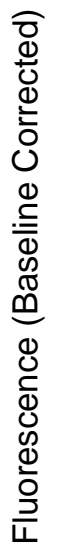

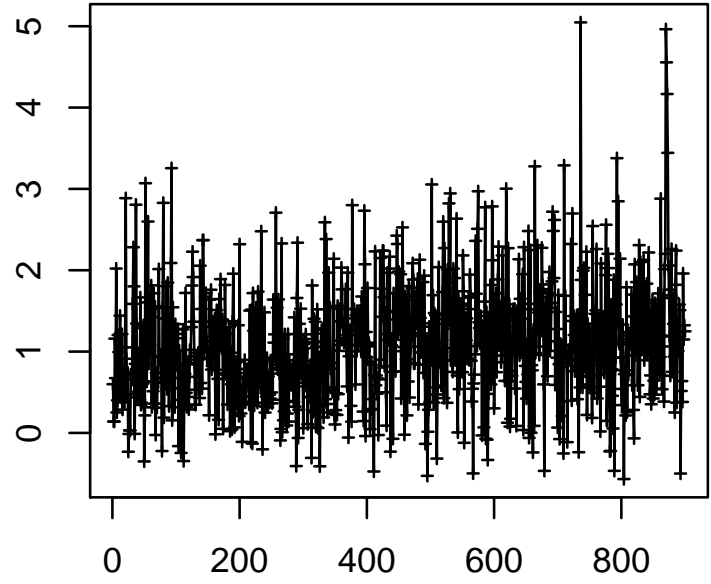

Time Point $(0.25 \mathrm{~Hz})$

\section{Cell 980}

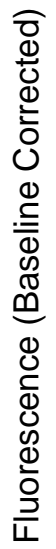

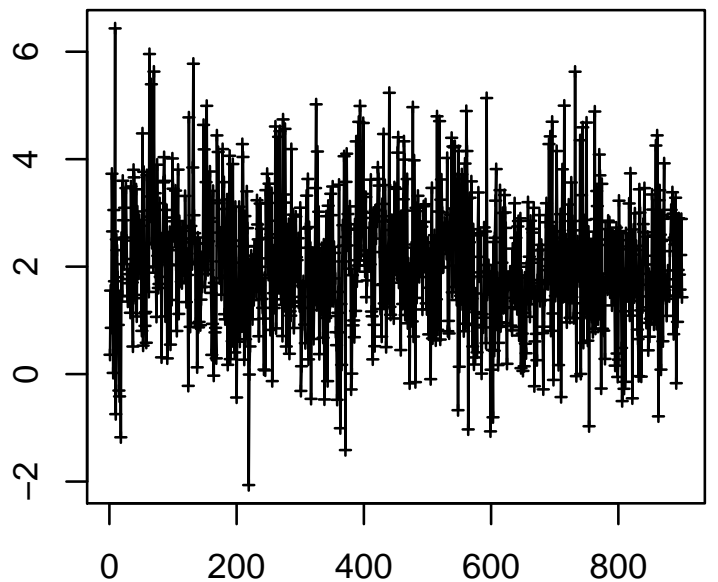

Time Point $(0.25 \mathrm{~Hz})$ 
Cell 981

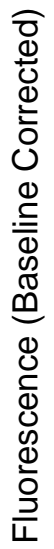

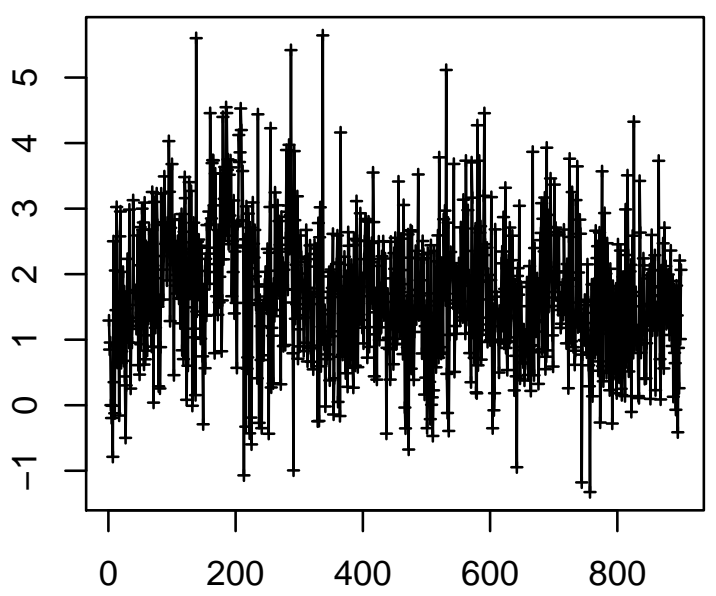

Time Point $(0.25 \mathrm{~Hz})$

\section{Cell 983}

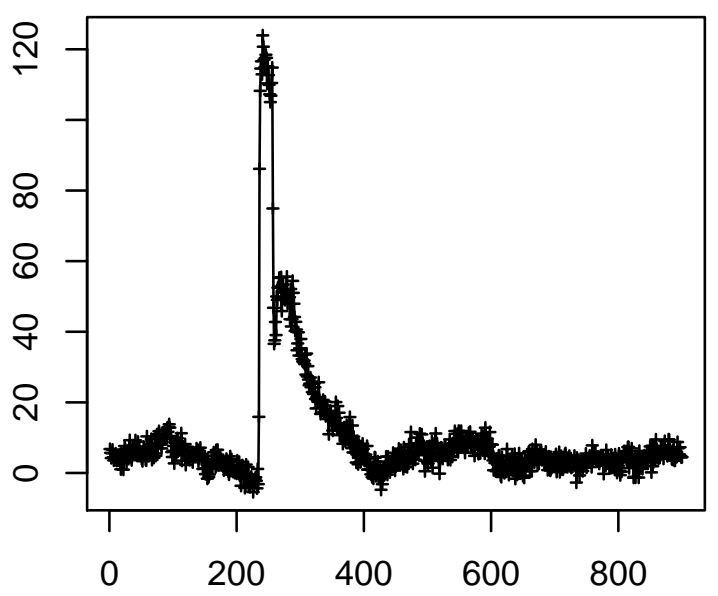

Time Point $(0.25 \mathrm{~Hz})$
Cell 982

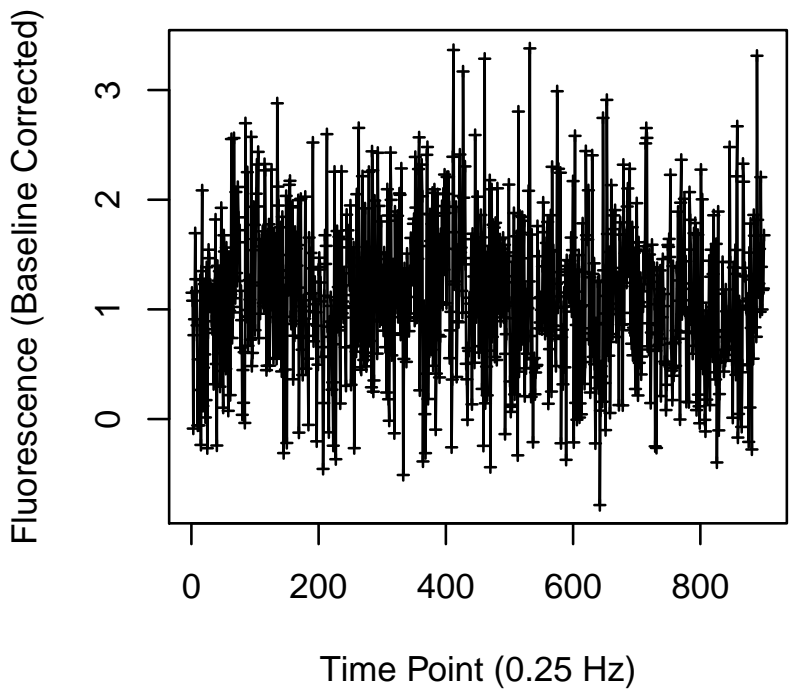

Cell 984

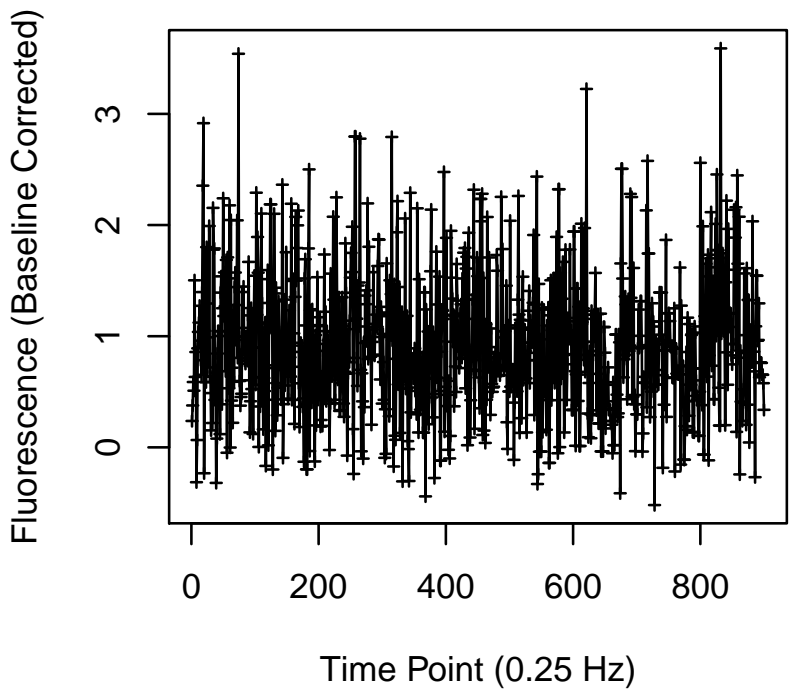


Cell 989

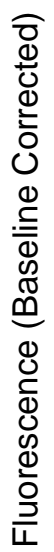

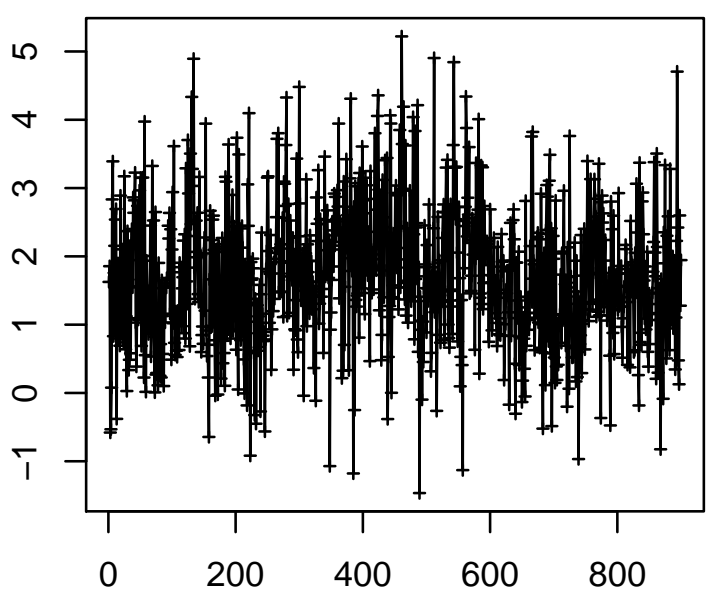

Time Point $(0.25 \mathrm{~Hz})$

Cell 991

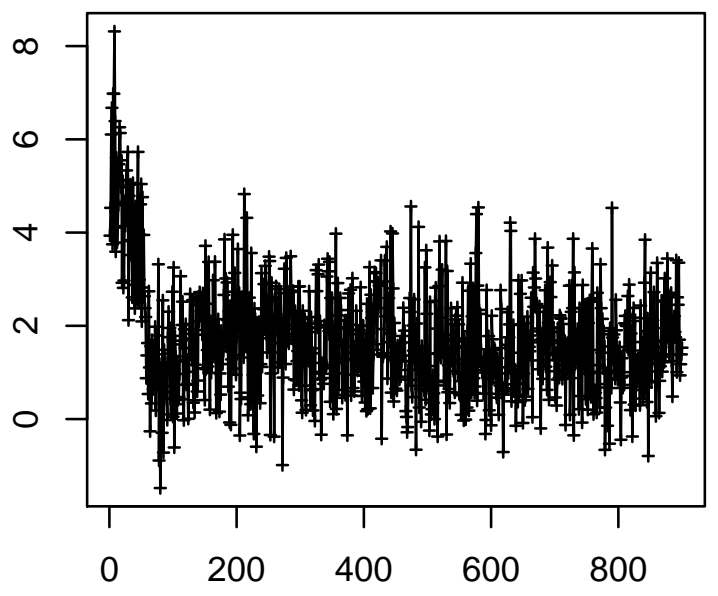

Time Point $(0.25 \mathrm{~Hz})$
Cell 990

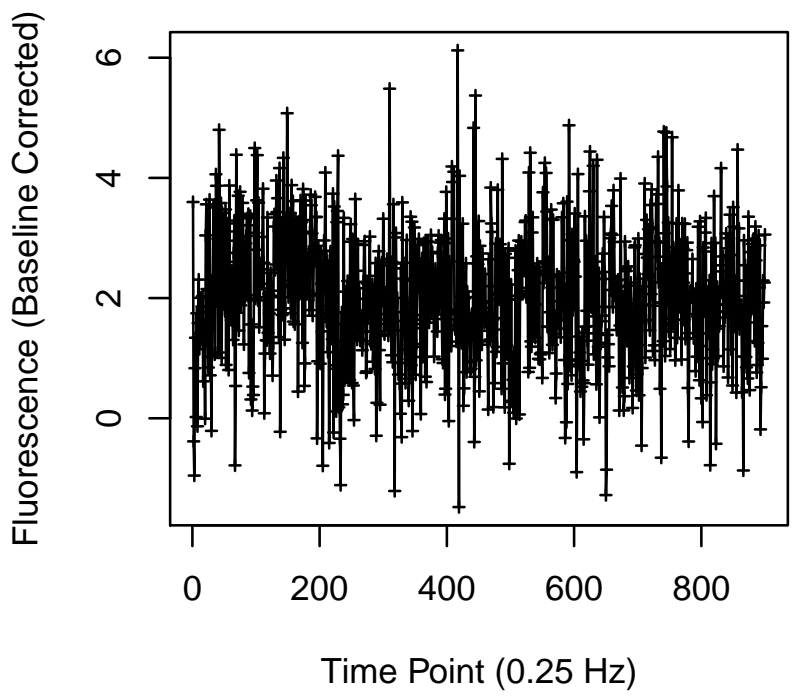

Cell 992

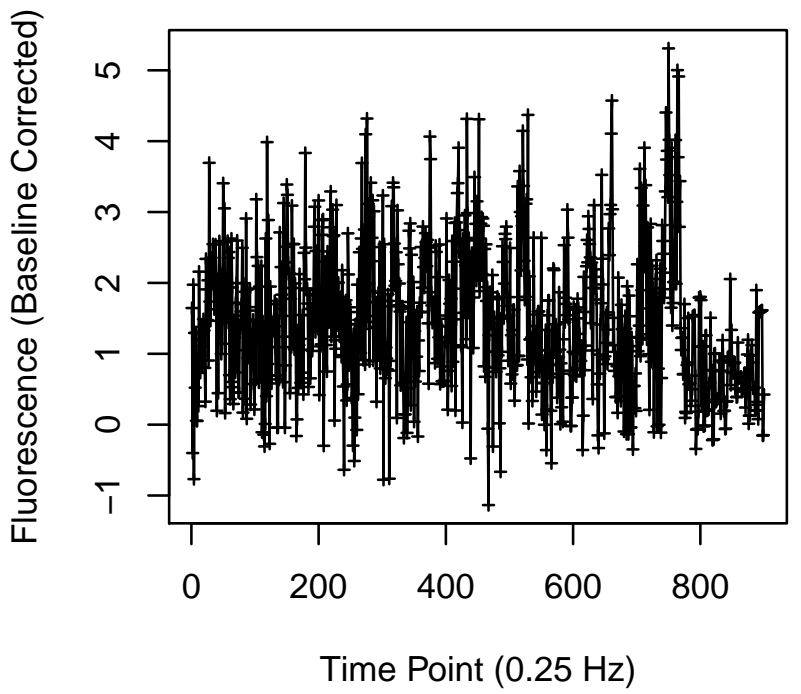


Cell 993

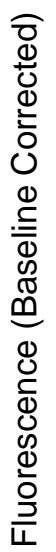

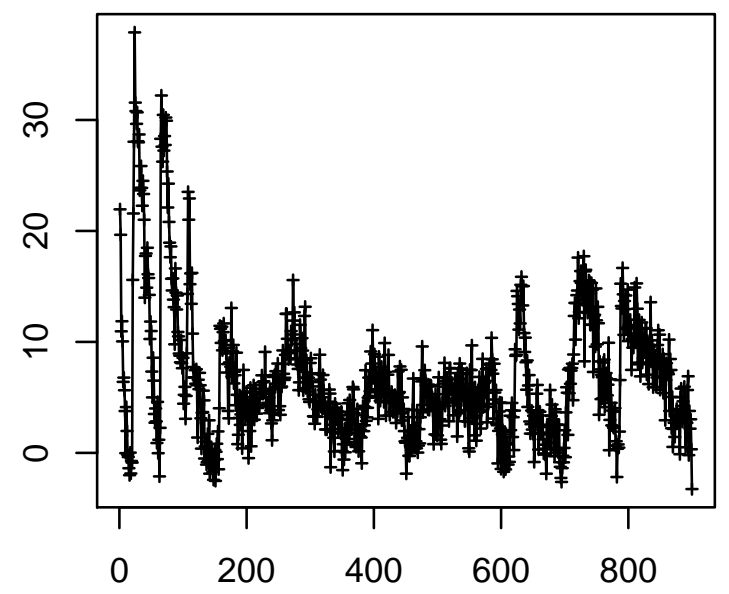

Time Point $(0.25 \mathrm{~Hz})$

Cell 995

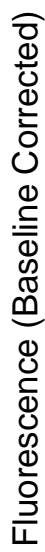

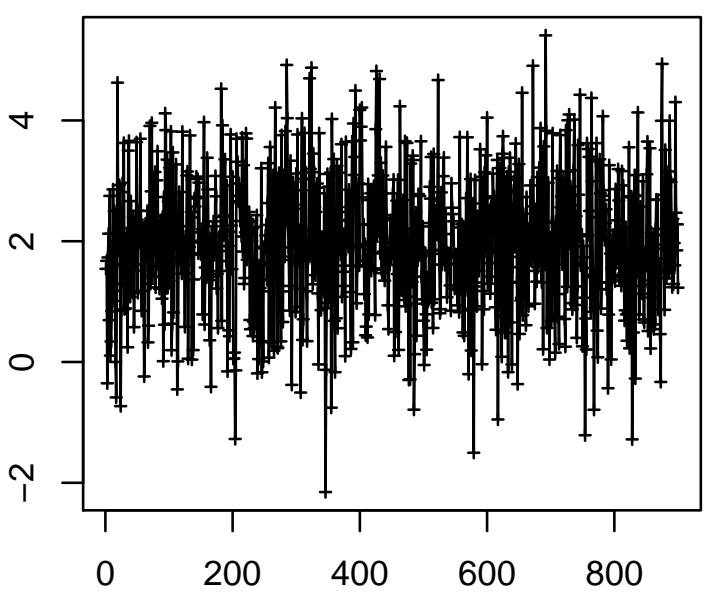

Time Point $(0.25 \mathrm{~Hz})$
Cell 994

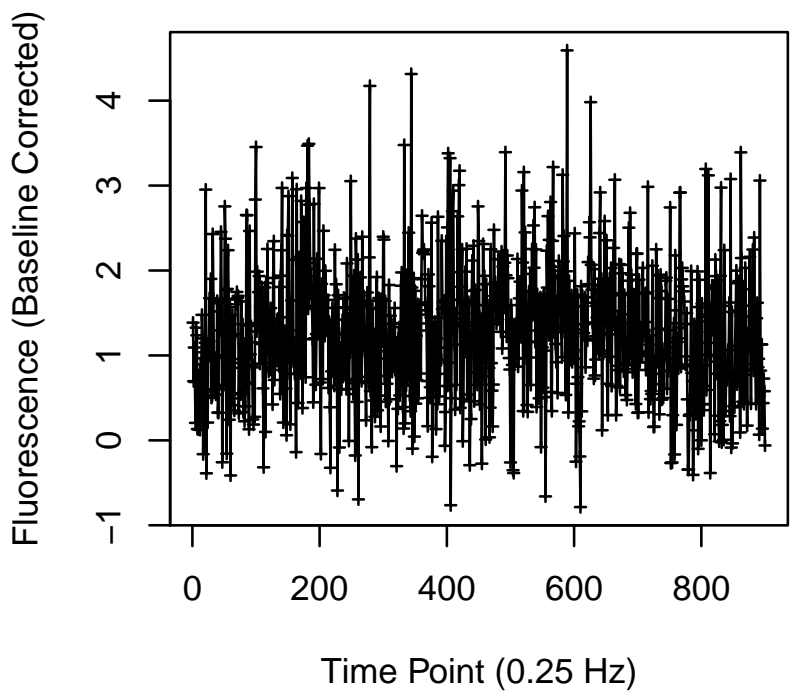

Cell 996

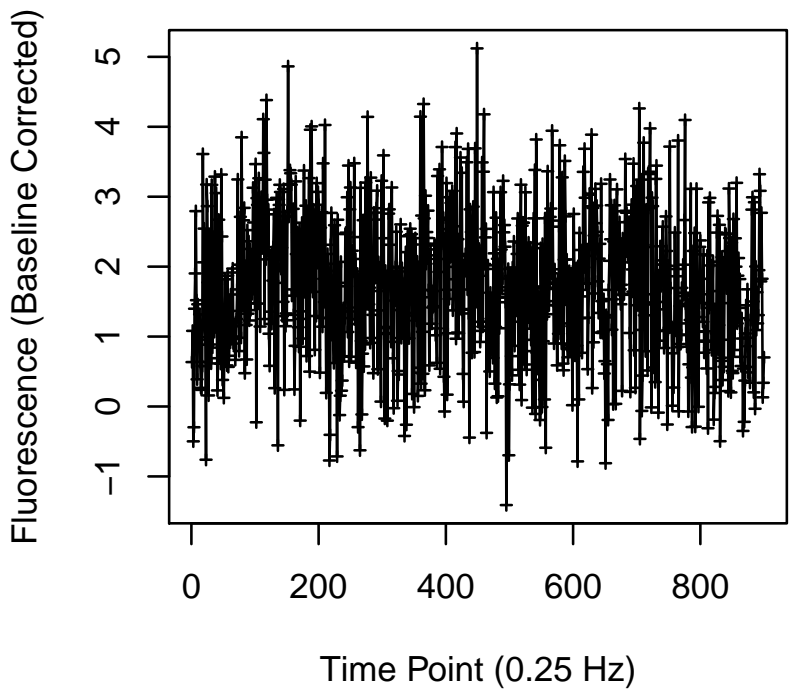



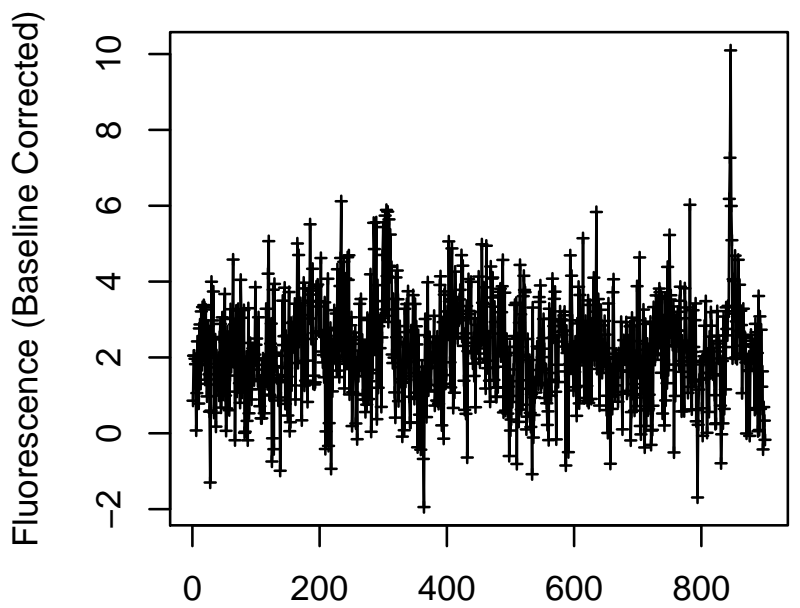

Time Point $(0.25 \mathrm{~Hz})$

Cell 1019

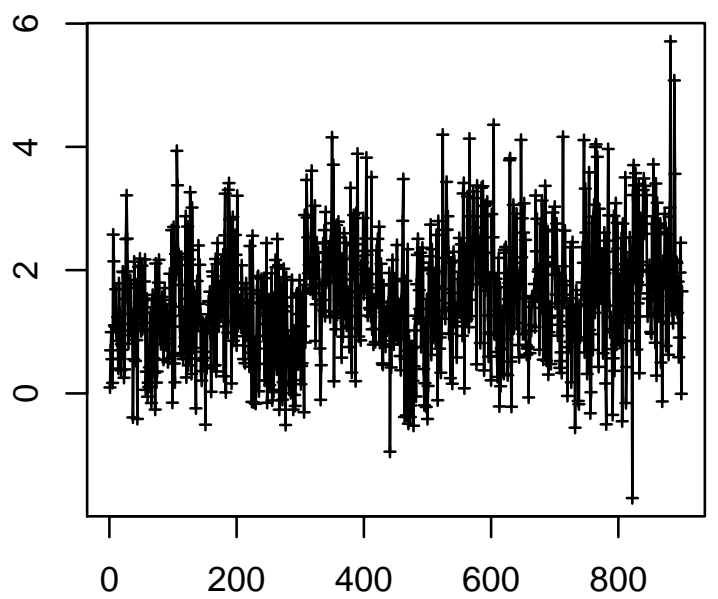

Time Point $(0.25 \mathrm{~Hz})$

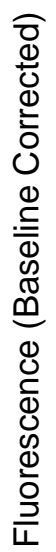

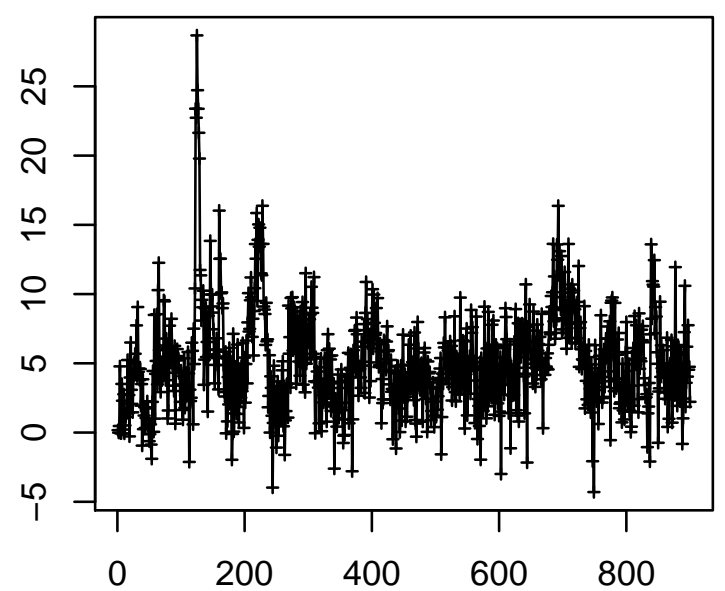

Time Point $(0.25 \mathrm{~Hz})$

Cell 1020

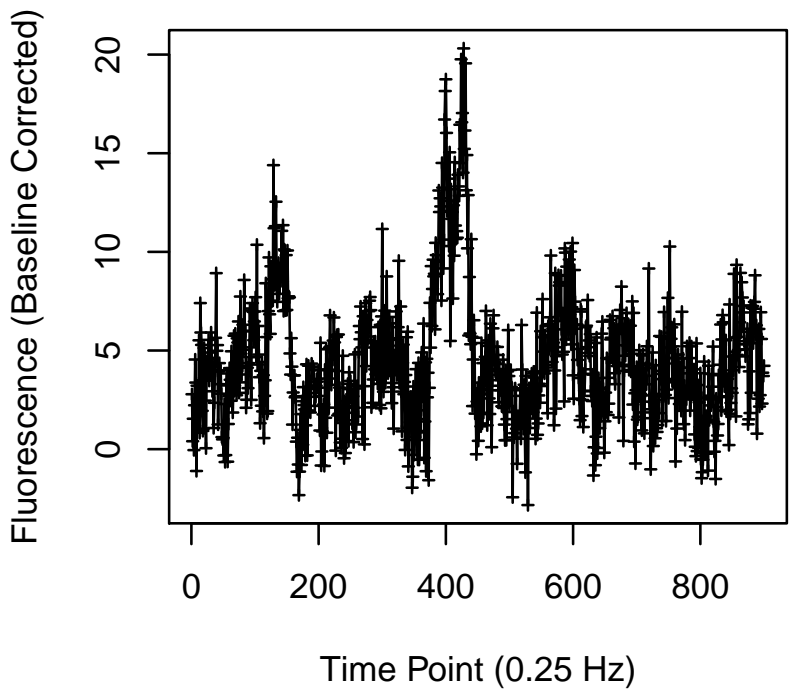


Cell 1029

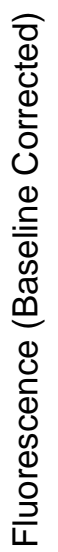

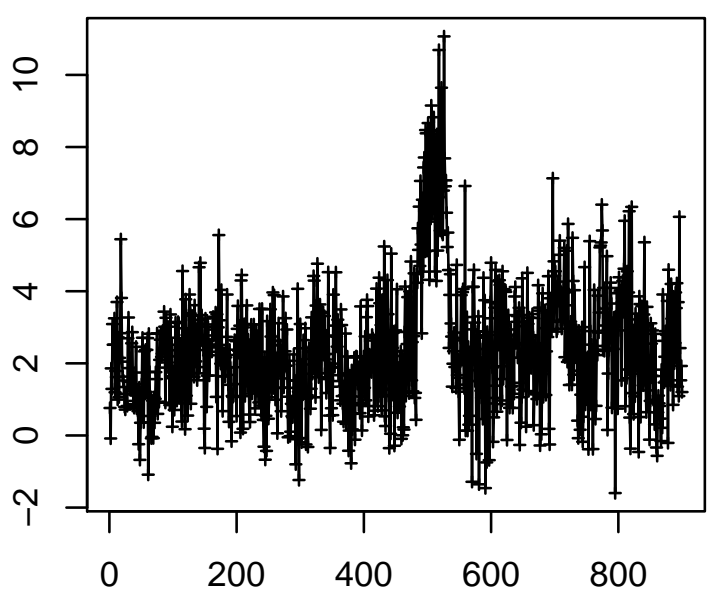

Time Point $(0.25 \mathrm{~Hz})$

Cell 1031

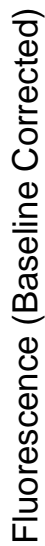

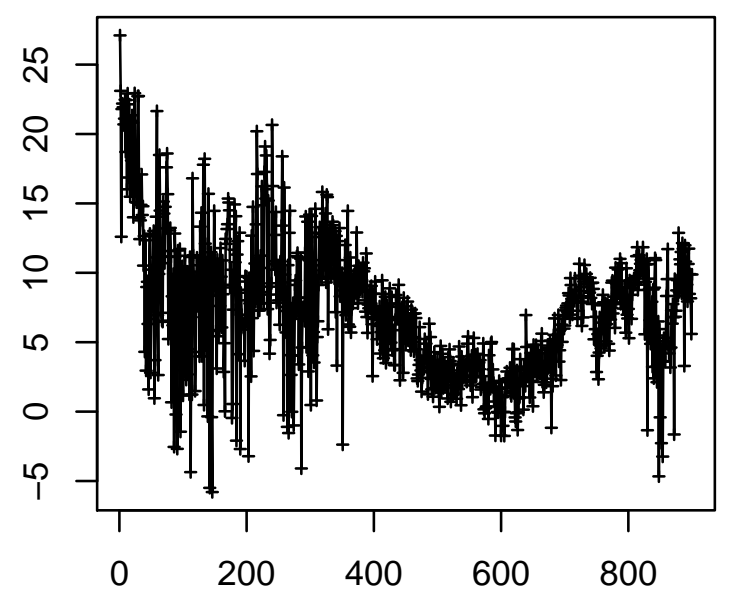

Time Point $(0.25 \mathrm{~Hz})$
Cell 1030

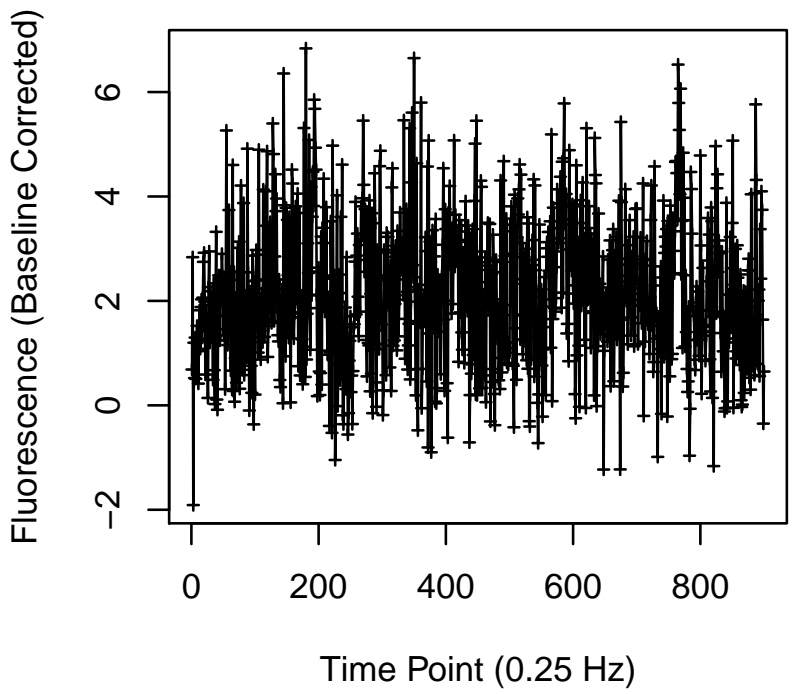

Cell 1032

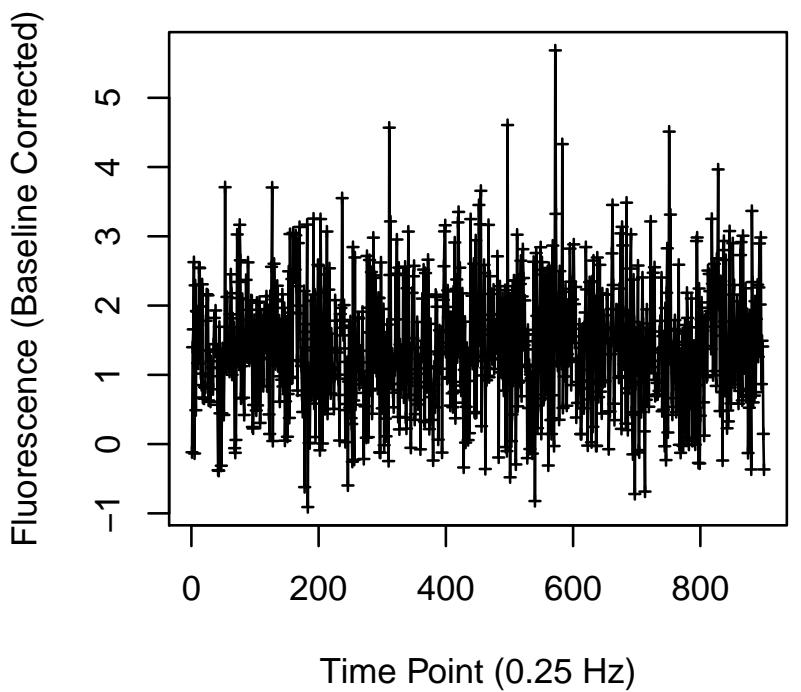


Cell 1037

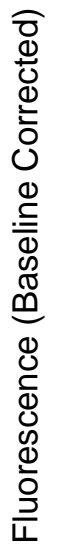

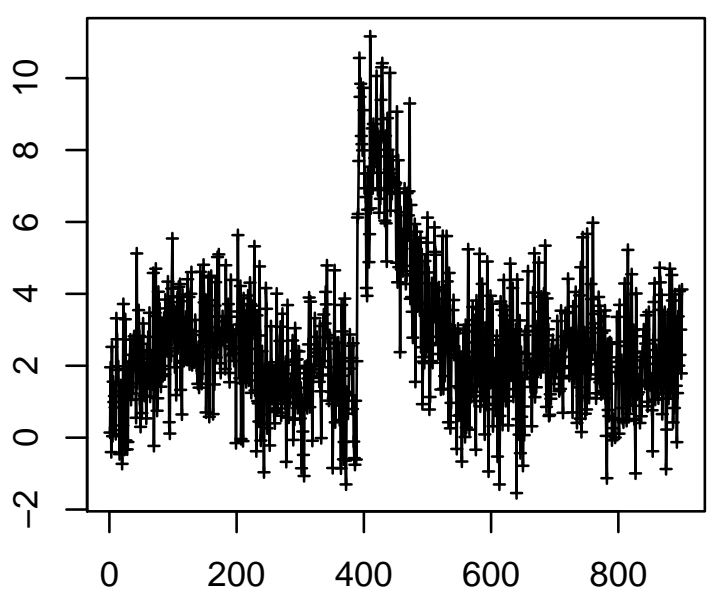

Time Point $(0.25 \mathrm{~Hz})$

Cell 1039

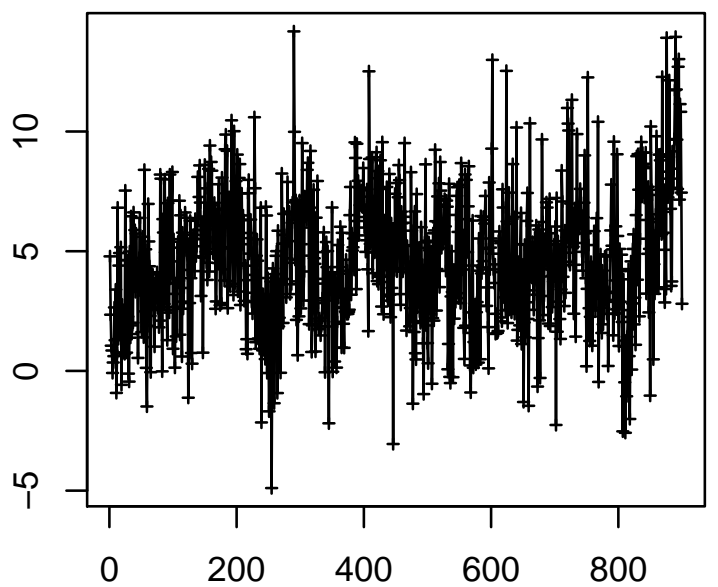

Time Point $(0.25 \mathrm{~Hz})$
Cell 1038

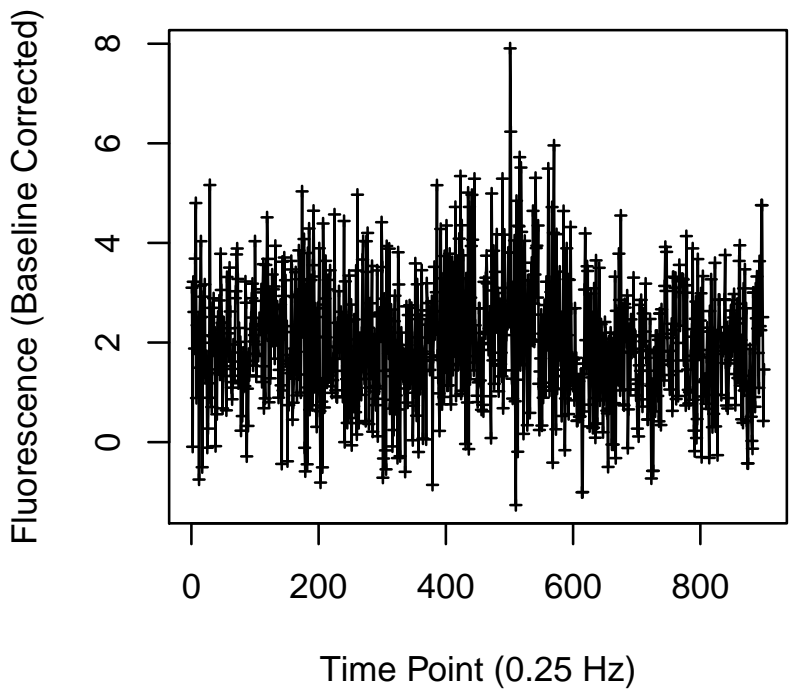

Cell 1040

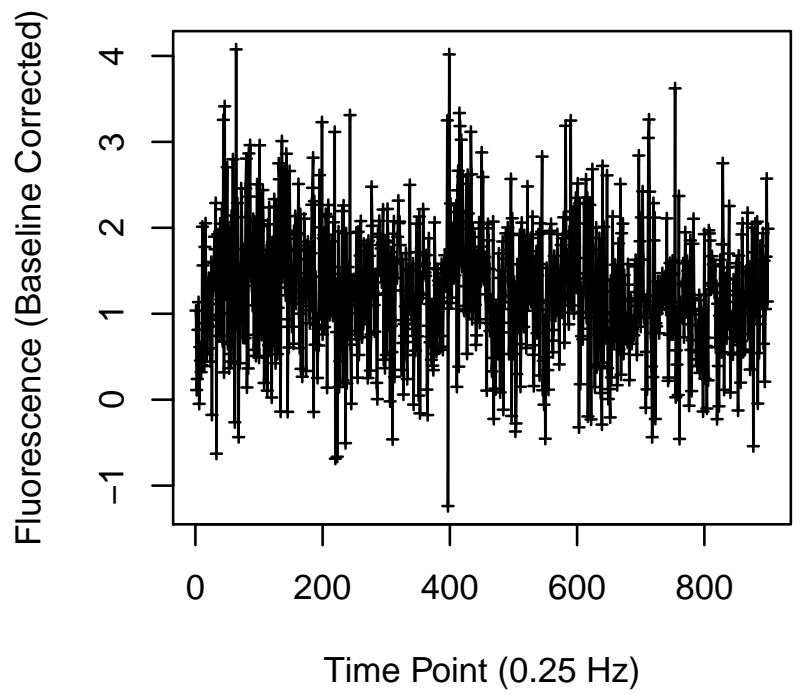




\section{Cell 1041}

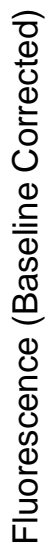

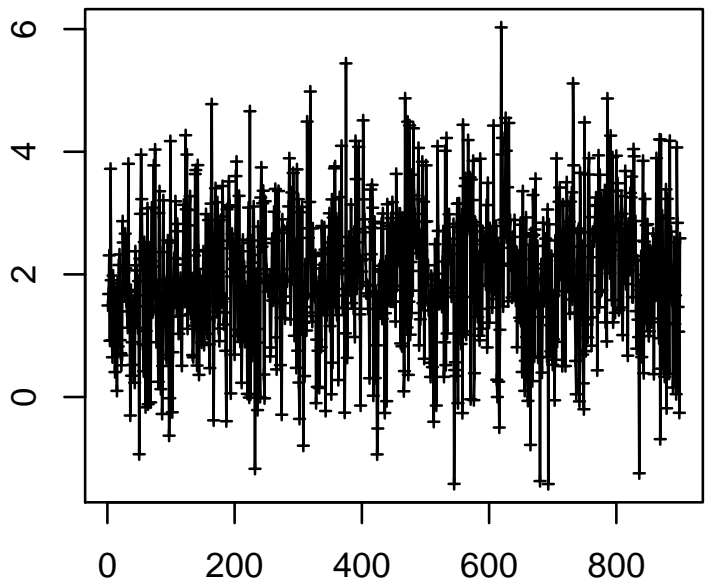

Time Point $(0.25 \mathrm{~Hz})$

Cell 1043

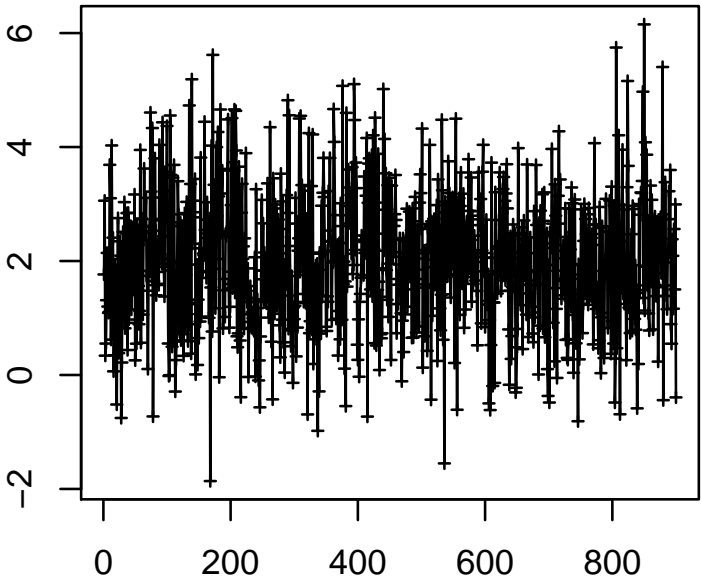

Time Point $(0.25 \mathrm{~Hz})$
Cell 1042

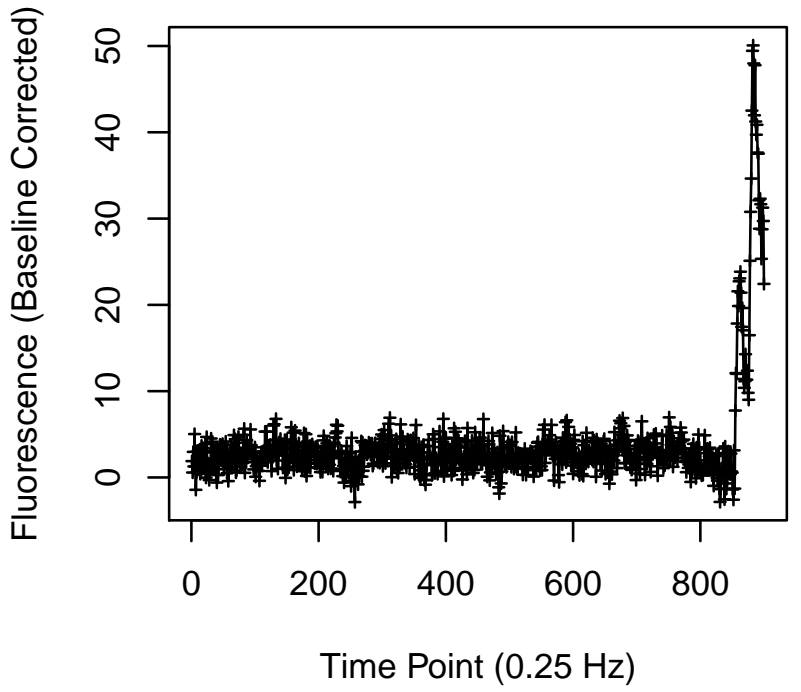

Cell 1044

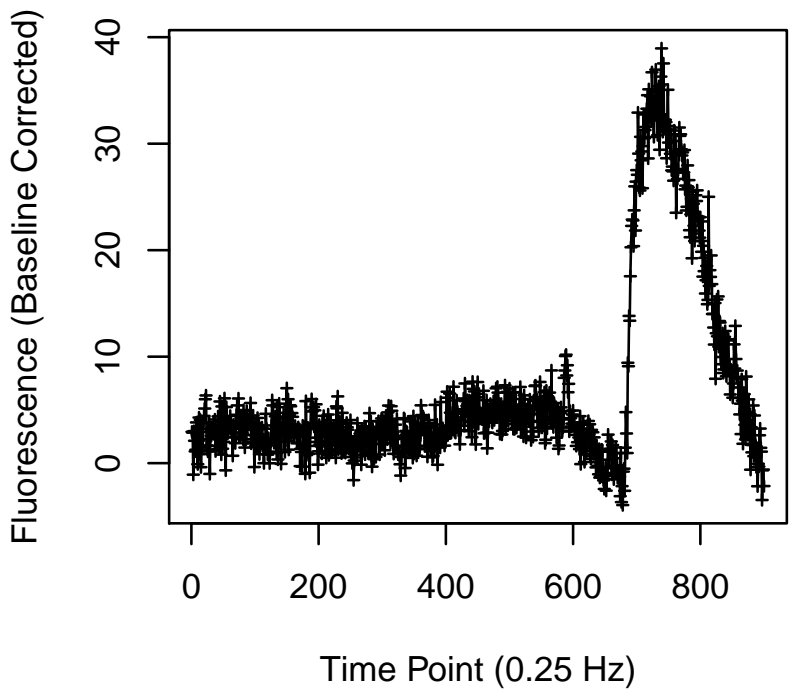


Cell 1045

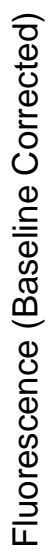

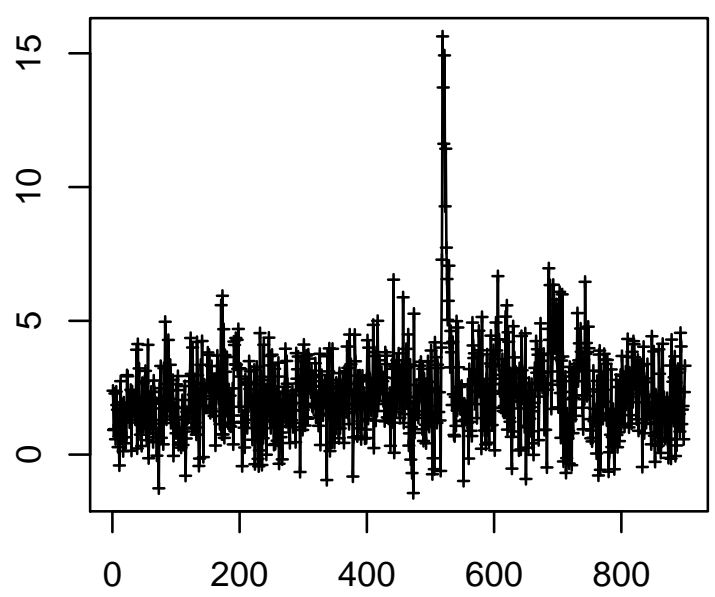

Time Point $(0.25 \mathrm{~Hz})$

Cell 1047

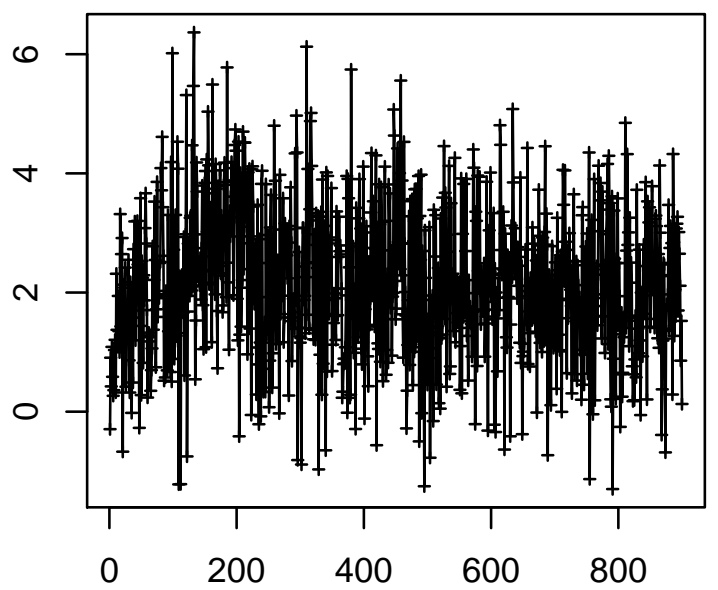

Time Point $(0.25 \mathrm{~Hz})$
Cell 1046

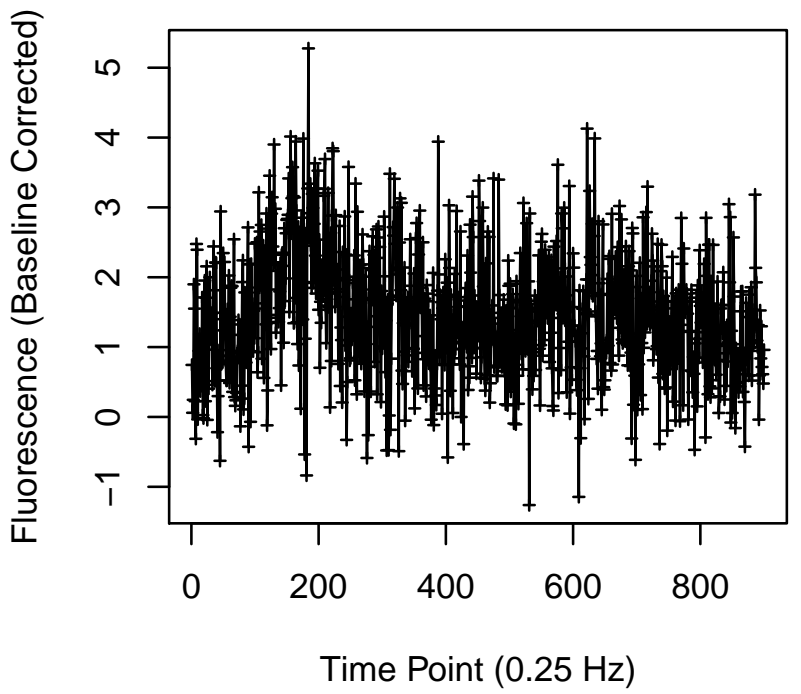

Cell 1048

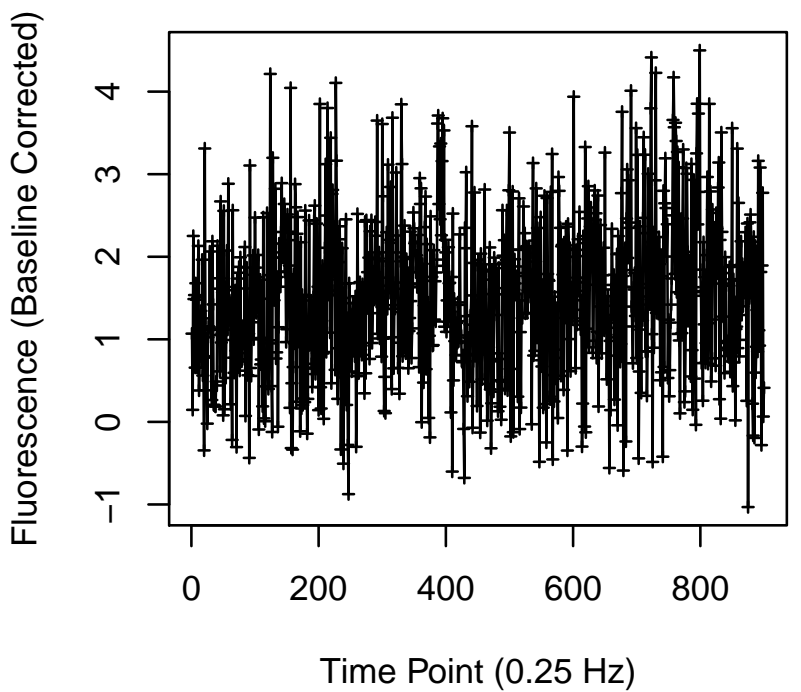




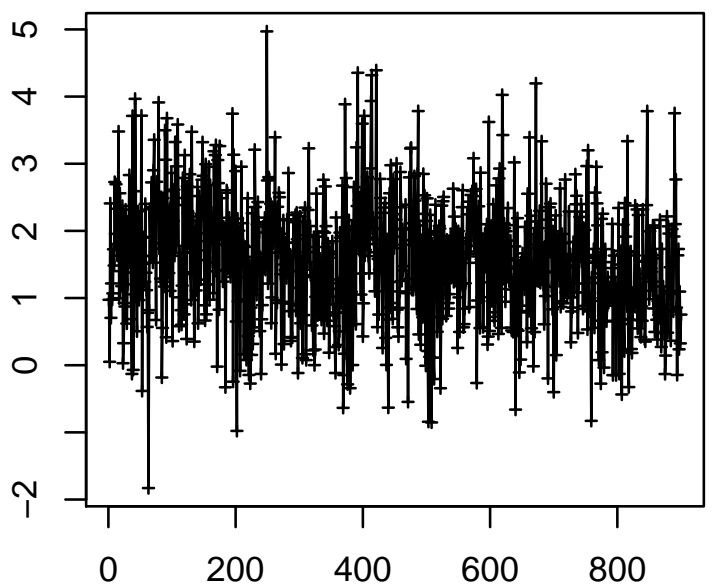

Time Point $(0.25 \mathrm{~Hz})$

Cell 1051

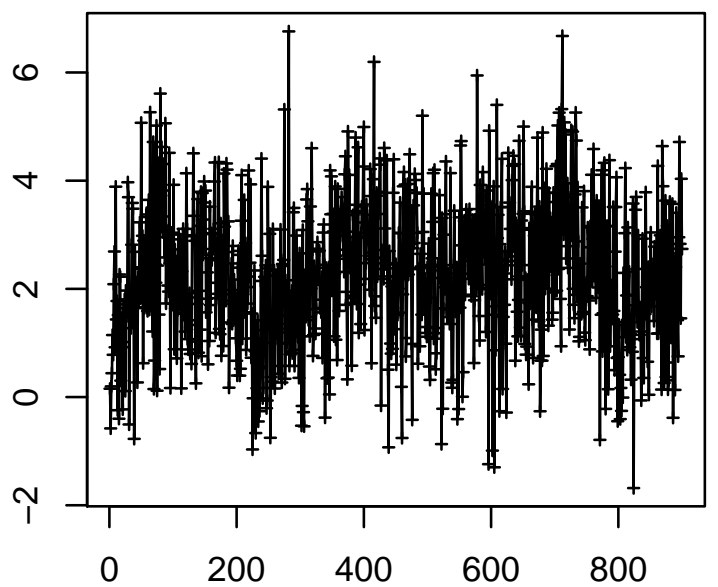

Time Point $(0.25 \mathrm{~Hz})$

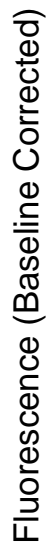

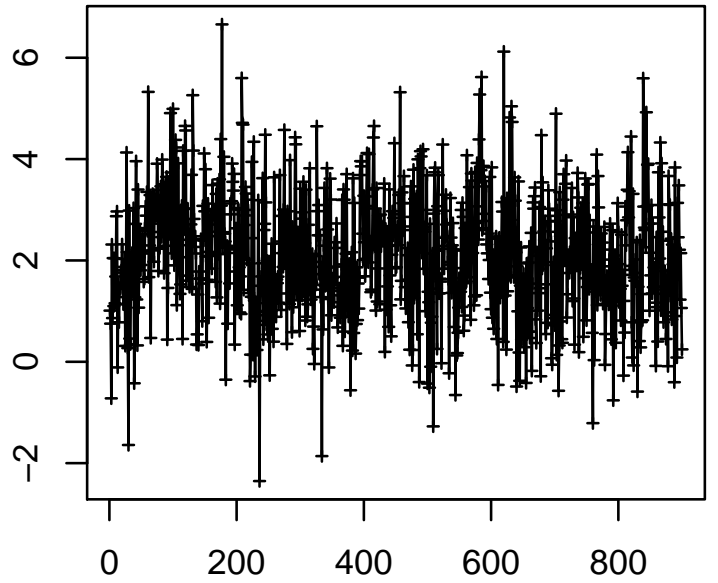

Time Point $(0.25 \mathrm{~Hz})$

Cell 1052

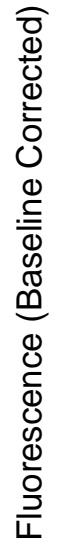

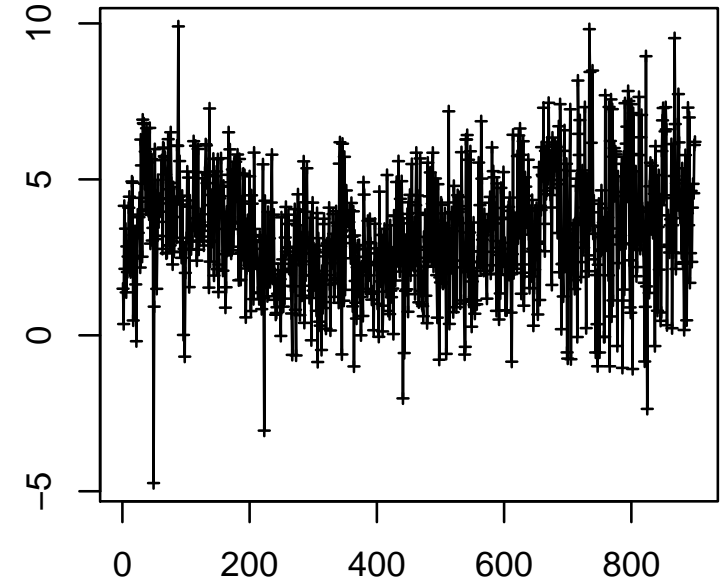

Time Point $(0.25 \mathrm{~Hz})$ 
Cell 1053

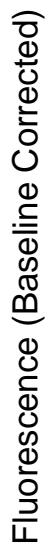

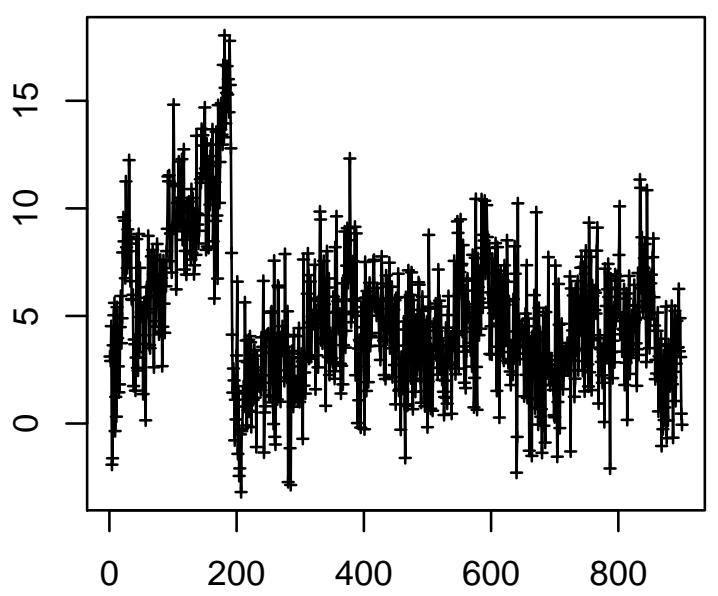

Time Point $(0.25 \mathrm{~Hz})$

Cell 1055

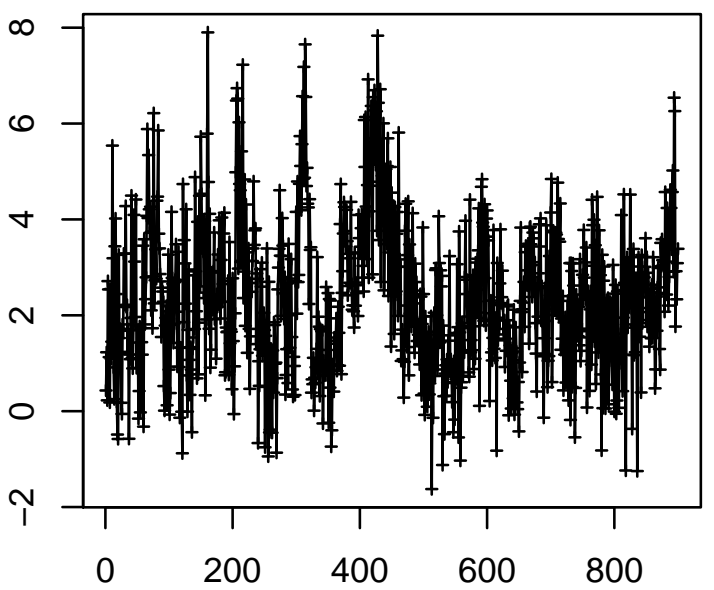

Time Point $(0.25 \mathrm{~Hz})$
Cell 1054

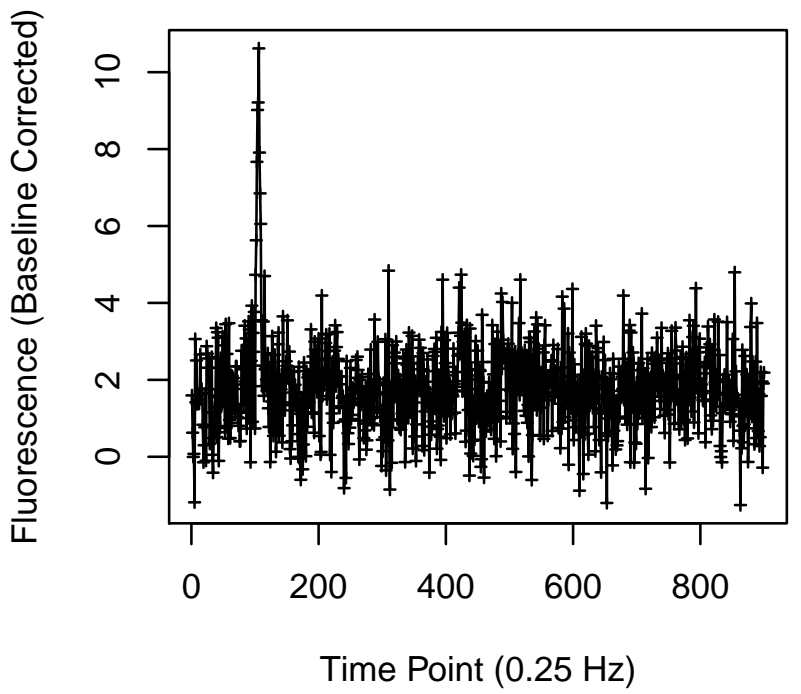

Cell 1056

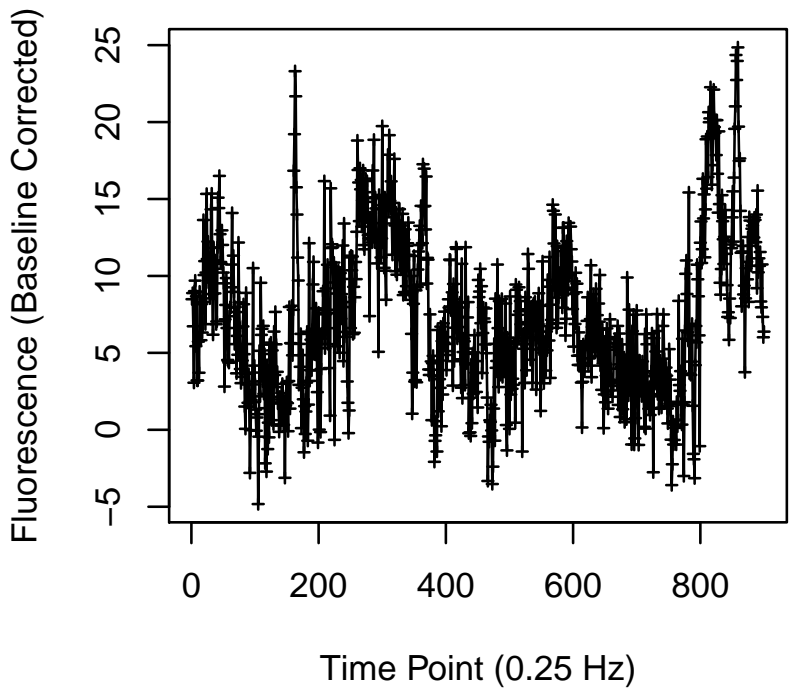


Cell 1061

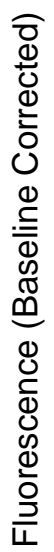

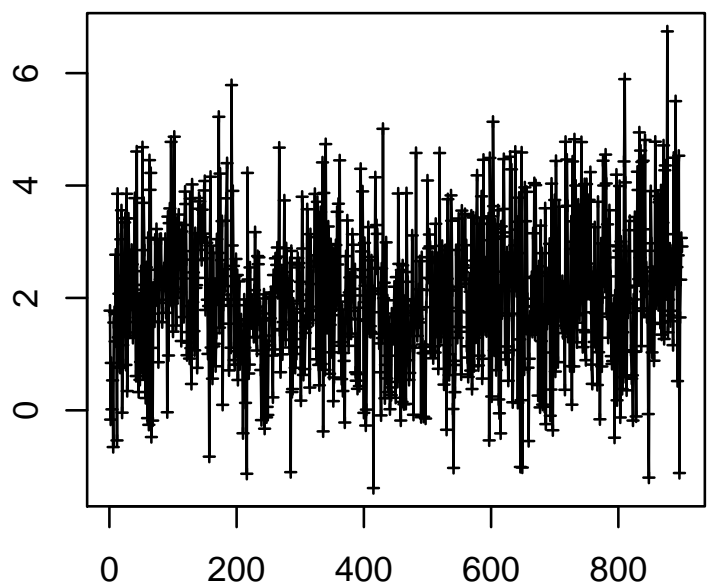

Time Point $(0.25 \mathrm{~Hz})$

Cell 1063

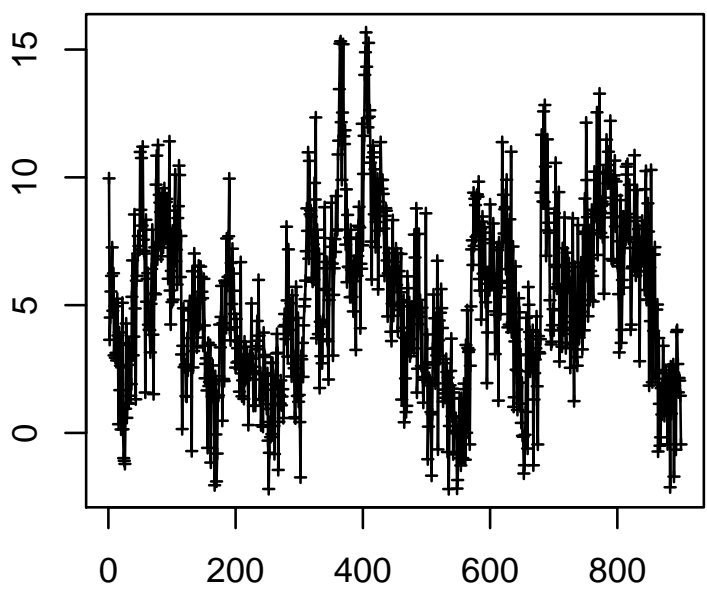

Time Point $(0.25 \mathrm{~Hz})$
Cell 1062

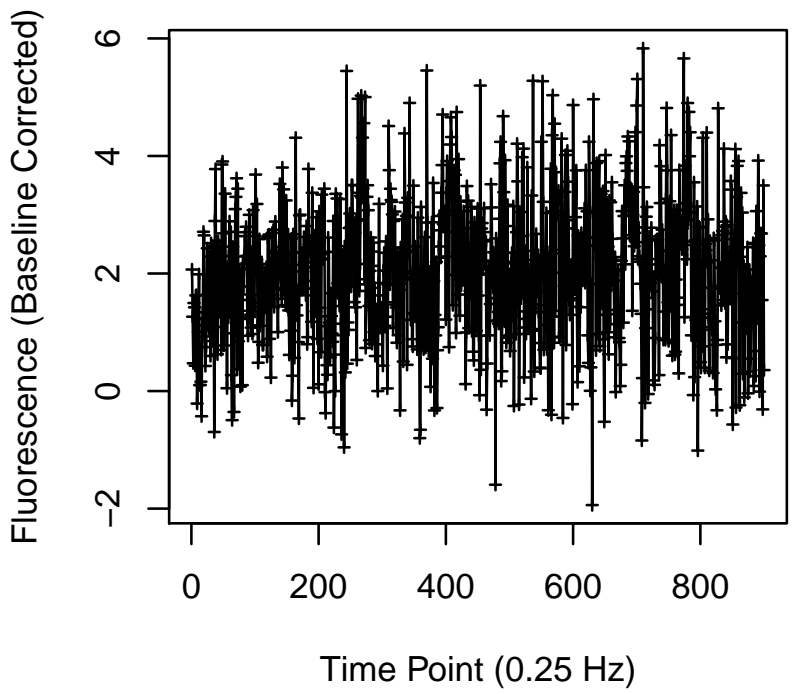

Cell 1064

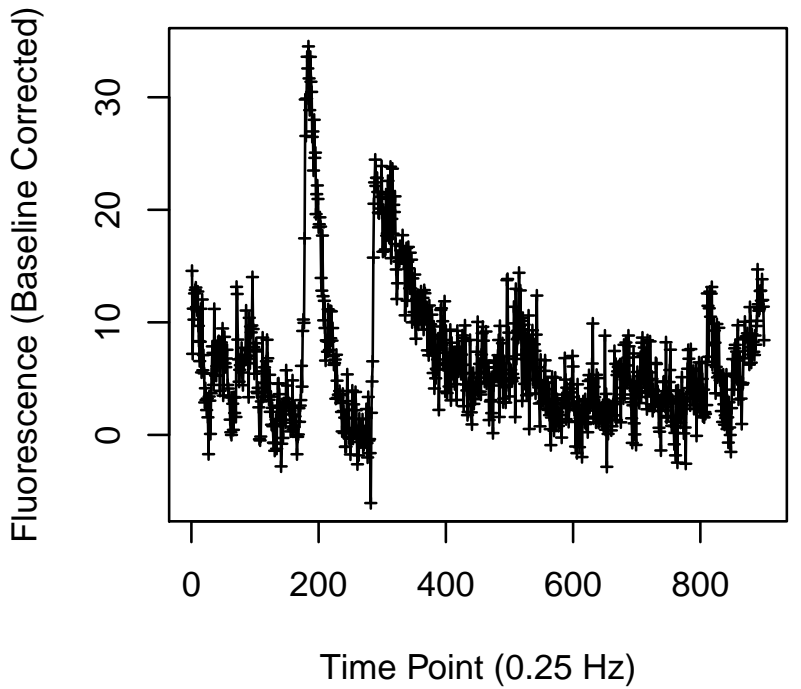


Cell 1065

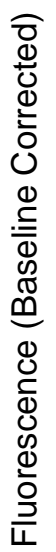

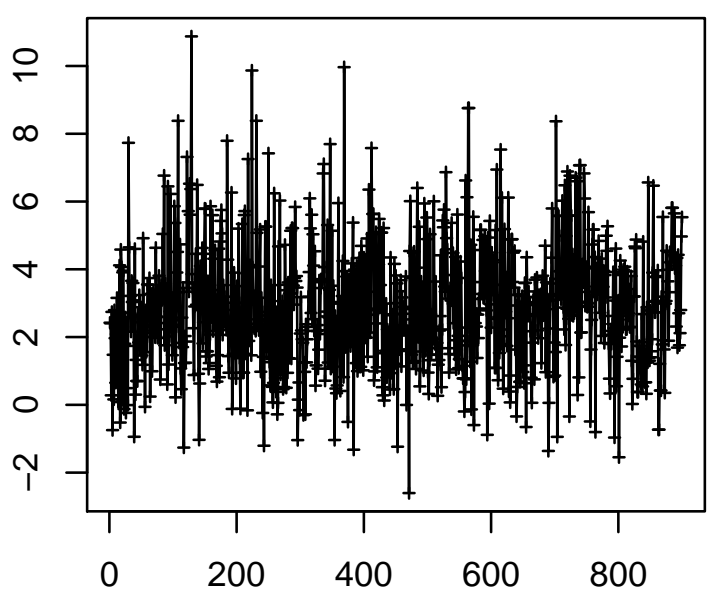

Time Point $(0.25 \mathrm{~Hz})$

Cell 1067

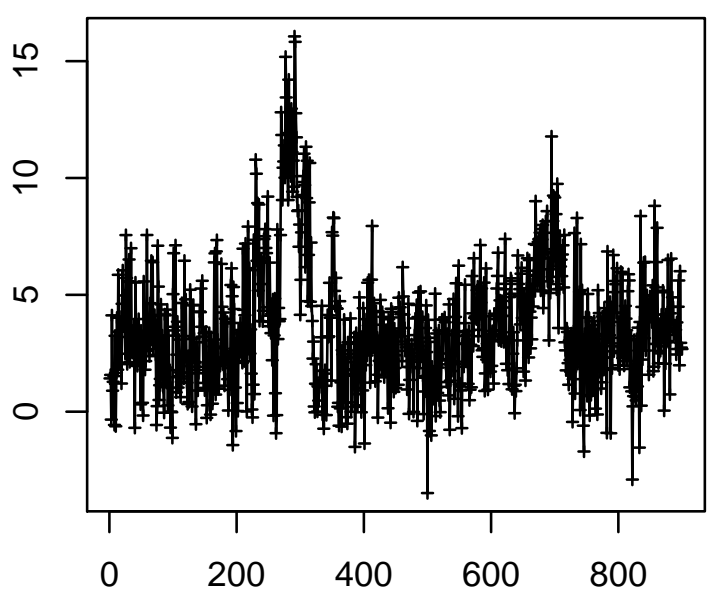

Time Point $(0.25 \mathrm{~Hz})$
Cell 1066

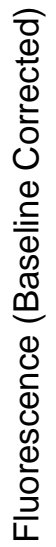

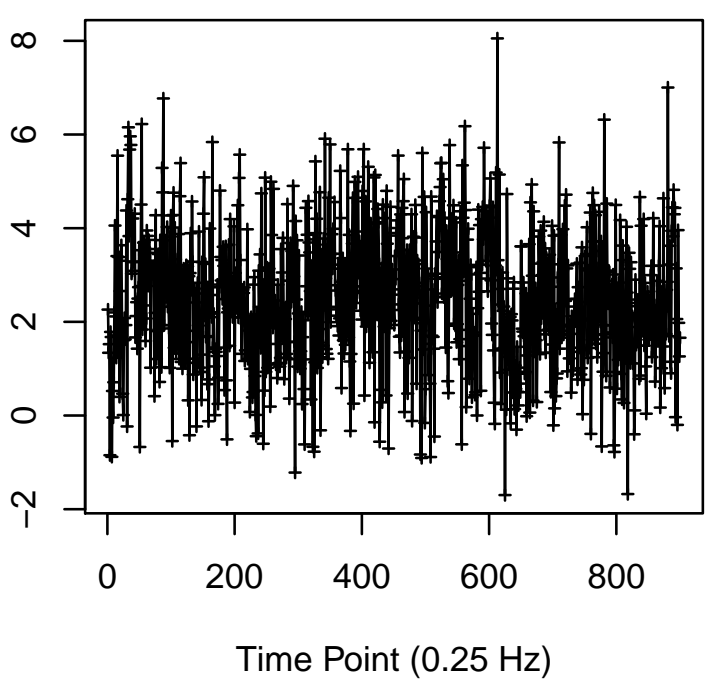

Cell 1068

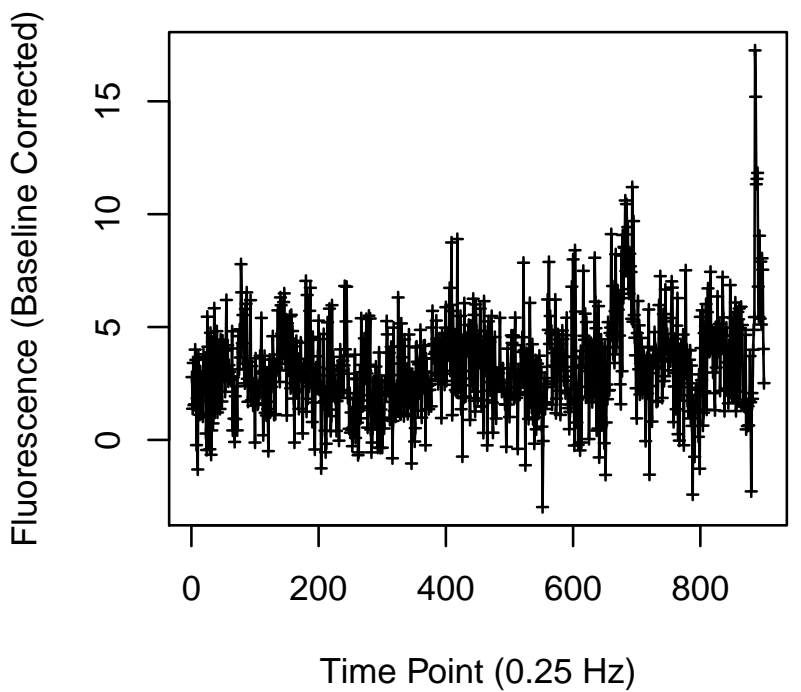


Cell 1069

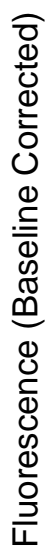

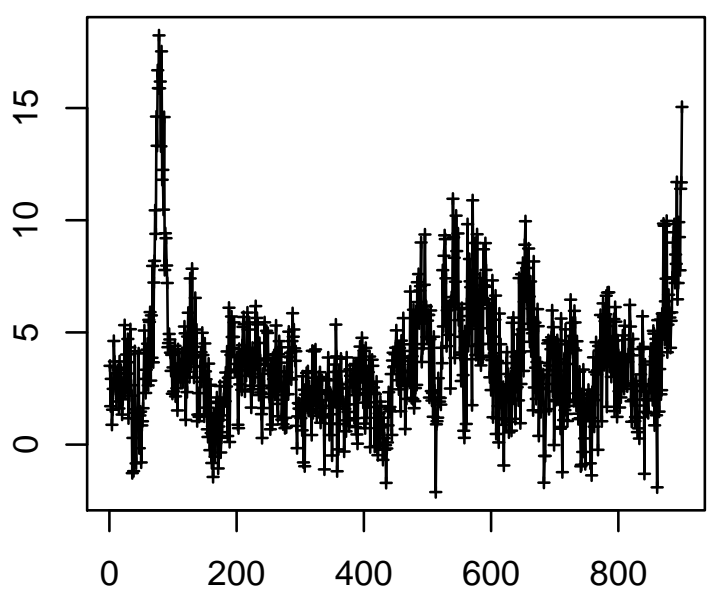

Time Point $(0.25 \mathrm{~Hz})$

Cell 1071

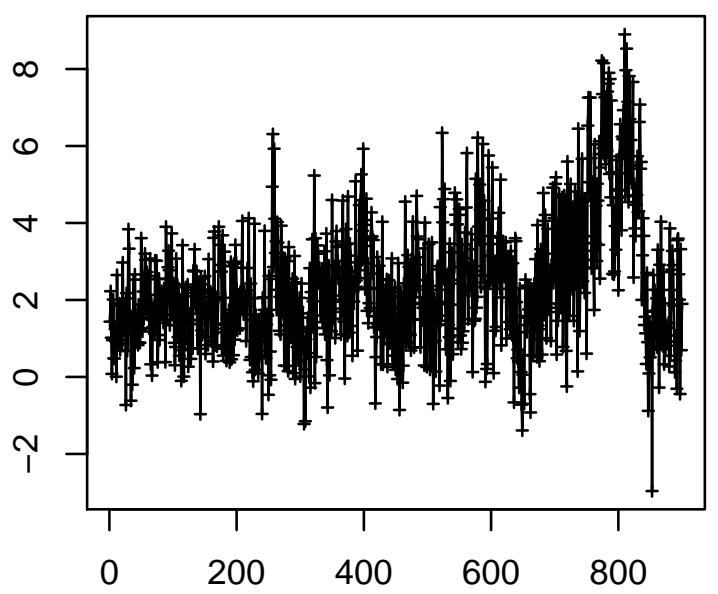

Time Point $(0.25 \mathrm{~Hz})$
Cell 1070

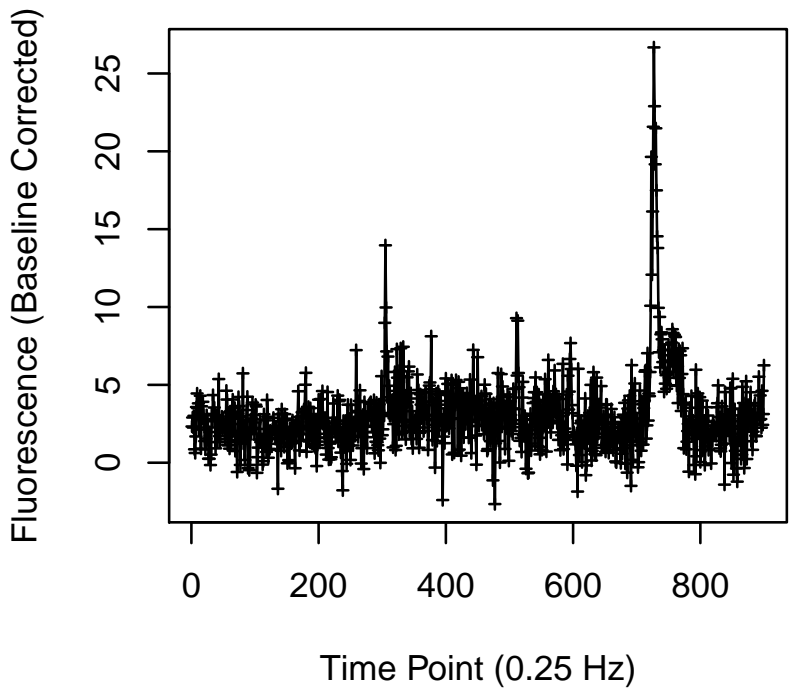

Cell 1072

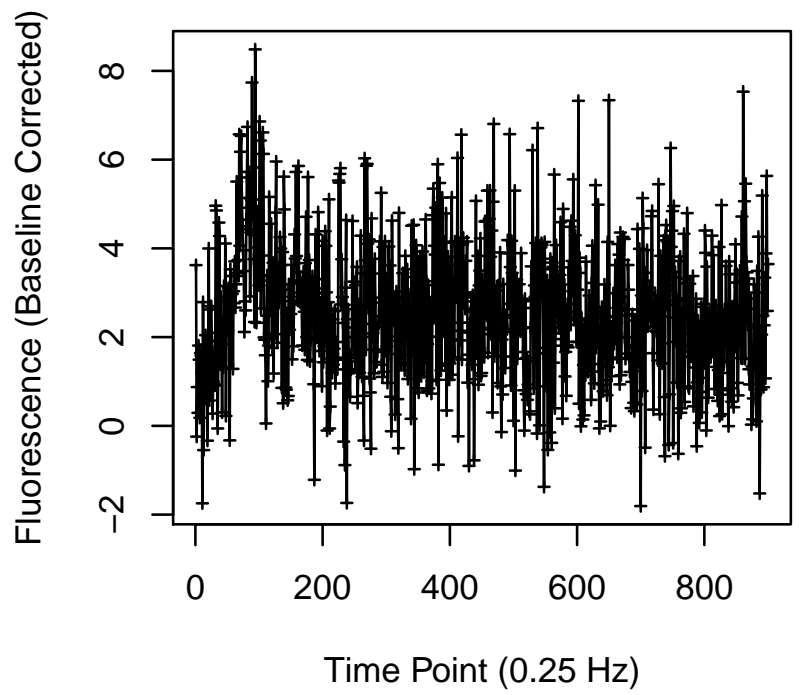


Cell 1081

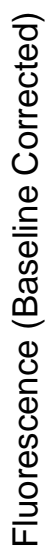

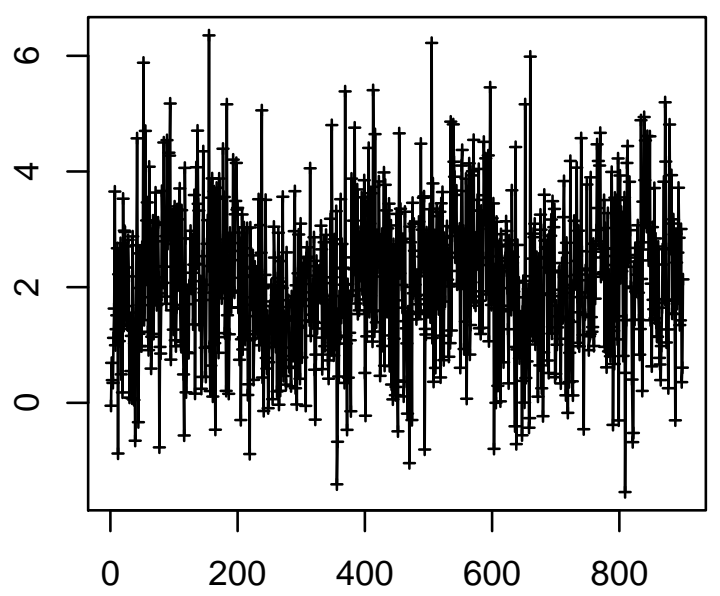

Time Point $(0.25 \mathrm{~Hz})$

Cell 1083

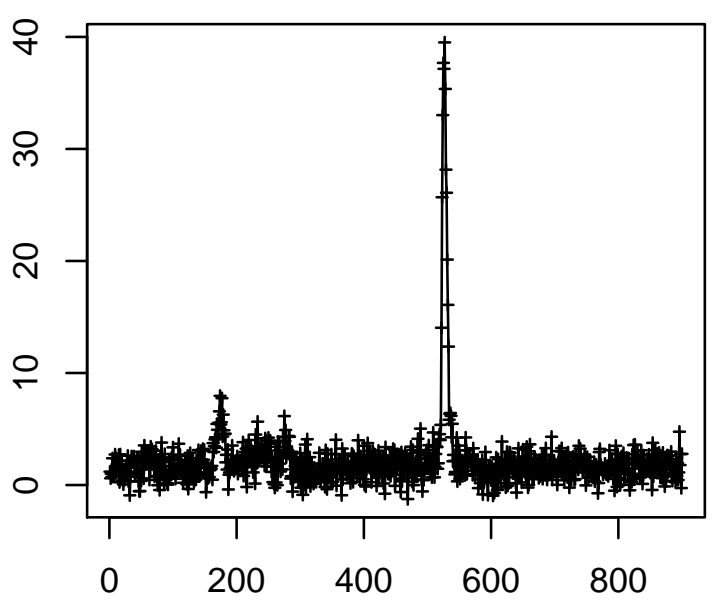

Time Point $(0.25 \mathrm{~Hz})$
Cell 1082

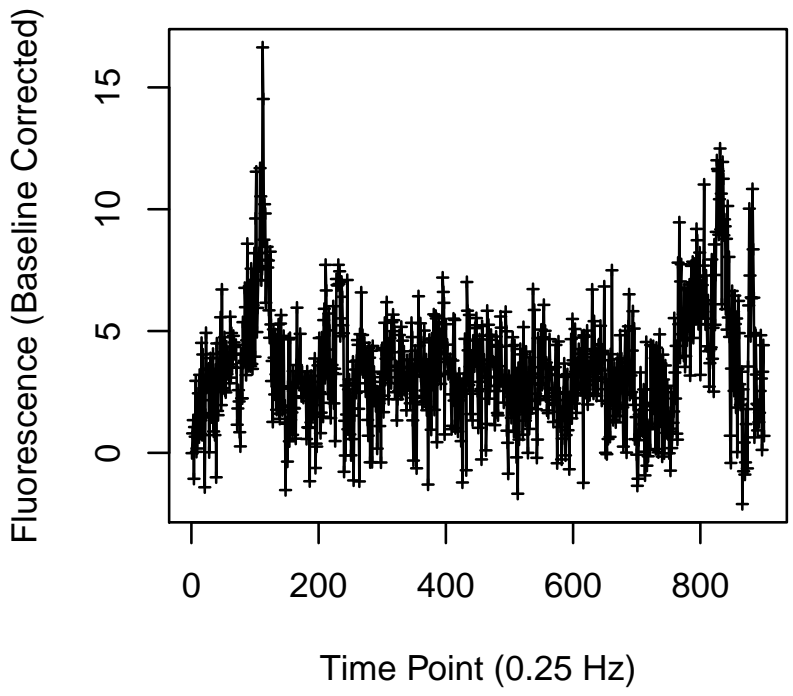

Cell 1084

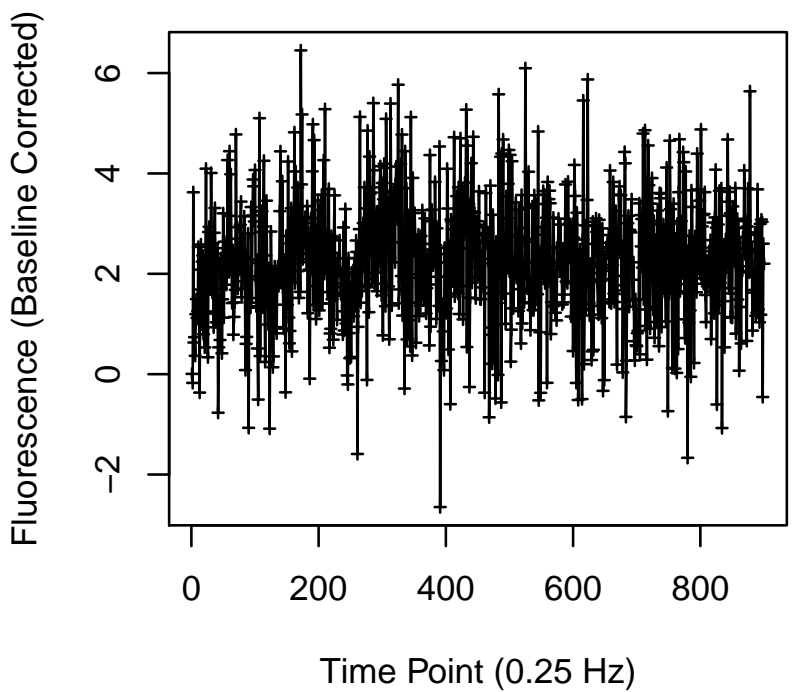


Cell 1097

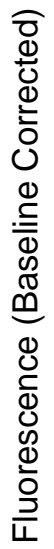

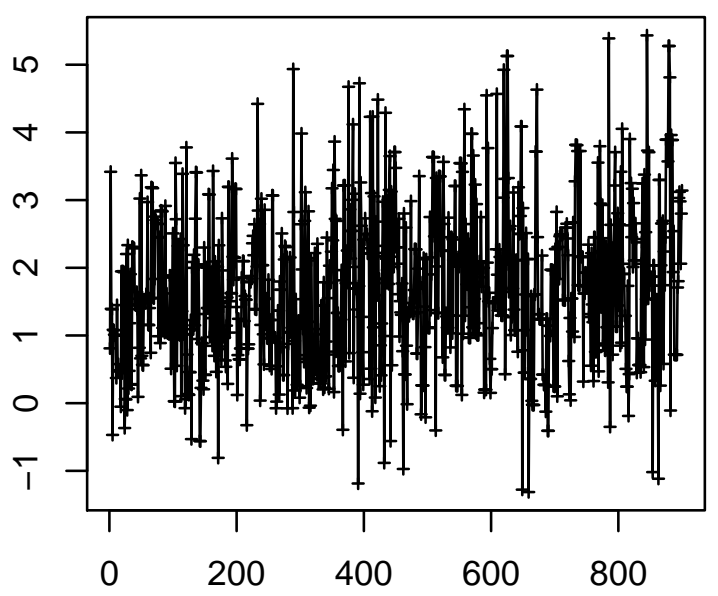

Time Point $(0.25 \mathrm{~Hz})$

Cell 1099

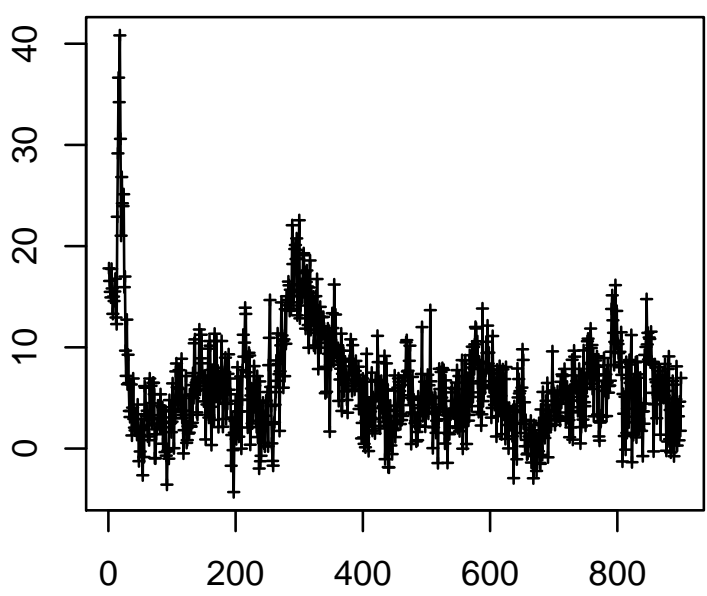

Time Point $(0.25 \mathrm{~Hz})$
Cell 1098

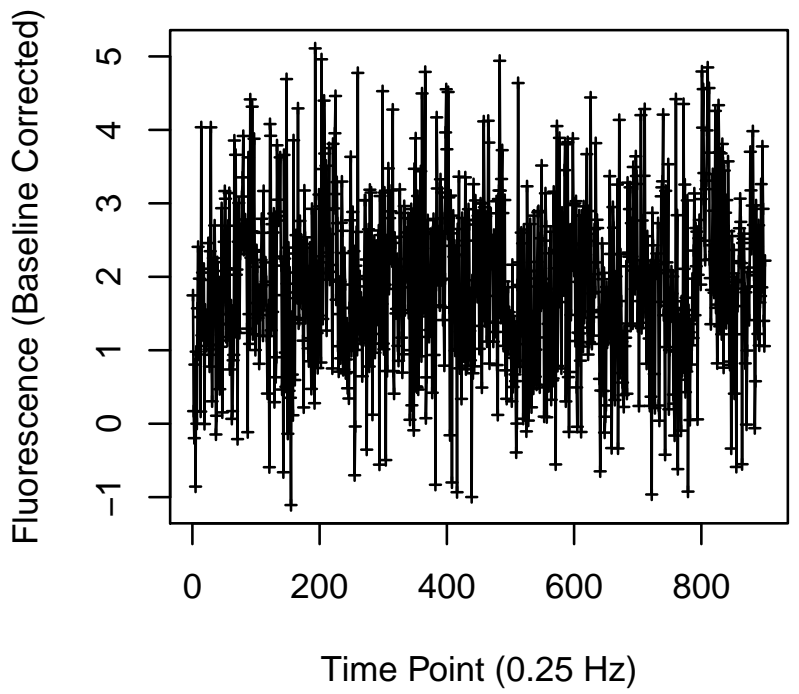

Cell 1100

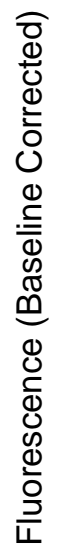

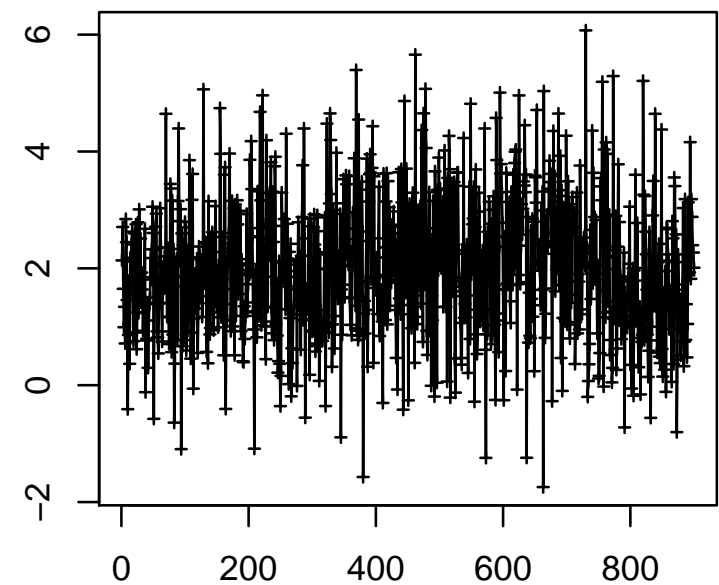

Time Point $(0.25 \mathrm{~Hz})$ 
Cell 1117

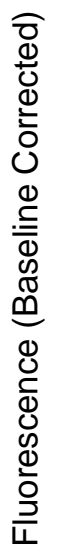

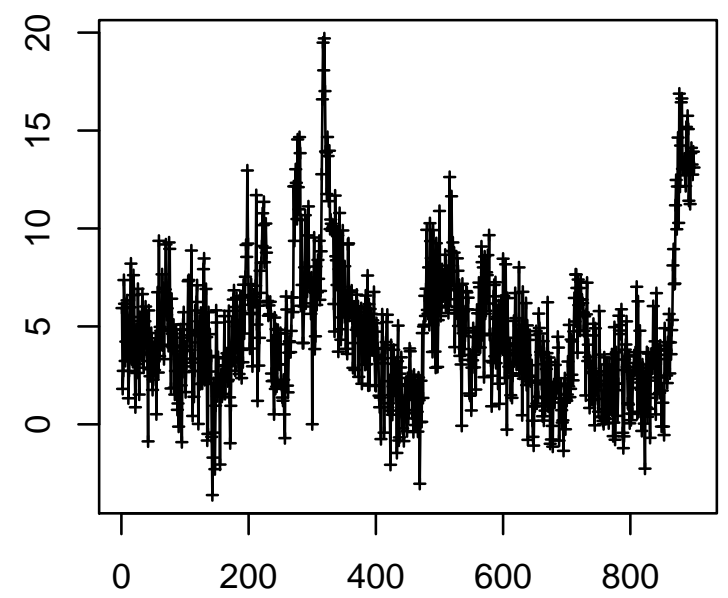

Time Point $(0.25 \mathrm{~Hz})$

Cell 1119

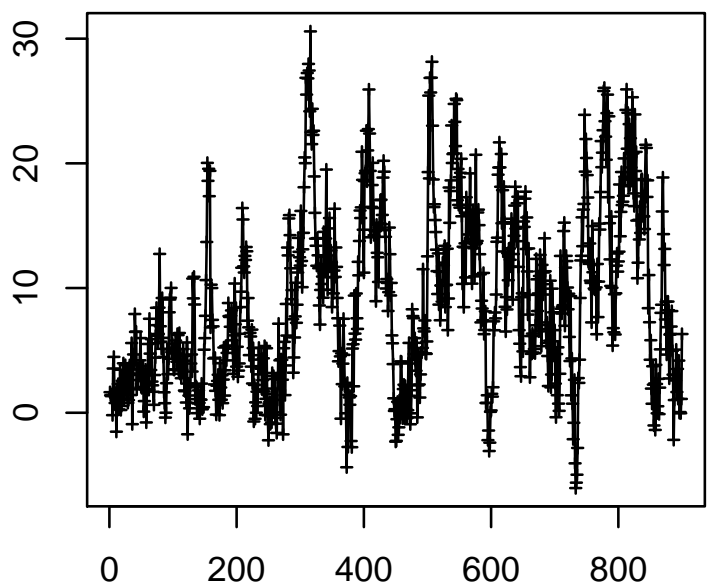

Time Point $(0.25 \mathrm{~Hz})$
Cell 1118

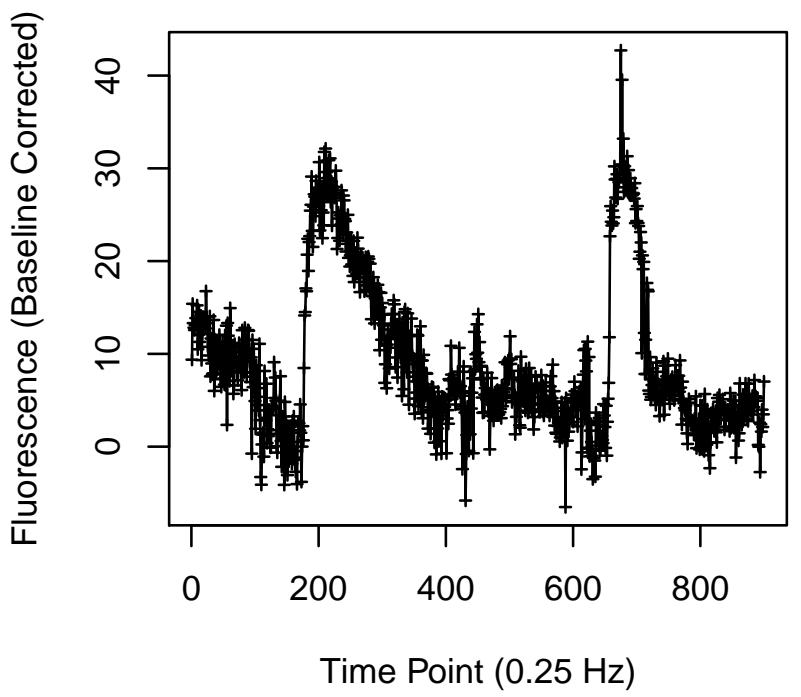

Cell 1120

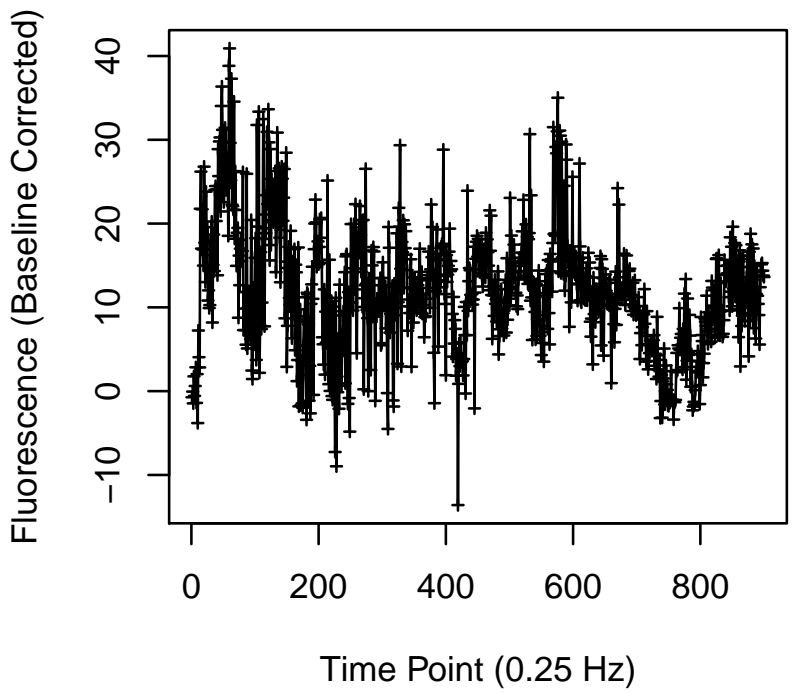


Cell 1121

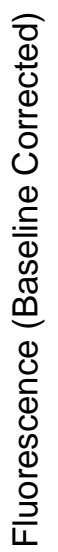

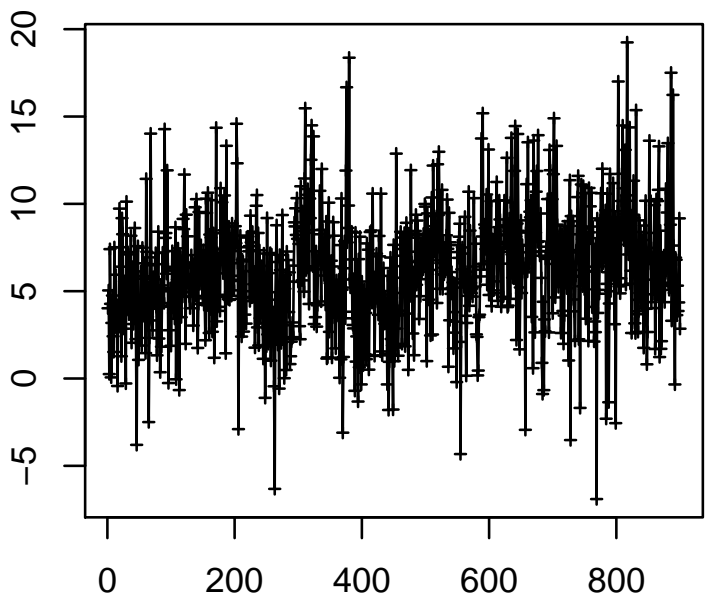

Time Point $(0.25 \mathrm{~Hz})$

Cell 1123

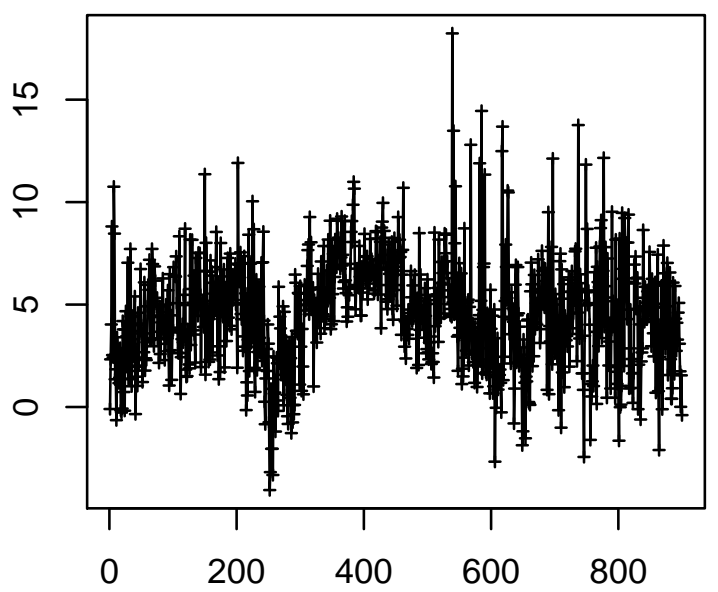

Time Point $(0.25 \mathrm{~Hz})$
Cell 1122

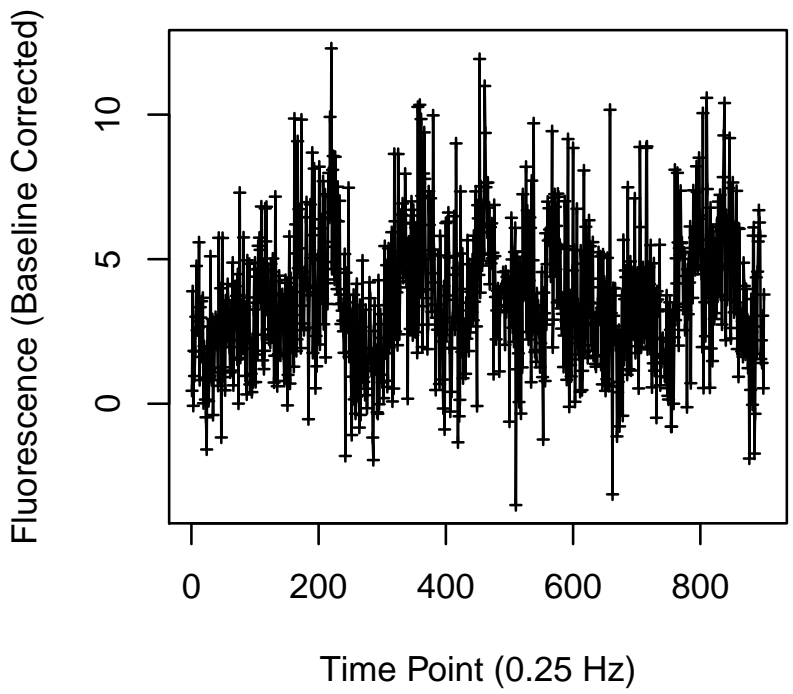

Cell 1124

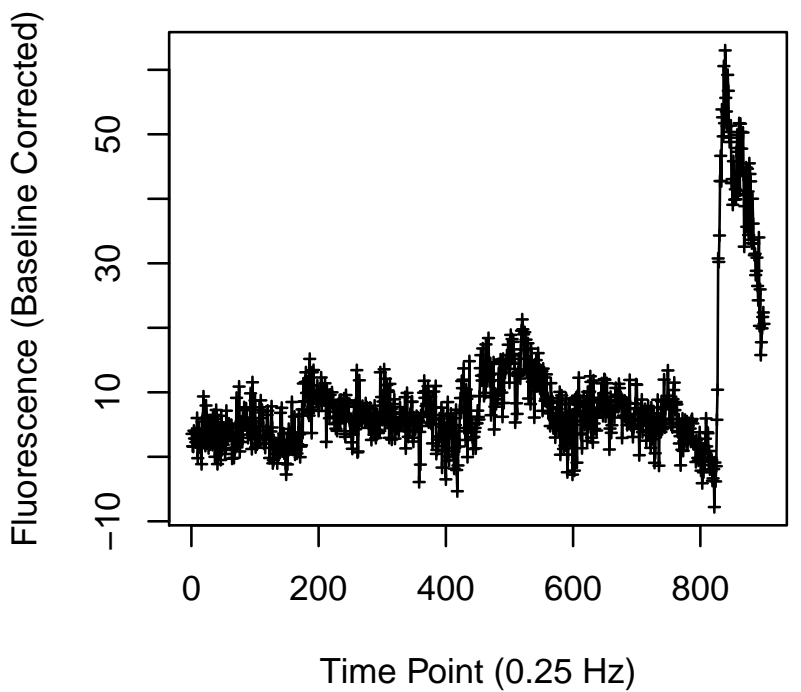




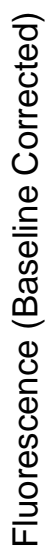

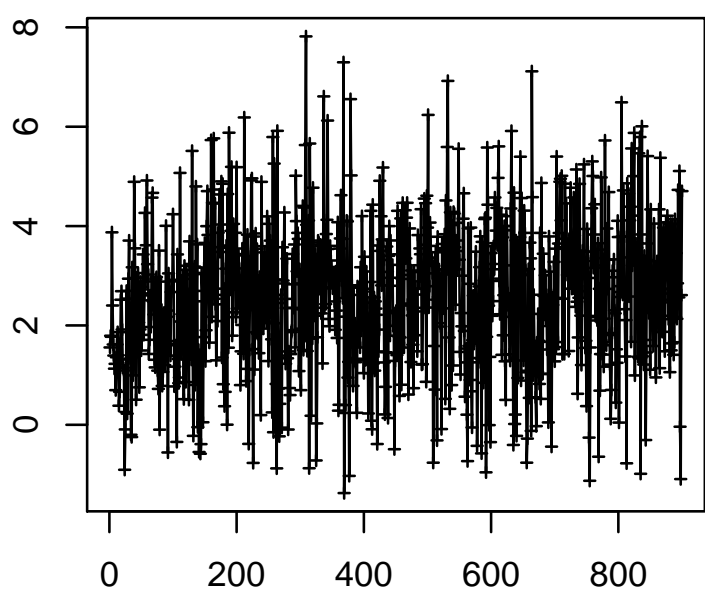

Time Point $(0.25 \mathrm{~Hz})$

Cell 1131

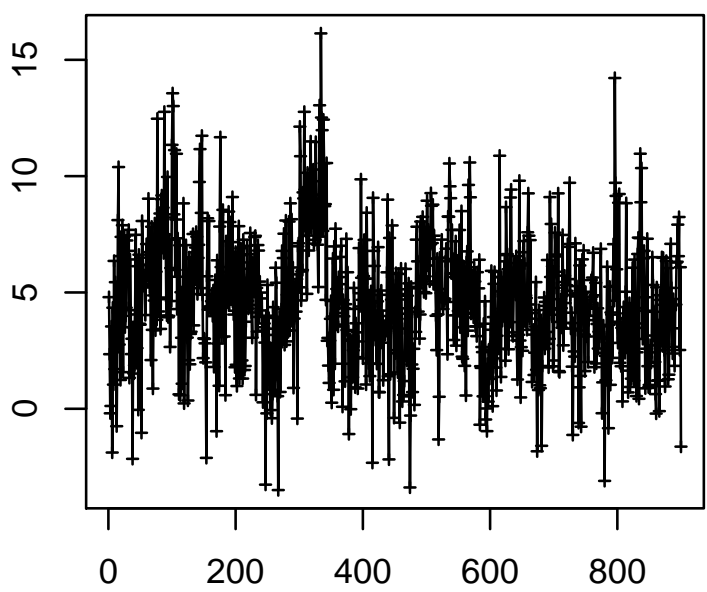

Time Point $(0.25 \mathrm{~Hz})$

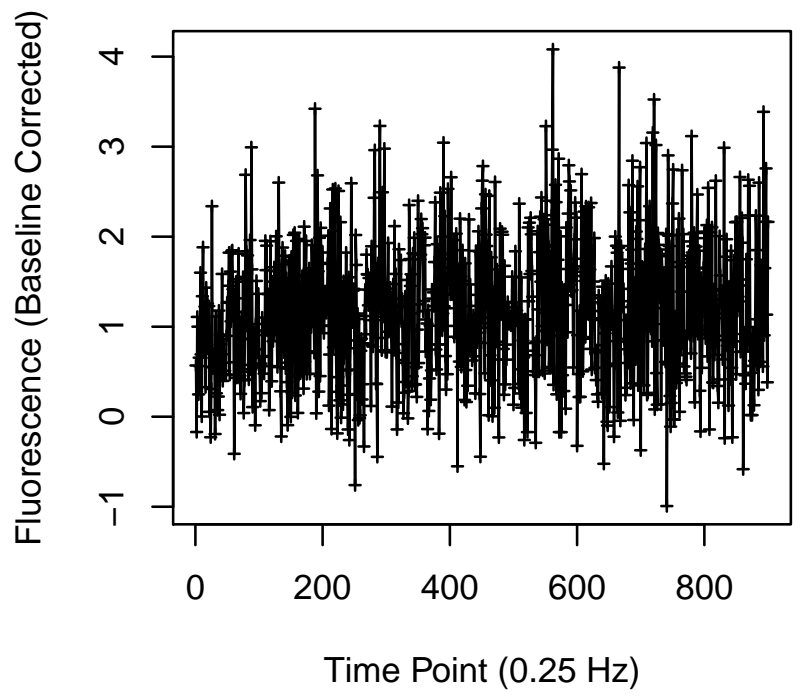

Cell 1132

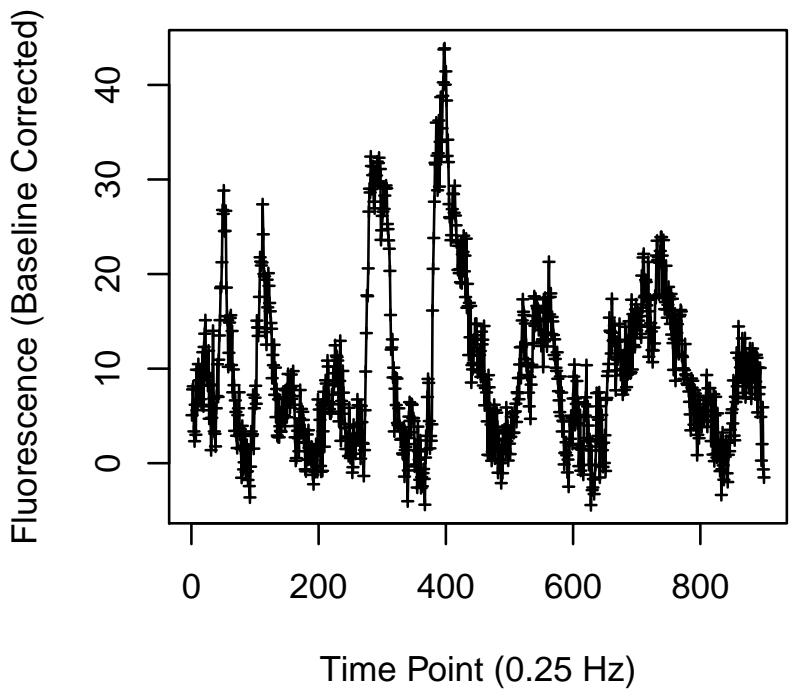




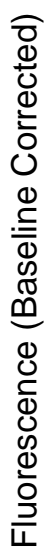

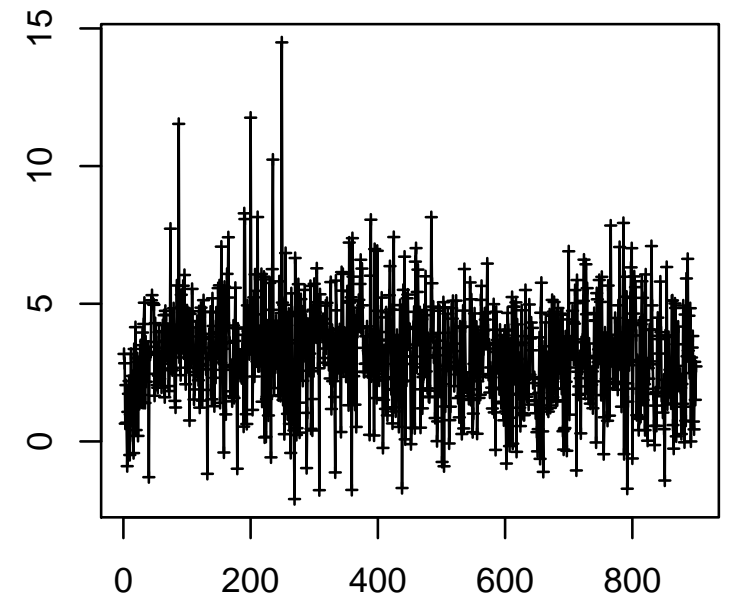

Time Point $(0.25 \mathrm{~Hz})$

Cell 1139

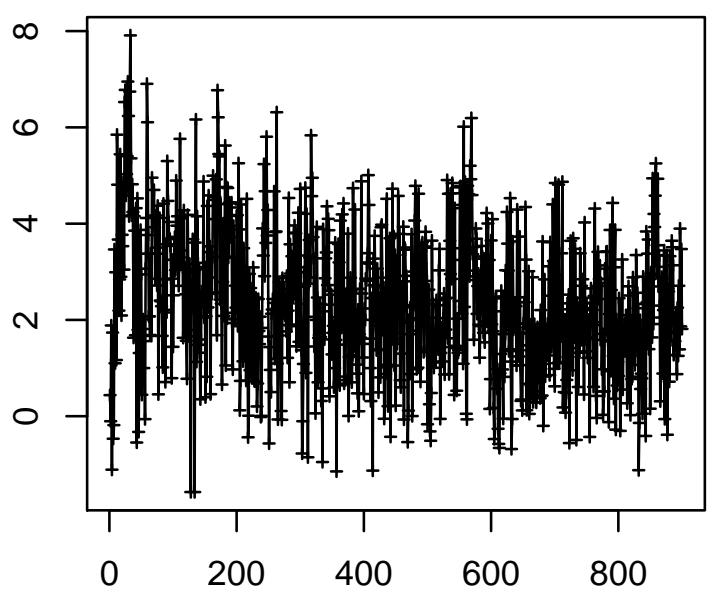

Time Point $(0.25 \mathrm{~Hz})$

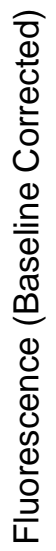

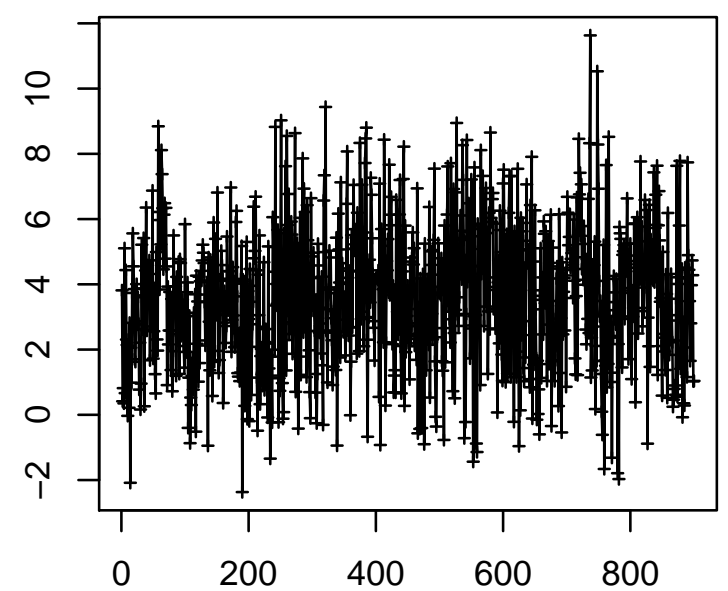

Time Point $(0.25 \mathrm{~Hz})$

Cell 1140

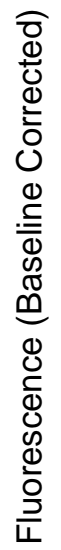

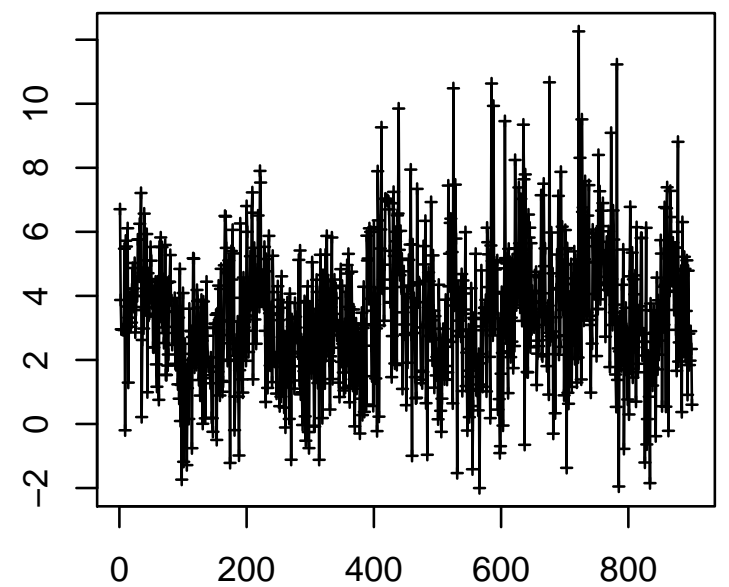

Time Point $(0.25 \mathrm{~Hz})$ 
Cell 1141

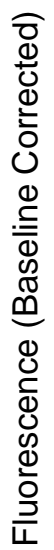

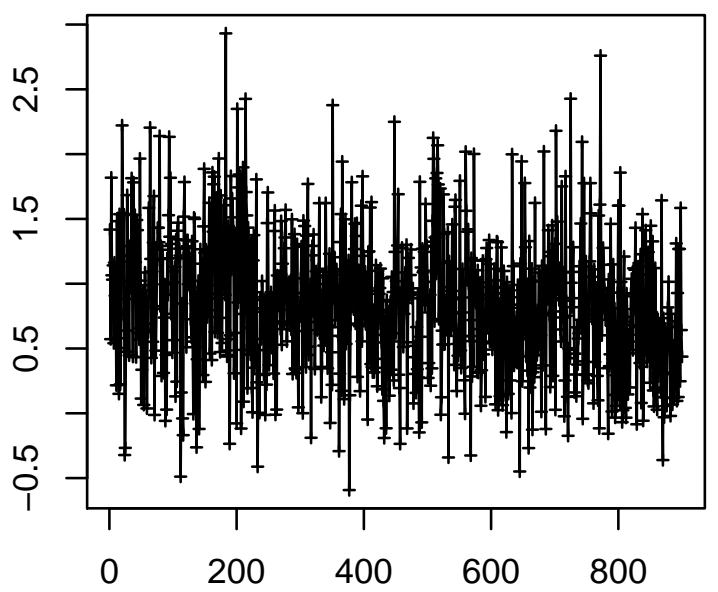

Time Point $(0.25 \mathrm{~Hz})$

Cell 1143

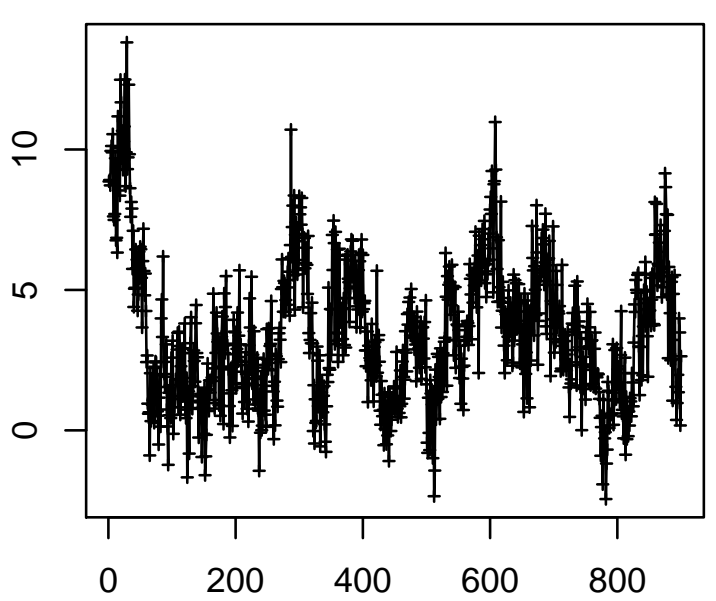

Time Point $(0.25 \mathrm{~Hz})$
Cell 1142

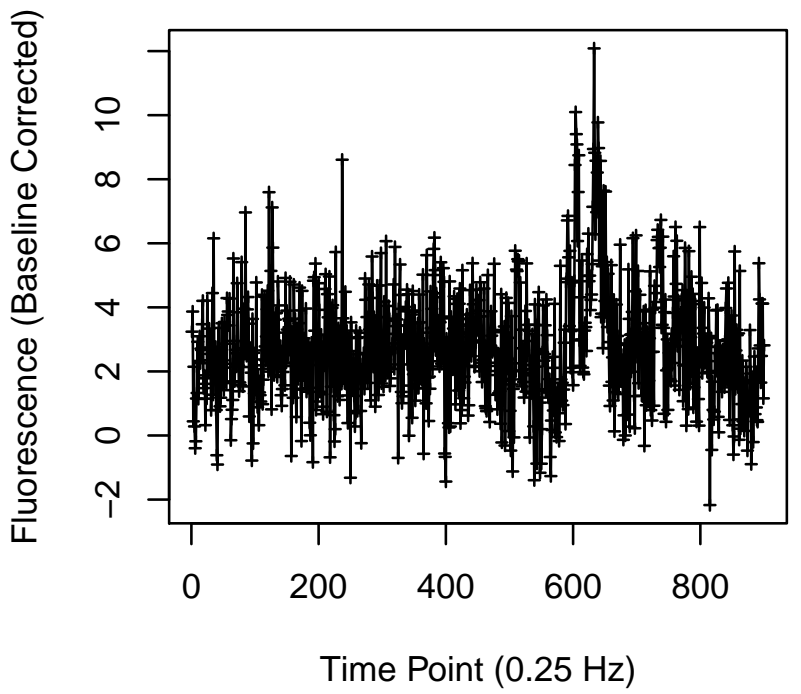

Cell 1144

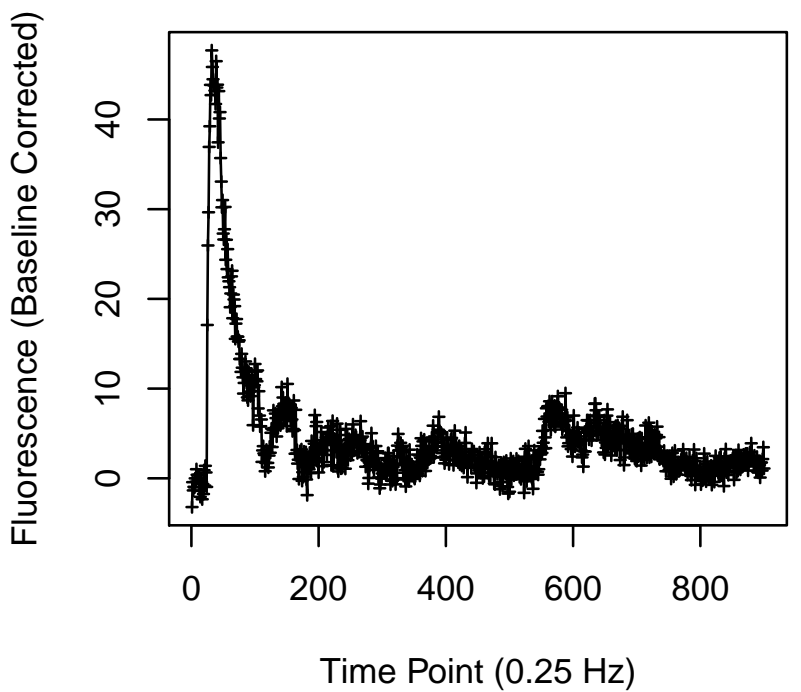


Cell 1145

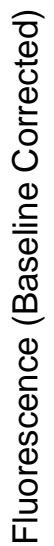

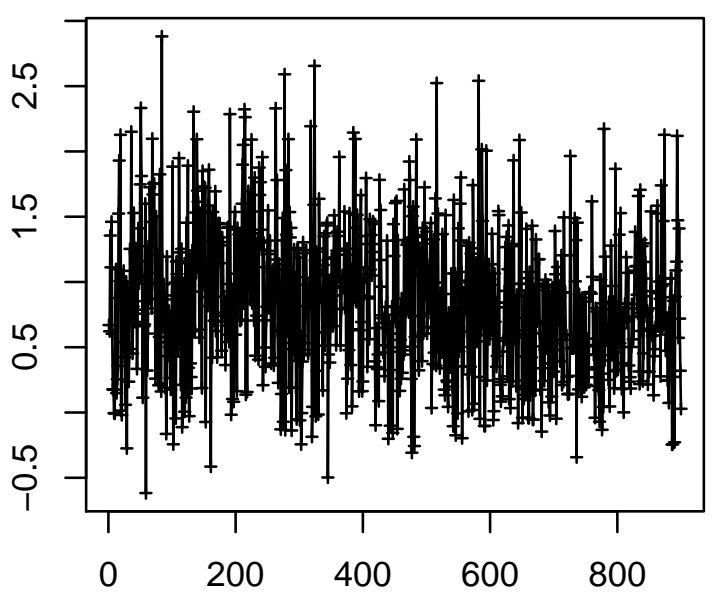

Time Point $(0.25 \mathrm{~Hz})$

Cell 1147

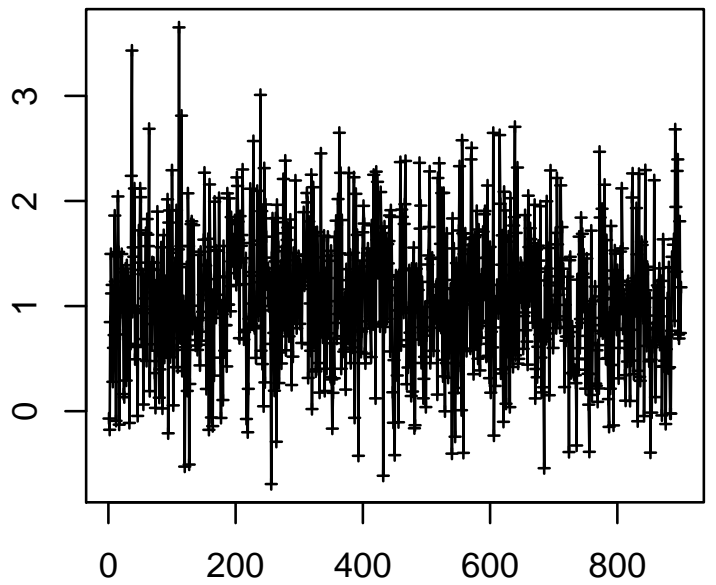

Time Point $(0.25 \mathrm{~Hz})$
Cell 1146

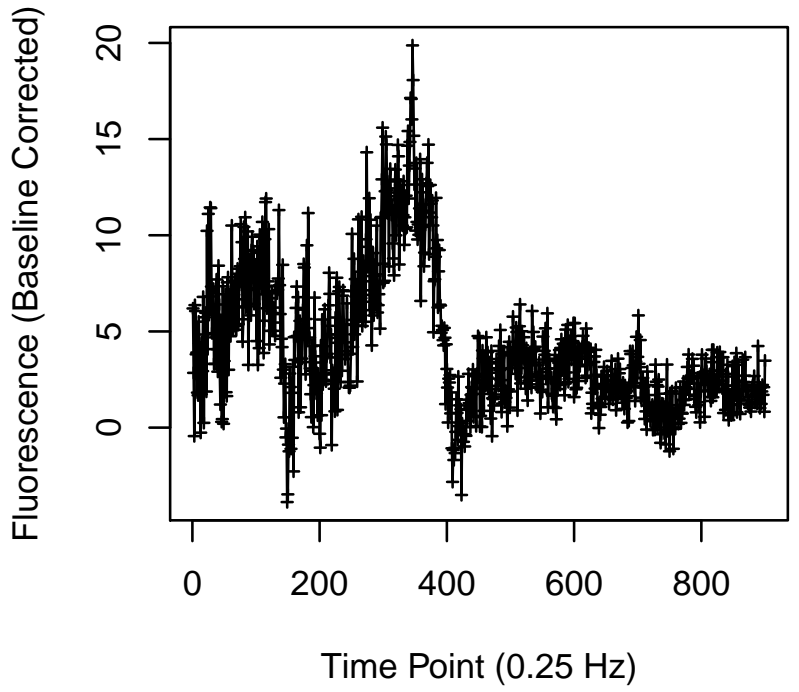

Cell 1148

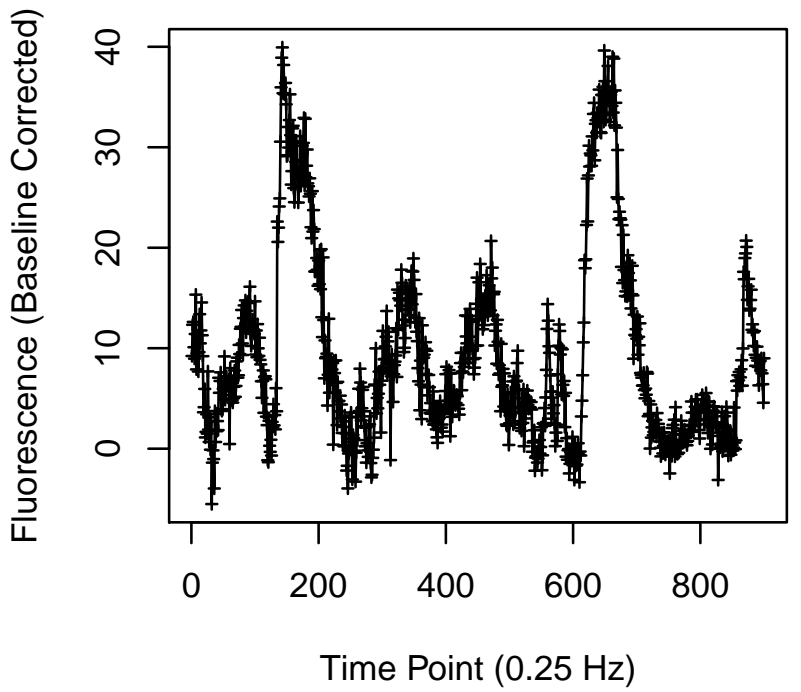




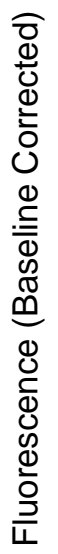

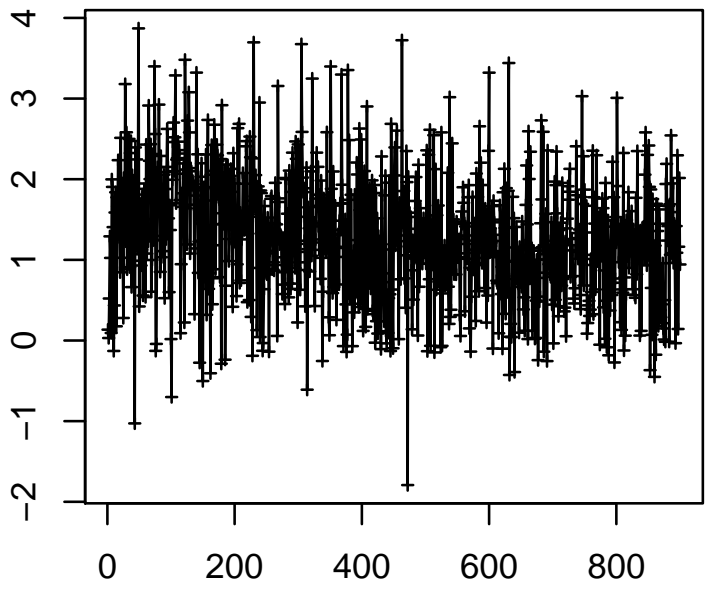

Time Point $(0.25 \mathrm{~Hz})$

Cell 1151

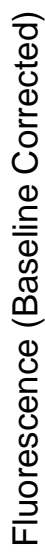

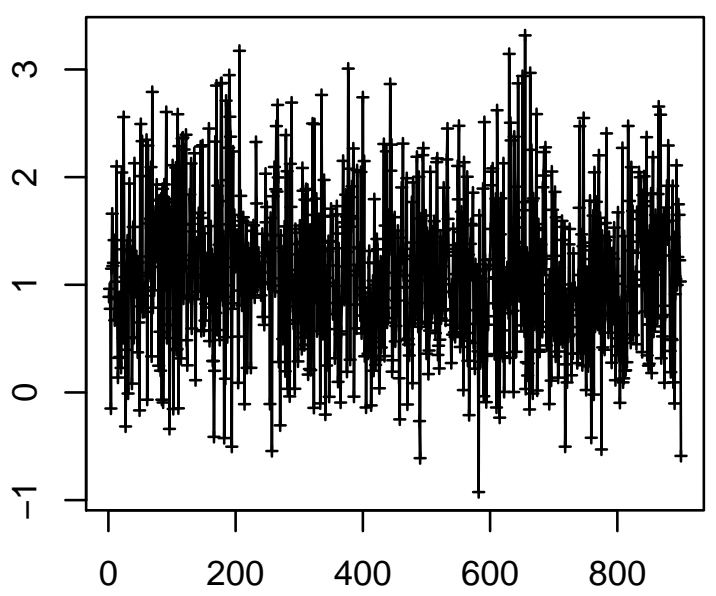

Time Point $(0.25 \mathrm{~Hz})$

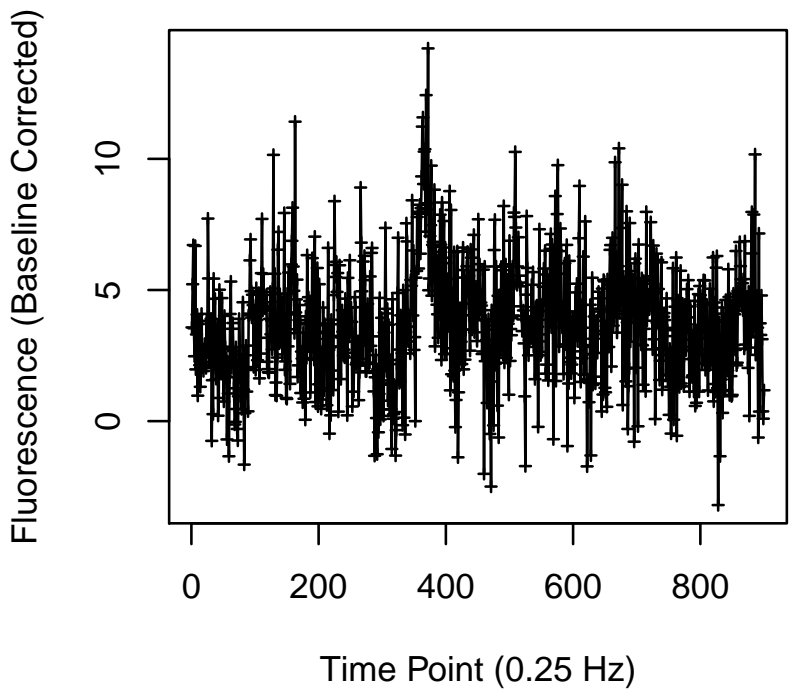

Cell 1152

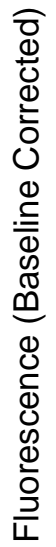

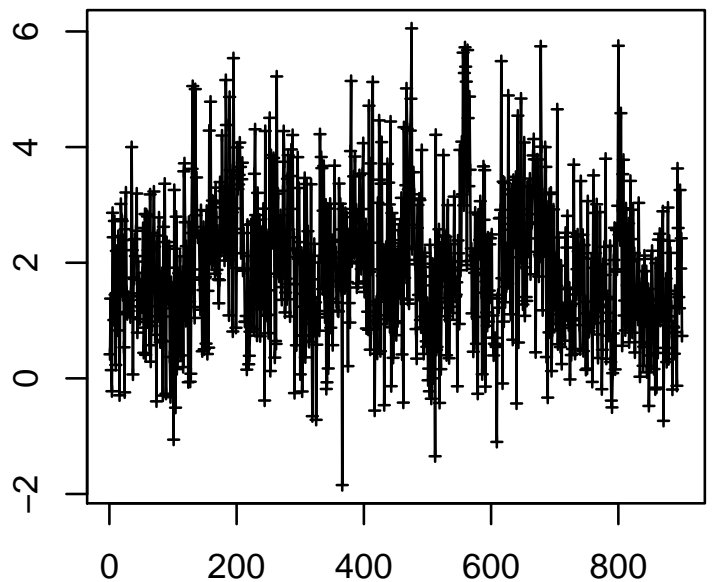

Time Point $(0.25 \mathrm{~Hz})$ 
Cell 1161

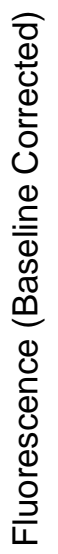

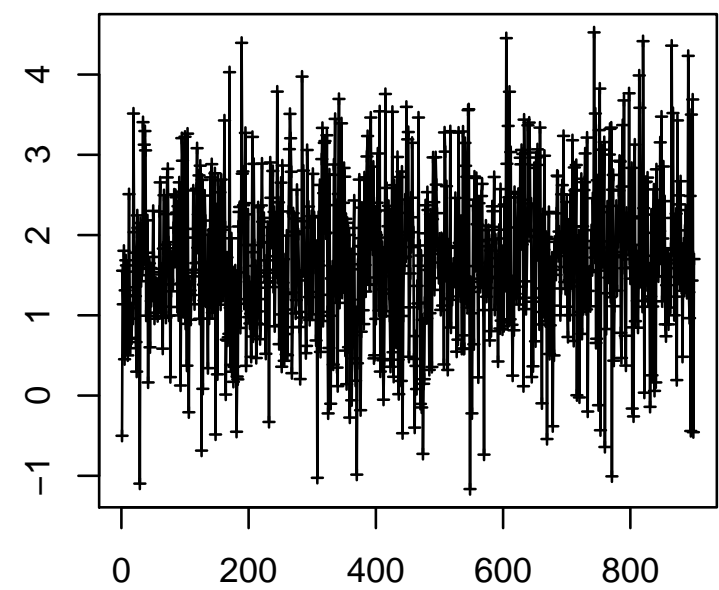

Time Point $(0.25 \mathrm{~Hz})$

Cell 1163

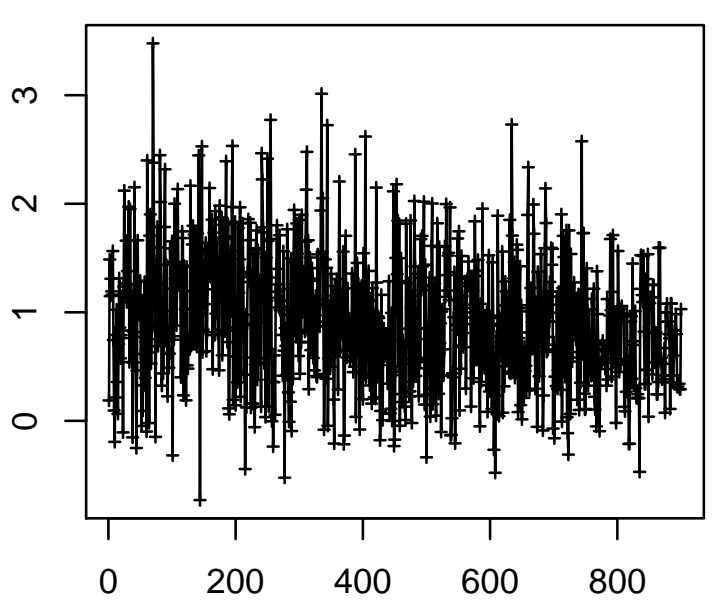

Time Point $(0.25 \mathrm{~Hz})$
Cell 1162

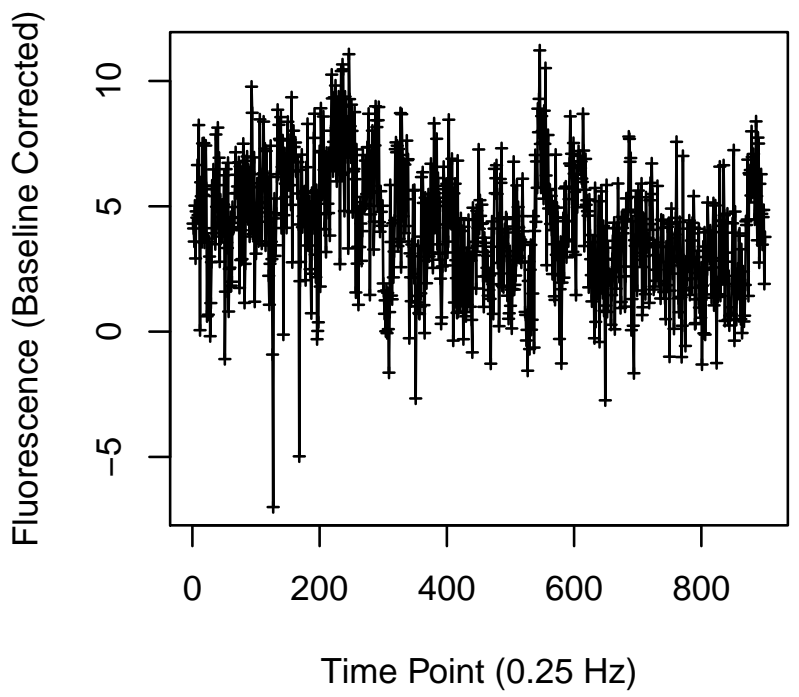

Cell 1164

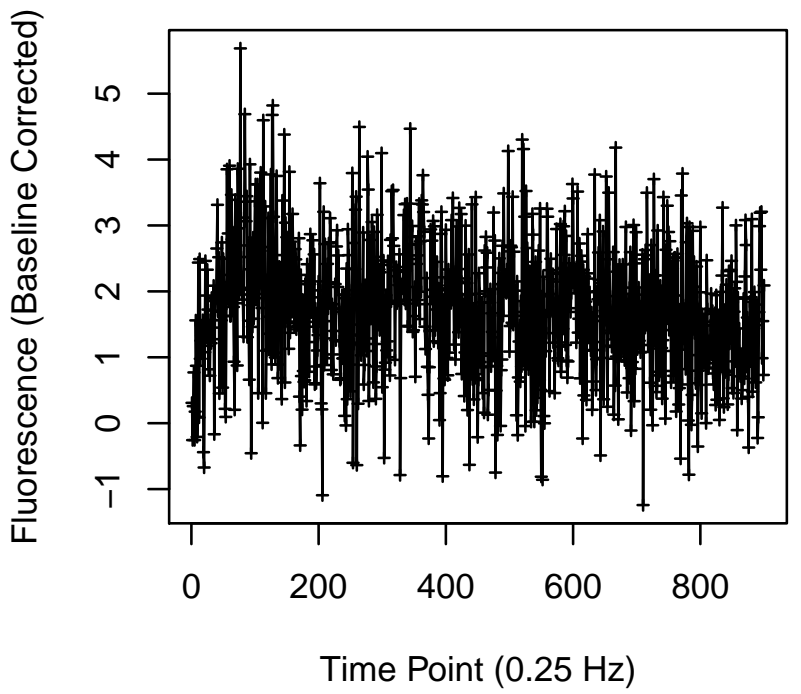


Cell 1165

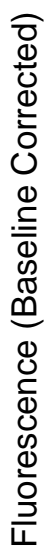

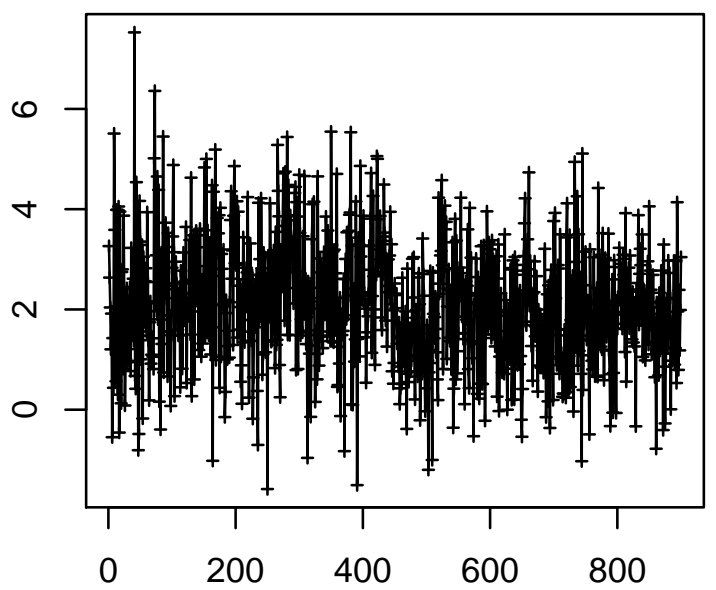

Time Point $(0.25 \mathrm{~Hz})$

Cell 1167

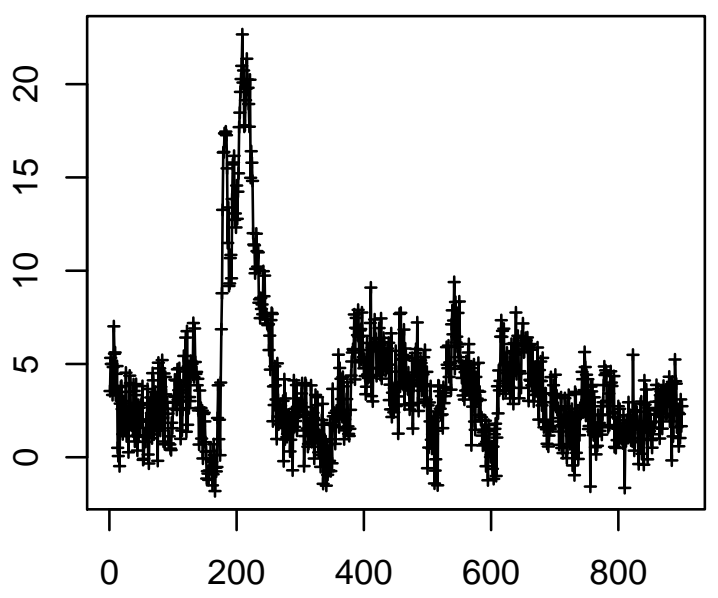

Time Point $(0.25 \mathrm{~Hz})$
Cell 1166

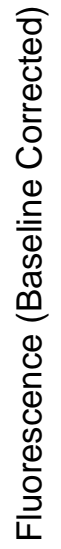

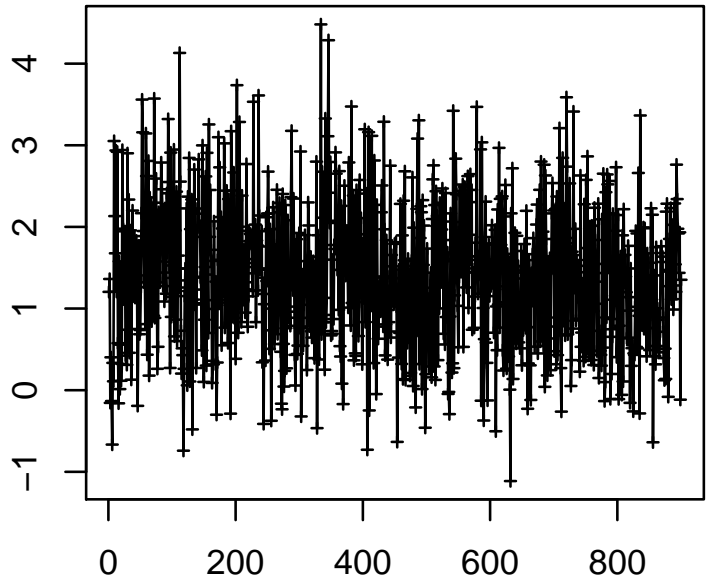

Time Point $(0.25 \mathrm{~Hz})$

Cell 1168

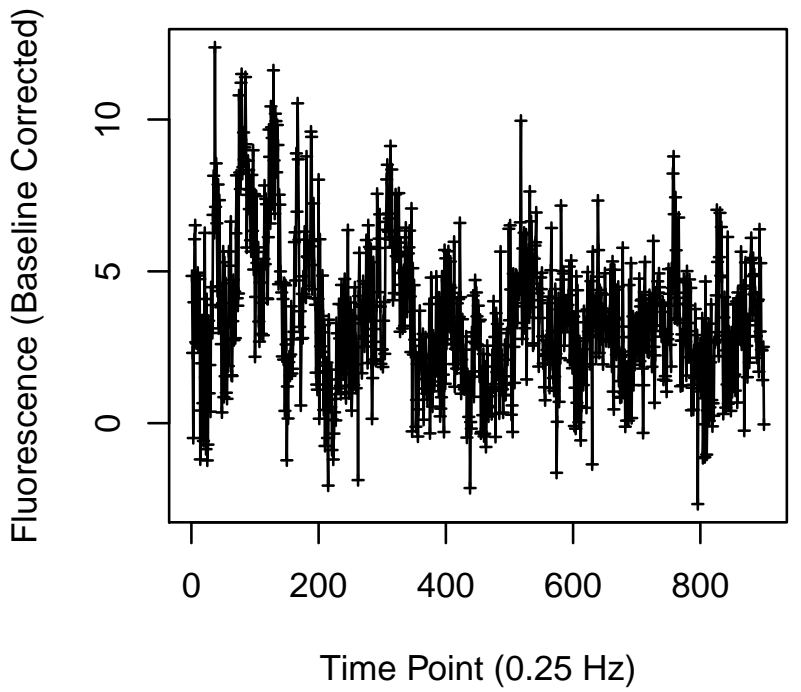


Cell 1173

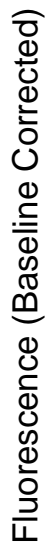

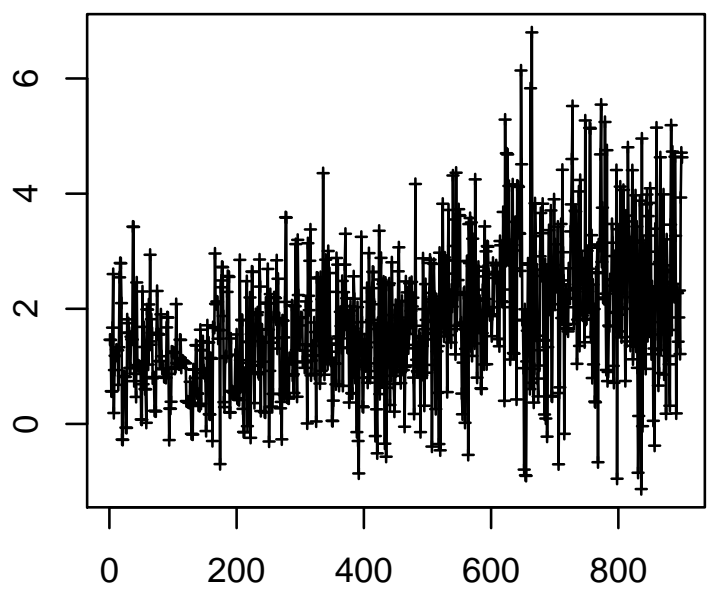

Time Point $(0.25 \mathrm{~Hz})$

Cell 1175

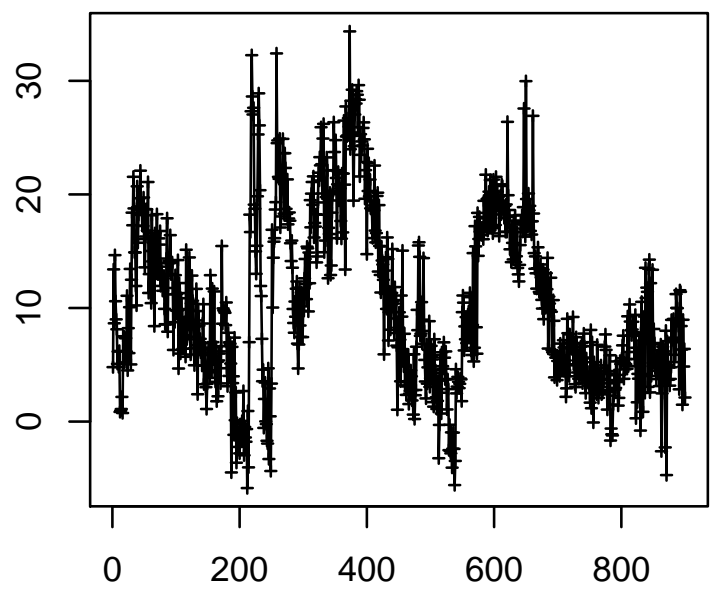

Time Point $(0.25 \mathrm{~Hz})$
Cell 1174

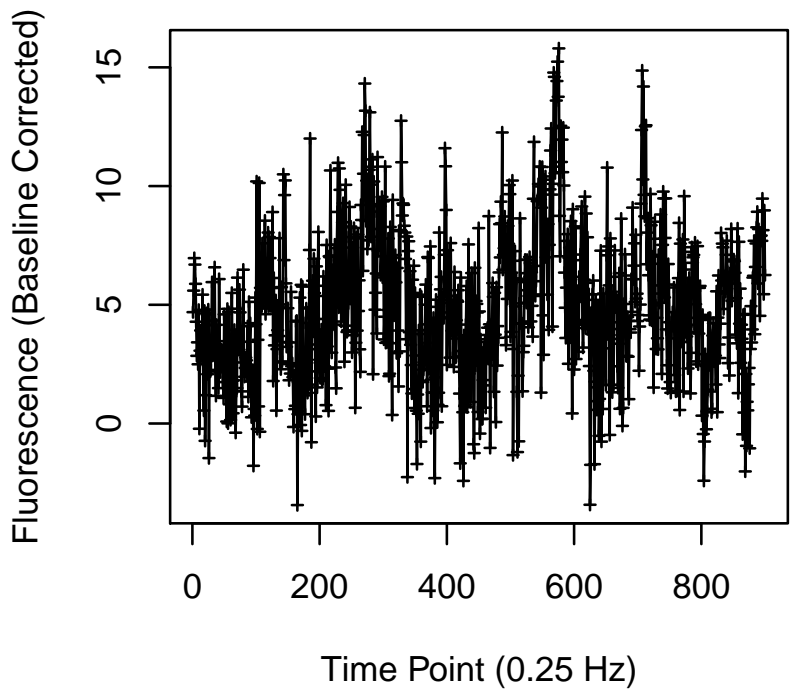

Cell 1176

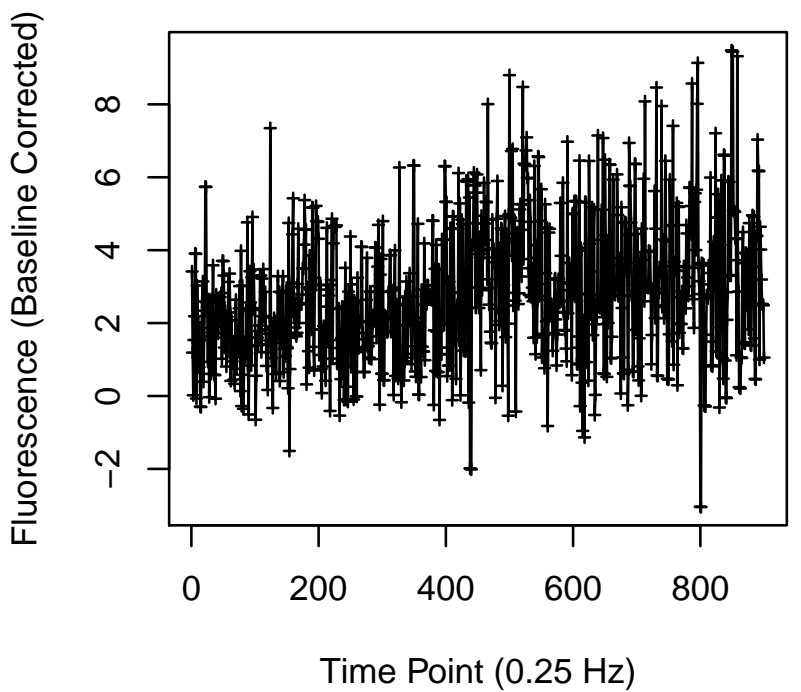


Cell 1181

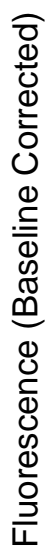

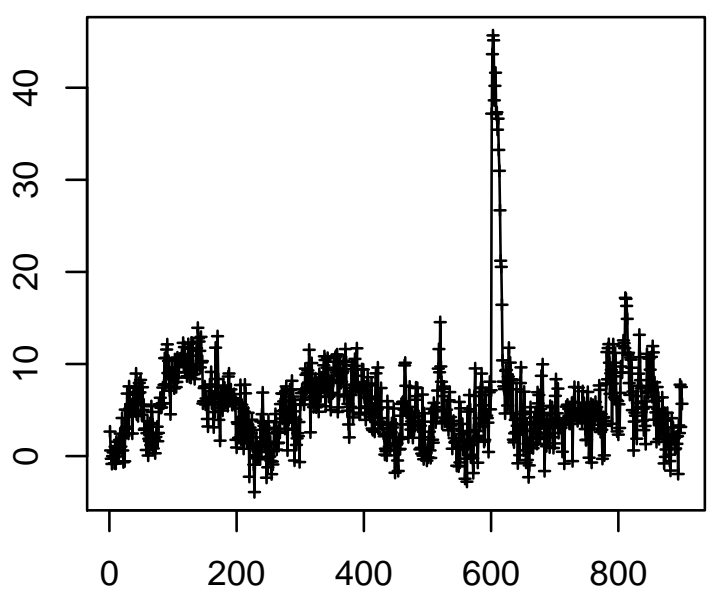

Time Point $(0.25 \mathrm{~Hz})$

Cell 1183

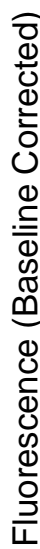

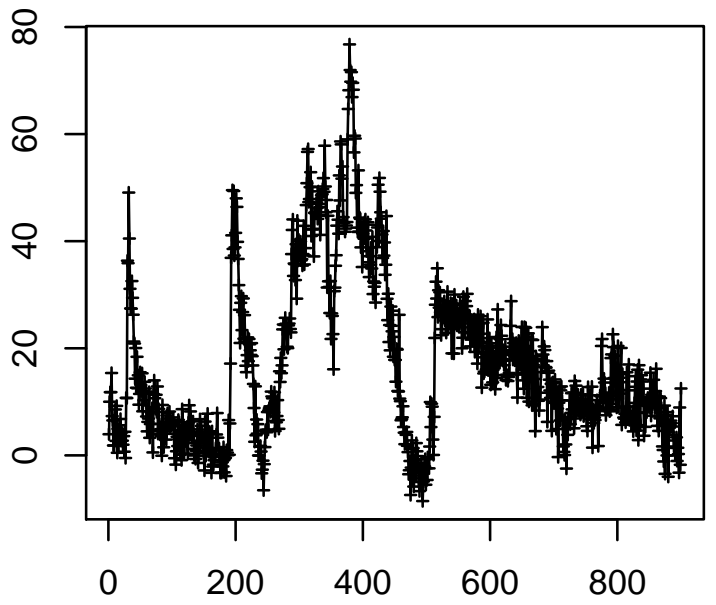

Time Point $(0.25 \mathrm{~Hz})$
Cell 1182

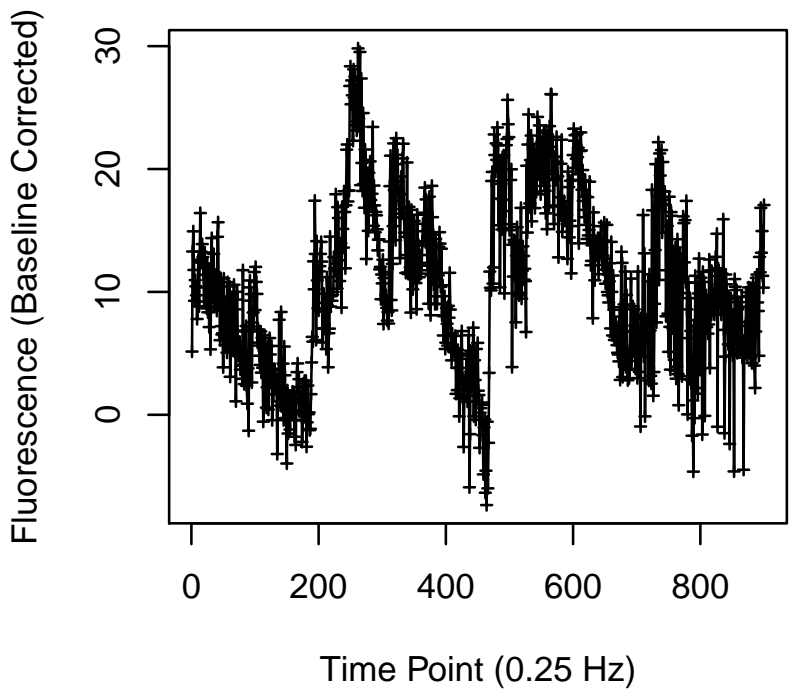

Cell 1184

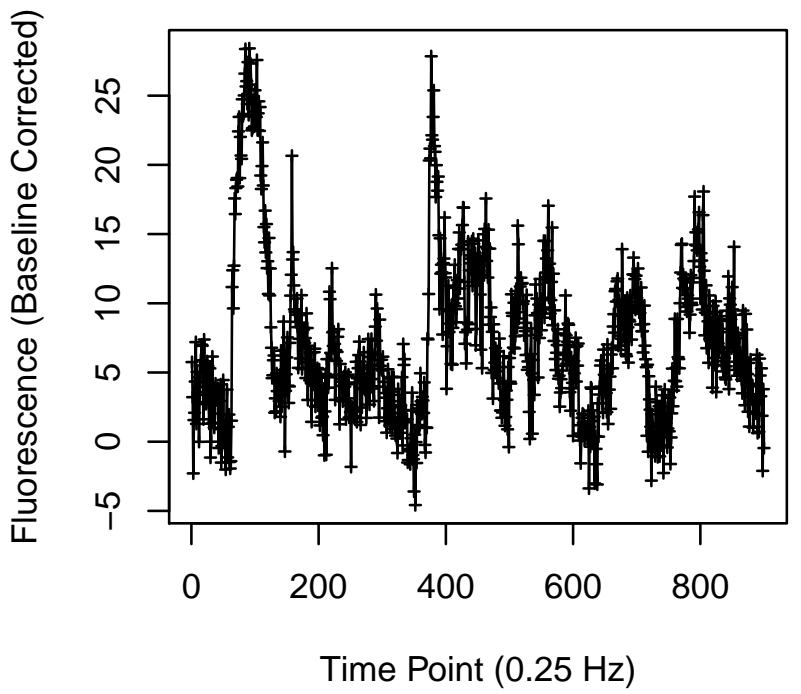


Cell 1193

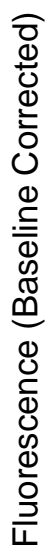

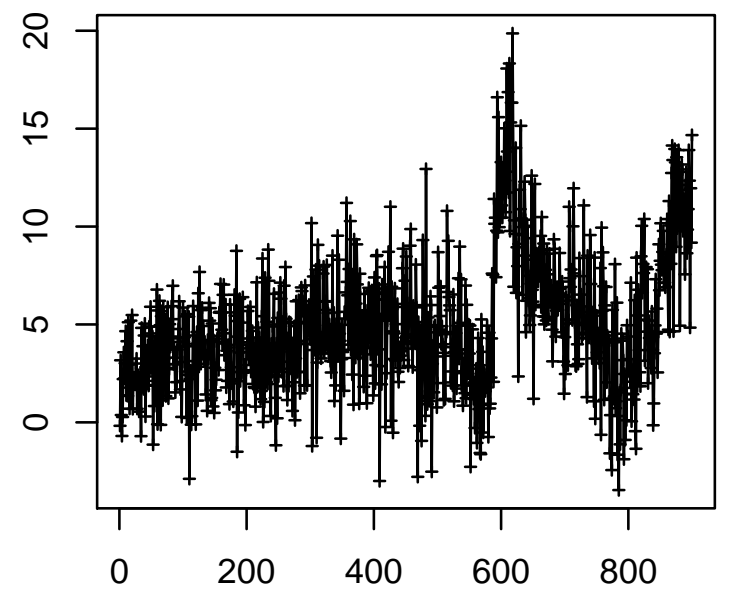

Time Point $(0.25 \mathrm{~Hz})$

Cell 1195

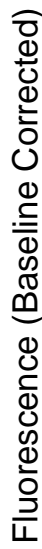

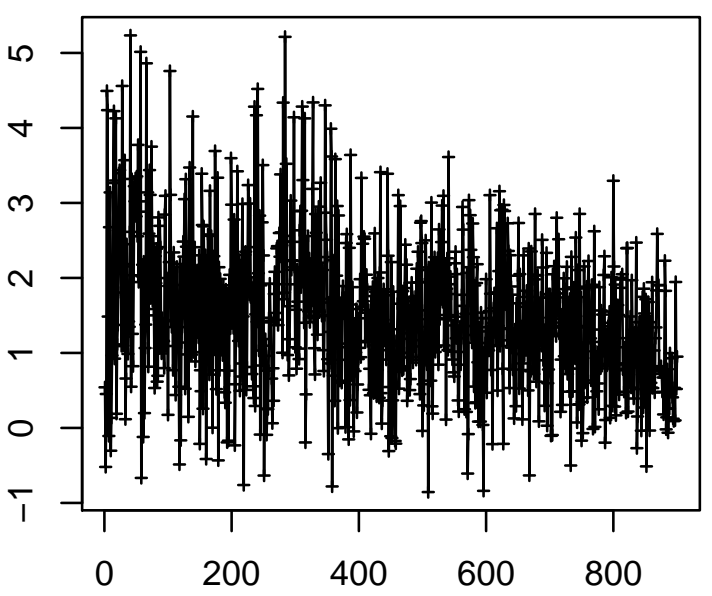

Time Point $(0.25 \mathrm{~Hz})$
Cell 1194

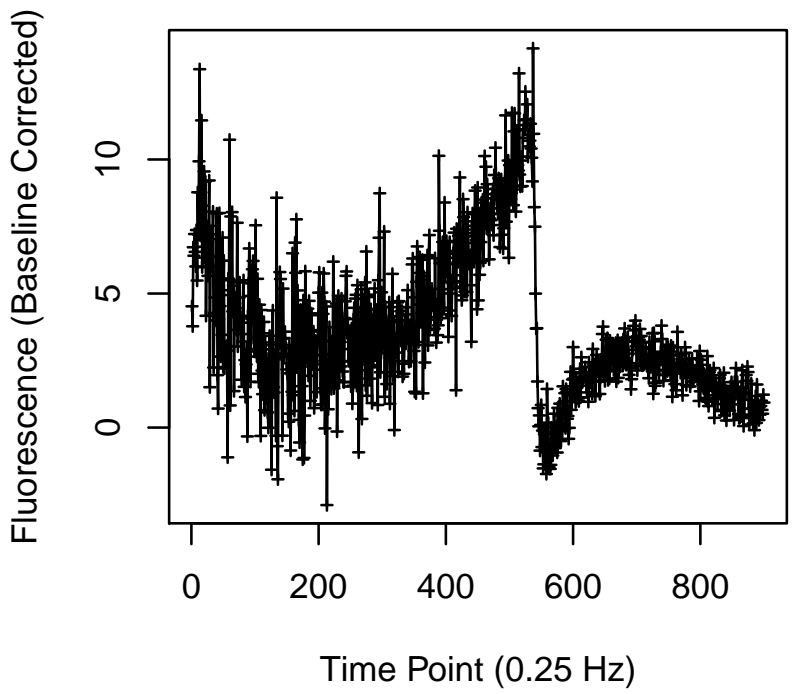

Cell 1196

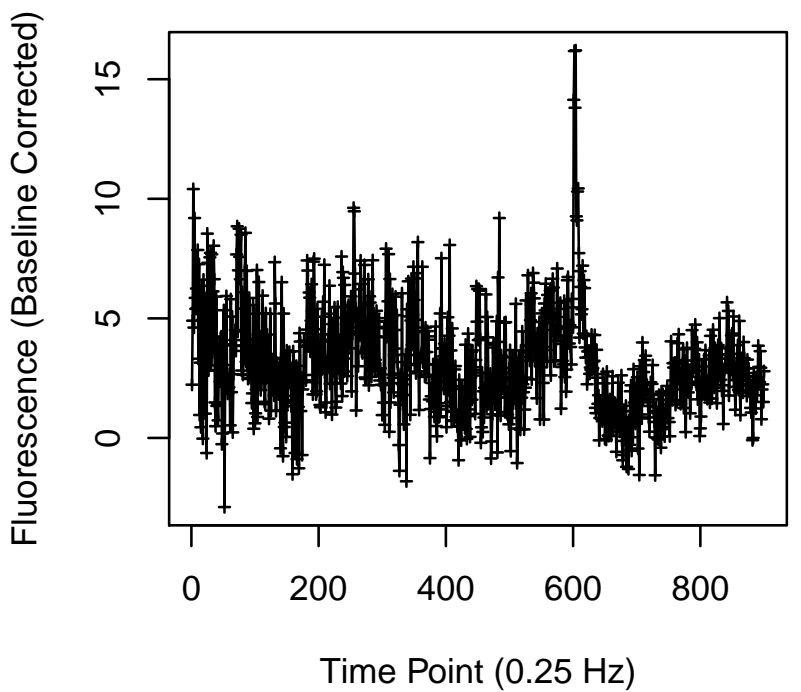



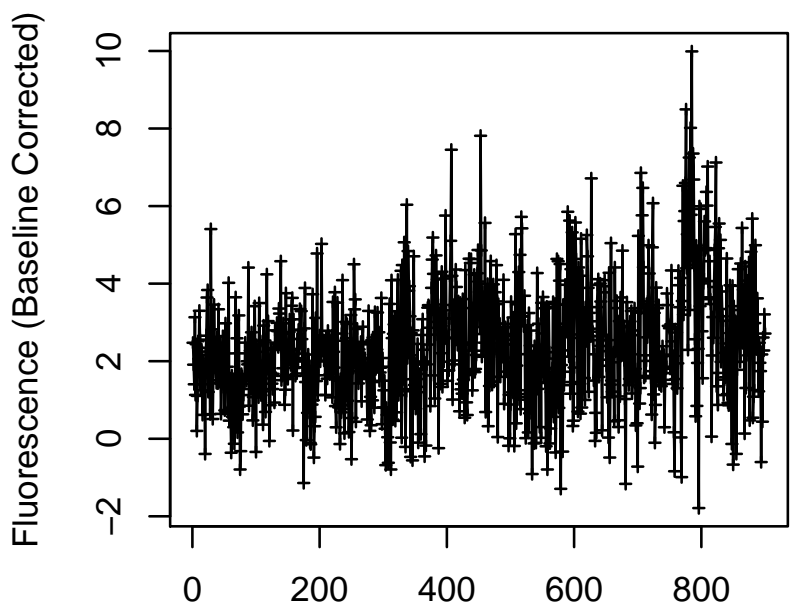

Time Point $(0.25 \mathrm{~Hz})$

Cell 1199

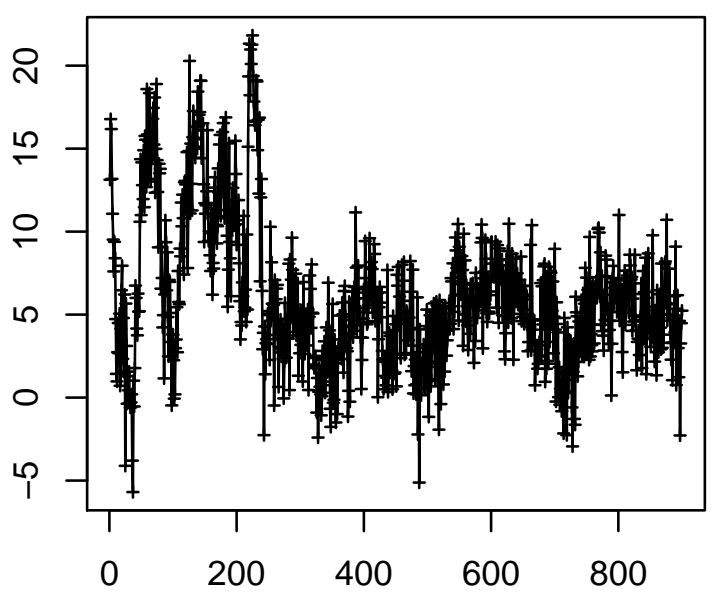

Time Point $(0.25 \mathrm{~Hz})$

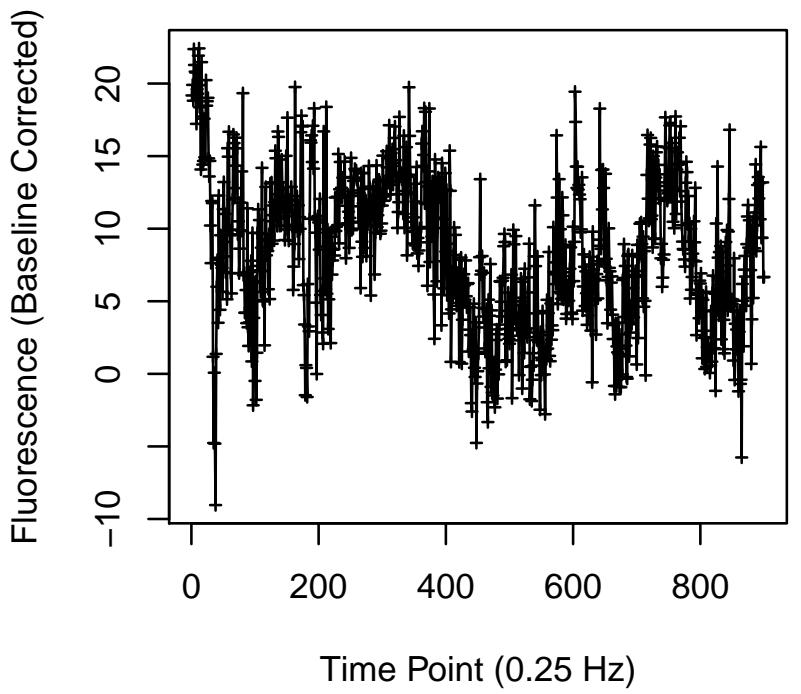

Cell 1200

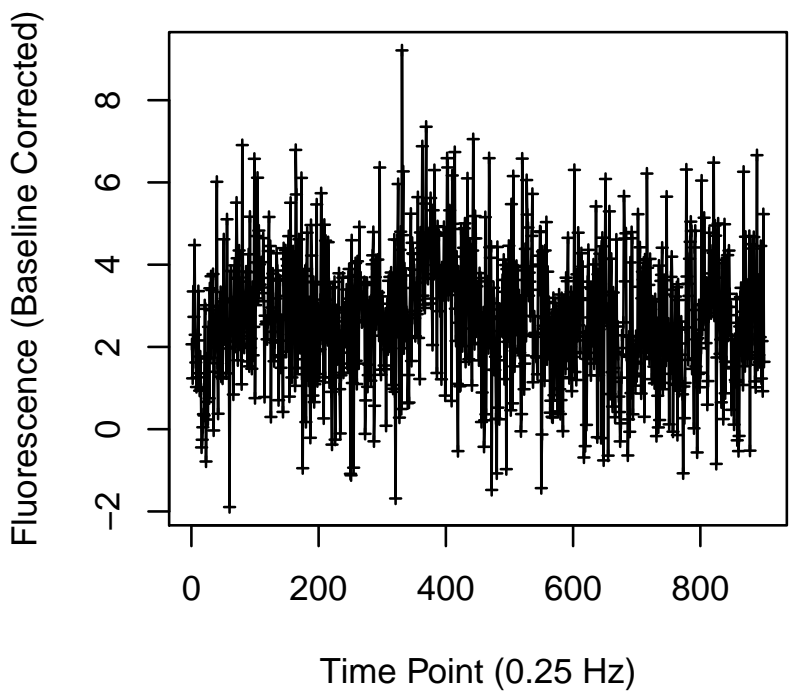


Cell 1201

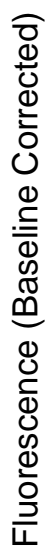

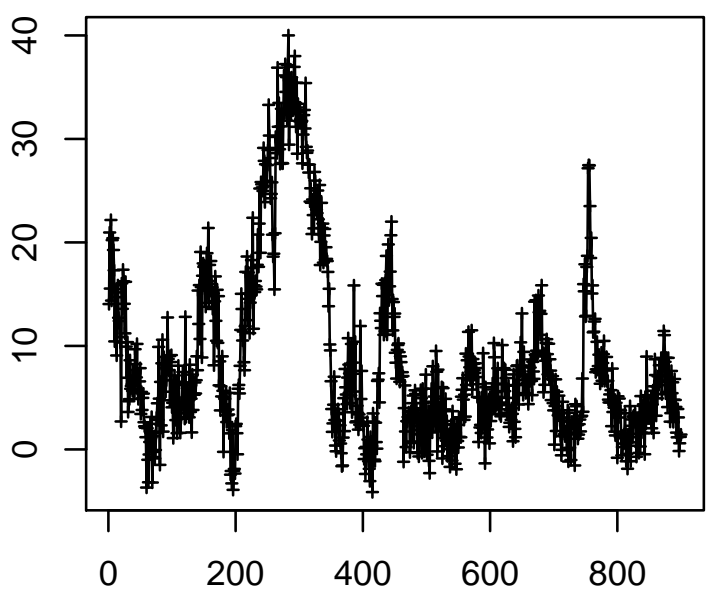

Time Point $(0.25 \mathrm{~Hz})$

Cell 1203

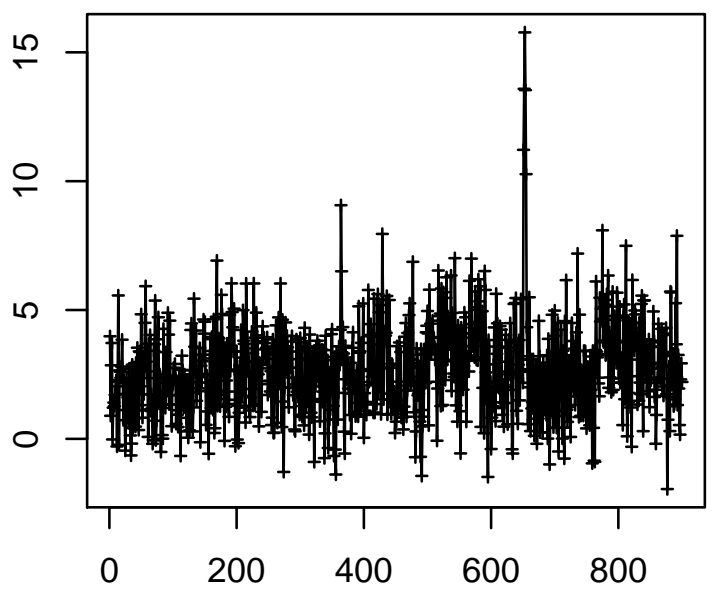

Time Point $(0.25 \mathrm{~Hz})$
Cell 1202

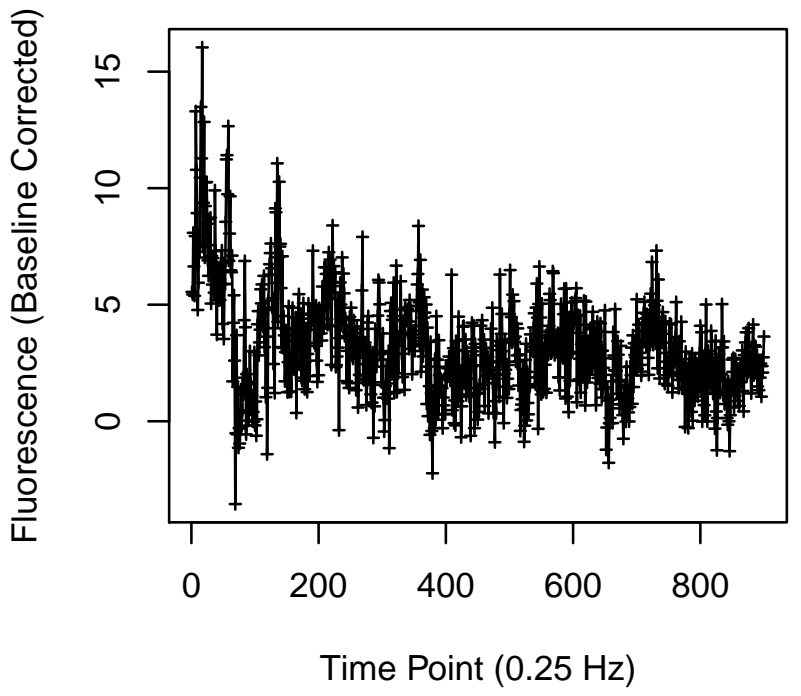

Cell 1204

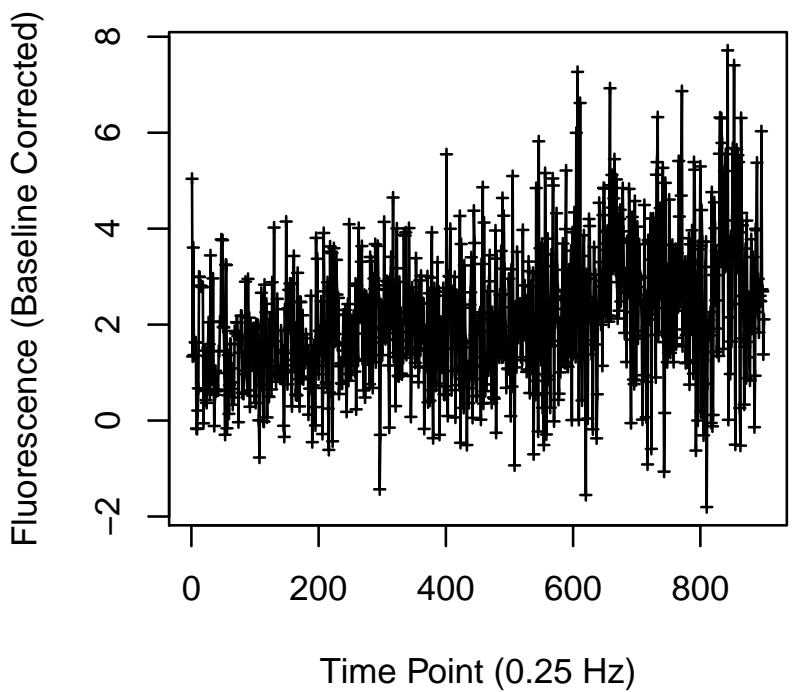


Cell 1205

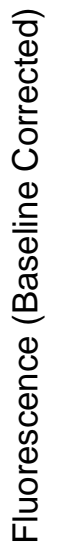

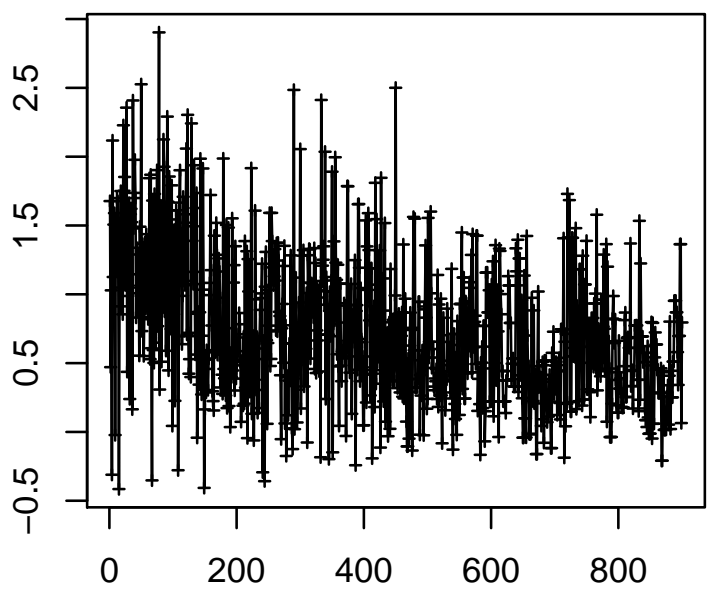

Time Point $(0.25 \mathrm{~Hz})$

Cell 1207

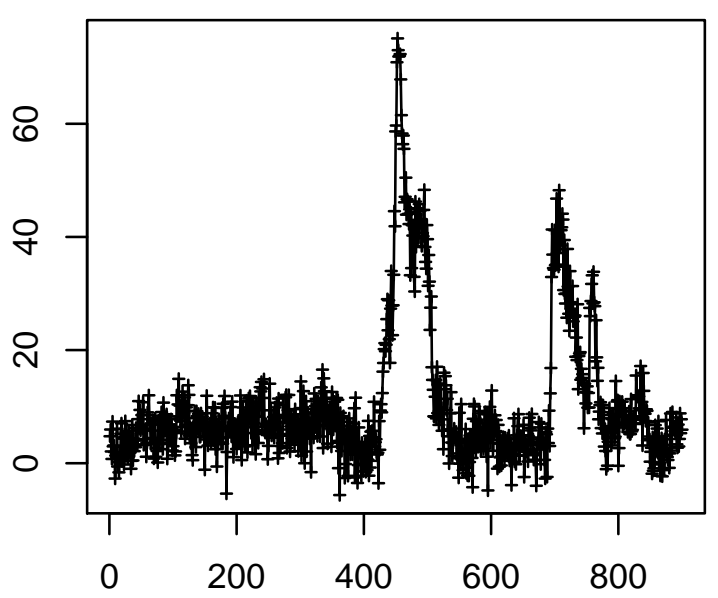

Time Point $(0.25 \mathrm{~Hz})$
Cell 1206

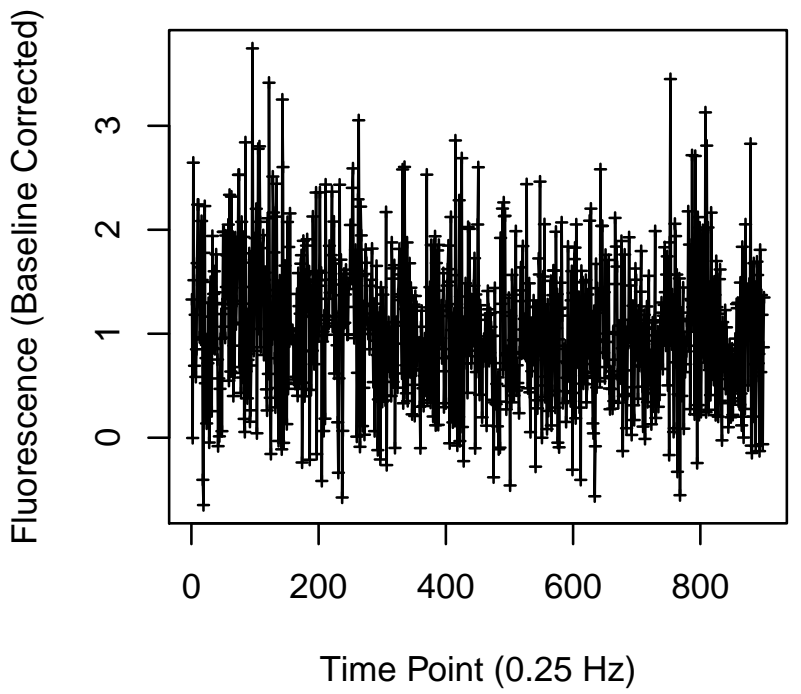

Cell 1208

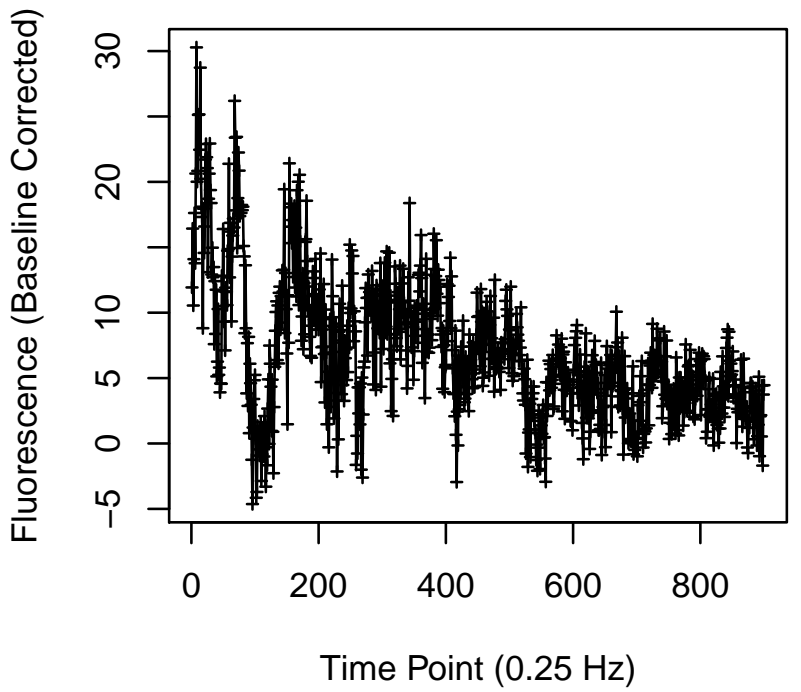


Cell 1217

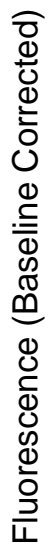

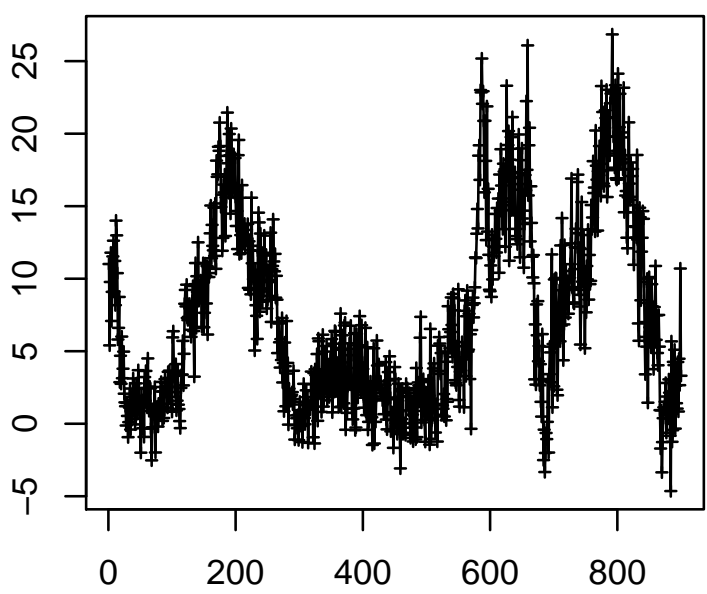

Time Point $(0.25 \mathrm{~Hz})$

Cell 1219

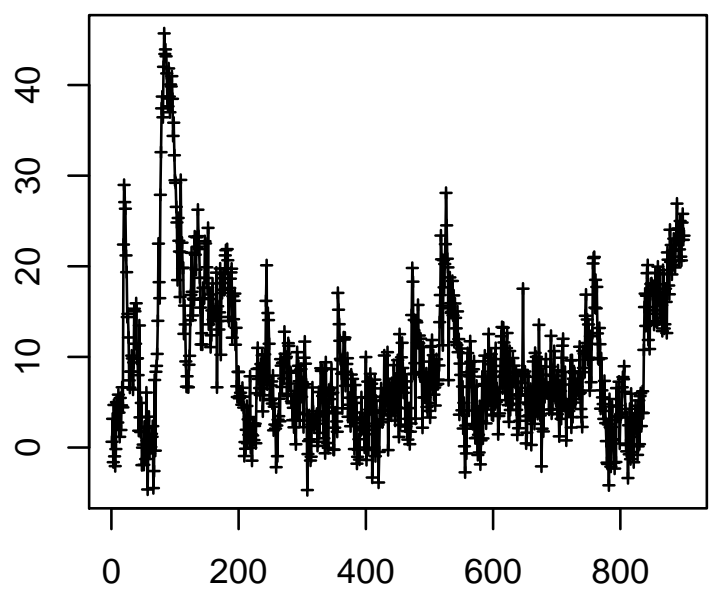

Time Point $(0.25 \mathrm{~Hz})$
Cell 1218

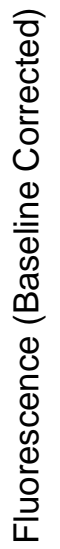

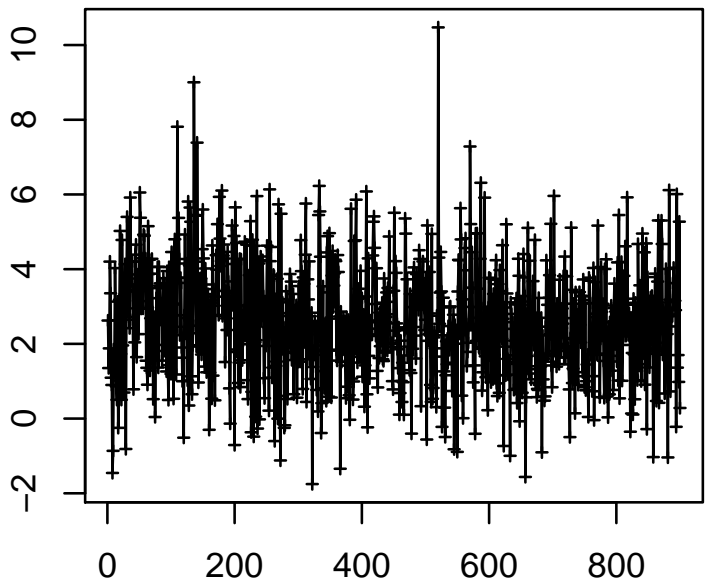

Time Point $(0.25 \mathrm{~Hz})$

Cell 1220

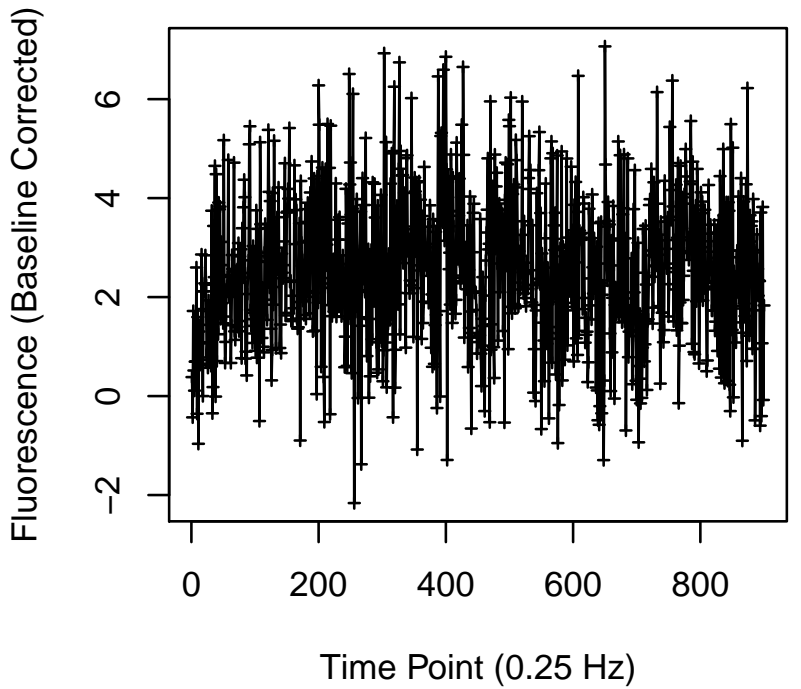


Cell 1225

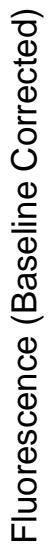

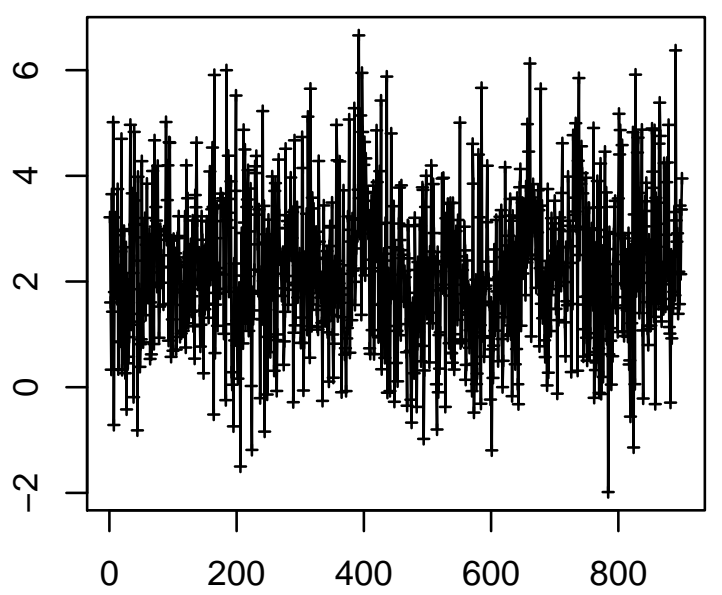

Time Point $(0.25 \mathrm{~Hz})$

Cell 1227

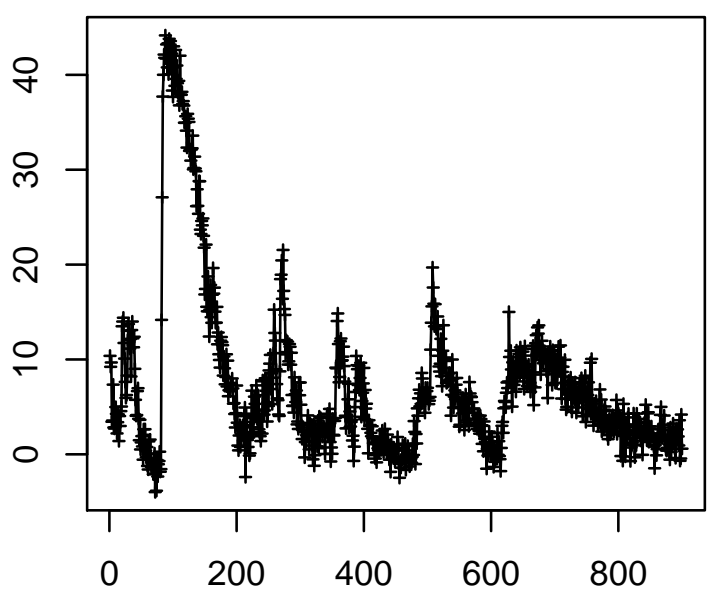

Time Point $(0.25 \mathrm{~Hz})$
Cell 1226

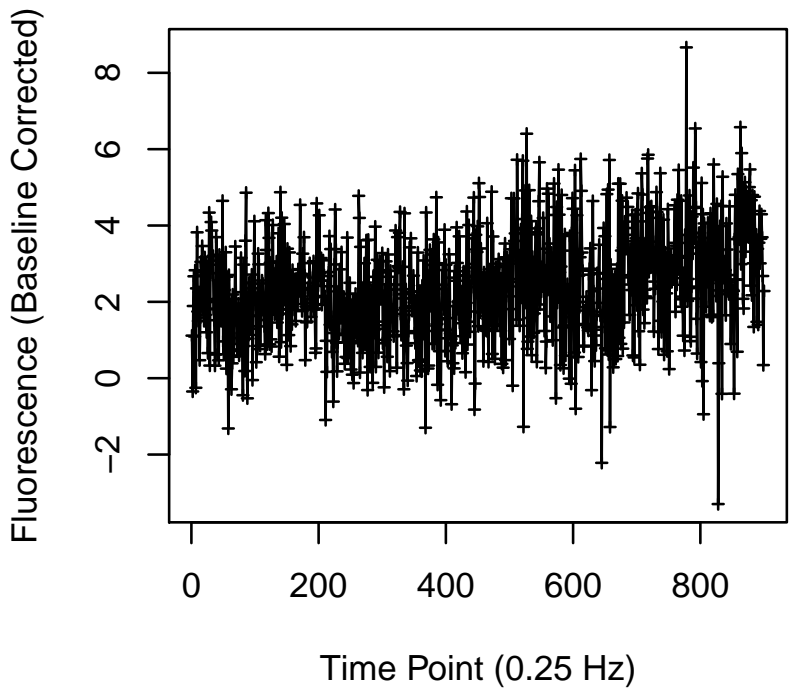

Cell 1228

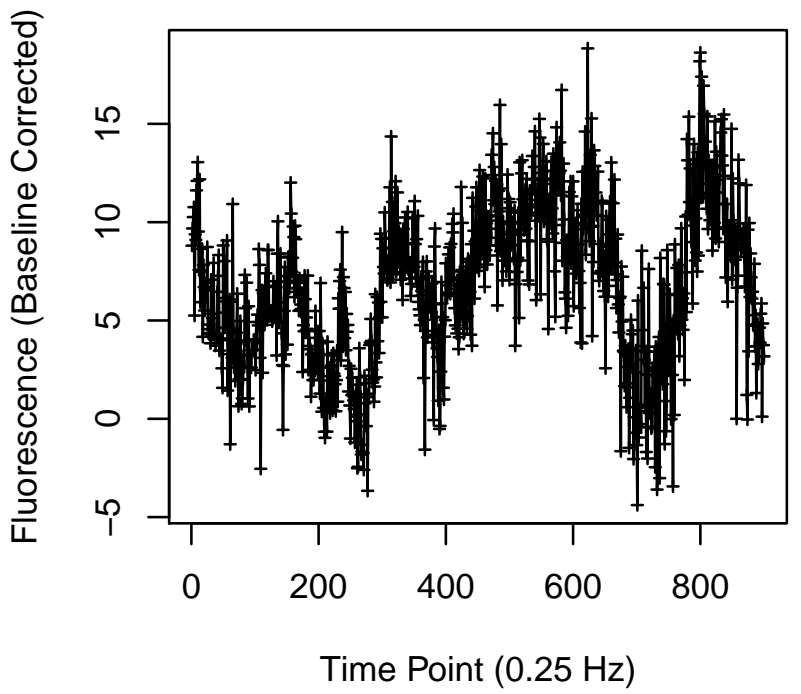


Cell 1229
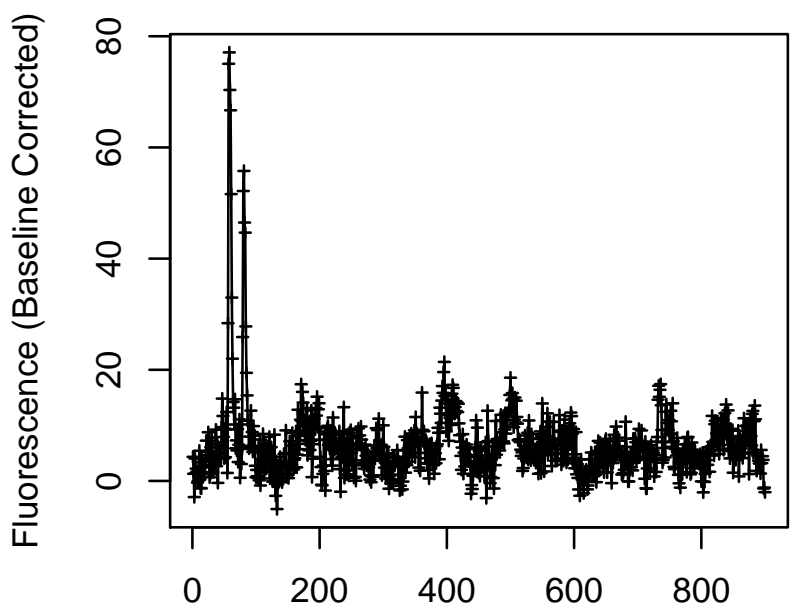

Time Point $(0.25 \mathrm{~Hz})$

Cell 1231

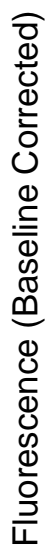

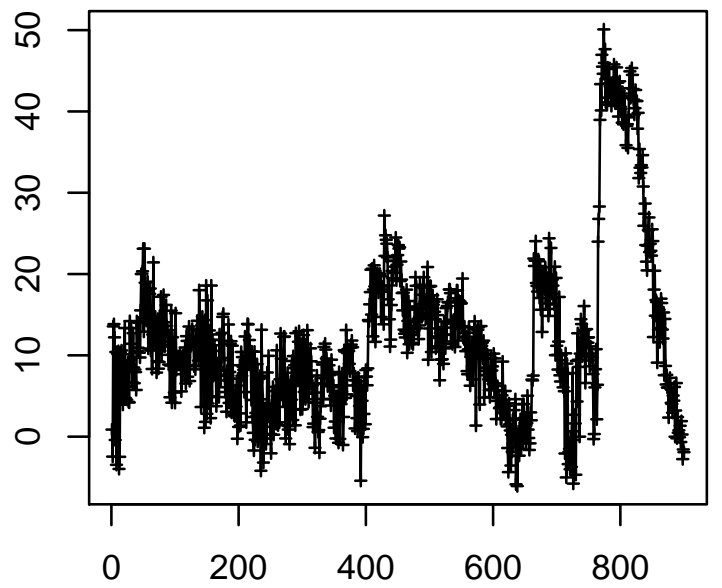

Time Point $(0.25 \mathrm{~Hz})$
Cell 1230

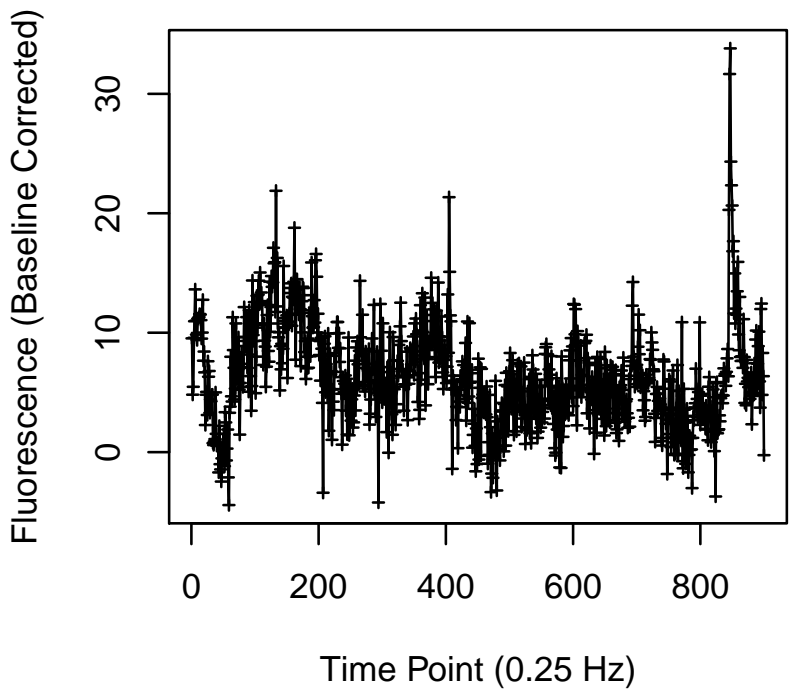

Cell 1232

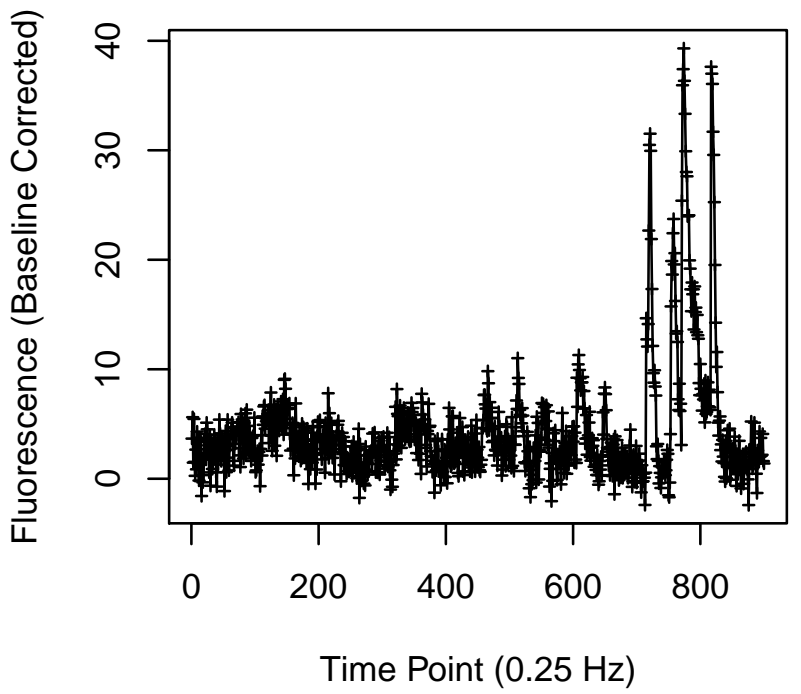


Cell 1233

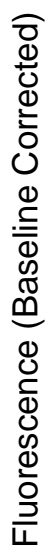

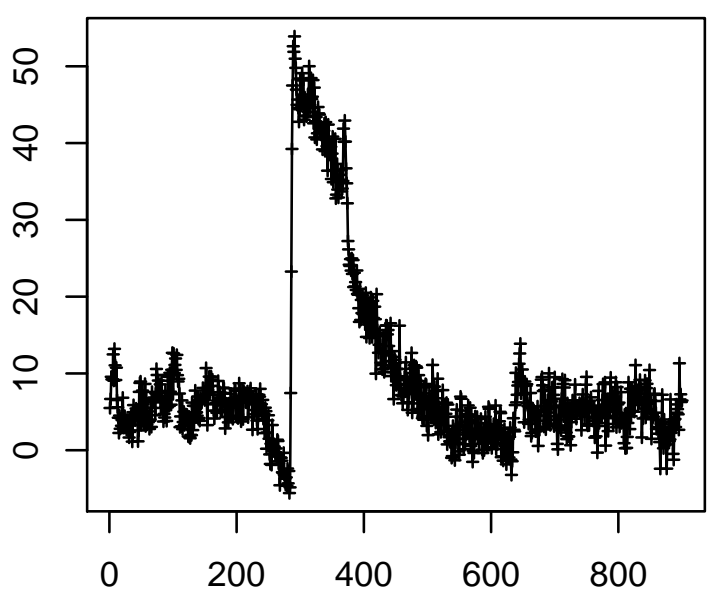

Time Point $(0.25 \mathrm{~Hz})$

Cell 1235

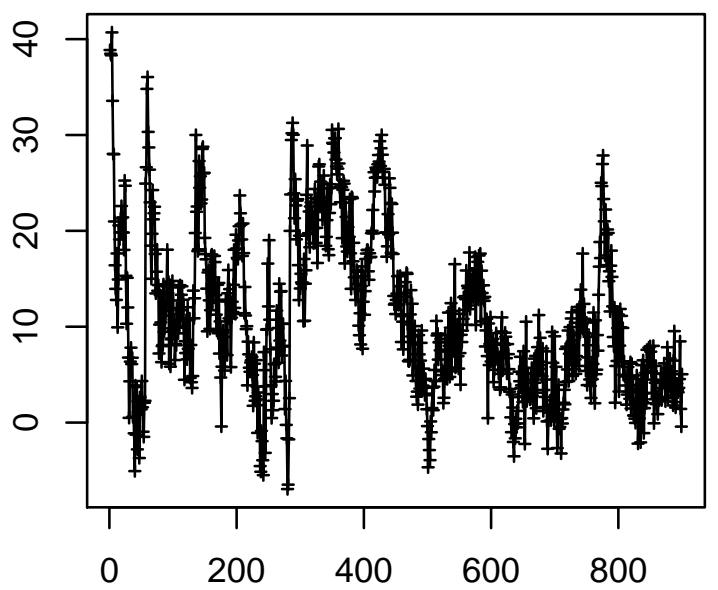

Time Point $(0.25 \mathrm{~Hz})$
Cell 1234

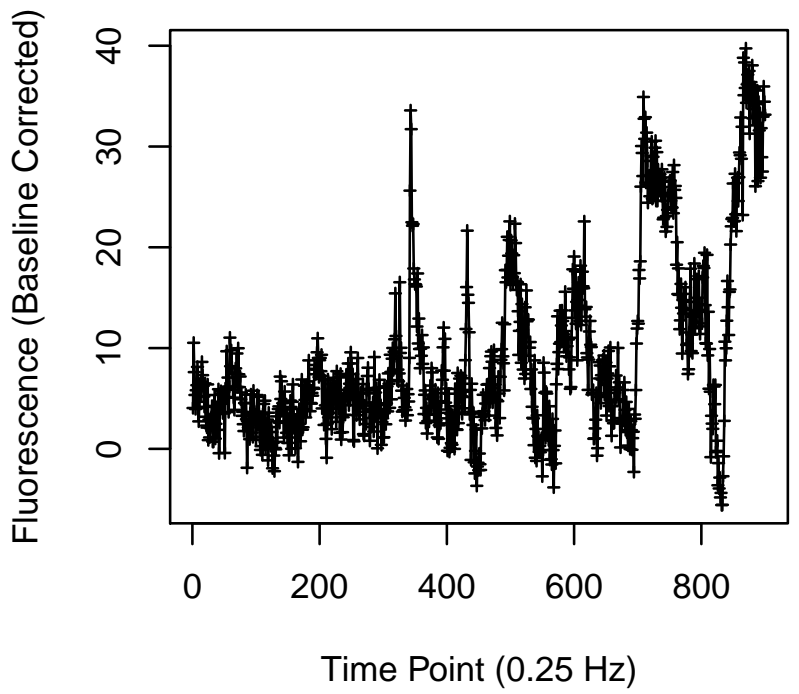

Cell 1236

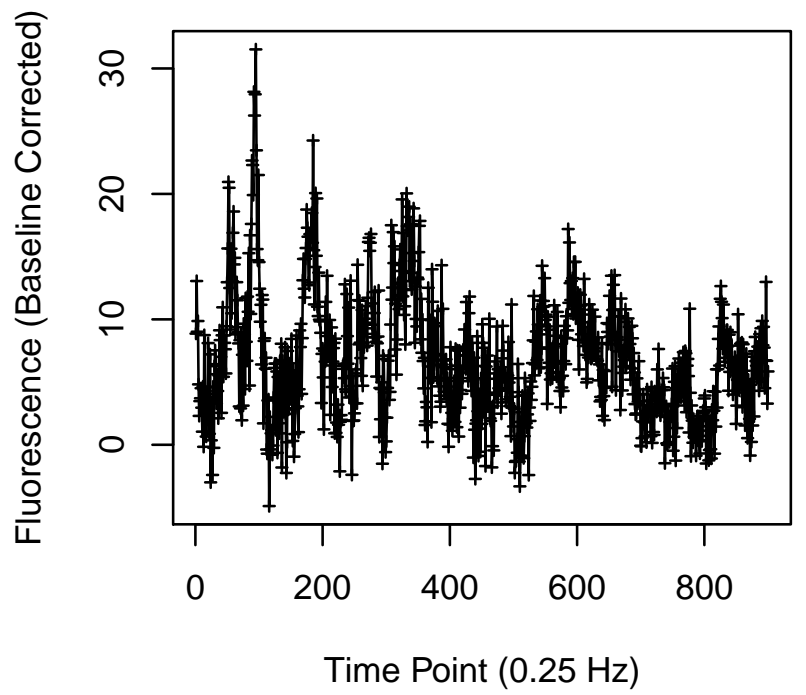


Cell 1237

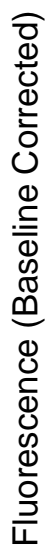

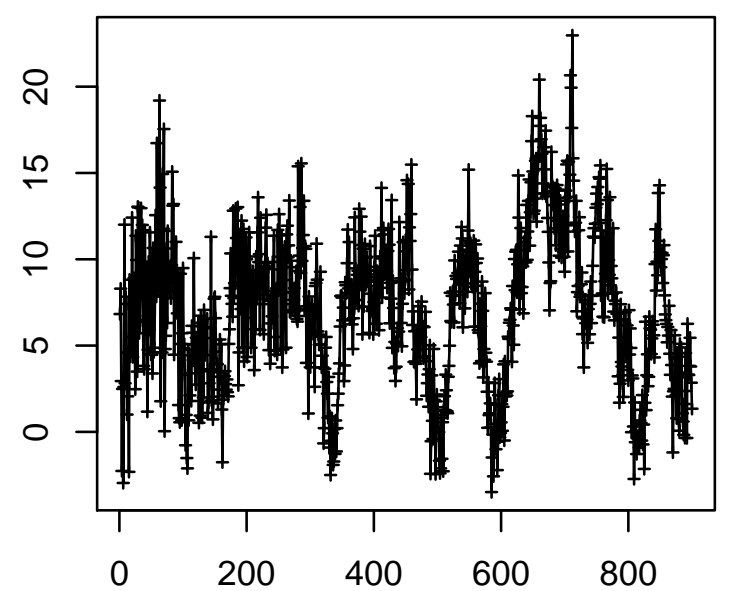

Time Point $(0.25 \mathrm{~Hz})$

Cell 1239

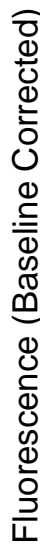

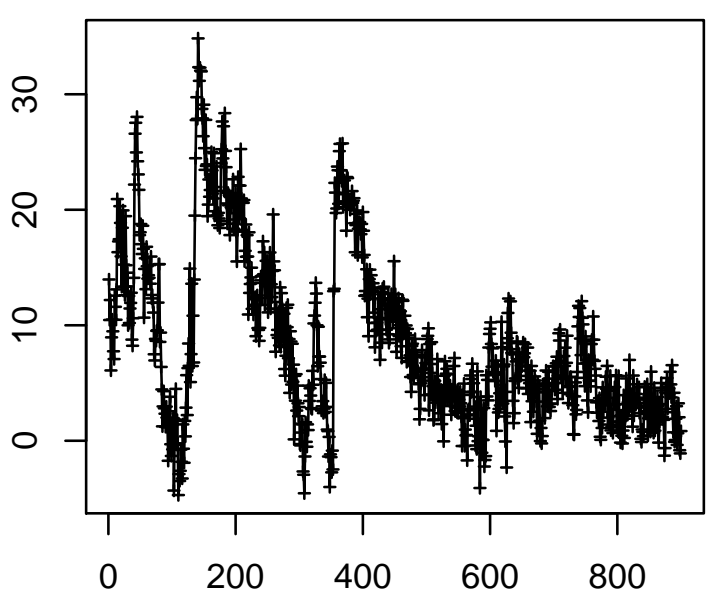

Time Point $(0.25 \mathrm{~Hz})$
Cell 1238

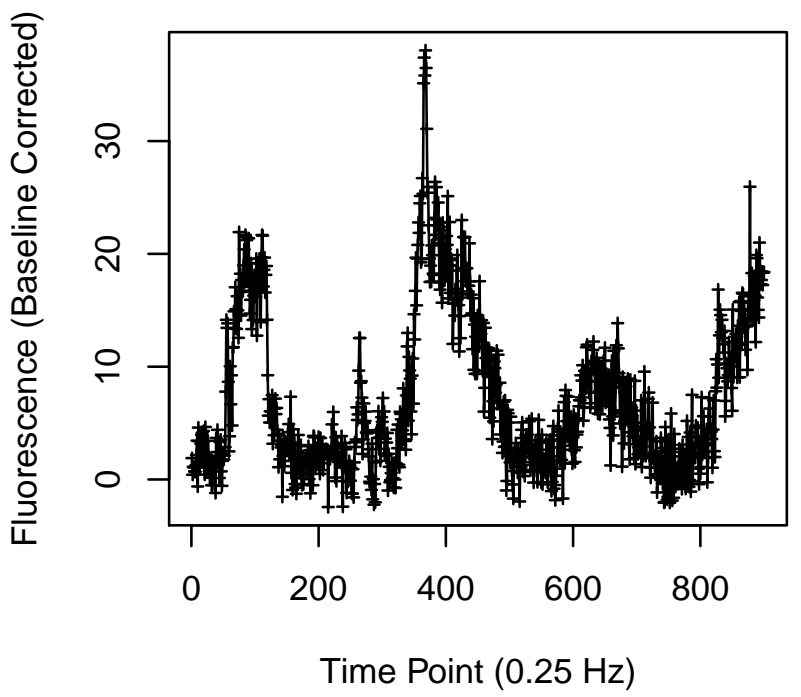

Cell 1240

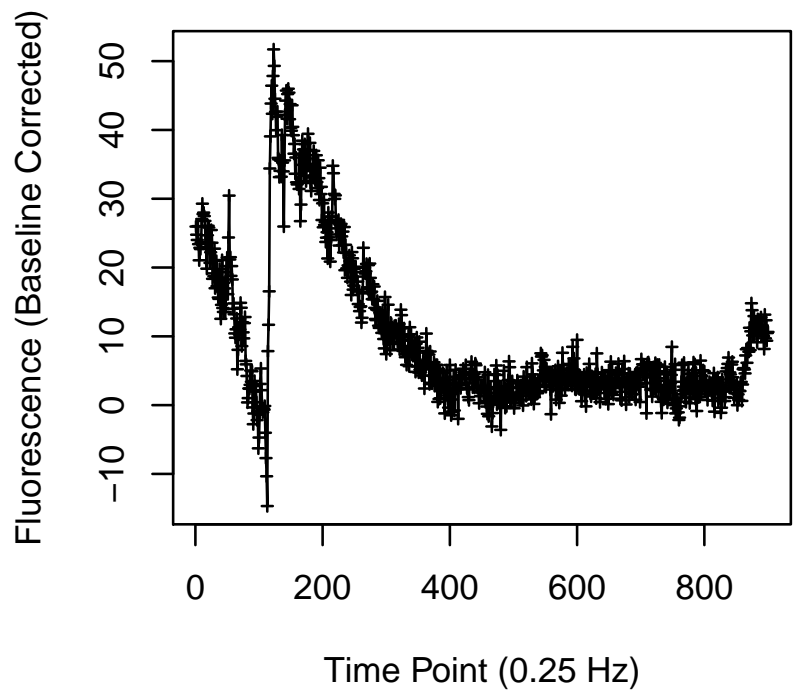


Cell 1241
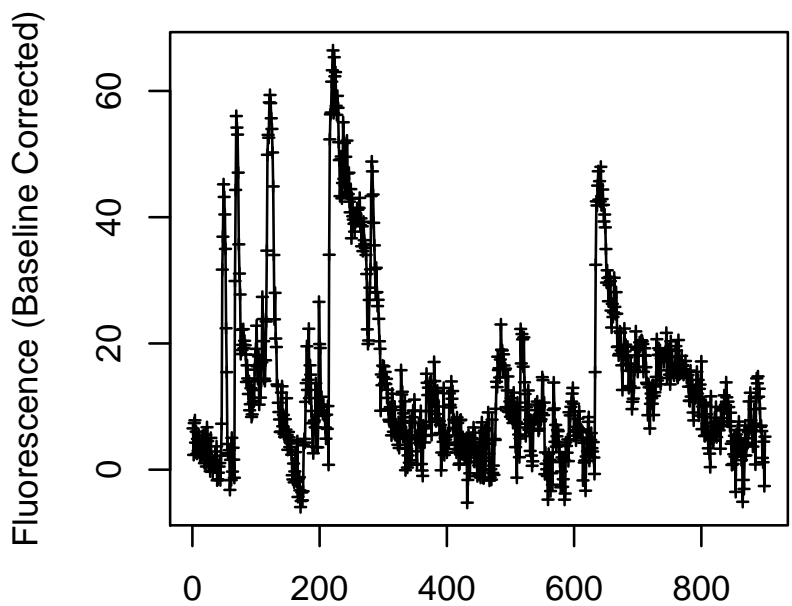

Time Point $(0.25 \mathrm{~Hz})$

Cell 1243

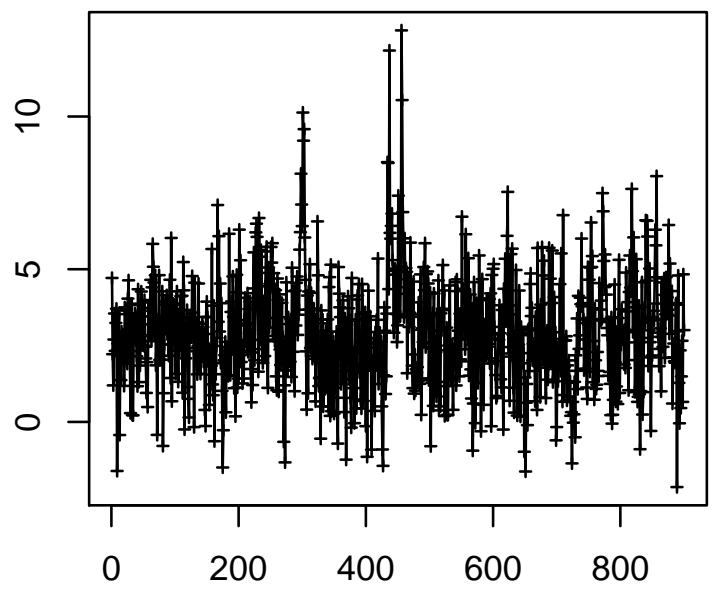

Time Point $(0.25 \mathrm{~Hz})$
Cell 1242

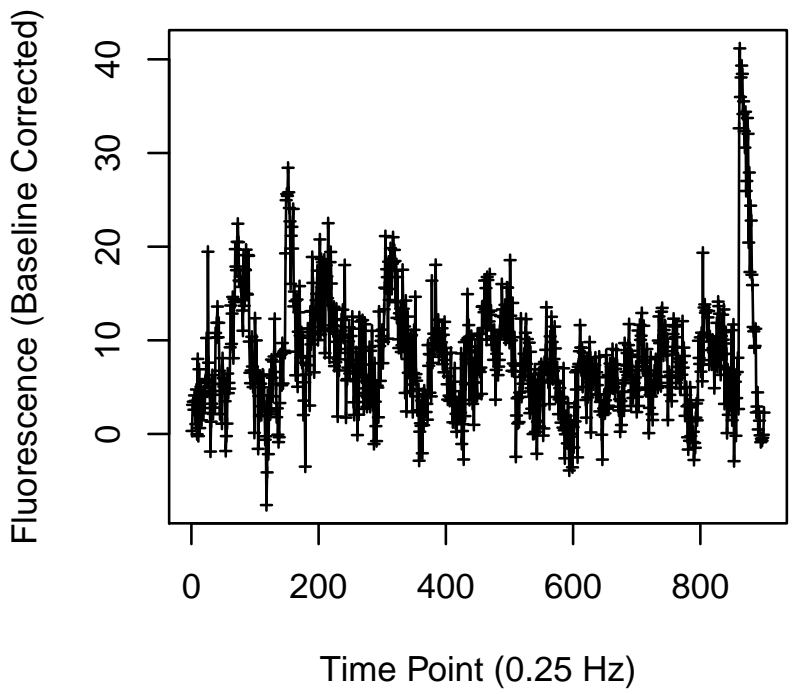

Cell 1244

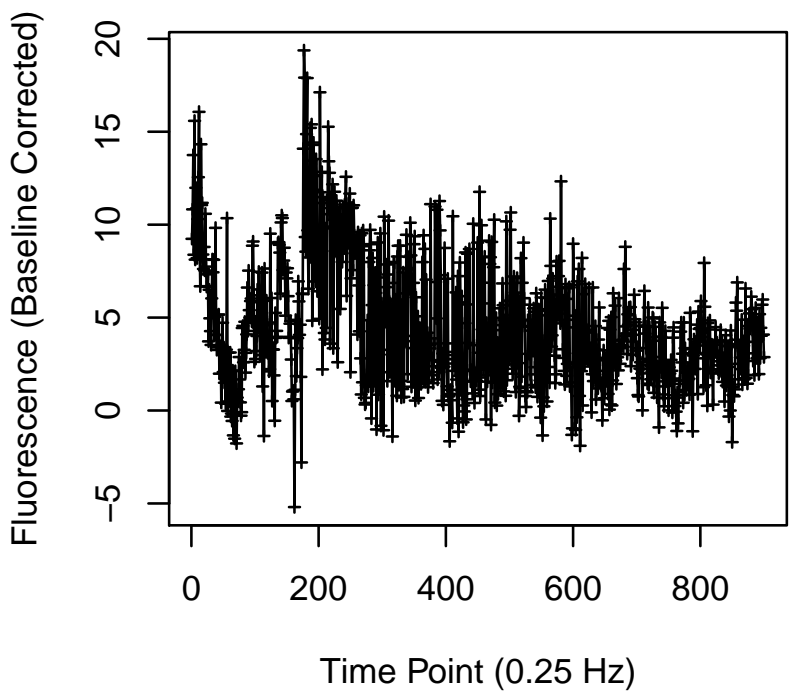


Cell 1245

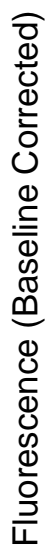

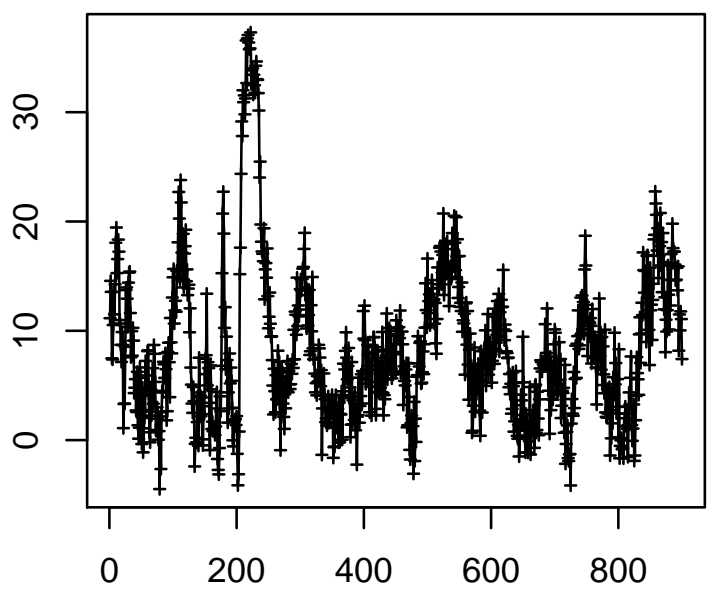

Time Point $(0.25 \mathrm{~Hz})$

Cell 1247

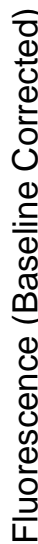

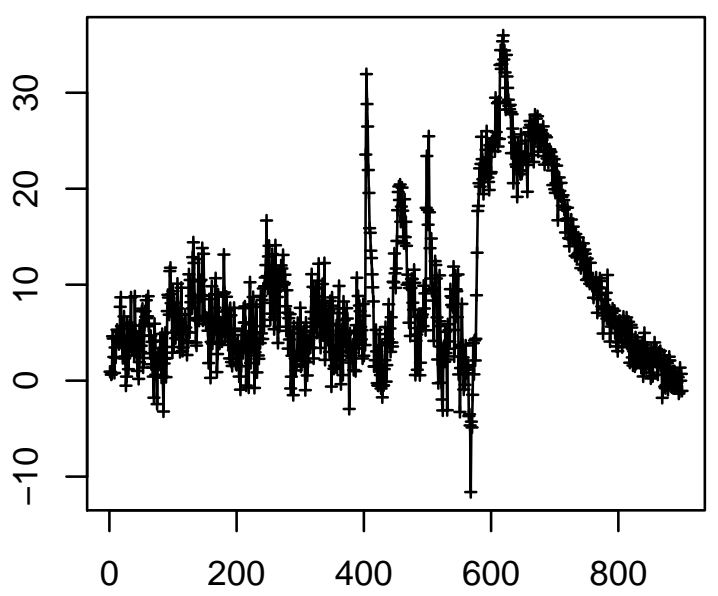

Time Point $(0.25 \mathrm{~Hz})$
Cell 1246

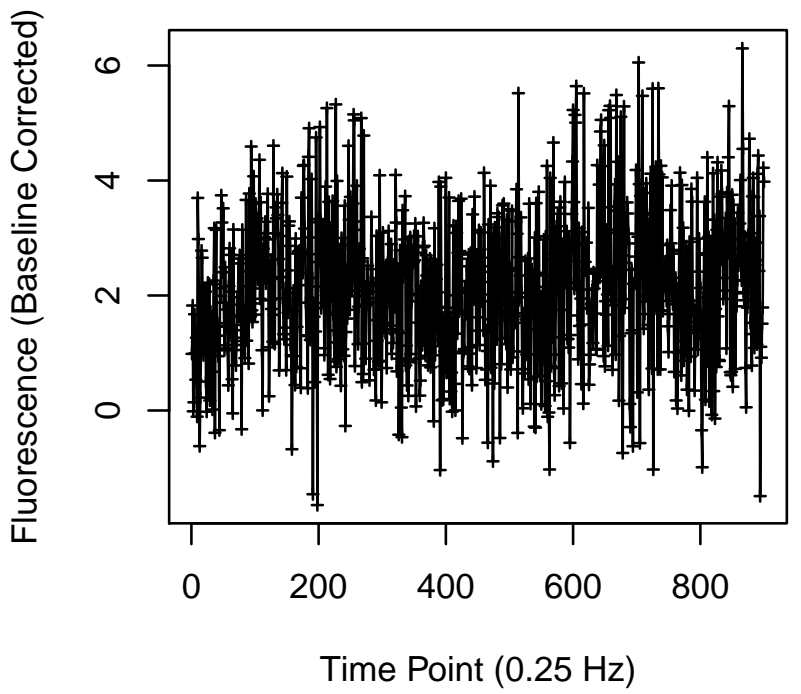

Cell 1248

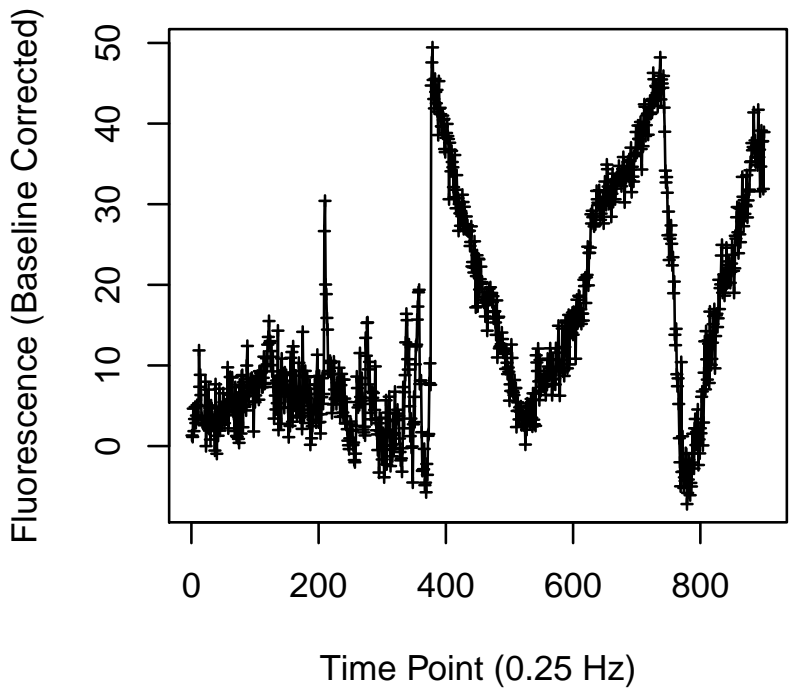


Cell 1249

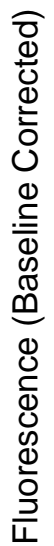

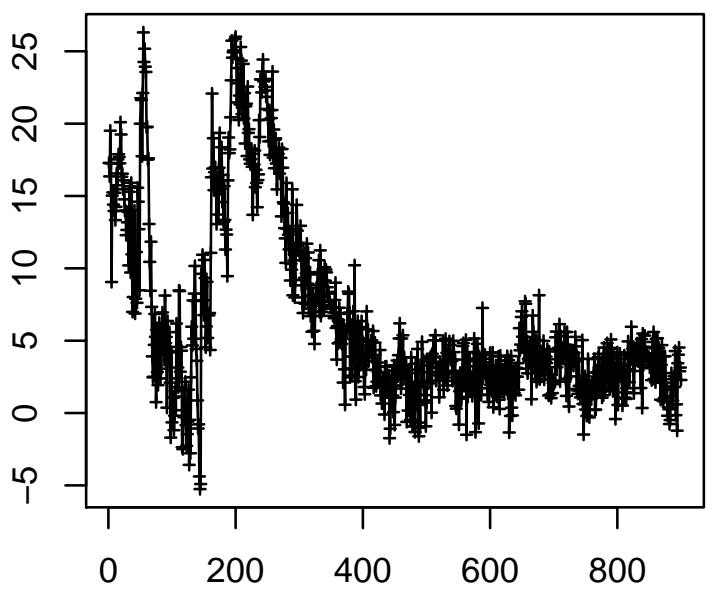

Time Point $(0.25 \mathrm{~Hz})$

Cell 1251

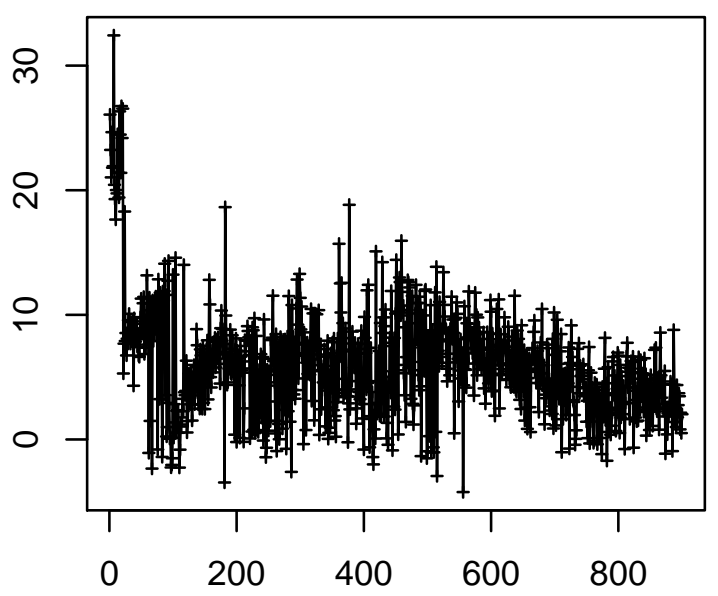

Time Point $(0.25 \mathrm{~Hz})$
Cell 1250

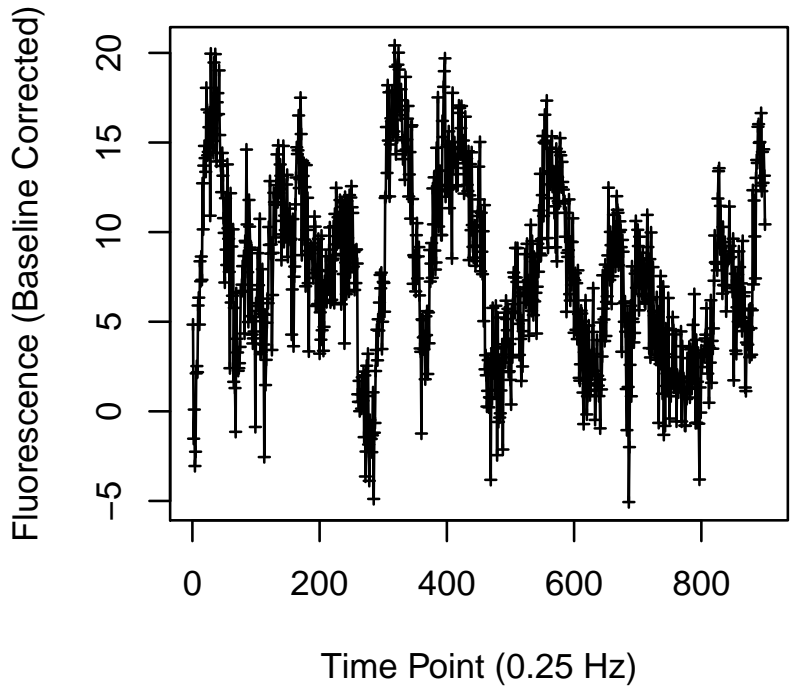

Cell 1252

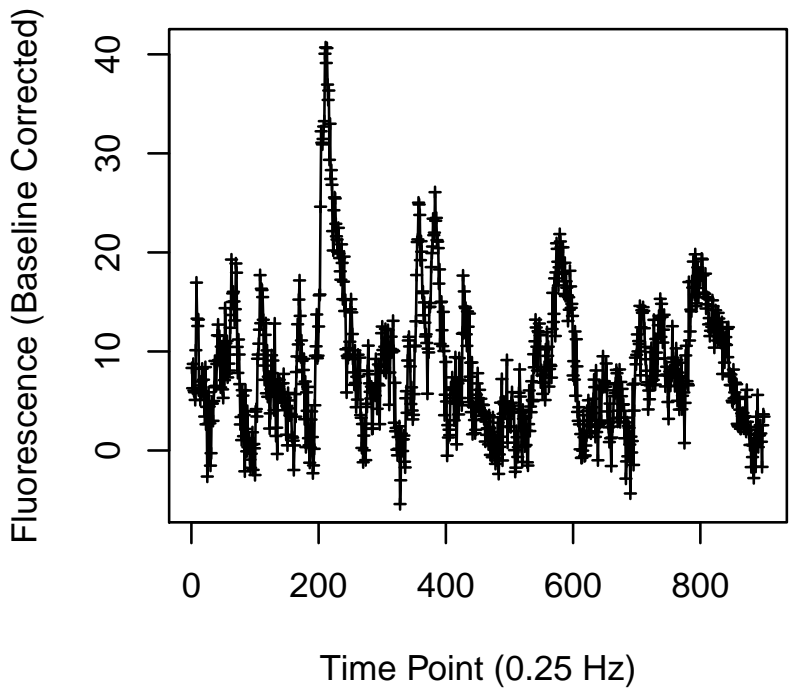


Cell 1257

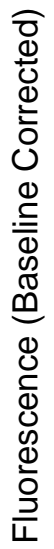

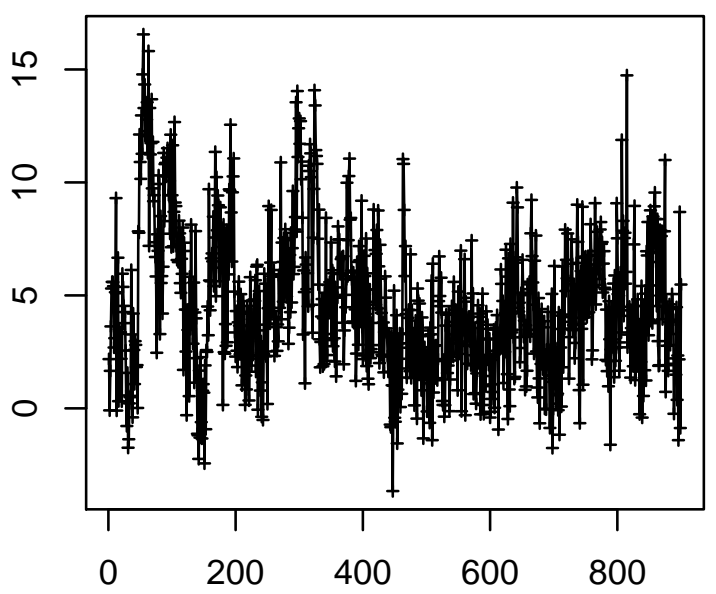

Time Point $(0.25 \mathrm{~Hz})$

Cell 1259

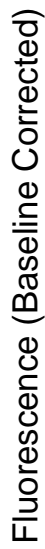

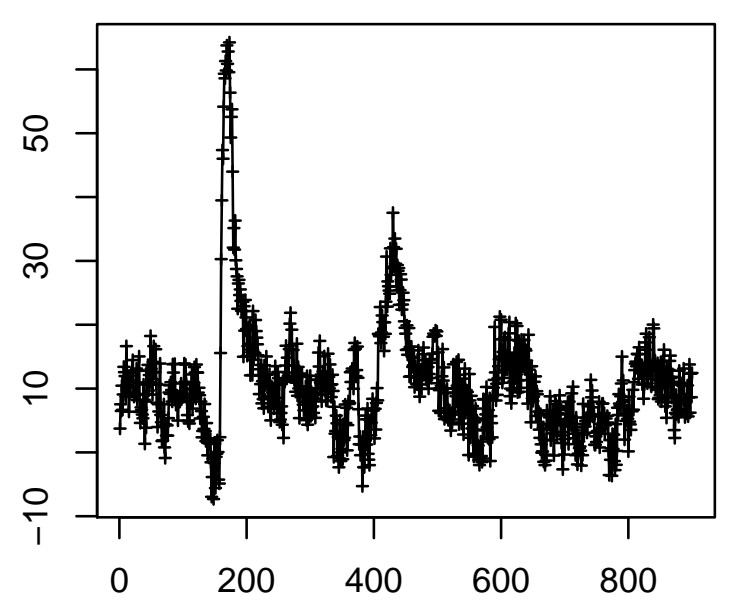

Time Point $(0.25 \mathrm{~Hz})$
Cell 1258

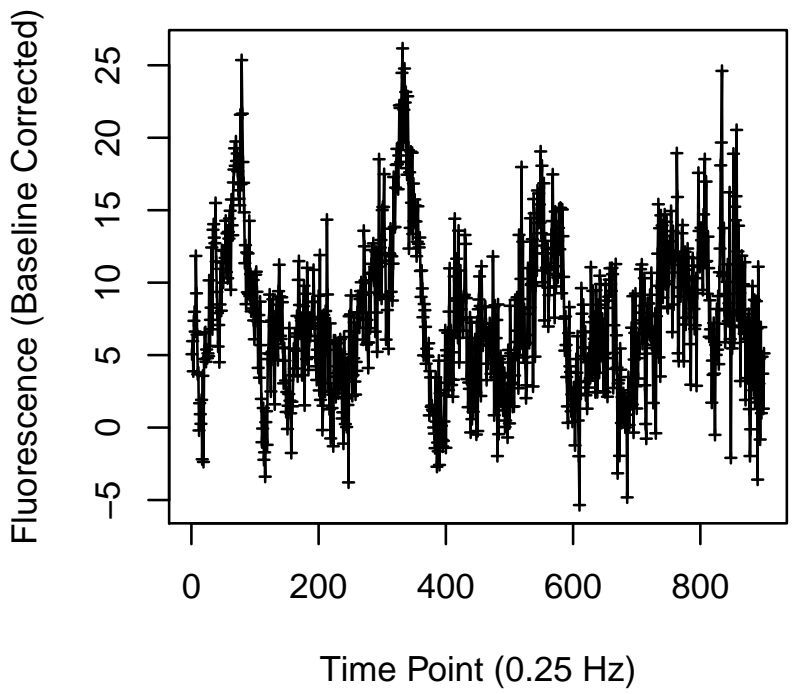

Cell 1260

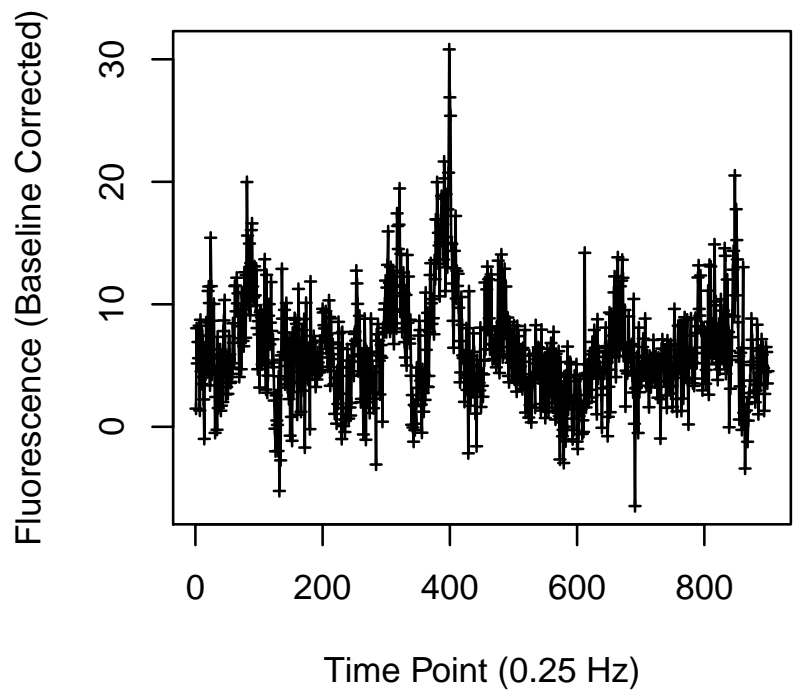


Cell 1261

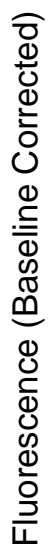

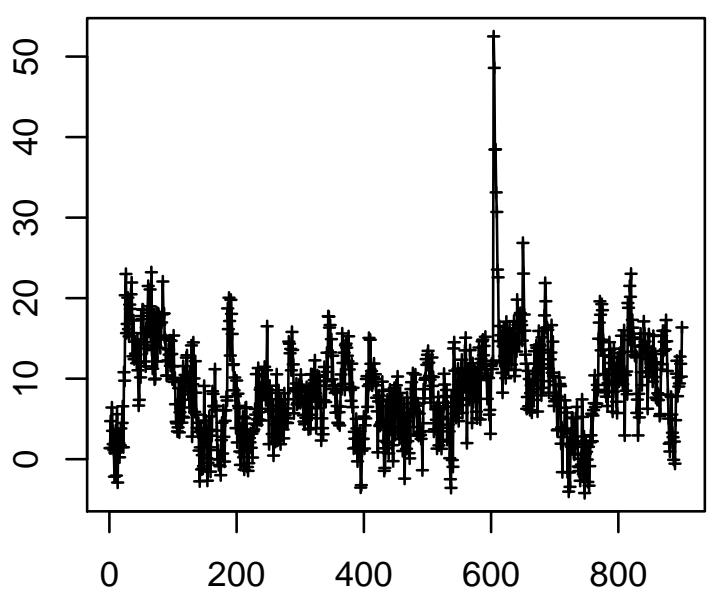

Time Point $(0.25 \mathrm{~Hz})$

Cell 1263

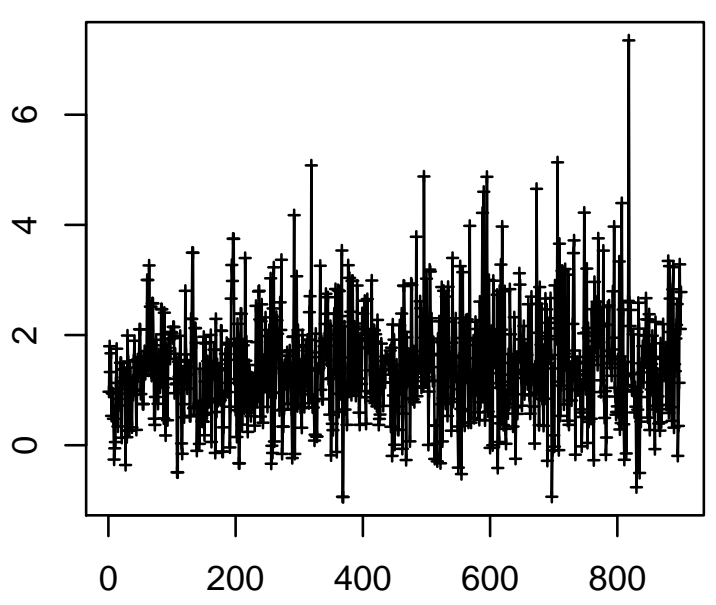

Time Point $(0.25 \mathrm{~Hz})$
Cell 1262

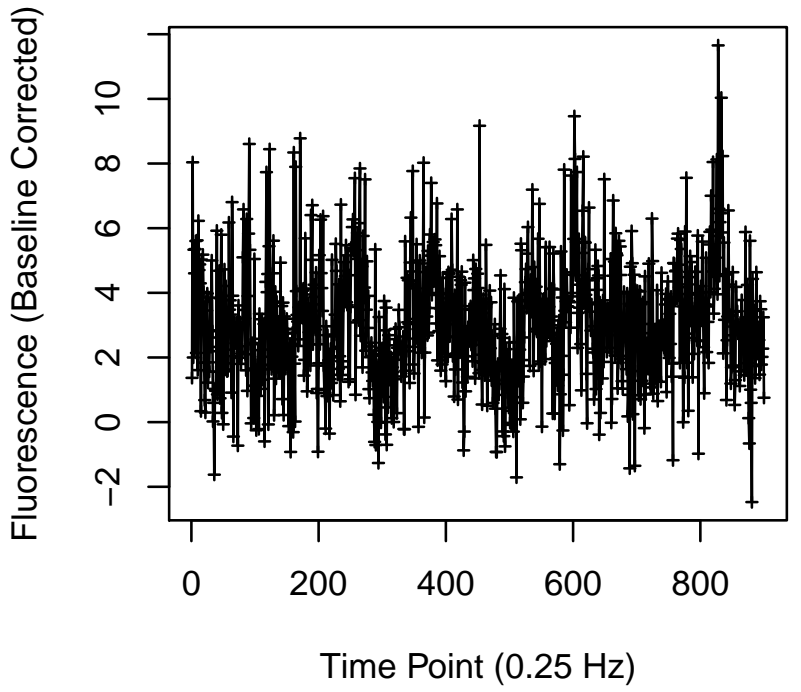

Cell 1264

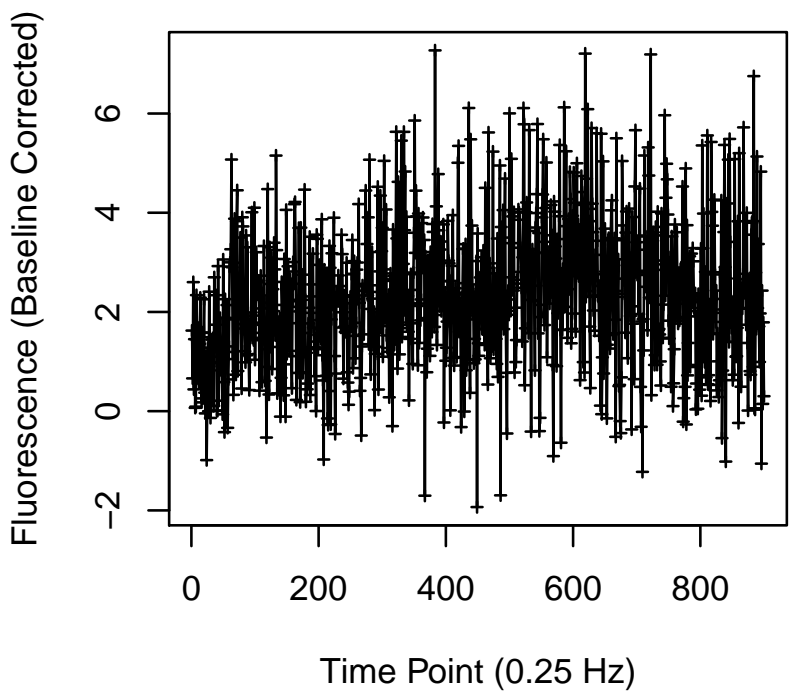


Cell 1265

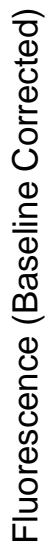

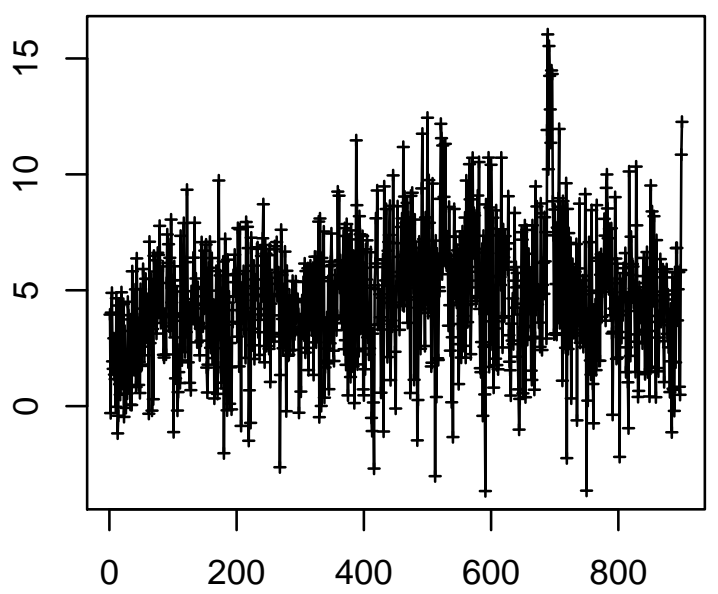

Time Point $(0.25 \mathrm{~Hz})$

Cell 1267

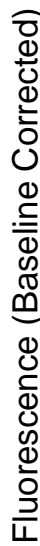

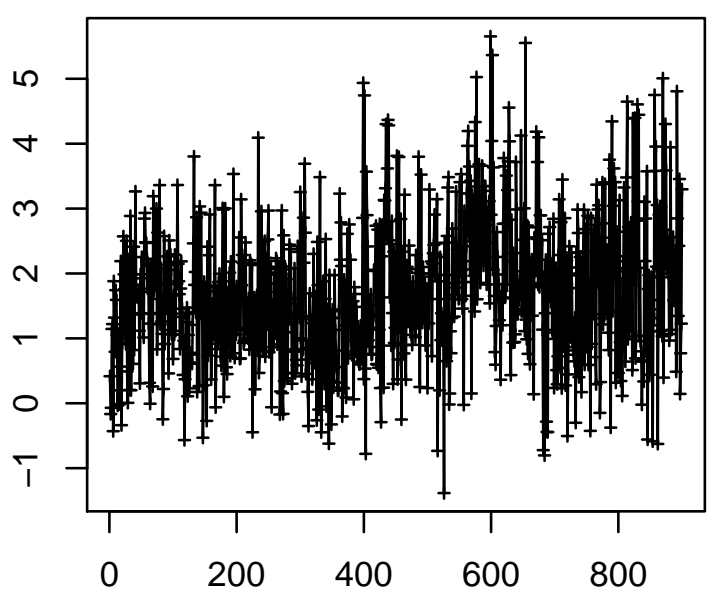

Time Point $(0.25 \mathrm{~Hz})$
Cell 1266

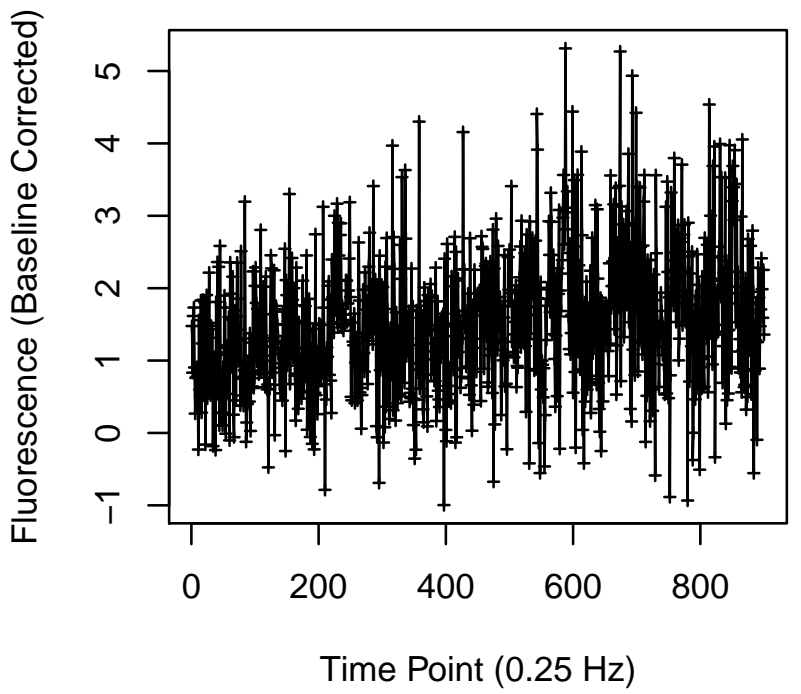

Cell 1268

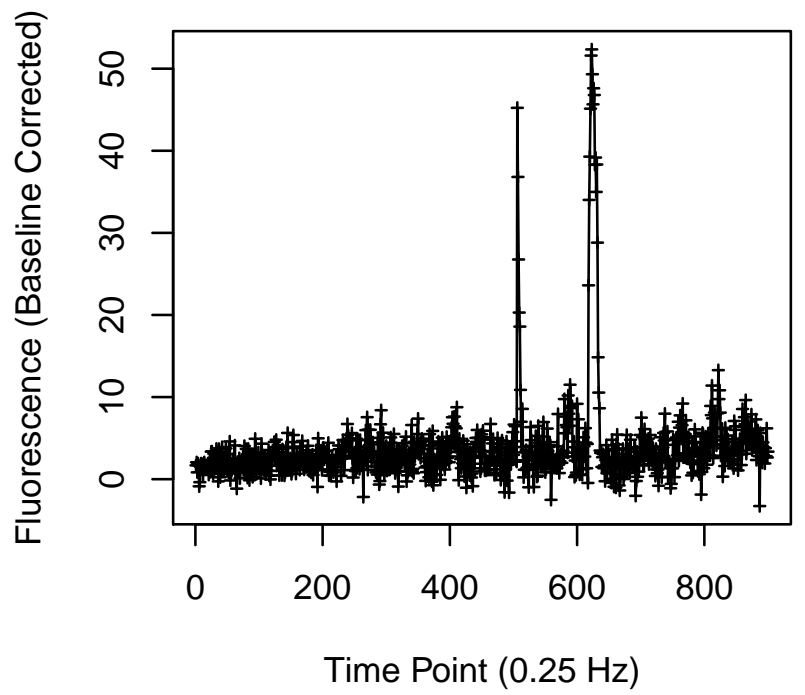


Cell 1269

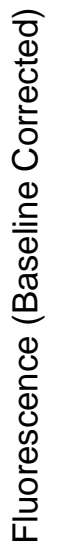

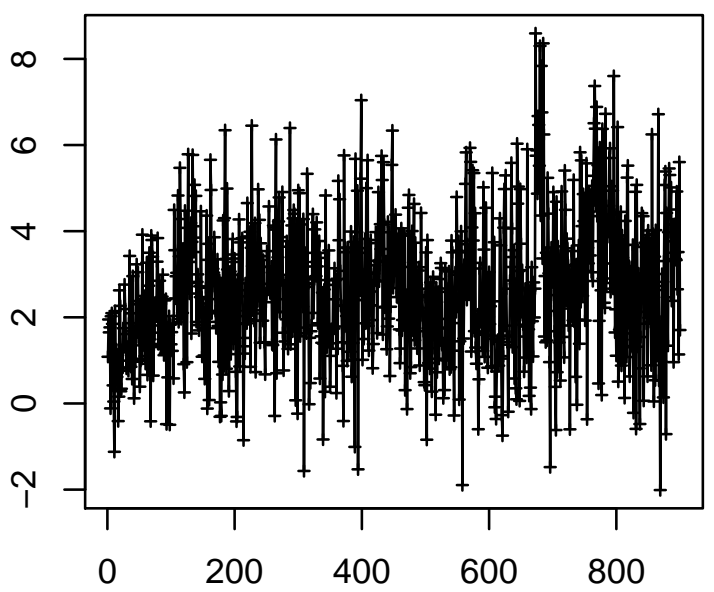

Time Point $(0.25 \mathrm{~Hz})$

Cell 1271

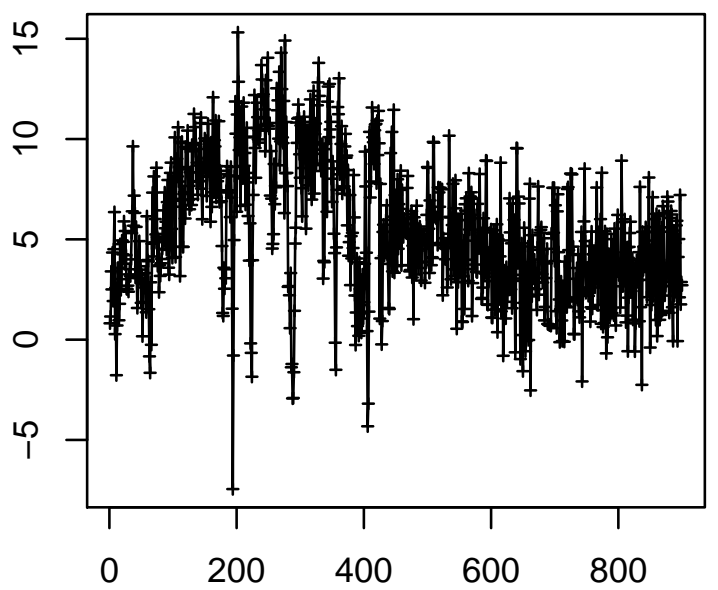

Time Point $(0.25 \mathrm{~Hz})$
Cell 1270

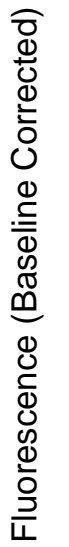

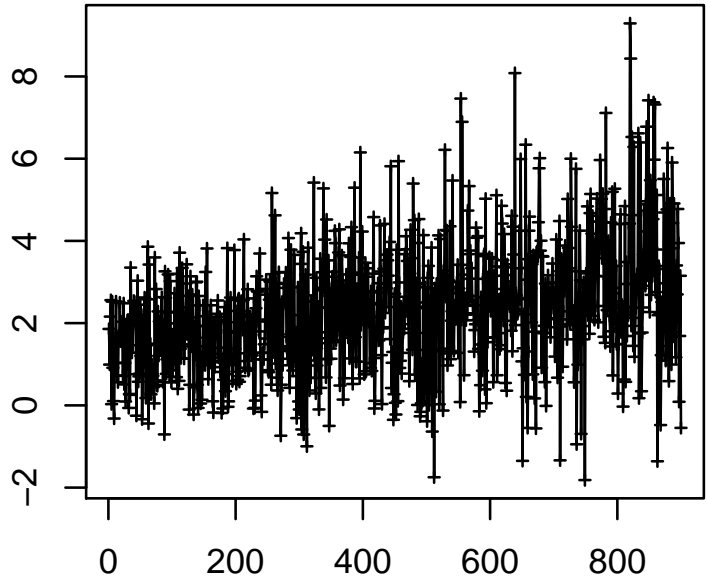

Time Point $(0.25 \mathrm{~Hz})$

Cell 1272

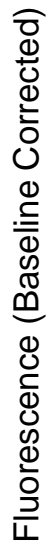

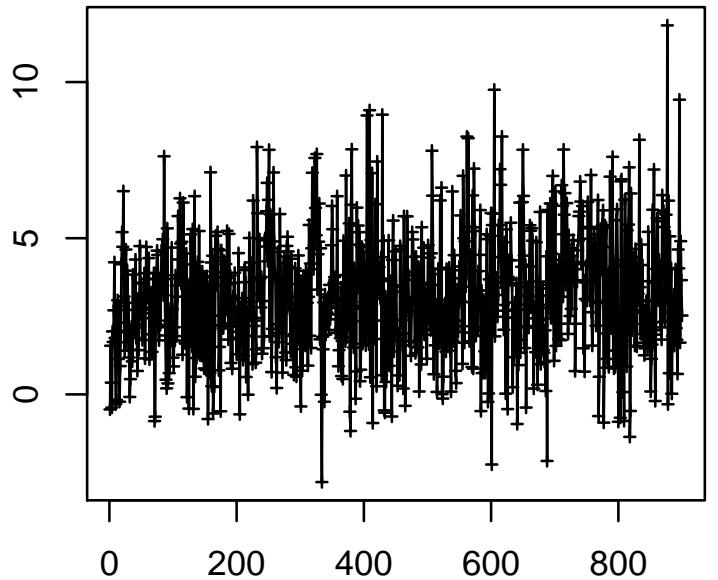

Time Point $(0.25 \mathrm{~Hz})$ 
Cell 1273

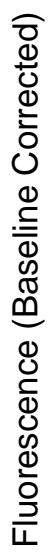

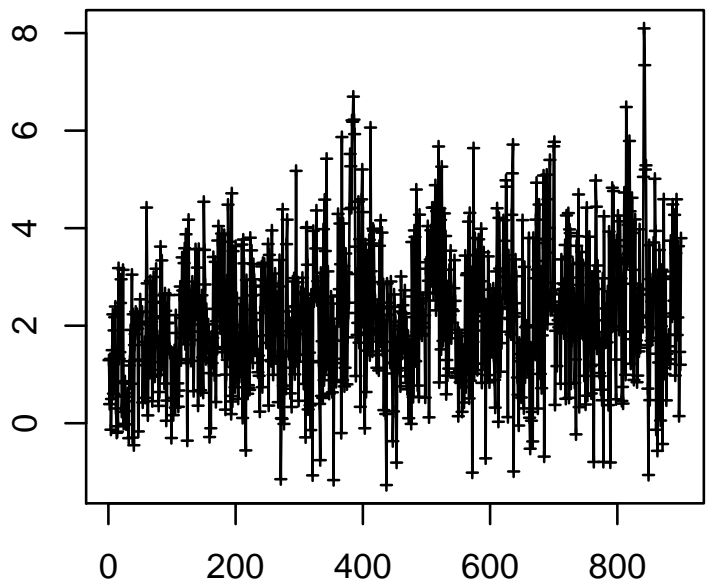

Time Point $(0.25 \mathrm{~Hz})$

Cell 1275

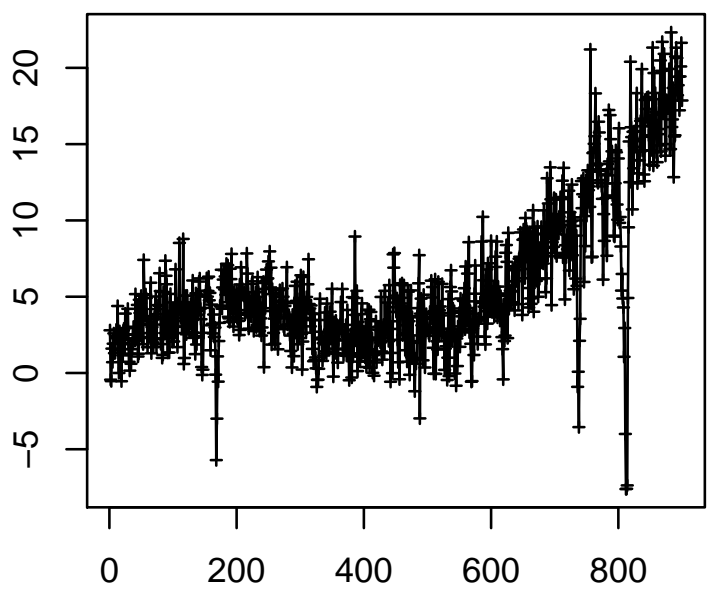

Time Point $(0.25 \mathrm{~Hz})$
Cell 1274

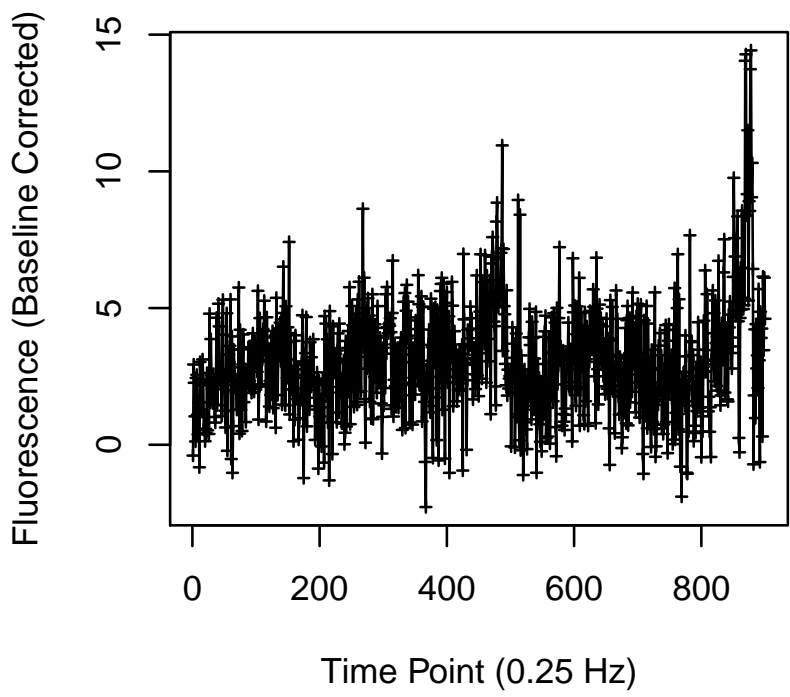

Cell 1276

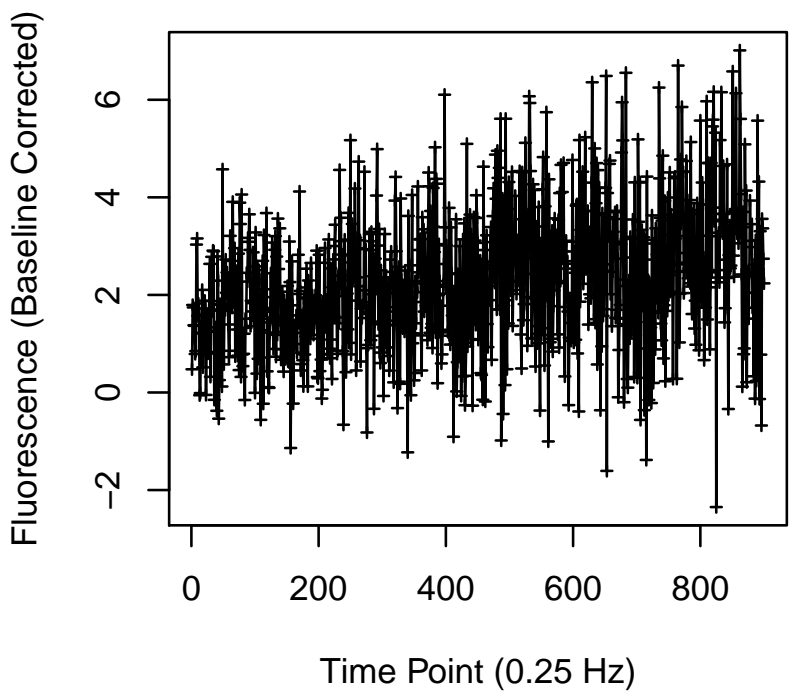


Cell 1281

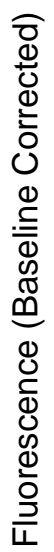

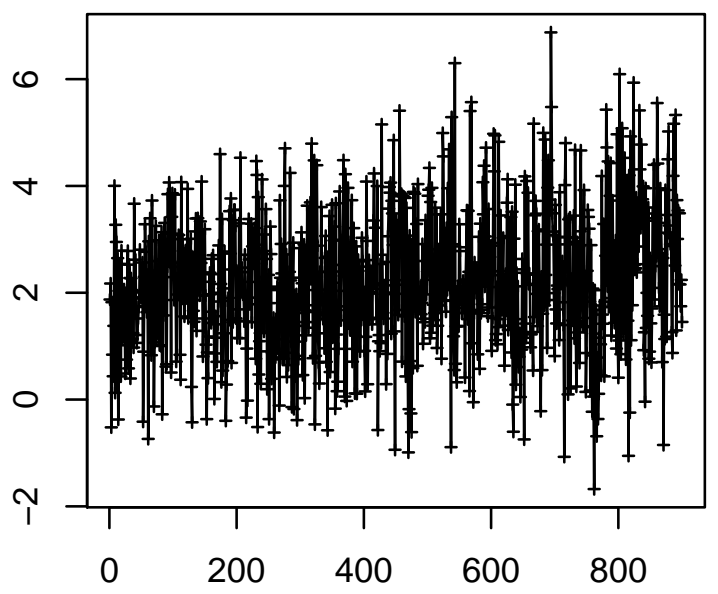

Time Point $(0.25 \mathrm{~Hz})$

Cell 1283

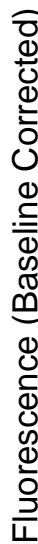

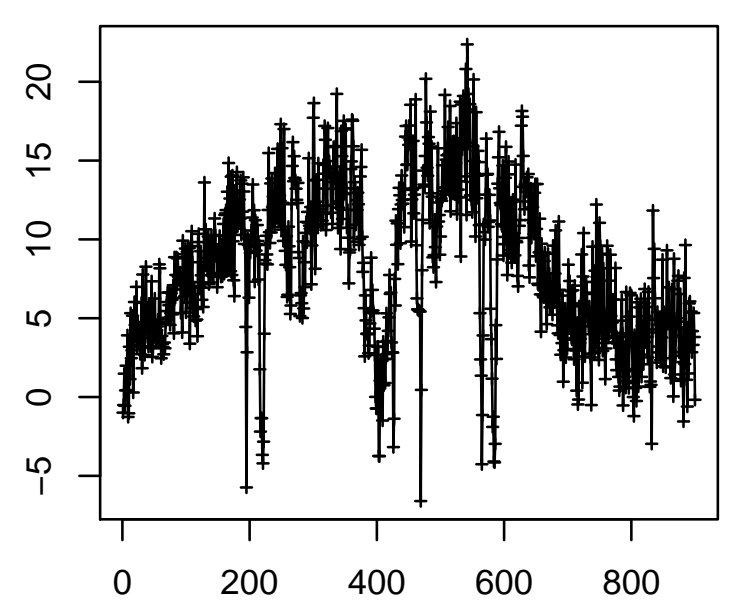

Time Point $(0.25 \mathrm{~Hz})$
Cell 1282

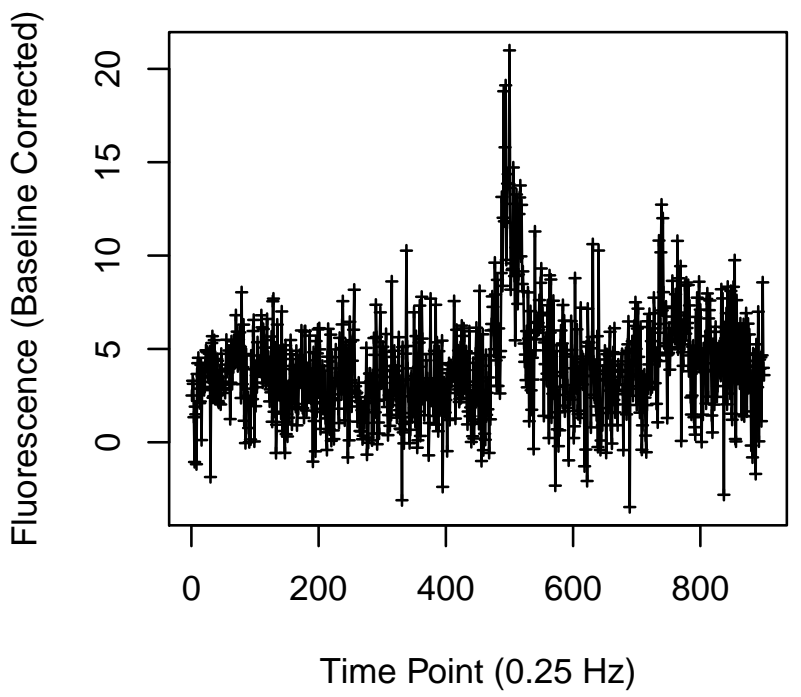

Cell 1284

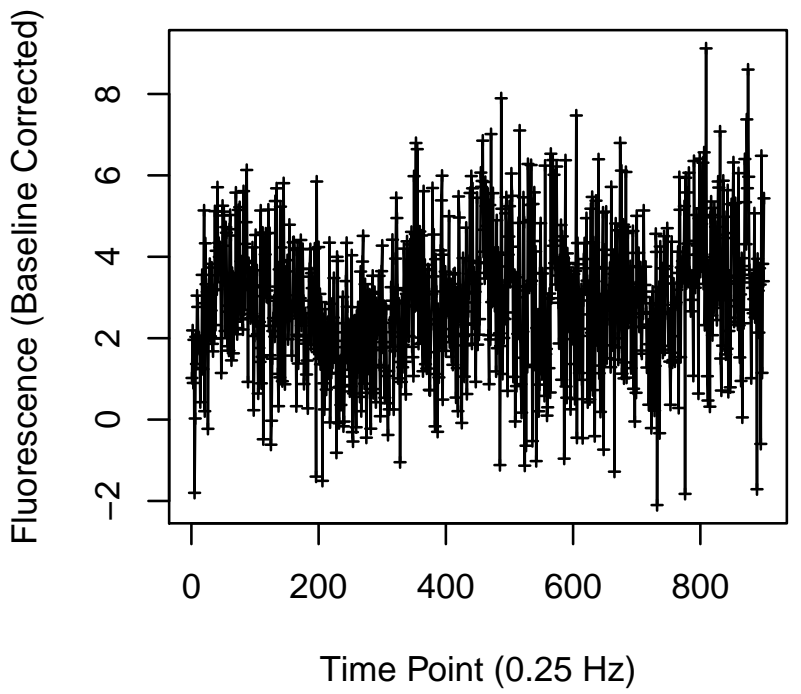


Cell 1289

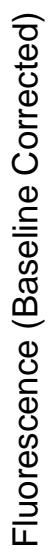

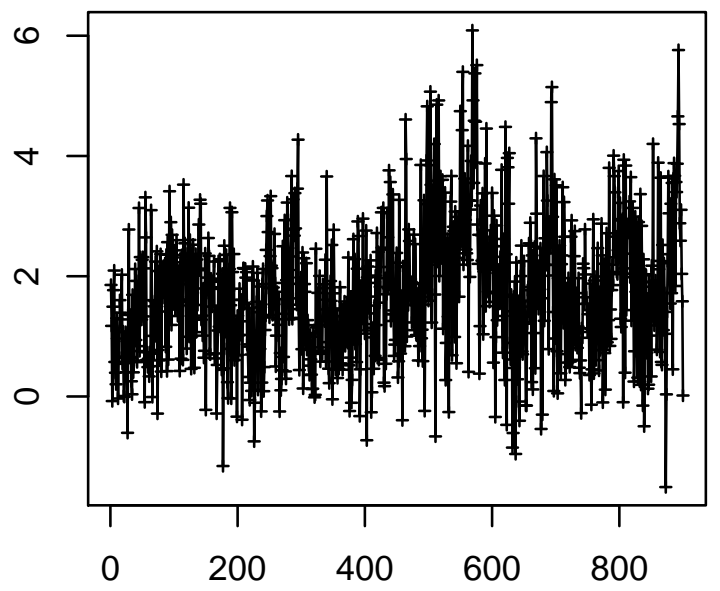

Time Point $(0.25 \mathrm{~Hz})$

Cell 1291

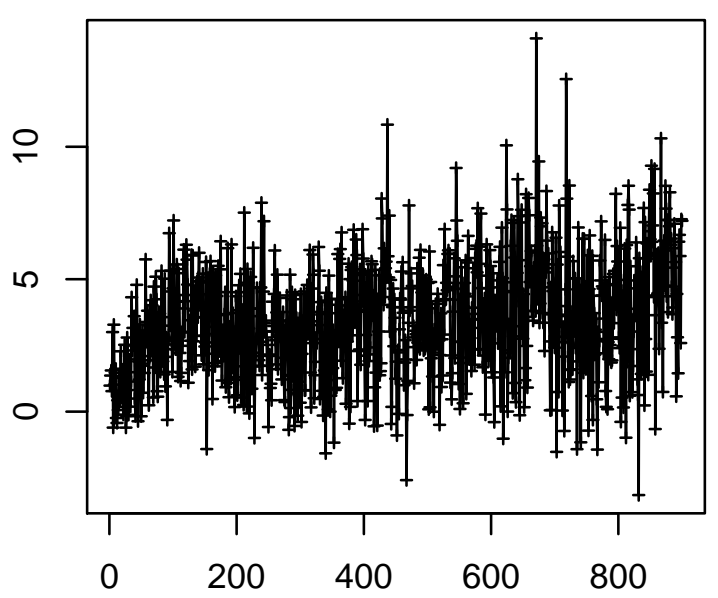

Time Point $(0.25 \mathrm{~Hz})$
Cell 1290

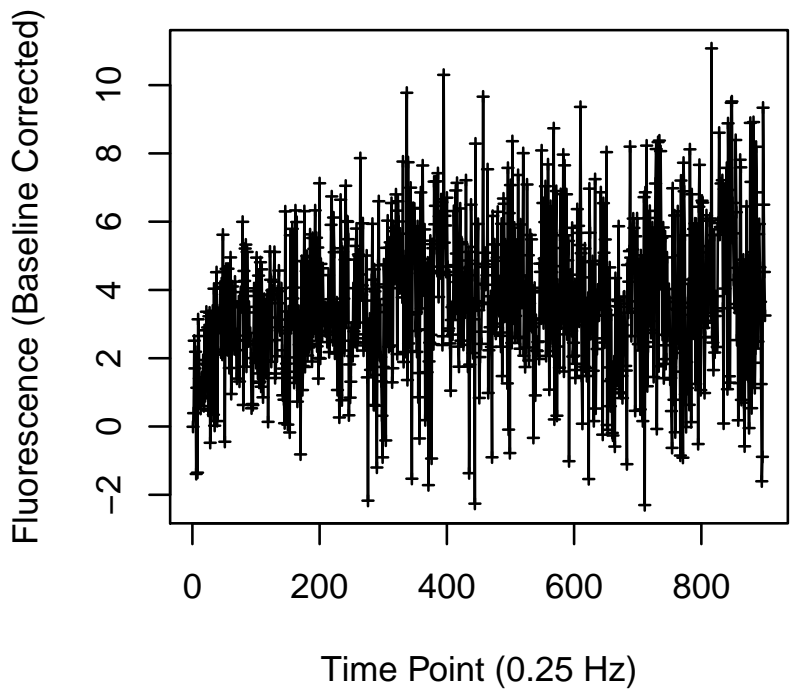

Cell 1292

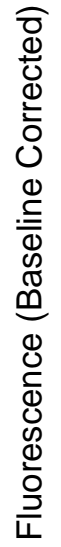

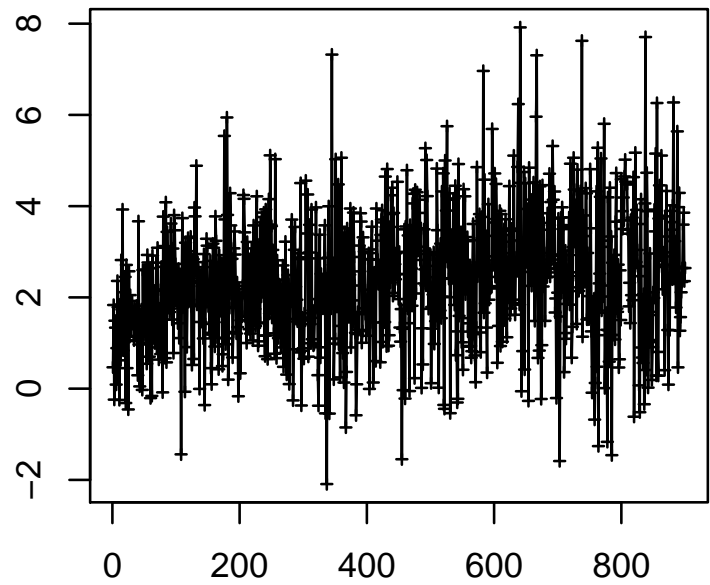

Time Point $(0.25 \mathrm{~Hz})$ 
Cell 1297

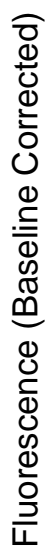

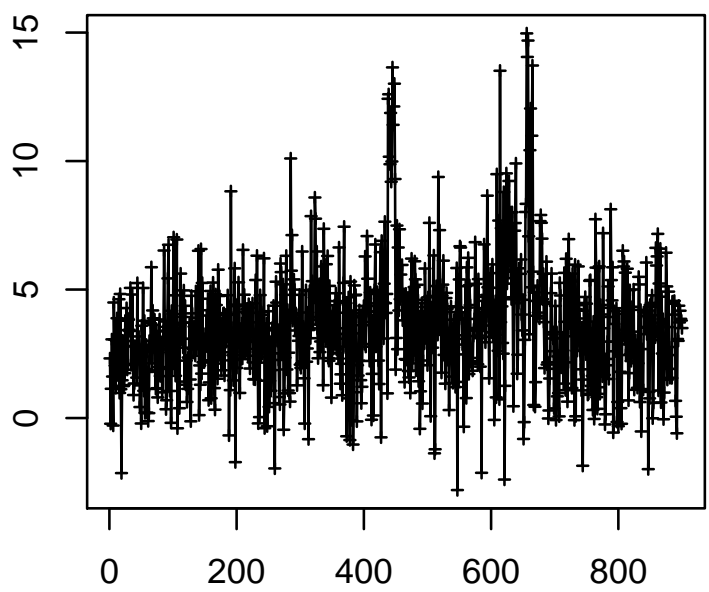

Time Point $(0.25 \mathrm{~Hz})$

Cell 1299

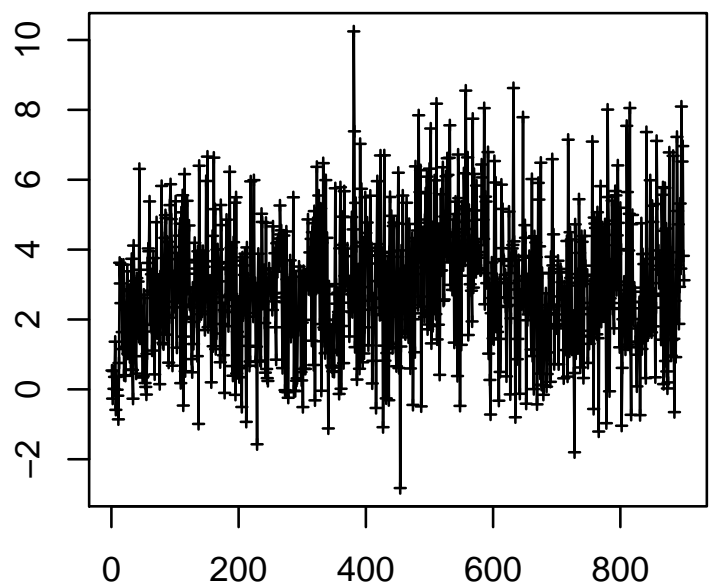

Time Point $(0.25 \mathrm{~Hz})$
Cell 1298

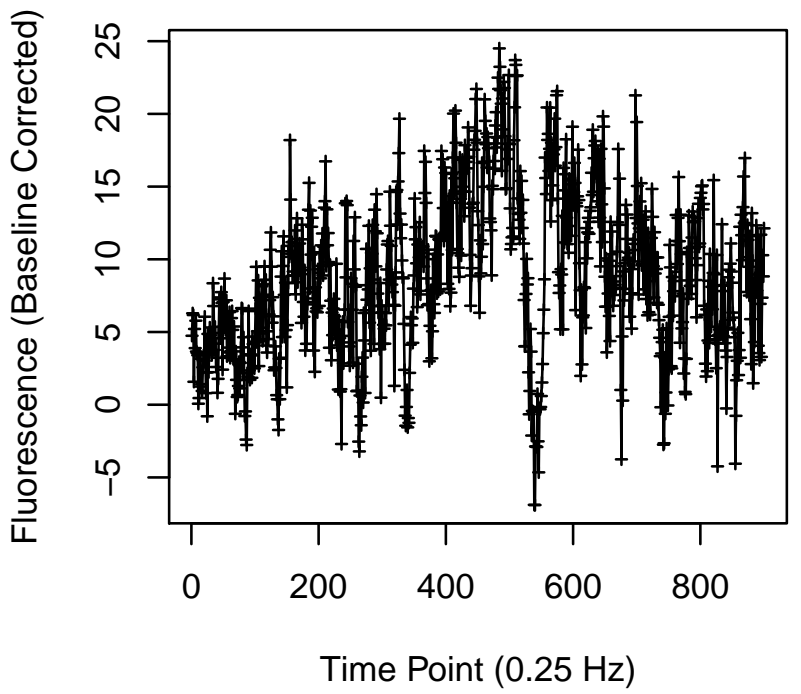

Cell 1300

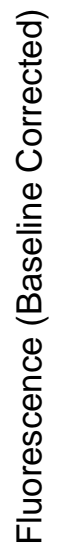

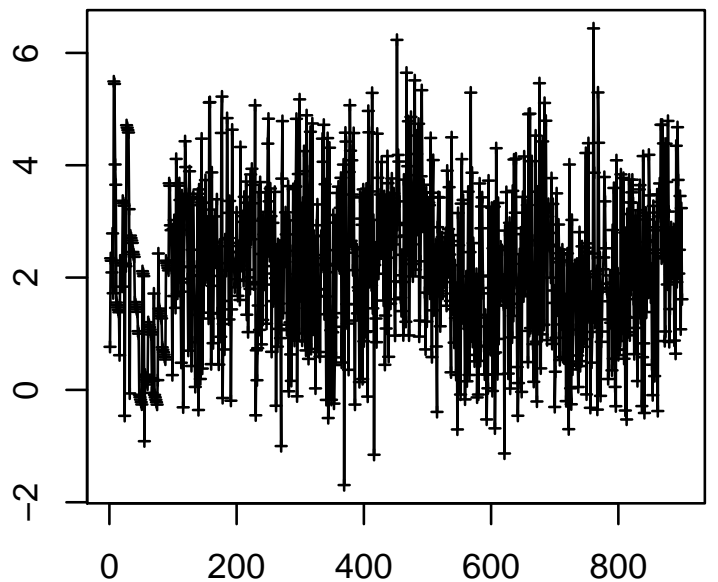

Time Point $(0.25 \mathrm{~Hz})$ 
Cell 1301

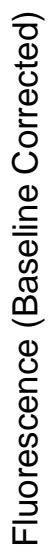

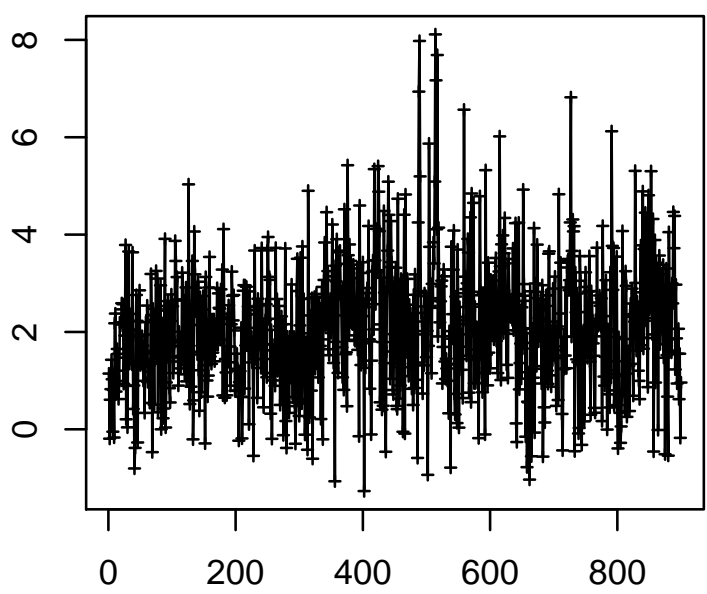

Time Point $(0.25 \mathrm{~Hz})$

Cell 1303

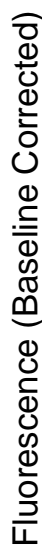

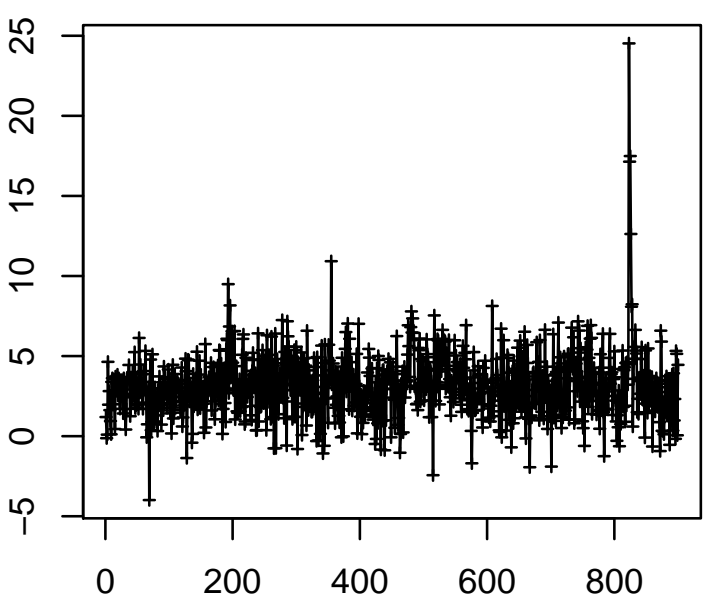

Time Point $(0.25 \mathrm{~Hz})$
Cell 1302

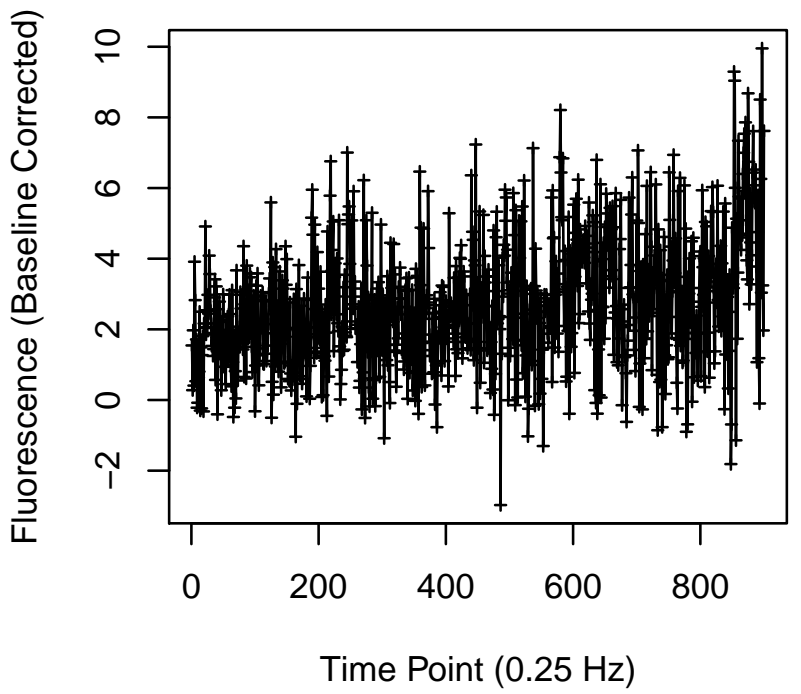

Cell 1304

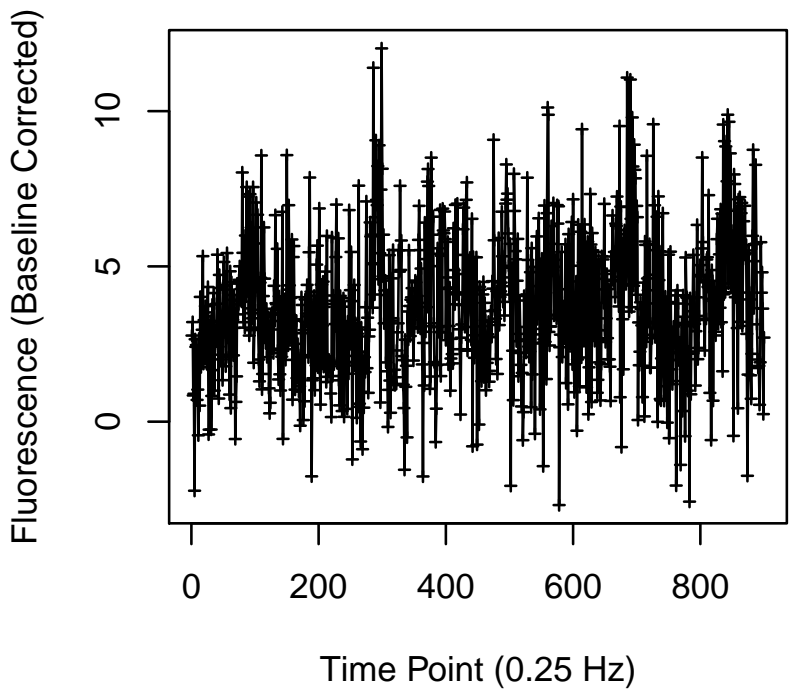


Cell 1305

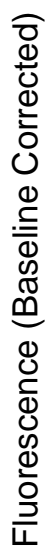

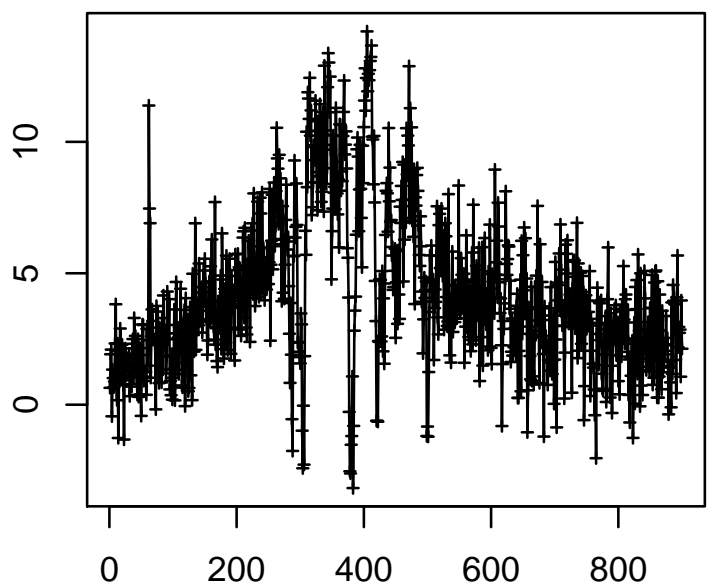

Time Point $(0.25 \mathrm{~Hz})$

Cell 1307

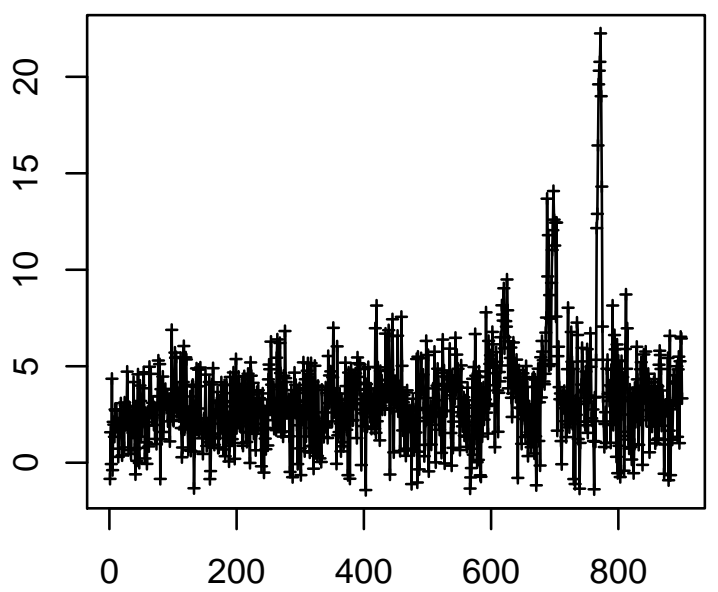

Time Point $(0.25 \mathrm{~Hz})$
Cell 1306

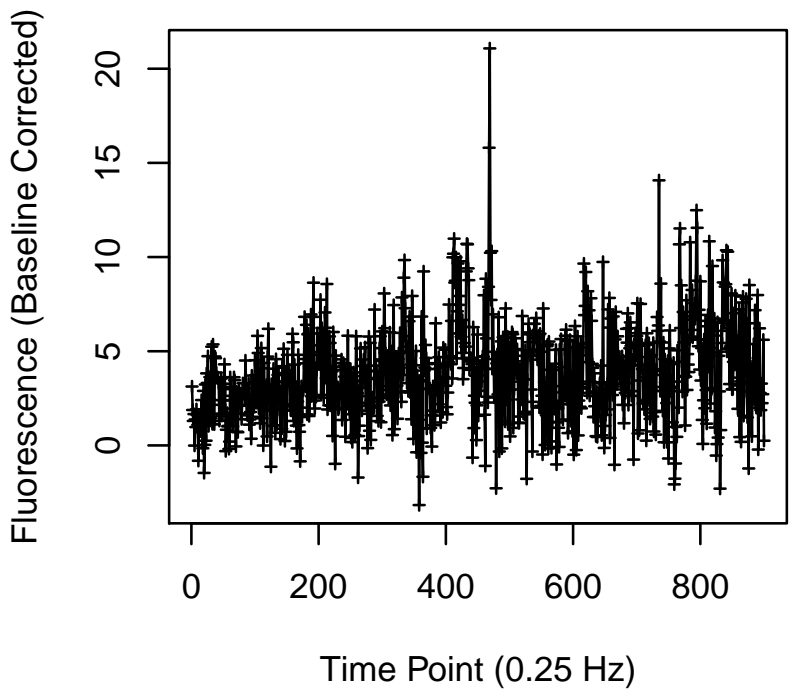

Cell 1308

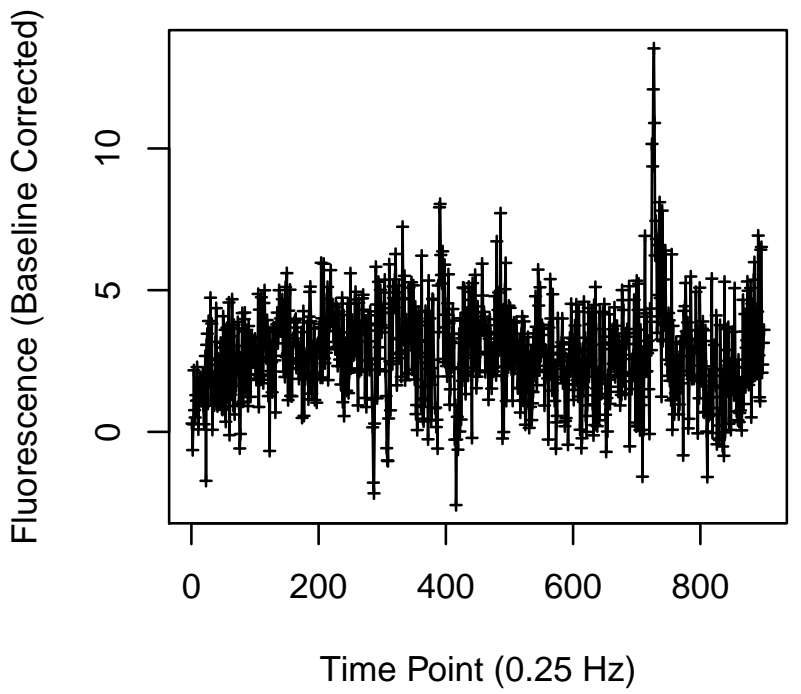


Cell 1309

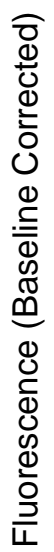

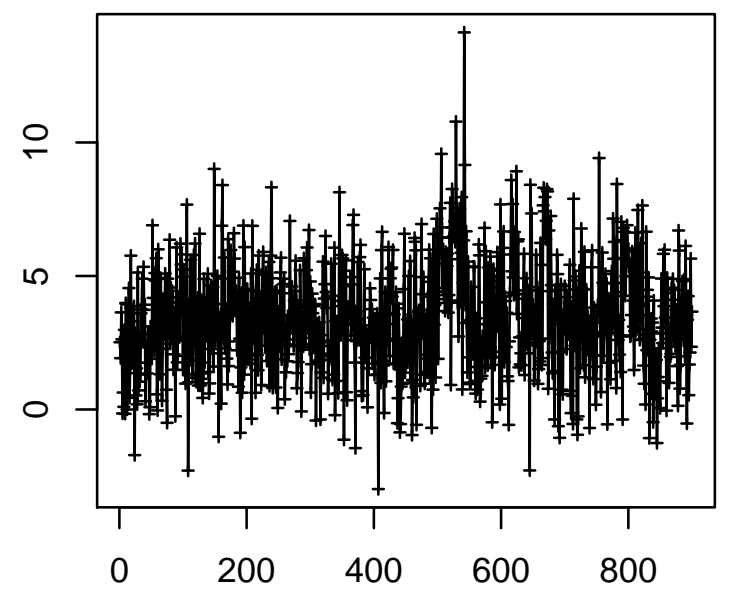

Time Point $(0.25 \mathrm{~Hz})$

Cell 1311

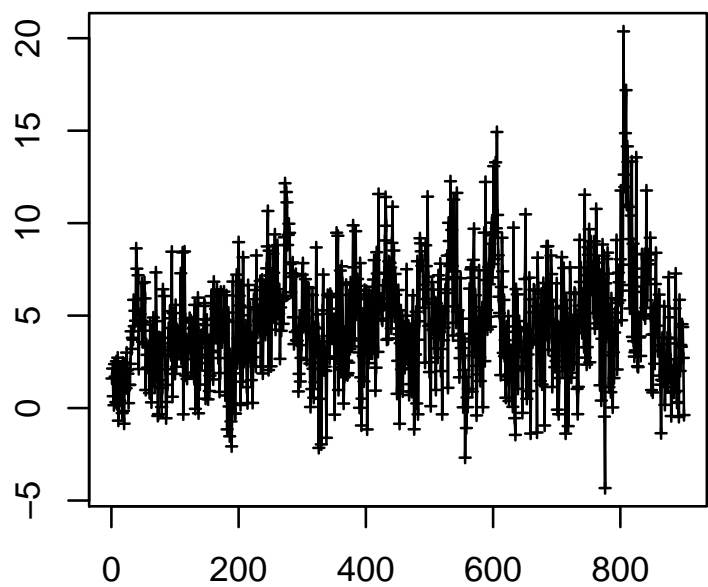

Time Point $(0.25 \mathrm{~Hz})$
Cell 1310

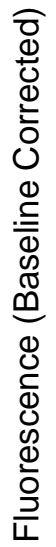

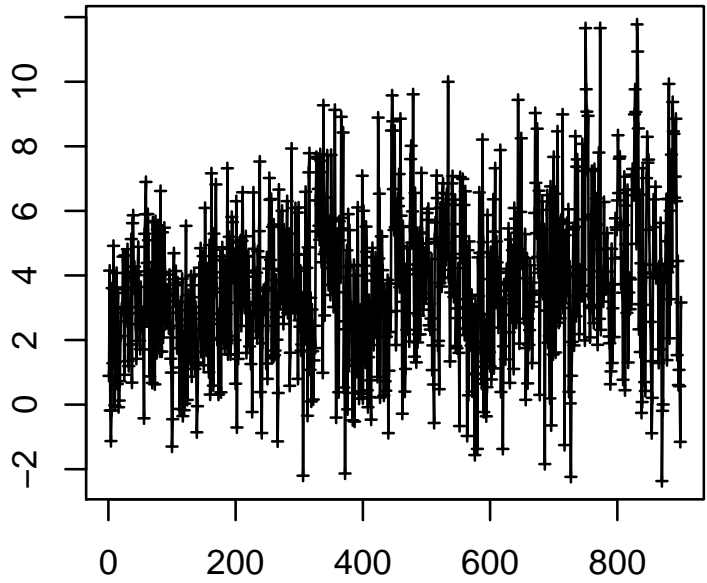

Time Point $(0.25 \mathrm{~Hz})$

Cell 1312

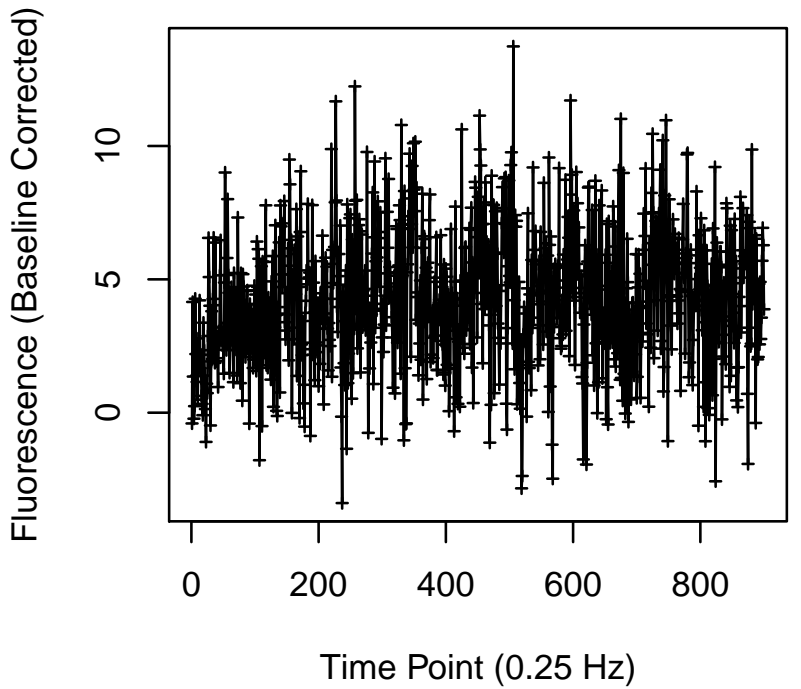


Cell 1313

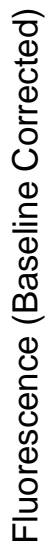

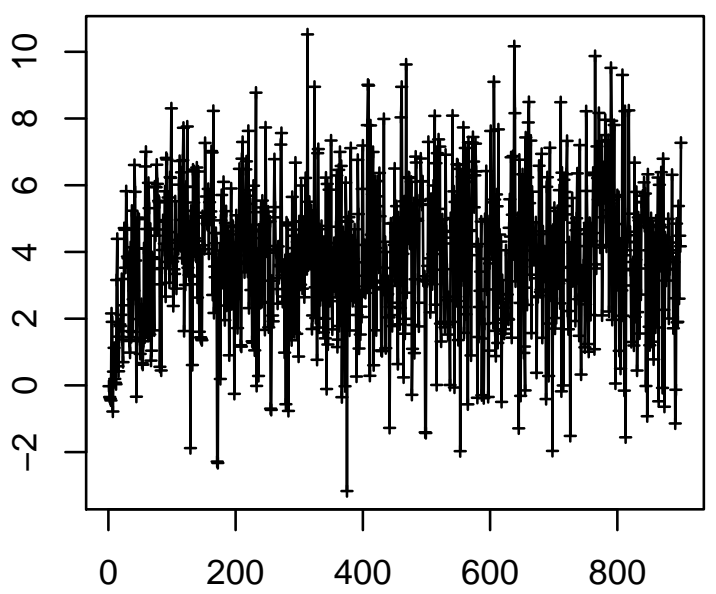

Time Point $(0.25 \mathrm{~Hz})$

Cell 1315

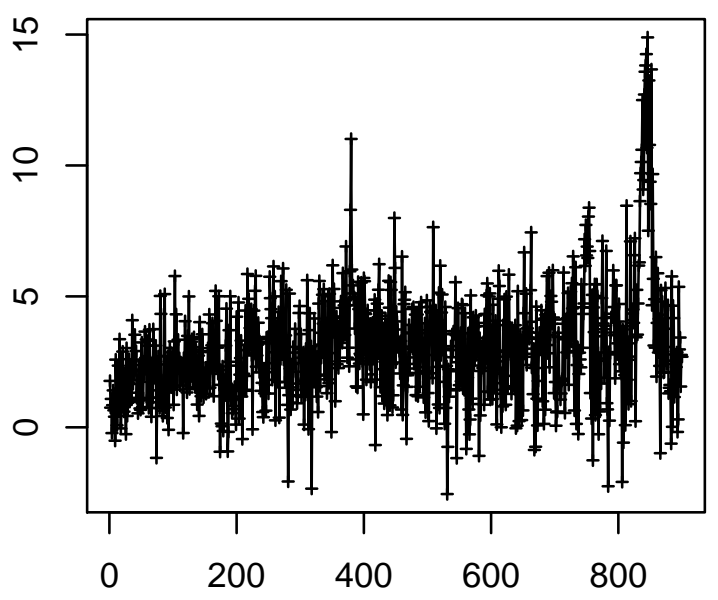

Time Point $(0.25 \mathrm{~Hz})$
Cell 1314

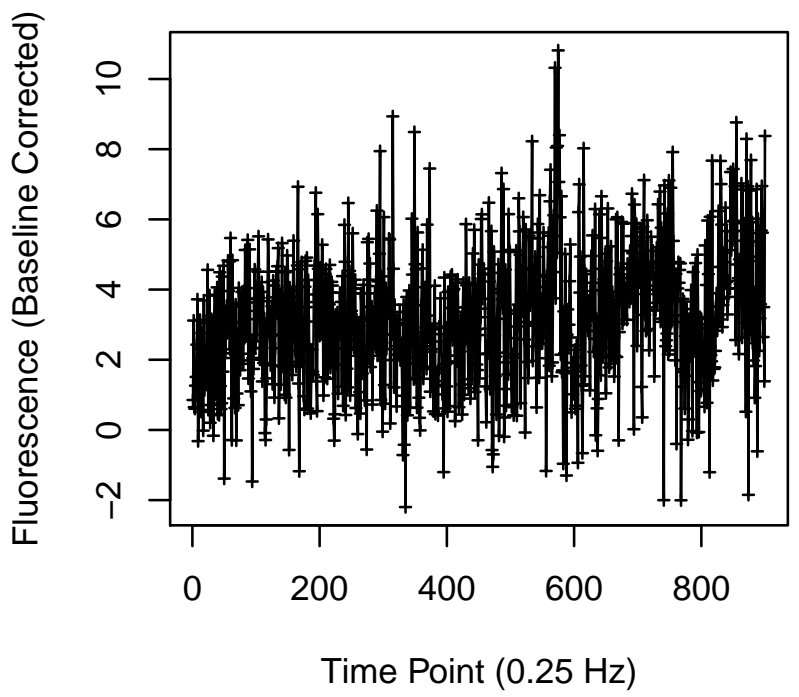

Cell 1316

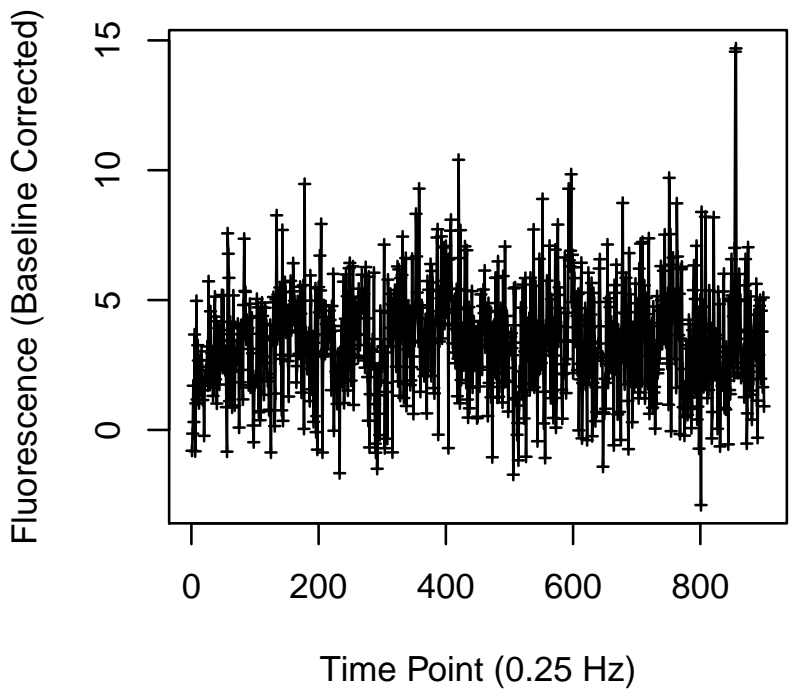


Cell 1317

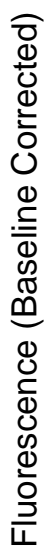

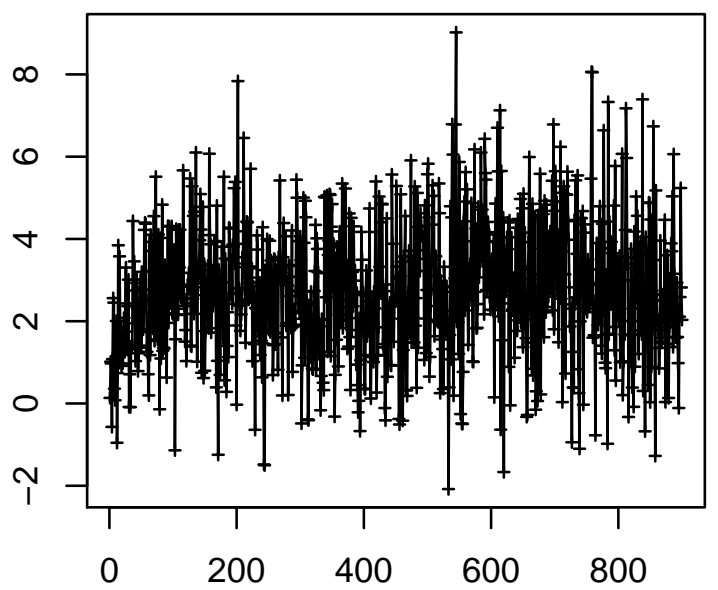

Time Point $(0.25 \mathrm{~Hz})$

Cell 1319

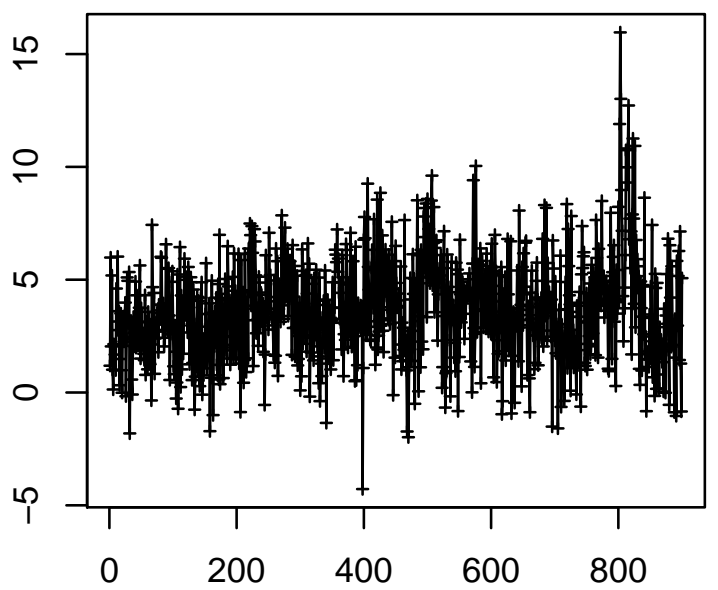

Time Point $(0.25 \mathrm{~Hz})$
Cell 1318

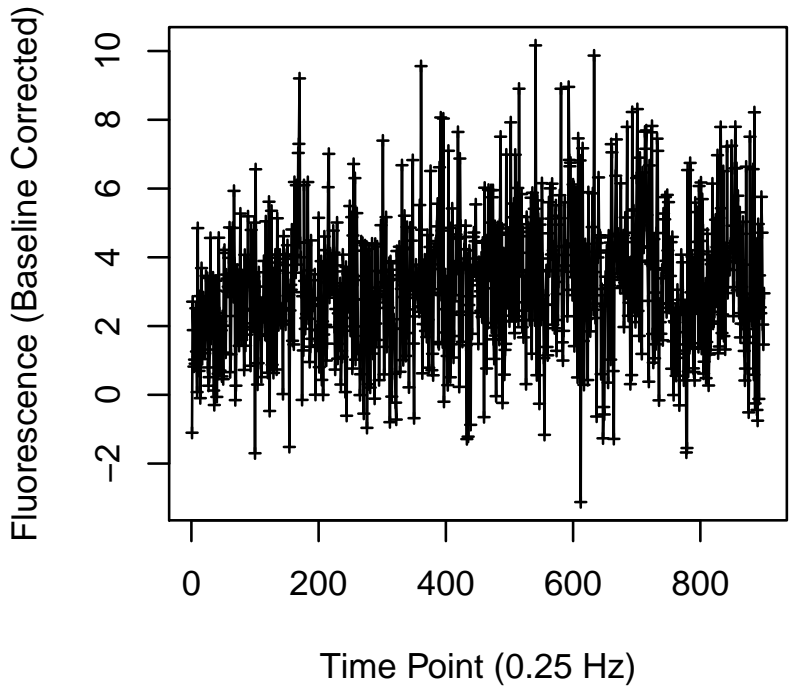

Cell 1320

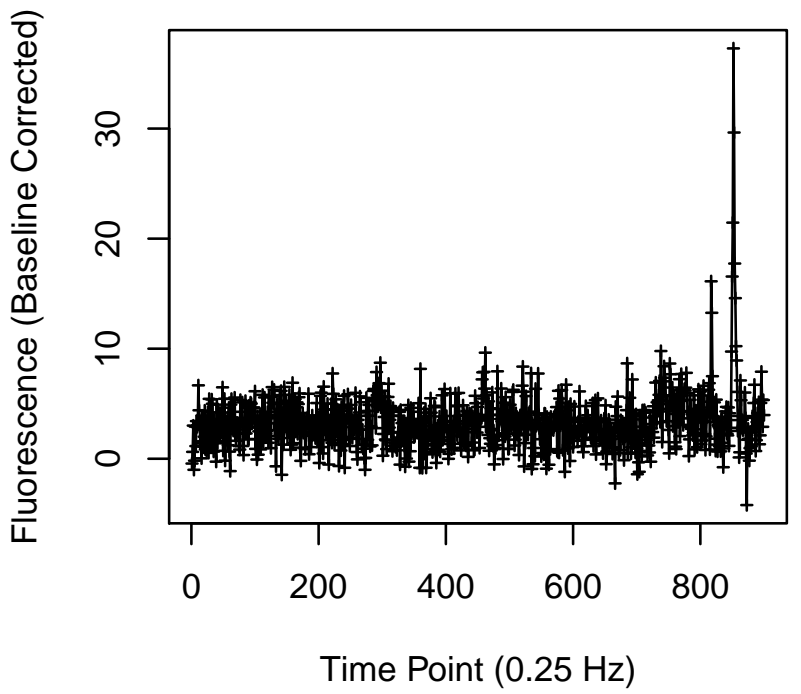


Cell 1321

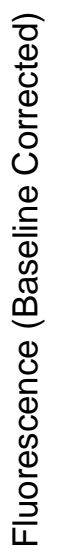

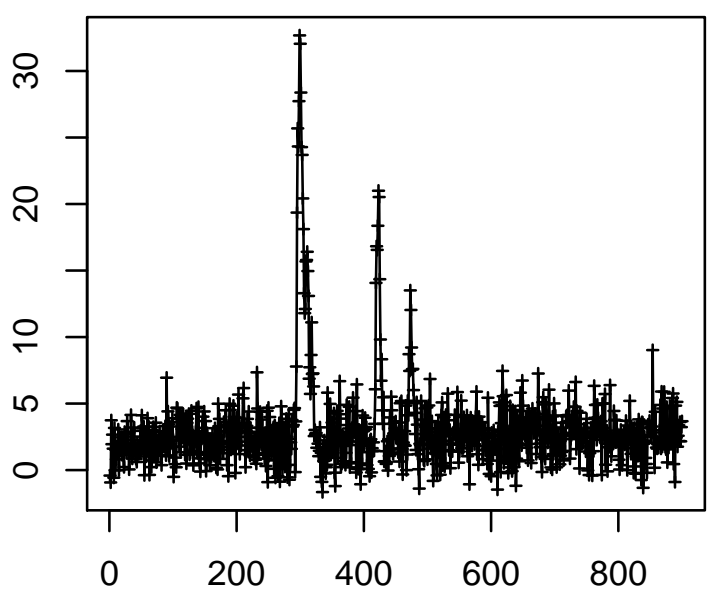

Time Point $(0.25 \mathrm{~Hz})$

Cell 1323

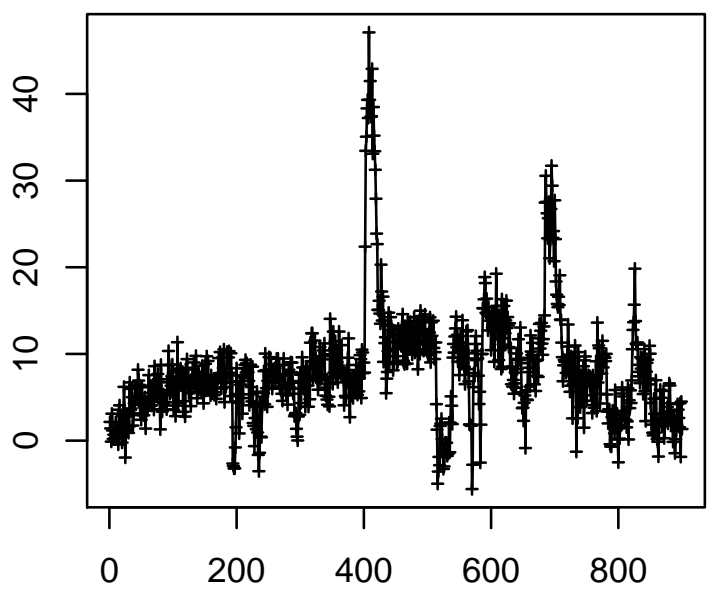

Time Point $(0.25 \mathrm{~Hz})$
Cell 1322

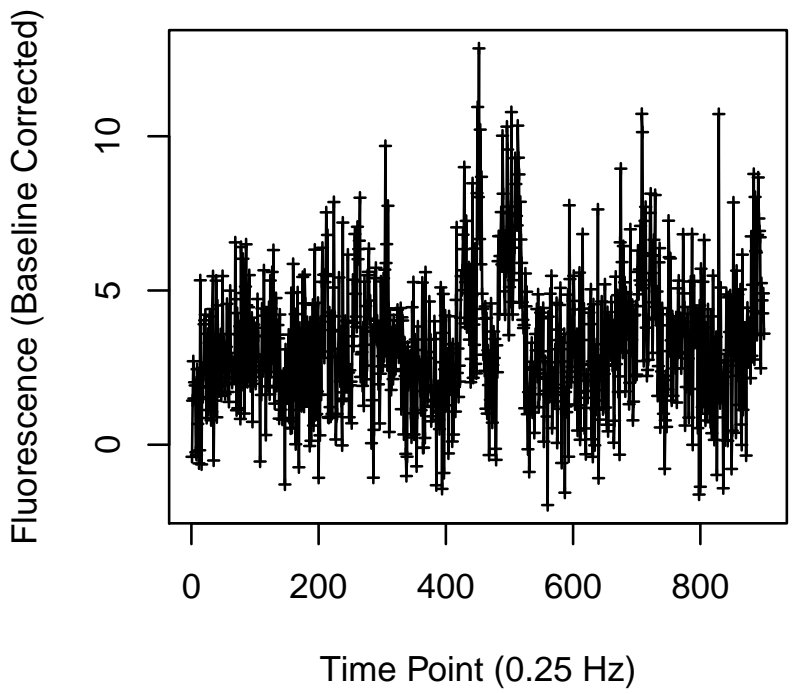

Cell 1324

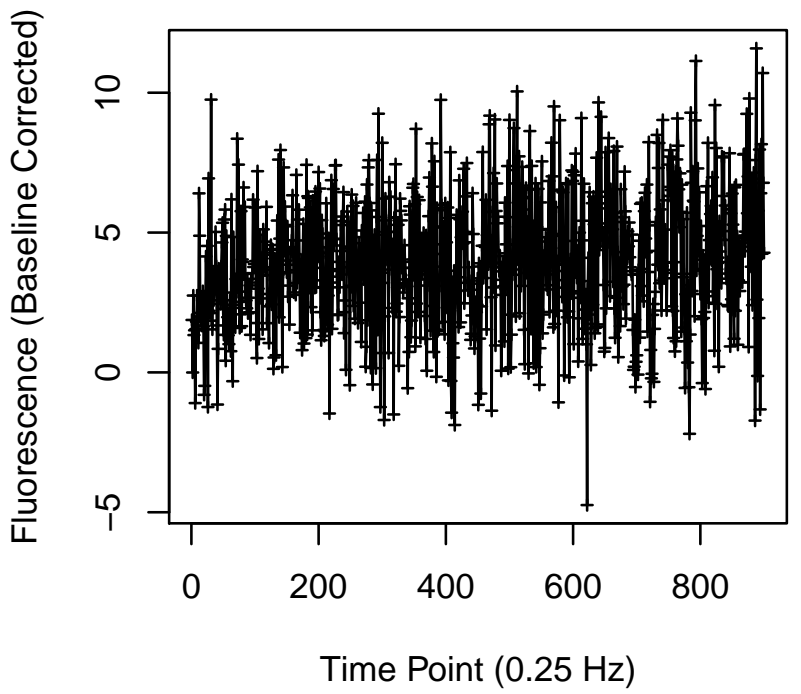




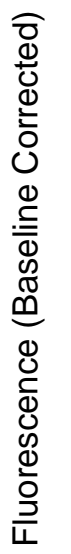

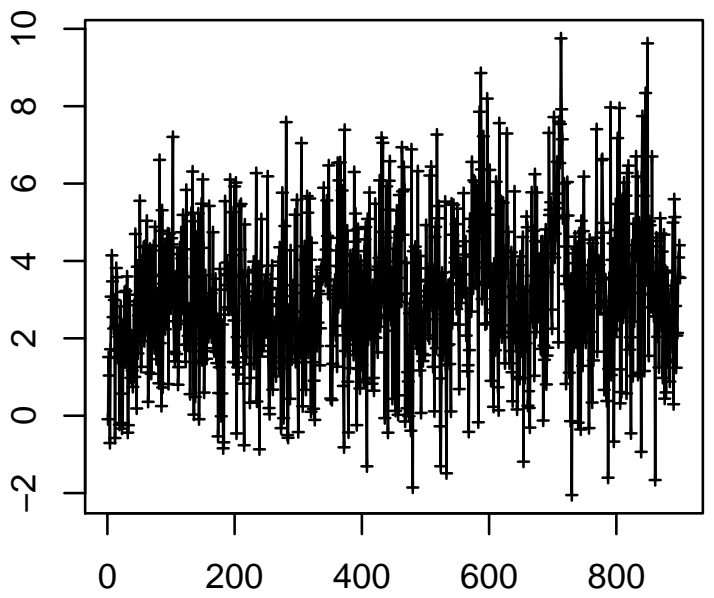

Time Point $(0.25 \mathrm{~Hz})$

Cell 1327

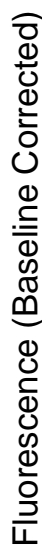

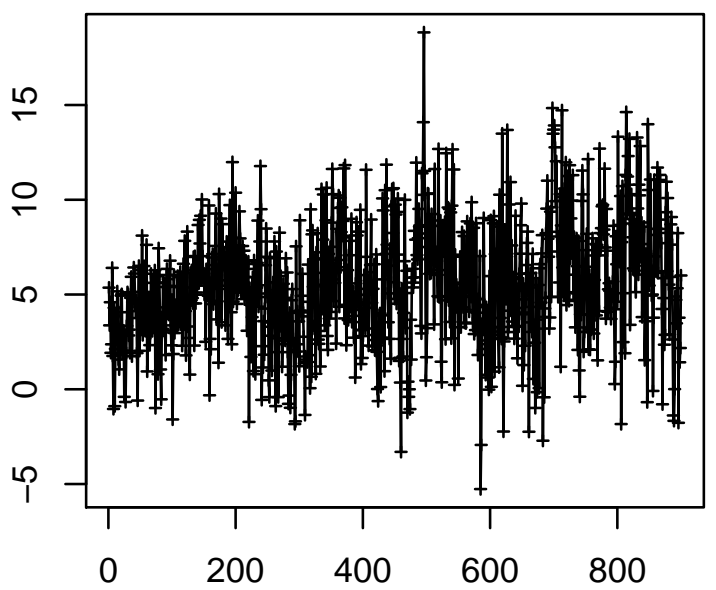

Time Point $(0.25 \mathrm{~Hz})$

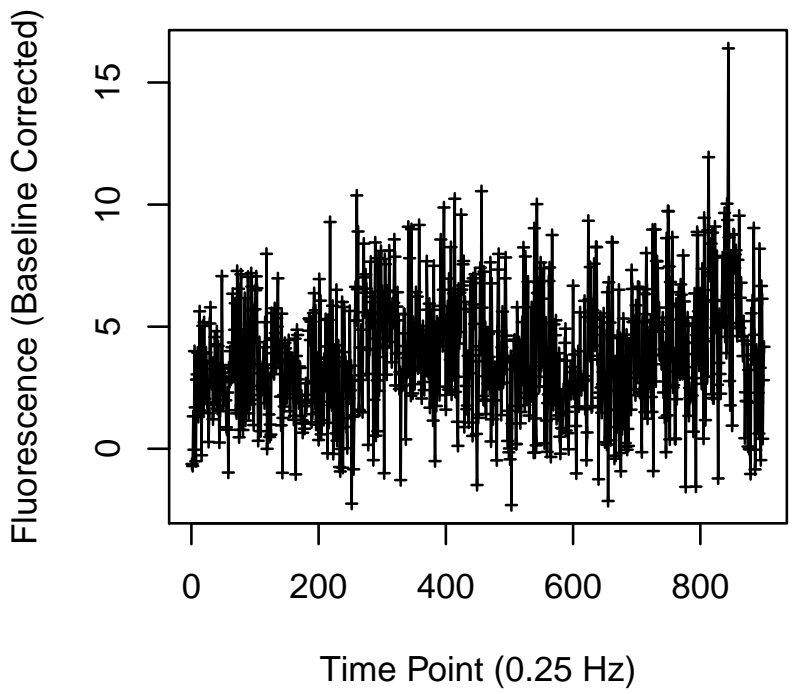

Cell 1328

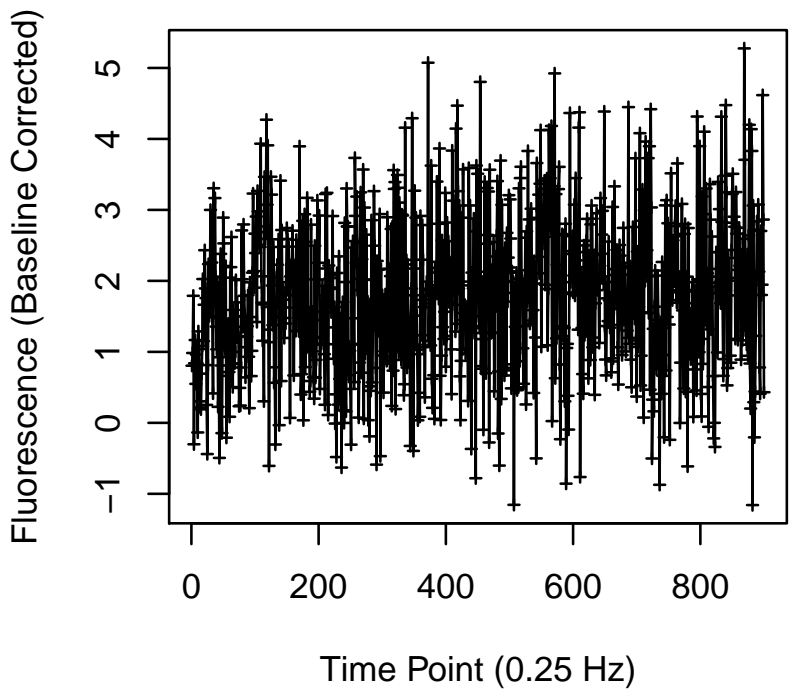


Cell 1329

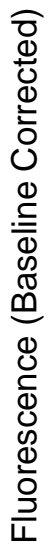

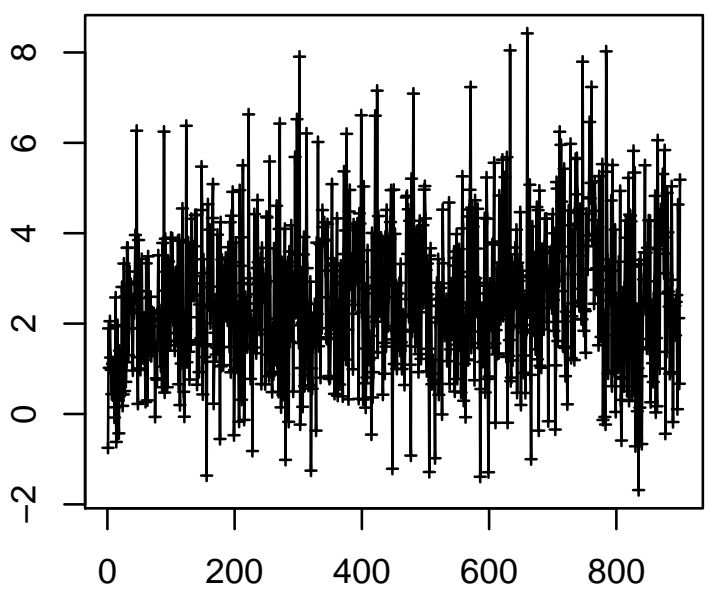

Time Point $(0.25 \mathrm{~Hz})$

Cell 1331

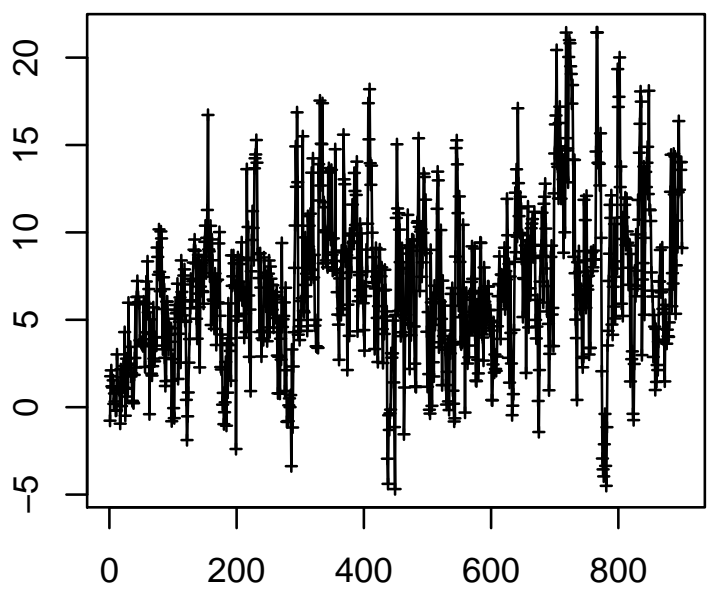

Time Point $(0.25 \mathrm{~Hz})$
Cell 1330

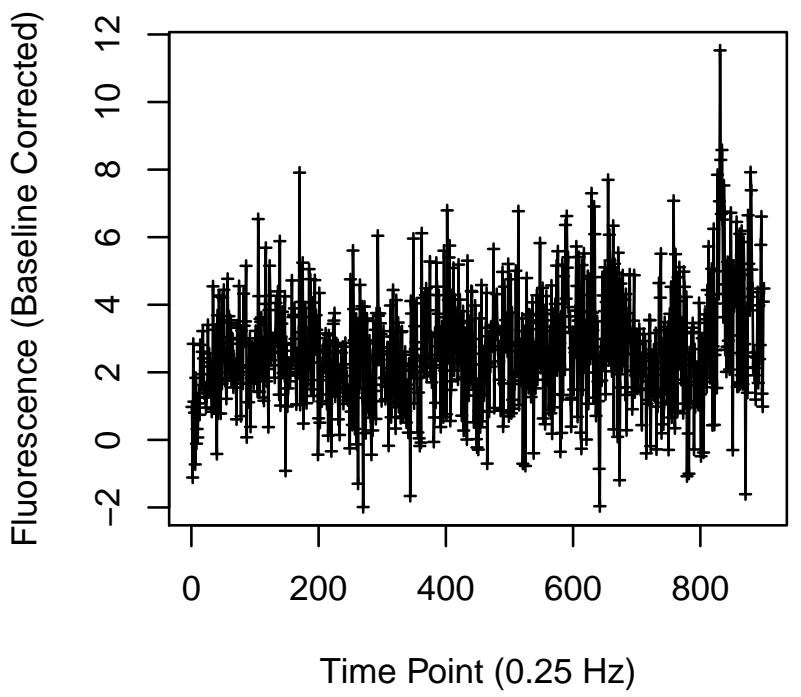

Cell 1332

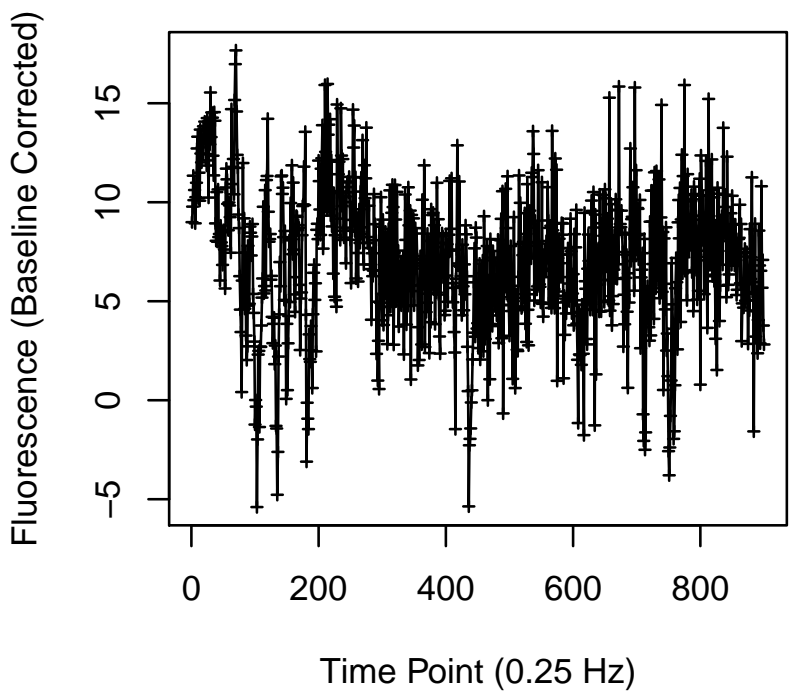


Cell 1333

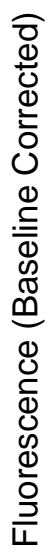

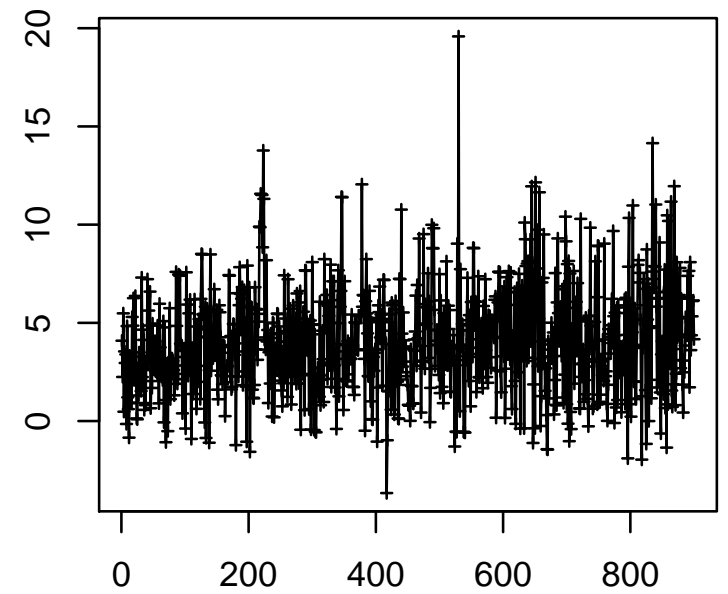

Time Point $(0.25 \mathrm{~Hz})$

Cell 1335

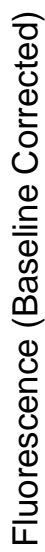

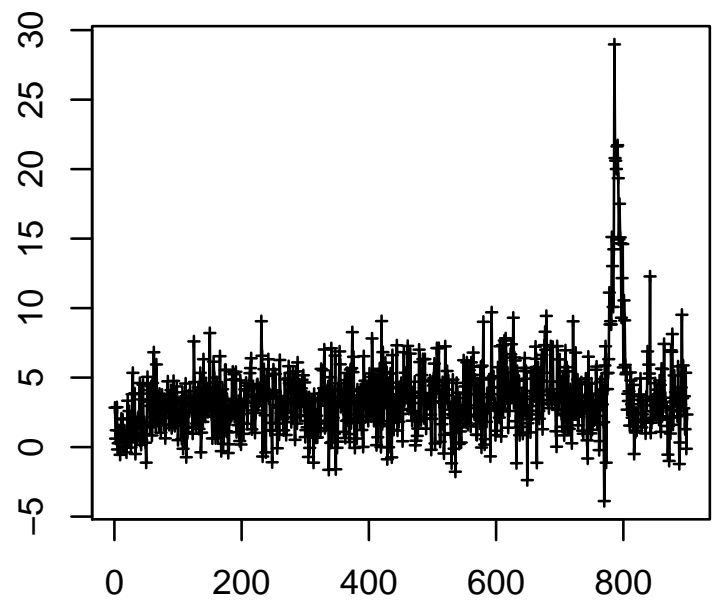

Time Point $(0.25 \mathrm{~Hz})$
Cell 1334

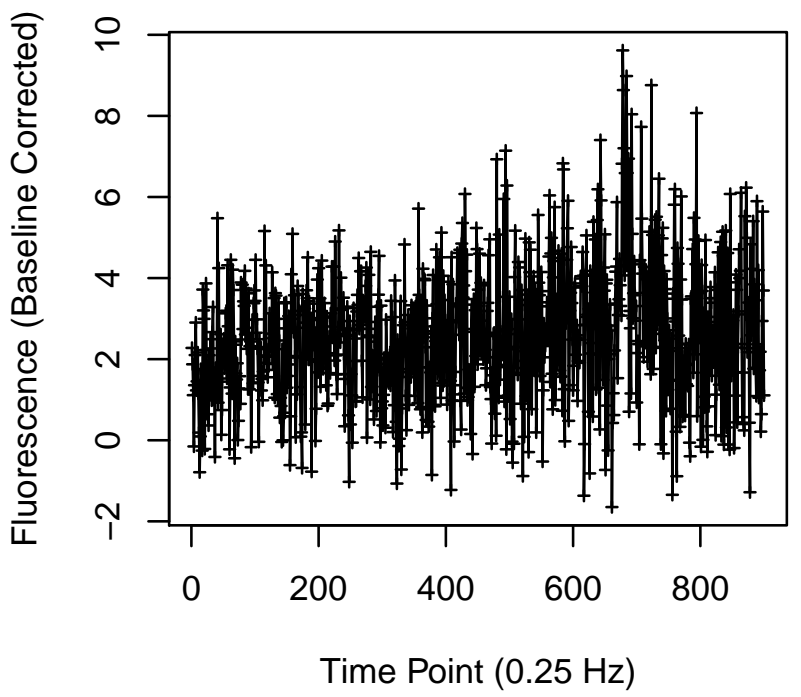

Cell 1336

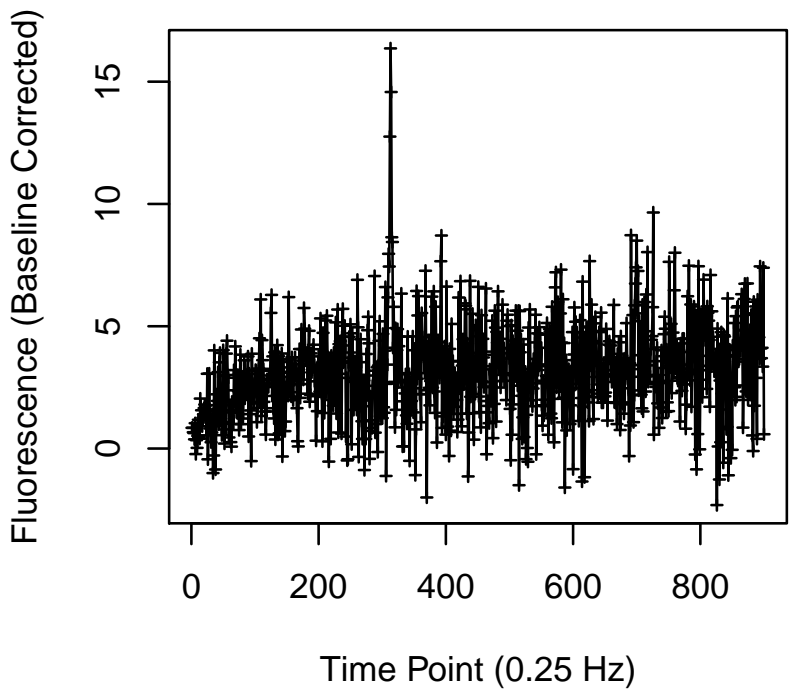


Cell 1349

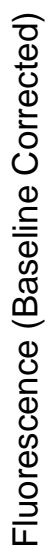

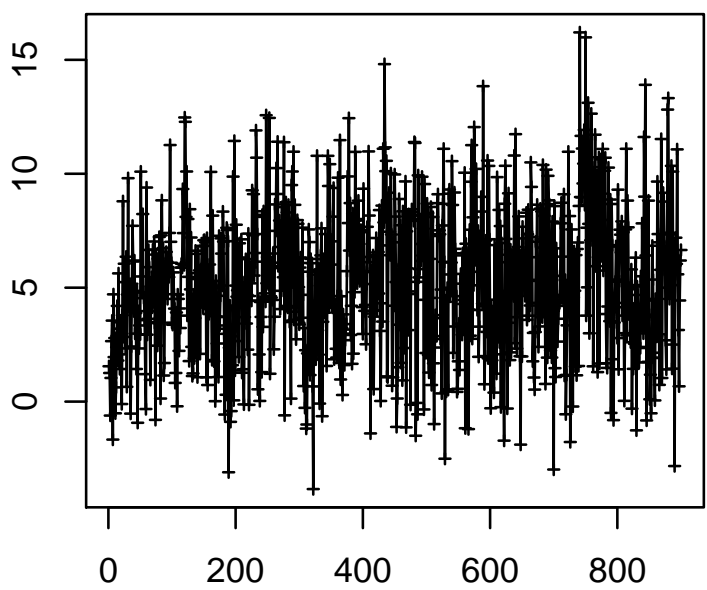

Time Point $(0.25 \mathrm{~Hz})$

Cell 1351

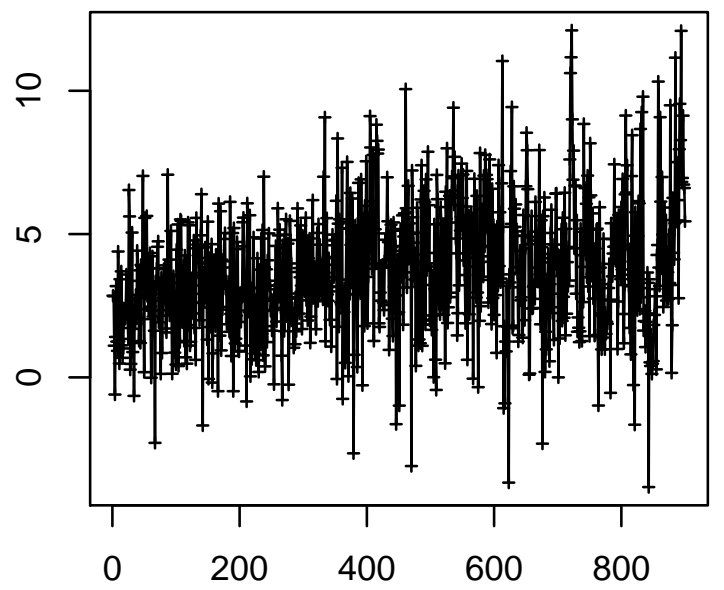

Time Point $(0.25 \mathrm{~Hz})$
Cell 1350

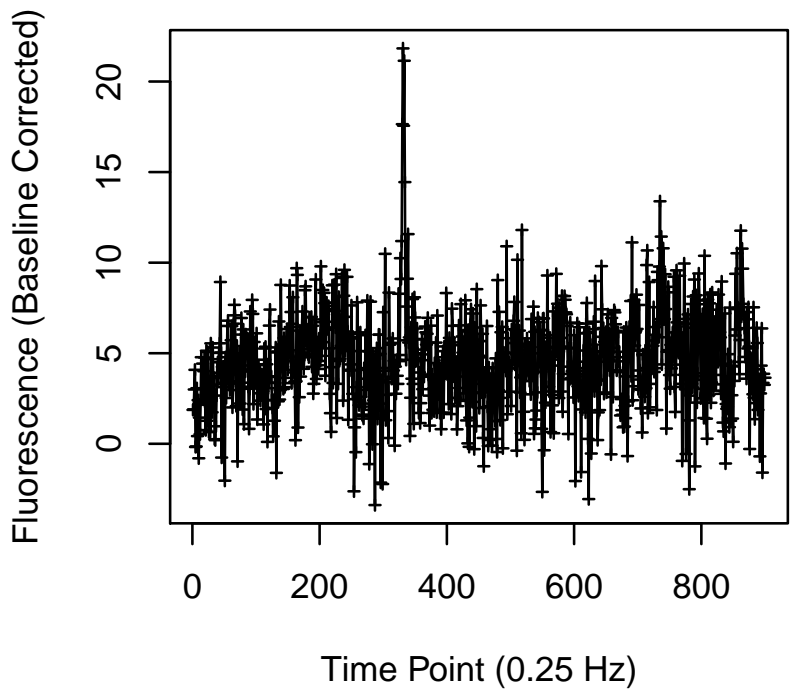

Cell 1352

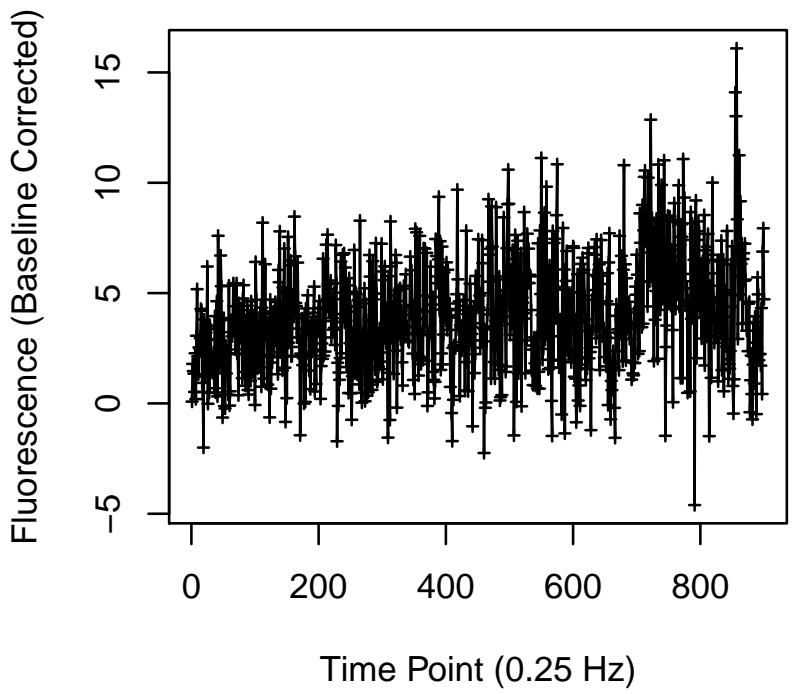




\section{Cell 1361}

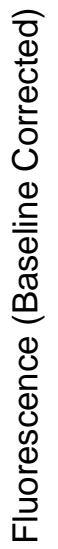

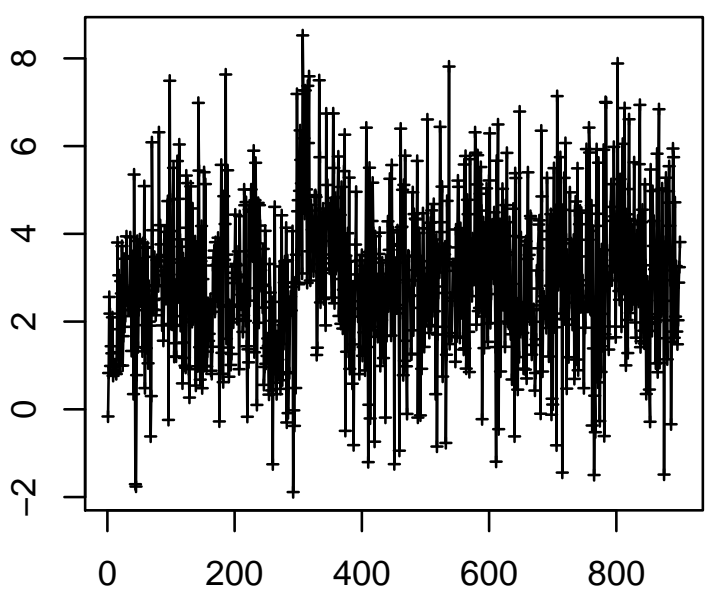

Time Point $(0.25 \mathrm{~Hz})$

Cell 1363

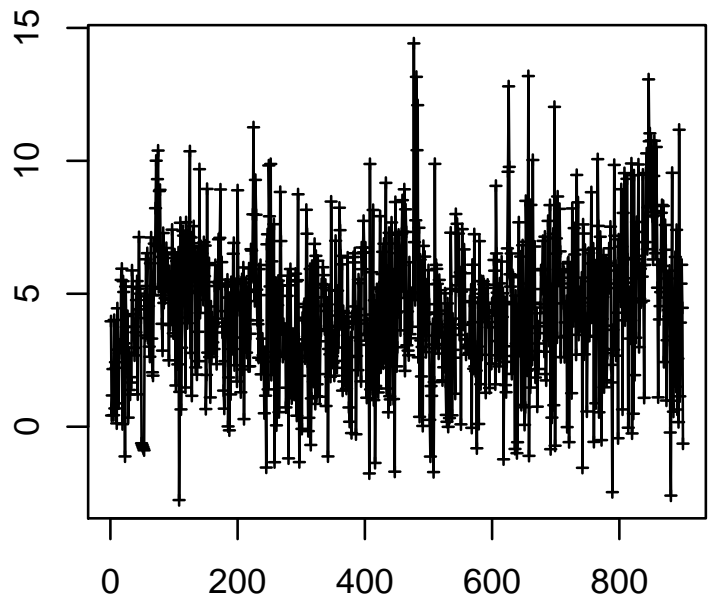

Time Point $(0.25 \mathrm{~Hz})$
Cell 1362

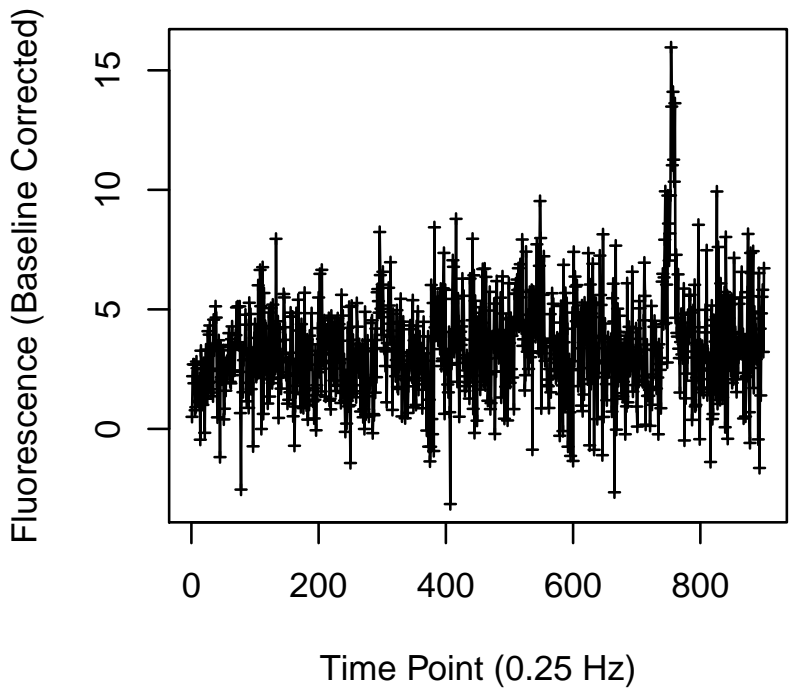

Cell 1364

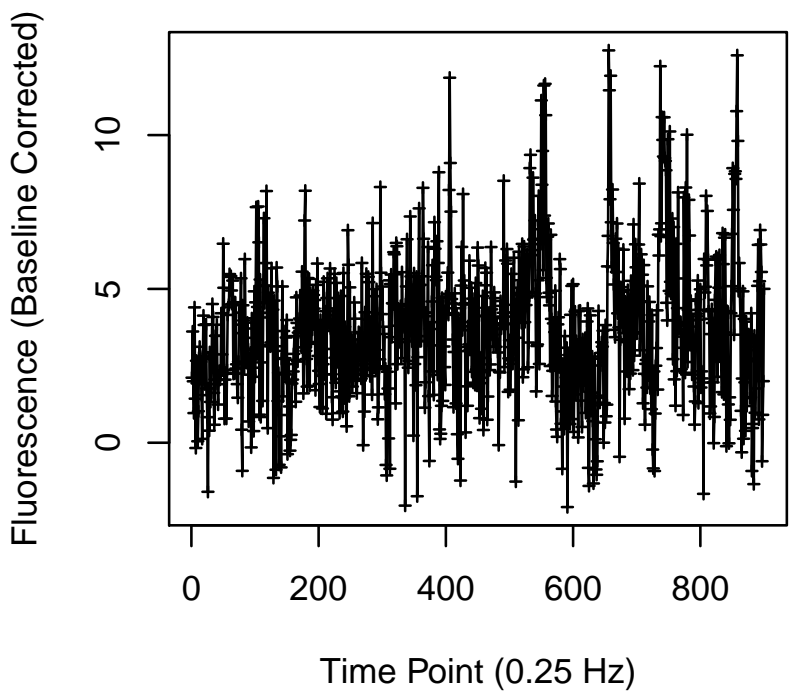


Cell 1369

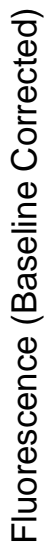

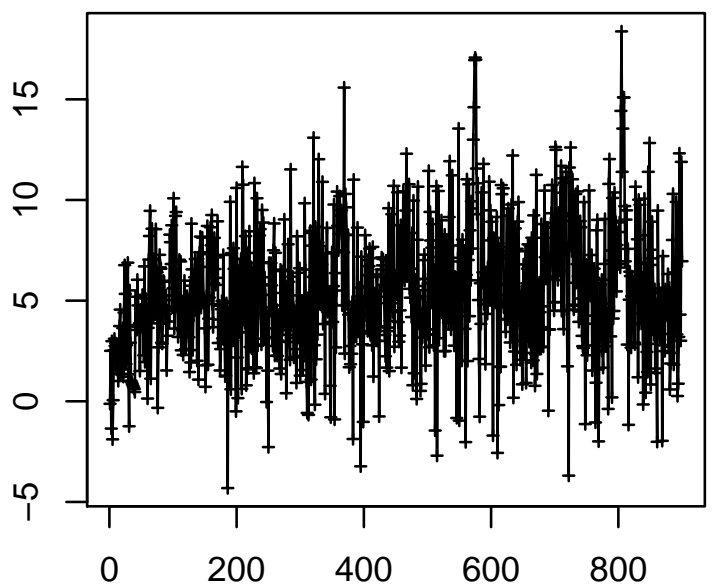

Time Point $(0.25 \mathrm{~Hz})$

Cell 1371

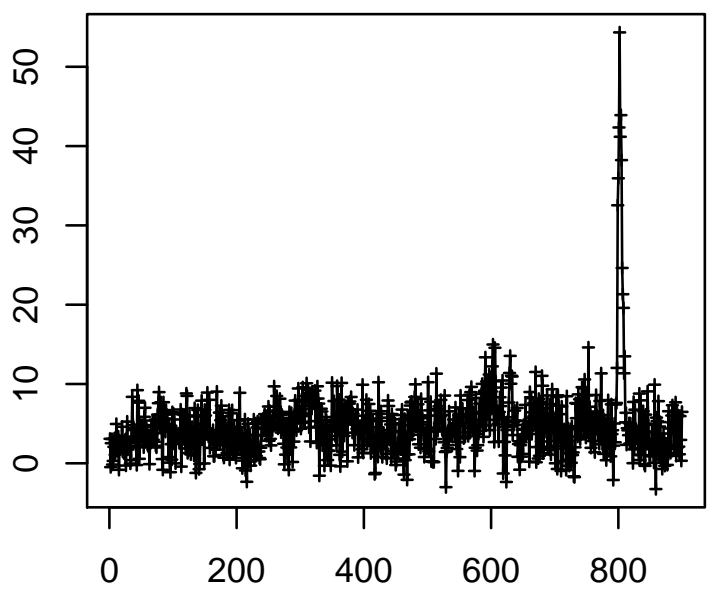

Time Point $(0.25 \mathrm{~Hz})$
Cell 1370

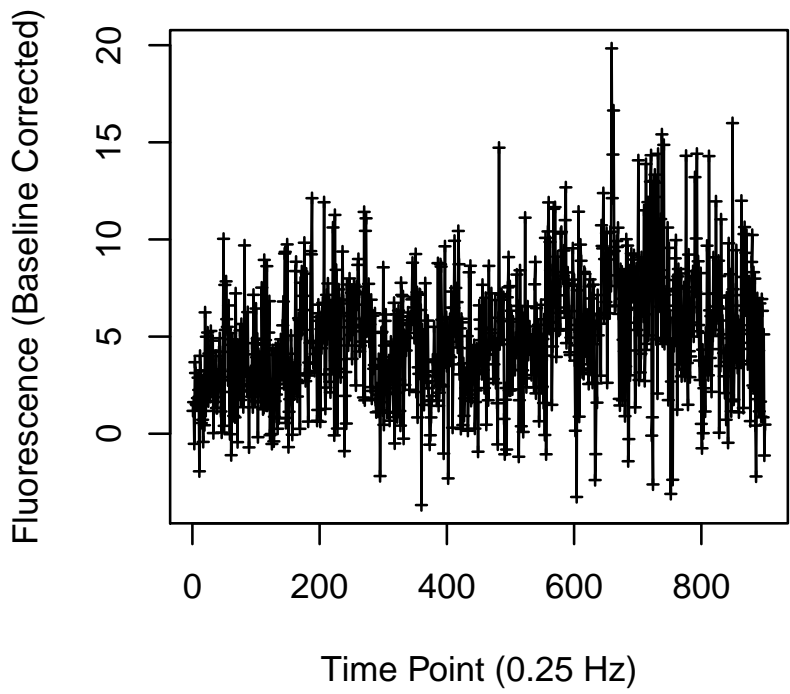

Cell 1372

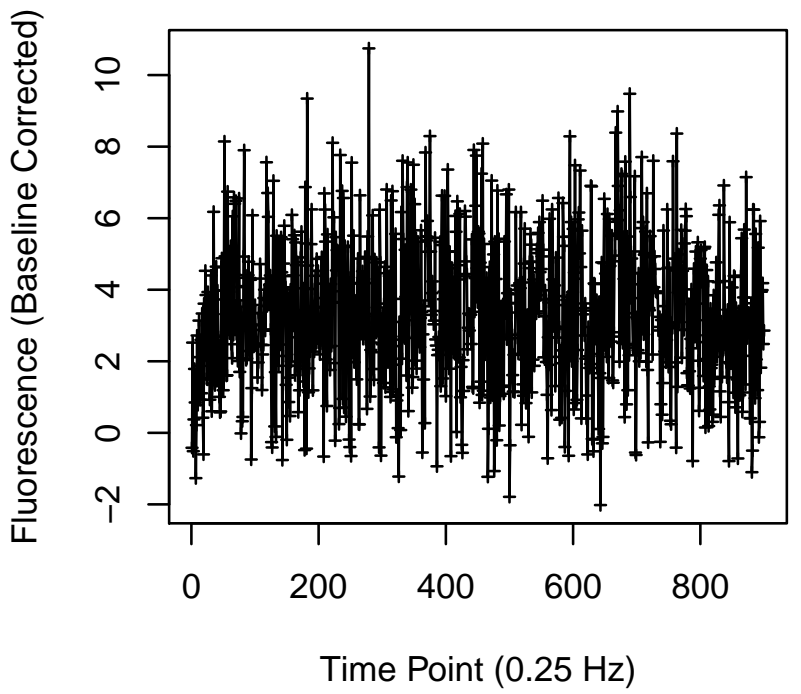


Cell 1373

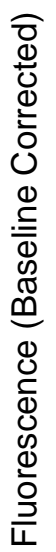

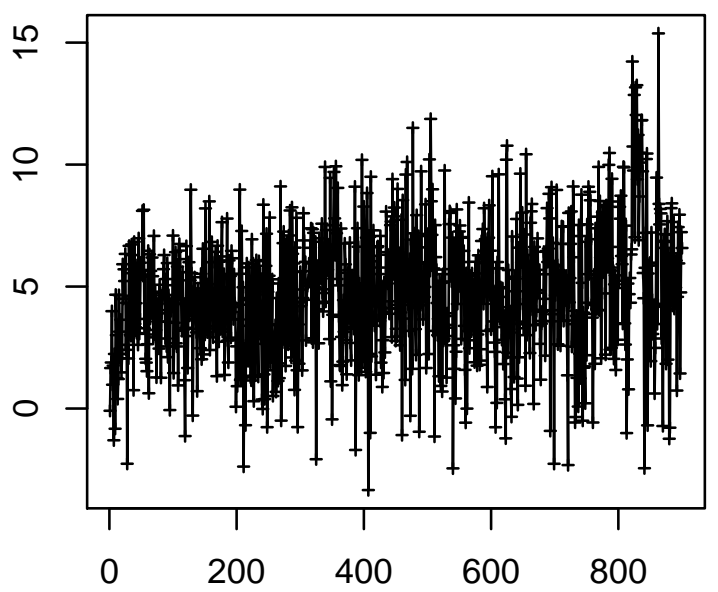

Time Point $(0.25 \mathrm{~Hz})$

Cell 1375

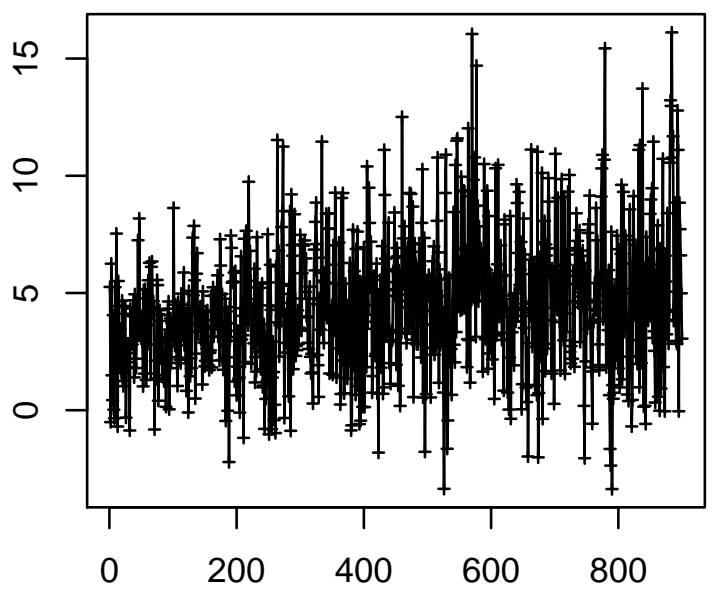

Time Point $(0.25 \mathrm{~Hz})$
Cell 1374

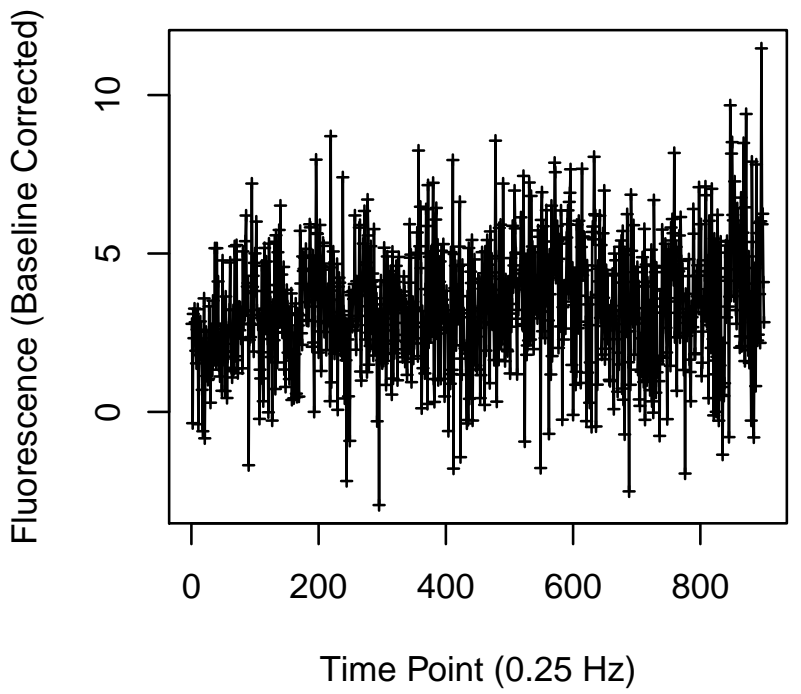

Cell 1376

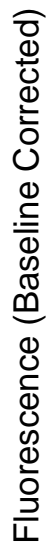

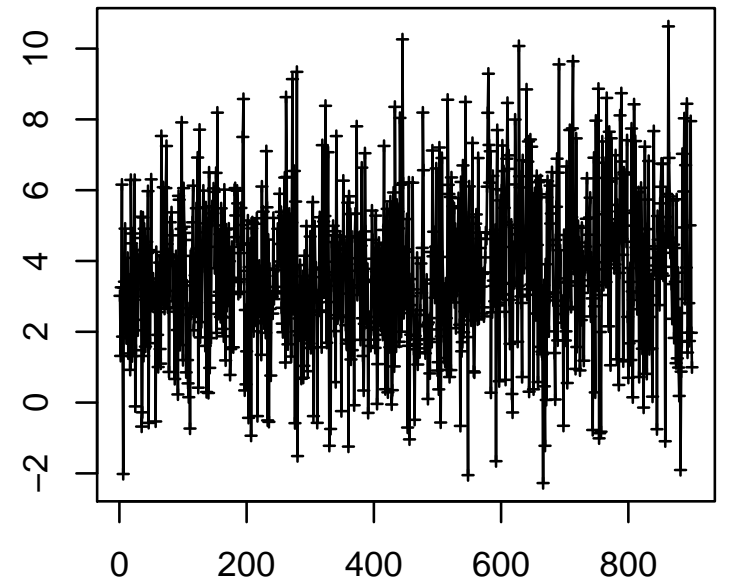

Time Point $(0.25 \mathrm{~Hz})$ 
Cell 1377

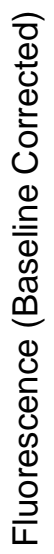

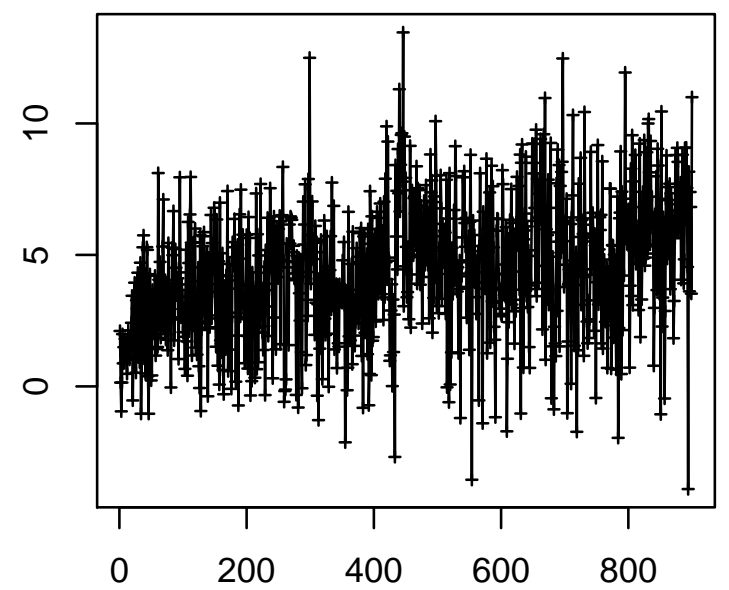

Time Point $(0.25 \mathrm{~Hz})$

Cell 1379

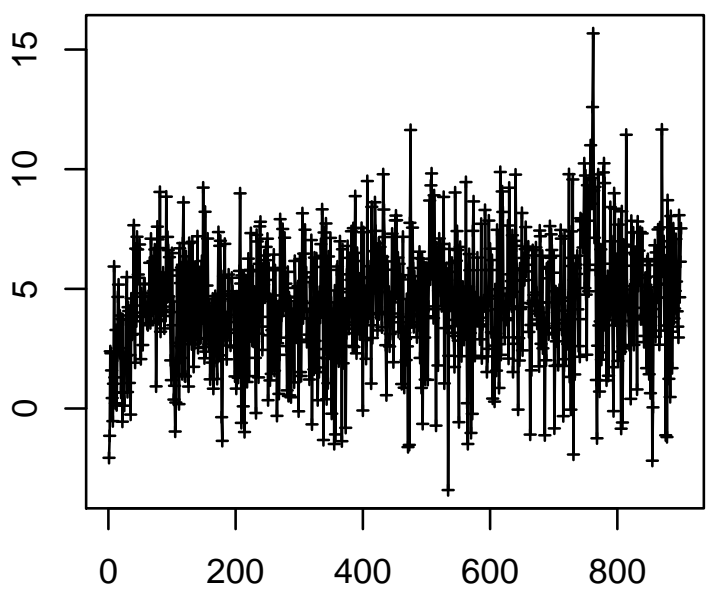

Time Point $(0.25 \mathrm{~Hz})$
Cell 1378

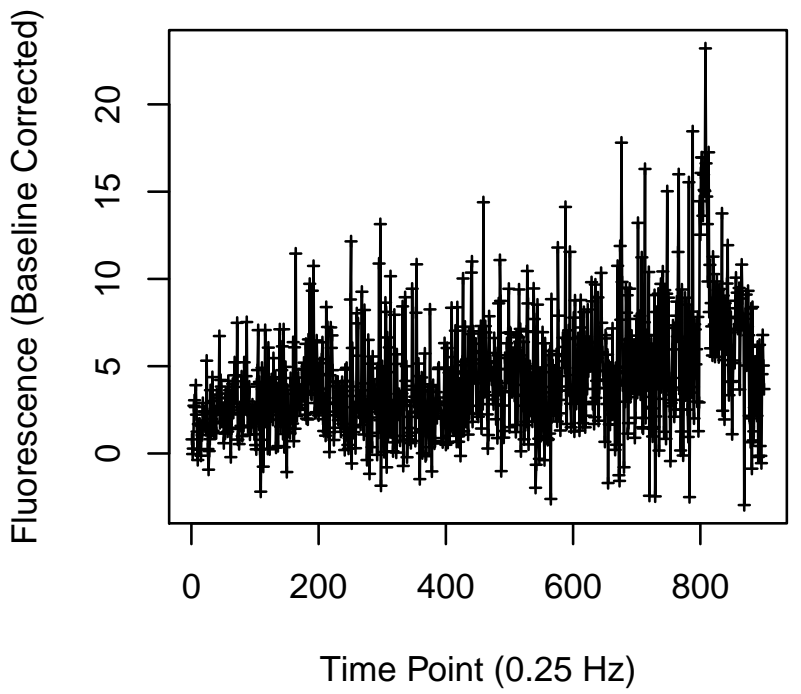

Cell 1380

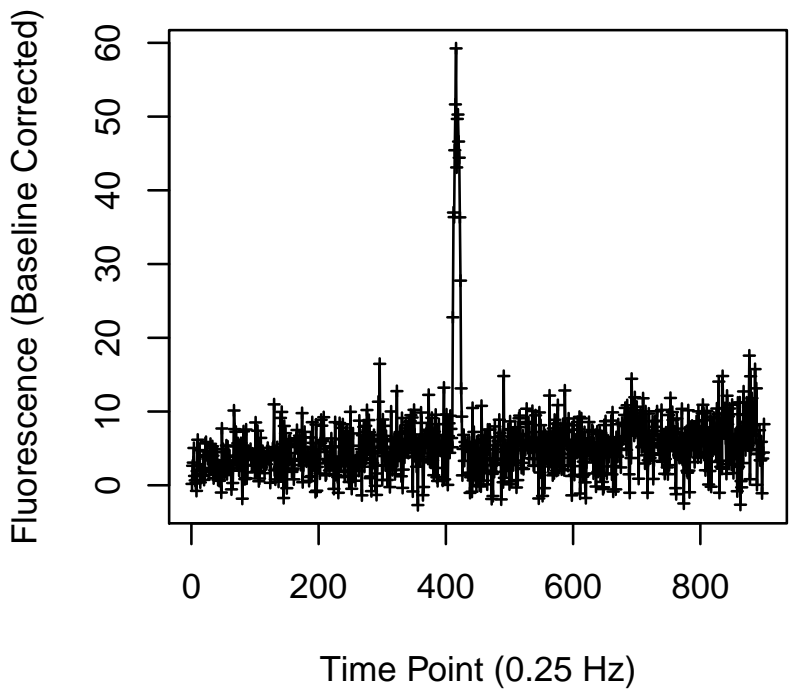


Cell 1381

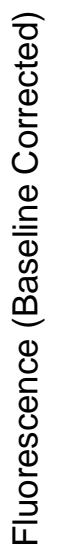

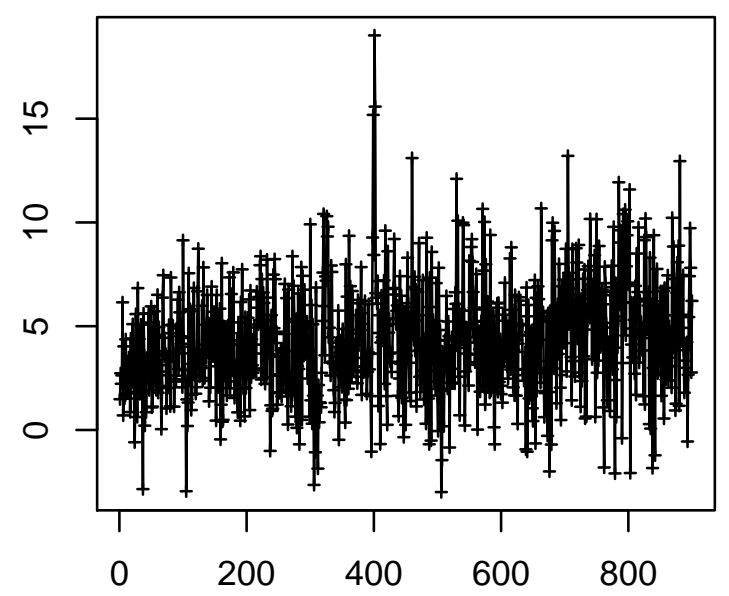

Time Point $(0.25 \mathrm{~Hz})$

Cell 1383

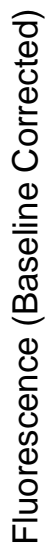

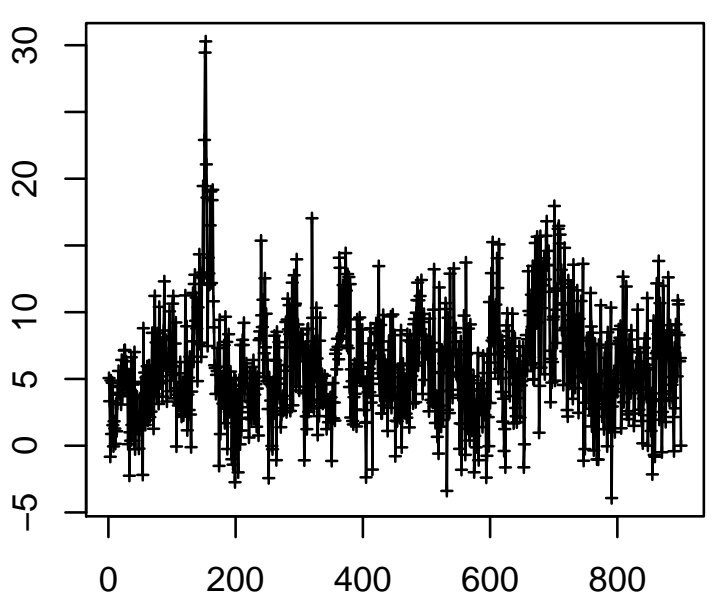

Time Point $(0.25 \mathrm{~Hz})$
Cell 1382

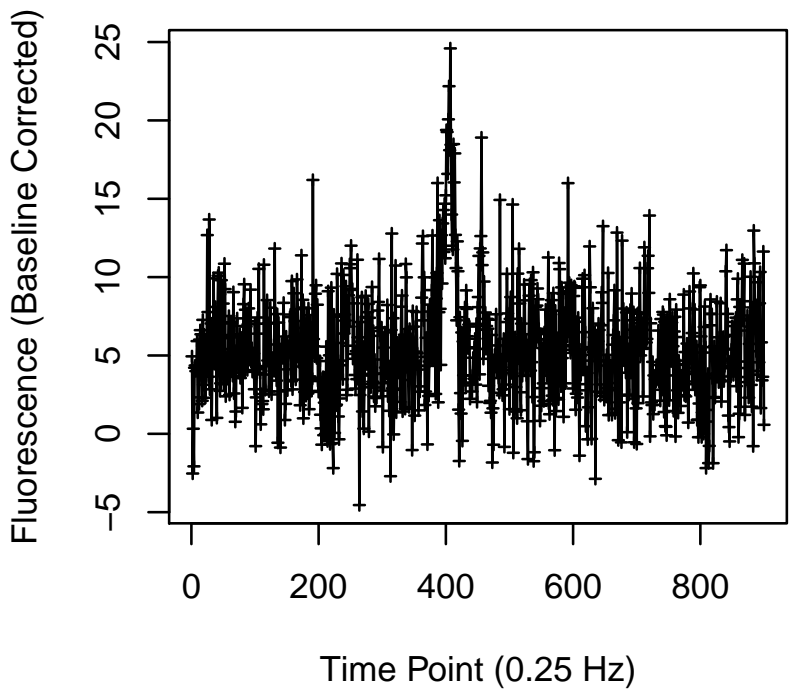

Cell 1384

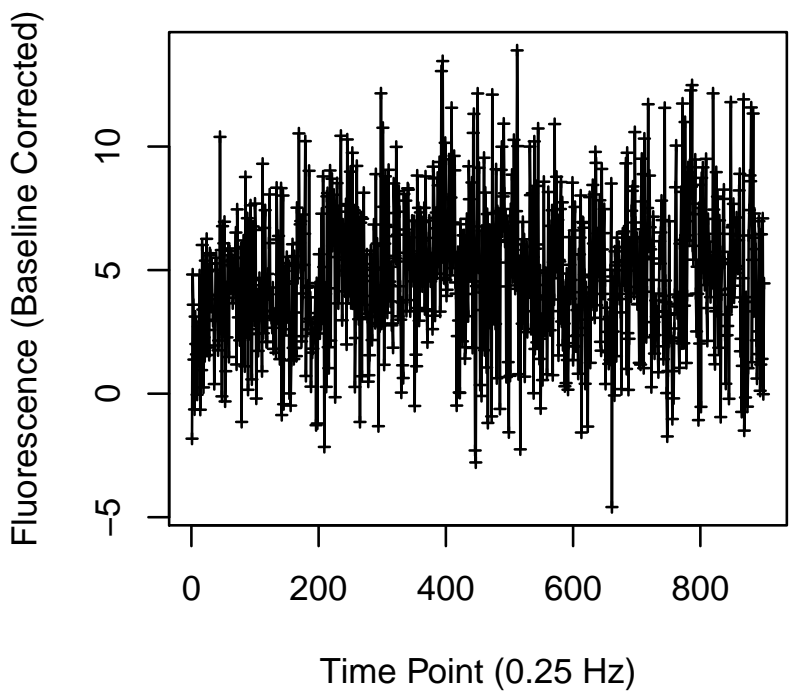


Cell 1385

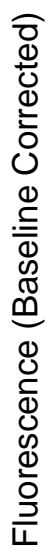

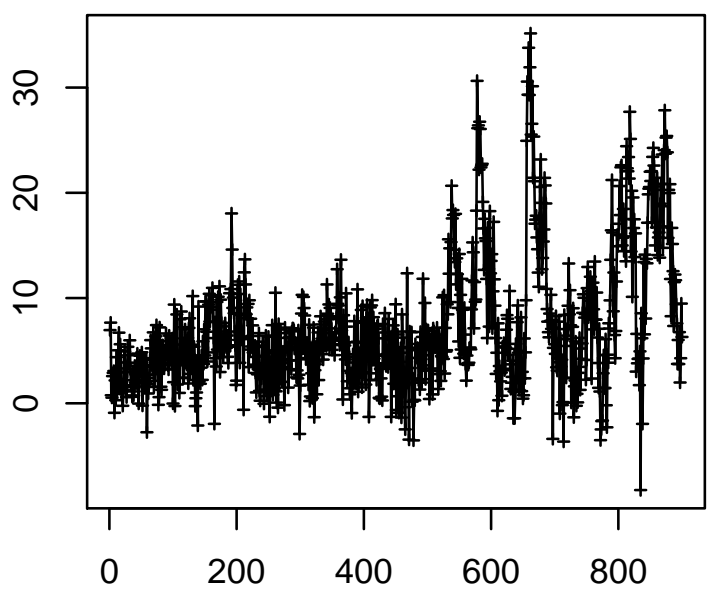

Time Point $(0.25 \mathrm{~Hz})$

Cell 1387

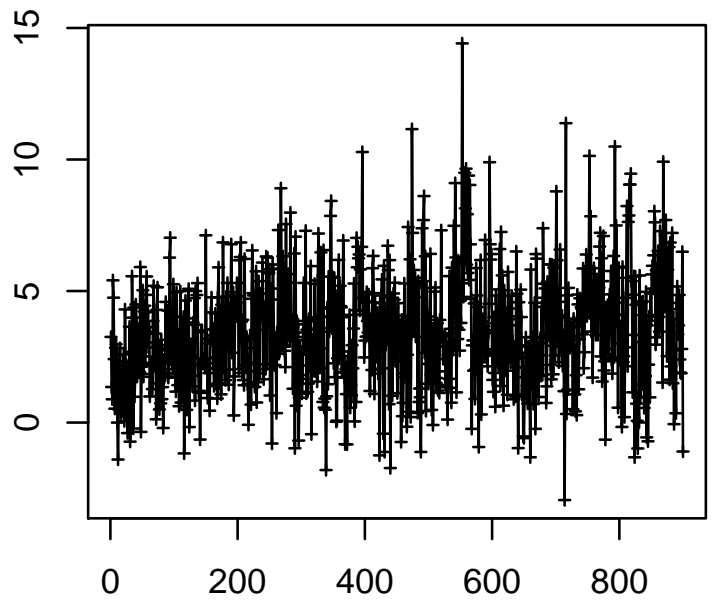

Time Point $(0.25 \mathrm{~Hz})$
Cell 1386

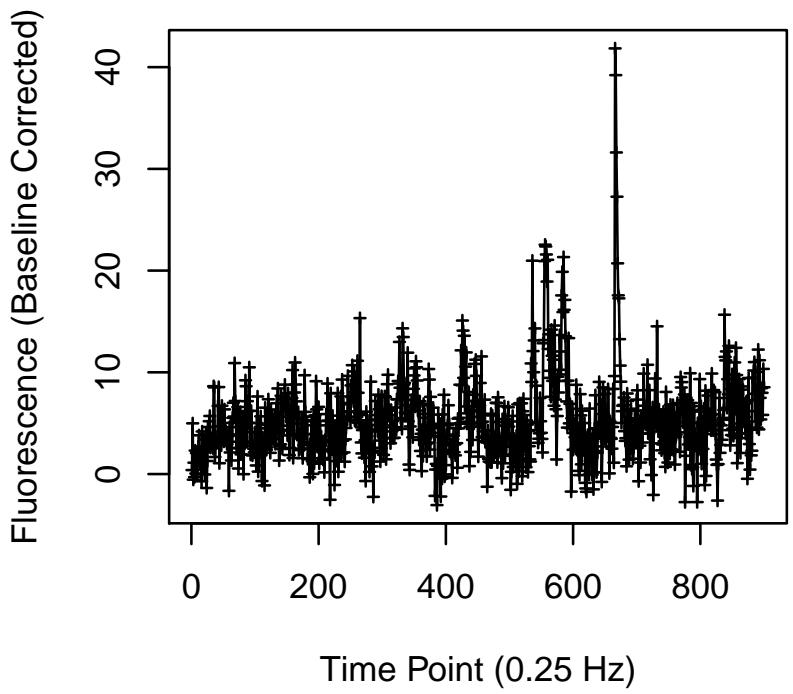

Cell 1388

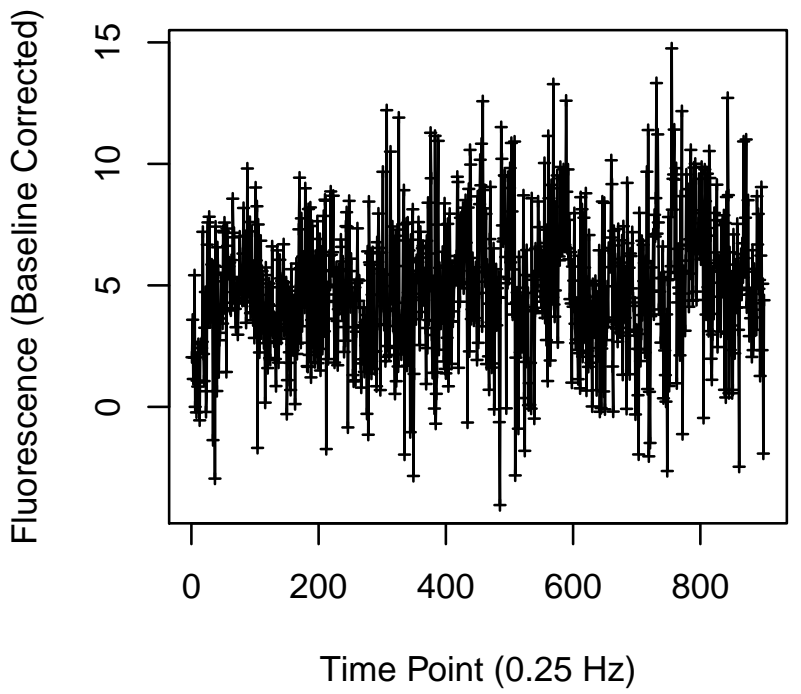


Cell 1389

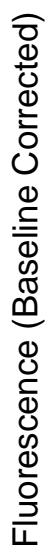

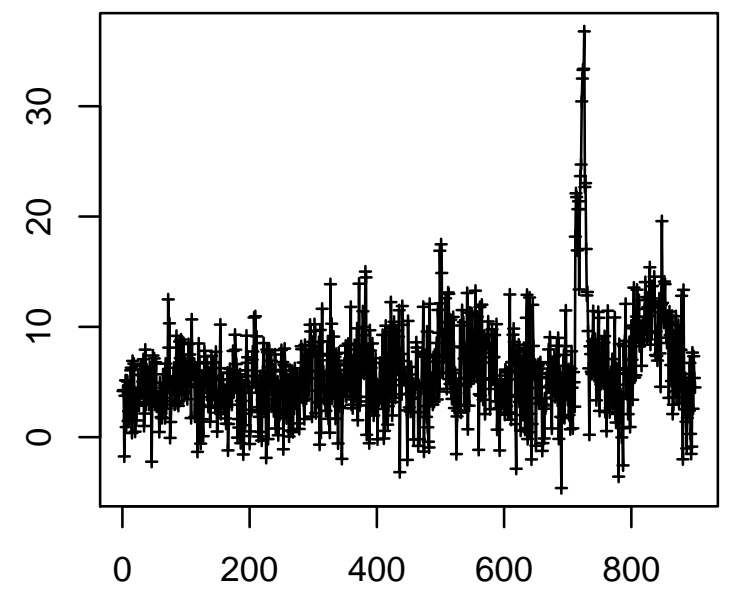

Time Point $(0.25 \mathrm{~Hz})$

Cell 1391

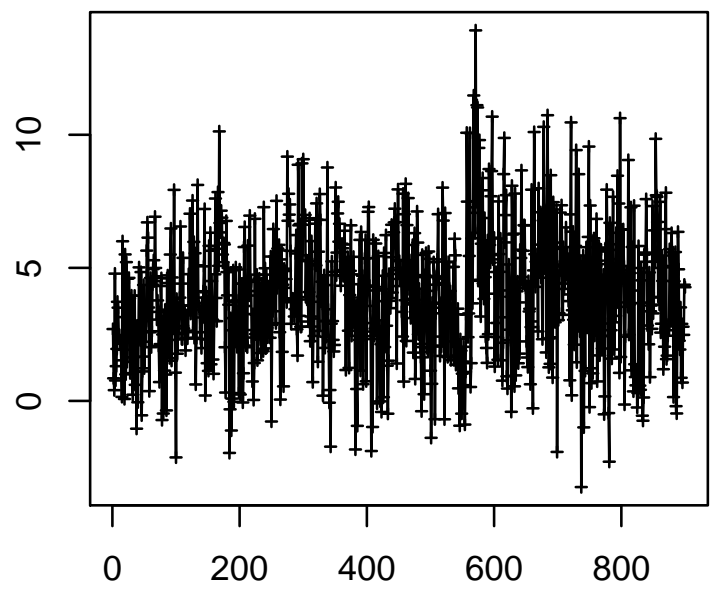

Time Point $(0.25 \mathrm{~Hz})$
Cell 1390

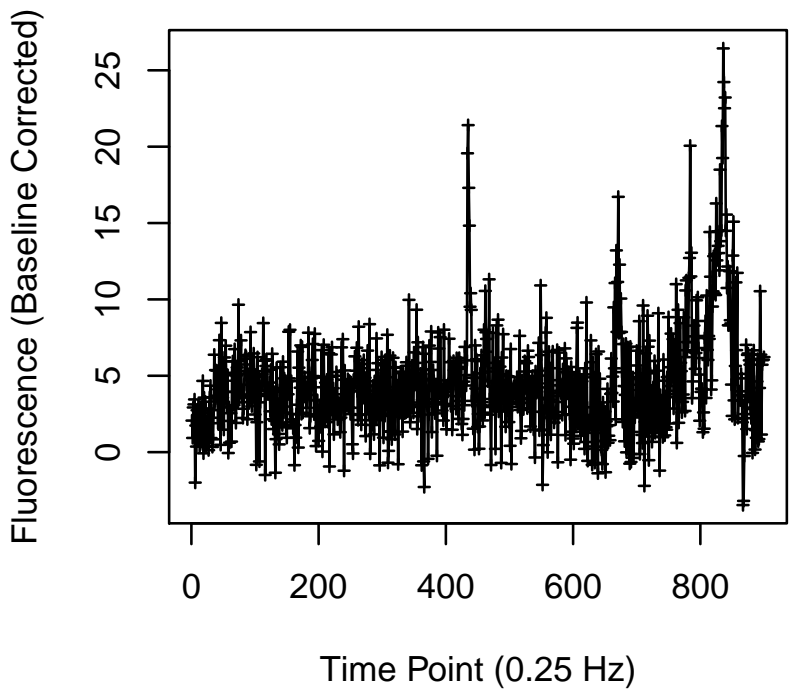

Cell 1392

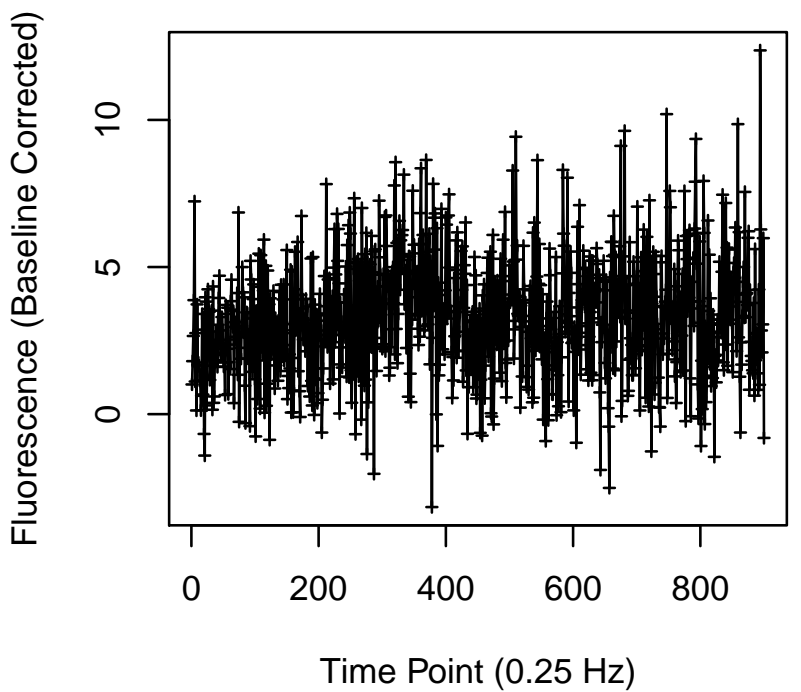


Cell 1393

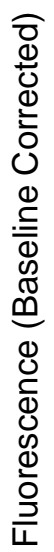

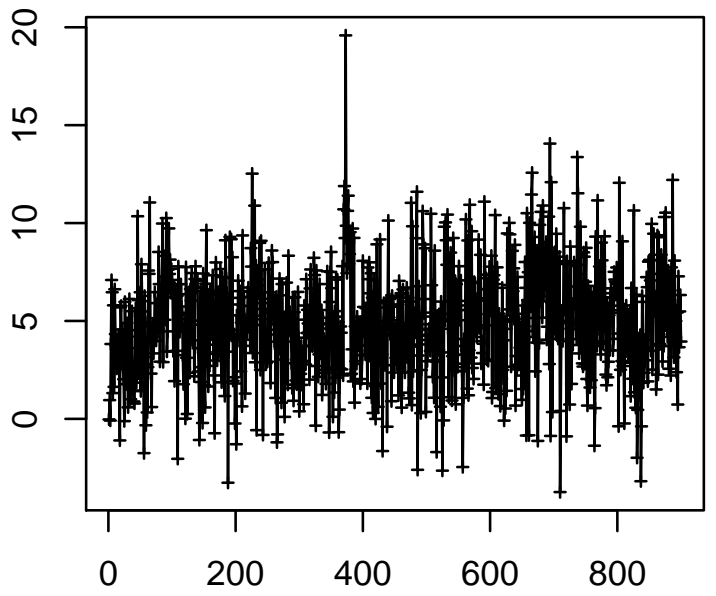

Time Point $(0.25 \mathrm{~Hz})$

Cell 1395

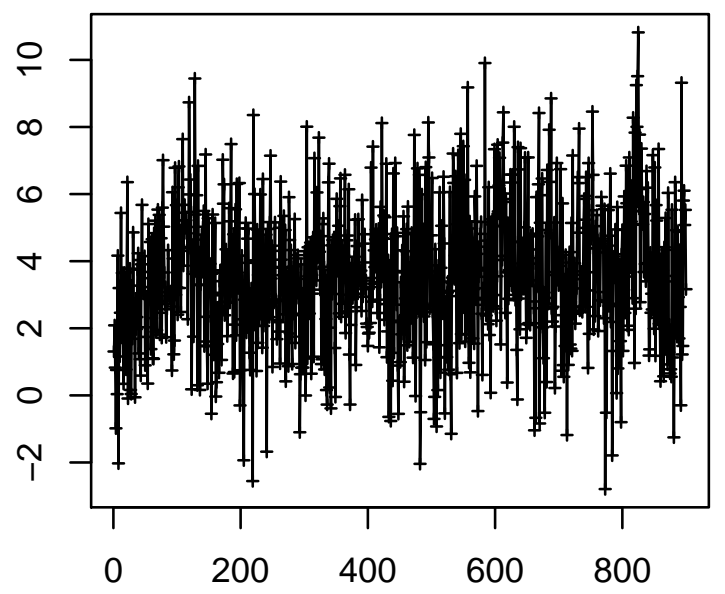

Time Point $(0.25 \mathrm{~Hz})$
Cell 1394

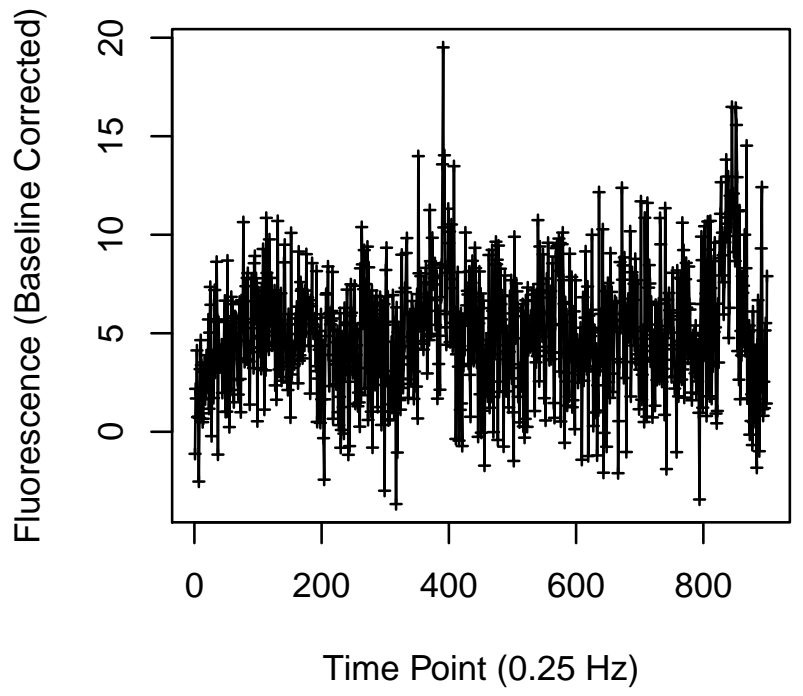

Cell 1396

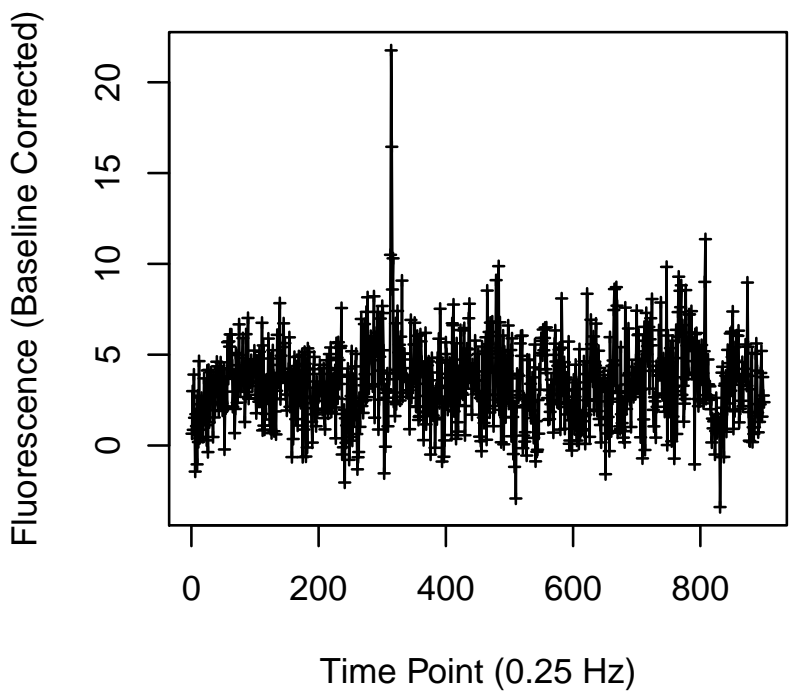




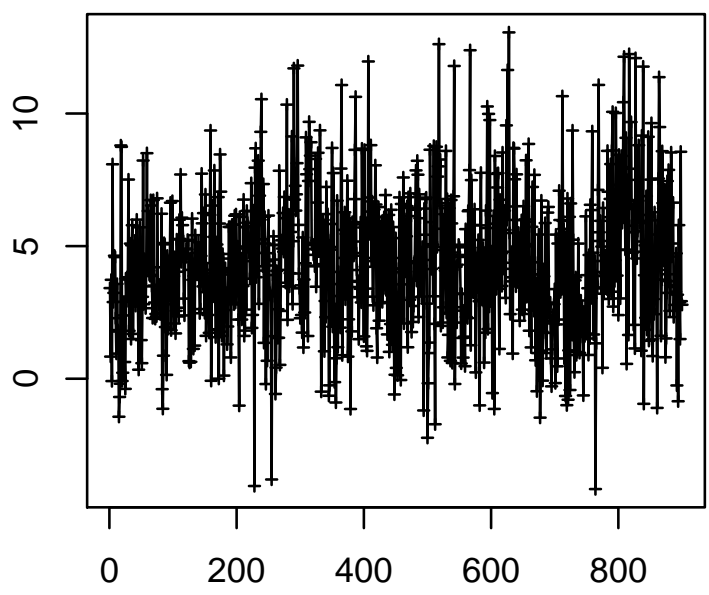

Time Point $(0.25 \mathrm{~Hz})$

Cell 1399

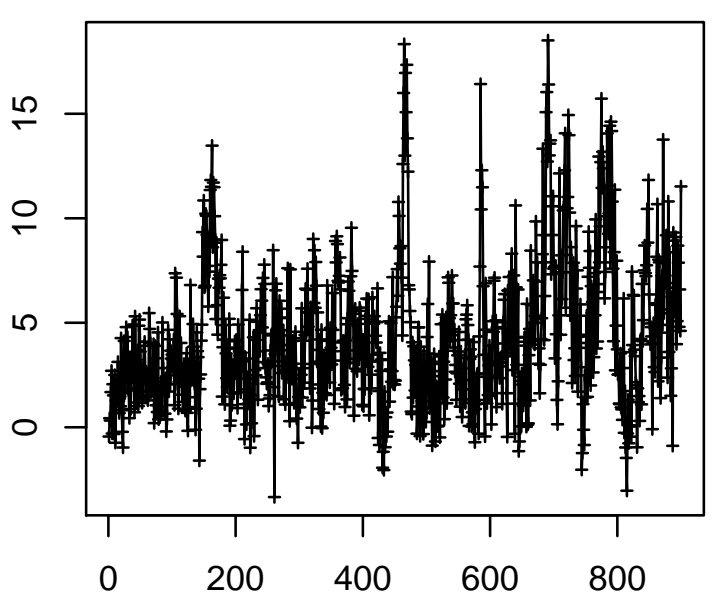

Time Point $(0.25 \mathrm{~Hz})$

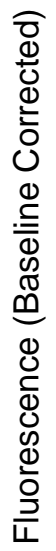

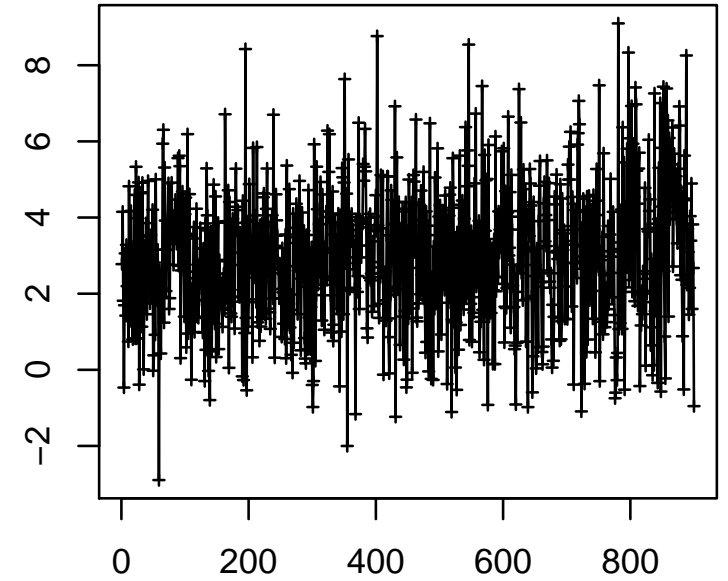

Time Point $(0.25 \mathrm{~Hz})$

Cell 1400

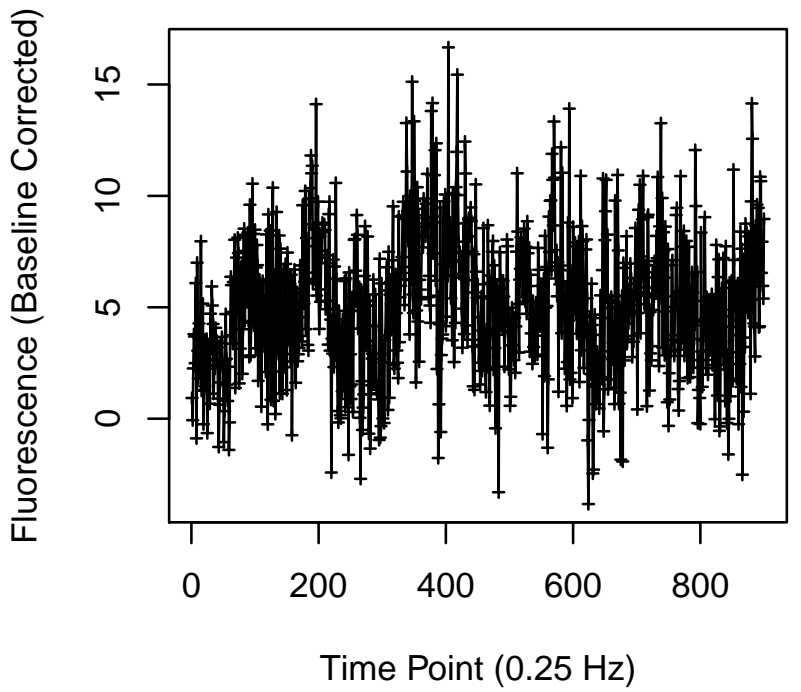


Cell 1405

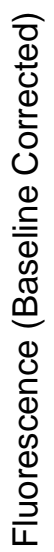

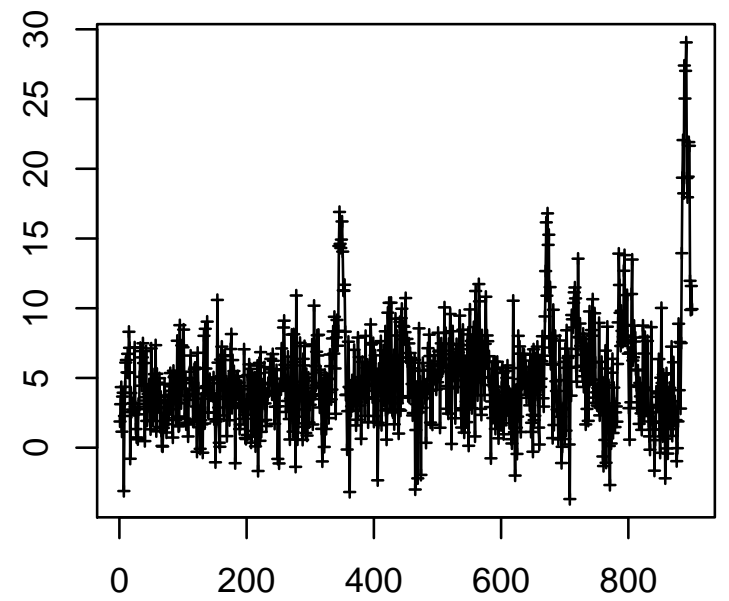

Time Point $(0.25 \mathrm{~Hz})$

Cell 1407

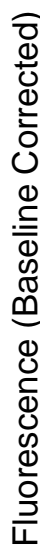

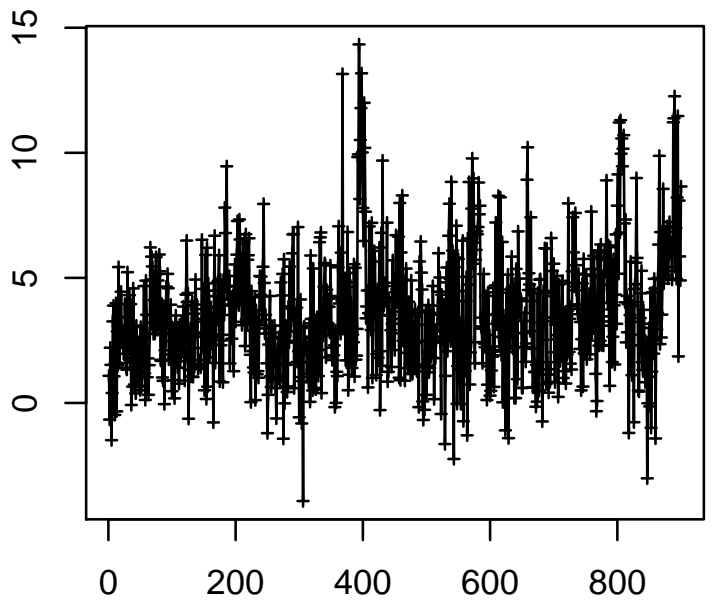

Time Point $(0.25 \mathrm{~Hz})$
Cell 1406

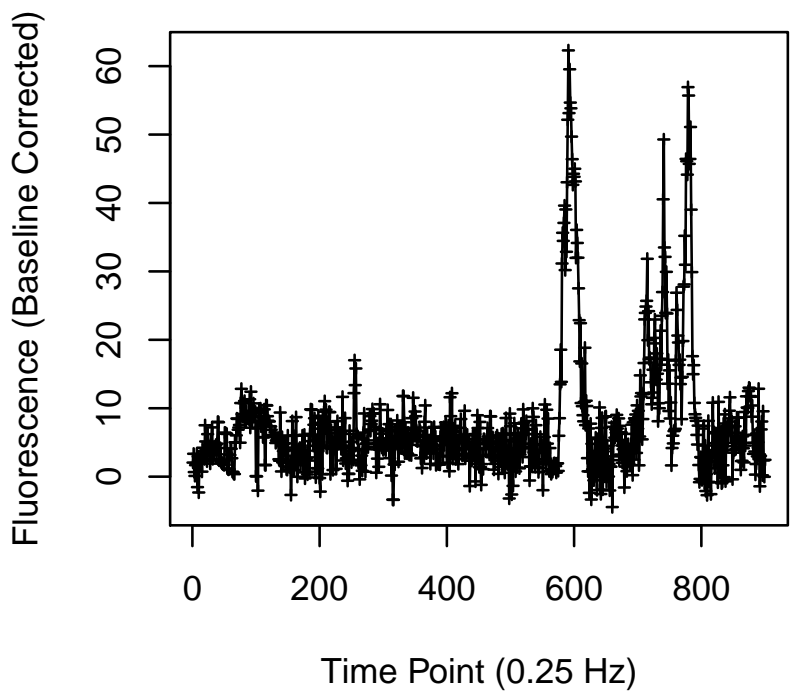

Cell 1408

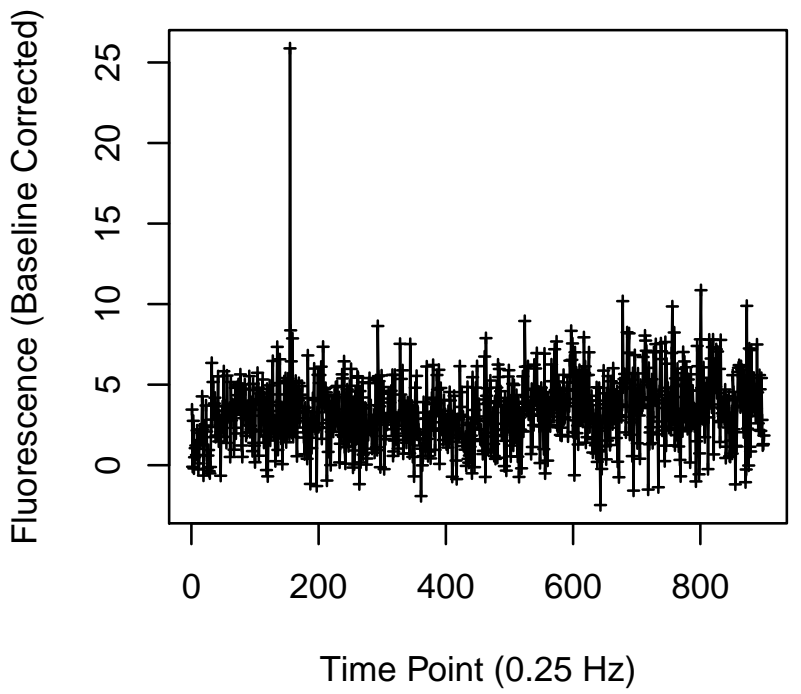


Cell 1413

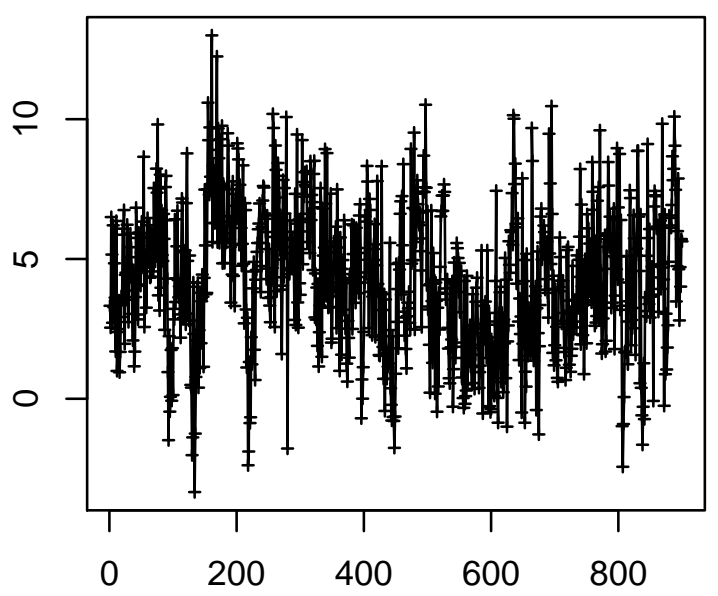

Time Point $(0.25 \mathrm{~Hz})$

Cell 1415

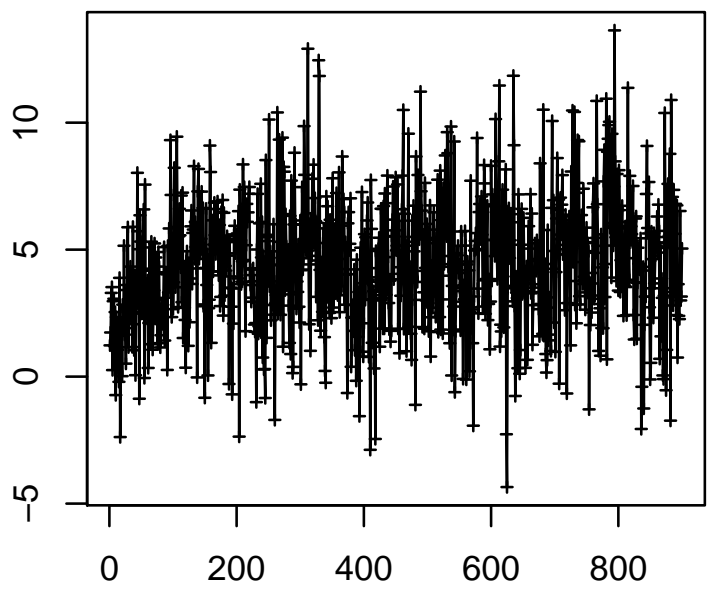

Time Point $(0.25 \mathrm{~Hz})$
Cell 1414

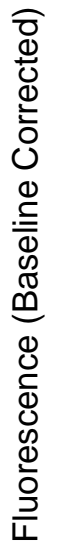

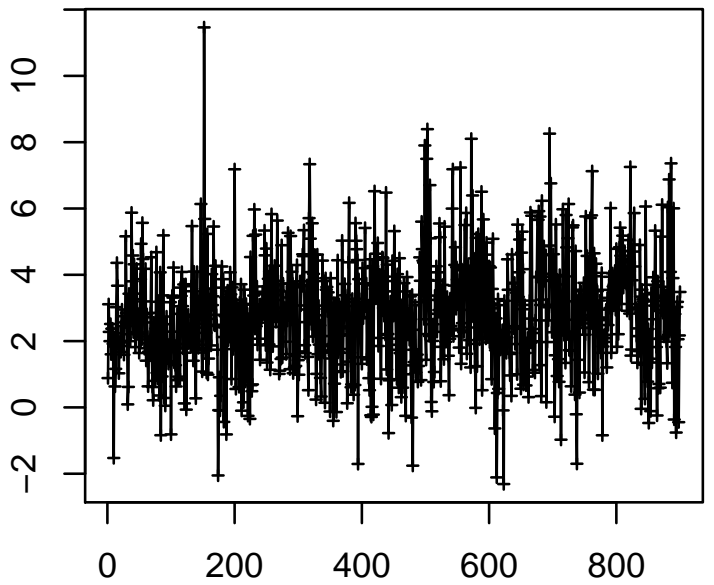

Time Point $(0.25 \mathrm{~Hz})$

Cell 1416

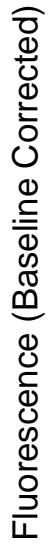

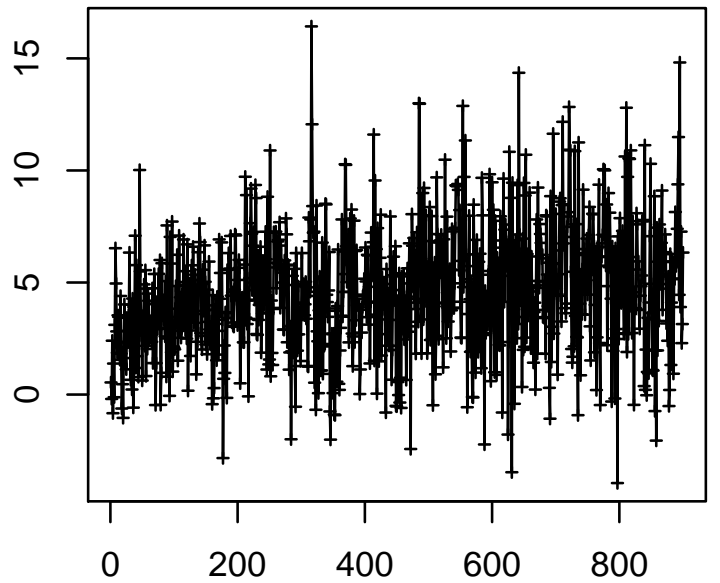

Time Point $(0.25 \mathrm{~Hz})$ 
Cell 1417

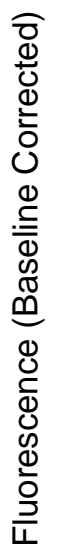

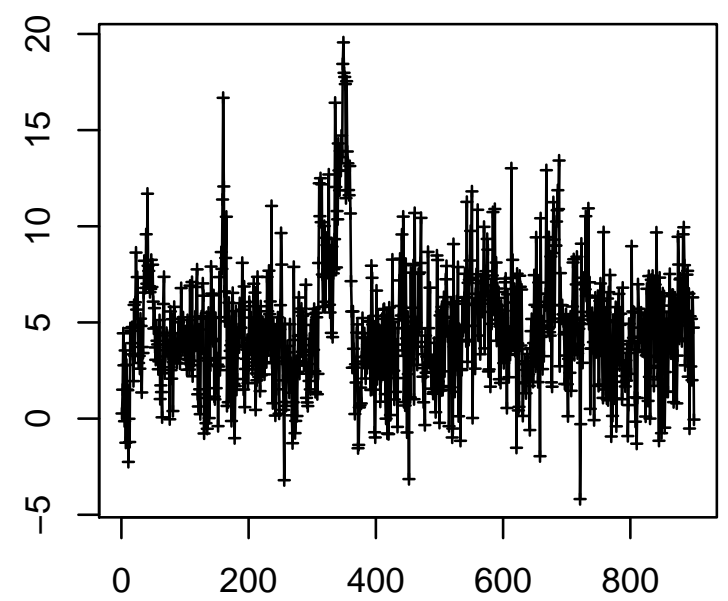

Time Point $(0.25 \mathrm{~Hz})$

Cell 1419

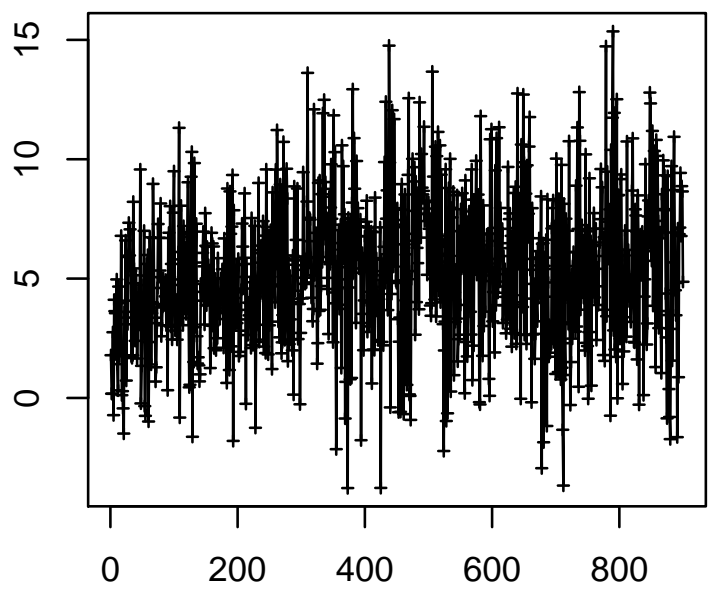

Time Point $(0.25 \mathrm{~Hz})$
Cell 1418

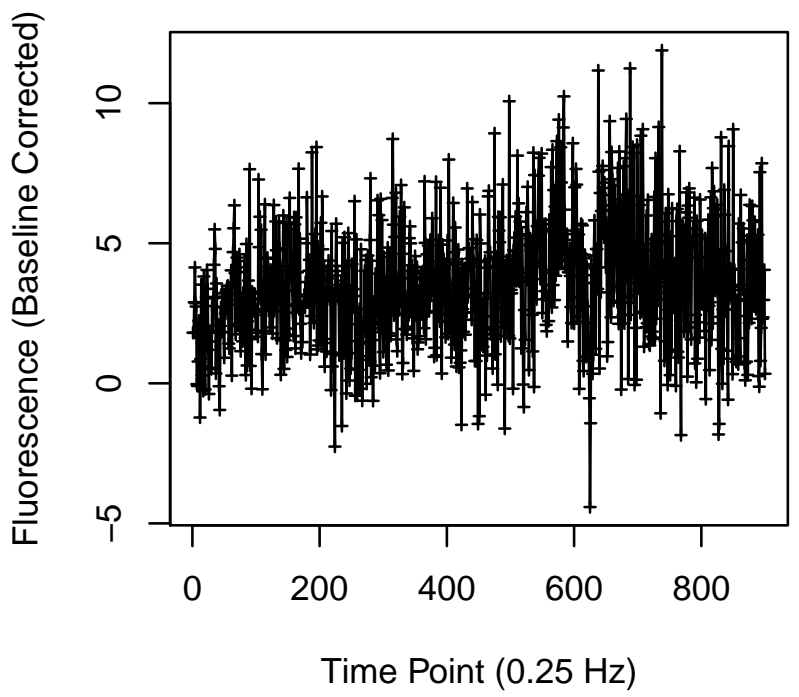

Cell 1420

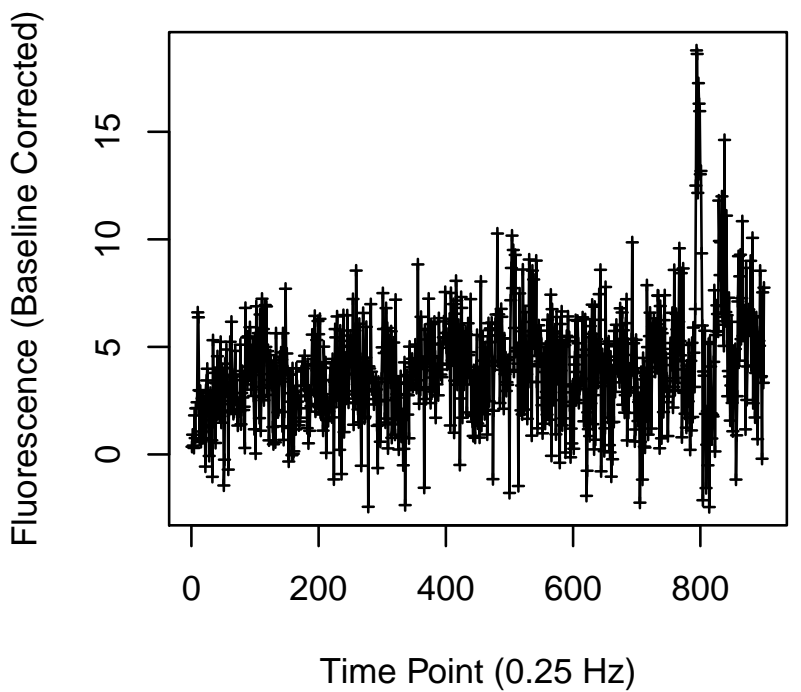


Cell 1421

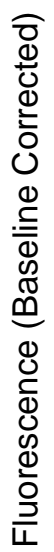

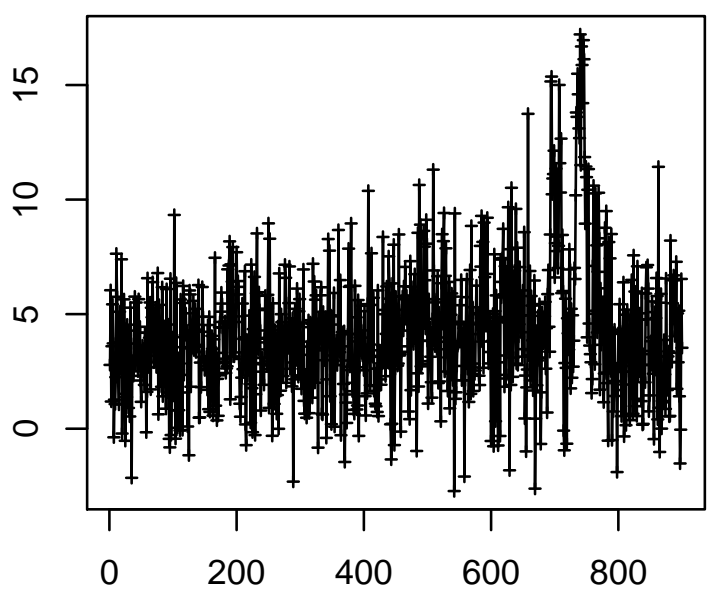

Time Point $(0.25 \mathrm{~Hz})$

Cell 1423

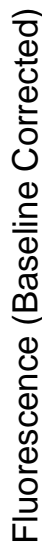

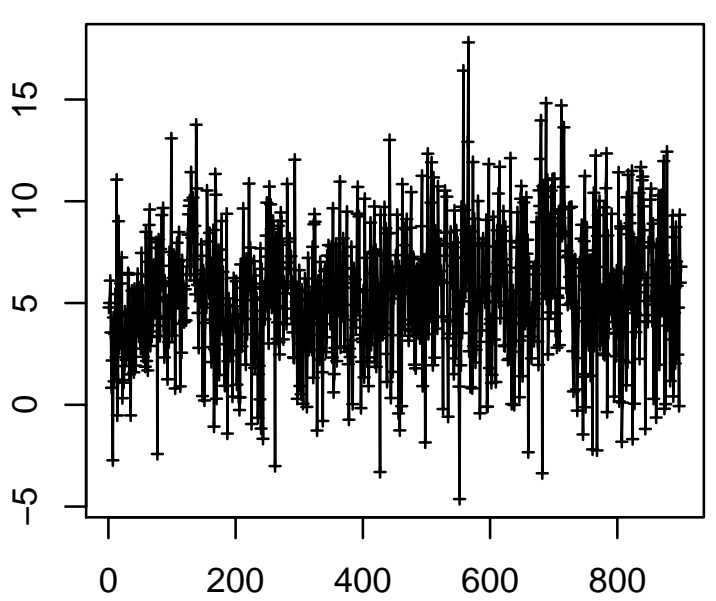

Time Point $(0.25 \mathrm{~Hz})$
Cell 1422

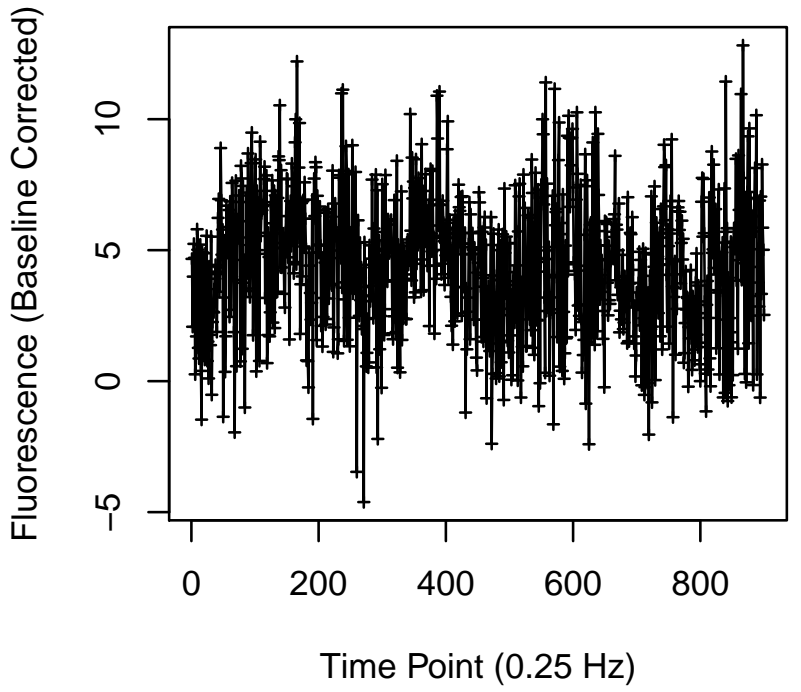

Cell 1424

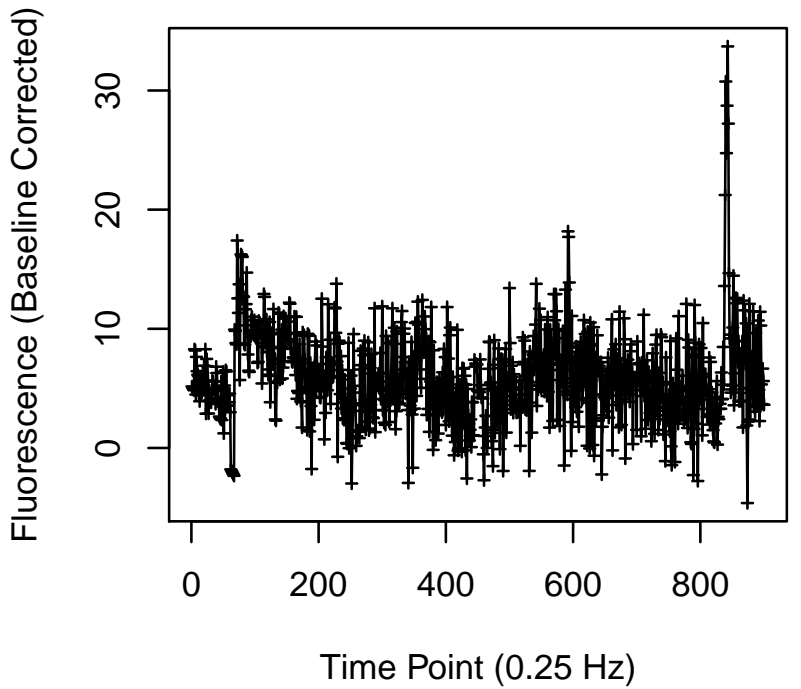


Cell 1433
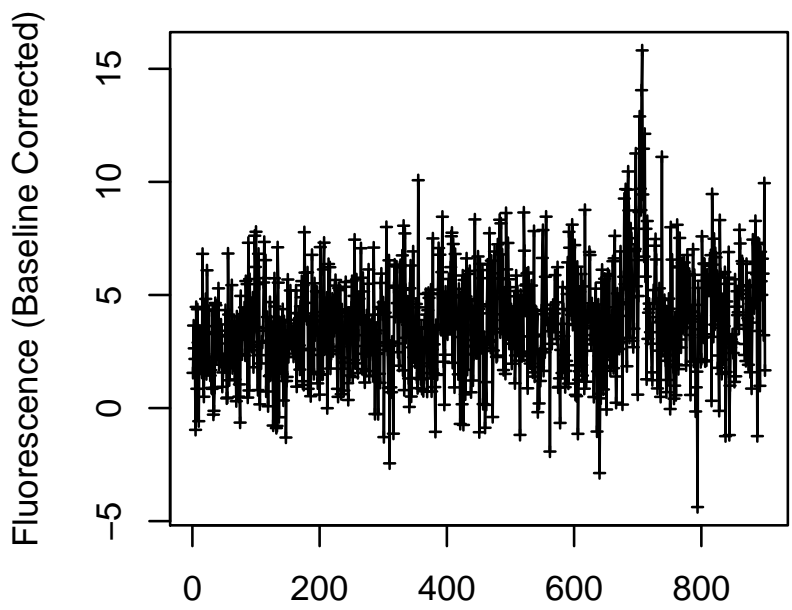

Time Point $(0.25 \mathrm{~Hz})$

Cell 1435

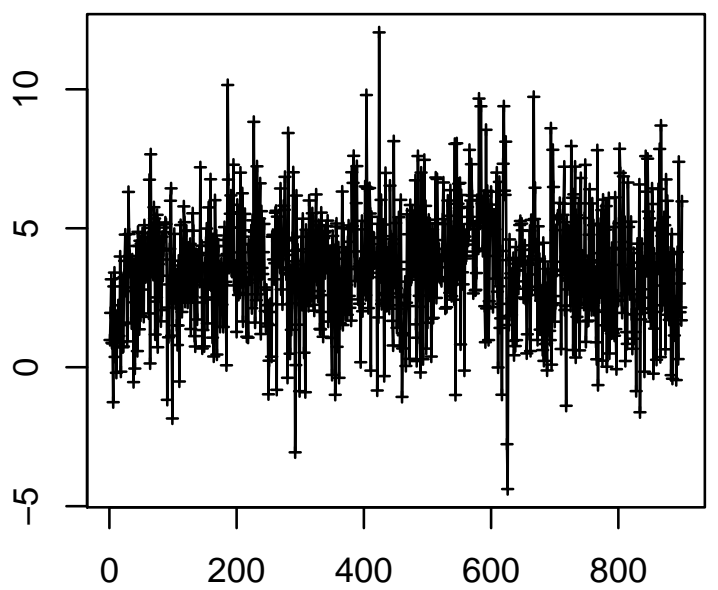

Time Point $(0.25 \mathrm{~Hz})$
Cell 1434

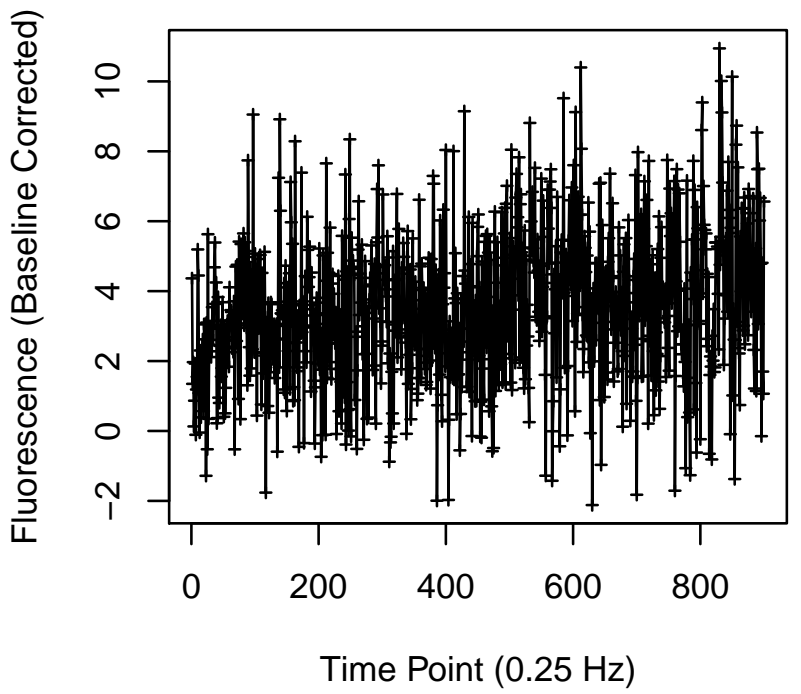

Cell 1436

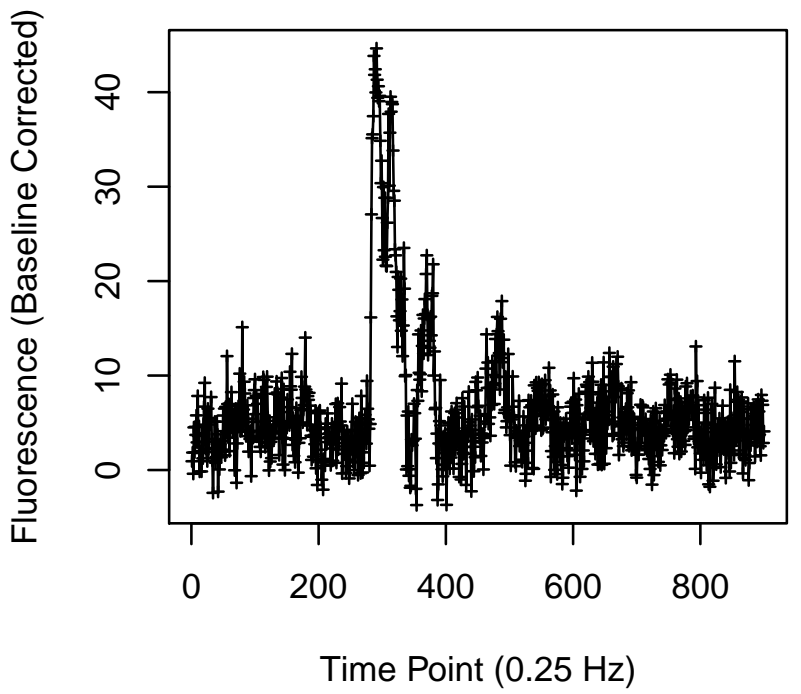




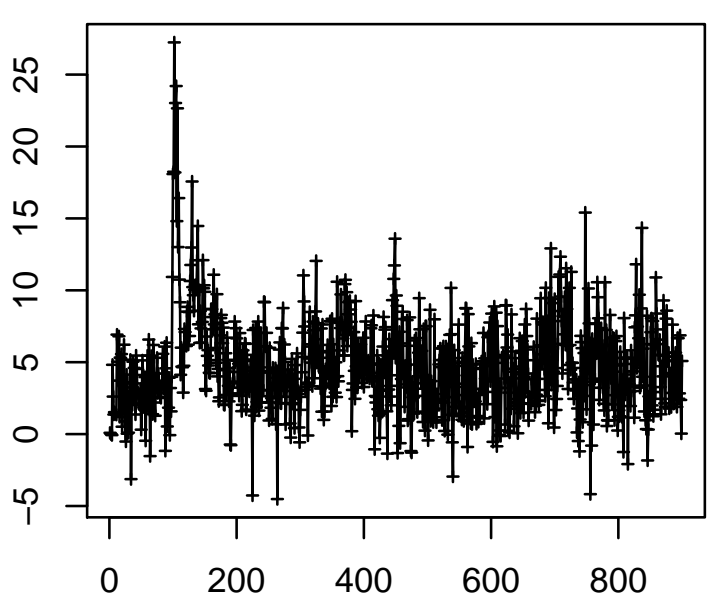

Time Point $(0.25 \mathrm{~Hz})$

Cell 1439

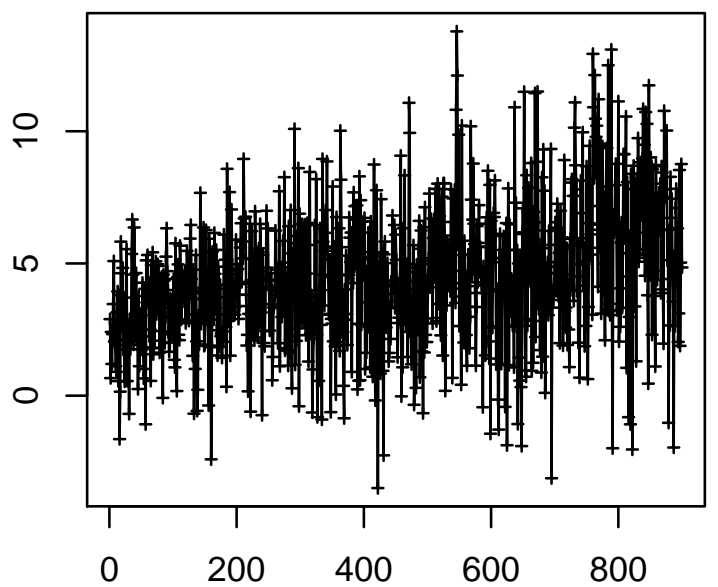

Time Point $(0.25 \mathrm{~Hz})$

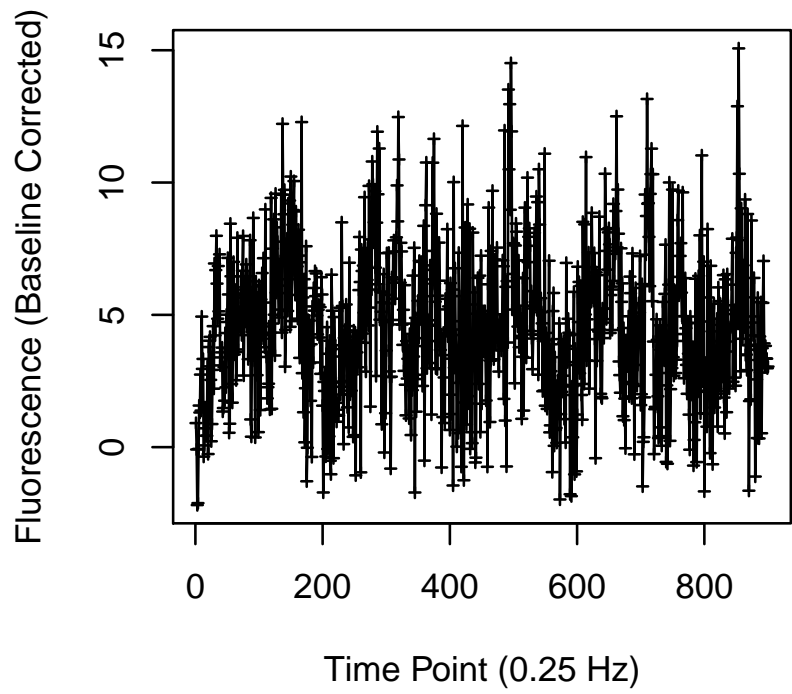

Cell 1440

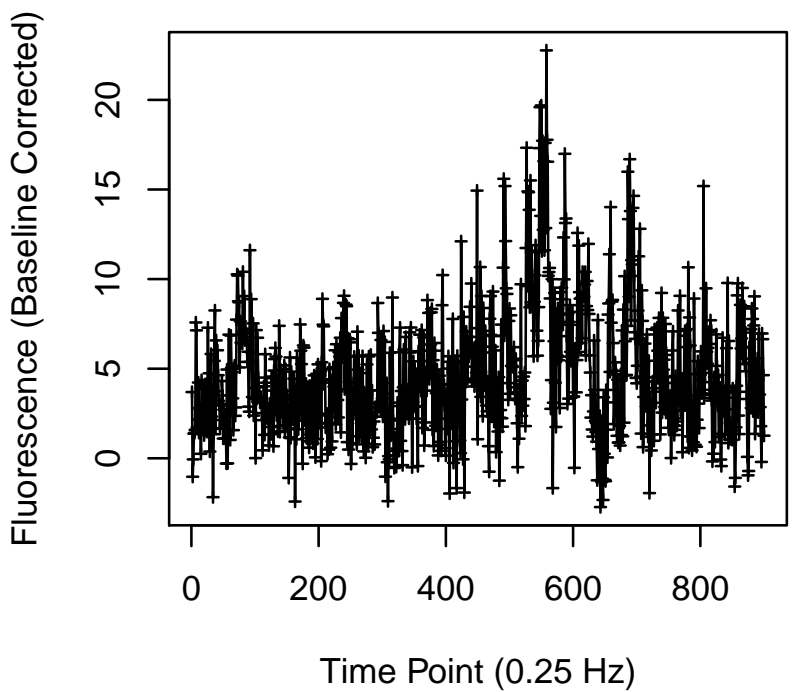


Cell 1441

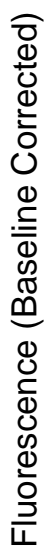

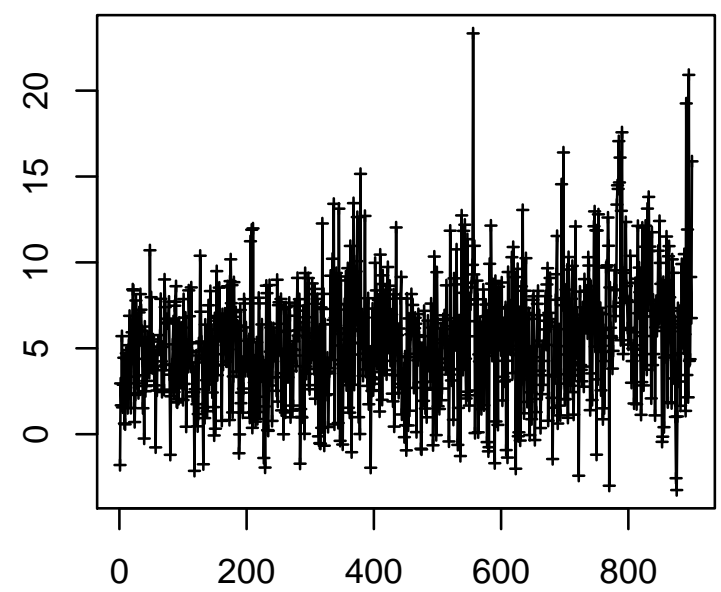

Time Point $(0.25 \mathrm{~Hz})$

Cell 1443

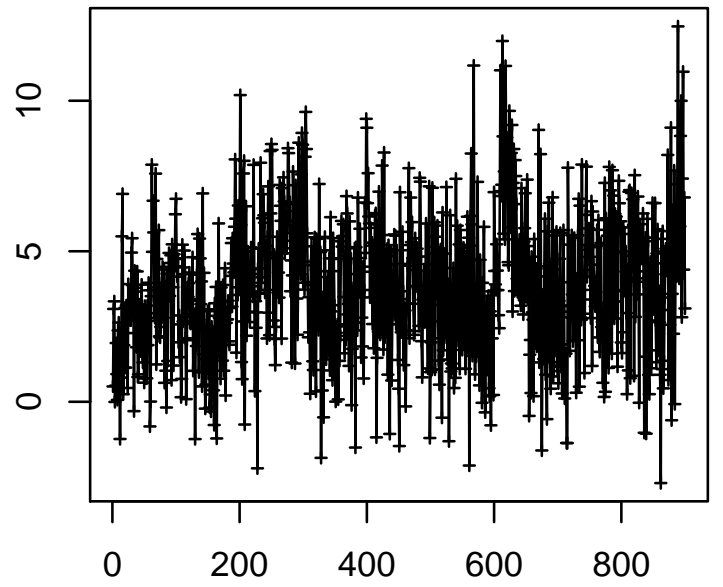

Time Point $(0.25 \mathrm{~Hz})$
Cell 1442

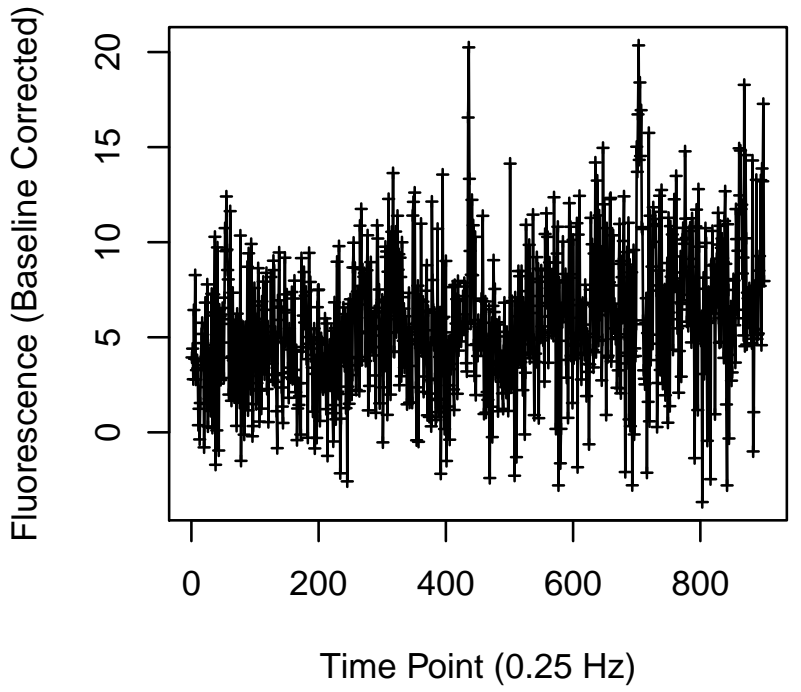

Cell 1444

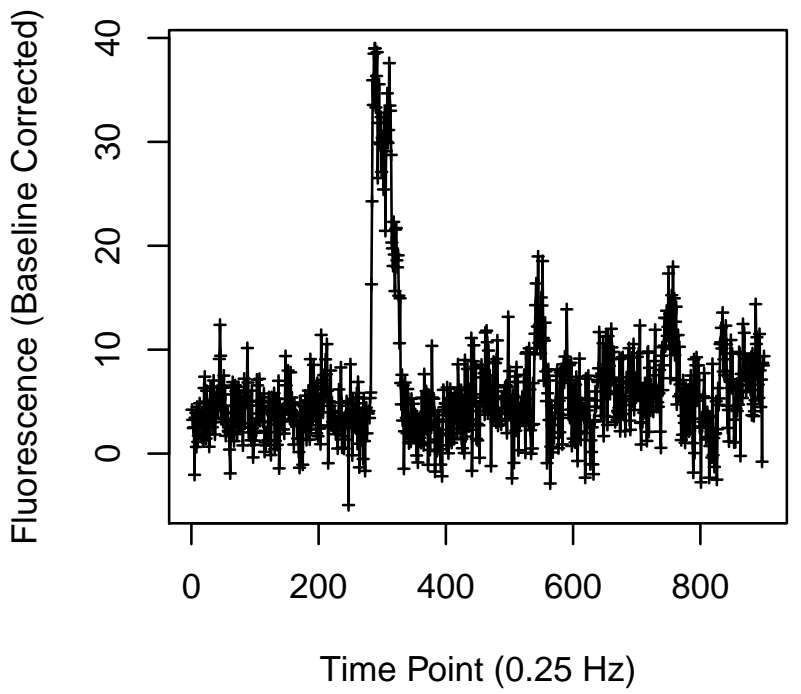




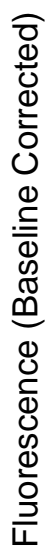

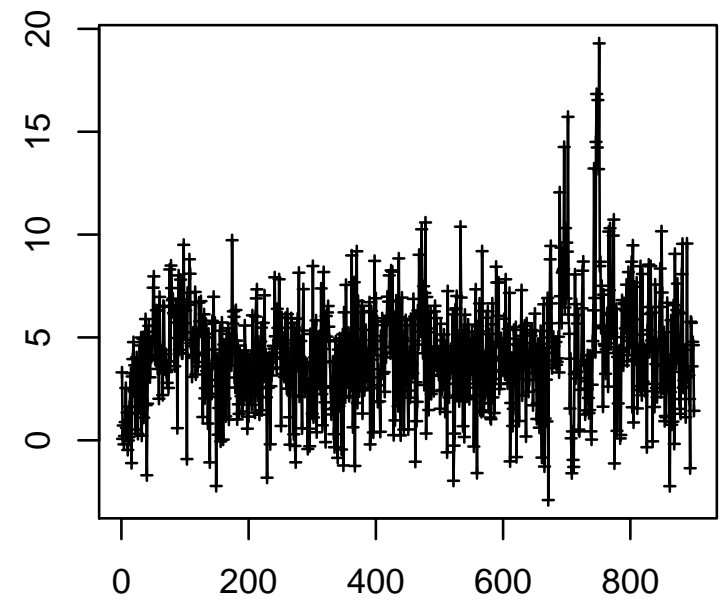

Time Point $(0.25 \mathrm{~Hz})$

Cell 1447

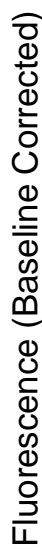

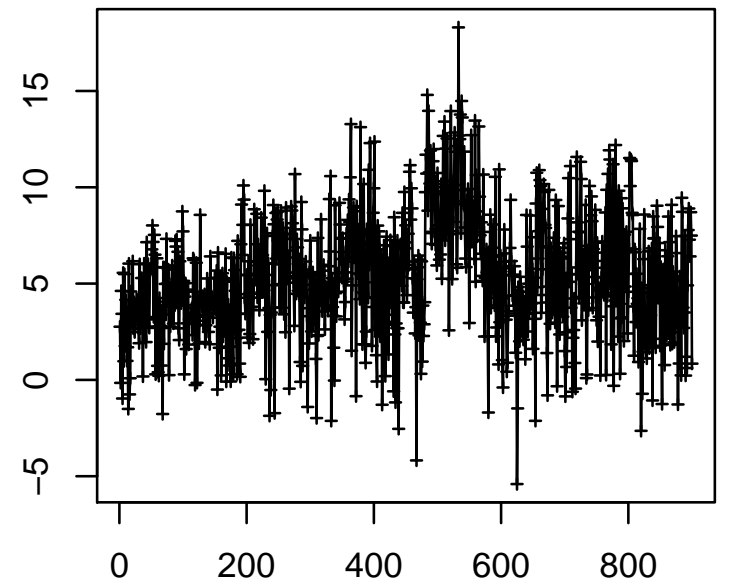

Time Point $(0.25 \mathrm{~Hz})$

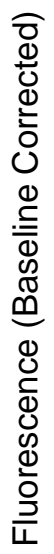

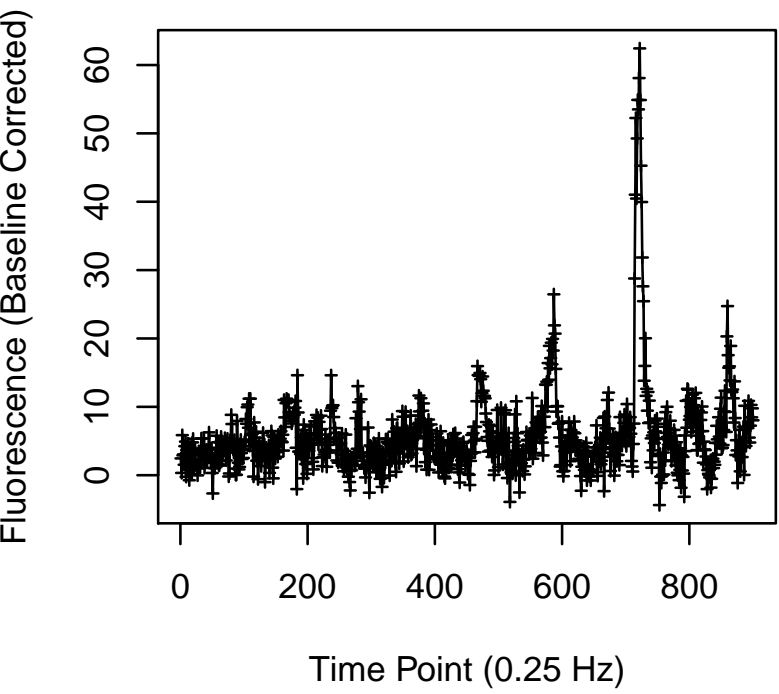

Cell 1448

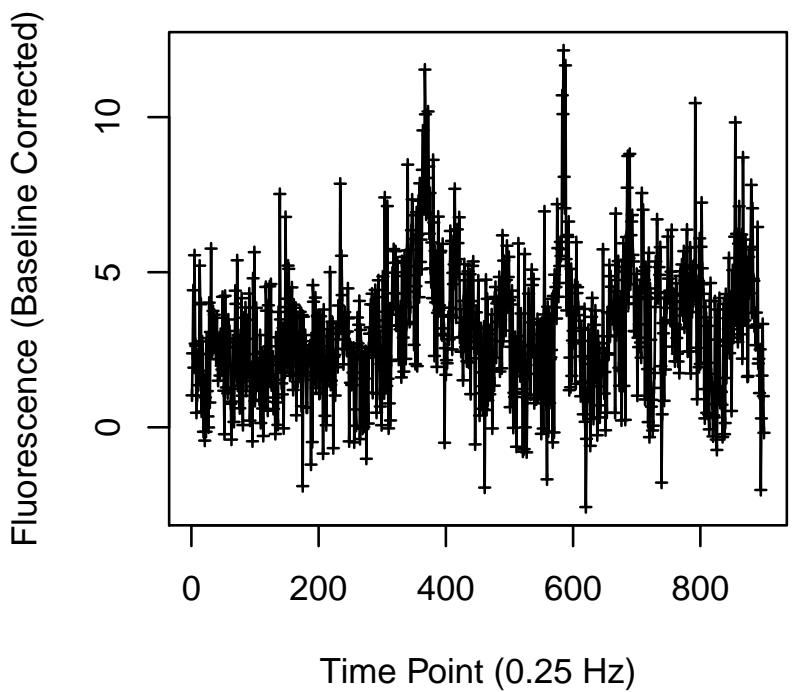


Cell 1449

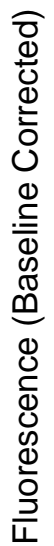

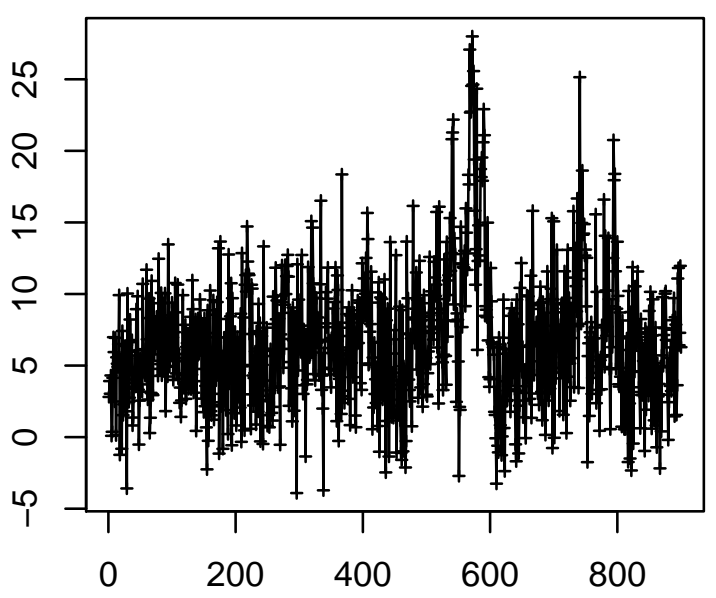

Time Point $(0.25 \mathrm{~Hz})$

Cell 1451

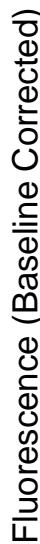

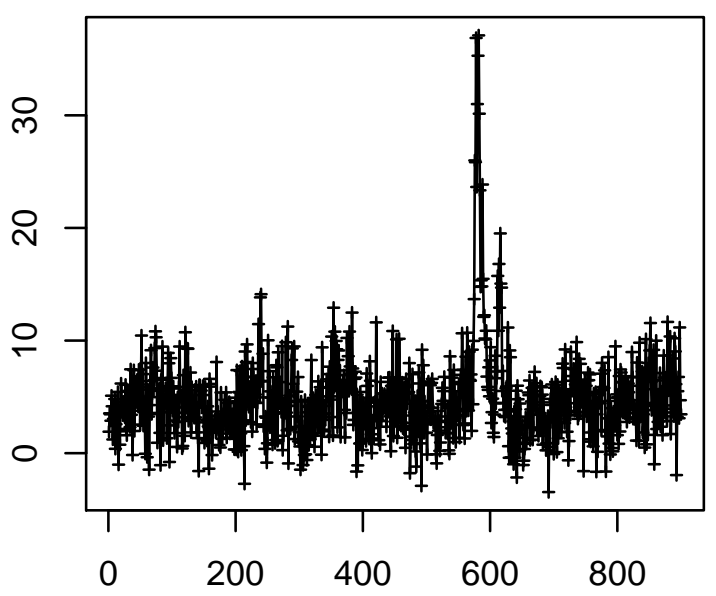

Time Point $(0.25 \mathrm{~Hz})$
Cell 1450

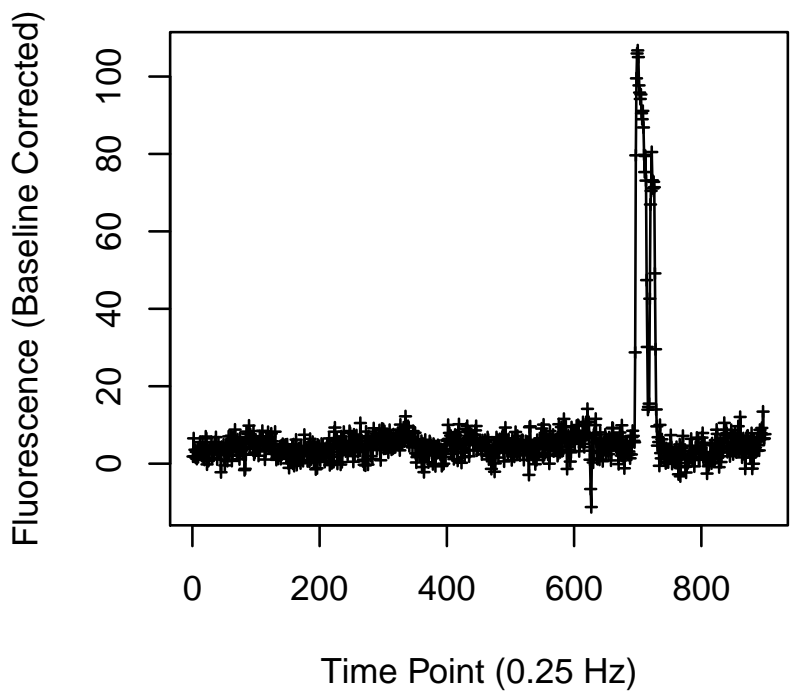

Cell 1452

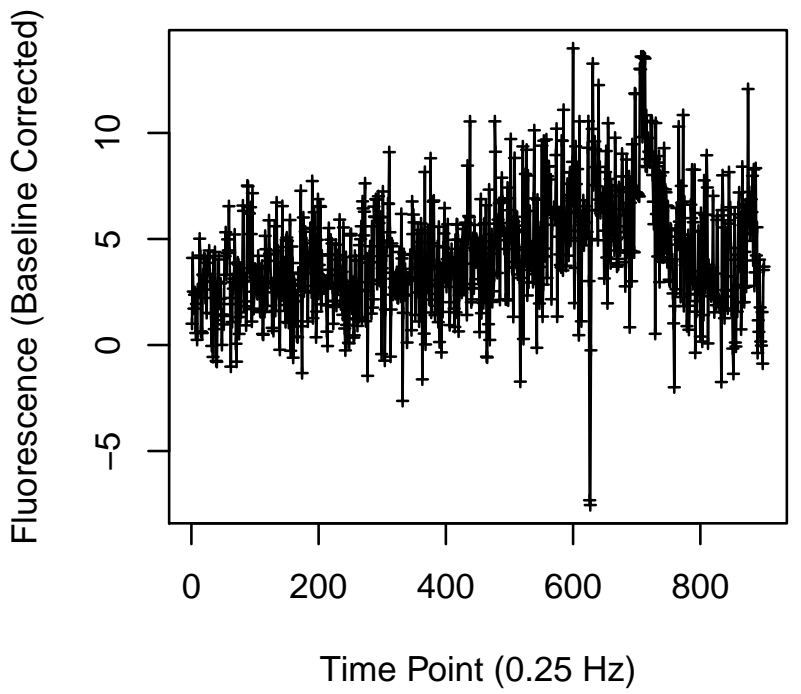


Cell 1453

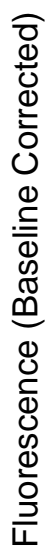

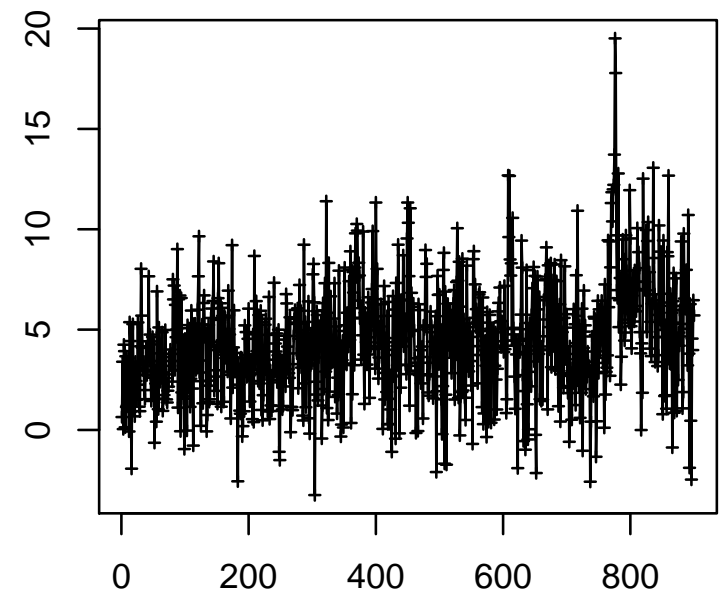

Time Point $(0.25 \mathrm{~Hz})$

Cell 1455

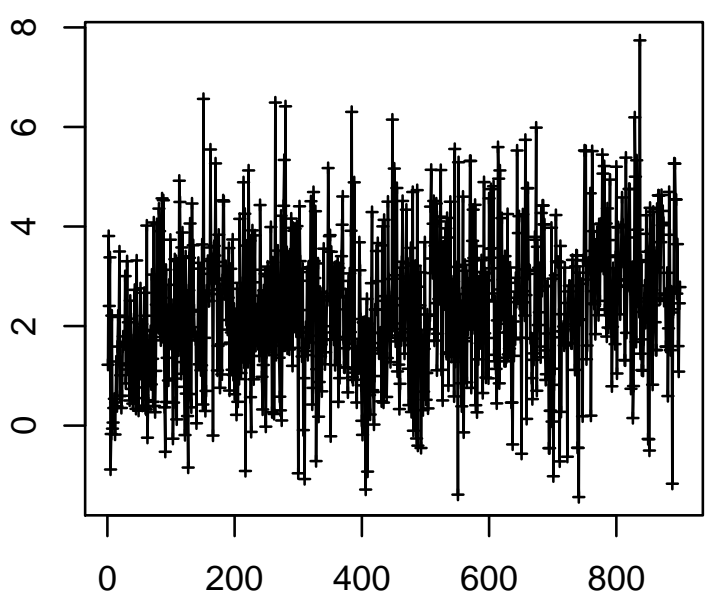

Time Point $(0.25 \mathrm{~Hz})$
Cell 1454

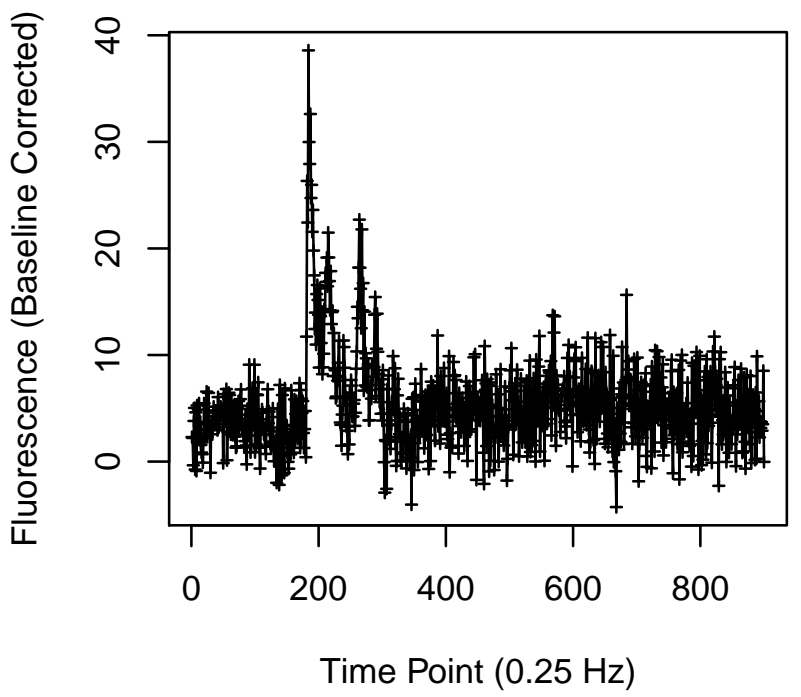

Cell 1456

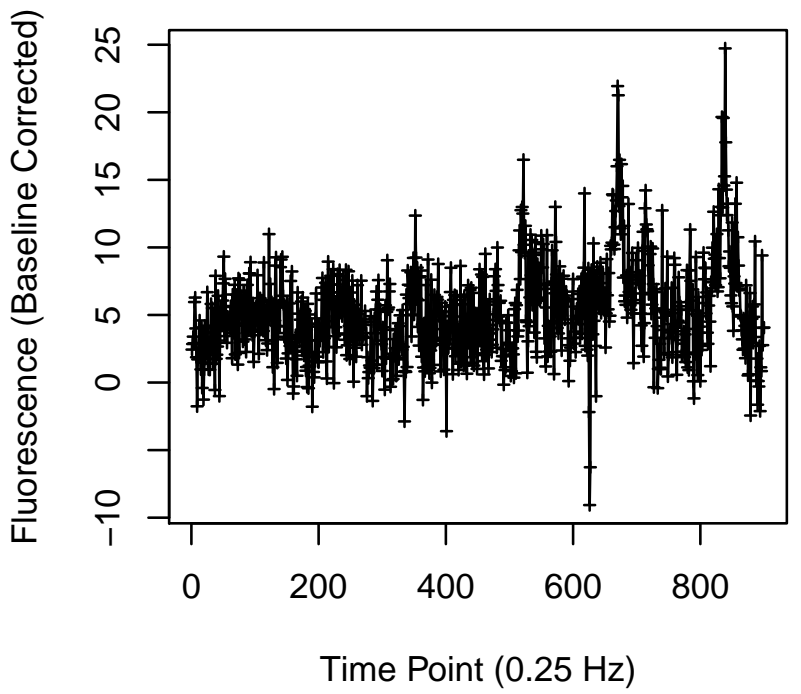


Cell 1457
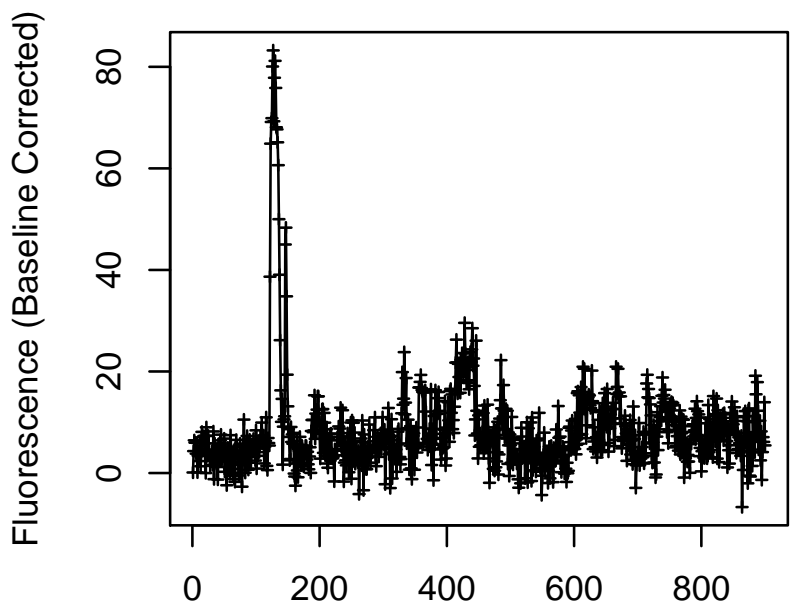

Time Point $(0.25 \mathrm{~Hz})$

Cell 1459

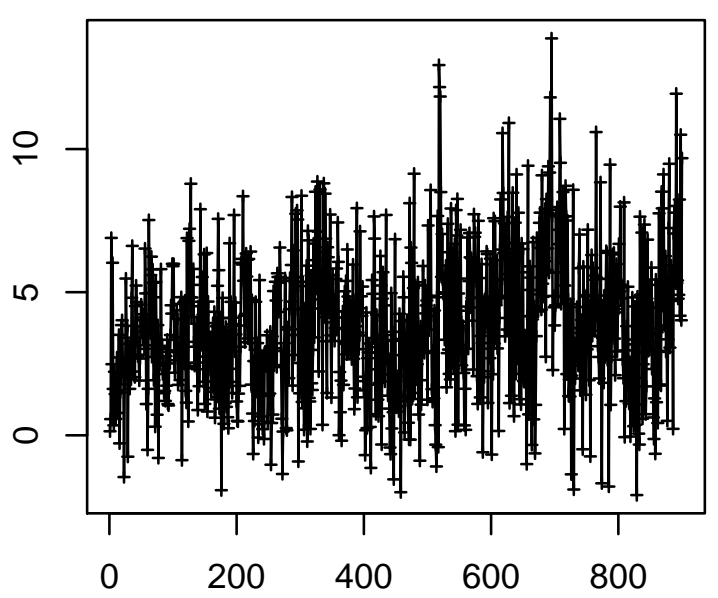

Time Point $(0.25 \mathrm{~Hz})$
Cell 1458

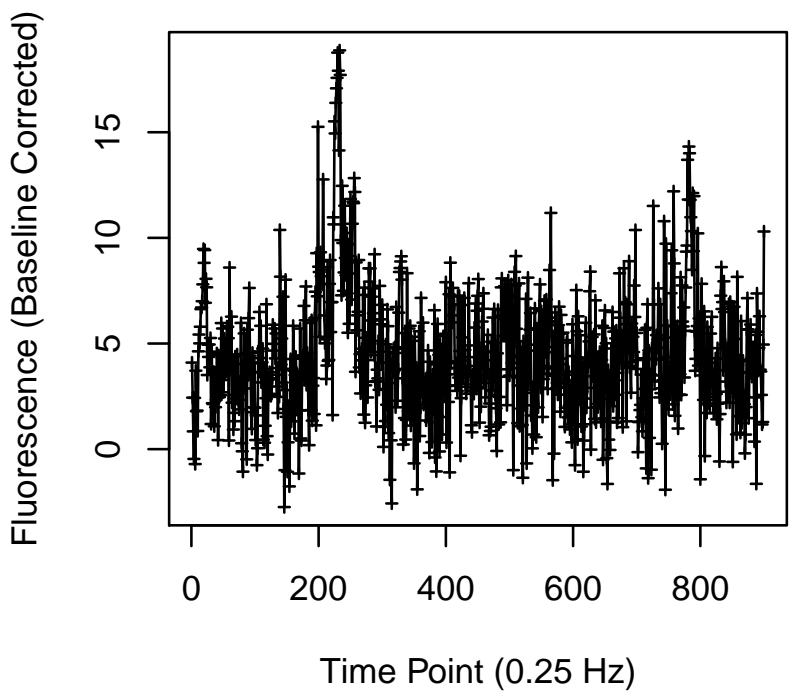

Cell 1460

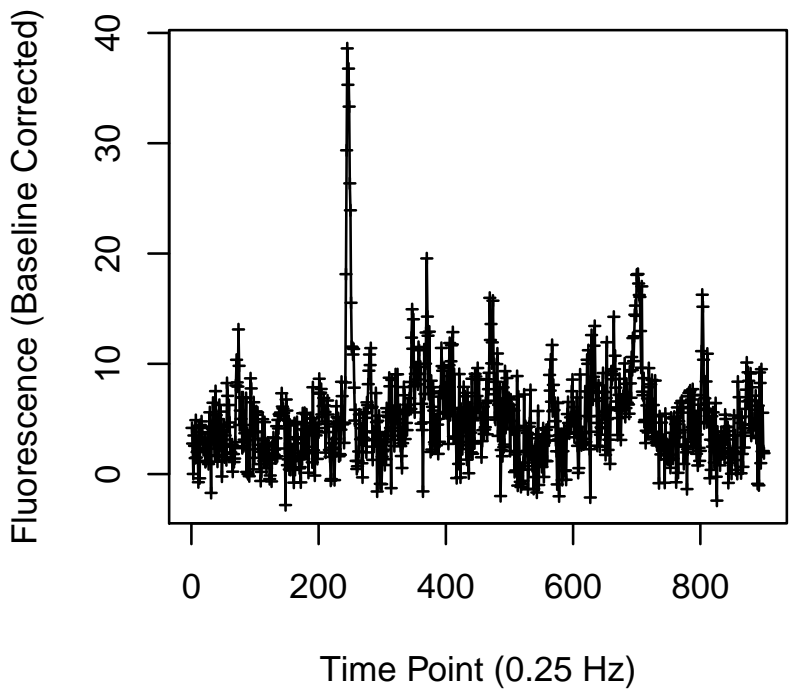


Cell 1461

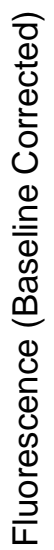

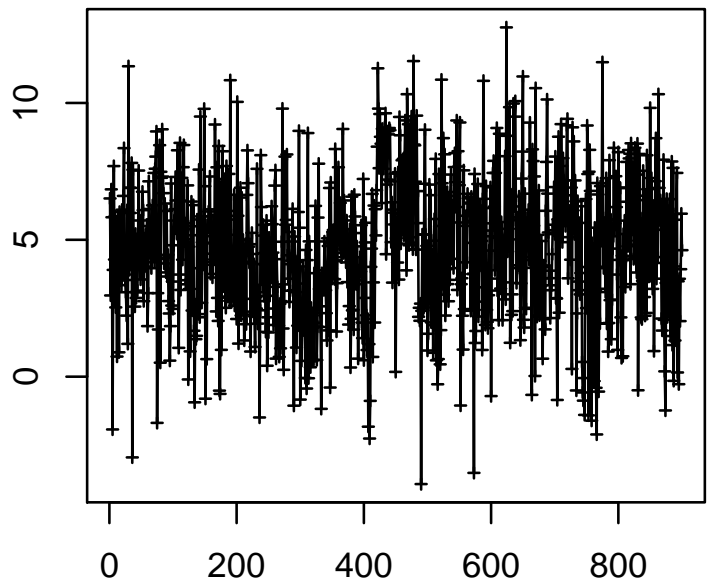

Time Point $(0.25 \mathrm{~Hz})$

Cell 1463

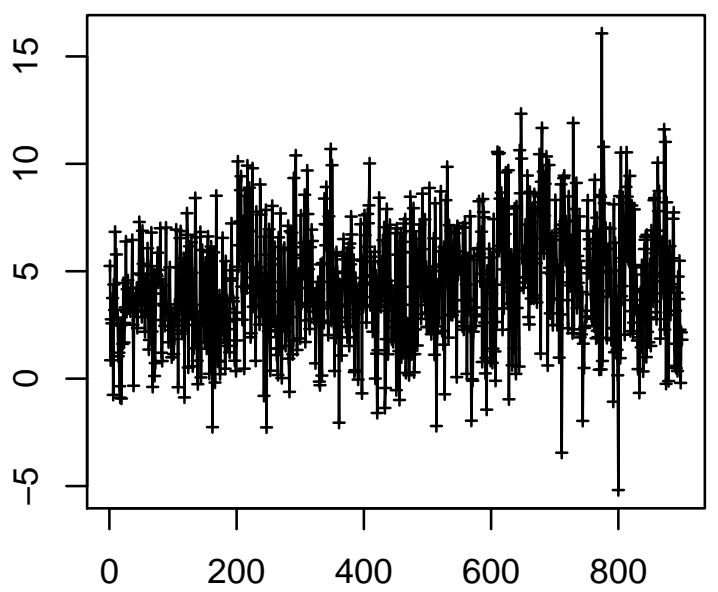

Time Point $(0.25 \mathrm{~Hz})$
Cell 1462

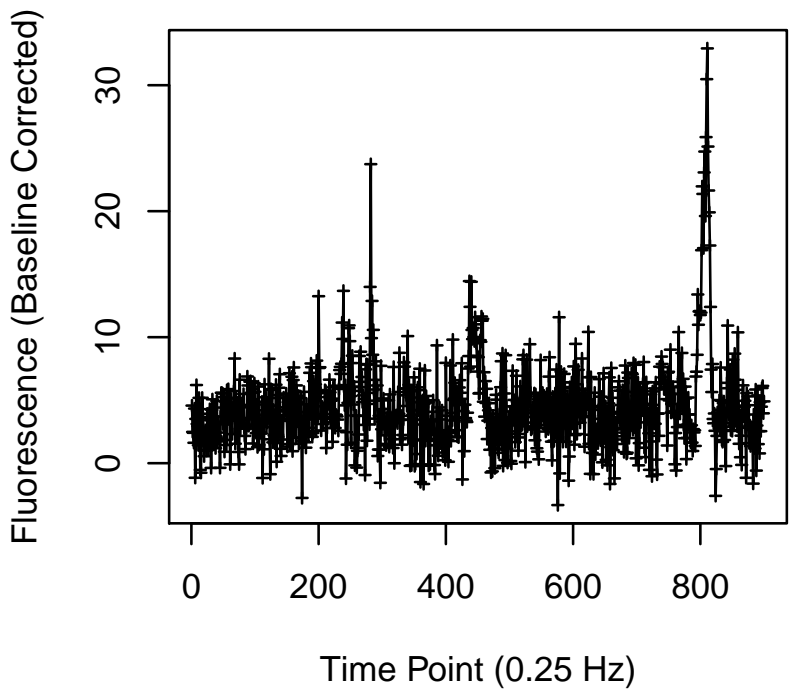

Cell 1464

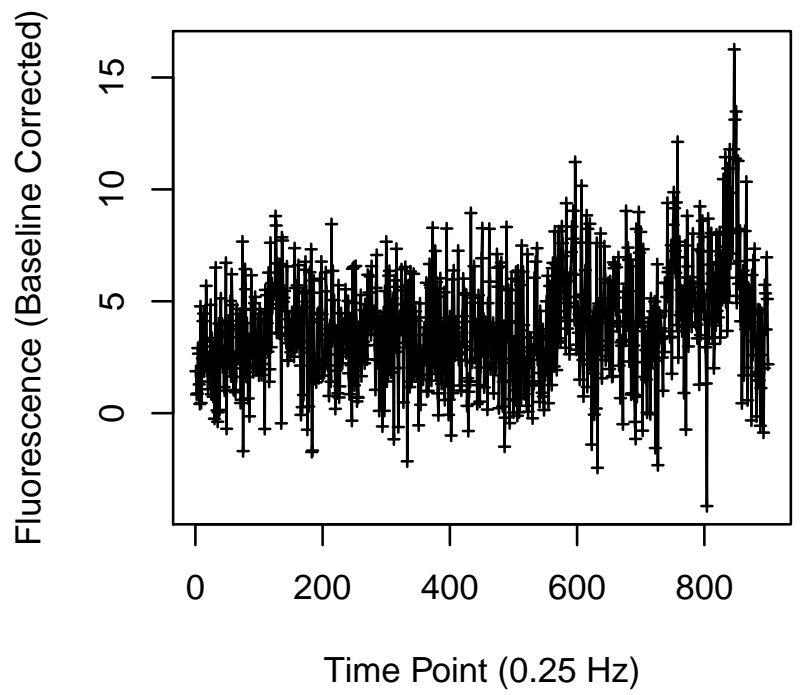


Cell 1465

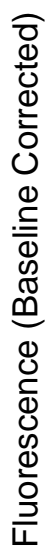

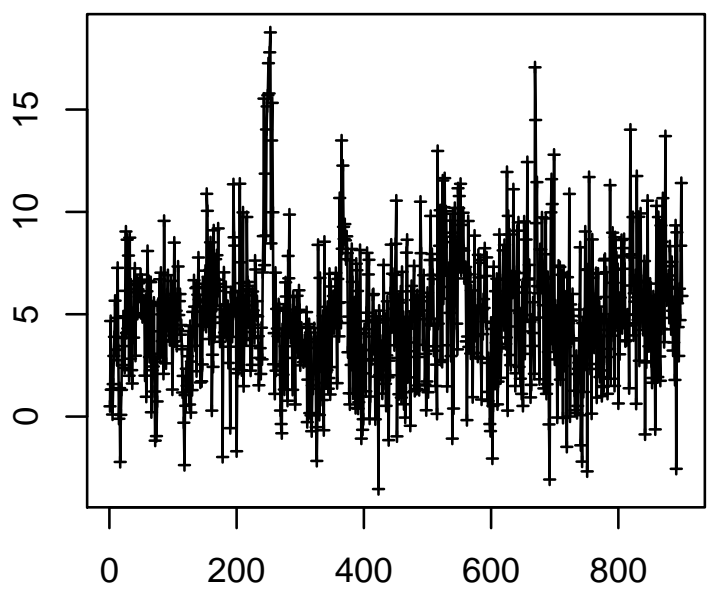

Time Point $(0.25 \mathrm{~Hz})$

Cell 1467

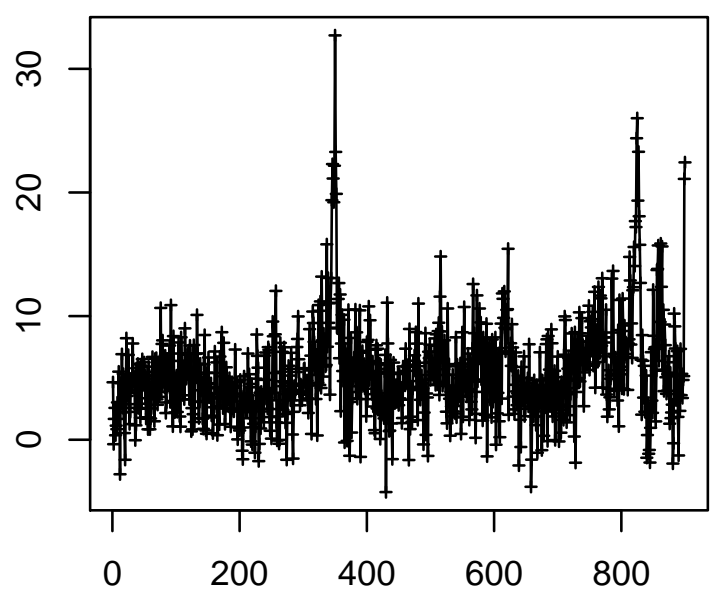

Time Point $(0.25 \mathrm{~Hz})$
Cell 1466

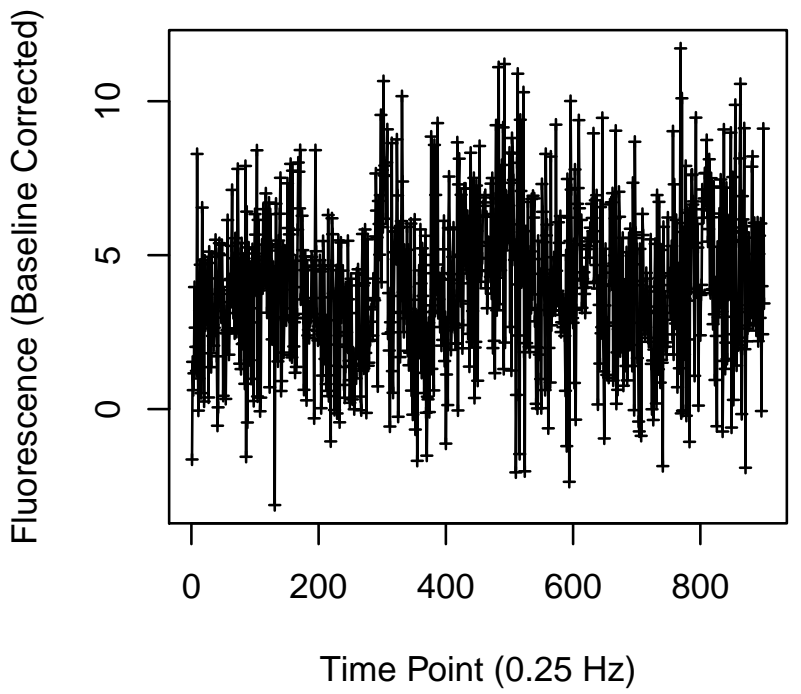

Cell 1468

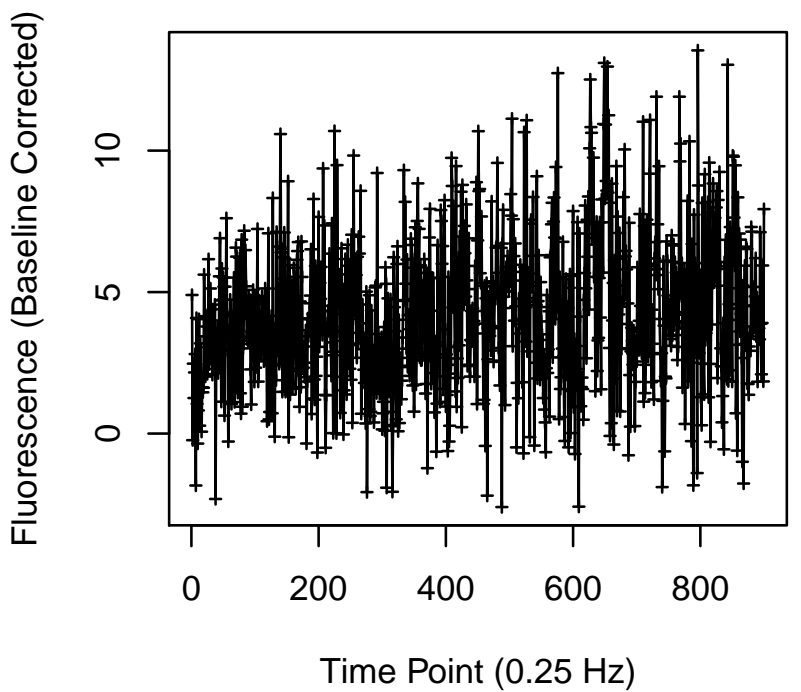


Cell 1469

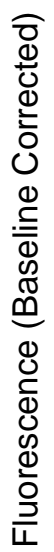

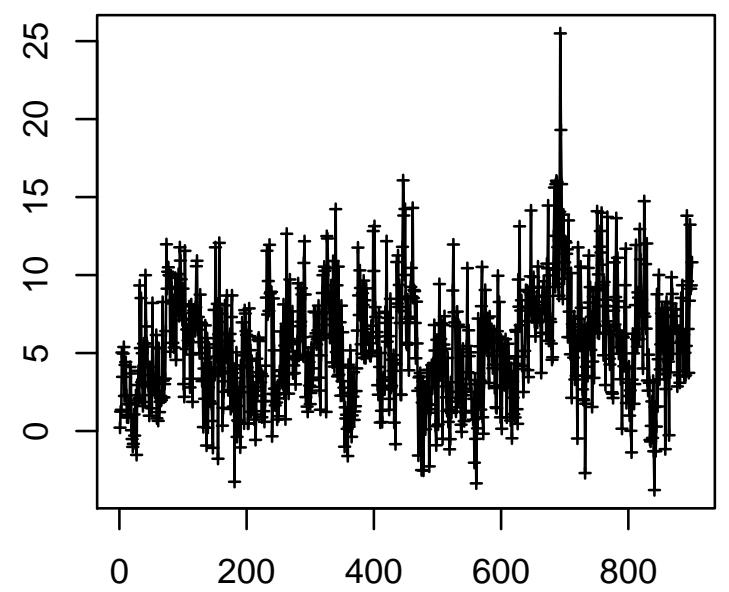

Time Point $(0.25 \mathrm{~Hz})$

Cell 1471

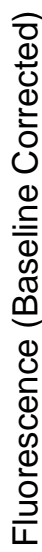

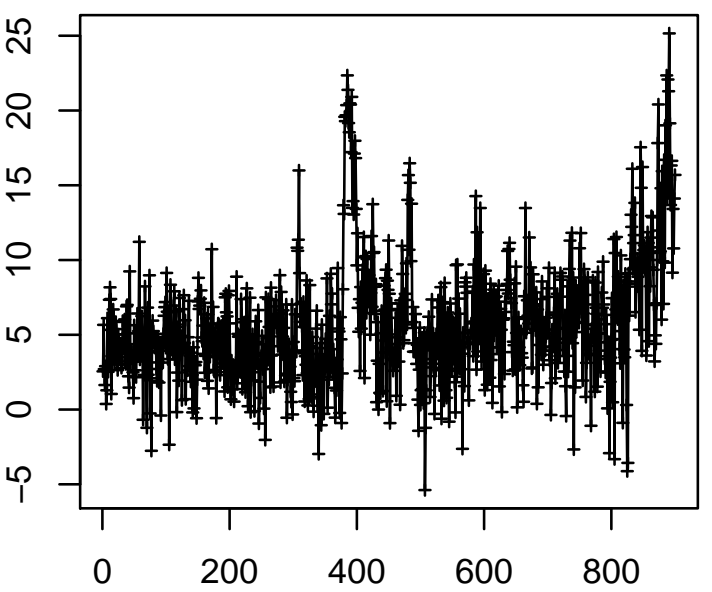

Time Point $(0.25 \mathrm{~Hz})$
Cell 1470

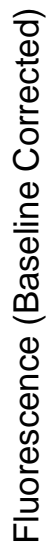

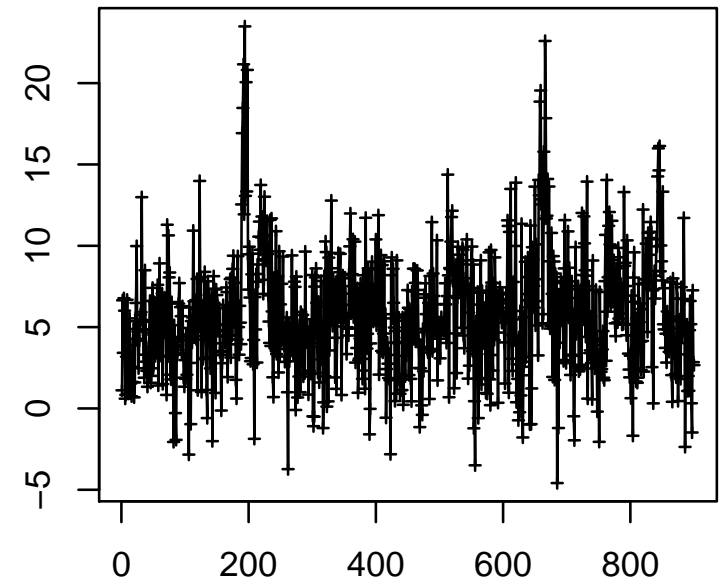

Time Point $(0.25 \mathrm{~Hz})$

Cell 1472

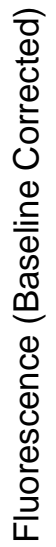

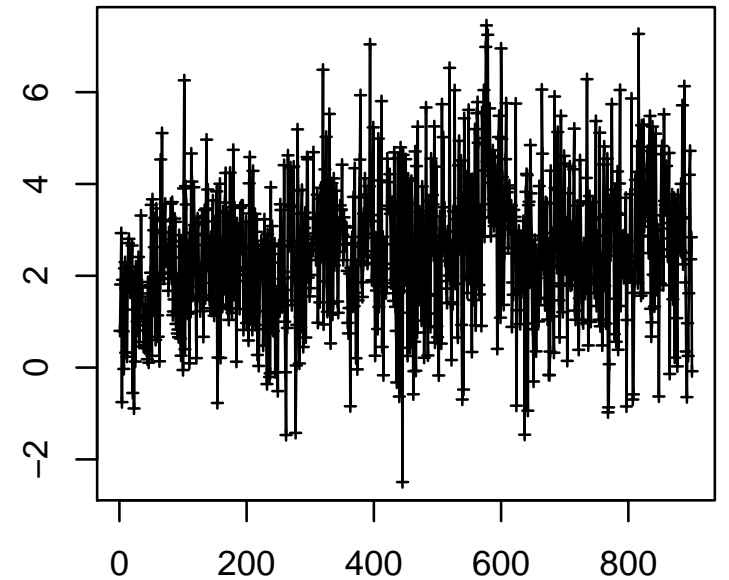

Time Point $(0.25 \mathrm{~Hz})$ 


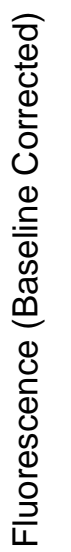

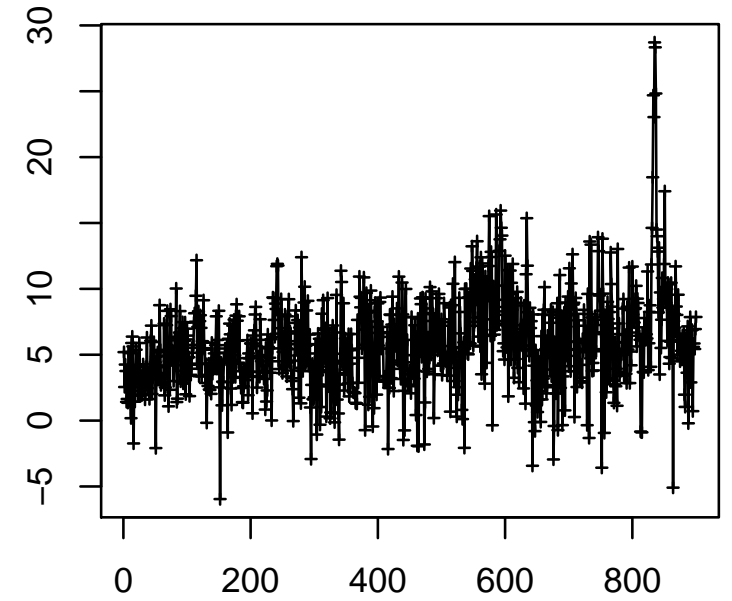

Time Point $(0.25 \mathrm{~Hz})$

Cell 1483

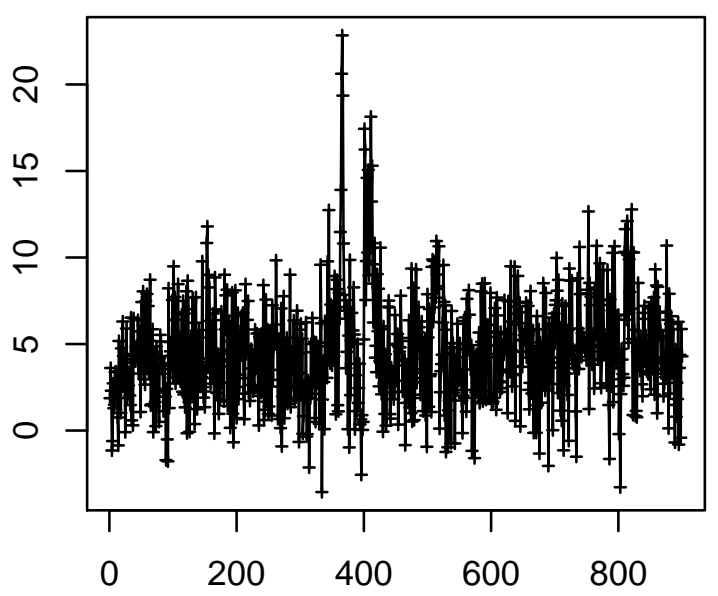

Time Point $(0.25 \mathrm{~Hz})$

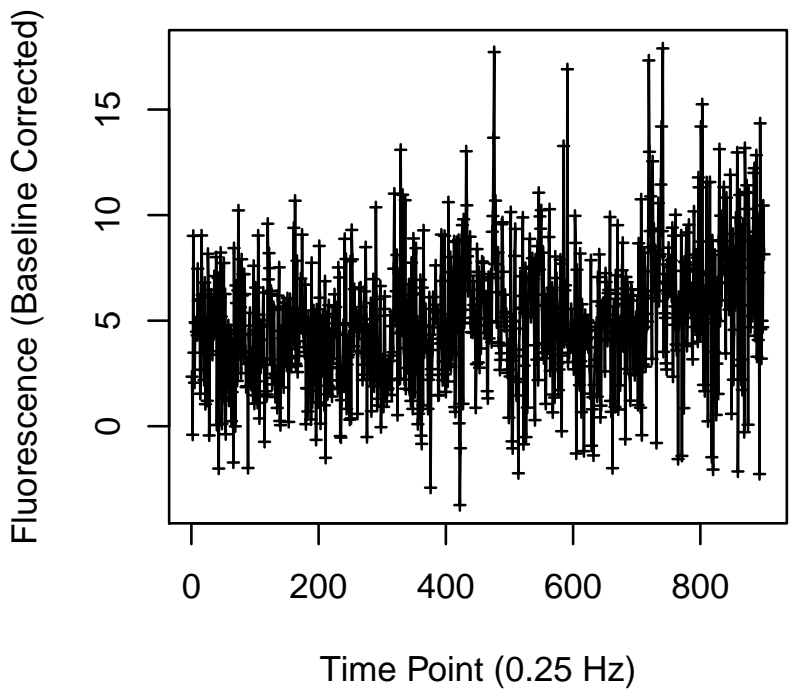

Cell 1484

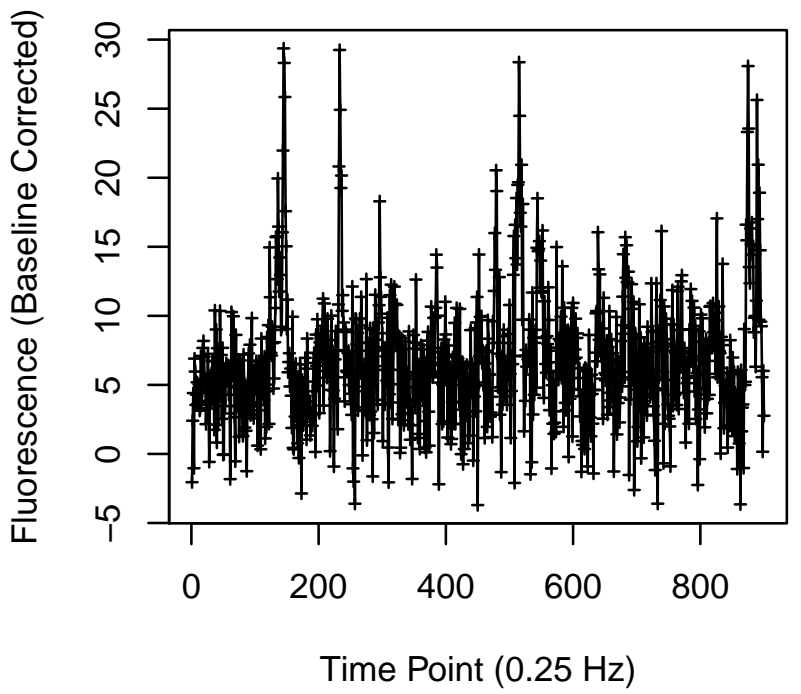


Cell 1485

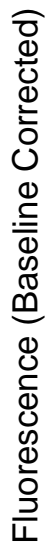

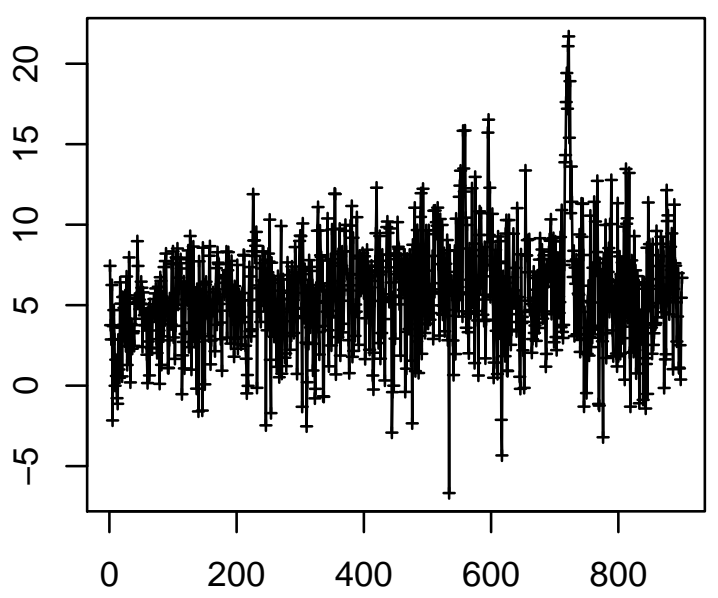

Time Point $(0.25 \mathrm{~Hz})$

Cell 1487

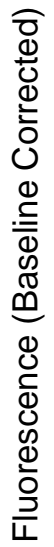

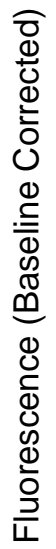

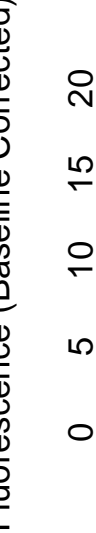

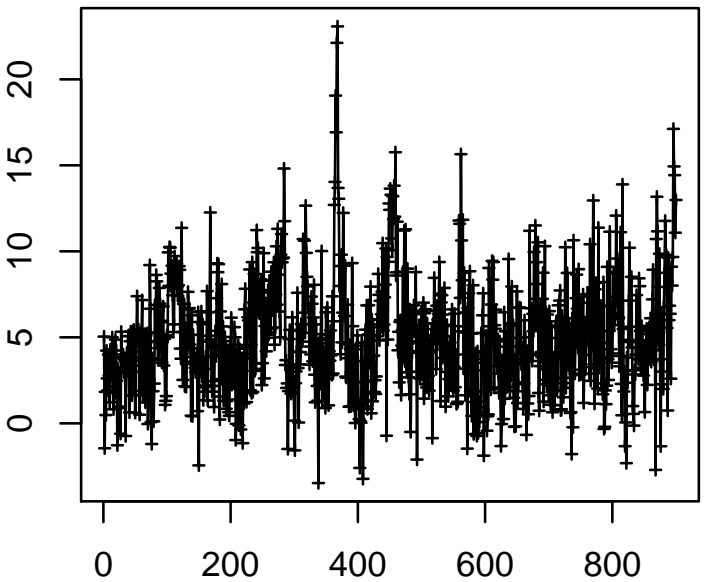

Time Point $(0.25 \mathrm{~Hz})$

Cell 1488

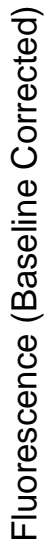

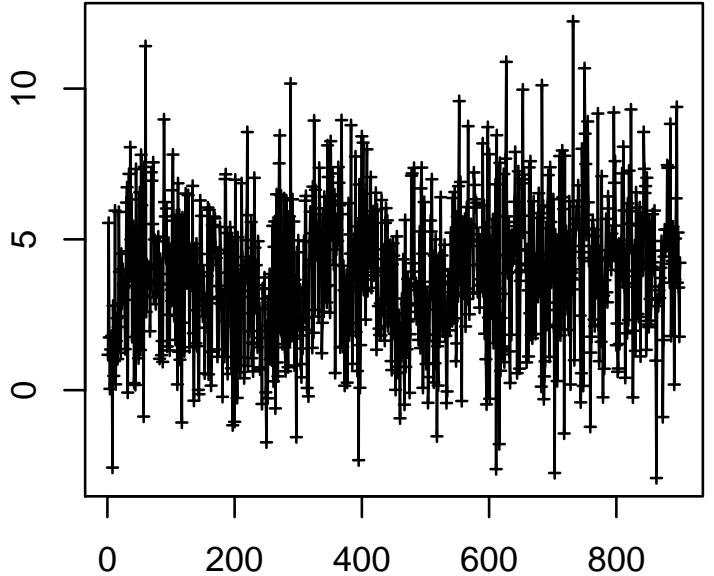

Time Point $(0.25 \mathrm{~Hz})$

Cell 1486 
Cell 1509
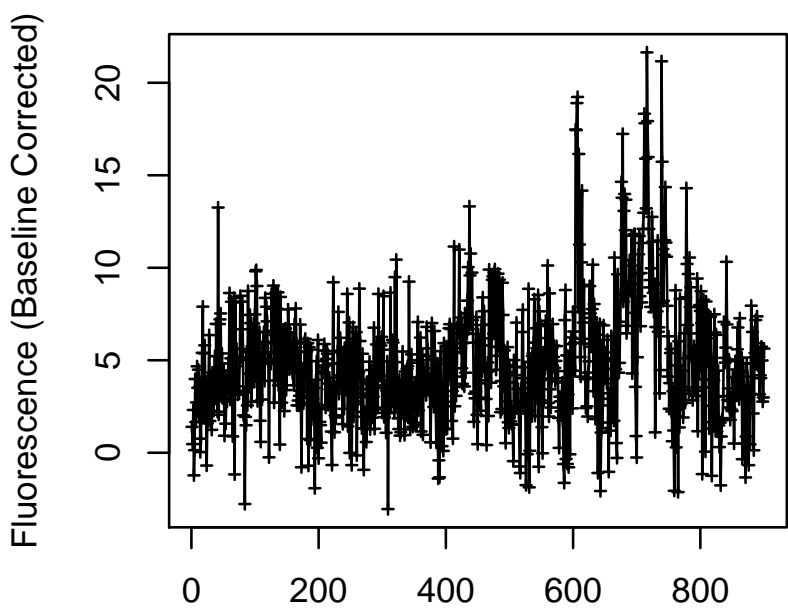

Time Point $(0.25 \mathrm{~Hz})$

Cell 1511

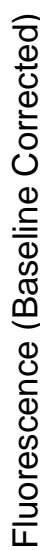

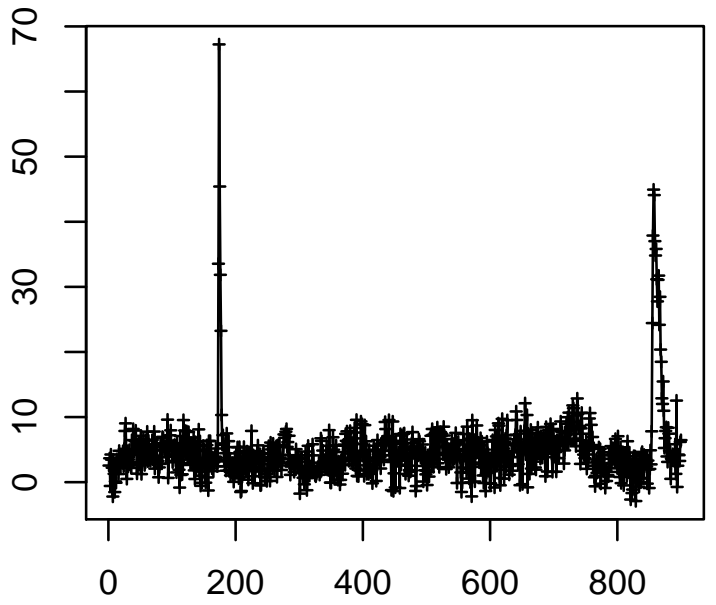

Time Point $(0.25 \mathrm{~Hz})$
Cell 1510

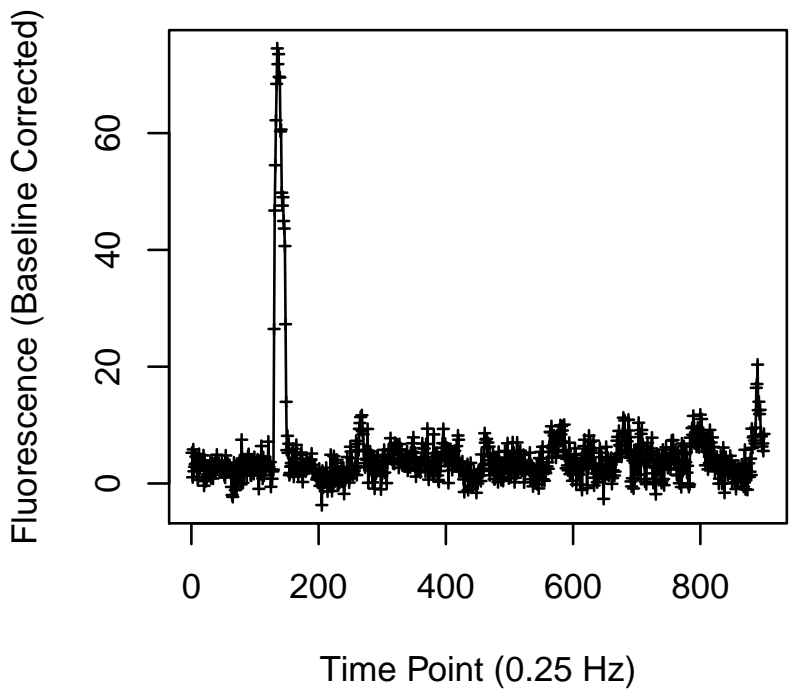

Cell 1512

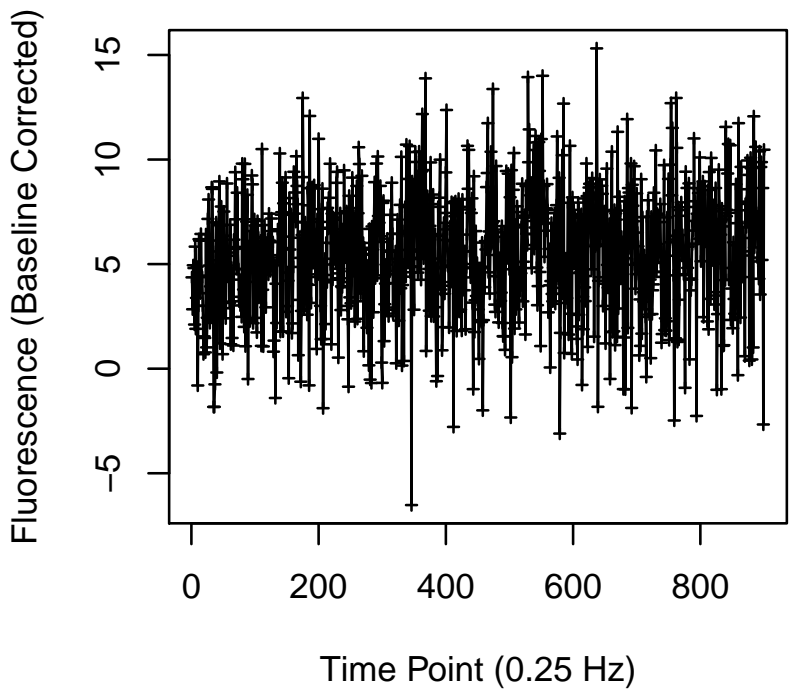




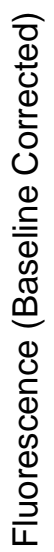

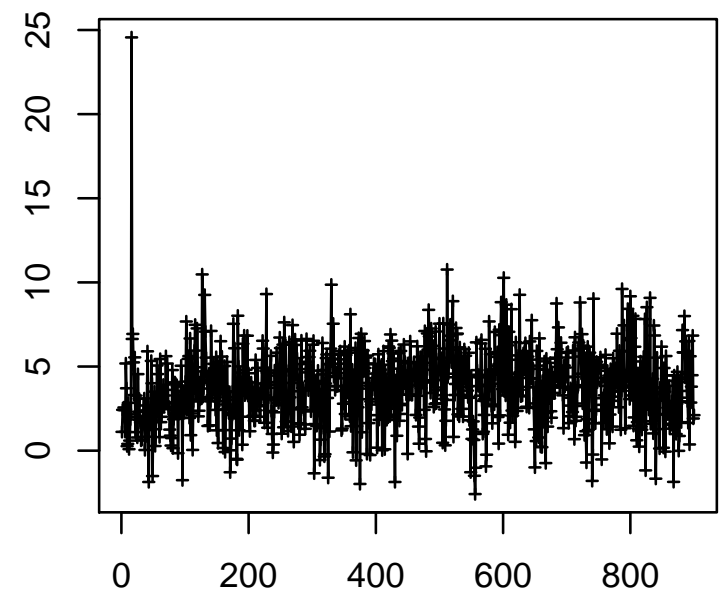

Time Point $(0.25 \mathrm{~Hz})$

Cell 1515

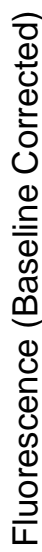

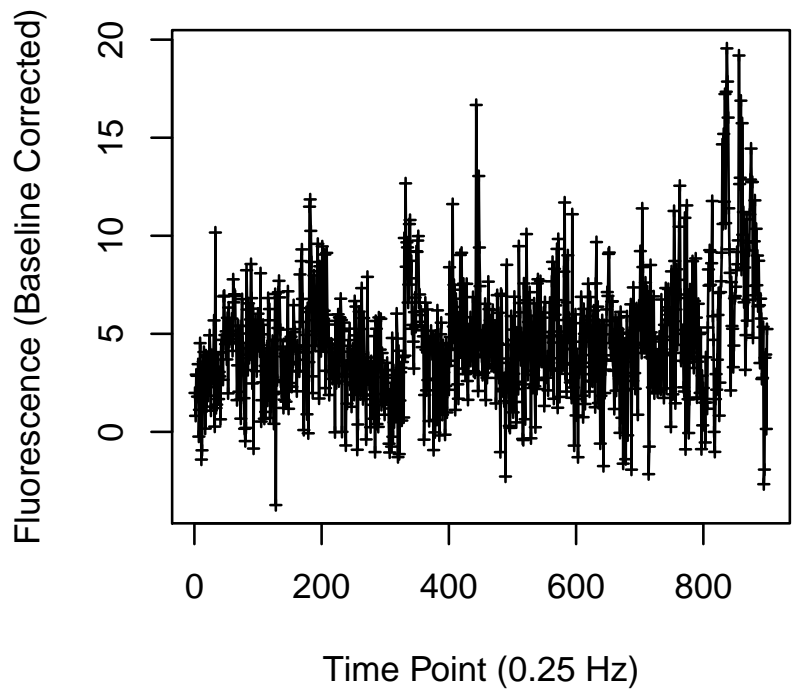

Cell 1516

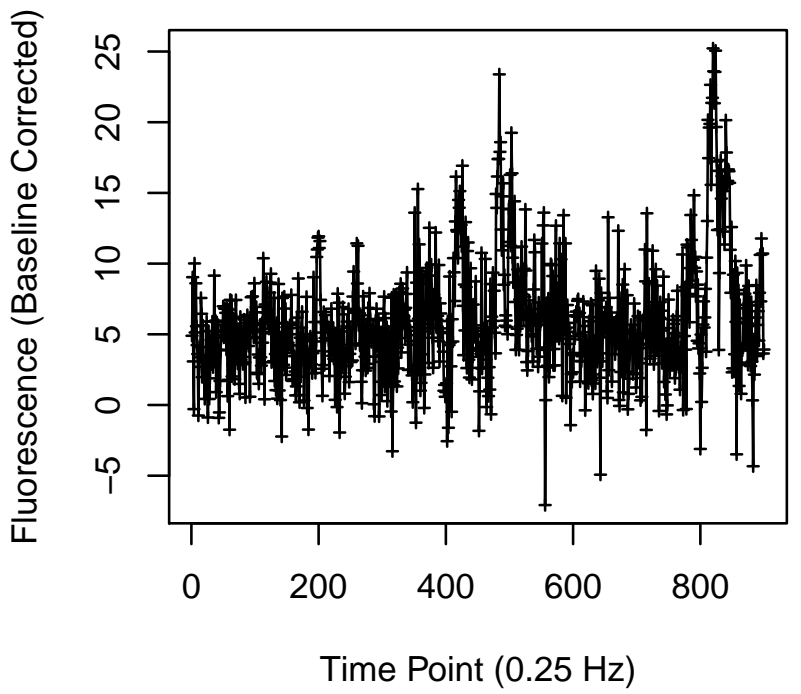


Cell 1517

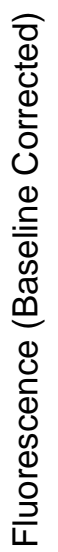

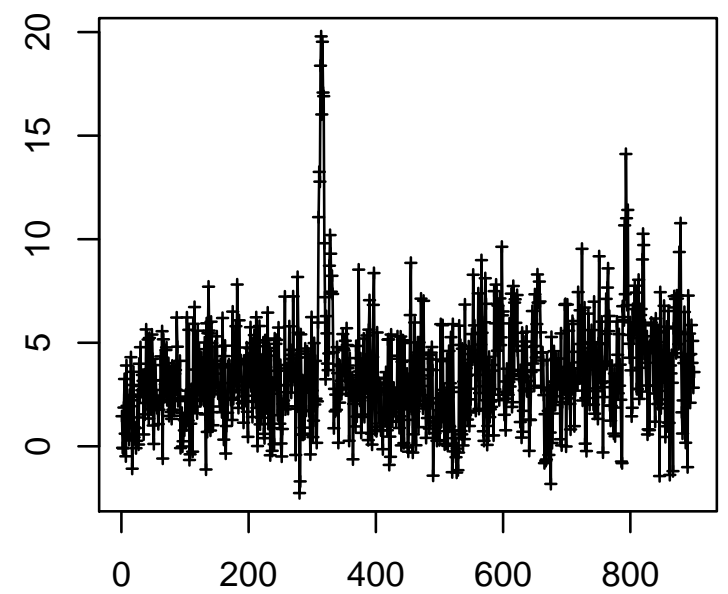

Time Point $(0.25 \mathrm{~Hz})$

Cell 1519

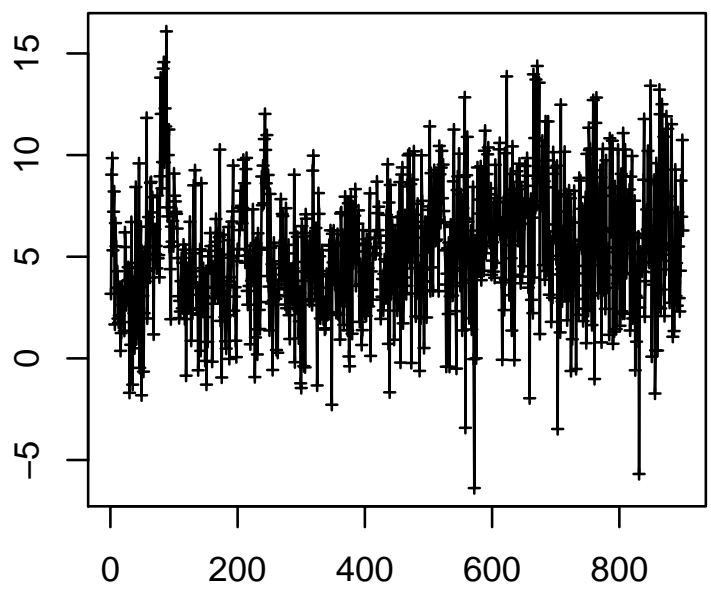

Time Point $(0.25 \mathrm{~Hz})$
Cell 1518

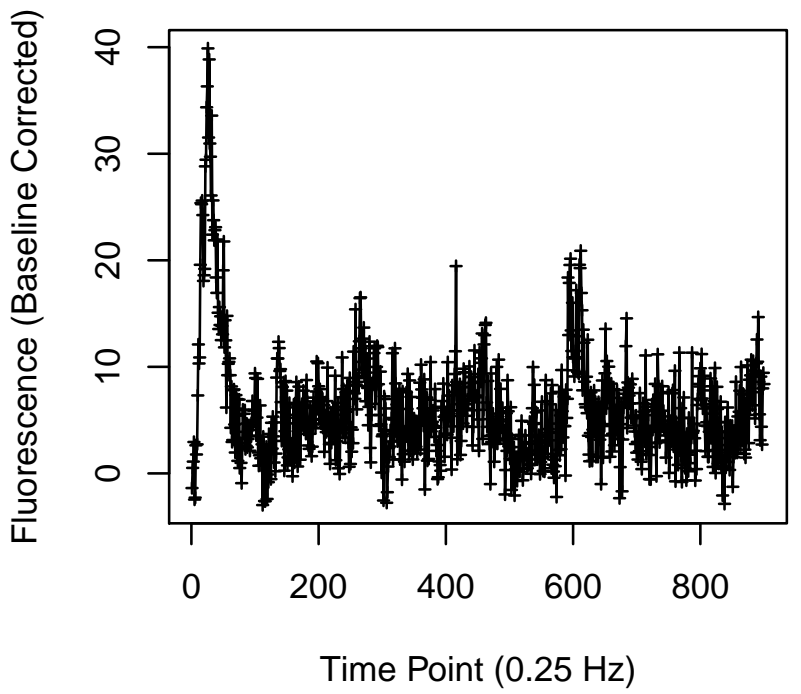

Cell 1520

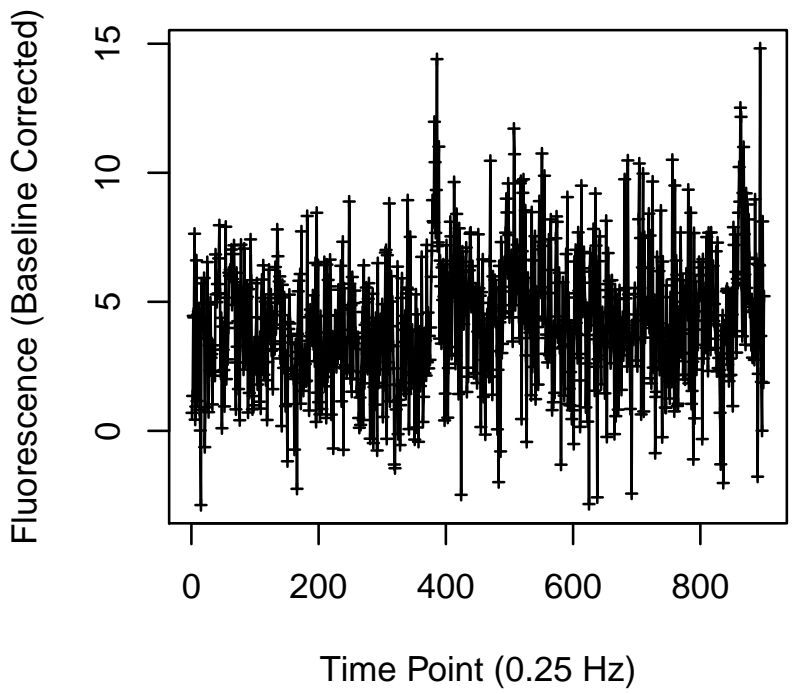


Cell 1521

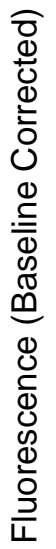

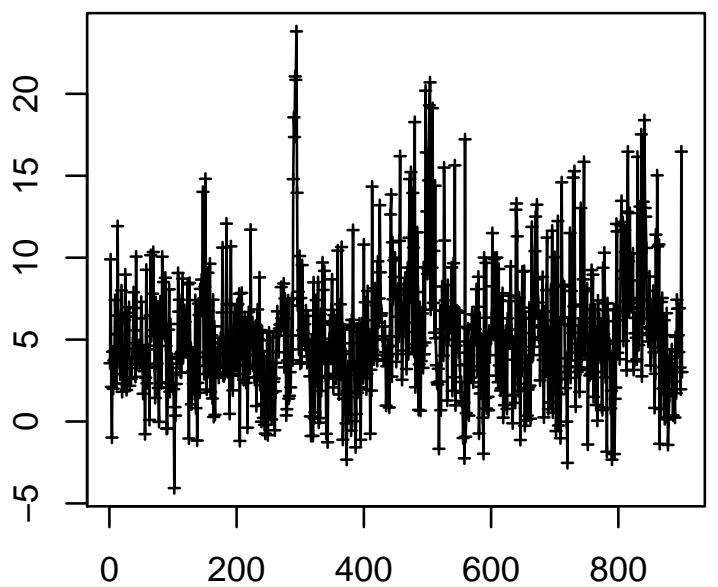

Time Point $(0.25 \mathrm{~Hz})$

Cell 1523

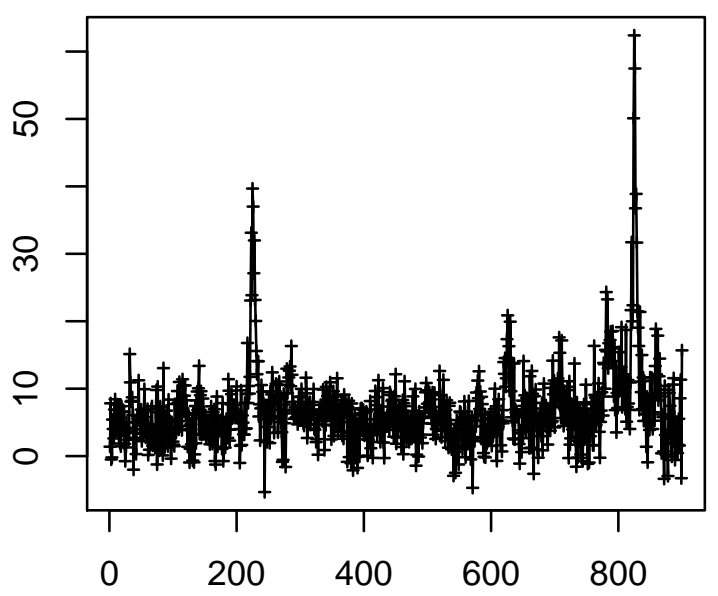

Time Point $(0.25 \mathrm{~Hz})$
Cell 1522

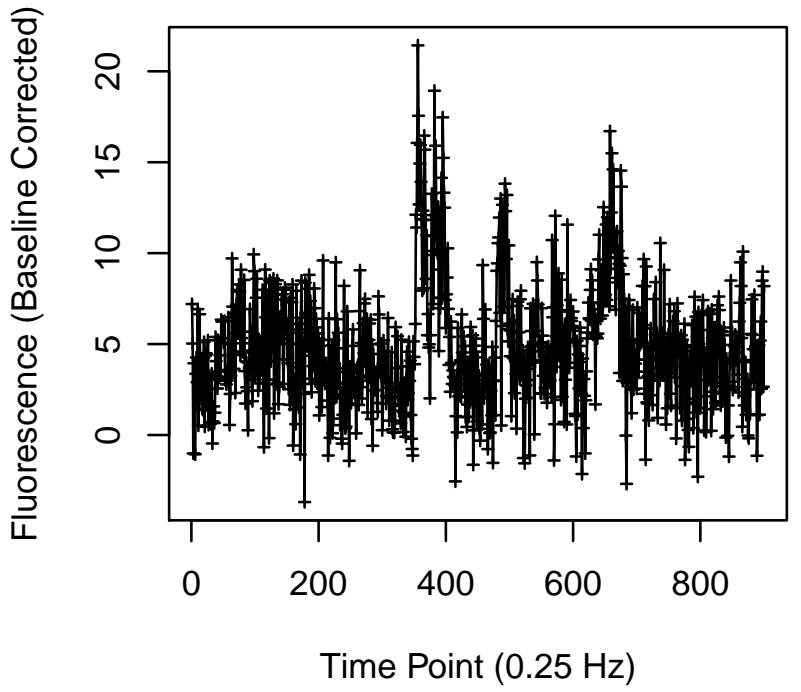

Cell 1524

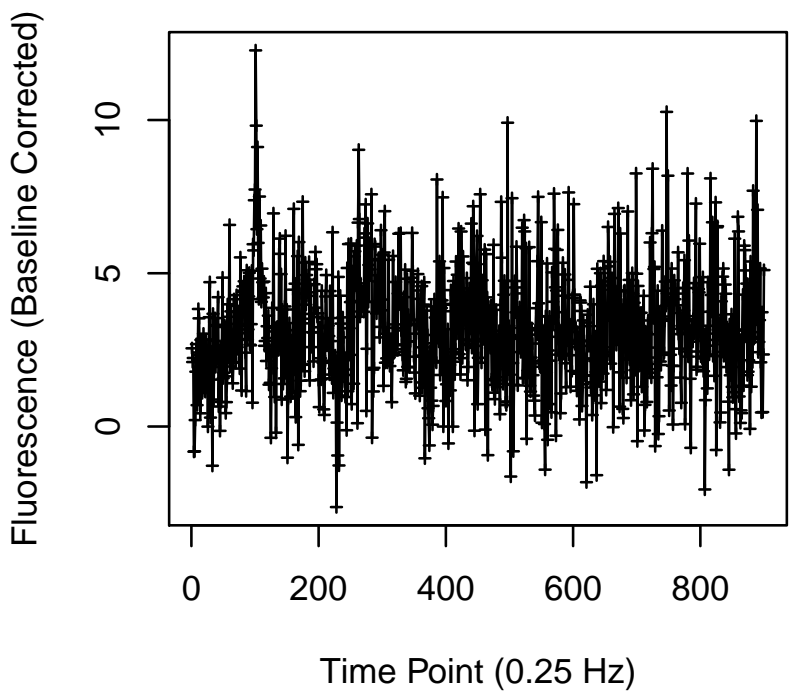


Cell 1525

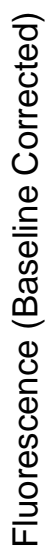

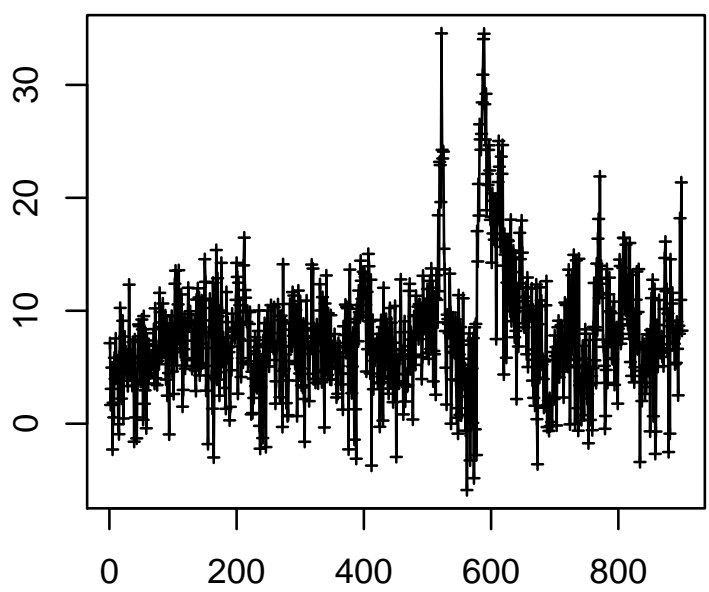

Time Point $(0.25 \mathrm{~Hz})$

Cell 1527

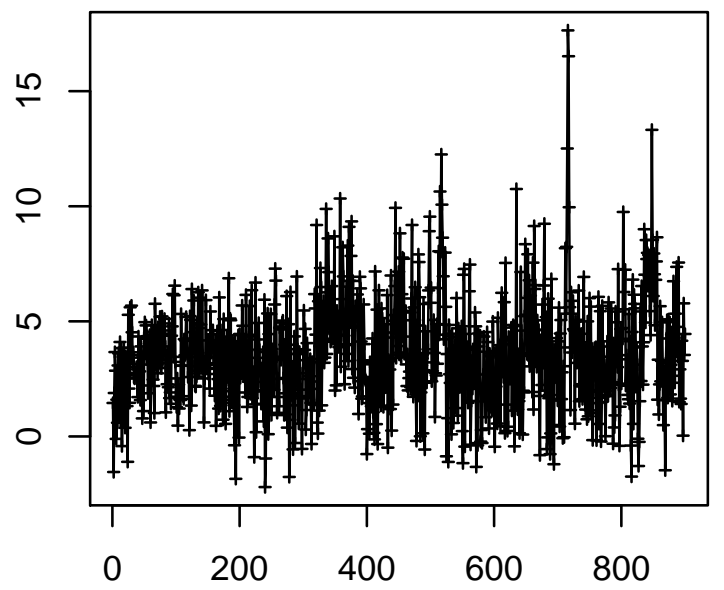

Time Point $(0.25 \mathrm{~Hz})$
Cell 1526

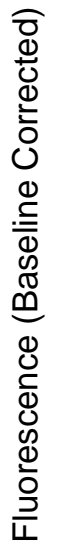

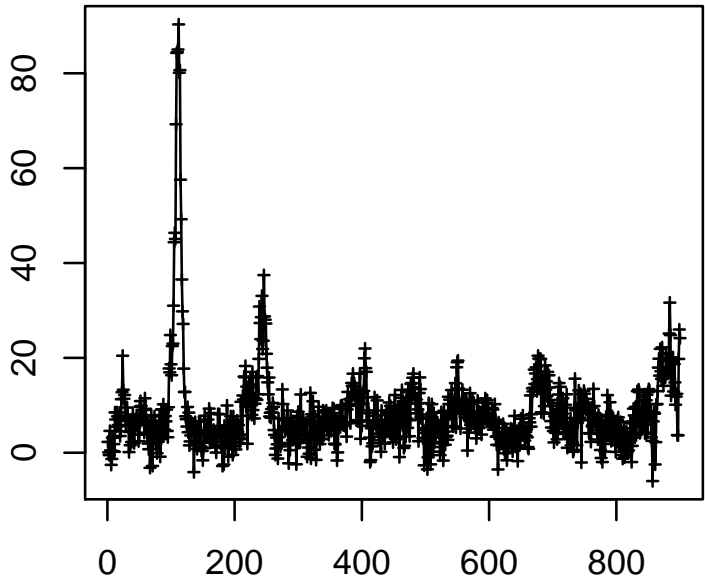

Time Point $(0.25 \mathrm{~Hz})$

Cell 1528

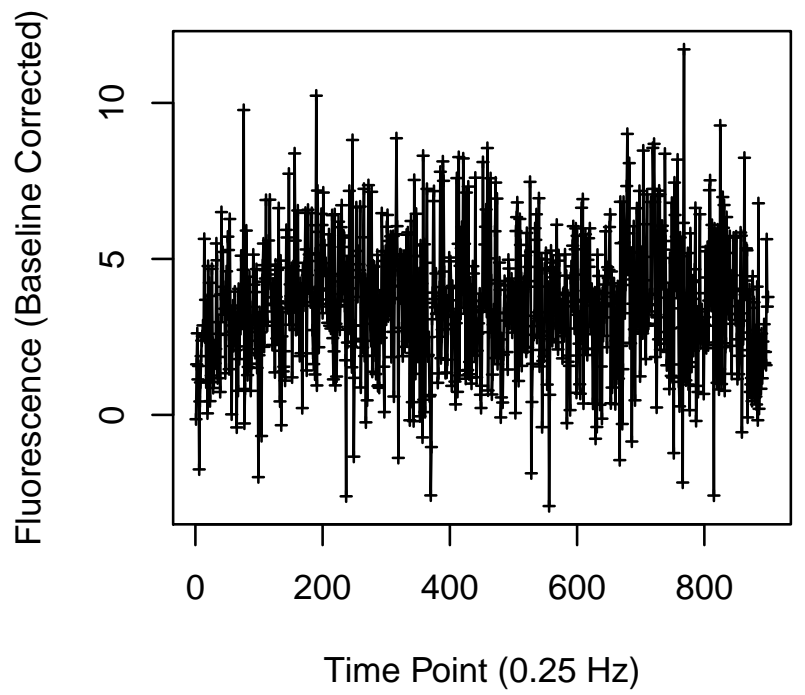


Cell 1529

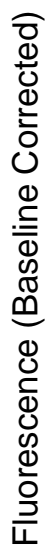

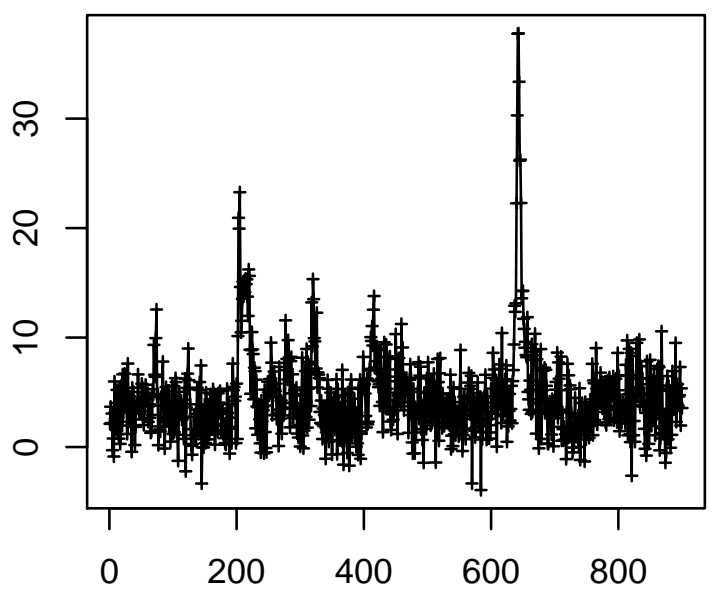

Time Point $(0.25 \mathrm{~Hz})$

Cell 1531

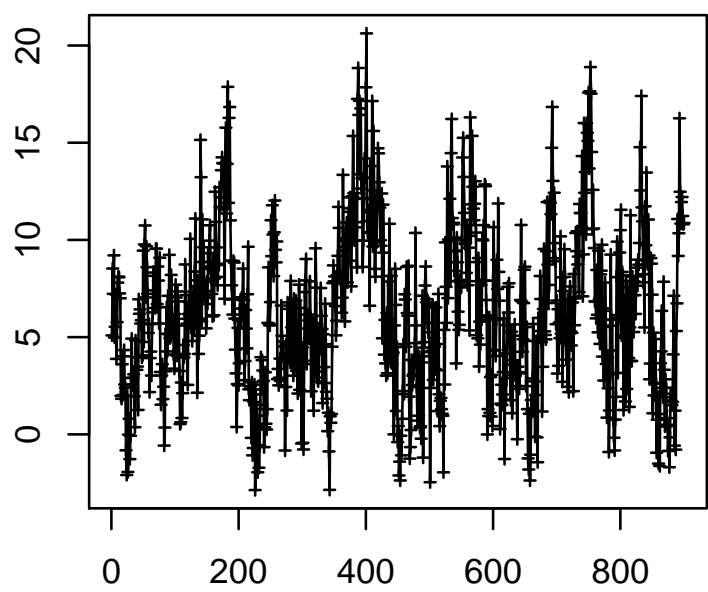

Time Point $(0.25 \mathrm{~Hz})$
Cell 1530

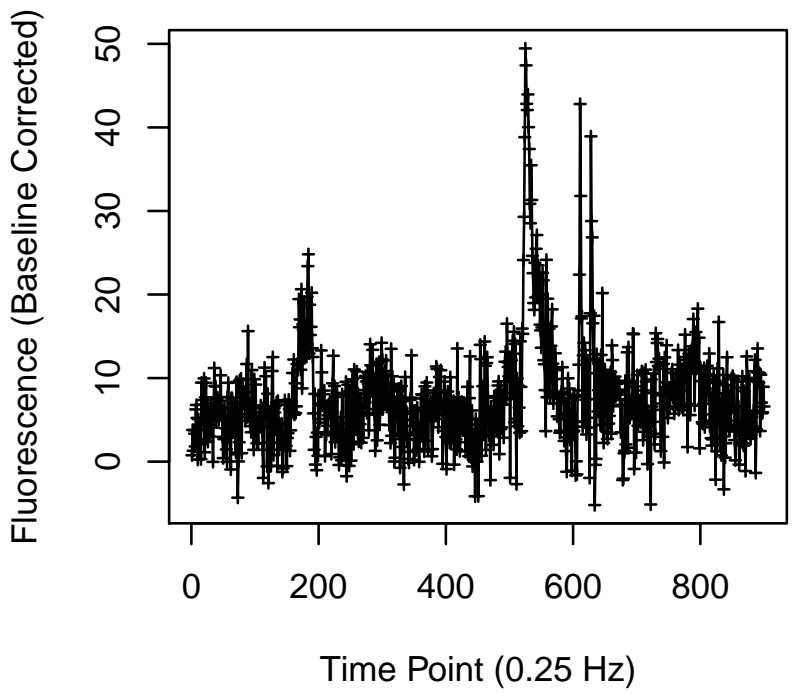

Cell 1532

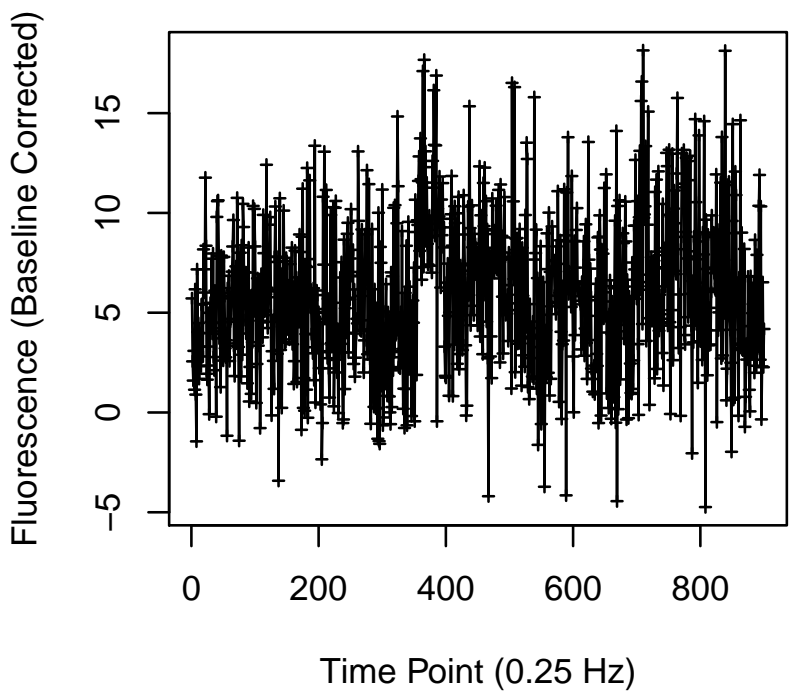


Cell 1533

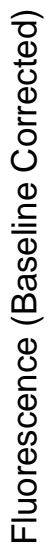

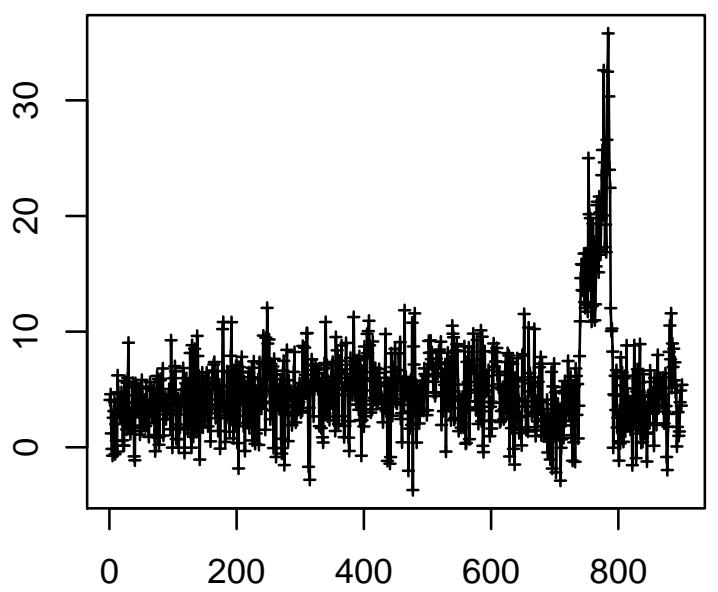

Time Point $(0.25 \mathrm{~Hz})$

Cell 1535

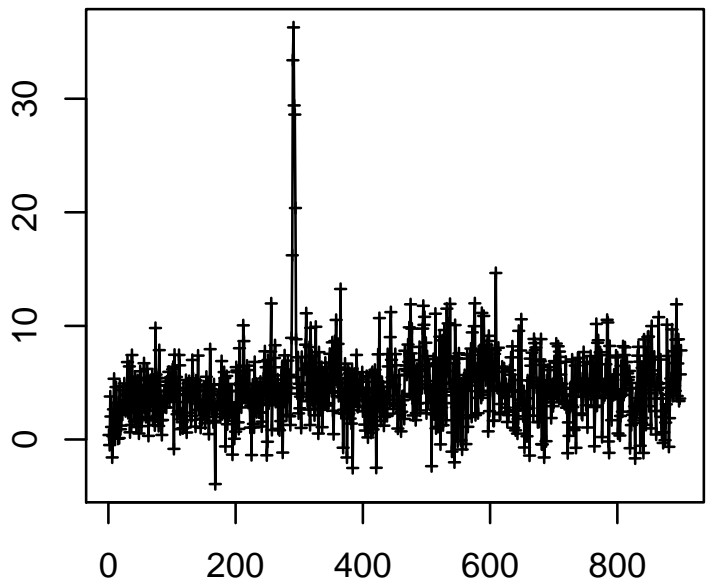

Time Point $(0.25 \mathrm{~Hz})$
Cell 1534

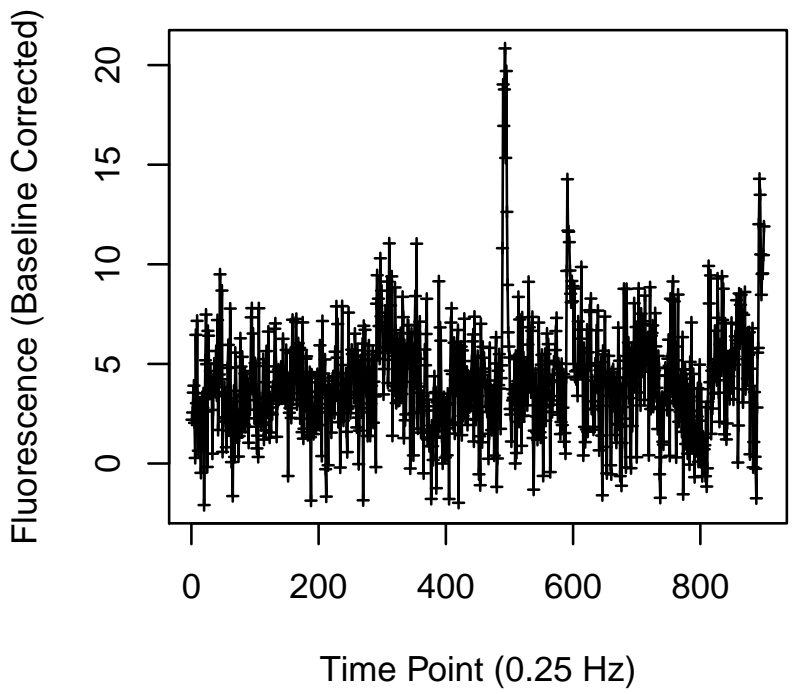

Cell 1536

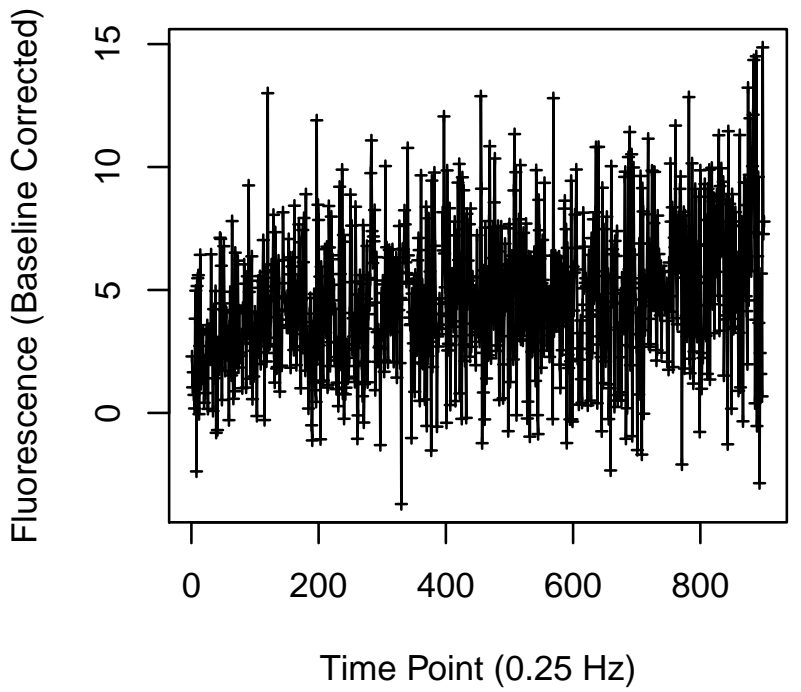


Cell 1537

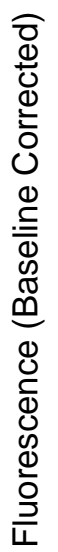

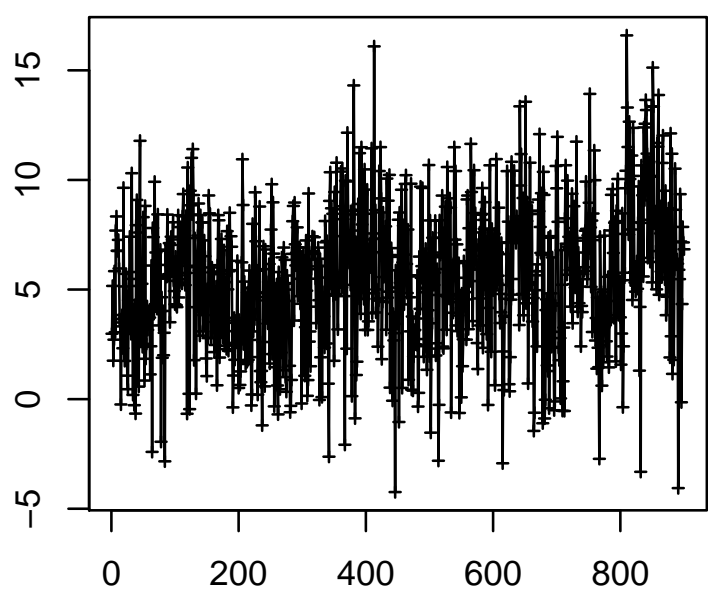

Time Point $(0.25 \mathrm{~Hz})$

Cell 1539

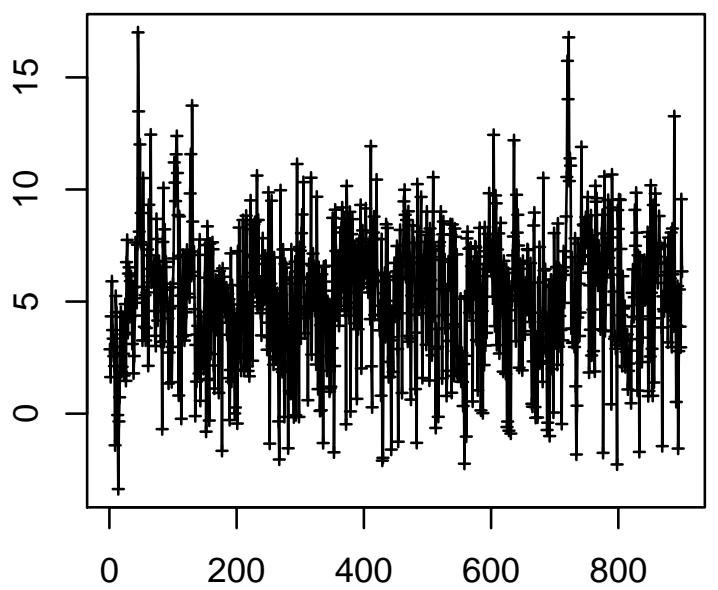

Time Point $(0.25 \mathrm{~Hz})$
Cell 1538

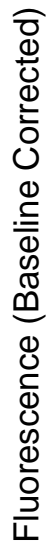

Cell 1540

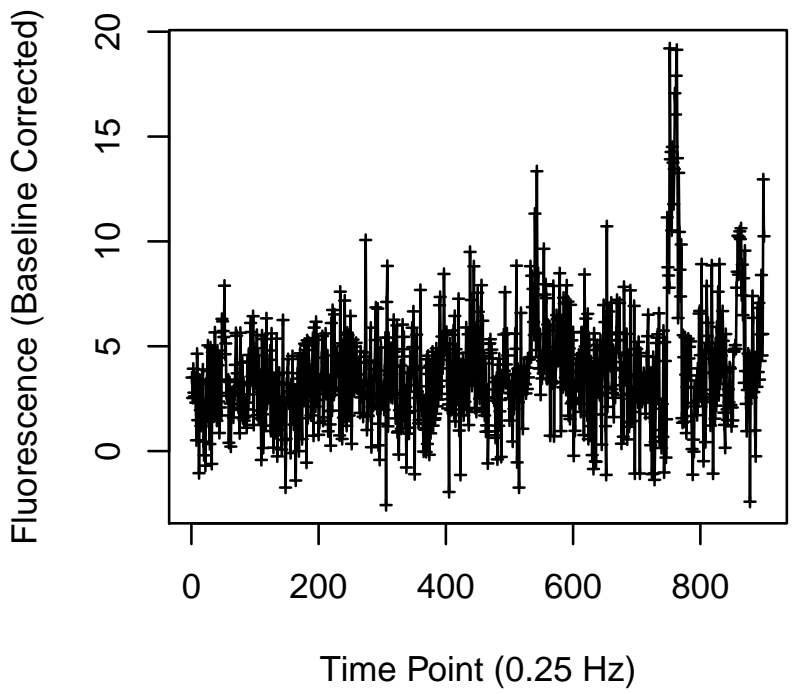


Cell 1541

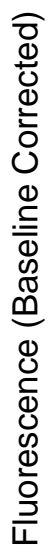

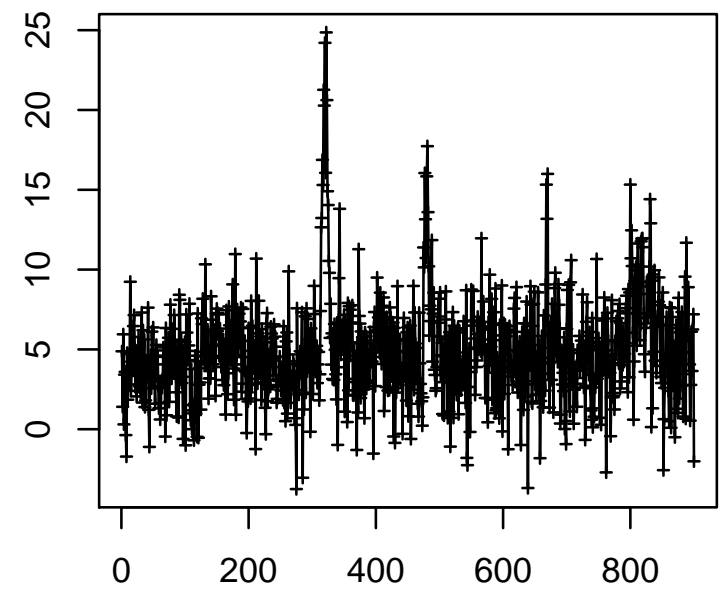

Time Point $(0.25 \mathrm{~Hz})$

Cell 1543

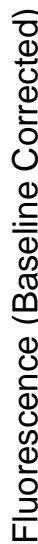

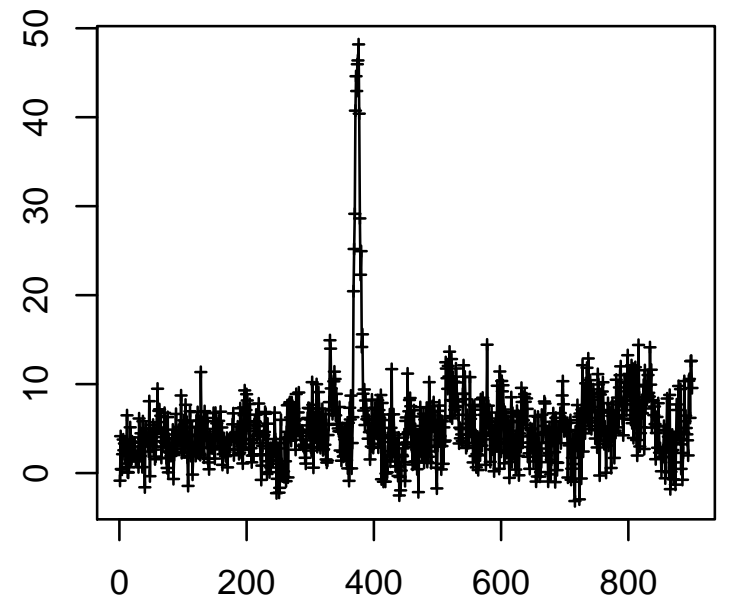

Time Point $(0.25 \mathrm{~Hz})$
Cell 1542

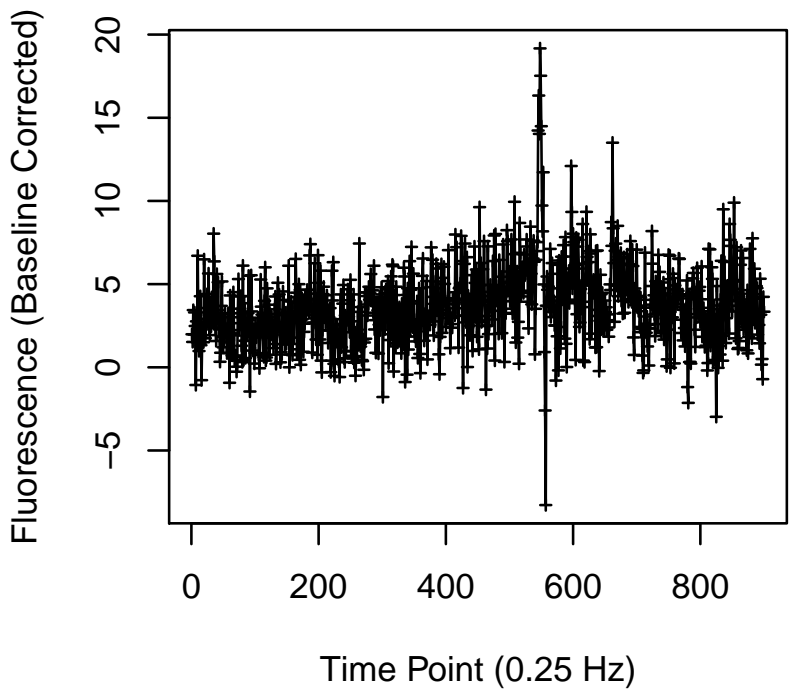

Cell 1544

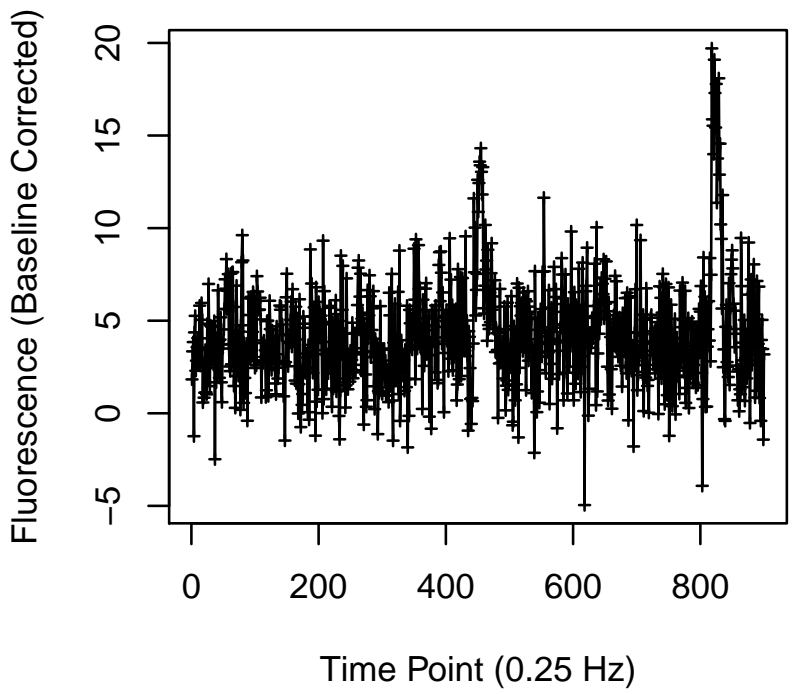


Cell 1545

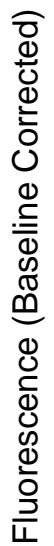

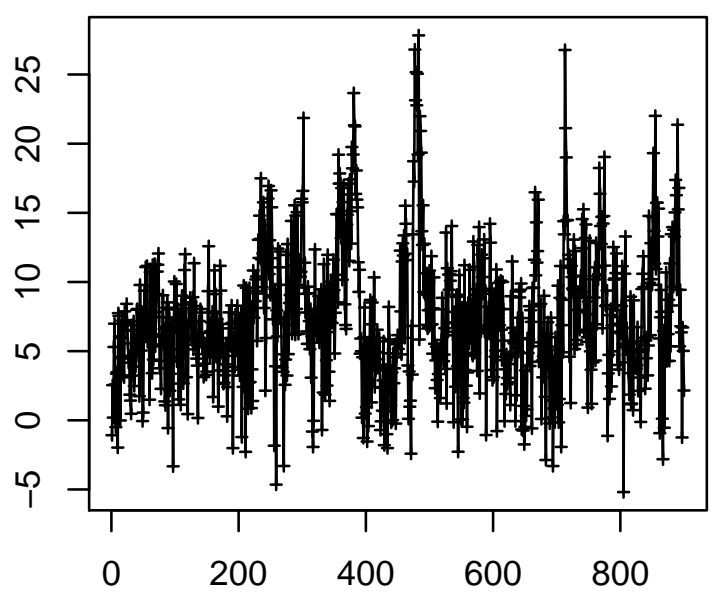

Time Point $(0.25 \mathrm{~Hz})$

Cell 1547

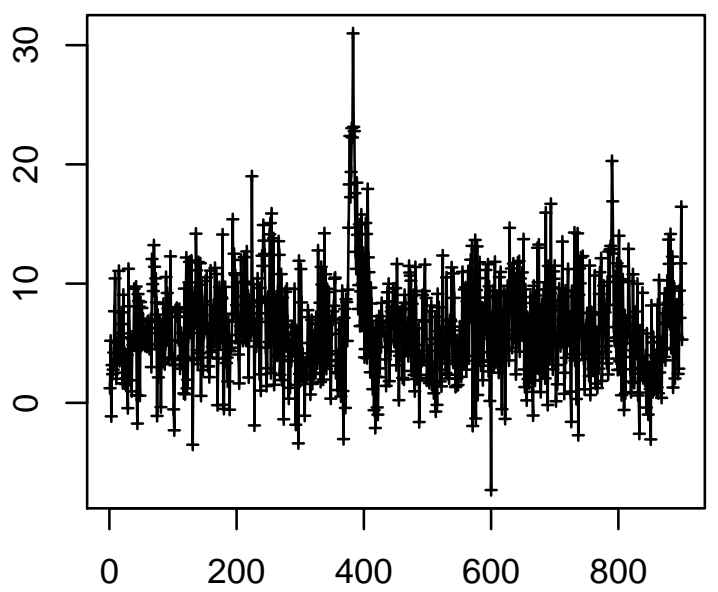

Time Point $(0.25 \mathrm{~Hz})$
Cell 1546

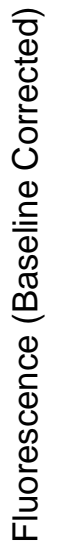

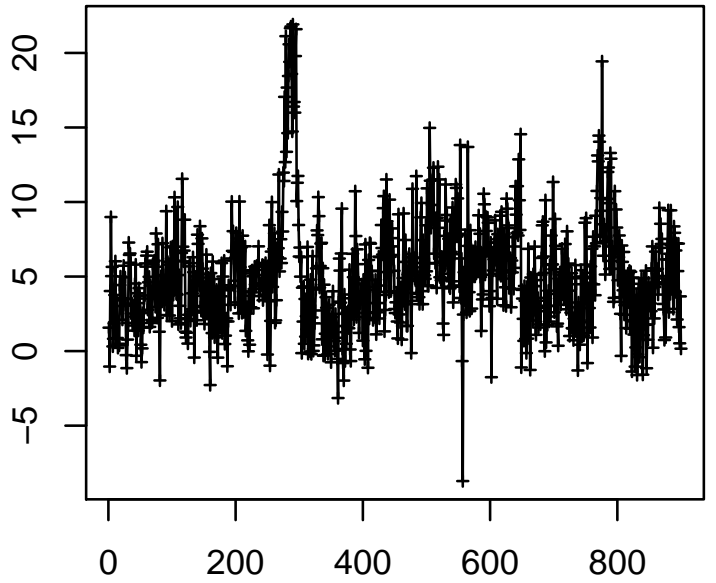

Time Point $(0.25 \mathrm{~Hz})$

Cell 1548

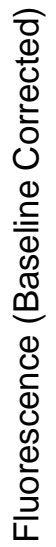

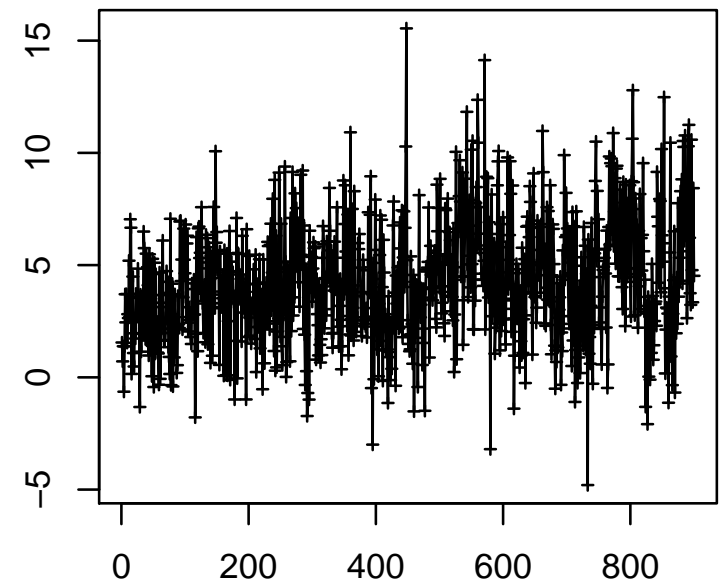

Time Point $(0.25 \mathrm{~Hz})$ 
Cell 1549

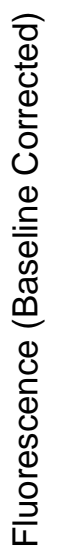

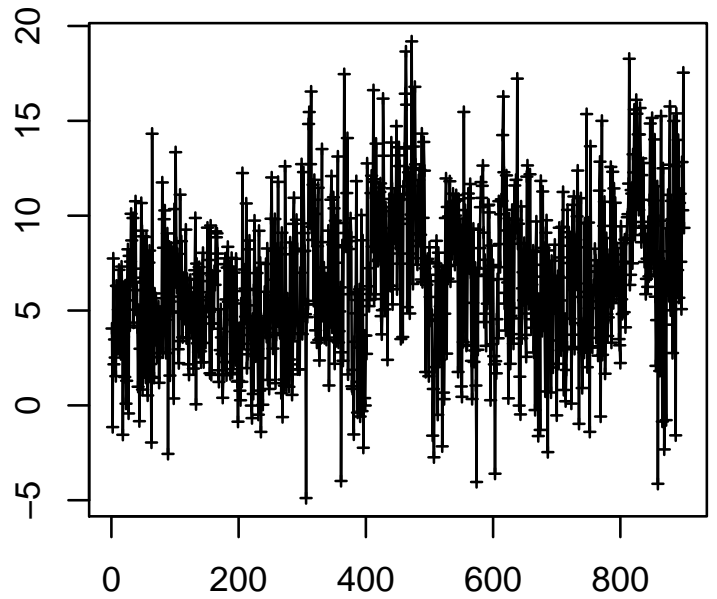

Time Point $(0.25 \mathrm{~Hz})$

Cell 1551

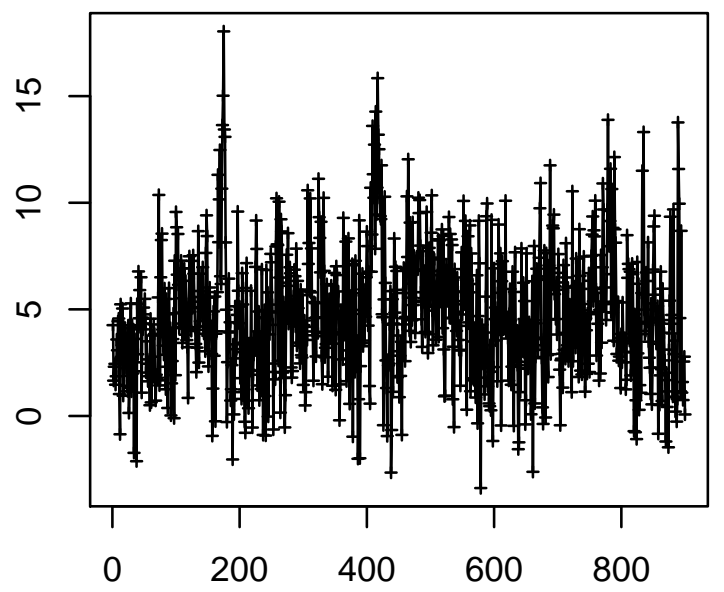

Time Point $(0.25 \mathrm{~Hz})$
Cell 1550

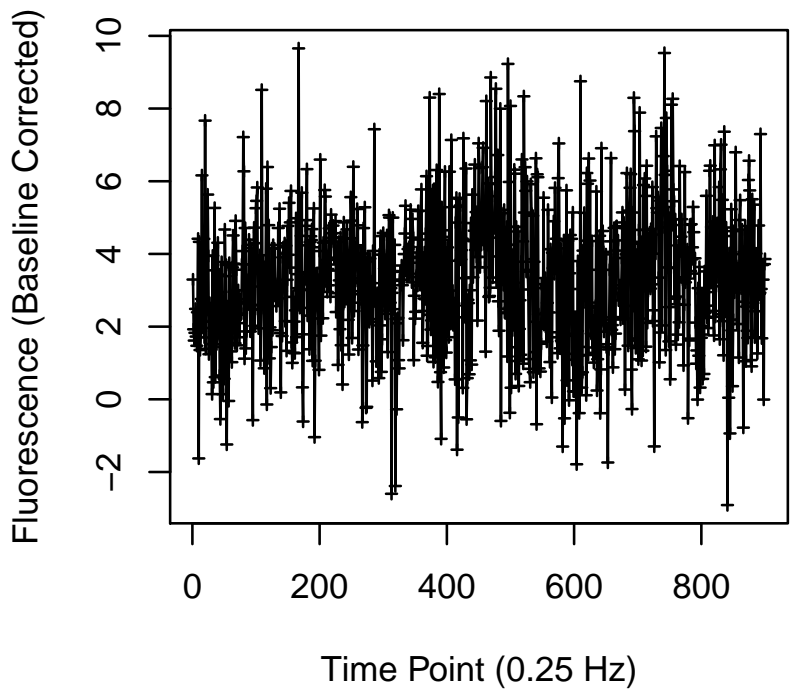

Cell 1552

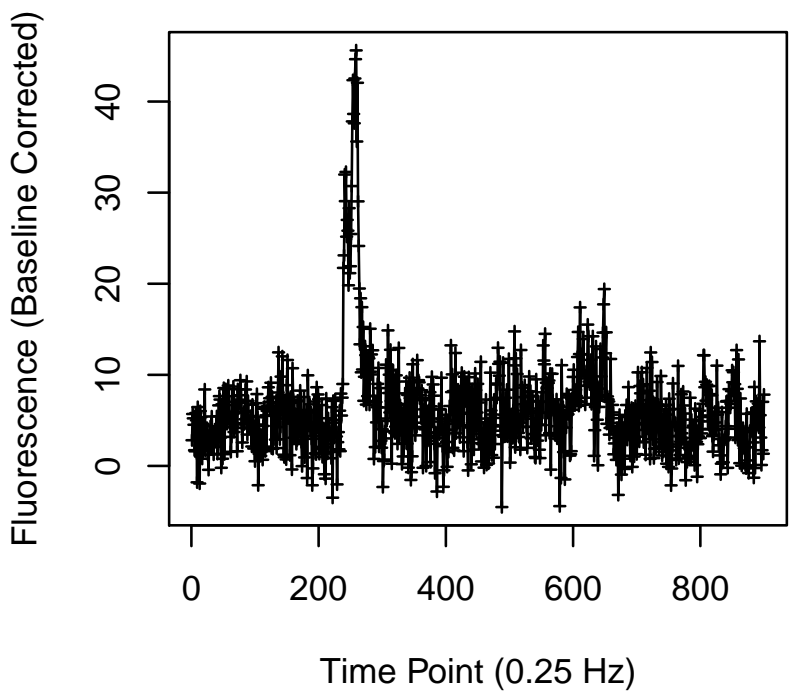


Cell 1553

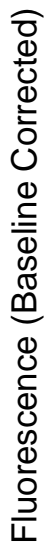

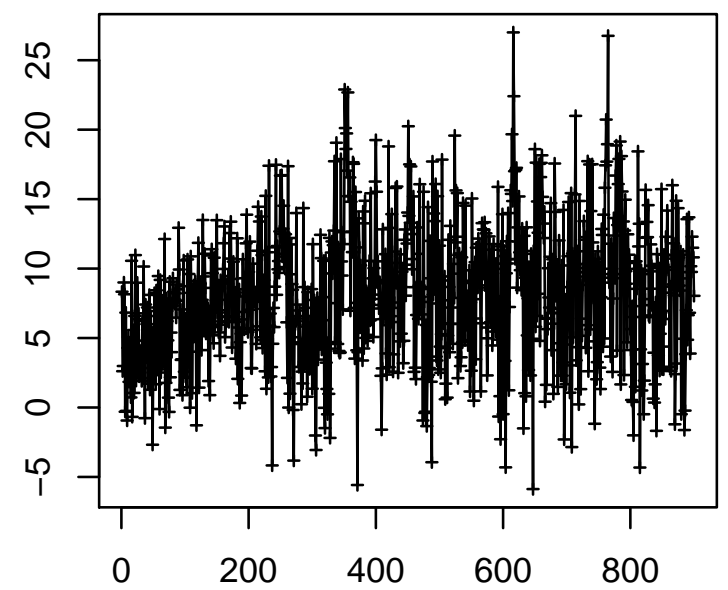

Time Point $(0.25 \mathrm{~Hz})$

Cell 1555

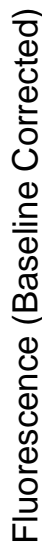

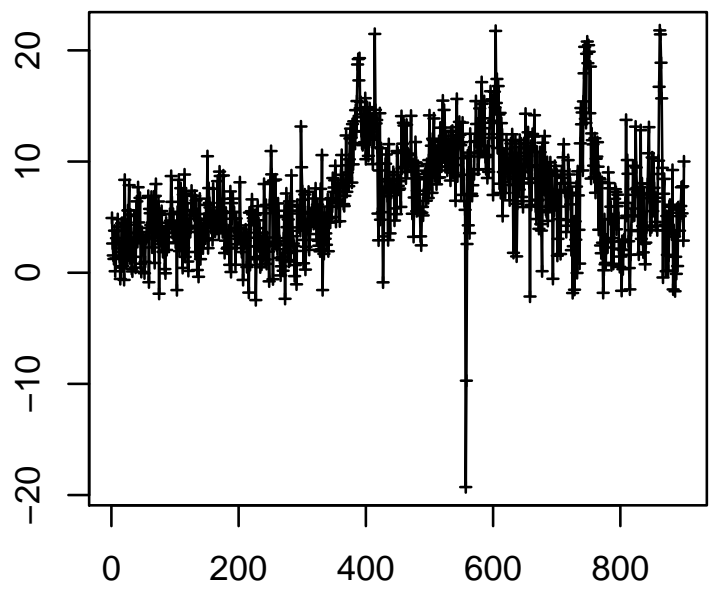

Time Point $(0.25 \mathrm{~Hz})$
Cell 1554

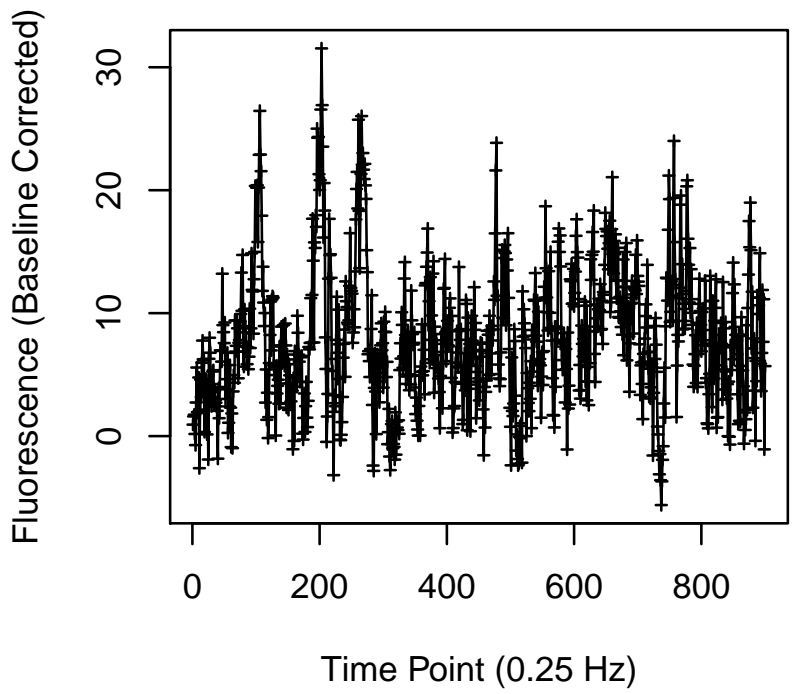

Cell 1556

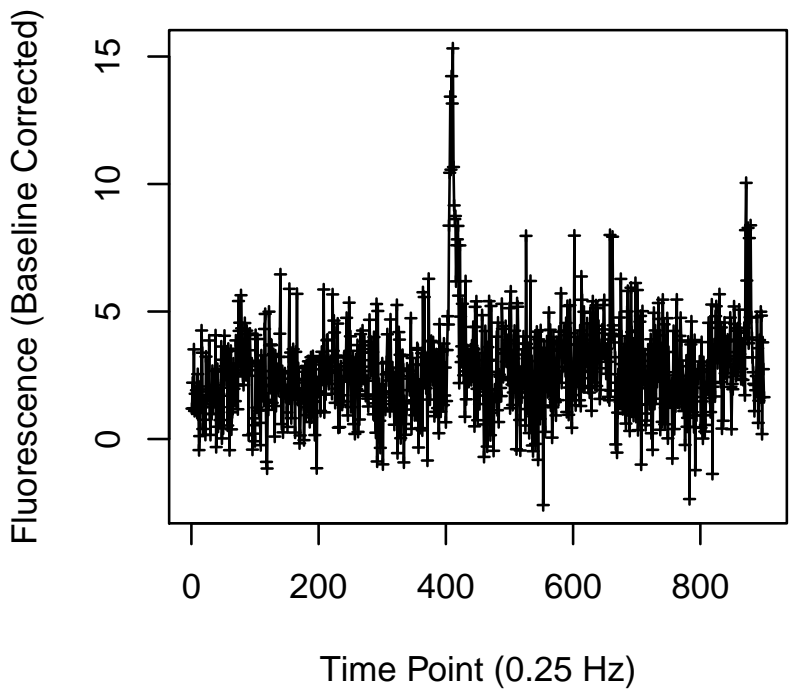


Cell 1557

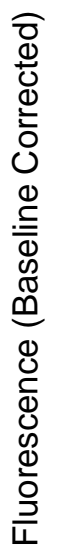

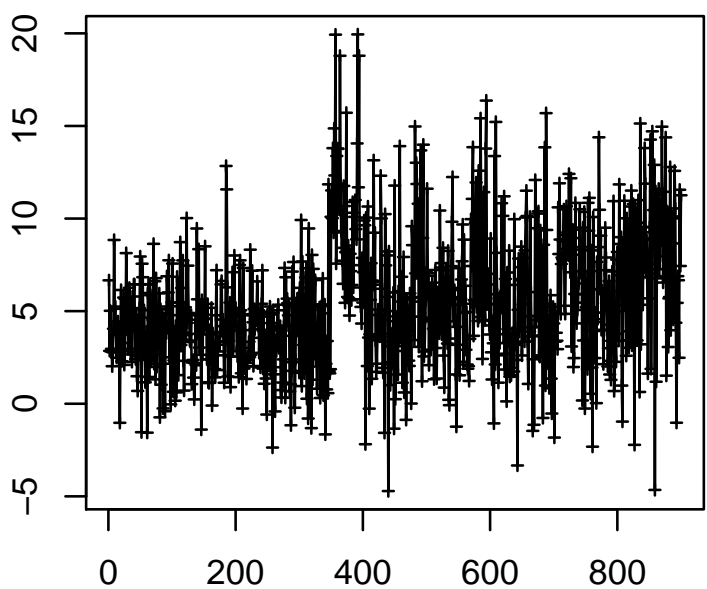

Time Point $(0.25 \mathrm{~Hz})$

Cell 1559

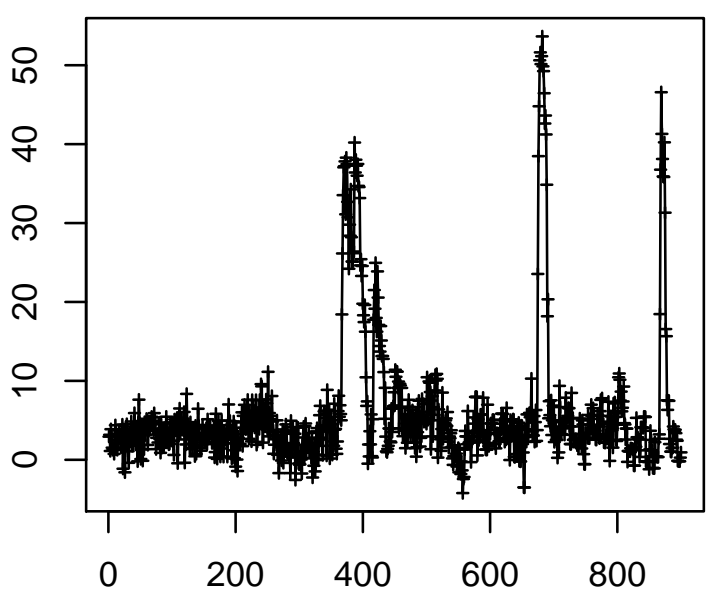

Time Point $(0.25 \mathrm{~Hz})$
Cell 1558

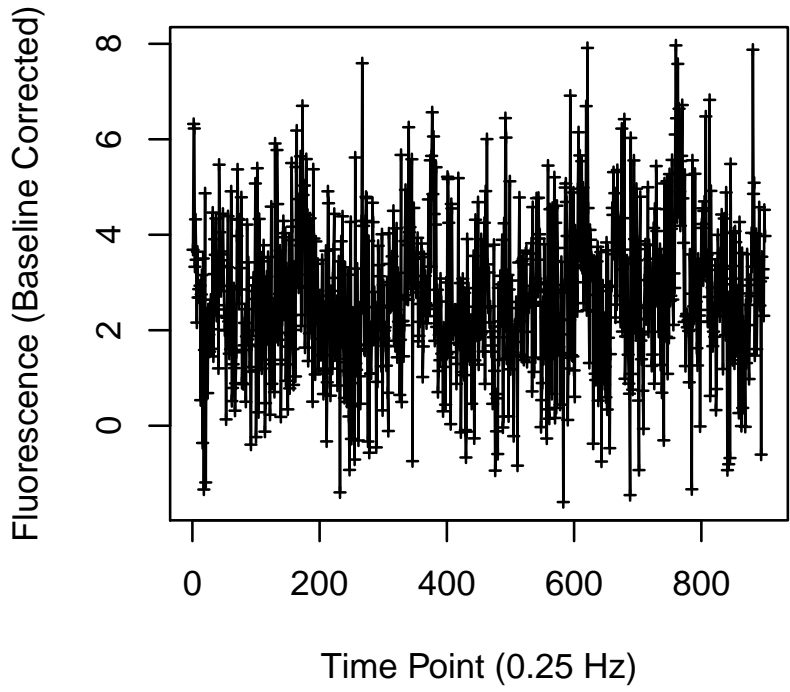

Cell 1560

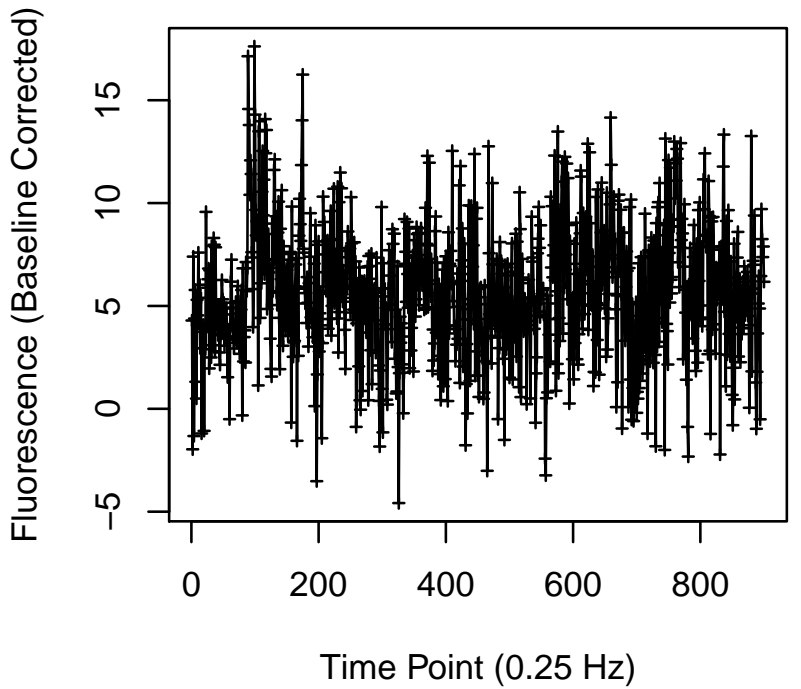


Cell 1561

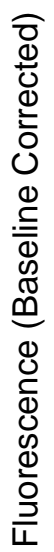

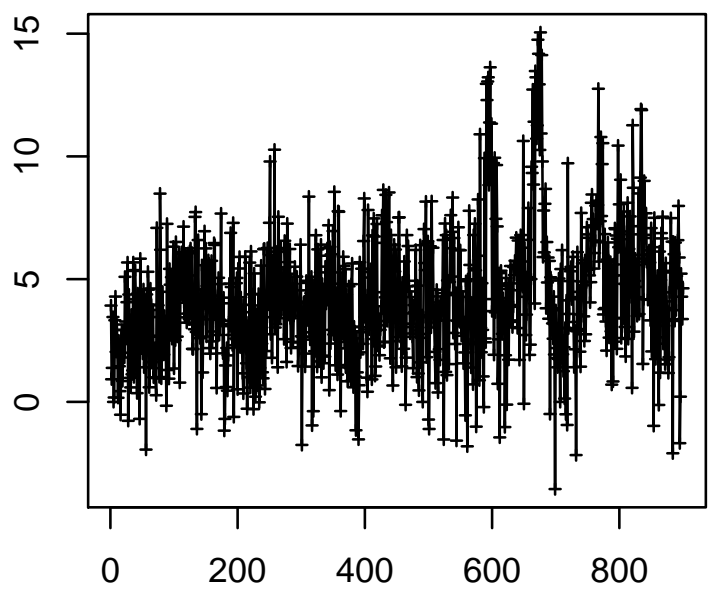

Time Point $(0.25 \mathrm{~Hz})$

Cell 1563

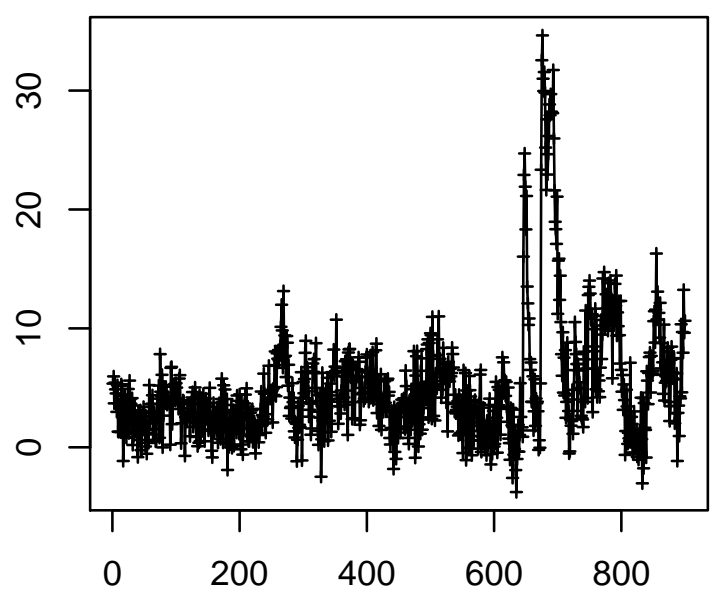

Time Point $(0.25 \mathrm{~Hz})$
Cell 1562

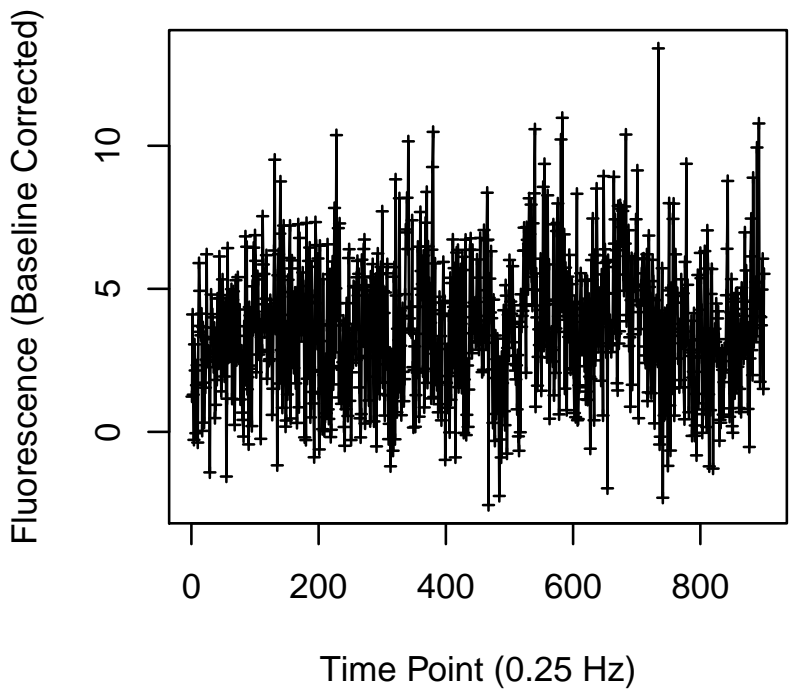

Cell 1564

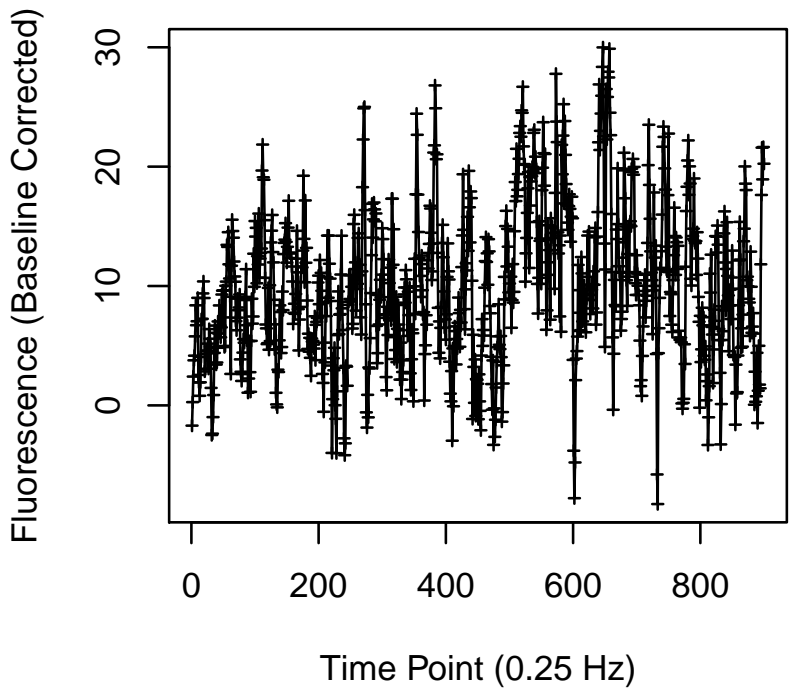


Cell 1569

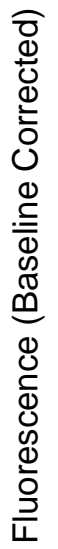

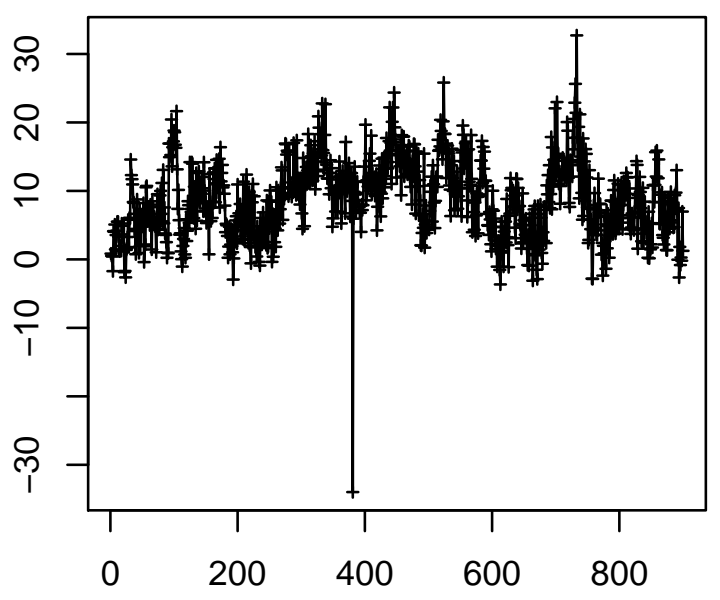

Time Point $(0.25 \mathrm{~Hz})$

Cell 1571

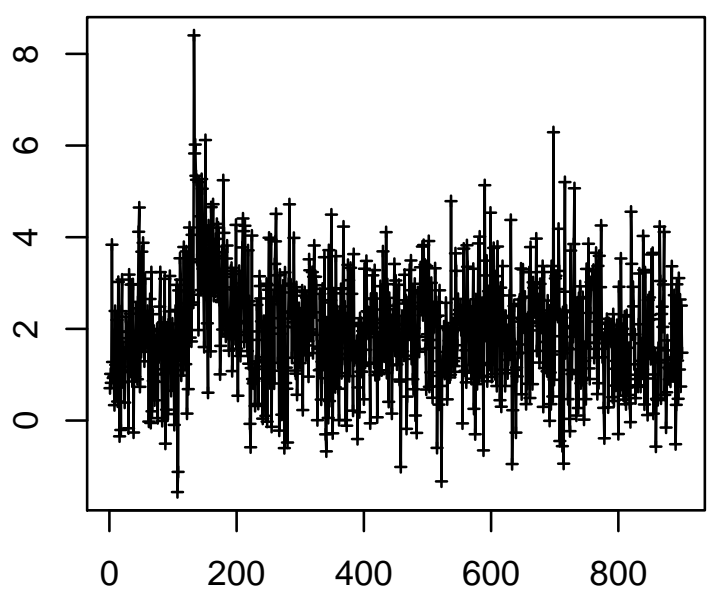

Time Point $(0.25 \mathrm{~Hz})$
Cell 1570

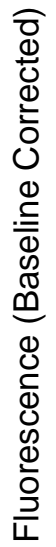

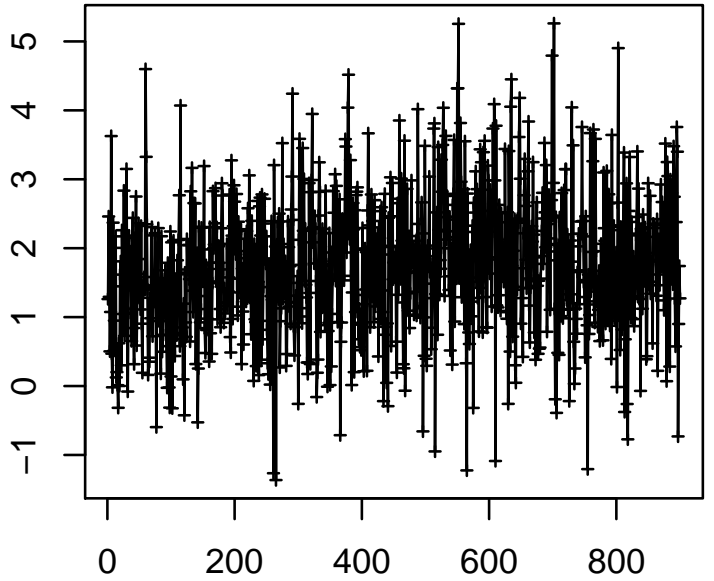

Time Point $(0.25 \mathrm{~Hz})$

Cell 1572

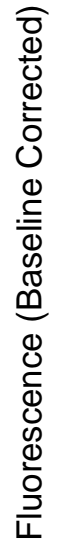

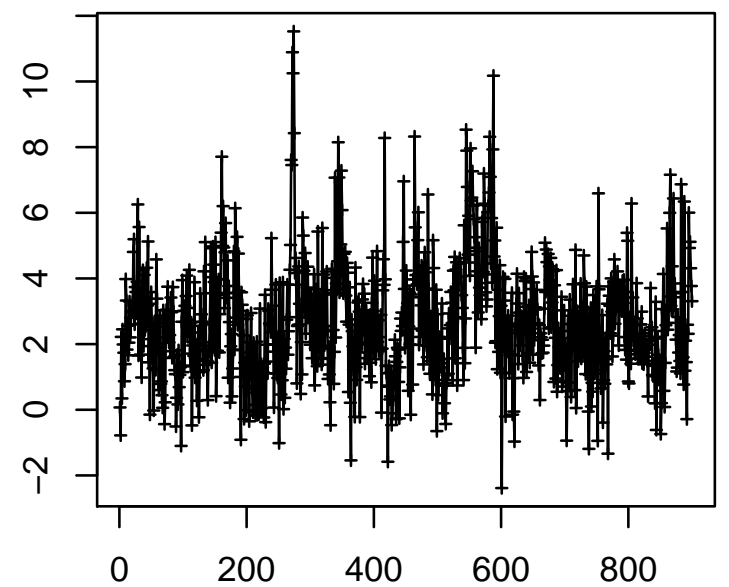

Time Point $(0.25 \mathrm{~Hz})$ 
Cell 1573

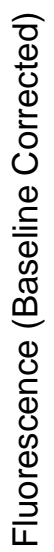

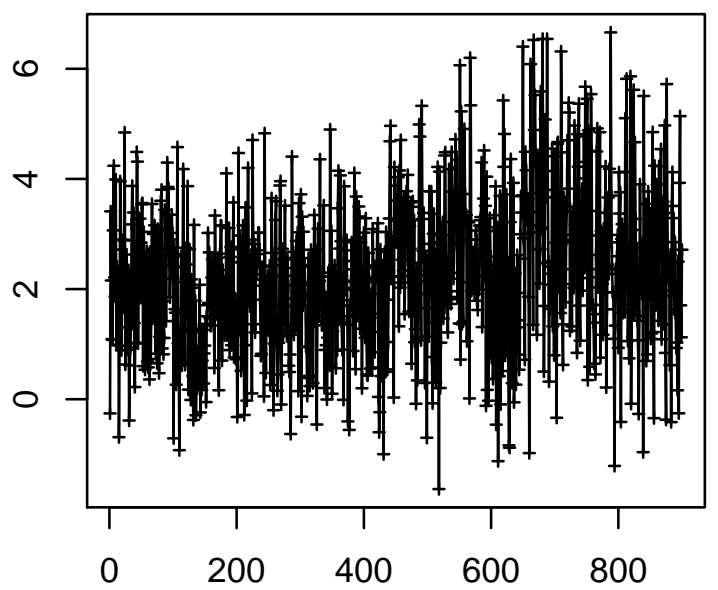

Time Point $(0.25 \mathrm{~Hz})$

Cell 1575

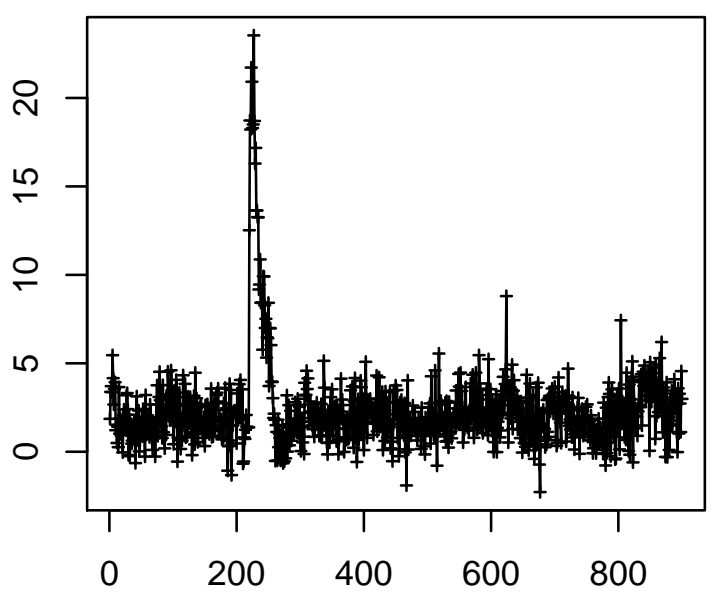

Time Point $(0.25 \mathrm{~Hz})$
Cell 1574

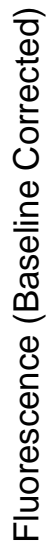

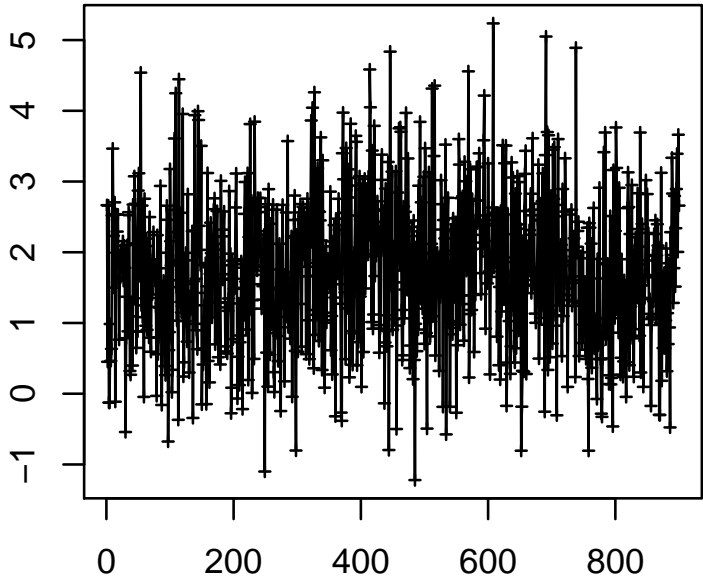

Time Point $(0.25 \mathrm{~Hz})$

Cell 1576

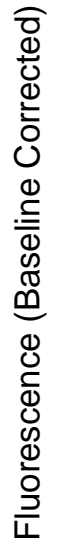

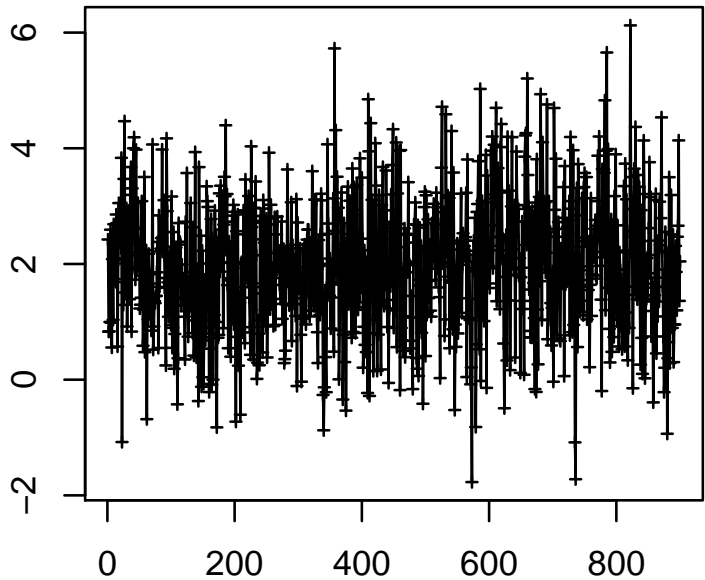

Time Point $(0.25 \mathrm{~Hz})$ 
Cell 1581

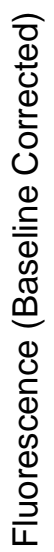

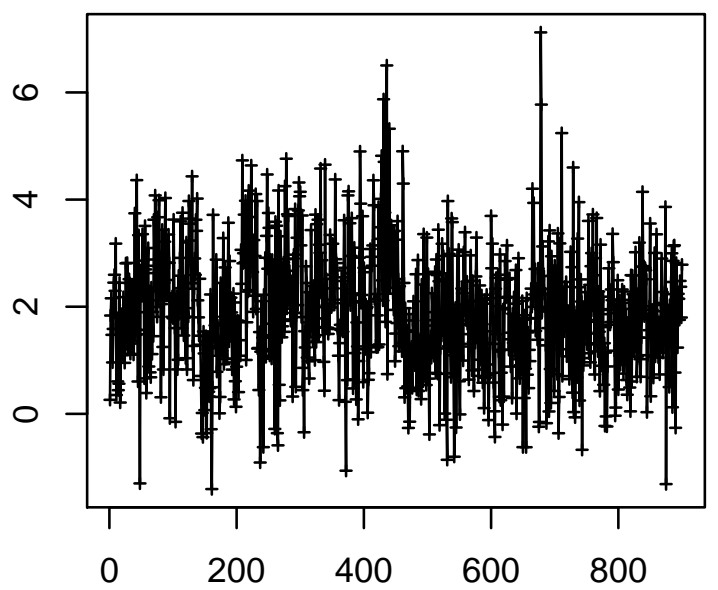

Time Point $(0.25 \mathrm{~Hz})$

Cell 1583

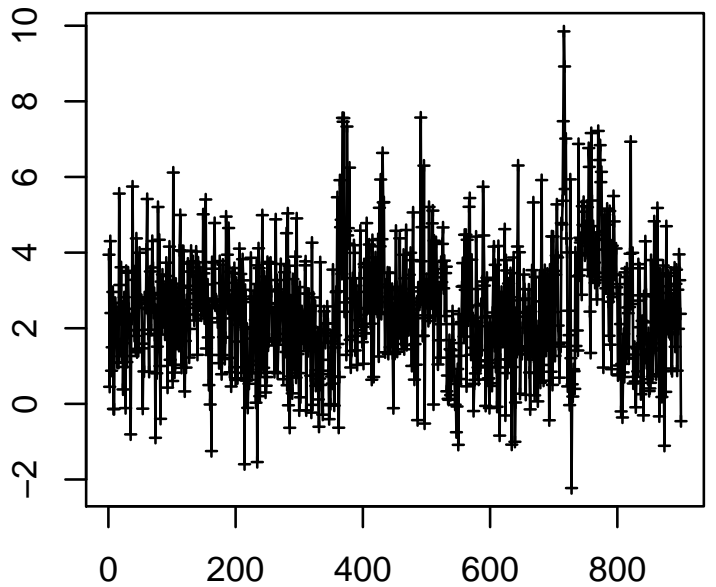

Time Point $(0.25 \mathrm{~Hz})$
Cell 1582

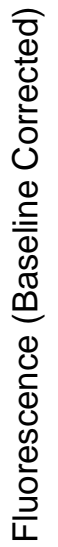

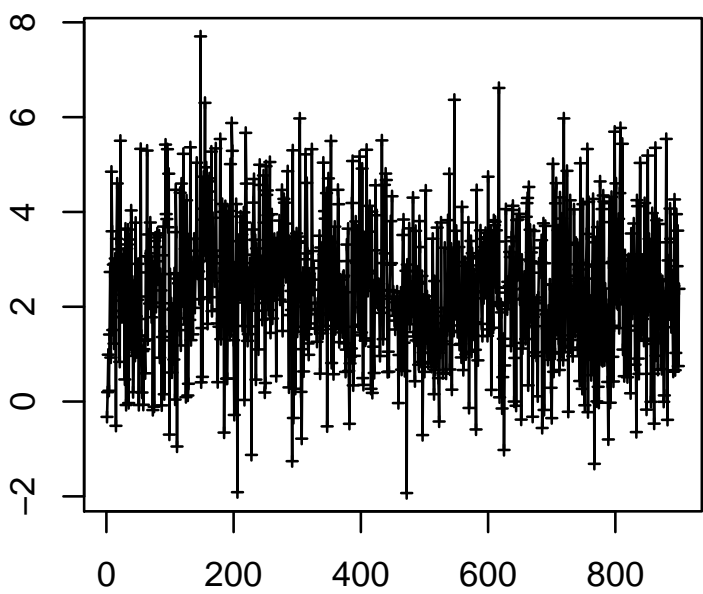

Time Point $(0.25 \mathrm{~Hz})$

Cell 1584

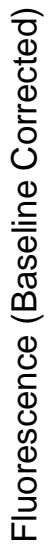

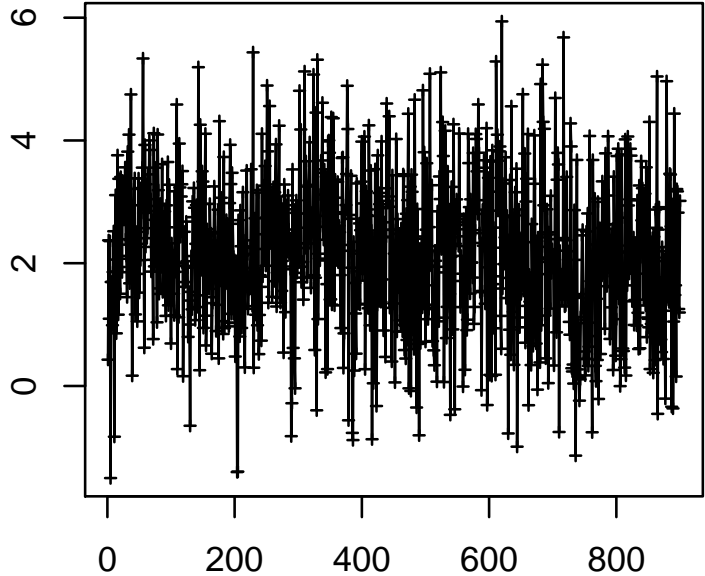

Time Point $(0.25 \mathrm{~Hz})$ 
Cell 1585

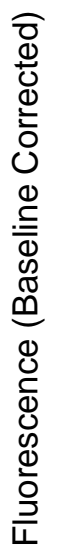

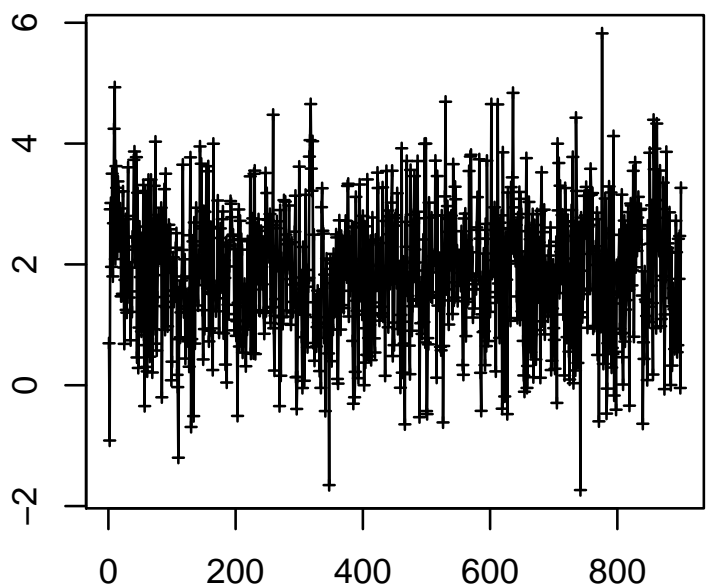

Time Point $(0.25 \mathrm{~Hz})$

Cell 1587

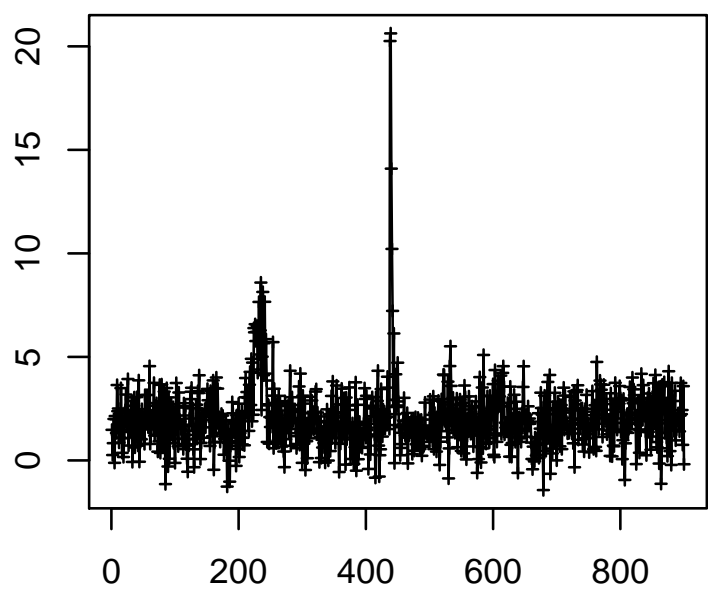

Time Point $(0.25 \mathrm{~Hz})$
Cell 1586

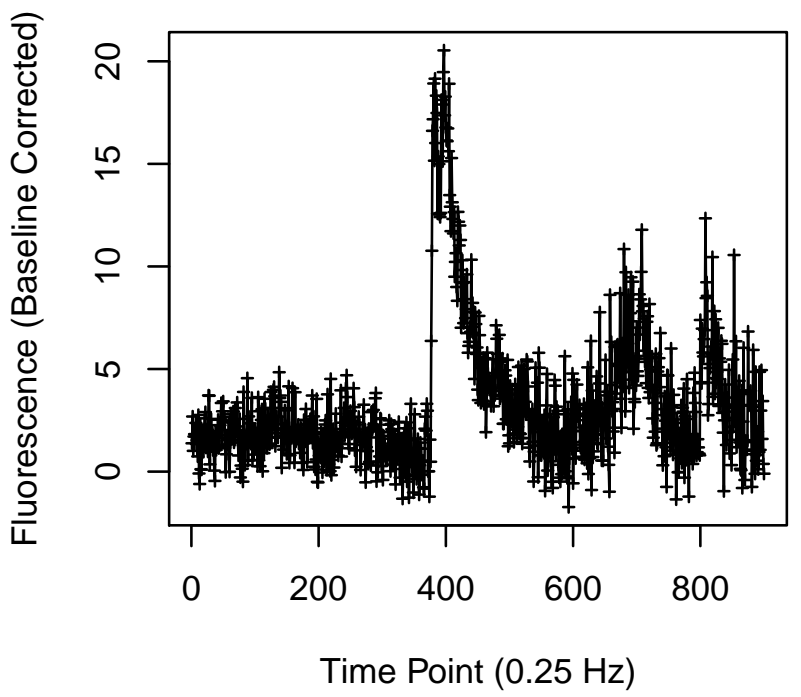

Cell 1588

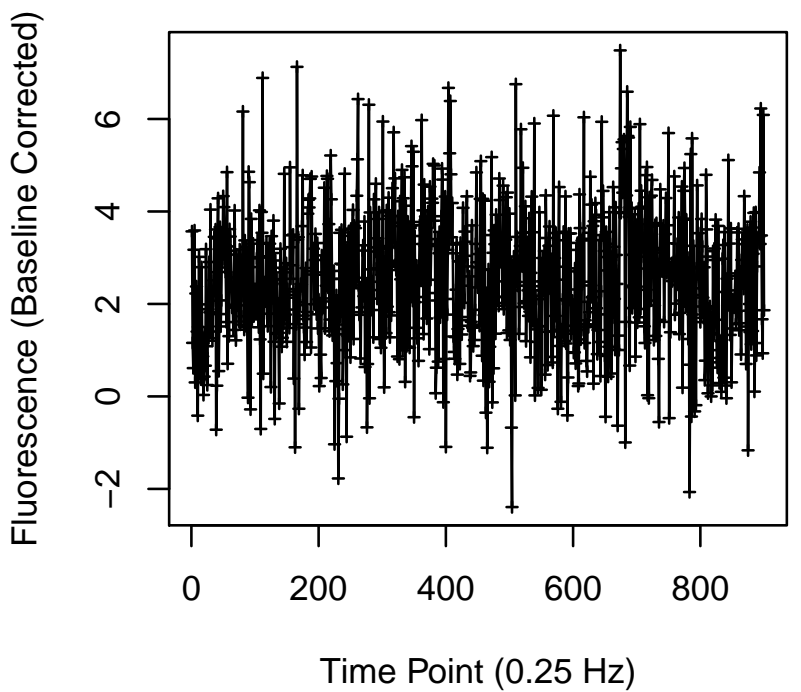


Cell 1589

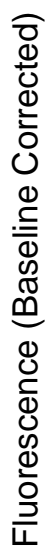

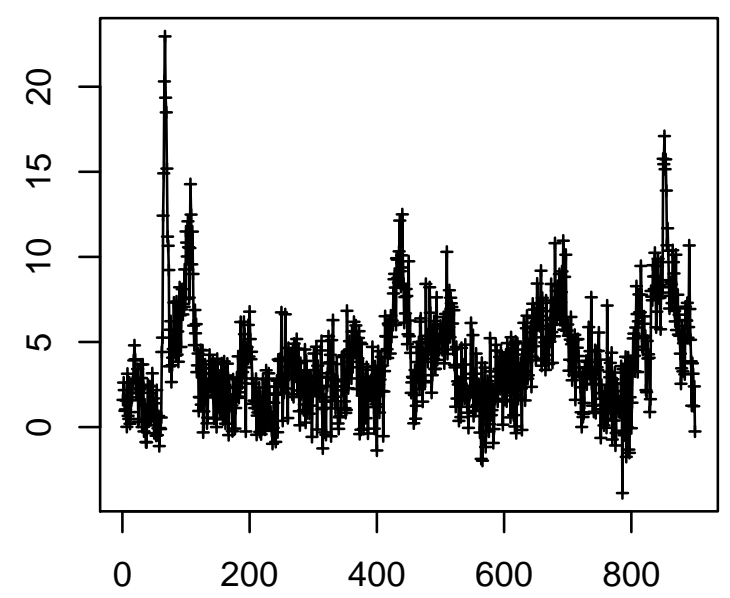

Time Point $(0.25 \mathrm{~Hz})$

Cell 1591

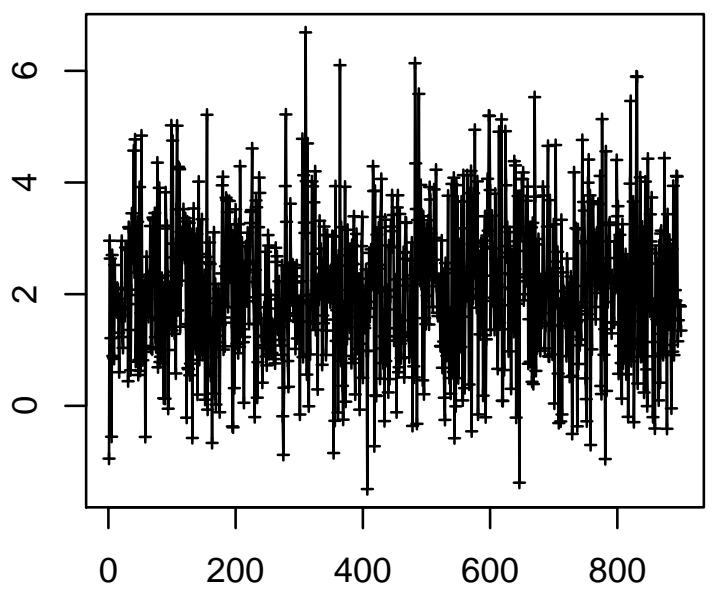

Time Point $(0.25 \mathrm{~Hz})$
Cell 1590

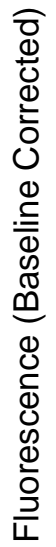

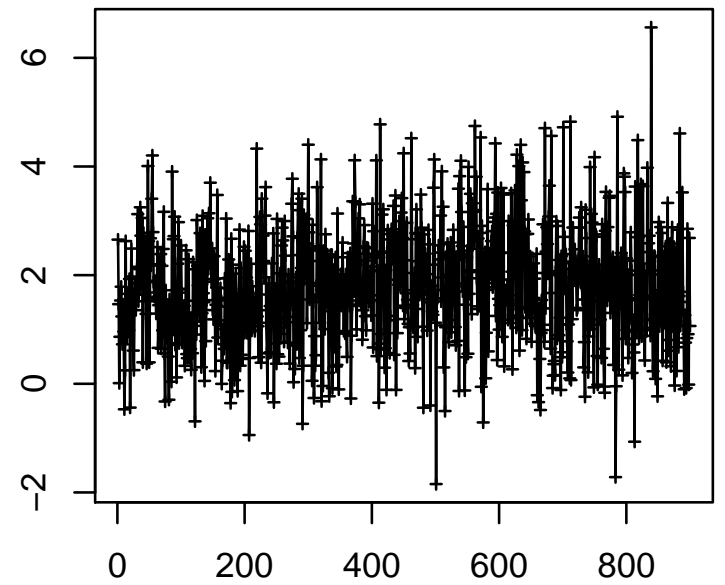

Time Point $(0.25 \mathrm{~Hz})$

Cell 1592

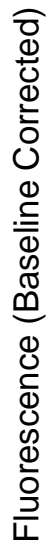

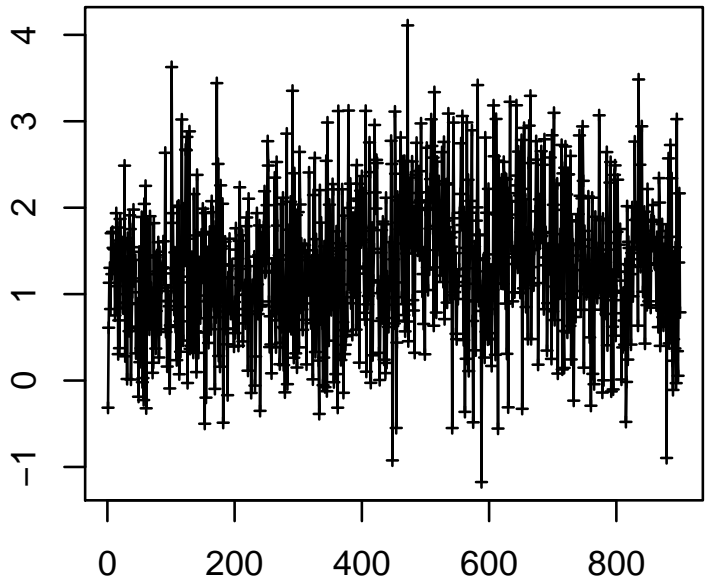

Time Point $(0.25 \mathrm{~Hz})$ 
Cell 1593

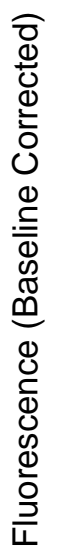

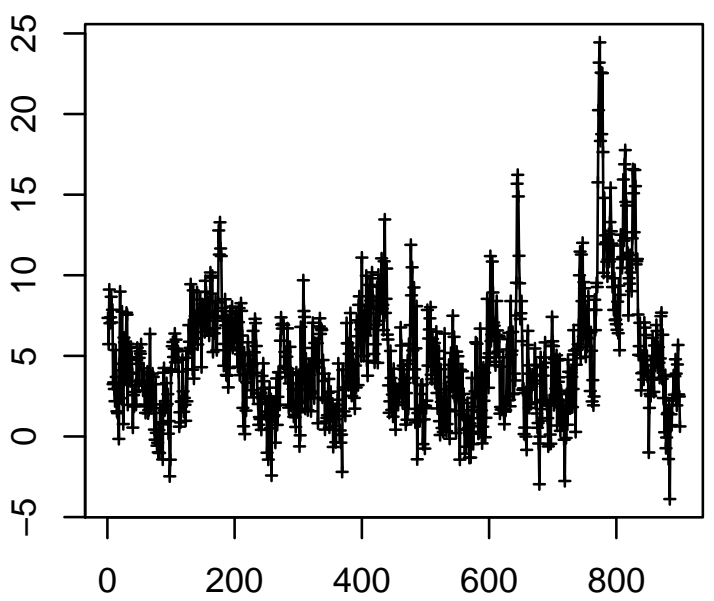

Time Point $(0.25 \mathrm{~Hz})$

Cell 1595

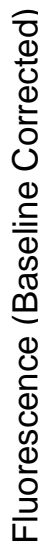

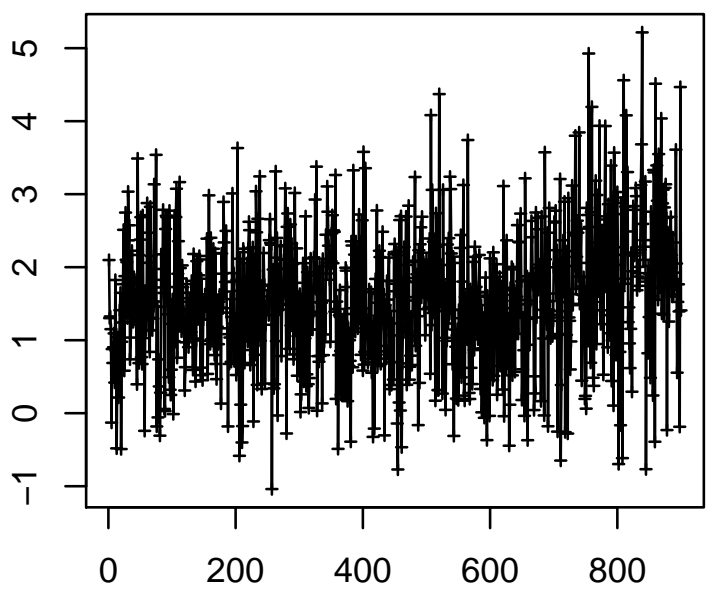

Time Point $(0.25 \mathrm{~Hz})$
Cell 1594

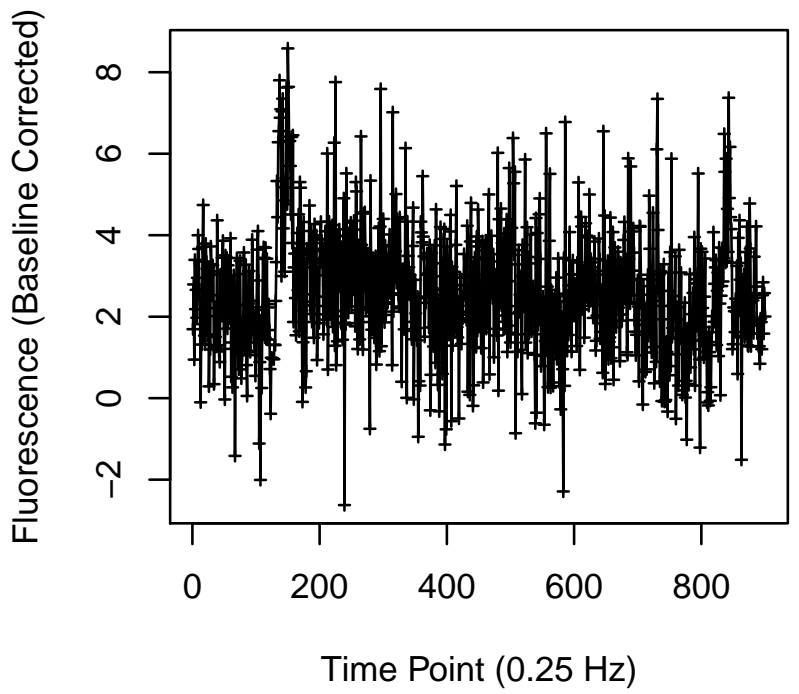

Cell 1596

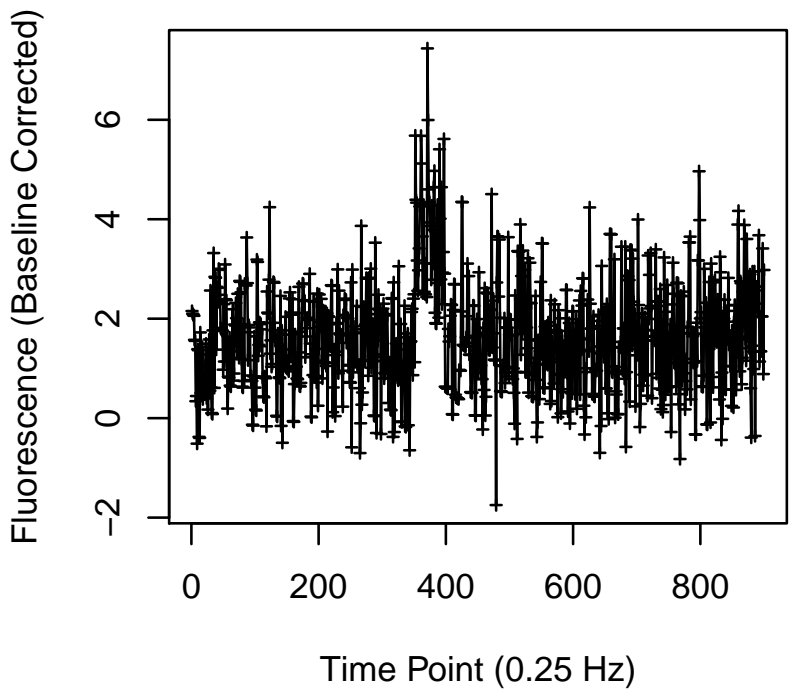


Cell 1597

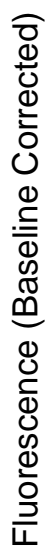

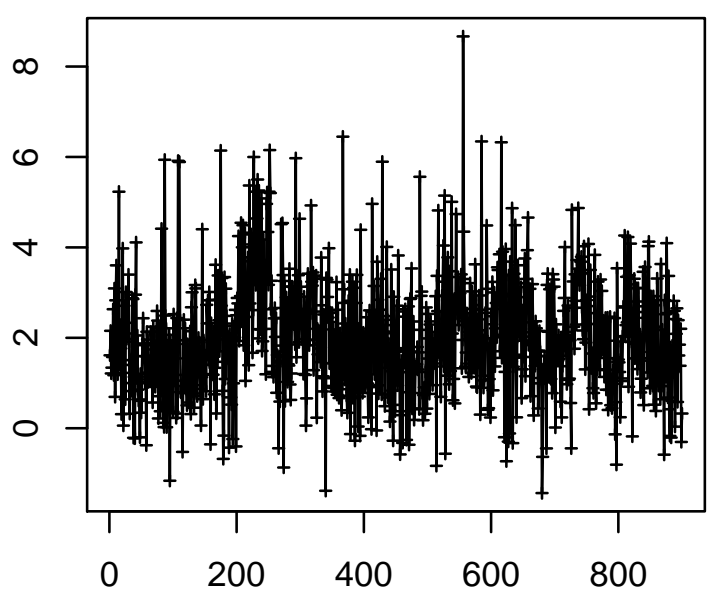

Time Point $(0.25 \mathrm{~Hz})$

Cell 1599

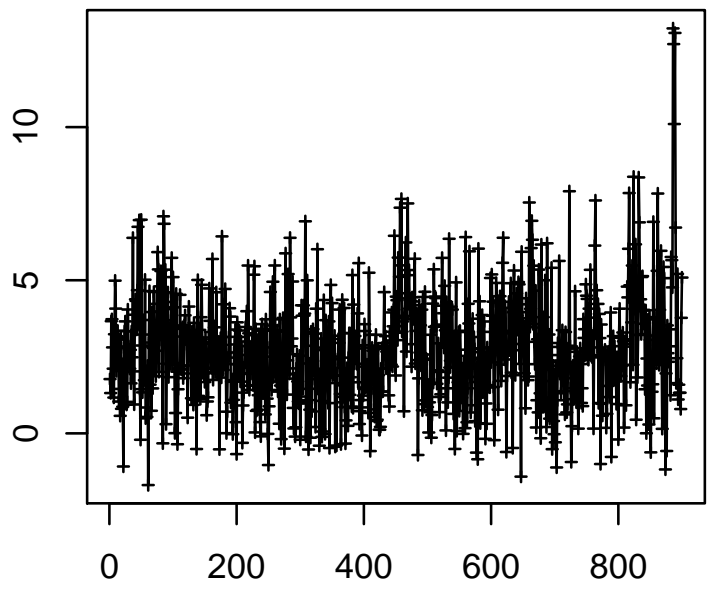

Time Point $(0.25 \mathrm{~Hz})$
Cell 1598

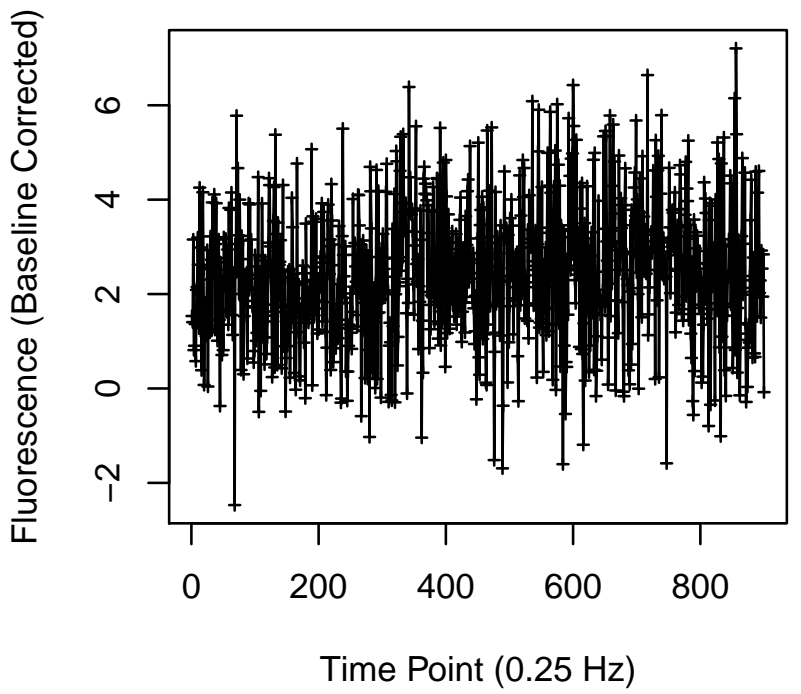

Cell 1600

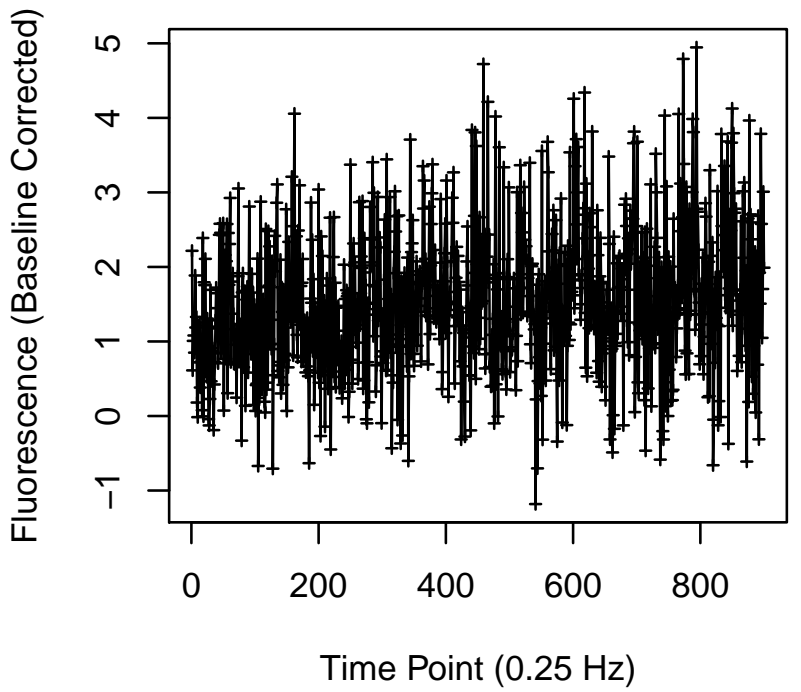


Cell 1601

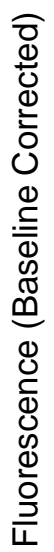

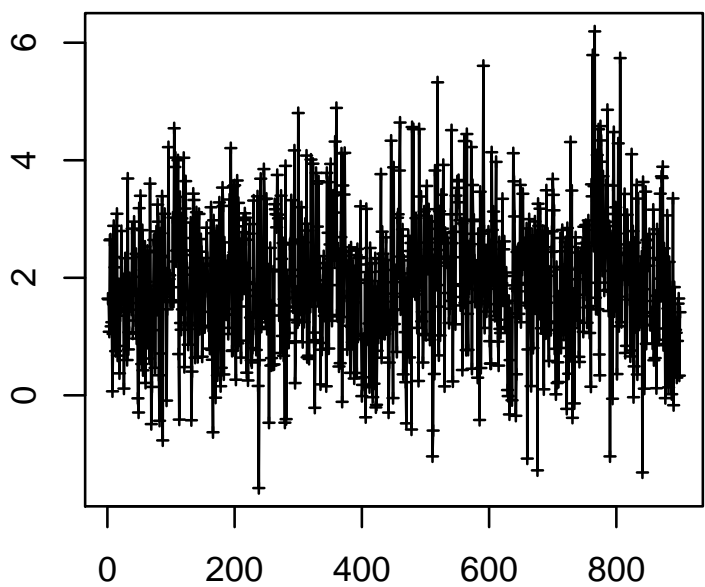

Time Point $(0.25 \mathrm{~Hz})$

Cell 1603

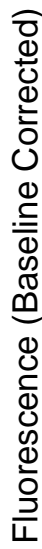

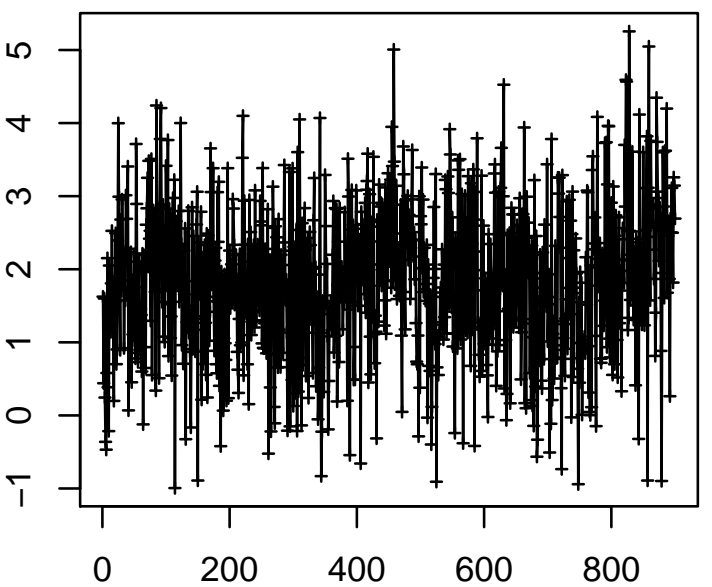

Time Point $(0.25 \mathrm{~Hz})$
Cell 1602

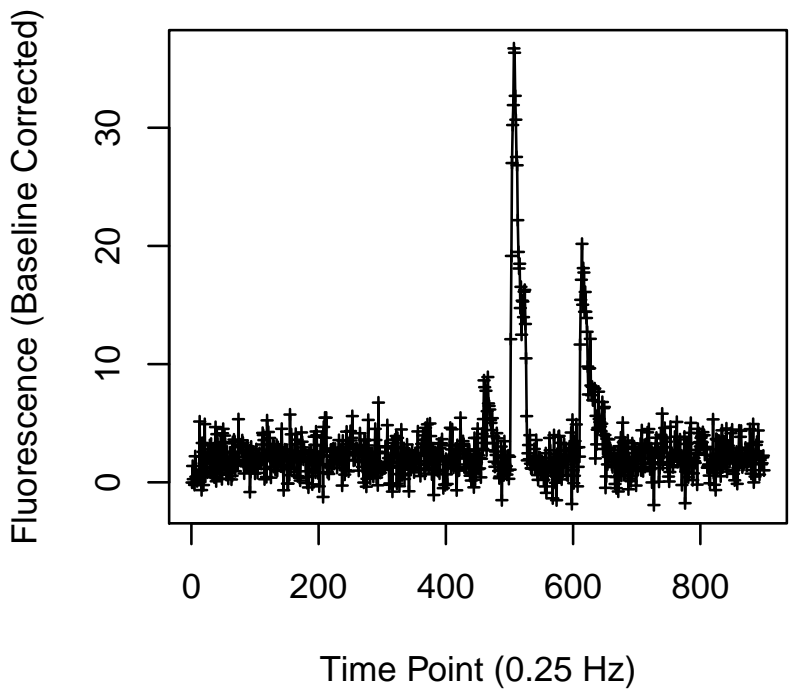

Cell 1604

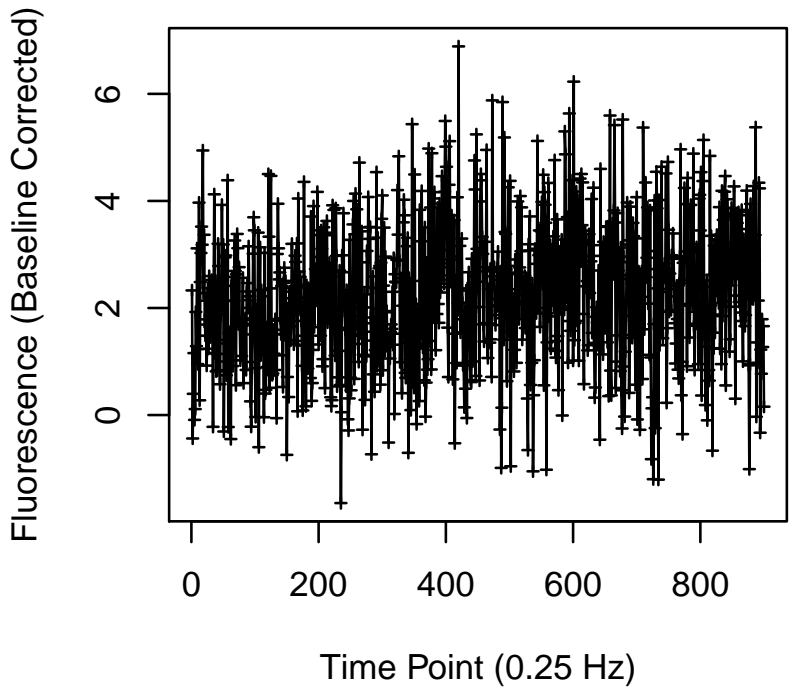


Cell 1609

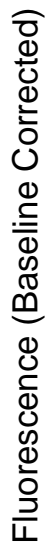

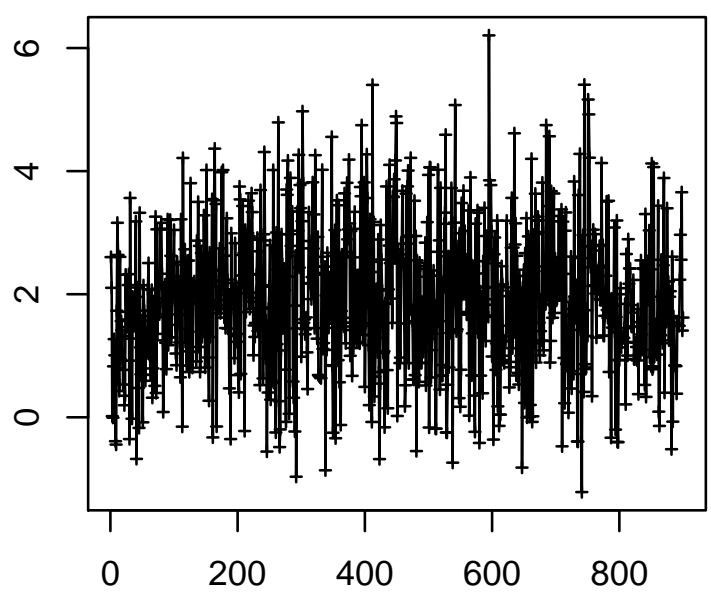

Time Point $(0.25 \mathrm{~Hz})$

Cell 1611

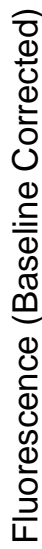

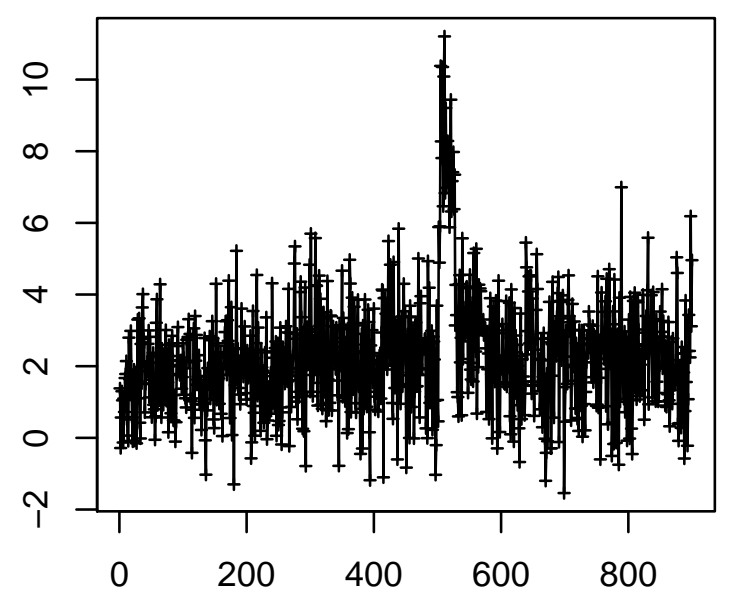

Time Point $(0.25 \mathrm{~Hz})$
Cell 1610

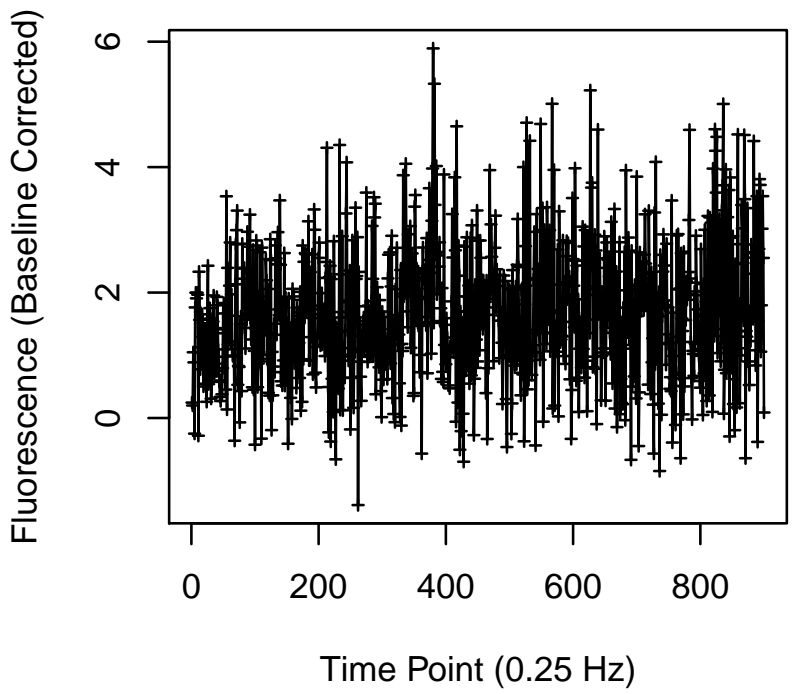

Cell 1612

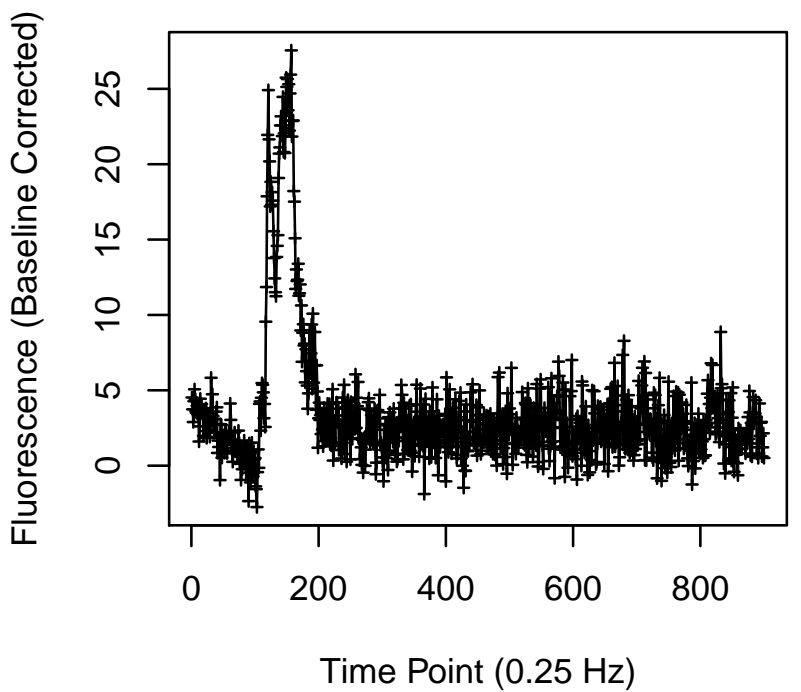




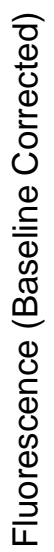

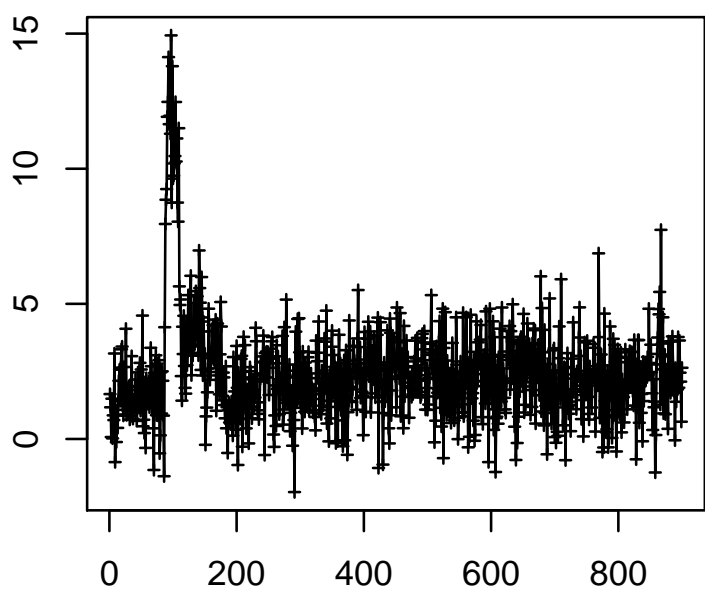

Time Point $(0.25 \mathrm{~Hz})$

Cell 1627

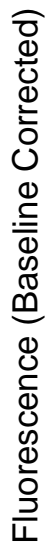

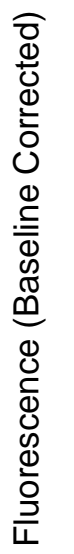

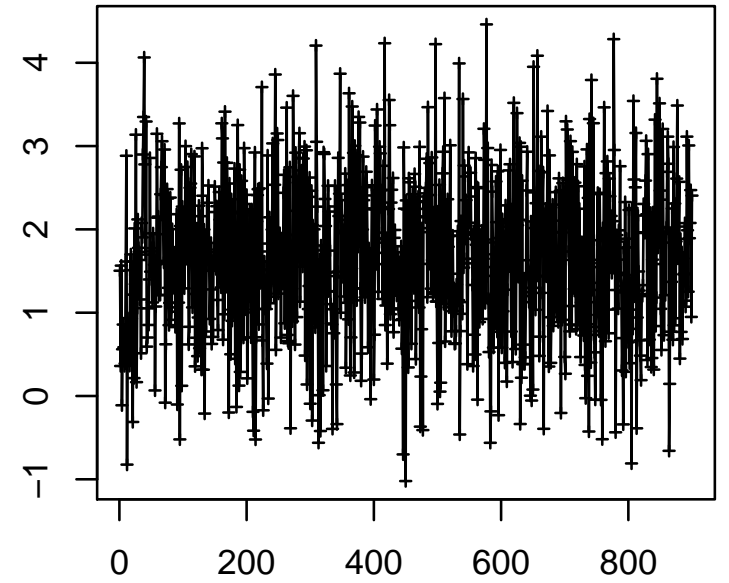

Time Point $(0.25 \mathrm{~Hz})$

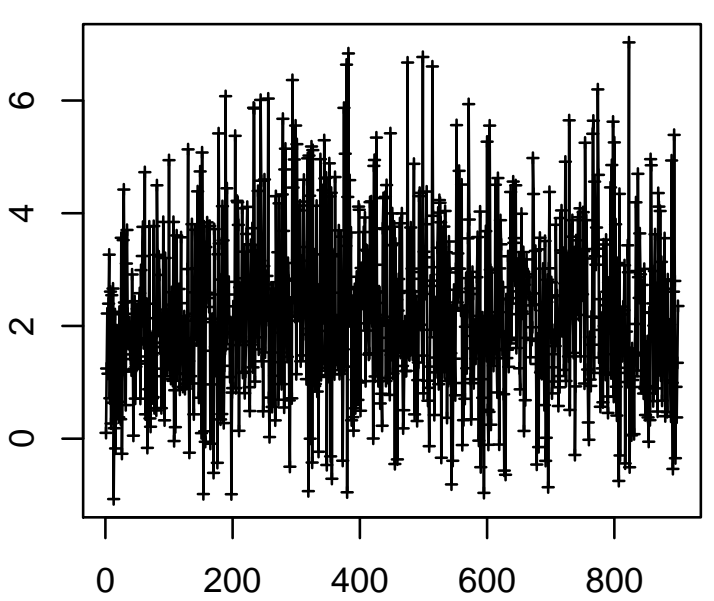

Time Point $(0.25 \mathrm{~Hz})$

Cell 1628

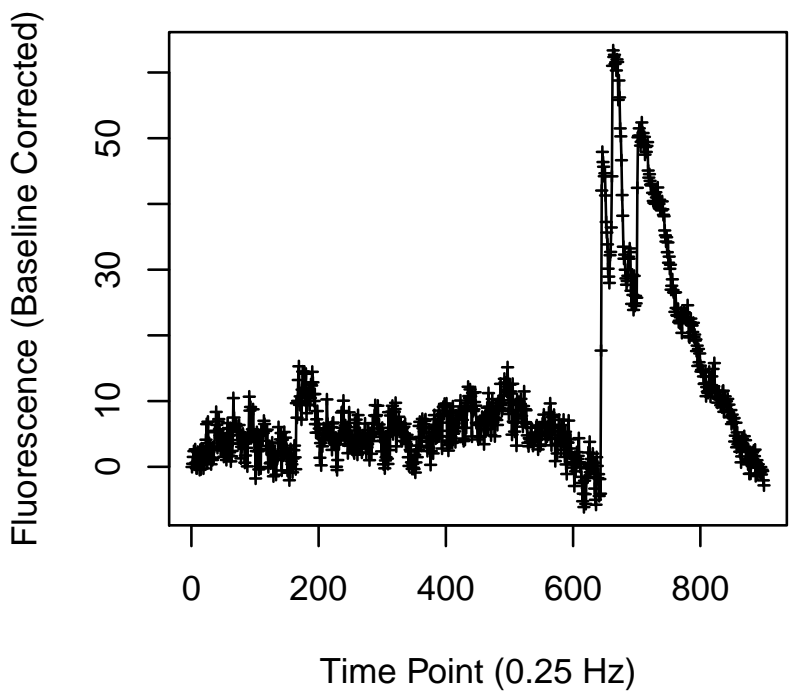




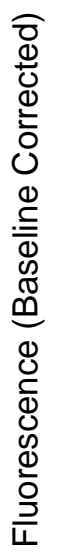

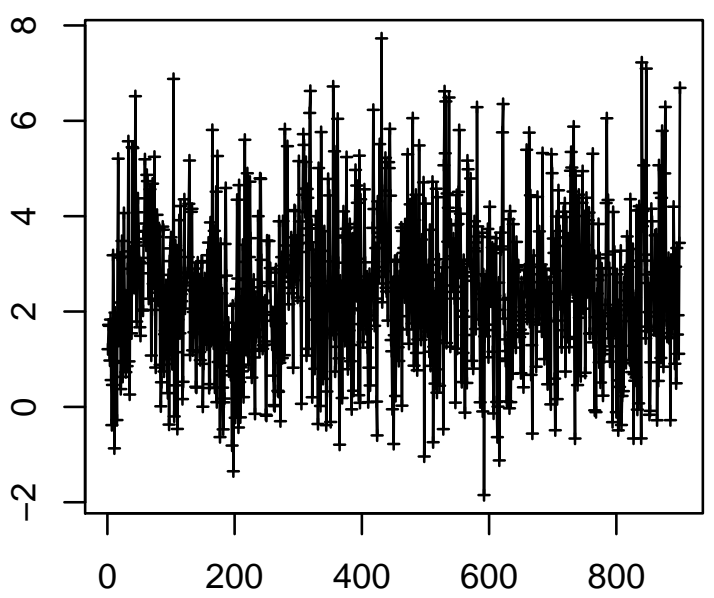

Time Point $(0.25 \mathrm{~Hz})$

Cell 1631

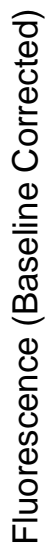

Time Point $(0.25 \mathrm{~Hz})$

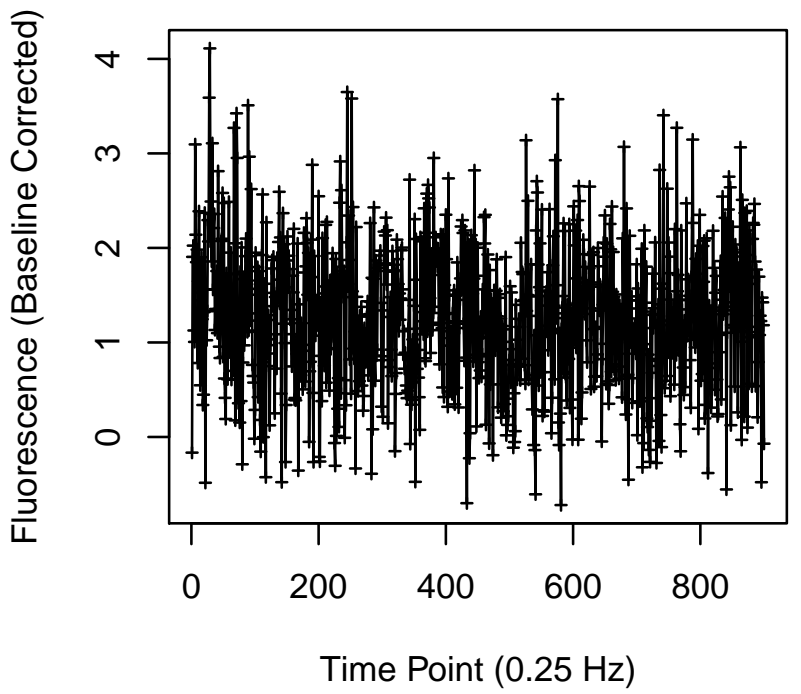

Cell 1632

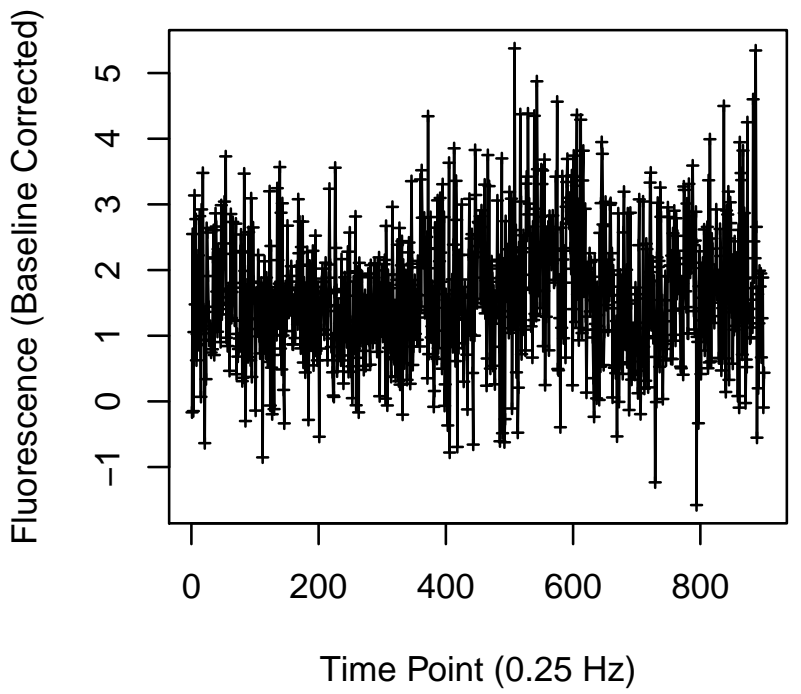


Cell 1641

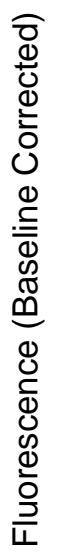

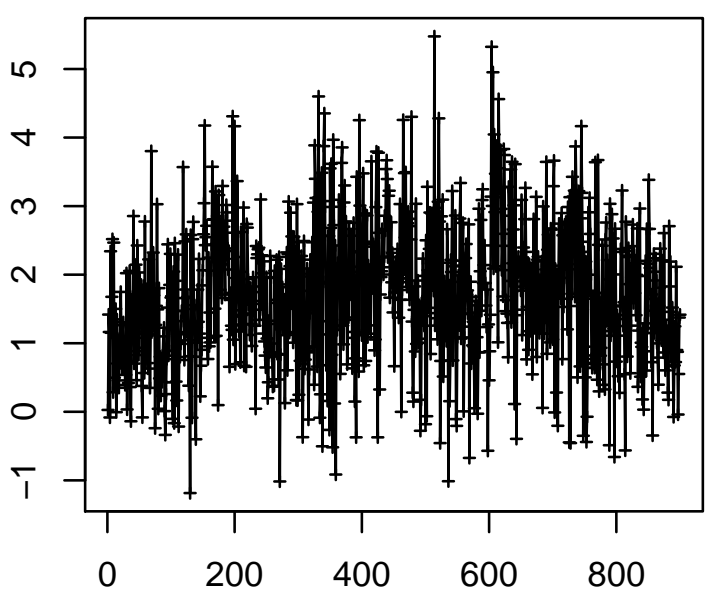

Time Point $(0.25 \mathrm{~Hz})$

Cell 1643

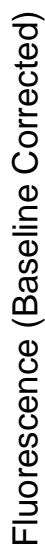

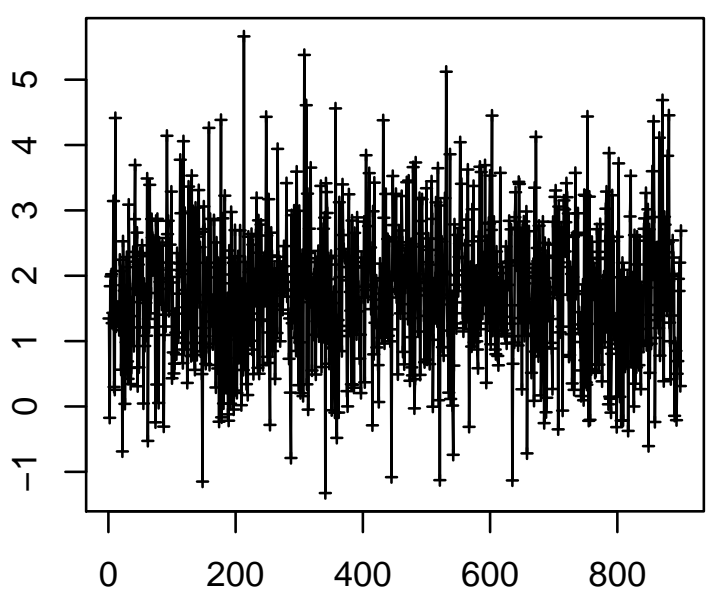

Time Point $(0.25 \mathrm{~Hz})$
Cell 1642

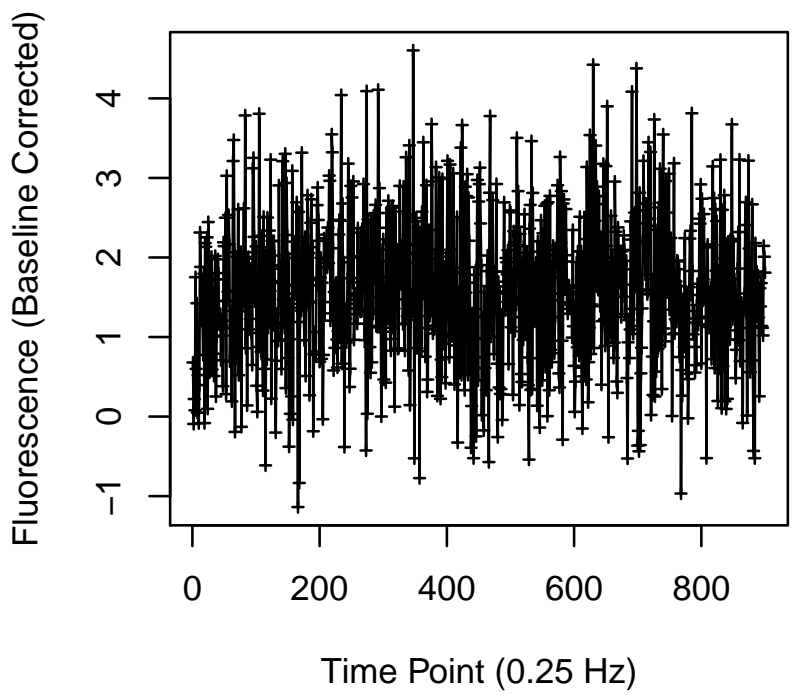

Cell 1644

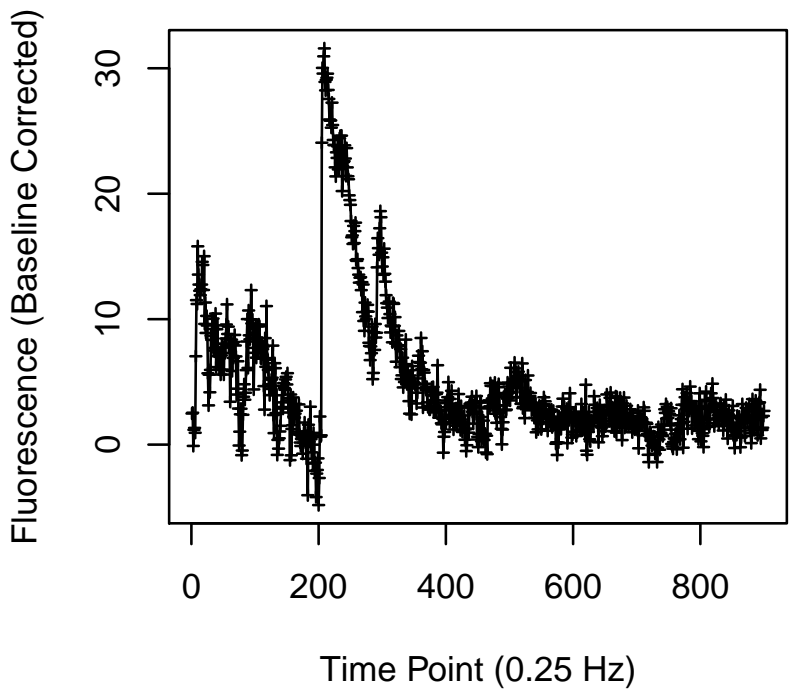


Cell 1649

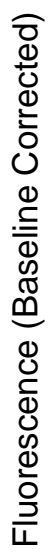

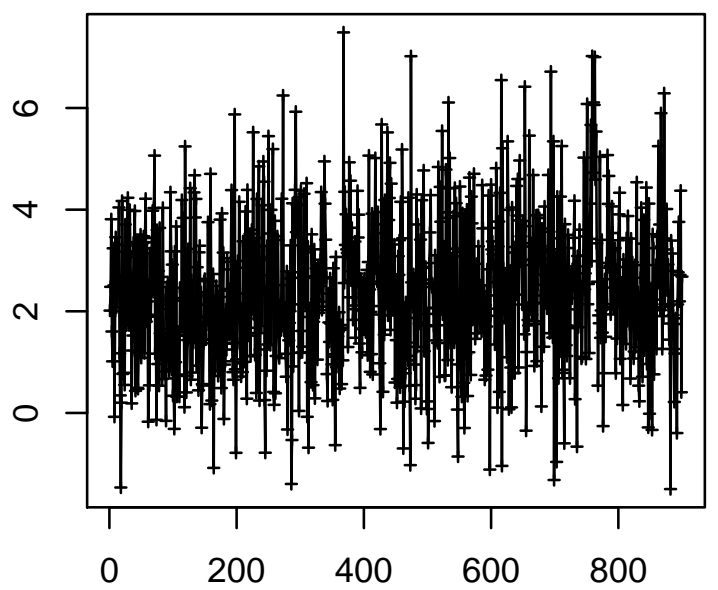

Time Point $(0.25 \mathrm{~Hz})$

Cell 1651

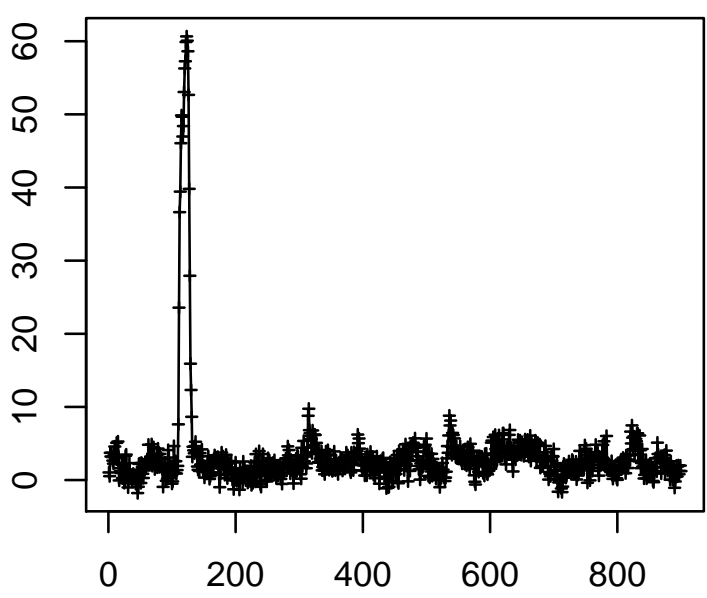

Time Point $(0.25 \mathrm{~Hz})$
Cell 1650

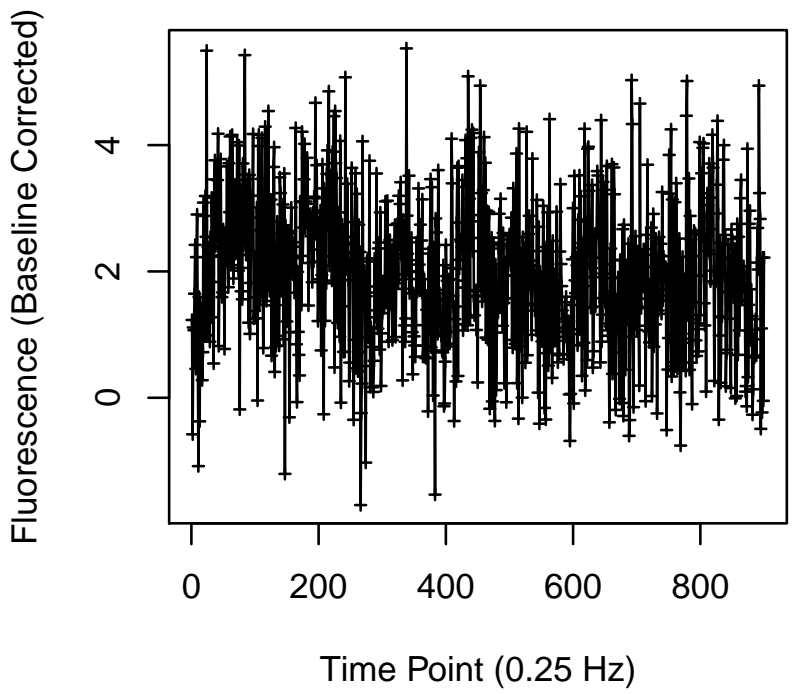

Cell 1652

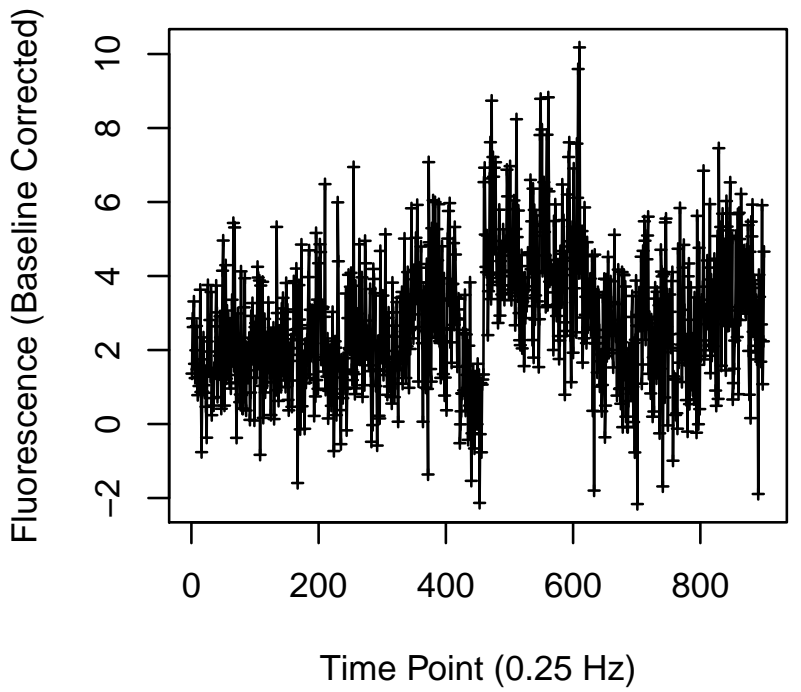


Cell 1657

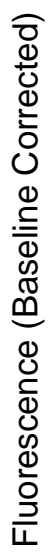

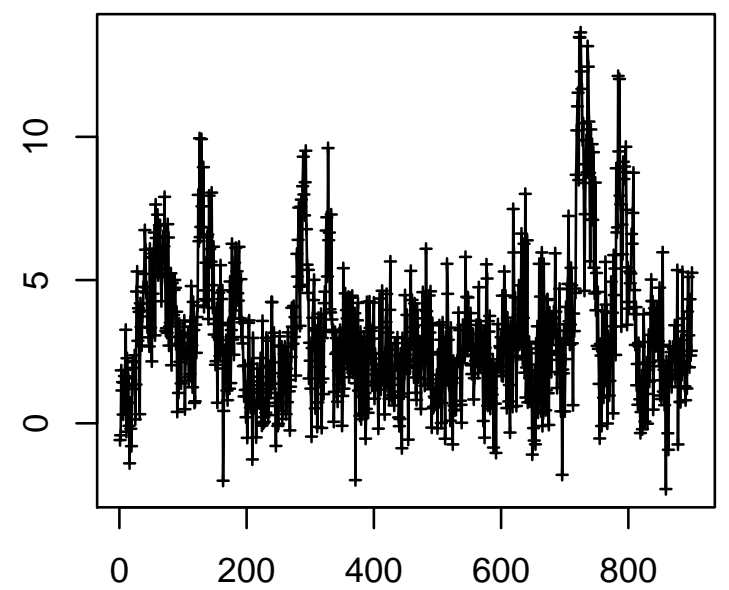

Time Point $(0.25 \mathrm{~Hz})$

Cell 1659

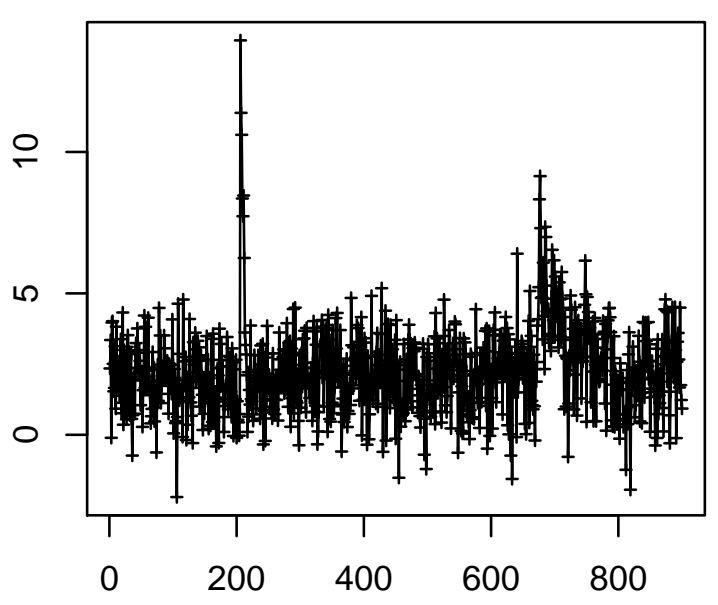

Time Point $(0.25 \mathrm{~Hz})$
Cell 1658

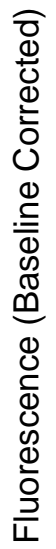

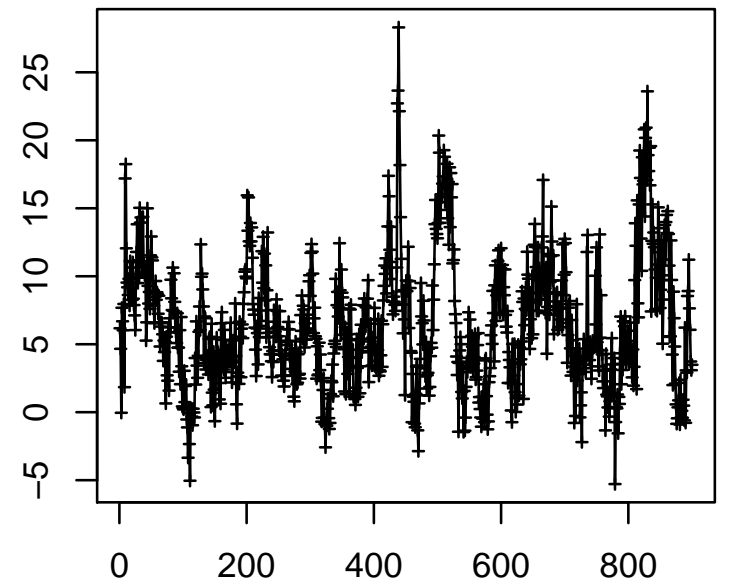

Time Point $(0.25 \mathrm{~Hz})$

Cell 1660

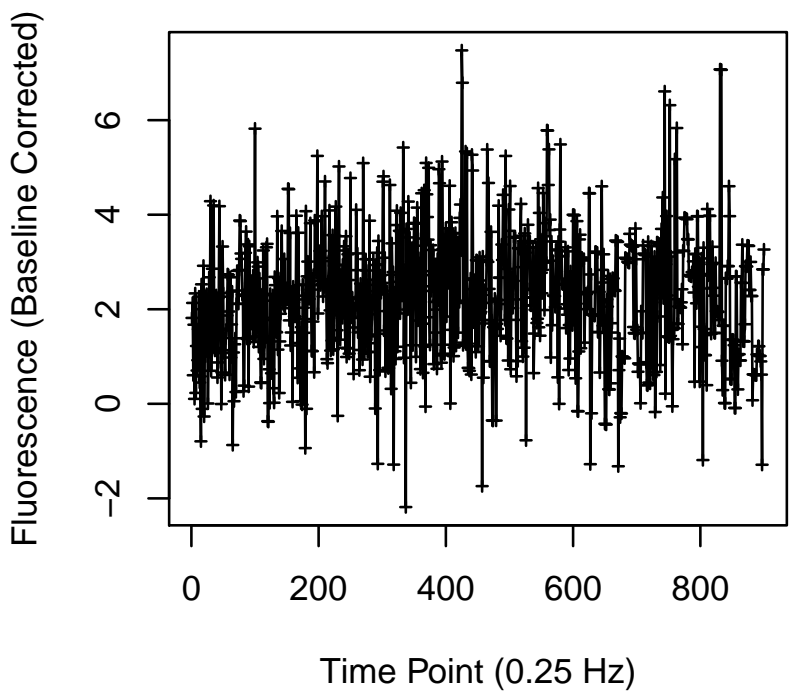


Cell 1669

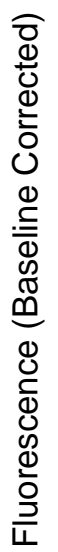

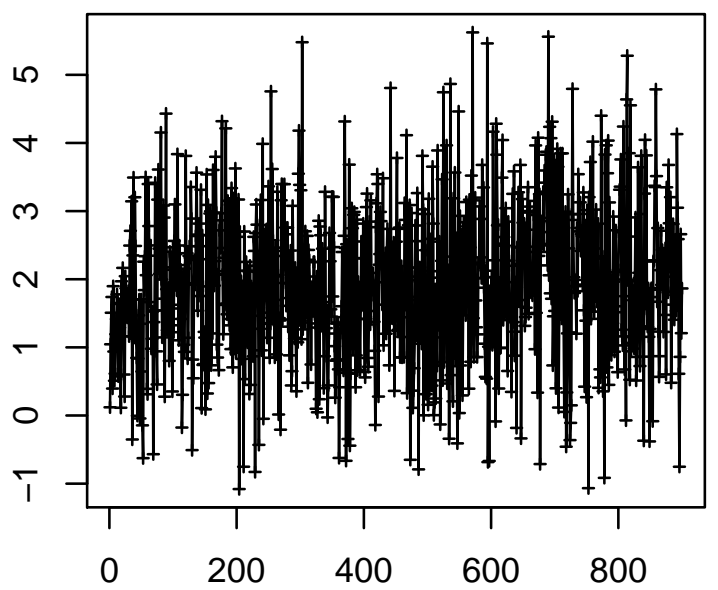

Time Point $(0.25 \mathrm{~Hz})$

Cell 1671

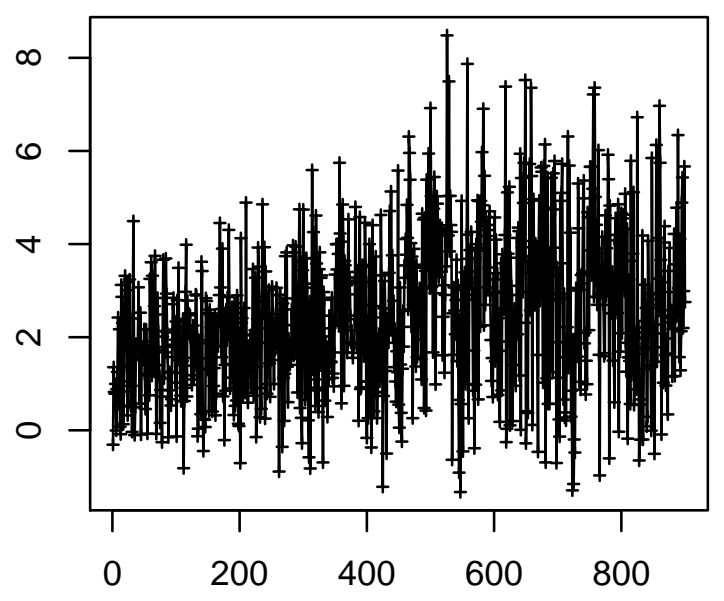

Time Point $(0.25 \mathrm{~Hz})$
Cell 1670

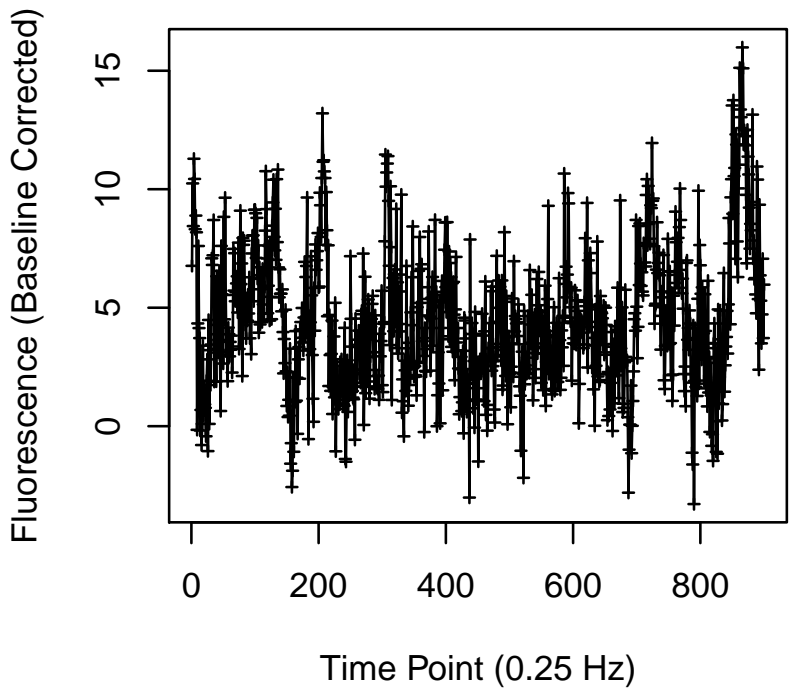

Cell 1672

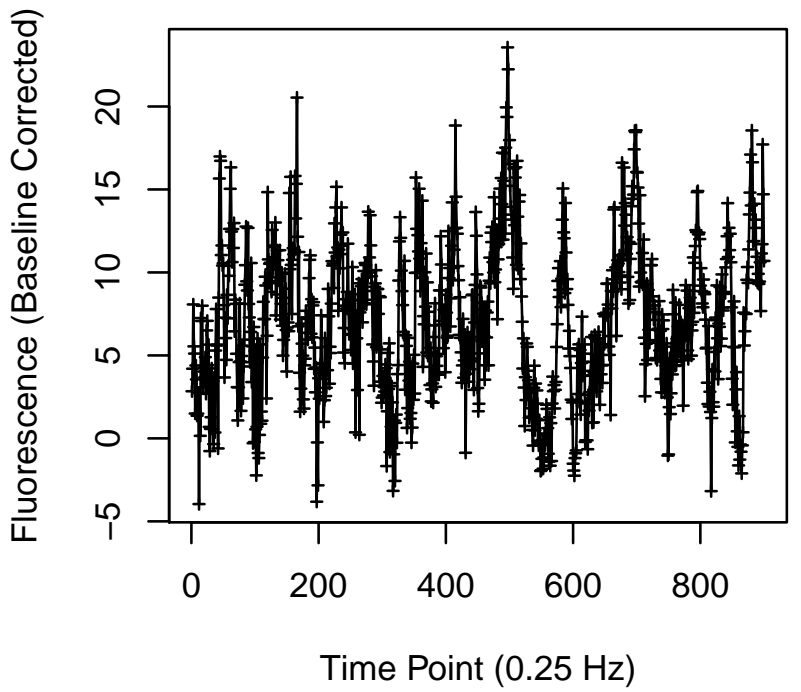


Cell 1677

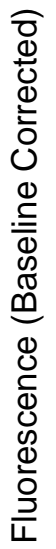

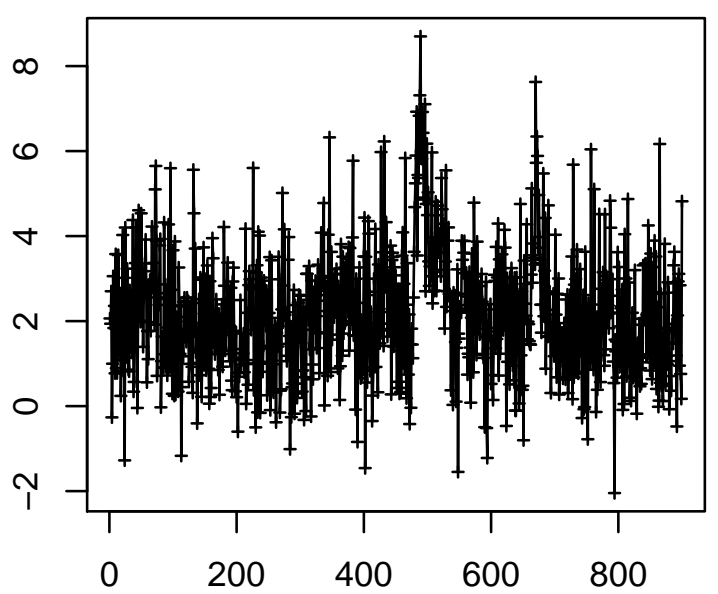

Time Point $(0.25 \mathrm{~Hz})$

Cell 1679

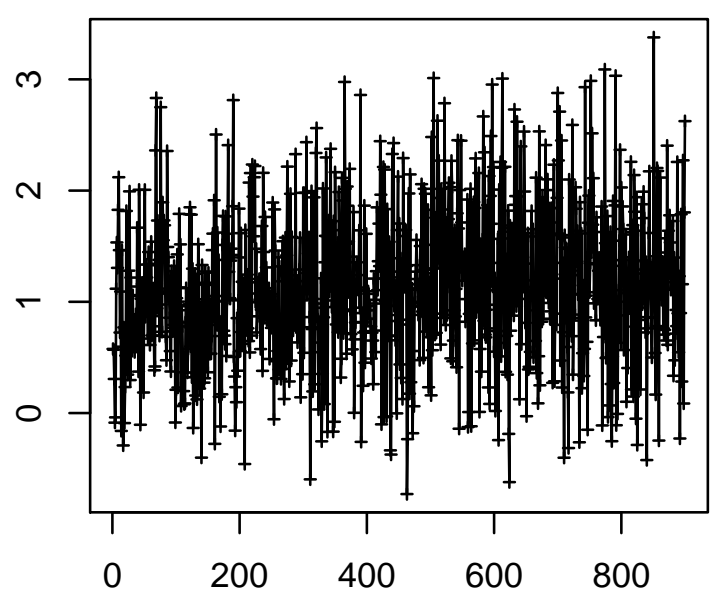

Time Point $(0.25 \mathrm{~Hz})$
Cell 1678

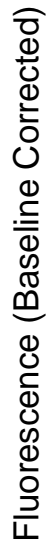

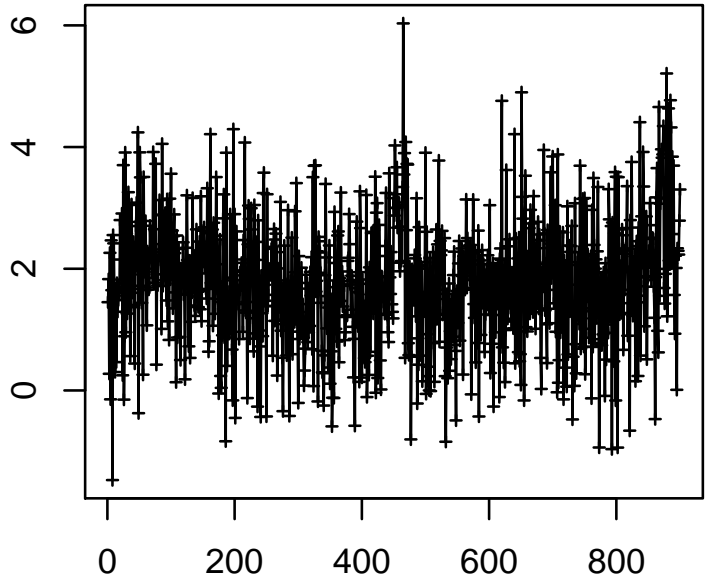

Time Point $(0.25 \mathrm{~Hz})$

Cell 1680

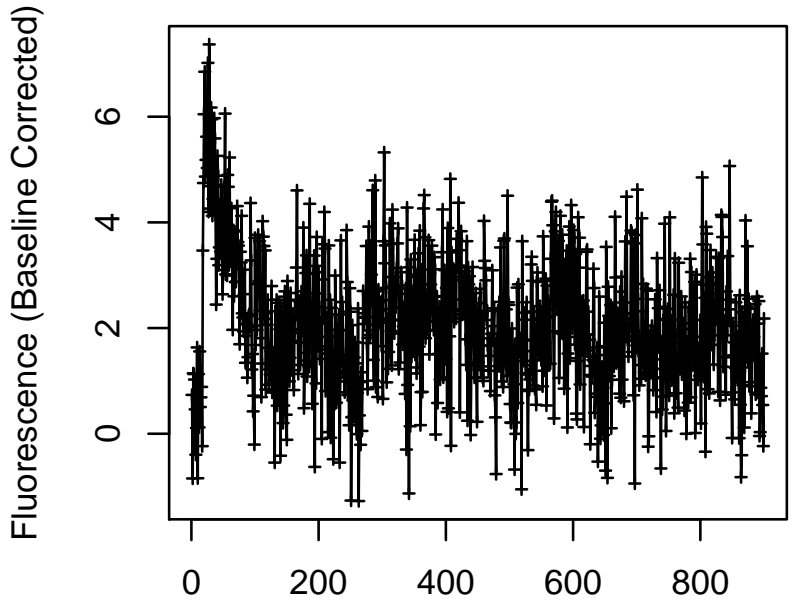

Time Point $(0.25 \mathrm{~Hz})$ 
Cell 1681

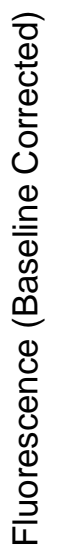

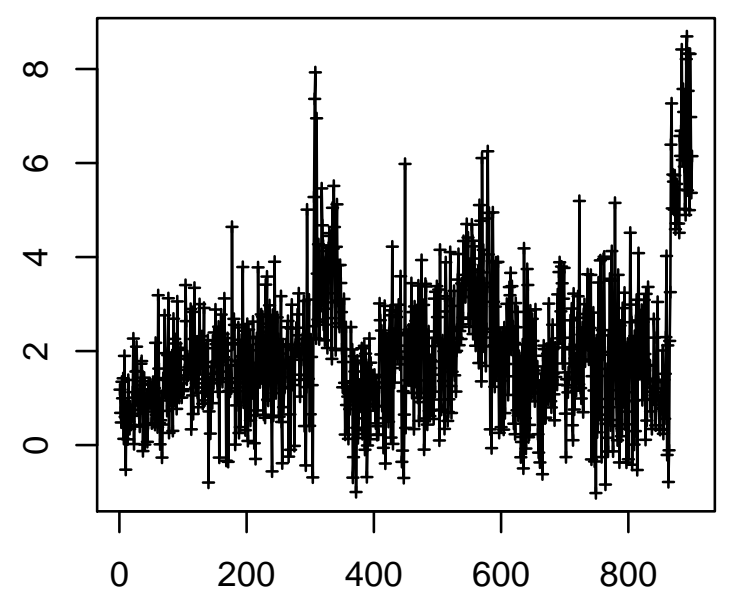

Time Point $(0.25 \mathrm{~Hz})$

Cell 1683

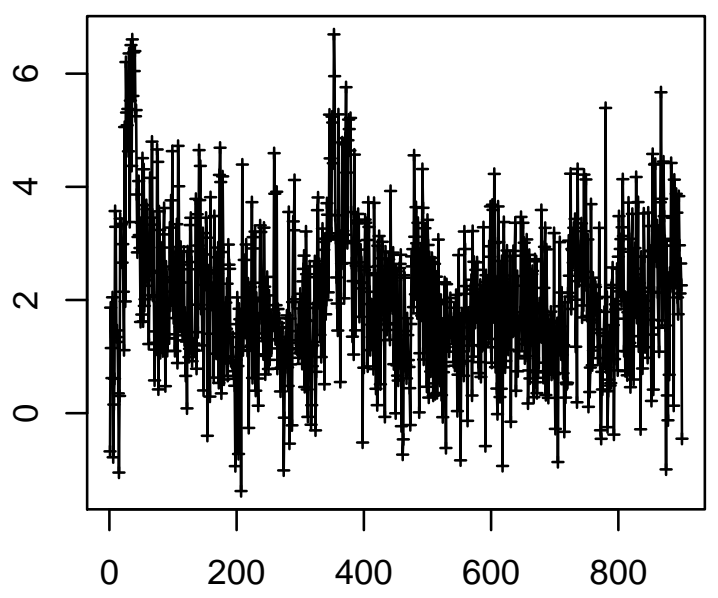

Time Point $(0.25 \mathrm{~Hz})$
Cell 1682

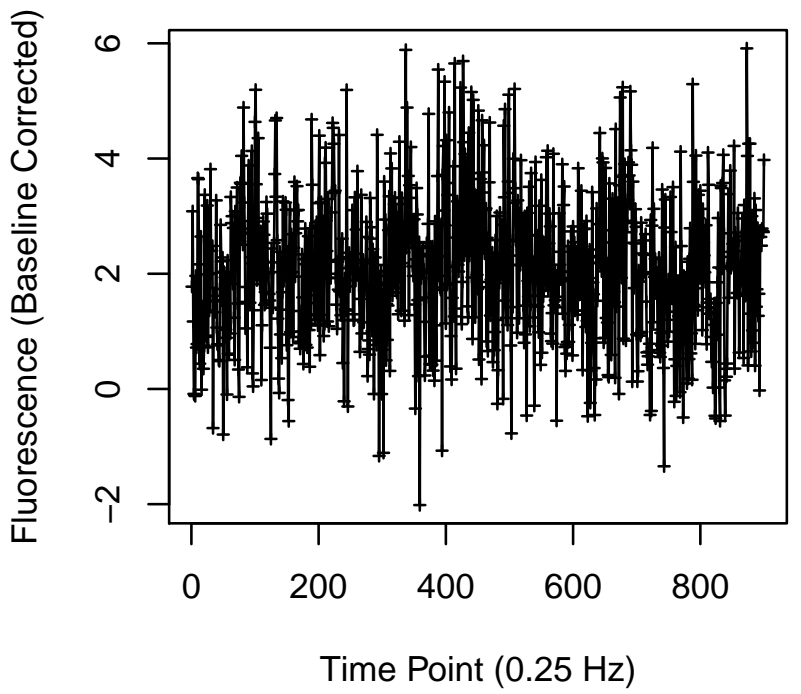

Cell 1684

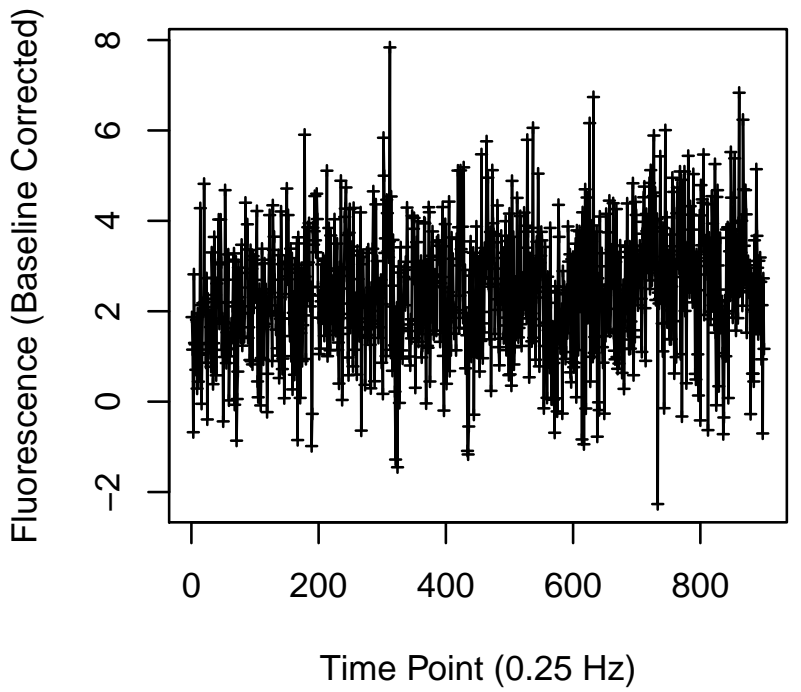


Cell 1685

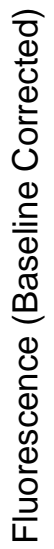

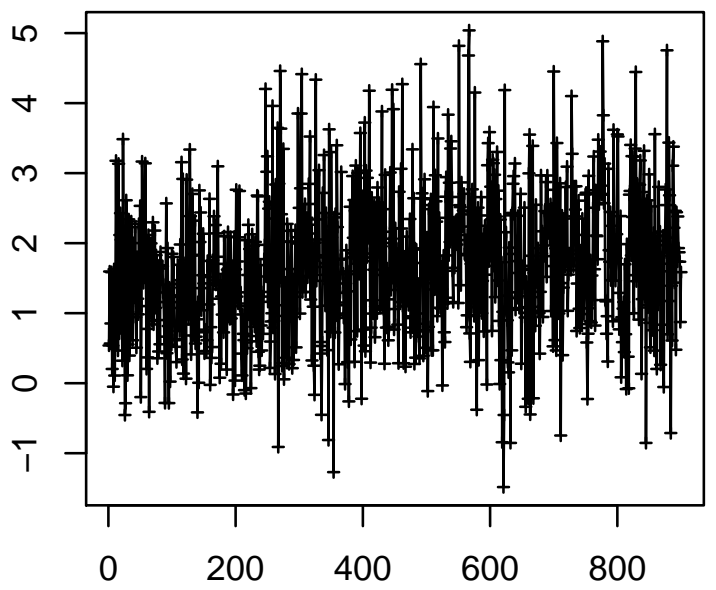

Time Point $(0.25 \mathrm{~Hz})$

Cell 1687

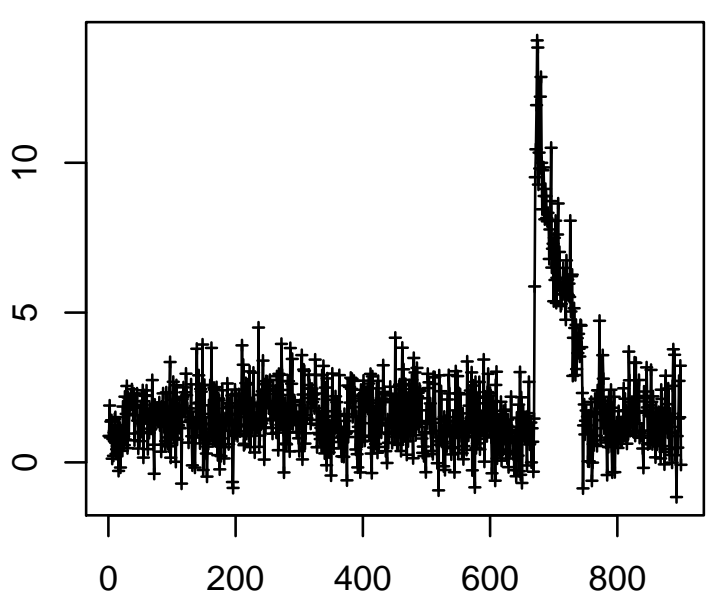

Time Point $(0.25 \mathrm{~Hz})$
Cell 1686

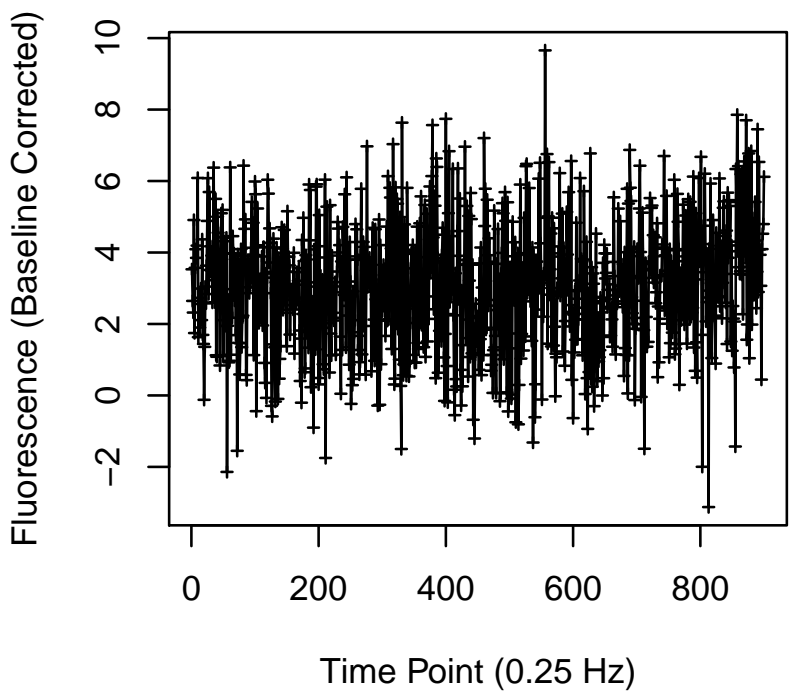

Cell 1688

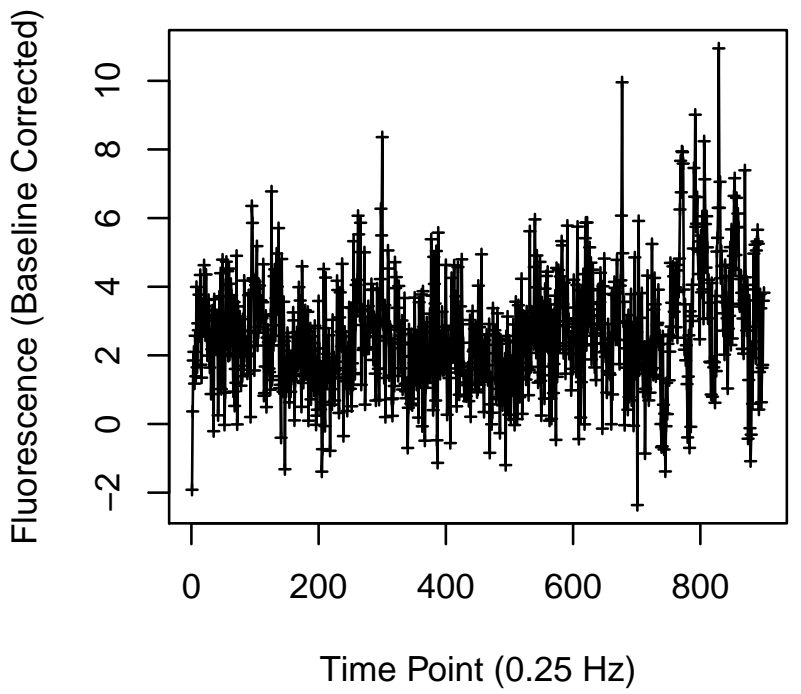


Cell 1689

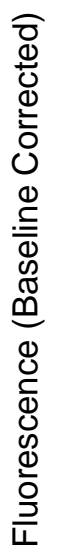

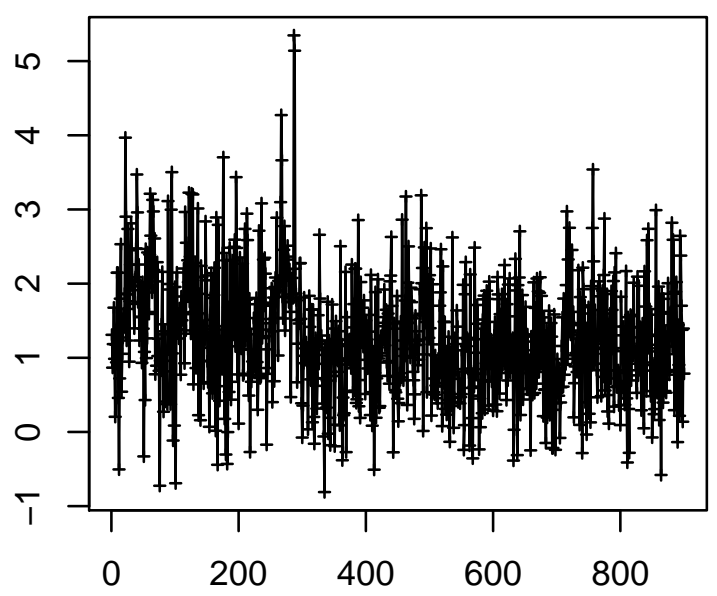

Time Point $(0.25 \mathrm{~Hz})$

Cell 1691

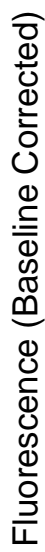

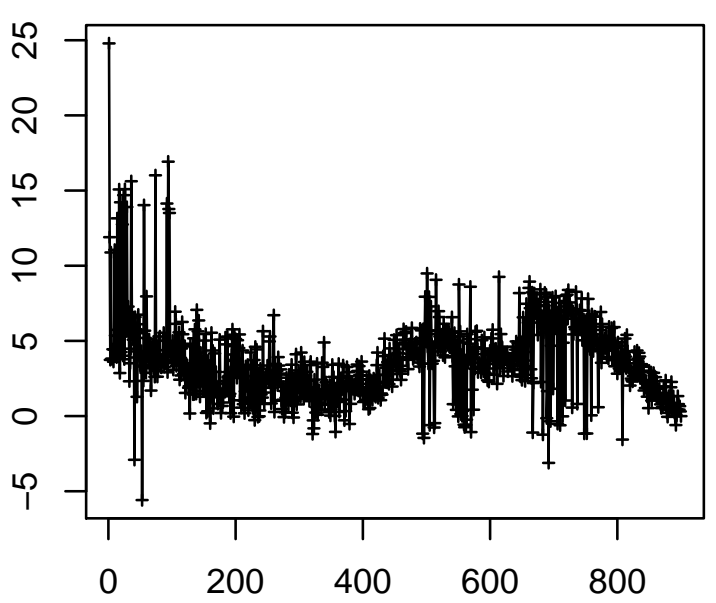

Time Point $(0.25 \mathrm{~Hz})$
Cell 1690

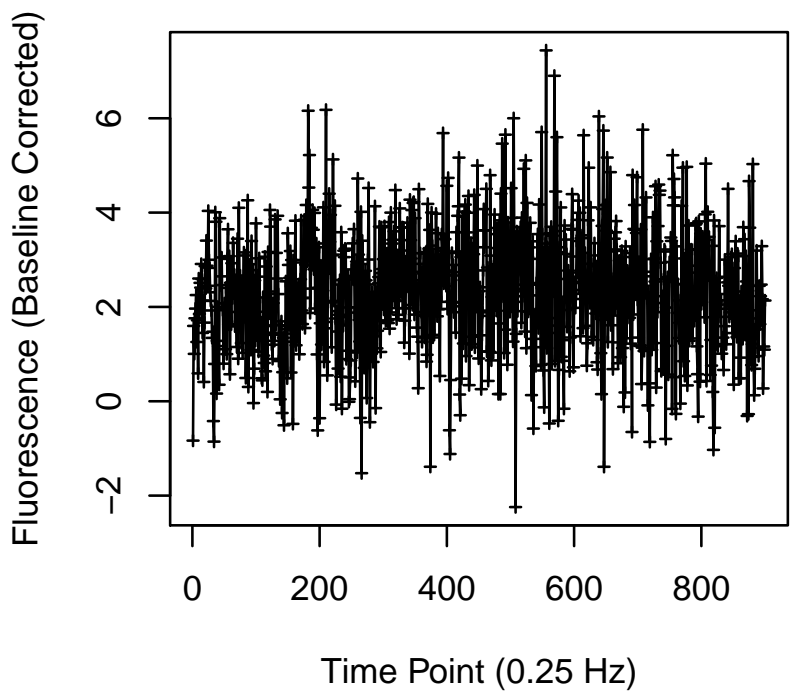

Cell 1692

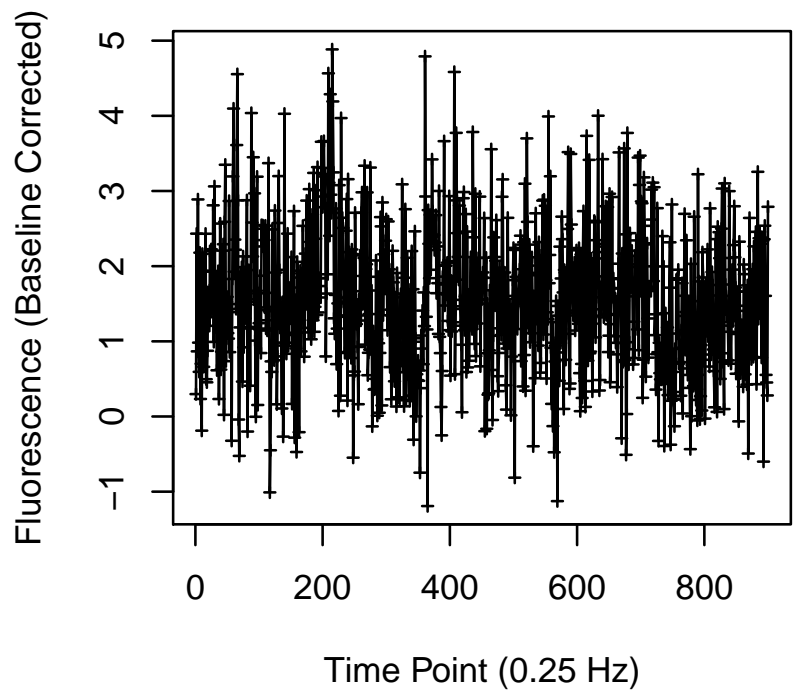


Cell 1693

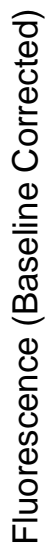

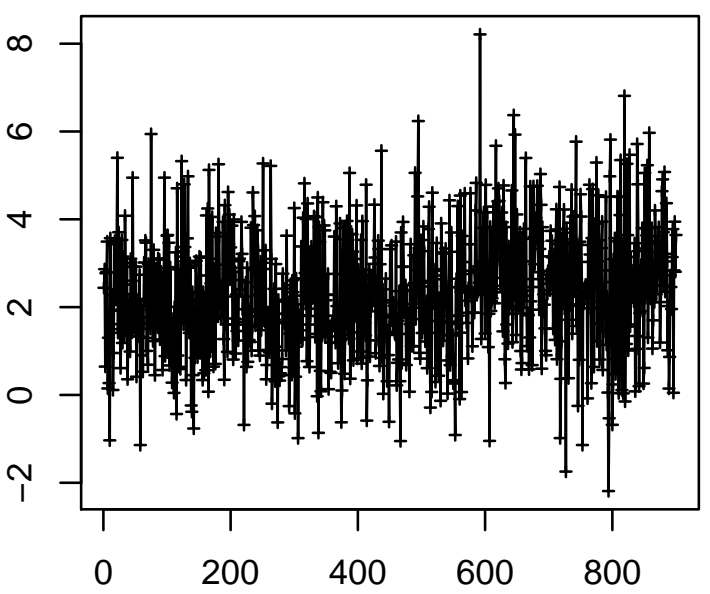

Time Point $(0.25 \mathrm{~Hz})$

Cell 1695

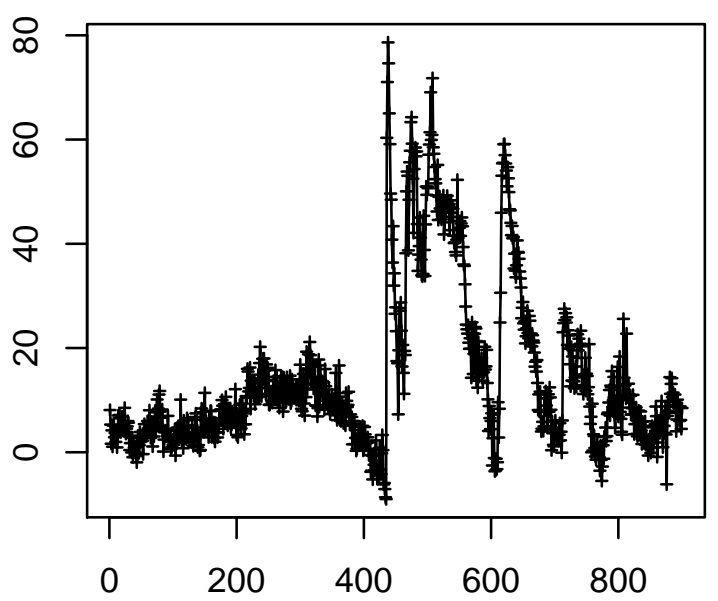

Time Point $(0.25 \mathrm{~Hz})$
Cell 1694

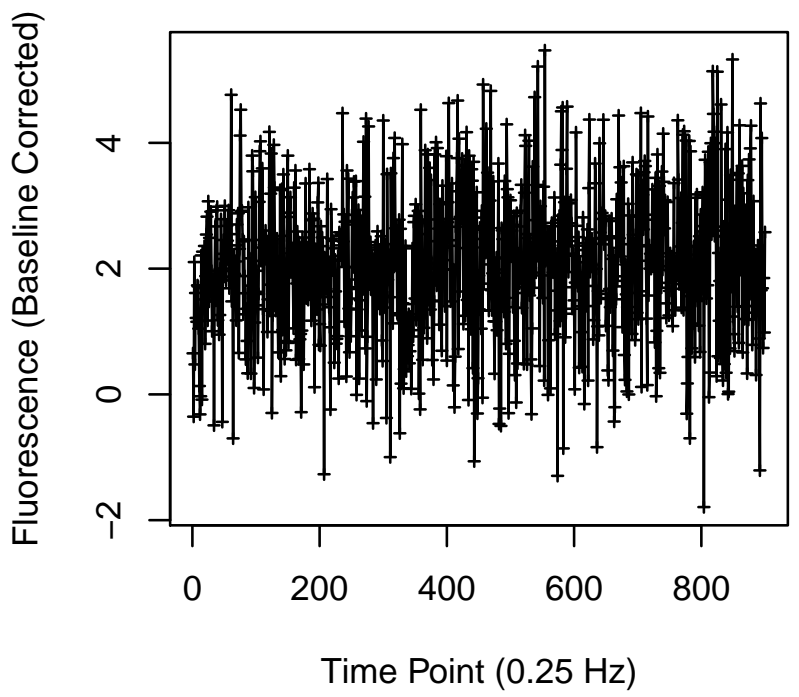

Cell 1696

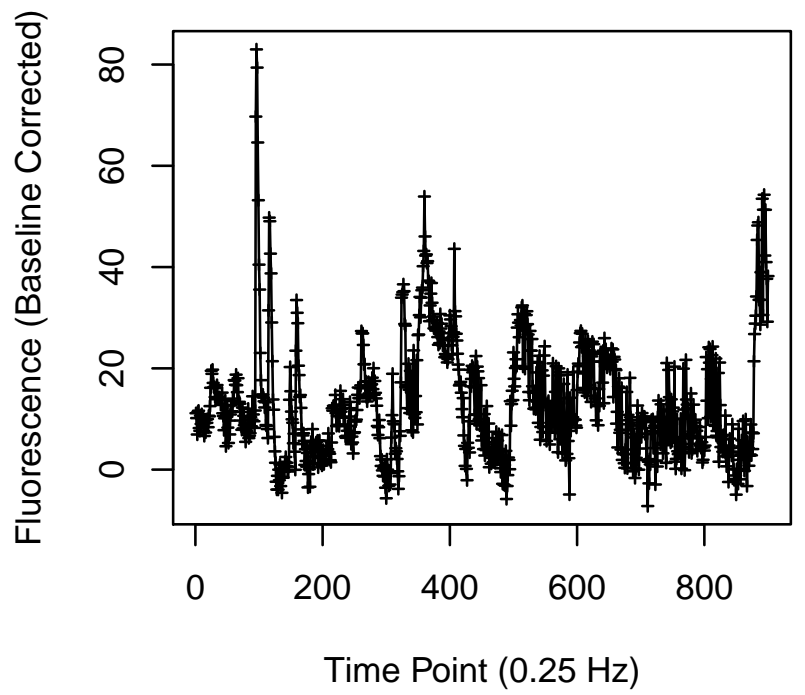


Cell 1713

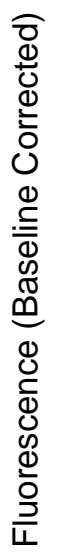

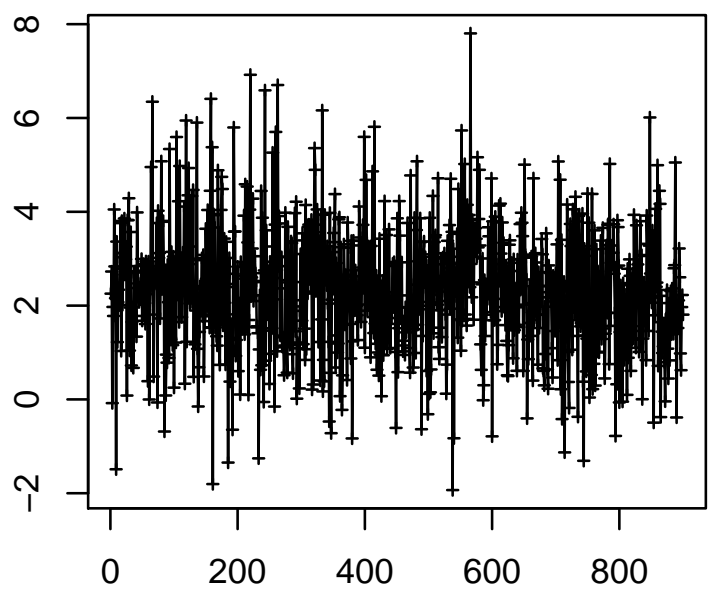

Time Point $(0.25 \mathrm{~Hz})$

Cell 1715

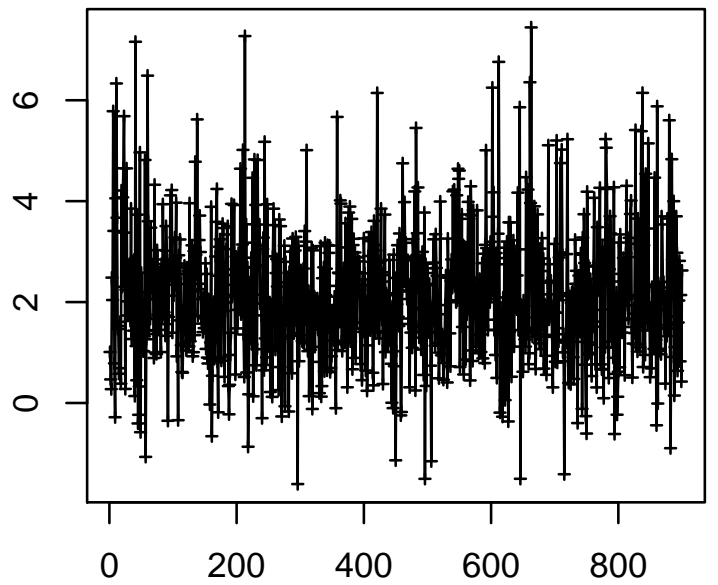

Time Point $(0.25 \mathrm{~Hz})$
Cell 1714

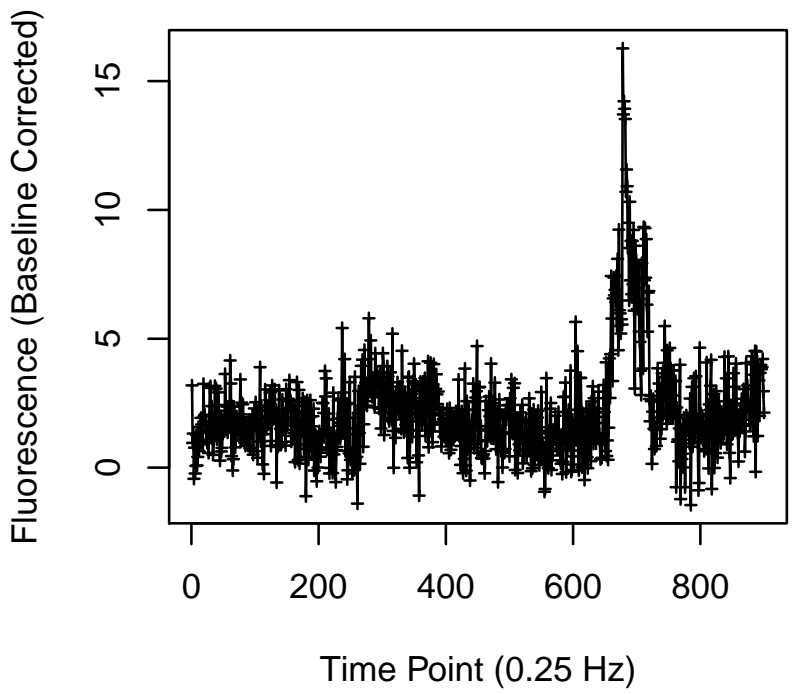

Cell 1716

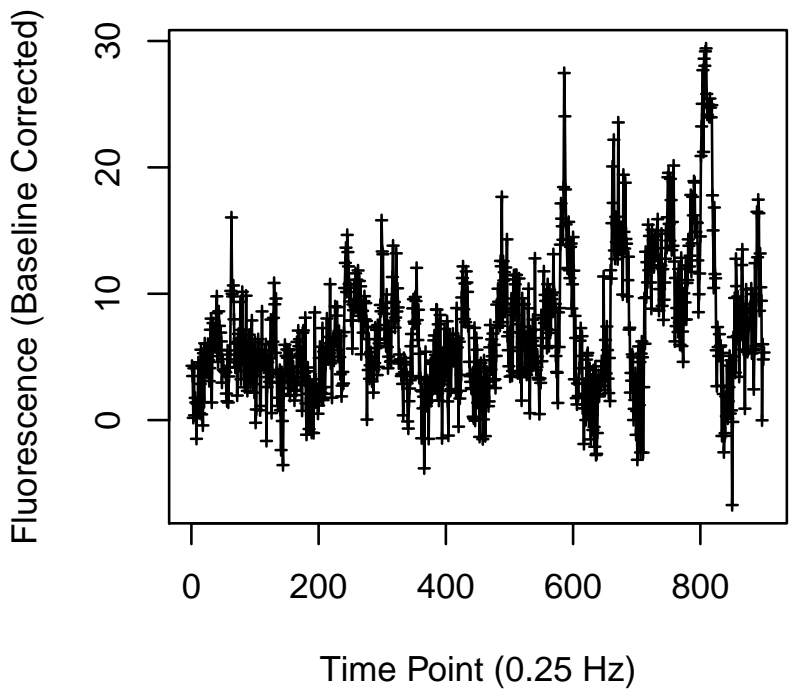


Cell 1717

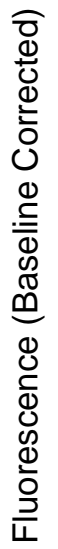

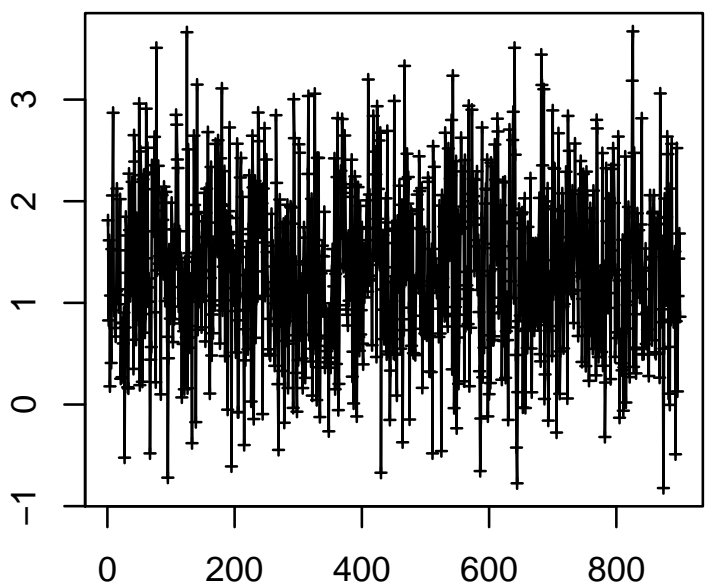

Time Point $(0.25 \mathrm{~Hz})$

Cell 1719

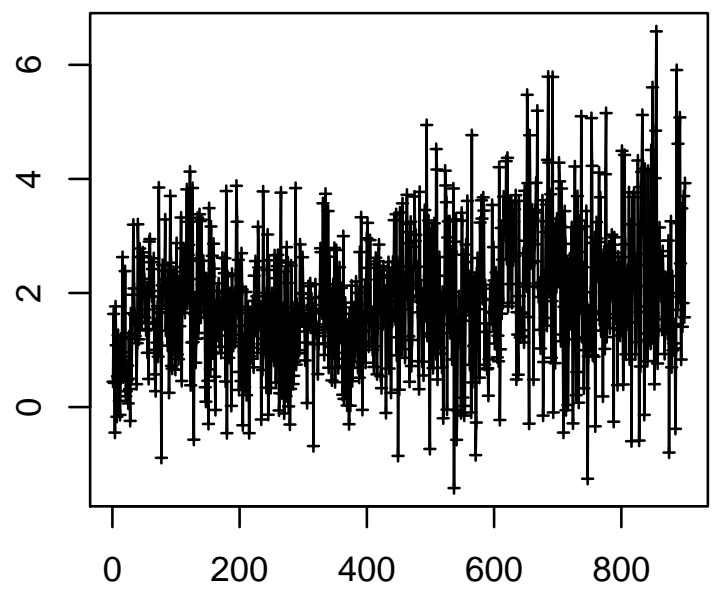

Time Point $(0.25 \mathrm{~Hz})$
Cell 1718

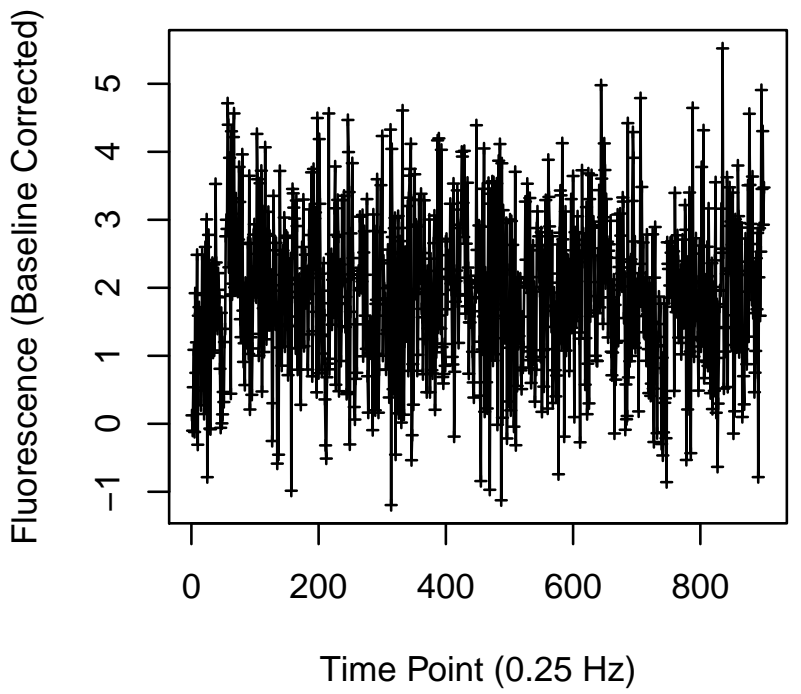

Cell 1720

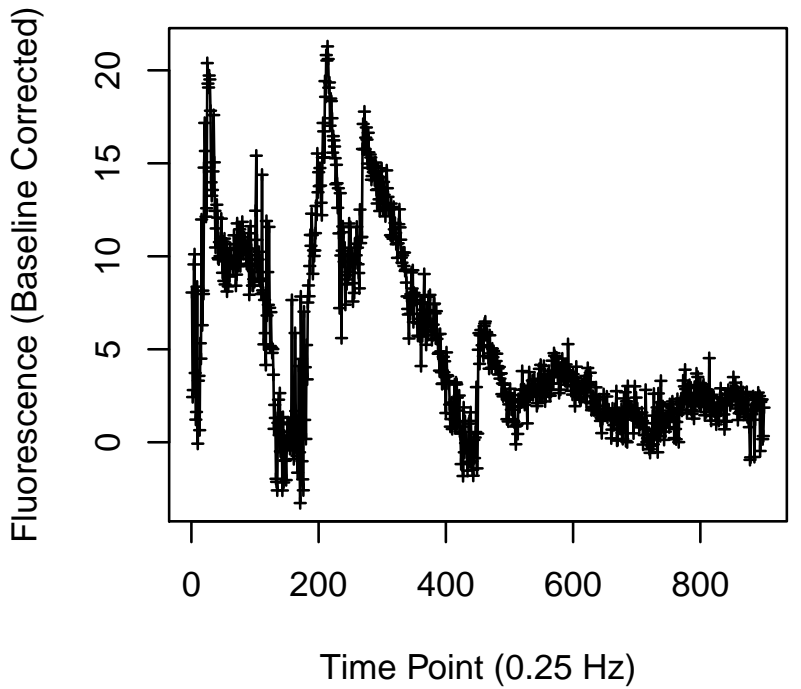


Cell 1725

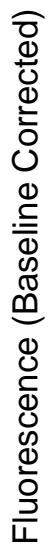

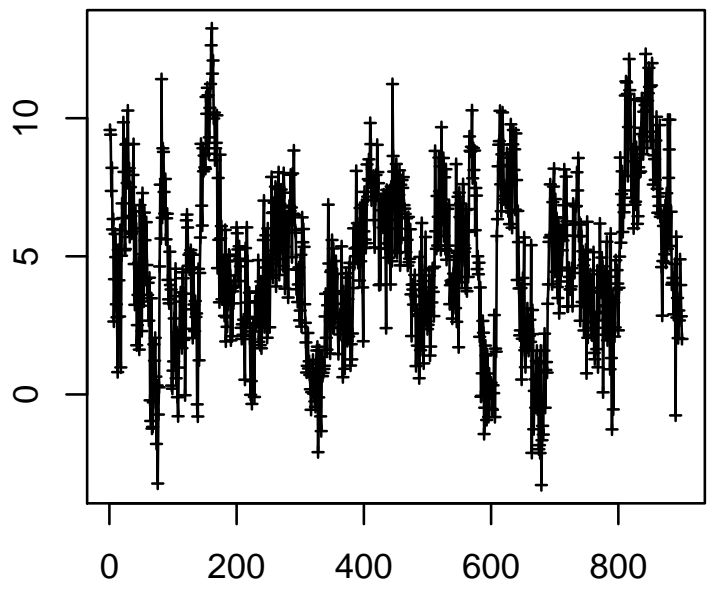

Time Point $(0.25 \mathrm{~Hz})$

Cell 1727

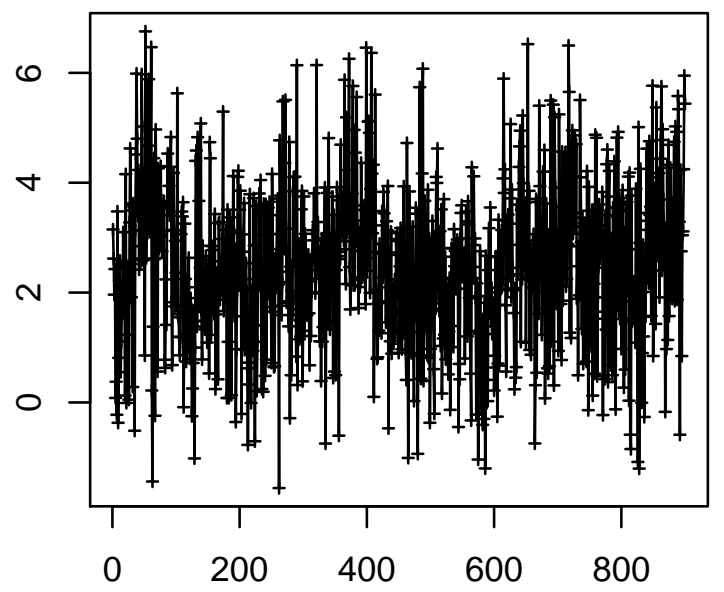

Time Point $(0.25 \mathrm{~Hz})$
Cell 1726

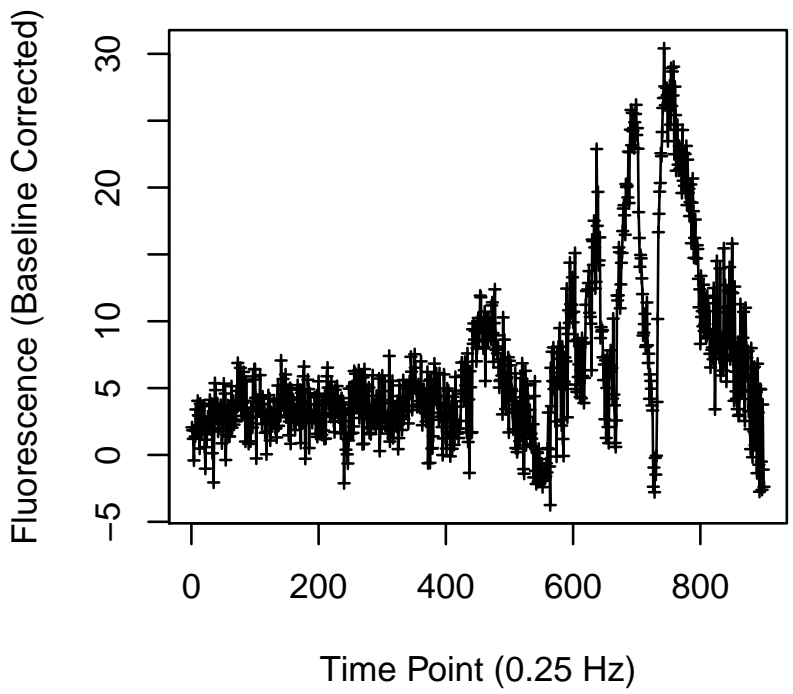

Cell 1728

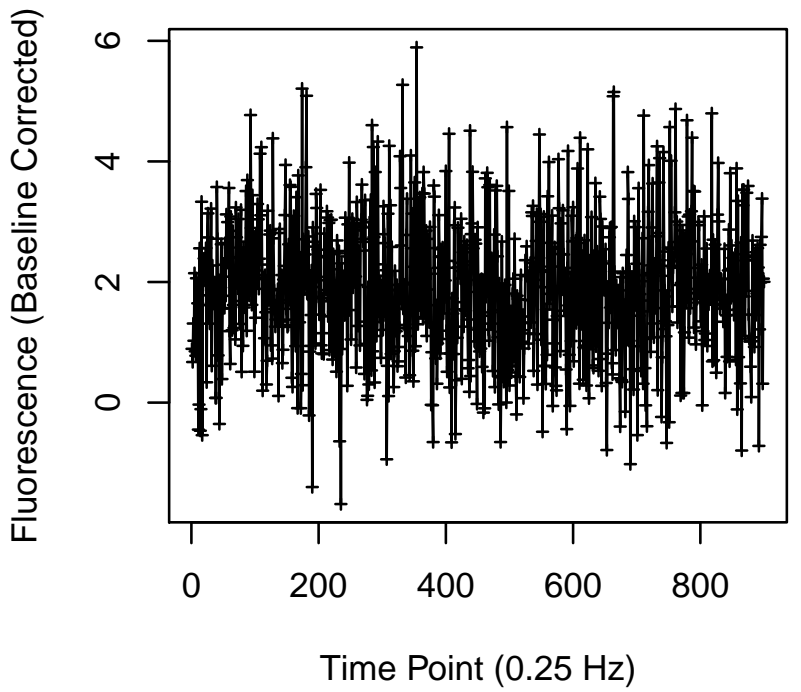


Cell 1729

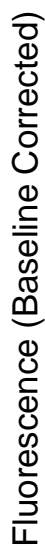

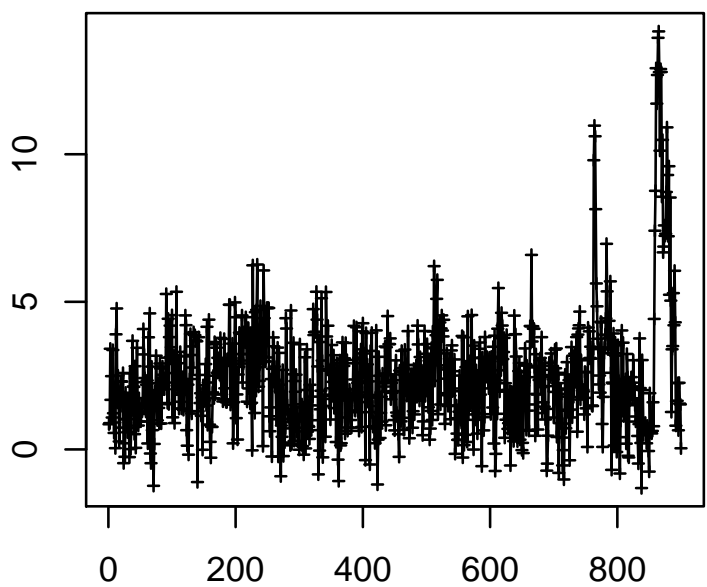

Time Point $(0.25 \mathrm{~Hz})$

Cell 1731

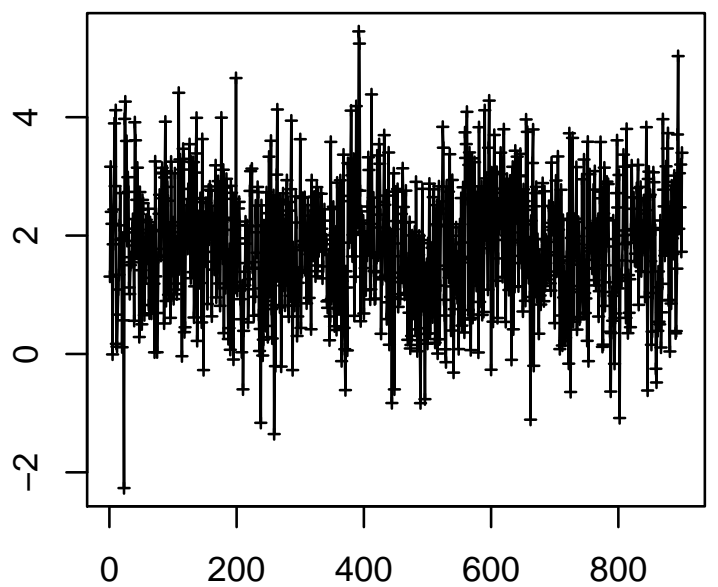

Time Point $(0.25 \mathrm{~Hz})$
Cell 1730

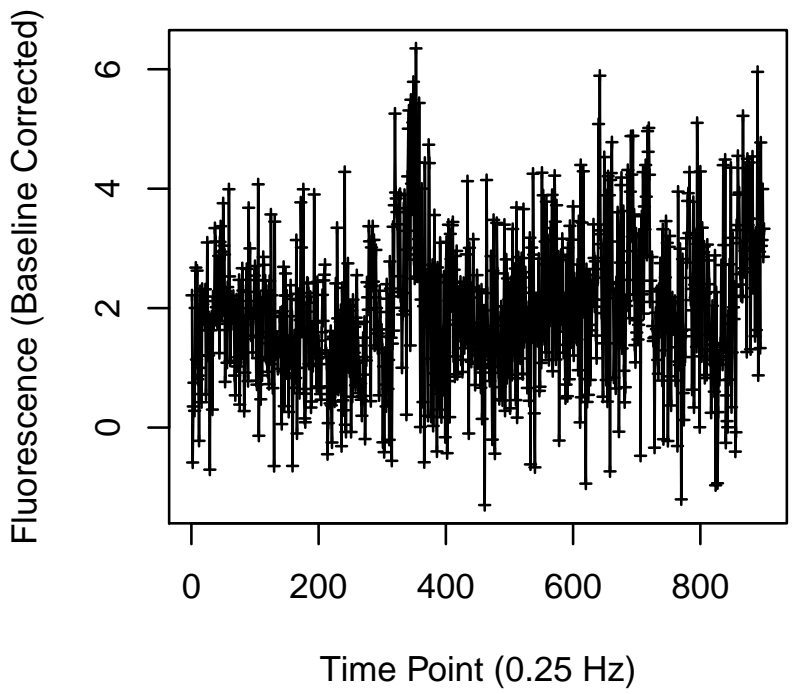

Cell 1732

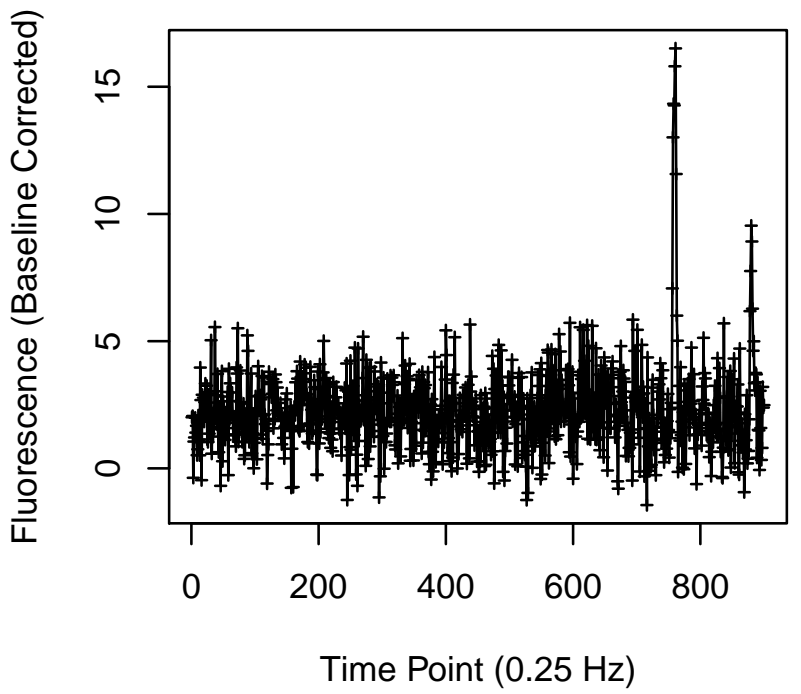


Cell 1733

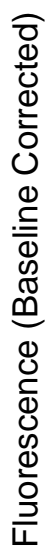

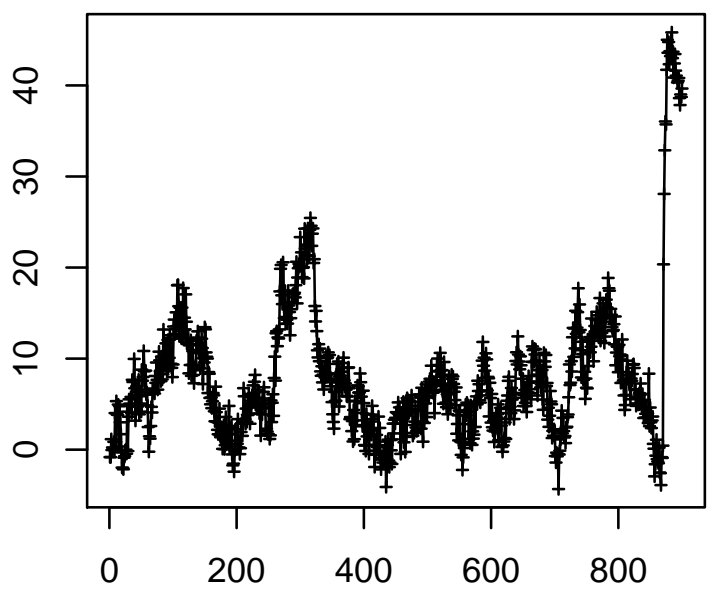

Time Point $(0.25 \mathrm{~Hz})$

Cell 1735

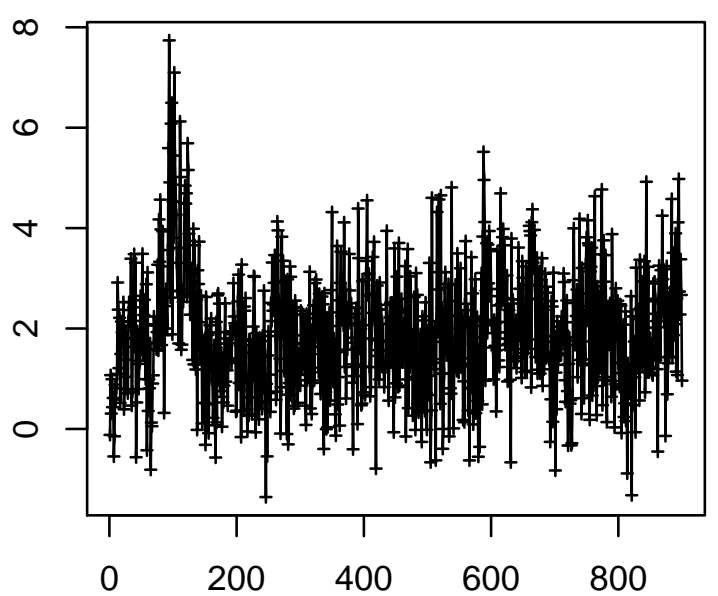

Time Point $(0.25 \mathrm{~Hz})$
Cell 1734

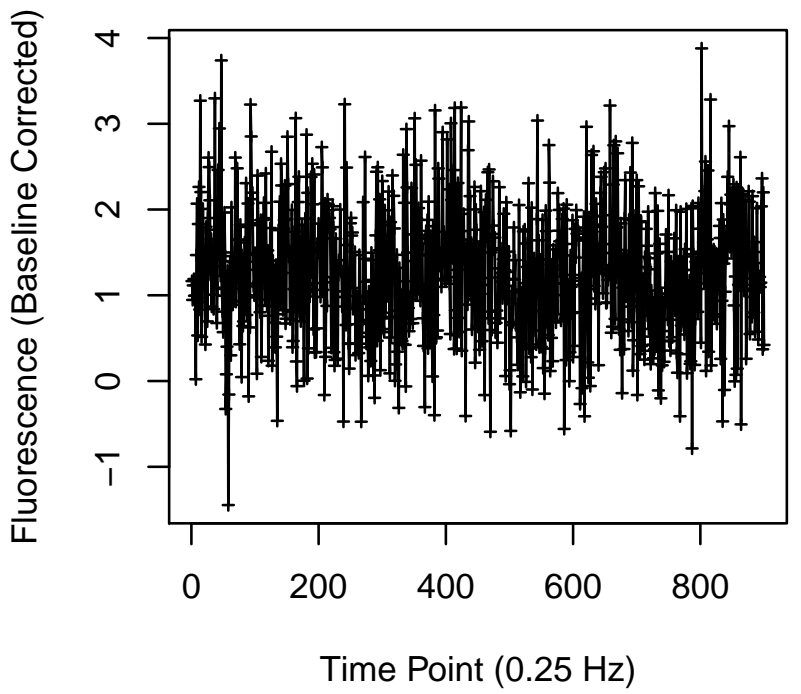

Cell 1736

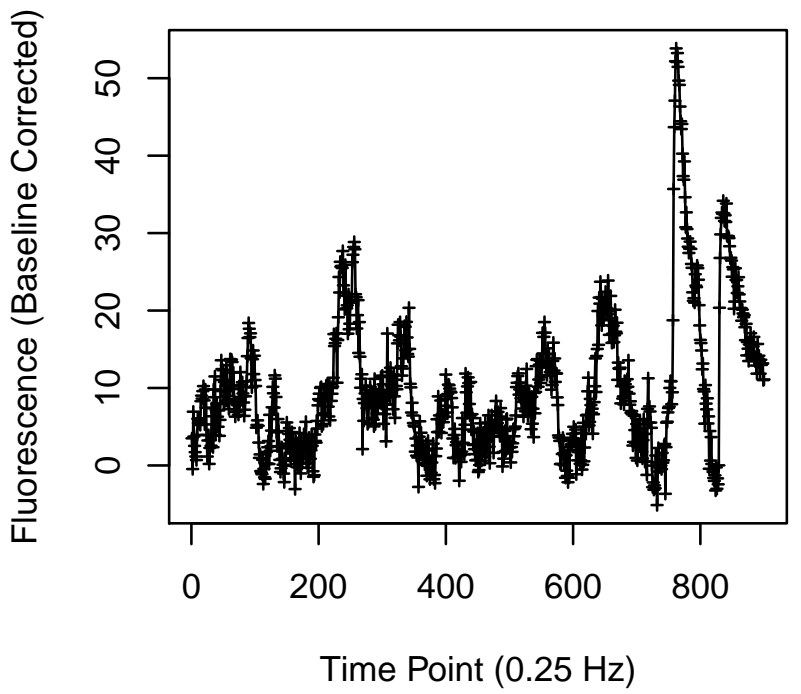


Cell 1737

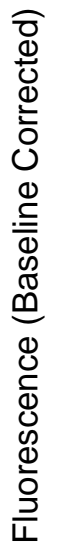

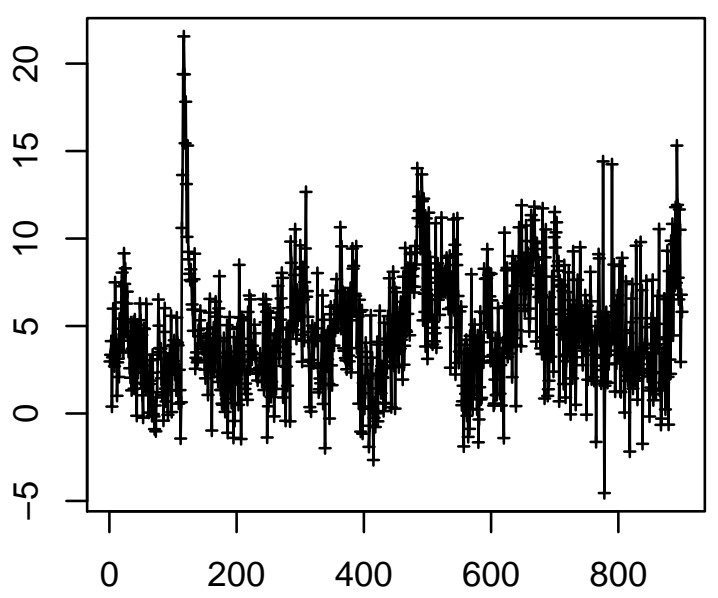

Time Point $(0.25 \mathrm{~Hz})$

Cell 1739

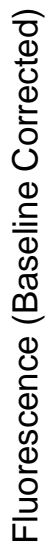

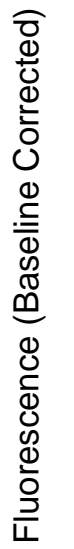

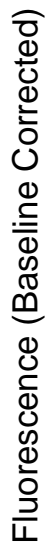

$\begin{array}{lllll}0 & 200 & 400 & 600 & 800\end{array}$

Time Point $(0.25 \mathrm{~Hz})$
Cell 1740

Cell 1738

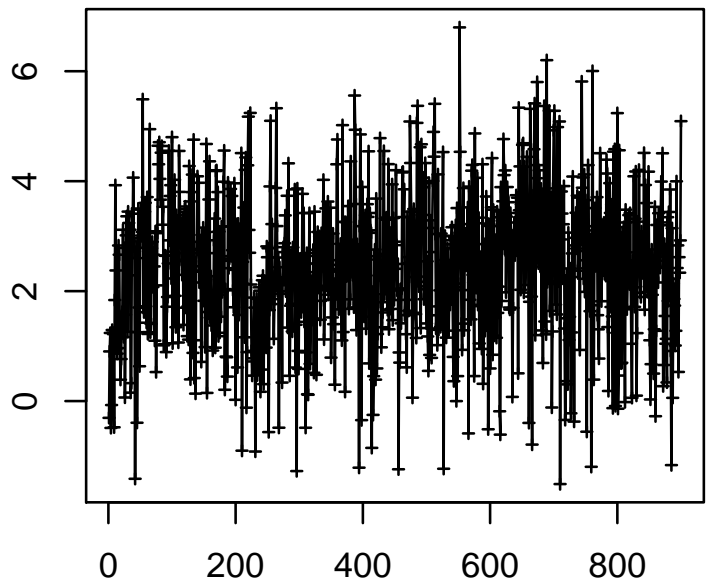

Time Point $(0.25 \mathrm{~Hz})$

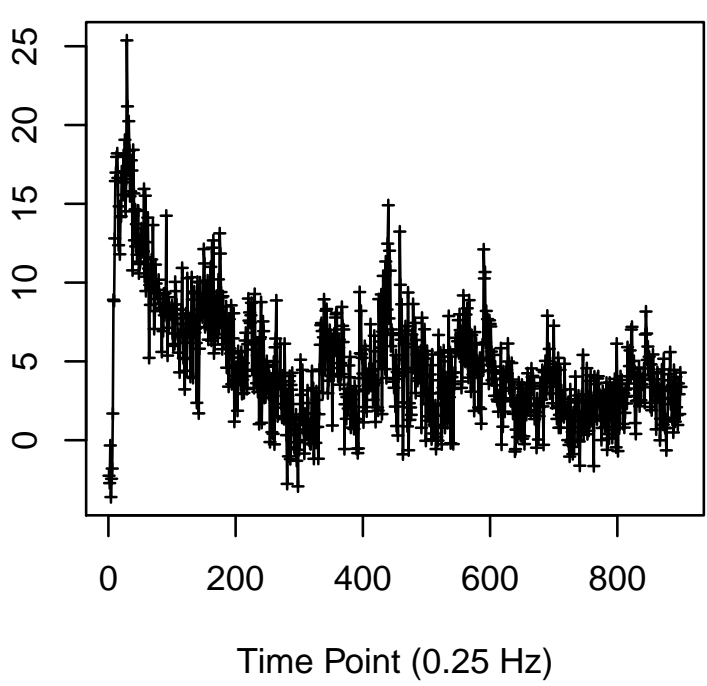


Cell 1741

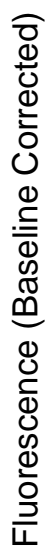

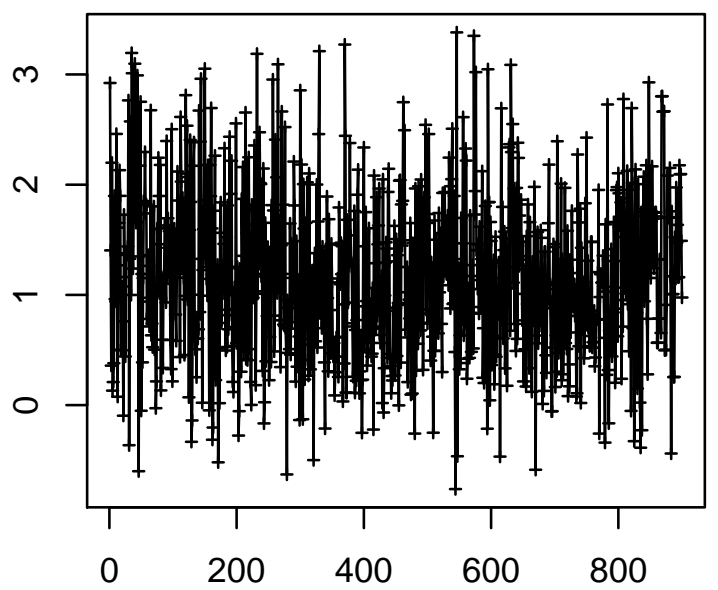

Time Point $(0.25 \mathrm{~Hz})$

Cell 1743

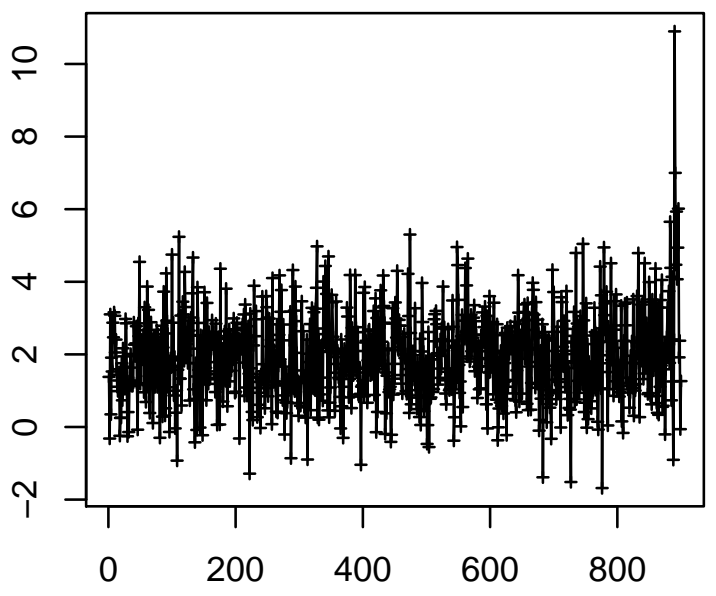

Time Point $(0.25 \mathrm{~Hz})$
Cell 1742

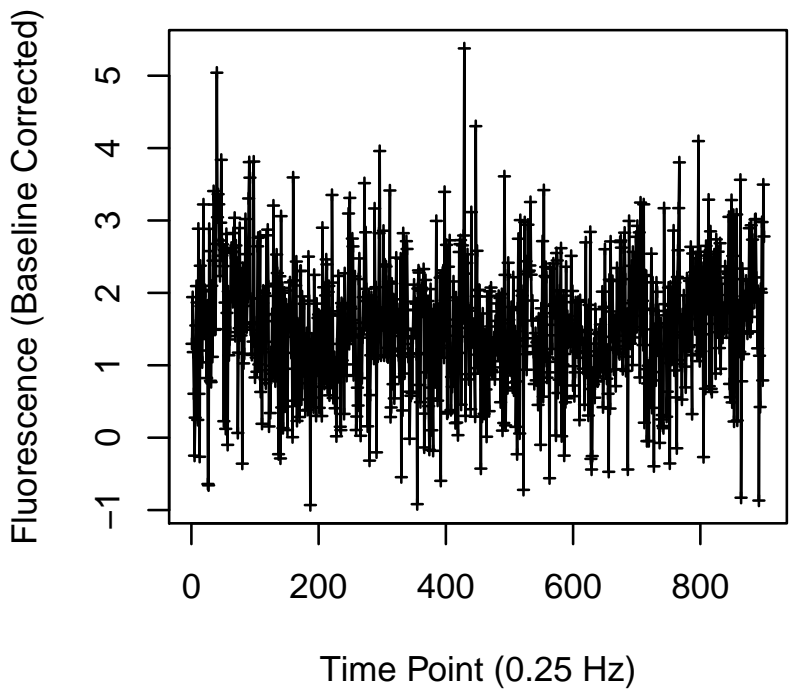

Cell 1744

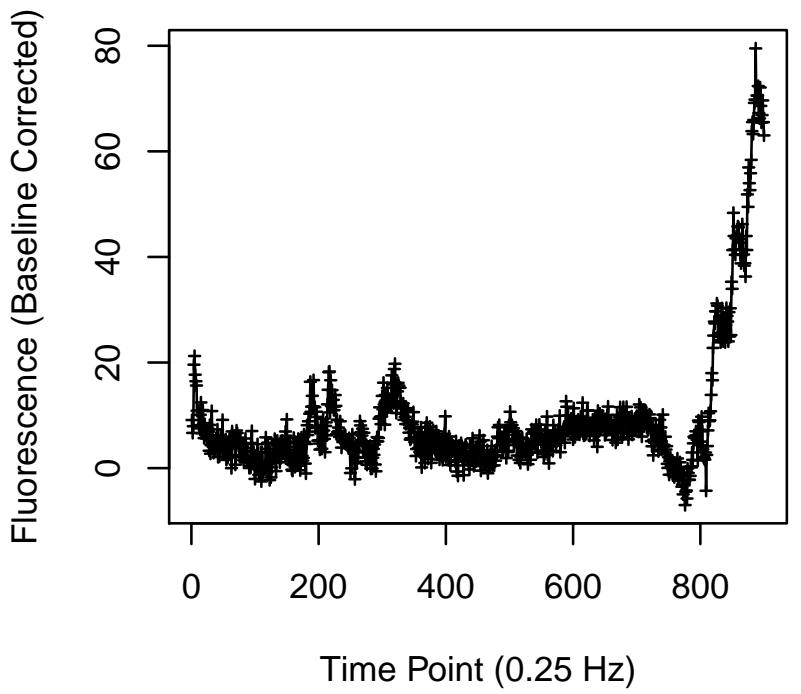


Cell 1749

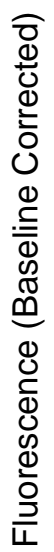

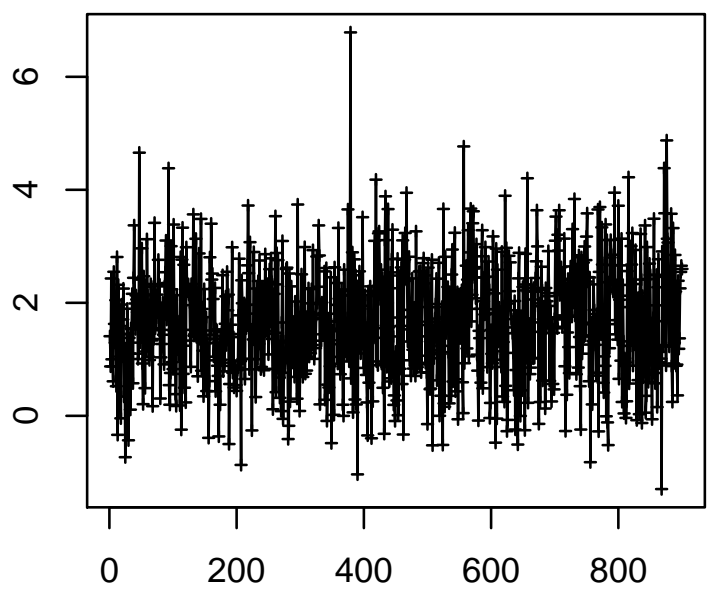

Time Point $(0.25 \mathrm{~Hz})$

Cell 1751

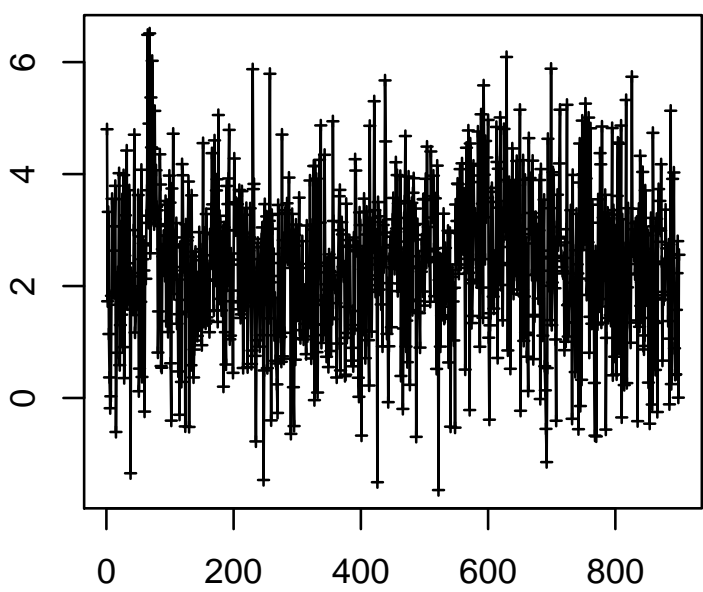

Time Point $(0.25 \mathrm{~Hz})$
Cell 1750

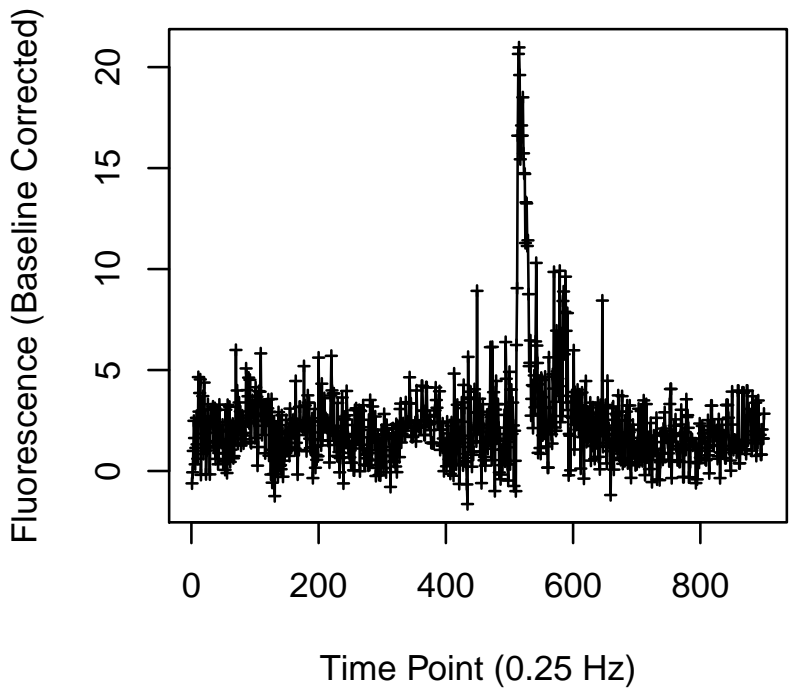

Cell 1752

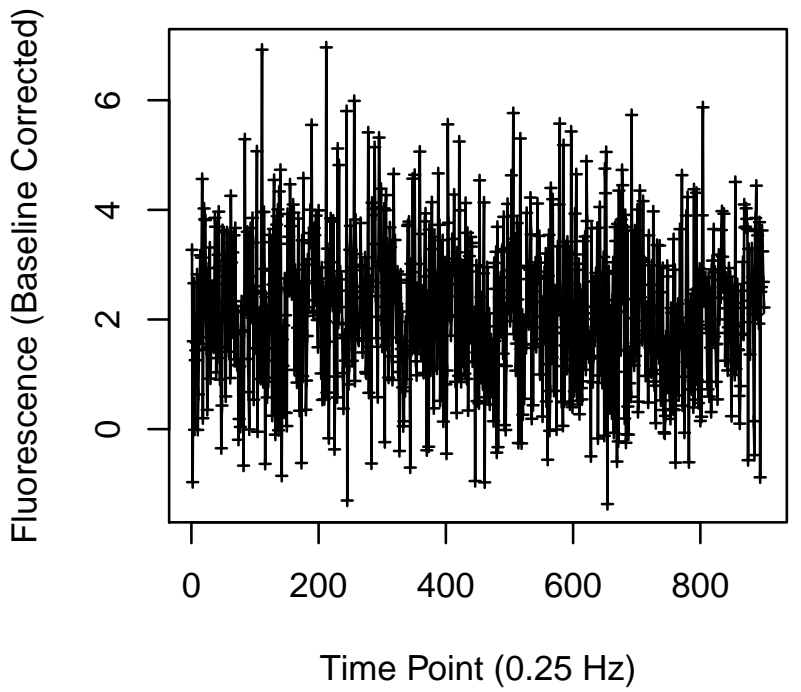




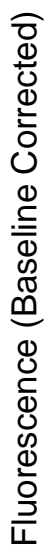

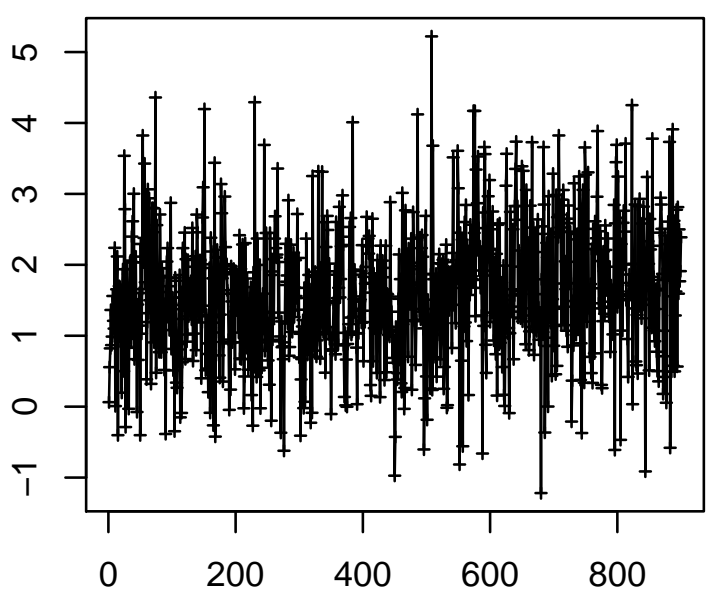

Time Point $(0.25 \mathrm{~Hz})$

Cell 1759

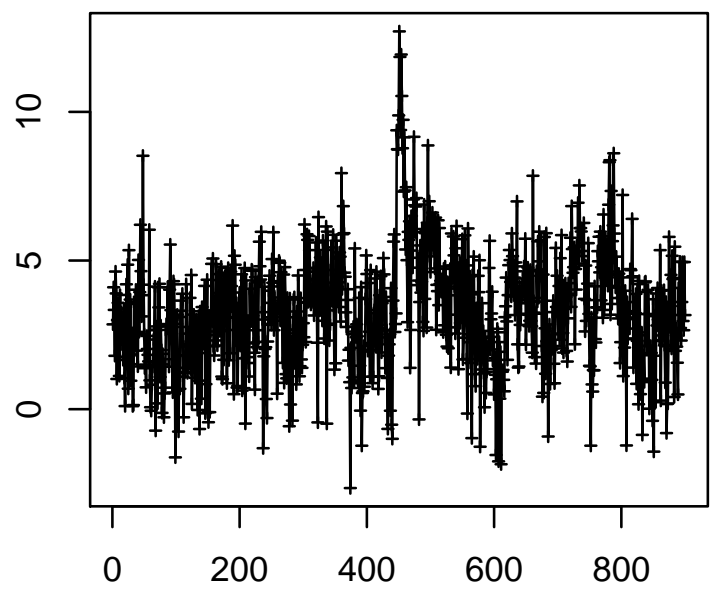

Time Point $(0.25 \mathrm{~Hz})$

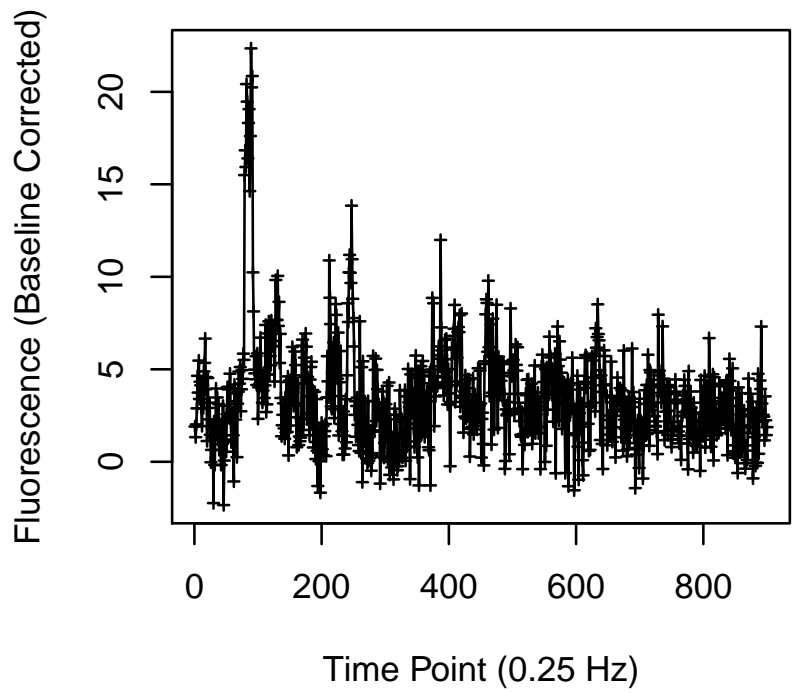

Cell 1760

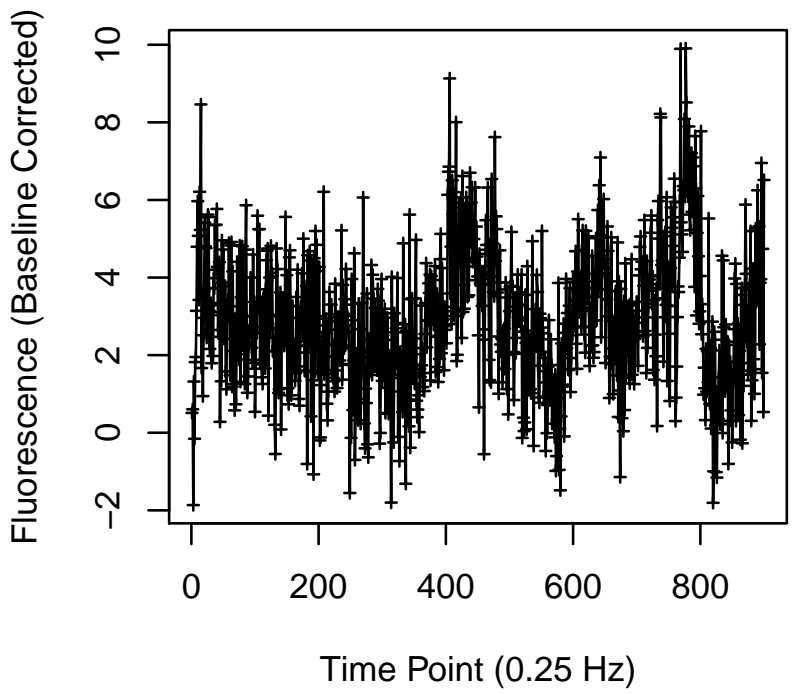


Cell 1769

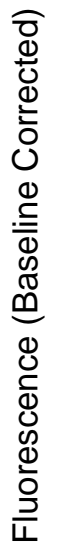

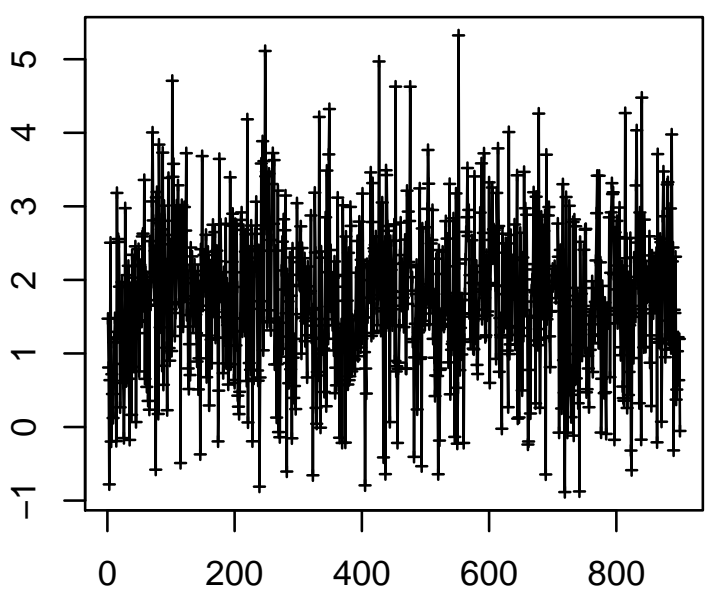

Time Point $(0.25 \mathrm{~Hz})$

Cell 1771

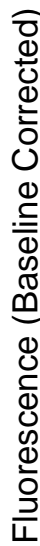

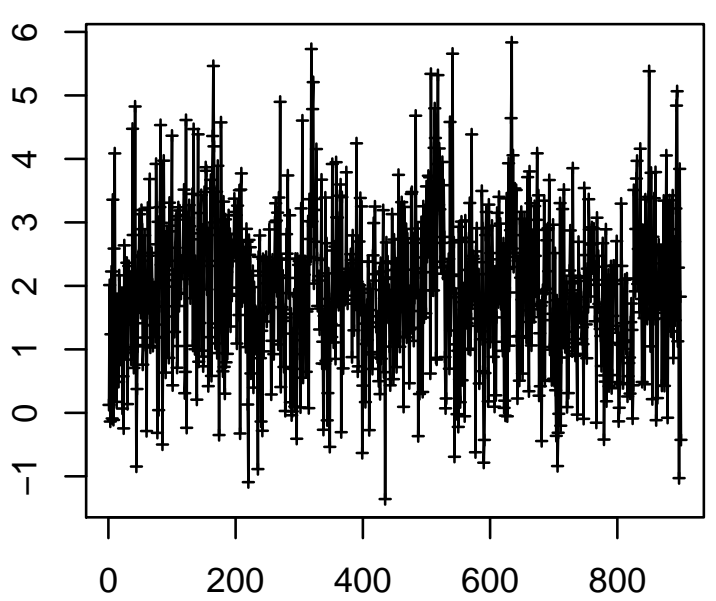

Time Point $(0.25 \mathrm{~Hz})$
Cell 1770

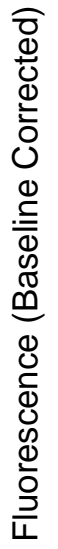

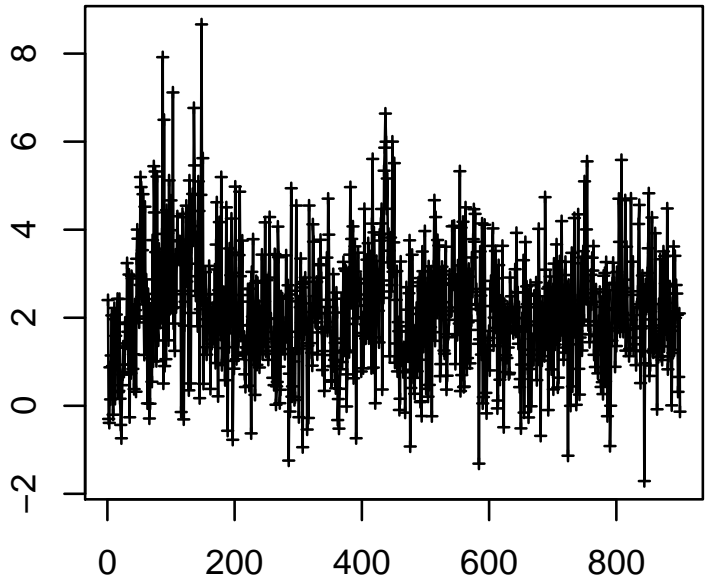

Time Point $(0.25 \mathrm{~Hz})$

Cell 1772

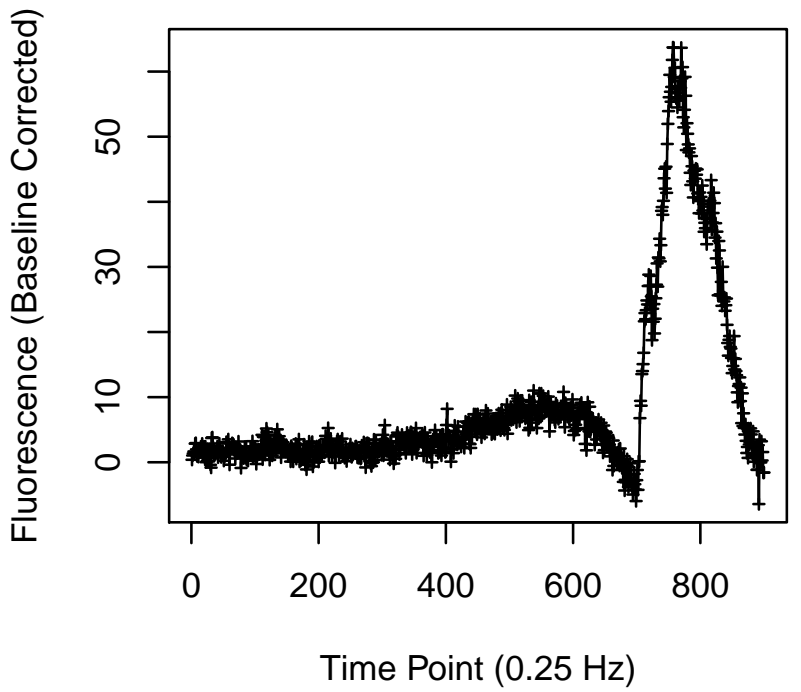


Cell 1781

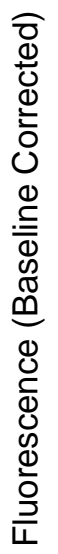

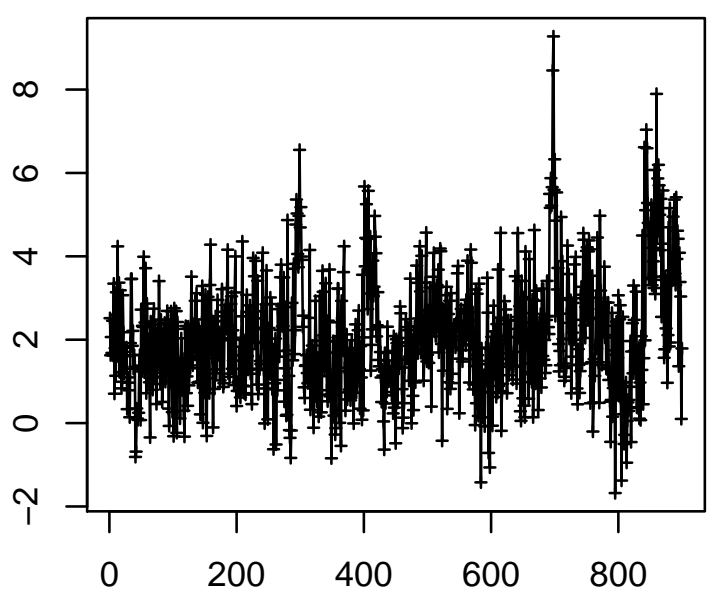

Time Point $(0.25 \mathrm{~Hz})$

Cell 1783

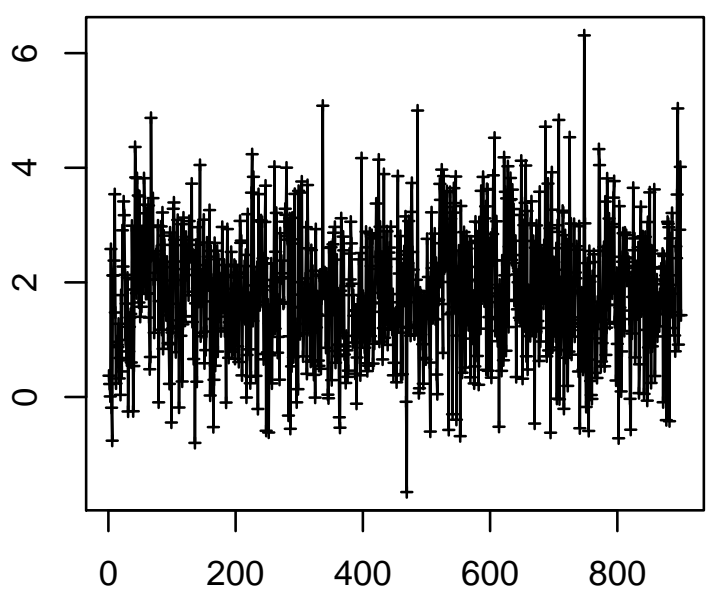

Time Point $(0.25 \mathrm{~Hz})$
Cell 1782

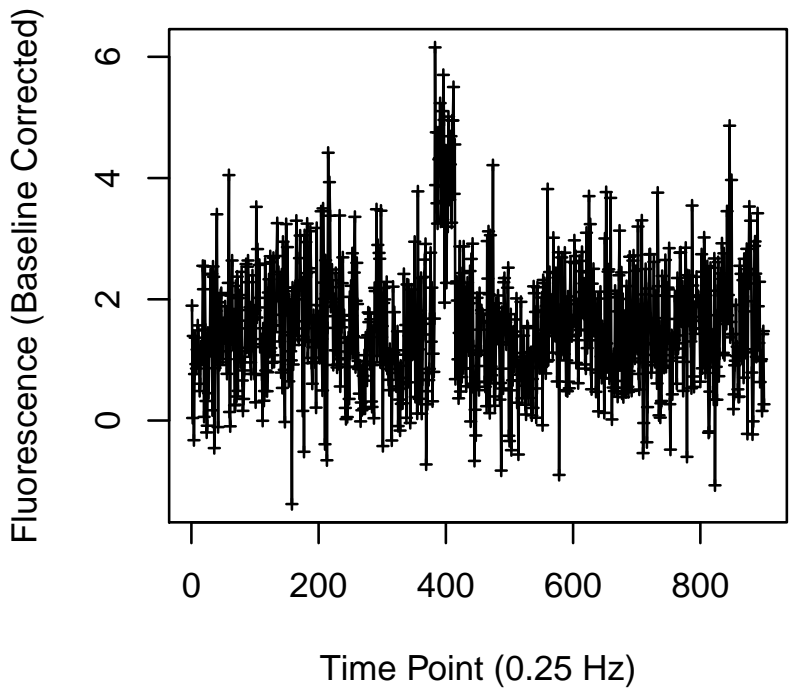

Cell 1784

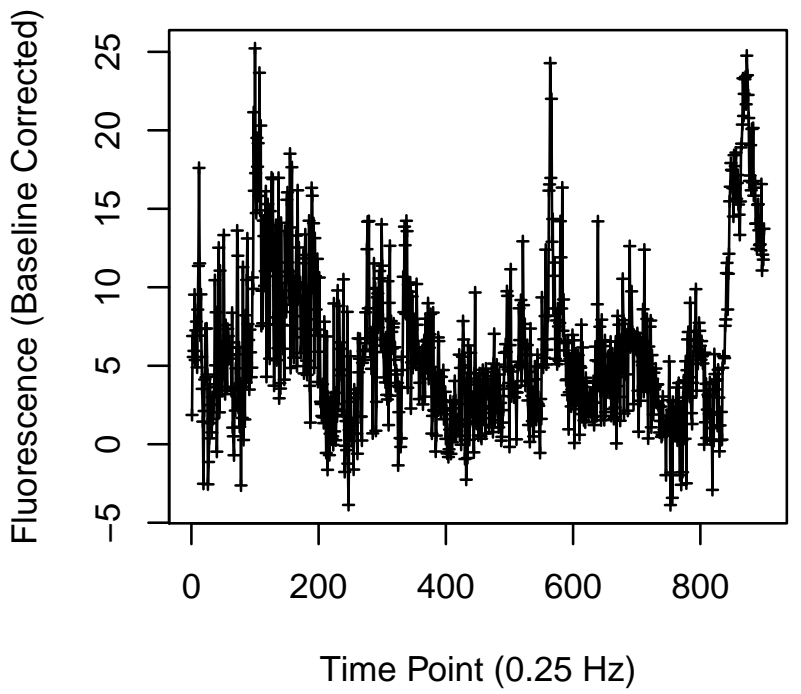




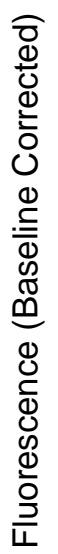

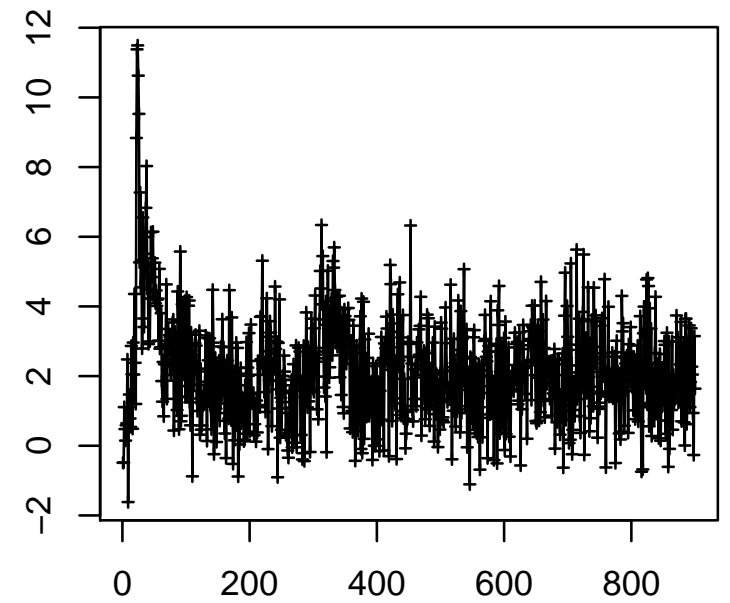

Time Point $(0.25 \mathrm{~Hz})$

Cell 1799

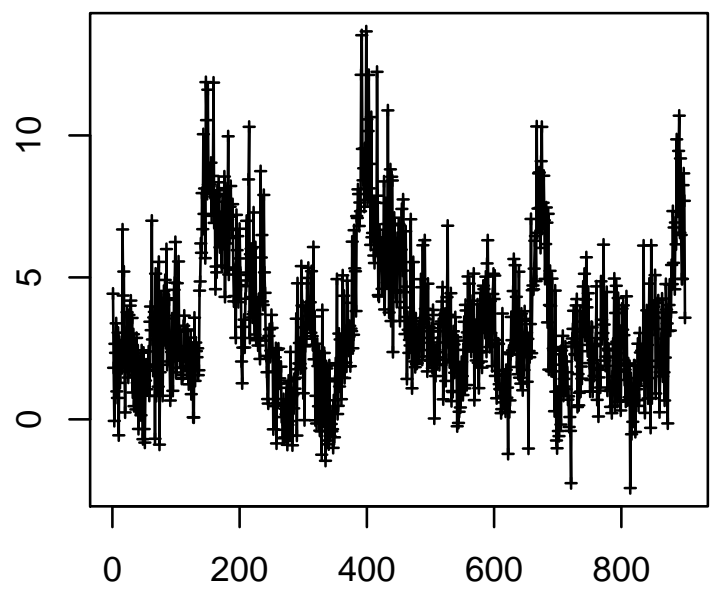

Time Point $(0.25 \mathrm{~Hz})$

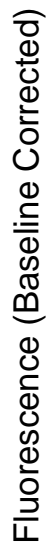

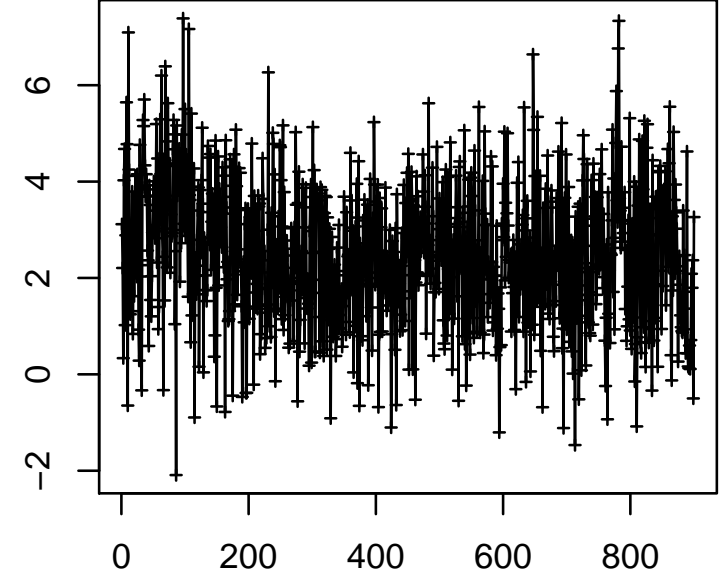

Time Point $(0.25 \mathrm{~Hz})$

Cell 1800

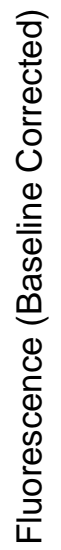

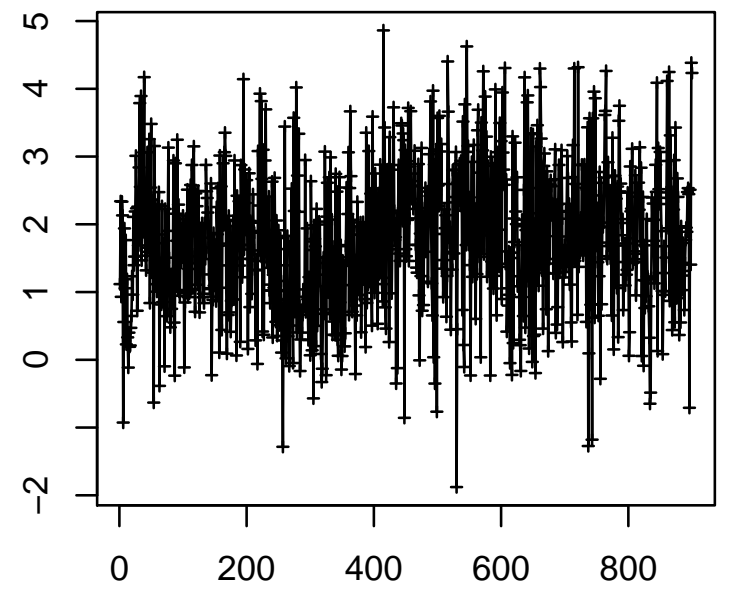

Time Point $(0.25 \mathrm{~Hz})$ 
Cell 1801
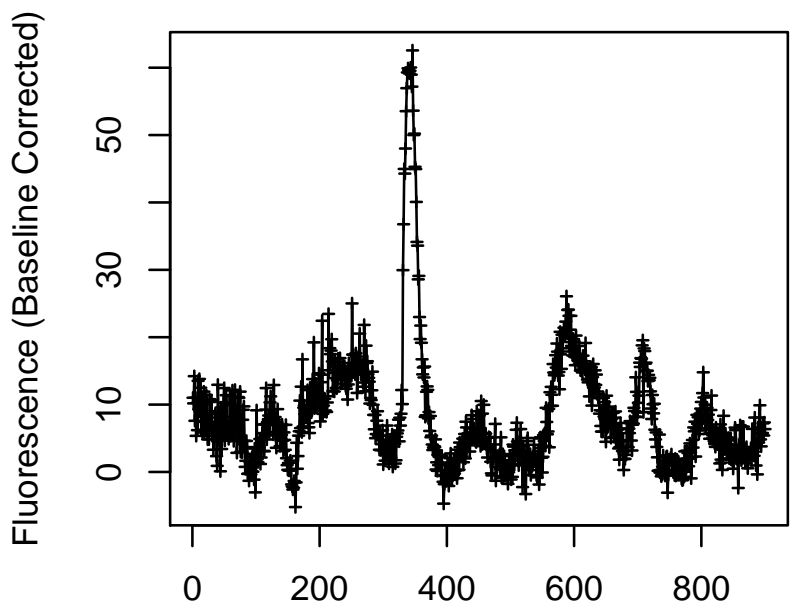

Time Point $(0.25 \mathrm{~Hz})$

Cell 1803

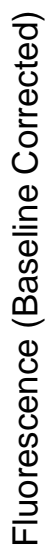

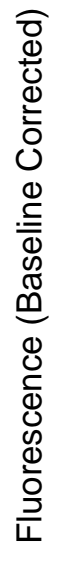

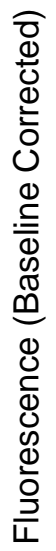

$\begin{array}{lllll}0 & 200 & 400 & 600 & 800\end{array}$
Cell 1802

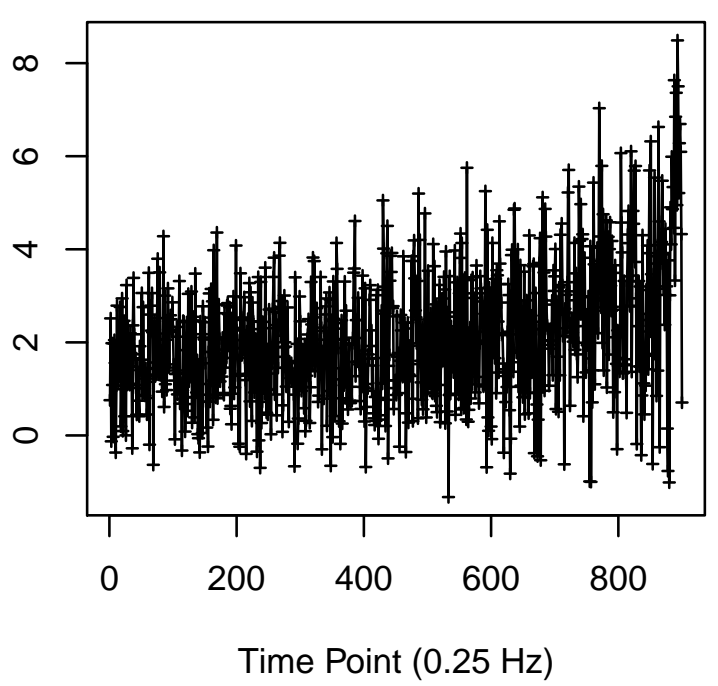

\section{Cell 1804}

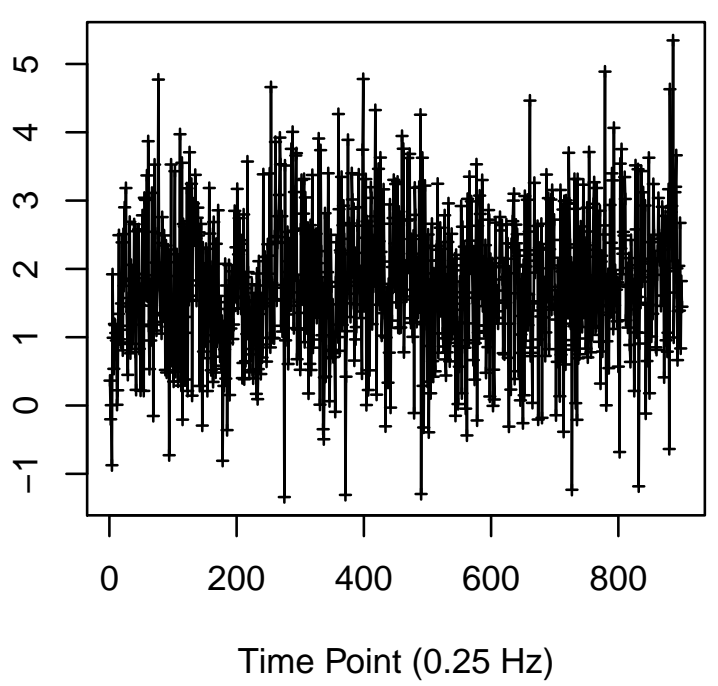


Cell 1809

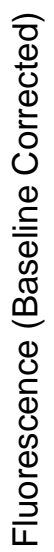

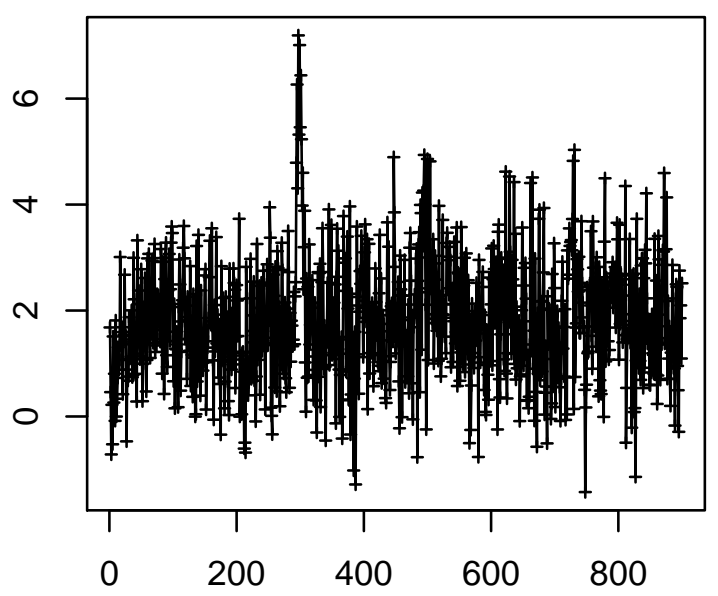

Time Point $(0.25 \mathrm{~Hz})$

Cell 1811

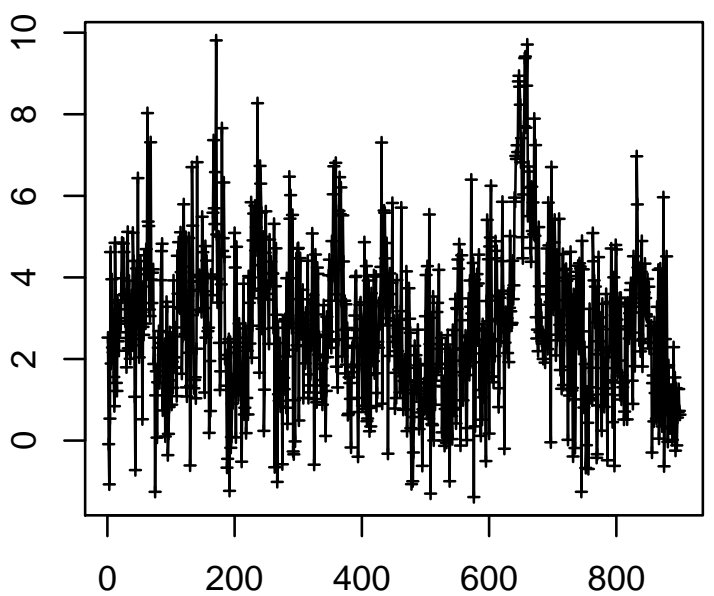

Time Point $(0.25 \mathrm{~Hz})$
Cell 1810

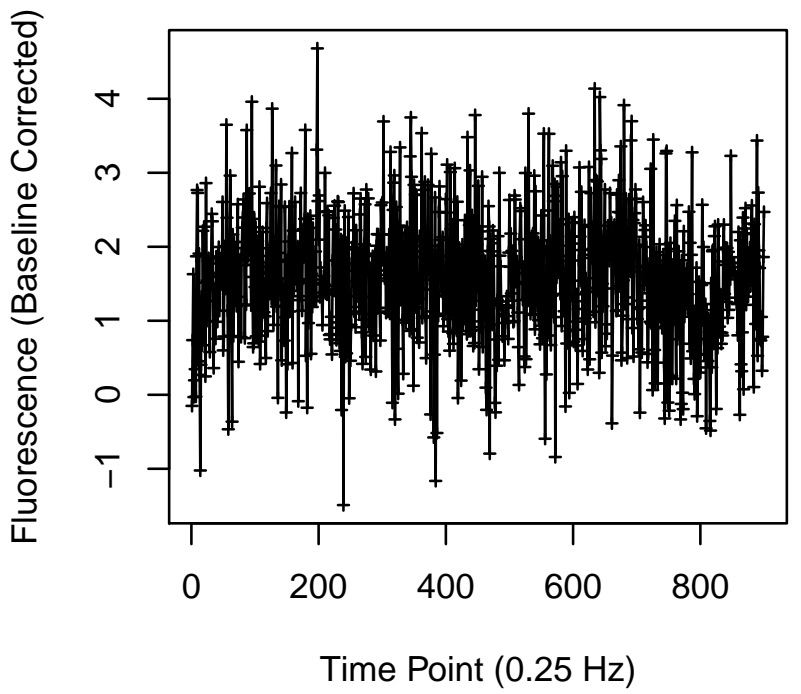

Cell 1812

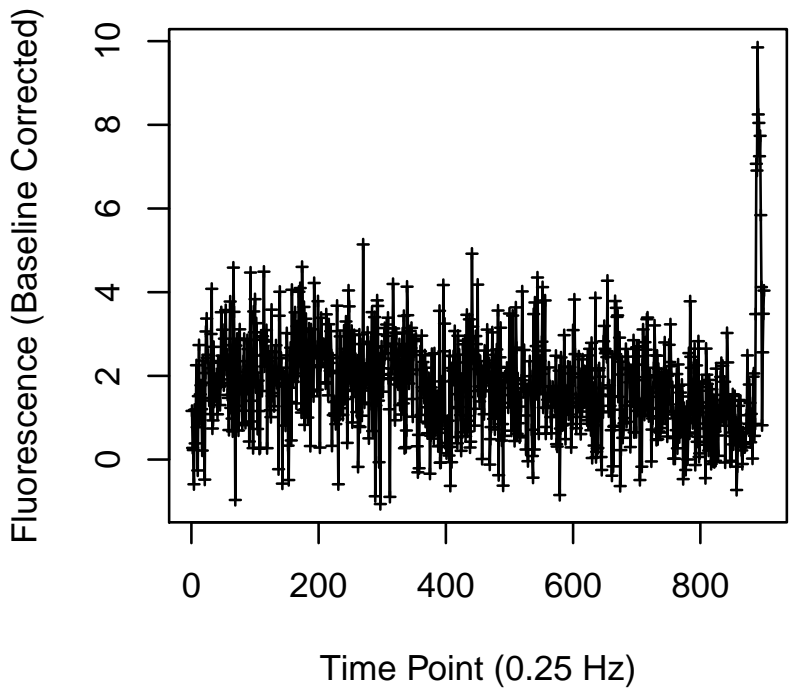


Cell 1813

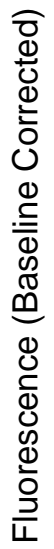

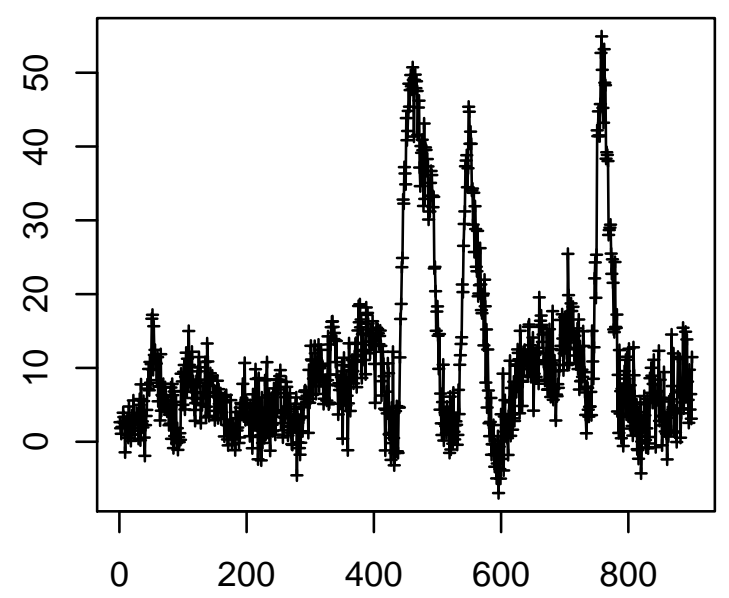

Time Point $(0.25 \mathrm{~Hz})$

Cell 1815

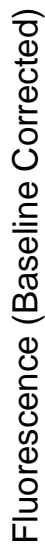

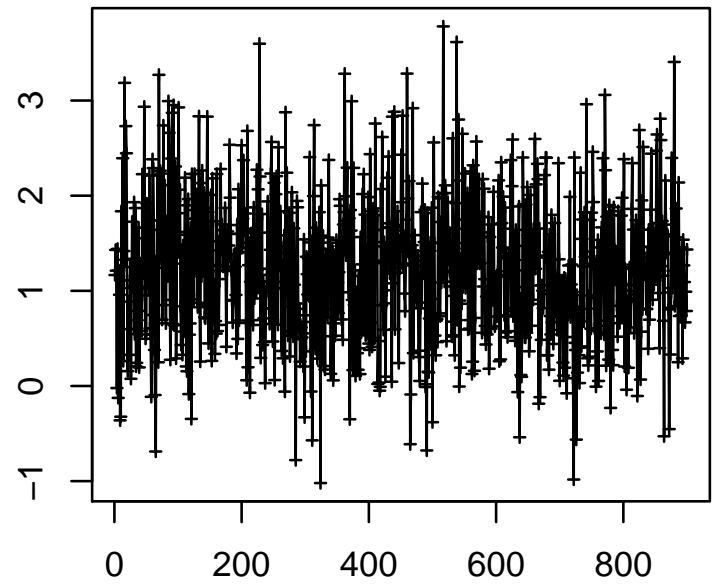

Time Point $(0.25 \mathrm{~Hz})$
Cell 1814

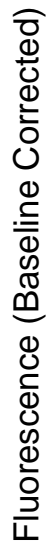

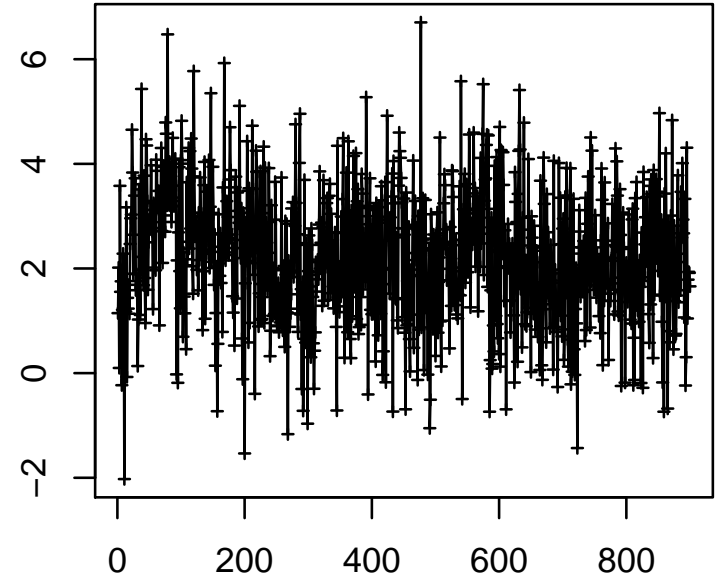

Time Point $(0.25 \mathrm{~Hz})$

Cell 1816

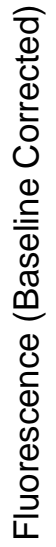

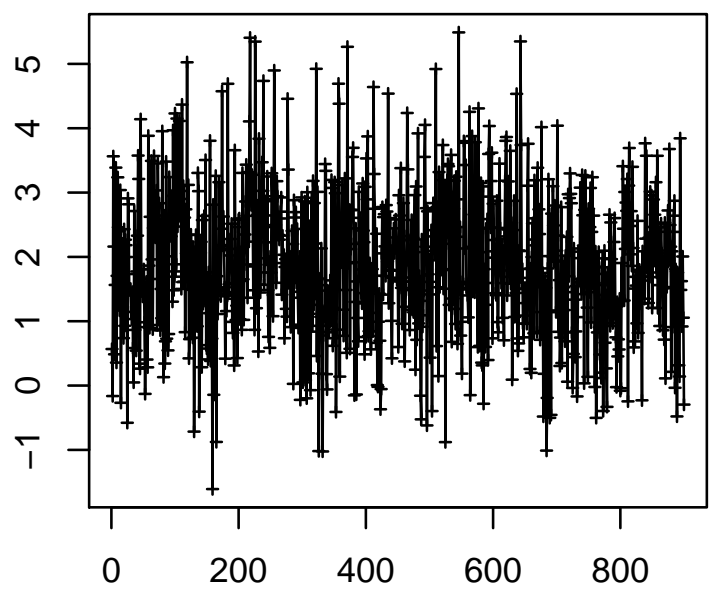

Time Point $(0.25 \mathrm{~Hz})$ 
Cell 1817

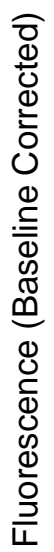

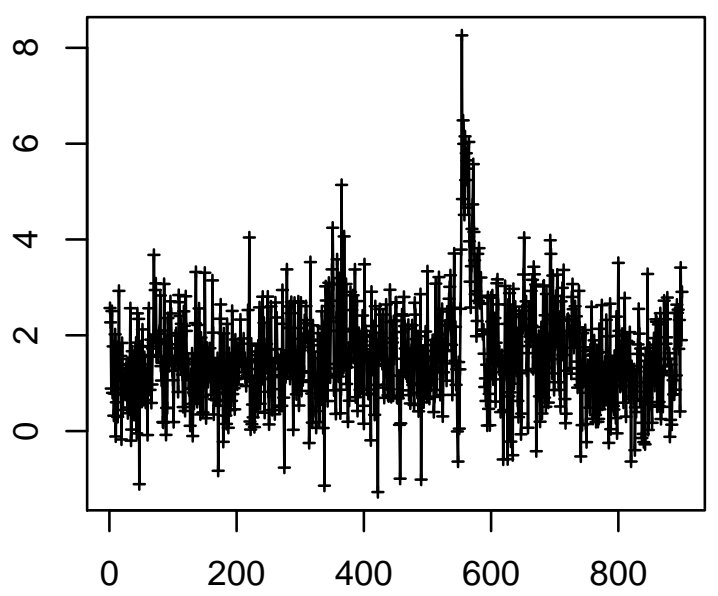

Time Point $(0.25 \mathrm{~Hz})$

Cell 1819

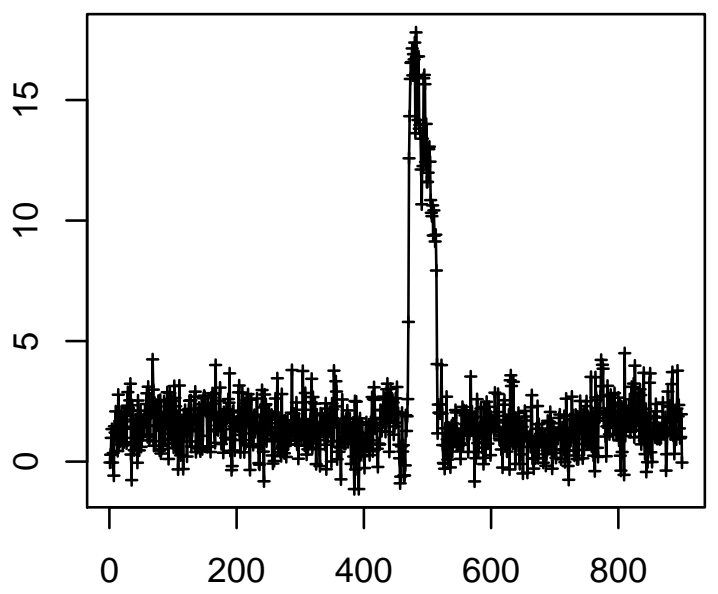

Time Point $(0.25 \mathrm{~Hz})$
Cell 1818

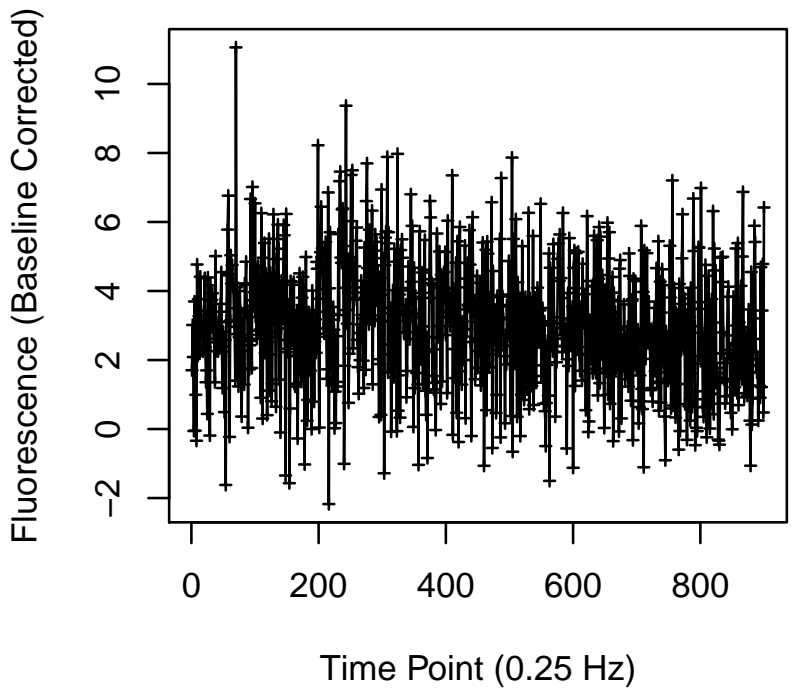

Cell 1820

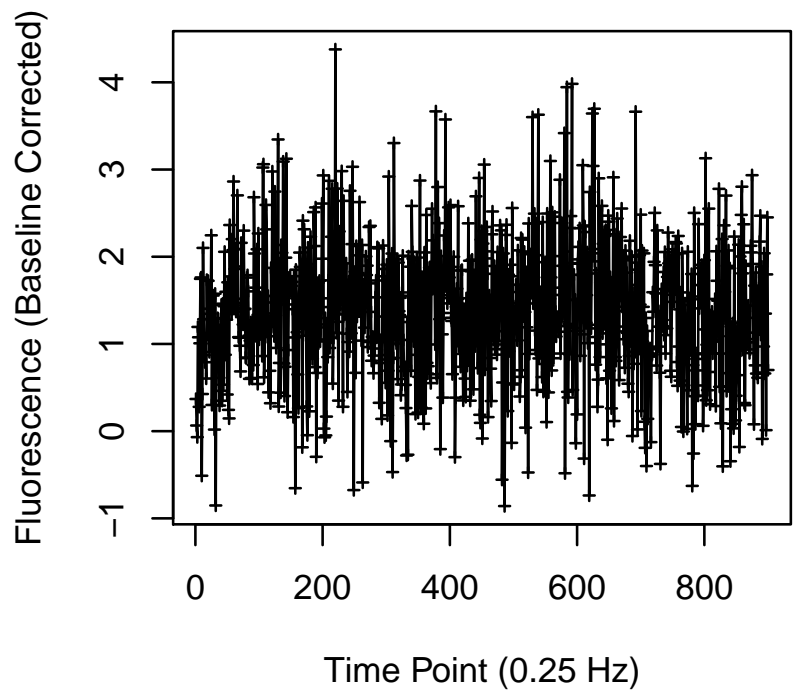


Cell 1821

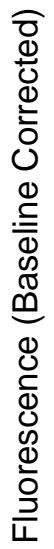

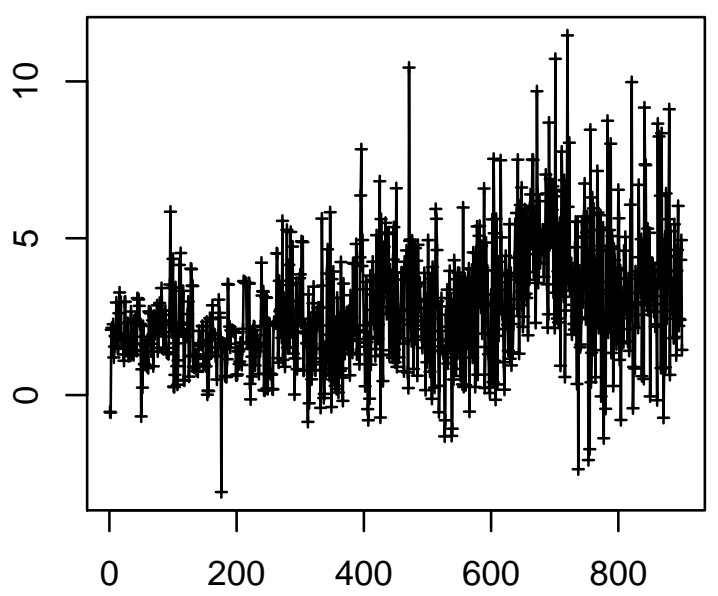

Time Point $(0.25 \mathrm{~Hz})$

Cell 1823

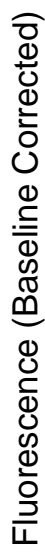

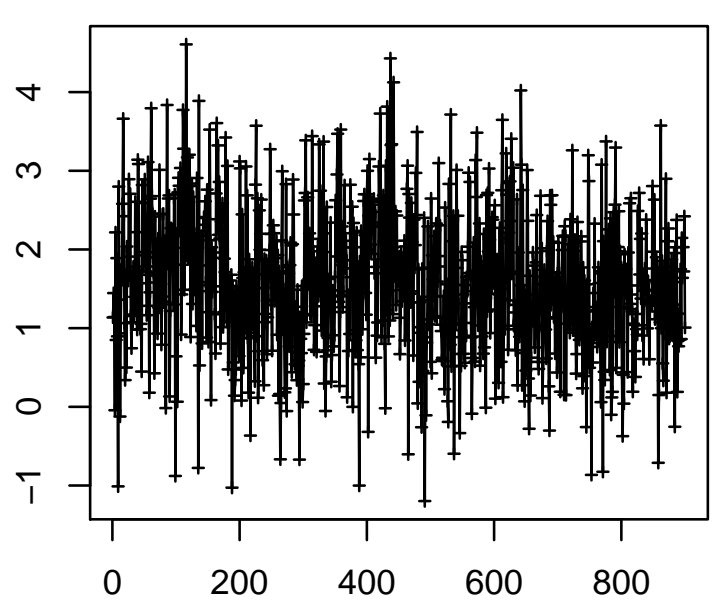

Time Point $(0.25 \mathrm{~Hz})$

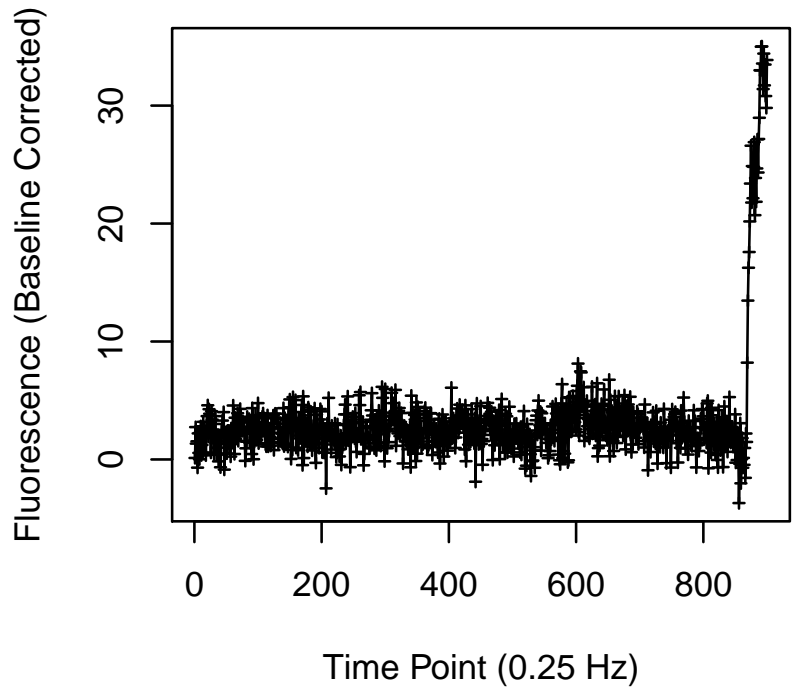

Cell 1824

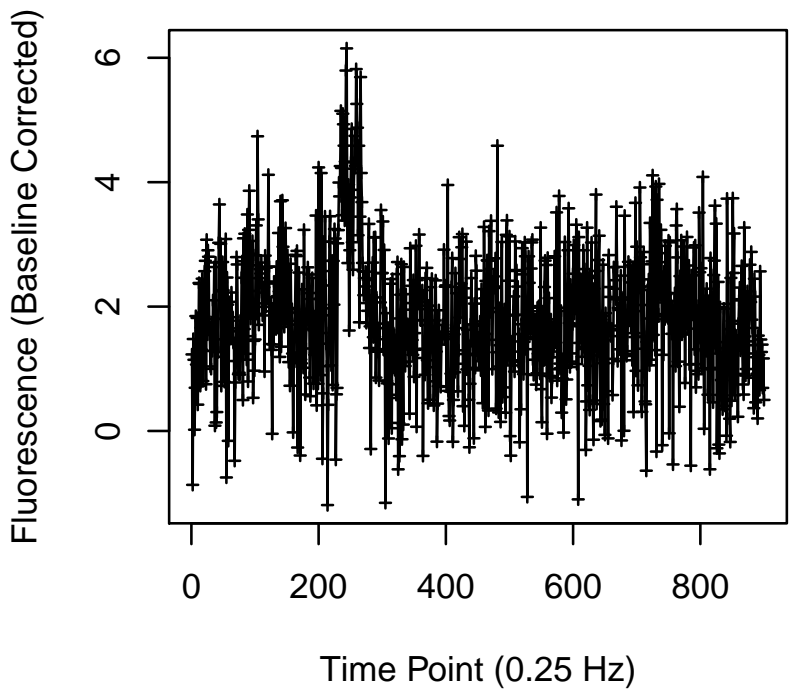


Cell 1845

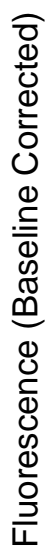

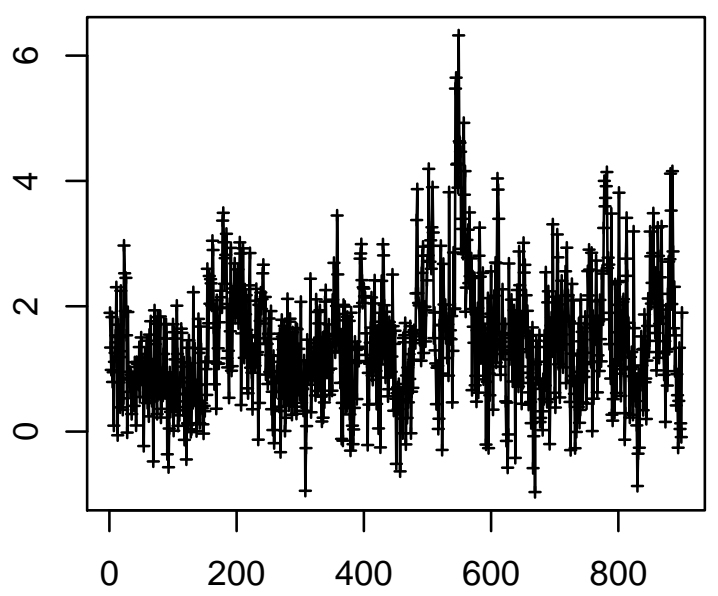

Time Point $(0.25 \mathrm{~Hz})$

Cell 1847

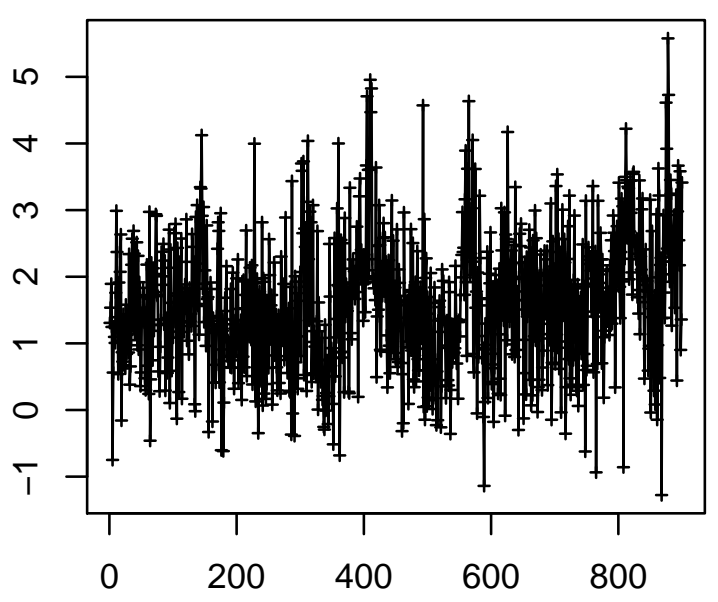

Time Point $(0.25 \mathrm{~Hz})$
Cell 1846

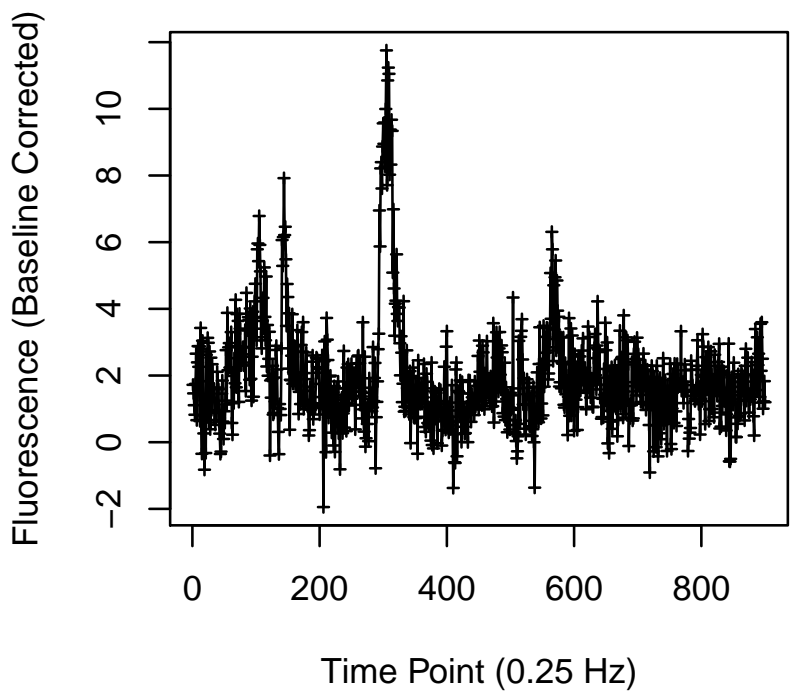

Cell 1848

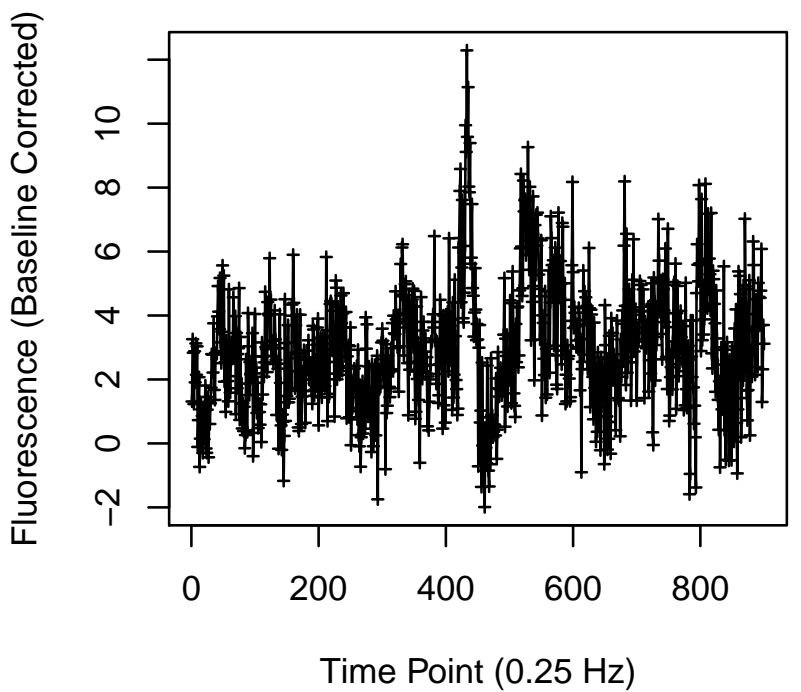


Cell 1853

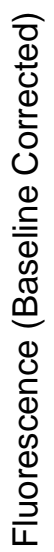

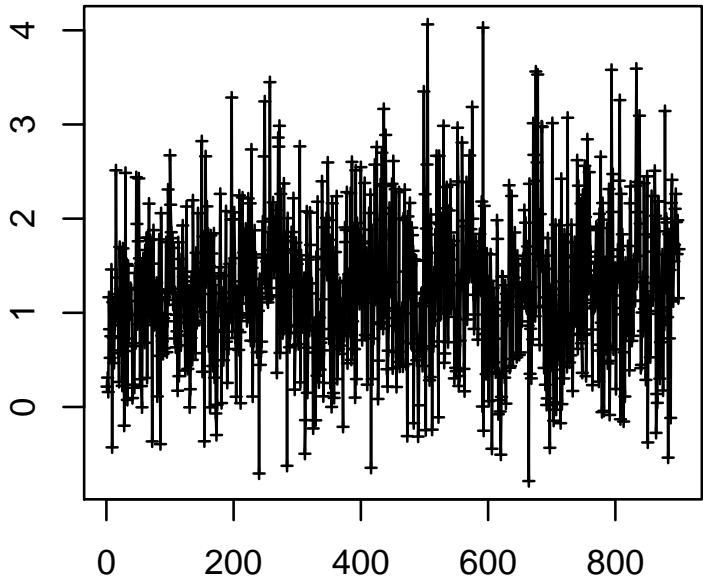

Time Point $(0.25 \mathrm{~Hz})$

Cell 1855

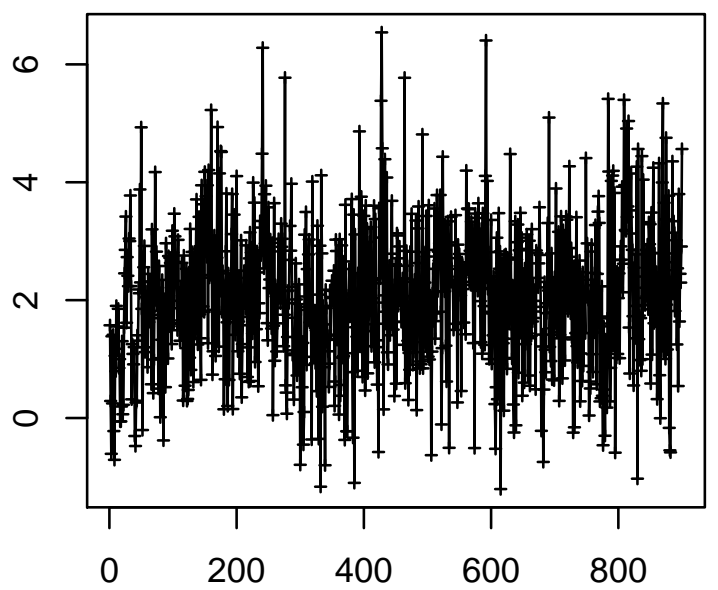

Time Point $(0.25 \mathrm{~Hz})$
Cell 1854

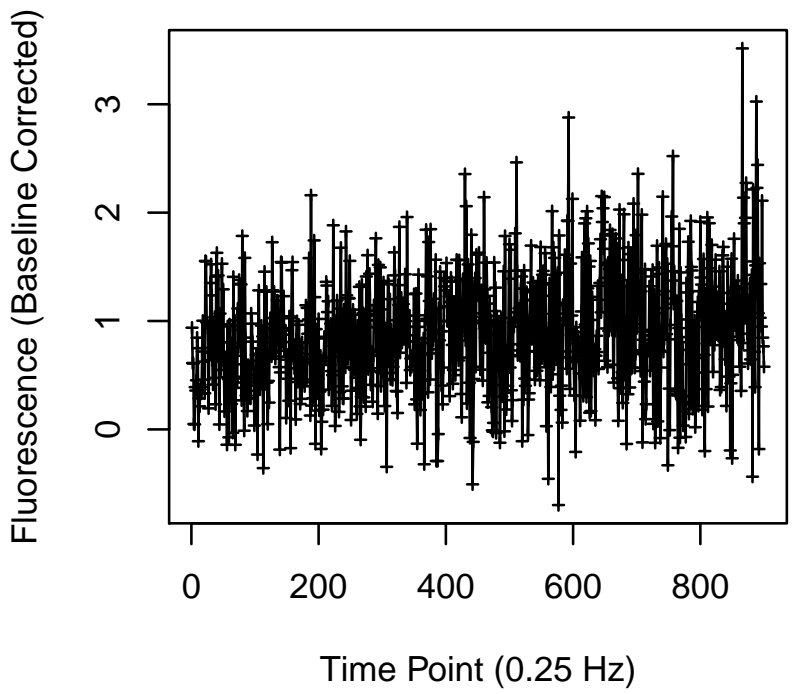

Cell 1856

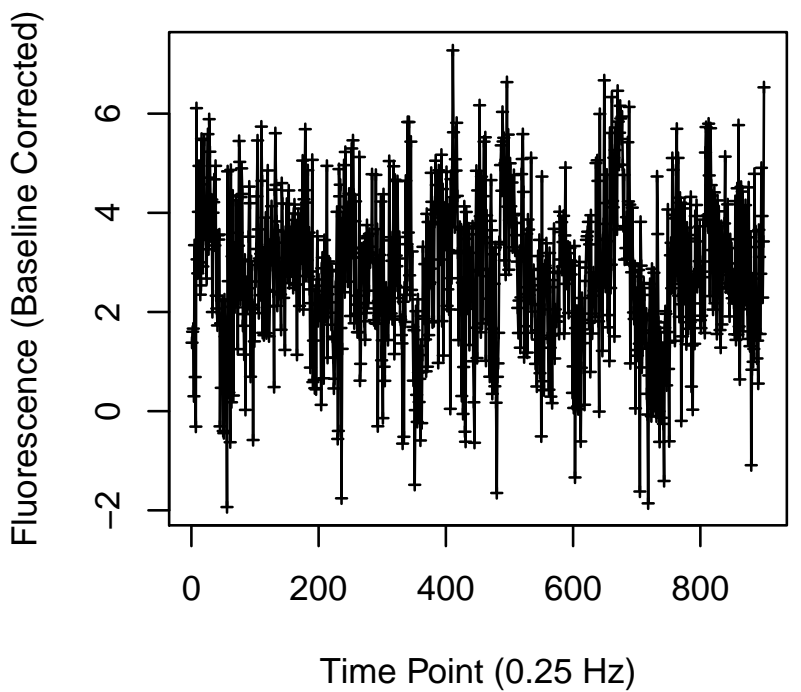


Cell 1865

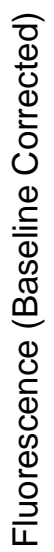

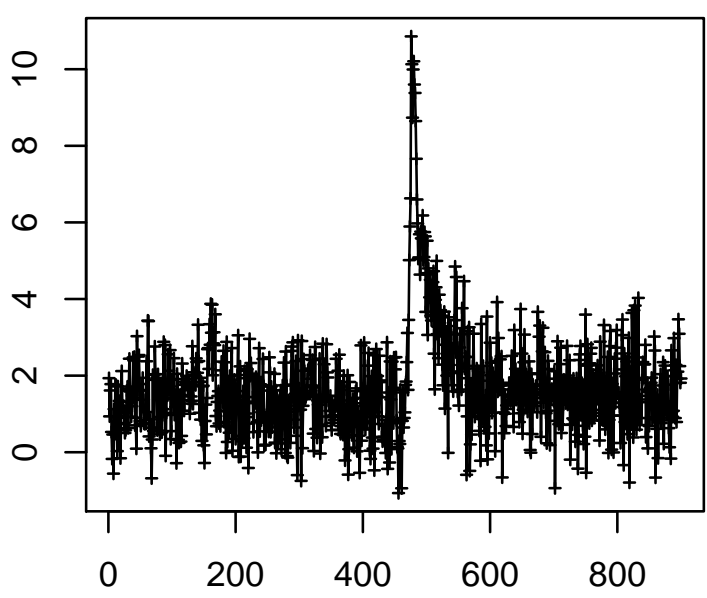

Time Point $(0.25 \mathrm{~Hz})$

Cell 1867

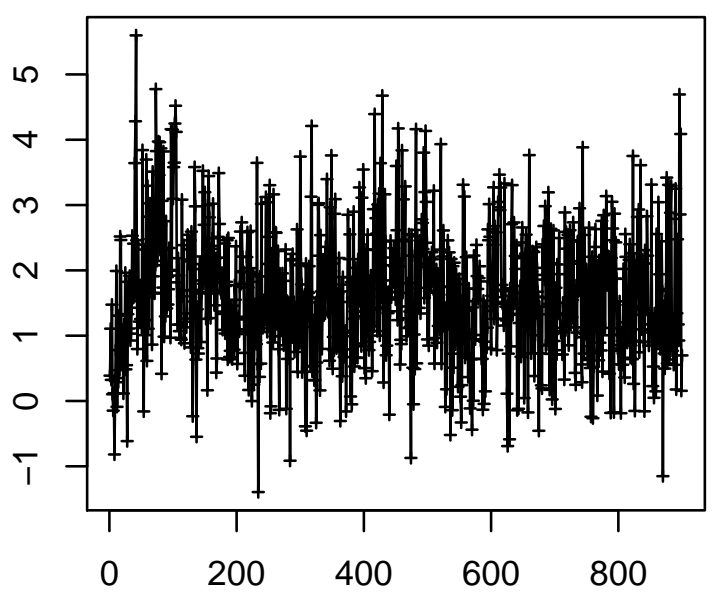

Time Point $(0.25 \mathrm{~Hz})$
Cell 1866

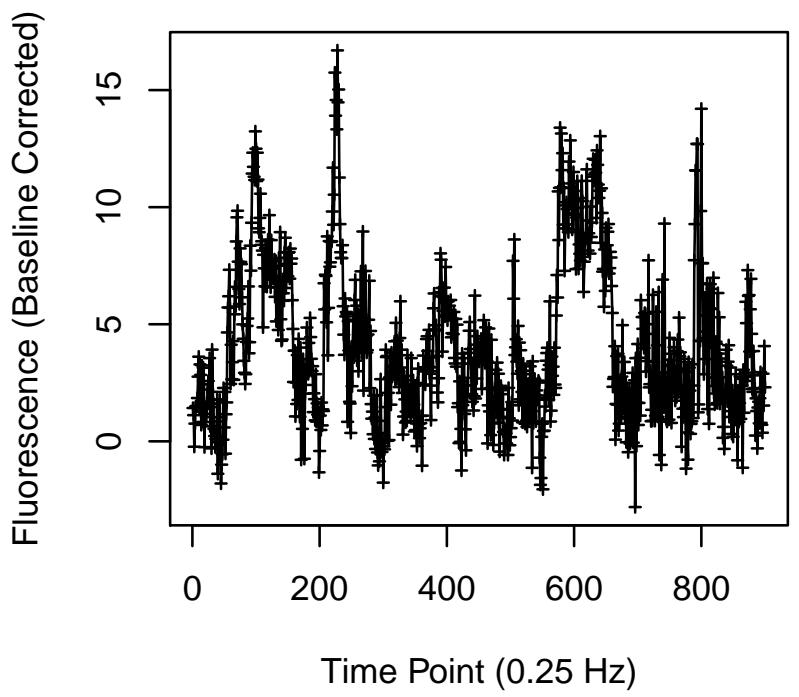

Cell 1868

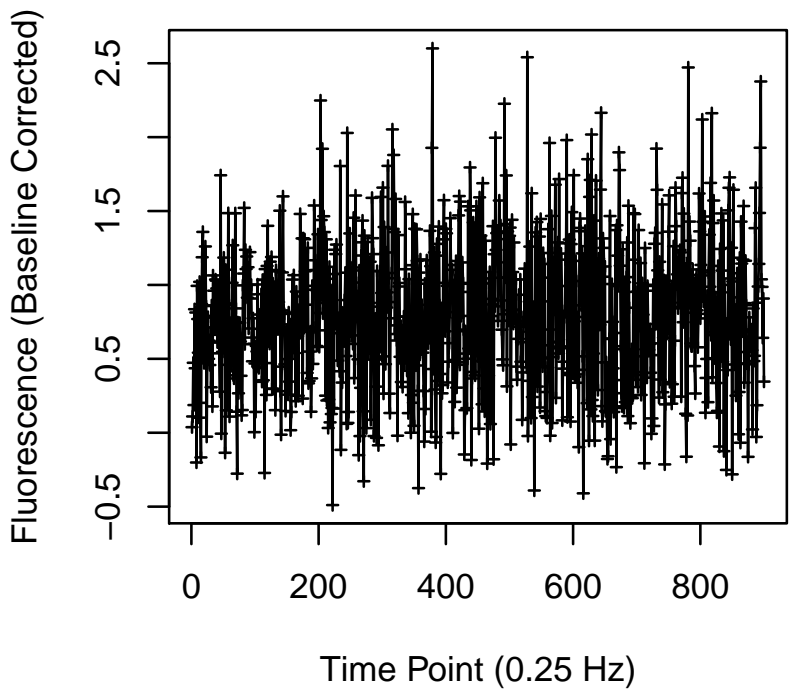


Cell 1869

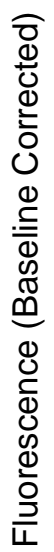

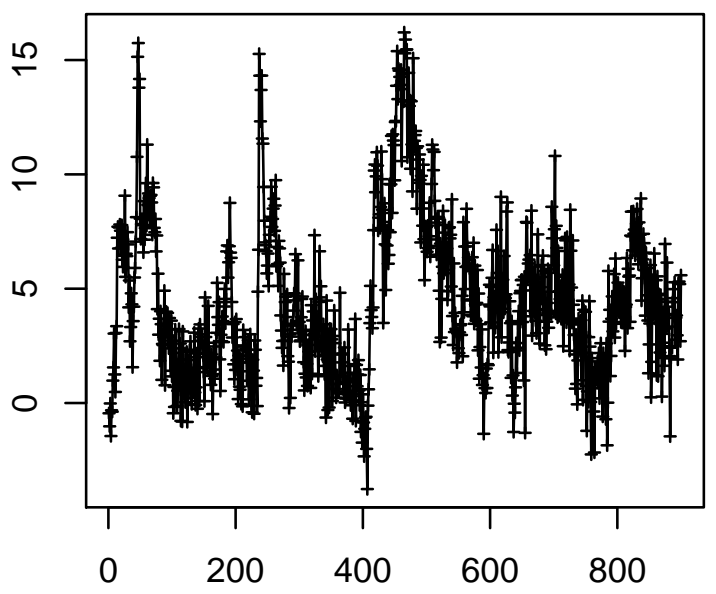

Time Point $(0.25 \mathrm{~Hz})$

Cell 1871

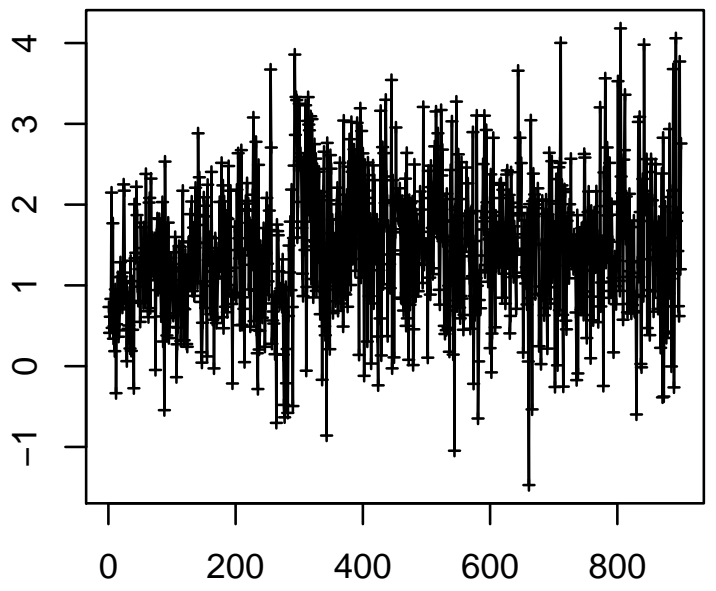

Time Point $(0.25 \mathrm{~Hz})$
Cell 1870

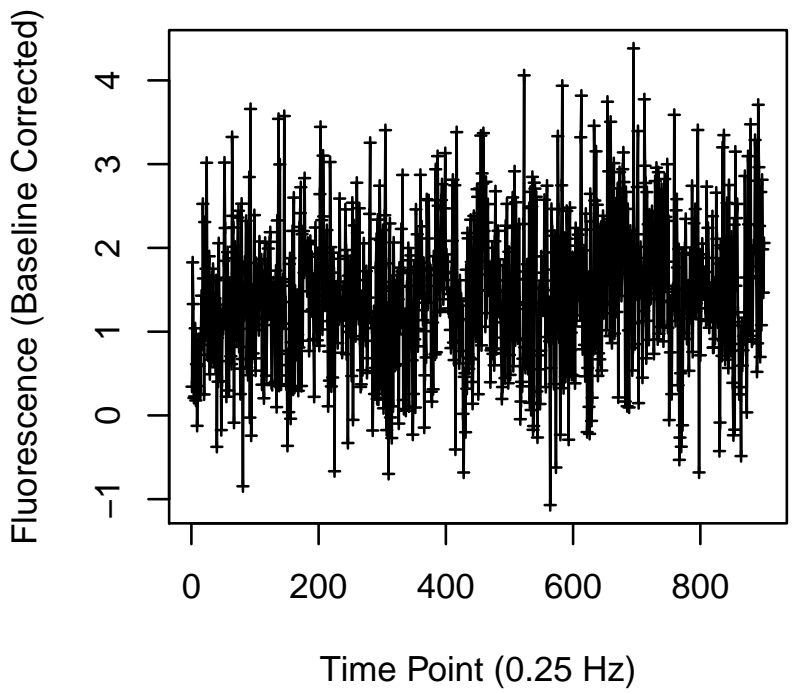

Cell 1872

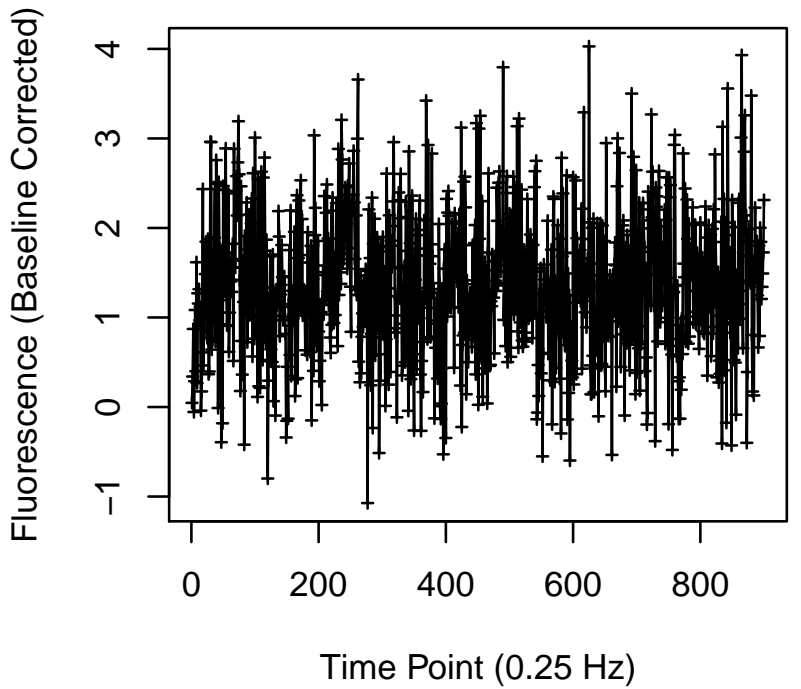


Cell 1873

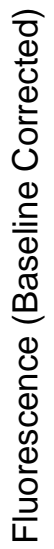

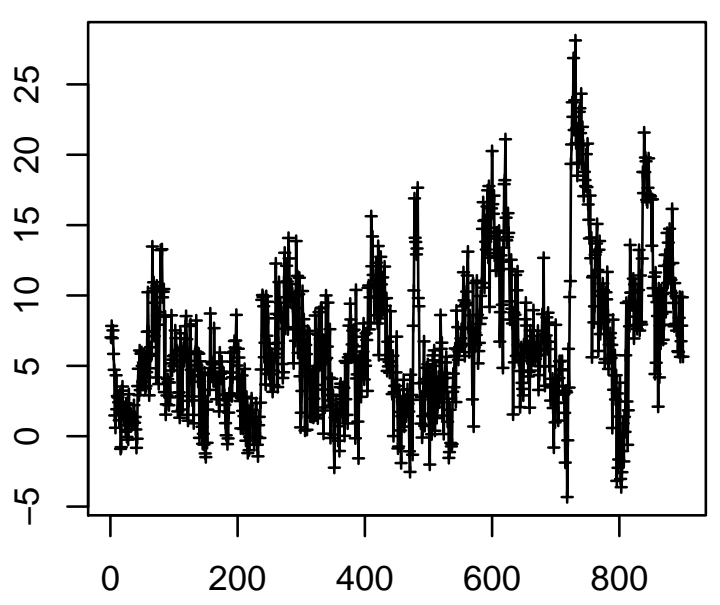

Time Point $(0.25 \mathrm{~Hz})$

Cell 1875

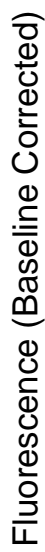

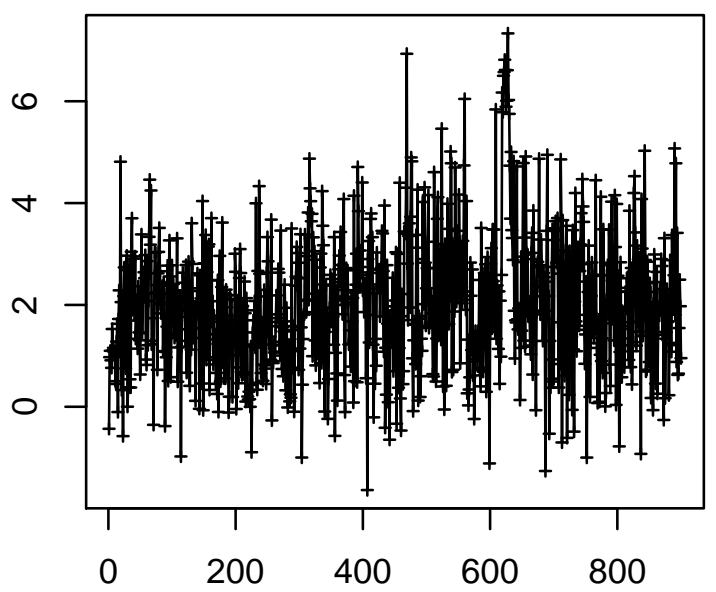

Time Point $(0.25 \mathrm{~Hz})$
Cell 1874

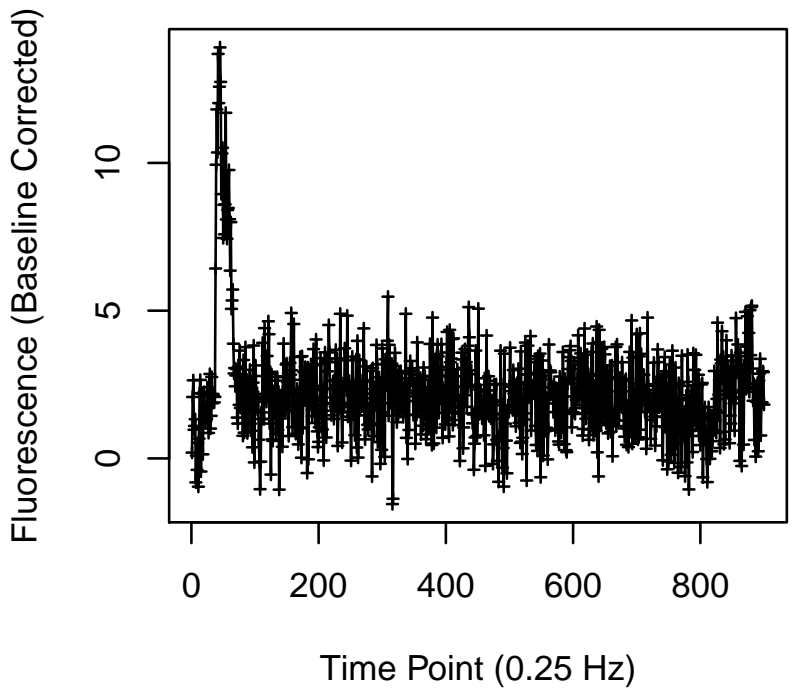

Cell 1876

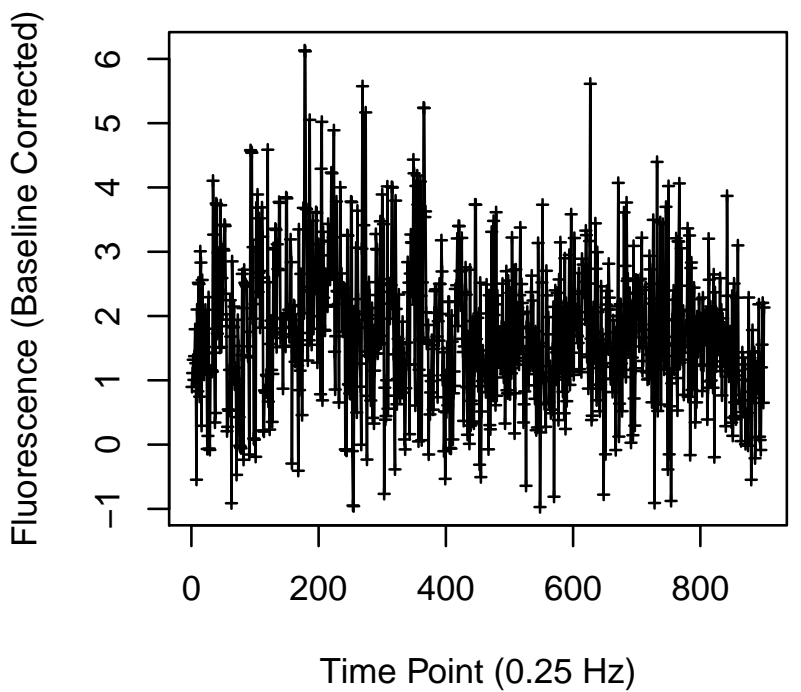


Cell 1881

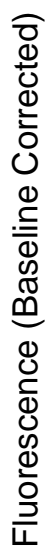

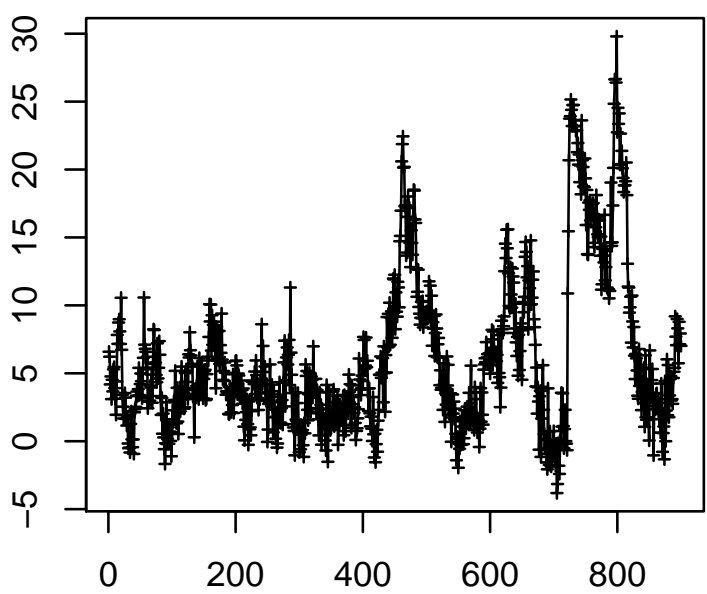

Time Point $(0.25 \mathrm{~Hz})$

Cell 1883

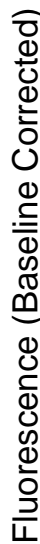

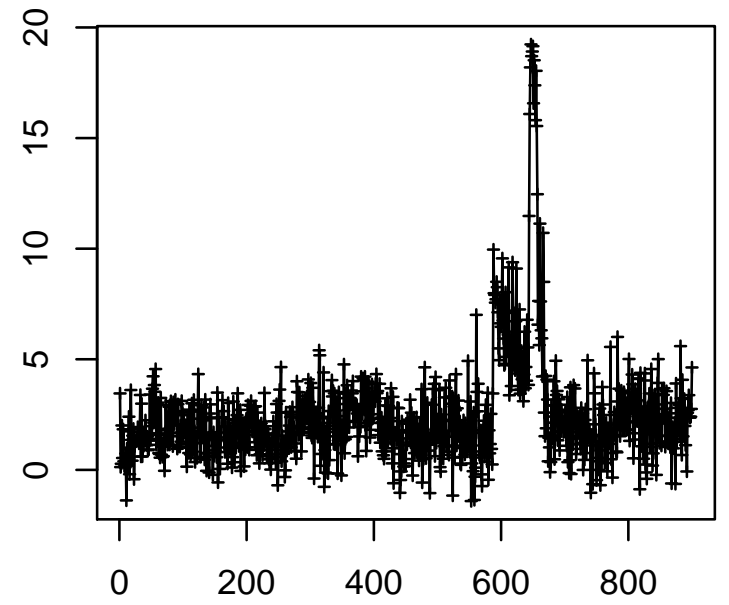

Time Point $(0.25 \mathrm{~Hz})$
Cell 1882

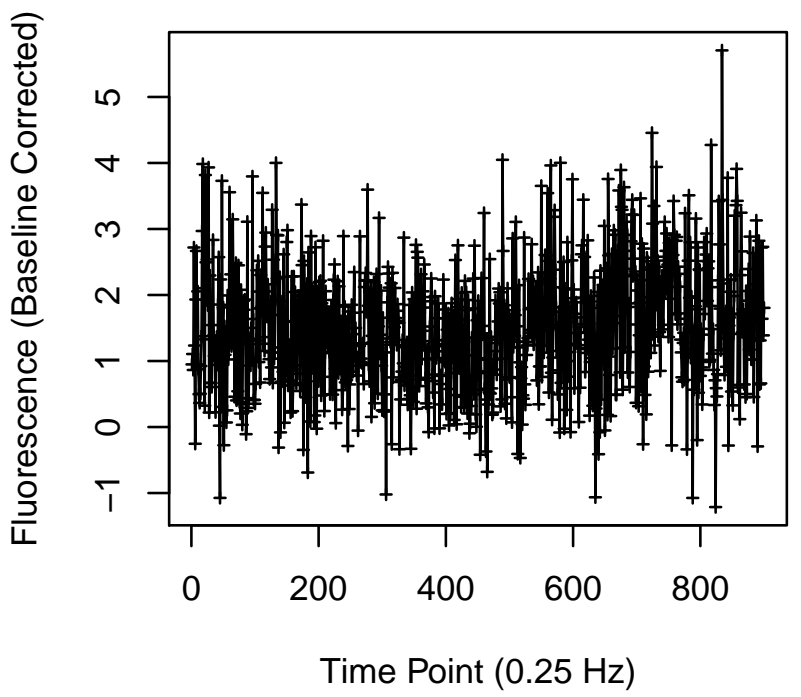

Cell 1884

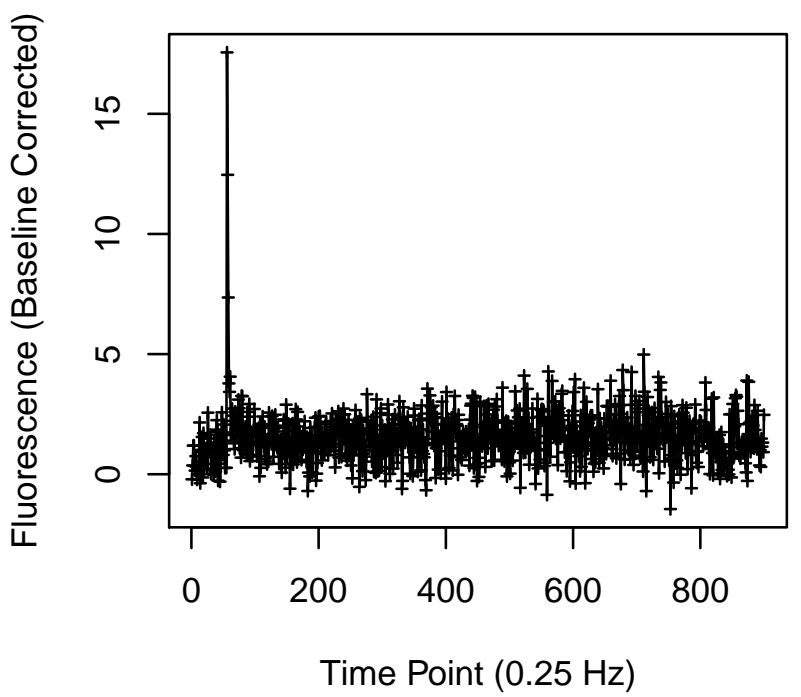


Cell 1889

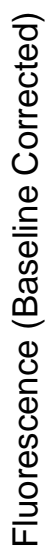

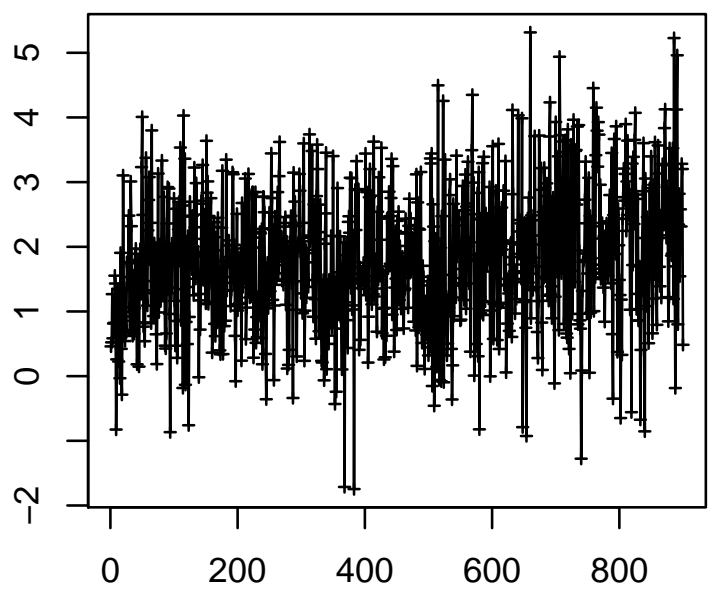

Time Point $(0.25 \mathrm{~Hz})$

\section{Cell 1891}

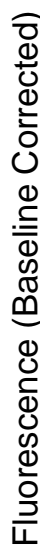

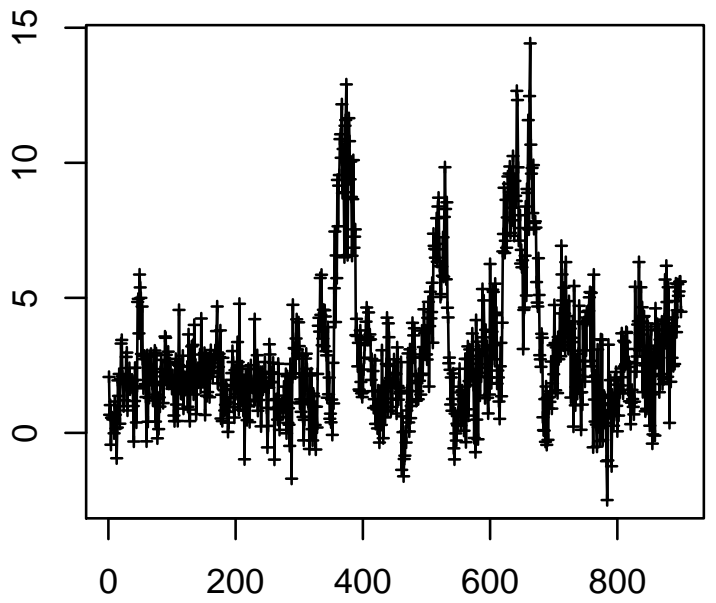

Time Point $(0.25 \mathrm{~Hz})$
Cell 1890

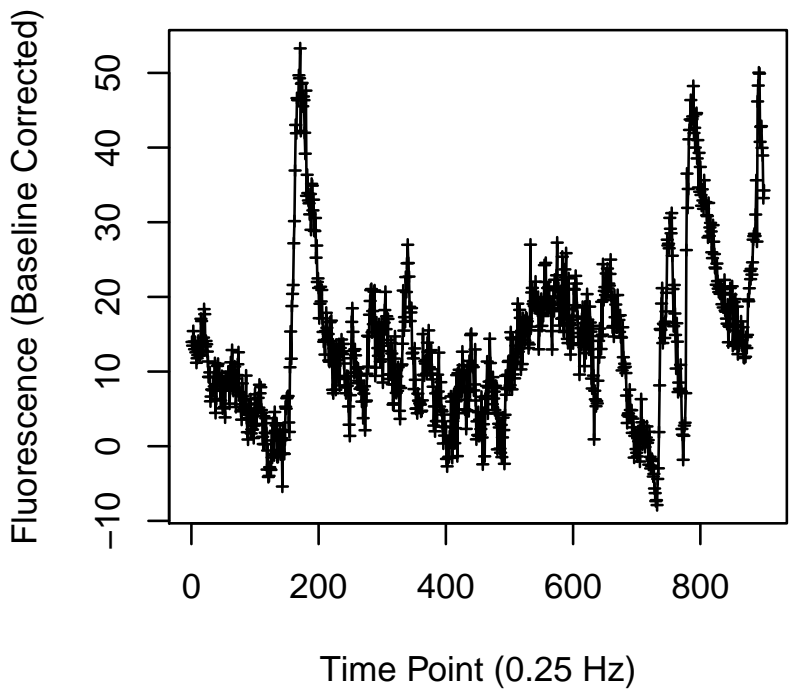

Cell 1892

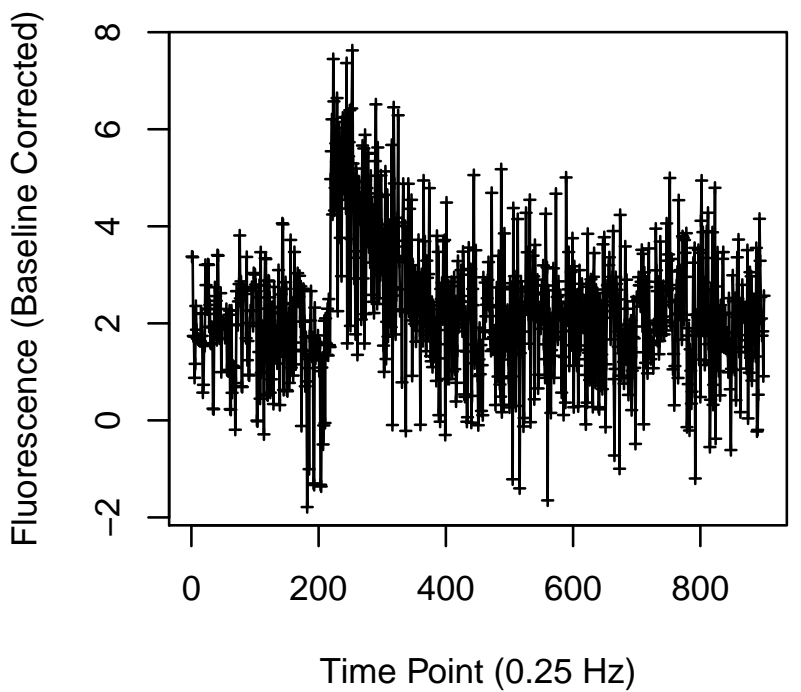




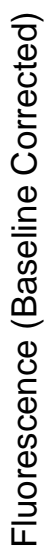

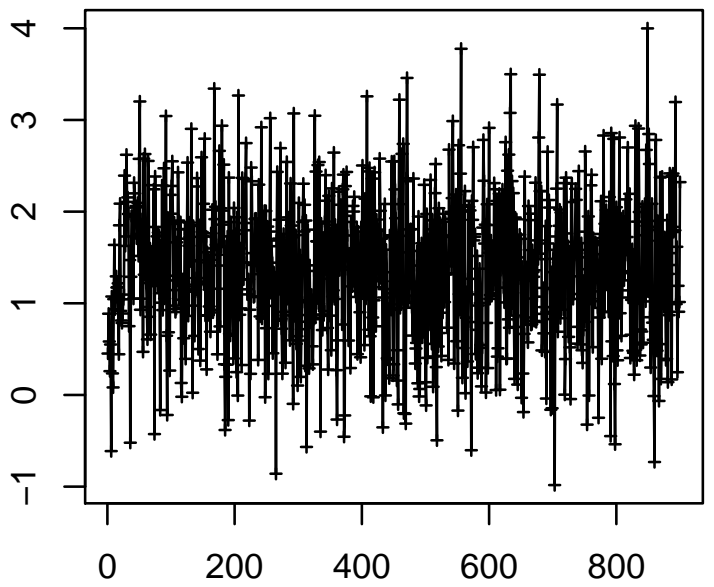

Time Point $(0.25 \mathrm{~Hz})$

Cell 1895

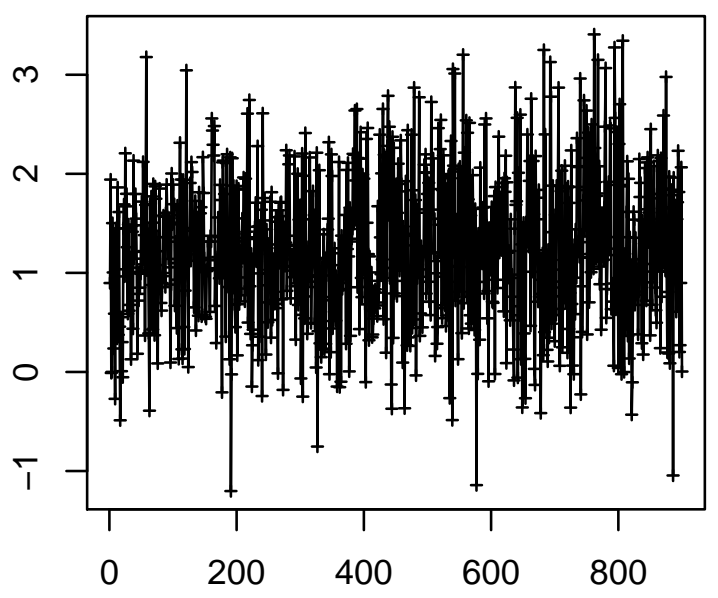

Time Point $(0.25 \mathrm{~Hz})$

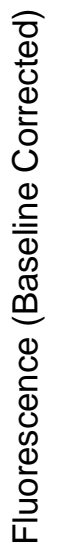

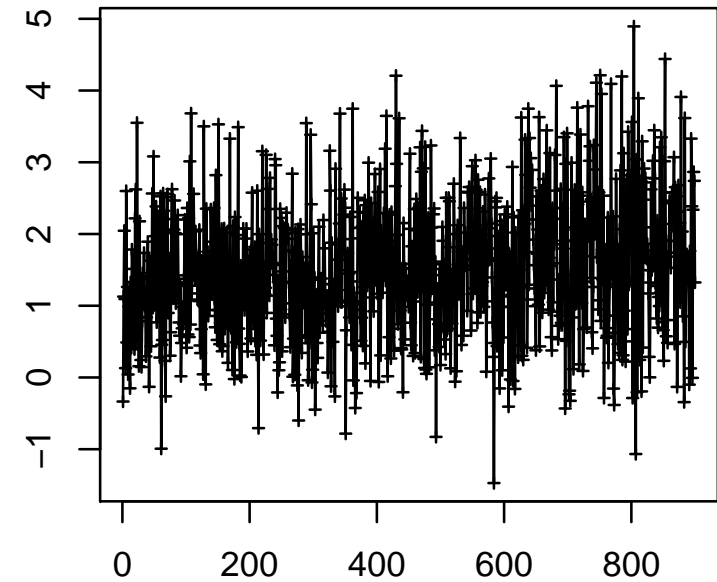

Time Point $(0.25 \mathrm{~Hz})$

Cell 1896

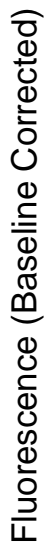

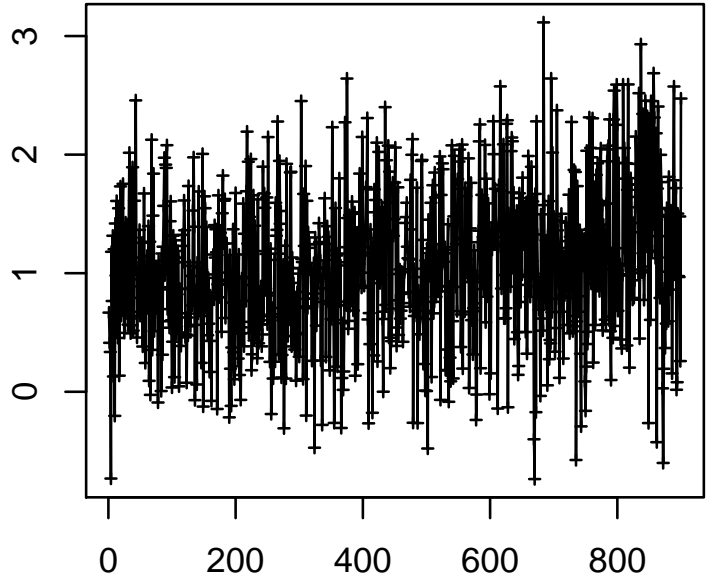

Time Point $(0.25 \mathrm{~Hz})$ 


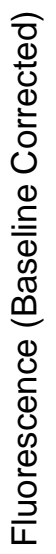

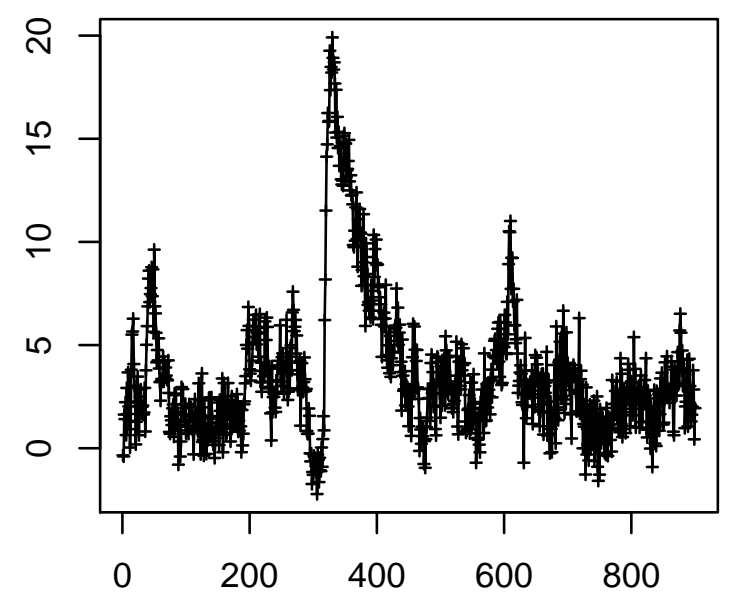

Time Point $(0.25 \mathrm{~Hz})$

Cell 1899

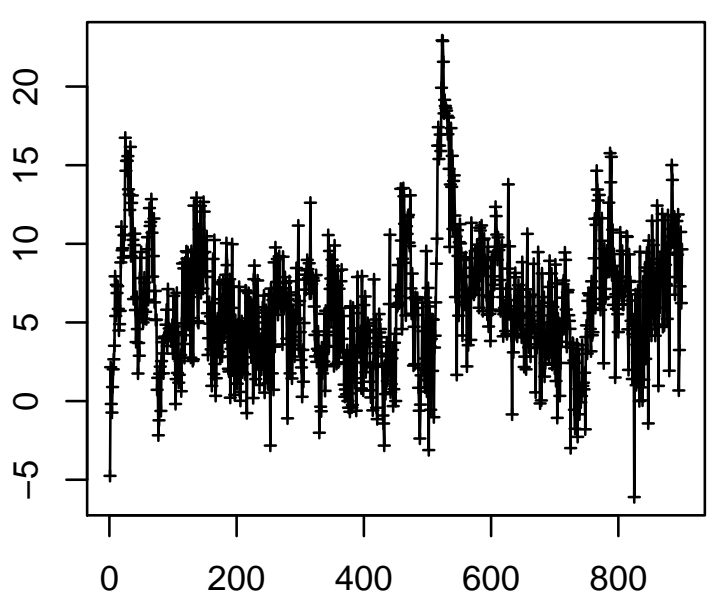

Time Point $(0.25 \mathrm{~Hz})$

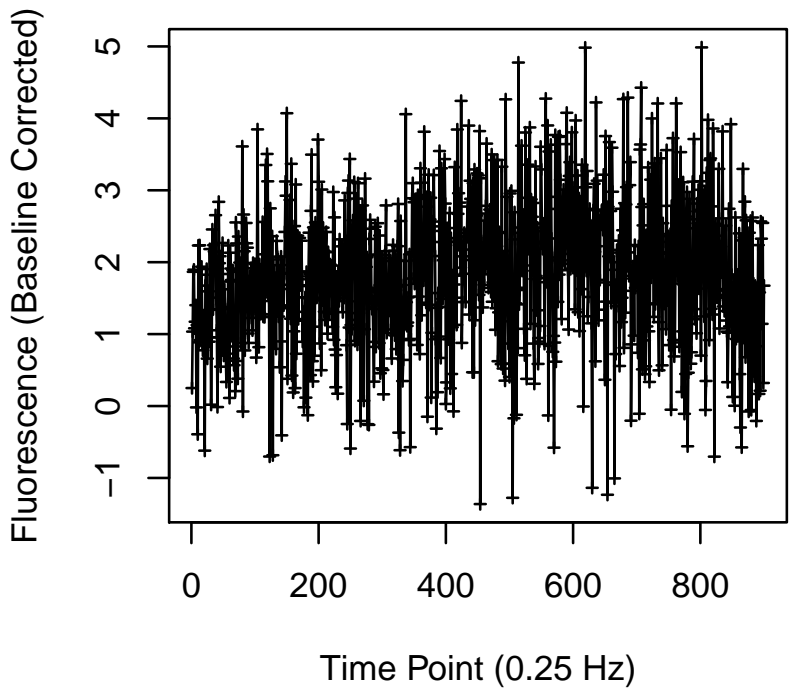

Cell 1900

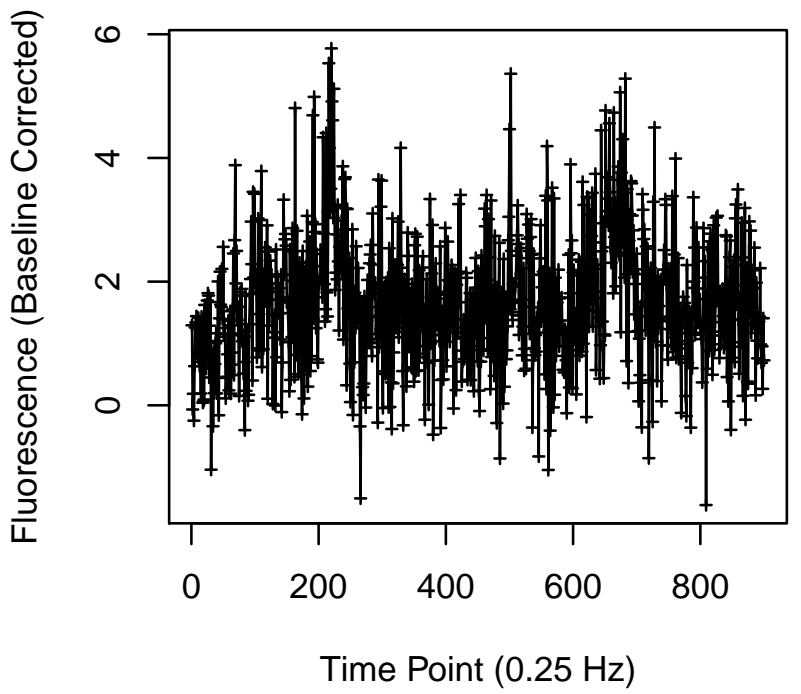


Cell 1905

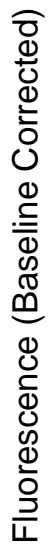

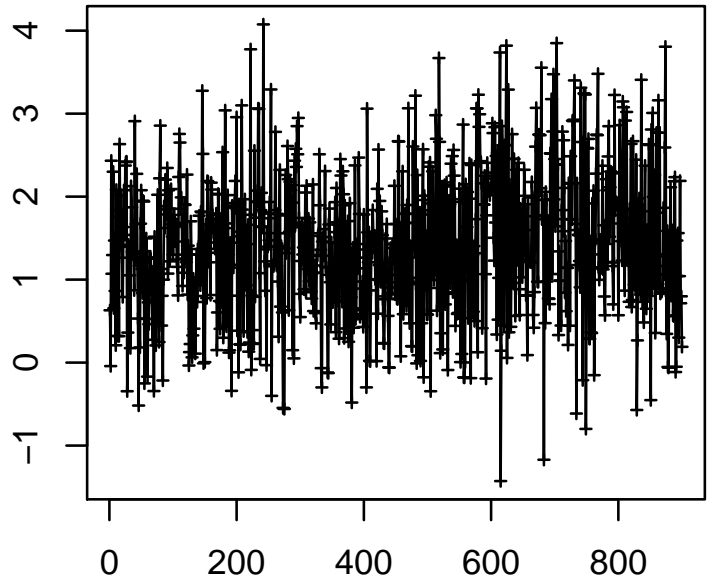

Time Point $(0.25 \mathrm{~Hz})$

Cell 1907

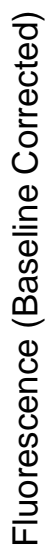

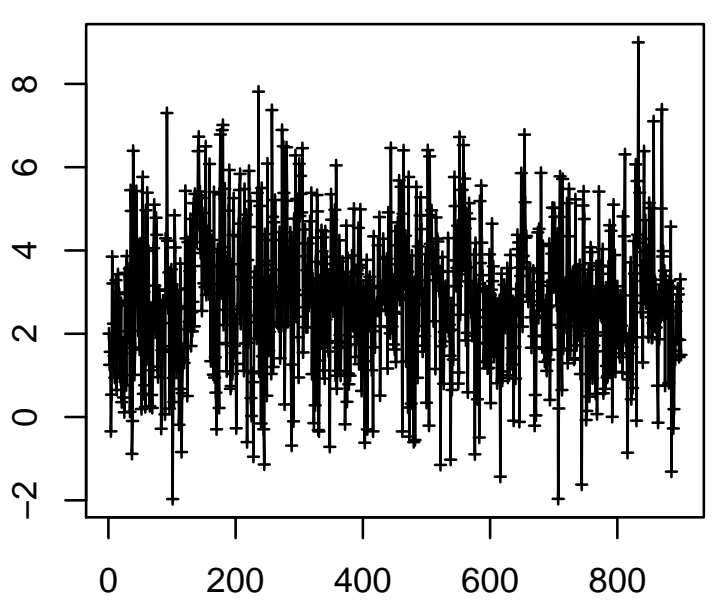

Time Point $(0.25 \mathrm{~Hz})$
Cell 1906

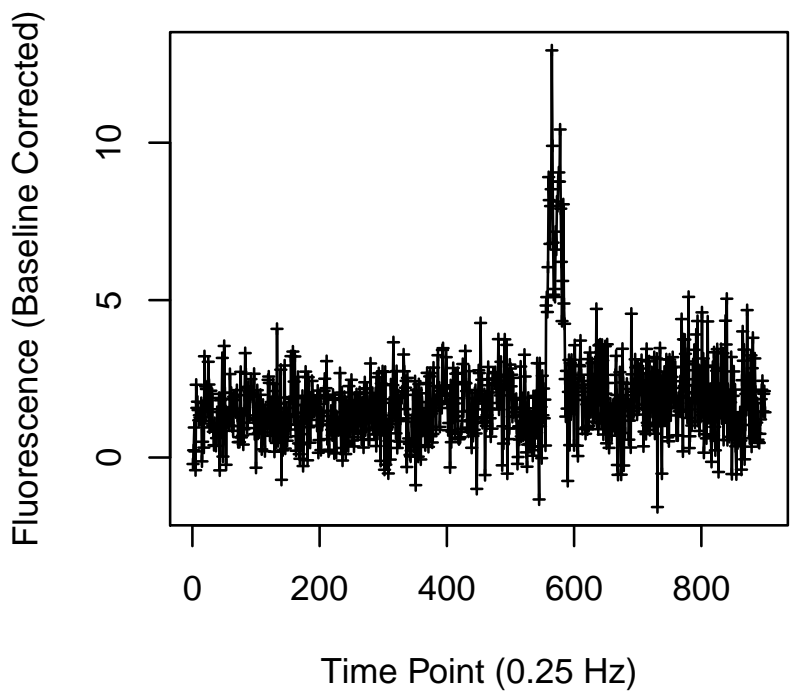

Cell 1908

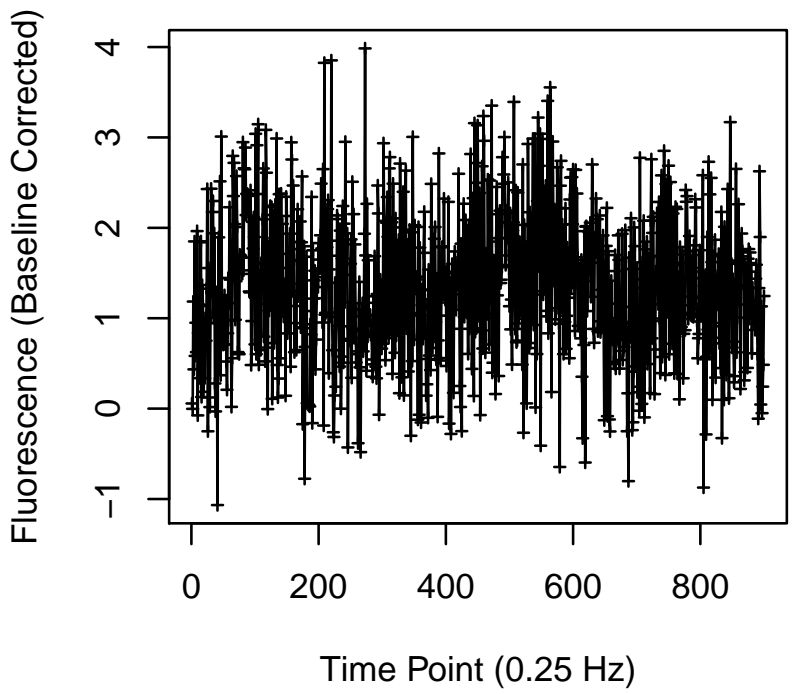


Cell 1917

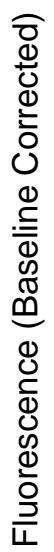

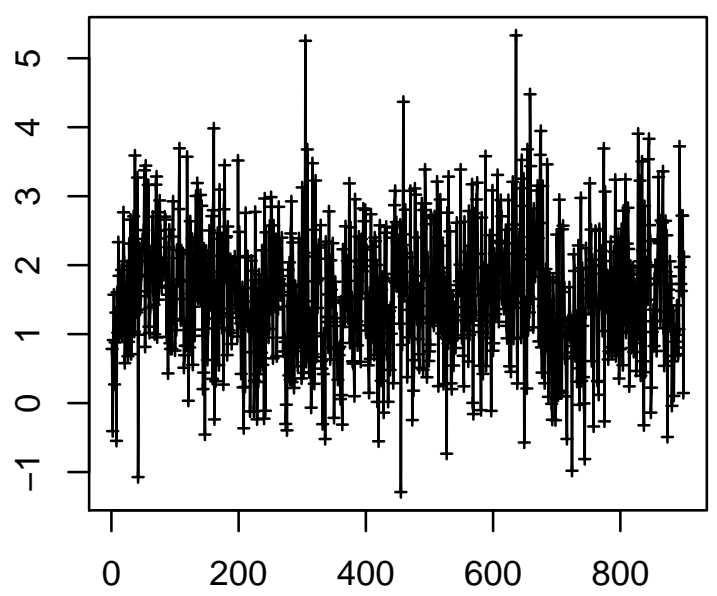

Time Point $(0.25 \mathrm{~Hz})$

Cell 1919

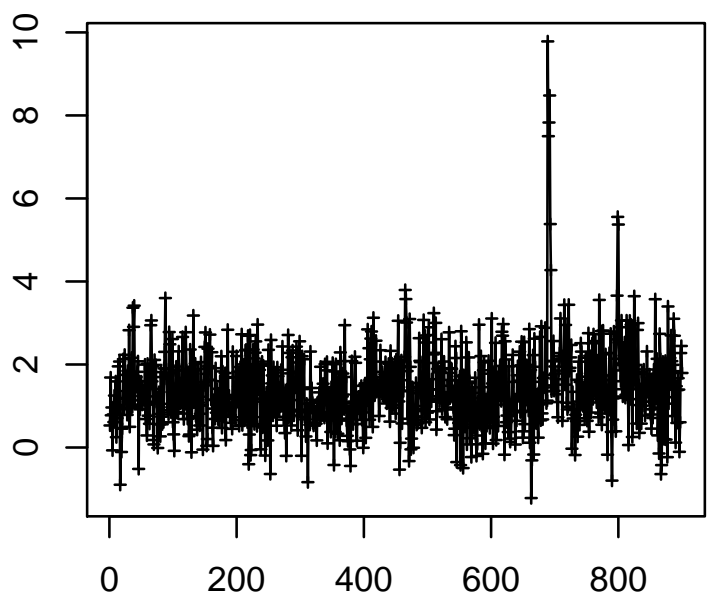

Time Point $(0.25 \mathrm{~Hz})$
Cell 1918

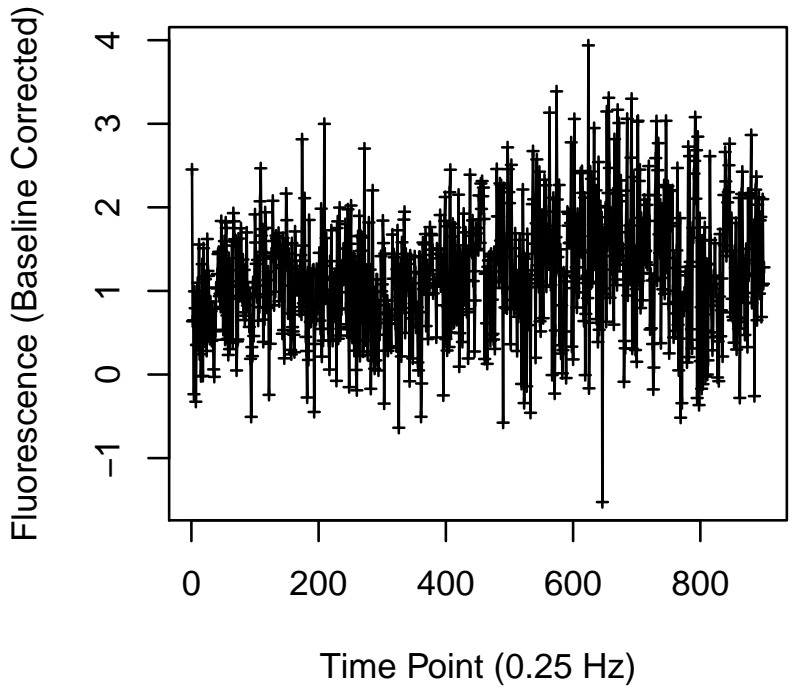

Cell 1920

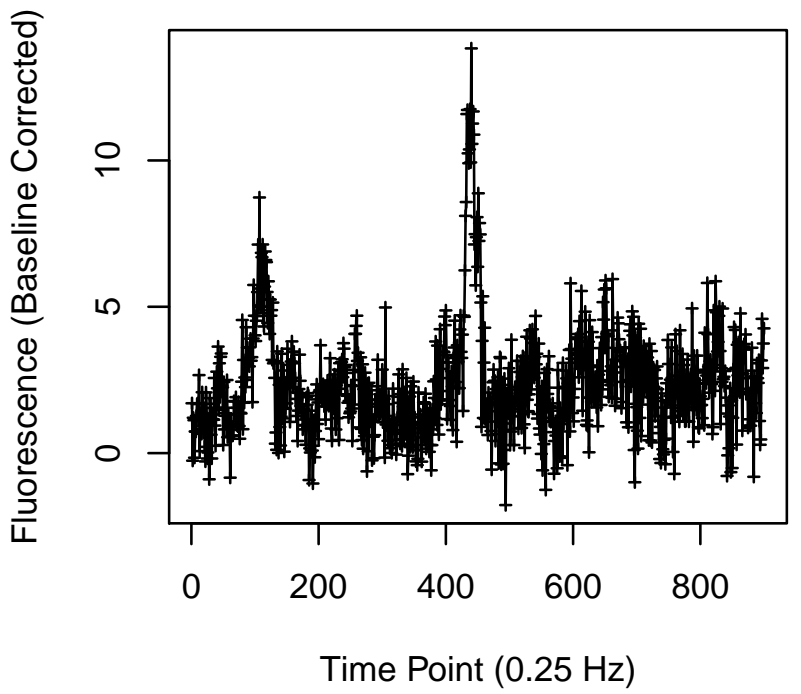




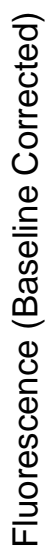

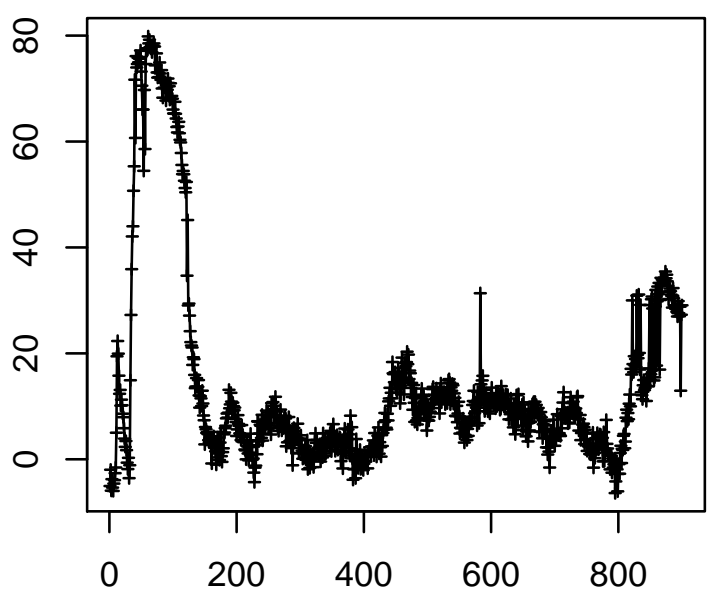

Time Point $(0.25 \mathrm{~Hz})$

Cell 1927

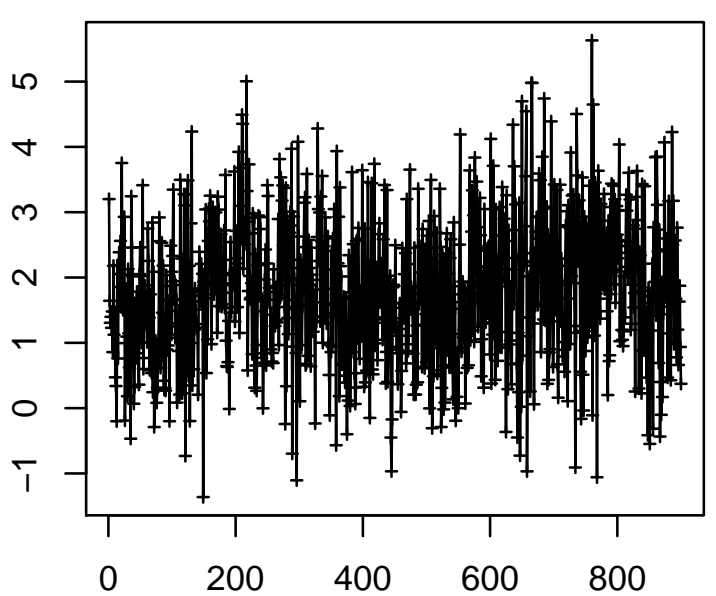

Time Point $(0.25 \mathrm{~Hz})$

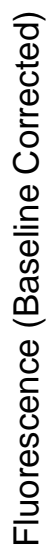

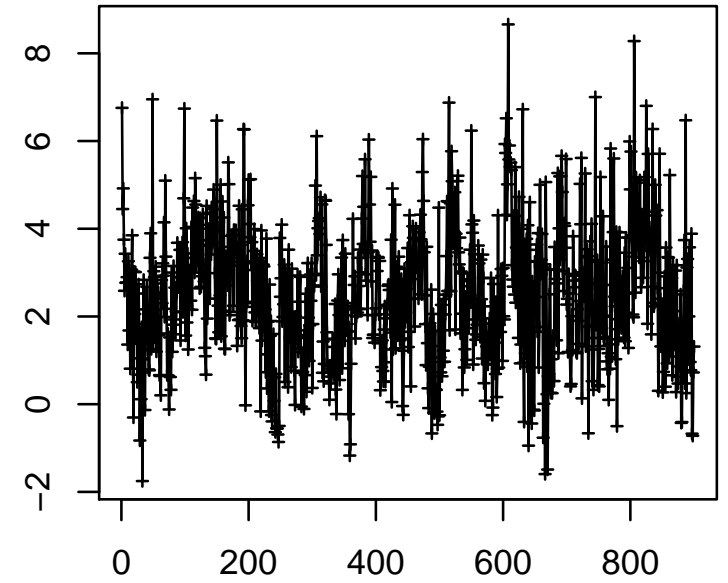

Time Point $(0.25 \mathrm{~Hz})$

Cell 1928

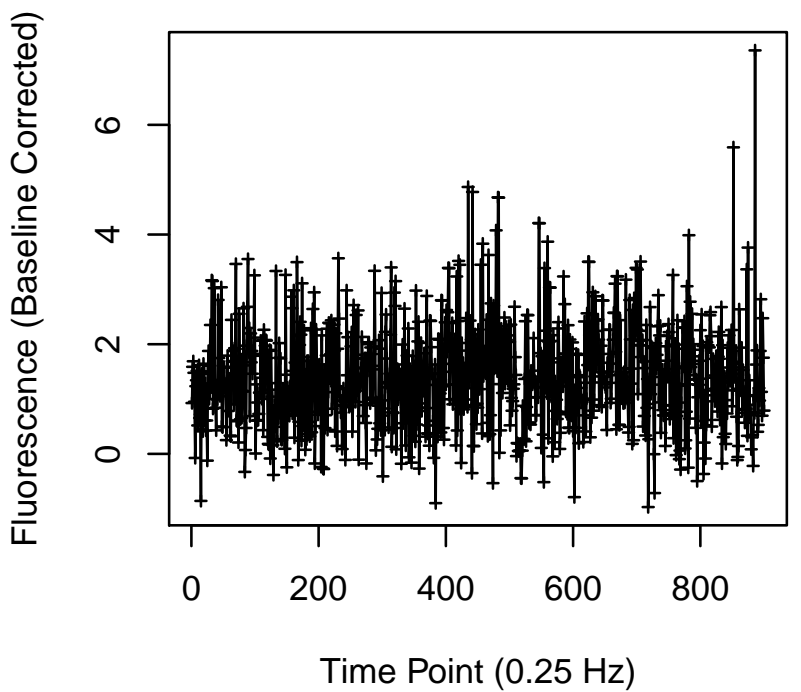


Cell 1929

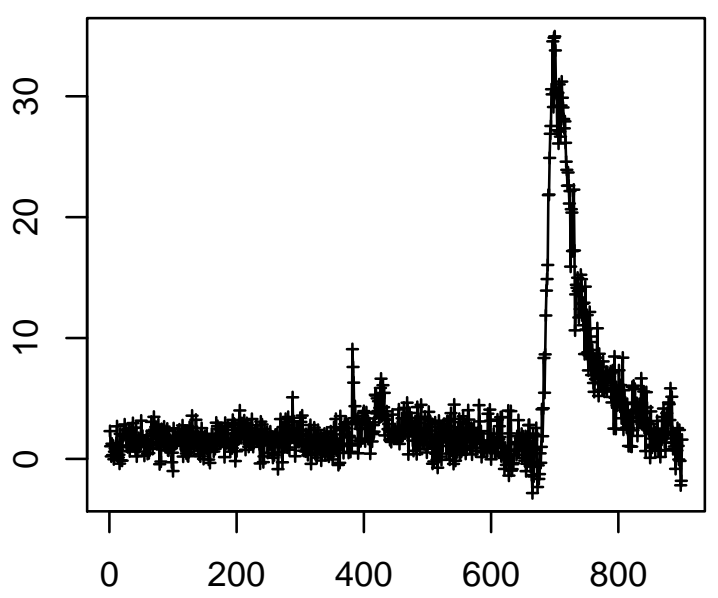

Time Point $(0.25 \mathrm{~Hz})$

Cell 1931

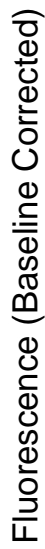

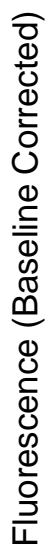

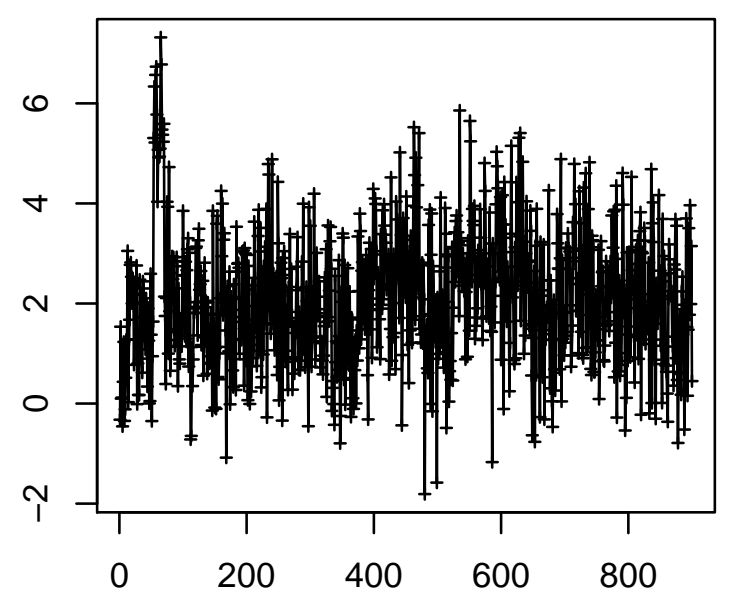

Time Point $(0.25 \mathrm{~Hz})$
Cell 1930

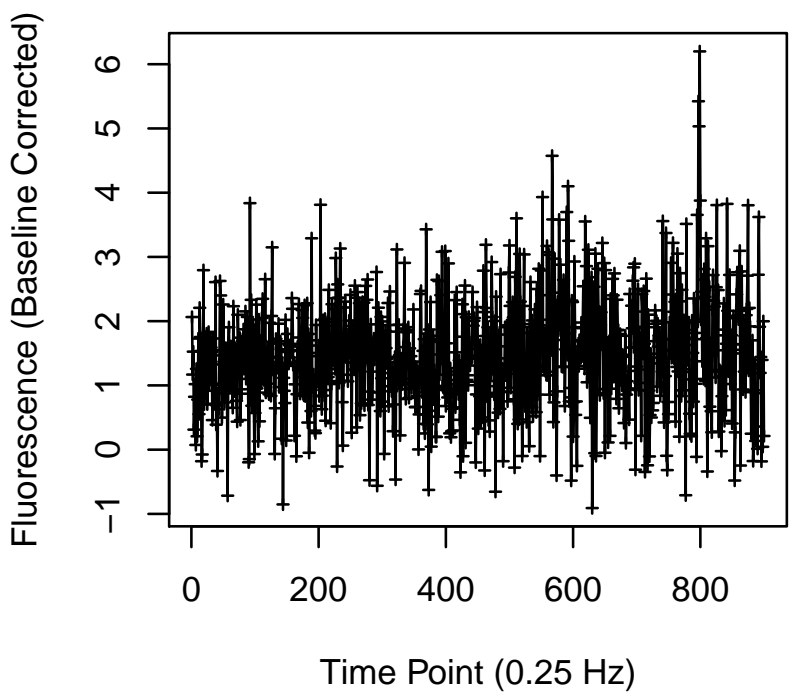

Cell 1932

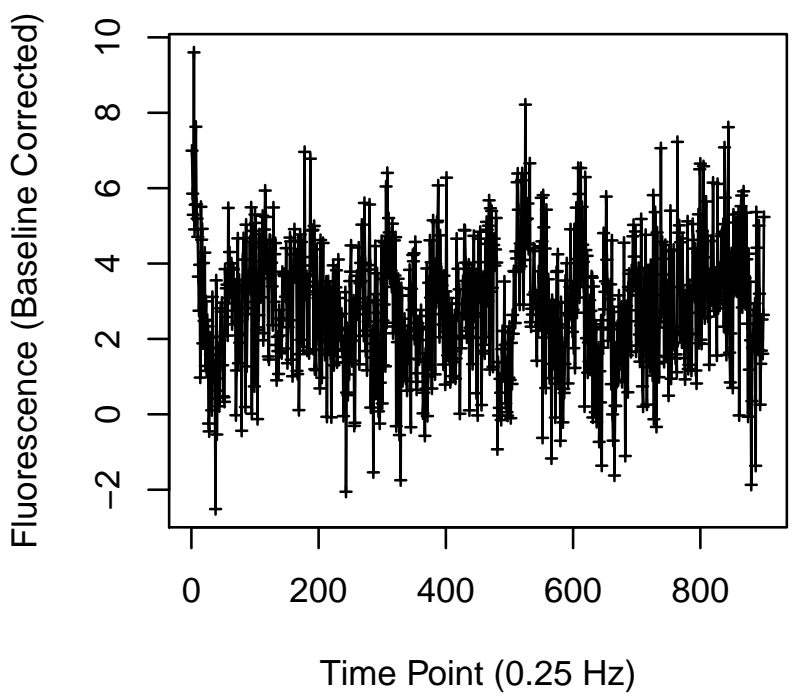


Cell 1937

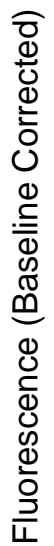

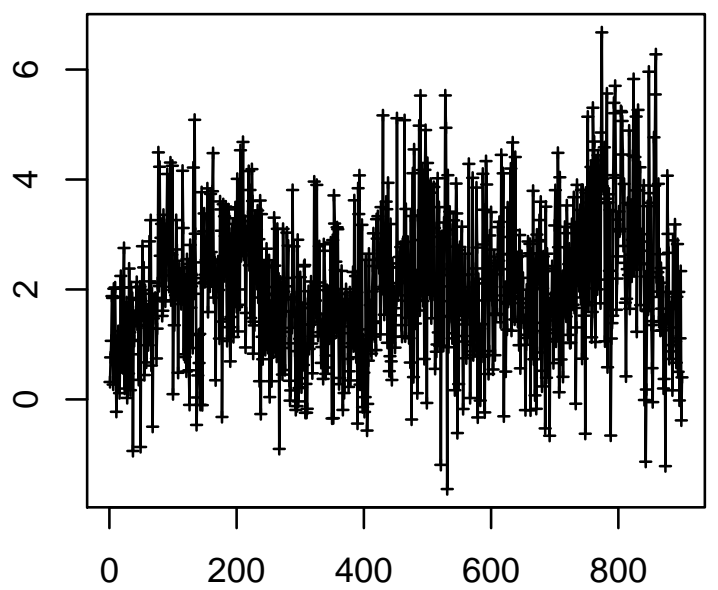

Time Point $(0.25 \mathrm{~Hz})$

Cell 1939

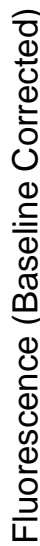

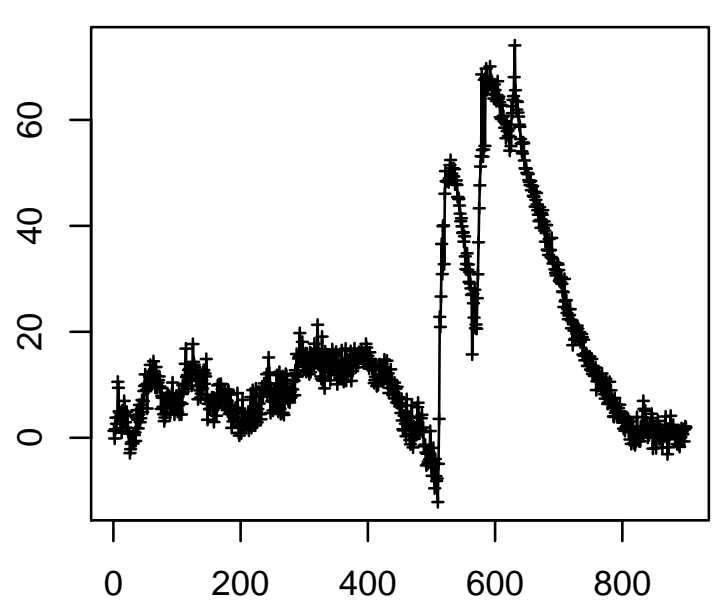

Time Point $(0.25 \mathrm{~Hz})$
Cell 1938

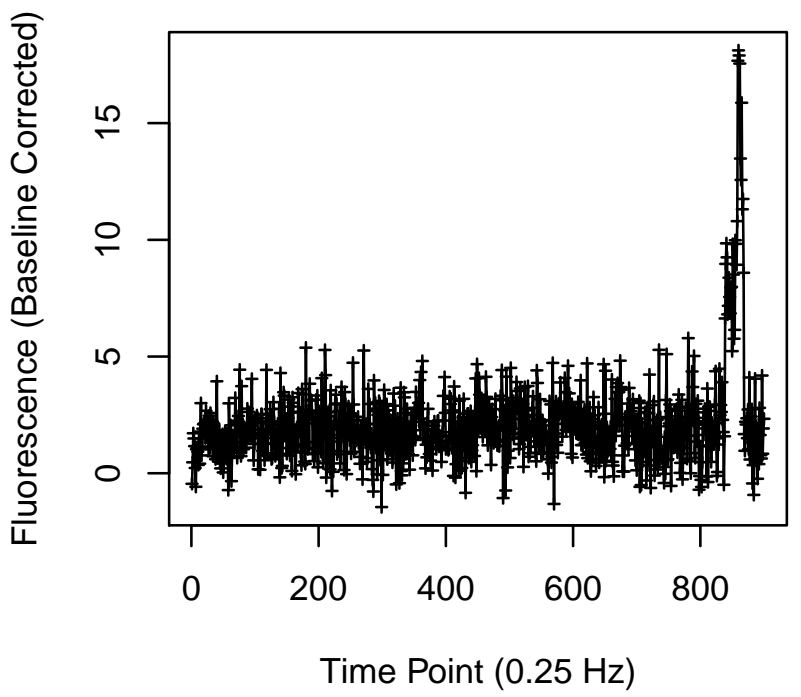

Cell 1940

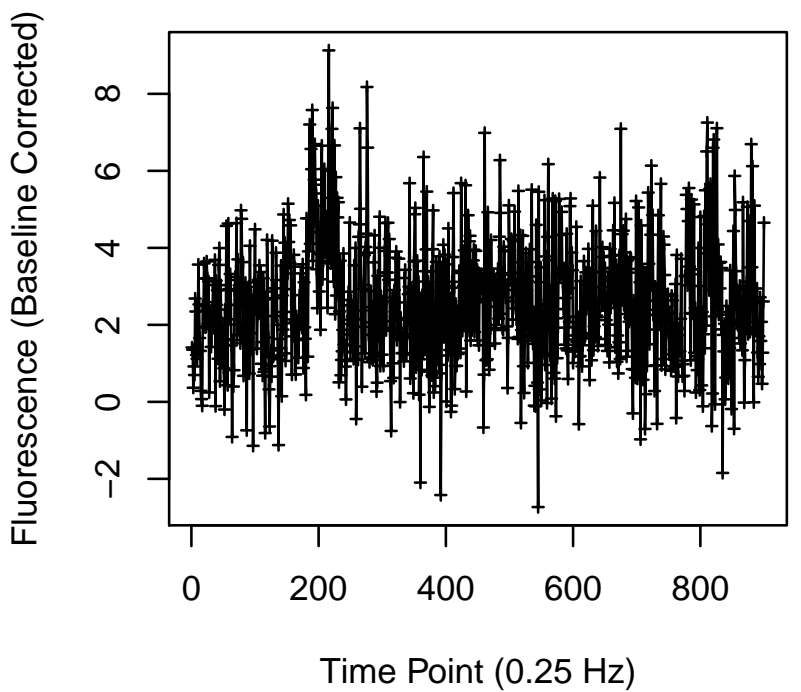


Cell 1941

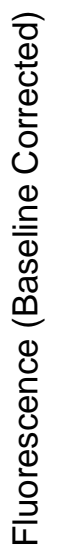

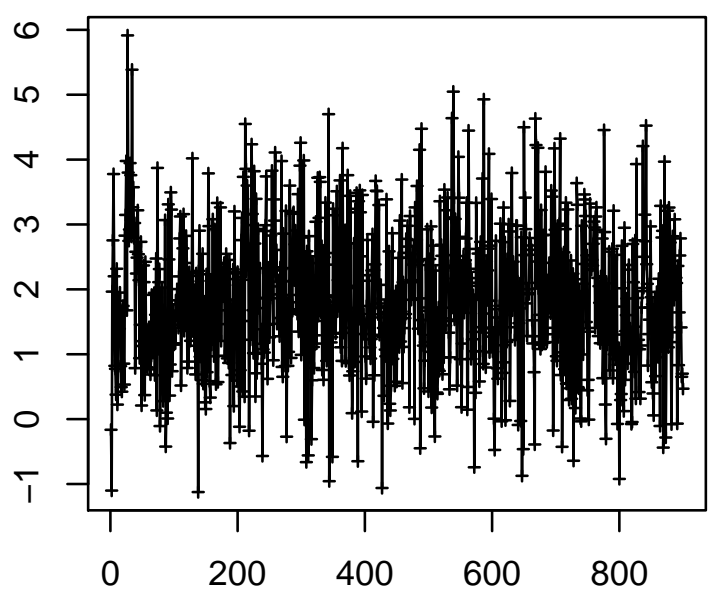

Time Point $(0.25 \mathrm{~Hz})$

Cell 1943

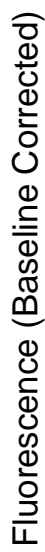

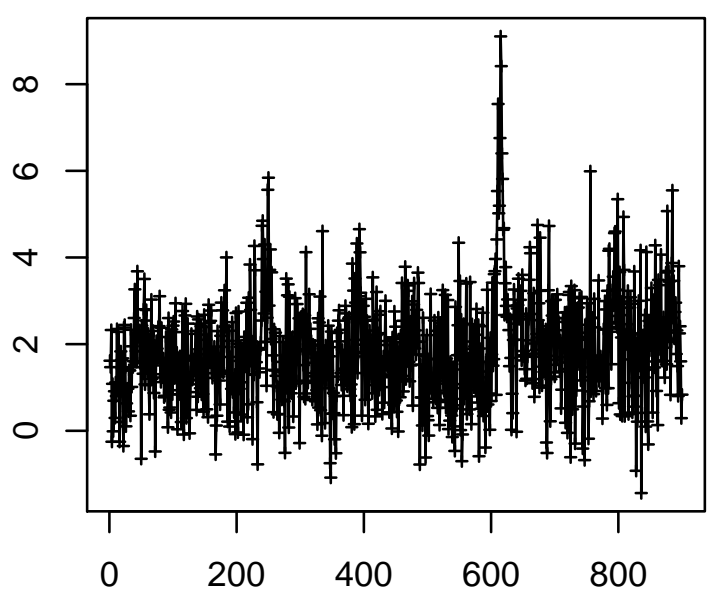

Time Point $(0.25 \mathrm{~Hz})$
Cell 1942

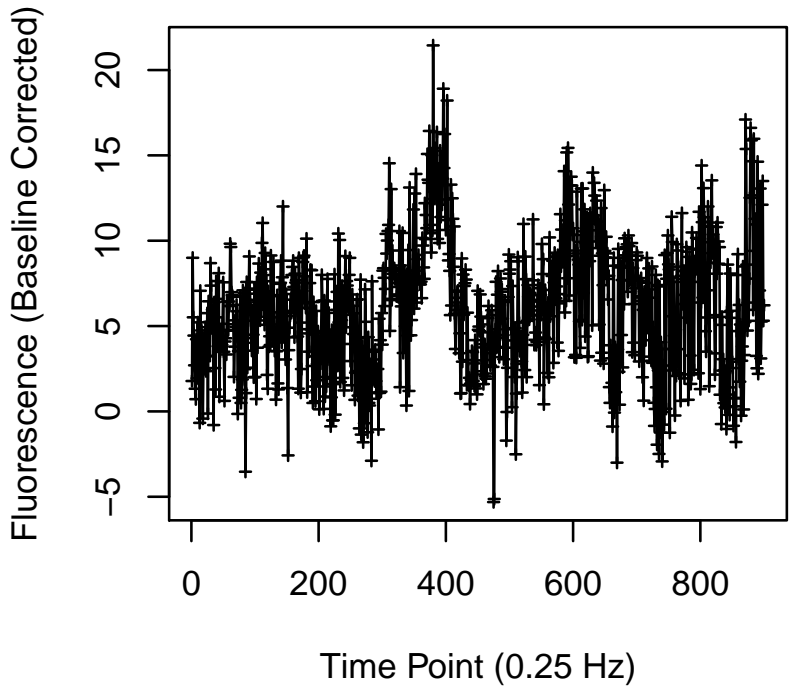

Cell 1944

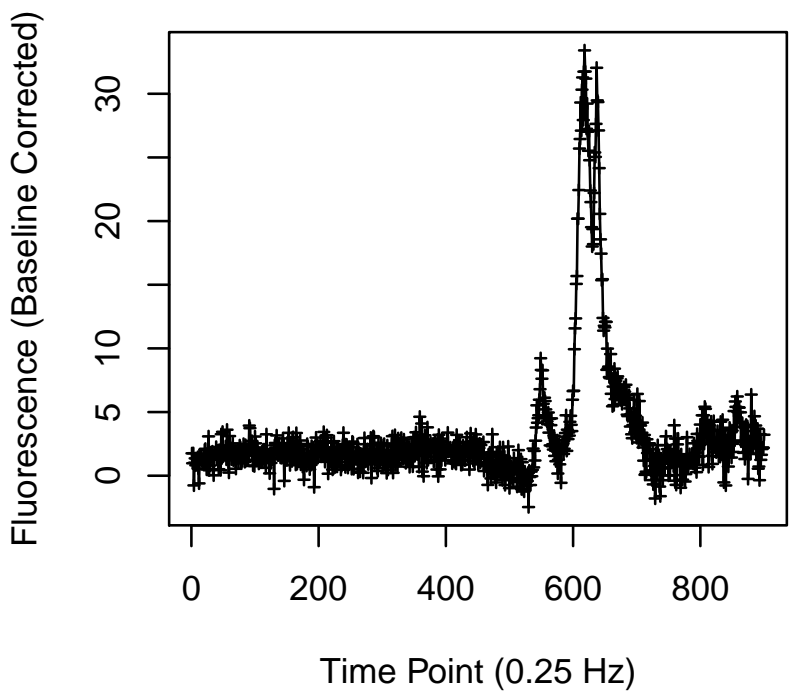


Cell 1949

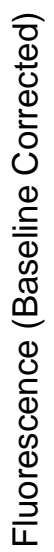

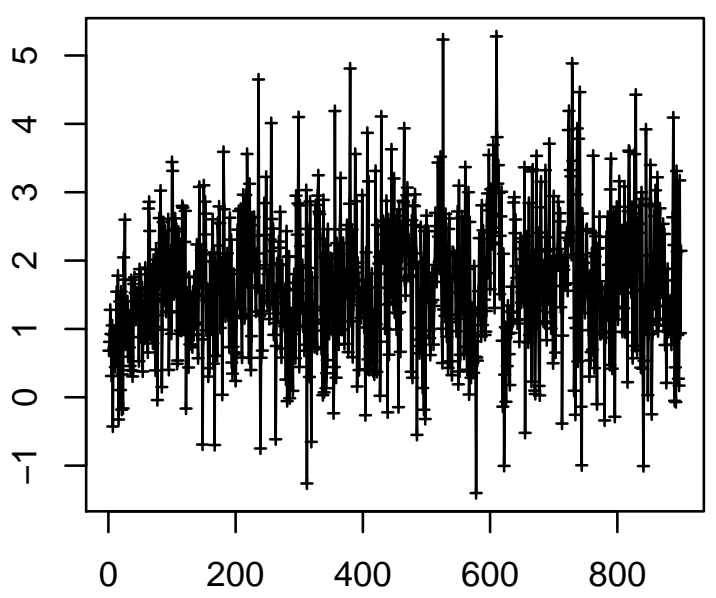

Time Point $(0.25 \mathrm{~Hz})$

Cell 1951

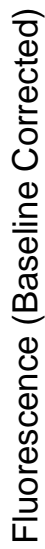

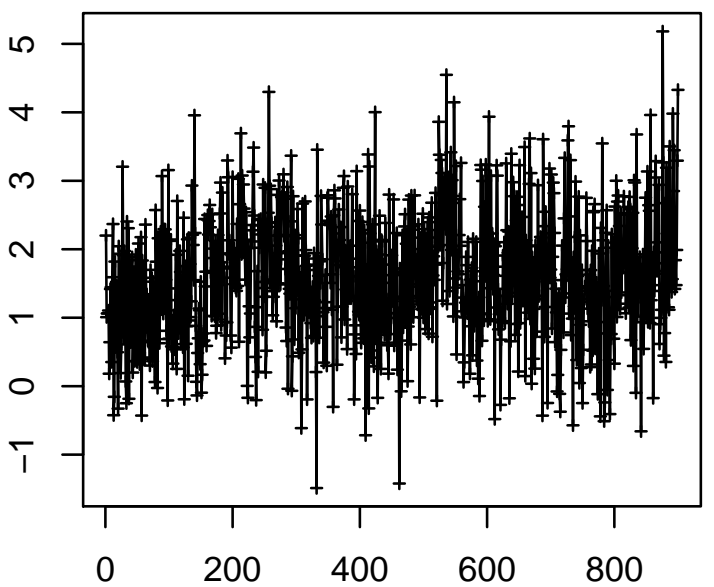

Time Point $(0.25 \mathrm{~Hz})$
Cell 1950

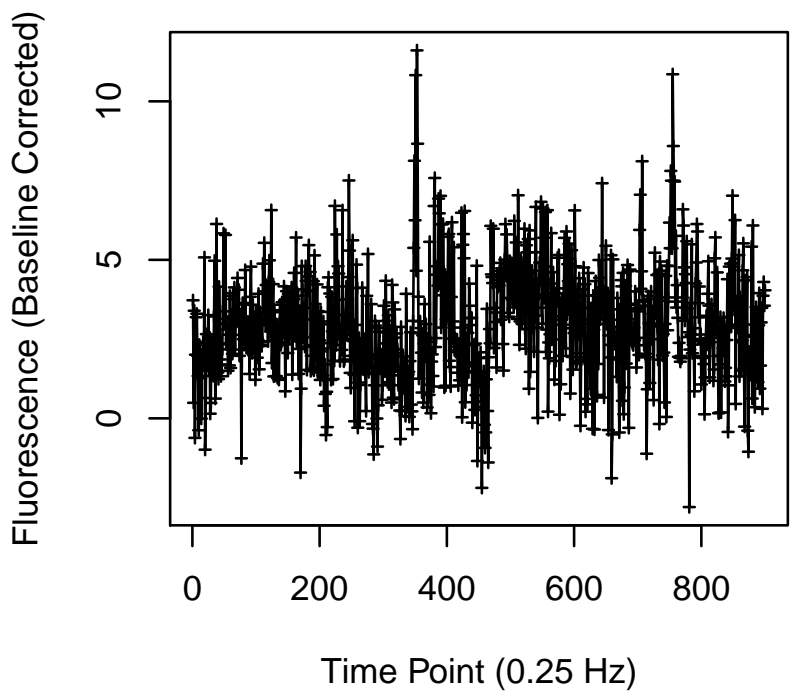

Cell 1952

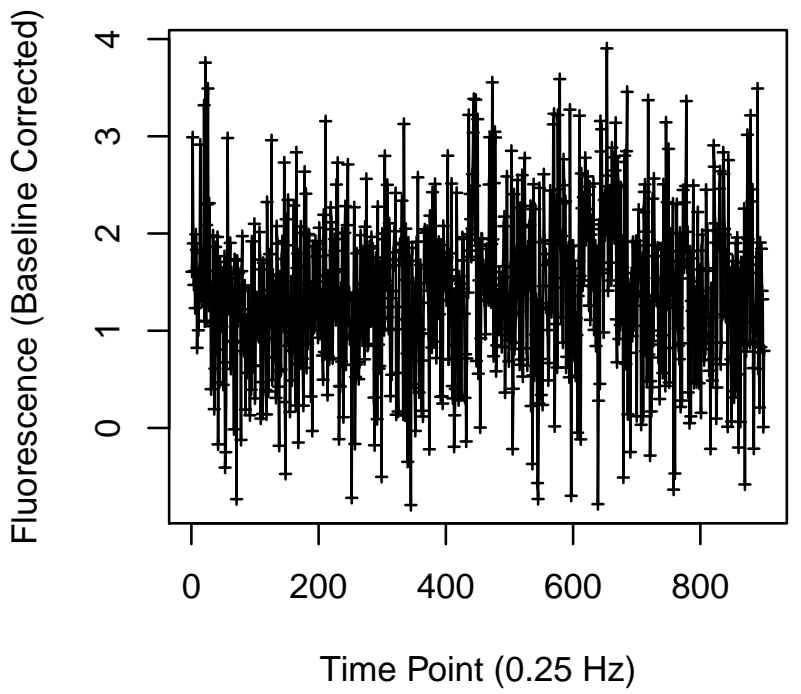


Cell 1957

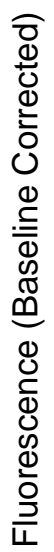

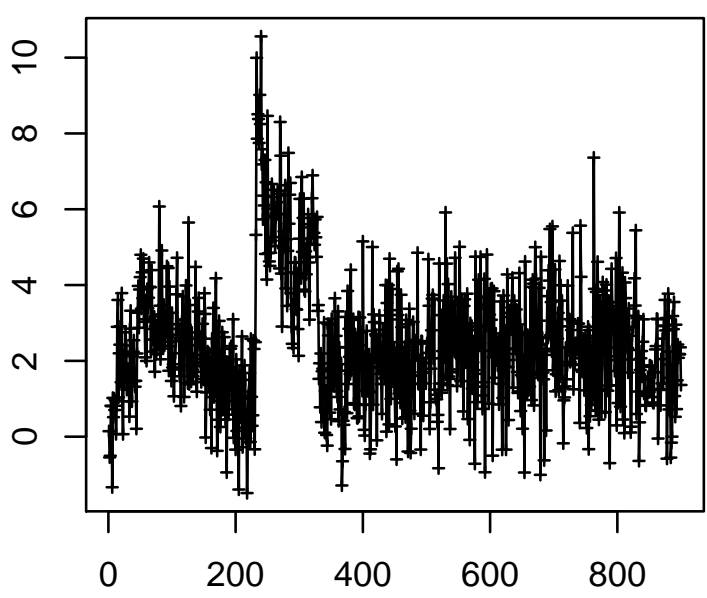

Time Point $(0.25 \mathrm{~Hz})$

Cell 1959

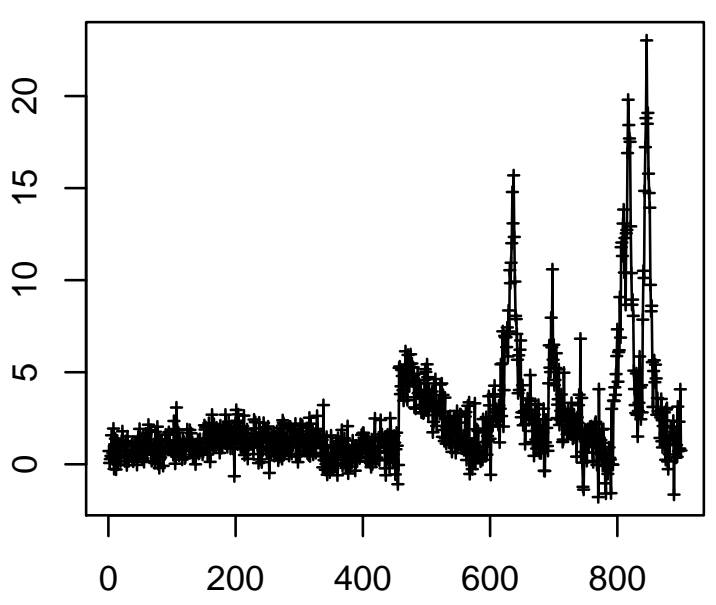

Time Point $(0.25 \mathrm{~Hz})$
Cell 1958

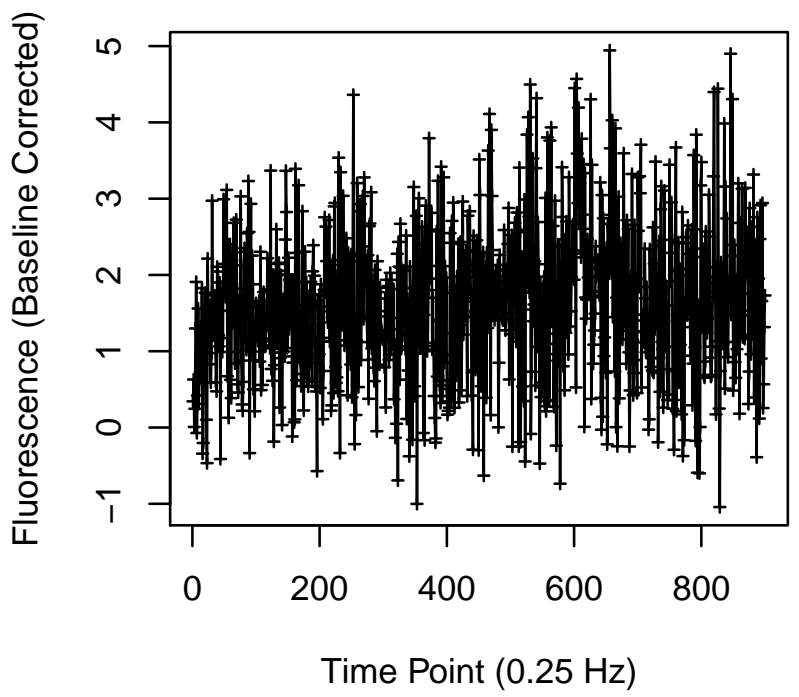

Cell 1960

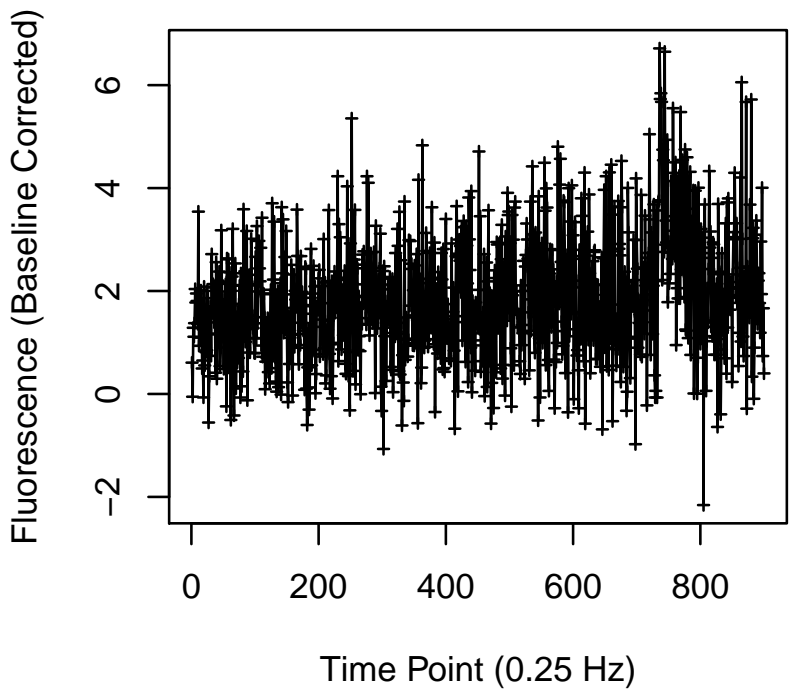


Cell 1973

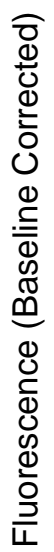

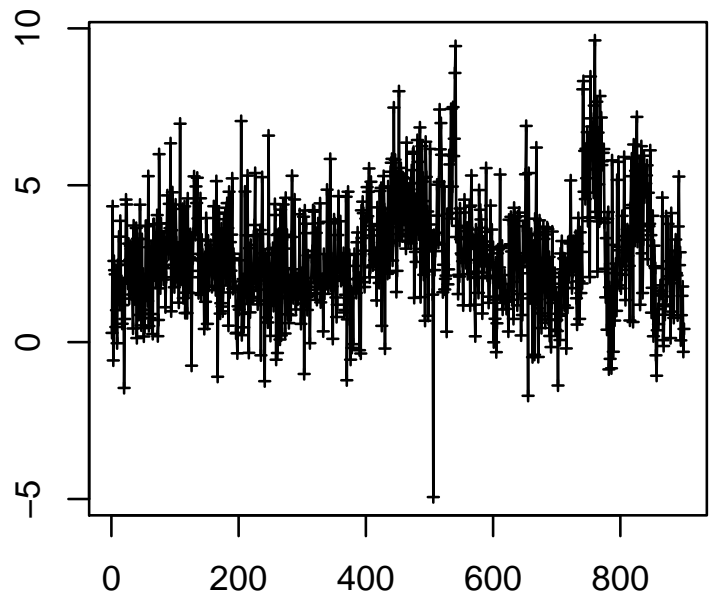

Time Point $(0.25 \mathrm{~Hz})$

Cell 1975

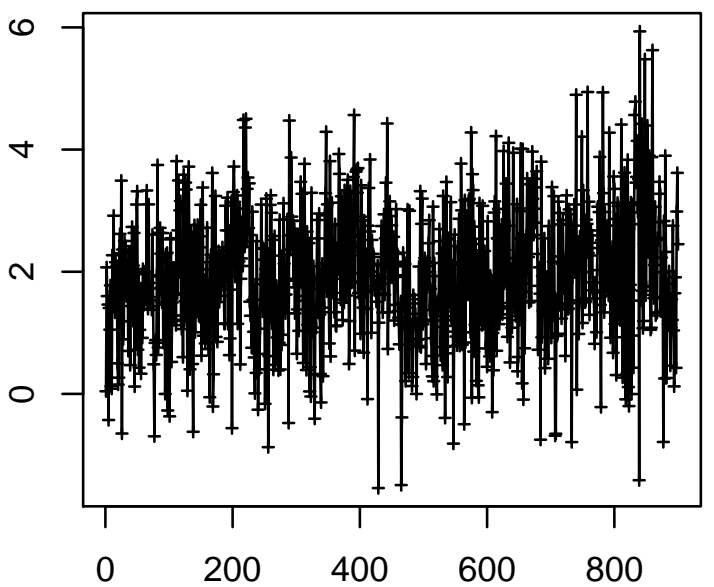

Time Point $(0.25 \mathrm{~Hz})$
Cell 1974

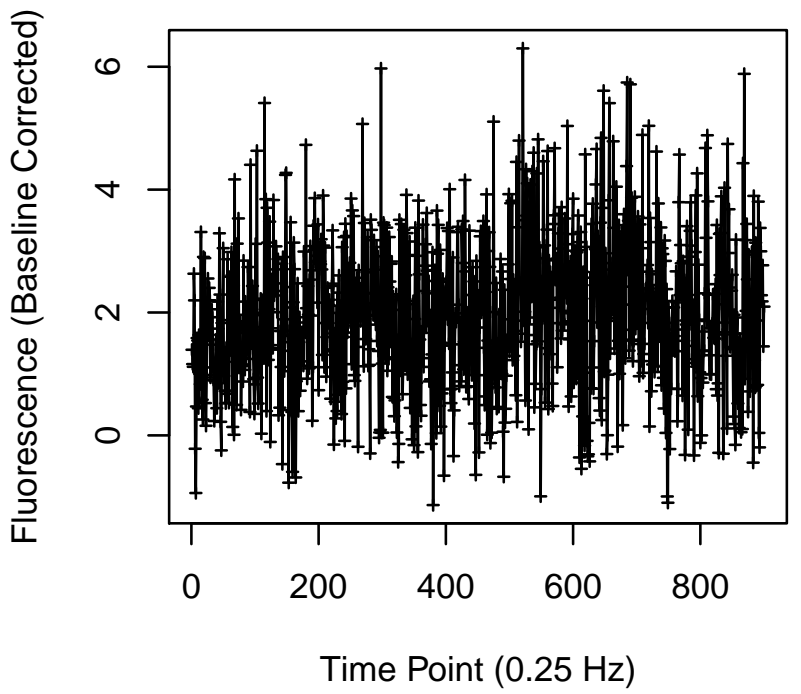

Cell 1976

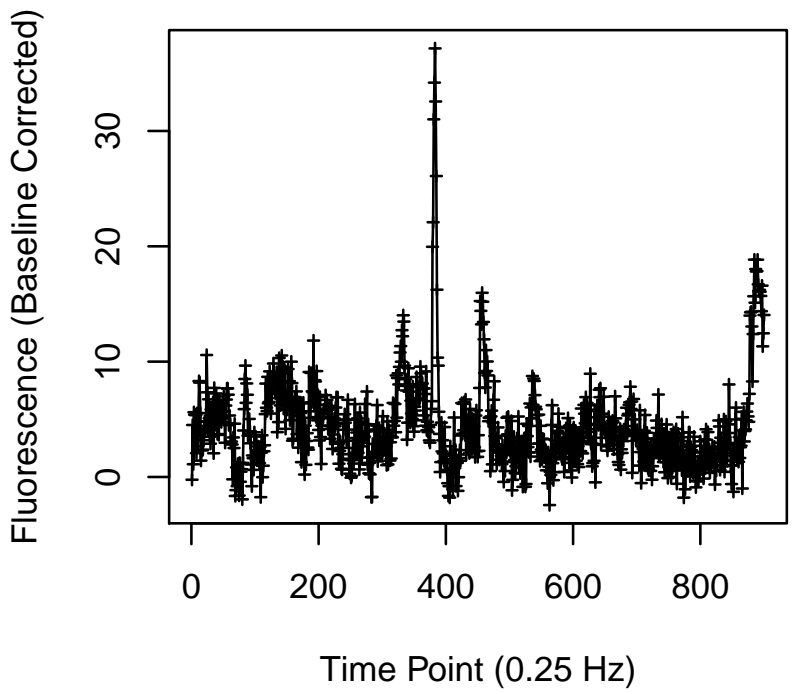


Cell 1981

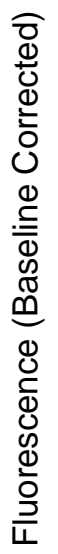

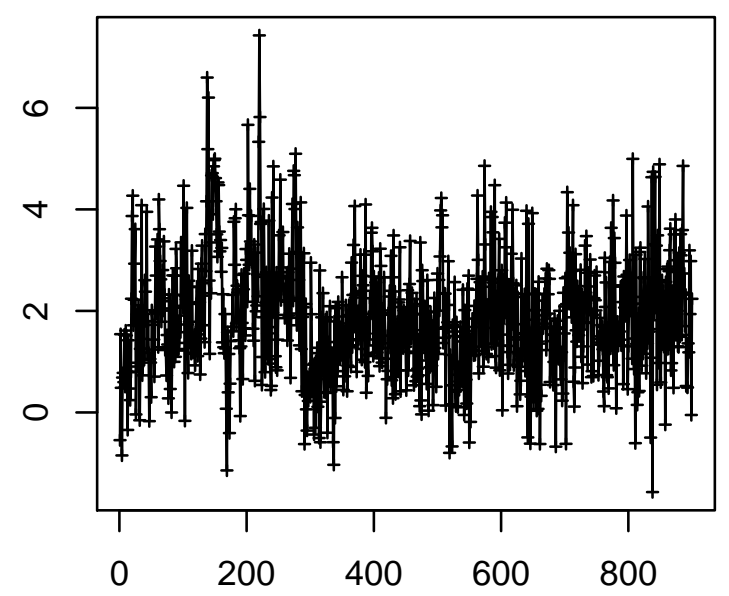

Time Point $(0.25 \mathrm{~Hz})$

Cell 1983

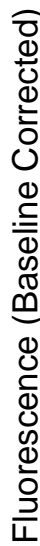

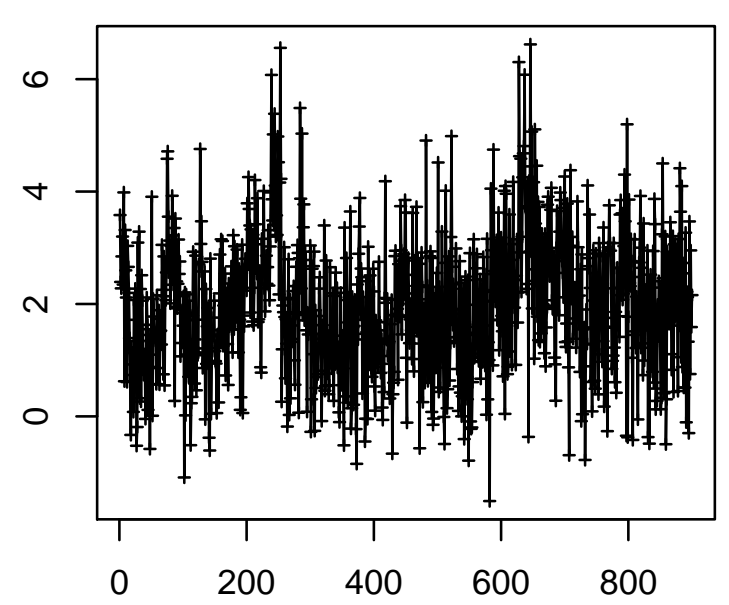

Time Point $(0.25 \mathrm{~Hz})$
Cell 1982

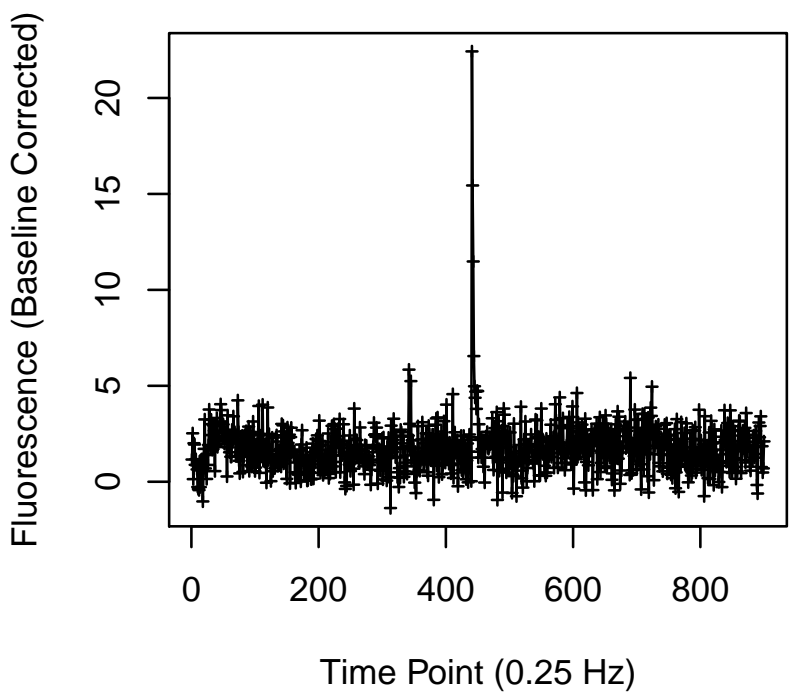

Cell 1984

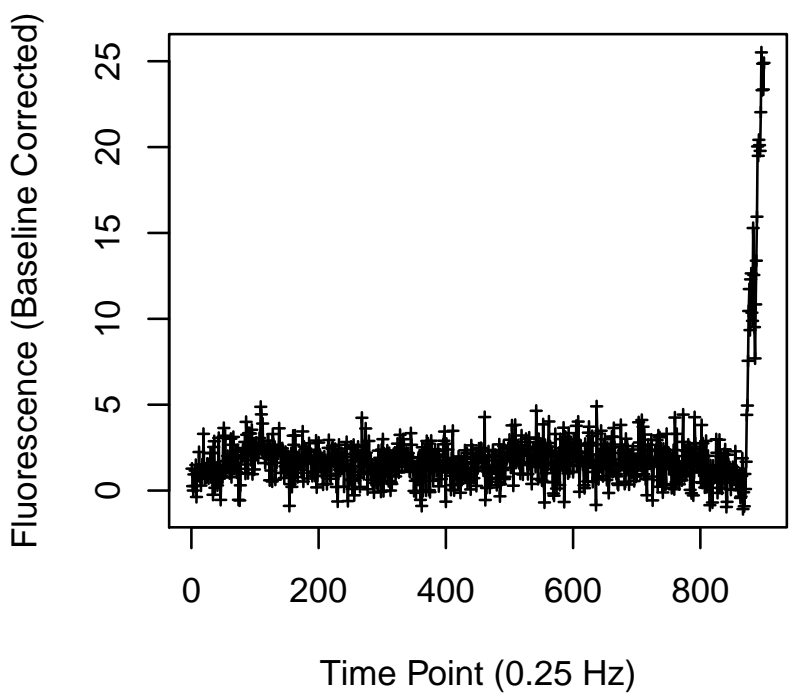


Cell 1985

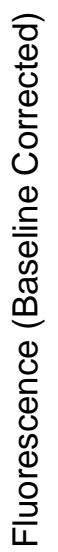

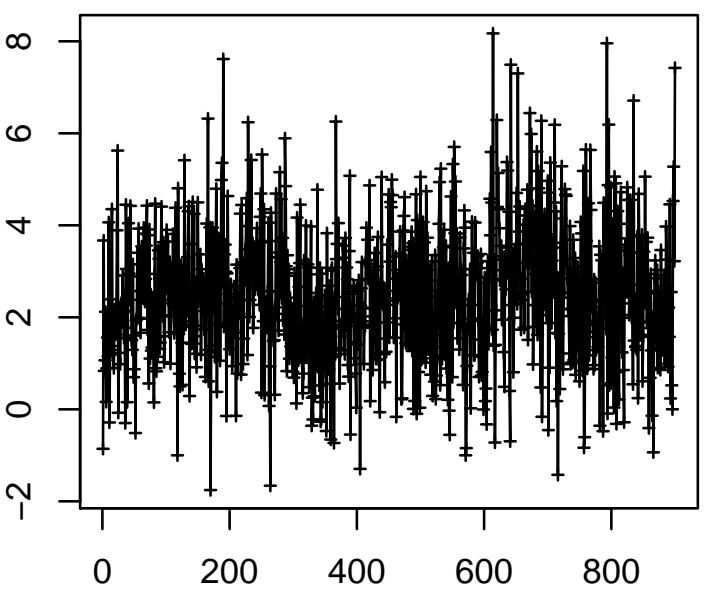

Time Point $(0.25 \mathrm{~Hz})$

Cell 1987

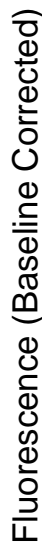

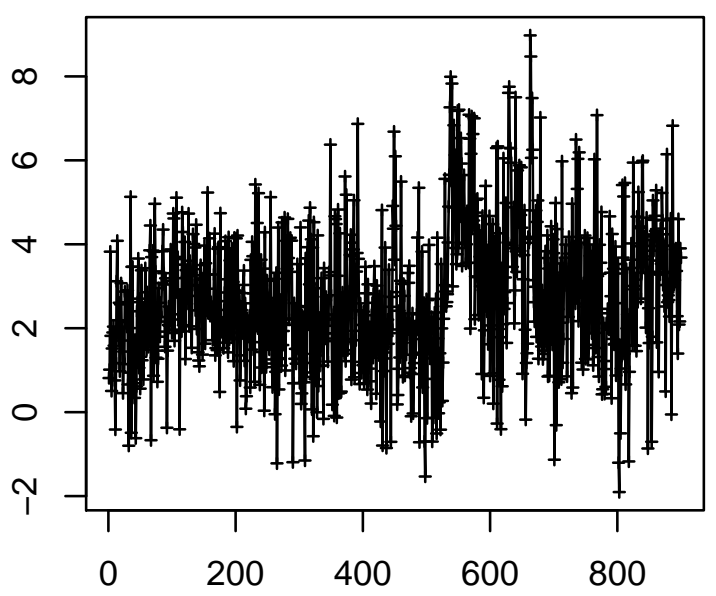

Time Point $(0.25 \mathrm{~Hz})$
Cell 1986

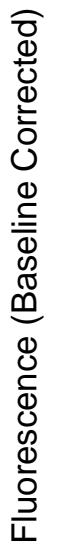

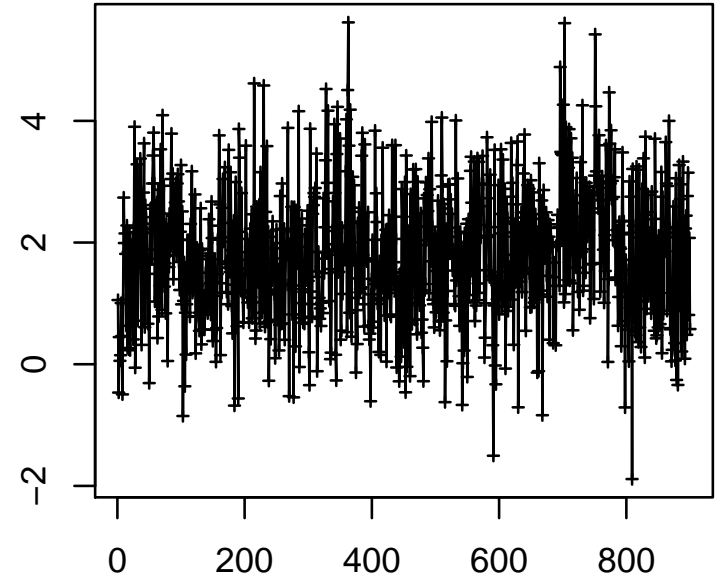

Time Point $(0.25 \mathrm{~Hz})$

Cell 1988

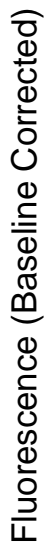

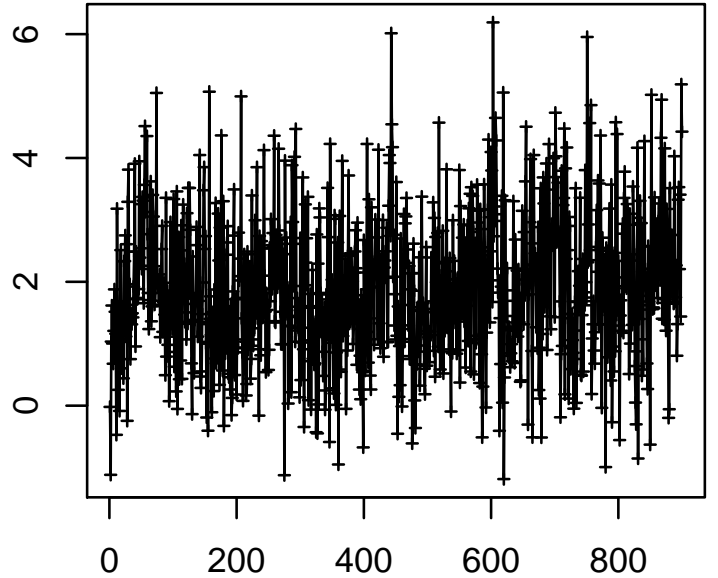

Time Point $(0.25 \mathrm{~Hz})$ 
Cell 1989

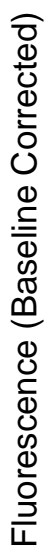

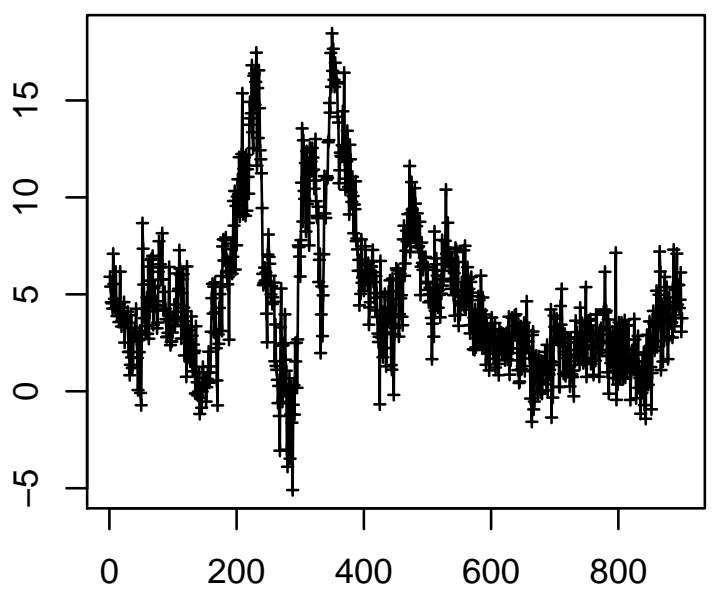

Time Point $(0.25 \mathrm{~Hz})$

Cell 1991

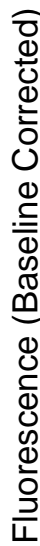

Cell 1990

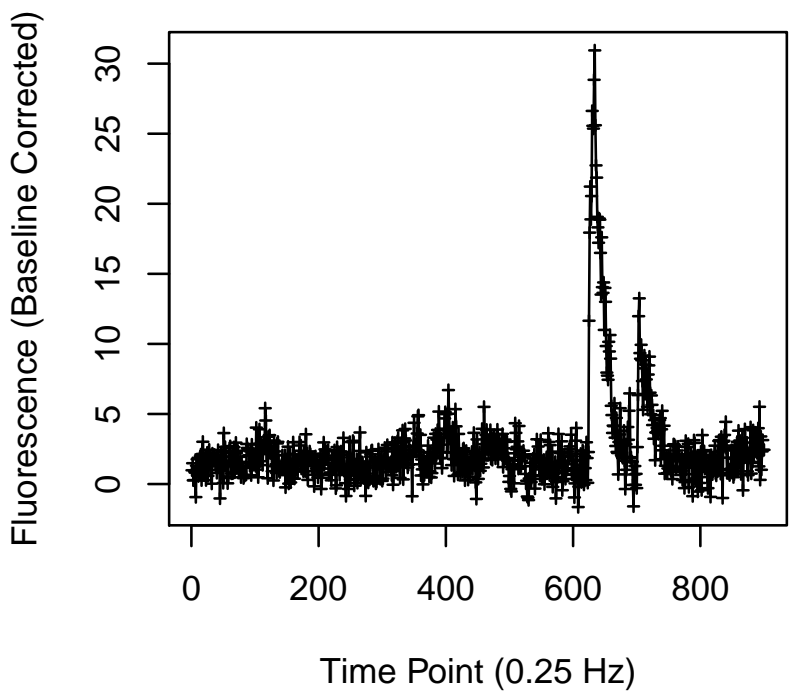

Cell 1992

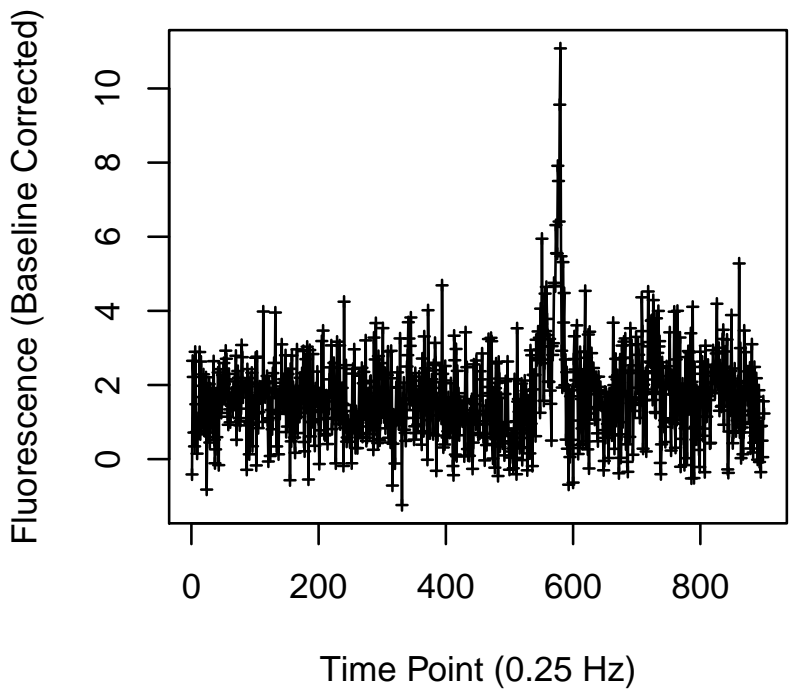


Cell 1993

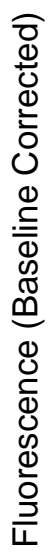

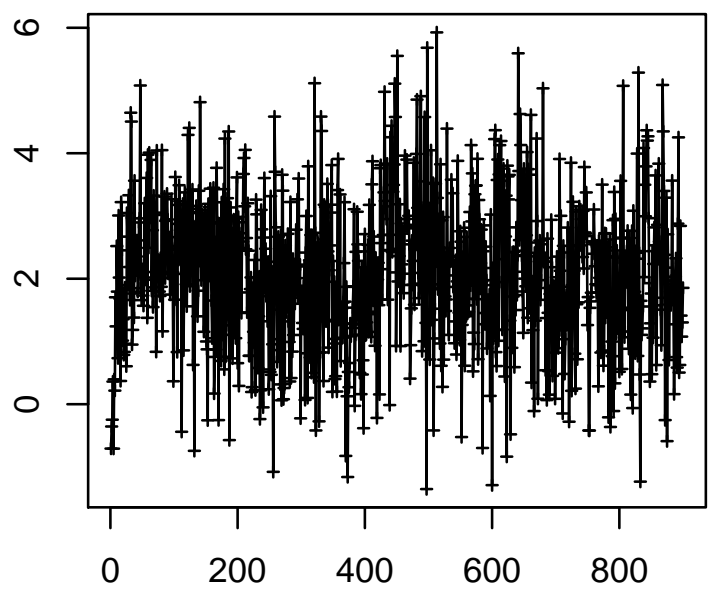

Time Point $(0.25 \mathrm{~Hz})$

Cell 1995

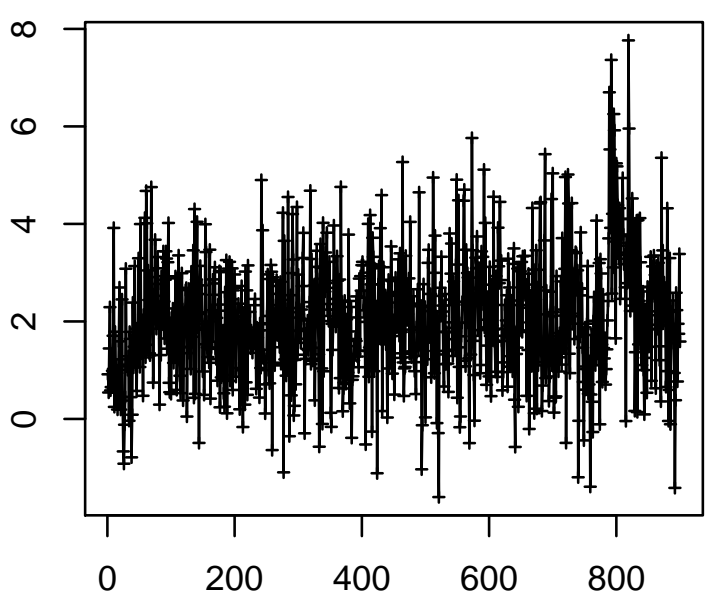

Time Point $(0.25 \mathrm{~Hz})$
Cell 1994

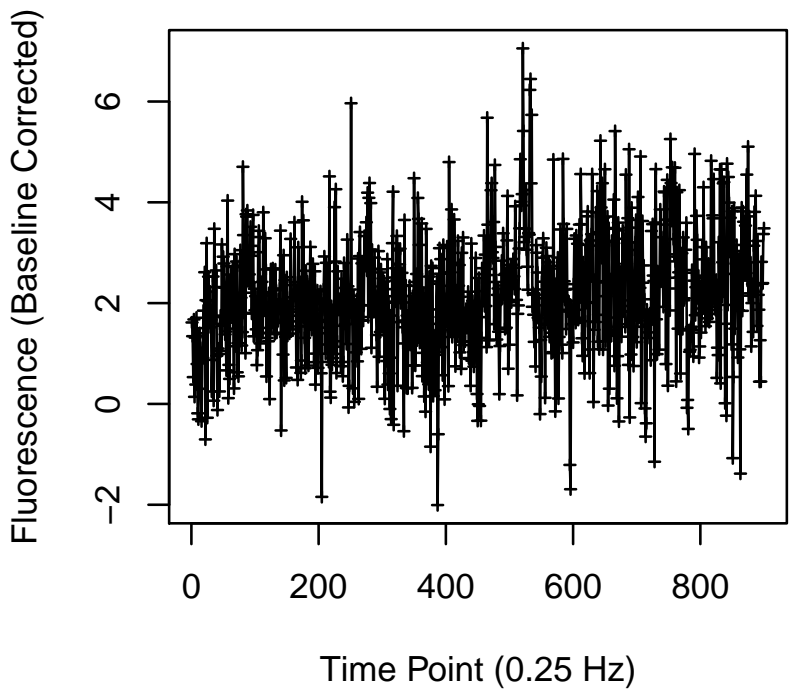

Cell 1996

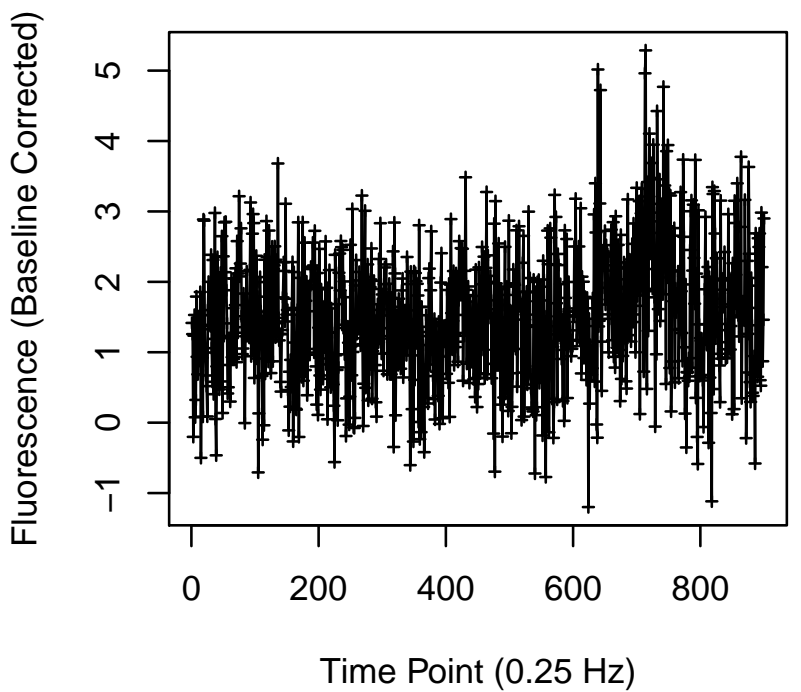


Cell 2005

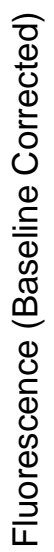

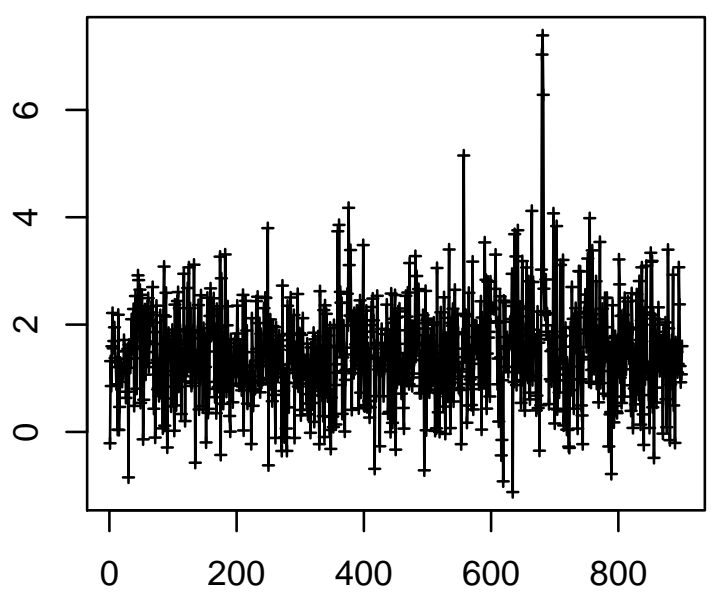

Time Point $(0.25 \mathrm{~Hz})$

Cell 2007

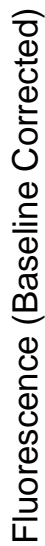

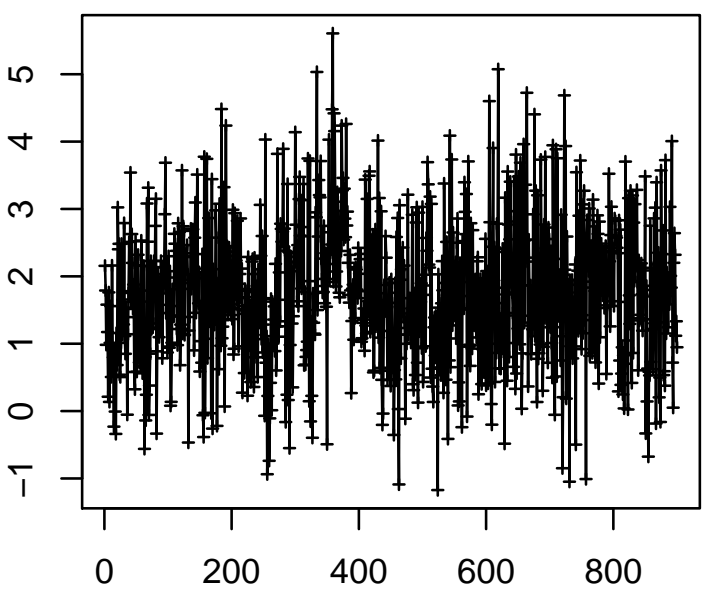

Time Point $(0.25 \mathrm{~Hz})$
Cell 2006

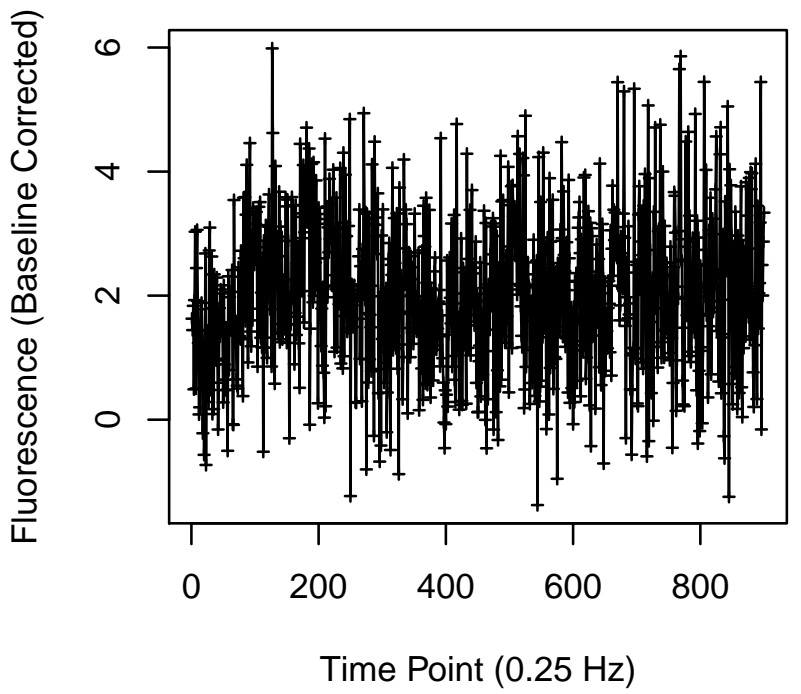

Cell 2008

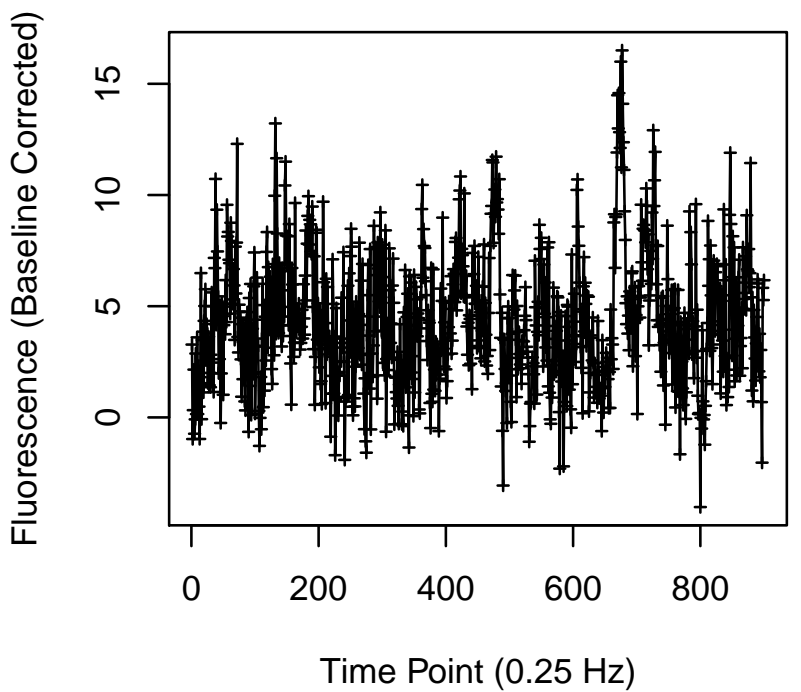


Cell 2009

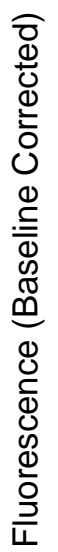

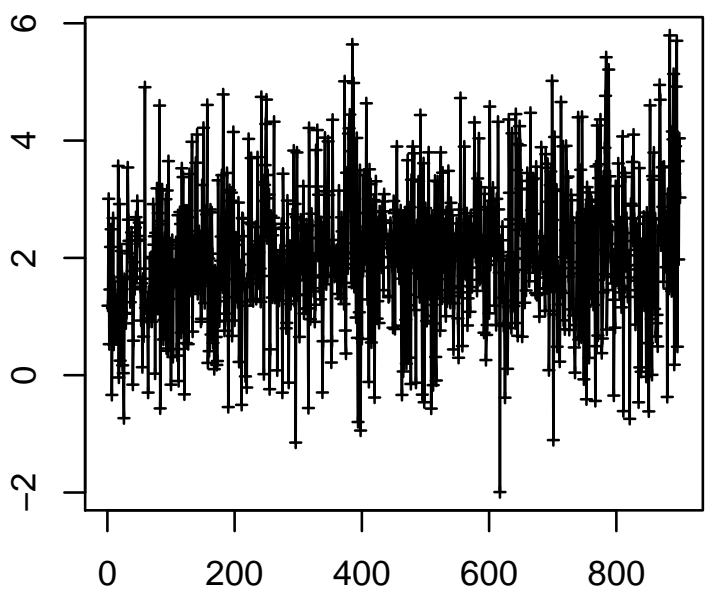

Time Point $(0.25 \mathrm{~Hz})$

Cell 2011

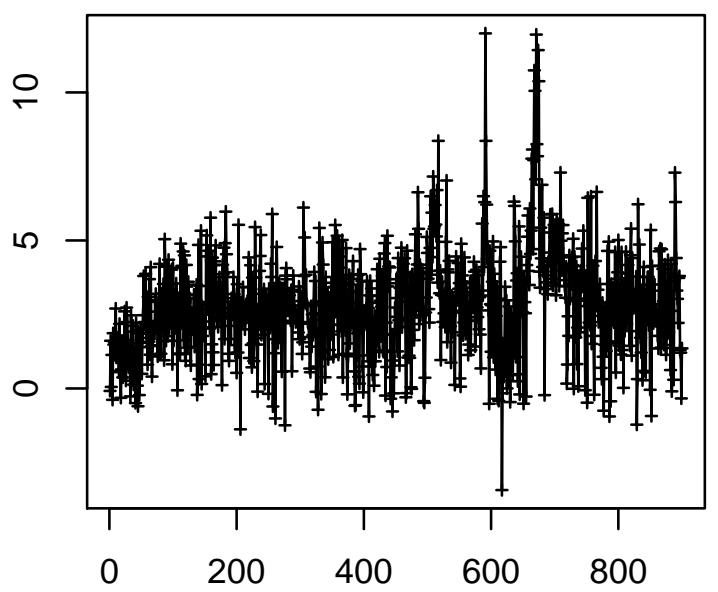

Time Point $(0.25 \mathrm{~Hz})$
Cell 2010

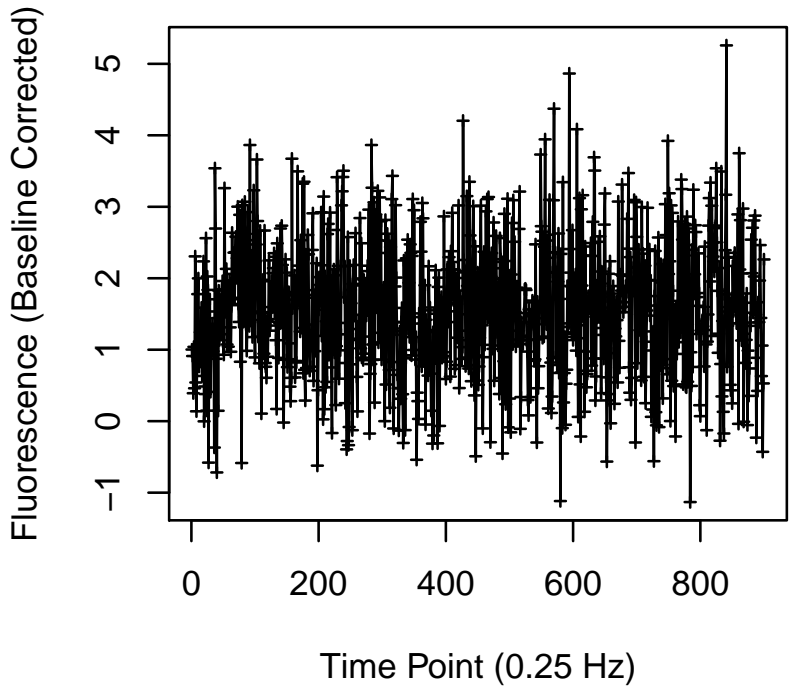

Cell 2012

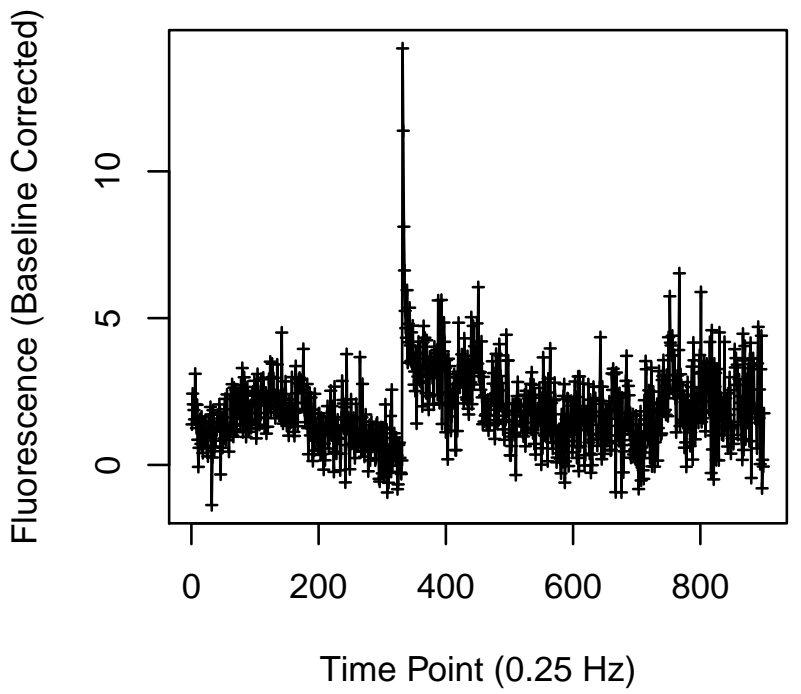


Cell 2013

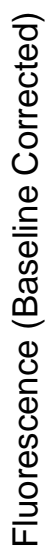

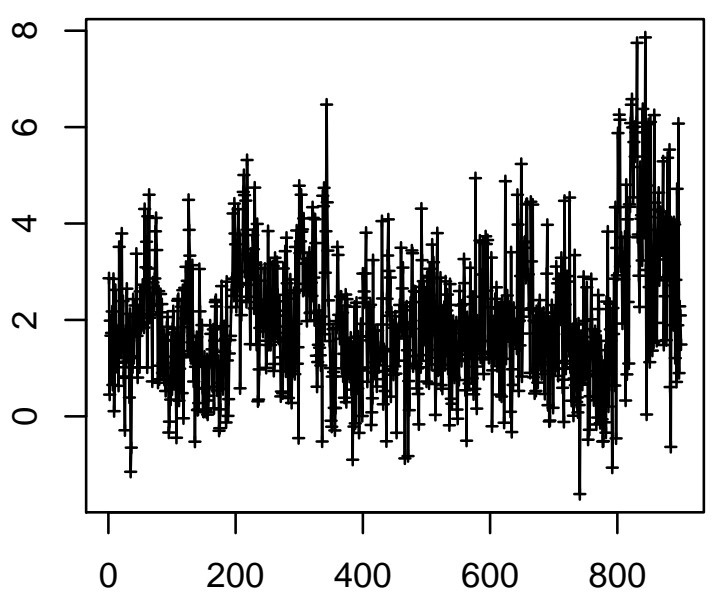

Time Point $(0.25 \mathrm{~Hz})$

Cell 2015

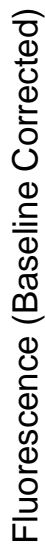

Cell 2014

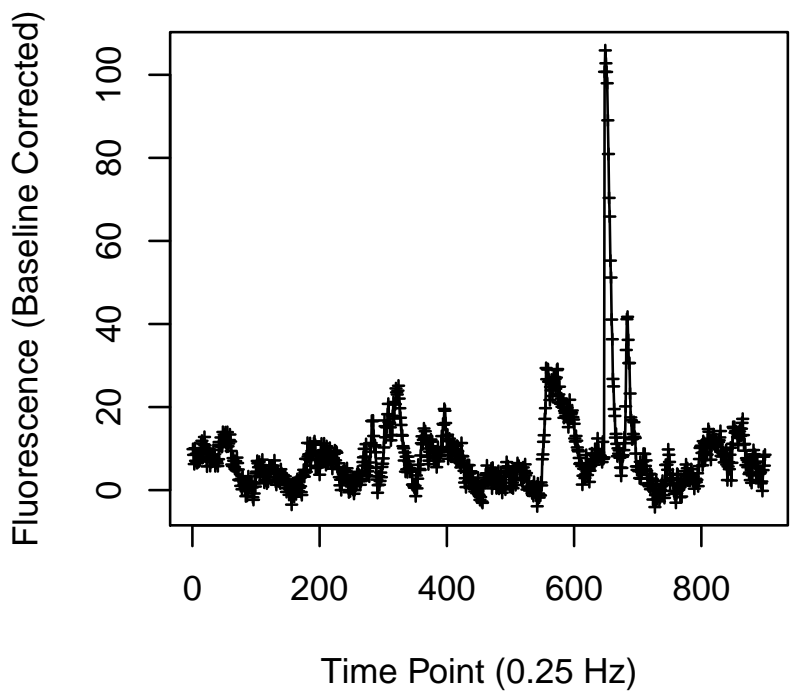

Cell 2016

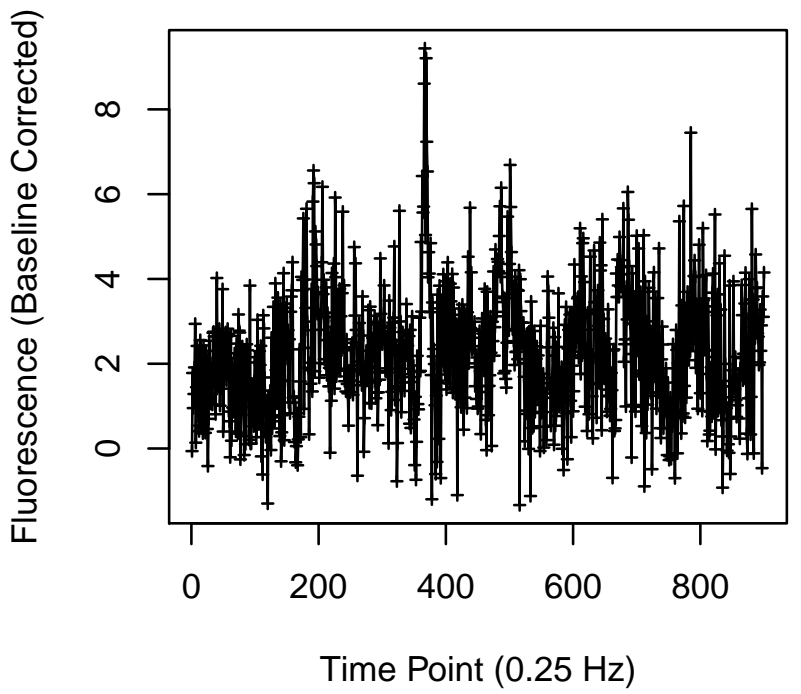


Cell 2021

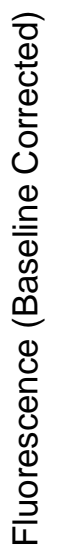

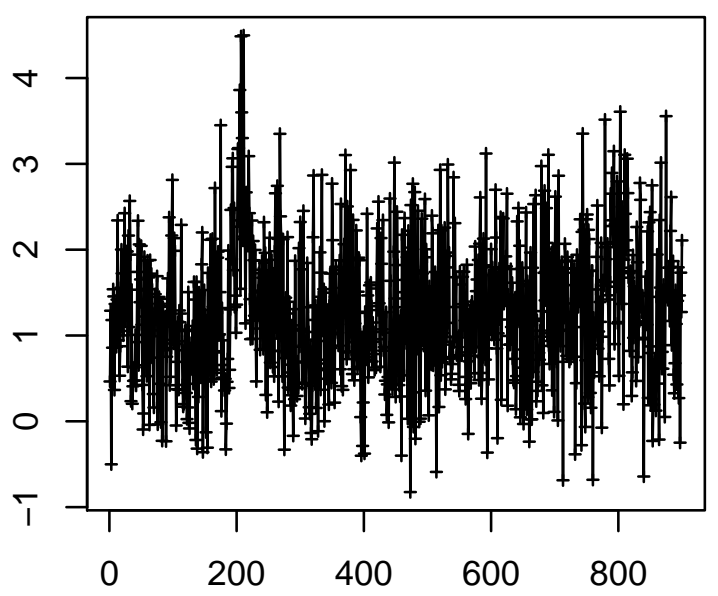

Time Point $(0.25 \mathrm{~Hz})$

Cell 2023

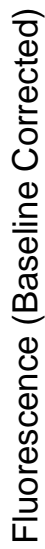

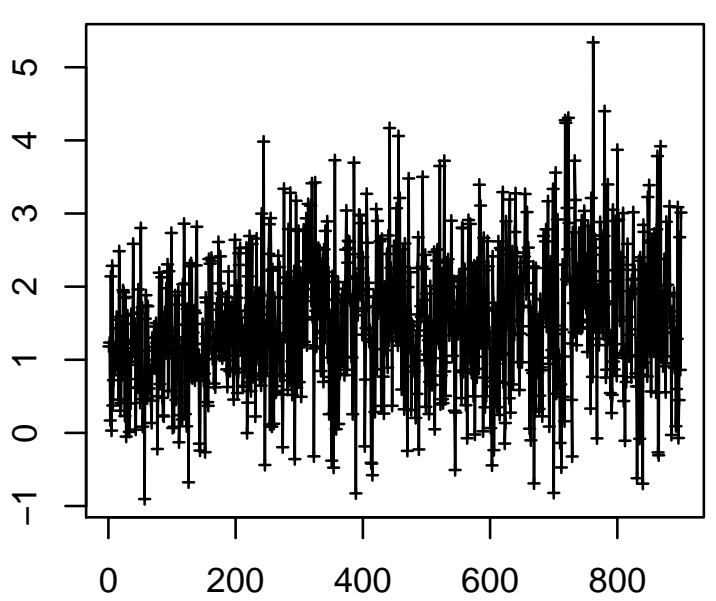

Time Point $(0.25 \mathrm{~Hz})$
Cell 2022

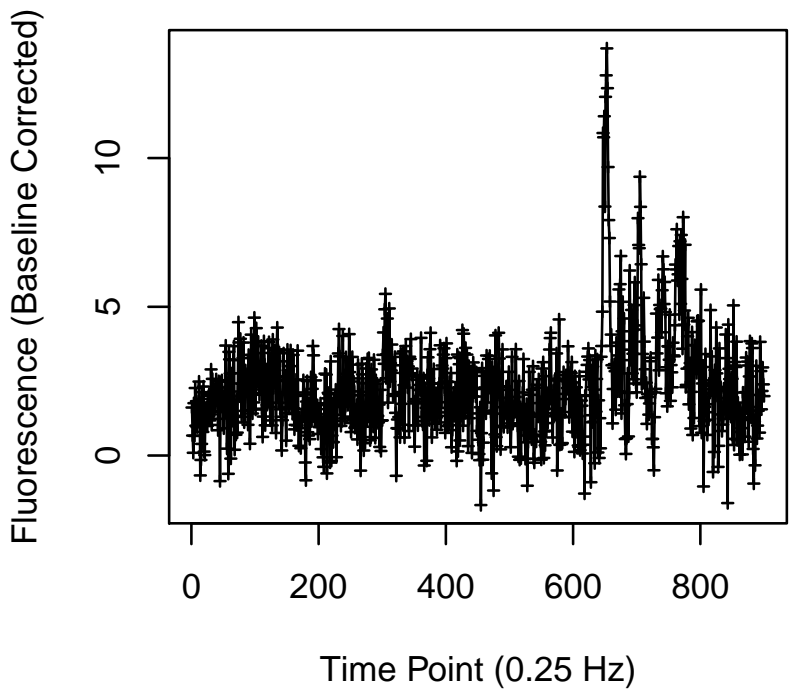

Cell 2024

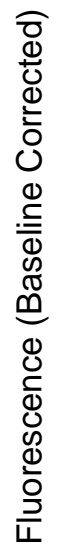

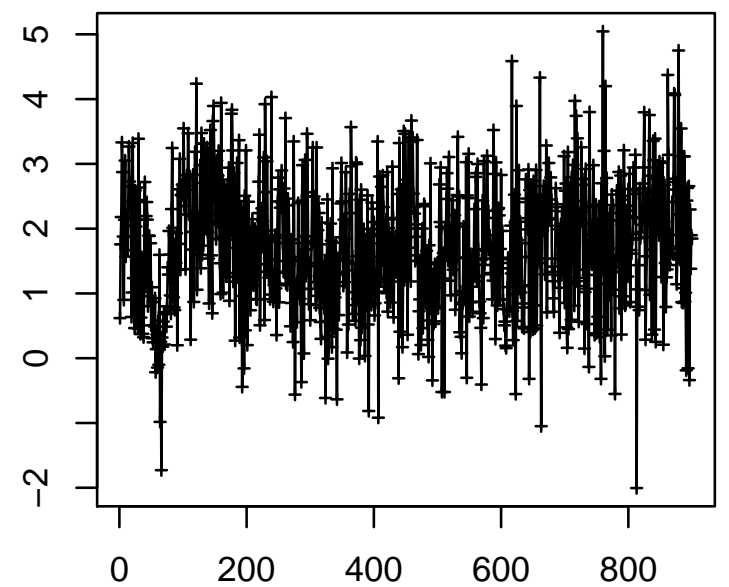

Time Point $(0.25 \mathrm{~Hz})$ 
Cell 2025

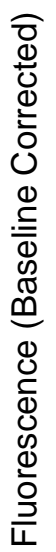

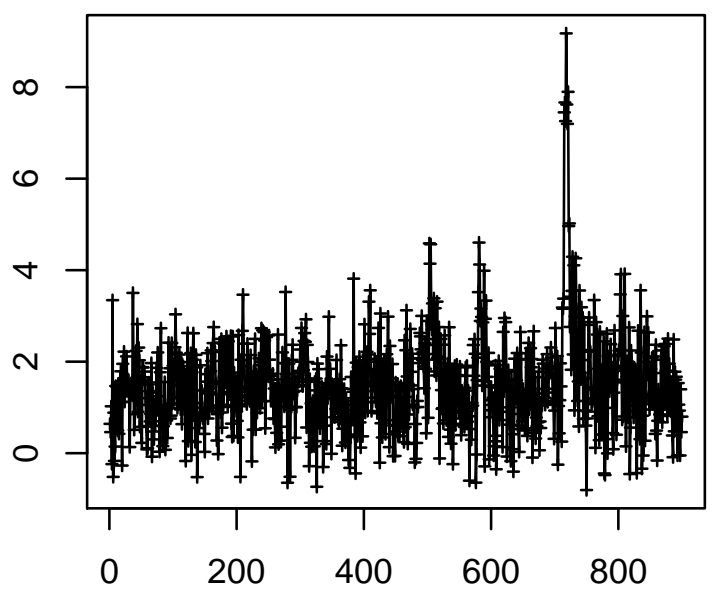

Time Point $(0.25 \mathrm{~Hz})$

Cell 2027

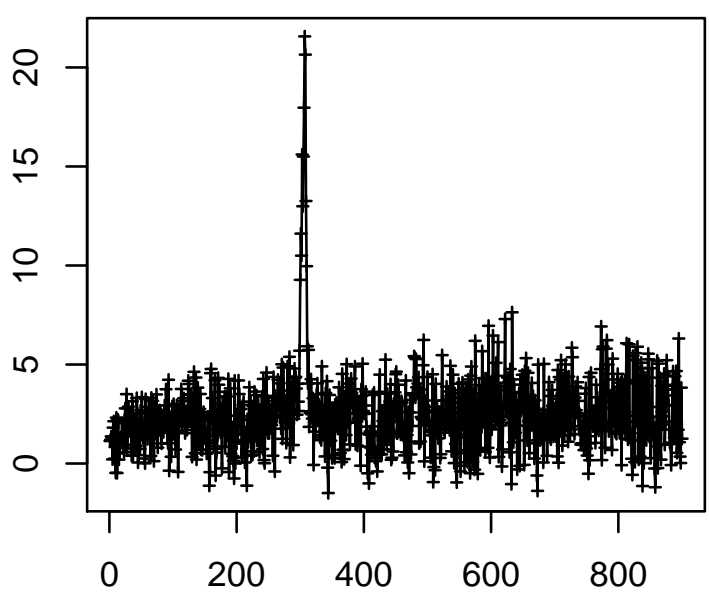

Time Point $(0.25 \mathrm{~Hz})$
Cell 2026

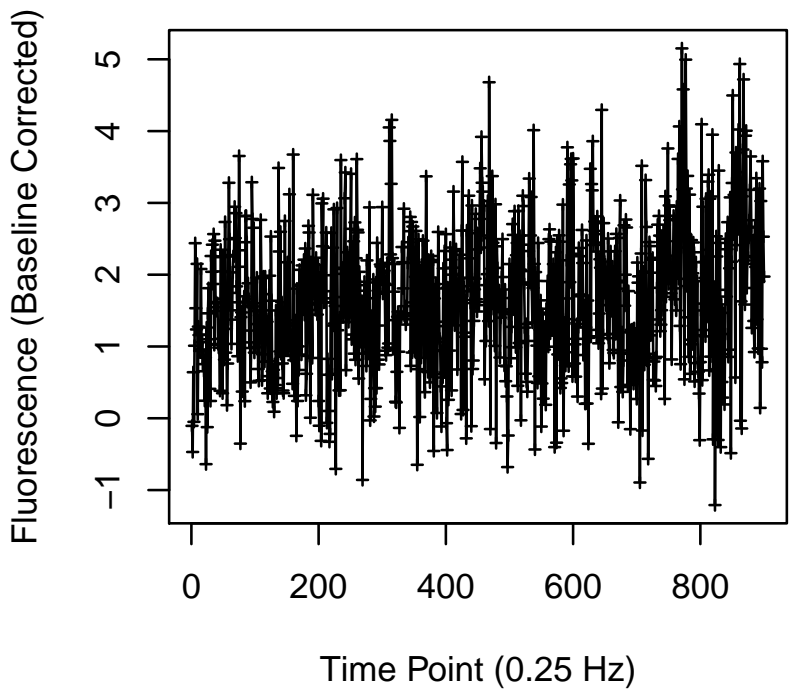

Cell 2028

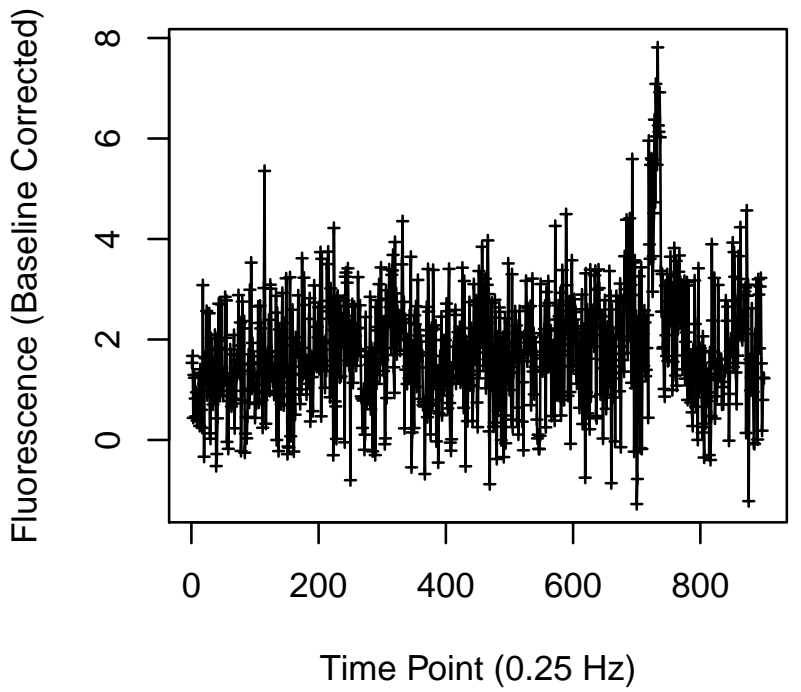


Cell 2033

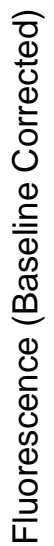

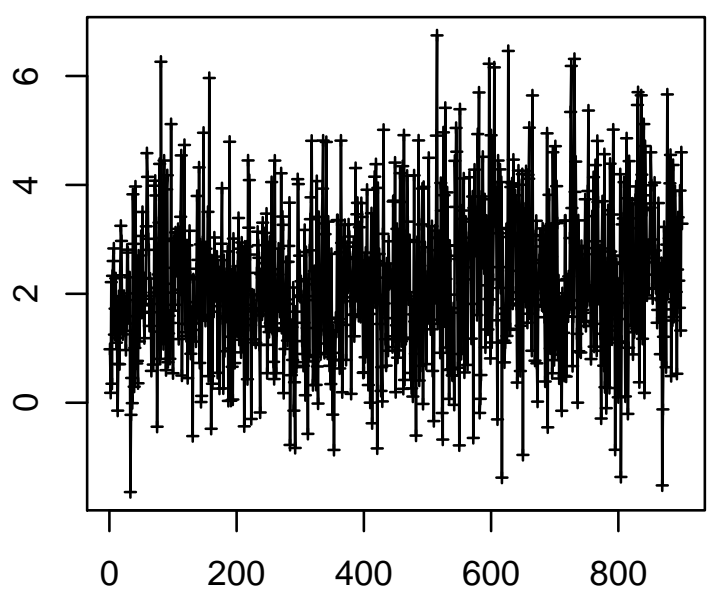

Time Point $(0.25 \mathrm{~Hz})$

Cell 2035

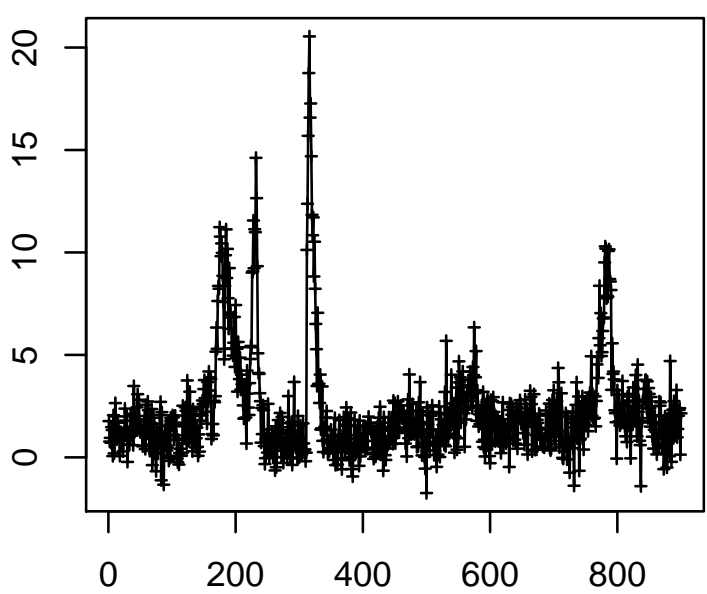

Time Point $(0.25 \mathrm{~Hz})$
Cell 2034

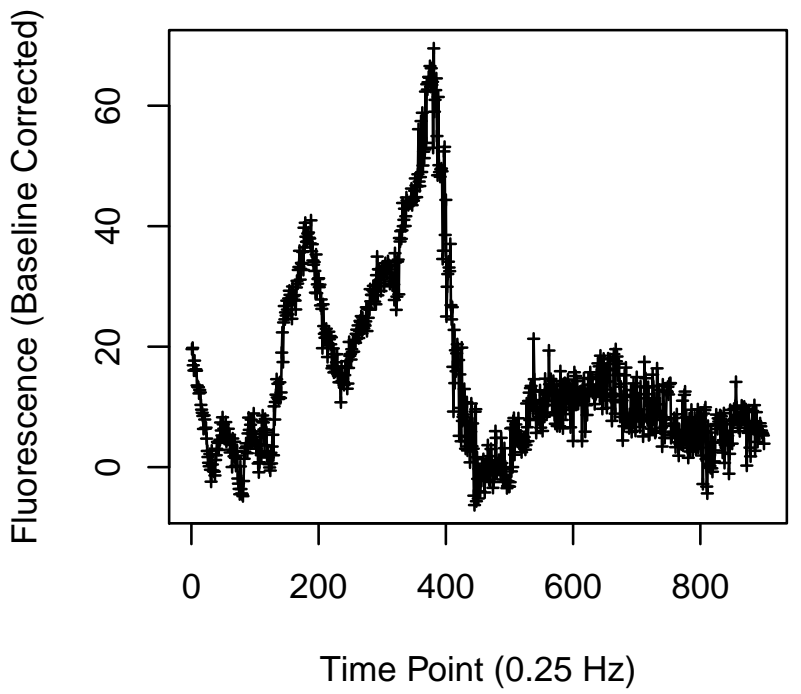

Cell 2036

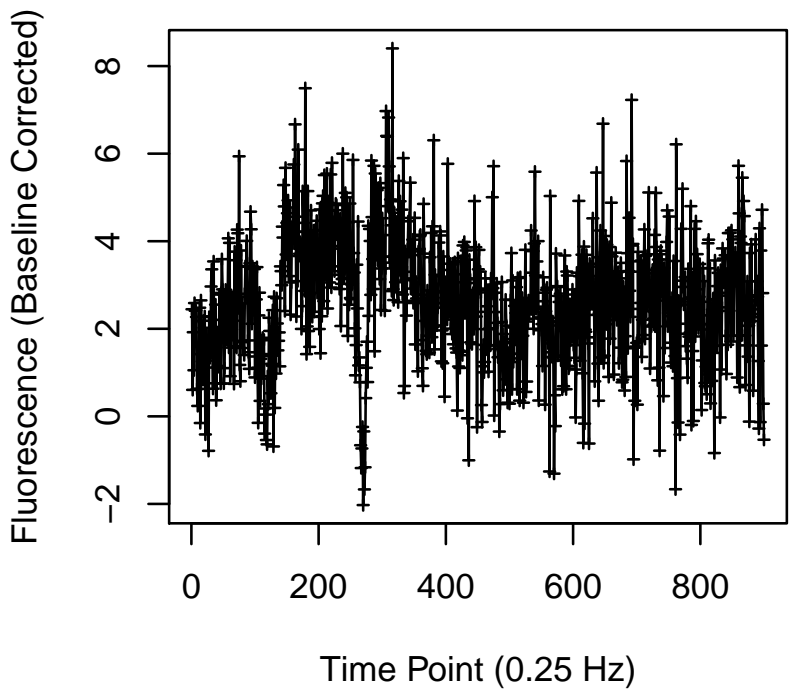


Cell 2037

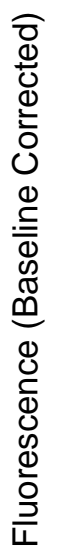

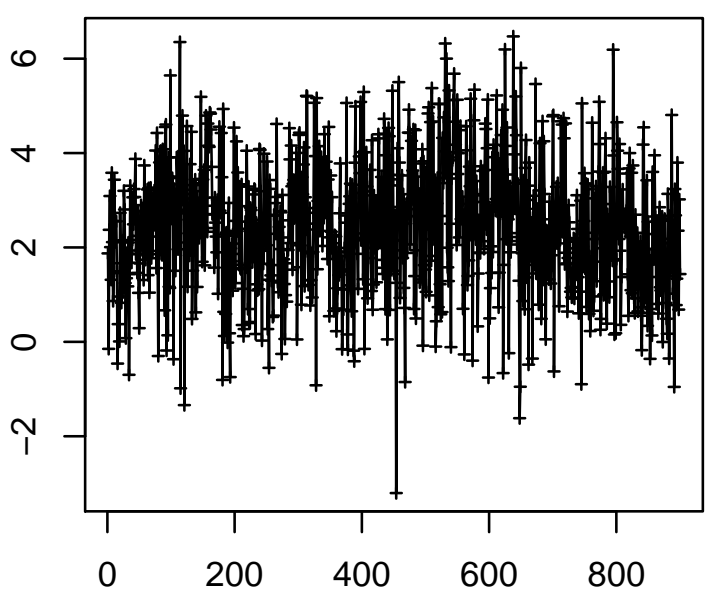

Time Point $(0.25 \mathrm{~Hz})$

Cell 2039

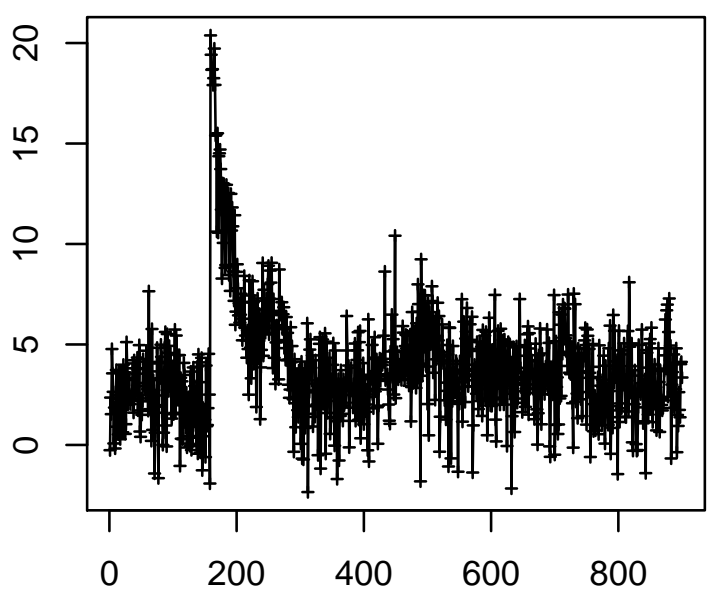

Time Point $(0.25 \mathrm{~Hz})$
Cell 2038

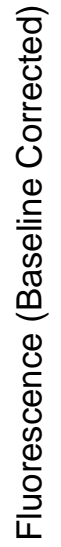

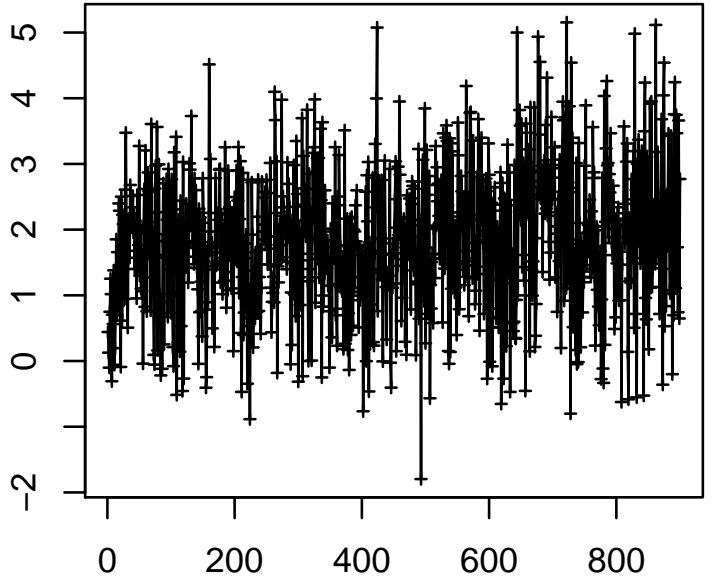

Time Point $(0.25 \mathrm{~Hz})$

Cell 2040

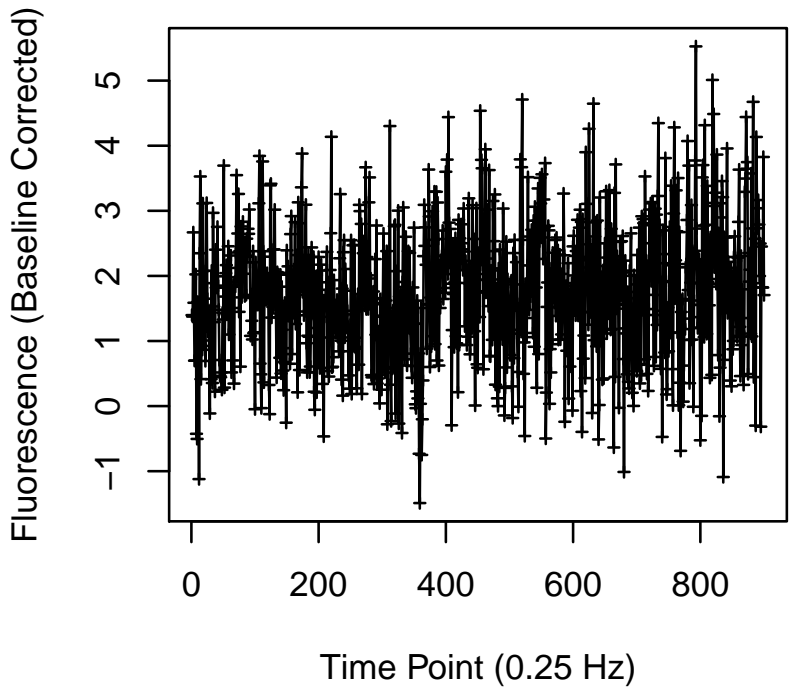


Cell 2049

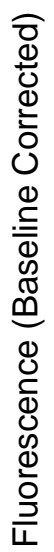

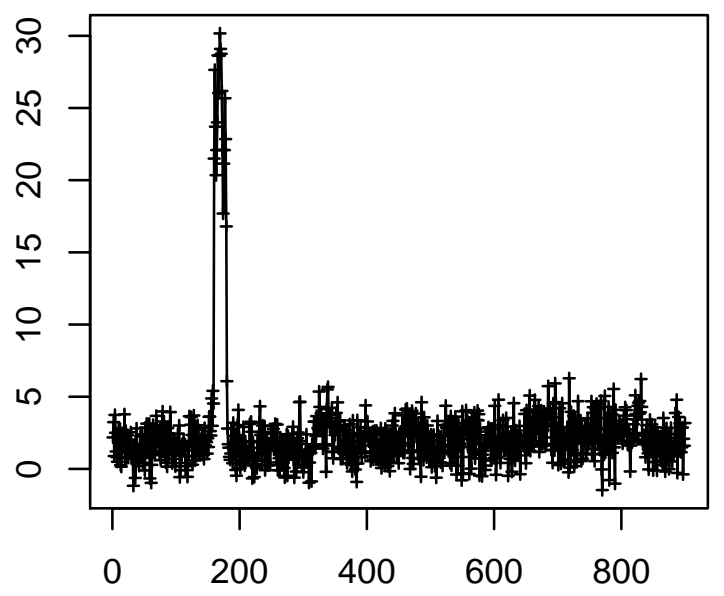

Time Point $(0.25 \mathrm{~Hz})$

Cell 2051

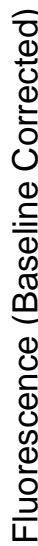

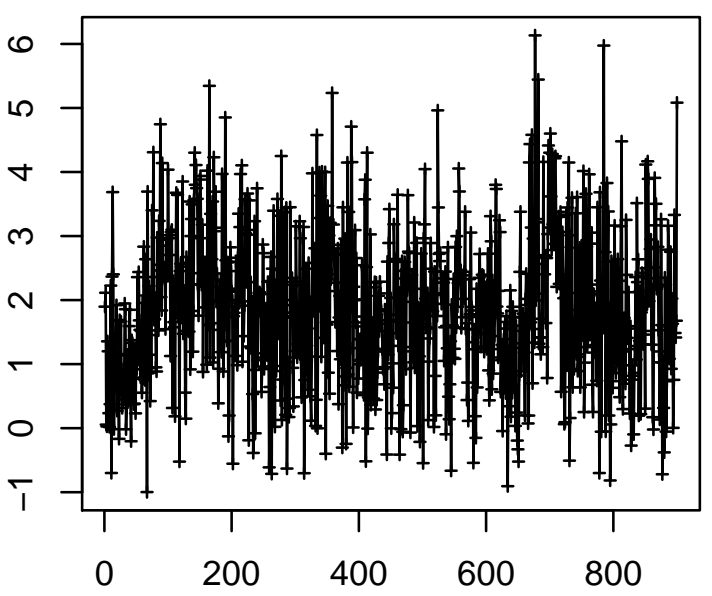

Time Point $(0.25 \mathrm{~Hz})$
Cell 2050

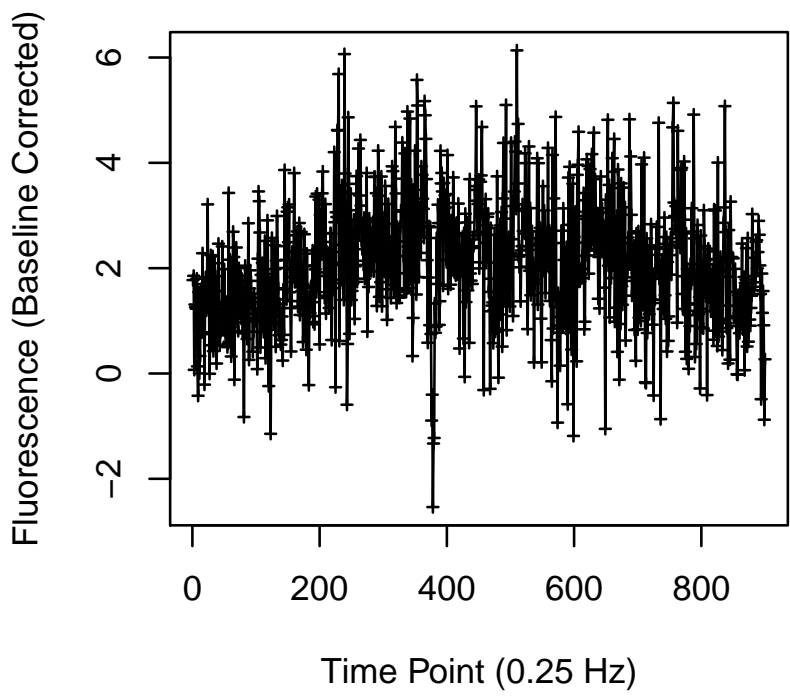

Cell 2052

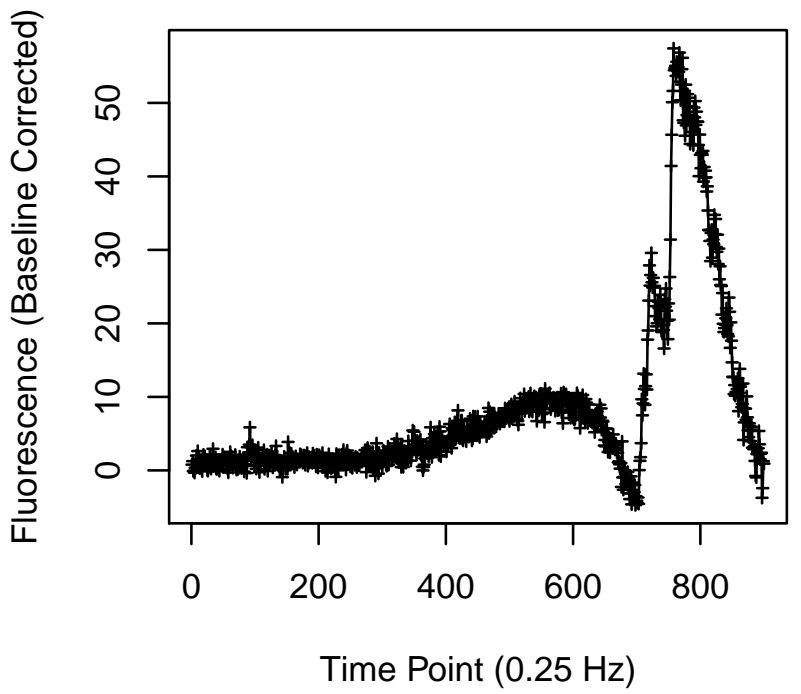


Cell 2053

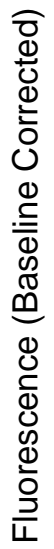

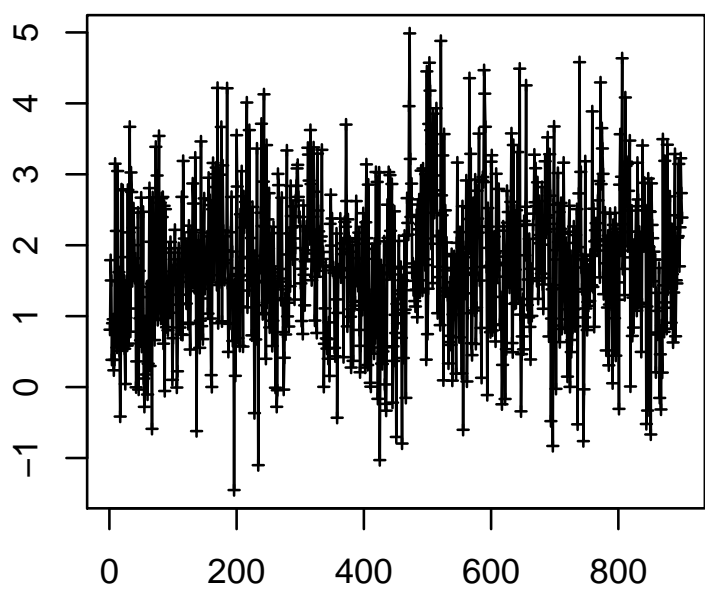

Time Point $(0.25 \mathrm{~Hz})$

Cell 2055

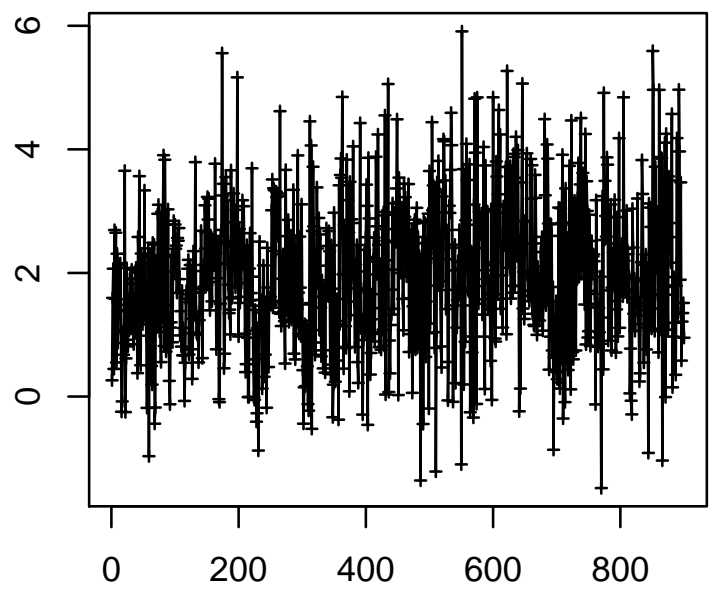

Time Point $(0.25 \mathrm{~Hz})$
Cell 2054

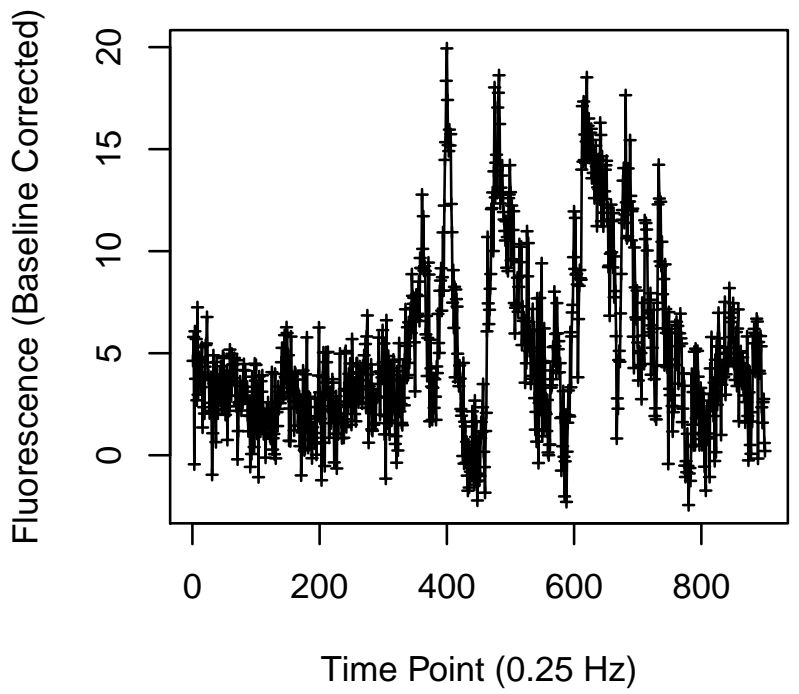

Cell 2056

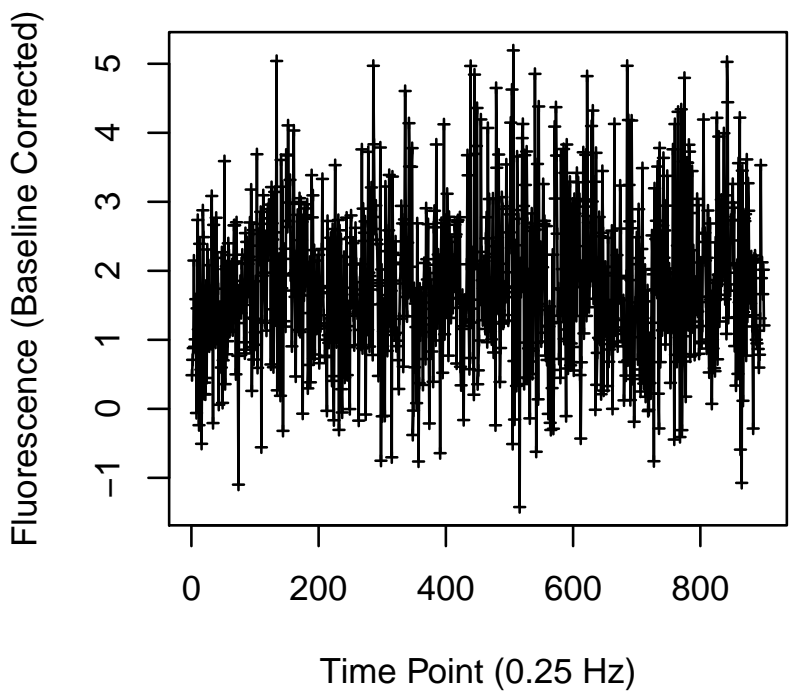


Cell 2057

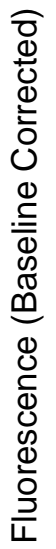

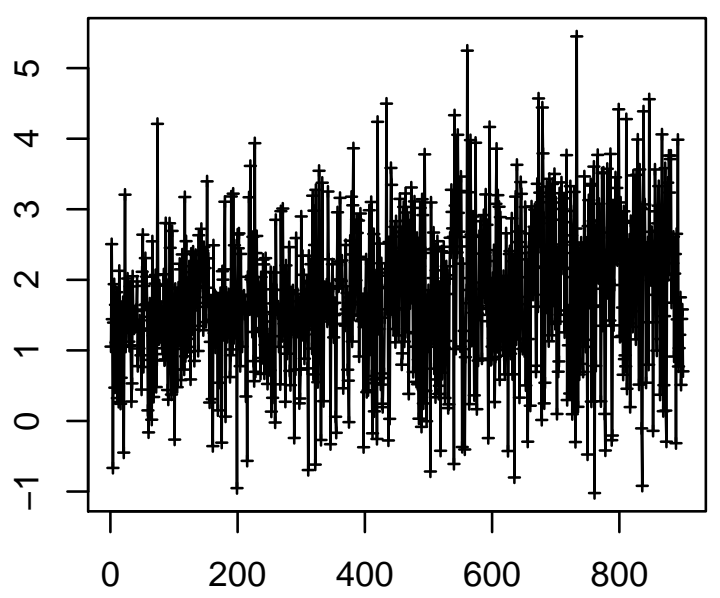

Time Point $(0.25 \mathrm{~Hz})$

Cell 2059

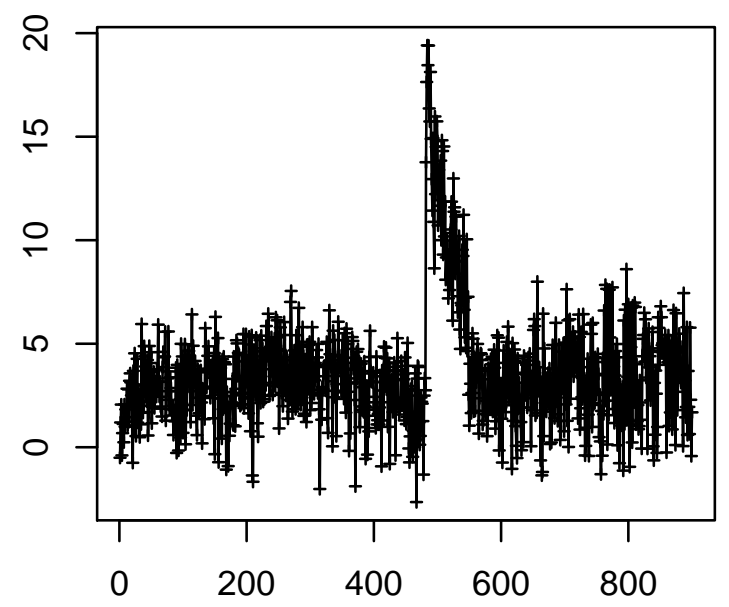

Time Point $(0.25 \mathrm{~Hz})$
Cell 2058

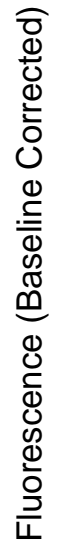

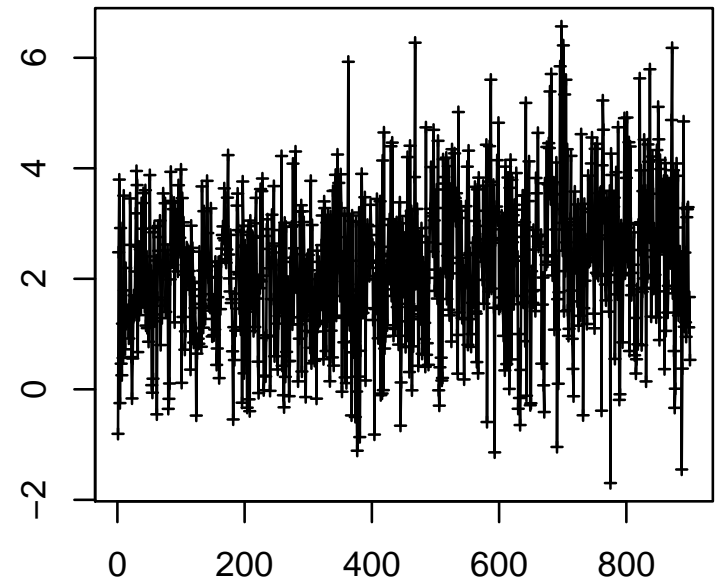

Time Point $(0.25 \mathrm{~Hz})$

Cell 2060

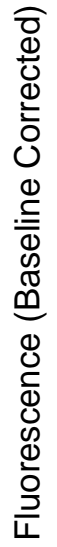

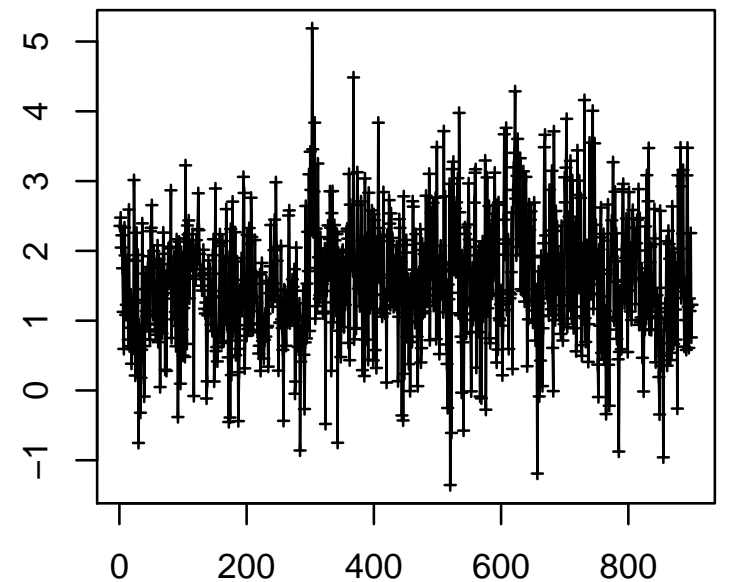

Time Point $(0.25 \mathrm{~Hz})$ 
Cell 2061

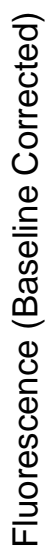

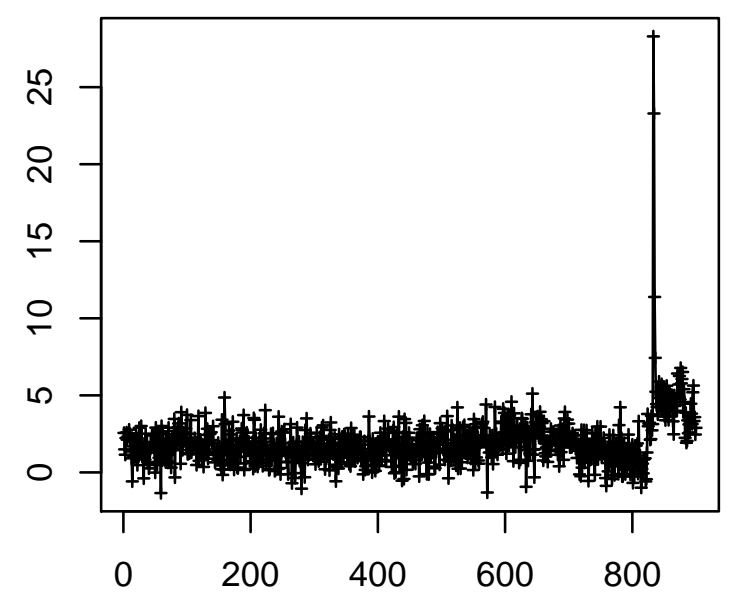

Time Point $(0.25 \mathrm{~Hz})$

Cell 2063

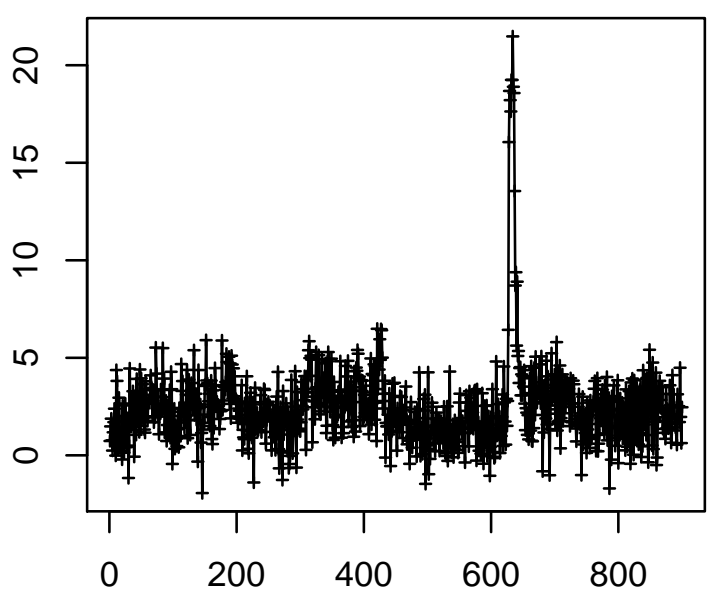

Time Point $(0.25 \mathrm{~Hz})$
Cell 2062

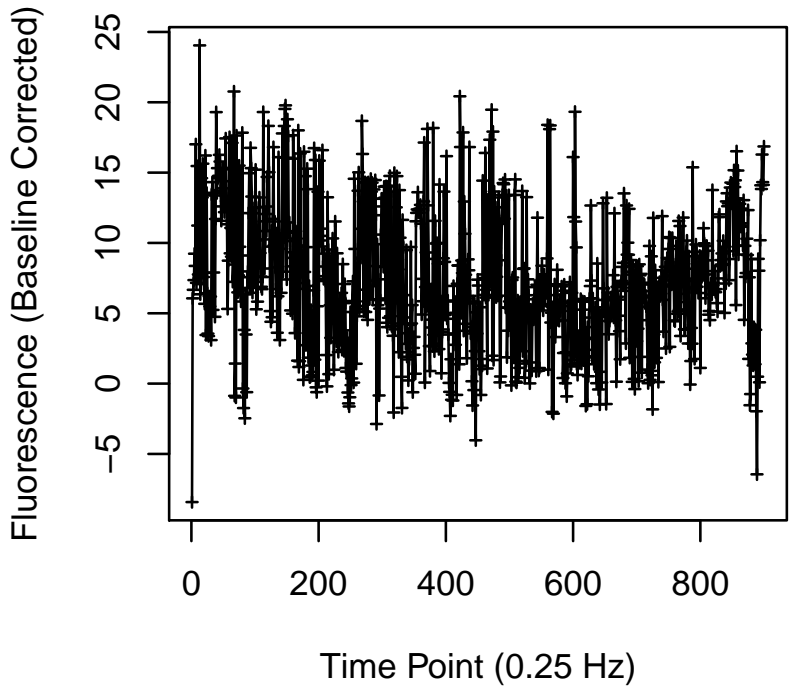

Cell 2064

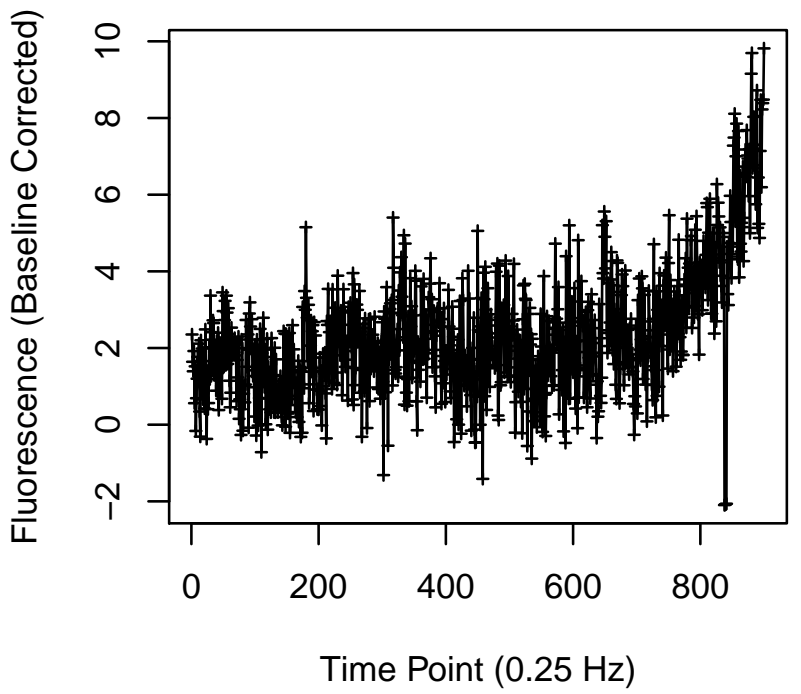


Cell 2069

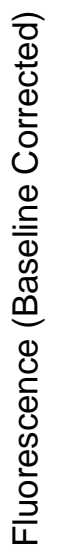

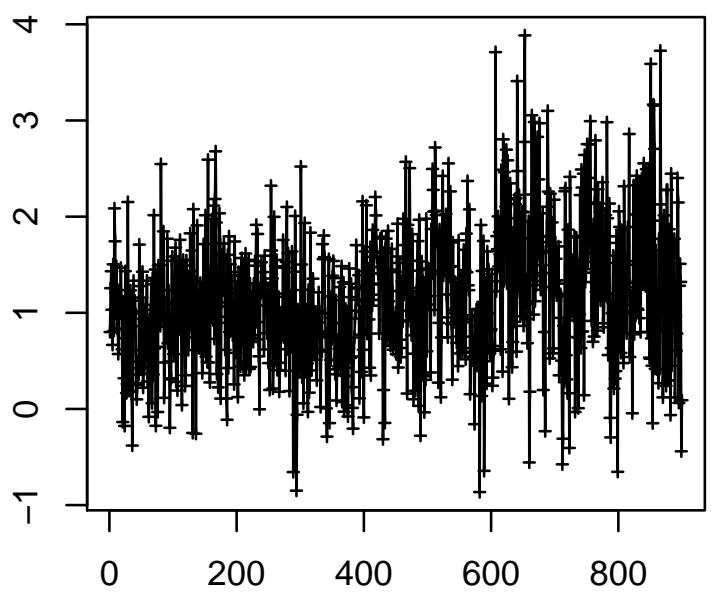

Time Point $(0.25 \mathrm{~Hz})$

Cell 2071

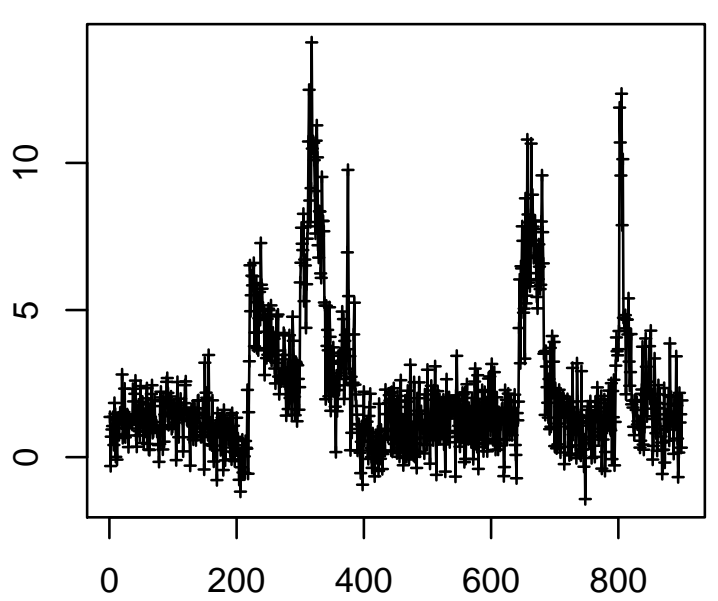

Time Point $(0.25 \mathrm{~Hz})$
Cell 2070

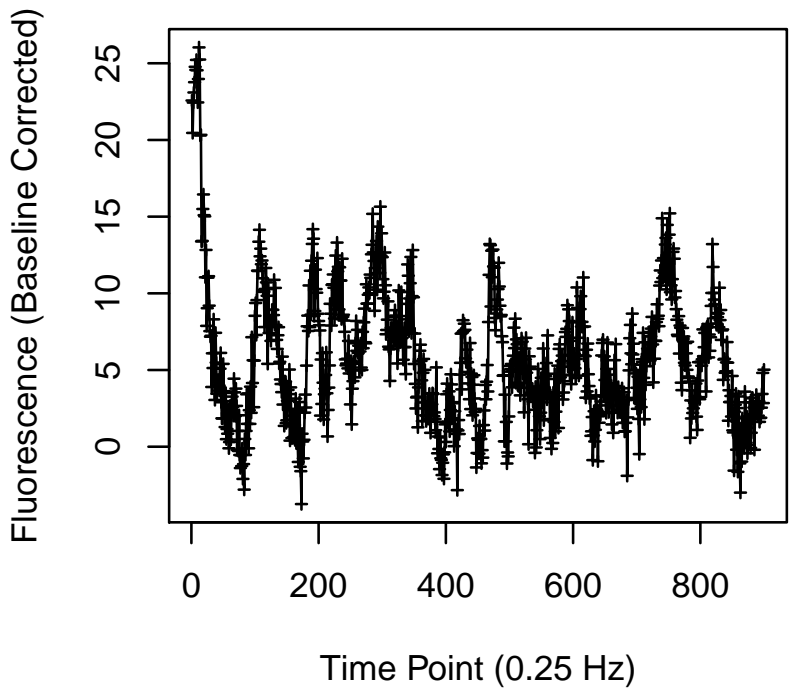

Cell 2072

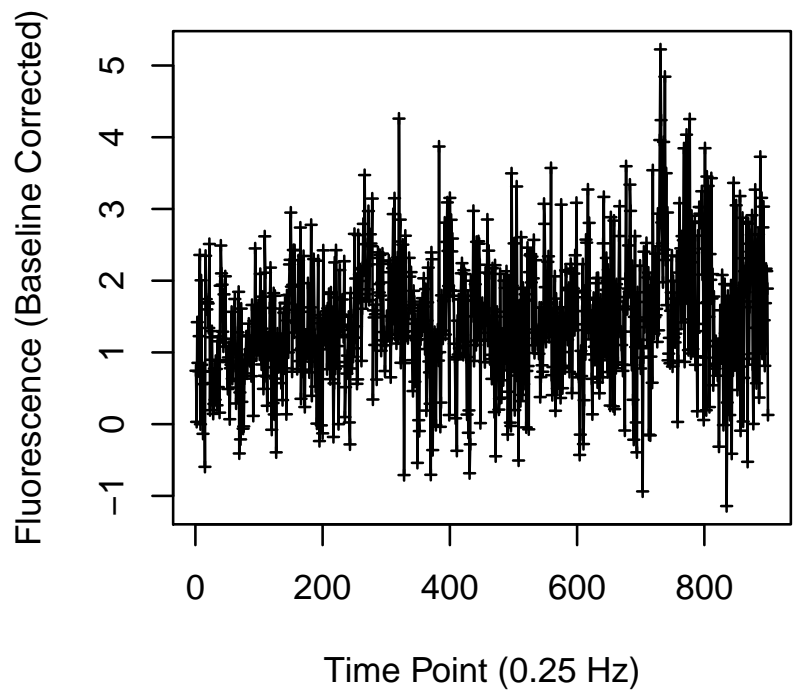


Cell 2081

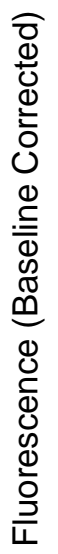

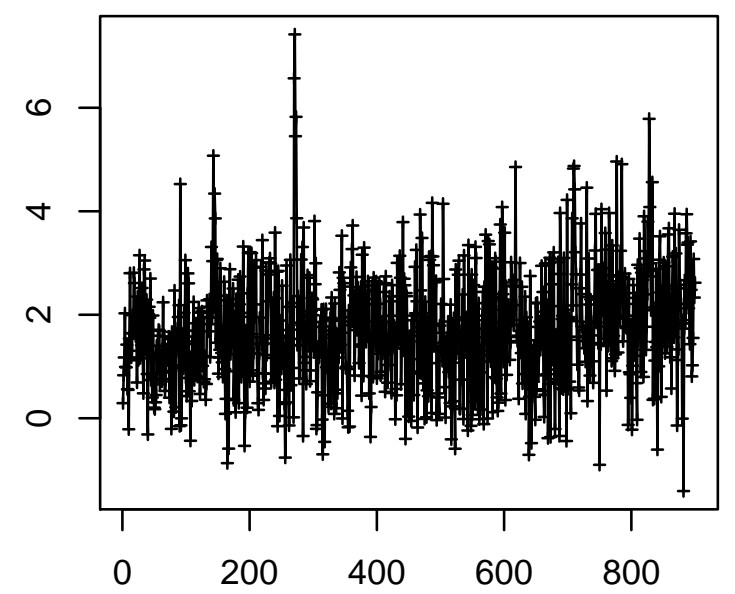

Time Point $(0.25 \mathrm{~Hz})$

Cell 2083

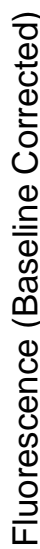

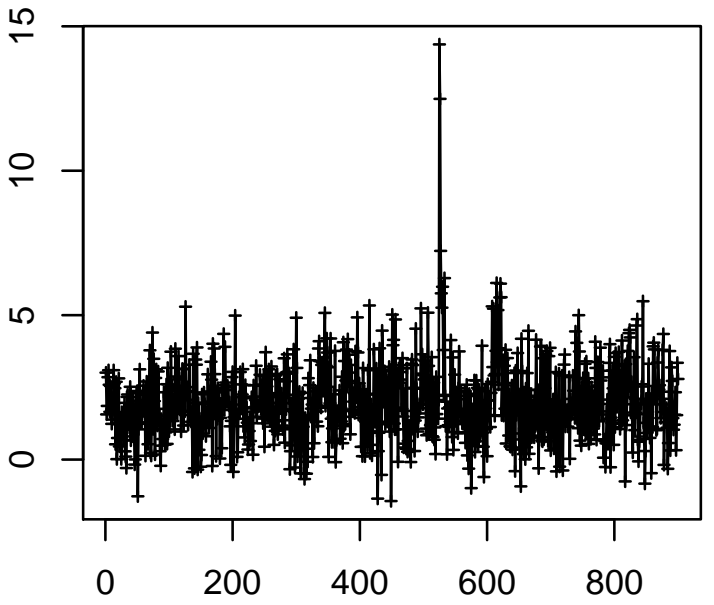

Time Point $(0.25 \mathrm{~Hz})$
Cell 2082

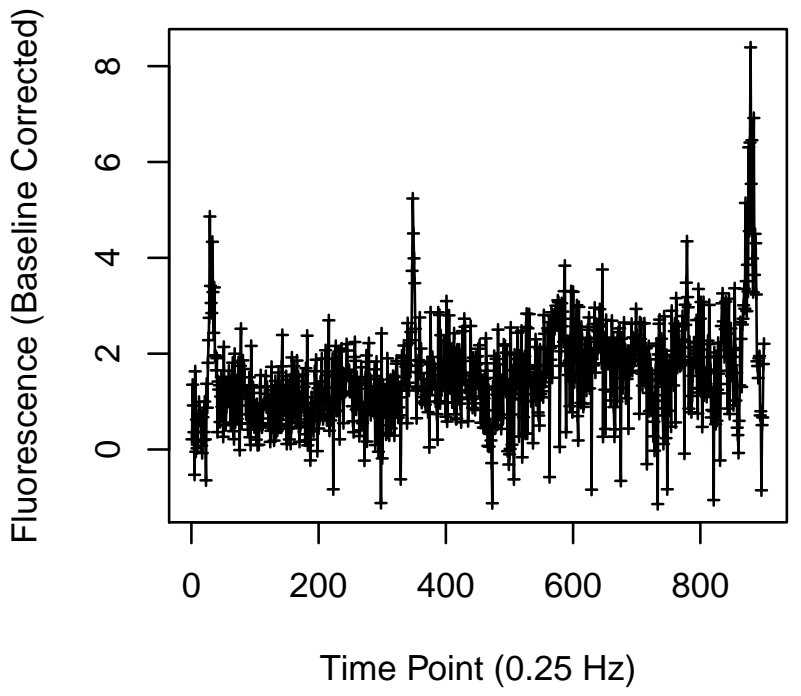

Cell 2084

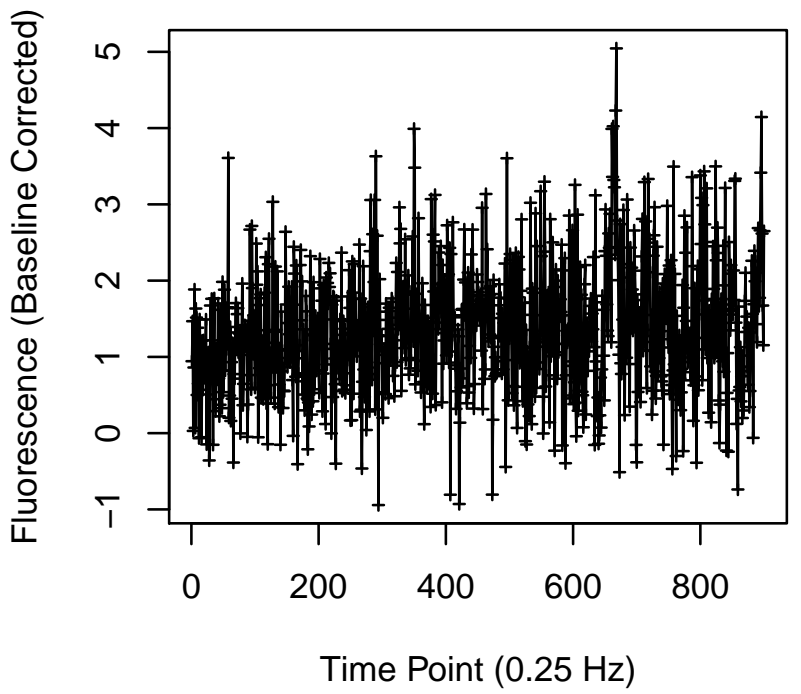


Cell 2089

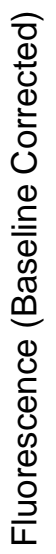

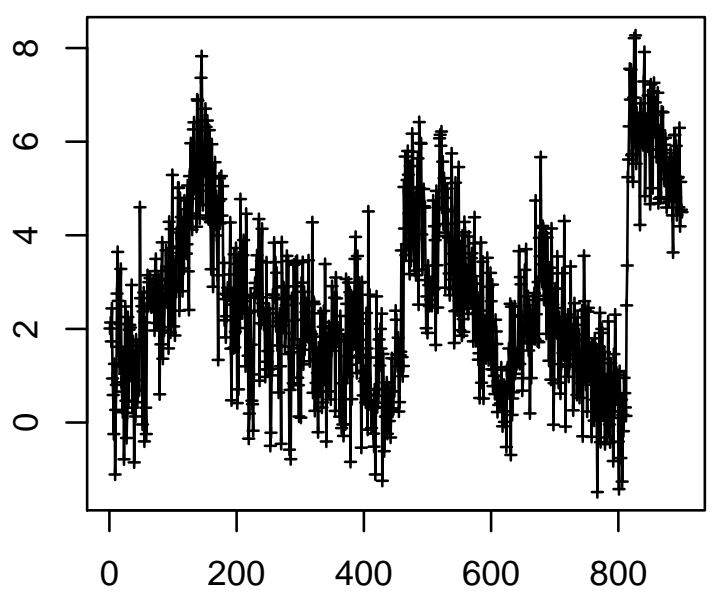

Time Point $(0.25 \mathrm{~Hz})$

Cell 2091

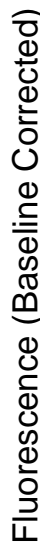

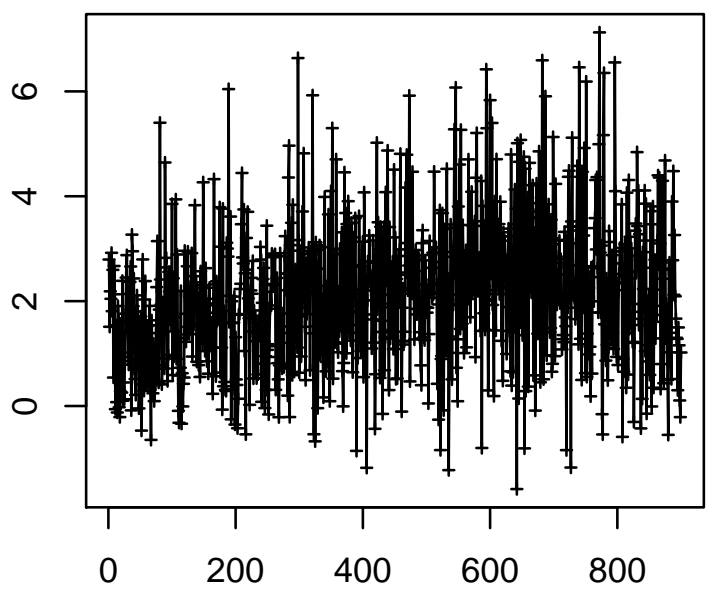

Time Point $(0.25 \mathrm{~Hz})$
Cell 2090

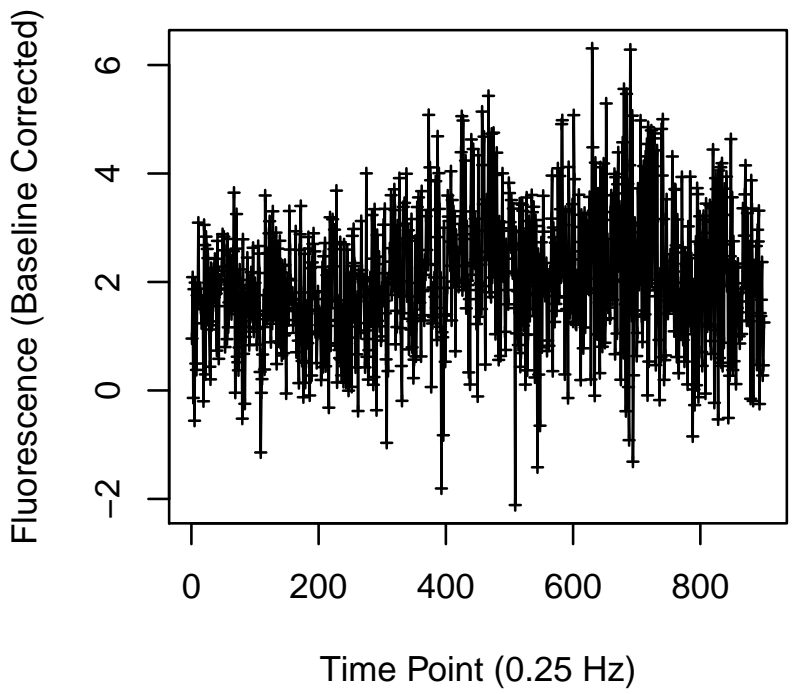

Cell 2092

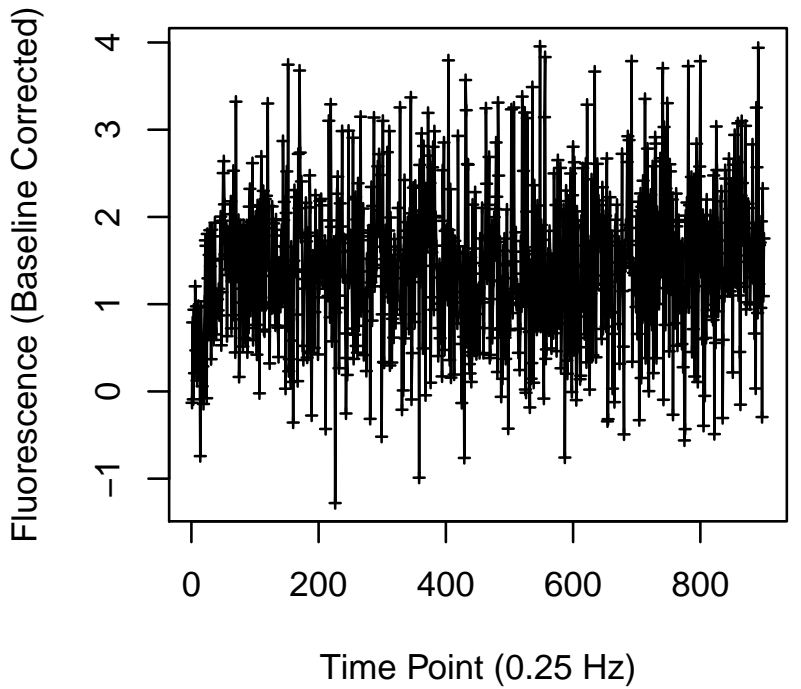


Cell 2093

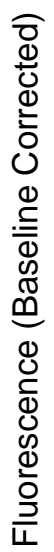

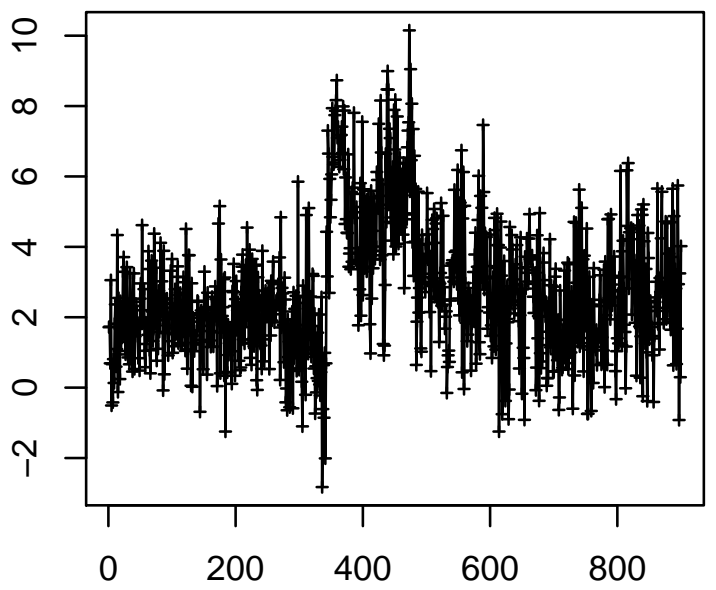

Time Point $(0.25 \mathrm{~Hz})$

Cell 2095

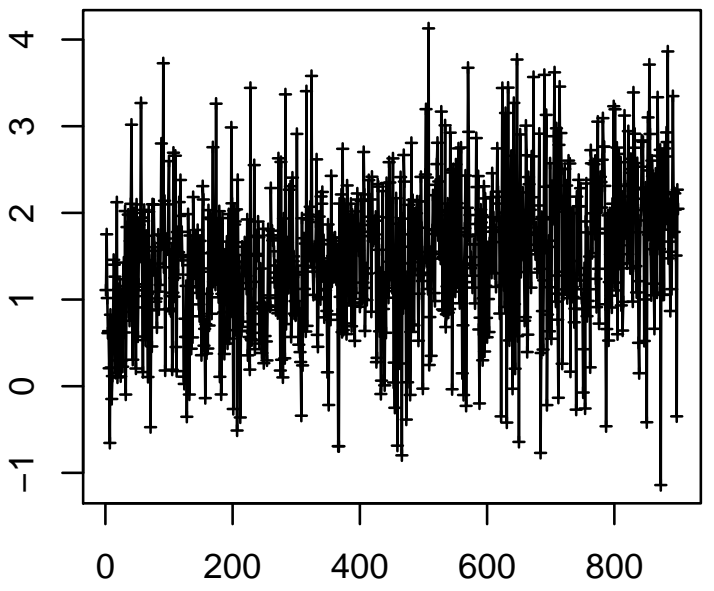

Time Point $(0.25 \mathrm{~Hz})$
Cell 2094

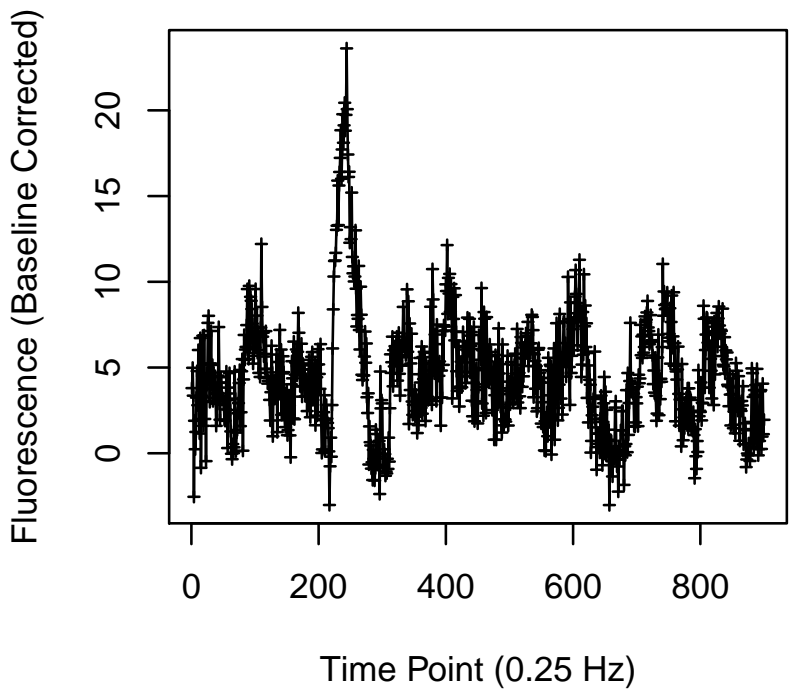

Cell 2096

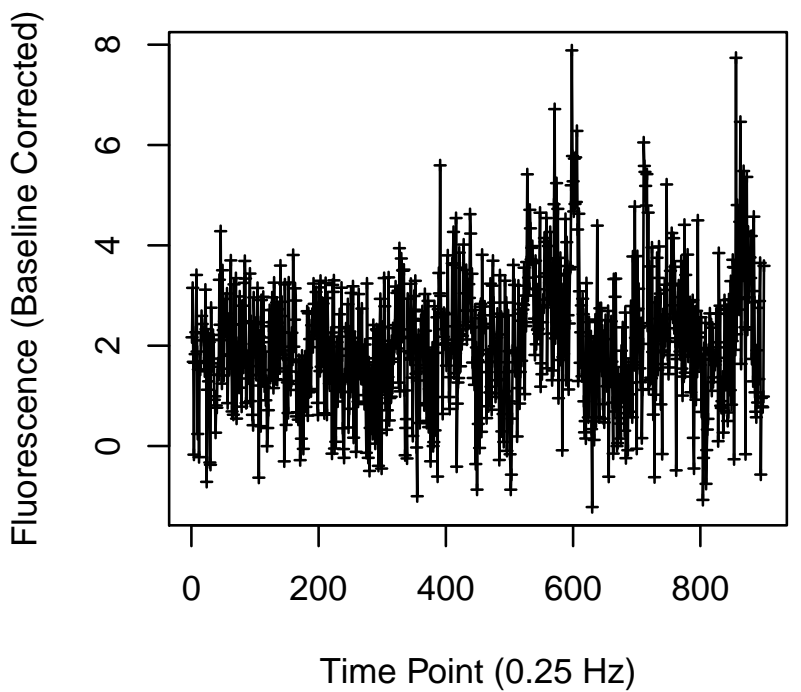


Cell 2097

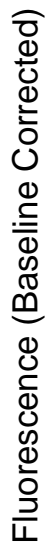

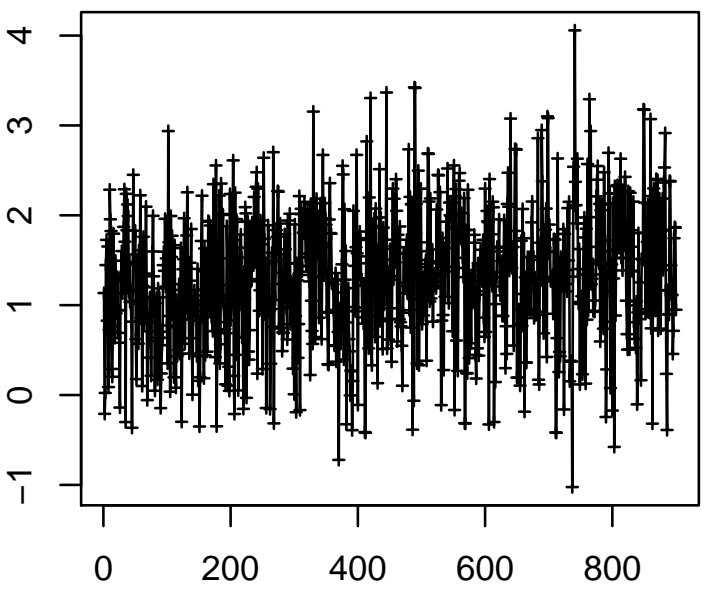

Time Point $(0.25 \mathrm{~Hz})$

Cell 2099

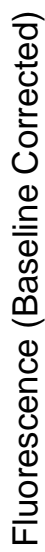

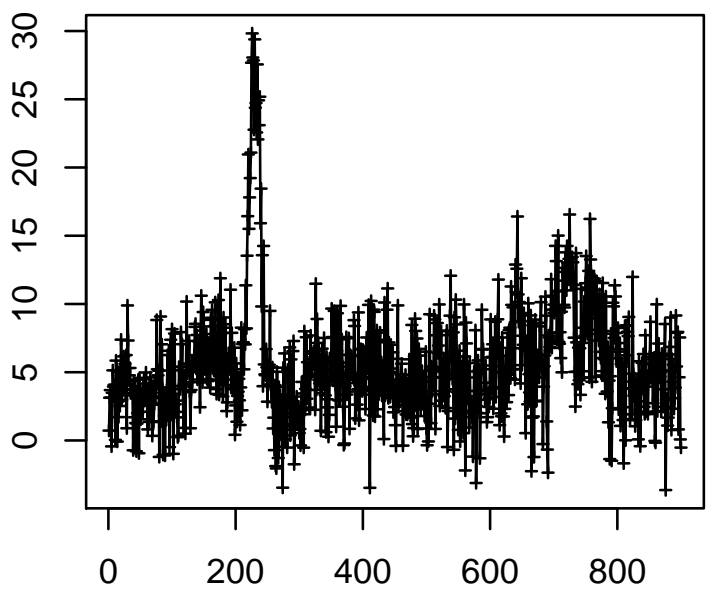

Time Point $(0.25 \mathrm{~Hz})$
Cell 2098

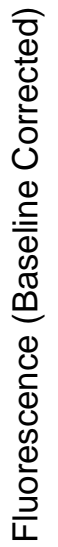

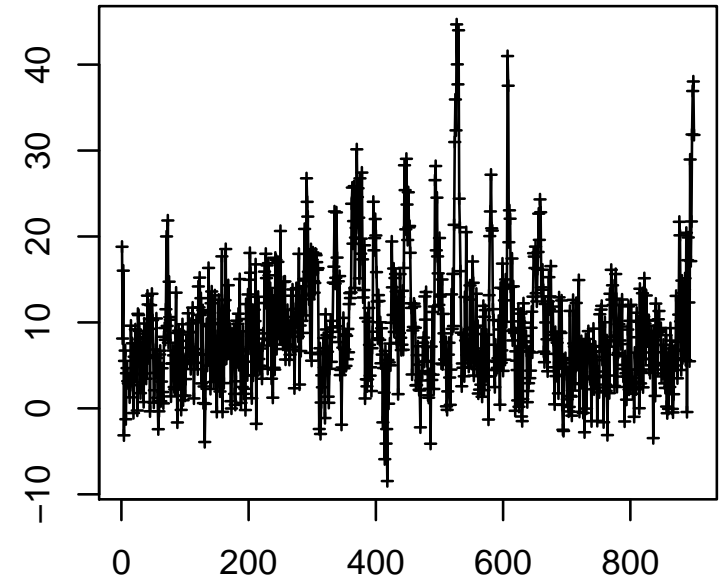

Time Point $(0.25 \mathrm{~Hz})$

Cell 2100

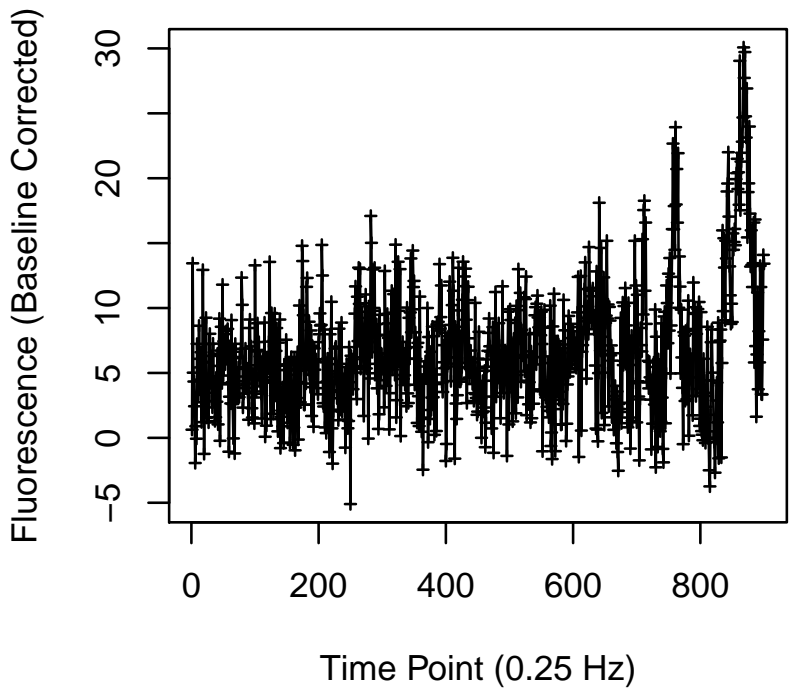


Cell 2101

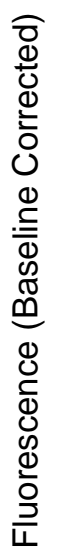

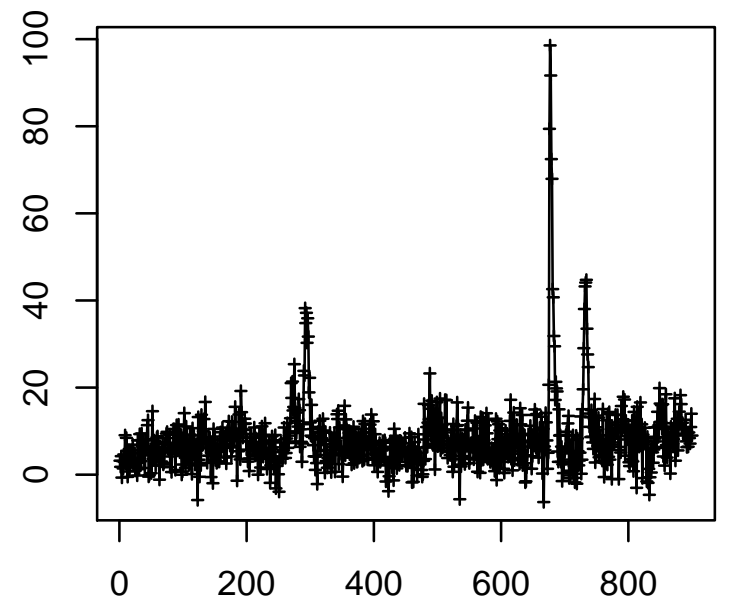

Time Point $(0.25 \mathrm{~Hz})$

Cell 2103

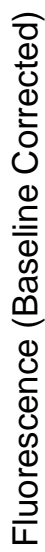

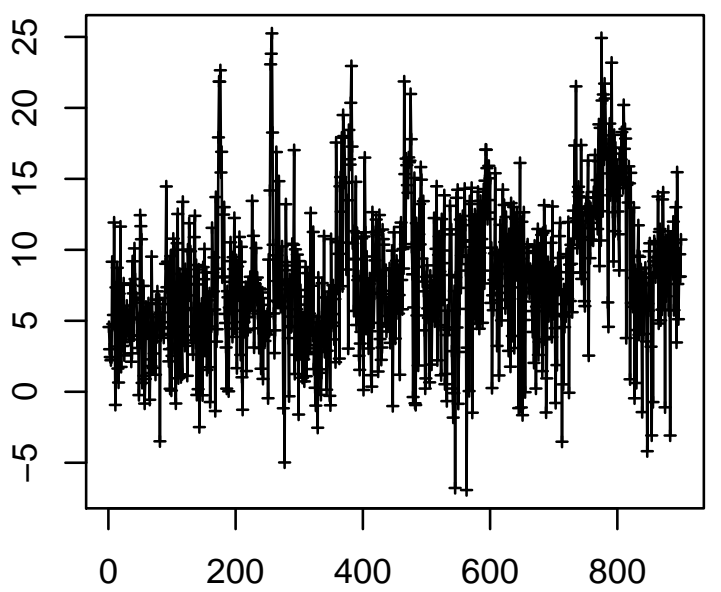

Time Point $(0.25 \mathrm{~Hz})$
Cell 2102

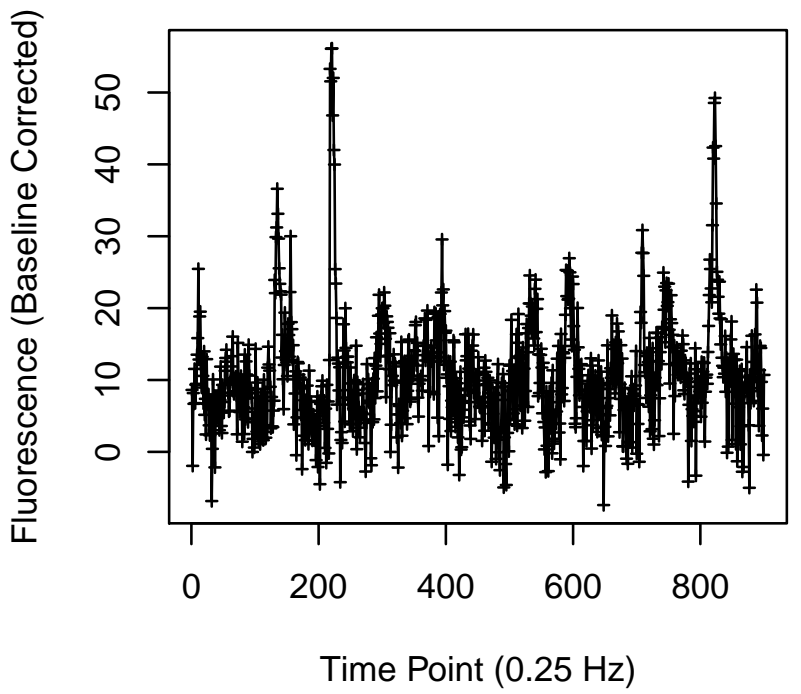

Cell 2104

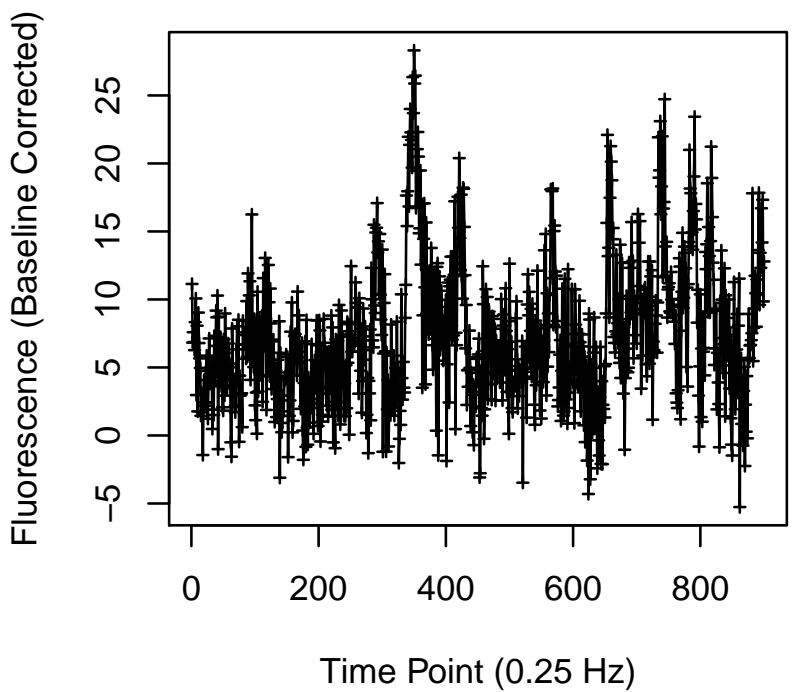


Cell 2109

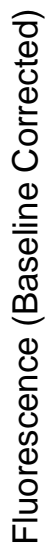

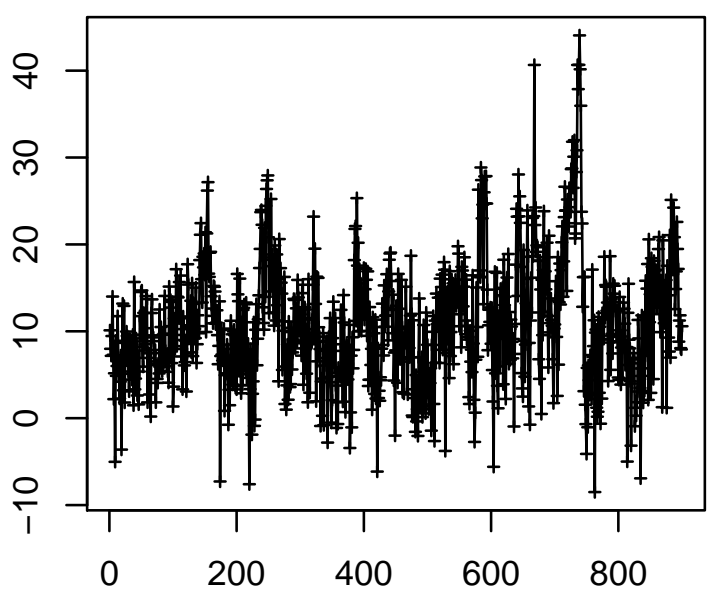

Time Point $(0.25 \mathrm{~Hz})$

Cell 2111

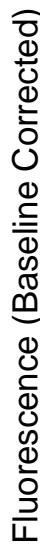

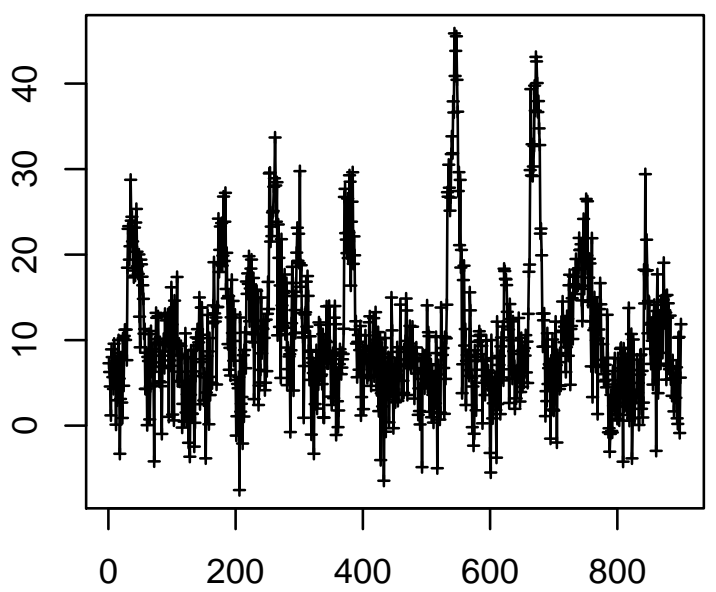

Time Point $(0.25 \mathrm{~Hz})$
Cell 2110

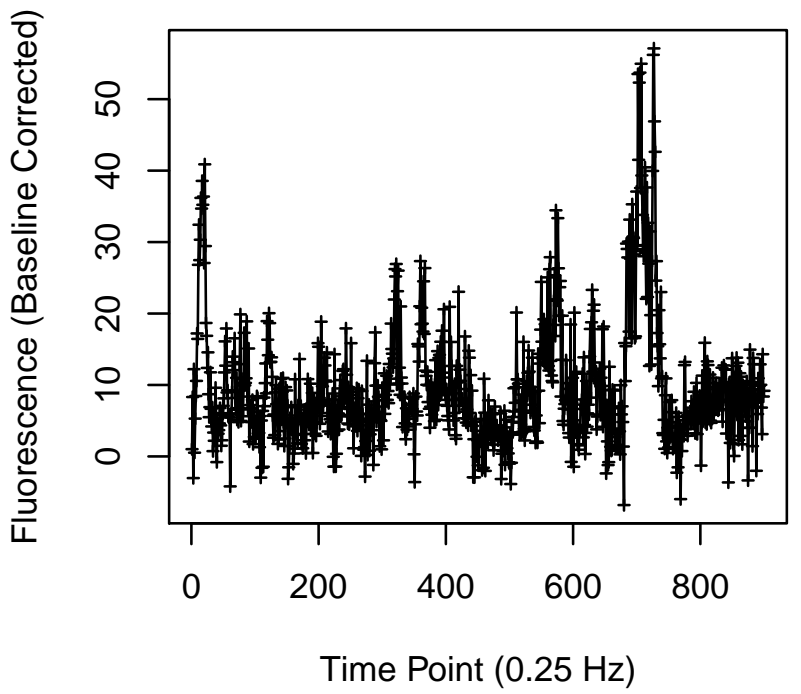

Cell 2112

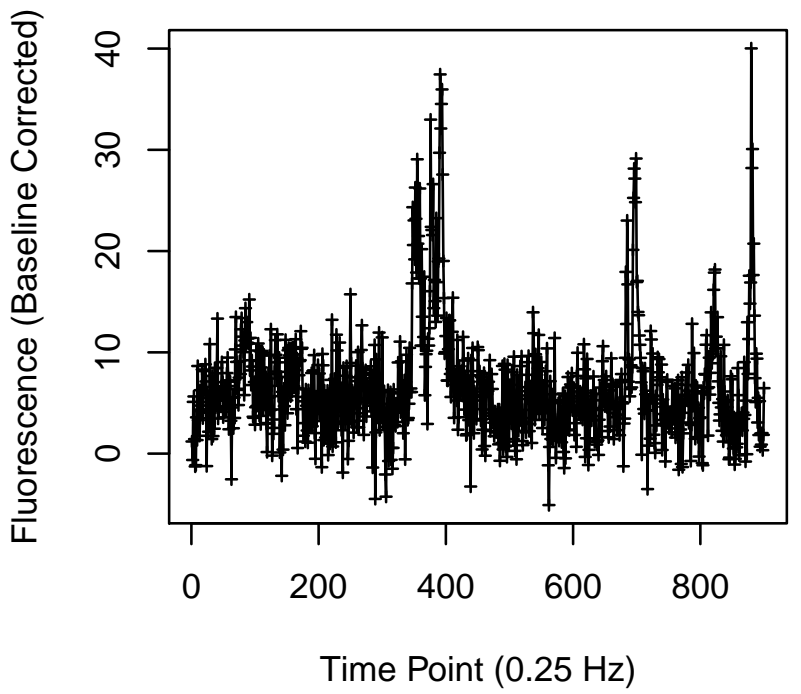


Cell 2121

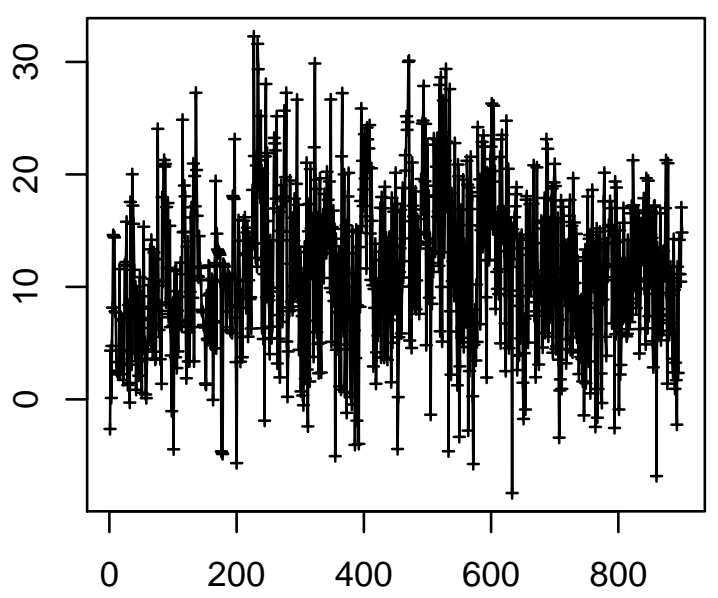

Time Point $(0.25 \mathrm{~Hz})$

Cell 2123

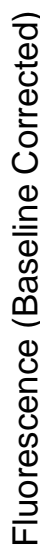

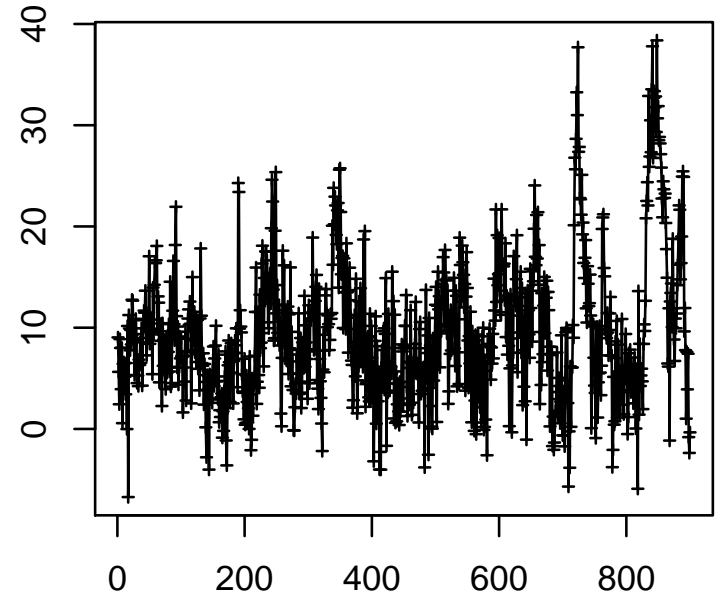

Time Point $(0.25 \mathrm{~Hz})$
Cell 2122

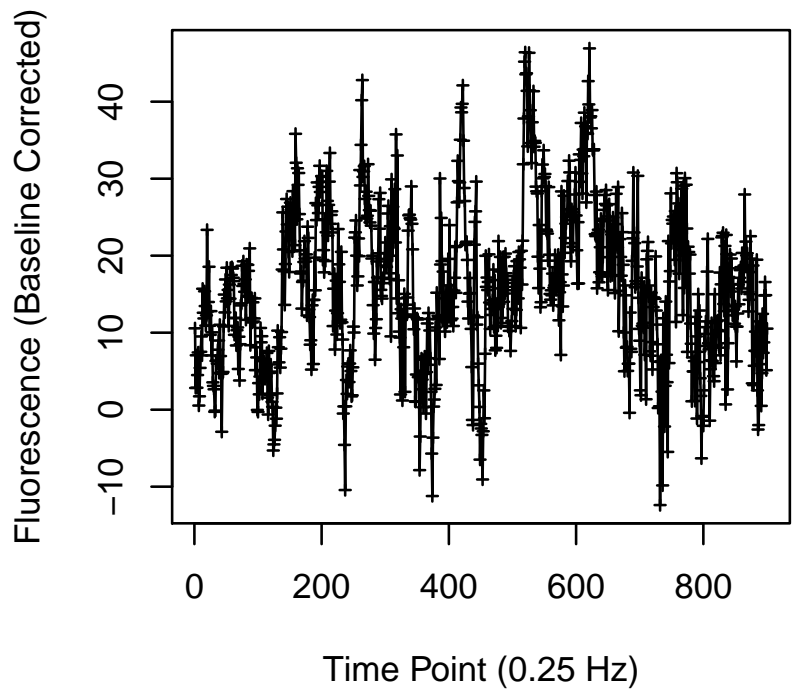

Cell 2124

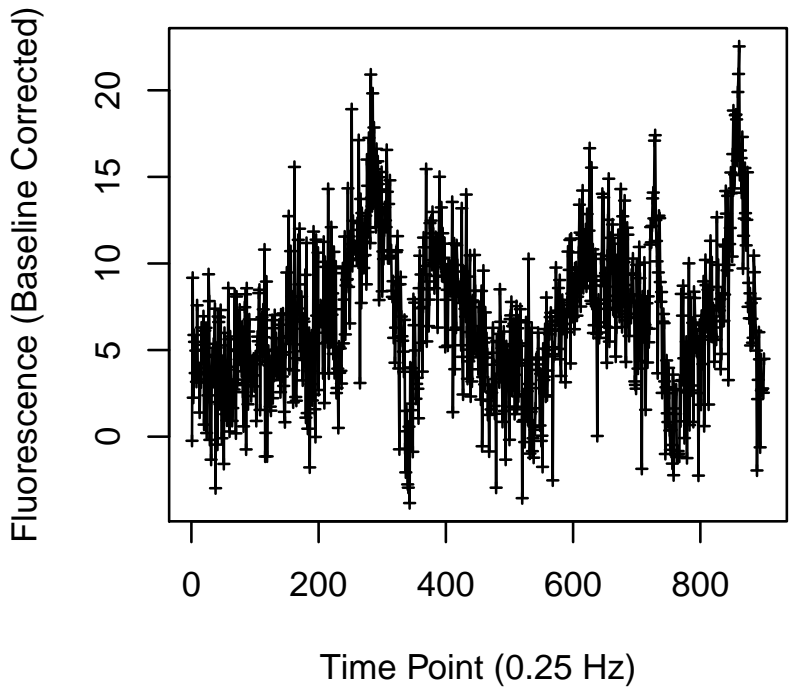




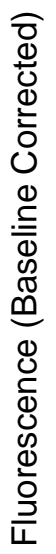

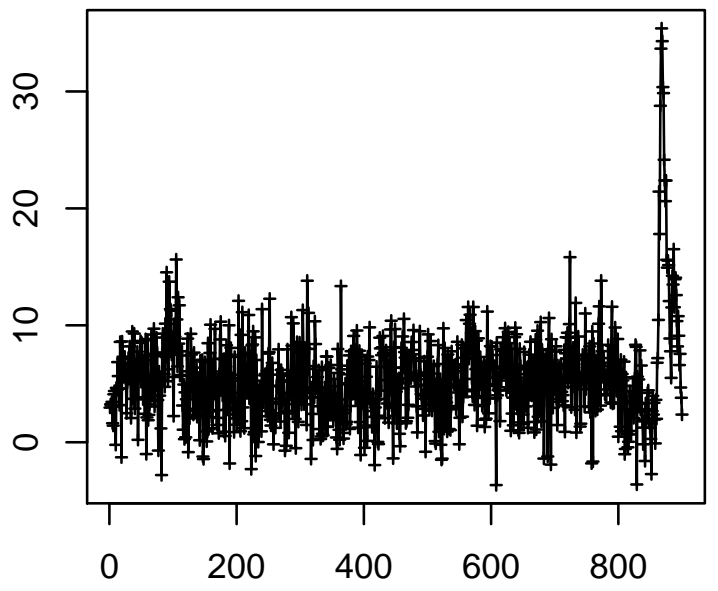

Time Point $(0.25 \mathrm{~Hz})$

Cell 2127

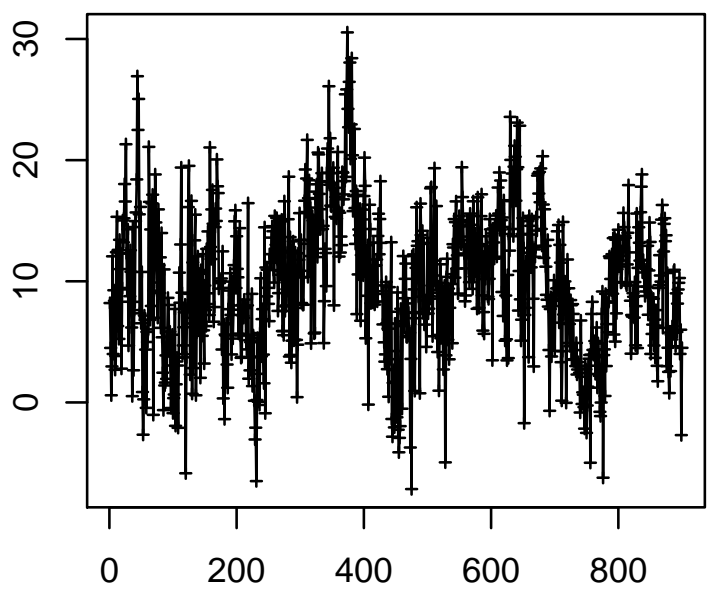

Time Point $(0.25 \mathrm{~Hz})$

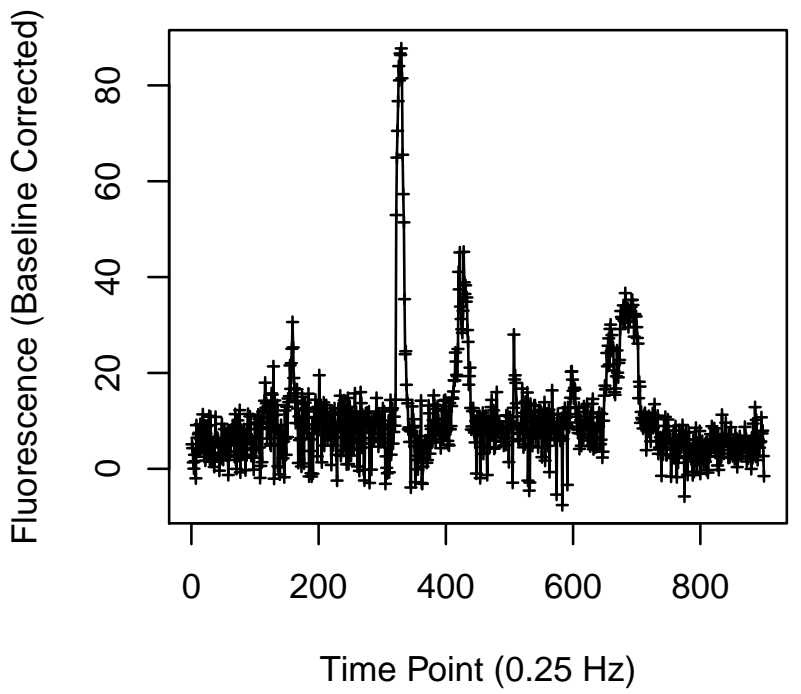

Cell 2128

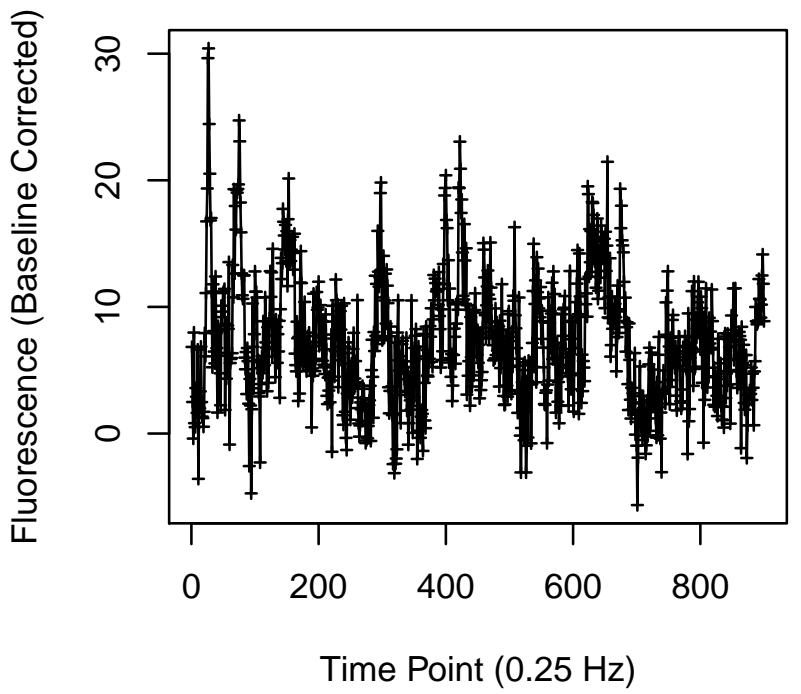


Cell 2133

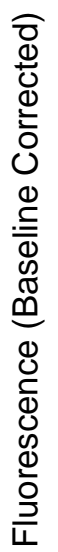

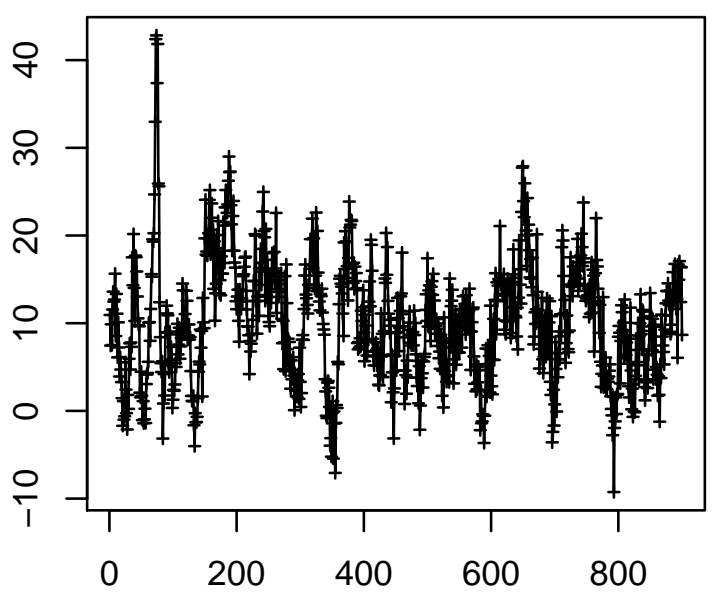

Time Point $(0.25 \mathrm{~Hz})$

Cell 2135

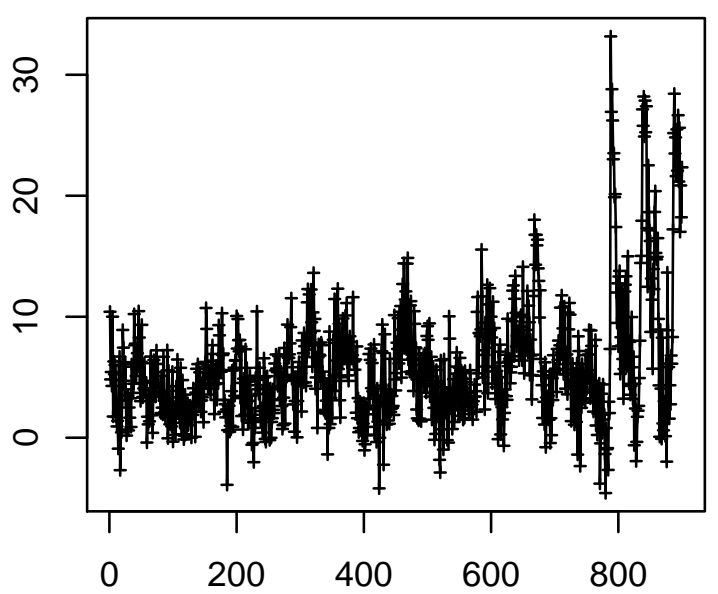

Time Point $(0.25 \mathrm{~Hz})$
Cell 2134

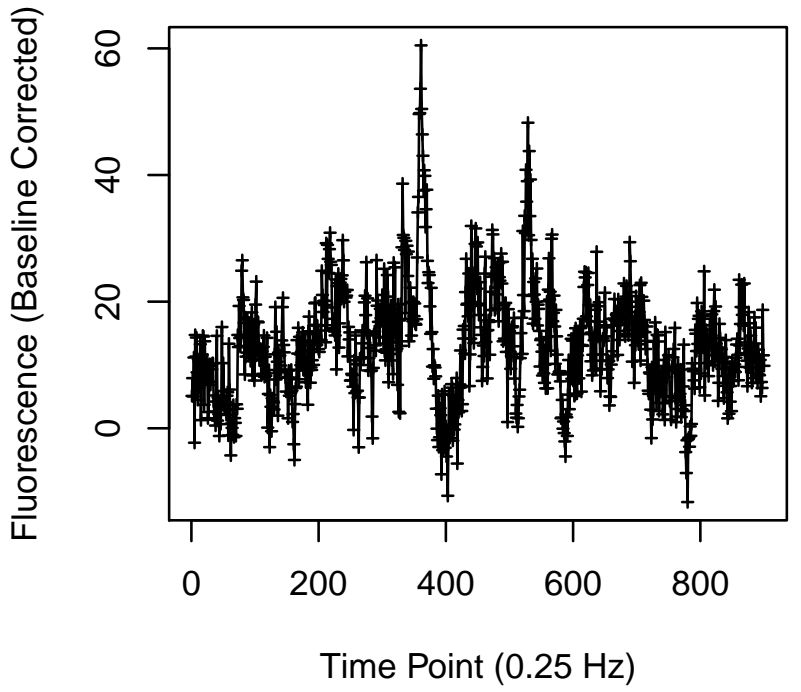

Cell 2136

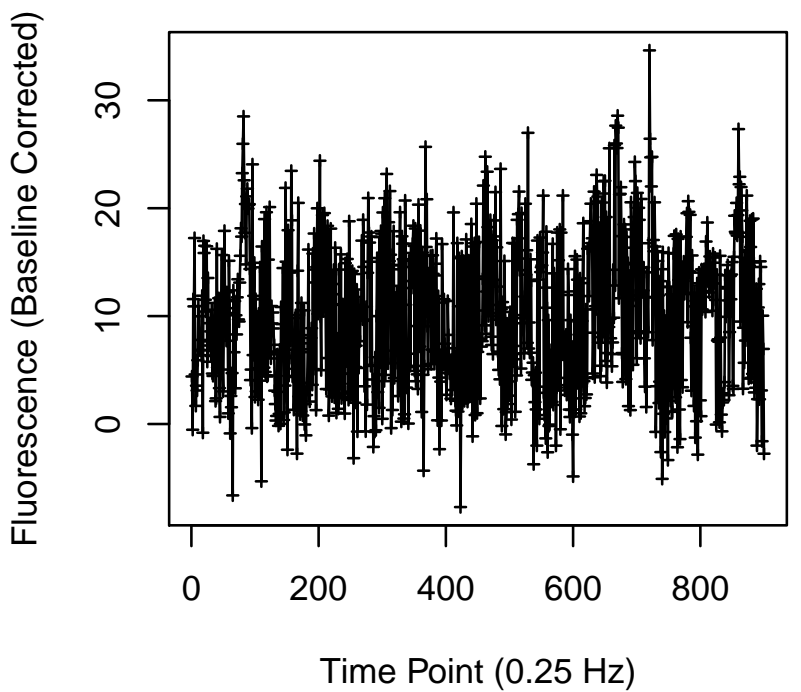


Cell 2141

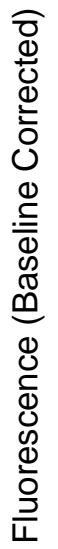

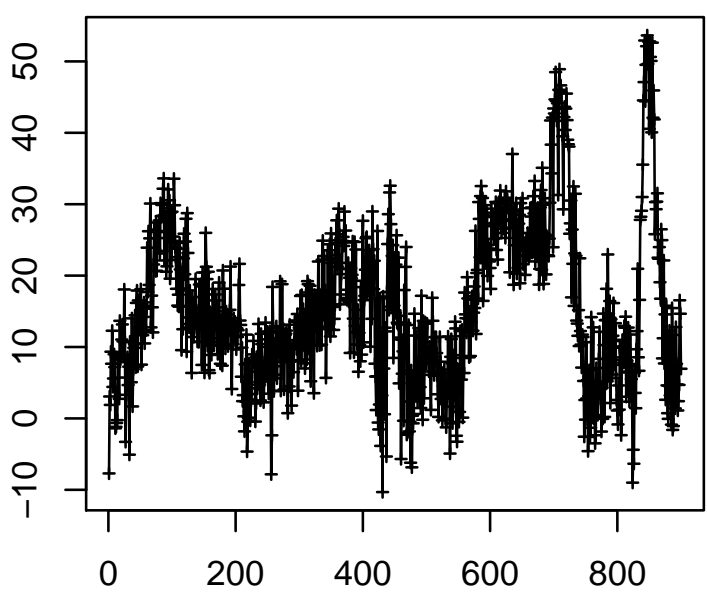

Time Point $(0.25 \mathrm{~Hz})$

Cell 2143

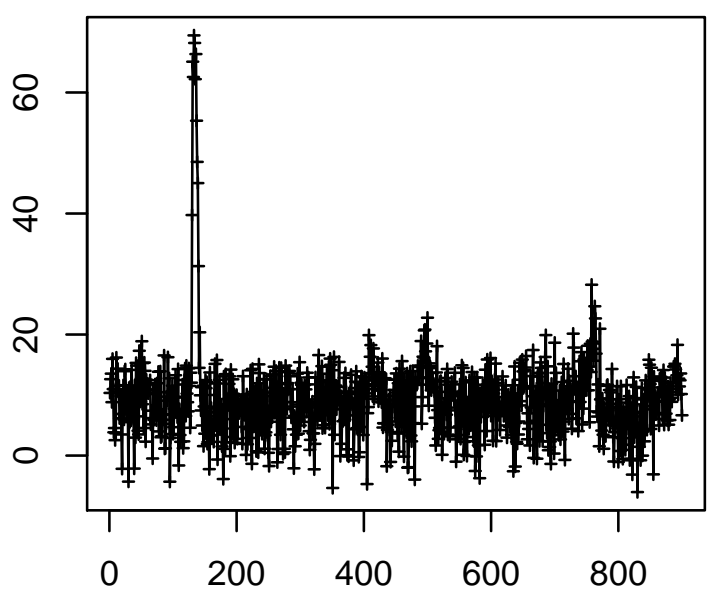

Time Point $(0.25 \mathrm{~Hz})$
Cell 2142

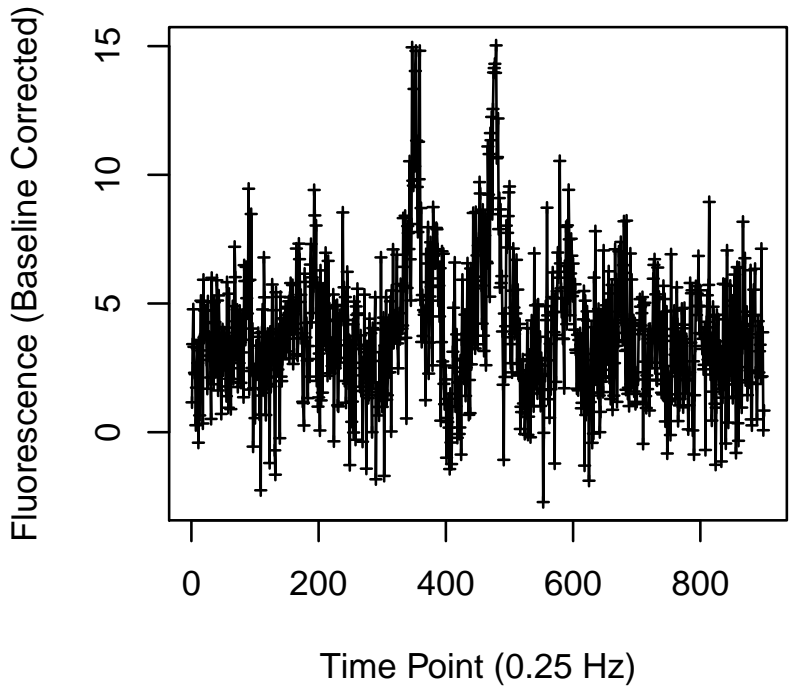

Cell 2144

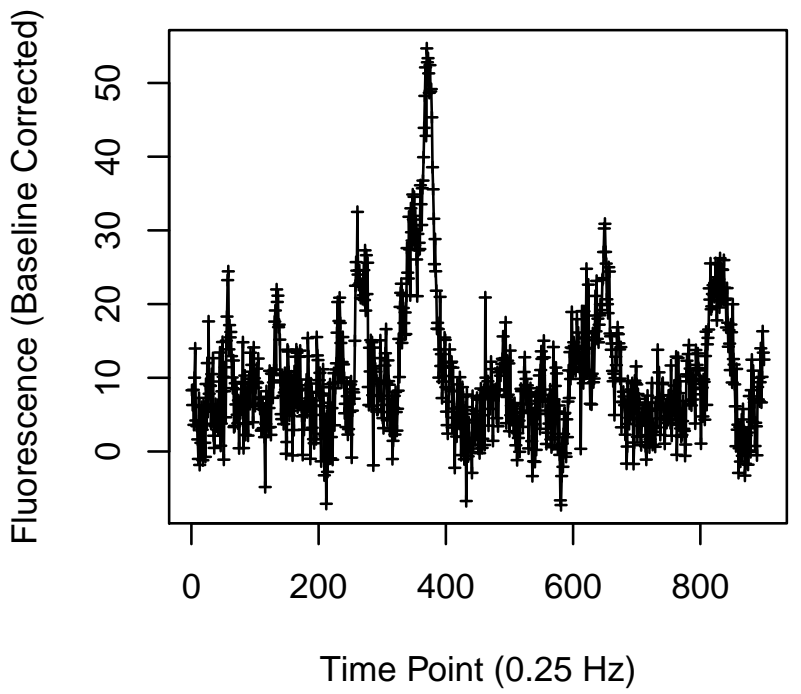


Cell 2149

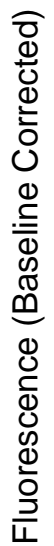

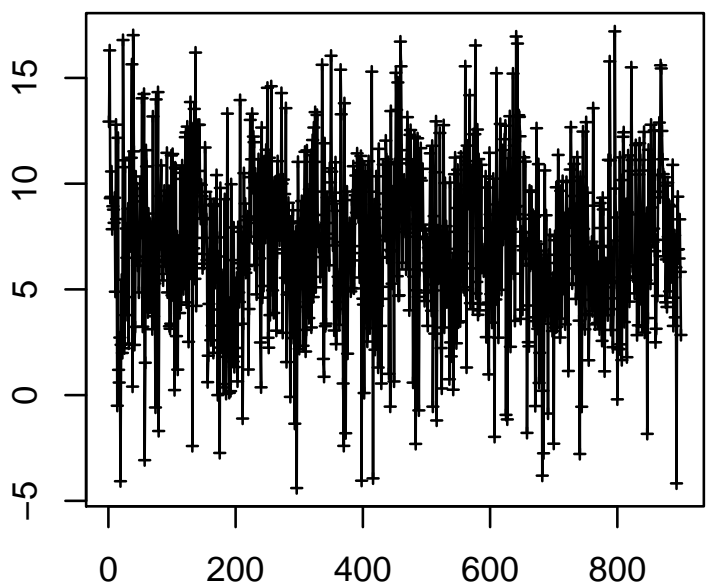

Time Point $(0.25 \mathrm{~Hz})$

Cell 2151

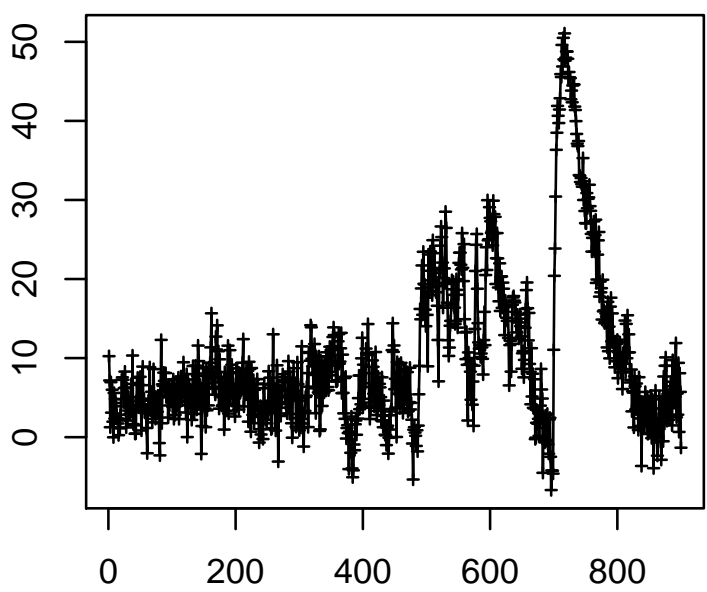

Time Point $(0.25 \mathrm{~Hz})$
Cell 2150

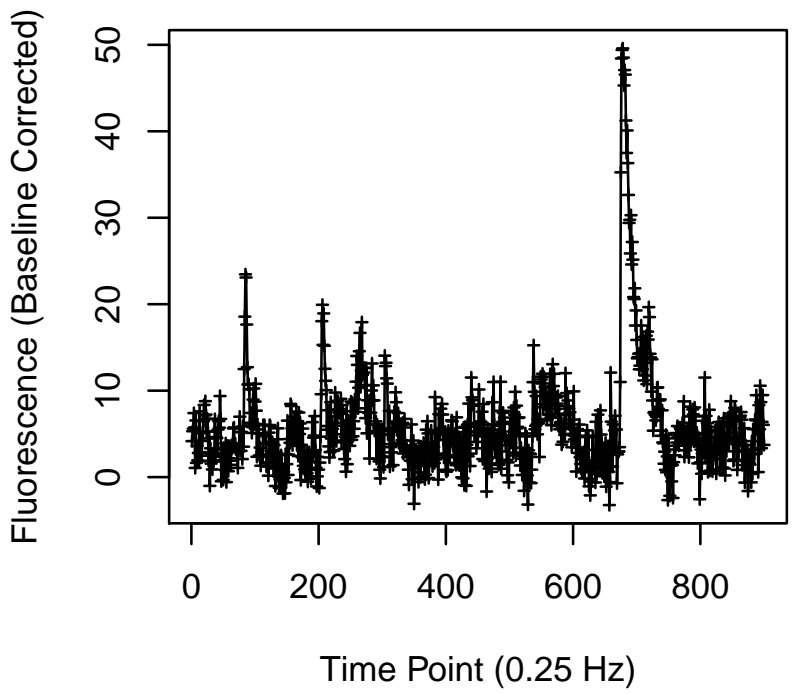

Cell 2152

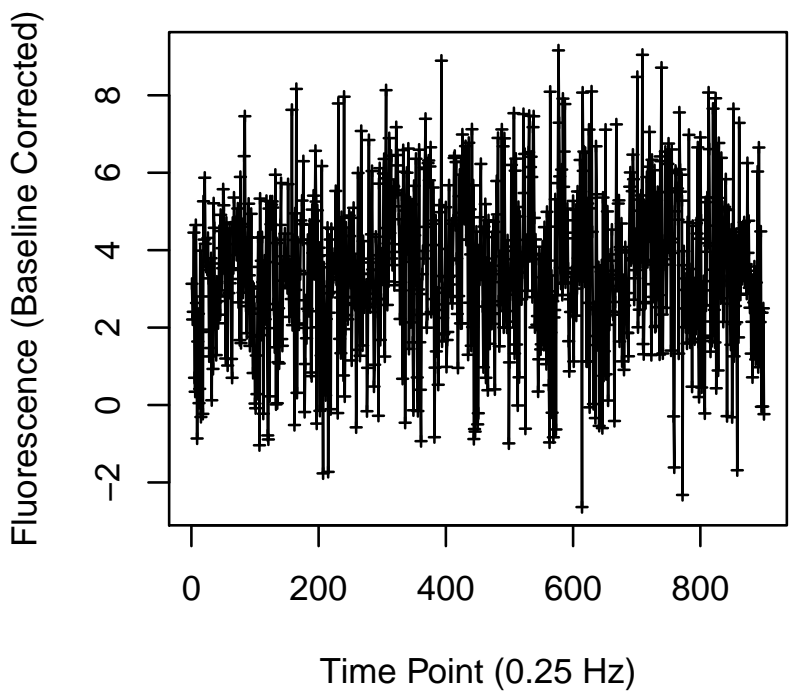


Cell 2153

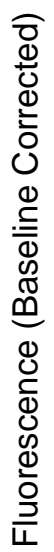

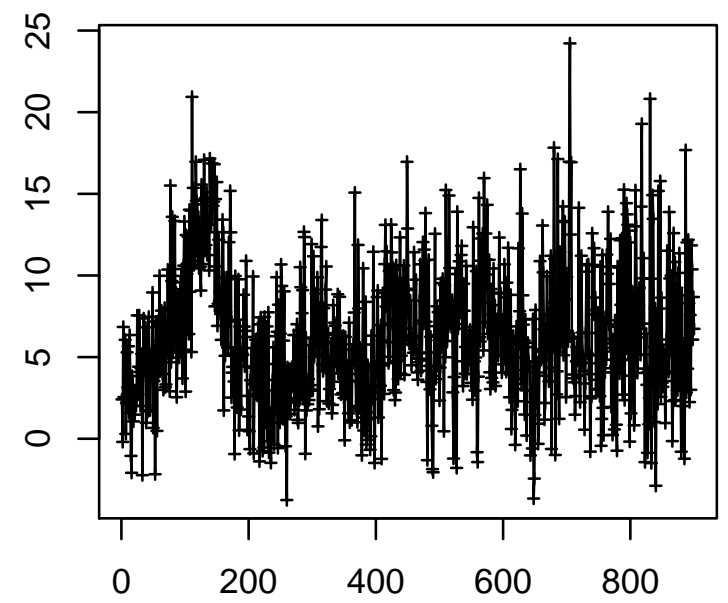

Time Point $(0.25 \mathrm{~Hz})$

Cell 2155

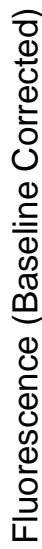

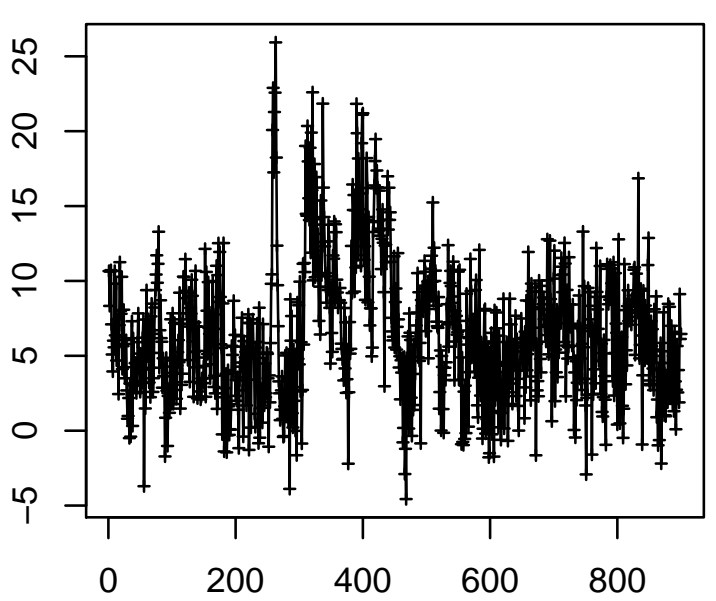

Time Point $(0.25 \mathrm{~Hz})$
Cell 2154

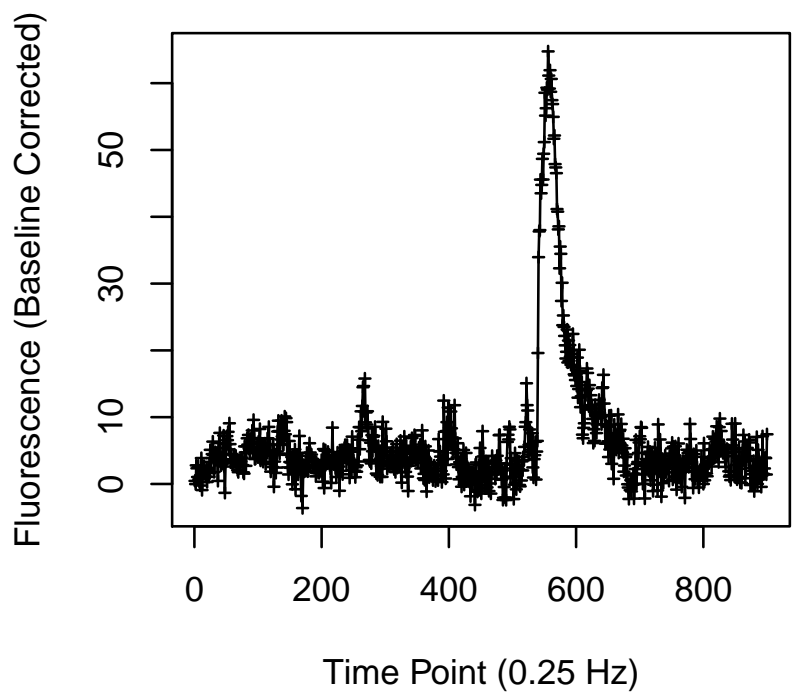

Cell 2156

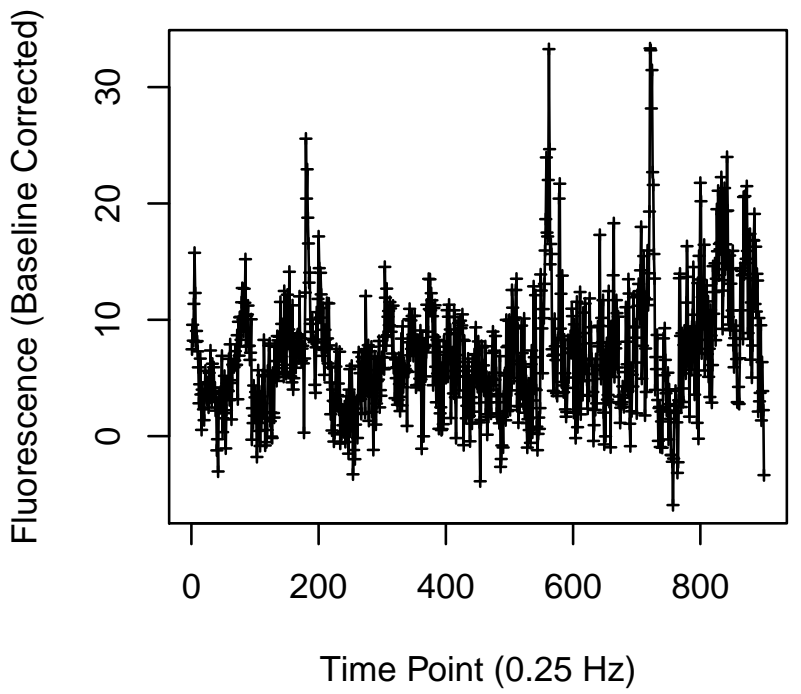


Cell 2165

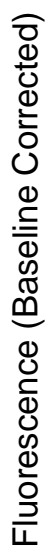

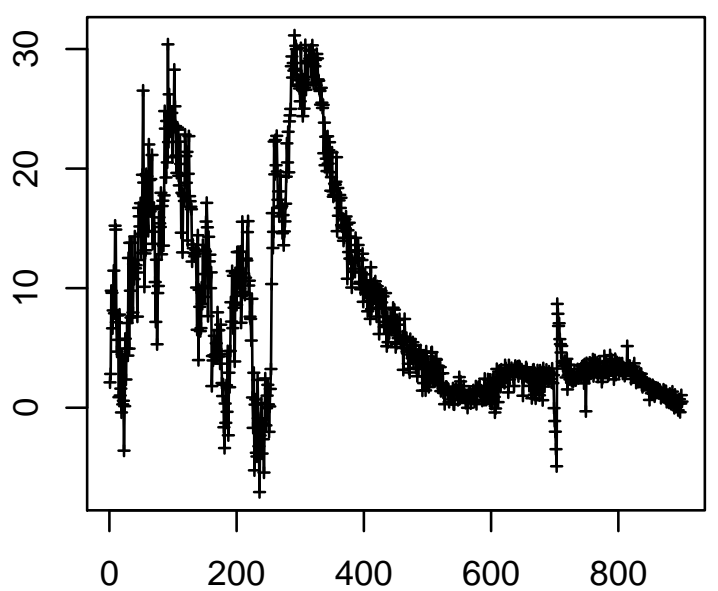

Time Point $(0.25 \mathrm{~Hz})$

Cell 2167

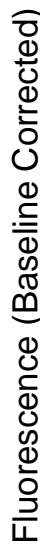

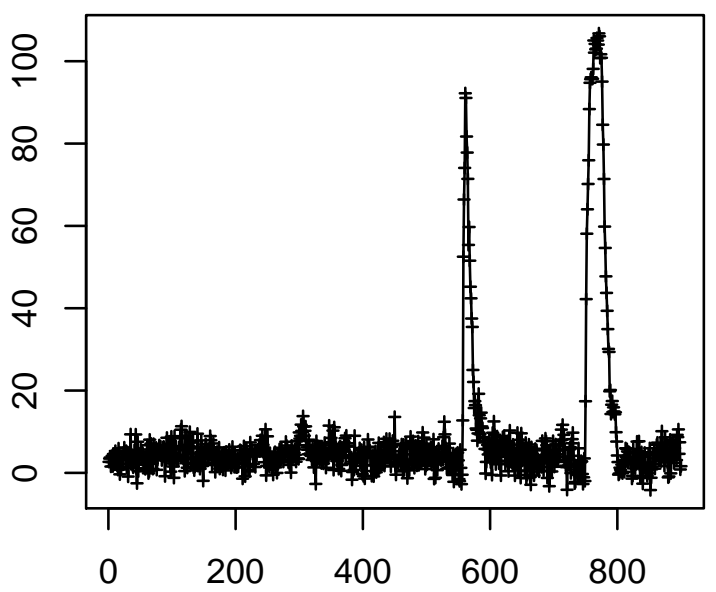

Time Point $(0.25 \mathrm{~Hz})$
Cell 2166

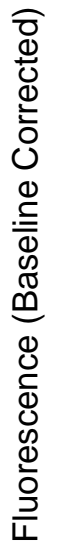

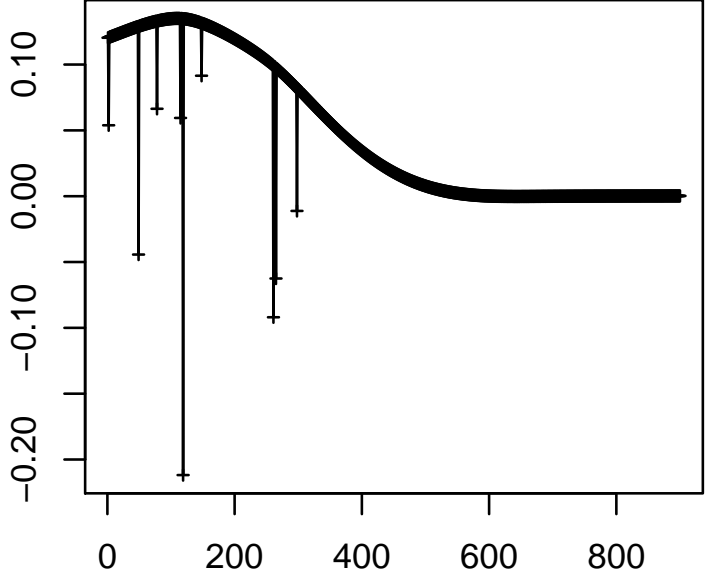

Time Point $(0.25 \mathrm{~Hz})$

Cell 2168

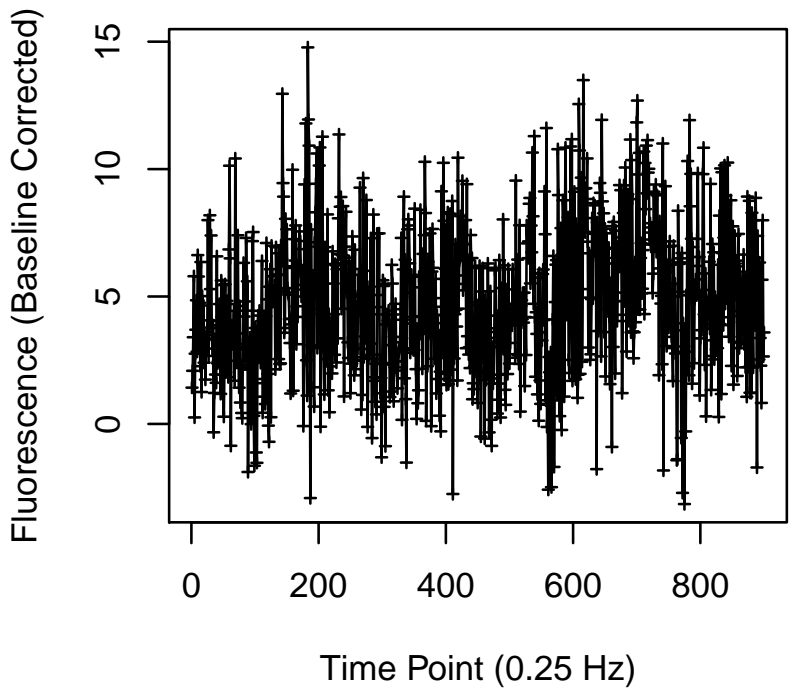


Cell 2173

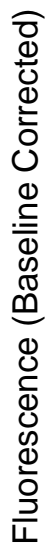

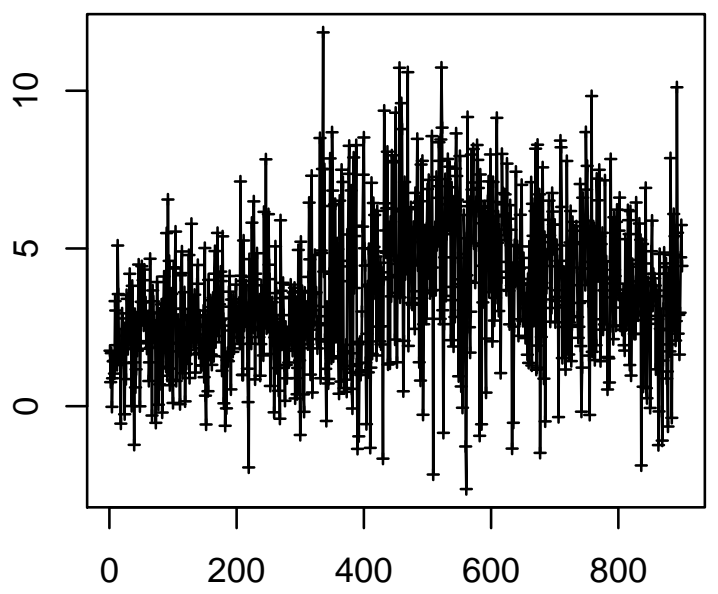

Time Point $(0.25 \mathrm{~Hz})$

Cell 2175

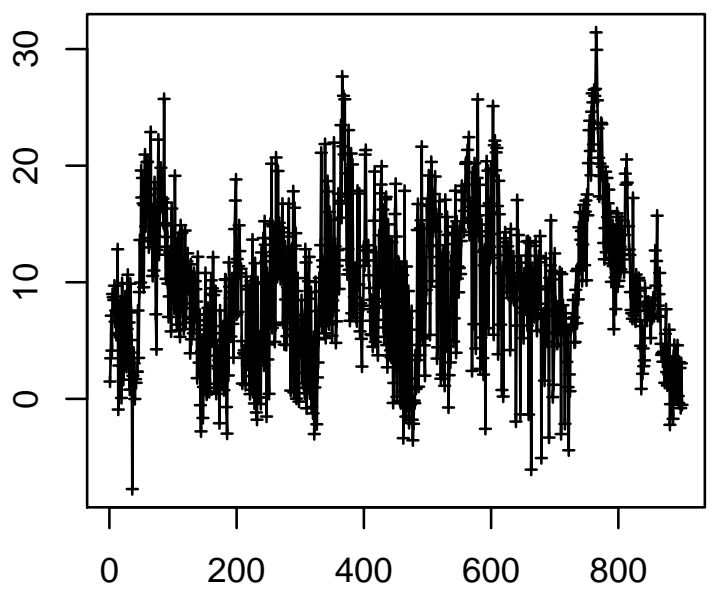

Time Point $(0.25 \mathrm{~Hz})$
Cell 2174

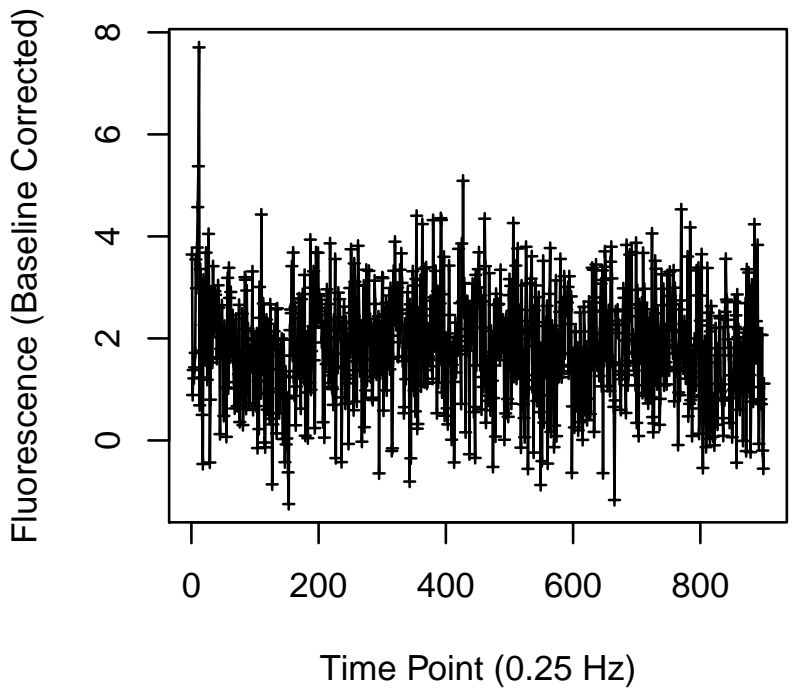

Cell 2176

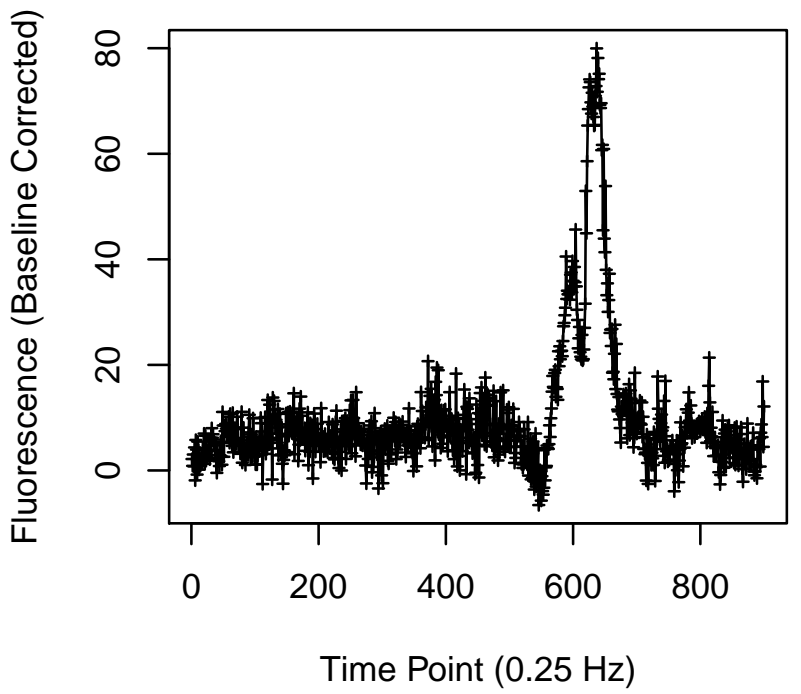

